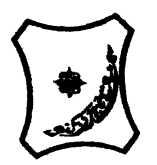

Bayero Journal of Pure and Applied Sciences, 13(1); 40 - 45

Received: September, 2019

Accepted: April, 2020

ISSN $2006-6996$

\title{
BACTERIOLOGICAL QUALITY OF STICK MEAT (Tsire) SOLD IN GARKO LOCAL GOVERNMENT AREA OF KANO STATE, NIGERIA
}

\author{
$*^{1}$ Dahiru A. T. and ${ }^{2}$ Maigari A. K. \\ ${ }^{1}$ Department of Hospitality Management, School of Technology, Kano State Polytechnic, PMB 3348, \\ Kano Nigeria. \\ ${ }^{2}$ Departmnt of Biological Sciences, Bayero University, Kano \\ Corresponding Author: dturajo61@gmail.com; GSM: 08087508262.
}

ABSTRACT

Stick meat, locally called Tsire in Hausa Language, is a significant portion of the diet of a large active population of Northern Nigeria. However, because of the handling and processing methods by the manufacturers as well as the hawking system of stick meat, the meat product may be exposed to both pre- and post-processed product contamination, and thus may poses danger to public health. Therefore, considering the role of Tsire in improving nutrition and increase household income to the populace, the need to improve the processing, distribution and overall quality of the product is simply indispensable. A total of 30 samples (5 samples from each of the 6 sampling points) of Tsire were collected randomly in Garko Town. Aerobic plate counts (APCs) and Total coliform counts (TCCS) of Tsire samples were determined using standard microbiological methods. APCs ranged from $1.02 \times 10^{5}$ to $4.00 \times 10^{5} \mathrm{CFU} / \mathrm{g}$; while TCCs ranged from $8 \mathrm{MPN} / \mathrm{g}$ to $68 \mathrm{MPN} / \mathrm{g}$. From the 30 samples screened, 16(53.33\%) bacteria namely, Campylobacter 2(6.66\%), Escherichia coli 6(20\%), Klebsiella pneumoniae 2(6.66\%), Salmonella spp. 1(3.33\%), Shigella 3(10\%) and Staphylococcus aureus 2(6.66\%) were detected. $E$. coli has the highest isolation rate of 6(20\%), while Salmonella spp. had the least frequency of 1(3.33\%). The distribution of isolated organisms within the study area were as follows: Dausai, 4(80\%), Kofar kudu, 4(80\%), Makwalla, 2(40\%), Rinji, 3(60\%), Tosaro, 2(40\%), and Tsohuwar Kasuwa, 1(20\%). The results have indicated that the Tsire was contaminated with bacteria thus exposing the product to fast deterioration, spoilage and also a vehicle for food borne illness, suggesting for adequate hygienic practices at all the stages, prior to consumption, to ensure safety of the meat product.

Key words: APCs, TCCs, Contamination, Microorganisms, Garko

\section{INTRODUCTION}

Nigeria is one of the developing nations with inadequate food supply and most often deficient in protein content (FAO, 2019). Nigerian's average animal protein intake per head per day is estimated at $7.9 \mathrm{~g}$ as against $35 \mathrm{~g}$ recommended value by Food and Agricultural Organization (Mubarak et al., 2016). These low levels of animal protein intake create great concern as it affects the nutritional status of Nigerians. Hence, there is the need for sufficient supply of animal protein from energy rich animal products to satisfy the nutritional requirements for Nigerians.

Meat is one major source of animal protein largely composed of water, protein and fats which can make it susceptible to microbial contamination within short time leading to spoilage (Apata et al., 2013; Mgbemere et al., 2011). Meat is mostly eaten after it has been cooked or processed in a variety of ways such as sun drying; smoking and roasting with or without fortifications (Borch et al., 1996). In Nigeria meat products such as Tsire, Kilishi and Balangu are locally produced using one or more of these methods in order to meet the nutritional requirements of the teeming Nigerians (Egbebi, 2011).

Tsire is a popular Nigerian traditional processed ready-to-eat roasted stick meat product (Shamsuddeen, 2015). It is sold in public places, along roads, in hotels, parks, quarters and even offices (Falegan et al., 2017). It is prepared from boneless healthy animal flesh such as beef and mutton, spiced with peanut cake, salt, vegetable oil and other flavorings followed by roasting (Shamsuddeen, 2015). Consumption of these products has extended to other parts of African countries such as Ghana, Somali, Cameroun and Chad (Ahmadu and Ibrahim, 2013). 
BAJOPAS Volume 13 Number 1, June, 2020

However, evidence of quality control sticking to procedural hygiene by the handlers during preparation and retailing of these products is poorly documented. Tsire is of great safety risk because of the fact that there are erratic cases of gastroenteritis and symptoms of food infection after consumption (WHO, 2015). Food borne illnesses are one of the major health problems in developing and developed countries (Razavilar, 2010). According to the World Health Organization, WHO (2015), $0.07 \%$ death of the 600 million global burdens of Foodborne illnesses have been reported to be caused by bacteria, viruses, fungi and chemicals. In America $0.27 \%$ of the estimated 48 million affected people is hospitalized and about $0.0063 \%$ deaths are recorded each year (Scallan et al., 2011). More than 91 million people in Africa fall ill and $0.15 \%$ dies each year, making Africa the highest burden bearer of Foodborne diseases per population (WHO, 2015).

Application of a Hazard Analysis Critical Control Point (HACCP) at all stages of meat products preparation is essential in order to ensure its safety. Thus, according to the guidelines of good manufacturing practice, the level of total aerobic bacterial contamination of thermally processed meat products should not exceed $10^{4}\left(\mathrm{cfu} \mathrm{g}^{-1}\right)$. Enterobacteriaceae and faecal coliform contamination in meat products should be within the range of $10^{2}-10^{4}$ and $10-10^{3} \mathrm{cfu} \mathrm{g}^{-1}$, respectively (Shamsuddeen, 2015). The aim of the study is therefore, to assess the total viable bacterial counts of tsire marketed locally within Garko town, and to isolate and identify the organisms at the point of consumption with the intention of promoting public health and food hygiene habits in the Nigerian populace.

\section{MATERIALS AND METHODS Study Area and Population}

Garko is one of the existing 44 local government areas located in Kano south west zone of Kano state with its capital administrative headquarters in the Garko town. It has coordinates $11^{\circ} 39^{\prime} \mathrm{N}$ $8^{\circ} 54^{\prime} \mathrm{E}$, and an area of $450 \mathrm{~km}^{2}$. The projected population of Garko local Government was 225,300 according to the National Population Census report (2018). Garko is known for agricultural activities both farming and animal husbandry. It is popularly known for large scale rice production. Other food crops include sweet potatoes, cassava, onions, sorghum, millet and sugarcane. Cows, sheep and goats are major groups of animals reared by majority of the populace. Meat products processed, retailed and consumed in Garko include roasted meat (Balangu), dried roasted meat (Kilishi), stick meat (Tsire), hide and skin pepper soup (Ragadada) and minced fried meat (Danbunnama).

\section{Samples Collection}

Five samples of Tsire products were collected from 6 different identified locations within Garko town in a sterile foil paper and immediately analyzed for the presence of bacteria.

\section{Sample Preparation}

Sample preparation for the bacteriological analysis was carried out in accordance with the method described by Atlas (1997). Twenty five grams $(25 \mathrm{~g})$ of the sample was homogenized in $225 \mathrm{ml}$ peptone water using Kenwood blender machine to obtain a $10^{1}$ homogenate. The homogenate was thoroughly shaken and $1 \mathrm{ml}$ pipetted into test tubes containing $9 \mathrm{ml}$ of peptone water $\left(10^{2}\right)$. The test tubes were further serially diluted to $10^{5}$.

Total Aerobic Mesophilic Bacterial Count

Total Aerobic mesophilic bacterial count was determined using the method described by Abdullahi et al. (2004) where $1 \mathrm{ml}$ of inoculums from $10^{1}$ to $10^{5}$ dilutions were transferred into duplicate Petri dishes and labeled accordingly. This was followed by pouring aseptically about $15 \mathrm{ml}$ of molten nutrient agar. The culture was homogenized by gentle spinning of the plates and allowed to solidify. The plates were incubated at $37^{\circ} \mathrm{C}$ for 24 hours. Plates containing 30-300 colonies were counted. The number of colony forming units per gram of a sample (cfu/g) was obtained by multiplying the average colony number with the inverse of the dilution factor.

\section{Enumeration and Detection of Coliform bacteria}

Detection and enumeration of coliform was carried out according to method described by Atlas, (1977). A set of 9 test tubes each containing $9 \mathrm{ml}$ of lactose broth and an inverted Durham tubes were autoclaved to expel air and to sterilize. Similarly, $1 \mathrm{ml}$ from the diluents $10^{1}$ was transferred to the first 3 test tubes, followed by $1 \mathrm{ml}$ from the diluents $10^{2}$ to the second set of 3 test tubes and finally the third diluents $10^{3}$ to the $3^{\text {rd }}$ set of 3 test tubes. All the 9 test tubes were incubated at $37^{\circ} \mathrm{C}$ for 24 hours. Tubes that showed gas and acid production after 24 hours were recorded as positive for the presence of Coliform. Negative tubes were further reincubated for 24 hours. Positive tubes were recorded. Estimate of most probable number of Coliform per gram of sample (MPN/g) was determined by comparing the number of gas positive tubes with the most probable number table. 
BAJOPAS Volume 13 Number 1, June, 2020 Identification of Coliform

A loop full of inoculum from gas positive tubes was streaked on to Eosine methylene blue (EMB) agar plate and incubated at $37^{\circ} \mathrm{C}$ for $24 \mathrm{hrs}$. Colonies which formed bluish black color with green metallic sheen, and reddish colonies were isolated on agar slants. Those colonies showing metallic sheen on EMB were sub cultured into tubes of lactose broth and incubated at $45^{\circ} \mathrm{C}$. The tubes were observed after $24 \mathrm{hrs}$ for gas production. This is the completed test for fecal coliform. Gram stain and other biochemical tests such as Indole, Methyl red, Voges-Proskauer and Citrate Utilization tests (IMVIC), Coagulase and Catalase tests were carried out for the Identification and confirmation of isolates.

\section{Procedure for Indole Test}

Indole test was carried out by preparing a Tryptone broth drawn in to test tubes, sterilized by autoclaving, inoculated with loopful of suspension and incubated at $37^{\circ} \mathrm{C}$ for 24 hours. Three drops of xylene was added in tubes, shaken vigorously and kept for the separation of two layers. One millilitre of Kovac's reagent was added and the formation of pink colour ring indicates positive Indole test.

\section{Procedure for Methyl Red Test}

Methyl red test was carried out by preparing Glucose phosphate broth, dispensed in test tubes, sterilized, inoculated with test culture and incubated at $37^{\circ} \mathrm{C}$ for 24 hours. Five drops of methyl-red indicator was added to the medium for the formation of red colour.

\section{Procedure for Voges-Proskauer Test}

Voges-Proskauer test was carried out by inoculating tubes with the bacterial culture followed by incubation for 48 hours at $37^{\circ} \mathrm{C}$. Separate pipettes were used to pipette $1 \mathrm{ml}$ from each culture tube into clean separate tubes. Eighteen drops $(0.5 \mathrm{ml})$ of Barrit's solution A (a-naphthol) was added to each tube containing glucose phosphate broth followed by the addition of an equal amount of solution $B$ into the same tube. The tubes were shaken at 30 seconds interval. A positive reaction was indicated by the development of a pink color, which turns red in 1-2 hours, after vigorous shaking.

\section{Procedure for Citrate Utilization Test}

Citrate Utilization Test was carried out by distributing melted agar (Simmon Citrate Agar) in to test tubes followed by sterilization at $121.5^{\circ} \mathrm{C}$ for 15 minutes. The test tubes were afterward held in slanted position, inoculated with the given bacterial culture and incubated at $37^{\circ} \mathrm{C}$ for $24 \mathrm{hrs}$. Positive test was indicated by color change of the media from green to blue.

\section{RESULTS AND DISCUSSIONS}

The results of this study are presented in tables $1,2,3$ and 4. Among the sampling areas Kofar Kudu had the highest aerobic mesophilic bacteria counts $4.0 \times 10^{5} \mathrm{cfu} / \mathrm{g}$ followed by Rinji $2.72 \times 10^{5} \mathrm{cfu} / \mathrm{g}$, while Tosaro had the least Aerobic mesophilic bacteria counts of $1.02 \times 10^{5}$ $\mathrm{cfu} / \mathrm{g}$ as indicated in Table 1.Makwalla had the highest coliform count $68 \mathrm{MPN} / \mathrm{g}$ followed by Rinji $37 \mathrm{MPN} / \mathrm{g}$. Tsohuwar Kasuwa had the least coliform counts $8 \mathrm{MPN} / \mathrm{g}$, (Table 2). Result from table 1 shows variation in the microbial contents among the samples which suggest variation in their sources, poor handling procedures and contamination from the processing environment. High coliform count and their differences within sampling areas is an indication of poor microbiological quality of the product. Ndahi et al. (2013) reported microbial load to be a function of the handling personnel and the environment. The results indicated that the samples were contaminated with bacteria as the counts exceeded the minimum safety level $\left(10^{4} \mathrm{cfu} / \mathrm{g}\right)$ for members of the Enterobacteriaceae family. However, it might be a reflection of poor hygienic practices which may contribute to health hazard to the potential consumers. Similarly, Inusa and Sa'id (2017); Osimani et al. (2015) reported that, the initial microbial content of the raw material play significant role in influencing the final microbial load of the finished product. Isolation of members of the Enterobacteriaceae such as $E$. coli, Klebsiella pneumoniae, Salmonella and Shigella signifies danger to the public health. These organisms are capable of producing endotoxins which trigger high fevers in infected individuals, and the enterotoxins which colonize the small intestines and lead to extreme dehydration as a result of vomiting and diarrhea sometimes with severe and fatal outcomes (Amaeze et al., 2016). From the 16 isolated organisms $E$. coli had the highest isolation rate $6(37.5 \%)$ (Table 3), this suggest faecal contamination of the products. $E$. coli is a common flora in the gastrointestinal tract responsible for diarrhea and extra-intestinal infections (CDC, 2011). The result is in conformity with the findings of Ndahi et al. (2013) and Shamsuddeen (2009). Also presence of campylobacter might be due to cross contamination from raw meat to finished product (Tsire). Staphylococcus aureus is a normal flora of the skin, nasal, genital, mouth or anal area in both humans and animals without any symptom of an infection (Matthew et al., 2013). Isolation of $S$. aureus in these study concords with the findings of Lucretia et al. (2018) from Suya sold in Rivers State. 
BAJOPAS Volume 13 Number 1, June, 2020

It is also in agreement with the findings of Yousafzai et al. (2018); Onuorah et al. (2015) and Tijjani and Jumare (2014) from tsire samples in different countries. Presence of $S$. aureus in foods is most of the time an indication of poor human handling, poor environment, unhygienic utensils and equipments used during processing (Igene et al., 2016; Okonko et al., 2013). Infections caused by $S$. aureus are difficult to treat leading to long hospitalization with consequent economic loss (Udobi et al., 2013). These include soft tissue infections, pneumonia, hospital-acquired postoperative wound infections, Staphylococcal food poisoning, impetigo and cellulitis (Charlene et al., 2013). Samples obtained from Dausai and Kofar Kudu had the highest isolation rate $4(80 \%)$ (Table 4 ) probably because of the much commercial activities taking place in the area which can lead to environmental contamination.

Table 1: Total Aerobic Mesophilic Bacterial Count of Tsire sold in Garko Town

\begin{tabular}{lll}
\hline Sampling Area & APC cfu/g & Mean \pm STD \\
\hline Dausai & $2.20 \times 10^{5}$ & $110000 \pm 14142.14$ \\
Kofar Kudu & $4.00 \times 10^{5}$ & $133333.3 \pm 23094.01$ \\
Makwalla & $1.30 \times 10^{5}$ & $32500 \pm 7187.953$ \\
Rinji & $2.72 \times 10^{5}$ & $90666.67 \pm 94769.90$ \\
Tosaro & $1.02 \times 10^{5}$ & $51000 \pm 15556.35$ \\
Tsohuwar Kasuwa & $1.75 \times 10^{5}$ & $35000 \pm 11357.82$ \\
\hline
\end{tabular}

Key: APC: Aerobic Mesophilic Counts

STD: Standard Deviation

Table 2: Total Coliform Count of Tsire sold in Garko Town

\begin{tabular}{lcc}
\hline \multicolumn{1}{c}{ Sampling Area } & TCC MPN/g & Mean \pm STD \\
\hline Dausai & 20 & $6.67 \pm 2.5166$ \\
Kofar Kudu & 32 & $16.00 \pm 5.6569$ \\
Makwalla & 68 & $13.60 \pm 8.7062$ \\
Rinji & 37 & $9.25 \pm 4.7871$ \\
Tosaro & 10 & $5.00 \pm 2.8284$ \\
Tsohuwar Kasuwa & 8 & $4.00 \pm 0.0000$ \\
\hline
\end{tabular}

Table 3: Organisms Isolated from Tsire Sold in Garko

\begin{tabular}{lcl}
\hline Isolated Organism & Frequency & Percentage (\%) \\
\hline Campylobacter & 2 & 06.66 \\
Escherichia coli & 6 & 20.00 \\
Klebsiella pneumoniae & 2 & 06.66 \\
Salmonella species & 1 & 03.33 \\
Shigella & 3 & 10.00 \\
Staphylococcus aureus & 2 & 06.66 \\
Total & 16 & \\
\hline
\end{tabular}

Table 4: Distribution of Organisms within Sampling Area

\begin{tabular}{lcc}
\hline \multicolumn{1}{c}{ Sampling Area } & No. Isolated & Percentage (\%) \\
\hline Dausai & 4 & 80 \\
Kofar Kudu & 4 & 80 \\
Makwalla & 2 & 40 \\
Rinji & 3 & 60 \\
Tosaro & 2 & 40 \\
Tsohuwar Kasuwa & 1 & 20 \\
Total & 16 & \\
\hline
\end{tabular}

\section{CONCLUSION}

Results indicated $4.00 \times 10^{5} \mathrm{CFU} / \mathrm{g}$ as the highest APCs count; while $68 \mathrm{MPN} / \mathrm{g}$ was the highest TCCs from the 30 samples analyzed. Among the isolates, $E$. coli has the highest isolation rate of $6(20 \%)$. Dausai and Kofar kudu were having the highest bacteria count of $4(80 \%)$, each, indicating higher contamination in those locations. 
BAJOPAS Volume 13 Number 1, June, 2020 RECOMMENDATIONS

The following recommendations are tenable:

1. Hygienic practices at all stages of production should be improved to safe guard the consumers against potential health hazard.

2. Monitoring of microbiological contamination of Tsire during preparations, packaging and marketing is essential to ensure product of good microbiological quality for consumers' health.

\section{REFERENCES}

Abdullahi, I. O., Umoh, V. J. and Galadima, M. (2004). Hazards Associated with Kilishi Preparations in Zaria. Nigerian Journal of Microbiology, 18 (1-2): $339-345$.

Ahmadu, J. and Ibrahim E. J., (2013): Determinants of Revenue in Suya Production in BeninCity, Edo State, Nigeria. Nigerian journal of agriculture, food and environment.9(3):1-5

Amaeze, N. Aboh, M. Itohan, A. Felix, E. Olatunji, T. and Oladosu, P. (2016) Microbial Profile, Antibiotic Sensitivity and Heat Resistance of Bacterial Isolates from Commercial Roasted Beef (Suya) in Abuja, Nigeria. JOPAT, 15(2): $22-30$.

Apata, E.S., Kuku1, I.A., Apata, O.C. and Adeyemi, K.O. (2013). Evaluation of Suya(Tsire) - An Intermediate Moisture Meat Product in Ogun State, Nigeria. J. Food Res 2 (1): 87.

Atlas, R. M. (1997) Principles of Microbiology Second Edition. C. Brown Publishers. Pp 802-803.

Borch, E. Kant-Muermans, M. L., Blixt, Y. (1996) Bacterial Spoilage of Meat and Cured Meat Products. Int $\mathrm{J}$ Food Microbiol .33(1): 103-20.

Centre for Disease Control, CDC (2011). "Escherichia coli 0157:H7" Division of Bacterial and Mycotic Diseasesht://www.cdc.gov/nczved/divisi ons/dfbmd/diseases/ecoli_0157h7/.

Charlene, R. J., Johnnie, A. D., and John, B. B., (2013) Prevalence and Characterization of Methicillin-Resistant Staphylococcus aureus Isolates from Retail Meat and Humans in Georgia. American society for Microbiology. J. of clinical microbiology. 12(1):123-6 doi:10.1128/JCM.0316612JCM.03166-12

Egbebi, A.O and Seidu, K., T. (2011). Microbiological Evaluation of Suya (dried smoked

meat) Sold in Ado and Akure, South West Nigeria.European Journal of Experinmental Biology, 1(4):1-5
3. Government should establish regulatory bodies responsible for inculcating hygiene habits to the local producers and vendors in order to prevent instant, cross and post processing contaminations by microbial pathogens.

4. Awareness and sensitization of local food producers about good hygienic practices in food handling and processing.

Falegan, C, R., Akoja, S. D., and Oyarekua, M. A., (2017) Microbiological Assessment of Suya (Sliced Roasted Beef) in Ado-Ekiti Metropolis, Ekiti State, Nigeria. MOJ Biology andMedicine.

Fonkem, D., N. Tanya, V., N. and Ebangi, A., L. (2010). Effect of Season on the Microbiological Quality of Kilishi, a Traditional Cameroonian Dried Beef Product. Tropicultura, 28(1): 10-15.

Food and Agricultural Organization of the United Nations (F A O, 1979). Manual of food quality control 4. Microbiological analysis.

Food and Agriculture Organisation of the United Nation (FAO), 2019. Nigeria at a glance.

Igene J.O., Uwadia, O.E., Ebabhamiegbebho, P.A. and Evivie, S.E., (2016) Shelf life Stability Studies of University of Benin (UNIBEN) Proff's Kilishi Product Asian Journal of Science and Technology 7(1): 2268-2274.

Inusa, S. K. and Said, I. S. (2017) Evaluation of the Chemical and Microbiological Properties Of Kilishi Sold in Kano Metropolis. Journal of Dry land Agriculture, 3 (1): $59-69$.

Lucretia, I. B, Patience, C. Obinna-Echem, Sophia, C. A. (2018) Microbiological quality andantibiotic sensitivity of potential pathogens isolated from meat product (Suya) sold in Rivers State University and its environs. International Journal of Biotechnology and Food Science, 6(4): 67-76.

Matthew, E., Drosos, E., John, L. and Ioanna, P. (2013) MRSA in Africa: Filling the Global Map of Antimicrobial Resistance PLOS One. 8(7): e68024 doi: 10.1371/journal.pone.0068024

Mgbemere, V.N., Akpapunam, M. A. and Igene, J. O., (2011). Effect of Groundnut FlourSubstitution on Yield, Quality and Storage Stability of Kilishi - a Nigerian Indigenous Dried Meat Product. African Journal of Food, Agriculture, Nutrition and Development, $\quad \mathbf{1 1}(2)$ : 4718-4738. 
BAJOPAS Volume 13 Number 1, June, 2020

Mubarak, A. A., Azeez, M. L., Amos A. O., Opeyemi, O. O. (2016) Assessment of Animal Protein Consumption and Food Security Among Rural Households in Kwara State, Nigeria American Journal of Business and Society, 1(4): 233245.

Ndahi, M., D. Kwaga, J., K. P. Bello, M. Kabir J., V. Umoh, .J. Yakubu, S., E. and Nok, A., J. (2013) Prevalence and Antimicrobial Susceptibility of Listeria Monocytogenes and Methicillin-Resistant Staphylococcus aureus Strains from Raw Meat and Meat Products in Zaria, Nigeria. Applied Journal of Microbiology, 58(3):262-9.

Okonko, I.O., Odu, N.N. and Igboh, I.E. (2013). Microbiological Analysis of Kilishi Sold In Port Harcourt, Nigeria. New York Science Journal, 6 (7):37-43.

Osimani, A., Aquilanti, L. and Clementi, F. (2015) Microbiological Quality of Meatbased Meals and Operation of Control Systems within a Food Service Environment. International Food Research Journal 22(4): 1692-1698.

Onuorah, S. Obika, I. Odibo, F. Orji, M. (2015)An Assessment of the Bacteriological Quality of Tsire-Suya (Grilled Beef) sold in Awka, Nigeria. American. J. Life. Sci. Res. 3(4):287292.

Razavilar, V, Khandaghi, J. Barzgari, A. (2010); Isolation of Eschericia coli 0157:H7 from manure fertilized farms and raw vegetables grown on it, in Tabriz city in
Iran. African Journal of Microbiology Research, 4(9): 891-895.

Scallan, E. Hoekstra, R. M. Angulo, F. J.Tauxe, R. V, Widdowson, M. Roy, S. L et al., (2011).Food borne illness acquired in the United States- Major Pathogens. Emerg. Infec Dis, 17(1): 7-15.

Shamsuddeen U (2009). Microbiological quality of spice used in the production of Kilishi a traditionally dried and grilled meat product. Bayero Journal of Pure andApplied Sciences, 2(2): 66-69.

Shamsuddeen, U. (2015) Microbiological Hazard and Critical control point Analysis of Dried and Minced Meat Snacks Produced in Kano Nigeria. Lambert Academic Publishing; Pp 1-36.

Tijani, O.and Jumare, S. (2014). Microblological Quality Assessment of Meat

Sold in KauraNamoda. International Conference on Earth, Environment and Life sciences (EELS) Dubai (UAE).

Udobi, C. E., Obajuluwa, A. F., and Onaolapo, J. A., (2013) Prevalence and Antibiotic Resistance Pattern of MethicillinResistant Staphylococcus aureus from an Orthopaedic Hospital in Nigeria BioMed Research International; 26(6); 6-7.

WHO, 2015 Foodborne diseases in the WHO African Region.

Yousafzai HA, Rind R, Khan MA, Abro SH, Korejo NA, Ejaz M, Kabir A, Shahid M, Memon S. (2019). Microbiological Contamination of Cattle and Meat in Peshawar, Pakistan. J. Anim. Health Prod. 7(1): 1116. 


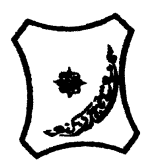

Bayero Journal of Pure and Applied Sciences, 13(1); 40 - 45

Received: September, 2019

Accepted: April, 2020

ISSN $2006-6996$

\title{
BACTERIOLOGICAL QUALITY OF STICK MEAT (Tsire) SOLD IN GARKO LOCAL GOVERNMENT AREA OF KANO STATE, NIGERIA
}

\author{
$*^{1}$ Dahiru A. T. and ${ }^{2}$ Maigari A. K. \\ ${ }^{1}$ Department of Hospitality Management, School of Technology, Kano State Polytechnic, PMB 3348, \\ Kano Nigeria. \\ ${ }^{2}$ Departmnt of Biological Sciences, Bayero University, Kano \\ Corresponding Author: dturajo61@gmail.com; GSM: 08087508262.
}

ABSTRACT

Stick meat, locally called Tsire in Hausa Language, is a significant portion of the diet of a large active population of Northern Nigeria. However, because of the handling and processing methods by the manufacturers as well as the hawking system of stick meat, the meat product may be exposed to both pre- and post-processed product contamination, and thus may poses danger to public health. Therefore, considering the role of Tsire in improving nutrition and increase household income to the populace, the need to improve the processing, distribution and overall quality of the product is simply indispensable. A total of 30 samples (5 samples from each of the 6 sampling points) of Tsire were collected randomly in Garko Town. Aerobic plate counts (APCs) and Total coliform counts (TCCS) of Tsire samples were determined using standard microbiological methods. APCs ranged from $1.02 \times 10^{5}$ to $4.00 \times 10^{5} \mathrm{CFU} / \mathrm{g}$; while TCCs ranged from $8 \mathrm{MPN} / \mathrm{g}$ to $68 \mathrm{MPN} / \mathrm{g}$. From the 30 samples screened, 16(53.33\%) bacteria namely, Campylobacter 2(6.66\%), Escherichia coli 6(20\%), Klebsiella pneumoniae 2(6.66\%), Salmonella spp. 1(3.33\%), Shigella 3(10\%) and Staphylococcus aureus 2(6.66\%) were detected. $E$. coli has the highest isolation rate of 6(20\%), while Salmonella spp. had the least frequency of 1(3.33\%). The distribution of isolated organisms within the study area were as follows: Dausai, 4(80\%), Kofar kudu, 4(80\%), Makwalla, 2(40\%), Rinji, 3(60\%), Tosaro, 2(40\%), and Tsohuwar Kasuwa, 1(20\%). The results have indicated that the Tsire was contaminated with bacteria thus exposing the product to fast deterioration, spoilage and also a vehicle for food borne illness, suggesting for adequate hygienic practices at all the stages, prior to consumption, to ensure safety of the meat product.

Key words: APCs, TCCs, Contamination, Microorganisms, Garko

\section{INTRODUCTION}

Nigeria is one of the developing nations with inadequate food supply and most often deficient in protein content (FAO, 2019). Nigerian's average animal protein intake per head per day is estimated at $7.9 \mathrm{~g}$ as against $35 \mathrm{~g}$ recommended value by Food and Agricultural Organization (Mubarak et al., 2016). These low levels of animal protein intake create great concern as it affects the nutritional status of Nigerians. Hence, there is the need for sufficient supply of animal protein from energy rich animal products to satisfy the nutritional requirements for Nigerians.

Meat is one major source of animal protein largely composed of water, protein and fats which can make it susceptible to microbial contamination within short time leading to spoilage (Apata et al., 2013; Mgbemere et al., 2011). Meat is mostly eaten after it has been cooked or processed in a variety of ways such as sun drying; smoking and roasting with or without fortifications (Borch et al., 1996). In Nigeria meat products such as Tsire, Kilishi and Balangu are locally produced using one or more of these methods in order to meet the nutritional requirements of the teeming Nigerians (Egbebi, 2011).

Tsire is a popular Nigerian traditional processed ready-to-eat roasted stick meat product (Shamsuddeen, 2015). It is sold in public places, along roads, in hotels, parks, quarters and even offices (Falegan et al., 2017). It is prepared from boneless healthy animal flesh such as beef and mutton, spiced with peanut cake, salt, vegetable oil and other flavorings followed by roasting (Shamsuddeen, 2015). Consumption of these products has extended to other parts of African countries such as Ghana, Somali, Cameroun and Chad (Ahmadu and Ibrahim, 2013). 
BAJOPAS Volume 13 Number 1, June, 2020

However, evidence of quality control sticking to procedural hygiene by the handlers during preparation and retailing of these products is poorly documented. Tsire is of great safety risk because of the fact that there are erratic cases of gastroenteritis and symptoms of food infection after consumption (WHO, 2015). Food borne illnesses are one of the major health problems in developing and developed countries (Razavilar, 2010). According to the World Health Organization, WHO (2015), $0.07 \%$ death of the 600 million global burdens of Foodborne illnesses have been reported to be caused by bacteria, viruses, fungi and chemicals. In America $0.27 \%$ of the estimated 48 million affected people is hospitalized and about $0.0063 \%$ deaths are recorded each year (Scallan et al., 2011). More than 91 million people in Africa fall ill and $0.15 \%$ dies each year, making Africa the highest burden bearer of Foodborne diseases per population (WHO, 2015).

Application of a Hazard Analysis Critical Control Point (HACCP) at all stages of meat products preparation is essential in order to ensure its safety. Thus, according to the guidelines of good manufacturing practice, the level of total aerobic bacterial contamination of thermally processed meat products should not exceed $10^{4}\left(\mathrm{cfu} \mathrm{g}^{-1}\right)$. Enterobacteriaceae and faecal coliform contamination in meat products should be within the range of $10^{2}-10^{4}$ and $10-10^{3} \mathrm{cfu} \mathrm{g}^{-1}$, respectively (Shamsuddeen, 2015). The aim of the study is therefore, to assess the total viable bacterial counts of tsire marketed locally within Garko town, and to isolate and identify the organisms at the point of consumption with the intention of promoting public health and food hygiene habits in the Nigerian populace.

\section{MATERIALS AND METHODS Study Area and Population}

Garko is one of the existing 44 local government areas located in Kano south west zone of Kano state with its capital administrative headquarters in the Garko town. It has coordinates $11^{\circ} 39^{\prime} \mathrm{N}$ $8^{\circ} 54^{\prime} \mathrm{E}$, and an area of $450 \mathrm{~km}^{2}$. The projected population of Garko local Government was 225,300 according to the National Population Census report (2018). Garko is known for agricultural activities both farming and animal husbandry. It is popularly known for large scale rice production. Other food crops include sweet potatoes, cassava, onions, sorghum, millet and sugarcane. Cows, sheep and goats are major groups of animals reared by majority of the populace. Meat products processed, retailed and consumed in Garko include roasted meat (Balangu), dried roasted meat (Kilishi), stick meat (Tsire), hide and skin pepper soup (Ragadada) and minced fried meat (Danbunnama).

\section{Samples Collection}

Five samples of Tsire products were collected from 6 different identified locations within Garko town in a sterile foil paper and immediately analyzed for the presence of bacteria.

\section{Sample Preparation}

Sample preparation for the bacteriological analysis was carried out in accordance with the method described by Atlas (1997). Twenty five grams $(25 \mathrm{~g})$ of the sample was homogenized in $225 \mathrm{ml}$ peptone water using Kenwood blender machine to obtain a $10^{1}$ homogenate. The homogenate was thoroughly shaken and $1 \mathrm{ml}$ pipetted into test tubes containing $9 \mathrm{ml}$ of peptone water $\left(10^{2}\right)$. The test tubes were further serially diluted to $10^{5}$.

Total Aerobic Mesophilic Bacterial Count

Total Aerobic mesophilic bacterial count was determined using the method described by Abdullahi et al. (2004) where $1 \mathrm{ml}$ of inoculums from $10^{1}$ to $10^{5}$ dilutions were transferred into duplicate Petri dishes and labeled accordingly. This was followed by pouring aseptically about $15 \mathrm{ml}$ of molten nutrient agar. The culture was homogenized by gentle spinning of the plates and allowed to solidify. The plates were incubated at $37^{\circ} \mathrm{C}$ for 24 hours. Plates containing 30-300 colonies were counted. The number of colony forming units per gram of a sample (cfu/g) was obtained by multiplying the average colony number with the inverse of the dilution factor.

\section{Enumeration and Detection of Coliform bacteria}

Detection and enumeration of coliform was carried out according to method described by Atlas, (1977). A set of 9 test tubes each containing $9 \mathrm{ml}$ of lactose broth and an inverted Durham tubes were autoclaved to expel air and to sterilize. Similarly, $1 \mathrm{ml}$ from the diluents $10^{1}$ was transferred to the first 3 test tubes, followed by $1 \mathrm{ml}$ from the diluents $10^{2}$ to the second set of 3 test tubes and finally the third diluents $10^{3}$ to the $3^{\text {rd }}$ set of 3 test tubes. All the 9 test tubes were incubated at $37^{\circ} \mathrm{C}$ for 24 hours. Tubes that showed gas and acid production after 24 hours were recorded as positive for the presence of Coliform. Negative tubes were further reincubated for 24 hours. Positive tubes were recorded. Estimate of most probable number of Coliform per gram of sample (MPN/g) was determined by comparing the number of gas positive tubes with the most probable number table. 
BAJOPAS Volume 13 Number 1, June, 2020 Identification of Coliform

A loop full of inoculum from gas positive tubes was streaked on to Eosine methylene blue (EMB) agar plate and incubated at $37^{\circ} \mathrm{C}$ for $24 \mathrm{hrs}$. Colonies which formed bluish black color with green metallic sheen, and reddish colonies were isolated on agar slants. Those colonies showing metallic sheen on EMB were sub cultured into tubes of lactose broth and incubated at $45^{\circ} \mathrm{C}$. The tubes were observed after $24 \mathrm{hrs}$ for gas production. This is the completed test for fecal coliform. Gram stain and other biochemical tests such as Indole, Methyl red, Voges-Proskauer and Citrate Utilization tests (IMVIC), Coagulase and Catalase tests were carried out for the Identification and confirmation of isolates.

\section{Procedure for Indole Test}

Indole test was carried out by preparing a Tryptone broth drawn in to test tubes, sterilized by autoclaving, inoculated with loopful of suspension and incubated at $37^{\circ} \mathrm{C}$ for 24 hours. Three drops of xylene was added in tubes, shaken vigorously and kept for the separation of two layers. One millilitre of Kovac's reagent was added and the formation of pink colour ring indicates positive Indole test.

\section{Procedure for Methyl Red Test}

Methyl red test was carried out by preparing Glucose phosphate broth, dispensed in test tubes, sterilized, inoculated with test culture and incubated at $37^{\circ} \mathrm{C}$ for 24 hours. Five drops of methyl-red indicator was added to the medium for the formation of red colour.

\section{Procedure for Voges-Proskauer Test}

Voges-Proskauer test was carried out by inoculating tubes with the bacterial culture followed by incubation for 48 hours at $37^{\circ} \mathrm{C}$. Separate pipettes were used to pipette $1 \mathrm{ml}$ from each culture tube into clean separate tubes. Eighteen drops $(0.5 \mathrm{ml})$ of Barrit's solution A (a-naphthol) was added to each tube containing glucose phosphate broth followed by the addition of an equal amount of solution $B$ into the same tube. The tubes were shaken at 30 seconds interval. A positive reaction was indicated by the development of a pink color, which turns red in 1-2 hours, after vigorous shaking.

\section{Procedure for Citrate Utilization Test}

Citrate Utilization Test was carried out by distributing melted agar (Simmon Citrate Agar) in to test tubes followed by sterilization at $121.5^{\circ} \mathrm{C}$ for 15 minutes. The test tubes were afterward held in slanted position, inoculated with the given bacterial culture and incubated at $37^{\circ} \mathrm{C}$ for $24 \mathrm{hrs}$. Positive test was indicated by color change of the media from green to blue.

\section{RESULTS AND DISCUSSIONS}

The results of this study are presented in tables $1,2,3$ and 4. Among the sampling areas Kofar Kudu had the highest aerobic mesophilic bacteria counts $4.0 \times 10^{5} \mathrm{cfu} / \mathrm{g}$ followed by Rinji $2.72 \times 10^{5} \mathrm{cfu} / \mathrm{g}$, while Tosaro had the least Aerobic mesophilic bacteria counts of $1.02 \times 10^{5}$ $\mathrm{cfu} / \mathrm{g}$ as indicated in Table 1.Makwalla had the highest coliform count $68 \mathrm{MPN} / \mathrm{g}$ followed by Rinji $37 \mathrm{MPN} / \mathrm{g}$. Tsohuwar Kasuwa had the least coliform counts $8 \mathrm{MPN} / \mathrm{g}$, (Table 2). Result from table 1 shows variation in the microbial contents among the samples which suggest variation in their sources, poor handling procedures and contamination from the processing environment. High coliform count and their differences within sampling areas is an indication of poor microbiological quality of the product. Ndahi et al. (2013) reported microbial load to be a function of the handling personnel and the environment. The results indicated that the samples were contaminated with bacteria as the counts exceeded the minimum safety level $\left(10^{4} \mathrm{cfu} / \mathrm{g}\right)$ for members of the Enterobacteriaceae family. However, it might be a reflection of poor hygienic practices which may contribute to health hazard to the potential consumers. Similarly, Inusa and Sa'id (2017); Osimani et al. (2015) reported that, the initial microbial content of the raw material play significant role in influencing the final microbial load of the finished product. Isolation of members of the Enterobacteriaceae such as $E$. coli, Klebsiella pneumoniae, Salmonella and Shigella signifies danger to the public health. These organisms are capable of producing endotoxins which trigger high fevers in infected individuals, and the enterotoxins which colonize the small intestines and lead to extreme dehydration as a result of vomiting and diarrhea sometimes with severe and fatal outcomes (Amaeze et al., 2016). From the 16 isolated organisms $E$. coli had the highest isolation rate $6(37.5 \%)$ (Table 3), this suggest faecal contamination of the products. $E$. coli is a common flora in the gastrointestinal tract responsible for diarrhea and extra-intestinal infections (CDC, 2011). The result is in conformity with the findings of Ndahi et al. (2013) and Shamsuddeen (2009). Also presence of campylobacter might be due to cross contamination from raw meat to finished product (Tsire). Staphylococcus aureus is a normal flora of the skin, nasal, genital, mouth or anal area in both humans and animals without any symptom of an infection (Matthew et al., 2013). Isolation of $S$. aureus in these study concords with the findings of Lucretia et al. (2018) from Suya sold in Rivers State. 
BAJOPAS Volume 13 Number 1, June, 2020

It is also in agreement with the findings of Yousafzai et al. (2018); Onuorah et al. (2015) and Tijjani and Jumare (2014) from tsire samples in different countries. Presence of $S$. aureus in foods is most of the time an indication of poor human handling, poor environment, unhygienic utensils and equipments used during processing (Igene et al., 2016; Okonko et al., 2013). Infections caused by $S$. aureus are difficult to treat leading to long hospitalization with consequent economic loss (Udobi et al., 2013). These include soft tissue infections, pneumonia, hospital-acquired postoperative wound infections, Staphylococcal food poisoning, impetigo and cellulitis (Charlene et al., 2013). Samples obtained from Dausai and Kofar Kudu had the highest isolation rate $4(80 \%)$ (Table 4 ) probably because of the much commercial activities taking place in the area which can lead to environmental contamination.

Table 1: Total Aerobic Mesophilic Bacterial Count of Tsire sold in Garko Town

\begin{tabular}{lll}
\hline Sampling Area & APC cfu/g & Mean \pm STD \\
\hline Dausai & $2.20 \times 10^{5}$ & $110000 \pm 14142.14$ \\
Kofar Kudu & $4.00 \times 10^{5}$ & $133333.3 \pm 23094.01$ \\
Makwalla & $1.30 \times 10^{5}$ & $32500 \pm 7187.953$ \\
Rinji & $2.72 \times 10^{5}$ & $90666.67 \pm 94769.90$ \\
Tosaro & $1.02 \times 10^{5}$ & $51000 \pm 15556.35$ \\
Tsohuwar Kasuwa & $1.75 \times 10^{5}$ & $35000 \pm 11357.82$ \\
\hline
\end{tabular}

Key: APC: Aerobic Mesophilic Counts

STD: Standard Deviation

Table 2: Total Coliform Count of Tsire sold in Garko Town

\begin{tabular}{lcc}
\hline \multicolumn{1}{c}{ Sampling Area } & TCC MPN/g & Mean \pm STD \\
\hline Dausai & 20 & $6.67 \pm 2.5166$ \\
Kofar Kudu & 32 & $16.00 \pm 5.6569$ \\
Makwalla & 68 & $13.60 \pm 8.7062$ \\
Rinji & 37 & $9.25 \pm 4.7871$ \\
Tosaro & 10 & $5.00 \pm 2.8284$ \\
Tsohuwar Kasuwa & 8 & $4.00 \pm 0.0000$ \\
\hline
\end{tabular}

Table 3: Organisms Isolated from Tsire Sold in Garko

\begin{tabular}{lcl}
\hline Isolated Organism & Frequency & Percentage (\%) \\
\hline Campylobacter & 2 & 06.66 \\
Escherichia coli & 6 & 20.00 \\
Klebsiella pneumoniae & 2 & 06.66 \\
Salmonella species & 1 & 03.33 \\
Shigella & 3 & 10.00 \\
Staphylococcus aureus & 2 & 06.66 \\
Total & 16 & \\
\hline
\end{tabular}

Table 4: Distribution of Organisms within Sampling Area

\begin{tabular}{lcc}
\hline \multicolumn{1}{c}{ Sampling Area } & No. Isolated & Percentage (\%) \\
\hline Dausai & 4 & 80 \\
Kofar Kudu & 4 & 80 \\
Makwalla & 2 & 40 \\
Rinji & 3 & 60 \\
Tosaro & 2 & 40 \\
Tsohuwar Kasuwa & 1 & 20 \\
Total & 16 & \\
\hline
\end{tabular}

\section{CONCLUSION}

Results indicated $4.00 \times 10^{5} \mathrm{CFU} / \mathrm{g}$ as the highest APCs count; while $68 \mathrm{MPN} / \mathrm{g}$ was the highest TCCs from the 30 samples analyzed. Among the isolates, $E$. coli has the highest isolation rate of $6(20 \%)$. Dausai and Kofar kudu were having the highest bacteria count of $4(80 \%)$, each, indicating higher contamination in those locations. 
BAJOPAS Volume 13 Number 1, June, 2020 RECOMMENDATIONS

The following recommendations are tenable:

1. Hygienic practices at all stages of production should be improved to safe guard the consumers against potential health hazard.

2. Monitoring of microbiological contamination of Tsire during preparations, packaging and marketing is essential to ensure product of good microbiological quality for consumers' health.

\section{REFERENCES}

Abdullahi, I. O., Umoh, V. J. and Galadima, M. (2004). Hazards Associated with Kilishi Preparations in Zaria. Nigerian Journal of Microbiology, 18 (1-2): $339-345$.

Ahmadu, J. and Ibrahim E. J., (2013): Determinants of Revenue in Suya Production in BeninCity, Edo State, Nigeria. Nigerian journal of agriculture, food and environment.9(3):1-5

Amaeze, N. Aboh, M. Itohan, A. Felix, E. Olatunji, T. and Oladosu, P. (2016) Microbial Profile, Antibiotic Sensitivity and Heat Resistance of Bacterial Isolates from Commercial Roasted Beef (Suya) in Abuja, Nigeria. JOPAT, 15(2): $22-30$.

Apata, E.S., Kuku1, I.A., Apata, O.C. and Adeyemi, K.O. (2013). Evaluation of Suya(Tsire) - An Intermediate Moisture Meat Product in Ogun State, Nigeria. J. Food Res 2 (1): 87.

Atlas, R. M. (1997) Principles of Microbiology Second Edition. C. Brown Publishers. Pp 802-803.

Borch, E. Kant-Muermans, M. L., Blixt, Y. (1996) Bacterial Spoilage of Meat and Cured Meat Products. Int $\mathrm{J}$ Food Microbiol .33(1): 103-20.

Centre for Disease Control, CDC (2011). "Escherichia coli 0157:H7" Division of Bacterial and Mycotic Diseasesht://www.cdc.gov/nczved/divisi ons/dfbmd/diseases/ecoli_0157h7/.

Charlene, R. J., Johnnie, A. D., and John, B. B., (2013) Prevalence and Characterization of Methicillin-Resistant Staphylococcus aureus Isolates from Retail Meat and Humans in Georgia. American society for Microbiology. J. of clinical microbiology. 12(1):123-6 doi:10.1128/JCM.0316612JCM.03166-12

Egbebi, A.O and Seidu, K., T. (2011). Microbiological Evaluation of Suya (dried smoked

meat) Sold in Ado and Akure, South West Nigeria.European Journal of Experinmental Biology, 1(4):1-5
3. Government should establish regulatory bodies responsible for inculcating hygiene habits to the local producers and vendors in order to prevent instant, cross and post processing contaminations by microbial pathogens.

4. Awareness and sensitization of local food producers about good hygienic practices in food handling and processing.

Falegan, C, R., Akoja, S. D., and Oyarekua, M. A., (2017) Microbiological Assessment of Suya (Sliced Roasted Beef) in Ado-Ekiti Metropolis, Ekiti State, Nigeria. MOJ Biology andMedicine.

Fonkem, D., N. Tanya, V., N. and Ebangi, A., L. (2010). Effect of Season on the Microbiological Quality of Kilishi, a Traditional Cameroonian Dried Beef Product. Tropicultura, 28(1): 10-15.

Food and Agricultural Organization of the United Nations (F A O, 1979). Manual of food quality control 4. Microbiological analysis.

Food and Agriculture Organisation of the United Nation (FAO), 2019. Nigeria at a glance.

Igene J.O., Uwadia, O.E., Ebabhamiegbebho, P.A. and Evivie, S.E., (2016) Shelf life Stability Studies of University of Benin (UNIBEN) Proff's Kilishi Product Asian Journal of Science and Technology 7(1): 2268-2274.

Inusa, S. K. and Said, I. S. (2017) Evaluation of the Chemical and Microbiological Properties Of Kilishi Sold in Kano Metropolis. Journal of Dry land Agriculture, 3 (1): $59-69$.

Lucretia, I. B, Patience, C. Obinna-Echem, Sophia, C. A. (2018) Microbiological quality andantibiotic sensitivity of potential pathogens isolated from meat product (Suya) sold in Rivers State University and its environs. International Journal of Biotechnology and Food Science, 6(4): 67-76.

Matthew, E., Drosos, E., John, L. and Ioanna, P. (2013) MRSA in Africa: Filling the Global Map of Antimicrobial Resistance PLOS One. 8(7): e68024 doi: 10.1371/journal.pone.0068024

Mgbemere, V.N., Akpapunam, M. A. and Igene, J. O., (2011). Effect of Groundnut FlourSubstitution on Yield, Quality and Storage Stability of Kilishi - a Nigerian Indigenous Dried Meat Product. African Journal of Food, Agriculture, Nutrition and Development, $\quad \mathbf{1 1}(2)$ : 4718-4738. 
BAJOPAS Volume 13 Number 1, June, 2020

Mubarak, A. A., Azeez, M. L., Amos A. O., Opeyemi, O. O. (2016) Assessment of Animal Protein Consumption and Food Security Among Rural Households in Kwara State, Nigeria American Journal of Business and Society, 1(4): 233245.

Ndahi, M., D. Kwaga, J., K. P. Bello, M. Kabir J., V. Umoh, .J. Yakubu, S., E. and Nok, A., J. (2013) Prevalence and Antimicrobial Susceptibility of Listeria Monocytogenes and Methicillin-Resistant Staphylococcus aureus Strains from Raw Meat and Meat Products in Zaria, Nigeria. Applied Journal of Microbiology, 58(3):262-9.

Okonko, I.O., Odu, N.N. and Igboh, I.E. (2013). Microbiological Analysis of Kilishi Sold In Port Harcourt, Nigeria. New York Science Journal, 6 (7):37-43.

Osimani, A., Aquilanti, L. and Clementi, F. (2015) Microbiological Quality of Meatbased Meals and Operation of Control Systems within a Food Service Environment. International Food Research Journal 22(4): 1692-1698.

Onuorah, S. Obika, I. Odibo, F. Orji, M. (2015)An Assessment of the Bacteriological Quality of Tsire-Suya (Grilled Beef) sold in Awka, Nigeria. American. J. Life. Sci. Res. 3(4):287292.

Razavilar, V, Khandaghi, J. Barzgari, A. (2010); Isolation of Eschericia coli 0157:H7 from manure fertilized farms and raw vegetables grown on it, in Tabriz city in
Iran. African Journal of Microbiology Research, 4(9): 891-895.

Scallan, E. Hoekstra, R. M. Angulo, F. J.Tauxe, R. V, Widdowson, M. Roy, S. L et al., (2011).Food borne illness acquired in the United States- Major Pathogens. Emerg. Infec Dis, 17(1): 7-15.

Shamsuddeen U (2009). Microbiological quality of spice used in the production of Kilishi a traditionally dried and grilled meat product. Bayero Journal of Pure andApplied Sciences, 2(2): 66-69.

Shamsuddeen, U. (2015) Microbiological Hazard and Critical control point Analysis of Dried and Minced Meat Snacks Produced in Kano Nigeria. Lambert Academic Publishing; Pp 1-36.

Tijani, O.and Jumare, S. (2014). Microblological Quality Assessment of Meat

Sold in KauraNamoda. International Conference on Earth, Environment and Life sciences (EELS) Dubai (UAE).

Udobi, C. E., Obajuluwa, A. F., and Onaolapo, J. A., (2013) Prevalence and Antibiotic Resistance Pattern of MethicillinResistant Staphylococcus aureus from an Orthopaedic Hospital in Nigeria BioMed Research International; 26(6); 6-7.

WHO, 2015 Foodborne diseases in the WHO African Region.

Yousafzai HA, Rind R, Khan MA, Abro SH, Korejo NA, Ejaz M, Kabir A, Shahid M, Memon S. (2019). Microbiological Contamination of Cattle and Meat in Peshawar, Pakistan. J. Anim. Health Prod. 7(1): 1116. 


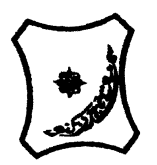

Bayero Journal of Pure and Applied Sciences, 13(1); 40 - 45

Received: September, 2019

Accepted: April, 2020

ISSN $2006-6996$

\title{
BACTERIOLOGICAL QUALITY OF STICK MEAT (Tsire) SOLD IN GARKO LOCAL GOVERNMENT AREA OF KANO STATE, NIGERIA
}

\author{
$*^{1}$ Dahiru A. T. and ${ }^{2}$ Maigari A. K. \\ ${ }^{1}$ Department of Hospitality Management, School of Technology, Kano State Polytechnic, PMB 3348, \\ Kano Nigeria. \\ ${ }^{2}$ Departmnt of Biological Sciences, Bayero University, Kano \\ Corresponding Author: dturajo61@gmail.com; GSM: 08087508262.
}

ABSTRACT

Stick meat, locally called Tsire in Hausa Language, is a significant portion of the diet of a large active population of Northern Nigeria. However, because of the handling and processing methods by the manufacturers as well as the hawking system of stick meat, the meat product may be exposed to both pre- and post-processed product contamination, and thus may poses danger to public health. Therefore, considering the role of Tsire in improving nutrition and increase household income to the populace, the need to improve the processing, distribution and overall quality of the product is simply indispensable. A total of 30 samples (5 samples from each of the 6 sampling points) of Tsire were collected randomly in Garko Town. Aerobic plate counts (APCs) and Total coliform counts (TCCS) of Tsire samples were determined using standard microbiological methods. APCs ranged from $1.02 \times 10^{5}$ to $4.00 \times 10^{5} \mathrm{CFU} / \mathrm{g}$; while TCCs ranged from $8 \mathrm{MPN} / \mathrm{g}$ to $68 \mathrm{MPN} / \mathrm{g}$. From the 30 samples screened, 16(53.33\%) bacteria namely, Campylobacter 2(6.66\%), Escherichia coli 6(20\%), Klebsiella pneumoniae 2(6.66\%), Salmonella spp. 1(3.33\%), Shigella 3(10\%) and Staphylococcus aureus 2(6.66\%) were detected. $E$. coli has the highest isolation rate of 6(20\%), while Salmonella spp. had the least frequency of 1(3.33\%). The distribution of isolated organisms within the study area were as follows: Dausai, 4(80\%), Kofar kudu, 4(80\%), Makwalla, 2(40\%), Rinji, 3(60\%), Tosaro, 2(40\%), and Tsohuwar Kasuwa, 1(20\%). The results have indicated that the Tsire was contaminated with bacteria thus exposing the product to fast deterioration, spoilage and also a vehicle for food borne illness, suggesting for adequate hygienic practices at all the stages, prior to consumption, to ensure safety of the meat product.

Key words: APCs, TCCs, Contamination, Microorganisms, Garko

\section{INTRODUCTION}

Nigeria is one of the developing nations with inadequate food supply and most often deficient in protein content (FAO, 2019). Nigerian's average animal protein intake per head per day is estimated at $7.9 \mathrm{~g}$ as against $35 \mathrm{~g}$ recommended value by Food and Agricultural Organization (Mubarak et al., 2016). These low levels of animal protein intake create great concern as it affects the nutritional status of Nigerians. Hence, there is the need for sufficient supply of animal protein from energy rich animal products to satisfy the nutritional requirements for Nigerians.

Meat is one major source of animal protein largely composed of water, protein and fats which can make it susceptible to microbial contamination within short time leading to spoilage (Apata et al., 2013; Mgbemere et al., 2011). Meat is mostly eaten after it has been cooked or processed in a variety of ways such as sun drying; smoking and roasting with or without fortifications (Borch et al., 1996). In Nigeria meat products such as Tsire, Kilishi and Balangu are locally produced using one or more of these methods in order to meet the nutritional requirements of the teeming Nigerians (Egbebi, 2011).

Tsire is a popular Nigerian traditional processed ready-to-eat roasted stick meat product (Shamsuddeen, 2015). It is sold in public places, along roads, in hotels, parks, quarters and even offices (Falegan et al., 2017). It is prepared from boneless healthy animal flesh such as beef and mutton, spiced with peanut cake, salt, vegetable oil and other flavorings followed by roasting (Shamsuddeen, 2015). Consumption of these products has extended to other parts of African countries such as Ghana, Somali, Cameroun and Chad (Ahmadu and Ibrahim, 2013). 
BAJOPAS Volume 13 Number 1, June, 2020

However, evidence of quality control sticking to procedural hygiene by the handlers during preparation and retailing of these products is poorly documented. Tsire is of great safety risk because of the fact that there are erratic cases of gastroenteritis and symptoms of food infection after consumption (WHO, 2015). Food borne illnesses are one of the major health problems in developing and developed countries (Razavilar, 2010). According to the World Health Organization, WHO (2015), $0.07 \%$ death of the 600 million global burdens of Foodborne illnesses have been reported to be caused by bacteria, viruses, fungi and chemicals. In America $0.27 \%$ of the estimated 48 million affected people is hospitalized and about $0.0063 \%$ deaths are recorded each year (Scallan et al., 2011). More than 91 million people in Africa fall ill and $0.15 \%$ dies each year, making Africa the highest burden bearer of Foodborne diseases per population (WHO, 2015).

Application of a Hazard Analysis Critical Control Point (HACCP) at all stages of meat products preparation is essential in order to ensure its safety. Thus, according to the guidelines of good manufacturing practice, the level of total aerobic bacterial contamination of thermally processed meat products should not exceed $10^{4}\left(\mathrm{cfu} \mathrm{g}^{-1}\right)$. Enterobacteriaceae and faecal coliform contamination in meat products should be within the range of $10^{2}-10^{4}$ and $10-10^{3} \mathrm{cfu} \mathrm{g}^{-1}$, respectively (Shamsuddeen, 2015). The aim of the study is therefore, to assess the total viable bacterial counts of tsire marketed locally within Garko town, and to isolate and identify the organisms at the point of consumption with the intention of promoting public health and food hygiene habits in the Nigerian populace.

\section{MATERIALS AND METHODS Study Area and Population}

Garko is one of the existing 44 local government areas located in Kano south west zone of Kano state with its capital administrative headquarters in the Garko town. It has coordinates $11^{\circ} 39^{\prime} \mathrm{N}$ $8^{\circ} 54^{\prime} \mathrm{E}$, and an area of $450 \mathrm{~km}^{2}$. The projected population of Garko local Government was 225,300 according to the National Population Census report (2018). Garko is known for agricultural activities both farming and animal husbandry. It is popularly known for large scale rice production. Other food crops include sweet potatoes, cassava, onions, sorghum, millet and sugarcane. Cows, sheep and goats are major groups of animals reared by majority of the populace. Meat products processed, retailed and consumed in Garko include roasted meat (Balangu), dried roasted meat (Kilishi), stick meat (Tsire), hide and skin pepper soup (Ragadada) and minced fried meat (Danbunnama).

\section{Samples Collection}

Five samples of Tsire products were collected from 6 different identified locations within Garko town in a sterile foil paper and immediately analyzed for the presence of bacteria.

\section{Sample Preparation}

Sample preparation for the bacteriological analysis was carried out in accordance with the method described by Atlas (1997). Twenty five grams $(25 \mathrm{~g})$ of the sample was homogenized in $225 \mathrm{ml}$ peptone water using Kenwood blender machine to obtain a $10^{1}$ homogenate. The homogenate was thoroughly shaken and $1 \mathrm{ml}$ pipetted into test tubes containing $9 \mathrm{ml}$ of peptone water $\left(10^{2}\right)$. The test tubes were further serially diluted to $10^{5}$.

Total Aerobic Mesophilic Bacterial Count

Total Aerobic mesophilic bacterial count was determined using the method described by Abdullahi et al. (2004) where $1 \mathrm{ml}$ of inoculums from $10^{1}$ to $10^{5}$ dilutions were transferred into duplicate Petri dishes and labeled accordingly. This was followed by pouring aseptically about $15 \mathrm{ml}$ of molten nutrient agar. The culture was homogenized by gentle spinning of the plates and allowed to solidify. The plates were incubated at $37^{\circ} \mathrm{C}$ for 24 hours. Plates containing 30-300 colonies were counted. The number of colony forming units per gram of a sample (cfu/g) was obtained by multiplying the average colony number with the inverse of the dilution factor.

\section{Enumeration and Detection of Coliform bacteria}

Detection and enumeration of coliform was carried out according to method described by Atlas, (1977). A set of 9 test tubes each containing $9 \mathrm{ml}$ of lactose broth and an inverted Durham tubes were autoclaved to expel air and to sterilize. Similarly, $1 \mathrm{ml}$ from the diluents $10^{1}$ was transferred to the first 3 test tubes, followed by $1 \mathrm{ml}$ from the diluents $10^{2}$ to the second set of 3 test tubes and finally the third diluents $10^{3}$ to the $3^{\text {rd }}$ set of 3 test tubes. All the 9 test tubes were incubated at $37^{\circ} \mathrm{C}$ for 24 hours. Tubes that showed gas and acid production after 24 hours were recorded as positive for the presence of Coliform. Negative tubes were further reincubated for 24 hours. Positive tubes were recorded. Estimate of most probable number of Coliform per gram of sample (MPN/g) was determined by comparing the number of gas positive tubes with the most probable number table. 
BAJOPAS Volume 13 Number 1, June, 2020 Identification of Coliform

A loop full of inoculum from gas positive tubes was streaked on to Eosine methylene blue (EMB) agar plate and incubated at $37^{\circ} \mathrm{C}$ for $24 \mathrm{hrs}$. Colonies which formed bluish black color with green metallic sheen, and reddish colonies were isolated on agar slants. Those colonies showing metallic sheen on EMB were sub cultured into tubes of lactose broth and incubated at $45^{\circ} \mathrm{C}$. The tubes were observed after $24 \mathrm{hrs}$ for gas production. This is the completed test for fecal coliform. Gram stain and other biochemical tests such as Indole, Methyl red, Voges-Proskauer and Citrate Utilization tests (IMVIC), Coagulase and Catalase tests were carried out for the Identification and confirmation of isolates.

\section{Procedure for Indole Test}

Indole test was carried out by preparing a Tryptone broth drawn in to test tubes, sterilized by autoclaving, inoculated with loopful of suspension and incubated at $37^{\circ} \mathrm{C}$ for 24 hours. Three drops of xylene was added in tubes, shaken vigorously and kept for the separation of two layers. One millilitre of Kovac's reagent was added and the formation of pink colour ring indicates positive Indole test.

\section{Procedure for Methyl Red Test}

Methyl red test was carried out by preparing Glucose phosphate broth, dispensed in test tubes, sterilized, inoculated with test culture and incubated at $37^{\circ} \mathrm{C}$ for 24 hours. Five drops of methyl-red indicator was added to the medium for the formation of red colour.

\section{Procedure for Voges-Proskauer Test}

Voges-Proskauer test was carried out by inoculating tubes with the bacterial culture followed by incubation for 48 hours at $37^{\circ} \mathrm{C}$. Separate pipettes were used to pipette $1 \mathrm{ml}$ from each culture tube into clean separate tubes. Eighteen drops $(0.5 \mathrm{ml})$ of Barrit's solution A (a-naphthol) was added to each tube containing glucose phosphate broth followed by the addition of an equal amount of solution $B$ into the same tube. The tubes were shaken at 30 seconds interval. A positive reaction was indicated by the development of a pink color, which turns red in 1-2 hours, after vigorous shaking.

\section{Procedure for Citrate Utilization Test}

Citrate Utilization Test was carried out by distributing melted agar (Simmon Citrate Agar) in to test tubes followed by sterilization at $121.5^{\circ} \mathrm{C}$ for 15 minutes. The test tubes were afterward held in slanted position, inoculated with the given bacterial culture and incubated at $37^{\circ} \mathrm{C}$ for $24 \mathrm{hrs}$. Positive test was indicated by color change of the media from green to blue.

\section{RESULTS AND DISCUSSIONS}

The results of this study are presented in tables $1,2,3$ and 4. Among the sampling areas Kofar Kudu had the highest aerobic mesophilic bacteria counts $4.0 \times 10^{5} \mathrm{cfu} / \mathrm{g}$ followed by Rinji $2.72 \times 10^{5} \mathrm{cfu} / \mathrm{g}$, while Tosaro had the least Aerobic mesophilic bacteria counts of $1.02 \times 10^{5}$ $\mathrm{cfu} / \mathrm{g}$ as indicated in Table 1.Makwalla had the highest coliform count $68 \mathrm{MPN} / \mathrm{g}$ followed by Rinji $37 \mathrm{MPN} / \mathrm{g}$. Tsohuwar Kasuwa had the least coliform counts $8 \mathrm{MPN} / \mathrm{g}$, (Table 2). Result from table 1 shows variation in the microbial contents among the samples which suggest variation in their sources, poor handling procedures and contamination from the processing environment. High coliform count and their differences within sampling areas is an indication of poor microbiological quality of the product. Ndahi et al. (2013) reported microbial load to be a function of the handling personnel and the environment. The results indicated that the samples were contaminated with bacteria as the counts exceeded the minimum safety level $\left(10^{4} \mathrm{cfu} / \mathrm{g}\right)$ for members of the Enterobacteriaceae family. However, it might be a reflection of poor hygienic practices which may contribute to health hazard to the potential consumers. Similarly, Inusa and Sa'id (2017); Osimani et al. (2015) reported that, the initial microbial content of the raw material play significant role in influencing the final microbial load of the finished product. Isolation of members of the Enterobacteriaceae such as $E$. coli, Klebsiella pneumoniae, Salmonella and Shigella signifies danger to the public health. These organisms are capable of producing endotoxins which trigger high fevers in infected individuals, and the enterotoxins which colonize the small intestines and lead to extreme dehydration as a result of vomiting and diarrhea sometimes with severe and fatal outcomes (Amaeze et al., 2016). From the 16 isolated organisms $E$. coli had the highest isolation rate $6(37.5 \%)$ (Table 3), this suggest faecal contamination of the products. $E$. coli is a common flora in the gastrointestinal tract responsible for diarrhea and extra-intestinal infections (CDC, 2011). The result is in conformity with the findings of Ndahi et al. (2013) and Shamsuddeen (2009). Also presence of campylobacter might be due to cross contamination from raw meat to finished product (Tsire). Staphylococcus aureus is a normal flora of the skin, nasal, genital, mouth or anal area in both humans and animals without any symptom of an infection (Matthew et al., 2013). Isolation of $S$. aureus in these study concords with the findings of Lucretia et al. (2018) from Suya sold in Rivers State. 
BAJOPAS Volume 13 Number 1, June, 2020

It is also in agreement with the findings of Yousafzai et al. (2018); Onuorah et al. (2015) and Tijjani and Jumare (2014) from tsire samples in different countries. Presence of $S$. aureus in foods is most of the time an indication of poor human handling, poor environment, unhygienic utensils and equipments used during processing (Igene et al., 2016; Okonko et al., 2013). Infections caused by $S$. aureus are difficult to treat leading to long hospitalization with consequent economic loss (Udobi et al., 2013). These include soft tissue infections, pneumonia, hospital-acquired postoperative wound infections, Staphylococcal food poisoning, impetigo and cellulitis (Charlene et al., 2013). Samples obtained from Dausai and Kofar Kudu had the highest isolation rate $4(80 \%)$ (Table 4 ) probably because of the much commercial activities taking place in the area which can lead to environmental contamination.

Table 1: Total Aerobic Mesophilic Bacterial Count of Tsire sold in Garko Town

\begin{tabular}{lll}
\hline Sampling Area & APC cfu/g & Mean \pm STD \\
\hline Dausai & $2.20 \times 10^{5}$ & $110000 \pm 14142.14$ \\
Kofar Kudu & $4.00 \times 10^{5}$ & $133333.3 \pm 23094.01$ \\
Makwalla & $1.30 \times 10^{5}$ & $32500 \pm 7187.953$ \\
Rinji & $2.72 \times 10^{5}$ & $90666.67 \pm 94769.90$ \\
Tosaro & $1.02 \times 10^{5}$ & $51000 \pm 15556.35$ \\
Tsohuwar Kasuwa & $1.75 \times 10^{5}$ & $35000 \pm 11357.82$ \\
\hline
\end{tabular}

Key: APC: Aerobic Mesophilic Counts

STD: Standard Deviation

Table 2: Total Coliform Count of Tsire sold in Garko Town

\begin{tabular}{lcc}
\hline \multicolumn{1}{c}{ Sampling Area } & TCC MPN/g & Mean \pm STD \\
\hline Dausai & 20 & $6.67 \pm 2.5166$ \\
Kofar Kudu & 32 & $16.00 \pm 5.6569$ \\
Makwalla & 68 & $13.60 \pm 8.7062$ \\
Rinji & 37 & $9.25 \pm 4.7871$ \\
Tosaro & 10 & $5.00 \pm 2.8284$ \\
Tsohuwar Kasuwa & 8 & $4.00 \pm 0.0000$ \\
\hline
\end{tabular}

Table 3: Organisms Isolated from Tsire Sold in Garko

\begin{tabular}{lcl}
\hline Isolated Organism & Frequency & Percentage (\%) \\
\hline Campylobacter & 2 & 06.66 \\
Escherichia coli & 6 & 20.00 \\
Klebsiella pneumoniae & 2 & 06.66 \\
Salmonella species & 1 & 03.33 \\
Shigella & 3 & 10.00 \\
Staphylococcus aureus & 2 & 06.66 \\
Total & 16 & \\
\hline
\end{tabular}

Table 4: Distribution of Organisms within Sampling Area

\begin{tabular}{lcc}
\hline \multicolumn{1}{c}{ Sampling Area } & No. Isolated & Percentage (\%) \\
\hline Dausai & 4 & 80 \\
Kofar Kudu & 4 & 80 \\
Makwalla & 2 & 40 \\
Rinji & 3 & 60 \\
Tosaro & 2 & 40 \\
Tsohuwar Kasuwa & 1 & 20 \\
Total & 16 & \\
\hline
\end{tabular}

\section{CONCLUSION}

Results indicated $4.00 \times 10^{5} \mathrm{CFU} / \mathrm{g}$ as the highest APCs count; while $68 \mathrm{MPN} / \mathrm{g}$ was the highest TCCs from the 30 samples analyzed. Among the isolates, $E$. coli has the highest isolation rate of $6(20 \%)$. Dausai and Kofar kudu were having the highest bacteria count of $4(80 \%)$, each, indicating higher contamination in those locations. 
BAJOPAS Volume 13 Number 1, June, 2020 RECOMMENDATIONS

The following recommendations are tenable:

1. Hygienic practices at all stages of production should be improved to safe guard the consumers against potential health hazard.

2. Monitoring of microbiological contamination of Tsire during preparations, packaging and marketing is essential to ensure product of good microbiological quality for consumers' health.

\section{REFERENCES}

Abdullahi, I. O., Umoh, V. J. and Galadima, M. (2004). Hazards Associated with Kilishi Preparations in Zaria. Nigerian Journal of Microbiology, 18 (1-2): $339-345$.

Ahmadu, J. and Ibrahim E. J., (2013): Determinants of Revenue in Suya Production in BeninCity, Edo State, Nigeria. Nigerian journal of agriculture, food and environment.9(3):1-5

Amaeze, N. Aboh, M. Itohan, A. Felix, E. Olatunji, T. and Oladosu, P. (2016) Microbial Profile, Antibiotic Sensitivity and Heat Resistance of Bacterial Isolates from Commercial Roasted Beef (Suya) in Abuja, Nigeria. JOPAT, 15(2): $22-30$.

Apata, E.S., Kuku1, I.A., Apata, O.C. and Adeyemi, K.O. (2013). Evaluation of Suya(Tsire) - An Intermediate Moisture Meat Product in Ogun State, Nigeria. J. Food Res 2 (1): 87.

Atlas, R. M. (1997) Principles of Microbiology Second Edition. C. Brown Publishers. Pp 802-803.

Borch, E. Kant-Muermans, M. L., Blixt, Y. (1996) Bacterial Spoilage of Meat and Cured Meat Products. Int $\mathrm{J}$ Food Microbiol .33(1): 103-20.

Centre for Disease Control, CDC (2011). "Escherichia coli 0157:H7" Division of Bacterial and Mycotic Diseasesht://www.cdc.gov/nczved/divisi ons/dfbmd/diseases/ecoli_0157h7/.

Charlene, R. J., Johnnie, A. D., and John, B. B., (2013) Prevalence and Characterization of Methicillin-Resistant Staphylococcus aureus Isolates from Retail Meat and Humans in Georgia. American society for Microbiology. J. of clinical microbiology. 12(1):123-6 doi:10.1128/JCM.0316612JCM.03166-12

Egbebi, A.O and Seidu, K., T. (2011). Microbiological Evaluation of Suya (dried smoked

meat) Sold in Ado and Akure, South West Nigeria.European Journal of Experinmental Biology, 1(4):1-5
3. Government should establish regulatory bodies responsible for inculcating hygiene habits to the local producers and vendors in order to prevent instant, cross and post processing contaminations by microbial pathogens.

4. Awareness and sensitization of local food producers about good hygienic practices in food handling and processing.

Falegan, C, R., Akoja, S. D., and Oyarekua, M. A., (2017) Microbiological Assessment of Suya (Sliced Roasted Beef) in Ado-Ekiti Metropolis, Ekiti State, Nigeria. MOJ Biology andMedicine.

Fonkem, D., N. Tanya, V., N. and Ebangi, A., L. (2010). Effect of Season on the Microbiological Quality of Kilishi, a Traditional Cameroonian Dried Beef Product. Tropicultura, 28(1): 10-15.

Food and Agricultural Organization of the United Nations (F A O, 1979). Manual of food quality control 4. Microbiological analysis.

Food and Agriculture Organisation of the United Nation (FAO), 2019. Nigeria at a glance.

Igene J.O., Uwadia, O.E., Ebabhamiegbebho, P.A. and Evivie, S.E., (2016) Shelf life Stability Studies of University of Benin (UNIBEN) Proff's Kilishi Product Asian Journal of Science and Technology 7(1): 2268-2274.

Inusa, S. K. and Said, I. S. (2017) Evaluation of the Chemical and Microbiological Properties Of Kilishi Sold in Kano Metropolis. Journal of Dry land Agriculture, 3 (1): $59-69$.

Lucretia, I. B, Patience, C. Obinna-Echem, Sophia, C. A. (2018) Microbiological quality andantibiotic sensitivity of potential pathogens isolated from meat product (Suya) sold in Rivers State University and its environs. International Journal of Biotechnology and Food Science, 6(4): 67-76.

Matthew, E., Drosos, E., John, L. and Ioanna, P. (2013) MRSA in Africa: Filling the Global Map of Antimicrobial Resistance PLOS One. 8(7): e68024 doi: 10.1371/journal.pone.0068024

Mgbemere, V.N., Akpapunam, M. A. and Igene, J. O., (2011). Effect of Groundnut FlourSubstitution on Yield, Quality and Storage Stability of Kilishi - a Nigerian Indigenous Dried Meat Product. African Journal of Food, Agriculture, Nutrition and Development, $\quad \mathbf{1 1}(2)$ : 4718-4738. 
BAJOPAS Volume 13 Number 1, June, 2020

Mubarak, A. A., Azeez, M. L., Amos A. O., Opeyemi, O. O. (2016) Assessment of Animal Protein Consumption and Food Security Among Rural Households in Kwara State, Nigeria American Journal of Business and Society, 1(4): 233245.

Ndahi, M., D. Kwaga, J., K. P. Bello, M. Kabir J., V. Umoh, .J. Yakubu, S., E. and Nok, A., J. (2013) Prevalence and Antimicrobial Susceptibility of Listeria Monocytogenes and Methicillin-Resistant Staphylococcus aureus Strains from Raw Meat and Meat Products in Zaria, Nigeria. Applied Journal of Microbiology, 58(3):262-9.

Okonko, I.O., Odu, N.N. and Igboh, I.E. (2013). Microbiological Analysis of Kilishi Sold In Port Harcourt, Nigeria. New York Science Journal, 6 (7):37-43.

Osimani, A., Aquilanti, L. and Clementi, F. (2015) Microbiological Quality of Meatbased Meals and Operation of Control Systems within a Food Service Environment. International Food Research Journal 22(4): 1692-1698.

Onuorah, S. Obika, I. Odibo, F. Orji, M. (2015)An Assessment of the Bacteriological Quality of Tsire-Suya (Grilled Beef) sold in Awka, Nigeria. American. J. Life. Sci. Res. 3(4):287292.

Razavilar, V, Khandaghi, J. Barzgari, A. (2010); Isolation of Eschericia coli 0157:H7 from manure fertilized farms and raw vegetables grown on it, in Tabriz city in
Iran. African Journal of Microbiology Research, 4(9): 891-895.

Scallan, E. Hoekstra, R. M. Angulo, F. J.Tauxe, R. V, Widdowson, M. Roy, S. L et al., (2011).Food borne illness acquired in the United States- Major Pathogens. Emerg. Infec Dis, 17(1): 7-15.

Shamsuddeen U (2009). Microbiological quality of spice used in the production of Kilishi a traditionally dried and grilled meat product. Bayero Journal of Pure andApplied Sciences, 2(2): 66-69.

Shamsuddeen, U. (2015) Microbiological Hazard and Critical control point Analysis of Dried and Minced Meat Snacks Produced in Kano Nigeria. Lambert Academic Publishing; Pp 1-36.

Tijani, O.and Jumare, S. (2014). Microblological Quality Assessment of Meat

Sold in KauraNamoda. International Conference on Earth, Environment and Life sciences (EELS) Dubai (UAE).

Udobi, C. E., Obajuluwa, A. F., and Onaolapo, J. A., (2013) Prevalence and Antibiotic Resistance Pattern of MethicillinResistant Staphylococcus aureus from an Orthopaedic Hospital in Nigeria BioMed Research International; 26(6); 6-7.

WHO, 2015 Foodborne diseases in the WHO African Region.

Yousafzai HA, Rind R, Khan MA, Abro SH, Korejo NA, Ejaz M, Kabir A, Shahid M, Memon S. (2019). Microbiological Contamination of Cattle and Meat in Peshawar, Pakistan. J. Anim. Health Prod. 7(1): 1116. 


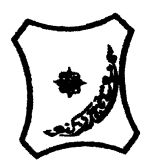

Bayero Journal of Pure and Applied Sciences, 13(1); 40 - 45

Received: September, 2019

Accepted: April, 2020

ISSN $2006-6996$

\title{
BACTERIOLOGICAL QUALITY OF STICK MEAT (Tsire) SOLD IN GARKO LOCAL GOVERNMENT AREA OF KANO STATE, NIGERIA
}

\author{
$*^{1}$ Dahiru A. T. and ${ }^{2}$ Maigari A. K. \\ ${ }^{1}$ Department of Hospitality Management, School of Technology, Kano State Polytechnic, PMB 3348, \\ Kano Nigeria. \\ ${ }^{2}$ Departmnt of Biological Sciences, Bayero University, Kano \\ Corresponding Author: dturajo61@gmail.com; GSM: 08087508262.
}

ABSTRACT

Stick meat, locally called Tsire in Hausa Language, is a significant portion of the diet of a large active population of Northern Nigeria. However, because of the handling and processing methods by the manufacturers as well as the hawking system of stick meat, the meat product may be exposed to both pre- and post-processed product contamination, and thus may poses danger to public health. Therefore, considering the role of Tsire in improving nutrition and increase household income to the populace, the need to improve the processing, distribution and overall quality of the product is simply indispensable. A total of 30 samples (5 samples from each of the 6 sampling points) of Tsire were collected randomly in Garko Town. Aerobic plate counts (APCs) and Total coliform counts (TCCS) of Tsire samples were determined using standard microbiological methods. APCs ranged from $1.02 \times 10^{5}$ to $4.00 \times 10^{5} \mathrm{CFU} / \mathrm{g}$; while TCCs ranged from $8 \mathrm{MPN} / \mathrm{g}$ to $68 \mathrm{MPN} / \mathrm{g}$. From the 30 samples screened, 16(53.33\%) bacteria namely, Campylobacter 2(6.66\%), Escherichia coli 6(20\%), Klebsiella pneumoniae 2(6.66\%), Salmonella spp. 1(3.33\%), Shigella 3(10\%) and Staphylococcus aureus 2(6.66\%) were detected. $E$. coli has the highest isolation rate of 6(20\%), while Salmonella spp. had the least frequency of 1(3.33\%). The distribution of isolated organisms within the study area were as follows: Dausai, 4(80\%), Kofar kudu, 4(80\%), Makwalla, 2(40\%), Rinji, 3(60\%), Tosaro, 2(40\%), and Tsohuwar Kasuwa, 1(20\%). The results have indicated that the Tsire was contaminated with bacteria thus exposing the product to fast deterioration, spoilage and also a vehicle for food borne illness, suggesting for adequate hygienic practices at all the stages, prior to consumption, to ensure safety of the meat product.

Key words: APCs, TCCs, Contamination, Microorganisms, Garko

\section{INTRODUCTION}

Nigeria is one of the developing nations with inadequate food supply and most often deficient in protein content (FAO, 2019). Nigerian's average animal protein intake per head per day is estimated at $7.9 \mathrm{~g}$ as against $35 \mathrm{~g}$ recommended value by Food and Agricultural Organization (Mubarak et al., 2016). These low levels of animal protein intake create great concern as it affects the nutritional status of Nigerians. Hence, there is the need for sufficient supply of animal protein from energy rich animal products to satisfy the nutritional requirements for Nigerians.

Meat is one major source of animal protein largely composed of water, protein and fats which can make it susceptible to microbial contamination within short time leading to spoilage (Apata et al., 2013; Mgbemere et al., 2011). Meat is mostly eaten after it has been cooked or processed in a variety of ways such as sun drying; smoking and roasting with or without fortifications (Borch et al., 1996). In Nigeria meat products such as Tsire, Kilishi and Balangu are locally produced using one or more of these methods in order to meet the nutritional requirements of the teeming Nigerians (Egbebi, 2011).

Tsire is a popular Nigerian traditional processed ready-to-eat roasted stick meat product (Shamsuddeen, 2015). It is sold in public places, along roads, in hotels, parks, quarters and even offices (Falegan et al., 2017). It is prepared from boneless healthy animal flesh such as beef and mutton, spiced with peanut cake, salt, vegetable oil and other flavorings followed by roasting (Shamsuddeen, 2015). Consumption of these products has extended to other parts of African countries such as Ghana, Somali, Cameroun and Chad (Ahmadu and Ibrahim, 2013). 
BAJOPAS Volume 13 Number 1, June, 2020

However, evidence of quality control sticking to procedural hygiene by the handlers during preparation and retailing of these products is poorly documented. Tsire is of great safety risk because of the fact that there are erratic cases of gastroenteritis and symptoms of food infection after consumption (WHO, 2015). Food borne illnesses are one of the major health problems in developing and developed countries (Razavilar, 2010). According to the World Health Organization, WHO (2015), $0.07 \%$ death of the 600 million global burdens of Foodborne illnesses have been reported to be caused by bacteria, viruses, fungi and chemicals. In America $0.27 \%$ of the estimated 48 million affected people is hospitalized and about $0.0063 \%$ deaths are recorded each year (Scallan et al., 2011). More than 91 million people in Africa fall ill and $0.15 \%$ dies each year, making Africa the highest burden bearer of Foodborne diseases per population (WHO, 2015).

Application of a Hazard Analysis Critical Control Point (HACCP) at all stages of meat products preparation is essential in order to ensure its safety. Thus, according to the guidelines of good manufacturing practice, the level of total aerobic bacterial contamination of thermally processed meat products should not exceed $10^{4}\left(\mathrm{cfu} \mathrm{g}^{-1}\right)$. Enterobacteriaceae and faecal coliform contamination in meat products should be within the range of $10^{2}-10^{4}$ and $10-10^{3} \mathrm{cfu} \mathrm{g}^{-1}$, respectively (Shamsuddeen, 2015). The aim of the study is therefore, to assess the total viable bacterial counts of tsire marketed locally within Garko town, and to isolate and identify the organisms at the point of consumption with the intention of promoting public health and food hygiene habits in the Nigerian populace.

\section{MATERIALS AND METHODS Study Area and Population}

Garko is one of the existing 44 local government areas located in Kano south west zone of Kano state with its capital administrative headquarters in the Garko town. It has coordinates $11^{\circ} 39^{\prime} \mathrm{N}$ $8^{\circ} 54^{\prime} \mathrm{E}$, and an area of $450 \mathrm{~km}^{2}$. The projected population of Garko local Government was 225,300 according to the National Population Census report (2018). Garko is known for agricultural activities both farming and animal husbandry. It is popularly known for large scale rice production. Other food crops include sweet potatoes, cassava, onions, sorghum, millet and sugarcane. Cows, sheep and goats are major groups of animals reared by majority of the populace. Meat products processed, retailed and consumed in Garko include roasted meat (Balangu), dried roasted meat (Kilishi), stick meat (Tsire), hide and skin pepper soup (Ragadada) and minced fried meat (Danbunnama).

\section{Samples Collection}

Five samples of Tsire products were collected from 6 different identified locations within Garko town in a sterile foil paper and immediately analyzed for the presence of bacteria.

\section{Sample Preparation}

Sample preparation for the bacteriological analysis was carried out in accordance with the method described by Atlas (1997). Twenty five grams $(25 \mathrm{~g})$ of the sample was homogenized in $225 \mathrm{ml}$ peptone water using Kenwood blender machine to obtain a $10^{1}$ homogenate. The homogenate was thoroughly shaken and $1 \mathrm{ml}$ pipetted into test tubes containing $9 \mathrm{ml}$ of peptone water $\left(10^{2}\right)$. The test tubes were further serially diluted to $10^{5}$.

Total Aerobic Mesophilic Bacterial Count

Total Aerobic mesophilic bacterial count was determined using the method described by Abdullahi et al. (2004) where $1 \mathrm{ml}$ of inoculums from $10^{1}$ to $10^{5}$ dilutions were transferred into duplicate Petri dishes and labeled accordingly. This was followed by pouring aseptically about $15 \mathrm{ml}$ of molten nutrient agar. The culture was homogenized by gentle spinning of the plates and allowed to solidify. The plates were incubated at $37^{\circ} \mathrm{C}$ for 24 hours. Plates containing 30-300 colonies were counted. The number of colony forming units per gram of a sample (cfu/g) was obtained by multiplying the average colony number with the inverse of the dilution factor.

\section{Enumeration and Detection of Coliform bacteria}

Detection and enumeration of coliform was carried out according to method described by Atlas, (1977). A set of 9 test tubes each containing $9 \mathrm{ml}$ of lactose broth and an inverted Durham tubes were autoclaved to expel air and to sterilize. Similarly, $1 \mathrm{ml}$ from the diluents $10^{1}$ was transferred to the first 3 test tubes, followed by $1 \mathrm{ml}$ from the diluents $10^{2}$ to the second set of 3 test tubes and finally the third diluents $10^{3}$ to the $3^{\text {rd }}$ set of 3 test tubes. All the 9 test tubes were incubated at $37^{\circ} \mathrm{C}$ for 24 hours. Tubes that showed gas and acid production after 24 hours were recorded as positive for the presence of Coliform. Negative tubes were further reincubated for 24 hours. Positive tubes were recorded. Estimate of most probable number of Coliform per gram of sample (MPN/g) was determined by comparing the number of gas positive tubes with the most probable number table. 
BAJOPAS Volume 13 Number 1, June, 2020 Identification of Coliform

A loop full of inoculum from gas positive tubes was streaked on to Eosine methylene blue (EMB) agar plate and incubated at $37^{\circ} \mathrm{C}$ for $24 \mathrm{hrs}$. Colonies which formed bluish black color with green metallic sheen, and reddish colonies were isolated on agar slants. Those colonies showing metallic sheen on EMB were sub cultured into tubes of lactose broth and incubated at $45^{\circ} \mathrm{C}$. The tubes were observed after $24 \mathrm{hrs}$ for gas production. This is the completed test for fecal coliform. Gram stain and other biochemical tests such as Indole, Methyl red, Voges-Proskauer and Citrate Utilization tests (IMVIC), Coagulase and Catalase tests were carried out for the Identification and confirmation of isolates.

\section{Procedure for Indole Test}

Indole test was carried out by preparing a Tryptone broth drawn in to test tubes, sterilized by autoclaving, inoculated with loopful of suspension and incubated at $37^{\circ} \mathrm{C}$ for 24 hours. Three drops of xylene was added in tubes, shaken vigorously and kept for the separation of two layers. One millilitre of Kovac's reagent was added and the formation of pink colour ring indicates positive Indole test.

\section{Procedure for Methyl Red Test}

Methyl red test was carried out by preparing Glucose phosphate broth, dispensed in test tubes, sterilized, inoculated with test culture and incubated at $37^{\circ} \mathrm{C}$ for 24 hours. Five drops of methyl-red indicator was added to the medium for the formation of red colour.

\section{Procedure for Voges-Proskauer Test}

Voges-Proskauer test was carried out by inoculating tubes with the bacterial culture followed by incubation for 48 hours at $37^{\circ} \mathrm{C}$. Separate pipettes were used to pipette $1 \mathrm{ml}$ from each culture tube into clean separate tubes. Eighteen drops $(0.5 \mathrm{ml})$ of Barrit's solution A (a-naphthol) was added to each tube containing glucose phosphate broth followed by the addition of an equal amount of solution $B$ into the same tube. The tubes were shaken at 30 seconds interval. A positive reaction was indicated by the development of a pink color, which turns red in 1-2 hours, after vigorous shaking.

\section{Procedure for Citrate Utilization Test}

Citrate Utilization Test was carried out by distributing melted agar (Simmon Citrate Agar) in to test tubes followed by sterilization at $121.5^{\circ} \mathrm{C}$ for 15 minutes. The test tubes were afterward held in slanted position, inoculated with the given bacterial culture and incubated at $37^{\circ} \mathrm{C}$ for $24 \mathrm{hrs}$. Positive test was indicated by color change of the media from green to blue.

\section{RESULTS AND DISCUSSIONS}

The results of this study are presented in tables $1,2,3$ and 4. Among the sampling areas Kofar Kudu had the highest aerobic mesophilic bacteria counts $4.0 \times 10^{5} \mathrm{cfu} / \mathrm{g}$ followed by Rinji $2.72 \times 10^{5} \mathrm{cfu} / \mathrm{g}$, while Tosaro had the least Aerobic mesophilic bacteria counts of $1.02 \times 10^{5}$ $\mathrm{cfu} / \mathrm{g}$ as indicated in Table 1.Makwalla had the highest coliform count $68 \mathrm{MPN} / \mathrm{g}$ followed by Rinji $37 \mathrm{MPN} / \mathrm{g}$. Tsohuwar Kasuwa had the least coliform counts $8 \mathrm{MPN} / \mathrm{g}$, (Table 2). Result from table 1 shows variation in the microbial contents among the samples which suggest variation in their sources, poor handling procedures and contamination from the processing environment. High coliform count and their differences within sampling areas is an indication of poor microbiological quality of the product. Ndahi et al. (2013) reported microbial load to be a function of the handling personnel and the environment. The results indicated that the samples were contaminated with bacteria as the counts exceeded the minimum safety level $\left(10^{4} \mathrm{cfu} / \mathrm{g}\right)$ for members of the Enterobacteriaceae family. However, it might be a reflection of poor hygienic practices which may contribute to health hazard to the potential consumers. Similarly, Inusa and Sa'id (2017); Osimani et al. (2015) reported that, the initial microbial content of the raw material play significant role in influencing the final microbial load of the finished product. Isolation of members of the Enterobacteriaceae such as $E$. coli, Klebsiella pneumoniae, Salmonella and Shigella signifies danger to the public health. These organisms are capable of producing endotoxins which trigger high fevers in infected individuals, and the enterotoxins which colonize the small intestines and lead to extreme dehydration as a result of vomiting and diarrhea sometimes with severe and fatal outcomes (Amaeze et al., 2016). From the 16 isolated organisms $E$. coli had the highest isolation rate $6(37.5 \%)$ (Table 3), this suggest faecal contamination of the products. $E$. coli is a common flora in the gastrointestinal tract responsible for diarrhea and extra-intestinal infections (CDC, 2011). The result is in conformity with the findings of Ndahi et al. (2013) and Shamsuddeen (2009). Also presence of campylobacter might be due to cross contamination from raw meat to finished product (Tsire). Staphylococcus aureus is a normal flora of the skin, nasal, genital, mouth or anal area in both humans and animals without any symptom of an infection (Matthew et al., 2013). Isolation of $S$. aureus in these study concords with the findings of Lucretia et al. (2018) from Suya sold in Rivers State. 
BAJOPAS Volume 13 Number 1, June, 2020

It is also in agreement with the findings of Yousafzai et al. (2018); Onuorah et al. (2015) and Tijjani and Jumare (2014) from tsire samples in different countries. Presence of $S$. aureus in foods is most of the time an indication of poor human handling, poor environment, unhygienic utensils and equipments used during processing (Igene et al., 2016; Okonko et al., 2013). Infections caused by $S$. aureus are difficult to treat leading to long hospitalization with consequent economic loss (Udobi et al., 2013). These include soft tissue infections, pneumonia, hospital-acquired postoperative wound infections, Staphylococcal food poisoning, impetigo and cellulitis (Charlene et al., 2013). Samples obtained from Dausai and Kofar Kudu had the highest isolation rate $4(80 \%)$ (Table 4 ) probably because of the much commercial activities taking place in the area which can lead to environmental contamination.

Table 1: Total Aerobic Mesophilic Bacterial Count of Tsire sold in Garko Town

\begin{tabular}{lll}
\hline Sampling Area & APC cfu/g & Mean \pm STD \\
\hline Dausai & $2.20 \times 10^{5}$ & $110000 \pm 14142.14$ \\
Kofar Kudu & $4.00 \times 10^{5}$ & $133333.3 \pm 23094.01$ \\
Makwalla & $1.30 \times 10^{5}$ & $32500 \pm 7187.953$ \\
Rinji & $2.72 \times 10^{5}$ & $90666.67 \pm 94769.90$ \\
Tosaro & $1.02 \times 10^{5}$ & $51000 \pm 15556.35$ \\
Tsohuwar Kasuwa & $1.75 \times 10^{5}$ & $35000 \pm 11357.82$ \\
\hline
\end{tabular}

Key: APC: Aerobic Mesophilic Counts

STD: Standard Deviation

Table 2: Total Coliform Count of Tsire sold in Garko Town

\begin{tabular}{lcc}
\hline \multicolumn{1}{c}{ Sampling Area } & TCC MPN/g & Mean \pm STD \\
\hline Dausai & 20 & $6.67 \pm 2.5166$ \\
Kofar Kudu & 32 & $16.00 \pm 5.6569$ \\
Makwalla & 68 & $13.60 \pm 8.7062$ \\
Rinji & 37 & $9.25 \pm 4.7871$ \\
Tosaro & 10 & $5.00 \pm 2.8284$ \\
Tsohuwar Kasuwa & 8 & $4.00 \pm 0.0000$ \\
\hline
\end{tabular}

Table 3: Organisms Isolated from Tsire Sold in Garko

\begin{tabular}{lcl}
\hline Isolated Organism & Frequency & Percentage (\%) \\
\hline Campylobacter & 2 & 06.66 \\
Escherichia coli & 6 & 20.00 \\
Klebsiella pneumoniae & 2 & 06.66 \\
Salmonella species & 1 & 03.33 \\
Shigella & 3 & 10.00 \\
Staphylococcus aureus & 2 & 06.66 \\
Total & 16 & \\
\hline
\end{tabular}

Table 4: Distribution of Organisms within Sampling Area

\begin{tabular}{lcc}
\hline \multicolumn{1}{c}{ Sampling Area } & No. Isolated & Percentage (\%) \\
\hline Dausai & 4 & 80 \\
Kofar Kudu & 4 & 80 \\
Makwalla & 2 & 40 \\
Rinji & 3 & 60 \\
Tosaro & 2 & 40 \\
Tsohuwar Kasuwa & 1 & 20 \\
Total & 16 & \\
\hline
\end{tabular}

\section{CONCLUSION}

Results indicated $4.00 \times 10^{5} \mathrm{CFU} / \mathrm{g}$ as the highest APCs count; while $68 \mathrm{MPN} / \mathrm{g}$ was the highest TCCs from the 30 samples analyzed. Among the isolates, $E$. coli has the highest isolation rate of $6(20 \%)$. Dausai and Kofar kudu were having the highest bacteria count of $4(80 \%)$, each, indicating higher contamination in those locations. 
BAJOPAS Volume 13 Number 1, June, 2020 RECOMMENDATIONS

The following recommendations are tenable:

1. Hygienic practices at all stages of production should be improved to safe guard the consumers against potential health hazard.

2. Monitoring of microbiological contamination of Tsire during preparations, packaging and marketing is essential to ensure product of good microbiological quality for consumers' health.

\section{REFERENCES}

Abdullahi, I. O., Umoh, V. J. and Galadima, M. (2004). Hazards Associated with Kilishi Preparations in Zaria. Nigerian Journal of Microbiology, 18 (1-2): $339-345$.

Ahmadu, J. and Ibrahim E. J., (2013): Determinants of Revenue in Suya Production in BeninCity, Edo State, Nigeria. Nigerian journal of agriculture, food and environment.9(3):1-5

Amaeze, N. Aboh, M. Itohan, A. Felix, E. Olatunji, T. and Oladosu, P. (2016) Microbial Profile, Antibiotic Sensitivity and Heat Resistance of Bacterial Isolates from Commercial Roasted Beef (Suya) in Abuja, Nigeria. JOPAT, 15(2): $22-30$.

Apata, E.S., Kuku1, I.A., Apata, O.C. and Adeyemi, K.O. (2013). Evaluation of Suya(Tsire) - An Intermediate Moisture Meat Product in Ogun State, Nigeria. J. Food Res 2 (1): 87.

Atlas, R. M. (1997) Principles of Microbiology Second Edition. C. Brown Publishers. Pp 802-803.

Borch, E. Kant-Muermans, M. L., Blixt, Y. (1996) Bacterial Spoilage of Meat and Cured Meat Products. Int $\mathrm{J}$ Food Microbiol .33(1): 103-20.

Centre for Disease Control, CDC (2011). "Escherichia coli 0157:H7" Division of Bacterial and Mycotic Diseasesht://www.cdc.gov/nczved/divisi ons/dfbmd/diseases/ecoli_0157h7/.

Charlene, R. J., Johnnie, A. D., and John, B. B., (2013) Prevalence and Characterization of Methicillin-Resistant Staphylococcus aureus Isolates from Retail Meat and Humans in Georgia. American society for Microbiology. J. of clinical microbiology. 12(1):123-6 doi:10.1128/JCM.0316612JCM.03166-12

Egbebi, A.O and Seidu, K., T. (2011). Microbiological Evaluation of Suya (dried smoked

meat) Sold in Ado and Akure, South West Nigeria.European Journal of Experinmental Biology, 1(4):1-5
3. Government should establish regulatory bodies responsible for inculcating hygiene habits to the local producers and vendors in order to prevent instant, cross and post processing contaminations by microbial pathogens.

4. Awareness and sensitization of local food producers about good hygienic practices in food handling and processing.

Falegan, C, R., Akoja, S. D., and Oyarekua, M. A., (2017) Microbiological Assessment of Suya (Sliced Roasted Beef) in Ado-Ekiti Metropolis, Ekiti State, Nigeria. MOJ Biology andMedicine.

Fonkem, D., N. Tanya, V., N. and Ebangi, A., L. (2010). Effect of Season on the Microbiological Quality of Kilishi, a Traditional Cameroonian Dried Beef Product. Tropicultura, 28(1): 10-15.

Food and Agricultural Organization of the United Nations (F A O, 1979). Manual of food quality control 4. Microbiological analysis.

Food and Agriculture Organisation of the United Nation (FAO), 2019. Nigeria at a glance.

Igene J.O., Uwadia, O.E., Ebabhamiegbebho, P.A. and Evivie, S.E., (2016) Shelf life Stability Studies of University of Benin (UNIBEN) Proff's Kilishi Product Asian Journal of Science and Technology 7(1): 2268-2274.

Inusa, S. K. and Said, I. S. (2017) Evaluation of the Chemical and Microbiological Properties Of Kilishi Sold in Kano Metropolis. Journal of Dry land Agriculture, 3 (1): $59-69$.

Lucretia, I. B, Patience, C. Obinna-Echem, Sophia, C. A. (2018) Microbiological quality andantibiotic sensitivity of potential pathogens isolated from meat product (Suya) sold in Rivers State University and its environs. International Journal of Biotechnology and Food Science, 6(4): 67-76.

Matthew, E., Drosos, E., John, L. and Ioanna, P. (2013) MRSA in Africa: Filling the Global Map of Antimicrobial Resistance PLOS One. 8(7): e68024 doi: 10.1371/journal.pone.0068024

Mgbemere, V.N., Akpapunam, M. A. and Igene, J. O., (2011). Effect of Groundnut FlourSubstitution on Yield, Quality and Storage Stability of Kilishi - a Nigerian Indigenous Dried Meat Product. African Journal of Food, Agriculture, Nutrition and Development, $\quad \mathbf{1 1}(2)$ : 4718-4738. 
BAJOPAS Volume 13 Number 1, June, 2020

Mubarak, A. A., Azeez, M. L., Amos A. O., Opeyemi, O. O. (2016) Assessment of Animal Protein Consumption and Food Security Among Rural Households in Kwara State, Nigeria American Journal of Business and Society, 1(4): 233245.

Ndahi, M., D. Kwaga, J., K. P. Bello, M. Kabir J., V. Umoh, .J. Yakubu, S., E. and Nok, A., J. (2013) Prevalence and Antimicrobial Susceptibility of Listeria Monocytogenes and Methicillin-Resistant Staphylococcus aureus Strains from Raw Meat and Meat Products in Zaria, Nigeria. Applied Journal of Microbiology, 58(3):262-9.

Okonko, I.O., Odu, N.N. and Igboh, I.E. (2013). Microbiological Analysis of Kilishi Sold In Port Harcourt, Nigeria. New York Science Journal, 6 (7):37-43.

Osimani, A., Aquilanti, L. and Clementi, F. (2015) Microbiological Quality of Meatbased Meals and Operation of Control Systems within a Food Service Environment. International Food Research Journal 22(4): 1692-1698.

Onuorah, S. Obika, I. Odibo, F. Orji, M. (2015)An Assessment of the Bacteriological Quality of Tsire-Suya (Grilled Beef) sold in Awka, Nigeria. American. J. Life. Sci. Res. 3(4):287292.

Razavilar, V, Khandaghi, J. Barzgari, A. (2010); Isolation of Eschericia coli 0157:H7 from manure fertilized farms and raw vegetables grown on it, in Tabriz city in
Iran. African Journal of Microbiology Research, 4(9): 891-895.

Scallan, E. Hoekstra, R. M. Angulo, F. J.Tauxe, R. V, Widdowson, M. Roy, S. L et al., (2011).Food borne illness acquired in the United States- Major Pathogens. Emerg. Infec Dis, 17(1): 7-15.

Shamsuddeen U (2009). Microbiological quality of spice used in the production of Kilishi a traditionally dried and grilled meat product. Bayero Journal of Pure andApplied Sciences, 2(2): 66-69.

Shamsuddeen, U. (2015) Microbiological Hazard and Critical control point Analysis of Dried and Minced Meat Snacks Produced in Kano Nigeria. Lambert Academic Publishing; Pp 1-36.

Tijani, O.and Jumare, S. (2014). Microblological Quality Assessment of Meat

Sold in KauraNamoda. International Conference on Earth, Environment and Life sciences (EELS) Dubai (UAE).

Udobi, C. E., Obajuluwa, A. F., and Onaolapo, J. A., (2013) Prevalence and Antibiotic Resistance Pattern of MethicillinResistant Staphylococcus aureus from an Orthopaedic Hospital in Nigeria BioMed Research International; 26(6); 6-7.

WHO, 2015 Foodborne diseases in the WHO African Region.

Yousafzai HA, Rind R, Khan MA, Abro SH, Korejo NA, Ejaz M, Kabir A, Shahid M, Memon S. (2019). Microbiological Contamination of Cattle and Meat in Peshawar, Pakistan. J. Anim. Health Prod. 7(1): 1116. 


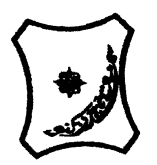

Bayero Journal of Pure and Applied Sciences, 13(1); 40 - 45

Received: September, 2019

Accepted: April, 2020

ISSN $2006-6996$

\title{
BACTERIOLOGICAL QUALITY OF STICK MEAT (Tsire) SOLD IN GARKO LOCAL GOVERNMENT AREA OF KANO STATE, NIGERIA
}

\author{
$*^{1}$ Dahiru A. T. and ${ }^{2}$ Maigari A. K. \\ ${ }^{1}$ Department of Hospitality Management, School of Technology, Kano State Polytechnic, PMB 3348, \\ Kano Nigeria. \\ ${ }^{2}$ Departmnt of Biological Sciences, Bayero University, Kano \\ Corresponding Author: dturajo61@gmail.com; GSM: 08087508262.
}

ABSTRACT

Stick meat, locally called Tsire in Hausa Language, is a significant portion of the diet of a large active population of Northern Nigeria. However, because of the handling and processing methods by the manufacturers as well as the hawking system of stick meat, the meat product may be exposed to both pre- and post-processed product contamination, and thus may poses danger to public health. Therefore, considering the role of Tsire in improving nutrition and increase household income to the populace, the need to improve the processing, distribution and overall quality of the product is simply indispensable. A total of 30 samples (5 samples from each of the 6 sampling points) of Tsire were collected randomly in Garko Town. Aerobic plate counts (APCs) and Total coliform counts (TCCS) of Tsire samples were determined using standard microbiological methods. APCs ranged from $1.02 \times 10^{5}$ to $4.00 \times 10^{5} \mathrm{CFU} / \mathrm{g}$; while TCCs ranged from $8 \mathrm{MPN} / \mathrm{g}$ to $68 \mathrm{MPN} / \mathrm{g}$. From the 30 samples screened, 16(53.33\%) bacteria namely, Campylobacter 2(6.66\%), Escherichia coli 6(20\%), Klebsiella pneumoniae 2(6.66\%), Salmonella spp. 1(3.33\%), Shigella 3(10\%) and Staphylococcus aureus 2(6.66\%) were detected. $E$. coli has the highest isolation rate of 6(20\%), while Salmonella spp. had the least frequency of 1(3.33\%). The distribution of isolated organisms within the study area were as follows: Dausai, 4(80\%), Kofar kudu, 4(80\%), Makwalla, 2(40\%), Rinji, 3(60\%), Tosaro, 2(40\%), and Tsohuwar Kasuwa, 1(20\%). The results have indicated that the Tsire was contaminated with bacteria thus exposing the product to fast deterioration, spoilage and also a vehicle for food borne illness, suggesting for adequate hygienic practices at all the stages, prior to consumption, to ensure safety of the meat product.

Key words: APCs, TCCs, Contamination, Microorganisms, Garko

\section{INTRODUCTION}

Nigeria is one of the developing nations with inadequate food supply and most often deficient in protein content (FAO, 2019). Nigerian's average animal protein intake per head per day is estimated at $7.9 \mathrm{~g}$ as against $35 \mathrm{~g}$ recommended value by Food and Agricultural Organization (Mubarak et al., 2016). These low levels of animal protein intake create great concern as it affects the nutritional status of Nigerians. Hence, there is the need for sufficient supply of animal protein from energy rich animal products to satisfy the nutritional requirements for Nigerians.

Meat is one major source of animal protein largely composed of water, protein and fats which can make it susceptible to microbial contamination within short time leading to spoilage (Apata et al., 2013; Mgbemere et al., 2011). Meat is mostly eaten after it has been cooked or processed in a variety of ways such as sun drying; smoking and roasting with or without fortifications (Borch et al., 1996). In Nigeria meat products such as Tsire, Kilishi and Balangu are locally produced using one or more of these methods in order to meet the nutritional requirements of the teeming Nigerians (Egbebi, 2011).

Tsire is a popular Nigerian traditional processed ready-to-eat roasted stick meat product (Shamsuddeen, 2015). It is sold in public places, along roads, in hotels, parks, quarters and even offices (Falegan et al., 2017). It is prepared from boneless healthy animal flesh such as beef and mutton, spiced with peanut cake, salt, vegetable oil and other flavorings followed by roasting (Shamsuddeen, 2015). Consumption of these products has extended to other parts of African countries such as Ghana, Somali, Cameroun and Chad (Ahmadu and Ibrahim, 2013). 
BAJOPAS Volume 13 Number 1, June, 2020

However, evidence of quality control sticking to procedural hygiene by the handlers during preparation and retailing of these products is poorly documented. Tsire is of great safety risk because of the fact that there are erratic cases of gastroenteritis and symptoms of food infection after consumption (WHO, 2015). Food borne illnesses are one of the major health problems in developing and developed countries (Razavilar, 2010). According to the World Health Organization, WHO (2015), $0.07 \%$ death of the 600 million global burdens of Foodborne illnesses have been reported to be caused by bacteria, viruses, fungi and chemicals. In America $0.27 \%$ of the estimated 48 million affected people is hospitalized and about $0.0063 \%$ deaths are recorded each year (Scallan et al., 2011). More than 91 million people in Africa fall ill and $0.15 \%$ dies each year, making Africa the highest burden bearer of Foodborne diseases per population (WHO, 2015).

Application of a Hazard Analysis Critical Control Point (HACCP) at all stages of meat products preparation is essential in order to ensure its safety. Thus, according to the guidelines of good manufacturing practice, the level of total aerobic bacterial contamination of thermally processed meat products should not exceed $10^{4}\left(\mathrm{cfu} \mathrm{g}^{-1}\right)$. Enterobacteriaceae and faecal coliform contamination in meat products should be within the range of $10^{2}-10^{4}$ and $10-10^{3} \mathrm{cfu} \mathrm{g}^{-1}$, respectively (Shamsuddeen, 2015). The aim of the study is therefore, to assess the total viable bacterial counts of tsire marketed locally within Garko town, and to isolate and identify the organisms at the point of consumption with the intention of promoting public health and food hygiene habits in the Nigerian populace.

\section{MATERIALS AND METHODS Study Area and Population}

Garko is one of the existing 44 local government areas located in Kano south west zone of Kano state with its capital administrative headquarters in the Garko town. It has coordinates $11^{\circ} 39^{\prime} \mathrm{N}$ $8^{\circ} 54^{\prime} \mathrm{E}$, and an area of $450 \mathrm{~km}^{2}$. The projected population of Garko local Government was 225,300 according to the National Population Census report (2018). Garko is known for agricultural activities both farming and animal husbandry. It is popularly known for large scale rice production. Other food crops include sweet potatoes, cassava, onions, sorghum, millet and sugarcane. Cows, sheep and goats are major groups of animals reared by majority of the populace. Meat products processed, retailed and consumed in Garko include roasted meat (Balangu), dried roasted meat (Kilishi), stick meat (Tsire), hide and skin pepper soup (Ragadada) and minced fried meat (Danbunnama).

\section{Samples Collection}

Five samples of Tsire products were collected from 6 different identified locations within Garko town in a sterile foil paper and immediately analyzed for the presence of bacteria.

\section{Sample Preparation}

Sample preparation for the bacteriological analysis was carried out in accordance with the method described by Atlas (1997). Twenty five grams $(25 \mathrm{~g})$ of the sample was homogenized in $225 \mathrm{ml}$ peptone water using Kenwood blender machine to obtain a $10^{1}$ homogenate. The homogenate was thoroughly shaken and $1 \mathrm{ml}$ pipetted into test tubes containing $9 \mathrm{ml}$ of peptone water $\left(10^{2}\right)$. The test tubes were further serially diluted to $10^{5}$.

Total Aerobic Mesophilic Bacterial Count

Total Aerobic mesophilic bacterial count was determined using the method described by Abdullahi et al. (2004) where $1 \mathrm{ml}$ of inoculums from $10^{1}$ to $10^{5}$ dilutions were transferred into duplicate Petri dishes and labeled accordingly. This was followed by pouring aseptically about $15 \mathrm{ml}$ of molten nutrient agar. The culture was homogenized by gentle spinning of the plates and allowed to solidify. The plates were incubated at $37^{\circ} \mathrm{C}$ for 24 hours. Plates containing 30-300 colonies were counted. The number of colony forming units per gram of a sample (cfu/g) was obtained by multiplying the average colony number with the inverse of the dilution factor.

\section{Enumeration and Detection of Coliform bacteria}

Detection and enumeration of coliform was carried out according to method described by Atlas, (1977). A set of 9 test tubes each containing $9 \mathrm{ml}$ of lactose broth and an inverted Durham tubes were autoclaved to expel air and to sterilize. Similarly, $1 \mathrm{ml}$ from the diluents $10^{1}$ was transferred to the first 3 test tubes, followed by $1 \mathrm{ml}$ from the diluents $10^{2}$ to the second set of 3 test tubes and finally the third diluents $10^{3}$ to the $3^{\text {rd }}$ set of 3 test tubes. All the 9 test tubes were incubated at $37^{\circ} \mathrm{C}$ for 24 hours. Tubes that showed gas and acid production after 24 hours were recorded as positive for the presence of Coliform. Negative tubes were further reincubated for 24 hours. Positive tubes were recorded. Estimate of most probable number of Coliform per gram of sample (MPN/g) was determined by comparing the number of gas positive tubes with the most probable number table. 
BAJOPAS Volume 13 Number 1, June, 2020 Identification of Coliform

A loop full of inoculum from gas positive tubes was streaked on to Eosine methylene blue (EMB) agar plate and incubated at $37^{\circ} \mathrm{C}$ for $24 \mathrm{hrs}$. Colonies which formed bluish black color with green metallic sheen, and reddish colonies were isolated on agar slants. Those colonies showing metallic sheen on EMB were sub cultured into tubes of lactose broth and incubated at $45^{\circ} \mathrm{C}$. The tubes were observed after $24 \mathrm{hrs}$ for gas production. This is the completed test for fecal coliform. Gram stain and other biochemical tests such as Indole, Methyl red, Voges-Proskauer and Citrate Utilization tests (IMVIC), Coagulase and Catalase tests were carried out for the Identification and confirmation of isolates.

\section{Procedure for Indole Test}

Indole test was carried out by preparing a Tryptone broth drawn in to test tubes, sterilized by autoclaving, inoculated with loopful of suspension and incubated at $37^{\circ} \mathrm{C}$ for 24 hours. Three drops of xylene was added in tubes, shaken vigorously and kept for the separation of two layers. One millilitre of Kovac's reagent was added and the formation of pink colour ring indicates positive Indole test.

\section{Procedure for Methyl Red Test}

Methyl red test was carried out by preparing Glucose phosphate broth, dispensed in test tubes, sterilized, inoculated with test culture and incubated at $37^{\circ} \mathrm{C}$ for 24 hours. Five drops of methyl-red indicator was added to the medium for the formation of red colour.

\section{Procedure for Voges-Proskauer Test}

Voges-Proskauer test was carried out by inoculating tubes with the bacterial culture followed by incubation for 48 hours at $37^{\circ} \mathrm{C}$. Separate pipettes were used to pipette $1 \mathrm{ml}$ from each culture tube into clean separate tubes. Eighteen drops $(0.5 \mathrm{ml})$ of Barrit's solution A (a-naphthol) was added to each tube containing glucose phosphate broth followed by the addition of an equal amount of solution $B$ into the same tube. The tubes were shaken at 30 seconds interval. A positive reaction was indicated by the development of a pink color, which turns red in 1-2 hours, after vigorous shaking.

\section{Procedure for Citrate Utilization Test}

Citrate Utilization Test was carried out by distributing melted agar (Simmon Citrate Agar) in to test tubes followed by sterilization at $121.5^{\circ} \mathrm{C}$ for 15 minutes. The test tubes were afterward held in slanted position, inoculated with the given bacterial culture and incubated at $37^{\circ} \mathrm{C}$ for $24 \mathrm{hrs}$. Positive test was indicated by color change of the media from green to blue.

\section{RESULTS AND DISCUSSIONS}

The results of this study are presented in tables $1,2,3$ and 4. Among the sampling areas Kofar Kudu had the highest aerobic mesophilic bacteria counts $4.0 \times 10^{5} \mathrm{cfu} / \mathrm{g}$ followed by Rinji $2.72 \times 10^{5} \mathrm{cfu} / \mathrm{g}$, while Tosaro had the least Aerobic mesophilic bacteria counts of $1.02 \times 10^{5}$ $\mathrm{cfu} / \mathrm{g}$ as indicated in Table 1.Makwalla had the highest coliform count $68 \mathrm{MPN} / \mathrm{g}$ followed by Rinji $37 \mathrm{MPN} / \mathrm{g}$. Tsohuwar Kasuwa had the least coliform counts $8 \mathrm{MPN} / \mathrm{g}$, (Table 2). Result from table 1 shows variation in the microbial contents among the samples which suggest variation in their sources, poor handling procedures and contamination from the processing environment. High coliform count and their differences within sampling areas is an indication of poor microbiological quality of the product. Ndahi et al. (2013) reported microbial load to be a function of the handling personnel and the environment. The results indicated that the samples were contaminated with bacteria as the counts exceeded the minimum safety level $\left(10^{4} \mathrm{cfu} / \mathrm{g}\right)$ for members of the Enterobacteriaceae family. However, it might be a reflection of poor hygienic practices which may contribute to health hazard to the potential consumers. Similarly, Inusa and Sa'id (2017); Osimani et al. (2015) reported that, the initial microbial content of the raw material play significant role in influencing the final microbial load of the finished product. Isolation of members of the Enterobacteriaceae such as $E$. coli, Klebsiella pneumoniae, Salmonella and Shigella signifies danger to the public health. These organisms are capable of producing endotoxins which trigger high fevers in infected individuals, and the enterotoxins which colonize the small intestines and lead to extreme dehydration as a result of vomiting and diarrhea sometimes with severe and fatal outcomes (Amaeze et al., 2016). From the 16 isolated organisms $E$. coli had the highest isolation rate $6(37.5 \%)$ (Table 3), this suggest faecal contamination of the products. $E$. coli is a common flora in the gastrointestinal tract responsible for diarrhea and extra-intestinal infections (CDC, 2011). The result is in conformity with the findings of Ndahi et al. (2013) and Shamsuddeen (2009). Also presence of campylobacter might be due to cross contamination from raw meat to finished product (Tsire). Staphylococcus aureus is a normal flora of the skin, nasal, genital, mouth or anal area in both humans and animals without any symptom of an infection (Matthew et al., 2013). Isolation of $S$. aureus in these study concords with the findings of Lucretia et al. (2018) from Suya sold in Rivers State. 
BAJOPAS Volume 13 Number 1, June, 2020

It is also in agreement with the findings of Yousafzai et al. (2018); Onuorah et al. (2015) and Tijjani and Jumare (2014) from tsire samples in different countries. Presence of $S$. aureus in foods is most of the time an indication of poor human handling, poor environment, unhygienic utensils and equipments used during processing (Igene et al., 2016; Okonko et al., 2013). Infections caused by $S$. aureus are difficult to treat leading to long hospitalization with consequent economic loss (Udobi et al., 2013). These include soft tissue infections, pneumonia, hospital-acquired postoperative wound infections, Staphylococcal food poisoning, impetigo and cellulitis (Charlene et al., 2013). Samples obtained from Dausai and Kofar Kudu had the highest isolation rate $4(80 \%)$ (Table 4 ) probably because of the much commercial activities taking place in the area which can lead to environmental contamination.

Table 1: Total Aerobic Mesophilic Bacterial Count of Tsire sold in Garko Town

\begin{tabular}{lll}
\hline Sampling Area & APC cfu/g & Mean \pm STD \\
\hline Dausai & $2.20 \times 10^{5}$ & $110000 \pm 14142.14$ \\
Kofar Kudu & $4.00 \times 10^{5}$ & $133333.3 \pm 23094.01$ \\
Makwalla & $1.30 \times 10^{5}$ & $32500 \pm 7187.953$ \\
Rinji & $2.72 \times 10^{5}$ & $90666.67 \pm 94769.90$ \\
Tosaro & $1.02 \times 10^{5}$ & $51000 \pm 15556.35$ \\
Tsohuwar Kasuwa & $1.75 \times 10^{5}$ & $35000 \pm 11357.82$ \\
\hline
\end{tabular}

Key: APC: Aerobic Mesophilic Counts

STD: Standard Deviation

Table 2: Total Coliform Count of Tsire sold in Garko Town

\begin{tabular}{lcc}
\hline \multicolumn{1}{c}{ Sampling Area } & TCC MPN/g & Mean \pm STD \\
\hline Dausai & 20 & $6.67 \pm 2.5166$ \\
Kofar Kudu & 32 & $16.00 \pm 5.6569$ \\
Makwalla & 68 & $13.60 \pm 8.7062$ \\
Rinji & 37 & $9.25 \pm 4.7871$ \\
Tosaro & 10 & $5.00 \pm 2.8284$ \\
Tsohuwar Kasuwa & 8 & $4.00 \pm 0.0000$ \\
\hline
\end{tabular}

Table 3: Organisms Isolated from Tsire Sold in Garko

\begin{tabular}{lcl}
\hline Isolated Organism & Frequency & Percentage (\%) \\
\hline Campylobacter & 2 & 06.66 \\
Escherichia coli & 6 & 20.00 \\
Klebsiella pneumoniae & 2 & 06.66 \\
Salmonella species & 1 & 03.33 \\
Shigella & 3 & 10.00 \\
Staphylococcus aureus & 2 & 06.66 \\
Total & 16 & \\
\hline
\end{tabular}

Table 4: Distribution of Organisms within Sampling Area

\begin{tabular}{lcc}
\hline \multicolumn{1}{c}{ Sampling Area } & No. Isolated & Percentage (\%) \\
\hline Dausai & 4 & 80 \\
Kofar Kudu & 4 & 80 \\
Makwalla & 2 & 40 \\
Rinji & 3 & 60 \\
Tosaro & 2 & 40 \\
Tsohuwar Kasuwa & 1 & 20 \\
Total & 16 & \\
\hline
\end{tabular}

\section{CONCLUSION}

Results indicated $4.00 \times 10^{5} \mathrm{CFU} / \mathrm{g}$ as the highest APCs count; while $68 \mathrm{MPN} / \mathrm{g}$ was the highest TCCs from the 30 samples analyzed. Among the isolates, $E$. coli has the highest isolation rate of $6(20 \%)$. Dausai and Kofar kudu were having the highest bacteria count of $4(80 \%)$, each, indicating higher contamination in those locations. 
BAJOPAS Volume 13 Number 1, June, 2020 RECOMMENDATIONS

The following recommendations are tenable:

1. Hygienic practices at all stages of production should be improved to safe guard the consumers against potential health hazard.

2. Monitoring of microbiological contamination of Tsire during preparations, packaging and marketing is essential to ensure product of good microbiological quality for consumers' health.

\section{REFERENCES}

Abdullahi, I. O., Umoh, V. J. and Galadima, M. (2004). Hazards Associated with Kilishi Preparations in Zaria. Nigerian Journal of Microbiology, 18 (1-2): $339-345$.

Ahmadu, J. and Ibrahim E. J., (2013): Determinants of Revenue in Suya Production in BeninCity, Edo State, Nigeria. Nigerian journal of agriculture, food and environment.9(3):1-5

Amaeze, N. Aboh, M. Itohan, A. Felix, E. Olatunji, T. and Oladosu, P. (2016) Microbial Profile, Antibiotic Sensitivity and Heat Resistance of Bacterial Isolates from Commercial Roasted Beef (Suya) in Abuja, Nigeria. JOPAT, 15(2): $22-30$.

Apata, E.S., Kuku1, I.A., Apata, O.C. and Adeyemi, K.O. (2013). Evaluation of Suya(Tsire) - An Intermediate Moisture Meat Product in Ogun State, Nigeria. J. Food Res 2 (1): 87.

Atlas, R. M. (1997) Principles of Microbiology Second Edition. C. Brown Publishers. Pp 802-803.

Borch, E. Kant-Muermans, M. L., Blixt, Y. (1996) Bacterial Spoilage of Meat and Cured Meat Products. Int $\mathrm{J}$ Food Microbiol .33(1): 103-20.

Centre for Disease Control, CDC (2011). "Escherichia coli 0157:H7" Division of Bacterial and Mycotic Diseasesht://www.cdc.gov/nczved/divisi ons/dfbmd/diseases/ecoli_0157h7/.

Charlene, R. J., Johnnie, A. D., and John, B. B., (2013) Prevalence and Characterization of Methicillin-Resistant Staphylococcus aureus Isolates from Retail Meat and Humans in Georgia. American society for Microbiology. J. of clinical microbiology. 12(1):123-6 doi:10.1128/JCM.0316612JCM.03166-12

Egbebi, A.O and Seidu, K., T. (2011). Microbiological Evaluation of Suya (dried smoked

meat) Sold in Ado and Akure, South West Nigeria.European Journal of Experinmental Biology, 1(4):1-5
3. Government should establish regulatory bodies responsible for inculcating hygiene habits to the local producers and vendors in order to prevent instant, cross and post processing contaminations by microbial pathogens.

4. Awareness and sensitization of local food producers about good hygienic practices in food handling and processing.

Falegan, C, R., Akoja, S. D., and Oyarekua, M. A., (2017) Microbiological Assessment of Suya (Sliced Roasted Beef) in Ado-Ekiti Metropolis, Ekiti State, Nigeria. MOJ Biology andMedicine.

Fonkem, D., N. Tanya, V., N. and Ebangi, A., L. (2010). Effect of Season on the Microbiological Quality of Kilishi, a Traditional Cameroonian Dried Beef Product. Tropicultura, 28(1): 10-15.

Food and Agricultural Organization of the United Nations (F A O, 1979). Manual of food quality control 4. Microbiological analysis.

Food and Agriculture Organisation of the United Nation (FAO), 2019. Nigeria at a glance.

Igene J.O., Uwadia, O.E., Ebabhamiegbebho, P.A. and Evivie, S.E., (2016) Shelf life Stability Studies of University of Benin (UNIBEN) Proff's Kilishi Product Asian Journal of Science and Technology 7(1): 2268-2274.

Inusa, S. K. and Said, I. S. (2017) Evaluation of the Chemical and Microbiological Properties Of Kilishi Sold in Kano Metropolis. Journal of Dry land Agriculture, 3 (1): $59-69$.

Lucretia, I. B, Patience, C. Obinna-Echem, Sophia, C. A. (2018) Microbiological quality andantibiotic sensitivity of potential pathogens isolated from meat product (Suya) sold in Rivers State University and its environs. International Journal of Biotechnology and Food Science, 6(4): 67-76.

Matthew, E., Drosos, E., John, L. and Ioanna, P. (2013) MRSA in Africa: Filling the Global Map of Antimicrobial Resistance PLOS One. 8(7): e68024 doi: 10.1371/journal.pone.0068024

Mgbemere, V.N., Akpapunam, M. A. and Igene, J. O., (2011). Effect of Groundnut FlourSubstitution on Yield, Quality and Storage Stability of Kilishi - a Nigerian Indigenous Dried Meat Product. African Journal of Food, Agriculture, Nutrition and Development, $\quad \mathbf{1 1}(2)$ : 4718-4738. 
BAJOPAS Volume 13 Number 1, June, 2020

Mubarak, A. A., Azeez, M. L., Amos A. O., Opeyemi, O. O. (2016) Assessment of Animal Protein Consumption and Food Security Among Rural Households in Kwara State, Nigeria American Journal of Business and Society, 1(4): 233245.

Ndahi, M., D. Kwaga, J., K. P. Bello, M. Kabir J., V. Umoh, .J. Yakubu, S., E. and Nok, A., J. (2013) Prevalence and Antimicrobial Susceptibility of Listeria Monocytogenes and Methicillin-Resistant Staphylococcus aureus Strains from Raw Meat and Meat Products in Zaria, Nigeria. Applied Journal of Microbiology, 58(3):262-9.

Okonko, I.O., Odu, N.N. and Igboh, I.E. (2013). Microbiological Analysis of Kilishi Sold In Port Harcourt, Nigeria. New York Science Journal, 6 (7):37-43.

Osimani, A., Aquilanti, L. and Clementi, F. (2015) Microbiological Quality of Meatbased Meals and Operation of Control Systems within a Food Service Environment. International Food Research Journal 22(4): 1692-1698.

Onuorah, S. Obika, I. Odibo, F. Orji, M. (2015)An Assessment of the Bacteriological Quality of Tsire-Suya (Grilled Beef) sold in Awka, Nigeria. American. J. Life. Sci. Res. 3(4):287292.

Razavilar, V, Khandaghi, J. Barzgari, A. (2010); Isolation of Eschericia coli 0157:H7 from manure fertilized farms and raw vegetables grown on it, in Tabriz city in
Iran. African Journal of Microbiology Research, 4(9): 891-895.

Scallan, E. Hoekstra, R. M. Angulo, F. J.Tauxe, R. V, Widdowson, M. Roy, S. L et al., (2011).Food borne illness acquired in the United States- Major Pathogens. Emerg. Infec Dis, 17(1): 7-15.

Shamsuddeen U (2009). Microbiological quality of spice used in the production of Kilishi a traditionally dried and grilled meat product. Bayero Journal of Pure andApplied Sciences, 2(2): 66-69.

Shamsuddeen, U. (2015) Microbiological Hazard and Critical control point Analysis of Dried and Minced Meat Snacks Produced in Kano Nigeria. Lambert Academic Publishing; Pp 1-36.

Tijani, O.and Jumare, S. (2014). Microblological Quality Assessment of Meat

Sold in KauraNamoda. International Conference on Earth, Environment and Life sciences (EELS) Dubai (UAE).

Udobi, C. E., Obajuluwa, A. F., and Onaolapo, J. A., (2013) Prevalence and Antibiotic Resistance Pattern of MethicillinResistant Staphylococcus aureus from an Orthopaedic Hospital in Nigeria BioMed Research International; 26(6); 6-7.

WHO, 2015 Foodborne diseases in the WHO African Region.

Yousafzai HA, Rind R, Khan MA, Abro SH, Korejo NA, Ejaz M, Kabir A, Shahid M, Memon S. (2019). Microbiological Contamination of Cattle and Meat in Peshawar, Pakistan. J. Anim. Health Prod. 7(1): 1116. 


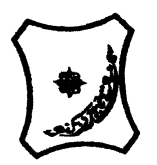

Bayero Journal of Pure and Applied Sciences, 13(1); 40 - 45

Received: September, 2019

Accepted: April, 2020

ISSN $2006-6996$

\title{
BACTERIOLOGICAL QUALITY OF STICK MEAT (Tsire) SOLD IN GARKO LOCAL GOVERNMENT AREA OF KANO STATE, NIGERIA
}

\author{
$*^{1}$ Dahiru A. T. and ${ }^{2}$ Maigari A. K. \\ ${ }^{1}$ Department of Hospitality Management, School of Technology, Kano State Polytechnic, PMB 3348, \\ Kano Nigeria. \\ ${ }^{2}$ Departmnt of Biological Sciences, Bayero University, Kano \\ Corresponding Author: dturajo61@gmail.com; GSM: 08087508262.
}

ABSTRACT

Stick meat, locally called Tsire in Hausa Language, is a significant portion of the diet of a large active population of Northern Nigeria. However, because of the handling and processing methods by the manufacturers as well as the hawking system of stick meat, the meat product may be exposed to both pre- and post-processed product contamination, and thus may poses danger to public health. Therefore, considering the role of Tsire in improving nutrition and increase household income to the populace, the need to improve the processing, distribution and overall quality of the product is simply indispensable. A total of 30 samples (5 samples from each of the 6 sampling points) of Tsire were collected randomly in Garko Town. Aerobic plate counts (APCs) and Total coliform counts (TCCS) of Tsire samples were determined using standard microbiological methods. APCs ranged from $1.02 \times 10^{5}$ to $4.00 \times 10^{5} \mathrm{CFU} / \mathrm{g}$; while TCCs ranged from $8 \mathrm{MPN} / \mathrm{g}$ to $68 \mathrm{MPN} / \mathrm{g}$. From the 30 samples screened, 16(53.33\%) bacteria namely, Campylobacter 2(6.66\%), Escherichia coli 6(20\%), Klebsiella pneumoniae 2(6.66\%), Salmonella spp. 1(3.33\%), Shigella 3(10\%) and Staphylococcus aureus 2(6.66\%) were detected. $E$. coli has the highest isolation rate of 6(20\%), while Salmonella spp. had the least frequency of 1(3.33\%). The distribution of isolated organisms within the study area were as follows: Dausai, 4(80\%), Kofar kudu, 4(80\%), Makwalla, 2(40\%), Rinji, 3(60\%), Tosaro, 2(40\%), and Tsohuwar Kasuwa, 1(20\%). The results have indicated that the Tsire was contaminated with bacteria thus exposing the product to fast deterioration, spoilage and also a vehicle for food borne illness, suggesting for adequate hygienic practices at all the stages, prior to consumption, to ensure safety of the meat product.

Key words: APCs, TCCs, Contamination, Microorganisms, Garko

\section{INTRODUCTION}

Nigeria is one of the developing nations with inadequate food supply and most often deficient in protein content (FAO, 2019). Nigerian's average animal protein intake per head per day is estimated at $7.9 \mathrm{~g}$ as against $35 \mathrm{~g}$ recommended value by Food and Agricultural Organization (Mubarak et al., 2016). These low levels of animal protein intake create great concern as it affects the nutritional status of Nigerians. Hence, there is the need for sufficient supply of animal protein from energy rich animal products to satisfy the nutritional requirements for Nigerians.

Meat is one major source of animal protein largely composed of water, protein and fats which can make it susceptible to microbial contamination within short time leading to spoilage (Apata et al., 2013; Mgbemere et al., 2011). Meat is mostly eaten after it has been cooked or processed in a variety of ways such as sun drying; smoking and roasting with or without fortifications (Borch et al., 1996). In Nigeria meat products such as Tsire, Kilishi and Balangu are locally produced using one or more of these methods in order to meet the nutritional requirements of the teeming Nigerians (Egbebi, 2011).

Tsire is a popular Nigerian traditional processed ready-to-eat roasted stick meat product (Shamsuddeen, 2015). It is sold in public places, along roads, in hotels, parks, quarters and even offices (Falegan et al., 2017). It is prepared from boneless healthy animal flesh such as beef and mutton, spiced with peanut cake, salt, vegetable oil and other flavorings followed by roasting (Shamsuddeen, 2015). Consumption of these products has extended to other parts of African countries such as Ghana, Somali, Cameroun and Chad (Ahmadu and Ibrahim, 2013). 
BAJOPAS Volume 13 Number 1, June, 2020

However, evidence of quality control sticking to procedural hygiene by the handlers during preparation and retailing of these products is poorly documented. Tsire is of great safety risk because of the fact that there are erratic cases of gastroenteritis and symptoms of food infection after consumption (WHO, 2015). Food borne illnesses are one of the major health problems in developing and developed countries (Razavilar, 2010). According to the World Health Organization, WHO (2015), $0.07 \%$ death of the 600 million global burdens of Foodborne illnesses have been reported to be caused by bacteria, viruses, fungi and chemicals. In America $0.27 \%$ of the estimated 48 million affected people is hospitalized and about $0.0063 \%$ deaths are recorded each year (Scallan et al., 2011). More than 91 million people in Africa fall ill and $0.15 \%$ dies each year, making Africa the highest burden bearer of Foodborne diseases per population (WHO, 2015).

Application of a Hazard Analysis Critical Control Point (HACCP) at all stages of meat products preparation is essential in order to ensure its safety. Thus, according to the guidelines of good manufacturing practice, the level of total aerobic bacterial contamination of thermally processed meat products should not exceed $10^{4}\left(\mathrm{cfu} \mathrm{g}^{-1}\right)$. Enterobacteriaceae and faecal coliform contamination in meat products should be within the range of $10^{2}-10^{4}$ and $10-10^{3} \mathrm{cfu} \mathrm{g}^{-1}$, respectively (Shamsuddeen, 2015). The aim of the study is therefore, to assess the total viable bacterial counts of tsire marketed locally within Garko town, and to isolate and identify the organisms at the point of consumption with the intention of promoting public health and food hygiene habits in the Nigerian populace.

\section{MATERIALS AND METHODS Study Area and Population}

Garko is one of the existing 44 local government areas located in Kano south west zone of Kano state with its capital administrative headquarters in the Garko town. It has coordinates $11^{\circ} 39^{\prime} \mathrm{N}$ $8^{\circ} 54^{\prime} \mathrm{E}$, and an area of $450 \mathrm{~km}^{2}$. The projected population of Garko local Government was 225,300 according to the National Population Census report (2018). Garko is known for agricultural activities both farming and animal husbandry. It is popularly known for large scale rice production. Other food crops include sweet potatoes, cassava, onions, sorghum, millet and sugarcane. Cows, sheep and goats are major groups of animals reared by majority of the populace. Meat products processed, retailed and consumed in Garko include roasted meat (Balangu), dried roasted meat (Kilishi), stick meat (Tsire), hide and skin pepper soup (Ragadada) and minced fried meat (Danbunnama).

\section{Samples Collection}

Five samples of Tsire products were collected from 6 different identified locations within Garko town in a sterile foil paper and immediately analyzed for the presence of bacteria.

\section{Sample Preparation}

Sample preparation for the bacteriological analysis was carried out in accordance with the method described by Atlas (1997). Twenty five grams $(25 \mathrm{~g})$ of the sample was homogenized in $225 \mathrm{ml}$ peptone water using Kenwood blender machine to obtain a $10^{1}$ homogenate. The homogenate was thoroughly shaken and $1 \mathrm{ml}$ pipetted into test tubes containing $9 \mathrm{ml}$ of peptone water $\left(10^{2}\right)$. The test tubes were further serially diluted to $10^{5}$.

Total Aerobic Mesophilic Bacterial Count

Total Aerobic mesophilic bacterial count was determined using the method described by Abdullahi et al. (2004) where $1 \mathrm{ml}$ of inoculums from $10^{1}$ to $10^{5}$ dilutions were transferred into duplicate Petri dishes and labeled accordingly. This was followed by pouring aseptically about $15 \mathrm{ml}$ of molten nutrient agar. The culture was homogenized by gentle spinning of the plates and allowed to solidify. The plates were incubated at $37^{\circ} \mathrm{C}$ for 24 hours. Plates containing 30-300 colonies were counted. The number of colony forming units per gram of a sample (cfu/g) was obtained by multiplying the average colony number with the inverse of the dilution factor.

\section{Enumeration and Detection of Coliform bacteria}

Detection and enumeration of coliform was carried out according to method described by Atlas, (1977). A set of 9 test tubes each containing $9 \mathrm{ml}$ of lactose broth and an inverted Durham tubes were autoclaved to expel air and to sterilize. Similarly, $1 \mathrm{ml}$ from the diluents $10^{1}$ was transferred to the first 3 test tubes, followed by $1 \mathrm{ml}$ from the diluents $10^{2}$ to the second set of 3 test tubes and finally the third diluents $10^{3}$ to the $3^{\text {rd }}$ set of 3 test tubes. All the 9 test tubes were incubated at $37^{\circ} \mathrm{C}$ for 24 hours. Tubes that showed gas and acid production after 24 hours were recorded as positive for the presence of Coliform. Negative tubes were further reincubated for 24 hours. Positive tubes were recorded. Estimate of most probable number of Coliform per gram of sample (MPN/g) was determined by comparing the number of gas positive tubes with the most probable number table. 
BAJOPAS Volume 13 Number 1, June, 2020 Identification of Coliform

A loop full of inoculum from gas positive tubes was streaked on to Eosine methylene blue (EMB) agar plate and incubated at $37^{\circ} \mathrm{C}$ for $24 \mathrm{hrs}$. Colonies which formed bluish black color with green metallic sheen, and reddish colonies were isolated on agar slants. Those colonies showing metallic sheen on EMB were sub cultured into tubes of lactose broth and incubated at $45^{\circ} \mathrm{C}$. The tubes were observed after $24 \mathrm{hrs}$ for gas production. This is the completed test for fecal coliform. Gram stain and other biochemical tests such as Indole, Methyl red, Voges-Proskauer and Citrate Utilization tests (IMVIC), Coagulase and Catalase tests were carried out for the Identification and confirmation of isolates.

\section{Procedure for Indole Test}

Indole test was carried out by preparing a Tryptone broth drawn in to test tubes, sterilized by autoclaving, inoculated with loopful of suspension and incubated at $37^{\circ} \mathrm{C}$ for 24 hours. Three drops of xylene was added in tubes, shaken vigorously and kept for the separation of two layers. One millilitre of Kovac's reagent was added and the formation of pink colour ring indicates positive Indole test.

\section{Procedure for Methyl Red Test}

Methyl red test was carried out by preparing Glucose phosphate broth, dispensed in test tubes, sterilized, inoculated with test culture and incubated at $37^{\circ} \mathrm{C}$ for 24 hours. Five drops of methyl-red indicator was added to the medium for the formation of red colour.

\section{Procedure for Voges-Proskauer Test}

Voges-Proskauer test was carried out by inoculating tubes with the bacterial culture followed by incubation for 48 hours at $37^{\circ} \mathrm{C}$. Separate pipettes were used to pipette $1 \mathrm{ml}$ from each culture tube into clean separate tubes. Eighteen drops $(0.5 \mathrm{ml})$ of Barrit's solution A (a-naphthol) was added to each tube containing glucose phosphate broth followed by the addition of an equal amount of solution $B$ into the same tube. The tubes were shaken at 30 seconds interval. A positive reaction was indicated by the development of a pink color, which turns red in 1-2 hours, after vigorous shaking.

\section{Procedure for Citrate Utilization Test}

Citrate Utilization Test was carried out by distributing melted agar (Simmon Citrate Agar) in to test tubes followed by sterilization at $121.5^{\circ} \mathrm{C}$ for 15 minutes. The test tubes were afterward held in slanted position, inoculated with the given bacterial culture and incubated at $37^{\circ} \mathrm{C}$ for $24 \mathrm{hrs}$. Positive test was indicated by color change of the media from green to blue.

\section{RESULTS AND DISCUSSIONS}

The results of this study are presented in tables $1,2,3$ and 4. Among the sampling areas Kofar Kudu had the highest aerobic mesophilic bacteria counts $4.0 \times 10^{5} \mathrm{cfu} / \mathrm{g}$ followed by Rinji $2.72 \times 10^{5} \mathrm{cfu} / \mathrm{g}$, while Tosaro had the least Aerobic mesophilic bacteria counts of $1.02 \times 10^{5}$ $\mathrm{cfu} / \mathrm{g}$ as indicated in Table 1.Makwalla had the highest coliform count $68 \mathrm{MPN} / \mathrm{g}$ followed by Rinji $37 \mathrm{MPN} / \mathrm{g}$. Tsohuwar Kasuwa had the least coliform counts $8 \mathrm{MPN} / \mathrm{g}$, (Table 2). Result from table 1 shows variation in the microbial contents among the samples which suggest variation in their sources, poor handling procedures and contamination from the processing environment. High coliform count and their differences within sampling areas is an indication of poor microbiological quality of the product. Ndahi et al. (2013) reported microbial load to be a function of the handling personnel and the environment. The results indicated that the samples were contaminated with bacteria as the counts exceeded the minimum safety level $\left(10^{4} \mathrm{cfu} / \mathrm{g}\right)$ for members of the Enterobacteriaceae family. However, it might be a reflection of poor hygienic practices which may contribute to health hazard to the potential consumers. Similarly, Inusa and Sa'id (2017); Osimani et al. (2015) reported that, the initial microbial content of the raw material play significant role in influencing the final microbial load of the finished product. Isolation of members of the Enterobacteriaceae such as $E$. coli, Klebsiella pneumoniae, Salmonella and Shigella signifies danger to the public health. These organisms are capable of producing endotoxins which trigger high fevers in infected individuals, and the enterotoxins which colonize the small intestines and lead to extreme dehydration as a result of vomiting and diarrhea sometimes with severe and fatal outcomes (Amaeze et al., 2016). From the 16 isolated organisms $E$. coli had the highest isolation rate $6(37.5 \%)$ (Table 3), this suggest faecal contamination of the products. $E$. coli is a common flora in the gastrointestinal tract responsible for diarrhea and extra-intestinal infections (CDC, 2011). The result is in conformity with the findings of Ndahi et al. (2013) and Shamsuddeen (2009). Also presence of campylobacter might be due to cross contamination from raw meat to finished product (Tsire). Staphylococcus aureus is a normal flora of the skin, nasal, genital, mouth or anal area in both humans and animals without any symptom of an infection (Matthew et al., 2013). Isolation of $S$. aureus in these study concords with the findings of Lucretia et al. (2018) from Suya sold in Rivers State. 
BAJOPAS Volume 13 Number 1, June, 2020

It is also in agreement with the findings of Yousafzai et al. (2018); Onuorah et al. (2015) and Tijjani and Jumare (2014) from tsire samples in different countries. Presence of $S$. aureus in foods is most of the time an indication of poor human handling, poor environment, unhygienic utensils and equipments used during processing (Igene et al., 2016; Okonko et al., 2013). Infections caused by $S$. aureus are difficult to treat leading to long hospitalization with consequent economic loss (Udobi et al., 2013). These include soft tissue infections, pneumonia, hospital-acquired postoperative wound infections, Staphylococcal food poisoning, impetigo and cellulitis (Charlene et al., 2013). Samples obtained from Dausai and Kofar Kudu had the highest isolation rate $4(80 \%)$ (Table 4 ) probably because of the much commercial activities taking place in the area which can lead to environmental contamination.

Table 1: Total Aerobic Mesophilic Bacterial Count of Tsire sold in Garko Town

\begin{tabular}{lll}
\hline Sampling Area & APC cfu/g & Mean \pm STD \\
\hline Dausai & $2.20 \times 10^{5}$ & $110000 \pm 14142.14$ \\
Kofar Kudu & $4.00 \times 10^{5}$ & $133333.3 \pm 23094.01$ \\
Makwalla & $1.30 \times 10^{5}$ & $32500 \pm 7187.953$ \\
Rinji & $2.72 \times 10^{5}$ & $90666.67 \pm 94769.90$ \\
Tosaro & $1.02 \times 10^{5}$ & $51000 \pm 15556.35$ \\
Tsohuwar Kasuwa & $1.75 \times 10^{5}$ & $35000 \pm 11357.82$ \\
\hline
\end{tabular}

Key: APC: Aerobic Mesophilic Counts

STD: Standard Deviation

Table 2: Total Coliform Count of Tsire sold in Garko Town

\begin{tabular}{lcc}
\hline \multicolumn{1}{c}{ Sampling Area } & TCC MPN/g & Mean \pm STD \\
\hline Dausai & 20 & $6.67 \pm 2.5166$ \\
Kofar Kudu & 32 & $16.00 \pm 5.6569$ \\
Makwalla & 68 & $13.60 \pm 8.7062$ \\
Rinji & 37 & $9.25 \pm 4.7871$ \\
Tosaro & 10 & $5.00 \pm 2.8284$ \\
Tsohuwar Kasuwa & 8 & $4.00 \pm 0.0000$ \\
\hline
\end{tabular}

Table 3: Organisms Isolated from Tsire Sold in Garko

\begin{tabular}{lcl}
\hline Isolated Organism & Frequency & Percentage (\%) \\
\hline Campylobacter & 2 & 06.66 \\
Escherichia coli & 6 & 20.00 \\
Klebsiella pneumoniae & 2 & 06.66 \\
Salmonella species & 1 & 03.33 \\
Shigella & 3 & 10.00 \\
Staphylococcus aureus & 2 & 06.66 \\
Total & 16 & \\
\hline
\end{tabular}

Table 4: Distribution of Organisms within Sampling Area

\begin{tabular}{lcc}
\hline \multicolumn{1}{c}{ Sampling Area } & No. Isolated & Percentage (\%) \\
\hline Dausai & 4 & 80 \\
Kofar Kudu & 4 & 80 \\
Makwalla & 2 & 40 \\
Rinji & 3 & 60 \\
Tosaro & 2 & 40 \\
Tsohuwar Kasuwa & 1 & 20 \\
Total & 16 & \\
\hline
\end{tabular}

\section{CONCLUSION}

Results indicated $4.00 \times 10^{5} \mathrm{CFU} / \mathrm{g}$ as the highest APCs count; while $68 \mathrm{MPN} / \mathrm{g}$ was the highest TCCs from the 30 samples analyzed. Among the isolates, $E$. coli has the highest isolation rate of $6(20 \%)$. Dausai and Kofar kudu were having the highest bacteria count of $4(80 \%)$, each, indicating higher contamination in those locations. 
BAJOPAS Volume 13 Number 1, June, 2020 RECOMMENDATIONS

The following recommendations are tenable:

1. Hygienic practices at all stages of production should be improved to safe guard the consumers against potential health hazard.

2. Monitoring of microbiological contamination of Tsire during preparations, packaging and marketing is essential to ensure product of good microbiological quality for consumers' health.

\section{REFERENCES}

Abdullahi, I. O., Umoh, V. J. and Galadima, M. (2004). Hazards Associated with Kilishi Preparations in Zaria. Nigerian Journal of Microbiology, 18 (1-2): $339-345$.

Ahmadu, J. and Ibrahim E. J., (2013): Determinants of Revenue in Suya Production in BeninCity, Edo State, Nigeria. Nigerian journal of agriculture, food and environment.9(3):1-5

Amaeze, N. Aboh, M. Itohan, A. Felix, E. Olatunji, T. and Oladosu, P. (2016) Microbial Profile, Antibiotic Sensitivity and Heat Resistance of Bacterial Isolates from Commercial Roasted Beef (Suya) in Abuja, Nigeria. JOPAT, 15(2): $22-30$.

Apata, E.S., Kuku1, I.A., Apata, O.C. and Adeyemi, K.O. (2013). Evaluation of Suya(Tsire) - An Intermediate Moisture Meat Product in Ogun State, Nigeria. J. Food Res 2 (1): 87.

Atlas, R. M. (1997) Principles of Microbiology Second Edition. C. Brown Publishers. Pp 802-803.

Borch, E. Kant-Muermans, M. L., Blixt, Y. (1996) Bacterial Spoilage of Meat and Cured Meat Products. Int $\mathrm{J}$ Food Microbiol .33(1): 103-20.

Centre for Disease Control, CDC (2011). "Escherichia coli 0157:H7" Division of Bacterial and Mycotic Diseasesht://www.cdc.gov/nczved/divisi ons/dfbmd/diseases/ecoli_0157h7/.

Charlene, R. J., Johnnie, A. D., and John, B. B., (2013) Prevalence and Characterization of Methicillin-Resistant Staphylococcus aureus Isolates from Retail Meat and Humans in Georgia. American society for Microbiology. J. of clinical microbiology. 12(1):123-6 doi:10.1128/JCM.0316612JCM.03166-12

Egbebi, A.O and Seidu, K., T. (2011). Microbiological Evaluation of Suya (dried smoked

meat) Sold in Ado and Akure, South West Nigeria.European Journal of Experinmental Biology, 1(4):1-5
3. Government should establish regulatory bodies responsible for inculcating hygiene habits to the local producers and vendors in order to prevent instant, cross and post processing contaminations by microbial pathogens.

4. Awareness and sensitization of local food producers about good hygienic practices in food handling and processing.

Falegan, C, R., Akoja, S. D., and Oyarekua, M. A., (2017) Microbiological Assessment of Suya (Sliced Roasted Beef) in Ado-Ekiti Metropolis, Ekiti State, Nigeria. MOJ Biology andMedicine.

Fonkem, D., N. Tanya, V., N. and Ebangi, A., L. (2010). Effect of Season on the Microbiological Quality of Kilishi, a Traditional Cameroonian Dried Beef Product. Tropicultura, 28(1): 10-15.

Food and Agricultural Organization of the United Nations (F A O, 1979). Manual of food quality control 4. Microbiological analysis.

Food and Agriculture Organisation of the United Nation (FAO), 2019. Nigeria at a glance.

Igene J.O., Uwadia, O.E., Ebabhamiegbebho, P.A. and Evivie, S.E., (2016) Shelf life Stability Studies of University of Benin (UNIBEN) Proff's Kilishi Product Asian Journal of Science and Technology 7(1): 2268-2274.

Inusa, S. K. and Said, I. S. (2017) Evaluation of the Chemical and Microbiological Properties Of Kilishi Sold in Kano Metropolis. Journal of Dry land Agriculture, 3 (1): $59-69$.

Lucretia, I. B, Patience, C. Obinna-Echem, Sophia, C. A. (2018) Microbiological quality andantibiotic sensitivity of potential pathogens isolated from meat product (Suya) sold in Rivers State University and its environs. International Journal of Biotechnology and Food Science, 6(4): 67-76.

Matthew, E., Drosos, E., John, L. and Ioanna, P. (2013) MRSA in Africa: Filling the Global Map of Antimicrobial Resistance PLOS One. 8(7): e68024 doi: 10.1371/journal.pone.0068024

Mgbemere, V.N., Akpapunam, M. A. and Igene, J. O., (2011). Effect of Groundnut FlourSubstitution on Yield, Quality and Storage Stability of Kilishi - a Nigerian Indigenous Dried Meat Product. African Journal of Food, Agriculture, Nutrition and Development, $\quad \mathbf{1 1}(2)$ : 4718-4738. 
BAJOPAS Volume 13 Number 1, June, 2020

Mubarak, A. A., Azeez, M. L., Amos A. O., Opeyemi, O. O. (2016) Assessment of Animal Protein Consumption and Food Security Among Rural Households in Kwara State, Nigeria American Journal of Business and Society, 1(4): 233245.

Ndahi, M., D. Kwaga, J., K. P. Bello, M. Kabir J., V. Umoh, .J. Yakubu, S., E. and Nok, A., J. (2013) Prevalence and Antimicrobial Susceptibility of Listeria Monocytogenes and Methicillin-Resistant Staphylococcus aureus Strains from Raw Meat and Meat Products in Zaria, Nigeria. Applied Journal of Microbiology, 58(3):262-9.

Okonko, I.O., Odu, N.N. and Igboh, I.E. (2013). Microbiological Analysis of Kilishi Sold In Port Harcourt, Nigeria. New York Science Journal, 6 (7):37-43.

Osimani, A., Aquilanti, L. and Clementi, F. (2015) Microbiological Quality of Meatbased Meals and Operation of Control Systems within a Food Service Environment. International Food Research Journal 22(4): 1692-1698.

Onuorah, S. Obika, I. Odibo, F. Orji, M. (2015)An Assessment of the Bacteriological Quality of Tsire-Suya (Grilled Beef) sold in Awka, Nigeria. American. J. Life. Sci. Res. 3(4):287292.

Razavilar, V, Khandaghi, J. Barzgari, A. (2010); Isolation of Eschericia coli 0157:H7 from manure fertilized farms and raw vegetables grown on it, in Tabriz city in
Iran. African Journal of Microbiology Research, 4(9): 891-895.

Scallan, E. Hoekstra, R. M. Angulo, F. J.Tauxe, R. V, Widdowson, M. Roy, S. L et al., (2011).Food borne illness acquired in the United States- Major Pathogens. Emerg. Infec Dis, 17(1): 7-15.

Shamsuddeen U (2009). Microbiological quality of spice used in the production of Kilishi a traditionally dried and grilled meat product. Bayero Journal of Pure andApplied Sciences, 2(2): 66-69.

Shamsuddeen, U. (2015) Microbiological Hazard and Critical control point Analysis of Dried and Minced Meat Snacks Produced in Kano Nigeria. Lambert Academic Publishing; Pp 1-36.

Tijani, O.and Jumare, S. (2014). Microblological Quality Assessment of Meat

Sold in KauraNamoda. International Conference on Earth, Environment and Life sciences (EELS) Dubai (UAE).

Udobi, C. E., Obajuluwa, A. F., and Onaolapo, J. A., (2013) Prevalence and Antibiotic Resistance Pattern of MethicillinResistant Staphylococcus aureus from an Orthopaedic Hospital in Nigeria BioMed Research International; 26(6); 6-7.

WHO, 2015 Foodborne diseases in the WHO African Region.

Yousafzai HA, Rind R, Khan MA, Abro SH, Korejo NA, Ejaz M, Kabir A, Shahid M, Memon S. (2019). Microbiological Contamination of Cattle and Meat in Peshawar, Pakistan. J. Anim. Health Prod. 7(1): 1116. 


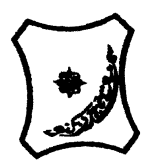

Bayero Journal of Pure and Applied Sciences, 13(1); 40 - 45

Received: September, 2019

Accepted: April, 2020

ISSN $2006-6996$

\title{
BACTERIOLOGICAL QUALITY OF STICK MEAT (Tsire) SOLD IN GARKO LOCAL GOVERNMENT AREA OF KANO STATE, NIGERIA
}

\author{
$*^{1}$ Dahiru A. T. and ${ }^{2}$ Maigari A. K. \\ ${ }^{1}$ Department of Hospitality Management, School of Technology, Kano State Polytechnic, PMB 3348, \\ Kano Nigeria. \\ ${ }^{2}$ Departmnt of Biological Sciences, Bayero University, Kano \\ Corresponding Author: dturajo61@gmail.com; GSM: 08087508262.
}

ABSTRACT

Stick meat, locally called Tsire in Hausa Language, is a significant portion of the diet of a large active population of Northern Nigeria. However, because of the handling and processing methods by the manufacturers as well as the hawking system of stick meat, the meat product may be exposed to both pre- and post-processed product contamination, and thus may poses danger to public health. Therefore, considering the role of Tsire in improving nutrition and increase household income to the populace, the need to improve the processing, distribution and overall quality of the product is simply indispensable. A total of 30 samples (5 samples from each of the 6 sampling points) of Tsire were collected randomly in Garko Town. Aerobic plate counts (APCs) and Total coliform counts (TCCS) of Tsire samples were determined using standard microbiological methods. APCs ranged from $1.02 \times 10^{5}$ to $4.00 \times 10^{5} \mathrm{CFU} / \mathrm{g}$; while TCCs ranged from $8 \mathrm{MPN} / \mathrm{g}$ to $68 \mathrm{MPN} / \mathrm{g}$. From the 30 samples screened, 16(53.33\%) bacteria namely, Campylobacter 2(6.66\%), Escherichia coli 6(20\%), Klebsiella pneumoniae 2(6.66\%), Salmonella spp. 1(3.33\%), Shigella 3(10\%) and Staphylococcus aureus 2(6.66\%) were detected. $E$. coli has the highest isolation rate of 6(20\%), while Salmonella spp. had the least frequency of 1(3.33\%). The distribution of isolated organisms within the study area were as follows: Dausai, 4(80\%), Kofar kudu, 4(80\%), Makwalla, 2(40\%), Rinji, 3(60\%), Tosaro, 2(40\%), and Tsohuwar Kasuwa, 1(20\%). The results have indicated that the Tsire was contaminated with bacteria thus exposing the product to fast deterioration, spoilage and also a vehicle for food borne illness, suggesting for adequate hygienic practices at all the stages, prior to consumption, to ensure safety of the meat product.

Key words: APCs, TCCs, Contamination, Microorganisms, Garko

\section{INTRODUCTION}

Nigeria is one of the developing nations with inadequate food supply and most often deficient in protein content (FAO, 2019). Nigerian's average animal protein intake per head per day is estimated at $7.9 \mathrm{~g}$ as against $35 \mathrm{~g}$ recommended value by Food and Agricultural Organization (Mubarak et al., 2016). These low levels of animal protein intake create great concern as it affects the nutritional status of Nigerians. Hence, there is the need for sufficient supply of animal protein from energy rich animal products to satisfy the nutritional requirements for Nigerians.

Meat is one major source of animal protein largely composed of water, protein and fats which can make it susceptible to microbial contamination within short time leading to spoilage (Apata et al., 2013; Mgbemere et al., 2011). Meat is mostly eaten after it has been cooked or processed in a variety of ways such as sun drying; smoking and roasting with or without fortifications (Borch et al., 1996). In Nigeria meat products such as Tsire, Kilishi and Balangu are locally produced using one or more of these methods in order to meet the nutritional requirements of the teeming Nigerians (Egbebi, 2011).

Tsire is a popular Nigerian traditional processed ready-to-eat roasted stick meat product (Shamsuddeen, 2015). It is sold in public places, along roads, in hotels, parks, quarters and even offices (Falegan et al., 2017). It is prepared from boneless healthy animal flesh such as beef and mutton, spiced with peanut cake, salt, vegetable oil and other flavorings followed by roasting (Shamsuddeen, 2015). Consumption of these products has extended to other parts of African countries such as Ghana, Somali, Cameroun and Chad (Ahmadu and Ibrahim, 2013). 
BAJOPAS Volume 13 Number 1, June, 2020

However, evidence of quality control sticking to procedural hygiene by the handlers during preparation and retailing of these products is poorly documented. Tsire is of great safety risk because of the fact that there are erratic cases of gastroenteritis and symptoms of food infection after consumption (WHO, 2015). Food borne illnesses are one of the major health problems in developing and developed countries (Razavilar, 2010). According to the World Health Organization, WHO (2015), $0.07 \%$ death of the 600 million global burdens of Foodborne illnesses have been reported to be caused by bacteria, viruses, fungi and chemicals. In America $0.27 \%$ of the estimated 48 million affected people is hospitalized and about $0.0063 \%$ deaths are recorded each year (Scallan et al., 2011). More than 91 million people in Africa fall ill and $0.15 \%$ dies each year, making Africa the highest burden bearer of Foodborne diseases per population (WHO, 2015).

Application of a Hazard Analysis Critical Control Point (HACCP) at all stages of meat products preparation is essential in order to ensure its safety. Thus, according to the guidelines of good manufacturing practice, the level of total aerobic bacterial contamination of thermally processed meat products should not exceed $10^{4}\left(\mathrm{cfu} \mathrm{g}^{-1}\right)$. Enterobacteriaceae and faecal coliform contamination in meat products should be within the range of $10^{2}-10^{4}$ and $10-10^{3} \mathrm{cfu} \mathrm{g}^{-1}$, respectively (Shamsuddeen, 2015). The aim of the study is therefore, to assess the total viable bacterial counts of tsire marketed locally within Garko town, and to isolate and identify the organisms at the point of consumption with the intention of promoting public health and food hygiene habits in the Nigerian populace.

\section{MATERIALS AND METHODS Study Area and Population}

Garko is one of the existing 44 local government areas located in Kano south west zone of Kano state with its capital administrative headquarters in the Garko town. It has coordinates $11^{\circ} 39^{\prime} \mathrm{N}$ $8^{\circ} 54^{\prime} \mathrm{E}$, and an area of $450 \mathrm{~km}^{2}$. The projected population of Garko local Government was 225,300 according to the National Population Census report (2018). Garko is known for agricultural activities both farming and animal husbandry. It is popularly known for large scale rice production. Other food crops include sweet potatoes, cassava, onions, sorghum, millet and sugarcane. Cows, sheep and goats are major groups of animals reared by majority of the populace. Meat products processed, retailed and consumed in Garko include roasted meat (Balangu), dried roasted meat (Kilishi), stick meat (Tsire), hide and skin pepper soup (Ragadada) and minced fried meat (Danbunnama).

\section{Samples Collection}

Five samples of Tsire products were collected from 6 different identified locations within Garko town in a sterile foil paper and immediately analyzed for the presence of bacteria.

\section{Sample Preparation}

Sample preparation for the bacteriological analysis was carried out in accordance with the method described by Atlas (1997). Twenty five grams $(25 \mathrm{~g})$ of the sample was homogenized in $225 \mathrm{ml}$ peptone water using Kenwood blender machine to obtain a $10^{1}$ homogenate. The homogenate was thoroughly shaken and $1 \mathrm{ml}$ pipetted into test tubes containing $9 \mathrm{ml}$ of peptone water $\left(10^{2}\right)$. The test tubes were further serially diluted to $10^{5}$.

Total Aerobic Mesophilic Bacterial Count

Total Aerobic mesophilic bacterial count was determined using the method described by Abdullahi et al. (2004) where $1 \mathrm{ml}$ of inoculums from $10^{1}$ to $10^{5}$ dilutions were transferred into duplicate Petri dishes and labeled accordingly. This was followed by pouring aseptically about $15 \mathrm{ml}$ of molten nutrient agar. The culture was homogenized by gentle spinning of the plates and allowed to solidify. The plates were incubated at $37^{\circ} \mathrm{C}$ for 24 hours. Plates containing 30-300 colonies were counted. The number of colony forming units per gram of a sample (cfu/g) was obtained by multiplying the average colony number with the inverse of the dilution factor.

\section{Enumeration and Detection of Coliform bacteria}

Detection and enumeration of coliform was carried out according to method described by Atlas, (1977). A set of 9 test tubes each containing $9 \mathrm{ml}$ of lactose broth and an inverted Durham tubes were autoclaved to expel air and to sterilize. Similarly, $1 \mathrm{ml}$ from the diluents $10^{1}$ was transferred to the first 3 test tubes, followed by $1 \mathrm{ml}$ from the diluents $10^{2}$ to the second set of 3 test tubes and finally the third diluents $10^{3}$ to the $3^{\text {rd }}$ set of 3 test tubes. All the 9 test tubes were incubated at $37^{\circ} \mathrm{C}$ for 24 hours. Tubes that showed gas and acid production after 24 hours were recorded as positive for the presence of Coliform. Negative tubes were further reincubated for 24 hours. Positive tubes were recorded. Estimate of most probable number of Coliform per gram of sample (MPN/g) was determined by comparing the number of gas positive tubes with the most probable number table. 
BAJOPAS Volume 13 Number 1, June, 2020 Identification of Coliform

A loop full of inoculum from gas positive tubes was streaked on to Eosine methylene blue (EMB) agar plate and incubated at $37^{\circ} \mathrm{C}$ for $24 \mathrm{hrs}$. Colonies which formed bluish black color with green metallic sheen, and reddish colonies were isolated on agar slants. Those colonies showing metallic sheen on EMB were sub cultured into tubes of lactose broth and incubated at $45^{\circ} \mathrm{C}$. The tubes were observed after $24 \mathrm{hrs}$ for gas production. This is the completed test for fecal coliform. Gram stain and other biochemical tests such as Indole, Methyl red, Voges-Proskauer and Citrate Utilization tests (IMVIC), Coagulase and Catalase tests were carried out for the Identification and confirmation of isolates.

\section{Procedure for Indole Test}

Indole test was carried out by preparing a Tryptone broth drawn in to test tubes, sterilized by autoclaving, inoculated with loopful of suspension and incubated at $37^{\circ} \mathrm{C}$ for 24 hours. Three drops of xylene was added in tubes, shaken vigorously and kept for the separation of two layers. One millilitre of Kovac's reagent was added and the formation of pink colour ring indicates positive Indole test.

\section{Procedure for Methyl Red Test}

Methyl red test was carried out by preparing Glucose phosphate broth, dispensed in test tubes, sterilized, inoculated with test culture and incubated at $37^{\circ} \mathrm{C}$ for 24 hours. Five drops of methyl-red indicator was added to the medium for the formation of red colour.

\section{Procedure for Voges-Proskauer Test}

Voges-Proskauer test was carried out by inoculating tubes with the bacterial culture followed by incubation for 48 hours at $37^{\circ} \mathrm{C}$. Separate pipettes were used to pipette $1 \mathrm{ml}$ from each culture tube into clean separate tubes. Eighteen drops $(0.5 \mathrm{ml})$ of Barrit's solution A (a-naphthol) was added to each tube containing glucose phosphate broth followed by the addition of an equal amount of solution $B$ into the same tube. The tubes were shaken at 30 seconds interval. A positive reaction was indicated by the development of a pink color, which turns red in 1-2 hours, after vigorous shaking.

\section{Procedure for Citrate Utilization Test}

Citrate Utilization Test was carried out by distributing melted agar (Simmon Citrate Agar) in to test tubes followed by sterilization at $121.5^{\circ} \mathrm{C}$ for 15 minutes. The test tubes were afterward held in slanted position, inoculated with the given bacterial culture and incubated at $37^{\circ} \mathrm{C}$ for $24 \mathrm{hrs}$. Positive test was indicated by color change of the media from green to blue.

\section{RESULTS AND DISCUSSIONS}

The results of this study are presented in tables $1,2,3$ and 4. Among the sampling areas Kofar Kudu had the highest aerobic mesophilic bacteria counts $4.0 \times 10^{5} \mathrm{cfu} / \mathrm{g}$ followed by Rinji $2.72 \times 10^{5} \mathrm{cfu} / \mathrm{g}$, while Tosaro had the least Aerobic mesophilic bacteria counts of $1.02 \times 10^{5}$ $\mathrm{cfu} / \mathrm{g}$ as indicated in Table 1.Makwalla had the highest coliform count $68 \mathrm{MPN} / \mathrm{g}$ followed by Rinji $37 \mathrm{MPN} / \mathrm{g}$. Tsohuwar Kasuwa had the least coliform counts $8 \mathrm{MPN} / \mathrm{g}$, (Table 2). Result from table 1 shows variation in the microbial contents among the samples which suggest variation in their sources, poor handling procedures and contamination from the processing environment. High coliform count and their differences within sampling areas is an indication of poor microbiological quality of the product. Ndahi et al. (2013) reported microbial load to be a function of the handling personnel and the environment. The results indicated that the samples were contaminated with bacteria as the counts exceeded the minimum safety level $\left(10^{4} \mathrm{cfu} / \mathrm{g}\right)$ for members of the Enterobacteriaceae family. However, it might be a reflection of poor hygienic practices which may contribute to health hazard to the potential consumers. Similarly, Inusa and Sa'id (2017); Osimani et al. (2015) reported that, the initial microbial content of the raw material play significant role in influencing the final microbial load of the finished product. Isolation of members of the Enterobacteriaceae such as $E$. coli, Klebsiella pneumoniae, Salmonella and Shigella signifies danger to the public health. These organisms are capable of producing endotoxins which trigger high fevers in infected individuals, and the enterotoxins which colonize the small intestines and lead to extreme dehydration as a result of vomiting and diarrhea sometimes with severe and fatal outcomes (Amaeze et al., 2016). From the 16 isolated organisms $E$. coli had the highest isolation rate $6(37.5 \%)$ (Table 3), this suggest faecal contamination of the products. $E$. coli is a common flora in the gastrointestinal tract responsible for diarrhea and extra-intestinal infections (CDC, 2011). The result is in conformity with the findings of Ndahi et al. (2013) and Shamsuddeen (2009). Also presence of campylobacter might be due to cross contamination from raw meat to finished product (Tsire). Staphylococcus aureus is a normal flora of the skin, nasal, genital, mouth or anal area in both humans and animals without any symptom of an infection (Matthew et al., 2013). Isolation of $S$. aureus in these study concords with the findings of Lucretia et al. (2018) from Suya sold in Rivers State. 
BAJOPAS Volume 13 Number 1, June, 2020

It is also in agreement with the findings of Yousafzai et al. (2018); Onuorah et al. (2015) and Tijjani and Jumare (2014) from tsire samples in different countries. Presence of $S$. aureus in foods is most of the time an indication of poor human handling, poor environment, unhygienic utensils and equipments used during processing (Igene et al., 2016; Okonko et al., 2013). Infections caused by $S$. aureus are difficult to treat leading to long hospitalization with consequent economic loss (Udobi et al., 2013). These include soft tissue infections, pneumonia, hospital-acquired postoperative wound infections, Staphylococcal food poisoning, impetigo and cellulitis (Charlene et al., 2013). Samples obtained from Dausai and Kofar Kudu had the highest isolation rate $4(80 \%)$ (Table 4 ) probably because of the much commercial activities taking place in the area which can lead to environmental contamination.

Table 1: Total Aerobic Mesophilic Bacterial Count of Tsire sold in Garko Town

\begin{tabular}{lll}
\hline Sampling Area & APC cfu/g & Mean \pm STD \\
\hline Dausai & $2.20 \times 10^{5}$ & $110000 \pm 14142.14$ \\
Kofar Kudu & $4.00 \times 10^{5}$ & $133333.3 \pm 23094.01$ \\
Makwalla & $1.30 \times 10^{5}$ & $32500 \pm 7187.953$ \\
Rinji & $2.72 \times 10^{5}$ & $90666.67 \pm 94769.90$ \\
Tosaro & $1.02 \times 10^{5}$ & $51000 \pm 15556.35$ \\
Tsohuwar Kasuwa & $1.75 \times 10^{5}$ & $35000 \pm 11357.82$ \\
\hline
\end{tabular}

Key: APC: Aerobic Mesophilic Counts

STD: Standard Deviation

Table 2: Total Coliform Count of Tsire sold in Garko Town

\begin{tabular}{lcc}
\hline \multicolumn{1}{c}{ Sampling Area } & TCC MPN/g & Mean \pm STD \\
\hline Dausai & 20 & $6.67 \pm 2.5166$ \\
Kofar Kudu & 32 & $16.00 \pm 5.6569$ \\
Makwalla & 68 & $13.60 \pm 8.7062$ \\
Rinji & 37 & $9.25 \pm 4.7871$ \\
Tosaro & 10 & $5.00 \pm 2.8284$ \\
Tsohuwar Kasuwa & 8 & $4.00 \pm 0.0000$ \\
\hline
\end{tabular}

Table 3: Organisms Isolated from Tsire Sold in Garko

\begin{tabular}{lcl}
\hline Isolated Organism & Frequency & Percentage (\%) \\
\hline Campylobacter & 2 & 06.66 \\
Escherichia coli & 6 & 20.00 \\
Klebsiella pneumoniae & 2 & 06.66 \\
Salmonella species & 1 & 03.33 \\
Shigella & 3 & 10.00 \\
Staphylococcus aureus & 2 & 06.66 \\
Total & 16 & \\
\hline
\end{tabular}

Table 4: Distribution of Organisms within Sampling Area

\begin{tabular}{lcc}
\hline \multicolumn{1}{c}{ Sampling Area } & No. Isolated & Percentage (\%) \\
\hline Dausai & 4 & 80 \\
Kofar Kudu & 4 & 80 \\
Makwalla & 2 & 40 \\
Rinji & 3 & 60 \\
Tosaro & 2 & 40 \\
Tsohuwar Kasuwa & 1 & 20 \\
Total & 16 & \\
\hline
\end{tabular}

\section{CONCLUSION}

Results indicated $4.00 \times 10^{5} \mathrm{CFU} / \mathrm{g}$ as the highest APCs count; while $68 \mathrm{MPN} / \mathrm{g}$ was the highest TCCs from the 30 samples analyzed. Among the isolates, $E$. coli has the highest isolation rate of $6(20 \%)$. Dausai and Kofar kudu were having the highest bacteria count of $4(80 \%)$, each, indicating higher contamination in those locations. 
BAJOPAS Volume 13 Number 1, June, 2020 RECOMMENDATIONS

The following recommendations are tenable:

1. Hygienic practices at all stages of production should be improved to safe guard the consumers against potential health hazard.

2. Monitoring of microbiological contamination of Tsire during preparations, packaging and marketing is essential to ensure product of good microbiological quality for consumers' health.

\section{REFERENCES}

Abdullahi, I. O., Umoh, V. J. and Galadima, M. (2004). Hazards Associated with Kilishi Preparations in Zaria. Nigerian Journal of Microbiology, 18 (1-2): $339-345$.

Ahmadu, J. and Ibrahim E. J., (2013): Determinants of Revenue in Suya Production in BeninCity, Edo State, Nigeria. Nigerian journal of agriculture, food and environment.9(3):1-5

Amaeze, N. Aboh, M. Itohan, A. Felix, E. Olatunji, T. and Oladosu, P. (2016) Microbial Profile, Antibiotic Sensitivity and Heat Resistance of Bacterial Isolates from Commercial Roasted Beef (Suya) in Abuja, Nigeria. JOPAT, 15(2): $22-30$.

Apata, E.S., Kuku1, I.A., Apata, O.C. and Adeyemi, K.O. (2013). Evaluation of Suya(Tsire) - An Intermediate Moisture Meat Product in Ogun State, Nigeria. J. Food Res 2 (1): 87.

Atlas, R. M. (1997) Principles of Microbiology Second Edition. C. Brown Publishers. Pp 802-803.

Borch, E. Kant-Muermans, M. L., Blixt, Y. (1996) Bacterial Spoilage of Meat and Cured Meat Products. Int $\mathrm{J}$ Food Microbiol .33(1): 103-20.

Centre for Disease Control, CDC (2011). "Escherichia coli 0157:H7" Division of Bacterial and Mycotic Diseasesht://www.cdc.gov/nczved/divisi ons/dfbmd/diseases/ecoli_0157h7/.

Charlene, R. J., Johnnie, A. D., and John, B. B., (2013) Prevalence and Characterization of Methicillin-Resistant Staphylococcus aureus Isolates from Retail Meat and Humans in Georgia. American society for Microbiology. J. of clinical microbiology. 12(1):123-6 doi:10.1128/JCM.0316612JCM.03166-12

Egbebi, A.O and Seidu, K., T. (2011). Microbiological Evaluation of Suya (dried smoked

meat) Sold in Ado and Akure, South West Nigeria.European Journal of Experinmental Biology, 1(4):1-5
3. Government should establish regulatory bodies responsible for inculcating hygiene habits to the local producers and vendors in order to prevent instant, cross and post processing contaminations by microbial pathogens.

4. Awareness and sensitization of local food producers about good hygienic practices in food handling and processing.

Falegan, C, R., Akoja, S. D., and Oyarekua, M. A., (2017) Microbiological Assessment of Suya (Sliced Roasted Beef) in Ado-Ekiti Metropolis, Ekiti State, Nigeria. MOJ Biology andMedicine.

Fonkem, D., N. Tanya, V., N. and Ebangi, A., L. (2010). Effect of Season on the Microbiological Quality of Kilishi, a Traditional Cameroonian Dried Beef Product. Tropicultura, 28(1): 10-15.

Food and Agricultural Organization of the United Nations (F A O, 1979). Manual of food quality control 4. Microbiological analysis.

Food and Agriculture Organisation of the United Nation (FAO), 2019. Nigeria at a glance.

Igene J.O., Uwadia, O.E., Ebabhamiegbebho, P.A. and Evivie, S.E., (2016) Shelf life Stability Studies of University of Benin (UNIBEN) Proff's Kilishi Product Asian Journal of Science and Technology 7(1): 2268-2274.

Inusa, S. K. and Said, I. S. (2017) Evaluation of the Chemical and Microbiological Properties Of Kilishi Sold in Kano Metropolis. Journal of Dry land Agriculture, 3 (1): $59-69$.

Lucretia, I. B, Patience, C. Obinna-Echem, Sophia, C. A. (2018) Microbiological quality andantibiotic sensitivity of potential pathogens isolated from meat product (Suya) sold in Rivers State University and its environs. International Journal of Biotechnology and Food Science, 6(4): 67-76.

Matthew, E., Drosos, E., John, L. and Ioanna, P. (2013) MRSA in Africa: Filling the Global Map of Antimicrobial Resistance PLOS One. 8(7): e68024 doi: 10.1371/journal.pone.0068024

Mgbemere, V.N., Akpapunam, M. A. and Igene, J. O., (2011). Effect of Groundnut FlourSubstitution on Yield, Quality and Storage Stability of Kilishi - a Nigerian Indigenous Dried Meat Product. African Journal of Food, Agriculture, Nutrition and Development, $\quad \mathbf{1 1}(2)$ : 4718-4738. 
BAJOPAS Volume 13 Number 1, June, 2020

Mubarak, A. A., Azeez, M. L., Amos A. O., Opeyemi, O. O. (2016) Assessment of Animal Protein Consumption and Food Security Among Rural Households in Kwara State, Nigeria American Journal of Business and Society, 1(4): 233245.

Ndahi, M., D. Kwaga, J., K. P. Bello, M. Kabir J., V. Umoh, .J. Yakubu, S., E. and Nok, A., J. (2013) Prevalence and Antimicrobial Susceptibility of Listeria Monocytogenes and Methicillin-Resistant Staphylococcus aureus Strains from Raw Meat and Meat Products in Zaria, Nigeria. Applied Journal of Microbiology, 58(3):262-9.

Okonko, I.O., Odu, N.N. and Igboh, I.E. (2013). Microbiological Analysis of Kilishi Sold In Port Harcourt, Nigeria. New York Science Journal, 6 (7):37-43.

Osimani, A., Aquilanti, L. and Clementi, F. (2015) Microbiological Quality of Meatbased Meals and Operation of Control Systems within a Food Service Environment. International Food Research Journal 22(4): 1692-1698.

Onuorah, S. Obika, I. Odibo, F. Orji, M. (2015)An Assessment of the Bacteriological Quality of Tsire-Suya (Grilled Beef) sold in Awka, Nigeria. American. J. Life. Sci. Res. 3(4):287292.

Razavilar, V, Khandaghi, J. Barzgari, A. (2010); Isolation of Eschericia coli 0157:H7 from manure fertilized farms and raw vegetables grown on it, in Tabriz city in
Iran. African Journal of Microbiology Research, 4(9): 891-895.

Scallan, E. Hoekstra, R. M. Angulo, F. J.Tauxe, R. V, Widdowson, M. Roy, S. L et al., (2011).Food borne illness acquired in the United States- Major Pathogens. Emerg. Infec Dis, 17(1): 7-15.

Shamsuddeen U (2009). Microbiological quality of spice used in the production of Kilishi a traditionally dried and grilled meat product. Bayero Journal of Pure andApplied Sciences, 2(2): 66-69.

Shamsuddeen, U. (2015) Microbiological Hazard and Critical control point Analysis of Dried and Minced Meat Snacks Produced in Kano Nigeria. Lambert Academic Publishing; Pp 1-36.

Tijani, O.and Jumare, S. (2014). Microblological Quality Assessment of Meat

Sold in KauraNamoda. International Conference on Earth, Environment and Life sciences (EELS) Dubai (UAE).

Udobi, C. E., Obajuluwa, A. F., and Onaolapo, J. A., (2013) Prevalence and Antibiotic Resistance Pattern of MethicillinResistant Staphylococcus aureus from an Orthopaedic Hospital in Nigeria BioMed Research International; 26(6); 6-7.

WHO, 2015 Foodborne diseases in the WHO African Region.

Yousafzai HA, Rind R, Khan MA, Abro SH, Korejo NA, Ejaz M, Kabir A, Shahid M, Memon S. (2019). Microbiological Contamination of Cattle and Meat in Peshawar, Pakistan. J. Anim. Health Prod. 7(1): 1116. 


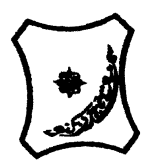

Bayero Journal of Pure and Applied Sciences, 13(1); 40 - 45

Received: September, 2019

Accepted: April, 2020

ISSN $2006-6996$

\title{
BACTERIOLOGICAL QUALITY OF STICK MEAT (Tsire) SOLD IN GARKO LOCAL GOVERNMENT AREA OF KANO STATE, NIGERIA
}

\author{
$*^{1}$ Dahiru A. T. and ${ }^{2}$ Maigari A. K. \\ ${ }^{1}$ Department of Hospitality Management, School of Technology, Kano State Polytechnic, PMB 3348, \\ Kano Nigeria. \\ ${ }^{2}$ Departmnt of Biological Sciences, Bayero University, Kano \\ Corresponding Author: dturajo61@gmail.com; GSM: 08087508262.
}

ABSTRACT

Stick meat, locally called Tsire in Hausa Language, is a significant portion of the diet of a large active population of Northern Nigeria. However, because of the handling and processing methods by the manufacturers as well as the hawking system of stick meat, the meat product may be exposed to both pre- and post-processed product contamination, and thus may poses danger to public health. Therefore, considering the role of Tsire in improving nutrition and increase household income to the populace, the need to improve the processing, distribution and overall quality of the product is simply indispensable. A total of 30 samples (5 samples from each of the 6 sampling points) of Tsire were collected randomly in Garko Town. Aerobic plate counts (APCs) and Total coliform counts (TCCS) of Tsire samples were determined using standard microbiological methods. APCs ranged from $1.02 \times 10^{5}$ to $4.00 \times 10^{5} \mathrm{CFU} / \mathrm{g}$; while TCCs ranged from $8 \mathrm{MPN} / \mathrm{g}$ to $68 \mathrm{MPN} / \mathrm{g}$. From the 30 samples screened, 16(53.33\%) bacteria namely, Campylobacter 2(6.66\%), Escherichia coli 6(20\%), Klebsiella pneumoniae 2(6.66\%), Salmonella spp. 1(3.33\%), Shigella 3(10\%) and Staphylococcus aureus 2(6.66\%) were detected. $E$. coli has the highest isolation rate of 6(20\%), while Salmonella spp. had the least frequency of 1(3.33\%). The distribution of isolated organisms within the study area were as follows: Dausai, 4(80\%), Kofar kudu, 4(80\%), Makwalla, 2(40\%), Rinji, 3(60\%), Tosaro, 2(40\%), and Tsohuwar Kasuwa, 1(20\%). The results have indicated that the Tsire was contaminated with bacteria thus exposing the product to fast deterioration, spoilage and also a vehicle for food borne illness, suggesting for adequate hygienic practices at all the stages, prior to consumption, to ensure safety of the meat product.

Key words: APCs, TCCs, Contamination, Microorganisms, Garko

\section{INTRODUCTION}

Nigeria is one of the developing nations with inadequate food supply and most often deficient in protein content (FAO, 2019). Nigerian's average animal protein intake per head per day is estimated at $7.9 \mathrm{~g}$ as against $35 \mathrm{~g}$ recommended value by Food and Agricultural Organization (Mubarak et al., 2016). These low levels of animal protein intake create great concern as it affects the nutritional status of Nigerians. Hence, there is the need for sufficient supply of animal protein from energy rich animal products to satisfy the nutritional requirements for Nigerians.

Meat is one major source of animal protein largely composed of water, protein and fats which can make it susceptible to microbial contamination within short time leading to spoilage (Apata et al., 2013; Mgbemere et al., 2011). Meat is mostly eaten after it has been cooked or processed in a variety of ways such as sun drying; smoking and roasting with or without fortifications (Borch et al., 1996). In Nigeria meat products such as Tsire, Kilishi and Balangu are locally produced using one or more of these methods in order to meet the nutritional requirements of the teeming Nigerians (Egbebi, 2011).

Tsire is a popular Nigerian traditional processed ready-to-eat roasted stick meat product (Shamsuddeen, 2015). It is sold in public places, along roads, in hotels, parks, quarters and even offices (Falegan et al., 2017). It is prepared from boneless healthy animal flesh such as beef and mutton, spiced with peanut cake, salt, vegetable oil and other flavorings followed by roasting (Shamsuddeen, 2015). Consumption of these products has extended to other parts of African countries such as Ghana, Somali, Cameroun and Chad (Ahmadu and Ibrahim, 2013). 
BAJOPAS Volume 13 Number 1, June, 2020

However, evidence of quality control sticking to procedural hygiene by the handlers during preparation and retailing of these products is poorly documented. Tsire is of great safety risk because of the fact that there are erratic cases of gastroenteritis and symptoms of food infection after consumption (WHO, 2015). Food borne illnesses are one of the major health problems in developing and developed countries (Razavilar, 2010). According to the World Health Organization, WHO (2015), $0.07 \%$ death of the 600 million global burdens of Foodborne illnesses have been reported to be caused by bacteria, viruses, fungi and chemicals. In America $0.27 \%$ of the estimated 48 million affected people is hospitalized and about $0.0063 \%$ deaths are recorded each year (Scallan et al., 2011). More than 91 million people in Africa fall ill and $0.15 \%$ dies each year, making Africa the highest burden bearer of Foodborne diseases per population (WHO, 2015).

Application of a Hazard Analysis Critical Control Point (HACCP) at all stages of meat products preparation is essential in order to ensure its safety. Thus, according to the guidelines of good manufacturing practice, the level of total aerobic bacterial contamination of thermally processed meat products should not exceed $10^{4}\left(\mathrm{cfu} \mathrm{g}^{-1}\right)$. Enterobacteriaceae and faecal coliform contamination in meat products should be within the range of $10^{2}-10^{4}$ and $10-10^{3} \mathrm{cfu} \mathrm{g}^{-1}$, respectively (Shamsuddeen, 2015). The aim of the study is therefore, to assess the total viable bacterial counts of tsire marketed locally within Garko town, and to isolate and identify the organisms at the point of consumption with the intention of promoting public health and food hygiene habits in the Nigerian populace.

\section{MATERIALS AND METHODS Study Area and Population}

Garko is one of the existing 44 local government areas located in Kano south west zone of Kano state with its capital administrative headquarters in the Garko town. It has coordinates $11^{\circ} 39^{\prime} \mathrm{N}$ $8^{\circ} 54^{\prime} \mathrm{E}$, and an area of $450 \mathrm{~km}^{2}$. The projected population of Garko local Government was 225,300 according to the National Population Census report (2018). Garko is known for agricultural activities both farming and animal husbandry. It is popularly known for large scale rice production. Other food crops include sweet potatoes, cassava, onions, sorghum, millet and sugarcane. Cows, sheep and goats are major groups of animals reared by majority of the populace. Meat products processed, retailed and consumed in Garko include roasted meat (Balangu), dried roasted meat (Kilishi), stick meat (Tsire), hide and skin pepper soup (Ragadada) and minced fried meat (Danbunnama).

\section{Samples Collection}

Five samples of Tsire products were collected from 6 different identified locations within Garko town in a sterile foil paper and immediately analyzed for the presence of bacteria.

\section{Sample Preparation}

Sample preparation for the bacteriological analysis was carried out in accordance with the method described by Atlas (1997). Twenty five grams $(25 \mathrm{~g})$ of the sample was homogenized in $225 \mathrm{ml}$ peptone water using Kenwood blender machine to obtain a $10^{1}$ homogenate. The homogenate was thoroughly shaken and $1 \mathrm{ml}$ pipetted into test tubes containing $9 \mathrm{ml}$ of peptone water $\left(10^{2}\right)$. The test tubes were further serially diluted to $10^{5}$.

Total Aerobic Mesophilic Bacterial Count

Total Aerobic mesophilic bacterial count was determined using the method described by Abdullahi et al. (2004) where $1 \mathrm{ml}$ of inoculums from $10^{1}$ to $10^{5}$ dilutions were transferred into duplicate Petri dishes and labeled accordingly. This was followed by pouring aseptically about $15 \mathrm{ml}$ of molten nutrient agar. The culture was homogenized by gentle spinning of the plates and allowed to solidify. The plates were incubated at $37^{\circ} \mathrm{C}$ for 24 hours. Plates containing 30-300 colonies were counted. The number of colony forming units per gram of a sample (cfu/g) was obtained by multiplying the average colony number with the inverse of the dilution factor.

\section{Enumeration and Detection of Coliform bacteria}

Detection and enumeration of coliform was carried out according to method described by Atlas, (1977). A set of 9 test tubes each containing $9 \mathrm{ml}$ of lactose broth and an inverted Durham tubes were autoclaved to expel air and to sterilize. Similarly, $1 \mathrm{ml}$ from the diluents $10^{1}$ was transferred to the first 3 test tubes, followed by $1 \mathrm{ml}$ from the diluents $10^{2}$ to the second set of 3 test tubes and finally the third diluents $10^{3}$ to the $3^{\text {rd }}$ set of 3 test tubes. All the 9 test tubes were incubated at $37^{\circ} \mathrm{C}$ for 24 hours. Tubes that showed gas and acid production after 24 hours were recorded as positive for the presence of Coliform. Negative tubes were further reincubated for 24 hours. Positive tubes were recorded. Estimate of most probable number of Coliform per gram of sample (MPN/g) was determined by comparing the number of gas positive tubes with the most probable number table. 
BAJOPAS Volume 13 Number 1, June, 2020 Identification of Coliform

A loop full of inoculum from gas positive tubes was streaked on to Eosine methylene blue (EMB) agar plate and incubated at $37^{\circ} \mathrm{C}$ for $24 \mathrm{hrs}$. Colonies which formed bluish black color with green metallic sheen, and reddish colonies were isolated on agar slants. Those colonies showing metallic sheen on EMB were sub cultured into tubes of lactose broth and incubated at $45^{\circ} \mathrm{C}$. The tubes were observed after $24 \mathrm{hrs}$ for gas production. This is the completed test for fecal coliform. Gram stain and other biochemical tests such as Indole, Methyl red, Voges-Proskauer and Citrate Utilization tests (IMVIC), Coagulase and Catalase tests were carried out for the Identification and confirmation of isolates.

\section{Procedure for Indole Test}

Indole test was carried out by preparing a Tryptone broth drawn in to test tubes, sterilized by autoclaving, inoculated with loopful of suspension and incubated at $37^{\circ} \mathrm{C}$ for 24 hours. Three drops of xylene was added in tubes, shaken vigorously and kept for the separation of two layers. One millilitre of Kovac's reagent was added and the formation of pink colour ring indicates positive Indole test.

\section{Procedure for Methyl Red Test}

Methyl red test was carried out by preparing Glucose phosphate broth, dispensed in test tubes, sterilized, inoculated with test culture and incubated at $37^{\circ} \mathrm{C}$ for 24 hours. Five drops of methyl-red indicator was added to the medium for the formation of red colour.

\section{Procedure for Voges-Proskauer Test}

Voges-Proskauer test was carried out by inoculating tubes with the bacterial culture followed by incubation for 48 hours at $37^{\circ} \mathrm{C}$. Separate pipettes were used to pipette $1 \mathrm{ml}$ from each culture tube into clean separate tubes. Eighteen drops $(0.5 \mathrm{ml})$ of Barrit's solution A (a-naphthol) was added to each tube containing glucose phosphate broth followed by the addition of an equal amount of solution $B$ into the same tube. The tubes were shaken at 30 seconds interval. A positive reaction was indicated by the development of a pink color, which turns red in 1-2 hours, after vigorous shaking.

\section{Procedure for Citrate Utilization Test}

Citrate Utilization Test was carried out by distributing melted agar (Simmon Citrate Agar) in to test tubes followed by sterilization at $121.5^{\circ} \mathrm{C}$ for 15 minutes. The test tubes were afterward held in slanted position, inoculated with the given bacterial culture and incubated at $37^{\circ} \mathrm{C}$ for $24 \mathrm{hrs}$. Positive test was indicated by color change of the media from green to blue.

\section{RESULTS AND DISCUSSIONS}

The results of this study are presented in tables $1,2,3$ and 4. Among the sampling areas Kofar Kudu had the highest aerobic mesophilic bacteria counts $4.0 \times 10^{5} \mathrm{cfu} / \mathrm{g}$ followed by Rinji $2.72 \times 10^{5} \mathrm{cfu} / \mathrm{g}$, while Tosaro had the least Aerobic mesophilic bacteria counts of $1.02 \times 10^{5}$ $\mathrm{cfu} / \mathrm{g}$ as indicated in Table 1.Makwalla had the highest coliform count $68 \mathrm{MPN} / \mathrm{g}$ followed by Rinji $37 \mathrm{MPN} / \mathrm{g}$. Tsohuwar Kasuwa had the least coliform counts $8 \mathrm{MPN} / \mathrm{g}$, (Table 2). Result from table 1 shows variation in the microbial contents among the samples which suggest variation in their sources, poor handling procedures and contamination from the processing environment. High coliform count and their differences within sampling areas is an indication of poor microbiological quality of the product. Ndahi et al. (2013) reported microbial load to be a function of the handling personnel and the environment. The results indicated that the samples were contaminated with bacteria as the counts exceeded the minimum safety level $\left(10^{4} \mathrm{cfu} / \mathrm{g}\right)$ for members of the Enterobacteriaceae family. However, it might be a reflection of poor hygienic practices which may contribute to health hazard to the potential consumers. Similarly, Inusa and Sa'id (2017); Osimani et al. (2015) reported that, the initial microbial content of the raw material play significant role in influencing the final microbial load of the finished product. Isolation of members of the Enterobacteriaceae such as $E$. coli, Klebsiella pneumoniae, Salmonella and Shigella signifies danger to the public health. These organisms are capable of producing endotoxins which trigger high fevers in infected individuals, and the enterotoxins which colonize the small intestines and lead to extreme dehydration as a result of vomiting and diarrhea sometimes with severe and fatal outcomes (Amaeze et al., 2016). From the 16 isolated organisms $E$. coli had the highest isolation rate $6(37.5 \%)$ (Table 3), this suggest faecal contamination of the products. $E$. coli is a common flora in the gastrointestinal tract responsible for diarrhea and extra-intestinal infections (CDC, 2011). The result is in conformity with the findings of Ndahi et al. (2013) and Shamsuddeen (2009). Also presence of campylobacter might be due to cross contamination from raw meat to finished product (Tsire). Staphylococcus aureus is a normal flora of the skin, nasal, genital, mouth or anal area in both humans and animals without any symptom of an infection (Matthew et al., 2013). Isolation of $S$. aureus in these study concords with the findings of Lucretia et al. (2018) from Suya sold in Rivers State. 
BAJOPAS Volume 13 Number 1, June, 2020

It is also in agreement with the findings of Yousafzai et al. (2018); Onuorah et al. (2015) and Tijjani and Jumare (2014) from tsire samples in different countries. Presence of $S$. aureus in foods is most of the time an indication of poor human handling, poor environment, unhygienic utensils and equipments used during processing (Igene et al., 2016; Okonko et al., 2013). Infections caused by $S$. aureus are difficult to treat leading to long hospitalization with consequent economic loss (Udobi et al., 2013). These include soft tissue infections, pneumonia, hospital-acquired postoperative wound infections, Staphylococcal food poisoning, impetigo and cellulitis (Charlene et al., 2013). Samples obtained from Dausai and Kofar Kudu had the highest isolation rate $4(80 \%)$ (Table 4 ) probably because of the much commercial activities taking place in the area which can lead to environmental contamination.

Table 1: Total Aerobic Mesophilic Bacterial Count of Tsire sold in Garko Town

\begin{tabular}{lll}
\hline Sampling Area & APC cfu/g & Mean \pm STD \\
\hline Dausai & $2.20 \times 10^{5}$ & $110000 \pm 14142.14$ \\
Kofar Kudu & $4.00 \times 10^{5}$ & $133333.3 \pm 23094.01$ \\
Makwalla & $1.30 \times 10^{5}$ & $32500 \pm 7187.953$ \\
Rinji & $2.72 \times 10^{5}$ & $90666.67 \pm 94769.90$ \\
Tosaro & $1.02 \times 10^{5}$ & $51000 \pm 15556.35$ \\
Tsohuwar Kasuwa & $1.75 \times 10^{5}$ & $35000 \pm 11357.82$ \\
\hline
\end{tabular}

Key: APC: Aerobic Mesophilic Counts

STD: Standard Deviation

Table 2: Total Coliform Count of Tsire sold in Garko Town

\begin{tabular}{lcc}
\hline \multicolumn{1}{c}{ Sampling Area } & TCC MPN/g & Mean \pm STD \\
\hline Dausai & 20 & $6.67 \pm 2.5166$ \\
Kofar Kudu & 32 & $16.00 \pm 5.6569$ \\
Makwalla & 68 & $13.60 \pm 8.7062$ \\
Rinji & 37 & $9.25 \pm 4.7871$ \\
Tosaro & 10 & $5.00 \pm 2.8284$ \\
Tsohuwar Kasuwa & 8 & $4.00 \pm 0.0000$ \\
\hline
\end{tabular}

Table 3: Organisms Isolated from Tsire Sold in Garko

\begin{tabular}{lcl}
\hline Isolated Organism & Frequency & Percentage (\%) \\
\hline Campylobacter & 2 & 06.66 \\
Escherichia coli & 6 & 20.00 \\
Klebsiella pneumoniae & 2 & 06.66 \\
Salmonella species & 1 & 03.33 \\
Shigella & 3 & 10.00 \\
Staphylococcus aureus & 2 & 06.66 \\
Total & 16 & \\
\hline
\end{tabular}

Table 4: Distribution of Organisms within Sampling Area

\begin{tabular}{lcc}
\hline \multicolumn{1}{c}{ Sampling Area } & No. Isolated & Percentage (\%) \\
\hline Dausai & 4 & 80 \\
Kofar Kudu & 4 & 80 \\
Makwalla & 2 & 40 \\
Rinji & 3 & 60 \\
Tosaro & 2 & 40 \\
Tsohuwar Kasuwa & 1 & 20 \\
Total & 16 & \\
\hline
\end{tabular}

\section{CONCLUSION}

Results indicated $4.00 \times 10^{5} \mathrm{CFU} / \mathrm{g}$ as the highest APCs count; while $68 \mathrm{MPN} / \mathrm{g}$ was the highest TCCs from the 30 samples analyzed. Among the isolates, $E$. coli has the highest isolation rate of $6(20 \%)$. Dausai and Kofar kudu were having the highest bacteria count of $4(80 \%)$, each, indicating higher contamination in those locations. 
BAJOPAS Volume 13 Number 1, June, 2020 RECOMMENDATIONS

The following recommendations are tenable:

1. Hygienic practices at all stages of production should be improved to safe guard the consumers against potential health hazard.

2. Monitoring of microbiological contamination of Tsire during preparations, packaging and marketing is essential to ensure product of good microbiological quality for consumers' health.

\section{REFERENCES}

Abdullahi, I. O., Umoh, V. J. and Galadima, M. (2004). Hazards Associated with Kilishi Preparations in Zaria. Nigerian Journal of Microbiology, 18 (1-2): $339-345$.

Ahmadu, J. and Ibrahim E. J., (2013): Determinants of Revenue in Suya Production in BeninCity, Edo State, Nigeria. Nigerian journal of agriculture, food and environment.9(3):1-5

Amaeze, N. Aboh, M. Itohan, A. Felix, E. Olatunji, T. and Oladosu, P. (2016) Microbial Profile, Antibiotic Sensitivity and Heat Resistance of Bacterial Isolates from Commercial Roasted Beef (Suya) in Abuja, Nigeria. JOPAT, 15(2): $22-30$.

Apata, E.S., Kuku1, I.A., Apata, O.C. and Adeyemi, K.O. (2013). Evaluation of Suya(Tsire) - An Intermediate Moisture Meat Product in Ogun State, Nigeria. J. Food Res 2 (1): 87.

Atlas, R. M. (1997) Principles of Microbiology Second Edition. C. Brown Publishers. Pp 802-803.

Borch, E. Kant-Muermans, M. L., Blixt, Y. (1996) Bacterial Spoilage of Meat and Cured Meat Products. Int $\mathrm{J}$ Food Microbiol .33(1): 103-20.

Centre for Disease Control, CDC (2011). "Escherichia coli 0157:H7" Division of Bacterial and Mycotic Diseasesht://www.cdc.gov/nczved/divisi ons/dfbmd/diseases/ecoli_0157h7/.

Charlene, R. J., Johnnie, A. D., and John, B. B., (2013) Prevalence and Characterization of Methicillin-Resistant Staphylococcus aureus Isolates from Retail Meat and Humans in Georgia. American society for Microbiology. J. of clinical microbiology. 12(1):123-6 doi:10.1128/JCM.0316612JCM.03166-12

Egbebi, A.O and Seidu, K., T. (2011). Microbiological Evaluation of Suya (dried smoked

meat) Sold in Ado and Akure, South West Nigeria.European Journal of Experinmental Biology, 1(4):1-5
3. Government should establish regulatory bodies responsible for inculcating hygiene habits to the local producers and vendors in order to prevent instant, cross and post processing contaminations by microbial pathogens.

4. Awareness and sensitization of local food producers about good hygienic practices in food handling and processing.

Falegan, C, R., Akoja, S. D., and Oyarekua, M. A., (2017) Microbiological Assessment of Suya (Sliced Roasted Beef) in Ado-Ekiti Metropolis, Ekiti State, Nigeria. MOJ Biology andMedicine.

Fonkem, D., N. Tanya, V., N. and Ebangi, A., L. (2010). Effect of Season on the Microbiological Quality of Kilishi, a Traditional Cameroonian Dried Beef Product. Tropicultura, 28(1): 10-15.

Food and Agricultural Organization of the United Nations (F A O, 1979). Manual of food quality control 4. Microbiological analysis.

Food and Agriculture Organisation of the United Nation (FAO), 2019. Nigeria at a glance.

Igene J.O., Uwadia, O.E., Ebabhamiegbebho, P.A. and Evivie, S.E., (2016) Shelf life Stability Studies of University of Benin (UNIBEN) Proff's Kilishi Product Asian Journal of Science and Technology 7(1): 2268-2274.

Inusa, S. K. and Said, I. S. (2017) Evaluation of the Chemical and Microbiological Properties Of Kilishi Sold in Kano Metropolis. Journal of Dry land Agriculture, 3 (1): $59-69$.

Lucretia, I. B, Patience, C. Obinna-Echem, Sophia, C. A. (2018) Microbiological quality andantibiotic sensitivity of potential pathogens isolated from meat product (Suya) sold in Rivers State University and its environs. International Journal of Biotechnology and Food Science, 6(4): 67-76.

Matthew, E., Drosos, E., John, L. and Ioanna, P. (2013) MRSA in Africa: Filling the Global Map of Antimicrobial Resistance PLOS One. 8(7): e68024 doi: 10.1371/journal.pone.0068024

Mgbemere, V.N., Akpapunam, M. A. and Igene, J. O., (2011). Effect of Groundnut FlourSubstitution on Yield, Quality and Storage Stability of Kilishi - a Nigerian Indigenous Dried Meat Product. African Journal of Food, Agriculture, Nutrition and Development, $\quad \mathbf{1 1}(2)$ : 4718-4738. 
BAJOPAS Volume 13 Number 1, June, 2020

Mubarak, A. A., Azeez, M. L., Amos A. O., Opeyemi, O. O. (2016) Assessment of Animal Protein Consumption and Food Security Among Rural Households in Kwara State, Nigeria American Journal of Business and Society, 1(4): 233245.

Ndahi, M., D. Kwaga, J., K. P. Bello, M. Kabir J., V. Umoh, .J. Yakubu, S., E. and Nok, A., J. (2013) Prevalence and Antimicrobial Susceptibility of Listeria Monocytogenes and Methicillin-Resistant Staphylococcus aureus Strains from Raw Meat and Meat Products in Zaria, Nigeria. Applied Journal of Microbiology, 58(3):262-9.

Okonko, I.O., Odu, N.N. and Igboh, I.E. (2013). Microbiological Analysis of Kilishi Sold In Port Harcourt, Nigeria. New York Science Journal, 6 (7):37-43.

Osimani, A., Aquilanti, L. and Clementi, F. (2015) Microbiological Quality of Meatbased Meals and Operation of Control Systems within a Food Service Environment. International Food Research Journal 22(4): 1692-1698.

Onuorah, S. Obika, I. Odibo, F. Orji, M. (2015)An Assessment of the Bacteriological Quality of Tsire-Suya (Grilled Beef) sold in Awka, Nigeria. American. J. Life. Sci. Res. 3(4):287292.

Razavilar, V, Khandaghi, J. Barzgari, A. (2010); Isolation of Eschericia coli 0157:H7 from manure fertilized farms and raw vegetables grown on it, in Tabriz city in
Iran. African Journal of Microbiology Research, 4(9): 891-895.

Scallan, E. Hoekstra, R. M. Angulo, F. J.Tauxe, R. V, Widdowson, M. Roy, S. L et al., (2011).Food borne illness acquired in the United States- Major Pathogens. Emerg. Infec Dis, 17(1): 7-15.

Shamsuddeen U (2009). Microbiological quality of spice used in the production of Kilishi a traditionally dried and grilled meat product. Bayero Journal of Pure andApplied Sciences, 2(2): 66-69.

Shamsuddeen, U. (2015) Microbiological Hazard and Critical control point Analysis of Dried and Minced Meat Snacks Produced in Kano Nigeria. Lambert Academic Publishing; Pp 1-36.

Tijani, O.and Jumare, S. (2014). Microblological Quality Assessment of Meat

Sold in KauraNamoda. International Conference on Earth, Environment and Life sciences (EELS) Dubai (UAE).

Udobi, C. E., Obajuluwa, A. F., and Onaolapo, J. A., (2013) Prevalence and Antibiotic Resistance Pattern of MethicillinResistant Staphylococcus aureus from an Orthopaedic Hospital in Nigeria BioMed Research International; 26(6); 6-7.

WHO, 2015 Foodborne diseases in the WHO African Region.

Yousafzai HA, Rind R, Khan MA, Abro SH, Korejo NA, Ejaz M, Kabir A, Shahid M, Memon S. (2019). Microbiological Contamination of Cattle and Meat in Peshawar, Pakistan. J. Anim. Health Prod. 7(1): 1116. 


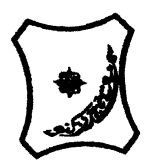

Bayero Journal of Pure and Applied Sciences, 13(1); 40 - 45

Received: September, 2019

Accepted: April, 2020

ISSN $2006-6996$

\title{
BACTERIOLOGICAL QUALITY OF STICK MEAT (Tsire) SOLD IN GARKO LOCAL GOVERNMENT AREA OF KANO STATE, NIGERIA
}

\author{
$*^{1}$ Dahiru A. T. and ${ }^{2}$ Maigari A. K. \\ ${ }^{1}$ Department of Hospitality Management, School of Technology, Kano State Polytechnic, PMB 3348, \\ Kano Nigeria. \\ ${ }^{2}$ Departmnt of Biological Sciences, Bayero University, Kano \\ Corresponding Author: dturajo61@gmail.com; GSM: 08087508262.
}

ABSTRACT

Stick meat, locally called Tsire in Hausa Language, is a significant portion of the diet of a large active population of Northern Nigeria. However, because of the handling and processing methods by the manufacturers as well as the hawking system of stick meat, the meat product may be exposed to both pre- and post-processed product contamination, and thus may poses danger to public health. Therefore, considering the role of Tsire in improving nutrition and increase household income to the populace, the need to improve the processing, distribution and overall quality of the product is simply indispensable. A total of 30 samples (5 samples from each of the 6 sampling points) of Tsire were collected randomly in Garko Town. Aerobic plate counts (APCs) and Total coliform counts (TCCS) of Tsire samples were determined using standard microbiological methods. APCs ranged from $1.02 \times 10^{5}$ to $4.00 \times 10^{5} \mathrm{CFU} / \mathrm{g}$; while TCCs ranged from $8 \mathrm{MPN} / \mathrm{g}$ to $68 \mathrm{MPN} / \mathrm{g}$. From the 30 samples screened, 16(53.33\%) bacteria namely, Campylobacter 2(6.66\%), Escherichia coli 6(20\%), Klebsiella pneumoniae 2(6.66\%), Salmonella spp. 1(3.33\%), Shigella 3(10\%) and Staphylococcus aureus 2(6.66\%) were detected. $E$. coli has the highest isolation rate of 6(20\%), while Salmonella spp. had the least frequency of 1(3.33\%). The distribution of isolated organisms within the study area were as follows: Dausai, 4(80\%), Kofar kudu, 4(80\%), Makwalla, 2(40\%), Rinji, 3(60\%), Tosaro, 2(40\%), and Tsohuwar Kasuwa, 1(20\%). The results have indicated that the Tsire was contaminated with bacteria thus exposing the product to fast deterioration, spoilage and also a vehicle for food borne illness, suggesting for adequate hygienic practices at all the stages, prior to consumption, to ensure safety of the meat product.

Key words: APCs, TCCs, Contamination, Microorganisms, Garko

\section{INTRODUCTION}

Nigeria is one of the developing nations with inadequate food supply and most often deficient in protein content (FAO, 2019). Nigerian's average animal protein intake per head per day is estimated at $7.9 \mathrm{~g}$ as against $35 \mathrm{~g}$ recommended value by Food and Agricultural Organization (Mubarak et al., 2016). These low levels of animal protein intake create great concern as it affects the nutritional status of Nigerians. Hence, there is the need for sufficient supply of animal protein from energy rich animal products to satisfy the nutritional requirements for Nigerians.

Meat is one major source of animal protein largely composed of water, protein and fats which can make it susceptible to microbial contamination within short time leading to spoilage (Apata et al., 2013; Mgbemere et al., 2011). Meat is mostly eaten after it has been cooked or processed in a variety of ways such as sun drying; smoking and roasting with or without fortifications (Borch et al., 1996). In Nigeria meat products such as Tsire, Kilishi and Balangu are locally produced using one or more of these methods in order to meet the nutritional requirements of the teeming Nigerians (Egbebi, 2011).

Tsire is a popular Nigerian traditional processed ready-to-eat roasted stick meat product (Shamsuddeen, 2015). It is sold in public places, along roads, in hotels, parks, quarters and even offices (Falegan et al., 2017). It is prepared from boneless healthy animal flesh such as beef and mutton, spiced with peanut cake, salt, vegetable oil and other flavorings followed by roasting (Shamsuddeen, 2015). Consumption of these products has extended to other parts of African countries such as Ghana, Somali, Cameroun and Chad (Ahmadu and Ibrahim, 2013). 
BAJOPAS Volume 13 Number 1, June, 2020

However, evidence of quality control sticking to procedural hygiene by the handlers during preparation and retailing of these products is poorly documented. Tsire is of great safety risk because of the fact that there are erratic cases of gastroenteritis and symptoms of food infection after consumption (WHO, 2015). Food borne illnesses are one of the major health problems in developing and developed countries (Razavilar, 2010). According to the World Health Organization, WHO (2015), $0.07 \%$ death of the 600 million global burdens of Foodborne illnesses have been reported to be caused by bacteria, viruses, fungi and chemicals. In America $0.27 \%$ of the estimated 48 million affected people is hospitalized and about $0.0063 \%$ deaths are recorded each year (Scallan et al., 2011). More than 91 million people in Africa fall ill and $0.15 \%$ dies each year, making Africa the highest burden bearer of Foodborne diseases per population (WHO, 2015).

Application of a Hazard Analysis Critical Control Point (HACCP) at all stages of meat products preparation is essential in order to ensure its safety. Thus, according to the guidelines of good manufacturing practice, the level of total aerobic bacterial contamination of thermally processed meat products should not exceed $10^{4}\left(\mathrm{cfu} \mathrm{g}^{-1}\right)$. Enterobacteriaceae and faecal coliform contamination in meat products should be within the range of $10^{2}-10^{4}$ and $10-10^{3} \mathrm{cfu} \mathrm{g}^{-1}$, respectively (Shamsuddeen, 2015). The aim of the study is therefore, to assess the total viable bacterial counts of tsire marketed locally within Garko town, and to isolate and identify the organisms at the point of consumption with the intention of promoting public health and food hygiene habits in the Nigerian populace.

\section{MATERIALS AND METHODS Study Area and Population}

Garko is one of the existing 44 local government areas located in Kano south west zone of Kano state with its capital administrative headquarters in the Garko town. It has coordinates $11^{\circ} 39^{\prime} \mathrm{N}$ $8^{\circ} 54^{\prime} \mathrm{E}$, and an area of $450 \mathrm{~km}^{2}$. The projected population of Garko local Government was 225,300 according to the National Population Census report (2018). Garko is known for agricultural activities both farming and animal husbandry. It is popularly known for large scale rice production. Other food crops include sweet potatoes, cassava, onions, sorghum, millet and sugarcane. Cows, sheep and goats are major groups of animals reared by majority of the populace. Meat products processed, retailed and consumed in Garko include roasted meat (Balangu), dried roasted meat (Kilishi), stick meat (Tsire), hide and skin pepper soup (Ragadada) and minced fried meat (Danbunnama).

\section{Samples Collection}

Five samples of Tsire products were collected from 6 different identified locations within Garko town in a sterile foil paper and immediately analyzed for the presence of bacteria.

\section{Sample Preparation}

Sample preparation for the bacteriological analysis was carried out in accordance with the method described by Atlas (1997). Twenty five grams $(25 \mathrm{~g})$ of the sample was homogenized in $225 \mathrm{ml}$ peptone water using Kenwood blender machine to obtain a $10^{1}$ homogenate. The homogenate was thoroughly shaken and $1 \mathrm{ml}$ pipetted into test tubes containing $9 \mathrm{ml}$ of peptone water $\left(10^{2}\right)$. The test tubes were further serially diluted to $10^{5}$.

Total Aerobic Mesophilic Bacterial Count

Total Aerobic mesophilic bacterial count was determined using the method described by Abdullahi et al. (2004) where $1 \mathrm{ml}$ of inoculums from $10^{1}$ to $10^{5}$ dilutions were transferred into duplicate Petri dishes and labeled accordingly. This was followed by pouring aseptically about $15 \mathrm{ml}$ of molten nutrient agar. The culture was homogenized by gentle spinning of the plates and allowed to solidify. The plates were incubated at $37^{\circ} \mathrm{C}$ for 24 hours. Plates containing 30-300 colonies were counted. The number of colony forming units per gram of a sample (cfu/g) was obtained by multiplying the average colony number with the inverse of the dilution factor.

\section{Enumeration and Detection of Coliform bacteria}

Detection and enumeration of coliform was carried out according to method described by Atlas, (1977). A set of 9 test tubes each containing $9 \mathrm{ml}$ of lactose broth and an inverted Durham tubes were autoclaved to expel air and to sterilize. Similarly, $1 \mathrm{ml}$ from the diluents $10^{1}$ was transferred to the first 3 test tubes, followed by $1 \mathrm{ml}$ from the diluents $10^{2}$ to the second set of 3 test tubes and finally the third diluents $10^{3}$ to the $3^{\text {rd }}$ set of 3 test tubes. All the 9 test tubes were incubated at $37^{\circ} \mathrm{C}$ for 24 hours. Tubes that showed gas and acid production after 24 hours were recorded as positive for the presence of Coliform. Negative tubes were further reincubated for 24 hours. Positive tubes were recorded. Estimate of most probable number of Coliform per gram of sample (MPN/g) was determined by comparing the number of gas positive tubes with the most probable number table. 
BAJOPAS Volume 13 Number 1, June, 2020 Identification of Coliform

A loop full of inoculum from gas positive tubes was streaked on to Eosine methylene blue (EMB) agar plate and incubated at $37^{\circ} \mathrm{C}$ for $24 \mathrm{hrs}$. Colonies which formed bluish black color with green metallic sheen, and reddish colonies were isolated on agar slants. Those colonies showing metallic sheen on EMB were sub cultured into tubes of lactose broth and incubated at $45^{\circ} \mathrm{C}$. The tubes were observed after $24 \mathrm{hrs}$ for gas production. This is the completed test for fecal coliform. Gram stain and other biochemical tests such as Indole, Methyl red, Voges-Proskauer and Citrate Utilization tests (IMVIC), Coagulase and Catalase tests were carried out for the Identification and confirmation of isolates.

\section{Procedure for Indole Test}

Indole test was carried out by preparing a Tryptone broth drawn in to test tubes, sterilized by autoclaving, inoculated with loopful of suspension and incubated at $37^{\circ} \mathrm{C}$ for 24 hours. Three drops of xylene was added in tubes, shaken vigorously and kept for the separation of two layers. One millilitre of Kovac's reagent was added and the formation of pink colour ring indicates positive Indole test.

\section{Procedure for Methyl Red Test}

Methyl red test was carried out by preparing Glucose phosphate broth, dispensed in test tubes, sterilized, inoculated with test culture and incubated at $37^{\circ} \mathrm{C}$ for 24 hours. Five drops of methyl-red indicator was added to the medium for the formation of red colour.

\section{Procedure for Voges-Proskauer Test}

Voges-Proskauer test was carried out by inoculating tubes with the bacterial culture followed by incubation for 48 hours at $37^{\circ} \mathrm{C}$. Separate pipettes were used to pipette $1 \mathrm{ml}$ from each culture tube into clean separate tubes. Eighteen drops $(0.5 \mathrm{ml})$ of Barrit's solution A (a-naphthol) was added to each tube containing glucose phosphate broth followed by the addition of an equal amount of solution $B$ into the same tube. The tubes were shaken at 30 seconds interval. A positive reaction was indicated by the development of a pink color, which turns red in 1-2 hours, after vigorous shaking.

\section{Procedure for Citrate Utilization Test}

Citrate Utilization Test was carried out by distributing melted agar (Simmon Citrate Agar) in to test tubes followed by sterilization at $121.5^{\circ} \mathrm{C}$ for 15 minutes. The test tubes were afterward held in slanted position, inoculated with the given bacterial culture and incubated at $37^{\circ} \mathrm{C}$ for $24 \mathrm{hrs}$. Positive test was indicated by color change of the media from green to blue.

\section{RESULTS AND DISCUSSIONS}

The results of this study are presented in tables $1,2,3$ and 4. Among the sampling areas Kofar Kudu had the highest aerobic mesophilic bacteria counts $4.0 \times 10^{5} \mathrm{cfu} / \mathrm{g}$ followed by Rinji $2.72 \times 10^{5} \mathrm{cfu} / \mathrm{g}$, while Tosaro had the least Aerobic mesophilic bacteria counts of $1.02 \times 10^{5}$ $\mathrm{cfu} / \mathrm{g}$ as indicated in Table 1.Makwalla had the highest coliform count $68 \mathrm{MPN} / \mathrm{g}$ followed by Rinji $37 \mathrm{MPN} / \mathrm{g}$. Tsohuwar Kasuwa had the least coliform counts $8 \mathrm{MPN} / \mathrm{g}$, (Table 2). Result from table 1 shows variation in the microbial contents among the samples which suggest variation in their sources, poor handling procedures and contamination from the processing environment. High coliform count and their differences within sampling areas is an indication of poor microbiological quality of the product. Ndahi et al. (2013) reported microbial load to be a function of the handling personnel and the environment. The results indicated that the samples were contaminated with bacteria as the counts exceeded the minimum safety level $\left(10^{4} \mathrm{cfu} / \mathrm{g}\right)$ for members of the Enterobacteriaceae family. However, it might be a reflection of poor hygienic practices which may contribute to health hazard to the potential consumers. Similarly, Inusa and Sa'id (2017); Osimani et al. (2015) reported that, the initial microbial content of the raw material play significant role in influencing the final microbial load of the finished product. Isolation of members of the Enterobacteriaceae such as $E$. coli, Klebsiella pneumoniae, Salmonella and Shigella signifies danger to the public health. These organisms are capable of producing endotoxins which trigger high fevers in infected individuals, and the enterotoxins which colonize the small intestines and lead to extreme dehydration as a result of vomiting and diarrhea sometimes with severe and fatal outcomes (Amaeze et al., 2016). From the 16 isolated organisms $E$. coli had the highest isolation rate $6(37.5 \%)$ (Table 3), this suggest faecal contamination of the products. $E$. coli is a common flora in the gastrointestinal tract responsible for diarrhea and extra-intestinal infections (CDC, 2011). The result is in conformity with the findings of Ndahi et al. (2013) and Shamsuddeen (2009). Also presence of campylobacter might be due to cross contamination from raw meat to finished product (Tsire). Staphylococcus aureus is a normal flora of the skin, nasal, genital, mouth or anal area in both humans and animals without any symptom of an infection (Matthew et al., 2013). Isolation of $S$. aureus in these study concords with the findings of Lucretia et al. (2018) from Suya sold in Rivers State. 
BAJOPAS Volume 13 Number 1, June, 2020

It is also in agreement with the findings of Yousafzai et al. (2018); Onuorah et al. (2015) and Tijjani and Jumare (2014) from tsire samples in different countries. Presence of $S$. aureus in foods is most of the time an indication of poor human handling, poor environment, unhygienic utensils and equipments used during processing (Igene et al., 2016; Okonko et al., 2013). Infections caused by $S$. aureus are difficult to treat leading to long hospitalization with consequent economic loss (Udobi et al., 2013). These include soft tissue infections, pneumonia, hospital-acquired postoperative wound infections, Staphylococcal food poisoning, impetigo and cellulitis (Charlene et al., 2013). Samples obtained from Dausai and Kofar Kudu had the highest isolation rate $4(80 \%)$ (Table 4 ) probably because of the much commercial activities taking place in the area which can lead to environmental contamination.

Table 1: Total Aerobic Mesophilic Bacterial Count of Tsire sold in Garko Town

\begin{tabular}{lll}
\hline Sampling Area & APC cfu/g & Mean \pm STD \\
\hline Dausai & $2.20 \times 10^{5}$ & $110000 \pm 14142.14$ \\
Kofar Kudu & $4.00 \times 10^{5}$ & $133333.3 \pm 23094.01$ \\
Makwalla & $1.30 \times 10^{5}$ & $32500 \pm 7187.953$ \\
Rinji & $2.72 \times 10^{5}$ & $90666.67 \pm 94769.90$ \\
Tosaro & $1.02 \times 10^{5}$ & $51000 \pm 15556.35$ \\
Tsohuwar Kasuwa & $1.75 \times 10^{5}$ & $35000 \pm 11357.82$ \\
\hline
\end{tabular}

Key: APC: Aerobic Mesophilic Counts

STD: Standard Deviation

Table 2: Total Coliform Count of Tsire sold in Garko Town

\begin{tabular}{lcc}
\hline \multicolumn{1}{c}{ Sampling Area } & TCC MPN/g & Mean \pm STD \\
\hline Dausai & 20 & $6.67 \pm 2.5166$ \\
Kofar Kudu & 32 & $16.00 \pm 5.6569$ \\
Makwalla & 68 & $13.60 \pm 8.7062$ \\
Rinji & 37 & $9.25 \pm 4.7871$ \\
Tosaro & 10 & $5.00 \pm 2.8284$ \\
Tsohuwar Kasuwa & 8 & $4.00 \pm 0.0000$ \\
\hline
\end{tabular}

Table 3: Organisms Isolated from Tsire Sold in Garko

\begin{tabular}{lcl}
\hline Isolated Organism & Frequency & Percentage (\%) \\
\hline Campylobacter & 2 & 06.66 \\
Escherichia coli & 6 & 20.00 \\
Klebsiella pneumoniae & 2 & 06.66 \\
Salmonella species & 1 & 03.33 \\
Shigella & 3 & 10.00 \\
Staphylococcus aureus & 2 & 06.66 \\
Total & 16 & \\
\hline
\end{tabular}

Table 4: Distribution of Organisms within Sampling Area

\begin{tabular}{lcc}
\hline \multicolumn{1}{c}{ Sampling Area } & No. Isolated & Percentage (\%) \\
\hline Dausai & 4 & 80 \\
Kofar Kudu & 4 & 80 \\
Makwalla & 2 & 40 \\
Rinji & 3 & 60 \\
Tosaro & 2 & 40 \\
Tsohuwar Kasuwa & 1 & 20 \\
Total & 16 & \\
\hline
\end{tabular}

\section{CONCLUSION}

Results indicated $4.00 \times 10^{5} \mathrm{CFU} / \mathrm{g}$ as the highest APCs count; while $68 \mathrm{MPN} / \mathrm{g}$ was the highest TCCs from the 30 samples analyzed. Among the isolates, $E$. coli has the highest isolation rate of $6(20 \%)$. Dausai and Kofar kudu were having the highest bacteria count of $4(80 \%)$, each, indicating higher contamination in those locations. 
BAJOPAS Volume 13 Number 1, June, 2020 RECOMMENDATIONS

The following recommendations are tenable:

1. Hygienic practices at all stages of production should be improved to safe guard the consumers against potential health hazard.

2. Monitoring of microbiological contamination of Tsire during preparations, packaging and marketing is essential to ensure product of good microbiological quality for consumers' health.

\section{REFERENCES}

Abdullahi, I. O., Umoh, V. J. and Galadima, M. (2004). Hazards Associated with Kilishi Preparations in Zaria. Nigerian Journal of Microbiology, 18 (1-2): $339-345$.

Ahmadu, J. and Ibrahim E. J., (2013): Determinants of Revenue in Suya Production in BeninCity, Edo State, Nigeria. Nigerian journal of agriculture, food and environment.9(3):1-5

Amaeze, N. Aboh, M. Itohan, A. Felix, E. Olatunji, T. and Oladosu, P. (2016) Microbial Profile, Antibiotic Sensitivity and Heat Resistance of Bacterial Isolates from Commercial Roasted Beef (Suya) in Abuja, Nigeria. JOPAT, 15(2): $22-30$.

Apata, E.S., Kuku1, I.A., Apata, O.C. and Adeyemi, K.O. (2013). Evaluation of Suya(Tsire) - An Intermediate Moisture Meat Product in Ogun State, Nigeria. J. Food Res 2 (1): 87.

Atlas, R. M. (1997) Principles of Microbiology Second Edition. C. Brown Publishers. Pp 802-803.

Borch, E. Kant-Muermans, M. L., Blixt, Y. (1996) Bacterial Spoilage of Meat and Cured Meat Products. Int $\mathrm{J}$ Food Microbiol .33(1): 103-20.

Centre for Disease Control, CDC (2011). "Escherichia coli 0157:H7" Division of Bacterial and Mycotic Diseasesht://www.cdc.gov/nczved/divisi ons/dfbmd/diseases/ecoli_0157h7/.

Charlene, R. J., Johnnie, A. D., and John, B. B., (2013) Prevalence and Characterization of Methicillin-Resistant Staphylococcus aureus Isolates from Retail Meat and Humans in Georgia. American society for Microbiology. J. of clinical microbiology. 12(1):123-6 doi:10.1128/JCM.0316612JCM.03166-12

Egbebi, A.O and Seidu, K., T. (2011). Microbiological Evaluation of Suya (dried smoked

meat) Sold in Ado and Akure, South West Nigeria.European Journal of Experinmental Biology, 1(4):1-5
3. Government should establish regulatory bodies responsible for inculcating hygiene habits to the local producers and vendors in order to prevent instant, cross and post processing contaminations by microbial pathogens.

4. Awareness and sensitization of local food producers about good hygienic practices in food handling and processing.

Falegan, C, R., Akoja, S. D., and Oyarekua, M. A., (2017) Microbiological Assessment of Suya (Sliced Roasted Beef) in Ado-Ekiti Metropolis, Ekiti State, Nigeria. MOJ Biology andMedicine.

Fonkem, D., N. Tanya, V., N. and Ebangi, A., L. (2010). Effect of Season on the Microbiological Quality of Kilishi, a Traditional Cameroonian Dried Beef Product. Tropicultura, 28(1): 10-15.

Food and Agricultural Organization of the United Nations (F A O, 1979). Manual of food quality control 4. Microbiological analysis.

Food and Agriculture Organisation of the United Nation (FAO), 2019. Nigeria at a glance.

Igene J.O., Uwadia, O.E., Ebabhamiegbebho, P.A. and Evivie, S.E., (2016) Shelf life Stability Studies of University of Benin (UNIBEN) Proff's Kilishi Product Asian Journal of Science and Technology 7(1): 2268-2274.

Inusa, S. K. and Said, I. S. (2017) Evaluation of the Chemical and Microbiological Properties Of Kilishi Sold in Kano Metropolis. Journal of Dry land Agriculture, 3 (1): $59-69$.

Lucretia, I. B, Patience, C. Obinna-Echem, Sophia, C. A. (2018) Microbiological quality andantibiotic sensitivity of potential pathogens isolated from meat product (Suya) sold in Rivers State University and its environs. International Journal of Biotechnology and Food Science, 6(4): 67-76.

Matthew, E., Drosos, E., John, L. and Ioanna, P. (2013) MRSA in Africa: Filling the Global Map of Antimicrobial Resistance PLOS One. 8(7): e68024 doi: 10.1371/journal.pone.0068024

Mgbemere, V.N., Akpapunam, M. A. and Igene, J. O., (2011). Effect of Groundnut FlourSubstitution on Yield, Quality and Storage Stability of Kilishi - a Nigerian Indigenous Dried Meat Product. African Journal of Food, Agriculture, Nutrition and Development, $\quad \mathbf{1 1}(2)$ : 4718-4738. 
BAJOPAS Volume 13 Number 1, June, 2020

Mubarak, A. A., Azeez, M. L., Amos A. O., Opeyemi, O. O. (2016) Assessment of Animal Protein Consumption and Food Security Among Rural Households in Kwara State, Nigeria American Journal of Business and Society, 1(4): 233245.

Ndahi, M., D. Kwaga, J., K. P. Bello, M. Kabir J., V. Umoh, .J. Yakubu, S., E. and Nok, A., J. (2013) Prevalence and Antimicrobial Susceptibility of Listeria Monocytogenes and Methicillin-Resistant Staphylococcus aureus Strains from Raw Meat and Meat Products in Zaria, Nigeria. Applied Journal of Microbiology, 58(3):262-9.

Okonko, I.O., Odu, N.N. and Igboh, I.E. (2013). Microbiological Analysis of Kilishi Sold In Port Harcourt, Nigeria. New York Science Journal, 6 (7):37-43.

Osimani, A., Aquilanti, L. and Clementi, F. (2015) Microbiological Quality of Meatbased Meals and Operation of Control Systems within a Food Service Environment. International Food Research Journal 22(4): 1692-1698.

Onuorah, S. Obika, I. Odibo, F. Orji, M. (2015)An Assessment of the Bacteriological Quality of Tsire-Suya (Grilled Beef) sold in Awka, Nigeria. American. J. Life. Sci. Res. 3(4):287292.

Razavilar, V, Khandaghi, J. Barzgari, A. (2010); Isolation of Eschericia coli 0157:H7 from manure fertilized farms and raw vegetables grown on it, in Tabriz city in
Iran. African Journal of Microbiology Research, 4(9): 891-895.

Scallan, E. Hoekstra, R. M. Angulo, F. J.Tauxe, R. V, Widdowson, M. Roy, S. L et al., (2011).Food borne illness acquired in the United States- Major Pathogens. Emerg. Infec Dis, 17(1): 7-15.

Shamsuddeen U (2009). Microbiological quality of spice used in the production of Kilishi a traditionally dried and grilled meat product. Bayero Journal of Pure andApplied Sciences, 2(2): 66-69.

Shamsuddeen, U. (2015) Microbiological Hazard and Critical control point Analysis of Dried and Minced Meat Snacks Produced in Kano Nigeria. Lambert Academic Publishing; Pp 1-36.

Tijani, O.and Jumare, S. (2014). Microblological Quality Assessment of Meat

Sold in KauraNamoda. International Conference on Earth, Environment and Life sciences (EELS) Dubai (UAE).

Udobi, C. E., Obajuluwa, A. F., and Onaolapo, J. A., (2013) Prevalence and Antibiotic Resistance Pattern of MethicillinResistant Staphylococcus aureus from an Orthopaedic Hospital in Nigeria BioMed Research International; 26(6); 6-7.

WHO, 2015 Foodborne diseases in the WHO African Region.

Yousafzai HA, Rind R, Khan MA, Abro SH, Korejo NA, Ejaz M, Kabir A, Shahid M, Memon S. (2019). Microbiological Contamination of Cattle and Meat in Peshawar, Pakistan. J. Anim. Health Prod. 7(1): 1116. 


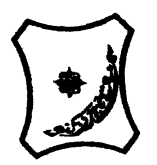

Bayero Journal of Pure and Applied Sciences, 13(1); 40 - 45

Received: September, 2019

Accepted: April, 2020

ISSN $2006-6996$

\title{
BACTERIOLOGICAL QUALITY OF STICK MEAT (Tsire) SOLD IN GARKO LOCAL GOVERNMENT AREA OF KANO STATE, NIGERIA
}

\author{
$*^{1}$ Dahiru A. T. and ${ }^{2}$ Maigari A. K. \\ ${ }^{1}$ Department of Hospitality Management, School of Technology, Kano State Polytechnic, PMB 3348, \\ Kano Nigeria. \\ ${ }^{2}$ Departmnt of Biological Sciences, Bayero University, Kano \\ Corresponding Author: dturajo61@gmail.com; GSM: 08087508262.
}

ABSTRACT

Stick meat, locally called Tsire in Hausa Language, is a significant portion of the diet of a large active population of Northern Nigeria. However, because of the handling and processing methods by the manufacturers as well as the hawking system of stick meat, the meat product may be exposed to both pre- and post-processed product contamination, and thus may poses danger to public health. Therefore, considering the role of Tsire in improving nutrition and increase household income to the populace, the need to improve the processing, distribution and overall quality of the product is simply indispensable. A total of 30 samples (5 samples from each of the 6 sampling points) of Tsire were collected randomly in Garko Town. Aerobic plate counts (APCs) and Total coliform counts (TCCS) of Tsire samples were determined using standard microbiological methods. APCs ranged from $1.02 \times 10^{5}$ to $4.00 \times 10^{5} \mathrm{CFU} / \mathrm{g}$; while TCCs ranged from $8 \mathrm{MPN} / \mathrm{g}$ to $68 \mathrm{MPN} / \mathrm{g}$. From the 30 samples screened, 16(53.33\%) bacteria namely, Campylobacter 2(6.66\%), Escherichia coli 6(20\%), Klebsiella pneumoniae 2(6.66\%), Salmonella spp. 1(3.33\%), Shigella 3(10\%) and Staphylococcus aureus 2(6.66\%) were detected. $E$. coli has the highest isolation rate of 6(20\%), while Salmonella spp. had the least frequency of 1(3.33\%). The distribution of isolated organisms within the study area were as follows: Dausai, 4(80\%), Kofar kudu, 4(80\%), Makwalla, 2(40\%), Rinji, 3(60\%), Tosaro, 2(40\%), and Tsohuwar Kasuwa, 1(20\%). The results have indicated that the Tsire was contaminated with bacteria thus exposing the product to fast deterioration, spoilage and also a vehicle for food borne illness, suggesting for adequate hygienic practices at all the stages, prior to consumption, to ensure safety of the meat product.

Key words: APCs, TCCs, Contamination, Microorganisms, Garko

\section{INTRODUCTION}

Nigeria is one of the developing nations with inadequate food supply and most often deficient in protein content (FAO, 2019). Nigerian's average animal protein intake per head per day is estimated at $7.9 \mathrm{~g}$ as against $35 \mathrm{~g}$ recommended value by Food and Agricultural Organization (Mubarak et al., 2016). These low levels of animal protein intake create great concern as it affects the nutritional status of Nigerians. Hence, there is the need for sufficient supply of animal protein from energy rich animal products to satisfy the nutritional requirements for Nigerians.

Meat is one major source of animal protein largely composed of water, protein and fats which can make it susceptible to microbial contamination within short time leading to spoilage (Apata et al., 2013; Mgbemere et al., 2011). Meat is mostly eaten after it has been cooked or processed in a variety of ways such as sun drying; smoking and roasting with or without fortifications (Borch et al., 1996). In Nigeria meat products such as Tsire, Kilishi and Balangu are locally produced using one or more of these methods in order to meet the nutritional requirements of the teeming Nigerians (Egbebi, 2011).

Tsire is a popular Nigerian traditional processed ready-to-eat roasted stick meat product (Shamsuddeen, 2015). It is sold in public places, along roads, in hotels, parks, quarters and even offices (Falegan et al., 2017). It is prepared from boneless healthy animal flesh such as beef and mutton, spiced with peanut cake, salt, vegetable oil and other flavorings followed by roasting (Shamsuddeen, 2015). Consumption of these products has extended to other parts of African countries such as Ghana, Somali, Cameroun and Chad (Ahmadu and Ibrahim, 2013). 
BAJOPAS Volume 13 Number 1, June, 2020

However, evidence of quality control sticking to procedural hygiene by the handlers during preparation and retailing of these products is poorly documented. Tsire is of great safety risk because of the fact that there are erratic cases of gastroenteritis and symptoms of food infection after consumption (WHO, 2015). Food borne illnesses are one of the major health problems in developing and developed countries (Razavilar, 2010). According to the World Health Organization, WHO (2015), $0.07 \%$ death of the 600 million global burdens of Foodborne illnesses have been reported to be caused by bacteria, viruses, fungi and chemicals. In America $0.27 \%$ of the estimated 48 million affected people is hospitalized and about $0.0063 \%$ deaths are recorded each year (Scallan et al., 2011). More than 91 million people in Africa fall ill and $0.15 \%$ dies each year, making Africa the highest burden bearer of Foodborne diseases per population (WHO, 2015).

Application of a Hazard Analysis Critical Control Point (HACCP) at all stages of meat products preparation is essential in order to ensure its safety. Thus, according to the guidelines of good manufacturing practice, the level of total aerobic bacterial contamination of thermally processed meat products should not exceed $10^{4}\left(\mathrm{cfu} \mathrm{g}^{-1}\right)$. Enterobacteriaceae and faecal coliform contamination in meat products should be within the range of $10^{2}-10^{4}$ and $10-10^{3} \mathrm{cfu} \mathrm{g}^{-1}$, respectively (Shamsuddeen, 2015). The aim of the study is therefore, to assess the total viable bacterial counts of tsire marketed locally within Garko town, and to isolate and identify the organisms at the point of consumption with the intention of promoting public health and food hygiene habits in the Nigerian populace.

\section{MATERIALS AND METHODS Study Area and Population}

Garko is one of the existing 44 local government areas located in Kano south west zone of Kano state with its capital administrative headquarters in the Garko town. It has coordinates $11^{\circ} 39^{\prime} \mathrm{N}$ $8^{\circ} 54^{\prime} \mathrm{E}$, and an area of $450 \mathrm{~km}^{2}$. The projected population of Garko local Government was 225,300 according to the National Population Census report (2018). Garko is known for agricultural activities both farming and animal husbandry. It is popularly known for large scale rice production. Other food crops include sweet potatoes, cassava, onions, sorghum, millet and sugarcane. Cows, sheep and goats are major groups of animals reared by majority of the populace. Meat products processed, retailed and consumed in Garko include roasted meat (Balangu), dried roasted meat (Kilishi), stick meat (Tsire), hide and skin pepper soup (Ragadada) and minced fried meat (Danbunnama).

\section{Samples Collection}

Five samples of Tsire products were collected from 6 different identified locations within Garko town in a sterile foil paper and immediately analyzed for the presence of bacteria.

\section{Sample Preparation}

Sample preparation for the bacteriological analysis was carried out in accordance with the method described by Atlas (1997). Twenty five grams $(25 \mathrm{~g})$ of the sample was homogenized in $225 \mathrm{ml}$ peptone water using Kenwood blender machine to obtain a $10^{1}$ homogenate. The homogenate was thoroughly shaken and $1 \mathrm{ml}$ pipetted into test tubes containing $9 \mathrm{ml}$ of peptone water $\left(10^{2}\right)$. The test tubes were further serially diluted to $10^{5}$.

Total Aerobic Mesophilic Bacterial Count

Total Aerobic mesophilic bacterial count was determined using the method described by Abdullahi et al. (2004) where $1 \mathrm{ml}$ of inoculums from $10^{1}$ to $10^{5}$ dilutions were transferred into duplicate Petri dishes and labeled accordingly. This was followed by pouring aseptically about $15 \mathrm{ml}$ of molten nutrient agar. The culture was homogenized by gentle spinning of the plates and allowed to solidify. The plates were incubated at $37^{\circ} \mathrm{C}$ for 24 hours. Plates containing 30-300 colonies were counted. The number of colony forming units per gram of a sample (cfu/g) was obtained by multiplying the average colony number with the inverse of the dilution factor.

\section{Enumeration and Detection of Coliform bacteria}

Detection and enumeration of coliform was carried out according to method described by Atlas, (1977). A set of 9 test tubes each containing $9 \mathrm{ml}$ of lactose broth and an inverted Durham tubes were autoclaved to expel air and to sterilize. Similarly, $1 \mathrm{ml}$ from the diluents $10^{1}$ was transferred to the first 3 test tubes, followed by $1 \mathrm{ml}$ from the diluents $10^{2}$ to the second set of 3 test tubes and finally the third diluents $10^{3}$ to the $3^{\text {rd }}$ set of 3 test tubes. All the 9 test tubes were incubated at $37^{\circ} \mathrm{C}$ for 24 hours. Tubes that showed gas and acid production after 24 hours were recorded as positive for the presence of Coliform. Negative tubes were further reincubated for 24 hours. Positive tubes were recorded. Estimate of most probable number of Coliform per gram of sample (MPN/g) was determined by comparing the number of gas positive tubes with the most probable number table. 
BAJOPAS Volume 13 Number 1, June, 2020 Identification of Coliform

A loop full of inoculum from gas positive tubes was streaked on to Eosine methylene blue (EMB) agar plate and incubated at $37^{\circ} \mathrm{C}$ for $24 \mathrm{hrs}$. Colonies which formed bluish black color with green metallic sheen, and reddish colonies were isolated on agar slants. Those colonies showing metallic sheen on EMB were sub cultured into tubes of lactose broth and incubated at $45^{\circ} \mathrm{C}$. The tubes were observed after $24 \mathrm{hrs}$ for gas production. This is the completed test for fecal coliform. Gram stain and other biochemical tests such as Indole, Methyl red, Voges-Proskauer and Citrate Utilization tests (IMVIC), Coagulase and Catalase tests were carried out for the Identification and confirmation of isolates.

\section{Procedure for Indole Test}

Indole test was carried out by preparing a Tryptone broth drawn in to test tubes, sterilized by autoclaving, inoculated with loopful of suspension and incubated at $37^{\circ} \mathrm{C}$ for 24 hours. Three drops of xylene was added in tubes, shaken vigorously and kept for the separation of two layers. One millilitre of Kovac's reagent was added and the formation of pink colour ring indicates positive Indole test.

\section{Procedure for Methyl Red Test}

Methyl red test was carried out by preparing Glucose phosphate broth, dispensed in test tubes, sterilized, inoculated with test culture and incubated at $37^{\circ} \mathrm{C}$ for 24 hours. Five drops of methyl-red indicator was added to the medium for the formation of red colour.

\section{Procedure for Voges-Proskauer Test}

Voges-Proskauer test was carried out by inoculating tubes with the bacterial culture followed by incubation for 48 hours at $37^{\circ} \mathrm{C}$. Separate pipettes were used to pipette $1 \mathrm{ml}$ from each culture tube into clean separate tubes. Eighteen drops $(0.5 \mathrm{ml})$ of Barrit's solution A (a-naphthol) was added to each tube containing glucose phosphate broth followed by the addition of an equal amount of solution $B$ into the same tube. The tubes were shaken at 30 seconds interval. A positive reaction was indicated by the development of a pink color, which turns red in 1-2 hours, after vigorous shaking.

\section{Procedure for Citrate Utilization Test}

Citrate Utilization Test was carried out by distributing melted agar (Simmon Citrate Agar) in to test tubes followed by sterilization at $121.5^{\circ} \mathrm{C}$ for 15 minutes. The test tubes were afterward held in slanted position, inoculated with the given bacterial culture and incubated at $37^{\circ} \mathrm{C}$ for $24 \mathrm{hrs}$. Positive test was indicated by color change of the media from green to blue.

\section{RESULTS AND DISCUSSIONS}

The results of this study are presented in tables $1,2,3$ and 4. Among the sampling areas Kofar Kudu had the highest aerobic mesophilic bacteria counts $4.0 \times 10^{5} \mathrm{cfu} / \mathrm{g}$ followed by Rinji $2.72 \times 10^{5} \mathrm{cfu} / \mathrm{g}$, while Tosaro had the least Aerobic mesophilic bacteria counts of $1.02 \times 10^{5}$ $\mathrm{cfu} / \mathrm{g}$ as indicated in Table 1.Makwalla had the highest coliform count $68 \mathrm{MPN} / \mathrm{g}$ followed by Rinji $37 \mathrm{MPN} / \mathrm{g}$. Tsohuwar Kasuwa had the least coliform counts $8 \mathrm{MPN} / \mathrm{g}$, (Table 2). Result from table 1 shows variation in the microbial contents among the samples which suggest variation in their sources, poor handling procedures and contamination from the processing environment. High coliform count and their differences within sampling areas is an indication of poor microbiological quality of the product. Ndahi et al. (2013) reported microbial load to be a function of the handling personnel and the environment. The results indicated that the samples were contaminated with bacteria as the counts exceeded the minimum safety level $\left(10^{4} \mathrm{cfu} / \mathrm{g}\right)$ for members of the Enterobacteriaceae family. However, it might be a reflection of poor hygienic practices which may contribute to health hazard to the potential consumers. Similarly, Inusa and Sa'id (2017); Osimani et al. (2015) reported that, the initial microbial content of the raw material play significant role in influencing the final microbial load of the finished product. Isolation of members of the Enterobacteriaceae such as $E$. coli, Klebsiella pneumoniae, Salmonella and Shigella signifies danger to the public health. These organisms are capable of producing endotoxins which trigger high fevers in infected individuals, and the enterotoxins which colonize the small intestines and lead to extreme dehydration as a result of vomiting and diarrhea sometimes with severe and fatal outcomes (Amaeze et al., 2016). From the 16 isolated organisms $E$. coli had the highest isolation rate $6(37.5 \%)$ (Table 3), this suggest faecal contamination of the products. $E$. coli is a common flora in the gastrointestinal tract responsible for diarrhea and extra-intestinal infections (CDC, 2011). The result is in conformity with the findings of Ndahi et al. (2013) and Shamsuddeen (2009). Also presence of campylobacter might be due to cross contamination from raw meat to finished product (Tsire). Staphylococcus aureus is a normal flora of the skin, nasal, genital, mouth or anal area in both humans and animals without any symptom of an infection (Matthew et al., 2013). Isolation of $S$. aureus in these study concords with the findings of Lucretia et al. (2018) from Suya sold in Rivers State. 
BAJOPAS Volume 13 Number 1, June, 2020

It is also in agreement with the findings of Yousafzai et al. (2018); Onuorah et al. (2015) and Tijjani and Jumare (2014) from tsire samples in different countries. Presence of $S$. aureus in foods is most of the time an indication of poor human handling, poor environment, unhygienic utensils and equipments used during processing (Igene et al., 2016; Okonko et al., 2013). Infections caused by $S$. aureus are difficult to treat leading to long hospitalization with consequent economic loss (Udobi et al., 2013). These include soft tissue infections, pneumonia, hospital-acquired postoperative wound infections, Staphylococcal food poisoning, impetigo and cellulitis (Charlene et al., 2013). Samples obtained from Dausai and Kofar Kudu had the highest isolation rate $4(80 \%)$ (Table 4 ) probably because of the much commercial activities taking place in the area which can lead to environmental contamination.

Table 1: Total Aerobic Mesophilic Bacterial Count of Tsire sold in Garko Town

\begin{tabular}{lll}
\hline Sampling Area & APC cfu/g & Mean \pm STD \\
\hline Dausai & $2.20 \times 10^{5}$ & $110000 \pm 14142.14$ \\
Kofar Kudu & $4.00 \times 10^{5}$ & $133333.3 \pm 23094.01$ \\
Makwalla & $1.30 \times 10^{5}$ & $32500 \pm 7187.953$ \\
Rinji & $2.72 \times 10^{5}$ & $90666.67 \pm 94769.90$ \\
Tosaro & $1.02 \times 10^{5}$ & $51000 \pm 15556.35$ \\
Tsohuwar Kasuwa & $1.75 \times 10^{5}$ & $35000 \pm 11357.82$ \\
\hline
\end{tabular}

Key: APC: Aerobic Mesophilic Counts

STD: Standard Deviation

Table 2: Total Coliform Count of Tsire sold in Garko Town

\begin{tabular}{lcc}
\hline \multicolumn{1}{c}{ Sampling Area } & TCC MPN/g & Mean \pm STD \\
\hline Dausai & 20 & $6.67 \pm 2.5166$ \\
Kofar Kudu & 32 & $16.00 \pm 5.6569$ \\
Makwalla & 68 & $13.60 \pm 8.7062$ \\
Rinji & 37 & $9.25 \pm 4.7871$ \\
Tosaro & 10 & $5.00 \pm 2.8284$ \\
Tsohuwar Kasuwa & 8 & $4.00 \pm 0.0000$ \\
\hline
\end{tabular}

Table 3: Organisms Isolated from Tsire Sold in Garko

\begin{tabular}{lcl}
\hline Isolated Organism & Frequency & Percentage (\%) \\
\hline Campylobacter & 2 & 06.66 \\
Escherichia coli & 6 & 20.00 \\
Klebsiella pneumoniae & 2 & 06.66 \\
Salmonella species & 1 & 03.33 \\
Shigella & 3 & 10.00 \\
Staphylococcus aureus & 2 & 06.66 \\
Total & 16 & \\
\hline
\end{tabular}

Table 4: Distribution of Organisms within Sampling Area

\begin{tabular}{lcc}
\hline \multicolumn{1}{c}{ Sampling Area } & No. Isolated & Percentage (\%) \\
\hline Dausai & 4 & 80 \\
Kofar Kudu & 4 & 80 \\
Makwalla & 2 & 40 \\
Rinji & 3 & 60 \\
Tosaro & 2 & 40 \\
Tsohuwar Kasuwa & 1 & 20 \\
Total & 16 & \\
\hline
\end{tabular}

\section{CONCLUSION}

Results indicated $4.00 \times 10^{5} \mathrm{CFU} / \mathrm{g}$ as the highest APCs count; while $68 \mathrm{MPN} / \mathrm{g}$ was the highest TCCs from the 30 samples analyzed. Among the isolates, $E$. coli has the highest isolation rate of $6(20 \%)$. Dausai and Kofar kudu were having the highest bacteria count of $4(80 \%)$, each, indicating higher contamination in those locations. 
BAJOPAS Volume 13 Number 1, June, 2020 RECOMMENDATIONS

The following recommendations are tenable:

1. Hygienic practices at all stages of production should be improved to safe guard the consumers against potential health hazard.

2. Monitoring of microbiological contamination of Tsire during preparations, packaging and marketing is essential to ensure product of good microbiological quality for consumers' health.

\section{REFERENCES}

Abdullahi, I. O., Umoh, V. J. and Galadima, M. (2004). Hazards Associated with Kilishi Preparations in Zaria. Nigerian Journal of Microbiology, 18 (1-2): $339-345$.

Ahmadu, J. and Ibrahim E. J., (2013): Determinants of Revenue in Suya Production in BeninCity, Edo State, Nigeria. Nigerian journal of agriculture, food and environment.9(3):1-5

Amaeze, N. Aboh, M. Itohan, A. Felix, E. Olatunji, T. and Oladosu, P. (2016) Microbial Profile, Antibiotic Sensitivity and Heat Resistance of Bacterial Isolates from Commercial Roasted Beef (Suya) in Abuja, Nigeria. JOPAT, 15(2): $22-30$.

Apata, E.S., Kuku1, I.A., Apata, O.C. and Adeyemi, K.O. (2013). Evaluation of Suya(Tsire) - An Intermediate Moisture Meat Product in Ogun State, Nigeria. J. Food Res 2 (1): 87.

Atlas, R. M. (1997) Principles of Microbiology Second Edition. C. Brown Publishers. Pp 802-803.

Borch, E. Kant-Muermans, M. L., Blixt, Y. (1996) Bacterial Spoilage of Meat and Cured Meat Products. Int $\mathrm{J}$ Food Microbiol .33(1): 103-20.

Centre for Disease Control, CDC (2011). "Escherichia coli 0157:H7" Division of Bacterial and Mycotic Diseasesht://www.cdc.gov/nczved/divisi ons/dfbmd/diseases/ecoli_0157h7/.

Charlene, R. J., Johnnie, A. D., and John, B. B., (2013) Prevalence and Characterization of Methicillin-Resistant Staphylococcus aureus Isolates from Retail Meat and Humans in Georgia. American society for Microbiology. J. of clinical microbiology. 12(1):123-6 doi:10.1128/JCM.0316612JCM.03166-12

Egbebi, A.O and Seidu, K., T. (2011). Microbiological Evaluation of Suya (dried smoked

meat) Sold in Ado and Akure, South West Nigeria.European Journal of Experinmental Biology, 1(4):1-5
3. Government should establish regulatory bodies responsible for inculcating hygiene habits to the local producers and vendors in order to prevent instant, cross and post processing contaminations by microbial pathogens.

4. Awareness and sensitization of local food producers about good hygienic practices in food handling and processing.

Falegan, C, R., Akoja, S. D., and Oyarekua, M. A., (2017) Microbiological Assessment of Suya (Sliced Roasted Beef) in Ado-Ekiti Metropolis, Ekiti State, Nigeria. MOJ Biology andMedicine.

Fonkem, D., N. Tanya, V., N. and Ebangi, A., L. (2010). Effect of Season on the Microbiological Quality of Kilishi, a Traditional Cameroonian Dried Beef Product. Tropicultura, 28(1): 10-15.

Food and Agricultural Organization of the United Nations (F A O, 1979). Manual of food quality control 4. Microbiological analysis.

Food and Agriculture Organisation of the United Nation (FAO), 2019. Nigeria at a glance.

Igene J.O., Uwadia, O.E., Ebabhamiegbebho, P.A. and Evivie, S.E., (2016) Shelf life Stability Studies of University of Benin (UNIBEN) Proff's Kilishi Product Asian Journal of Science and Technology 7(1): 2268-2274.

Inusa, S. K. and Said, I. S. (2017) Evaluation of the Chemical and Microbiological Properties Of Kilishi Sold in Kano Metropolis. Journal of Dry land Agriculture, 3 (1): $59-69$.

Lucretia, I. B, Patience, C. Obinna-Echem, Sophia, C. A. (2018) Microbiological quality andantibiotic sensitivity of potential pathogens isolated from meat product (Suya) sold in Rivers State University and its environs. International Journal of Biotechnology and Food Science, 6(4): 67-76.

Matthew, E., Drosos, E., John, L. and Ioanna, P. (2013) MRSA in Africa: Filling the Global Map of Antimicrobial Resistance PLOS One. 8(7): e68024 doi: 10.1371/journal.pone.0068024

Mgbemere, V.N., Akpapunam, M. A. and Igene, J. O., (2011). Effect of Groundnut FlourSubstitution on Yield, Quality and Storage Stability of Kilishi - a Nigerian Indigenous Dried Meat Product. African Journal of Food, Agriculture, Nutrition and Development, $\quad \mathbf{1 1}(2)$ : 4718-4738. 
BAJOPAS Volume 13 Number 1, June, 2020

Mubarak, A. A., Azeez, M. L., Amos A. O., Opeyemi, O. O. (2016) Assessment of Animal Protein Consumption and Food Security Among Rural Households in Kwara State, Nigeria American Journal of Business and Society, 1(4): 233245.

Ndahi, M., D. Kwaga, J., K. P. Bello, M. Kabir J., V. Umoh, .J. Yakubu, S., E. and Nok, A., J. (2013) Prevalence and Antimicrobial Susceptibility of Listeria Monocytogenes and Methicillin-Resistant Staphylococcus aureus Strains from Raw Meat and Meat Products in Zaria, Nigeria. Applied Journal of Microbiology, 58(3):262-9.

Okonko, I.O., Odu, N.N. and Igboh, I.E. (2013). Microbiological Analysis of Kilishi Sold In Port Harcourt, Nigeria. New York Science Journal, 6 (7):37-43.

Osimani, A., Aquilanti, L. and Clementi, F. (2015) Microbiological Quality of Meatbased Meals and Operation of Control Systems within a Food Service Environment. International Food Research Journal 22(4): 1692-1698.

Onuorah, S. Obika, I. Odibo, F. Orji, M. (2015)An Assessment of the Bacteriological Quality of Tsire-Suya (Grilled Beef) sold in Awka, Nigeria. American. J. Life. Sci. Res. 3(4):287292.

Razavilar, V, Khandaghi, J. Barzgari, A. (2010); Isolation of Eschericia coli 0157:H7 from manure fertilized farms and raw vegetables grown on it, in Tabriz city in
Iran. African Journal of Microbiology Research, 4(9): 891-895.

Scallan, E. Hoekstra, R. M. Angulo, F. J.Tauxe, R. V, Widdowson, M. Roy, S. L et al., (2011).Food borne illness acquired in the United States- Major Pathogens. Emerg. Infec Dis, 17(1): 7-15.

Shamsuddeen U (2009). Microbiological quality of spice used in the production of Kilishi a traditionally dried and grilled meat product. Bayero Journal of Pure andApplied Sciences, 2(2): 66-69.

Shamsuddeen, U. (2015) Microbiological Hazard and Critical control point Analysis of Dried and Minced Meat Snacks Produced in Kano Nigeria. Lambert Academic Publishing; Pp 1-36.

Tijani, O.and Jumare, S. (2014). Microblological Quality Assessment of Meat

Sold in KauraNamoda. International Conference on Earth, Environment and Life sciences (EELS) Dubai (UAE).

Udobi, C. E., Obajuluwa, A. F., and Onaolapo, J. A., (2013) Prevalence and Antibiotic Resistance Pattern of MethicillinResistant Staphylococcus aureus from an Orthopaedic Hospital in Nigeria BioMed Research International; 26(6); 6-7.

WHO, 2015 Foodborne diseases in the WHO African Region.

Yousafzai HA, Rind R, Khan MA, Abro SH, Korejo NA, Ejaz M, Kabir A, Shahid M, Memon S. (2019). Microbiological Contamination of Cattle and Meat in Peshawar, Pakistan. J. Anim. Health Prod. 7(1): 1116. 


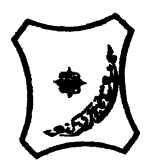

Bayero Journal of Pure and Applied Sciences, 13(1); 40 - 45

Received: September, 2019

Accepted: April, 2020

ISSN $2006-6996$

\title{
BACTERIOLOGICAL QUALITY OF STICK MEAT (Tsire) SOLD IN GARKO LOCAL GOVERNMENT AREA OF KANO STATE, NIGERIA
}

\author{
$*^{1}$ Dahiru A. T. and ${ }^{2}$ Maigari A. K. \\ ${ }^{1}$ Department of Hospitality Management, School of Technology, Kano State Polytechnic, PMB 3348, \\ Kano Nigeria. \\ ${ }^{2}$ Departmnt of Biological Sciences, Bayero University, Kano \\ Corresponding Author: dturajo61@gmail.com; GSM: 08087508262.
}

ABSTRACT

Stick meat, locally called Tsire in Hausa Language, is a significant portion of the diet of a large active population of Northern Nigeria. However, because of the handling and processing methods by the manufacturers as well as the hawking system of stick meat, the meat product may be exposed to both pre- and post-processed product contamination, and thus may poses danger to public health. Therefore, considering the role of Tsire in improving nutrition and increase household income to the populace, the need to improve the processing, distribution and overall quality of the product is simply indispensable. A total of 30 samples (5 samples from each of the 6 sampling points) of Tsire were collected randomly in Garko Town. Aerobic plate counts (APCs) and Total coliform counts (TCCS) of Tsire samples were determined using standard microbiological methods. APCs ranged from $1.02 \times 10^{5}$ to $4.00 \times 10^{5} \mathrm{CFU} / \mathrm{g}$; while TCCs ranged from $8 \mathrm{MPN} / \mathrm{g}$ to $68 \mathrm{MPN} / \mathrm{g}$. From the 30 samples screened, 16(53.33\%) bacteria namely, Campylobacter 2(6.66\%), Escherichia coli 6(20\%), Klebsiella pneumoniae 2(6.66\%), Salmonella spp. 1(3.33\%), Shigella 3(10\%) and Staphylococcus aureus 2(6.66\%) were detected. $E$. coli has the highest isolation rate of 6(20\%), while Salmonella spp. had the least frequency of 1(3.33\%). The distribution of isolated organisms within the study area were as follows: Dausai, 4(80\%), Kofar kudu, 4(80\%), Makwalla, 2(40\%), Rinji, 3(60\%), Tosaro, 2(40\%), and Tsohuwar Kasuwa, 1(20\%). The results have indicated that the Tsire was contaminated with bacteria thus exposing the product to fast deterioration, spoilage and also a vehicle for food borne illness, suggesting for adequate hygienic practices at all the stages, prior to consumption, to ensure safety of the meat product.

Key words: APCs, TCCs, Contamination, Microorganisms, Garko

\section{INTRODUCTION}

Nigeria is one of the developing nations with inadequate food supply and most often deficient in protein content (FAO, 2019). Nigerian's average animal protein intake per head per day is estimated at $7.9 \mathrm{~g}$ as against $35 \mathrm{~g}$ recommended value by Food and Agricultural Organization (Mubarak et al., 2016). These low levels of animal protein intake create great concern as it affects the nutritional status of Nigerians. Hence, there is the need for sufficient supply of animal protein from energy rich animal products to satisfy the nutritional requirements for Nigerians.

Meat is one major source of animal protein largely composed of water, protein and fats which can make it susceptible to microbial contamination within short time leading to spoilage (Apata et al., 2013; Mgbemere et al., 2011). Meat is mostly eaten after it has been cooked or processed in a variety of ways such as sun drying; smoking and roasting with or without fortifications (Borch et al., 1996). In Nigeria meat products such as Tsire, Kilishi and Balangu are locally produced using one or more of these methods in order to meet the nutritional requirements of the teeming Nigerians (Egbebi, 2011).

Tsire is a popular Nigerian traditional processed ready-to-eat roasted stick meat product (Shamsuddeen, 2015). It is sold in public places, along roads, in hotels, parks, quarters and even offices (Falegan et al., 2017). It is prepared from boneless healthy animal flesh such as beef and mutton, spiced with peanut cake, salt, vegetable oil and other flavorings followed by roasting (Shamsuddeen, 2015). Consumption of these products has extended to other parts of African countries such as Ghana, Somali, Cameroun and Chad (Ahmadu and Ibrahim, 2013). 
BAJOPAS Volume 13 Number 1, June, 2020

However, evidence of quality control sticking to procedural hygiene by the handlers during preparation and retailing of these products is poorly documented. Tsire is of great safety risk because of the fact that there are erratic cases of gastroenteritis and symptoms of food infection after consumption (WHO, 2015). Food borne illnesses are one of the major health problems in developing and developed countries (Razavilar, 2010). According to the World Health Organization, WHO (2015), $0.07 \%$ death of the 600 million global burdens of Foodborne illnesses have been reported to be caused by bacteria, viruses, fungi and chemicals. In America $0.27 \%$ of the estimated 48 million affected people is hospitalized and about $0.0063 \%$ deaths are recorded each year (Scallan et al., 2011). More than 91 million people in Africa fall ill and $0.15 \%$ dies each year, making Africa the highest burden bearer of Foodborne diseases per population (WHO, 2015).

Application of a Hazard Analysis Critical Control Point (HACCP) at all stages of meat products preparation is essential in order to ensure its safety. Thus, according to the guidelines of good manufacturing practice, the level of total aerobic bacterial contamination of thermally processed meat products should not exceed $10^{4}\left(\mathrm{cfu} \mathrm{g}^{-1}\right)$. Enterobacteriaceae and faecal coliform contamination in meat products should be within the range of $10^{2}-10^{4}$ and $10-10^{3} \mathrm{cfu} \mathrm{g}^{-1}$, respectively (Shamsuddeen, 2015). The aim of the study is therefore, to assess the total viable bacterial counts of tsire marketed locally within Garko town, and to isolate and identify the organisms at the point of consumption with the intention of promoting public health and food hygiene habits in the Nigerian populace.

\section{MATERIALS AND METHODS Study Area and Population}

Garko is one of the existing 44 local government areas located in Kano south west zone of Kano state with its capital administrative headquarters in the Garko town. It has coordinates $11^{\circ} 39^{\prime} \mathrm{N}$ $8^{\circ} 54^{\prime} \mathrm{E}$, and an area of $450 \mathrm{~km}^{2}$. The projected population of Garko local Government was 225,300 according to the National Population Census report (2018). Garko is known for agricultural activities both farming and animal husbandry. It is popularly known for large scale rice production. Other food crops include sweet potatoes, cassava, onions, sorghum, millet and sugarcane. Cows, sheep and goats are major groups of animals reared by majority of the populace. Meat products processed, retailed and consumed in Garko include roasted meat (Balangu), dried roasted meat (Kilishi), stick meat (Tsire), hide and skin pepper soup (Ragadada) and minced fried meat (Danbunnama).

\section{Samples Collection}

Five samples of Tsire products were collected from 6 different identified locations within Garko town in a sterile foil paper and immediately analyzed for the presence of bacteria.

\section{Sample Preparation}

Sample preparation for the bacteriological analysis was carried out in accordance with the method described by Atlas (1997). Twenty five grams $(25 \mathrm{~g})$ of the sample was homogenized in $225 \mathrm{ml}$ peptone water using Kenwood blender machine to obtain a $10^{1}$ homogenate. The homogenate was thoroughly shaken and $1 \mathrm{ml}$ pipetted into test tubes containing $9 \mathrm{ml}$ of peptone water $\left(10^{2}\right)$. The test tubes were further serially diluted to $10^{5}$.

Total Aerobic Mesophilic Bacterial Count

Total Aerobic mesophilic bacterial count was determined using the method described by Abdullahi et al. (2004) where $1 \mathrm{ml}$ of inoculums from $10^{1}$ to $10^{5}$ dilutions were transferred into duplicate Petri dishes and labeled accordingly. This was followed by pouring aseptically about $15 \mathrm{ml}$ of molten nutrient agar. The culture was homogenized by gentle spinning of the plates and allowed to solidify. The plates were incubated at $37^{\circ} \mathrm{C}$ for 24 hours. Plates containing 30-300 colonies were counted. The number of colony forming units per gram of a sample (cfu/g) was obtained by multiplying the average colony number with the inverse of the dilution factor.

\section{Enumeration and Detection of Coliform bacteria}

Detection and enumeration of coliform was carried out according to method described by Atlas, (1977). A set of 9 test tubes each containing $9 \mathrm{ml}$ of lactose broth and an inverted Durham tubes were autoclaved to expel air and to sterilize. Similarly, $1 \mathrm{ml}$ from the diluents $10^{1}$ was transferred to the first 3 test tubes, followed by $1 \mathrm{ml}$ from the diluents $10^{2}$ to the second set of 3 test tubes and finally the third diluents $10^{3}$ to the $3^{\text {rd }}$ set of 3 test tubes. All the 9 test tubes were incubated at $37^{\circ} \mathrm{C}$ for 24 hours. Tubes that showed gas and acid production after 24 hours were recorded as positive for the presence of Coliform. Negative tubes were further reincubated for 24 hours. Positive tubes were recorded. Estimate of most probable number of Coliform per gram of sample (MPN/g) was determined by comparing the number of gas positive tubes with the most probable number table. 
BAJOPAS Volume 13 Number 1, June, 2020 Identification of Coliform

A loop full of inoculum from gas positive tubes was streaked on to Eosine methylene blue (EMB) agar plate and incubated at $37^{\circ} \mathrm{C}$ for $24 \mathrm{hrs}$. Colonies which formed bluish black color with green metallic sheen, and reddish colonies were isolated on agar slants. Those colonies showing metallic sheen on EMB were sub cultured into tubes of lactose broth and incubated at $45^{\circ} \mathrm{C}$. The tubes were observed after $24 \mathrm{hrs}$ for gas production. This is the completed test for fecal coliform. Gram stain and other biochemical tests such as Indole, Methyl red, Voges-Proskauer and Citrate Utilization tests (IMVIC), Coagulase and Catalase tests were carried out for the Identification and confirmation of isolates.

\section{Procedure for Indole Test}

Indole test was carried out by preparing a Tryptone broth drawn in to test tubes, sterilized by autoclaving, inoculated with loopful of suspension and incubated at $37^{\circ} \mathrm{C}$ for 24 hours. Three drops of xylene was added in tubes, shaken vigorously and kept for the separation of two layers. One millilitre of Kovac's reagent was added and the formation of pink colour ring indicates positive Indole test.

\section{Procedure for Methyl Red Test}

Methyl red test was carried out by preparing Glucose phosphate broth, dispensed in test tubes, sterilized, inoculated with test culture and incubated at $37^{\circ} \mathrm{C}$ for 24 hours. Five drops of methyl-red indicator was added to the medium for the formation of red colour.

\section{Procedure for Voges-Proskauer Test}

Voges-Proskauer test was carried out by inoculating tubes with the bacterial culture followed by incubation for 48 hours at $37^{\circ} \mathrm{C}$. Separate pipettes were used to pipette $1 \mathrm{ml}$ from each culture tube into clean separate tubes. Eighteen drops $(0.5 \mathrm{ml})$ of Barrit's solution A (a-naphthol) was added to each tube containing glucose phosphate broth followed by the addition of an equal amount of solution $B$ into the same tube. The tubes were shaken at 30 seconds interval. A positive reaction was indicated by the development of a pink color, which turns red in 1-2 hours, after vigorous shaking.

\section{Procedure for Citrate Utilization Test}

Citrate Utilization Test was carried out by distributing melted agar (Simmon Citrate Agar) in to test tubes followed by sterilization at $121.5^{\circ} \mathrm{C}$ for 15 minutes. The test tubes were afterward held in slanted position, inoculated with the given bacterial culture and incubated at $37^{\circ} \mathrm{C}$ for $24 \mathrm{hrs}$. Positive test was indicated by color change of the media from green to blue.

\section{RESULTS AND DISCUSSIONS}

The results of this study are presented in tables $1,2,3$ and 4. Among the sampling areas Kofar Kudu had the highest aerobic mesophilic bacteria counts $4.0 \times 10^{5} \mathrm{cfu} / \mathrm{g}$ followed by Rinji $2.72 \times 10^{5} \mathrm{cfu} / \mathrm{g}$, while Tosaro had the least Aerobic mesophilic bacteria counts of $1.02 \times 10^{5}$ $\mathrm{cfu} / \mathrm{g}$ as indicated in Table 1.Makwalla had the highest coliform count $68 \mathrm{MPN} / \mathrm{g}$ followed by Rinji $37 \mathrm{MPN} / \mathrm{g}$. Tsohuwar Kasuwa had the least coliform counts $8 \mathrm{MPN} / \mathrm{g}$, (Table 2). Result from table 1 shows variation in the microbial contents among the samples which suggest variation in their sources, poor handling procedures and contamination from the processing environment. High coliform count and their differences within sampling areas is an indication of poor microbiological quality of the product. Ndahi et al. (2013) reported microbial load to be a function of the handling personnel and the environment. The results indicated that the samples were contaminated with bacteria as the counts exceeded the minimum safety level $\left(10^{4} \mathrm{cfu} / \mathrm{g}\right)$ for members of the Enterobacteriaceae family. However, it might be a reflection of poor hygienic practices which may contribute to health hazard to the potential consumers. Similarly, Inusa and Sa'id (2017); Osimani et al. (2015) reported that, the initial microbial content of the raw material play significant role in influencing the final microbial load of the finished product. Isolation of members of the Enterobacteriaceae such as $E$. coli, Klebsiella pneumoniae, Salmonella and Shigella signifies danger to the public health. These organisms are capable of producing endotoxins which trigger high fevers in infected individuals, and the enterotoxins which colonize the small intestines and lead to extreme dehydration as a result of vomiting and diarrhea sometimes with severe and fatal outcomes (Amaeze et al., 2016). From the 16 isolated organisms $E$. coli had the highest isolation rate $6(37.5 \%)$ (Table 3), this suggest faecal contamination of the products. $E$. coli is a common flora in the gastrointestinal tract responsible for diarrhea and extra-intestinal infections (CDC, 2011). The result is in conformity with the findings of Ndahi et al. (2013) and Shamsuddeen (2009). Also presence of campylobacter might be due to cross contamination from raw meat to finished product (Tsire). Staphylococcus aureus is a normal flora of the skin, nasal, genital, mouth or anal area in both humans and animals without any symptom of an infection (Matthew et al., 2013). Isolation of $S$. aureus in these study concords with the findings of Lucretia et al. (2018) from Suya sold in Rivers State. 
BAJOPAS Volume 13 Number 1, June, 2020

It is also in agreement with the findings of Yousafzai et al. (2018); Onuorah et al. (2015) and Tijjani and Jumare (2014) from tsire samples in different countries. Presence of $S$. aureus in foods is most of the time an indication of poor human handling, poor environment, unhygienic utensils and equipments used during processing (Igene et al., 2016; Okonko et al., 2013). Infections caused by $S$. aureus are difficult to treat leading to long hospitalization with consequent economic loss (Udobi et al., 2013). These include soft tissue infections, pneumonia, hospital-acquired postoperative wound infections, Staphylococcal food poisoning, impetigo and cellulitis (Charlene et al., 2013). Samples obtained from Dausai and Kofar Kudu had the highest isolation rate $4(80 \%)$ (Table 4 ) probably because of the much commercial activities taking place in the area which can lead to environmental contamination.

Table 1: Total Aerobic Mesophilic Bacterial Count of Tsire sold in Garko Town

\begin{tabular}{lll}
\hline Sampling Area & APC cfu/g & Mean \pm STD \\
\hline Dausai & $2.20 \times 10^{5}$ & $110000 \pm 14142.14$ \\
Kofar Kudu & $4.00 \times 10^{5}$ & $133333.3 \pm 23094.01$ \\
Makwalla & $1.30 \times 10^{5}$ & $32500 \pm 7187.953$ \\
Rinji & $2.72 \times 10^{5}$ & $90666.67 \pm 94769.90$ \\
Tosaro & $1.02 \times 10^{5}$ & $51000 \pm 15556.35$ \\
Tsohuwar Kasuwa & $1.75 \times 10^{5}$ & $35000 \pm 11357.82$ \\
\hline
\end{tabular}

Key: APC: Aerobic Mesophilic Counts

STD: Standard Deviation

Table 2: Total Coliform Count of Tsire sold in Garko Town

\begin{tabular}{lcc}
\hline \multicolumn{1}{c}{ Sampling Area } & TCC MPN/g & Mean \pm STD \\
\hline Dausai & 20 & $6.67 \pm 2.5166$ \\
Kofar Kudu & 32 & $16.00 \pm 5.6569$ \\
Makwalla & 68 & $13.60 \pm 8.7062$ \\
Rinji & 37 & $9.25 \pm 4.7871$ \\
Tosaro & 10 & $5.00 \pm 2.8284$ \\
Tsohuwar Kasuwa & 8 & $4.00 \pm 0.0000$ \\
\hline
\end{tabular}

Table 3: Organisms Isolated from Tsire Sold in Garko

\begin{tabular}{lcl}
\hline Isolated Organism & Frequency & Percentage (\%) \\
\hline Campylobacter & 2 & 06.66 \\
Escherichia coli & 6 & 20.00 \\
Klebsiella pneumoniae & 2 & 06.66 \\
Salmonella species & 1 & 03.33 \\
Shigella & 3 & 10.00 \\
Staphylococcus aureus & 2 & 06.66 \\
Total & 16 & \\
\hline
\end{tabular}

Table 4: Distribution of Organisms within Sampling Area

\begin{tabular}{lcc}
\hline \multicolumn{1}{c}{ Sampling Area } & No. Isolated & Percentage (\%) \\
\hline Dausai & 4 & 80 \\
Kofar Kudu & 4 & 80 \\
Makwalla & 2 & 40 \\
Rinji & 3 & 60 \\
Tosaro & 2 & 40 \\
Tsohuwar Kasuwa & 1 & 20 \\
Total & 16 & \\
\hline
\end{tabular}

\section{CONCLUSION}

Results indicated $4.00 \times 10^{5} \mathrm{CFU} / \mathrm{g}$ as the highest APCs count; while $68 \mathrm{MPN} / \mathrm{g}$ was the highest TCCs from the 30 samples analyzed. Among the isolates, $E$. coli has the highest isolation rate of $6(20 \%)$. Dausai and Kofar kudu were having the highest bacteria count of $4(80 \%)$, each, indicating higher contamination in those locations. 
BAJOPAS Volume 13 Number 1, June, 2020 RECOMMENDATIONS

The following recommendations are tenable:

1. Hygienic practices at all stages of production should be improved to safe guard the consumers against potential health hazard.

2. Monitoring of microbiological contamination of Tsire during preparations, packaging and marketing is essential to ensure product of good microbiological quality for consumers' health.

\section{REFERENCES}

Abdullahi, I. O., Umoh, V. J. and Galadima, M. (2004). Hazards Associated with Kilishi Preparations in Zaria. Nigerian Journal of Microbiology, 18 (1-2): $339-345$.

Ahmadu, J. and Ibrahim E. J., (2013): Determinants of Revenue in Suya Production in BeninCity, Edo State, Nigeria. Nigerian journal of agriculture, food and environment.9(3):1-5

Amaeze, N. Aboh, M. Itohan, A. Felix, E. Olatunji, T. and Oladosu, P. (2016) Microbial Profile, Antibiotic Sensitivity and Heat Resistance of Bacterial Isolates from Commercial Roasted Beef (Suya) in Abuja, Nigeria. JOPAT, 15(2): $22-30$.

Apata, E.S., Kuku1, I.A., Apata, O.C. and Adeyemi, K.O. (2013). Evaluation of Suya(Tsire) - An Intermediate Moisture Meat Product in Ogun State, Nigeria. J. Food Res 2 (1): 87.

Atlas, R. M. (1997) Principles of Microbiology Second Edition. C. Brown Publishers. Pp 802-803.

Borch, E. Kant-Muermans, M. L., Blixt, Y. (1996) Bacterial Spoilage of Meat and Cured Meat Products. Int $\mathrm{J}$ Food Microbiol .33(1): 103-20.

Centre for Disease Control, CDC (2011). "Escherichia coli 0157:H7" Division of Bacterial and Mycotic Diseasesht://www.cdc.gov/nczved/divisi ons/dfbmd/diseases/ecoli_0157h7/.

Charlene, R. J., Johnnie, A. D., and John, B. B., (2013) Prevalence and Characterization of Methicillin-Resistant Staphylococcus aureus Isolates from Retail Meat and Humans in Georgia. American society for Microbiology. J. of clinical microbiology. 12(1):123-6 doi:10.1128/JCM.0316612JCM.03166-12

Egbebi, A.O and Seidu, K., T. (2011). Microbiological Evaluation of Suya (dried smoked

meat) Sold in Ado and Akure, South West Nigeria.European Journal of Experinmental Biology, 1(4):1-5
3. Government should establish regulatory bodies responsible for inculcating hygiene habits to the local producers and vendors in order to prevent instant, cross and post processing contaminations by microbial pathogens.

4. Awareness and sensitization of local food producers about good hygienic practices in food handling and processing.

Falegan, C, R., Akoja, S. D., and Oyarekua, M. A., (2017) Microbiological Assessment of Suya (Sliced Roasted Beef) in Ado-Ekiti Metropolis, Ekiti State, Nigeria. MOJ Biology andMedicine.

Fonkem, D., N. Tanya, V., N. and Ebangi, A., L. (2010). Effect of Season on the Microbiological Quality of Kilishi, a Traditional Cameroonian Dried Beef Product. Tropicultura, 28(1): 10-15.

Food and Agricultural Organization of the United Nations (F A O, 1979). Manual of food quality control 4. Microbiological analysis.

Food and Agriculture Organisation of the United Nation (FAO), 2019. Nigeria at a glance.

Igene J.O., Uwadia, O.E., Ebabhamiegbebho, P.A. and Evivie, S.E., (2016) Shelf life Stability Studies of University of Benin (UNIBEN) Proff's Kilishi Product Asian Journal of Science and Technology 7(1): 2268-2274.

Inusa, S. K. and Said, I. S. (2017) Evaluation of the Chemical and Microbiological Properties Of Kilishi Sold in Kano Metropolis. Journal of Dry land Agriculture, 3 (1): $59-69$.

Lucretia, I. B, Patience, C. Obinna-Echem, Sophia, C. A. (2018) Microbiological quality andantibiotic sensitivity of potential pathogens isolated from meat product (Suya) sold in Rivers State University and its environs. International Journal of Biotechnology and Food Science, 6(4): 67-76.

Matthew, E., Drosos, E., John, L. and Ioanna, P. (2013) MRSA in Africa: Filling the Global Map of Antimicrobial Resistance PLOS One. 8(7): e68024 doi: 10.1371/journal.pone.0068024

Mgbemere, V.N., Akpapunam, M. A. and Igene, J. O., (2011). Effect of Groundnut FlourSubstitution on Yield, Quality and Storage Stability of Kilishi - a Nigerian Indigenous Dried Meat Product. African Journal of Food, Agriculture, Nutrition and Development, $\quad \mathbf{1 1}(2)$ : 4718-4738. 
BAJOPAS Volume 13 Number 1, June, 2020

Mubarak, A. A., Azeez, M. L., Amos A. O., Opeyemi, O. O. (2016) Assessment of Animal Protein Consumption and Food Security Among Rural Households in Kwara State, Nigeria American Journal of Business and Society, 1(4): 233245.

Ndahi, M., D. Kwaga, J., K. P. Bello, M. Kabir J., V. Umoh, .J. Yakubu, S., E. and Nok, A., J. (2013) Prevalence and Antimicrobial Susceptibility of Listeria Monocytogenes and Methicillin-Resistant Staphylococcus aureus Strains from Raw Meat and Meat Products in Zaria, Nigeria. Applied Journal of Microbiology, 58(3):262-9.

Okonko, I.O., Odu, N.N. and Igboh, I.E. (2013). Microbiological Analysis of Kilishi Sold In Port Harcourt, Nigeria. New York Science Journal, 6 (7):37-43.

Osimani, A., Aquilanti, L. and Clementi, F. (2015) Microbiological Quality of Meatbased Meals and Operation of Control Systems within a Food Service Environment. International Food Research Journal 22(4): 1692-1698.

Onuorah, S. Obika, I. Odibo, F. Orji, M. (2015)An Assessment of the Bacteriological Quality of Tsire-Suya (Grilled Beef) sold in Awka, Nigeria. American. J. Life. Sci. Res. 3(4):287292.

Razavilar, V, Khandaghi, J. Barzgari, A. (2010); Isolation of Eschericia coli 0157:H7 from manure fertilized farms and raw vegetables grown on it, in Tabriz city in
Iran. African Journal of Microbiology Research, 4(9): 891-895.

Scallan, E. Hoekstra, R. M. Angulo, F. J.Tauxe, R. V, Widdowson, M. Roy, S. L et al., (2011).Food borne illness acquired in the United States- Major Pathogens. Emerg. Infec Dis, 17(1): 7-15.

Shamsuddeen U (2009). Microbiological quality of spice used in the production of Kilishi a traditionally dried and grilled meat product. Bayero Journal of Pure andApplied Sciences, 2(2): 66-69.

Shamsuddeen, U. (2015) Microbiological Hazard and Critical control point Analysis of Dried and Minced Meat Snacks Produced in Kano Nigeria. Lambert Academic Publishing; Pp 1-36.

Tijani, O.and Jumare, S. (2014). Microblological Quality Assessment of Meat

Sold in KauraNamoda. International Conference on Earth, Environment and Life sciences (EELS) Dubai (UAE).

Udobi, C. E., Obajuluwa, A. F., and Onaolapo, J. A., (2013) Prevalence and Antibiotic Resistance Pattern of MethicillinResistant Staphylococcus aureus from an Orthopaedic Hospital in Nigeria BioMed Research International; 26(6); 6-7.

WHO, 2015 Foodborne diseases in the WHO African Region.

Yousafzai HA, Rind R, Khan MA, Abro SH, Korejo NA, Ejaz M, Kabir A, Shahid M, Memon S. (2019). Microbiological Contamination of Cattle and Meat in Peshawar, Pakistan. J. Anim. Health Prod. 7(1): 1116. 


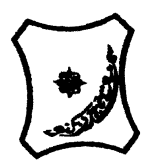

Bayero Journal of Pure and Applied Sciences, 13(1); 40 - 45

Received: September, 2019

Accepted: April, 2020

ISSN $2006-6996$

\title{
BACTERIOLOGICAL QUALITY OF STICK MEAT (Tsire) SOLD IN GARKO LOCAL GOVERNMENT AREA OF KANO STATE, NIGERIA
}

\author{
$*^{1}$ Dahiru A. T. and ${ }^{2}$ Maigari A. K. \\ ${ }^{1}$ Department of Hospitality Management, School of Technology, Kano State Polytechnic, PMB 3348, \\ Kano Nigeria. \\ ${ }^{2}$ Departmnt of Biological Sciences, Bayero University, Kano \\ Corresponding Author: dturajo61@gmail.com; GSM: 08087508262.
}

ABSTRACT

Stick meat, locally called Tsire in Hausa Language, is a significant portion of the diet of a large active population of Northern Nigeria. However, because of the handling and processing methods by the manufacturers as well as the hawking system of stick meat, the meat product may be exposed to both pre- and post-processed product contamination, and thus may poses danger to public health. Therefore, considering the role of Tsire in improving nutrition and increase household income to the populace, the need to improve the processing, distribution and overall quality of the product is simply indispensable. A total of 30 samples (5 samples from each of the 6 sampling points) of Tsire were collected randomly in Garko Town. Aerobic plate counts (APCs) and Total coliform counts (TCCS) of Tsire samples were determined using standard microbiological methods. APCs ranged from $1.02 \times 10^{5}$ to $4.00 \times 10^{5} \mathrm{CFU} / \mathrm{g}$; while TCCs ranged from $8 \mathrm{MPN} / \mathrm{g}$ to $68 \mathrm{MPN} / \mathrm{g}$. From the 30 samples screened, 16(53.33\%) bacteria namely, Campylobacter 2(6.66\%), Escherichia coli 6(20\%), Klebsiella pneumoniae 2(6.66\%), Salmonella spp. 1(3.33\%), Shigella 3(10\%) and Staphylococcus aureus 2(6.66\%) were detected. $E$. coli has the highest isolation rate of 6(20\%), while Salmonella spp. had the least frequency of 1(3.33\%). The distribution of isolated organisms within the study area were as follows: Dausai, 4(80\%), Kofar kudu, 4(80\%), Makwalla, 2(40\%), Rinji, 3(60\%), Tosaro, 2(40\%), and Tsohuwar Kasuwa, 1(20\%). The results have indicated that the Tsire was contaminated with bacteria thus exposing the product to fast deterioration, spoilage and also a vehicle for food borne illness, suggesting for adequate hygienic practices at all the stages, prior to consumption, to ensure safety of the meat product.

Key words: APCs, TCCs, Contamination, Microorganisms, Garko

\section{INTRODUCTION}

Nigeria is one of the developing nations with inadequate food supply and most often deficient in protein content (FAO, 2019). Nigerian's average animal protein intake per head per day is estimated at $7.9 \mathrm{~g}$ as against $35 \mathrm{~g}$ recommended value by Food and Agricultural Organization (Mubarak et al., 2016). These low levels of animal protein intake create great concern as it affects the nutritional status of Nigerians. Hence, there is the need for sufficient supply of animal protein from energy rich animal products to satisfy the nutritional requirements for Nigerians.

Meat is one major source of animal protein largely composed of water, protein and fats which can make it susceptible to microbial contamination within short time leading to spoilage (Apata et al., 2013; Mgbemere et al., 2011). Meat is mostly eaten after it has been cooked or processed in a variety of ways such as sun drying; smoking and roasting with or without fortifications (Borch et al., 1996). In Nigeria meat products such as Tsire, Kilishi and Balangu are locally produced using one or more of these methods in order to meet the nutritional requirements of the teeming Nigerians (Egbebi, 2011).

Tsire is a popular Nigerian traditional processed ready-to-eat roasted stick meat product (Shamsuddeen, 2015). It is sold in public places, along roads, in hotels, parks, quarters and even offices (Falegan et al., 2017). It is prepared from boneless healthy animal flesh such as beef and mutton, spiced with peanut cake, salt, vegetable oil and other flavorings followed by roasting (Shamsuddeen, 2015). Consumption of these products has extended to other parts of African countries such as Ghana, Somali, Cameroun and Chad (Ahmadu and Ibrahim, 2013). 
BAJOPAS Volume 13 Number 1, June, 2020

However, evidence of quality control sticking to procedural hygiene by the handlers during preparation and retailing of these products is poorly documented. Tsire is of great safety risk because of the fact that there are erratic cases of gastroenteritis and symptoms of food infection after consumption (WHO, 2015). Food borne illnesses are one of the major health problems in developing and developed countries (Razavilar, 2010). According to the World Health Organization, WHO (2015), $0.07 \%$ death of the 600 million global burdens of Foodborne illnesses have been reported to be caused by bacteria, viruses, fungi and chemicals. In America $0.27 \%$ of the estimated 48 million affected people is hospitalized and about $0.0063 \%$ deaths are recorded each year (Scallan et al., 2011). More than 91 million people in Africa fall ill and $0.15 \%$ dies each year, making Africa the highest burden bearer of Foodborne diseases per population (WHO, 2015).

Application of a Hazard Analysis Critical Control Point (HACCP) at all stages of meat products preparation is essential in order to ensure its safety. Thus, according to the guidelines of good manufacturing practice, the level of total aerobic bacterial contamination of thermally processed meat products should not exceed $10^{4}\left(\mathrm{cfu} \mathrm{g}^{-1}\right)$. Enterobacteriaceae and faecal coliform contamination in meat products should be within the range of $10^{2}-10^{4}$ and $10-10^{3} \mathrm{cfu} \mathrm{g}^{-1}$, respectively (Shamsuddeen, 2015). The aim of the study is therefore, to assess the total viable bacterial counts of tsire marketed locally within Garko town, and to isolate and identify the organisms at the point of consumption with the intention of promoting public health and food hygiene habits in the Nigerian populace.

\section{MATERIALS AND METHODS Study Area and Population}

Garko is one of the existing 44 local government areas located in Kano south west zone of Kano state with its capital administrative headquarters in the Garko town. It has coordinates $11^{\circ} 39^{\prime} \mathrm{N}$ $8^{\circ} 54^{\prime} \mathrm{E}$, and an area of $450 \mathrm{~km}^{2}$. The projected population of Garko local Government was 225,300 according to the National Population Census report (2018). Garko is known for agricultural activities both farming and animal husbandry. It is popularly known for large scale rice production. Other food crops include sweet potatoes, cassava, onions, sorghum, millet and sugarcane. Cows, sheep and goats are major groups of animals reared by majority of the populace. Meat products processed, retailed and consumed in Garko include roasted meat (Balangu), dried roasted meat (Kilishi), stick meat (Tsire), hide and skin pepper soup (Ragadada) and minced fried meat (Danbunnama).

\section{Samples Collection}

Five samples of Tsire products were collected from 6 different identified locations within Garko town in a sterile foil paper and immediately analyzed for the presence of bacteria.

\section{Sample Preparation}

Sample preparation for the bacteriological analysis was carried out in accordance with the method described by Atlas (1997). Twenty five grams $(25 \mathrm{~g})$ of the sample was homogenized in $225 \mathrm{ml}$ peptone water using Kenwood blender machine to obtain a $10^{1}$ homogenate. The homogenate was thoroughly shaken and $1 \mathrm{ml}$ pipetted into test tubes containing $9 \mathrm{ml}$ of peptone water $\left(10^{2}\right)$. The test tubes were further serially diluted to $10^{5}$.

Total Aerobic Mesophilic Bacterial Count

Total Aerobic mesophilic bacterial count was determined using the method described by Abdullahi et al. (2004) where $1 \mathrm{ml}$ of inoculums from $10^{1}$ to $10^{5}$ dilutions were transferred into duplicate Petri dishes and labeled accordingly. This was followed by pouring aseptically about $15 \mathrm{ml}$ of molten nutrient agar. The culture was homogenized by gentle spinning of the plates and allowed to solidify. The plates were incubated at $37^{\circ} \mathrm{C}$ for 24 hours. Plates containing 30-300 colonies were counted. The number of colony forming units per gram of a sample (cfu/g) was obtained by multiplying the average colony number with the inverse of the dilution factor.

\section{Enumeration and Detection of Coliform bacteria}

Detection and enumeration of coliform was carried out according to method described by Atlas, (1977). A set of 9 test tubes each containing $9 \mathrm{ml}$ of lactose broth and an inverted Durham tubes were autoclaved to expel air and to sterilize. Similarly, $1 \mathrm{ml}$ from the diluents $10^{1}$ was transferred to the first 3 test tubes, followed by $1 \mathrm{ml}$ from the diluents $10^{2}$ to the second set of 3 test tubes and finally the third diluents $10^{3}$ to the $3^{\text {rd }}$ set of 3 test tubes. All the 9 test tubes were incubated at $37^{\circ} \mathrm{C}$ for 24 hours. Tubes that showed gas and acid production after 24 hours were recorded as positive for the presence of Coliform. Negative tubes were further reincubated for 24 hours. Positive tubes were recorded. Estimate of most probable number of Coliform per gram of sample (MPN/g) was determined by comparing the number of gas positive tubes with the most probable number table. 
BAJOPAS Volume 13 Number 1, June, 2020 Identification of Coliform

A loop full of inoculum from gas positive tubes was streaked on to Eosine methylene blue (EMB) agar plate and incubated at $37^{\circ} \mathrm{C}$ for $24 \mathrm{hrs}$. Colonies which formed bluish black color with green metallic sheen, and reddish colonies were isolated on agar slants. Those colonies showing metallic sheen on EMB were sub cultured into tubes of lactose broth and incubated at $45^{\circ} \mathrm{C}$. The tubes were observed after $24 \mathrm{hrs}$ for gas production. This is the completed test for fecal coliform. Gram stain and other biochemical tests such as Indole, Methyl red, Voges-Proskauer and Citrate Utilization tests (IMVIC), Coagulase and Catalase tests were carried out for the Identification and confirmation of isolates.

\section{Procedure for Indole Test}

Indole test was carried out by preparing a Tryptone broth drawn in to test tubes, sterilized by autoclaving, inoculated with loopful of suspension and incubated at $37^{\circ} \mathrm{C}$ for 24 hours. Three drops of xylene was added in tubes, shaken vigorously and kept for the separation of two layers. One millilitre of Kovac's reagent was added and the formation of pink colour ring indicates positive Indole test.

\section{Procedure for Methyl Red Test}

Methyl red test was carried out by preparing Glucose phosphate broth, dispensed in test tubes, sterilized, inoculated with test culture and incubated at $37^{\circ} \mathrm{C}$ for 24 hours. Five drops of methyl-red indicator was added to the medium for the formation of red colour.

\section{Procedure for Voges-Proskauer Test}

Voges-Proskauer test was carried out by inoculating tubes with the bacterial culture followed by incubation for 48 hours at $37^{\circ} \mathrm{C}$. Separate pipettes were used to pipette $1 \mathrm{ml}$ from each culture tube into clean separate tubes. Eighteen drops $(0.5 \mathrm{ml})$ of Barrit's solution A (a-naphthol) was added to each tube containing glucose phosphate broth followed by the addition of an equal amount of solution $B$ into the same tube. The tubes were shaken at 30 seconds interval. A positive reaction was indicated by the development of a pink color, which turns red in 1-2 hours, after vigorous shaking.

\section{Procedure for Citrate Utilization Test}

Citrate Utilization Test was carried out by distributing melted agar (Simmon Citrate Agar) in to test tubes followed by sterilization at $121.5^{\circ} \mathrm{C}$ for 15 minutes. The test tubes were afterward held in slanted position, inoculated with the given bacterial culture and incubated at $37^{\circ} \mathrm{C}$ for $24 \mathrm{hrs}$. Positive test was indicated by color change of the media from green to blue.

\section{RESULTS AND DISCUSSIONS}

The results of this study are presented in tables $1,2,3$ and 4. Among the sampling areas Kofar Kudu had the highest aerobic mesophilic bacteria counts $4.0 \times 10^{5} \mathrm{cfu} / \mathrm{g}$ followed by Rinji $2.72 \times 10^{5} \mathrm{cfu} / \mathrm{g}$, while Tosaro had the least Aerobic mesophilic bacteria counts of $1.02 \times 10^{5}$ $\mathrm{cfu} / \mathrm{g}$ as indicated in Table 1.Makwalla had the highest coliform count $68 \mathrm{MPN} / \mathrm{g}$ followed by Rinji $37 \mathrm{MPN} / \mathrm{g}$. Tsohuwar Kasuwa had the least coliform counts $8 \mathrm{MPN} / \mathrm{g}$, (Table 2). Result from table 1 shows variation in the microbial contents among the samples which suggest variation in their sources, poor handling procedures and contamination from the processing environment. High coliform count and their differences within sampling areas is an indication of poor microbiological quality of the product. Ndahi et al. (2013) reported microbial load to be a function of the handling personnel and the environment. The results indicated that the samples were contaminated with bacteria as the counts exceeded the minimum safety level $\left(10^{4} \mathrm{cfu} / \mathrm{g}\right)$ for members of the Enterobacteriaceae family. However, it might be a reflection of poor hygienic practices which may contribute to health hazard to the potential consumers. Similarly, Inusa and Sa'id (2017); Osimani et al. (2015) reported that, the initial microbial content of the raw material play significant role in influencing the final microbial load of the finished product. Isolation of members of the Enterobacteriaceae such as $E$. coli, Klebsiella pneumoniae, Salmonella and Shigella signifies danger to the public health. These organisms are capable of producing endotoxins which trigger high fevers in infected individuals, and the enterotoxins which colonize the small intestines and lead to extreme dehydration as a result of vomiting and diarrhea sometimes with severe and fatal outcomes (Amaeze et al., 2016). From the 16 isolated organisms $E$. coli had the highest isolation rate $6(37.5 \%)$ (Table 3), this suggest faecal contamination of the products. $E$. coli is a common flora in the gastrointestinal tract responsible for diarrhea and extra-intestinal infections (CDC, 2011). The result is in conformity with the findings of Ndahi et al. (2013) and Shamsuddeen (2009). Also presence of campylobacter might be due to cross contamination from raw meat to finished product (Tsire). Staphylococcus aureus is a normal flora of the skin, nasal, genital, mouth or anal area in both humans and animals without any symptom of an infection (Matthew et al., 2013). Isolation of $S$. aureus in these study concords with the findings of Lucretia et al. (2018) from Suya sold in Rivers State. 
BAJOPAS Volume 13 Number 1, June, 2020

It is also in agreement with the findings of Yousafzai et al. (2018); Onuorah et al. (2015) and Tijjani and Jumare (2014) from tsire samples in different countries. Presence of $S$. aureus in foods is most of the time an indication of poor human handling, poor environment, unhygienic utensils and equipments used during processing (Igene et al., 2016; Okonko et al., 2013). Infections caused by $S$. aureus are difficult to treat leading to long hospitalization with consequent economic loss (Udobi et al., 2013). These include soft tissue infections, pneumonia, hospital-acquired postoperative wound infections, Staphylococcal food poisoning, impetigo and cellulitis (Charlene et al., 2013). Samples obtained from Dausai and Kofar Kudu had the highest isolation rate $4(80 \%)$ (Table 4 ) probably because of the much commercial activities taking place in the area which can lead to environmental contamination.

Table 1: Total Aerobic Mesophilic Bacterial Count of Tsire sold in Garko Town

\begin{tabular}{lll}
\hline Sampling Area & APC cfu/g & Mean \pm STD \\
\hline Dausai & $2.20 \times 10^{5}$ & $110000 \pm 14142.14$ \\
Kofar Kudu & $4.00 \times 10^{5}$ & $133333.3 \pm 23094.01$ \\
Makwalla & $1.30 \times 10^{5}$ & $32500 \pm 7187.953$ \\
Rinji & $2.72 \times 10^{5}$ & $90666.67 \pm 94769.90$ \\
Tosaro & $1.02 \times 10^{5}$ & $51000 \pm 15556.35$ \\
Tsohuwar Kasuwa & $1.75 \times 10^{5}$ & $35000 \pm 11357.82$ \\
\hline
\end{tabular}

Key: APC: Aerobic Mesophilic Counts

STD: Standard Deviation

Table 2: Total Coliform Count of Tsire sold in Garko Town

\begin{tabular}{lcc}
\hline \multicolumn{1}{c}{ Sampling Area } & TCC MPN/g & Mean \pm STD \\
\hline Dausai & 20 & $6.67 \pm 2.5166$ \\
Kofar Kudu & 32 & $16.00 \pm 5.6569$ \\
Makwalla & 68 & $13.60 \pm 8.7062$ \\
Rinji & 37 & $9.25 \pm 4.7871$ \\
Tosaro & 10 & $5.00 \pm 2.8284$ \\
Tsohuwar Kasuwa & 8 & $4.00 \pm 0.0000$ \\
\hline
\end{tabular}

Table 3: Organisms Isolated from Tsire Sold in Garko

\begin{tabular}{lcl}
\hline Isolated Organism & Frequency & Percentage (\%) \\
\hline Campylobacter & 2 & 06.66 \\
Escherichia coli & 6 & 20.00 \\
Klebsiella pneumoniae & 2 & 06.66 \\
Salmonella species & 1 & 03.33 \\
Shigella & 3 & 10.00 \\
Staphylococcus aureus & 2 & 06.66 \\
Total & 16 & \\
\hline
\end{tabular}

Table 4: Distribution of Organisms within Sampling Area

\begin{tabular}{lcc}
\hline \multicolumn{1}{c}{ Sampling Area } & No. Isolated & Percentage (\%) \\
\hline Dausai & 4 & 80 \\
Kofar Kudu & 4 & 80 \\
Makwalla & 2 & 40 \\
Rinji & 3 & 60 \\
Tosaro & 2 & 40 \\
Tsohuwar Kasuwa & 1 & 20 \\
Total & 16 & \\
\hline
\end{tabular}

\section{CONCLUSION}

Results indicated $4.00 \times 10^{5} \mathrm{CFU} / \mathrm{g}$ as the highest APCs count; while $68 \mathrm{MPN} / \mathrm{g}$ was the highest TCCs from the 30 samples analyzed. Among the isolates, $E$. coli has the highest isolation rate of $6(20 \%)$. Dausai and Kofar kudu were having the highest bacteria count of $4(80 \%)$, each, indicating higher contamination in those locations. 
BAJOPAS Volume 13 Number 1, June, 2020 RECOMMENDATIONS

The following recommendations are tenable:

1. Hygienic practices at all stages of production should be improved to safe guard the consumers against potential health hazard.

2. Monitoring of microbiological contamination of Tsire during preparations, packaging and marketing is essential to ensure product of good microbiological quality for consumers' health.

\section{REFERENCES}

Abdullahi, I. O., Umoh, V. J. and Galadima, M. (2004). Hazards Associated with Kilishi Preparations in Zaria. Nigerian Journal of Microbiology, 18 (1-2): $339-345$.

Ahmadu, J. and Ibrahim E. J., (2013): Determinants of Revenue in Suya Production in BeninCity, Edo State, Nigeria. Nigerian journal of agriculture, food and environment.9(3):1-5

Amaeze, N. Aboh, M. Itohan, A. Felix, E. Olatunji, T. and Oladosu, P. (2016) Microbial Profile, Antibiotic Sensitivity and Heat Resistance of Bacterial Isolates from Commercial Roasted Beef (Suya) in Abuja, Nigeria. JOPAT, 15(2): $22-30$.

Apata, E.S., Kuku1, I.A., Apata, O.C. and Adeyemi, K.O. (2013). Evaluation of Suya(Tsire) - An Intermediate Moisture Meat Product in Ogun State, Nigeria. J. Food Res 2 (1): 87.

Atlas, R. M. (1997) Principles of Microbiology Second Edition. C. Brown Publishers. Pp 802-803.

Borch, E. Kant-Muermans, M. L., Blixt, Y. (1996) Bacterial Spoilage of Meat and Cured Meat Products. Int $\mathrm{J}$ Food Microbiol .33(1): 103-20.

Centre for Disease Control, CDC (2011). "Escherichia coli 0157:H7" Division of Bacterial and Mycotic Diseasesht://www.cdc.gov/nczved/divisi ons/dfbmd/diseases/ecoli_0157h7/.

Charlene, R. J., Johnnie, A. D., and John, B. B., (2013) Prevalence and Characterization of Methicillin-Resistant Staphylococcus aureus Isolates from Retail Meat and Humans in Georgia. American society for Microbiology. J. of clinical microbiology. 12(1):123-6 doi:10.1128/JCM.0316612JCM.03166-12

Egbebi, A.O and Seidu, K., T. (2011). Microbiological Evaluation of Suya (dried smoked

meat) Sold in Ado and Akure, South West Nigeria.European Journal of Experinmental Biology, 1(4):1-5
3. Government should establish regulatory bodies responsible for inculcating hygiene habits to the local producers and vendors in order to prevent instant, cross and post processing contaminations by microbial pathogens.

4. Awareness and sensitization of local food producers about good hygienic practices in food handling and processing.

Falegan, C, R., Akoja, S. D., and Oyarekua, M. A., (2017) Microbiological Assessment of Suya (Sliced Roasted Beef) in Ado-Ekiti Metropolis, Ekiti State, Nigeria. MOJ Biology andMedicine.

Fonkem, D., N. Tanya, V., N. and Ebangi, A., L. (2010). Effect of Season on the Microbiological Quality of Kilishi, a Traditional Cameroonian Dried Beef Product. Tropicultura, 28(1): 10-15.

Food and Agricultural Organization of the United Nations (F A O, 1979). Manual of food quality control 4. Microbiological analysis.

Food and Agriculture Organisation of the United Nation (FAO), 2019. Nigeria at a glance.

Igene J.O., Uwadia, O.E., Ebabhamiegbebho, P.A. and Evivie, S.E., (2016) Shelf life Stability Studies of University of Benin (UNIBEN) Proff's Kilishi Product Asian Journal of Science and Technology 7(1): 2268-2274.

Inusa, S. K. and Said, I. S. (2017) Evaluation of the Chemical and Microbiological Properties Of Kilishi Sold in Kano Metropolis. Journal of Dry land Agriculture, 3 (1): $59-69$.

Lucretia, I. B, Patience, C. Obinna-Echem, Sophia, C. A. (2018) Microbiological quality andantibiotic sensitivity of potential pathogens isolated from meat product (Suya) sold in Rivers State University and its environs. International Journal of Biotechnology and Food Science, 6(4): 67-76.

Matthew, E., Drosos, E., John, L. and Ioanna, P. (2013) MRSA in Africa: Filling the Global Map of Antimicrobial Resistance PLOS One. 8(7): e68024 doi: 10.1371/journal.pone.0068024

Mgbemere, V.N., Akpapunam, M. A. and Igene, J. O., (2011). Effect of Groundnut FlourSubstitution on Yield, Quality and Storage Stability of Kilishi - a Nigerian Indigenous Dried Meat Product. African Journal of Food, Agriculture, Nutrition and Development, $\quad \mathbf{1 1}(2)$ : 4718-4738. 
BAJOPAS Volume 13 Number 1, June, 2020

Mubarak, A. A., Azeez, M. L., Amos A. O., Opeyemi, O. O. (2016) Assessment of Animal Protein Consumption and Food Security Among Rural Households in Kwara State, Nigeria American Journal of Business and Society, 1(4): 233245.

Ndahi, M., D. Kwaga, J., K. P. Bello, M. Kabir J., V. Umoh, .J. Yakubu, S., E. and Nok, A., J. (2013) Prevalence and Antimicrobial Susceptibility of Listeria Monocytogenes and Methicillin-Resistant Staphylococcus aureus Strains from Raw Meat and Meat Products in Zaria, Nigeria. Applied Journal of Microbiology, 58(3):262-9.

Okonko, I.O., Odu, N.N. and Igboh, I.E. (2013). Microbiological Analysis of Kilishi Sold In Port Harcourt, Nigeria. New York Science Journal, 6 (7):37-43.

Osimani, A., Aquilanti, L. and Clementi, F. (2015) Microbiological Quality of Meatbased Meals and Operation of Control Systems within a Food Service Environment. International Food Research Journal 22(4): 1692-1698.

Onuorah, S. Obika, I. Odibo, F. Orji, M. (2015)An Assessment of the Bacteriological Quality of Tsire-Suya (Grilled Beef) sold in Awka, Nigeria. American. J. Life. Sci. Res. 3(4):287292.

Razavilar, V, Khandaghi, J. Barzgari, A. (2010); Isolation of Eschericia coli 0157:H7 from manure fertilized farms and raw vegetables grown on it, in Tabriz city in
Iran. African Journal of Microbiology Research, 4(9): 891-895.

Scallan, E. Hoekstra, R. M. Angulo, F. J.Tauxe, R. V, Widdowson, M. Roy, S. L et al., (2011).Food borne illness acquired in the United States- Major Pathogens. Emerg. Infec Dis, 17(1): 7-15.

Shamsuddeen U (2009). Microbiological quality of spice used in the production of Kilishi a traditionally dried and grilled meat product. Bayero Journal of Pure andApplied Sciences, 2(2): 66-69.

Shamsuddeen, U. (2015) Microbiological Hazard and Critical control point Analysis of Dried and Minced Meat Snacks Produced in Kano Nigeria. Lambert Academic Publishing; Pp 1-36.

Tijani, O.and Jumare, S. (2014). Microblological Quality Assessment of Meat

Sold in KauraNamoda. International Conference on Earth, Environment and Life sciences (EELS) Dubai (UAE).

Udobi, C. E., Obajuluwa, A. F., and Onaolapo, J. A., (2013) Prevalence and Antibiotic Resistance Pattern of MethicillinResistant Staphylococcus aureus from an Orthopaedic Hospital in Nigeria BioMed Research International; 26(6); 6-7.

WHO, 2015 Foodborne diseases in the WHO African Region.

Yousafzai HA, Rind R, Khan MA, Abro SH, Korejo NA, Ejaz M, Kabir A, Shahid M, Memon S. (2019). Microbiological Contamination of Cattle and Meat in Peshawar, Pakistan. J. Anim. Health Prod. 7(1): 1116. 


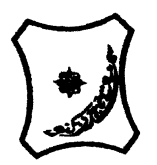

Bayero Journal of Pure and Applied Sciences, 13(1); 40 - 45

Received: September, 2019

Accepted: April, 2020

ISSN $2006-6996$

\title{
BACTERIOLOGICAL QUALITY OF STICK MEAT (Tsire) SOLD IN GARKO LOCAL GOVERNMENT AREA OF KANO STATE, NIGERIA
}

\author{
$*^{1}$ Dahiru A. T. and ${ }^{2}$ Maigari A. K. \\ ${ }^{1}$ Department of Hospitality Management, School of Technology, Kano State Polytechnic, PMB 3348, \\ Kano Nigeria. \\ ${ }^{2}$ Departmnt of Biological Sciences, Bayero University, Kano \\ Corresponding Author: dturajo61@gmail.com; GSM: 08087508262.
}

ABSTRACT

Stick meat, locally called Tsire in Hausa Language, is a significant portion of the diet of a large active population of Northern Nigeria. However, because of the handling and processing methods by the manufacturers as well as the hawking system of stick meat, the meat product may be exposed to both pre- and post-processed product contamination, and thus may poses danger to public health. Therefore, considering the role of Tsire in improving nutrition and increase household income to the populace, the need to improve the processing, distribution and overall quality of the product is simply indispensable. A total of 30 samples (5 samples from each of the 6 sampling points) of Tsire were collected randomly in Garko Town. Aerobic plate counts (APCs) and Total coliform counts (TCCS) of Tsire samples were determined using standard microbiological methods. APCs ranged from $1.02 \times 10^{5}$ to $4.00 \times 10^{5} \mathrm{CFU} / \mathrm{g}$; while TCCs ranged from $8 \mathrm{MPN} / \mathrm{g}$ to $68 \mathrm{MPN} / \mathrm{g}$. From the 30 samples screened, 16(53.33\%) bacteria namely, Campylobacter 2(6.66\%), Escherichia coli 6(20\%), Klebsiella pneumoniae 2(6.66\%), Salmonella spp. 1(3.33\%), Shigella 3(10\%) and Staphylococcus aureus 2(6.66\%) were detected. $E$. coli has the highest isolation rate of 6(20\%), while Salmonella spp. had the least frequency of 1(3.33\%). The distribution of isolated organisms within the study area were as follows: Dausai, 4(80\%), Kofar kudu, 4(80\%), Makwalla, 2(40\%), Rinji, 3(60\%), Tosaro, 2(40\%), and Tsohuwar Kasuwa, 1(20\%). The results have indicated that the Tsire was contaminated with bacteria thus exposing the product to fast deterioration, spoilage and also a vehicle for food borne illness, suggesting for adequate hygienic practices at all the stages, prior to consumption, to ensure safety of the meat product.

Key words: APCs, TCCs, Contamination, Microorganisms, Garko

\section{INTRODUCTION}

Nigeria is one of the developing nations with inadequate food supply and most often deficient in protein content (FAO, 2019). Nigerian's average animal protein intake per head per day is estimated at $7.9 \mathrm{~g}$ as against $35 \mathrm{~g}$ recommended value by Food and Agricultural Organization (Mubarak et al., 2016). These low levels of animal protein intake create great concern as it affects the nutritional status of Nigerians. Hence, there is the need for sufficient supply of animal protein from energy rich animal products to satisfy the nutritional requirements for Nigerians.

Meat is one major source of animal protein largely composed of water, protein and fats which can make it susceptible to microbial contamination within short time leading to spoilage (Apata et al., 2013; Mgbemere et al., 2011). Meat is mostly eaten after it has been cooked or processed in a variety of ways such as sun drying; smoking and roasting with or without fortifications (Borch et al., 1996). In Nigeria meat products such as Tsire, Kilishi and Balangu are locally produced using one or more of these methods in order to meet the nutritional requirements of the teeming Nigerians (Egbebi, 2011).

Tsire is a popular Nigerian traditional processed ready-to-eat roasted stick meat product (Shamsuddeen, 2015). It is sold in public places, along roads, in hotels, parks, quarters and even offices (Falegan et al., 2017). It is prepared from boneless healthy animal flesh such as beef and mutton, spiced with peanut cake, salt, vegetable oil and other flavorings followed by roasting (Shamsuddeen, 2015). Consumption of these products has extended to other parts of African countries such as Ghana, Somali, Cameroun and Chad (Ahmadu and Ibrahim, 2013). 
BAJOPAS Volume 13 Number 1, June, 2020

However, evidence of quality control sticking to procedural hygiene by the handlers during preparation and retailing of these products is poorly documented. Tsire is of great safety risk because of the fact that there are erratic cases of gastroenteritis and symptoms of food infection after consumption (WHO, 2015). Food borne illnesses are one of the major health problems in developing and developed countries (Razavilar, 2010). According to the World Health Organization, WHO (2015), $0.07 \%$ death of the 600 million global burdens of Foodborne illnesses have been reported to be caused by bacteria, viruses, fungi and chemicals. In America $0.27 \%$ of the estimated 48 million affected people is hospitalized and about $0.0063 \%$ deaths are recorded each year (Scallan et al., 2011). More than 91 million people in Africa fall ill and $0.15 \%$ dies each year, making Africa the highest burden bearer of Foodborne diseases per population (WHO, 2015).

Application of a Hazard Analysis Critical Control Point (HACCP) at all stages of meat products preparation is essential in order to ensure its safety. Thus, according to the guidelines of good manufacturing practice, the level of total aerobic bacterial contamination of thermally processed meat products should not exceed $10^{4}\left(\mathrm{cfu} \mathrm{g}^{-1}\right)$. Enterobacteriaceae and faecal coliform contamination in meat products should be within the range of $10^{2}-10^{4}$ and $10-10^{3} \mathrm{cfu} \mathrm{g}^{-1}$, respectively (Shamsuddeen, 2015). The aim of the study is therefore, to assess the total viable bacterial counts of tsire marketed locally within Garko town, and to isolate and identify the organisms at the point of consumption with the intention of promoting public health and food hygiene habits in the Nigerian populace.

\section{MATERIALS AND METHODS Study Area and Population}

Garko is one of the existing 44 local government areas located in Kano south west zone of Kano state with its capital administrative headquarters in the Garko town. It has coordinates $11^{\circ} 39^{\prime} \mathrm{N}$ $8^{\circ} 54^{\prime} \mathrm{E}$, and an area of $450 \mathrm{~km}^{2}$. The projected population of Garko local Government was 225,300 according to the National Population Census report (2018). Garko is known for agricultural activities both farming and animal husbandry. It is popularly known for large scale rice production. Other food crops include sweet potatoes, cassava, onions, sorghum, millet and sugarcane. Cows, sheep and goats are major groups of animals reared by majority of the populace. Meat products processed, retailed and consumed in Garko include roasted meat (Balangu), dried roasted meat (Kilishi), stick meat (Tsire), hide and skin pepper soup (Ragadada) and minced fried meat (Danbunnama).

\section{Samples Collection}

Five samples of Tsire products were collected from 6 different identified locations within Garko town in a sterile foil paper and immediately analyzed for the presence of bacteria.

\section{Sample Preparation}

Sample preparation for the bacteriological analysis was carried out in accordance with the method described by Atlas (1997). Twenty five grams $(25 \mathrm{~g})$ of the sample was homogenized in $225 \mathrm{ml}$ peptone water using Kenwood blender machine to obtain a $10^{1}$ homogenate. The homogenate was thoroughly shaken and $1 \mathrm{ml}$ pipetted into test tubes containing $9 \mathrm{ml}$ of peptone water $\left(10^{2}\right)$. The test tubes were further serially diluted to $10^{5}$.

Total Aerobic Mesophilic Bacterial Count

Total Aerobic mesophilic bacterial count was determined using the method described by Abdullahi et al. (2004) where $1 \mathrm{ml}$ of inoculums from $10^{1}$ to $10^{5}$ dilutions were transferred into duplicate Petri dishes and labeled accordingly. This was followed by pouring aseptically about $15 \mathrm{ml}$ of molten nutrient agar. The culture was homogenized by gentle spinning of the plates and allowed to solidify. The plates were incubated at $37^{\circ} \mathrm{C}$ for 24 hours. Plates containing 30-300 colonies were counted. The number of colony forming units per gram of a sample (cfu/g) was obtained by multiplying the average colony number with the inverse of the dilution factor.

\section{Enumeration and Detection of Coliform bacteria}

Detection and enumeration of coliform was carried out according to method described by Atlas, (1977). A set of 9 test tubes each containing $9 \mathrm{ml}$ of lactose broth and an inverted Durham tubes were autoclaved to expel air and to sterilize. Similarly, $1 \mathrm{ml}$ from the diluents $10^{1}$ was transferred to the first 3 test tubes, followed by $1 \mathrm{ml}$ from the diluents $10^{2}$ to the second set of 3 test tubes and finally the third diluents $10^{3}$ to the $3^{\text {rd }}$ set of 3 test tubes. All the 9 test tubes were incubated at $37^{\circ} \mathrm{C}$ for 24 hours. Tubes that showed gas and acid production after 24 hours were recorded as positive for the presence of Coliform. Negative tubes were further reincubated for 24 hours. Positive tubes were recorded. Estimate of most probable number of Coliform per gram of sample (MPN/g) was determined by comparing the number of gas positive tubes with the most probable number table. 
BAJOPAS Volume 13 Number 1, June, 2020 Identification of Coliform

A loop full of inoculum from gas positive tubes was streaked on to Eosine methylene blue (EMB) agar plate and incubated at $37^{\circ} \mathrm{C}$ for $24 \mathrm{hrs}$. Colonies which formed bluish black color with green metallic sheen, and reddish colonies were isolated on agar slants. Those colonies showing metallic sheen on EMB were sub cultured into tubes of lactose broth and incubated at $45^{\circ} \mathrm{C}$. The tubes were observed after $24 \mathrm{hrs}$ for gas production. This is the completed test for fecal coliform. Gram stain and other biochemical tests such as Indole, Methyl red, Voges-Proskauer and Citrate Utilization tests (IMVIC), Coagulase and Catalase tests were carried out for the Identification and confirmation of isolates.

\section{Procedure for Indole Test}

Indole test was carried out by preparing a Tryptone broth drawn in to test tubes, sterilized by autoclaving, inoculated with loopful of suspension and incubated at $37^{\circ} \mathrm{C}$ for 24 hours. Three drops of xylene was added in tubes, shaken vigorously and kept for the separation of two layers. One millilitre of Kovac's reagent was added and the formation of pink colour ring indicates positive Indole test.

\section{Procedure for Methyl Red Test}

Methyl red test was carried out by preparing Glucose phosphate broth, dispensed in test tubes, sterilized, inoculated with test culture and incubated at $37^{\circ} \mathrm{C}$ for 24 hours. Five drops of methyl-red indicator was added to the medium for the formation of red colour.

\section{Procedure for Voges-Proskauer Test}

Voges-Proskauer test was carried out by inoculating tubes with the bacterial culture followed by incubation for 48 hours at $37^{\circ} \mathrm{C}$. Separate pipettes were used to pipette $1 \mathrm{ml}$ from each culture tube into clean separate tubes. Eighteen drops $(0.5 \mathrm{ml})$ of Barrit's solution A (a-naphthol) was added to each tube containing glucose phosphate broth followed by the addition of an equal amount of solution $B$ into the same tube. The tubes were shaken at 30 seconds interval. A positive reaction was indicated by the development of a pink color, which turns red in 1-2 hours, after vigorous shaking.

\section{Procedure for Citrate Utilization Test}

Citrate Utilization Test was carried out by distributing melted agar (Simmon Citrate Agar) in to test tubes followed by sterilization at $121.5^{\circ} \mathrm{C}$ for 15 minutes. The test tubes were afterward held in slanted position, inoculated with the given bacterial culture and incubated at $37^{\circ} \mathrm{C}$ for $24 \mathrm{hrs}$. Positive test was indicated by color change of the media from green to blue.

\section{RESULTS AND DISCUSSIONS}

The results of this study are presented in tables $1,2,3$ and 4. Among the sampling areas Kofar Kudu had the highest aerobic mesophilic bacteria counts $4.0 \times 10^{5} \mathrm{cfu} / \mathrm{g}$ followed by Rinji $2.72 \times 10^{5} \mathrm{cfu} / \mathrm{g}$, while Tosaro had the least Aerobic mesophilic bacteria counts of $1.02 \times 10^{5}$ $\mathrm{cfu} / \mathrm{g}$ as indicated in Table 1.Makwalla had the highest coliform count $68 \mathrm{MPN} / \mathrm{g}$ followed by Rinji $37 \mathrm{MPN} / \mathrm{g}$. Tsohuwar Kasuwa had the least coliform counts $8 \mathrm{MPN} / \mathrm{g}$, (Table 2). Result from table 1 shows variation in the microbial contents among the samples which suggest variation in their sources, poor handling procedures and contamination from the processing environment. High coliform count and their differences within sampling areas is an indication of poor microbiological quality of the product. Ndahi et al. (2013) reported microbial load to be a function of the handling personnel and the environment. The results indicated that the samples were contaminated with bacteria as the counts exceeded the minimum safety level $\left(10^{4} \mathrm{cfu} / \mathrm{g}\right)$ for members of the Enterobacteriaceae family. However, it might be a reflection of poor hygienic practices which may contribute to health hazard to the potential consumers. Similarly, Inusa and Sa'id (2017); Osimani et al. (2015) reported that, the initial microbial content of the raw material play significant role in influencing the final microbial load of the finished product. Isolation of members of the Enterobacteriaceae such as $E$. coli, Klebsiella pneumoniae, Salmonella and Shigella signifies danger to the public health. These organisms are capable of producing endotoxins which trigger high fevers in infected individuals, and the enterotoxins which colonize the small intestines and lead to extreme dehydration as a result of vomiting and diarrhea sometimes with severe and fatal outcomes (Amaeze et al., 2016). From the 16 isolated organisms $E$. coli had the highest isolation rate $6(37.5 \%)$ (Table 3), this suggest faecal contamination of the products. $E$. coli is a common flora in the gastrointestinal tract responsible for diarrhea and extra-intestinal infections (CDC, 2011). The result is in conformity with the findings of Ndahi et al. (2013) and Shamsuddeen (2009). Also presence of campylobacter might be due to cross contamination from raw meat to finished product (Tsire). Staphylococcus aureus is a normal flora of the skin, nasal, genital, mouth or anal area in both humans and animals without any symptom of an infection (Matthew et al., 2013). Isolation of $S$. aureus in these study concords with the findings of Lucretia et al. (2018) from Suya sold in Rivers State. 
BAJOPAS Volume 13 Number 1, June, 2020

It is also in agreement with the findings of Yousafzai et al. (2018); Onuorah et al. (2015) and Tijjani and Jumare (2014) from tsire samples in different countries. Presence of $S$. aureus in foods is most of the time an indication of poor human handling, poor environment, unhygienic utensils and equipments used during processing (Igene et al., 2016; Okonko et al., 2013). Infections caused by $S$. aureus are difficult to treat leading to long hospitalization with consequent economic loss (Udobi et al., 2013). These include soft tissue infections, pneumonia, hospital-acquired postoperative wound infections, Staphylococcal food poisoning, impetigo and cellulitis (Charlene et al., 2013). Samples obtained from Dausai and Kofar Kudu had the highest isolation rate $4(80 \%)$ (Table 4 ) probably because of the much commercial activities taking place in the area which can lead to environmental contamination.

Table 1: Total Aerobic Mesophilic Bacterial Count of Tsire sold in Garko Town

\begin{tabular}{lll}
\hline Sampling Area & APC cfu/g & Mean \pm STD \\
\hline Dausai & $2.20 \times 10^{5}$ & $110000 \pm 14142.14$ \\
Kofar Kudu & $4.00 \times 10^{5}$ & $133333.3 \pm 23094.01$ \\
Makwalla & $1.30 \times 10^{5}$ & $32500 \pm 7187.953$ \\
Rinji & $2.72 \times 10^{5}$ & $90666.67 \pm 94769.90$ \\
Tosaro & $1.02 \times 10^{5}$ & $51000 \pm 15556.35$ \\
Tsohuwar Kasuwa & $1.75 \times 10^{5}$ & $35000 \pm 11357.82$ \\
\hline
\end{tabular}

Key: APC: Aerobic Mesophilic Counts

STD: Standard Deviation

Table 2: Total Coliform Count of Tsire sold in Garko Town

\begin{tabular}{lcc}
\hline \multicolumn{1}{c}{ Sampling Area } & TCC MPN/g & Mean \pm STD \\
\hline Dausai & 20 & $6.67 \pm 2.5166$ \\
Kofar Kudu & 32 & $16.00 \pm 5.6569$ \\
Makwalla & 68 & $13.60 \pm 8.7062$ \\
Rinji & 37 & $9.25 \pm 4.7871$ \\
Tosaro & 10 & $5.00 \pm 2.8284$ \\
Tsohuwar Kasuwa & 8 & $4.00 \pm 0.0000$ \\
\hline
\end{tabular}

Table 3: Organisms Isolated from Tsire Sold in Garko

\begin{tabular}{lcl}
\hline Isolated Organism & Frequency & Percentage (\%) \\
\hline Campylobacter & 2 & 06.66 \\
Escherichia coli & 6 & 20.00 \\
Klebsiella pneumoniae & 2 & 06.66 \\
Salmonella species & 1 & 03.33 \\
Shigella & 3 & 10.00 \\
Staphylococcus aureus & 2 & 06.66 \\
Total & 16 & \\
\hline
\end{tabular}

Table 4: Distribution of Organisms within Sampling Area

\begin{tabular}{lcc}
\hline \multicolumn{1}{c}{ Sampling Area } & No. Isolated & Percentage (\%) \\
\hline Dausai & 4 & 80 \\
Kofar Kudu & 4 & 80 \\
Makwalla & 2 & 40 \\
Rinji & 3 & 60 \\
Tosaro & 2 & 40 \\
Tsohuwar Kasuwa & 1 & 20 \\
Total & 16 & \\
\hline
\end{tabular}

\section{CONCLUSION}

Results indicated $4.00 \times 10^{5} \mathrm{CFU} / \mathrm{g}$ as the highest APCs count; while $68 \mathrm{MPN} / \mathrm{g}$ was the highest TCCs from the 30 samples analyzed. Among the isolates, $E$. coli has the highest isolation rate of $6(20 \%)$. Dausai and Kofar kudu were having the highest bacteria count of $4(80 \%)$, each, indicating higher contamination in those locations. 
BAJOPAS Volume 13 Number 1, June, 2020 RECOMMENDATIONS

The following recommendations are tenable:

1. Hygienic practices at all stages of production should be improved to safe guard the consumers against potential health hazard.

2. Monitoring of microbiological contamination of Tsire during preparations, packaging and marketing is essential to ensure product of good microbiological quality for consumers' health.

\section{REFERENCES}

Abdullahi, I. O., Umoh, V. J. and Galadima, M. (2004). Hazards Associated with Kilishi Preparations in Zaria. Nigerian Journal of Microbiology, 18 (1-2): $339-345$.

Ahmadu, J. and Ibrahim E. J., (2013): Determinants of Revenue in Suya Production in BeninCity, Edo State, Nigeria. Nigerian journal of agriculture, food and environment.9(3):1-5

Amaeze, N. Aboh, M. Itohan, A. Felix, E. Olatunji, T. and Oladosu, P. (2016) Microbial Profile, Antibiotic Sensitivity and Heat Resistance of Bacterial Isolates from Commercial Roasted Beef (Suya) in Abuja, Nigeria. JOPAT, 15(2): $22-30$.

Apata, E.S., Kuku1, I.A., Apata, O.C. and Adeyemi, K.O. (2013). Evaluation of Suya(Tsire) - An Intermediate Moisture Meat Product in Ogun State, Nigeria. J. Food Res 2 (1): 87.

Atlas, R. M. (1997) Principles of Microbiology Second Edition. C. Brown Publishers. Pp 802-803.

Borch, E. Kant-Muermans, M. L., Blixt, Y. (1996) Bacterial Spoilage of Meat and Cured Meat Products. Int $\mathrm{J}$ Food Microbiol .33(1): 103-20.

Centre for Disease Control, CDC (2011). "Escherichia coli 0157:H7" Division of Bacterial and Mycotic Diseasesht://www.cdc.gov/nczved/divisi ons/dfbmd/diseases/ecoli_0157h7/.

Charlene, R. J., Johnnie, A. D., and John, B. B., (2013) Prevalence and Characterization of Methicillin-Resistant Staphylococcus aureus Isolates from Retail Meat and Humans in Georgia. American society for Microbiology. J. of clinical microbiology. 12(1):123-6 doi:10.1128/JCM.0316612JCM.03166-12

Egbebi, A.O and Seidu, K., T. (2011). Microbiological Evaluation of Suya (dried smoked

meat) Sold in Ado and Akure, South West Nigeria.European Journal of Experinmental Biology, 1(4):1-5
3. Government should establish regulatory bodies responsible for inculcating hygiene habits to the local producers and vendors in order to prevent instant, cross and post processing contaminations by microbial pathogens.

4. Awareness and sensitization of local food producers about good hygienic practices in food handling and processing.

Falegan, C, R., Akoja, S. D., and Oyarekua, M. A., (2017) Microbiological Assessment of Suya (Sliced Roasted Beef) in Ado-Ekiti Metropolis, Ekiti State, Nigeria. MOJ Biology andMedicine.

Fonkem, D., N. Tanya, V., N. and Ebangi, A., L. (2010). Effect of Season on the Microbiological Quality of Kilishi, a Traditional Cameroonian Dried Beef Product. Tropicultura, 28(1): 10-15.

Food and Agricultural Organization of the United Nations (F A O, 1979). Manual of food quality control 4. Microbiological analysis.

Food and Agriculture Organisation of the United Nation (FAO), 2019. Nigeria at a glance.

Igene J.O., Uwadia, O.E., Ebabhamiegbebho, P.A. and Evivie, S.E., (2016) Shelf life Stability Studies of University of Benin (UNIBEN) Proff's Kilishi Product Asian Journal of Science and Technology 7(1): 2268-2274.

Inusa, S. K. and Said, I. S. (2017) Evaluation of the Chemical and Microbiological Properties Of Kilishi Sold in Kano Metropolis. Journal of Dry land Agriculture, 3 (1): $59-69$.

Lucretia, I. B, Patience, C. Obinna-Echem, Sophia, C. A. (2018) Microbiological quality andantibiotic sensitivity of potential pathogens isolated from meat product (Suya) sold in Rivers State University and its environs. International Journal of Biotechnology and Food Science, 6(4): 67-76.

Matthew, E., Drosos, E., John, L. and Ioanna, P. (2013) MRSA in Africa: Filling the Global Map of Antimicrobial Resistance PLOS One. 8(7): e68024 doi: 10.1371/journal.pone.0068024

Mgbemere, V.N., Akpapunam, M. A. and Igene, J. O., (2011). Effect of Groundnut FlourSubstitution on Yield, Quality and Storage Stability of Kilishi - a Nigerian Indigenous Dried Meat Product. African Journal of Food, Agriculture, Nutrition and Development, $\quad \mathbf{1 1}(2)$ : 4718-4738. 
BAJOPAS Volume 13 Number 1, June, 2020

Mubarak, A. A., Azeez, M. L., Amos A. O., Opeyemi, O. O. (2016) Assessment of Animal Protein Consumption and Food Security Among Rural Households in Kwara State, Nigeria American Journal of Business and Society, 1(4): 233245.

Ndahi, M., D. Kwaga, J., K. P. Bello, M. Kabir J., V. Umoh, .J. Yakubu, S., E. and Nok, A., J. (2013) Prevalence and Antimicrobial Susceptibility of Listeria Monocytogenes and Methicillin-Resistant Staphylococcus aureus Strains from Raw Meat and Meat Products in Zaria, Nigeria. Applied Journal of Microbiology, 58(3):262-9.

Okonko, I.O., Odu, N.N. and Igboh, I.E. (2013). Microbiological Analysis of Kilishi Sold In Port Harcourt, Nigeria. New York Science Journal, 6 (7):37-43.

Osimani, A., Aquilanti, L. and Clementi, F. (2015) Microbiological Quality of Meatbased Meals and Operation of Control Systems within a Food Service Environment. International Food Research Journal 22(4): 1692-1698.

Onuorah, S. Obika, I. Odibo, F. Orji, M. (2015)An Assessment of the Bacteriological Quality of Tsire-Suya (Grilled Beef) sold in Awka, Nigeria. American. J. Life. Sci. Res. 3(4):287292.

Razavilar, V, Khandaghi, J. Barzgari, A. (2010); Isolation of Eschericia coli 0157:H7 from manure fertilized farms and raw vegetables grown on it, in Tabriz city in
Iran. African Journal of Microbiology Research, 4(9): 891-895.

Scallan, E. Hoekstra, R. M. Angulo, F. J.Tauxe, R. V, Widdowson, M. Roy, S. L et al., (2011).Food borne illness acquired in the United States- Major Pathogens. Emerg. Infec Dis, 17(1): 7-15.

Shamsuddeen U (2009). Microbiological quality of spice used in the production of Kilishi a traditionally dried and grilled meat product. Bayero Journal of Pure andApplied Sciences, 2(2): 66-69.

Shamsuddeen, U. (2015) Microbiological Hazard and Critical control point Analysis of Dried and Minced Meat Snacks Produced in Kano Nigeria. Lambert Academic Publishing; Pp 1-36.

Tijani, O.and Jumare, S. (2014). Microblological Quality Assessment of Meat

Sold in KauraNamoda. International Conference on Earth, Environment and Life sciences (EELS) Dubai (UAE).

Udobi, C. E., Obajuluwa, A. F., and Onaolapo, J. A., (2013) Prevalence and Antibiotic Resistance Pattern of MethicillinResistant Staphylococcus aureus from an Orthopaedic Hospital in Nigeria BioMed Research International; 26(6); 6-7.

WHO, 2015 Foodborne diseases in the WHO African Region.

Yousafzai HA, Rind R, Khan MA, Abro SH, Korejo NA, Ejaz M, Kabir A, Shahid M, Memon S. (2019). Microbiological Contamination of Cattle and Meat in Peshawar, Pakistan. J. Anim. Health Prod. 7(1): 1116. 


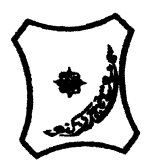

Bayero Journal of Pure and Applied Sciences, 13(1); 40 - 45

Received: September, 2019

Accepted: April, 2020

ISSN $2006-6996$

\title{
BACTERIOLOGICAL QUALITY OF STICK MEAT (Tsire) SOLD IN GARKO LOCAL GOVERNMENT AREA OF KANO STATE, NIGERIA
}

\author{
$*^{1}$ Dahiru A. T. and ${ }^{2}$ Maigari A. K. \\ ${ }^{1}$ Department of Hospitality Management, School of Technology, Kano State Polytechnic, PMB 3348, \\ Kano Nigeria. \\ ${ }^{2}$ Departmnt of Biological Sciences, Bayero University, Kano \\ Corresponding Author: dturajo61@gmail.com; GSM: 08087508262.
}

ABSTRACT

Stick meat, locally called Tsire in Hausa Language, is a significant portion of the diet of a large active population of Northern Nigeria. However, because of the handling and processing methods by the manufacturers as well as the hawking system of stick meat, the meat product may be exposed to both pre- and post-processed product contamination, and thus may poses danger to public health. Therefore, considering the role of Tsire in improving nutrition and increase household income to the populace, the need to improve the processing, distribution and overall quality of the product is simply indispensable. A total of 30 samples (5 samples from each of the 6 sampling points) of Tsire were collected randomly in Garko Town. Aerobic plate counts (APCs) and Total coliform counts (TCCS) of Tsire samples were determined using standard microbiological methods. APCs ranged from $1.02 \times 10^{5}$ to $4.00 \times 10^{5} \mathrm{CFU} / \mathrm{g}$; while TCCs ranged from $8 \mathrm{MPN} / \mathrm{g}$ to $68 \mathrm{MPN} / \mathrm{g}$. From the 30 samples screened, 16(53.33\%) bacteria namely, Campylobacter 2(6.66\%), Escherichia coli 6(20\%), Klebsiella pneumoniae 2(6.66\%), Salmonella spp. 1(3.33\%), Shigella 3(10\%) and Staphylococcus aureus 2(6.66\%) were detected. $E$. coli has the highest isolation rate of 6(20\%), while Salmonella spp. had the least frequency of 1(3.33\%). The distribution of isolated organisms within the study area were as follows: Dausai, 4(80\%), Kofar kudu, 4(80\%), Makwalla, 2(40\%), Rinji, 3(60\%), Tosaro, 2(40\%), and Tsohuwar Kasuwa, 1(20\%). The results have indicated that the Tsire was contaminated with bacteria thus exposing the product to fast deterioration, spoilage and also a vehicle for food borne illness, suggesting for adequate hygienic practices at all the stages, prior to consumption, to ensure safety of the meat product.

Key words: APCs, TCCs, Contamination, Microorganisms, Garko

\section{INTRODUCTION}

Nigeria is one of the developing nations with inadequate food supply and most often deficient in protein content (FAO, 2019). Nigerian's average animal protein intake per head per day is estimated at $7.9 \mathrm{~g}$ as against $35 \mathrm{~g}$ recommended value by Food and Agricultural Organization (Mubarak et al., 2016). These low levels of animal protein intake create great concern as it affects the nutritional status of Nigerians. Hence, there is the need for sufficient supply of animal protein from energy rich animal products to satisfy the nutritional requirements for Nigerians.

Meat is one major source of animal protein largely composed of water, protein and fats which can make it susceptible to microbial contamination within short time leading to spoilage (Apata et al., 2013; Mgbemere et al., 2011). Meat is mostly eaten after it has been cooked or processed in a variety of ways such as sun drying; smoking and roasting with or without fortifications (Borch et al., 1996). In Nigeria meat products such as Tsire, Kilishi and Balangu are locally produced using one or more of these methods in order to meet the nutritional requirements of the teeming Nigerians (Egbebi, 2011).

Tsire is a popular Nigerian traditional processed ready-to-eat roasted stick meat product (Shamsuddeen, 2015). It is sold in public places, along roads, in hotels, parks, quarters and even offices (Falegan et al., 2017). It is prepared from boneless healthy animal flesh such as beef and mutton, spiced with peanut cake, salt, vegetable oil and other flavorings followed by roasting (Shamsuddeen, 2015). Consumption of these products has extended to other parts of African countries such as Ghana, Somali, Cameroun and Chad (Ahmadu and Ibrahim, 2013). 
BAJOPAS Volume 13 Number 1, June, 2020

However, evidence of quality control sticking to procedural hygiene by the handlers during preparation and retailing of these products is poorly documented. Tsire is of great safety risk because of the fact that there are erratic cases of gastroenteritis and symptoms of food infection after consumption (WHO, 2015). Food borne illnesses are one of the major health problems in developing and developed countries (Razavilar, 2010). According to the World Health Organization, WHO (2015), $0.07 \%$ death of the 600 million global burdens of Foodborne illnesses have been reported to be caused by bacteria, viruses, fungi and chemicals. In America $0.27 \%$ of the estimated 48 million affected people is hospitalized and about $0.0063 \%$ deaths are recorded each year (Scallan et al., 2011). More than 91 million people in Africa fall ill and $0.15 \%$ dies each year, making Africa the highest burden bearer of Foodborne diseases per population (WHO, 2015).

Application of a Hazard Analysis Critical Control Point (HACCP) at all stages of meat products preparation is essential in order to ensure its safety. Thus, according to the guidelines of good manufacturing practice, the level of total aerobic bacterial contamination of thermally processed meat products should not exceed $10^{4}\left(\mathrm{cfu} \mathrm{g}^{-1}\right)$. Enterobacteriaceae and faecal coliform contamination in meat products should be within the range of $10^{2}-10^{4}$ and $10-10^{3} \mathrm{cfu} \mathrm{g}^{-1}$, respectively (Shamsuddeen, 2015). The aim of the study is therefore, to assess the total viable bacterial counts of tsire marketed locally within Garko town, and to isolate and identify the organisms at the point of consumption with the intention of promoting public health and food hygiene habits in the Nigerian populace.

\section{MATERIALS AND METHODS Study Area and Population}

Garko is one of the existing 44 local government areas located in Kano south west zone of Kano state with its capital administrative headquarters in the Garko town. It has coordinates $11^{\circ} 39^{\prime} \mathrm{N}$ $8^{\circ} 54^{\prime} \mathrm{E}$, and an area of $450 \mathrm{~km}^{2}$. The projected population of Garko local Government was 225,300 according to the National Population Census report (2018). Garko is known for agricultural activities both farming and animal husbandry. It is popularly known for large scale rice production. Other food crops include sweet potatoes, cassava, onions, sorghum, millet and sugarcane. Cows, sheep and goats are major groups of animals reared by majority of the populace. Meat products processed, retailed and consumed in Garko include roasted meat (Balangu), dried roasted meat (Kilishi), stick meat (Tsire), hide and skin pepper soup (Ragadada) and minced fried meat (Danbunnama).

\section{Samples Collection}

Five samples of Tsire products were collected from 6 different identified locations within Garko town in a sterile foil paper and immediately analyzed for the presence of bacteria.

\section{Sample Preparation}

Sample preparation for the bacteriological analysis was carried out in accordance with the method described by Atlas (1997). Twenty five grams $(25 \mathrm{~g})$ of the sample was homogenized in $225 \mathrm{ml}$ peptone water using Kenwood blender machine to obtain a $10^{1}$ homogenate. The homogenate was thoroughly shaken and $1 \mathrm{ml}$ pipetted into test tubes containing $9 \mathrm{ml}$ of peptone water $\left(10^{2}\right)$. The test tubes were further serially diluted to $10^{5}$.

Total Aerobic Mesophilic Bacterial Count

Total Aerobic mesophilic bacterial count was determined using the method described by Abdullahi et al. (2004) where $1 \mathrm{ml}$ of inoculums from $10^{1}$ to $10^{5}$ dilutions were transferred into duplicate Petri dishes and labeled accordingly. This was followed by pouring aseptically about $15 \mathrm{ml}$ of molten nutrient agar. The culture was homogenized by gentle spinning of the plates and allowed to solidify. The plates were incubated at $37^{\circ} \mathrm{C}$ for 24 hours. Plates containing 30-300 colonies were counted. The number of colony forming units per gram of a sample (cfu/g) was obtained by multiplying the average colony number with the inverse of the dilution factor.

\section{Enumeration and Detection of Coliform bacteria}

Detection and enumeration of coliform was carried out according to method described by Atlas, (1977). A set of 9 test tubes each containing $9 \mathrm{ml}$ of lactose broth and an inverted Durham tubes were autoclaved to expel air and to sterilize. Similarly, $1 \mathrm{ml}$ from the diluents $10^{1}$ was transferred to the first 3 test tubes, followed by $1 \mathrm{ml}$ from the diluents $10^{2}$ to the second set of 3 test tubes and finally the third diluents $10^{3}$ to the $3^{\text {rd }}$ set of 3 test tubes. All the 9 test tubes were incubated at $37^{\circ} \mathrm{C}$ for 24 hours. Tubes that showed gas and acid production after 24 hours were recorded as positive for the presence of Coliform. Negative tubes were further reincubated for 24 hours. Positive tubes were recorded. Estimate of most probable number of Coliform per gram of sample (MPN/g) was determined by comparing the number of gas positive tubes with the most probable number table. 
BAJOPAS Volume 13 Number 1, June, 2020 Identification of Coliform

A loop full of inoculum from gas positive tubes was streaked on to Eosine methylene blue (EMB) agar plate and incubated at $37^{\circ} \mathrm{C}$ for $24 \mathrm{hrs}$. Colonies which formed bluish black color with green metallic sheen, and reddish colonies were isolated on agar slants. Those colonies showing metallic sheen on EMB were sub cultured into tubes of lactose broth and incubated at $45^{\circ} \mathrm{C}$. The tubes were observed after $24 \mathrm{hrs}$ for gas production. This is the completed test for fecal coliform. Gram stain and other biochemical tests such as Indole, Methyl red, Voges-Proskauer and Citrate Utilization tests (IMVIC), Coagulase and Catalase tests were carried out for the Identification and confirmation of isolates.

\section{Procedure for Indole Test}

Indole test was carried out by preparing a Tryptone broth drawn in to test tubes, sterilized by autoclaving, inoculated with loopful of suspension and incubated at $37^{\circ} \mathrm{C}$ for 24 hours. Three drops of xylene was added in tubes, shaken vigorously and kept for the separation of two layers. One millilitre of Kovac's reagent was added and the formation of pink colour ring indicates positive Indole test.

\section{Procedure for Methyl Red Test}

Methyl red test was carried out by preparing Glucose phosphate broth, dispensed in test tubes, sterilized, inoculated with test culture and incubated at $37^{\circ} \mathrm{C}$ for 24 hours. Five drops of methyl-red indicator was added to the medium for the formation of red colour.

\section{Procedure for Voges-Proskauer Test}

Voges-Proskauer test was carried out by inoculating tubes with the bacterial culture followed by incubation for 48 hours at $37^{\circ} \mathrm{C}$. Separate pipettes were used to pipette $1 \mathrm{ml}$ from each culture tube into clean separate tubes. Eighteen drops $(0.5 \mathrm{ml})$ of Barrit's solution A (a-naphthol) was added to each tube containing glucose phosphate broth followed by the addition of an equal amount of solution $B$ into the same tube. The tubes were shaken at 30 seconds interval. A positive reaction was indicated by the development of a pink color, which turns red in 1-2 hours, after vigorous shaking.

\section{Procedure for Citrate Utilization Test}

Citrate Utilization Test was carried out by distributing melted agar (Simmon Citrate Agar) in to test tubes followed by sterilization at $121.5^{\circ} \mathrm{C}$ for 15 minutes. The test tubes were afterward held in slanted position, inoculated with the given bacterial culture and incubated at $37^{\circ} \mathrm{C}$ for $24 \mathrm{hrs}$. Positive test was indicated by color change of the media from green to blue.

\section{RESULTS AND DISCUSSIONS}

The results of this study are presented in tables $1,2,3$ and 4. Among the sampling areas Kofar Kudu had the highest aerobic mesophilic bacteria counts $4.0 \times 10^{5} \mathrm{cfu} / \mathrm{g}$ followed by Rinji $2.72 \times 10^{5} \mathrm{cfu} / \mathrm{g}$, while Tosaro had the least Aerobic mesophilic bacteria counts of $1.02 \times 10^{5}$ $\mathrm{cfu} / \mathrm{g}$ as indicated in Table 1.Makwalla had the highest coliform count $68 \mathrm{MPN} / \mathrm{g}$ followed by Rinji $37 \mathrm{MPN} / \mathrm{g}$. Tsohuwar Kasuwa had the least coliform counts $8 \mathrm{MPN} / \mathrm{g}$, (Table 2). Result from table 1 shows variation in the microbial contents among the samples which suggest variation in their sources, poor handling procedures and contamination from the processing environment. High coliform count and their differences within sampling areas is an indication of poor microbiological quality of the product. Ndahi et al. (2013) reported microbial load to be a function of the handling personnel and the environment. The results indicated that the samples were contaminated with bacteria as the counts exceeded the minimum safety level $\left(10^{4} \mathrm{cfu} / \mathrm{g}\right)$ for members of the Enterobacteriaceae family. However, it might be a reflection of poor hygienic practices which may contribute to health hazard to the potential consumers. Similarly, Inusa and Sa'id (2017); Osimani et al. (2015) reported that, the initial microbial content of the raw material play significant role in influencing the final microbial load of the finished product. Isolation of members of the Enterobacteriaceae such as $E$. coli, Klebsiella pneumoniae, Salmonella and Shigella signifies danger to the public health. These organisms are capable of producing endotoxins which trigger high fevers in infected individuals, and the enterotoxins which colonize the small intestines and lead to extreme dehydration as a result of vomiting and diarrhea sometimes with severe and fatal outcomes (Amaeze et al., 2016). From the 16 isolated organisms $E$. coli had the highest isolation rate $6(37.5 \%)$ (Table 3), this suggest faecal contamination of the products. $E$. coli is a common flora in the gastrointestinal tract responsible for diarrhea and extra-intestinal infections (CDC, 2011). The result is in conformity with the findings of Ndahi et al. (2013) and Shamsuddeen (2009). Also presence of campylobacter might be due to cross contamination from raw meat to finished product (Tsire). Staphylococcus aureus is a normal flora of the skin, nasal, genital, mouth or anal area in both humans and animals without any symptom of an infection (Matthew et al., 2013). Isolation of $S$. aureus in these study concords with the findings of Lucretia et al. (2018) from Suya sold in Rivers State. 
BAJOPAS Volume 13 Number 1, June, 2020

It is also in agreement with the findings of Yousafzai et al. (2018); Onuorah et al. (2015) and Tijjani and Jumare (2014) from tsire samples in different countries. Presence of $S$. aureus in foods is most of the time an indication of poor human handling, poor environment, unhygienic utensils and equipments used during processing (Igene et al., 2016; Okonko et al., 2013). Infections caused by $S$. aureus are difficult to treat leading to long hospitalization with consequent economic loss (Udobi et al., 2013). These include soft tissue infections, pneumonia, hospital-acquired postoperative wound infections, Staphylococcal food poisoning, impetigo and cellulitis (Charlene et al., 2013). Samples obtained from Dausai and Kofar Kudu had the highest isolation rate $4(80 \%)$ (Table 4 ) probably because of the much commercial activities taking place in the area which can lead to environmental contamination.

Table 1: Total Aerobic Mesophilic Bacterial Count of Tsire sold in Garko Town

\begin{tabular}{lll}
\hline Sampling Area & APC cfu/g & Mean \pm STD \\
\hline Dausai & $2.20 \times 10^{5}$ & $110000 \pm 14142.14$ \\
Kofar Kudu & $4.00 \times 10^{5}$ & $133333.3 \pm 23094.01$ \\
Makwalla & $1.30 \times 10^{5}$ & $32500 \pm 7187.953$ \\
Rinji & $2.72 \times 10^{5}$ & $90666.67 \pm 94769.90$ \\
Tosaro & $1.02 \times 10^{5}$ & $51000 \pm 15556.35$ \\
Tsohuwar Kasuwa & $1.75 \times 10^{5}$ & $35000 \pm 11357.82$ \\
\hline
\end{tabular}

Key: APC: Aerobic Mesophilic Counts

STD: Standard Deviation

Table 2: Total Coliform Count of Tsire sold in Garko Town

\begin{tabular}{lcc}
\hline \multicolumn{1}{c}{ Sampling Area } & TCC MPN/g & Mean \pm STD \\
\hline Dausai & 20 & $6.67 \pm 2.5166$ \\
Kofar Kudu & 32 & $16.00 \pm 5.6569$ \\
Makwalla & 68 & $13.60 \pm 8.7062$ \\
Rinji & 37 & $9.25 \pm 4.7871$ \\
Tosaro & 10 & $5.00 \pm 2.8284$ \\
Tsohuwar Kasuwa & 8 & $4.00 \pm 0.0000$ \\
\hline
\end{tabular}

Table 3: Organisms Isolated from Tsire Sold in Garko

\begin{tabular}{lcl}
\hline Isolated Organism & Frequency & Percentage (\%) \\
\hline Campylobacter & 2 & 06.66 \\
Escherichia coli & 6 & 20.00 \\
Klebsiella pneumoniae & 2 & 06.66 \\
Salmonella species & 1 & 03.33 \\
Shigella & 3 & 10.00 \\
Staphylococcus aureus & 2 & 06.66 \\
Total & 16 & \\
\hline
\end{tabular}

Table 4: Distribution of Organisms within Sampling Area

\begin{tabular}{lcc}
\hline \multicolumn{1}{c}{ Sampling Area } & No. Isolated & Percentage (\%) \\
\hline Dausai & 4 & 80 \\
Kofar Kudu & 4 & 80 \\
Makwalla & 2 & 40 \\
Rinji & 3 & 60 \\
Tosaro & 2 & 40 \\
Tsohuwar Kasuwa & 1 & 20 \\
Total & 16 & \\
\hline
\end{tabular}

\section{CONCLUSION}

Results indicated $4.00 \times 10^{5} \mathrm{CFU} / \mathrm{g}$ as the highest APCs count; while $68 \mathrm{MPN} / \mathrm{g}$ was the highest TCCs from the 30 samples analyzed. Among the isolates, $E$. coli has the highest isolation rate of $6(20 \%)$. Dausai and Kofar kudu were having the highest bacteria count of $4(80 \%)$, each, indicating higher contamination in those locations. 
BAJOPAS Volume 13 Number 1, June, 2020 RECOMMENDATIONS

The following recommendations are tenable:

1. Hygienic practices at all stages of production should be improved to safe guard the consumers against potential health hazard.

2. Monitoring of microbiological contamination of Tsire during preparations, packaging and marketing is essential to ensure product of good microbiological quality for consumers' health.

\section{REFERENCES}

Abdullahi, I. O., Umoh, V. J. and Galadima, M. (2004). Hazards Associated with Kilishi Preparations in Zaria. Nigerian Journal of Microbiology, 18 (1-2): $339-345$.

Ahmadu, J. and Ibrahim E. J., (2013): Determinants of Revenue in Suya Production in BeninCity, Edo State, Nigeria. Nigerian journal of agriculture, food and environment.9(3):1-5

Amaeze, N. Aboh, M. Itohan, A. Felix, E. Olatunji, T. and Oladosu, P. (2016) Microbial Profile, Antibiotic Sensitivity and Heat Resistance of Bacterial Isolates from Commercial Roasted Beef (Suya) in Abuja, Nigeria. JOPAT, 15(2): $22-30$.

Apata, E.S., Kuku1, I.A., Apata, O.C. and Adeyemi, K.O. (2013). Evaluation of Suya(Tsire) - An Intermediate Moisture Meat Product in Ogun State, Nigeria. J. Food Res 2 (1): 87.

Atlas, R. M. (1997) Principles of Microbiology Second Edition. C. Brown Publishers. Pp 802-803.

Borch, E. Kant-Muermans, M. L., Blixt, Y. (1996) Bacterial Spoilage of Meat and Cured Meat Products. Int $\mathrm{J}$ Food Microbiol .33(1): 103-20.

Centre for Disease Control, CDC (2011). "Escherichia coli 0157:H7" Division of Bacterial and Mycotic Diseasesht://www.cdc.gov/nczved/divisi ons/dfbmd/diseases/ecoli_0157h7/.

Charlene, R. J., Johnnie, A. D., and John, B. B., (2013) Prevalence and Characterization of Methicillin-Resistant Staphylococcus aureus Isolates from Retail Meat and Humans in Georgia. American society for Microbiology. J. of clinical microbiology. 12(1):123-6 doi:10.1128/JCM.0316612JCM.03166-12

Egbebi, A.O and Seidu, K., T. (2011). Microbiological Evaluation of Suya (dried smoked

meat) Sold in Ado and Akure, South West Nigeria.European Journal of Experinmental Biology, 1(4):1-5
3. Government should establish regulatory bodies responsible for inculcating hygiene habits to the local producers and vendors in order to prevent instant, cross and post processing contaminations by microbial pathogens.

4. Awareness and sensitization of local food producers about good hygienic practices in food handling and processing.

Falegan, C, R., Akoja, S. D., and Oyarekua, M. A., (2017) Microbiological Assessment of Suya (Sliced Roasted Beef) in Ado-Ekiti Metropolis, Ekiti State, Nigeria. MOJ Biology andMedicine.

Fonkem, D., N. Tanya, V., N. and Ebangi, A., L. (2010). Effect of Season on the Microbiological Quality of Kilishi, a Traditional Cameroonian Dried Beef Product. Tropicultura, 28(1): 10-15.

Food and Agricultural Organization of the United Nations (F A O, 1979). Manual of food quality control 4. Microbiological analysis.

Food and Agriculture Organisation of the United Nation (FAO), 2019. Nigeria at a glance.

Igene J.O., Uwadia, O.E., Ebabhamiegbebho, P.A. and Evivie, S.E., (2016) Shelf life Stability Studies of University of Benin (UNIBEN) Proff's Kilishi Product Asian Journal of Science and Technology 7(1): 2268-2274.

Inusa, S. K. and Said, I. S. (2017) Evaluation of the Chemical and Microbiological Properties Of Kilishi Sold in Kano Metropolis. Journal of Dry land Agriculture, 3 (1): $59-69$.

Lucretia, I. B, Patience, C. Obinna-Echem, Sophia, C. A. (2018) Microbiological quality andantibiotic sensitivity of potential pathogens isolated from meat product (Suya) sold in Rivers State University and its environs. International Journal of Biotechnology and Food Science, 6(4): 67-76.

Matthew, E., Drosos, E., John, L. and Ioanna, P. (2013) MRSA in Africa: Filling the Global Map of Antimicrobial Resistance PLOS One. 8(7): e68024 doi: 10.1371/journal.pone.0068024

Mgbemere, V.N., Akpapunam, M. A. and Igene, J. O., (2011). Effect of Groundnut FlourSubstitution on Yield, Quality and Storage Stability of Kilishi - a Nigerian Indigenous Dried Meat Product. African Journal of Food, Agriculture, Nutrition and Development, $\quad \mathbf{1 1}(2)$ : 4718-4738. 
BAJOPAS Volume 13 Number 1, June, 2020

Mubarak, A. A., Azeez, M. L., Amos A. O., Opeyemi, O. O. (2016) Assessment of Animal Protein Consumption and Food Security Among Rural Households in Kwara State, Nigeria American Journal of Business and Society, 1(4): 233245.

Ndahi, M., D. Kwaga, J., K. P. Bello, M. Kabir J., V. Umoh, .J. Yakubu, S., E. and Nok, A., J. (2013) Prevalence and Antimicrobial Susceptibility of Listeria Monocytogenes and Methicillin-Resistant Staphylococcus aureus Strains from Raw Meat and Meat Products in Zaria, Nigeria. Applied Journal of Microbiology, 58(3):262-9.

Okonko, I.O., Odu, N.N. and Igboh, I.E. (2013). Microbiological Analysis of Kilishi Sold In Port Harcourt, Nigeria. New York Science Journal, 6 (7):37-43.

Osimani, A., Aquilanti, L. and Clementi, F. (2015) Microbiological Quality of Meatbased Meals and Operation of Control Systems within a Food Service Environment. International Food Research Journal 22(4): 1692-1698.

Onuorah, S. Obika, I. Odibo, F. Orji, M. (2015)An Assessment of the Bacteriological Quality of Tsire-Suya (Grilled Beef) sold in Awka, Nigeria. American. J. Life. Sci. Res. 3(4):287292.

Razavilar, V, Khandaghi, J. Barzgari, A. (2010); Isolation of Eschericia coli 0157:H7 from manure fertilized farms and raw vegetables grown on it, in Tabriz city in
Iran. African Journal of Microbiology Research, 4(9): 891-895.

Scallan, E. Hoekstra, R. M. Angulo, F. J.Tauxe, R. V, Widdowson, M. Roy, S. L et al., (2011).Food borne illness acquired in the United States- Major Pathogens. Emerg. Infec Dis, 17(1): 7-15.

Shamsuddeen U (2009). Microbiological quality of spice used in the production of Kilishi a traditionally dried and grilled meat product. Bayero Journal of Pure andApplied Sciences, 2(2): 66-69.

Shamsuddeen, U. (2015) Microbiological Hazard and Critical control point Analysis of Dried and Minced Meat Snacks Produced in Kano Nigeria. Lambert Academic Publishing; Pp 1-36.

Tijani, O.and Jumare, S. (2014). Microblological Quality Assessment of Meat

Sold in KauraNamoda. International Conference on Earth, Environment and Life sciences (EELS) Dubai (UAE).

Udobi, C. E., Obajuluwa, A. F., and Onaolapo, J. A., (2013) Prevalence and Antibiotic Resistance Pattern of MethicillinResistant Staphylococcus aureus from an Orthopaedic Hospital in Nigeria BioMed Research International; 26(6); 6-7.

WHO, 2015 Foodborne diseases in the WHO African Region.

Yousafzai HA, Rind R, Khan MA, Abro SH, Korejo NA, Ejaz M, Kabir A, Shahid M, Memon S. (2019). Microbiological Contamination of Cattle and Meat in Peshawar, Pakistan. J. Anim. Health Prod. 7(1): 1116. 


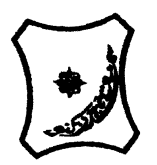

Bayero Journal of Pure and Applied Sciences, 13(1); 40 - 45

Received: September, 2019

Accepted: April, 2020

ISSN $2006-6996$

\title{
BACTERIOLOGICAL QUALITY OF STICK MEAT (Tsire) SOLD IN GARKO LOCAL GOVERNMENT AREA OF KANO STATE, NIGERIA
}

\author{
$*^{1}$ Dahiru A. T. and ${ }^{2}$ Maigari A. K. \\ ${ }^{1}$ Department of Hospitality Management, School of Technology, Kano State Polytechnic, PMB 3348, \\ Kano Nigeria. \\ ${ }^{2}$ Departmnt of Biological Sciences, Bayero University, Kano \\ Corresponding Author: dturajo61@gmail.com; GSM: 08087508262.
}

ABSTRACT

Stick meat, locally called Tsire in Hausa Language, is a significant portion of the diet of a large active population of Northern Nigeria. However, because of the handling and processing methods by the manufacturers as well as the hawking system of stick meat, the meat product may be exposed to both pre- and post-processed product contamination, and thus may poses danger to public health. Therefore, considering the role of Tsire in improving nutrition and increase household income to the populace, the need to improve the processing, distribution and overall quality of the product is simply indispensable. A total of 30 samples (5 samples from each of the 6 sampling points) of Tsire were collected randomly in Garko Town. Aerobic plate counts (APCs) and Total coliform counts (TCCS) of Tsire samples were determined using standard microbiological methods. APCs ranged from $1.02 \times 10^{5}$ to $4.00 \times 10^{5} \mathrm{CFU} / \mathrm{g}$; while TCCs ranged from $8 \mathrm{MPN} / \mathrm{g}$ to $68 \mathrm{MPN} / \mathrm{g}$. From the 30 samples screened, 16(53.33\%) bacteria namely, Campylobacter 2(6.66\%), Escherichia coli 6(20\%), Klebsiella pneumoniae 2(6.66\%), Salmonella spp. 1(3.33\%), Shigella 3(10\%) and Staphylococcus aureus 2(6.66\%) were detected. $E$. coli has the highest isolation rate of 6(20\%), while Salmonella spp. had the least frequency of 1(3.33\%). The distribution of isolated organisms within the study area were as follows: Dausai, 4(80\%), Kofar kudu, 4(80\%), Makwalla, 2(40\%), Rinji, 3(60\%), Tosaro, 2(40\%), and Tsohuwar Kasuwa, 1(20\%). The results have indicated that the Tsire was contaminated with bacteria thus exposing the product to fast deterioration, spoilage and also a vehicle for food borne illness, suggesting for adequate hygienic practices at all the stages, prior to consumption, to ensure safety of the meat product.

Key words: APCs, TCCs, Contamination, Microorganisms, Garko

\section{INTRODUCTION}

Nigeria is one of the developing nations with inadequate food supply and most often deficient in protein content (FAO, 2019). Nigerian's average animal protein intake per head per day is estimated at $7.9 \mathrm{~g}$ as against $35 \mathrm{~g}$ recommended value by Food and Agricultural Organization (Mubarak et al., 2016). These low levels of animal protein intake create great concern as it affects the nutritional status of Nigerians. Hence, there is the need for sufficient supply of animal protein from energy rich animal products to satisfy the nutritional requirements for Nigerians.

Meat is one major source of animal protein largely composed of water, protein and fats which can make it susceptible to microbial contamination within short time leading to spoilage (Apata et al., 2013; Mgbemere et al., 2011). Meat is mostly eaten after it has been cooked or processed in a variety of ways such as sun drying; smoking and roasting with or without fortifications (Borch et al., 1996). In Nigeria meat products such as Tsire, Kilishi and Balangu are locally produced using one or more of these methods in order to meet the nutritional requirements of the teeming Nigerians (Egbebi, 2011).

Tsire is a popular Nigerian traditional processed ready-to-eat roasted stick meat product (Shamsuddeen, 2015). It is sold in public places, along roads, in hotels, parks, quarters and even offices (Falegan et al., 2017). It is prepared from boneless healthy animal flesh such as beef and mutton, spiced with peanut cake, salt, vegetable oil and other flavorings followed by roasting (Shamsuddeen, 2015). Consumption of these products has extended to other parts of African countries such as Ghana, Somali, Cameroun and Chad (Ahmadu and Ibrahim, 2013). 
BAJOPAS Volume 13 Number 1, June, 2020

However, evidence of quality control sticking to procedural hygiene by the handlers during preparation and retailing of these products is poorly documented. Tsire is of great safety risk because of the fact that there are erratic cases of gastroenteritis and symptoms of food infection after consumption (WHO, 2015). Food borne illnesses are one of the major health problems in developing and developed countries (Razavilar, 2010). According to the World Health Organization, WHO (2015), $0.07 \%$ death of the 600 million global burdens of Foodborne illnesses have been reported to be caused by bacteria, viruses, fungi and chemicals. In America $0.27 \%$ of the estimated 48 million affected people is hospitalized and about $0.0063 \%$ deaths are recorded each year (Scallan et al., 2011). More than 91 million people in Africa fall ill and $0.15 \%$ dies each year, making Africa the highest burden bearer of Foodborne diseases per population (WHO, 2015).

Application of a Hazard Analysis Critical Control Point (HACCP) at all stages of meat products preparation is essential in order to ensure its safety. Thus, according to the guidelines of good manufacturing practice, the level of total aerobic bacterial contamination of thermally processed meat products should not exceed $10^{4}\left(\mathrm{cfu} \mathrm{g}^{-1}\right)$. Enterobacteriaceae and faecal coliform contamination in meat products should be within the range of $10^{2}-10^{4}$ and $10-10^{3} \mathrm{cfu} \mathrm{g}^{-1}$, respectively (Shamsuddeen, 2015). The aim of the study is therefore, to assess the total viable bacterial counts of tsire marketed locally within Garko town, and to isolate and identify the organisms at the point of consumption with the intention of promoting public health and food hygiene habits in the Nigerian populace.

\section{MATERIALS AND METHODS Study Area and Population}

Garko is one of the existing 44 local government areas located in Kano south west zone of Kano state with its capital administrative headquarters in the Garko town. It has coordinates $11^{\circ} 39^{\prime} \mathrm{N}$ $8^{\circ} 54^{\prime} \mathrm{E}$, and an area of $450 \mathrm{~km}^{2}$. The projected population of Garko local Government was 225,300 according to the National Population Census report (2018). Garko is known for agricultural activities both farming and animal husbandry. It is popularly known for large scale rice production. Other food crops include sweet potatoes, cassava, onions, sorghum, millet and sugarcane. Cows, sheep and goats are major groups of animals reared by majority of the populace. Meat products processed, retailed and consumed in Garko include roasted meat (Balangu), dried roasted meat (Kilishi), stick meat (Tsire), hide and skin pepper soup (Ragadada) and minced fried meat (Danbunnama).

\section{Samples Collection}

Five samples of Tsire products were collected from 6 different identified locations within Garko town in a sterile foil paper and immediately analyzed for the presence of bacteria.

\section{Sample Preparation}

Sample preparation for the bacteriological analysis was carried out in accordance with the method described by Atlas (1997). Twenty five grams $(25 \mathrm{~g})$ of the sample was homogenized in $225 \mathrm{ml}$ peptone water using Kenwood blender machine to obtain a $10^{1}$ homogenate. The homogenate was thoroughly shaken and $1 \mathrm{ml}$ pipetted into test tubes containing $9 \mathrm{ml}$ of peptone water $\left(10^{2}\right)$. The test tubes were further serially diluted to $10^{5}$.

Total Aerobic Mesophilic Bacterial Count

Total Aerobic mesophilic bacterial count was determined using the method described by Abdullahi et al. (2004) where $1 \mathrm{ml}$ of inoculums from $10^{1}$ to $10^{5}$ dilutions were transferred into duplicate Petri dishes and labeled accordingly. This was followed by pouring aseptically about $15 \mathrm{ml}$ of molten nutrient agar. The culture was homogenized by gentle spinning of the plates and allowed to solidify. The plates were incubated at $37^{\circ} \mathrm{C}$ for 24 hours. Plates containing 30-300 colonies were counted. The number of colony forming units per gram of a sample (cfu/g) was obtained by multiplying the average colony number with the inverse of the dilution factor.

\section{Enumeration and Detection of Coliform bacteria}

Detection and enumeration of coliform was carried out according to method described by Atlas, (1977). A set of 9 test tubes each containing $9 \mathrm{ml}$ of lactose broth and an inverted Durham tubes were autoclaved to expel air and to sterilize. Similarly, $1 \mathrm{ml}$ from the diluents $10^{1}$ was transferred to the first 3 test tubes, followed by $1 \mathrm{ml}$ from the diluents $10^{2}$ to the second set of 3 test tubes and finally the third diluents $10^{3}$ to the $3^{\text {rd }}$ set of 3 test tubes. All the 9 test tubes were incubated at $37^{\circ} \mathrm{C}$ for 24 hours. Tubes that showed gas and acid production after 24 hours were recorded as positive for the presence of Coliform. Negative tubes were further reincubated for 24 hours. Positive tubes were recorded. Estimate of most probable number of Coliform per gram of sample (MPN/g) was determined by comparing the number of gas positive tubes with the most probable number table. 
BAJOPAS Volume 13 Number 1, June, 2020 Identification of Coliform

A loop full of inoculum from gas positive tubes was streaked on to Eosine methylene blue (EMB) agar plate and incubated at $37^{\circ} \mathrm{C}$ for $24 \mathrm{hrs}$. Colonies which formed bluish black color with green metallic sheen, and reddish colonies were isolated on agar slants. Those colonies showing metallic sheen on EMB were sub cultured into tubes of lactose broth and incubated at $45^{\circ} \mathrm{C}$. The tubes were observed after $24 \mathrm{hrs}$ for gas production. This is the completed test for fecal coliform. Gram stain and other biochemical tests such as Indole, Methyl red, Voges-Proskauer and Citrate Utilization tests (IMVIC), Coagulase and Catalase tests were carried out for the Identification and confirmation of isolates.

\section{Procedure for Indole Test}

Indole test was carried out by preparing a Tryptone broth drawn in to test tubes, sterilized by autoclaving, inoculated with loopful of suspension and incubated at $37^{\circ} \mathrm{C}$ for 24 hours. Three drops of xylene was added in tubes, shaken vigorously and kept for the separation of two layers. One millilitre of Kovac's reagent was added and the formation of pink colour ring indicates positive Indole test.

\section{Procedure for Methyl Red Test}

Methyl red test was carried out by preparing Glucose phosphate broth, dispensed in test tubes, sterilized, inoculated with test culture and incubated at $37^{\circ} \mathrm{C}$ for 24 hours. Five drops of methyl-red indicator was added to the medium for the formation of red colour.

\section{Procedure for Voges-Proskauer Test}

Voges-Proskauer test was carried out by inoculating tubes with the bacterial culture followed by incubation for 48 hours at $37^{\circ} \mathrm{C}$. Separate pipettes were used to pipette $1 \mathrm{ml}$ from each culture tube into clean separate tubes. Eighteen drops $(0.5 \mathrm{ml})$ of Barrit's solution A (a-naphthol) was added to each tube containing glucose phosphate broth followed by the addition of an equal amount of solution $B$ into the same tube. The tubes were shaken at 30 seconds interval. A positive reaction was indicated by the development of a pink color, which turns red in 1-2 hours, after vigorous shaking.

\section{Procedure for Citrate Utilization Test}

Citrate Utilization Test was carried out by distributing melted agar (Simmon Citrate Agar) in to test tubes followed by sterilization at $121.5^{\circ} \mathrm{C}$ for 15 minutes. The test tubes were afterward held in slanted position, inoculated with the given bacterial culture and incubated at $37^{\circ} \mathrm{C}$ for $24 \mathrm{hrs}$. Positive test was indicated by color change of the media from green to blue.

\section{RESULTS AND DISCUSSIONS}

The results of this study are presented in tables $1,2,3$ and 4. Among the sampling areas Kofar Kudu had the highest aerobic mesophilic bacteria counts $4.0 \times 10^{5} \mathrm{cfu} / \mathrm{g}$ followed by Rinji $2.72 \times 10^{5} \mathrm{cfu} / \mathrm{g}$, while Tosaro had the least Aerobic mesophilic bacteria counts of $1.02 \times 10^{5}$ $\mathrm{cfu} / \mathrm{g}$ as indicated in Table 1.Makwalla had the highest coliform count $68 \mathrm{MPN} / \mathrm{g}$ followed by Rinji $37 \mathrm{MPN} / \mathrm{g}$. Tsohuwar Kasuwa had the least coliform counts $8 \mathrm{MPN} / \mathrm{g}$, (Table 2). Result from table 1 shows variation in the microbial contents among the samples which suggest variation in their sources, poor handling procedures and contamination from the processing environment. High coliform count and their differences within sampling areas is an indication of poor microbiological quality of the product. Ndahi et al. (2013) reported microbial load to be a function of the handling personnel and the environment. The results indicated that the samples were contaminated with bacteria as the counts exceeded the minimum safety level $\left(10^{4} \mathrm{cfu} / \mathrm{g}\right)$ for members of the Enterobacteriaceae family. However, it might be a reflection of poor hygienic practices which may contribute to health hazard to the potential consumers. Similarly, Inusa and Sa'id (2017); Osimani et al. (2015) reported that, the initial microbial content of the raw material play significant role in influencing the final microbial load of the finished product. Isolation of members of the Enterobacteriaceae such as $E$. coli, Klebsiella pneumoniae, Salmonella and Shigella signifies danger to the public health. These organisms are capable of producing endotoxins which trigger high fevers in infected individuals, and the enterotoxins which colonize the small intestines and lead to extreme dehydration as a result of vomiting and diarrhea sometimes with severe and fatal outcomes (Amaeze et al., 2016). From the 16 isolated organisms $E$. coli had the highest isolation rate $6(37.5 \%)$ (Table 3), this suggest faecal contamination of the products. $E$. coli is a common flora in the gastrointestinal tract responsible for diarrhea and extra-intestinal infections (CDC, 2011). The result is in conformity with the findings of Ndahi et al. (2013) and Shamsuddeen (2009). Also presence of campylobacter might be due to cross contamination from raw meat to finished product (Tsire). Staphylococcus aureus is a normal flora of the skin, nasal, genital, mouth or anal area in both humans and animals without any symptom of an infection (Matthew et al., 2013). Isolation of $S$. aureus in these study concords with the findings of Lucretia et al. (2018) from Suya sold in Rivers State. 
BAJOPAS Volume 13 Number 1, June, 2020

It is also in agreement with the findings of Yousafzai et al. (2018); Onuorah et al. (2015) and Tijjani and Jumare (2014) from tsire samples in different countries. Presence of $S$. aureus in foods is most of the time an indication of poor human handling, poor environment, unhygienic utensils and equipments used during processing (Igene et al., 2016; Okonko et al., 2013). Infections caused by $S$. aureus are difficult to treat leading to long hospitalization with consequent economic loss (Udobi et al., 2013). These include soft tissue infections, pneumonia, hospital-acquired postoperative wound infections, Staphylococcal food poisoning, impetigo and cellulitis (Charlene et al., 2013). Samples obtained from Dausai and Kofar Kudu had the highest isolation rate $4(80 \%)$ (Table 4 ) probably because of the much commercial activities taking place in the area which can lead to environmental contamination.

Table 1: Total Aerobic Mesophilic Bacterial Count of Tsire sold in Garko Town

\begin{tabular}{lll}
\hline Sampling Area & APC cfu/g & Mean \pm STD \\
\hline Dausai & $2.20 \times 10^{5}$ & $110000 \pm 14142.14$ \\
Kofar Kudu & $4.00 \times 10^{5}$ & $133333.3 \pm 23094.01$ \\
Makwalla & $1.30 \times 10^{5}$ & $32500 \pm 7187.953$ \\
Rinji & $2.72 \times 10^{5}$ & $90666.67 \pm 94769.90$ \\
Tosaro & $1.02 \times 10^{5}$ & $51000 \pm 15556.35$ \\
Tsohuwar Kasuwa & $1.75 \times 10^{5}$ & $35000 \pm 11357.82$ \\
\hline
\end{tabular}

Key: APC: Aerobic Mesophilic Counts

STD: Standard Deviation

Table 2: Total Coliform Count of Tsire sold in Garko Town

\begin{tabular}{lcc}
\hline \multicolumn{1}{c}{ Sampling Area } & TCC MPN/g & Mean \pm STD \\
\hline Dausai & 20 & $6.67 \pm 2.5166$ \\
Kofar Kudu & 32 & $16.00 \pm 5.6569$ \\
Makwalla & 68 & $13.60 \pm 8.7062$ \\
Rinji & 37 & $9.25 \pm 4.7871$ \\
Tosaro & 10 & $5.00 \pm 2.8284$ \\
Tsohuwar Kasuwa & 8 & $4.00 \pm 0.0000$ \\
\hline
\end{tabular}

Table 3: Organisms Isolated from Tsire Sold in Garko

\begin{tabular}{lcl}
\hline Isolated Organism & Frequency & Percentage (\%) \\
\hline Campylobacter & 2 & 06.66 \\
Escherichia coli & 6 & 20.00 \\
Klebsiella pneumoniae & 2 & 06.66 \\
Salmonella species & 1 & 03.33 \\
Shigella & 3 & 10.00 \\
Staphylococcus aureus & 2 & 06.66 \\
Total & 16 & \\
\hline
\end{tabular}

Table 4: Distribution of Organisms within Sampling Area

\begin{tabular}{lcc}
\hline \multicolumn{1}{c}{ Sampling Area } & No. Isolated & Percentage (\%) \\
\hline Dausai & 4 & 80 \\
Kofar Kudu & 4 & 80 \\
Makwalla & 2 & 40 \\
Rinji & 3 & 60 \\
Tosaro & 2 & 40 \\
Tsohuwar Kasuwa & 1 & 20 \\
Total & 16 & \\
\hline
\end{tabular}

\section{CONCLUSION}

Results indicated $4.00 \times 10^{5} \mathrm{CFU} / \mathrm{g}$ as the highest APCs count; while $68 \mathrm{MPN} / \mathrm{g}$ was the highest TCCs from the 30 samples analyzed. Among the isolates, $E$. coli has the highest isolation rate of $6(20 \%)$. Dausai and Kofar kudu were having the highest bacteria count of $4(80 \%)$, each, indicating higher contamination in those locations. 
BAJOPAS Volume 13 Number 1, June, 2020 RECOMMENDATIONS

The following recommendations are tenable:

1. Hygienic practices at all stages of production should be improved to safe guard the consumers against potential health hazard.

2. Monitoring of microbiological contamination of Tsire during preparations, packaging and marketing is essential to ensure product of good microbiological quality for consumers' health.

\section{REFERENCES}

Abdullahi, I. O., Umoh, V. J. and Galadima, M. (2004). Hazards Associated with Kilishi Preparations in Zaria. Nigerian Journal of Microbiology, 18 (1-2): $339-345$.

Ahmadu, J. and Ibrahim E. J., (2013): Determinants of Revenue in Suya Production in BeninCity, Edo State, Nigeria. Nigerian journal of agriculture, food and environment.9(3):1-5

Amaeze, N. Aboh, M. Itohan, A. Felix, E. Olatunji, T. and Oladosu, P. (2016) Microbial Profile, Antibiotic Sensitivity and Heat Resistance of Bacterial Isolates from Commercial Roasted Beef (Suya) in Abuja, Nigeria. JOPAT, 15(2): $22-30$.

Apata, E.S., Kuku1, I.A., Apata, O.C. and Adeyemi, K.O. (2013). Evaluation of Suya(Tsire) - An Intermediate Moisture Meat Product in Ogun State, Nigeria. J. Food Res 2 (1): 87.

Atlas, R. M. (1997) Principles of Microbiology Second Edition. C. Brown Publishers. Pp 802-803.

Borch, E. Kant-Muermans, M. L., Blixt, Y. (1996) Bacterial Spoilage of Meat and Cured Meat Products. Int $\mathrm{J}$ Food Microbiol .33(1): 103-20.

Centre for Disease Control, CDC (2011). "Escherichia coli 0157:H7" Division of Bacterial and Mycotic Diseasesht://www.cdc.gov/nczved/divisi ons/dfbmd/diseases/ecoli_0157h7/.

Charlene, R. J., Johnnie, A. D., and John, B. B., (2013) Prevalence and Characterization of Methicillin-Resistant Staphylococcus aureus Isolates from Retail Meat and Humans in Georgia. American society for Microbiology. J. of clinical microbiology. 12(1):123-6 doi:10.1128/JCM.0316612JCM.03166-12

Egbebi, A.O and Seidu, K., T. (2011). Microbiological Evaluation of Suya (dried smoked

meat) Sold in Ado and Akure, South West Nigeria.European Journal of Experinmental Biology, 1(4):1-5
3. Government should establish regulatory bodies responsible for inculcating hygiene habits to the local producers and vendors in order to prevent instant, cross and post processing contaminations by microbial pathogens.

4. Awareness and sensitization of local food producers about good hygienic practices in food handling and processing.

Falegan, C, R., Akoja, S. D., and Oyarekua, M. A., (2017) Microbiological Assessment of Suya (Sliced Roasted Beef) in Ado-Ekiti Metropolis, Ekiti State, Nigeria. MOJ Biology andMedicine.

Fonkem, D., N. Tanya, V., N. and Ebangi, A., L. (2010). Effect of Season on the Microbiological Quality of Kilishi, a Traditional Cameroonian Dried Beef Product. Tropicultura, 28(1): 10-15.

Food and Agricultural Organization of the United Nations (F A O, 1979). Manual of food quality control 4. Microbiological analysis.

Food and Agriculture Organisation of the United Nation (FAO), 2019. Nigeria at a glance.

Igene J.O., Uwadia, O.E., Ebabhamiegbebho, P.A. and Evivie, S.E., (2016) Shelf life Stability Studies of University of Benin (UNIBEN) Proff's Kilishi Product Asian Journal of Science and Technology 7(1): 2268-2274.

Inusa, S. K. and Said, I. S. (2017) Evaluation of the Chemical and Microbiological Properties Of Kilishi Sold in Kano Metropolis. Journal of Dry land Agriculture, 3 (1): $59-69$.

Lucretia, I. B, Patience, C. Obinna-Echem, Sophia, C. A. (2018) Microbiological quality andantibiotic sensitivity of potential pathogens isolated from meat product (Suya) sold in Rivers State University and its environs. International Journal of Biotechnology and Food Science, 6(4): 67-76.

Matthew, E., Drosos, E., John, L. and Ioanna, P. (2013) MRSA in Africa: Filling the Global Map of Antimicrobial Resistance PLOS One. 8(7): e68024 doi: 10.1371/journal.pone.0068024

Mgbemere, V.N., Akpapunam, M. A. and Igene, J. O., (2011). Effect of Groundnut FlourSubstitution on Yield, Quality and Storage Stability of Kilishi - a Nigerian Indigenous Dried Meat Product. African Journal of Food, Agriculture, Nutrition and Development, $\quad \mathbf{1 1}(2)$ : 4718-4738. 
BAJOPAS Volume 13 Number 1, June, 2020

Mubarak, A. A., Azeez, M. L., Amos A. O., Opeyemi, O. O. (2016) Assessment of Animal Protein Consumption and Food Security Among Rural Households in Kwara State, Nigeria American Journal of Business and Society, 1(4): 233245.

Ndahi, M., D. Kwaga, J., K. P. Bello, M. Kabir J., V. Umoh, .J. Yakubu, S., E. and Nok, A., J. (2013) Prevalence and Antimicrobial Susceptibility of Listeria Monocytogenes and Methicillin-Resistant Staphylococcus aureus Strains from Raw Meat and Meat Products in Zaria, Nigeria. Applied Journal of Microbiology, 58(3):262-9.

Okonko, I.O., Odu, N.N. and Igboh, I.E. (2013). Microbiological Analysis of Kilishi Sold In Port Harcourt, Nigeria. New York Science Journal, 6 (7):37-43.

Osimani, A., Aquilanti, L. and Clementi, F. (2015) Microbiological Quality of Meatbased Meals and Operation of Control Systems within a Food Service Environment. International Food Research Journal 22(4): 1692-1698.

Onuorah, S. Obika, I. Odibo, F. Orji, M. (2015)An Assessment of the Bacteriological Quality of Tsire-Suya (Grilled Beef) sold in Awka, Nigeria. American. J. Life. Sci. Res. 3(4):287292.

Razavilar, V, Khandaghi, J. Barzgari, A. (2010); Isolation of Eschericia coli 0157:H7 from manure fertilized farms and raw vegetables grown on it, in Tabriz city in
Iran. African Journal of Microbiology Research, 4(9): 891-895.

Scallan, E. Hoekstra, R. M. Angulo, F. J.Tauxe, R. V, Widdowson, M. Roy, S. L et al., (2011).Food borne illness acquired in the United States- Major Pathogens. Emerg. Infec Dis, 17(1): 7-15.

Shamsuddeen U (2009). Microbiological quality of spice used in the production of Kilishi a traditionally dried and grilled meat product. Bayero Journal of Pure andApplied Sciences, 2(2): 66-69.

Shamsuddeen, U. (2015) Microbiological Hazard and Critical control point Analysis of Dried and Minced Meat Snacks Produced in Kano Nigeria. Lambert Academic Publishing; Pp 1-36.

Tijani, O.and Jumare, S. (2014). Microblological Quality Assessment of Meat

Sold in KauraNamoda. International Conference on Earth, Environment and Life sciences (EELS) Dubai (UAE).

Udobi, C. E., Obajuluwa, A. F., and Onaolapo, J. A., (2013) Prevalence and Antibiotic Resistance Pattern of MethicillinResistant Staphylococcus aureus from an Orthopaedic Hospital in Nigeria BioMed Research International; 26(6); 6-7.

WHO, 2015 Foodborne diseases in the WHO African Region.

Yousafzai HA, Rind R, Khan MA, Abro SH, Korejo NA, Ejaz M, Kabir A, Shahid M, Memon S. (2019). Microbiological Contamination of Cattle and Meat in Peshawar, Pakistan. J. Anim. Health Prod. 7(1): 1116. 


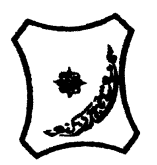

Bayero Journal of Pure and Applied Sciences, 13(1); 40 - 45

Received: September, 2019

Accepted: April, 2020

ISSN $2006-6996$

\title{
BACTERIOLOGICAL QUALITY OF STICK MEAT (Tsire) SOLD IN GARKO LOCAL GOVERNMENT AREA OF KANO STATE, NIGERIA
}

\author{
$*^{1}$ Dahiru A. T. and ${ }^{2}$ Maigari A. K. \\ ${ }^{1}$ Department of Hospitality Management, School of Technology, Kano State Polytechnic, PMB 3348, \\ Kano Nigeria. \\ ${ }^{2}$ Departmnt of Biological Sciences, Bayero University, Kano \\ Corresponding Author: dturajo61@gmail.com; GSM: 08087508262.
}

ABSTRACT

Stick meat, locally called Tsire in Hausa Language, is a significant portion of the diet of a large active population of Northern Nigeria. However, because of the handling and processing methods by the manufacturers as well as the hawking system of stick meat, the meat product may be exposed to both pre- and post-processed product contamination, and thus may poses danger to public health. Therefore, considering the role of Tsire in improving nutrition and increase household income to the populace, the need to improve the processing, distribution and overall quality of the product is simply indispensable. A total of 30 samples (5 samples from each of the 6 sampling points) of Tsire were collected randomly in Garko Town. Aerobic plate counts (APCs) and Total coliform counts (TCCS) of Tsire samples were determined using standard microbiological methods. APCs ranged from $1.02 \times 10^{5}$ to $4.00 \times 10^{5} \mathrm{CFU} / \mathrm{g}$; while TCCs ranged from $8 \mathrm{MPN} / \mathrm{g}$ to $68 \mathrm{MPN} / \mathrm{g}$. From the 30 samples screened, 16(53.33\%) bacteria namely, Campylobacter 2(6.66\%), Escherichia coli 6(20\%), Klebsiella pneumoniae 2(6.66\%), Salmonella spp. 1(3.33\%), Shigella 3(10\%) and Staphylococcus aureus 2(6.66\%) were detected. $E$. coli has the highest isolation rate of 6(20\%), while Salmonella spp. had the least frequency of 1(3.33\%). The distribution of isolated organisms within the study area were as follows: Dausai, 4(80\%), Kofar kudu, 4(80\%), Makwalla, 2(40\%), Rinji, 3(60\%), Tosaro, 2(40\%), and Tsohuwar Kasuwa, 1(20\%). The results have indicated that the Tsire was contaminated with bacteria thus exposing the product to fast deterioration, spoilage and also a vehicle for food borne illness, suggesting for adequate hygienic practices at all the stages, prior to consumption, to ensure safety of the meat product.

Key words: APCs, TCCs, Contamination, Microorganisms, Garko

\section{INTRODUCTION}

Nigeria is one of the developing nations with inadequate food supply and most often deficient in protein content (FAO, 2019). Nigerian's average animal protein intake per head per day is estimated at $7.9 \mathrm{~g}$ as against $35 \mathrm{~g}$ recommended value by Food and Agricultural Organization (Mubarak et al., 2016). These low levels of animal protein intake create great concern as it affects the nutritional status of Nigerians. Hence, there is the need for sufficient supply of animal protein from energy rich animal products to satisfy the nutritional requirements for Nigerians.

Meat is one major source of animal protein largely composed of water, protein and fats which can make it susceptible to microbial contamination within short time leading to spoilage (Apata et al., 2013; Mgbemere et al., 2011). Meat is mostly eaten after it has been cooked or processed in a variety of ways such as sun drying; smoking and roasting with or without fortifications (Borch et al., 1996). In Nigeria meat products such as Tsire, Kilishi and Balangu are locally produced using one or more of these methods in order to meet the nutritional requirements of the teeming Nigerians (Egbebi, 2011).

Tsire is a popular Nigerian traditional processed ready-to-eat roasted stick meat product (Shamsuddeen, 2015). It is sold in public places, along roads, in hotels, parks, quarters and even offices (Falegan et al., 2017). It is prepared from boneless healthy animal flesh such as beef and mutton, spiced with peanut cake, salt, vegetable oil and other flavorings followed by roasting (Shamsuddeen, 2015). Consumption of these products has extended to other parts of African countries such as Ghana, Somali, Cameroun and Chad (Ahmadu and Ibrahim, 2013). 
BAJOPAS Volume 13 Number 1, June, 2020

However, evidence of quality control sticking to procedural hygiene by the handlers during preparation and retailing of these products is poorly documented. Tsire is of great safety risk because of the fact that there are erratic cases of gastroenteritis and symptoms of food infection after consumption (WHO, 2015). Food borne illnesses are one of the major health problems in developing and developed countries (Razavilar, 2010). According to the World Health Organization, WHO (2015), $0.07 \%$ death of the 600 million global burdens of Foodborne illnesses have been reported to be caused by bacteria, viruses, fungi and chemicals. In America $0.27 \%$ of the estimated 48 million affected people is hospitalized and about $0.0063 \%$ deaths are recorded each year (Scallan et al., 2011). More than 91 million people in Africa fall ill and $0.15 \%$ dies each year, making Africa the highest burden bearer of Foodborne diseases per population (WHO, 2015).

Application of a Hazard Analysis Critical Control Point (HACCP) at all stages of meat products preparation is essential in order to ensure its safety. Thus, according to the guidelines of good manufacturing practice, the level of total aerobic bacterial contamination of thermally processed meat products should not exceed $10^{4}\left(\mathrm{cfu} \mathrm{g}^{-1}\right)$. Enterobacteriaceae and faecal coliform contamination in meat products should be within the range of $10^{2}-10^{4}$ and $10-10^{3} \mathrm{cfu} \mathrm{g}^{-1}$, respectively (Shamsuddeen, 2015). The aim of the study is therefore, to assess the total viable bacterial counts of tsire marketed locally within Garko town, and to isolate and identify the organisms at the point of consumption with the intention of promoting public health and food hygiene habits in the Nigerian populace.

\section{MATERIALS AND METHODS Study Area and Population}

Garko is one of the existing 44 local government areas located in Kano south west zone of Kano state with its capital administrative headquarters in the Garko town. It has coordinates $11^{\circ} 39^{\prime} \mathrm{N}$ $8^{\circ} 54^{\prime} \mathrm{E}$, and an area of $450 \mathrm{~km}^{2}$. The projected population of Garko local Government was 225,300 according to the National Population Census report (2018). Garko is known for agricultural activities both farming and animal husbandry. It is popularly known for large scale rice production. Other food crops include sweet potatoes, cassava, onions, sorghum, millet and sugarcane. Cows, sheep and goats are major groups of animals reared by majority of the populace. Meat products processed, retailed and consumed in Garko include roasted meat (Balangu), dried roasted meat (Kilishi), stick meat (Tsire), hide and skin pepper soup (Ragadada) and minced fried meat (Danbunnama).

\section{Samples Collection}

Five samples of Tsire products were collected from 6 different identified locations within Garko town in a sterile foil paper and immediately analyzed for the presence of bacteria.

\section{Sample Preparation}

Sample preparation for the bacteriological analysis was carried out in accordance with the method described by Atlas (1997). Twenty five grams $(25 \mathrm{~g})$ of the sample was homogenized in $225 \mathrm{ml}$ peptone water using Kenwood blender machine to obtain a $10^{1}$ homogenate. The homogenate was thoroughly shaken and $1 \mathrm{ml}$ pipetted into test tubes containing $9 \mathrm{ml}$ of peptone water $\left(10^{2}\right)$. The test tubes were further serially diluted to $10^{5}$.

Total Aerobic Mesophilic Bacterial Count

Total Aerobic mesophilic bacterial count was determined using the method described by Abdullahi et al. (2004) where $1 \mathrm{ml}$ of inoculums from $10^{1}$ to $10^{5}$ dilutions were transferred into duplicate Petri dishes and labeled accordingly. This was followed by pouring aseptically about $15 \mathrm{ml}$ of molten nutrient agar. The culture was homogenized by gentle spinning of the plates and allowed to solidify. The plates were incubated at $37^{\circ} \mathrm{C}$ for 24 hours. Plates containing 30-300 colonies were counted. The number of colony forming units per gram of a sample (cfu/g) was obtained by multiplying the average colony number with the inverse of the dilution factor.

\section{Enumeration and Detection of Coliform bacteria}

Detection and enumeration of coliform was carried out according to method described by Atlas, (1977). A set of 9 test tubes each containing $9 \mathrm{ml}$ of lactose broth and an inverted Durham tubes were autoclaved to expel air and to sterilize. Similarly, $1 \mathrm{ml}$ from the diluents $10^{1}$ was transferred to the first 3 test tubes, followed by $1 \mathrm{ml}$ from the diluents $10^{2}$ to the second set of 3 test tubes and finally the third diluents $10^{3}$ to the $3^{\text {rd }}$ set of 3 test tubes. All the 9 test tubes were incubated at $37^{\circ} \mathrm{C}$ for 24 hours. Tubes that showed gas and acid production after 24 hours were recorded as positive for the presence of Coliform. Negative tubes were further reincubated for 24 hours. Positive tubes were recorded. Estimate of most probable number of Coliform per gram of sample (MPN/g) was determined by comparing the number of gas positive tubes with the most probable number table. 
BAJOPAS Volume 13 Number 1, June, 2020 Identification of Coliform

A loop full of inoculum from gas positive tubes was streaked on to Eosine methylene blue (EMB) agar plate and incubated at $37^{\circ} \mathrm{C}$ for $24 \mathrm{hrs}$. Colonies which formed bluish black color with green metallic sheen, and reddish colonies were isolated on agar slants. Those colonies showing metallic sheen on EMB were sub cultured into tubes of lactose broth and incubated at $45^{\circ} \mathrm{C}$. The tubes were observed after $24 \mathrm{hrs}$ for gas production. This is the completed test for fecal coliform. Gram stain and other biochemical tests such as Indole, Methyl red, Voges-Proskauer and Citrate Utilization tests (IMVIC), Coagulase and Catalase tests were carried out for the Identification and confirmation of isolates.

\section{Procedure for Indole Test}

Indole test was carried out by preparing a Tryptone broth drawn in to test tubes, sterilized by autoclaving, inoculated with loopful of suspension and incubated at $37^{\circ} \mathrm{C}$ for 24 hours. Three drops of xylene was added in tubes, shaken vigorously and kept for the separation of two layers. One millilitre of Kovac's reagent was added and the formation of pink colour ring indicates positive Indole test.

\section{Procedure for Methyl Red Test}

Methyl red test was carried out by preparing Glucose phosphate broth, dispensed in test tubes, sterilized, inoculated with test culture and incubated at $37^{\circ} \mathrm{C}$ for 24 hours. Five drops of methyl-red indicator was added to the medium for the formation of red colour.

\section{Procedure for Voges-Proskauer Test}

Voges-Proskauer test was carried out by inoculating tubes with the bacterial culture followed by incubation for 48 hours at $37^{\circ} \mathrm{C}$. Separate pipettes were used to pipette $1 \mathrm{ml}$ from each culture tube into clean separate tubes. Eighteen drops $(0.5 \mathrm{ml})$ of Barrit's solution A (a-naphthol) was added to each tube containing glucose phosphate broth followed by the addition of an equal amount of solution $B$ into the same tube. The tubes were shaken at 30 seconds interval. A positive reaction was indicated by the development of a pink color, which turns red in 1-2 hours, after vigorous shaking.

\section{Procedure for Citrate Utilization Test}

Citrate Utilization Test was carried out by distributing melted agar (Simmon Citrate Agar) in to test tubes followed by sterilization at $121.5^{\circ} \mathrm{C}$ for 15 minutes. The test tubes were afterward held in slanted position, inoculated with the given bacterial culture and incubated at $37^{\circ} \mathrm{C}$ for $24 \mathrm{hrs}$. Positive test was indicated by color change of the media from green to blue.

\section{RESULTS AND DISCUSSIONS}

The results of this study are presented in tables $1,2,3$ and 4. Among the sampling areas Kofar Kudu had the highest aerobic mesophilic bacteria counts $4.0 \times 10^{5} \mathrm{cfu} / \mathrm{g}$ followed by Rinji $2.72 \times 10^{5} \mathrm{cfu} / \mathrm{g}$, while Tosaro had the least Aerobic mesophilic bacteria counts of $1.02 \times 10^{5}$ $\mathrm{cfu} / \mathrm{g}$ as indicated in Table 1.Makwalla had the highest coliform count $68 \mathrm{MPN} / \mathrm{g}$ followed by Rinji $37 \mathrm{MPN} / \mathrm{g}$. Tsohuwar Kasuwa had the least coliform counts $8 \mathrm{MPN} / \mathrm{g}$, (Table 2). Result from table 1 shows variation in the microbial contents among the samples which suggest variation in their sources, poor handling procedures and contamination from the processing environment. High coliform count and their differences within sampling areas is an indication of poor microbiological quality of the product. Ndahi et al. (2013) reported microbial load to be a function of the handling personnel and the environment. The results indicated that the samples were contaminated with bacteria as the counts exceeded the minimum safety level $\left(10^{4} \mathrm{cfu} / \mathrm{g}\right)$ for members of the Enterobacteriaceae family. However, it might be a reflection of poor hygienic practices which may contribute to health hazard to the potential consumers. Similarly, Inusa and Sa'id (2017); Osimani et al. (2015) reported that, the initial microbial content of the raw material play significant role in influencing the final microbial load of the finished product. Isolation of members of the Enterobacteriaceae such as $E$. coli, Klebsiella pneumoniae, Salmonella and Shigella signifies danger to the public health. These organisms are capable of producing endotoxins which trigger high fevers in infected individuals, and the enterotoxins which colonize the small intestines and lead to extreme dehydration as a result of vomiting and diarrhea sometimes with severe and fatal outcomes (Amaeze et al., 2016). From the 16 isolated organisms $E$. coli had the highest isolation rate $6(37.5 \%)$ (Table 3), this suggest faecal contamination of the products. $E$. coli is a common flora in the gastrointestinal tract responsible for diarrhea and extra-intestinal infections (CDC, 2011). The result is in conformity with the findings of Ndahi et al. (2013) and Shamsuddeen (2009). Also presence of campylobacter might be due to cross contamination from raw meat to finished product (Tsire). Staphylococcus aureus is a normal flora of the skin, nasal, genital, mouth or anal area in both humans and animals without any symptom of an infection (Matthew et al., 2013). Isolation of $S$. aureus in these study concords with the findings of Lucretia et al. (2018) from Suya sold in Rivers State. 
BAJOPAS Volume 13 Number 1, June, 2020

It is also in agreement with the findings of Yousafzai et al. (2018); Onuorah et al. (2015) and Tijjani and Jumare (2014) from tsire samples in different countries. Presence of $S$. aureus in foods is most of the time an indication of poor human handling, poor environment, unhygienic utensils and equipments used during processing (Igene et al., 2016; Okonko et al., 2013). Infections caused by $S$. aureus are difficult to treat leading to long hospitalization with consequent economic loss (Udobi et al., 2013). These include soft tissue infections, pneumonia, hospital-acquired postoperative wound infections, Staphylococcal food poisoning, impetigo and cellulitis (Charlene et al., 2013). Samples obtained from Dausai and Kofar Kudu had the highest isolation rate $4(80 \%)$ (Table 4 ) probably because of the much commercial activities taking place in the area which can lead to environmental contamination.

Table 1: Total Aerobic Mesophilic Bacterial Count of Tsire sold in Garko Town

\begin{tabular}{lll}
\hline Sampling Area & APC cfu/g & Mean \pm STD \\
\hline Dausai & $2.20 \times 10^{5}$ & $110000 \pm 14142.14$ \\
Kofar Kudu & $4.00 \times 10^{5}$ & $133333.3 \pm 23094.01$ \\
Makwalla & $1.30 \times 10^{5}$ & $32500 \pm 7187.953$ \\
Rinji & $2.72 \times 10^{5}$ & $90666.67 \pm 94769.90$ \\
Tosaro & $1.02 \times 10^{5}$ & $51000 \pm 15556.35$ \\
Tsohuwar Kasuwa & $1.75 \times 10^{5}$ & $35000 \pm 11357.82$ \\
\hline
\end{tabular}

Key: APC: Aerobic Mesophilic Counts

STD: Standard Deviation

Table 2: Total Coliform Count of Tsire sold in Garko Town

\begin{tabular}{lcc}
\hline \multicolumn{1}{c}{ Sampling Area } & TCC MPN/g & Mean \pm STD \\
\hline Dausai & 20 & $6.67 \pm 2.5166$ \\
Kofar Kudu & 32 & $16.00 \pm 5.6569$ \\
Makwalla & 68 & $13.60 \pm 8.7062$ \\
Rinji & 37 & $9.25 \pm 4.7871$ \\
Tosaro & 10 & $5.00 \pm 2.8284$ \\
Tsohuwar Kasuwa & 8 & $4.00 \pm 0.0000$ \\
\hline
\end{tabular}

Table 3: Organisms Isolated from Tsire Sold in Garko

\begin{tabular}{lcl}
\hline Isolated Organism & Frequency & Percentage (\%) \\
\hline Campylobacter & 2 & 06.66 \\
Escherichia coli & 6 & 20.00 \\
Klebsiella pneumoniae & 2 & 06.66 \\
Salmonella species & 1 & 03.33 \\
Shigella & 3 & 10.00 \\
Staphylococcus aureus & 2 & 06.66 \\
Total & 16 & \\
\hline
\end{tabular}

Table 4: Distribution of Organisms within Sampling Area

\begin{tabular}{lcc}
\hline \multicolumn{1}{c}{ Sampling Area } & No. Isolated & Percentage (\%) \\
\hline Dausai & 4 & 80 \\
Kofar Kudu & 4 & 80 \\
Makwalla & 2 & 40 \\
Rinji & 3 & 60 \\
Tosaro & 2 & 40 \\
Tsohuwar Kasuwa & 1 & 20 \\
Total & 16 & \\
\hline
\end{tabular}

\section{CONCLUSION}

Results indicated $4.00 \times 10^{5} \mathrm{CFU} / \mathrm{g}$ as the highest APCs count; while $68 \mathrm{MPN} / \mathrm{g}$ was the highest TCCs from the 30 samples analyzed. Among the isolates, $E$. coli has the highest isolation rate of $6(20 \%)$. Dausai and Kofar kudu were having the highest bacteria count of $4(80 \%)$, each, indicating higher contamination in those locations. 
BAJOPAS Volume 13 Number 1, June, 2020 RECOMMENDATIONS

The following recommendations are tenable:

1. Hygienic practices at all stages of production should be improved to safe guard the consumers against potential health hazard.

2. Monitoring of microbiological contamination of Tsire during preparations, packaging and marketing is essential to ensure product of good microbiological quality for consumers' health.

\section{REFERENCES}

Abdullahi, I. O., Umoh, V. J. and Galadima, M. (2004). Hazards Associated with Kilishi Preparations in Zaria. Nigerian Journal of Microbiology, 18 (1-2): $339-345$.

Ahmadu, J. and Ibrahim E. J., (2013): Determinants of Revenue in Suya Production in BeninCity, Edo State, Nigeria. Nigerian journal of agriculture, food and environment.9(3):1-5

Amaeze, N. Aboh, M. Itohan, A. Felix, E. Olatunji, T. and Oladosu, P. (2016) Microbial Profile, Antibiotic Sensitivity and Heat Resistance of Bacterial Isolates from Commercial Roasted Beef (Suya) in Abuja, Nigeria. JOPAT, 15(2): $22-30$.

Apata, E.S., Kuku1, I.A., Apata, O.C. and Adeyemi, K.O. (2013). Evaluation of Suya(Tsire) - An Intermediate Moisture Meat Product in Ogun State, Nigeria. J. Food Res 2 (1): 87.

Atlas, R. M. (1997) Principles of Microbiology Second Edition. C. Brown Publishers. Pp 802-803.

Borch, E. Kant-Muermans, M. L., Blixt, Y. (1996) Bacterial Spoilage of Meat and Cured Meat Products. Int $\mathrm{J}$ Food Microbiol .33(1): 103-20.

Centre for Disease Control, CDC (2011). "Escherichia coli 0157:H7" Division of Bacterial and Mycotic Diseasesht://www.cdc.gov/nczved/divisi ons/dfbmd/diseases/ecoli_0157h7/.

Charlene, R. J., Johnnie, A. D., and John, B. B., (2013) Prevalence and Characterization of Methicillin-Resistant Staphylococcus aureus Isolates from Retail Meat and Humans in Georgia. American society for Microbiology. J. of clinical microbiology. 12(1):123-6 doi:10.1128/JCM.0316612JCM.03166-12

Egbebi, A.O and Seidu, K., T. (2011). Microbiological Evaluation of Suya (dried smoked

meat) Sold in Ado and Akure, South West Nigeria.European Journal of Experinmental Biology, 1(4):1-5
3. Government should establish regulatory bodies responsible for inculcating hygiene habits to the local producers and vendors in order to prevent instant, cross and post processing contaminations by microbial pathogens.

4. Awareness and sensitization of local food producers about good hygienic practices in food handling and processing.

Falegan, C, R., Akoja, S. D., and Oyarekua, M. A., (2017) Microbiological Assessment of Suya (Sliced Roasted Beef) in Ado-Ekiti Metropolis, Ekiti State, Nigeria. MOJ Biology andMedicine.

Fonkem, D., N. Tanya, V., N. and Ebangi, A., L. (2010). Effect of Season on the Microbiological Quality of Kilishi, a Traditional Cameroonian Dried Beef Product. Tropicultura, 28(1): 10-15.

Food and Agricultural Organization of the United Nations (F A O, 1979). Manual of food quality control 4. Microbiological analysis.

Food and Agriculture Organisation of the United Nation (FAO), 2019. Nigeria at a glance.

Igene J.O., Uwadia, O.E., Ebabhamiegbebho, P.A. and Evivie, S.E., (2016) Shelf life Stability Studies of University of Benin (UNIBEN) Proff's Kilishi Product Asian Journal of Science and Technology 7(1): 2268-2274.

Inusa, S. K. and Said, I. S. (2017) Evaluation of the Chemical and Microbiological Properties Of Kilishi Sold in Kano Metropolis. Journal of Dry land Agriculture, 3 (1): $59-69$.

Lucretia, I. B, Patience, C. Obinna-Echem, Sophia, C. A. (2018) Microbiological quality andantibiotic sensitivity of potential pathogens isolated from meat product (Suya) sold in Rivers State University and its environs. International Journal of Biotechnology and Food Science, 6(4): 67-76.

Matthew, E., Drosos, E., John, L. and Ioanna, P. (2013) MRSA in Africa: Filling the Global Map of Antimicrobial Resistance PLOS One. 8(7): e68024 doi: 10.1371/journal.pone.0068024

Mgbemere, V.N., Akpapunam, M. A. and Igene, J. O., (2011). Effect of Groundnut FlourSubstitution on Yield, Quality and Storage Stability of Kilishi - a Nigerian Indigenous Dried Meat Product. African Journal of Food, Agriculture, Nutrition and Development, $\quad \mathbf{1 1}(2)$ : 4718-4738. 
BAJOPAS Volume 13 Number 1, June, 2020

Mubarak, A. A., Azeez, M. L., Amos A. O., Opeyemi, O. O. (2016) Assessment of Animal Protein Consumption and Food Security Among Rural Households in Kwara State, Nigeria American Journal of Business and Society, 1(4): 233245.

Ndahi, M., D. Kwaga, J., K. P. Bello, M. Kabir J., V. Umoh, .J. Yakubu, S., E. and Nok, A., J. (2013) Prevalence and Antimicrobial Susceptibility of Listeria Monocytogenes and Methicillin-Resistant Staphylococcus aureus Strains from Raw Meat and Meat Products in Zaria, Nigeria. Applied Journal of Microbiology, 58(3):262-9.

Okonko, I.O., Odu, N.N. and Igboh, I.E. (2013). Microbiological Analysis of Kilishi Sold In Port Harcourt, Nigeria. New York Science Journal, 6 (7):37-43.

Osimani, A., Aquilanti, L. and Clementi, F. (2015) Microbiological Quality of Meatbased Meals and Operation of Control Systems within a Food Service Environment. International Food Research Journal 22(4): 1692-1698.

Onuorah, S. Obika, I. Odibo, F. Orji, M. (2015)An Assessment of the Bacteriological Quality of Tsire-Suya (Grilled Beef) sold in Awka, Nigeria. American. J. Life. Sci. Res. 3(4):287292.

Razavilar, V, Khandaghi, J. Barzgari, A. (2010); Isolation of Eschericia coli 0157:H7 from manure fertilized farms and raw vegetables grown on it, in Tabriz city in
Iran. African Journal of Microbiology Research, 4(9): 891-895.

Scallan, E. Hoekstra, R. M. Angulo, F. J.Tauxe, R. V, Widdowson, M. Roy, S. L et al., (2011).Food borne illness acquired in the United States- Major Pathogens. Emerg. Infec Dis, 17(1): 7-15.

Shamsuddeen U (2009). Microbiological quality of spice used in the production of Kilishi a traditionally dried and grilled meat product. Bayero Journal of Pure andApplied Sciences, 2(2): 66-69.

Shamsuddeen, U. (2015) Microbiological Hazard and Critical control point Analysis of Dried and Minced Meat Snacks Produced in Kano Nigeria. Lambert Academic Publishing; Pp 1-36.

Tijani, O.and Jumare, S. (2014). Microblological Quality Assessment of Meat

Sold in KauraNamoda. International Conference on Earth, Environment and Life sciences (EELS) Dubai (UAE).

Udobi, C. E., Obajuluwa, A. F., and Onaolapo, J. A., (2013) Prevalence and Antibiotic Resistance Pattern of MethicillinResistant Staphylococcus aureus from an Orthopaedic Hospital in Nigeria BioMed Research International; 26(6); 6-7.

WHO, 2015 Foodborne diseases in the WHO African Region.

Yousafzai HA, Rind R, Khan MA, Abro SH, Korejo NA, Ejaz M, Kabir A, Shahid M, Memon S. (2019). Microbiological Contamination of Cattle and Meat in Peshawar, Pakistan. J. Anim. Health Prod. 7(1): 1116. 


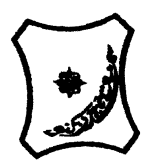

Bayero Journal of Pure and Applied Sciences, 13(1); 40 - 45

Received: September, 2019

Accepted: April, 2020

ISSN $2006-6996$

\title{
BACTERIOLOGICAL QUALITY OF STICK MEAT (Tsire) SOLD IN GARKO LOCAL GOVERNMENT AREA OF KANO STATE, NIGERIA
}

\author{
$*^{1}$ Dahiru A. T. and ${ }^{2}$ Maigari A. K. \\ ${ }^{1}$ Department of Hospitality Management, School of Technology, Kano State Polytechnic, PMB 3348, \\ Kano Nigeria. \\ ${ }^{2}$ Departmnt of Biological Sciences, Bayero University, Kano \\ Corresponding Author: dturajo61@gmail.com; GSM: 08087508262.
}

ABSTRACT

Stick meat, locally called Tsire in Hausa Language, is a significant portion of the diet of a large active population of Northern Nigeria. However, because of the handling and processing methods by the manufacturers as well as the hawking system of stick meat, the meat product may be exposed to both pre- and post-processed product contamination, and thus may poses danger to public health. Therefore, considering the role of Tsire in improving nutrition and increase household income to the populace, the need to improve the processing, distribution and overall quality of the product is simply indispensable. A total of 30 samples (5 samples from each of the 6 sampling points) of Tsire were collected randomly in Garko Town. Aerobic plate counts (APCs) and Total coliform counts (TCCS) of Tsire samples were determined using standard microbiological methods. APCs ranged from $1.02 \times 10^{5}$ to $4.00 \times 10^{5} \mathrm{CFU} / \mathrm{g}$; while TCCs ranged from $8 \mathrm{MPN} / \mathrm{g}$ to $68 \mathrm{MPN} / \mathrm{g}$. From the 30 samples screened, 16(53.33\%) bacteria namely, Campylobacter 2(6.66\%), Escherichia coli 6(20\%), Klebsiella pneumoniae 2(6.66\%), Salmonella spp. 1(3.33\%), Shigella 3(10\%) and Staphylococcus aureus 2(6.66\%) were detected. $E$. coli has the highest isolation rate of 6(20\%), while Salmonella spp. had the least frequency of 1(3.33\%). The distribution of isolated organisms within the study area were as follows: Dausai, 4(80\%), Kofar kudu, 4(80\%), Makwalla, 2(40\%), Rinji, 3(60\%), Tosaro, 2(40\%), and Tsohuwar Kasuwa, 1(20\%). The results have indicated that the Tsire was contaminated with bacteria thus exposing the product to fast deterioration, spoilage and also a vehicle for food borne illness, suggesting for adequate hygienic practices at all the stages, prior to consumption, to ensure safety of the meat product.

Key words: APCs, TCCs, Contamination, Microorganisms, Garko

\section{INTRODUCTION}

Nigeria is one of the developing nations with inadequate food supply and most often deficient in protein content (FAO, 2019). Nigerian's average animal protein intake per head per day is estimated at $7.9 \mathrm{~g}$ as against $35 \mathrm{~g}$ recommended value by Food and Agricultural Organization (Mubarak et al., 2016). These low levels of animal protein intake create great concern as it affects the nutritional status of Nigerians. Hence, there is the need for sufficient supply of animal protein from energy rich animal products to satisfy the nutritional requirements for Nigerians.

Meat is one major source of animal protein largely composed of water, protein and fats which can make it susceptible to microbial contamination within short time leading to spoilage (Apata et al., 2013; Mgbemere et al., 2011). Meat is mostly eaten after it has been cooked or processed in a variety of ways such as sun drying; smoking and roasting with or without fortifications (Borch et al., 1996). In Nigeria meat products such as Tsire, Kilishi and Balangu are locally produced using one or more of these methods in order to meet the nutritional requirements of the teeming Nigerians (Egbebi, 2011).

Tsire is a popular Nigerian traditional processed ready-to-eat roasted stick meat product (Shamsuddeen, 2015). It is sold in public places, along roads, in hotels, parks, quarters and even offices (Falegan et al., 2017). It is prepared from boneless healthy animal flesh such as beef and mutton, spiced with peanut cake, salt, vegetable oil and other flavorings followed by roasting (Shamsuddeen, 2015). Consumption of these products has extended to other parts of African countries such as Ghana, Somali, Cameroun and Chad (Ahmadu and Ibrahim, 2013). 
BAJOPAS Volume 13 Number 1, June, 2020

However, evidence of quality control sticking to procedural hygiene by the handlers during preparation and retailing of these products is poorly documented. Tsire is of great safety risk because of the fact that there are erratic cases of gastroenteritis and symptoms of food infection after consumption (WHO, 2015). Food borne illnesses are one of the major health problems in developing and developed countries (Razavilar, 2010). According to the World Health Organization, WHO (2015), $0.07 \%$ death of the 600 million global burdens of Foodborne illnesses have been reported to be caused by bacteria, viruses, fungi and chemicals. In America $0.27 \%$ of the estimated 48 million affected people is hospitalized and about $0.0063 \%$ deaths are recorded each year (Scallan et al., 2011). More than 91 million people in Africa fall ill and $0.15 \%$ dies each year, making Africa the highest burden bearer of Foodborne diseases per population (WHO, 2015).

Application of a Hazard Analysis Critical Control Point (HACCP) at all stages of meat products preparation is essential in order to ensure its safety. Thus, according to the guidelines of good manufacturing practice, the level of total aerobic bacterial contamination of thermally processed meat products should not exceed $10^{4}\left(\mathrm{cfu} \mathrm{g}^{-1}\right)$. Enterobacteriaceae and faecal coliform contamination in meat products should be within the range of $10^{2}-10^{4}$ and $10-10^{3} \mathrm{cfu} \mathrm{g}^{-1}$, respectively (Shamsuddeen, 2015). The aim of the study is therefore, to assess the total viable bacterial counts of tsire marketed locally within Garko town, and to isolate and identify the organisms at the point of consumption with the intention of promoting public health and food hygiene habits in the Nigerian populace.

\section{MATERIALS AND METHODS Study Area and Population}

Garko is one of the existing 44 local government areas located in Kano south west zone of Kano state with its capital administrative headquarters in the Garko town. It has coordinates $11^{\circ} 39^{\prime} \mathrm{N}$ $8^{\circ} 54^{\prime} \mathrm{E}$, and an area of $450 \mathrm{~km}^{2}$. The projected population of Garko local Government was 225,300 according to the National Population Census report (2018). Garko is known for agricultural activities both farming and animal husbandry. It is popularly known for large scale rice production. Other food crops include sweet potatoes, cassava, onions, sorghum, millet and sugarcane. Cows, sheep and goats are major groups of animals reared by majority of the populace. Meat products processed, retailed and consumed in Garko include roasted meat (Balangu), dried roasted meat (Kilishi), stick meat (Tsire), hide and skin pepper soup (Ragadada) and minced fried meat (Danbunnama).

\section{Samples Collection}

Five samples of Tsire products were collected from 6 different identified locations within Garko town in a sterile foil paper and immediately analyzed for the presence of bacteria.

\section{Sample Preparation}

Sample preparation for the bacteriological analysis was carried out in accordance with the method described by Atlas (1997). Twenty five grams $(25 \mathrm{~g})$ of the sample was homogenized in $225 \mathrm{ml}$ peptone water using Kenwood blender machine to obtain a $10^{1}$ homogenate. The homogenate was thoroughly shaken and $1 \mathrm{ml}$ pipetted into test tubes containing $9 \mathrm{ml}$ of peptone water $\left(10^{2}\right)$. The test tubes were further serially diluted to $10^{5}$.

Total Aerobic Mesophilic Bacterial Count

Total Aerobic mesophilic bacterial count was determined using the method described by Abdullahi et al. (2004) where $1 \mathrm{ml}$ of inoculums from $10^{1}$ to $10^{5}$ dilutions were transferred into duplicate Petri dishes and labeled accordingly. This was followed by pouring aseptically about $15 \mathrm{ml}$ of molten nutrient agar. The culture was homogenized by gentle spinning of the plates and allowed to solidify. The plates were incubated at $37^{\circ} \mathrm{C}$ for 24 hours. Plates containing 30-300 colonies were counted. The number of colony forming units per gram of a sample (cfu/g) was obtained by multiplying the average colony number with the inverse of the dilution factor.

\section{Enumeration and Detection of Coliform bacteria}

Detection and enumeration of coliform was carried out according to method described by Atlas, (1977). A set of 9 test tubes each containing $9 \mathrm{ml}$ of lactose broth and an inverted Durham tubes were autoclaved to expel air and to sterilize. Similarly, $1 \mathrm{ml}$ from the diluents $10^{1}$ was transferred to the first 3 test tubes, followed by $1 \mathrm{ml}$ from the diluents $10^{2}$ to the second set of 3 test tubes and finally the third diluents $10^{3}$ to the $3^{\text {rd }}$ set of 3 test tubes. All the 9 test tubes were incubated at $37^{\circ} \mathrm{C}$ for 24 hours. Tubes that showed gas and acid production after 24 hours were recorded as positive for the presence of Coliform. Negative tubes were further reincubated for 24 hours. Positive tubes were recorded. Estimate of most probable number of Coliform per gram of sample (MPN/g) was determined by comparing the number of gas positive tubes with the most probable number table. 
BAJOPAS Volume 13 Number 1, June, 2020 Identification of Coliform

A loop full of inoculum from gas positive tubes was streaked on to Eosine methylene blue (EMB) agar plate and incubated at $37^{\circ} \mathrm{C}$ for $24 \mathrm{hrs}$. Colonies which formed bluish black color with green metallic sheen, and reddish colonies were isolated on agar slants. Those colonies showing metallic sheen on EMB were sub cultured into tubes of lactose broth and incubated at $45^{\circ} \mathrm{C}$. The tubes were observed after $24 \mathrm{hrs}$ for gas production. This is the completed test for fecal coliform. Gram stain and other biochemical tests such as Indole, Methyl red, Voges-Proskauer and Citrate Utilization tests (IMVIC), Coagulase and Catalase tests were carried out for the Identification and confirmation of isolates.

\section{Procedure for Indole Test}

Indole test was carried out by preparing a Tryptone broth drawn in to test tubes, sterilized by autoclaving, inoculated with loopful of suspension and incubated at $37^{\circ} \mathrm{C}$ for 24 hours. Three drops of xylene was added in tubes, shaken vigorously and kept for the separation of two layers. One millilitre of Kovac's reagent was added and the formation of pink colour ring indicates positive Indole test.

\section{Procedure for Methyl Red Test}

Methyl red test was carried out by preparing Glucose phosphate broth, dispensed in test tubes, sterilized, inoculated with test culture and incubated at $37^{\circ} \mathrm{C}$ for 24 hours. Five drops of methyl-red indicator was added to the medium for the formation of red colour.

\section{Procedure for Voges-Proskauer Test}

Voges-Proskauer test was carried out by inoculating tubes with the bacterial culture followed by incubation for 48 hours at $37^{\circ} \mathrm{C}$. Separate pipettes were used to pipette $1 \mathrm{ml}$ from each culture tube into clean separate tubes. Eighteen drops $(0.5 \mathrm{ml})$ of Barrit's solution A (a-naphthol) was added to each tube containing glucose phosphate broth followed by the addition of an equal amount of solution $B$ into the same tube. The tubes were shaken at 30 seconds interval. A positive reaction was indicated by the development of a pink color, which turns red in 1-2 hours, after vigorous shaking.

\section{Procedure for Citrate Utilization Test}

Citrate Utilization Test was carried out by distributing melted agar (Simmon Citrate Agar) in to test tubes followed by sterilization at $121.5^{\circ} \mathrm{C}$ for 15 minutes. The test tubes were afterward held in slanted position, inoculated with the given bacterial culture and incubated at $37^{\circ} \mathrm{C}$ for $24 \mathrm{hrs}$. Positive test was indicated by color change of the media from green to blue.

\section{RESULTS AND DISCUSSIONS}

The results of this study are presented in tables $1,2,3$ and 4. Among the sampling areas Kofar Kudu had the highest aerobic mesophilic bacteria counts $4.0 \times 10^{5} \mathrm{cfu} / \mathrm{g}$ followed by Rinji $2.72 \times 10^{5} \mathrm{cfu} / \mathrm{g}$, while Tosaro had the least Aerobic mesophilic bacteria counts of $1.02 \times 10^{5}$ $\mathrm{cfu} / \mathrm{g}$ as indicated in Table 1.Makwalla had the highest coliform count $68 \mathrm{MPN} / \mathrm{g}$ followed by Rinji $37 \mathrm{MPN} / \mathrm{g}$. Tsohuwar Kasuwa had the least coliform counts $8 \mathrm{MPN} / \mathrm{g}$, (Table 2). Result from table 1 shows variation in the microbial contents among the samples which suggest variation in their sources, poor handling procedures and contamination from the processing environment. High coliform count and their differences within sampling areas is an indication of poor microbiological quality of the product. Ndahi et al. (2013) reported microbial load to be a function of the handling personnel and the environment. The results indicated that the samples were contaminated with bacteria as the counts exceeded the minimum safety level $\left(10^{4} \mathrm{cfu} / \mathrm{g}\right)$ for members of the Enterobacteriaceae family. However, it might be a reflection of poor hygienic practices which may contribute to health hazard to the potential consumers. Similarly, Inusa and Sa'id (2017); Osimani et al. (2015) reported that, the initial microbial content of the raw material play significant role in influencing the final microbial load of the finished product. Isolation of members of the Enterobacteriaceae such as $E$. coli, Klebsiella pneumoniae, Salmonella and Shigella signifies danger to the public health. These organisms are capable of producing endotoxins which trigger high fevers in infected individuals, and the enterotoxins which colonize the small intestines and lead to extreme dehydration as a result of vomiting and diarrhea sometimes with severe and fatal outcomes (Amaeze et al., 2016). From the 16 isolated organisms $E$. coli had the highest isolation rate $6(37.5 \%)$ (Table 3), this suggest faecal contamination of the products. $E$. coli is a common flora in the gastrointestinal tract responsible for diarrhea and extra-intestinal infections (CDC, 2011). The result is in conformity with the findings of Ndahi et al. (2013) and Shamsuddeen (2009). Also presence of campylobacter might be due to cross contamination from raw meat to finished product (Tsire). Staphylococcus aureus is a normal flora of the skin, nasal, genital, mouth or anal area in both humans and animals without any symptom of an infection (Matthew et al., 2013). Isolation of $S$. aureus in these study concords with the findings of Lucretia et al. (2018) from Suya sold in Rivers State. 
BAJOPAS Volume 13 Number 1, June, 2020

It is also in agreement with the findings of Yousafzai et al. (2018); Onuorah et al. (2015) and Tijjani and Jumare (2014) from tsire samples in different countries. Presence of $S$. aureus in foods is most of the time an indication of poor human handling, poor environment, unhygienic utensils and equipments used during processing (Igene et al., 2016; Okonko et al., 2013). Infections caused by $S$. aureus are difficult to treat leading to long hospitalization with consequent economic loss (Udobi et al., 2013). These include soft tissue infections, pneumonia, hospital-acquired postoperative wound infections, Staphylococcal food poisoning, impetigo and cellulitis (Charlene et al., 2013). Samples obtained from Dausai and Kofar Kudu had the highest isolation rate $4(80 \%)$ (Table 4 ) probably because of the much commercial activities taking place in the area which can lead to environmental contamination.

Table 1: Total Aerobic Mesophilic Bacterial Count of Tsire sold in Garko Town

\begin{tabular}{lll}
\hline Sampling Area & APC cfu/g & Mean \pm STD \\
\hline Dausai & $2.20 \times 10^{5}$ & $110000 \pm 14142.14$ \\
Kofar Kudu & $4.00 \times 10^{5}$ & $133333.3 \pm 23094.01$ \\
Makwalla & $1.30 \times 10^{5}$ & $32500 \pm 7187.953$ \\
Rinji & $2.72 \times 10^{5}$ & $90666.67 \pm 94769.90$ \\
Tosaro & $1.02 \times 10^{5}$ & $51000 \pm 15556.35$ \\
Tsohuwar Kasuwa & $1.75 \times 10^{5}$ & $35000 \pm 11357.82$ \\
\hline
\end{tabular}

Key: APC: Aerobic Mesophilic Counts

STD: Standard Deviation

Table 2: Total Coliform Count of Tsire sold in Garko Town

\begin{tabular}{lcc}
\hline \multicolumn{1}{c}{ Sampling Area } & TCC MPN/g & Mean \pm STD \\
\hline Dausai & 20 & $6.67 \pm 2.5166$ \\
Kofar Kudu & 32 & $16.00 \pm 5.6569$ \\
Makwalla & 68 & $13.60 \pm 8.7062$ \\
Rinji & 37 & $9.25 \pm 4.7871$ \\
Tosaro & 10 & $5.00 \pm 2.8284$ \\
Tsohuwar Kasuwa & 8 & $4.00 \pm 0.0000$ \\
\hline
\end{tabular}

Table 3: Organisms Isolated from Tsire Sold in Garko

\begin{tabular}{lcl}
\hline Isolated Organism & Frequency & Percentage (\%) \\
\hline Campylobacter & 2 & 06.66 \\
Escherichia coli & 6 & 20.00 \\
Klebsiella pneumoniae & 2 & 06.66 \\
Salmonella species & 1 & 03.33 \\
Shigella & 3 & 10.00 \\
Staphylococcus aureus & 2 & 06.66 \\
Total & 16 & \\
\hline
\end{tabular}

Table 4: Distribution of Organisms within Sampling Area

\begin{tabular}{lcc}
\hline \multicolumn{1}{c}{ Sampling Area } & No. Isolated & Percentage (\%) \\
\hline Dausai & 4 & 80 \\
Kofar Kudu & 4 & 80 \\
Makwalla & 2 & 40 \\
Rinji & 3 & 60 \\
Tosaro & 2 & 40 \\
Tsohuwar Kasuwa & 1 & 20 \\
Total & 16 & \\
\hline
\end{tabular}

\section{CONCLUSION}

Results indicated $4.00 \times 10^{5} \mathrm{CFU} / \mathrm{g}$ as the highest APCs count; while $68 \mathrm{MPN} / \mathrm{g}$ was the highest TCCs from the 30 samples analyzed. Among the isolates, $E$. coli has the highest isolation rate of $6(20 \%)$. Dausai and Kofar kudu were having the highest bacteria count of $4(80 \%)$, each, indicating higher contamination in those locations. 
BAJOPAS Volume 13 Number 1, June, 2020 RECOMMENDATIONS

The following recommendations are tenable:

1. Hygienic practices at all stages of production should be improved to safe guard the consumers against potential health hazard.

2. Monitoring of microbiological contamination of Tsire during preparations, packaging and marketing is essential to ensure product of good microbiological quality for consumers' health.

\section{REFERENCES}

Abdullahi, I. O., Umoh, V. J. and Galadima, M. (2004). Hazards Associated with Kilishi Preparations in Zaria. Nigerian Journal of Microbiology, 18 (1-2): $339-345$.

Ahmadu, J. and Ibrahim E. J., (2013): Determinants of Revenue in Suya Production in BeninCity, Edo State, Nigeria. Nigerian journal of agriculture, food and environment.9(3):1-5

Amaeze, N. Aboh, M. Itohan, A. Felix, E. Olatunji, T. and Oladosu, P. (2016) Microbial Profile, Antibiotic Sensitivity and Heat Resistance of Bacterial Isolates from Commercial Roasted Beef (Suya) in Abuja, Nigeria. JOPAT, 15(2): $22-30$.

Apata, E.S., Kuku1, I.A., Apata, O.C. and Adeyemi, K.O. (2013). Evaluation of Suya(Tsire) - An Intermediate Moisture Meat Product in Ogun State, Nigeria. J. Food Res 2 (1): 87.

Atlas, R. M. (1997) Principles of Microbiology Second Edition. C. Brown Publishers. Pp 802-803.

Borch, E. Kant-Muermans, M. L., Blixt, Y. (1996) Bacterial Spoilage of Meat and Cured Meat Products. Int $\mathrm{J}$ Food Microbiol .33(1): 103-20.

Centre for Disease Control, CDC (2011). "Escherichia coli 0157:H7" Division of Bacterial and Mycotic Diseasesht://www.cdc.gov/nczved/divisi ons/dfbmd/diseases/ecoli_0157h7/.

Charlene, R. J., Johnnie, A. D., and John, B. B., (2013) Prevalence and Characterization of Methicillin-Resistant Staphylococcus aureus Isolates from Retail Meat and Humans in Georgia. American society for Microbiology. J. of clinical microbiology. 12(1):123-6 doi:10.1128/JCM.0316612JCM.03166-12

Egbebi, A.O and Seidu, K., T. (2011). Microbiological Evaluation of Suya (dried smoked

meat) Sold in Ado and Akure, South West Nigeria.European Journal of Experinmental Biology, 1(4):1-5
3. Government should establish regulatory bodies responsible for inculcating hygiene habits to the local producers and vendors in order to prevent instant, cross and post processing contaminations by microbial pathogens.

4. Awareness and sensitization of local food producers about good hygienic practices in food handling and processing.

Falegan, C, R., Akoja, S. D., and Oyarekua, M. A., (2017) Microbiological Assessment of Suya (Sliced Roasted Beef) in Ado-Ekiti Metropolis, Ekiti State, Nigeria. MOJ Biology andMedicine.

Fonkem, D., N. Tanya, V., N. and Ebangi, A., L. (2010). Effect of Season on the Microbiological Quality of Kilishi, a Traditional Cameroonian Dried Beef Product. Tropicultura, 28(1): 10-15.

Food and Agricultural Organization of the United Nations (F A O, 1979). Manual of food quality control 4. Microbiological analysis.

Food and Agriculture Organisation of the United Nation (FAO), 2019. Nigeria at a glance.

Igene J.O., Uwadia, O.E., Ebabhamiegbebho, P.A. and Evivie, S.E., (2016) Shelf life Stability Studies of University of Benin (UNIBEN) Proff's Kilishi Product Asian Journal of Science and Technology 7(1): 2268-2274.

Inusa, S. K. and Said, I. S. (2017) Evaluation of the Chemical and Microbiological Properties Of Kilishi Sold in Kano Metropolis. Journal of Dry land Agriculture, 3 (1): $59-69$.

Lucretia, I. B, Patience, C. Obinna-Echem, Sophia, C. A. (2018) Microbiological quality andantibiotic sensitivity of potential pathogens isolated from meat product (Suya) sold in Rivers State University and its environs. International Journal of Biotechnology and Food Science, 6(4): 67-76.

Matthew, E., Drosos, E., John, L. and Ioanna, P. (2013) MRSA in Africa: Filling the Global Map of Antimicrobial Resistance PLOS One. 8(7): e68024 doi: 10.1371/journal.pone.0068024

Mgbemere, V.N., Akpapunam, M. A. and Igene, J. O., (2011). Effect of Groundnut FlourSubstitution on Yield, Quality and Storage Stability of Kilishi - a Nigerian Indigenous Dried Meat Product. African Journal of Food, Agriculture, Nutrition and Development, $\quad \mathbf{1 1}(2)$ : 4718-4738. 
BAJOPAS Volume 13 Number 1, June, 2020

Mubarak, A. A., Azeez, M. L., Amos A. O., Opeyemi, O. O. (2016) Assessment of Animal Protein Consumption and Food Security Among Rural Households in Kwara State, Nigeria American Journal of Business and Society, 1(4): 233245.

Ndahi, M., D. Kwaga, J., K. P. Bello, M. Kabir J., V. Umoh, .J. Yakubu, S., E. and Nok, A., J. (2013) Prevalence and Antimicrobial Susceptibility of Listeria Monocytogenes and Methicillin-Resistant Staphylococcus aureus Strains from Raw Meat and Meat Products in Zaria, Nigeria. Applied Journal of Microbiology, 58(3):262-9.

Okonko, I.O., Odu, N.N. and Igboh, I.E. (2013). Microbiological Analysis of Kilishi Sold In Port Harcourt, Nigeria. New York Science Journal, 6 (7):37-43.

Osimani, A., Aquilanti, L. and Clementi, F. (2015) Microbiological Quality of Meatbased Meals and Operation of Control Systems within a Food Service Environment. International Food Research Journal 22(4): 1692-1698.

Onuorah, S. Obika, I. Odibo, F. Orji, M. (2015)An Assessment of the Bacteriological Quality of Tsire-Suya (Grilled Beef) sold in Awka, Nigeria. American. J. Life. Sci. Res. 3(4):287292.

Razavilar, V, Khandaghi, J. Barzgari, A. (2010); Isolation of Eschericia coli 0157:H7 from manure fertilized farms and raw vegetables grown on it, in Tabriz city in
Iran. African Journal of Microbiology Research, 4(9): 891-895.

Scallan, E. Hoekstra, R. M. Angulo, F. J.Tauxe, R. V, Widdowson, M. Roy, S. L et al., (2011).Food borne illness acquired in the United States- Major Pathogens. Emerg. Infec Dis, 17(1): 7-15.

Shamsuddeen U (2009). Microbiological quality of spice used in the production of Kilishi a traditionally dried and grilled meat product. Bayero Journal of Pure andApplied Sciences, 2(2): 66-69.

Shamsuddeen, U. (2015) Microbiological Hazard and Critical control point Analysis of Dried and Minced Meat Snacks Produced in Kano Nigeria. Lambert Academic Publishing; Pp 1-36.

Tijani, O.and Jumare, S. (2014). Microblological Quality Assessment of Meat

Sold in KauraNamoda. International Conference on Earth, Environment and Life sciences (EELS) Dubai (UAE).

Udobi, C. E., Obajuluwa, A. F., and Onaolapo, J. A., (2013) Prevalence and Antibiotic Resistance Pattern of MethicillinResistant Staphylococcus aureus from an Orthopaedic Hospital in Nigeria BioMed Research International; 26(6); 6-7.

WHO, 2015 Foodborne diseases in the WHO African Region.

Yousafzai HA, Rind R, Khan MA, Abro SH, Korejo NA, Ejaz M, Kabir A, Shahid M, Memon S. (2019). Microbiological Contamination of Cattle and Meat in Peshawar, Pakistan. J. Anim. Health Prod. 7(1): 1116. 


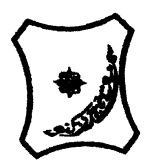

Bayero Journal of Pure and Applied Sciences, 13(1); 40 - 45

Received: September, 2019

Accepted: April, 2020

ISSN $2006-6996$

\title{
BACTERIOLOGICAL QUALITY OF STICK MEAT (Tsire) SOLD IN GARKO LOCAL GOVERNMENT AREA OF KANO STATE, NIGERIA
}

\author{
$*^{1}$ Dahiru A. T. and ${ }^{2}$ Maigari A. K. \\ ${ }^{1}$ Department of Hospitality Management, School of Technology, Kano State Polytechnic, PMB 3348, \\ Kano Nigeria. \\ ${ }^{2}$ Departmnt of Biological Sciences, Bayero University, Kano \\ Corresponding Author: dturajo61@gmail.com; GSM: 08087508262.
}

ABSTRACT

Stick meat, locally called Tsire in Hausa Language, is a significant portion of the diet of a large active population of Northern Nigeria. However, because of the handling and processing methods by the manufacturers as well as the hawking system of stick meat, the meat product may be exposed to both pre- and post-processed product contamination, and thus may poses danger to public health. Therefore, considering the role of Tsire in improving nutrition and increase household income to the populace, the need to improve the processing, distribution and overall quality of the product is simply indispensable. A total of 30 samples (5 samples from each of the 6 sampling points) of Tsire were collected randomly in Garko Town. Aerobic plate counts (APCs) and Total coliform counts (TCCS) of Tsire samples were determined using standard microbiological methods. APCs ranged from $1.02 \times 10^{5}$ to $4.00 \times 10^{5} \mathrm{CFU} / \mathrm{g}$; while TCCs ranged from $8 \mathrm{MPN} / \mathrm{g}$ to $68 \mathrm{MPN} / \mathrm{g}$. From the 30 samples screened, 16(53.33\%) bacteria namely, Campylobacter 2(6.66\%), Escherichia coli 6(20\%), Klebsiella pneumoniae 2(6.66\%), Salmonella spp. 1(3.33\%), Shigella 3(10\%) and Staphylococcus aureus 2(6.66\%) were detected. $E$. coli has the highest isolation rate of 6(20\%), while Salmonella spp. had the least frequency of 1(3.33\%). The distribution of isolated organisms within the study area were as follows: Dausai, 4(80\%), Kofar kudu, 4(80\%), Makwalla, 2(40\%), Rinji, 3(60\%), Tosaro, 2(40\%), and Tsohuwar Kasuwa, 1(20\%). The results have indicated that the Tsire was contaminated with bacteria thus exposing the product to fast deterioration, spoilage and also a vehicle for food borne illness, suggesting for adequate hygienic practices at all the stages, prior to consumption, to ensure safety of the meat product.

Key words: APCs, TCCs, Contamination, Microorganisms, Garko

\section{INTRODUCTION}

Nigeria is one of the developing nations with inadequate food supply and most often deficient in protein content (FAO, 2019). Nigerian's average animal protein intake per head per day is estimated at $7.9 \mathrm{~g}$ as against $35 \mathrm{~g}$ recommended value by Food and Agricultural Organization (Mubarak et al., 2016). These low levels of animal protein intake create great concern as it affects the nutritional status of Nigerians. Hence, there is the need for sufficient supply of animal protein from energy rich animal products to satisfy the nutritional requirements for Nigerians.

Meat is one major source of animal protein largely composed of water, protein and fats which can make it susceptible to microbial contamination within short time leading to spoilage (Apata et al., 2013; Mgbemere et al., 2011). Meat is mostly eaten after it has been cooked or processed in a variety of ways such as sun drying; smoking and roasting with or without fortifications (Borch et al., 1996). In Nigeria meat products such as Tsire, Kilishi and Balangu are locally produced using one or more of these methods in order to meet the nutritional requirements of the teeming Nigerians (Egbebi, 2011).

Tsire is a popular Nigerian traditional processed ready-to-eat roasted stick meat product (Shamsuddeen, 2015). It is sold in public places, along roads, in hotels, parks, quarters and even offices (Falegan et al., 2017). It is prepared from boneless healthy animal flesh such as beef and mutton, spiced with peanut cake, salt, vegetable oil and other flavorings followed by roasting (Shamsuddeen, 2015). Consumption of these products has extended to other parts of African countries such as Ghana, Somali, Cameroun and Chad (Ahmadu and Ibrahim, 2013). 
BAJOPAS Volume 13 Number 1, June, 2020

However, evidence of quality control sticking to procedural hygiene by the handlers during preparation and retailing of these products is poorly documented. Tsire is of great safety risk because of the fact that there are erratic cases of gastroenteritis and symptoms of food infection after consumption (WHO, 2015). Food borne illnesses are one of the major health problems in developing and developed countries (Razavilar, 2010). According to the World Health Organization, WHO (2015), $0.07 \%$ death of the 600 million global burdens of Foodborne illnesses have been reported to be caused by bacteria, viruses, fungi and chemicals. In America $0.27 \%$ of the estimated 48 million affected people is hospitalized and about $0.0063 \%$ deaths are recorded each year (Scallan et al., 2011). More than 91 million people in Africa fall ill and $0.15 \%$ dies each year, making Africa the highest burden bearer of Foodborne diseases per population (WHO, 2015).

Application of a Hazard Analysis Critical Control Point (HACCP) at all stages of meat products preparation is essential in order to ensure its safety. Thus, according to the guidelines of good manufacturing practice, the level of total aerobic bacterial contamination of thermally processed meat products should not exceed $10^{4}\left(\mathrm{cfu} \mathrm{g}^{-1}\right)$. Enterobacteriaceae and faecal coliform contamination in meat products should be within the range of $10^{2}-10^{4}$ and $10-10^{3} \mathrm{cfu} \mathrm{g}^{-1}$, respectively (Shamsuddeen, 2015). The aim of the study is therefore, to assess the total viable bacterial counts of tsire marketed locally within Garko town, and to isolate and identify the organisms at the point of consumption with the intention of promoting public health and food hygiene habits in the Nigerian populace.

\section{MATERIALS AND METHODS Study Area and Population}

Garko is one of the existing 44 local government areas located in Kano south west zone of Kano state with its capital administrative headquarters in the Garko town. It has coordinates $11^{\circ} 39^{\prime} \mathrm{N}$ $8^{\circ} 54^{\prime} \mathrm{E}$, and an area of $450 \mathrm{~km}^{2}$. The projected population of Garko local Government was 225,300 according to the National Population Census report (2018). Garko is known for agricultural activities both farming and animal husbandry. It is popularly known for large scale rice production. Other food crops include sweet potatoes, cassava, onions, sorghum, millet and sugarcane. Cows, sheep and goats are major groups of animals reared by majority of the populace. Meat products processed, retailed and consumed in Garko include roasted meat (Balangu), dried roasted meat (Kilishi), stick meat (Tsire), hide and skin pepper soup (Ragadada) and minced fried meat (Danbunnama).

\section{Samples Collection}

Five samples of Tsire products were collected from 6 different identified locations within Garko town in a sterile foil paper and immediately analyzed for the presence of bacteria.

\section{Sample Preparation}

Sample preparation for the bacteriological analysis was carried out in accordance with the method described by Atlas (1997). Twenty five grams $(25 \mathrm{~g})$ of the sample was homogenized in $225 \mathrm{ml}$ peptone water using Kenwood blender machine to obtain a $10^{1}$ homogenate. The homogenate was thoroughly shaken and $1 \mathrm{ml}$ pipetted into test tubes containing $9 \mathrm{ml}$ of peptone water $\left(10^{2}\right)$. The test tubes were further serially diluted to $10^{5}$.

Total Aerobic Mesophilic Bacterial Count

Total Aerobic mesophilic bacterial count was determined using the method described by Abdullahi et al. (2004) where $1 \mathrm{ml}$ of inoculums from $10^{1}$ to $10^{5}$ dilutions were transferred into duplicate Petri dishes and labeled accordingly. This was followed by pouring aseptically about $15 \mathrm{ml}$ of molten nutrient agar. The culture was homogenized by gentle spinning of the plates and allowed to solidify. The plates were incubated at $37^{\circ} \mathrm{C}$ for 24 hours. Plates containing 30-300 colonies were counted. The number of colony forming units per gram of a sample (cfu/g) was obtained by multiplying the average colony number with the inverse of the dilution factor.

\section{Enumeration and Detection of Coliform bacteria}

Detection and enumeration of coliform was carried out according to method described by Atlas, (1977). A set of 9 test tubes each containing $9 \mathrm{ml}$ of lactose broth and an inverted Durham tubes were autoclaved to expel air and to sterilize. Similarly, $1 \mathrm{ml}$ from the diluents $10^{1}$ was transferred to the first 3 test tubes, followed by $1 \mathrm{ml}$ from the diluents $10^{2}$ to the second set of 3 test tubes and finally the third diluents $10^{3}$ to the $3^{\text {rd }}$ set of 3 test tubes. All the 9 test tubes were incubated at $37^{\circ} \mathrm{C}$ for 24 hours. Tubes that showed gas and acid production after 24 hours were recorded as positive for the presence of Coliform. Negative tubes were further reincubated for 24 hours. Positive tubes were recorded. Estimate of most probable number of Coliform per gram of sample (MPN/g) was determined by comparing the number of gas positive tubes with the most probable number table. 
BAJOPAS Volume 13 Number 1, June, 2020 Identification of Coliform

A loop full of inoculum from gas positive tubes was streaked on to Eosine methylene blue (EMB) agar plate and incubated at $37^{\circ} \mathrm{C}$ for $24 \mathrm{hrs}$. Colonies which formed bluish black color with green metallic sheen, and reddish colonies were isolated on agar slants. Those colonies showing metallic sheen on EMB were sub cultured into tubes of lactose broth and incubated at $45^{\circ} \mathrm{C}$. The tubes were observed after $24 \mathrm{hrs}$ for gas production. This is the completed test for fecal coliform. Gram stain and other biochemical tests such as Indole, Methyl red, Voges-Proskauer and Citrate Utilization tests (IMVIC), Coagulase and Catalase tests were carried out for the Identification and confirmation of isolates.

\section{Procedure for Indole Test}

Indole test was carried out by preparing a Tryptone broth drawn in to test tubes, sterilized by autoclaving, inoculated with loopful of suspension and incubated at $37^{\circ} \mathrm{C}$ for 24 hours. Three drops of xylene was added in tubes, shaken vigorously and kept for the separation of two layers. One millilitre of Kovac's reagent was added and the formation of pink colour ring indicates positive Indole test.

\section{Procedure for Methyl Red Test}

Methyl red test was carried out by preparing Glucose phosphate broth, dispensed in test tubes, sterilized, inoculated with test culture and incubated at $37^{\circ} \mathrm{C}$ for 24 hours. Five drops of methyl-red indicator was added to the medium for the formation of red colour.

\section{Procedure for Voges-Proskauer Test}

Voges-Proskauer test was carried out by inoculating tubes with the bacterial culture followed by incubation for 48 hours at $37^{\circ} \mathrm{C}$. Separate pipettes were used to pipette $1 \mathrm{ml}$ from each culture tube into clean separate tubes. Eighteen drops $(0.5 \mathrm{ml})$ of Barrit's solution A (a-naphthol) was added to each tube containing glucose phosphate broth followed by the addition of an equal amount of solution $B$ into the same tube. The tubes were shaken at 30 seconds interval. A positive reaction was indicated by the development of a pink color, which turns red in 1-2 hours, after vigorous shaking.

\section{Procedure for Citrate Utilization Test}

Citrate Utilization Test was carried out by distributing melted agar (Simmon Citrate Agar) in to test tubes followed by sterilization at $121.5^{\circ} \mathrm{C}$ for 15 minutes. The test tubes were afterward held in slanted position, inoculated with the given bacterial culture and incubated at $37^{\circ} \mathrm{C}$ for $24 \mathrm{hrs}$. Positive test was indicated by color change of the media from green to blue.

\section{RESULTS AND DISCUSSIONS}

The results of this study are presented in tables $1,2,3$ and 4. Among the sampling areas Kofar Kudu had the highest aerobic mesophilic bacteria counts $4.0 \times 10^{5} \mathrm{cfu} / \mathrm{g}$ followed by Rinji $2.72 \times 10^{5} \mathrm{cfu} / \mathrm{g}$, while Tosaro had the least Aerobic mesophilic bacteria counts of $1.02 \times 10^{5}$ $\mathrm{cfu} / \mathrm{g}$ as indicated in Table 1.Makwalla had the highest coliform count $68 \mathrm{MPN} / \mathrm{g}$ followed by Rinji $37 \mathrm{MPN} / \mathrm{g}$. Tsohuwar Kasuwa had the least coliform counts $8 \mathrm{MPN} / \mathrm{g}$, (Table 2). Result from table 1 shows variation in the microbial contents among the samples which suggest variation in their sources, poor handling procedures and contamination from the processing environment. High coliform count and their differences within sampling areas is an indication of poor microbiological quality of the product. Ndahi et al. (2013) reported microbial load to be a function of the handling personnel and the environment. The results indicated that the samples were contaminated with bacteria as the counts exceeded the minimum safety level $\left(10^{4} \mathrm{cfu} / \mathrm{g}\right)$ for members of the Enterobacteriaceae family. However, it might be a reflection of poor hygienic practices which may contribute to health hazard to the potential consumers. Similarly, Inusa and Sa'id (2017); Osimani et al. (2015) reported that, the initial microbial content of the raw material play significant role in influencing the final microbial load of the finished product. Isolation of members of the Enterobacteriaceae such as $E$. coli, Klebsiella pneumoniae, Salmonella and Shigella signifies danger to the public health. These organisms are capable of producing endotoxins which trigger high fevers in infected individuals, and the enterotoxins which colonize the small intestines and lead to extreme dehydration as a result of vomiting and diarrhea sometimes with severe and fatal outcomes (Amaeze et al., 2016). From the 16 isolated organisms $E$. coli had the highest isolation rate $6(37.5 \%)$ (Table 3), this suggest faecal contamination of the products. $E$. coli is a common flora in the gastrointestinal tract responsible for diarrhea and extra-intestinal infections (CDC, 2011). The result is in conformity with the findings of Ndahi et al. (2013) and Shamsuddeen (2009). Also presence of campylobacter might be due to cross contamination from raw meat to finished product (Tsire). Staphylococcus aureus is a normal flora of the skin, nasal, genital, mouth or anal area in both humans and animals without any symptom of an infection (Matthew et al., 2013). Isolation of $S$. aureus in these study concords with the findings of Lucretia et al. (2018) from Suya sold in Rivers State. 
BAJOPAS Volume 13 Number 1, June, 2020

It is also in agreement with the findings of Yousafzai et al. (2018); Onuorah et al. (2015) and Tijjani and Jumare (2014) from tsire samples in different countries. Presence of $S$. aureus in foods is most of the time an indication of poor human handling, poor environment, unhygienic utensils and equipments used during processing (Igene et al., 2016; Okonko et al., 2013). Infections caused by $S$. aureus are difficult to treat leading to long hospitalization with consequent economic loss (Udobi et al., 2013). These include soft tissue infections, pneumonia, hospital-acquired postoperative wound infections, Staphylococcal food poisoning, impetigo and cellulitis (Charlene et al., 2013). Samples obtained from Dausai and Kofar Kudu had the highest isolation rate $4(80 \%)$ (Table 4 ) probably because of the much commercial activities taking place in the area which can lead to environmental contamination.

Table 1: Total Aerobic Mesophilic Bacterial Count of Tsire sold in Garko Town

\begin{tabular}{lll}
\hline Sampling Area & APC cfu/g & Mean \pm STD \\
\hline Dausai & $2.20 \times 10^{5}$ & $110000 \pm 14142.14$ \\
Kofar Kudu & $4.00 \times 10^{5}$ & $133333.3 \pm 23094.01$ \\
Makwalla & $1.30 \times 10^{5}$ & $32500 \pm 7187.953$ \\
Rinji & $2.72 \times 10^{5}$ & $90666.67 \pm 94769.90$ \\
Tosaro & $1.02 \times 10^{5}$ & $51000 \pm 15556.35$ \\
Tsohuwar Kasuwa & $1.75 \times 10^{5}$ & $35000 \pm 11357.82$ \\
\hline
\end{tabular}

Key: APC: Aerobic Mesophilic Counts

STD: Standard Deviation

Table 2: Total Coliform Count of Tsire sold in Garko Town

\begin{tabular}{lcc}
\hline \multicolumn{1}{c}{ Sampling Area } & TCC MPN/g & Mean \pm STD \\
\hline Dausai & 20 & $6.67 \pm 2.5166$ \\
Kofar Kudu & 32 & $16.00 \pm 5.6569$ \\
Makwalla & 68 & $13.60 \pm 8.7062$ \\
Rinji & 37 & $9.25 \pm 4.7871$ \\
Tosaro & 10 & $5.00 \pm 2.8284$ \\
Tsohuwar Kasuwa & 8 & $4.00 \pm 0.0000$ \\
\hline
\end{tabular}

Table 3: Organisms Isolated from Tsire Sold in Garko

\begin{tabular}{lcl}
\hline Isolated Organism & Frequency & Percentage (\%) \\
\hline Campylobacter & 2 & 06.66 \\
Escherichia coli & 6 & 20.00 \\
Klebsiella pneumoniae & 2 & 06.66 \\
Salmonella species & 1 & 03.33 \\
Shigella & 3 & 10.00 \\
Staphylococcus aureus & 2 & 06.66 \\
Total & 16 & \\
\hline
\end{tabular}

Table 4: Distribution of Organisms within Sampling Area

\begin{tabular}{lcc}
\hline \multicolumn{1}{c}{ Sampling Area } & No. Isolated & Percentage (\%) \\
\hline Dausai & 4 & 80 \\
Kofar Kudu & 4 & 80 \\
Makwalla & 2 & 40 \\
Rinji & 3 & 60 \\
Tosaro & 2 & 40 \\
Tsohuwar Kasuwa & 1 & 20 \\
Total & 16 & \\
\hline
\end{tabular}

\section{CONCLUSION}

Results indicated $4.00 \times 10^{5} \mathrm{CFU} / \mathrm{g}$ as the highest APCs count; while $68 \mathrm{MPN} / \mathrm{g}$ was the highest TCCs from the 30 samples analyzed. Among the isolates, $E$. coli has the highest isolation rate of $6(20 \%)$. Dausai and Kofar kudu were having the highest bacteria count of $4(80 \%)$, each, indicating higher contamination in those locations. 
BAJOPAS Volume 13 Number 1, June, 2020 RECOMMENDATIONS

The following recommendations are tenable:

1. Hygienic practices at all stages of production should be improved to safe guard the consumers against potential health hazard.

2. Monitoring of microbiological contamination of Tsire during preparations, packaging and marketing is essential to ensure product of good microbiological quality for consumers' health.

\section{REFERENCES}

Abdullahi, I. O., Umoh, V. J. and Galadima, M. (2004). Hazards Associated with Kilishi Preparations in Zaria. Nigerian Journal of Microbiology, 18 (1-2): $339-345$.

Ahmadu, J. and Ibrahim E. J., (2013): Determinants of Revenue in Suya Production in BeninCity, Edo State, Nigeria. Nigerian journal of agriculture, food and environment.9(3):1-5

Amaeze, N. Aboh, M. Itohan, A. Felix, E. Olatunji, T. and Oladosu, P. (2016) Microbial Profile, Antibiotic Sensitivity and Heat Resistance of Bacterial Isolates from Commercial Roasted Beef (Suya) in Abuja, Nigeria. JOPAT, 15(2): $22-30$.

Apata, E.S., Kuku1, I.A., Apata, O.C. and Adeyemi, K.O. (2013). Evaluation of Suya(Tsire) - An Intermediate Moisture Meat Product in Ogun State, Nigeria. J. Food Res 2 (1): 87.

Atlas, R. M. (1997) Principles of Microbiology Second Edition. C. Brown Publishers. Pp 802-803.

Borch, E. Kant-Muermans, M. L., Blixt, Y. (1996) Bacterial Spoilage of Meat and Cured Meat Products. Int $\mathrm{J}$ Food Microbiol .33(1): 103-20.

Centre for Disease Control, CDC (2011). "Escherichia coli 0157:H7" Division of Bacterial and Mycotic Diseasesht://www.cdc.gov/nczved/divisi ons/dfbmd/diseases/ecoli_0157h7/.

Charlene, R. J., Johnnie, A. D., and John, B. B., (2013) Prevalence and Characterization of Methicillin-Resistant Staphylococcus aureus Isolates from Retail Meat and Humans in Georgia. American society for Microbiology. J. of clinical microbiology. 12(1):123-6 doi:10.1128/JCM.0316612JCM.03166-12

Egbebi, A.O and Seidu, K., T. (2011). Microbiological Evaluation of Suya (dried smoked

meat) Sold in Ado and Akure, South West Nigeria.European Journal of Experinmental Biology, 1(4):1-5
3. Government should establish regulatory bodies responsible for inculcating hygiene habits to the local producers and vendors in order to prevent instant, cross and post processing contaminations by microbial pathogens.

4. Awareness and sensitization of local food producers about good hygienic practices in food handling and processing.

Falegan, C, R., Akoja, S. D., and Oyarekua, M. A., (2017) Microbiological Assessment of Suya (Sliced Roasted Beef) in Ado-Ekiti Metropolis, Ekiti State, Nigeria. MOJ Biology andMedicine.

Fonkem, D., N. Tanya, V., N. and Ebangi, A., L. (2010). Effect of Season on the Microbiological Quality of Kilishi, a Traditional Cameroonian Dried Beef Product. Tropicultura, 28(1): 10-15.

Food and Agricultural Organization of the United Nations (F A O, 1979). Manual of food quality control 4. Microbiological analysis.

Food and Agriculture Organisation of the United Nation (FAO), 2019. Nigeria at a glance.

Igene J.O., Uwadia, O.E., Ebabhamiegbebho, P.A. and Evivie, S.E., (2016) Shelf life Stability Studies of University of Benin (UNIBEN) Proff's Kilishi Product Asian Journal of Science and Technology 7(1): 2268-2274.

Inusa, S. K. and Said, I. S. (2017) Evaluation of the Chemical and Microbiological Properties Of Kilishi Sold in Kano Metropolis. Journal of Dry land Agriculture, 3 (1): $59-69$.

Lucretia, I. B, Patience, C. Obinna-Echem, Sophia, C. A. (2018) Microbiological quality andantibiotic sensitivity of potential pathogens isolated from meat product (Suya) sold in Rivers State University and its environs. International Journal of Biotechnology and Food Science, 6(4): 67-76.

Matthew, E., Drosos, E., John, L. and Ioanna, P. (2013) MRSA in Africa: Filling the Global Map of Antimicrobial Resistance PLOS One. 8(7): e68024 doi: 10.1371/journal.pone.0068024

Mgbemere, V.N., Akpapunam, M. A. and Igene, J. O., (2011). Effect of Groundnut FlourSubstitution on Yield, Quality and Storage Stability of Kilishi - a Nigerian Indigenous Dried Meat Product. African Journal of Food, Agriculture, Nutrition and Development, $\quad \mathbf{1 1}(2)$ : 4718-4738. 
BAJOPAS Volume 13 Number 1, June, 2020

Mubarak, A. A., Azeez, M. L., Amos A. O., Opeyemi, O. O. (2016) Assessment of Animal Protein Consumption and Food Security Among Rural Households in Kwara State, Nigeria American Journal of Business and Society, 1(4): 233245.

Ndahi, M., D. Kwaga, J., K. P. Bello, M. Kabir J., V. Umoh, .J. Yakubu, S., E. and Nok, A., J. (2013) Prevalence and Antimicrobial Susceptibility of Listeria Monocytogenes and Methicillin-Resistant Staphylococcus aureus Strains from Raw Meat and Meat Products in Zaria, Nigeria. Applied Journal of Microbiology, 58(3):262-9.

Okonko, I.O., Odu, N.N. and Igboh, I.E. (2013). Microbiological Analysis of Kilishi Sold In Port Harcourt, Nigeria. New York Science Journal, 6 (7):37-43.

Osimani, A., Aquilanti, L. and Clementi, F. (2015) Microbiological Quality of Meatbased Meals and Operation of Control Systems within a Food Service Environment. International Food Research Journal 22(4): 1692-1698.

Onuorah, S. Obika, I. Odibo, F. Orji, M. (2015)An Assessment of the Bacteriological Quality of Tsire-Suya (Grilled Beef) sold in Awka, Nigeria. American. J. Life. Sci. Res. 3(4):287292.

Razavilar, V, Khandaghi, J. Barzgari, A. (2010); Isolation of Eschericia coli 0157:H7 from manure fertilized farms and raw vegetables grown on it, in Tabriz city in
Iran. African Journal of Microbiology Research, 4(9): 891-895.

Scallan, E. Hoekstra, R. M. Angulo, F. J.Tauxe, R. V, Widdowson, M. Roy, S. L et al., (2011).Food borne illness acquired in the United States- Major Pathogens. Emerg. Infec Dis, 17(1): 7-15.

Shamsuddeen U (2009). Microbiological quality of spice used in the production of Kilishi a traditionally dried and grilled meat product. Bayero Journal of Pure andApplied Sciences, 2(2): 66-69.

Shamsuddeen, U. (2015) Microbiological Hazard and Critical control point Analysis of Dried and Minced Meat Snacks Produced in Kano Nigeria. Lambert Academic Publishing; Pp 1-36.

Tijani, O.and Jumare, S. (2014). Microblological Quality Assessment of Meat

Sold in KauraNamoda. International Conference on Earth, Environment and Life sciences (EELS) Dubai (UAE).

Udobi, C. E., Obajuluwa, A. F., and Onaolapo, J. A., (2013) Prevalence and Antibiotic Resistance Pattern of MethicillinResistant Staphylococcus aureus from an Orthopaedic Hospital in Nigeria BioMed Research International; 26(6); 6-7.

WHO, 2015 Foodborne diseases in the WHO African Region.

Yousafzai HA, Rind R, Khan MA, Abro SH, Korejo NA, Ejaz M, Kabir A, Shahid M, Memon S. (2019). Microbiological Contamination of Cattle and Meat in Peshawar, Pakistan. J. Anim. Health Prod. 7(1): 1116. 


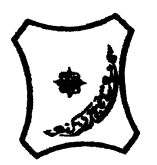

Bayero Journal of Pure and Applied Sciences, 13(1); 40 - 45

Received: September, 2019

Accepted: April, 2020

ISSN $2006-6996$

\title{
BACTERIOLOGICAL QUALITY OF STICK MEAT (Tsire) SOLD IN GARKO LOCAL GOVERNMENT AREA OF KANO STATE, NIGERIA
}

\author{
$*^{1}$ Dahiru A. T. and ${ }^{2}$ Maigari A. K. \\ ${ }^{1}$ Department of Hospitality Management, School of Technology, Kano State Polytechnic, PMB 3348, \\ Kano Nigeria. \\ ${ }^{2}$ Departmnt of Biological Sciences, Bayero University, Kano \\ Corresponding Author: dturajo61@gmail.com; GSM: 08087508262.
}

ABSTRACT

Stick meat, locally called Tsire in Hausa Language, is a significant portion of the diet of a large active population of Northern Nigeria. However, because of the handling and processing methods by the manufacturers as well as the hawking system of stick meat, the meat product may be exposed to both pre- and post-processed product contamination, and thus may poses danger to public health. Therefore, considering the role of Tsire in improving nutrition and increase household income to the populace, the need to improve the processing, distribution and overall quality of the product is simply indispensable. A total of 30 samples (5 samples from each of the 6 sampling points) of Tsire were collected randomly in Garko Town. Aerobic plate counts (APCs) and Total coliform counts (TCCS) of Tsire samples were determined using standard microbiological methods. APCs ranged from $1.02 \times 10^{5}$ to $4.00 \times 10^{5} \mathrm{CFU} / \mathrm{g}$; while TCCs ranged from $8 \mathrm{MPN} / \mathrm{g}$ to $68 \mathrm{MPN} / \mathrm{g}$. From the 30 samples screened, 16(53.33\%) bacteria namely, Campylobacter 2(6.66\%), Escherichia coli 6(20\%), Klebsiella pneumoniae 2(6.66\%), Salmonella spp. 1(3.33\%), Shigella 3(10\%) and Staphylococcus aureus 2(6.66\%) were detected. $E$. coli has the highest isolation rate of 6(20\%), while Salmonella spp. had the least frequency of 1(3.33\%). The distribution of isolated organisms within the study area were as follows: Dausai, 4(80\%), Kofar kudu, 4(80\%), Makwalla, 2(40\%), Rinji, 3(60\%), Tosaro, 2(40\%), and Tsohuwar Kasuwa, 1(20\%). The results have indicated that the Tsire was contaminated with bacteria thus exposing the product to fast deterioration, spoilage and also a vehicle for food borne illness, suggesting for adequate hygienic practices at all the stages, prior to consumption, to ensure safety of the meat product.

Key words: APCs, TCCs, Contamination, Microorganisms, Garko

\section{INTRODUCTION}

Nigeria is one of the developing nations with inadequate food supply and most often deficient in protein content (FAO, 2019). Nigerian's average animal protein intake per head per day is estimated at $7.9 \mathrm{~g}$ as against $35 \mathrm{~g}$ recommended value by Food and Agricultural Organization (Mubarak et al., 2016). These low levels of animal protein intake create great concern as it affects the nutritional status of Nigerians. Hence, there is the need for sufficient supply of animal protein from energy rich animal products to satisfy the nutritional requirements for Nigerians.

Meat is one major source of animal protein largely composed of water, protein and fats which can make it susceptible to microbial contamination within short time leading to spoilage (Apata et al., 2013; Mgbemere et al., 2011). Meat is mostly eaten after it has been cooked or processed in a variety of ways such as sun drying; smoking and roasting with or without fortifications (Borch et al., 1996). In Nigeria meat products such as Tsire, Kilishi and Balangu are locally produced using one or more of these methods in order to meet the nutritional requirements of the teeming Nigerians (Egbebi, 2011).

Tsire is a popular Nigerian traditional processed ready-to-eat roasted stick meat product (Shamsuddeen, 2015). It is sold in public places, along roads, in hotels, parks, quarters and even offices (Falegan et al., 2017). It is prepared from boneless healthy animal flesh such as beef and mutton, spiced with peanut cake, salt, vegetable oil and other flavorings followed by roasting (Shamsuddeen, 2015). Consumption of these products has extended to other parts of African countries such as Ghana, Somali, Cameroun and Chad (Ahmadu and Ibrahim, 2013). 
BAJOPAS Volume 13 Number 1, June, 2020

However, evidence of quality control sticking to procedural hygiene by the handlers during preparation and retailing of these products is poorly documented. Tsire is of great safety risk because of the fact that there are erratic cases of gastroenteritis and symptoms of food infection after consumption (WHO, 2015). Food borne illnesses are one of the major health problems in developing and developed countries (Razavilar, 2010). According to the World Health Organization, WHO (2015), $0.07 \%$ death of the 600 million global burdens of Foodborne illnesses have been reported to be caused by bacteria, viruses, fungi and chemicals. In America $0.27 \%$ of the estimated 48 million affected people is hospitalized and about $0.0063 \%$ deaths are recorded each year (Scallan et al., 2011). More than 91 million people in Africa fall ill and $0.15 \%$ dies each year, making Africa the highest burden bearer of Foodborne diseases per population (WHO, 2015).

Application of a Hazard Analysis Critical Control Point (HACCP) at all stages of meat products preparation is essential in order to ensure its safety. Thus, according to the guidelines of good manufacturing practice, the level of total aerobic bacterial contamination of thermally processed meat products should not exceed $10^{4}\left(\mathrm{cfu} \mathrm{g}^{-1}\right)$. Enterobacteriaceae and faecal coliform contamination in meat products should be within the range of $10^{2}-10^{4}$ and $10-10^{3} \mathrm{cfu} \mathrm{g}^{-1}$, respectively (Shamsuddeen, 2015). The aim of the study is therefore, to assess the total viable bacterial counts of tsire marketed locally within Garko town, and to isolate and identify the organisms at the point of consumption with the intention of promoting public health and food hygiene habits in the Nigerian populace.

\section{MATERIALS AND METHODS Study Area and Population}

Garko is one of the existing 44 local government areas located in Kano south west zone of Kano state with its capital administrative headquarters in the Garko town. It has coordinates $11^{\circ} 39^{\prime} \mathrm{N}$ $8^{\circ} 54^{\prime} \mathrm{E}$, and an area of $450 \mathrm{~km}^{2}$. The projected population of Garko local Government was 225,300 according to the National Population Census report (2018). Garko is known for agricultural activities both farming and animal husbandry. It is popularly known for large scale rice production. Other food crops include sweet potatoes, cassava, onions, sorghum, millet and sugarcane. Cows, sheep and goats are major groups of animals reared by majority of the populace. Meat products processed, retailed and consumed in Garko include roasted meat (Balangu), dried roasted meat (Kilishi), stick meat (Tsire), hide and skin pepper soup (Ragadada) and minced fried meat (Danbunnama).

\section{Samples Collection}

Five samples of Tsire products were collected from 6 different identified locations within Garko town in a sterile foil paper and immediately analyzed for the presence of bacteria.

\section{Sample Preparation}

Sample preparation for the bacteriological analysis was carried out in accordance with the method described by Atlas (1997). Twenty five grams $(25 \mathrm{~g})$ of the sample was homogenized in $225 \mathrm{ml}$ peptone water using Kenwood blender machine to obtain a $10^{1}$ homogenate. The homogenate was thoroughly shaken and $1 \mathrm{ml}$ pipetted into test tubes containing $9 \mathrm{ml}$ of peptone water $\left(10^{2}\right)$. The test tubes were further serially diluted to $10^{5}$.

Total Aerobic Mesophilic Bacterial Count

Total Aerobic mesophilic bacterial count was determined using the method described by Abdullahi et al. (2004) where $1 \mathrm{ml}$ of inoculums from $10^{1}$ to $10^{5}$ dilutions were transferred into duplicate Petri dishes and labeled accordingly. This was followed by pouring aseptically about $15 \mathrm{ml}$ of molten nutrient agar. The culture was homogenized by gentle spinning of the plates and allowed to solidify. The plates were incubated at $37^{\circ} \mathrm{C}$ for 24 hours. Plates containing 30-300 colonies were counted. The number of colony forming units per gram of a sample (cfu/g) was obtained by multiplying the average colony number with the inverse of the dilution factor.

\section{Enumeration and Detection of Coliform bacteria}

Detection and enumeration of coliform was carried out according to method described by Atlas, (1977). A set of 9 test tubes each containing $9 \mathrm{ml}$ of lactose broth and an inverted Durham tubes were autoclaved to expel air and to sterilize. Similarly, $1 \mathrm{ml}$ from the diluents $10^{1}$ was transferred to the first 3 test tubes, followed by $1 \mathrm{ml}$ from the diluents $10^{2}$ to the second set of 3 test tubes and finally the third diluents $10^{3}$ to the $3^{\text {rd }}$ set of 3 test tubes. All the 9 test tubes were incubated at $37^{\circ} \mathrm{C}$ for 24 hours. Tubes that showed gas and acid production after 24 hours were recorded as positive for the presence of Coliform. Negative tubes were further reincubated for 24 hours. Positive tubes were recorded. Estimate of most probable number of Coliform per gram of sample (MPN/g) was determined by comparing the number of gas positive tubes with the most probable number table. 
BAJOPAS Volume 13 Number 1, June, 2020 Identification of Coliform

A loop full of inoculum from gas positive tubes was streaked on to Eosine methylene blue (EMB) agar plate and incubated at $37^{\circ} \mathrm{C}$ for $24 \mathrm{hrs}$. Colonies which formed bluish black color with green metallic sheen, and reddish colonies were isolated on agar slants. Those colonies showing metallic sheen on EMB were sub cultured into tubes of lactose broth and incubated at $45^{\circ} \mathrm{C}$. The tubes were observed after $24 \mathrm{hrs}$ for gas production. This is the completed test for fecal coliform. Gram stain and other biochemical tests such as Indole, Methyl red, Voges-Proskauer and Citrate Utilization tests (IMVIC), Coagulase and Catalase tests were carried out for the Identification and confirmation of isolates.

\section{Procedure for Indole Test}

Indole test was carried out by preparing a Tryptone broth drawn in to test tubes, sterilized by autoclaving, inoculated with loopful of suspension and incubated at $37^{\circ} \mathrm{C}$ for 24 hours. Three drops of xylene was added in tubes, shaken vigorously and kept for the separation of two layers. One millilitre of Kovac's reagent was added and the formation of pink colour ring indicates positive Indole test.

\section{Procedure for Methyl Red Test}

Methyl red test was carried out by preparing Glucose phosphate broth, dispensed in test tubes, sterilized, inoculated with test culture and incubated at $37^{\circ} \mathrm{C}$ for 24 hours. Five drops of methyl-red indicator was added to the medium for the formation of red colour.

\section{Procedure for Voges-Proskauer Test}

Voges-Proskauer test was carried out by inoculating tubes with the bacterial culture followed by incubation for 48 hours at $37^{\circ} \mathrm{C}$. Separate pipettes were used to pipette $1 \mathrm{ml}$ from each culture tube into clean separate tubes. Eighteen drops $(0.5 \mathrm{ml})$ of Barrit's solution A (a-naphthol) was added to each tube containing glucose phosphate broth followed by the addition of an equal amount of solution $B$ into the same tube. The tubes were shaken at 30 seconds interval. A positive reaction was indicated by the development of a pink color, which turns red in 1-2 hours, after vigorous shaking.

\section{Procedure for Citrate Utilization Test}

Citrate Utilization Test was carried out by distributing melted agar (Simmon Citrate Agar) in to test tubes followed by sterilization at $121.5^{\circ} \mathrm{C}$ for 15 minutes. The test tubes were afterward held in slanted position, inoculated with the given bacterial culture and incubated at $37^{\circ} \mathrm{C}$ for $24 \mathrm{hrs}$. Positive test was indicated by color change of the media from green to blue.

\section{RESULTS AND DISCUSSIONS}

The results of this study are presented in tables $1,2,3$ and 4. Among the sampling areas Kofar Kudu had the highest aerobic mesophilic bacteria counts $4.0 \times 10^{5} \mathrm{cfu} / \mathrm{g}$ followed by Rinji $2.72 \times 10^{5} \mathrm{cfu} / \mathrm{g}$, while Tosaro had the least Aerobic mesophilic bacteria counts of $1.02 \times 10^{5}$ $\mathrm{cfu} / \mathrm{g}$ as indicated in Table 1.Makwalla had the highest coliform count $68 \mathrm{MPN} / \mathrm{g}$ followed by Rinji $37 \mathrm{MPN} / \mathrm{g}$. Tsohuwar Kasuwa had the least coliform counts $8 \mathrm{MPN} / \mathrm{g}$, (Table 2). Result from table 1 shows variation in the microbial contents among the samples which suggest variation in their sources, poor handling procedures and contamination from the processing environment. High coliform count and their differences within sampling areas is an indication of poor microbiological quality of the product. Ndahi et al. (2013) reported microbial load to be a function of the handling personnel and the environment. The results indicated that the samples were contaminated with bacteria as the counts exceeded the minimum safety level $\left(10^{4} \mathrm{cfu} / \mathrm{g}\right)$ for members of the Enterobacteriaceae family. However, it might be a reflection of poor hygienic practices which may contribute to health hazard to the potential consumers. Similarly, Inusa and Sa'id (2017); Osimani et al. (2015) reported that, the initial microbial content of the raw material play significant role in influencing the final microbial load of the finished product. Isolation of members of the Enterobacteriaceae such as $E$. coli, Klebsiella pneumoniae, Salmonella and Shigella signifies danger to the public health. These organisms are capable of producing endotoxins which trigger high fevers in infected individuals, and the enterotoxins which colonize the small intestines and lead to extreme dehydration as a result of vomiting and diarrhea sometimes with severe and fatal outcomes (Amaeze et al., 2016). From the 16 isolated organisms $E$. coli had the highest isolation rate $6(37.5 \%)$ (Table 3), this suggest faecal contamination of the products. $E$. coli is a common flora in the gastrointestinal tract responsible for diarrhea and extra-intestinal infections (CDC, 2011). The result is in conformity with the findings of Ndahi et al. (2013) and Shamsuddeen (2009). Also presence of campylobacter might be due to cross contamination from raw meat to finished product (Tsire). Staphylococcus aureus is a normal flora of the skin, nasal, genital, mouth or anal area in both humans and animals without any symptom of an infection (Matthew et al., 2013). Isolation of $S$. aureus in these study concords with the findings of Lucretia et al. (2018) from Suya sold in Rivers State. 
BAJOPAS Volume 13 Number 1, June, 2020

It is also in agreement with the findings of Yousafzai et al. (2018); Onuorah et al. (2015) and Tijjani and Jumare (2014) from tsire samples in different countries. Presence of $S$. aureus in foods is most of the time an indication of poor human handling, poor environment, unhygienic utensils and equipments used during processing (Igene et al., 2016; Okonko et al., 2013). Infections caused by $S$. aureus are difficult to treat leading to long hospitalization with consequent economic loss (Udobi et al., 2013). These include soft tissue infections, pneumonia, hospital-acquired postoperative wound infections, Staphylococcal food poisoning, impetigo and cellulitis (Charlene et al., 2013). Samples obtained from Dausai and Kofar Kudu had the highest isolation rate $4(80 \%)$ (Table 4 ) probably because of the much commercial activities taking place in the area which can lead to environmental contamination.

Table 1: Total Aerobic Mesophilic Bacterial Count of Tsire sold in Garko Town

\begin{tabular}{lll}
\hline Sampling Area & APC cfu/g & Mean \pm STD \\
\hline Dausai & $2.20 \times 10^{5}$ & $110000 \pm 14142.14$ \\
Kofar Kudu & $4.00 \times 10^{5}$ & $133333.3 \pm 23094.01$ \\
Makwalla & $1.30 \times 10^{5}$ & $32500 \pm 7187.953$ \\
Rinji & $2.72 \times 10^{5}$ & $90666.67 \pm 94769.90$ \\
Tosaro & $1.02 \times 10^{5}$ & $51000 \pm 15556.35$ \\
Tsohuwar Kasuwa & $1.75 \times 10^{5}$ & $35000 \pm 11357.82$ \\
\hline
\end{tabular}

Key: APC: Aerobic Mesophilic Counts

STD: Standard Deviation

Table 2: Total Coliform Count of Tsire sold in Garko Town

\begin{tabular}{lcc}
\hline \multicolumn{1}{c}{ Sampling Area } & TCC MPN/g & Mean \pm STD \\
\hline Dausai & 20 & $6.67 \pm 2.5166$ \\
Kofar Kudu & 32 & $16.00 \pm 5.6569$ \\
Makwalla & 68 & $13.60 \pm 8.7062$ \\
Rinji & 37 & $9.25 \pm 4.7871$ \\
Tosaro & 10 & $5.00 \pm 2.8284$ \\
Tsohuwar Kasuwa & 8 & $4.00 \pm 0.0000$ \\
\hline
\end{tabular}

Table 3: Organisms Isolated from Tsire Sold in Garko

\begin{tabular}{lcl}
\hline Isolated Organism & Frequency & Percentage (\%) \\
\hline Campylobacter & 2 & 06.66 \\
Escherichia coli & 6 & 20.00 \\
Klebsiella pneumoniae & 2 & 06.66 \\
Salmonella species & 1 & 03.33 \\
Shigella & 3 & 10.00 \\
Staphylococcus aureus & 2 & 06.66 \\
Total & 16 & \\
\hline
\end{tabular}

Table 4: Distribution of Organisms within Sampling Area

\begin{tabular}{lcc}
\hline \multicolumn{1}{c}{ Sampling Area } & No. Isolated & Percentage (\%) \\
\hline Dausai & 4 & 80 \\
Kofar Kudu & 4 & 80 \\
Makwalla & 2 & 40 \\
Rinji & 3 & 60 \\
Tosaro & 2 & 40 \\
Tsohuwar Kasuwa & 1 & 20 \\
Total & 16 & \\
\hline
\end{tabular}

\section{CONCLUSION}

Results indicated $4.00 \times 10^{5} \mathrm{CFU} / \mathrm{g}$ as the highest APCs count; while $68 \mathrm{MPN} / \mathrm{g}$ was the highest TCCs from the 30 samples analyzed. Among the isolates, $E$. coli has the highest isolation rate of $6(20 \%)$. Dausai and Kofar kudu were having the highest bacteria count of $4(80 \%)$, each, indicating higher contamination in those locations. 
BAJOPAS Volume 13 Number 1, June, 2020 RECOMMENDATIONS

The following recommendations are tenable:

1. Hygienic practices at all stages of production should be improved to safe guard the consumers against potential health hazard.

2. Monitoring of microbiological contamination of Tsire during preparations, packaging and marketing is essential to ensure product of good microbiological quality for consumers' health.

\section{REFERENCES}

Abdullahi, I. O., Umoh, V. J. and Galadima, M. (2004). Hazards Associated with Kilishi Preparations in Zaria. Nigerian Journal of Microbiology, 18 (1-2): $339-345$.

Ahmadu, J. and Ibrahim E. J., (2013): Determinants of Revenue in Suya Production in BeninCity, Edo State, Nigeria. Nigerian journal of agriculture, food and environment.9(3):1-5

Amaeze, N. Aboh, M. Itohan, A. Felix, E. Olatunji, T. and Oladosu, P. (2016) Microbial Profile, Antibiotic Sensitivity and Heat Resistance of Bacterial Isolates from Commercial Roasted Beef (Suya) in Abuja, Nigeria. JOPAT, 15(2): $22-30$.

Apata, E.S., Kuku1, I.A., Apata, O.C. and Adeyemi, K.O. (2013). Evaluation of Suya(Tsire) - An Intermediate Moisture Meat Product in Ogun State, Nigeria. J. Food Res 2 (1): 87.

Atlas, R. M. (1997) Principles of Microbiology Second Edition. C. Brown Publishers. Pp 802-803.

Borch, E. Kant-Muermans, M. L., Blixt, Y. (1996) Bacterial Spoilage of Meat and Cured Meat Products. Int $\mathrm{J}$ Food Microbiol .33(1): 103-20.

Centre for Disease Control, CDC (2011). "Escherichia coli 0157:H7" Division of Bacterial and Mycotic Diseasesht://www.cdc.gov/nczved/divisi ons/dfbmd/diseases/ecoli_0157h7/.

Charlene, R. J., Johnnie, A. D., and John, B. B., (2013) Prevalence and Characterization of Methicillin-Resistant Staphylococcus aureus Isolates from Retail Meat and Humans in Georgia. American society for Microbiology. J. of clinical microbiology. 12(1):123-6 doi:10.1128/JCM.0316612JCM.03166-12

Egbebi, A.O and Seidu, K., T. (2011). Microbiological Evaluation of Suya (dried smoked

meat) Sold in Ado and Akure, South West Nigeria.European Journal of Experinmental Biology, 1(4):1-5
3. Government should establish regulatory bodies responsible for inculcating hygiene habits to the local producers and vendors in order to prevent instant, cross and post processing contaminations by microbial pathogens.

4. Awareness and sensitization of local food producers about good hygienic practices in food handling and processing.

Falegan, C, R., Akoja, S. D., and Oyarekua, M. A., (2017) Microbiological Assessment of Suya (Sliced Roasted Beef) in Ado-Ekiti Metropolis, Ekiti State, Nigeria. MOJ Biology andMedicine.

Fonkem, D., N. Tanya, V., N. and Ebangi, A., L. (2010). Effect of Season on the Microbiological Quality of Kilishi, a Traditional Cameroonian Dried Beef Product. Tropicultura, 28(1): 10-15.

Food and Agricultural Organization of the United Nations (F A O, 1979). Manual of food quality control 4. Microbiological analysis.

Food and Agriculture Organisation of the United Nation (FAO), 2019. Nigeria at a glance.

Igene J.O., Uwadia, O.E., Ebabhamiegbebho, P.A. and Evivie, S.E., (2016) Shelf life Stability Studies of University of Benin (UNIBEN) Proff's Kilishi Product Asian Journal of Science and Technology 7(1): 2268-2274.

Inusa, S. K. and Said, I. S. (2017) Evaluation of the Chemical and Microbiological Properties Of Kilishi Sold in Kano Metropolis. Journal of Dry land Agriculture, 3 (1): $59-69$.

Lucretia, I. B, Patience, C. Obinna-Echem, Sophia, C. A. (2018) Microbiological quality andantibiotic sensitivity of potential pathogens isolated from meat product (Suya) sold in Rivers State University and its environs. International Journal of Biotechnology and Food Science, 6(4): 67-76.

Matthew, E., Drosos, E., John, L. and Ioanna, P. (2013) MRSA in Africa: Filling the Global Map of Antimicrobial Resistance PLOS One. 8(7): e68024 doi: 10.1371/journal.pone.0068024

Mgbemere, V.N., Akpapunam, M. A. and Igene, J. O., (2011). Effect of Groundnut FlourSubstitution on Yield, Quality and Storage Stability of Kilishi - a Nigerian Indigenous Dried Meat Product. African Journal of Food, Agriculture, Nutrition and Development, $\quad \mathbf{1 1}(2)$ : 4718-4738. 
BAJOPAS Volume 13 Number 1, June, 2020

Mubarak, A. A., Azeez, M. L., Amos A. O., Opeyemi, O. O. (2016) Assessment of Animal Protein Consumption and Food Security Among Rural Households in Kwara State, Nigeria American Journal of Business and Society, 1(4): 233245.

Ndahi, M., D. Kwaga, J., K. P. Bello, M. Kabir J., V. Umoh, .J. Yakubu, S., E. and Nok, A., J. (2013) Prevalence and Antimicrobial Susceptibility of Listeria Monocytogenes and Methicillin-Resistant Staphylococcus aureus Strains from Raw Meat and Meat Products in Zaria, Nigeria. Applied Journal of Microbiology, 58(3):262-9.

Okonko, I.O., Odu, N.N. and Igboh, I.E. (2013). Microbiological Analysis of Kilishi Sold In Port Harcourt, Nigeria. New York Science Journal, 6 (7):37-43.

Osimani, A., Aquilanti, L. and Clementi, F. (2015) Microbiological Quality of Meatbased Meals and Operation of Control Systems within a Food Service Environment. International Food Research Journal 22(4): 1692-1698.

Onuorah, S. Obika, I. Odibo, F. Orji, M. (2015)An Assessment of the Bacteriological Quality of Tsire-Suya (Grilled Beef) sold in Awka, Nigeria. American. J. Life. Sci. Res. 3(4):287292.

Razavilar, V, Khandaghi, J. Barzgari, A. (2010); Isolation of Eschericia coli 0157:H7 from manure fertilized farms and raw vegetables grown on it, in Tabriz city in
Iran. African Journal of Microbiology Research, 4(9): 891-895.

Scallan, E. Hoekstra, R. M. Angulo, F. J.Tauxe, R. V, Widdowson, M. Roy, S. L et al., (2011).Food borne illness acquired in the United States- Major Pathogens. Emerg. Infec Dis, 17(1): 7-15.

Shamsuddeen U (2009). Microbiological quality of spice used in the production of Kilishi a traditionally dried and grilled meat product. Bayero Journal of Pure andApplied Sciences, 2(2): 66-69.

Shamsuddeen, U. (2015) Microbiological Hazard and Critical control point Analysis of Dried and Minced Meat Snacks Produced in Kano Nigeria. Lambert Academic Publishing; Pp 1-36.

Tijani, O.and Jumare, S. (2014). Microblological Quality Assessment of Meat

Sold in KauraNamoda. International Conference on Earth, Environment and Life sciences (EELS) Dubai (UAE).

Udobi, C. E., Obajuluwa, A. F., and Onaolapo, J. A., (2013) Prevalence and Antibiotic Resistance Pattern of MethicillinResistant Staphylococcus aureus from an Orthopaedic Hospital in Nigeria BioMed Research International; 26(6); 6-7.

WHO, 2015 Foodborne diseases in the WHO African Region.

Yousafzai HA, Rind R, Khan MA, Abro SH, Korejo NA, Ejaz M, Kabir A, Shahid M, Memon S. (2019). Microbiological Contamination of Cattle and Meat in Peshawar, Pakistan. J. Anim. Health Prod. 7(1): 1116. 


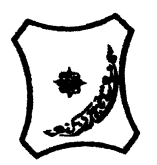

Bayero Journal of Pure and Applied Sciences, 13(1); 40 - 45

Received: September, 2019

Accepted: April, 2020

ISSN $2006-6996$

\title{
BACTERIOLOGICAL QUALITY OF STICK MEAT (Tsire) SOLD IN GARKO LOCAL GOVERNMENT AREA OF KANO STATE, NIGERIA
}

\author{
$*^{1}$ Dahiru A. T. and ${ }^{2}$ Maigari A. K. \\ ${ }^{1}$ Department of Hospitality Management, School of Technology, Kano State Polytechnic, PMB 3348, \\ Kano Nigeria. \\ ${ }^{2}$ Departmnt of Biological Sciences, Bayero University, Kano \\ Corresponding Author: dturajo61@gmail.com; GSM: 08087508262.
}

ABSTRACT

Stick meat, locally called Tsire in Hausa Language, is a significant portion of the diet of a large active population of Northern Nigeria. However, because of the handling and processing methods by the manufacturers as well as the hawking system of stick meat, the meat product may be exposed to both pre- and post-processed product contamination, and thus may poses danger to public health. Therefore, considering the role of Tsire in improving nutrition and increase household income to the populace, the need to improve the processing, distribution and overall quality of the product is simply indispensable. A total of 30 samples (5 samples from each of the 6 sampling points) of Tsire were collected randomly in Garko Town. Aerobic plate counts (APCs) and Total coliform counts (TCCS) of Tsire samples were determined using standard microbiological methods. APCs ranged from $1.02 \times 10^{5}$ to $4.00 \times 10^{5} \mathrm{CFU} / \mathrm{g}$; while TCCs ranged from $8 \mathrm{MPN} / \mathrm{g}$ to $68 \mathrm{MPN} / \mathrm{g}$. From the 30 samples screened, 16(53.33\%) bacteria namely, Campylobacter 2(6.66\%), Escherichia coli 6(20\%), Klebsiella pneumoniae 2(6.66\%), Salmonella spp. 1(3.33\%), Shigella 3(10\%) and Staphylococcus aureus 2(6.66\%) were detected. $E$. coli has the highest isolation rate of 6(20\%), while Salmonella spp. had the least frequency of 1(3.33\%). The distribution of isolated organisms within the study area were as follows: Dausai, 4(80\%), Kofar kudu, 4(80\%), Makwalla, 2(40\%), Rinji, 3(60\%), Tosaro, 2(40\%), and Tsohuwar Kasuwa, 1(20\%). The results have indicated that the Tsire was contaminated with bacteria thus exposing the product to fast deterioration, spoilage and also a vehicle for food borne illness, suggesting for adequate hygienic practices at all the stages, prior to consumption, to ensure safety of the meat product.

Key words: APCs, TCCs, Contamination, Microorganisms, Garko

\section{INTRODUCTION}

Nigeria is one of the developing nations with inadequate food supply and most often deficient in protein content (FAO, 2019). Nigerian's average animal protein intake per head per day is estimated at $7.9 \mathrm{~g}$ as against $35 \mathrm{~g}$ recommended value by Food and Agricultural Organization (Mubarak et al., 2016). These low levels of animal protein intake create great concern as it affects the nutritional status of Nigerians. Hence, there is the need for sufficient supply of animal protein from energy rich animal products to satisfy the nutritional requirements for Nigerians.

Meat is one major source of animal protein largely composed of water, protein and fats which can make it susceptible to microbial contamination within short time leading to spoilage (Apata et al., 2013; Mgbemere et al., 2011). Meat is mostly eaten after it has been cooked or processed in a variety of ways such as sun drying; smoking and roasting with or without fortifications (Borch et al., 1996). In Nigeria meat products such as Tsire, Kilishi and Balangu are locally produced using one or more of these methods in order to meet the nutritional requirements of the teeming Nigerians (Egbebi, 2011).

Tsire is a popular Nigerian traditional processed ready-to-eat roasted stick meat product (Shamsuddeen, 2015). It is sold in public places, along roads, in hotels, parks, quarters and even offices (Falegan et al., 2017). It is prepared from boneless healthy animal flesh such as beef and mutton, spiced with peanut cake, salt, vegetable oil and other flavorings followed by roasting (Shamsuddeen, 2015). Consumption of these products has extended to other parts of African countries such as Ghana, Somali, Cameroun and Chad (Ahmadu and Ibrahim, 2013). 
BAJOPAS Volume 13 Number 1, June, 2020

However, evidence of quality control sticking to procedural hygiene by the handlers during preparation and retailing of these products is poorly documented. Tsire is of great safety risk because of the fact that there are erratic cases of gastroenteritis and symptoms of food infection after consumption (WHO, 2015). Food borne illnesses are one of the major health problems in developing and developed countries (Razavilar, 2010). According to the World Health Organization, WHO (2015), $0.07 \%$ death of the 600 million global burdens of Foodborne illnesses have been reported to be caused by bacteria, viruses, fungi and chemicals. In America $0.27 \%$ of the estimated 48 million affected people is hospitalized and about $0.0063 \%$ deaths are recorded each year (Scallan et al., 2011). More than 91 million people in Africa fall ill and $0.15 \%$ dies each year, making Africa the highest burden bearer of Foodborne diseases per population (WHO, 2015).

Application of a Hazard Analysis Critical Control Point (HACCP) at all stages of meat products preparation is essential in order to ensure its safety. Thus, according to the guidelines of good manufacturing practice, the level of total aerobic bacterial contamination of thermally processed meat products should not exceed $10^{4}\left(\mathrm{cfu} \mathrm{g}^{-1}\right)$. Enterobacteriaceae and faecal coliform contamination in meat products should be within the range of $10^{2}-10^{4}$ and $10-10^{3} \mathrm{cfu} \mathrm{g}^{-1}$, respectively (Shamsuddeen, 2015). The aim of the study is therefore, to assess the total viable bacterial counts of tsire marketed locally within Garko town, and to isolate and identify the organisms at the point of consumption with the intention of promoting public health and food hygiene habits in the Nigerian populace.

\section{MATERIALS AND METHODS Study Area and Population}

Garko is one of the existing 44 local government areas located in Kano south west zone of Kano state with its capital administrative headquarters in the Garko town. It has coordinates $11^{\circ} 39^{\prime} \mathrm{N}$ $8^{\circ} 54^{\prime} \mathrm{E}$, and an area of $450 \mathrm{~km}^{2}$. The projected population of Garko local Government was 225,300 according to the National Population Census report (2018). Garko is known for agricultural activities both farming and animal husbandry. It is popularly known for large scale rice production. Other food crops include sweet potatoes, cassava, onions, sorghum, millet and sugarcane. Cows, sheep and goats are major groups of animals reared by majority of the populace. Meat products processed, retailed and consumed in Garko include roasted meat (Balangu), dried roasted meat (Kilishi), stick meat (Tsire), hide and skin pepper soup (Ragadada) and minced fried meat (Danbunnama).

\section{Samples Collection}

Five samples of Tsire products were collected from 6 different identified locations within Garko town in a sterile foil paper and immediately analyzed for the presence of bacteria.

\section{Sample Preparation}

Sample preparation for the bacteriological analysis was carried out in accordance with the method described by Atlas (1997). Twenty five grams $(25 \mathrm{~g})$ of the sample was homogenized in $225 \mathrm{ml}$ peptone water using Kenwood blender machine to obtain a $10^{1}$ homogenate. The homogenate was thoroughly shaken and $1 \mathrm{ml}$ pipetted into test tubes containing $9 \mathrm{ml}$ of peptone water $\left(10^{2}\right)$. The test tubes were further serially diluted to $10^{5}$.

Total Aerobic Mesophilic Bacterial Count

Total Aerobic mesophilic bacterial count was determined using the method described by Abdullahi et al. (2004) where $1 \mathrm{ml}$ of inoculums from $10^{1}$ to $10^{5}$ dilutions were transferred into duplicate Petri dishes and labeled accordingly. This was followed by pouring aseptically about $15 \mathrm{ml}$ of molten nutrient agar. The culture was homogenized by gentle spinning of the plates and allowed to solidify. The plates were incubated at $37^{\circ} \mathrm{C}$ for 24 hours. Plates containing 30-300 colonies were counted. The number of colony forming units per gram of a sample (cfu/g) was obtained by multiplying the average colony number with the inverse of the dilution factor.

\section{Enumeration and Detection of Coliform bacteria}

Detection and enumeration of coliform was carried out according to method described by Atlas, (1977). A set of 9 test tubes each containing $9 \mathrm{ml}$ of lactose broth and an inverted Durham tubes were autoclaved to expel air and to sterilize. Similarly, $1 \mathrm{ml}$ from the diluents $10^{1}$ was transferred to the first 3 test tubes, followed by $1 \mathrm{ml}$ from the diluents $10^{2}$ to the second set of 3 test tubes and finally the third diluents $10^{3}$ to the $3^{\text {rd }}$ set of 3 test tubes. All the 9 test tubes were incubated at $37^{\circ} \mathrm{C}$ for 24 hours. Tubes that showed gas and acid production after 24 hours were recorded as positive for the presence of Coliform. Negative tubes were further reincubated for 24 hours. Positive tubes were recorded. Estimate of most probable number of Coliform per gram of sample (MPN/g) was determined by comparing the number of gas positive tubes with the most probable number table. 
BAJOPAS Volume 13 Number 1, June, 2020 Identification of Coliform

A loop full of inoculum from gas positive tubes was streaked on to Eosine methylene blue (EMB) agar plate and incubated at $37^{\circ} \mathrm{C}$ for $24 \mathrm{hrs}$. Colonies which formed bluish black color with green metallic sheen, and reddish colonies were isolated on agar slants. Those colonies showing metallic sheen on EMB were sub cultured into tubes of lactose broth and incubated at $45^{\circ} \mathrm{C}$. The tubes were observed after $24 \mathrm{hrs}$ for gas production. This is the completed test for fecal coliform. Gram stain and other biochemical tests such as Indole, Methyl red, Voges-Proskauer and Citrate Utilization tests (IMVIC), Coagulase and Catalase tests were carried out for the Identification and confirmation of isolates.

\section{Procedure for Indole Test}

Indole test was carried out by preparing a Tryptone broth drawn in to test tubes, sterilized by autoclaving, inoculated with loopful of suspension and incubated at $37^{\circ} \mathrm{C}$ for 24 hours. Three drops of xylene was added in tubes, shaken vigorously and kept for the separation of two layers. One millilitre of Kovac's reagent was added and the formation of pink colour ring indicates positive Indole test.

\section{Procedure for Methyl Red Test}

Methyl red test was carried out by preparing Glucose phosphate broth, dispensed in test tubes, sterilized, inoculated with test culture and incubated at $37^{\circ} \mathrm{C}$ for 24 hours. Five drops of methyl-red indicator was added to the medium for the formation of red colour.

\section{Procedure for Voges-Proskauer Test}

Voges-Proskauer test was carried out by inoculating tubes with the bacterial culture followed by incubation for 48 hours at $37^{\circ} \mathrm{C}$. Separate pipettes were used to pipette $1 \mathrm{ml}$ from each culture tube into clean separate tubes. Eighteen drops $(0.5 \mathrm{ml})$ of Barrit's solution A (a-naphthol) was added to each tube containing glucose phosphate broth followed by the addition of an equal amount of solution $B$ into the same tube. The tubes were shaken at 30 seconds interval. A positive reaction was indicated by the development of a pink color, which turns red in 1-2 hours, after vigorous shaking.

\section{Procedure for Citrate Utilization Test}

Citrate Utilization Test was carried out by distributing melted agar (Simmon Citrate Agar) in to test tubes followed by sterilization at $121.5^{\circ} \mathrm{C}$ for 15 minutes. The test tubes were afterward held in slanted position, inoculated with the given bacterial culture and incubated at $37^{\circ} \mathrm{C}$ for $24 \mathrm{hrs}$. Positive test was indicated by color change of the media from green to blue.

\section{RESULTS AND DISCUSSIONS}

The results of this study are presented in tables $1,2,3$ and 4. Among the sampling areas Kofar Kudu had the highest aerobic mesophilic bacteria counts $4.0 \times 10^{5} \mathrm{cfu} / \mathrm{g}$ followed by Rinji $2.72 \times 10^{5} \mathrm{cfu} / \mathrm{g}$, while Tosaro had the least Aerobic mesophilic bacteria counts of $1.02 \times 10^{5}$ $\mathrm{cfu} / \mathrm{g}$ as indicated in Table 1.Makwalla had the highest coliform count $68 \mathrm{MPN} / \mathrm{g}$ followed by Rinji $37 \mathrm{MPN} / \mathrm{g}$. Tsohuwar Kasuwa had the least coliform counts $8 \mathrm{MPN} / \mathrm{g}$, (Table 2). Result from table 1 shows variation in the microbial contents among the samples which suggest variation in their sources, poor handling procedures and contamination from the processing environment. High coliform count and their differences within sampling areas is an indication of poor microbiological quality of the product. Ndahi et al. (2013) reported microbial load to be a function of the handling personnel and the environment. The results indicated that the samples were contaminated with bacteria as the counts exceeded the minimum safety level $\left(10^{4} \mathrm{cfu} / \mathrm{g}\right)$ for members of the Enterobacteriaceae family. However, it might be a reflection of poor hygienic practices which may contribute to health hazard to the potential consumers. Similarly, Inusa and Sa'id (2017); Osimani et al. (2015) reported that, the initial microbial content of the raw material play significant role in influencing the final microbial load of the finished product. Isolation of members of the Enterobacteriaceae such as $E$. coli, Klebsiella pneumoniae, Salmonella and Shigella signifies danger to the public health. These organisms are capable of producing endotoxins which trigger high fevers in infected individuals, and the enterotoxins which colonize the small intestines and lead to extreme dehydration as a result of vomiting and diarrhea sometimes with severe and fatal outcomes (Amaeze et al., 2016). From the 16 isolated organisms $E$. coli had the highest isolation rate $6(37.5 \%)$ (Table 3), this suggest faecal contamination of the products. $E$. coli is a common flora in the gastrointestinal tract responsible for diarrhea and extra-intestinal infections (CDC, 2011). The result is in conformity with the findings of Ndahi et al. (2013) and Shamsuddeen (2009). Also presence of campylobacter might be due to cross contamination from raw meat to finished product (Tsire). Staphylococcus aureus is a normal flora of the skin, nasal, genital, mouth or anal area in both humans and animals without any symptom of an infection (Matthew et al., 2013). Isolation of $S$. aureus in these study concords with the findings of Lucretia et al. (2018) from Suya sold in Rivers State. 
BAJOPAS Volume 13 Number 1, June, 2020

It is also in agreement with the findings of Yousafzai et al. (2018); Onuorah et al. (2015) and Tijjani and Jumare (2014) from tsire samples in different countries. Presence of $S$. aureus in foods is most of the time an indication of poor human handling, poor environment, unhygienic utensils and equipments used during processing (Igene et al., 2016; Okonko et al., 2013). Infections caused by $S$. aureus are difficult to treat leading to long hospitalization with consequent economic loss (Udobi et al., 2013). These include soft tissue infections, pneumonia, hospital-acquired postoperative wound infections, Staphylococcal food poisoning, impetigo and cellulitis (Charlene et al., 2013). Samples obtained from Dausai and Kofar Kudu had the highest isolation rate $4(80 \%)$ (Table 4 ) probably because of the much commercial activities taking place in the area which can lead to environmental contamination.

Table 1: Total Aerobic Mesophilic Bacterial Count of Tsire sold in Garko Town

\begin{tabular}{lll}
\hline Sampling Area & APC cfu/g & Mean \pm STD \\
\hline Dausai & $2.20 \times 10^{5}$ & $110000 \pm 14142.14$ \\
Kofar Kudu & $4.00 \times 10^{5}$ & $133333.3 \pm 23094.01$ \\
Makwalla & $1.30 \times 10^{5}$ & $32500 \pm 7187.953$ \\
Rinji & $2.72 \times 10^{5}$ & $90666.67 \pm 94769.90$ \\
Tosaro & $1.02 \times 10^{5}$ & $51000 \pm 15556.35$ \\
Tsohuwar Kasuwa & $1.75 \times 10^{5}$ & $35000 \pm 11357.82$ \\
\hline
\end{tabular}

Key: APC: Aerobic Mesophilic Counts

STD: Standard Deviation

Table 2: Total Coliform Count of Tsire sold in Garko Town

\begin{tabular}{lcc}
\hline \multicolumn{1}{c}{ Sampling Area } & TCC MPN/g & Mean \pm STD \\
\hline Dausai & 20 & $6.67 \pm 2.5166$ \\
Kofar Kudu & 32 & $16.00 \pm 5.6569$ \\
Makwalla & 68 & $13.60 \pm 8.7062$ \\
Rinji & 37 & $9.25 \pm 4.7871$ \\
Tosaro & 10 & $5.00 \pm 2.8284$ \\
Tsohuwar Kasuwa & 8 & $4.00 \pm 0.0000$ \\
\hline
\end{tabular}

Table 3: Organisms Isolated from Tsire Sold in Garko

\begin{tabular}{lcl}
\hline Isolated Organism & Frequency & Percentage (\%) \\
\hline Campylobacter & 2 & 06.66 \\
Escherichia coli & 6 & 20.00 \\
Klebsiella pneumoniae & 2 & 06.66 \\
Salmonella species & 1 & 03.33 \\
Shigella & 3 & 10.00 \\
Staphylococcus aureus & 2 & 06.66 \\
Total & 16 & \\
\hline
\end{tabular}

Table 4: Distribution of Organisms within Sampling Area

\begin{tabular}{lcc}
\hline \multicolumn{1}{c}{ Sampling Area } & No. Isolated & Percentage (\%) \\
\hline Dausai & 4 & 80 \\
Kofar Kudu & 4 & 80 \\
Makwalla & 2 & 40 \\
Rinji & 3 & 60 \\
Tosaro & 2 & 40 \\
Tsohuwar Kasuwa & 1 & 20 \\
Total & 16 & \\
\hline
\end{tabular}

\section{CONCLUSION}

Results indicated $4.00 \times 10^{5} \mathrm{CFU} / \mathrm{g}$ as the highest APCs count; while $68 \mathrm{MPN} / \mathrm{g}$ was the highest TCCs from the 30 samples analyzed. Among the isolates, $E$. coli has the highest isolation rate of $6(20 \%)$. Dausai and Kofar kudu were having the highest bacteria count of $4(80 \%)$, each, indicating higher contamination in those locations. 
BAJOPAS Volume 13 Number 1, June, 2020 RECOMMENDATIONS

The following recommendations are tenable:

1. Hygienic practices at all stages of production should be improved to safe guard the consumers against potential health hazard.

2. Monitoring of microbiological contamination of Tsire during preparations, packaging and marketing is essential to ensure product of good microbiological quality for consumers' health.

\section{REFERENCES}

Abdullahi, I. O., Umoh, V. J. and Galadima, M. (2004). Hazards Associated with Kilishi Preparations in Zaria. Nigerian Journal of Microbiology, 18 (1-2): $339-345$.

Ahmadu, J. and Ibrahim E. J., (2013): Determinants of Revenue in Suya Production in BeninCity, Edo State, Nigeria. Nigerian journal of agriculture, food and environment.9(3):1-5

Amaeze, N. Aboh, M. Itohan, A. Felix, E. Olatunji, T. and Oladosu, P. (2016) Microbial Profile, Antibiotic Sensitivity and Heat Resistance of Bacterial Isolates from Commercial Roasted Beef (Suya) in Abuja, Nigeria. JOPAT, 15(2): $22-30$.

Apata, E.S., Kuku1, I.A., Apata, O.C. and Adeyemi, K.O. (2013). Evaluation of Suya(Tsire) - An Intermediate Moisture Meat Product in Ogun State, Nigeria. J. Food Res 2 (1): 87.

Atlas, R. M. (1997) Principles of Microbiology Second Edition. C. Brown Publishers. Pp 802-803.

Borch, E. Kant-Muermans, M. L., Blixt, Y. (1996) Bacterial Spoilage of Meat and Cured Meat Products. Int $\mathrm{J}$ Food Microbiol .33(1): 103-20.

Centre for Disease Control, CDC (2011). "Escherichia coli 0157:H7" Division of Bacterial and Mycotic Diseasesht://www.cdc.gov/nczved/divisi ons/dfbmd/diseases/ecoli_0157h7/.

Charlene, R. J., Johnnie, A. D., and John, B. B., (2013) Prevalence and Characterization of Methicillin-Resistant Staphylococcus aureus Isolates from Retail Meat and Humans in Georgia. American society for Microbiology. J. of clinical microbiology. 12(1):123-6 doi:10.1128/JCM.0316612JCM.03166-12

Egbebi, A.O and Seidu, K., T. (2011). Microbiological Evaluation of Suya (dried smoked

meat) Sold in Ado and Akure, South West Nigeria.European Journal of Experinmental Biology, 1(4):1-5
3. Government should establish regulatory bodies responsible for inculcating hygiene habits to the local producers and vendors in order to prevent instant, cross and post processing contaminations by microbial pathogens.

4. Awareness and sensitization of local food producers about good hygienic practices in food handling and processing.

Falegan, C, R., Akoja, S. D., and Oyarekua, M. A., (2017) Microbiological Assessment of Suya (Sliced Roasted Beef) in Ado-Ekiti Metropolis, Ekiti State, Nigeria. MOJ Biology andMedicine.

Fonkem, D., N. Tanya, V., N. and Ebangi, A., L. (2010). Effect of Season on the Microbiological Quality of Kilishi, a Traditional Cameroonian Dried Beef Product. Tropicultura, 28(1): 10-15.

Food and Agricultural Organization of the United Nations (F A O, 1979). Manual of food quality control 4. Microbiological analysis.

Food and Agriculture Organisation of the United Nation (FAO), 2019. Nigeria at a glance.

Igene J.O., Uwadia, O.E., Ebabhamiegbebho, P.A. and Evivie, S.E., (2016) Shelf life Stability Studies of University of Benin (UNIBEN) Proff's Kilishi Product Asian Journal of Science and Technology 7(1): 2268-2274.

Inusa, S. K. and Said, I. S. (2017) Evaluation of the Chemical and Microbiological Properties Of Kilishi Sold in Kano Metropolis. Journal of Dry land Agriculture, 3 (1): $59-69$.

Lucretia, I. B, Patience, C. Obinna-Echem, Sophia, C. A. (2018) Microbiological quality andantibiotic sensitivity of potential pathogens isolated from meat product (Suya) sold in Rivers State University and its environs. International Journal of Biotechnology and Food Science, 6(4): 67-76.

Matthew, E., Drosos, E., John, L. and Ioanna, P. (2013) MRSA in Africa: Filling the Global Map of Antimicrobial Resistance PLOS One. 8(7): e68024 doi: 10.1371/journal.pone.0068024

Mgbemere, V.N., Akpapunam, M. A. and Igene, J. O., (2011). Effect of Groundnut FlourSubstitution on Yield, Quality and Storage Stability of Kilishi - a Nigerian Indigenous Dried Meat Product. African Journal of Food, Agriculture, Nutrition and Development, $\quad \mathbf{1 1}(2)$ : 4718-4738. 
BAJOPAS Volume 13 Number 1, June, 2020

Mubarak, A. A., Azeez, M. L., Amos A. O., Opeyemi, O. O. (2016) Assessment of Animal Protein Consumption and Food Security Among Rural Households in Kwara State, Nigeria American Journal of Business and Society, 1(4): 233245.

Ndahi, M., D. Kwaga, J., K. P. Bello, M. Kabir J., V. Umoh, .J. Yakubu, S., E. and Nok, A., J. (2013) Prevalence and Antimicrobial Susceptibility of Listeria Monocytogenes and Methicillin-Resistant Staphylococcus aureus Strains from Raw Meat and Meat Products in Zaria, Nigeria. Applied Journal of Microbiology, 58(3):262-9.

Okonko, I.O., Odu, N.N. and Igboh, I.E. (2013). Microbiological Analysis of Kilishi Sold In Port Harcourt, Nigeria. New York Science Journal, 6 (7):37-43.

Osimani, A., Aquilanti, L. and Clementi, F. (2015) Microbiological Quality of Meatbased Meals and Operation of Control Systems within a Food Service Environment. International Food Research Journal 22(4): 1692-1698.

Onuorah, S. Obika, I. Odibo, F. Orji, M. (2015)An Assessment of the Bacteriological Quality of Tsire-Suya (Grilled Beef) sold in Awka, Nigeria. American. J. Life. Sci. Res. 3(4):287292.

Razavilar, V, Khandaghi, J. Barzgari, A. (2010); Isolation of Eschericia coli 0157:H7 from manure fertilized farms and raw vegetables grown on it, in Tabriz city in
Iran. African Journal of Microbiology Research, 4(9): 891-895.

Scallan, E. Hoekstra, R. M. Angulo, F. J.Tauxe, R. V, Widdowson, M. Roy, S. L et al., (2011).Food borne illness acquired in the United States- Major Pathogens. Emerg. Infec Dis, 17(1): 7-15.

Shamsuddeen U (2009). Microbiological quality of spice used in the production of Kilishi a traditionally dried and grilled meat product. Bayero Journal of Pure andApplied Sciences, 2(2): 66-69.

Shamsuddeen, U. (2015) Microbiological Hazard and Critical control point Analysis of Dried and Minced Meat Snacks Produced in Kano Nigeria. Lambert Academic Publishing; Pp 1-36.

Tijani, O.and Jumare, S. (2014). Microblological Quality Assessment of Meat

Sold in KauraNamoda. International Conference on Earth, Environment and Life sciences (EELS) Dubai (UAE).

Udobi, C. E., Obajuluwa, A. F., and Onaolapo, J. A., (2013) Prevalence and Antibiotic Resistance Pattern of MethicillinResistant Staphylococcus aureus from an Orthopaedic Hospital in Nigeria BioMed Research International; 26(6); 6-7.

WHO, 2015 Foodborne diseases in the WHO African Region.

Yousafzai HA, Rind R, Khan MA, Abro SH, Korejo NA, Ejaz M, Kabir A, Shahid M, Memon S. (2019). Microbiological Contamination of Cattle and Meat in Peshawar, Pakistan. J. Anim. Health Prod. 7(1): 1116. 


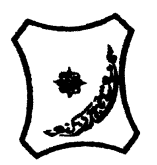

Bayero Journal of Pure and Applied Sciences, 13(1); 40 - 45

Received: September, 2019

Accepted: April, 2020

ISSN $2006-6996$

\title{
BACTERIOLOGICAL QUALITY OF STICK MEAT (Tsire) SOLD IN GARKO LOCAL GOVERNMENT AREA OF KANO STATE, NIGERIA
}

\author{
$*^{1}$ Dahiru A. T. and ${ }^{2}$ Maigari A. K. \\ ${ }^{1}$ Department of Hospitality Management, School of Technology, Kano State Polytechnic, PMB 3348, \\ Kano Nigeria. \\ ${ }^{2}$ Departmnt of Biological Sciences, Bayero University, Kano \\ Corresponding Author: dturajo61@gmail.com; GSM: 08087508262.
}

ABSTRACT

Stick meat, locally called Tsire in Hausa Language, is a significant portion of the diet of a large active population of Northern Nigeria. However, because of the handling and processing methods by the manufacturers as well as the hawking system of stick meat, the meat product may be exposed to both pre- and post-processed product contamination, and thus may poses danger to public health. Therefore, considering the role of Tsire in improving nutrition and increase household income to the populace, the need to improve the processing, distribution and overall quality of the product is simply indispensable. A total of 30 samples (5 samples from each of the 6 sampling points) of Tsire were collected randomly in Garko Town. Aerobic plate counts (APCs) and Total coliform counts (TCCS) of Tsire samples were determined using standard microbiological methods. APCs ranged from $1.02 \times 10^{5}$ to $4.00 \times 10^{5} \mathrm{CFU} / \mathrm{g}$; while TCCs ranged from $8 \mathrm{MPN} / \mathrm{g}$ to $68 \mathrm{MPN} / \mathrm{g}$. From the 30 samples screened, 16(53.33\%) bacteria namely, Campylobacter 2(6.66\%), Escherichia coli 6(20\%), Klebsiella pneumoniae 2(6.66\%), Salmonella spp. 1(3.33\%), Shigella 3(10\%) and Staphylococcus aureus 2(6.66\%) were detected. $E$. coli has the highest isolation rate of 6(20\%), while Salmonella spp. had the least frequency of 1(3.33\%). The distribution of isolated organisms within the study area were as follows: Dausai, 4(80\%), Kofar kudu, 4(80\%), Makwalla, 2(40\%), Rinji, 3(60\%), Tosaro, 2(40\%), and Tsohuwar Kasuwa, 1(20\%). The results have indicated that the Tsire was contaminated with bacteria thus exposing the product to fast deterioration, spoilage and also a vehicle for food borne illness, suggesting for adequate hygienic practices at all the stages, prior to consumption, to ensure safety of the meat product.

Key words: APCs, TCCs, Contamination, Microorganisms, Garko

\section{INTRODUCTION}

Nigeria is one of the developing nations with inadequate food supply and most often deficient in protein content (FAO, 2019). Nigerian's average animal protein intake per head per day is estimated at $7.9 \mathrm{~g}$ as against $35 \mathrm{~g}$ recommended value by Food and Agricultural Organization (Mubarak et al., 2016). These low levels of animal protein intake create great concern as it affects the nutritional status of Nigerians. Hence, there is the need for sufficient supply of animal protein from energy rich animal products to satisfy the nutritional requirements for Nigerians.

Meat is one major source of animal protein largely composed of water, protein and fats which can make it susceptible to microbial contamination within short time leading to spoilage (Apata et al., 2013; Mgbemere et al., 2011). Meat is mostly eaten after it has been cooked or processed in a variety of ways such as sun drying; smoking and roasting with or without fortifications (Borch et al., 1996). In Nigeria meat products such as Tsire, Kilishi and Balangu are locally produced using one or more of these methods in order to meet the nutritional requirements of the teeming Nigerians (Egbebi, 2011).

Tsire is a popular Nigerian traditional processed ready-to-eat roasted stick meat product (Shamsuddeen, 2015). It is sold in public places, along roads, in hotels, parks, quarters and even offices (Falegan et al., 2017). It is prepared from boneless healthy animal flesh such as beef and mutton, spiced with peanut cake, salt, vegetable oil and other flavorings followed by roasting (Shamsuddeen, 2015). Consumption of these products has extended to other parts of African countries such as Ghana, Somali, Cameroun and Chad (Ahmadu and Ibrahim, 2013). 
BAJOPAS Volume 13 Number 1, June, 2020

However, evidence of quality control sticking to procedural hygiene by the handlers during preparation and retailing of these products is poorly documented. Tsire is of great safety risk because of the fact that there are erratic cases of gastroenteritis and symptoms of food infection after consumption (WHO, 2015). Food borne illnesses are one of the major health problems in developing and developed countries (Razavilar, 2010). According to the World Health Organization, WHO (2015), $0.07 \%$ death of the 600 million global burdens of Foodborne illnesses have been reported to be caused by bacteria, viruses, fungi and chemicals. In America $0.27 \%$ of the estimated 48 million affected people is hospitalized and about $0.0063 \%$ deaths are recorded each year (Scallan et al., 2011). More than 91 million people in Africa fall ill and $0.15 \%$ dies each year, making Africa the highest burden bearer of Foodborne diseases per population (WHO, 2015).

Application of a Hazard Analysis Critical Control Point (HACCP) at all stages of meat products preparation is essential in order to ensure its safety. Thus, according to the guidelines of good manufacturing practice, the level of total aerobic bacterial contamination of thermally processed meat products should not exceed $10^{4}\left(\mathrm{cfu} \mathrm{g}^{-1}\right)$. Enterobacteriaceae and faecal coliform contamination in meat products should be within the range of $10^{2}-10^{4}$ and $10-10^{3} \mathrm{cfu} \mathrm{g}^{-1}$, respectively (Shamsuddeen, 2015). The aim of the study is therefore, to assess the total viable bacterial counts of tsire marketed locally within Garko town, and to isolate and identify the organisms at the point of consumption with the intention of promoting public health and food hygiene habits in the Nigerian populace.

\section{MATERIALS AND METHODS Study Area and Population}

Garko is one of the existing 44 local government areas located in Kano south west zone of Kano state with its capital administrative headquarters in the Garko town. It has coordinates $11^{\circ} 39^{\prime} \mathrm{N}$ $8^{\circ} 54^{\prime} \mathrm{E}$, and an area of $450 \mathrm{~km}^{2}$. The projected population of Garko local Government was 225,300 according to the National Population Census report (2018). Garko is known for agricultural activities both farming and animal husbandry. It is popularly known for large scale rice production. Other food crops include sweet potatoes, cassava, onions, sorghum, millet and sugarcane. Cows, sheep and goats are major groups of animals reared by majority of the populace. Meat products processed, retailed and consumed in Garko include roasted meat (Balangu), dried roasted meat (Kilishi), stick meat (Tsire), hide and skin pepper soup (Ragadada) and minced fried meat (Danbunnama).

\section{Samples Collection}

Five samples of Tsire products were collected from 6 different identified locations within Garko town in a sterile foil paper and immediately analyzed for the presence of bacteria.

\section{Sample Preparation}

Sample preparation for the bacteriological analysis was carried out in accordance with the method described by Atlas (1997). Twenty five grams $(25 \mathrm{~g})$ of the sample was homogenized in $225 \mathrm{ml}$ peptone water using Kenwood blender machine to obtain a $10^{1}$ homogenate. The homogenate was thoroughly shaken and $1 \mathrm{ml}$ pipetted into test tubes containing $9 \mathrm{ml}$ of peptone water $\left(10^{2}\right)$. The test tubes were further serially diluted to $10^{5}$.

Total Aerobic Mesophilic Bacterial Count

Total Aerobic mesophilic bacterial count was determined using the method described by Abdullahi et al. (2004) where $1 \mathrm{ml}$ of inoculums from $10^{1}$ to $10^{5}$ dilutions were transferred into duplicate Petri dishes and labeled accordingly. This was followed by pouring aseptically about $15 \mathrm{ml}$ of molten nutrient agar. The culture was homogenized by gentle spinning of the plates and allowed to solidify. The plates were incubated at $37^{\circ} \mathrm{C}$ for 24 hours. Plates containing 30-300 colonies were counted. The number of colony forming units per gram of a sample (cfu/g) was obtained by multiplying the average colony number with the inverse of the dilution factor.

\section{Enumeration and Detection of Coliform bacteria}

Detection and enumeration of coliform was carried out according to method described by Atlas, (1977). A set of 9 test tubes each containing $9 \mathrm{ml}$ of lactose broth and an inverted Durham tubes were autoclaved to expel air and to sterilize. Similarly, $1 \mathrm{ml}$ from the diluents $10^{1}$ was transferred to the first 3 test tubes, followed by $1 \mathrm{ml}$ from the diluents $10^{2}$ to the second set of 3 test tubes and finally the third diluents $10^{3}$ to the $3^{\text {rd }}$ set of 3 test tubes. All the 9 test tubes were incubated at $37^{\circ} \mathrm{C}$ for 24 hours. Tubes that showed gas and acid production after 24 hours were recorded as positive for the presence of Coliform. Negative tubes were further reincubated for 24 hours. Positive tubes were recorded. Estimate of most probable number of Coliform per gram of sample (MPN/g) was determined by comparing the number of gas positive tubes with the most probable number table. 
BAJOPAS Volume 13 Number 1, June, 2020 Identification of Coliform

A loop full of inoculum from gas positive tubes was streaked on to Eosine methylene blue (EMB) agar plate and incubated at $37^{\circ} \mathrm{C}$ for $24 \mathrm{hrs}$. Colonies which formed bluish black color with green metallic sheen, and reddish colonies were isolated on agar slants. Those colonies showing metallic sheen on EMB were sub cultured into tubes of lactose broth and incubated at $45^{\circ} \mathrm{C}$. The tubes were observed after $24 \mathrm{hrs}$ for gas production. This is the completed test for fecal coliform. Gram stain and other biochemical tests such as Indole, Methyl red, Voges-Proskauer and Citrate Utilization tests (IMVIC), Coagulase and Catalase tests were carried out for the Identification and confirmation of isolates.

\section{Procedure for Indole Test}

Indole test was carried out by preparing a Tryptone broth drawn in to test tubes, sterilized by autoclaving, inoculated with loopful of suspension and incubated at $37^{\circ} \mathrm{C}$ for 24 hours. Three drops of xylene was added in tubes, shaken vigorously and kept for the separation of two layers. One millilitre of Kovac's reagent was added and the formation of pink colour ring indicates positive Indole test.

\section{Procedure for Methyl Red Test}

Methyl red test was carried out by preparing Glucose phosphate broth, dispensed in test tubes, sterilized, inoculated with test culture and incubated at $37^{\circ} \mathrm{C}$ for 24 hours. Five drops of methyl-red indicator was added to the medium for the formation of red colour.

\section{Procedure for Voges-Proskauer Test}

Voges-Proskauer test was carried out by inoculating tubes with the bacterial culture followed by incubation for 48 hours at $37^{\circ} \mathrm{C}$. Separate pipettes were used to pipette $1 \mathrm{ml}$ from each culture tube into clean separate tubes. Eighteen drops $(0.5 \mathrm{ml})$ of Barrit's solution A (a-naphthol) was added to each tube containing glucose phosphate broth followed by the addition of an equal amount of solution $B$ into the same tube. The tubes were shaken at 30 seconds interval. A positive reaction was indicated by the development of a pink color, which turns red in 1-2 hours, after vigorous shaking.

\section{Procedure for Citrate Utilization Test}

Citrate Utilization Test was carried out by distributing melted agar (Simmon Citrate Agar) in to test tubes followed by sterilization at $121.5^{\circ} \mathrm{C}$ for 15 minutes. The test tubes were afterward held in slanted position, inoculated with the given bacterial culture and incubated at $37^{\circ} \mathrm{C}$ for $24 \mathrm{hrs}$. Positive test was indicated by color change of the media from green to blue.

\section{RESULTS AND DISCUSSIONS}

The results of this study are presented in tables $1,2,3$ and 4. Among the sampling areas Kofar Kudu had the highest aerobic mesophilic bacteria counts $4.0 \times 10^{5} \mathrm{cfu} / \mathrm{g}$ followed by Rinji $2.72 \times 10^{5} \mathrm{cfu} / \mathrm{g}$, while Tosaro had the least Aerobic mesophilic bacteria counts of $1.02 \times 10^{5}$ $\mathrm{cfu} / \mathrm{g}$ as indicated in Table 1.Makwalla had the highest coliform count $68 \mathrm{MPN} / \mathrm{g}$ followed by Rinji $37 \mathrm{MPN} / \mathrm{g}$. Tsohuwar Kasuwa had the least coliform counts $8 \mathrm{MPN} / \mathrm{g}$, (Table 2). Result from table 1 shows variation in the microbial contents among the samples which suggest variation in their sources, poor handling procedures and contamination from the processing environment. High coliform count and their differences within sampling areas is an indication of poor microbiological quality of the product. Ndahi et al. (2013) reported microbial load to be a function of the handling personnel and the environment. The results indicated that the samples were contaminated with bacteria as the counts exceeded the minimum safety level $\left(10^{4} \mathrm{cfu} / \mathrm{g}\right)$ for members of the Enterobacteriaceae family. However, it might be a reflection of poor hygienic practices which may contribute to health hazard to the potential consumers. Similarly, Inusa and Sa'id (2017); Osimani et al. (2015) reported that, the initial microbial content of the raw material play significant role in influencing the final microbial load of the finished product. Isolation of members of the Enterobacteriaceae such as $E$. coli, Klebsiella pneumoniae, Salmonella and Shigella signifies danger to the public health. These organisms are capable of producing endotoxins which trigger high fevers in infected individuals, and the enterotoxins which colonize the small intestines and lead to extreme dehydration as a result of vomiting and diarrhea sometimes with severe and fatal outcomes (Amaeze et al., 2016). From the 16 isolated organisms $E$. coli had the highest isolation rate $6(37.5 \%)$ (Table 3), this suggest faecal contamination of the products. $E$. coli is a common flora in the gastrointestinal tract responsible for diarrhea and extra-intestinal infections (CDC, 2011). The result is in conformity with the findings of Ndahi et al. (2013) and Shamsuddeen (2009). Also presence of campylobacter might be due to cross contamination from raw meat to finished product (Tsire). Staphylococcus aureus is a normal flora of the skin, nasal, genital, mouth or anal area in both humans and animals without any symptom of an infection (Matthew et al., 2013). Isolation of $S$. aureus in these study concords with the findings of Lucretia et al. (2018) from Suya sold in Rivers State. 
BAJOPAS Volume 13 Number 1, June, 2020

It is also in agreement with the findings of Yousafzai et al. (2018); Onuorah et al. (2015) and Tijjani and Jumare (2014) from tsire samples in different countries. Presence of $S$. aureus in foods is most of the time an indication of poor human handling, poor environment, unhygienic utensils and equipments used during processing (Igene et al., 2016; Okonko et al., 2013). Infections caused by $S$. aureus are difficult to treat leading to long hospitalization with consequent economic loss (Udobi et al., 2013). These include soft tissue infections, pneumonia, hospital-acquired postoperative wound infections, Staphylococcal food poisoning, impetigo and cellulitis (Charlene et al., 2013). Samples obtained from Dausai and Kofar Kudu had the highest isolation rate $4(80 \%)$ (Table 4 ) probably because of the much commercial activities taking place in the area which can lead to environmental contamination.

Table 1: Total Aerobic Mesophilic Bacterial Count of Tsire sold in Garko Town

\begin{tabular}{lll}
\hline Sampling Area & APC cfu/g & Mean \pm STD \\
\hline Dausai & $2.20 \times 10^{5}$ & $110000 \pm 14142.14$ \\
Kofar Kudu & $4.00 \times 10^{5}$ & $133333.3 \pm 23094.01$ \\
Makwalla & $1.30 \times 10^{5}$ & $32500 \pm 7187.953$ \\
Rinji & $2.72 \times 10^{5}$ & $90666.67 \pm 94769.90$ \\
Tosaro & $1.02 \times 10^{5}$ & $51000 \pm 15556.35$ \\
Tsohuwar Kasuwa & $1.75 \times 10^{5}$ & $35000 \pm 11357.82$ \\
\hline
\end{tabular}

Key: APC: Aerobic Mesophilic Counts

STD: Standard Deviation

Table 2: Total Coliform Count of Tsire sold in Garko Town

\begin{tabular}{lcc}
\hline \multicolumn{1}{c}{ Sampling Area } & TCC MPN/g & Mean \pm STD \\
\hline Dausai & 20 & $6.67 \pm 2.5166$ \\
Kofar Kudu & 32 & $16.00 \pm 5.6569$ \\
Makwalla & 68 & $13.60 \pm 8.7062$ \\
Rinji & 37 & $9.25 \pm 4.7871$ \\
Tosaro & 10 & $5.00 \pm 2.8284$ \\
Tsohuwar Kasuwa & 8 & $4.00 \pm 0.0000$ \\
\hline
\end{tabular}

Table 3: Organisms Isolated from Tsire Sold in Garko

\begin{tabular}{lcl}
\hline Isolated Organism & Frequency & Percentage (\%) \\
\hline Campylobacter & 2 & 06.66 \\
Escherichia coli & 6 & 20.00 \\
Klebsiella pneumoniae & 2 & 06.66 \\
Salmonella species & 1 & 03.33 \\
Shigella & 3 & 10.00 \\
Staphylococcus aureus & 2 & 06.66 \\
Total & 16 & \\
\hline
\end{tabular}

Table 4: Distribution of Organisms within Sampling Area

\begin{tabular}{lcc}
\hline \multicolumn{1}{c}{ Sampling Area } & No. Isolated & Percentage (\%) \\
\hline Dausai & 4 & 80 \\
Kofar Kudu & 4 & 80 \\
Makwalla & 2 & 40 \\
Rinji & 3 & 60 \\
Tosaro & 2 & 40 \\
Tsohuwar Kasuwa & 1 & 20 \\
Total & 16 & \\
\hline
\end{tabular}

\section{CONCLUSION}

Results indicated $4.00 \times 10^{5} \mathrm{CFU} / \mathrm{g}$ as the highest APCs count; while $68 \mathrm{MPN} / \mathrm{g}$ was the highest TCCs from the 30 samples analyzed. Among the isolates, $E$. coli has the highest isolation rate of $6(20 \%)$. Dausai and Kofar kudu were having the highest bacteria count of $4(80 \%)$, each, indicating higher contamination in those locations. 
BAJOPAS Volume 13 Number 1, June, 2020 RECOMMENDATIONS

The following recommendations are tenable:

1. Hygienic practices at all stages of production should be improved to safe guard the consumers against potential health hazard.

2. Monitoring of microbiological contamination of Tsire during preparations, packaging and marketing is essential to ensure product of good microbiological quality for consumers' health.

\section{REFERENCES}

Abdullahi, I. O., Umoh, V. J. and Galadima, M. (2004). Hazards Associated with Kilishi Preparations in Zaria. Nigerian Journal of Microbiology, 18 (1-2): $339-345$.

Ahmadu, J. and Ibrahim E. J., (2013): Determinants of Revenue in Suya Production in BeninCity, Edo State, Nigeria. Nigerian journal of agriculture, food and environment.9(3):1-5

Amaeze, N. Aboh, M. Itohan, A. Felix, E. Olatunji, T. and Oladosu, P. (2016) Microbial Profile, Antibiotic Sensitivity and Heat Resistance of Bacterial Isolates from Commercial Roasted Beef (Suya) in Abuja, Nigeria. JOPAT, 15(2): $22-30$.

Apata, E.S., Kuku1, I.A., Apata, O.C. and Adeyemi, K.O. (2013). Evaluation of Suya(Tsire) - An Intermediate Moisture Meat Product in Ogun State, Nigeria. J. Food Res 2 (1): 87.

Atlas, R. M. (1997) Principles of Microbiology Second Edition. C. Brown Publishers. Pp 802-803.

Borch, E. Kant-Muermans, M. L., Blixt, Y. (1996) Bacterial Spoilage of Meat and Cured Meat Products. Int $\mathrm{J}$ Food Microbiol .33(1): 103-20.

Centre for Disease Control, CDC (2011). "Escherichia coli 0157:H7" Division of Bacterial and Mycotic Diseasesht://www.cdc.gov/nczved/divisi ons/dfbmd/diseases/ecoli_0157h7/.

Charlene, R. J., Johnnie, A. D., and John, B. B., (2013) Prevalence and Characterization of Methicillin-Resistant Staphylococcus aureus Isolates from Retail Meat and Humans in Georgia. American society for Microbiology. J. of clinical microbiology. 12(1):123-6 doi:10.1128/JCM.0316612JCM.03166-12

Egbebi, A.O and Seidu, K., T. (2011). Microbiological Evaluation of Suya (dried smoked

meat) Sold in Ado and Akure, South West Nigeria.European Journal of Experinmental Biology, 1(4):1-5
3. Government should establish regulatory bodies responsible for inculcating hygiene habits to the local producers and vendors in order to prevent instant, cross and post processing contaminations by microbial pathogens.

4. Awareness and sensitization of local food producers about good hygienic practices in food handling and processing.

Falegan, C, R., Akoja, S. D., and Oyarekua, M. A., (2017) Microbiological Assessment of Suya (Sliced Roasted Beef) in Ado-Ekiti Metropolis, Ekiti State, Nigeria. MOJ Biology andMedicine.

Fonkem, D., N. Tanya, V., N. and Ebangi, A., L. (2010). Effect of Season on the Microbiological Quality of Kilishi, a Traditional Cameroonian Dried Beef Product. Tropicultura, 28(1): 10-15.

Food and Agricultural Organization of the United Nations (F A O, 1979). Manual of food quality control 4. Microbiological analysis.

Food and Agriculture Organisation of the United Nation (FAO), 2019. Nigeria at a glance.

Igene J.O., Uwadia, O.E., Ebabhamiegbebho, P.A. and Evivie, S.E., (2016) Shelf life Stability Studies of University of Benin (UNIBEN) Proff's Kilishi Product Asian Journal of Science and Technology 7(1): 2268-2274.

Inusa, S. K. and Said, I. S. (2017) Evaluation of the Chemical and Microbiological Properties Of Kilishi Sold in Kano Metropolis. Journal of Dry land Agriculture, 3 (1): $59-69$.

Lucretia, I. B, Patience, C. Obinna-Echem, Sophia, C. A. (2018) Microbiological quality andantibiotic sensitivity of potential pathogens isolated from meat product (Suya) sold in Rivers State University and its environs. International Journal of Biotechnology and Food Science, 6(4): 67-76.

Matthew, E., Drosos, E., John, L. and Ioanna, P. (2013) MRSA in Africa: Filling the Global Map of Antimicrobial Resistance PLOS One. 8(7): e68024 doi: 10.1371/journal.pone.0068024

Mgbemere, V.N., Akpapunam, M. A. and Igene, J. O., (2011). Effect of Groundnut FlourSubstitution on Yield, Quality and Storage Stability of Kilishi - a Nigerian Indigenous Dried Meat Product. African Journal of Food, Agriculture, Nutrition and Development, $\quad \mathbf{1 1}(2)$ : 4718-4738. 
BAJOPAS Volume 13 Number 1, June, 2020

Mubarak, A. A., Azeez, M. L., Amos A. O., Opeyemi, O. O. (2016) Assessment of Animal Protein Consumption and Food Security Among Rural Households in Kwara State, Nigeria American Journal of Business and Society, 1(4): 233245.

Ndahi, M., D. Kwaga, J., K. P. Bello, M. Kabir J., V. Umoh, .J. Yakubu, S., E. and Nok, A., J. (2013) Prevalence and Antimicrobial Susceptibility of Listeria Monocytogenes and Methicillin-Resistant Staphylococcus aureus Strains from Raw Meat and Meat Products in Zaria, Nigeria. Applied Journal of Microbiology, 58(3):262-9.

Okonko, I.O., Odu, N.N. and Igboh, I.E. (2013). Microbiological Analysis of Kilishi Sold In Port Harcourt, Nigeria. New York Science Journal, 6 (7):37-43.

Osimani, A., Aquilanti, L. and Clementi, F. (2015) Microbiological Quality of Meatbased Meals and Operation of Control Systems within a Food Service Environment. International Food Research Journal 22(4): 1692-1698.

Onuorah, S. Obika, I. Odibo, F. Orji, M. (2015)An Assessment of the Bacteriological Quality of Tsire-Suya (Grilled Beef) sold in Awka, Nigeria. American. J. Life. Sci. Res. 3(4):287292.

Razavilar, V, Khandaghi, J. Barzgari, A. (2010); Isolation of Eschericia coli 0157:H7 from manure fertilized farms and raw vegetables grown on it, in Tabriz city in
Iran. African Journal of Microbiology Research, 4(9): 891-895.

Scallan, E. Hoekstra, R. M. Angulo, F. J.Tauxe, R. V, Widdowson, M. Roy, S. L et al., (2011).Food borne illness acquired in the United States- Major Pathogens. Emerg. Infec Dis, 17(1): 7-15.

Shamsuddeen U (2009). Microbiological quality of spice used in the production of Kilishi a traditionally dried and grilled meat product. Bayero Journal of Pure andApplied Sciences, 2(2): 66-69.

Shamsuddeen, U. (2015) Microbiological Hazard and Critical control point Analysis of Dried and Minced Meat Snacks Produced in Kano Nigeria. Lambert Academic Publishing; Pp 1-36.

Tijani, O.and Jumare, S. (2014). Microblological Quality Assessment of Meat

Sold in KauraNamoda. International Conference on Earth, Environment and Life sciences (EELS) Dubai (UAE).

Udobi, C. E., Obajuluwa, A. F., and Onaolapo, J. A., (2013) Prevalence and Antibiotic Resistance Pattern of MethicillinResistant Staphylococcus aureus from an Orthopaedic Hospital in Nigeria BioMed Research International; 26(6); 6-7.

WHO, 2015 Foodborne diseases in the WHO African Region.

Yousafzai HA, Rind R, Khan MA, Abro SH, Korejo NA, Ejaz M, Kabir A, Shahid M, Memon S. (2019). Microbiological Contamination of Cattle and Meat in Peshawar, Pakistan. J. Anim. Health Prod. 7(1): 1116. 


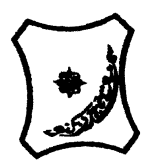

Bayero Journal of Pure and Applied Sciences, 13(1); 40 - 45

Received: September, 2019

Accepted: April, 2020

ISSN $2006-6996$

\title{
BACTERIOLOGICAL QUALITY OF STICK MEAT (Tsire) SOLD IN GARKO LOCAL GOVERNMENT AREA OF KANO STATE, NIGERIA
}

\author{
$*^{1}$ Dahiru A. T. and ${ }^{2}$ Maigari A. K. \\ ${ }^{1}$ Department of Hospitality Management, School of Technology, Kano State Polytechnic, PMB 3348, \\ Kano Nigeria. \\ ${ }^{2}$ Departmnt of Biological Sciences, Bayero University, Kano \\ Corresponding Author: dturajo61@gmail.com; GSM: 08087508262.
}

ABSTRACT

Stick meat, locally called Tsire in Hausa Language, is a significant portion of the diet of a large active population of Northern Nigeria. However, because of the handling and processing methods by the manufacturers as well as the hawking system of stick meat, the meat product may be exposed to both pre- and post-processed product contamination, and thus may poses danger to public health. Therefore, considering the role of Tsire in improving nutrition and increase household income to the populace, the need to improve the processing, distribution and overall quality of the product is simply indispensable. A total of 30 samples (5 samples from each of the 6 sampling points) of Tsire were collected randomly in Garko Town. Aerobic plate counts (APCs) and Total coliform counts (TCCS) of Tsire samples were determined using standard microbiological methods. APCs ranged from $1.02 \times 10^{5}$ to $4.00 \times 10^{5} \mathrm{CFU} / \mathrm{g}$; while TCCs ranged from $8 \mathrm{MPN} / \mathrm{g}$ to $68 \mathrm{MPN} / \mathrm{g}$. From the 30 samples screened, 16(53.33\%) bacteria namely, Campylobacter 2(6.66\%), Escherichia coli 6(20\%), Klebsiella pneumoniae 2(6.66\%), Salmonella spp. 1(3.33\%), Shigella 3(10\%) and Staphylococcus aureus 2(6.66\%) were detected. $E$. coli has the highest isolation rate of 6(20\%), while Salmonella spp. had the least frequency of 1(3.33\%). The distribution of isolated organisms within the study area were as follows: Dausai, 4(80\%), Kofar kudu, 4(80\%), Makwalla, 2(40\%), Rinji, 3(60\%), Tosaro, 2(40\%), and Tsohuwar Kasuwa, 1(20\%). The results have indicated that the Tsire was contaminated with bacteria thus exposing the product to fast deterioration, spoilage and also a vehicle for food borne illness, suggesting for adequate hygienic practices at all the stages, prior to consumption, to ensure safety of the meat product.

Key words: APCs, TCCs, Contamination, Microorganisms, Garko

\section{INTRODUCTION}

Nigeria is one of the developing nations with inadequate food supply and most often deficient in protein content (FAO, 2019). Nigerian's average animal protein intake per head per day is estimated at $7.9 \mathrm{~g}$ as against $35 \mathrm{~g}$ recommended value by Food and Agricultural Organization (Mubarak et al., 2016). These low levels of animal protein intake create great concern as it affects the nutritional status of Nigerians. Hence, there is the need for sufficient supply of animal protein from energy rich animal products to satisfy the nutritional requirements for Nigerians.

Meat is one major source of animal protein largely composed of water, protein and fats which can make it susceptible to microbial contamination within short time leading to spoilage (Apata et al., 2013; Mgbemere et al., 2011). Meat is mostly eaten after it has been cooked or processed in a variety of ways such as sun drying; smoking and roasting with or without fortifications (Borch et al., 1996). In Nigeria meat products such as Tsire, Kilishi and Balangu are locally produced using one or more of these methods in order to meet the nutritional requirements of the teeming Nigerians (Egbebi, 2011).

Tsire is a popular Nigerian traditional processed ready-to-eat roasted stick meat product (Shamsuddeen, 2015). It is sold in public places, along roads, in hotels, parks, quarters and even offices (Falegan et al., 2017). It is prepared from boneless healthy animal flesh such as beef and mutton, spiced with peanut cake, salt, vegetable oil and other flavorings followed by roasting (Shamsuddeen, 2015). Consumption of these products has extended to other parts of African countries such as Ghana, Somali, Cameroun and Chad (Ahmadu and Ibrahim, 2013). 
BAJOPAS Volume 13 Number 1, June, 2020

However, evidence of quality control sticking to procedural hygiene by the handlers during preparation and retailing of these products is poorly documented. Tsire is of great safety risk because of the fact that there are erratic cases of gastroenteritis and symptoms of food infection after consumption (WHO, 2015). Food borne illnesses are one of the major health problems in developing and developed countries (Razavilar, 2010). According to the World Health Organization, WHO (2015), $0.07 \%$ death of the 600 million global burdens of Foodborne illnesses have been reported to be caused by bacteria, viruses, fungi and chemicals. In America $0.27 \%$ of the estimated 48 million affected people is hospitalized and about $0.0063 \%$ deaths are recorded each year (Scallan et al., 2011). More than 91 million people in Africa fall ill and $0.15 \%$ dies each year, making Africa the highest burden bearer of Foodborne diseases per population (WHO, 2015).

Application of a Hazard Analysis Critical Control Point (HACCP) at all stages of meat products preparation is essential in order to ensure its safety. Thus, according to the guidelines of good manufacturing practice, the level of total aerobic bacterial contamination of thermally processed meat products should not exceed $10^{4}\left(\mathrm{cfu} \mathrm{g}^{-1}\right)$. Enterobacteriaceae and faecal coliform contamination in meat products should be within the range of $10^{2}-10^{4}$ and $10-10^{3} \mathrm{cfu} \mathrm{g}^{-1}$, respectively (Shamsuddeen, 2015). The aim of the study is therefore, to assess the total viable bacterial counts of tsire marketed locally within Garko town, and to isolate and identify the organisms at the point of consumption with the intention of promoting public health and food hygiene habits in the Nigerian populace.

\section{MATERIALS AND METHODS Study Area and Population}

Garko is one of the existing 44 local government areas located in Kano south west zone of Kano state with its capital administrative headquarters in the Garko town. It has coordinates $11^{\circ} 39^{\prime} \mathrm{N}$ $8^{\circ} 54^{\prime} \mathrm{E}$, and an area of $450 \mathrm{~km}^{2}$. The projected population of Garko local Government was 225,300 according to the National Population Census report (2018). Garko is known for agricultural activities both farming and animal husbandry. It is popularly known for large scale rice production. Other food crops include sweet potatoes, cassava, onions, sorghum, millet and sugarcane. Cows, sheep and goats are major groups of animals reared by majority of the populace. Meat products processed, retailed and consumed in Garko include roasted meat (Balangu), dried roasted meat (Kilishi), stick meat (Tsire), hide and skin pepper soup (Ragadada) and minced fried meat (Danbunnama).

\section{Samples Collection}

Five samples of Tsire products were collected from 6 different identified locations within Garko town in a sterile foil paper and immediately analyzed for the presence of bacteria.

\section{Sample Preparation}

Sample preparation for the bacteriological analysis was carried out in accordance with the method described by Atlas (1997). Twenty five grams $(25 \mathrm{~g})$ of the sample was homogenized in $225 \mathrm{ml}$ peptone water using Kenwood blender machine to obtain a $10^{1}$ homogenate. The homogenate was thoroughly shaken and $1 \mathrm{ml}$ pipetted into test tubes containing $9 \mathrm{ml}$ of peptone water $\left(10^{2}\right)$. The test tubes were further serially diluted to $10^{5}$.

Total Aerobic Mesophilic Bacterial Count

Total Aerobic mesophilic bacterial count was determined using the method described by Abdullahi et al. (2004) where $1 \mathrm{ml}$ of inoculums from $10^{1}$ to $10^{5}$ dilutions were transferred into duplicate Petri dishes and labeled accordingly. This was followed by pouring aseptically about $15 \mathrm{ml}$ of molten nutrient agar. The culture was homogenized by gentle spinning of the plates and allowed to solidify. The plates were incubated at $37^{\circ} \mathrm{C}$ for 24 hours. Plates containing 30-300 colonies were counted. The number of colony forming units per gram of a sample (cfu/g) was obtained by multiplying the average colony number with the inverse of the dilution factor.

\section{Enumeration and Detection of Coliform bacteria}

Detection and enumeration of coliform was carried out according to method described by Atlas, (1977). A set of 9 test tubes each containing $9 \mathrm{ml}$ of lactose broth and an inverted Durham tubes were autoclaved to expel air and to sterilize. Similarly, $1 \mathrm{ml}$ from the diluents $10^{1}$ was transferred to the first 3 test tubes, followed by $1 \mathrm{ml}$ from the diluents $10^{2}$ to the second set of 3 test tubes and finally the third diluents $10^{3}$ to the $3^{\text {rd }}$ set of 3 test tubes. All the 9 test tubes were incubated at $37^{\circ} \mathrm{C}$ for 24 hours. Tubes that showed gas and acid production after 24 hours were recorded as positive for the presence of Coliform. Negative tubes were further reincubated for 24 hours. Positive tubes were recorded. Estimate of most probable number of Coliform per gram of sample (MPN/g) was determined by comparing the number of gas positive tubes with the most probable number table. 
BAJOPAS Volume 13 Number 1, June, 2020 Identification of Coliform

A loop full of inoculum from gas positive tubes was streaked on to Eosine methylene blue (EMB) agar plate and incubated at $37^{\circ} \mathrm{C}$ for $24 \mathrm{hrs}$. Colonies which formed bluish black color with green metallic sheen, and reddish colonies were isolated on agar slants. Those colonies showing metallic sheen on EMB were sub cultured into tubes of lactose broth and incubated at $45^{\circ} \mathrm{C}$. The tubes were observed after $24 \mathrm{hrs}$ for gas production. This is the completed test for fecal coliform. Gram stain and other biochemical tests such as Indole, Methyl red, Voges-Proskauer and Citrate Utilization tests (IMVIC), Coagulase and Catalase tests were carried out for the Identification and confirmation of isolates.

\section{Procedure for Indole Test}

Indole test was carried out by preparing a Tryptone broth drawn in to test tubes, sterilized by autoclaving, inoculated with loopful of suspension and incubated at $37^{\circ} \mathrm{C}$ for 24 hours. Three drops of xylene was added in tubes, shaken vigorously and kept for the separation of two layers. One millilitre of Kovac's reagent was added and the formation of pink colour ring indicates positive Indole test.

\section{Procedure for Methyl Red Test}

Methyl red test was carried out by preparing Glucose phosphate broth, dispensed in test tubes, sterilized, inoculated with test culture and incubated at $37^{\circ} \mathrm{C}$ for 24 hours. Five drops of methyl-red indicator was added to the medium for the formation of red colour.

\section{Procedure for Voges-Proskauer Test}

Voges-Proskauer test was carried out by inoculating tubes with the bacterial culture followed by incubation for 48 hours at $37^{\circ} \mathrm{C}$. Separate pipettes were used to pipette $1 \mathrm{ml}$ from each culture tube into clean separate tubes. Eighteen drops $(0.5 \mathrm{ml})$ of Barrit's solution A (a-naphthol) was added to each tube containing glucose phosphate broth followed by the addition of an equal amount of solution $B$ into the same tube. The tubes were shaken at 30 seconds interval. A positive reaction was indicated by the development of a pink color, which turns red in 1-2 hours, after vigorous shaking.

\section{Procedure for Citrate Utilization Test}

Citrate Utilization Test was carried out by distributing melted agar (Simmon Citrate Agar) in to test tubes followed by sterilization at $121.5^{\circ} \mathrm{C}$ for 15 minutes. The test tubes were afterward held in slanted position, inoculated with the given bacterial culture and incubated at $37^{\circ} \mathrm{C}$ for $24 \mathrm{hrs}$. Positive test was indicated by color change of the media from green to blue.

\section{RESULTS AND DISCUSSIONS}

The results of this study are presented in tables $1,2,3$ and 4. Among the sampling areas Kofar Kudu had the highest aerobic mesophilic bacteria counts $4.0 \times 10^{5} \mathrm{cfu} / \mathrm{g}$ followed by Rinji $2.72 \times 10^{5} \mathrm{cfu} / \mathrm{g}$, while Tosaro had the least Aerobic mesophilic bacteria counts of $1.02 \times 10^{5}$ $\mathrm{cfu} / \mathrm{g}$ as indicated in Table 1.Makwalla had the highest coliform count $68 \mathrm{MPN} / \mathrm{g}$ followed by Rinji $37 \mathrm{MPN} / \mathrm{g}$. Tsohuwar Kasuwa had the least coliform counts $8 \mathrm{MPN} / \mathrm{g}$, (Table 2). Result from table 1 shows variation in the microbial contents among the samples which suggest variation in their sources, poor handling procedures and contamination from the processing environment. High coliform count and their differences within sampling areas is an indication of poor microbiological quality of the product. Ndahi et al. (2013) reported microbial load to be a function of the handling personnel and the environment. The results indicated that the samples were contaminated with bacteria as the counts exceeded the minimum safety level $\left(10^{4} \mathrm{cfu} / \mathrm{g}\right)$ for members of the Enterobacteriaceae family. However, it might be a reflection of poor hygienic practices which may contribute to health hazard to the potential consumers. Similarly, Inusa and Sa'id (2017); Osimani et al. (2015) reported that, the initial microbial content of the raw material play significant role in influencing the final microbial load of the finished product. Isolation of members of the Enterobacteriaceae such as $E$. coli, Klebsiella pneumoniae, Salmonella and Shigella signifies danger to the public health. These organisms are capable of producing endotoxins which trigger high fevers in infected individuals, and the enterotoxins which colonize the small intestines and lead to extreme dehydration as a result of vomiting and diarrhea sometimes with severe and fatal outcomes (Amaeze et al., 2016). From the 16 isolated organisms $E$. coli had the highest isolation rate $6(37.5 \%)$ (Table 3), this suggest faecal contamination of the products. $E$. coli is a common flora in the gastrointestinal tract responsible for diarrhea and extra-intestinal infections (CDC, 2011). The result is in conformity with the findings of Ndahi et al. (2013) and Shamsuddeen (2009). Also presence of campylobacter might be due to cross contamination from raw meat to finished product (Tsire). Staphylococcus aureus is a normal flora of the skin, nasal, genital, mouth or anal area in both humans and animals without any symptom of an infection (Matthew et al., 2013). Isolation of $S$. aureus in these study concords with the findings of Lucretia et al. (2018) from Suya sold in Rivers State. 
BAJOPAS Volume 13 Number 1, June, 2020

It is also in agreement with the findings of Yousafzai et al. (2018); Onuorah et al. (2015) and Tijjani and Jumare (2014) from tsire samples in different countries. Presence of $S$. aureus in foods is most of the time an indication of poor human handling, poor environment, unhygienic utensils and equipments used during processing (Igene et al., 2016; Okonko et al., 2013). Infections caused by $S$. aureus are difficult to treat leading to long hospitalization with consequent economic loss (Udobi et al., 2013). These include soft tissue infections, pneumonia, hospital-acquired postoperative wound infections, Staphylococcal food poisoning, impetigo and cellulitis (Charlene et al., 2013). Samples obtained from Dausai and Kofar Kudu had the highest isolation rate $4(80 \%)$ (Table 4 ) probably because of the much commercial activities taking place in the area which can lead to environmental contamination.

Table 1: Total Aerobic Mesophilic Bacterial Count of Tsire sold in Garko Town

\begin{tabular}{lll}
\hline Sampling Area & APC cfu/g & Mean \pm STD \\
\hline Dausai & $2.20 \times 10^{5}$ & $110000 \pm 14142.14$ \\
Kofar Kudu & $4.00 \times 10^{5}$ & $133333.3 \pm 23094.01$ \\
Makwalla & $1.30 \times 10^{5}$ & $32500 \pm 7187.953$ \\
Rinji & $2.72 \times 10^{5}$ & $90666.67 \pm 94769.90$ \\
Tosaro & $1.02 \times 10^{5}$ & $51000 \pm 15556.35$ \\
Tsohuwar Kasuwa & $1.75 \times 10^{5}$ & $35000 \pm 11357.82$ \\
\hline
\end{tabular}

Key: APC: Aerobic Mesophilic Counts

STD: Standard Deviation

Table 2: Total Coliform Count of Tsire sold in Garko Town

\begin{tabular}{lcc}
\hline \multicolumn{1}{c}{ Sampling Area } & TCC MPN/g & Mean \pm STD \\
\hline Dausai & 20 & $6.67 \pm 2.5166$ \\
Kofar Kudu & 32 & $16.00 \pm 5.6569$ \\
Makwalla & 68 & $13.60 \pm 8.7062$ \\
Rinji & 37 & $9.25 \pm 4.7871$ \\
Tosaro & 10 & $5.00 \pm 2.8284$ \\
Tsohuwar Kasuwa & 8 & $4.00 \pm 0.0000$ \\
\hline
\end{tabular}

Table 3: Organisms Isolated from Tsire Sold in Garko

\begin{tabular}{lcl}
\hline Isolated Organism & Frequency & Percentage (\%) \\
\hline Campylobacter & 2 & 06.66 \\
Escherichia coli & 6 & 20.00 \\
Klebsiella pneumoniae & 2 & 06.66 \\
Salmonella species & 1 & 03.33 \\
Shigella & 3 & 10.00 \\
Staphylococcus aureus & 2 & 06.66 \\
Total & 16 & \\
\hline
\end{tabular}

Table 4: Distribution of Organisms within Sampling Area

\begin{tabular}{lcc}
\hline \multicolumn{1}{c}{ Sampling Area } & No. Isolated & Percentage (\%) \\
\hline Dausai & 4 & 80 \\
Kofar Kudu & 4 & 80 \\
Makwalla & 2 & 40 \\
Rinji & 3 & 60 \\
Tosaro & 2 & 40 \\
Tsohuwar Kasuwa & 1 & 20 \\
Total & 16 & \\
\hline
\end{tabular}

\section{CONCLUSION}

Results indicated $4.00 \times 10^{5} \mathrm{CFU} / \mathrm{g}$ as the highest APCs count; while $68 \mathrm{MPN} / \mathrm{g}$ was the highest TCCs from the 30 samples analyzed. Among the isolates, $E$. coli has the highest isolation rate of $6(20 \%)$. Dausai and Kofar kudu were having the highest bacteria count of $4(80 \%)$, each, indicating higher contamination in those locations. 
BAJOPAS Volume 13 Number 1, June, 2020 RECOMMENDATIONS

The following recommendations are tenable:

1. Hygienic practices at all stages of production should be improved to safe guard the consumers against potential health hazard.

2. Monitoring of microbiological contamination of Tsire during preparations, packaging and marketing is essential to ensure product of good microbiological quality for consumers' health.

\section{REFERENCES}

Abdullahi, I. O., Umoh, V. J. and Galadima, M. (2004). Hazards Associated with Kilishi Preparations in Zaria. Nigerian Journal of Microbiology, 18 (1-2): $339-345$.

Ahmadu, J. and Ibrahim E. J., (2013): Determinants of Revenue in Suya Production in BeninCity, Edo State, Nigeria. Nigerian journal of agriculture, food and environment.9(3):1-5

Amaeze, N. Aboh, M. Itohan, A. Felix, E. Olatunji, T. and Oladosu, P. (2016) Microbial Profile, Antibiotic Sensitivity and Heat Resistance of Bacterial Isolates from Commercial Roasted Beef (Suya) in Abuja, Nigeria. JOPAT, 15(2): $22-30$.

Apata, E.S., Kuku1, I.A., Apata, O.C. and Adeyemi, K.O. (2013). Evaluation of Suya(Tsire) - An Intermediate Moisture Meat Product in Ogun State, Nigeria. J. Food Res 2 (1): 87.

Atlas, R. M. (1997) Principles of Microbiology Second Edition. C. Brown Publishers. Pp 802-803.

Borch, E. Kant-Muermans, M. L., Blixt, Y. (1996) Bacterial Spoilage of Meat and Cured Meat Products. Int $\mathrm{J}$ Food Microbiol .33(1): 103-20.

Centre for Disease Control, CDC (2011). "Escherichia coli 0157:H7" Division of Bacterial and Mycotic Diseasesht://www.cdc.gov/nczved/divisi ons/dfbmd/diseases/ecoli_0157h7/.

Charlene, R. J., Johnnie, A. D., and John, B. B., (2013) Prevalence and Characterization of Methicillin-Resistant Staphylococcus aureus Isolates from Retail Meat and Humans in Georgia. American society for Microbiology. J. of clinical microbiology. 12(1):123-6 doi:10.1128/JCM.0316612JCM.03166-12

Egbebi, A.O and Seidu, K., T. (2011). Microbiological Evaluation of Suya (dried smoked

meat) Sold in Ado and Akure, South West Nigeria.European Journal of Experinmental Biology, 1(4):1-5
3. Government should establish regulatory bodies responsible for inculcating hygiene habits to the local producers and vendors in order to prevent instant, cross and post processing contaminations by microbial pathogens.

4. Awareness and sensitization of local food producers about good hygienic practices in food handling and processing.

Falegan, C, R., Akoja, S. D., and Oyarekua, M. A., (2017) Microbiological Assessment of Suya (Sliced Roasted Beef) in Ado-Ekiti Metropolis, Ekiti State, Nigeria. MOJ Biology andMedicine.

Fonkem, D., N. Tanya, V., N. and Ebangi, A., L. (2010). Effect of Season on the Microbiological Quality of Kilishi, a Traditional Cameroonian Dried Beef Product. Tropicultura, 28(1): 10-15.

Food and Agricultural Organization of the United Nations (F A O, 1979). Manual of food quality control 4. Microbiological analysis.

Food and Agriculture Organisation of the United Nation (FAO), 2019. Nigeria at a glance.

Igene J.O., Uwadia, O.E., Ebabhamiegbebho, P.A. and Evivie, S.E., (2016) Shelf life Stability Studies of University of Benin (UNIBEN) Proff's Kilishi Product Asian Journal of Science and Technology 7(1): 2268-2274.

Inusa, S. K. and Said, I. S. (2017) Evaluation of the Chemical and Microbiological Properties Of Kilishi Sold in Kano Metropolis. Journal of Dry land Agriculture, 3 (1): $59-69$.

Lucretia, I. B, Patience, C. Obinna-Echem, Sophia, C. A. (2018) Microbiological quality andantibiotic sensitivity of potential pathogens isolated from meat product (Suya) sold in Rivers State University and its environs. International Journal of Biotechnology and Food Science, 6(4): 67-76.

Matthew, E., Drosos, E., John, L. and Ioanna, P. (2013) MRSA in Africa: Filling the Global Map of Antimicrobial Resistance PLOS One. 8(7): e68024 doi: 10.1371/journal.pone.0068024

Mgbemere, V.N., Akpapunam, M. A. and Igene, J. O., (2011). Effect of Groundnut FlourSubstitution on Yield, Quality and Storage Stability of Kilishi - a Nigerian Indigenous Dried Meat Product. African Journal of Food, Agriculture, Nutrition and Development, $\quad \mathbf{1 1}(2)$ : 4718-4738. 
BAJOPAS Volume 13 Number 1, June, 2020

Mubarak, A. A., Azeez, M. L., Amos A. O., Opeyemi, O. O. (2016) Assessment of Animal Protein Consumption and Food Security Among Rural Households in Kwara State, Nigeria American Journal of Business and Society, 1(4): 233245.

Ndahi, M., D. Kwaga, J., K. P. Bello, M. Kabir J., V. Umoh, .J. Yakubu, S., E. and Nok, A., J. (2013) Prevalence and Antimicrobial Susceptibility of Listeria Monocytogenes and Methicillin-Resistant Staphylococcus aureus Strains from Raw Meat and Meat Products in Zaria, Nigeria. Applied Journal of Microbiology, 58(3):262-9.

Okonko, I.O., Odu, N.N. and Igboh, I.E. (2013). Microbiological Analysis of Kilishi Sold In Port Harcourt, Nigeria. New York Science Journal, 6 (7):37-43.

Osimani, A., Aquilanti, L. and Clementi, F. (2015) Microbiological Quality of Meatbased Meals and Operation of Control Systems within a Food Service Environment. International Food Research Journal 22(4): 1692-1698.

Onuorah, S. Obika, I. Odibo, F. Orji, M. (2015)An Assessment of the Bacteriological Quality of Tsire-Suya (Grilled Beef) sold in Awka, Nigeria. American. J. Life. Sci. Res. 3(4):287292.

Razavilar, V, Khandaghi, J. Barzgari, A. (2010); Isolation of Eschericia coli 0157:H7 from manure fertilized farms and raw vegetables grown on it, in Tabriz city in
Iran. African Journal of Microbiology Research, 4(9): 891-895.

Scallan, E. Hoekstra, R. M. Angulo, F. J.Tauxe, R. V, Widdowson, M. Roy, S. L et al., (2011).Food borne illness acquired in the United States- Major Pathogens. Emerg. Infec Dis, 17(1): 7-15.

Shamsuddeen U (2009). Microbiological quality of spice used in the production of Kilishi a traditionally dried and grilled meat product. Bayero Journal of Pure andApplied Sciences, 2(2): 66-69.

Shamsuddeen, U. (2015) Microbiological Hazard and Critical control point Analysis of Dried and Minced Meat Snacks Produced in Kano Nigeria. Lambert Academic Publishing; Pp 1-36.

Tijani, O.and Jumare, S. (2014). Microblological Quality Assessment of Meat

Sold in KauraNamoda. International Conference on Earth, Environment and Life sciences (EELS) Dubai (UAE).

Udobi, C. E., Obajuluwa, A. F., and Onaolapo, J. A., (2013) Prevalence and Antibiotic Resistance Pattern of MethicillinResistant Staphylococcus aureus from an Orthopaedic Hospital in Nigeria BioMed Research International; 26(6); 6-7.

WHO, 2015 Foodborne diseases in the WHO African Region.

Yousafzai HA, Rind R, Khan MA, Abro SH, Korejo NA, Ejaz M, Kabir A, Shahid M, Memon S. (2019). Microbiological Contamination of Cattle and Meat in Peshawar, Pakistan. J. Anim. Health Prod. 7(1): 1116. 


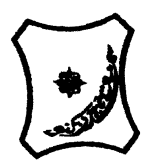

Bayero Journal of Pure and Applied Sciences, 13(1); 40 - 45

Received: September, 2019

Accepted: April, 2020

ISSN $2006-6996$

\title{
BACTERIOLOGICAL QUALITY OF STICK MEAT (Tsire) SOLD IN GARKO LOCAL GOVERNMENT AREA OF KANO STATE, NIGERIA
}

\author{
$*^{1}$ Dahiru A. T. and ${ }^{2}$ Maigari A. K. \\ ${ }^{1}$ Department of Hospitality Management, School of Technology, Kano State Polytechnic, PMB 3348, \\ Kano Nigeria. \\ ${ }^{2}$ Departmnt of Biological Sciences, Bayero University, Kano \\ Corresponding Author: dturajo61@gmail.com; GSM: 08087508262.
}

ABSTRACT

Stick meat, locally called Tsire in Hausa Language, is a significant portion of the diet of a large active population of Northern Nigeria. However, because of the handling and processing methods by the manufacturers as well as the hawking system of stick meat, the meat product may be exposed to both pre- and post-processed product contamination, and thus may poses danger to public health. Therefore, considering the role of Tsire in improving nutrition and increase household income to the populace, the need to improve the processing, distribution and overall quality of the product is simply indispensable. A total of 30 samples (5 samples from each of the 6 sampling points) of Tsire were collected randomly in Garko Town. Aerobic plate counts (APCs) and Total coliform counts (TCCS) of Tsire samples were determined using standard microbiological methods. APCs ranged from $1.02 \times 10^{5}$ to $4.00 \times 10^{5} \mathrm{CFU} / \mathrm{g}$; while TCCs ranged from $8 \mathrm{MPN} / \mathrm{g}$ to $68 \mathrm{MPN} / \mathrm{g}$. From the 30 samples screened, 16(53.33\%) bacteria namely, Campylobacter 2(6.66\%), Escherichia coli 6(20\%), Klebsiella pneumoniae 2(6.66\%), Salmonella spp. 1(3.33\%), Shigella 3(10\%) and Staphylococcus aureus 2(6.66\%) were detected. $E$. coli has the highest isolation rate of 6(20\%), while Salmonella spp. had the least frequency of 1(3.33\%). The distribution of isolated organisms within the study area were as follows: Dausai, 4(80\%), Kofar kudu, 4(80\%), Makwalla, 2(40\%), Rinji, 3(60\%), Tosaro, 2(40\%), and Tsohuwar Kasuwa, 1(20\%). The results have indicated that the Tsire was contaminated with bacteria thus exposing the product to fast deterioration, spoilage and also a vehicle for food borne illness, suggesting for adequate hygienic practices at all the stages, prior to consumption, to ensure safety of the meat product.

Key words: APCs, TCCs, Contamination, Microorganisms, Garko

\section{INTRODUCTION}

Nigeria is one of the developing nations with inadequate food supply and most often deficient in protein content (FAO, 2019). Nigerian's average animal protein intake per head per day is estimated at $7.9 \mathrm{~g}$ as against $35 \mathrm{~g}$ recommended value by Food and Agricultural Organization (Mubarak et al., 2016). These low levels of animal protein intake create great concern as it affects the nutritional status of Nigerians. Hence, there is the need for sufficient supply of animal protein from energy rich animal products to satisfy the nutritional requirements for Nigerians.

Meat is one major source of animal protein largely composed of water, protein and fats which can make it susceptible to microbial contamination within short time leading to spoilage (Apata et al., 2013; Mgbemere et al., 2011). Meat is mostly eaten after it has been cooked or processed in a variety of ways such as sun drying; smoking and roasting with or without fortifications (Borch et al., 1996). In Nigeria meat products such as Tsire, Kilishi and Balangu are locally produced using one or more of these methods in order to meet the nutritional requirements of the teeming Nigerians (Egbebi, 2011).

Tsire is a popular Nigerian traditional processed ready-to-eat roasted stick meat product (Shamsuddeen, 2015). It is sold in public places, along roads, in hotels, parks, quarters and even offices (Falegan et al., 2017). It is prepared from boneless healthy animal flesh such as beef and mutton, spiced with peanut cake, salt, vegetable oil and other flavorings followed by roasting (Shamsuddeen, 2015). Consumption of these products has extended to other parts of African countries such as Ghana, Somali, Cameroun and Chad (Ahmadu and Ibrahim, 2013). 
BAJOPAS Volume 13 Number 1, June, 2020

However, evidence of quality control sticking to procedural hygiene by the handlers during preparation and retailing of these products is poorly documented. Tsire is of great safety risk because of the fact that there are erratic cases of gastroenteritis and symptoms of food infection after consumption (WHO, 2015). Food borne illnesses are one of the major health problems in developing and developed countries (Razavilar, 2010). According to the World Health Organization, WHO (2015), $0.07 \%$ death of the 600 million global burdens of Foodborne illnesses have been reported to be caused by bacteria, viruses, fungi and chemicals. In America $0.27 \%$ of the estimated 48 million affected people is hospitalized and about $0.0063 \%$ deaths are recorded each year (Scallan et al., 2011). More than 91 million people in Africa fall ill and $0.15 \%$ dies each year, making Africa the highest burden bearer of Foodborne diseases per population (WHO, 2015).

Application of a Hazard Analysis Critical Control Point (HACCP) at all stages of meat products preparation is essential in order to ensure its safety. Thus, according to the guidelines of good manufacturing practice, the level of total aerobic bacterial contamination of thermally processed meat products should not exceed $10^{4}\left(\mathrm{cfu} \mathrm{g}^{-1}\right)$. Enterobacteriaceae and faecal coliform contamination in meat products should be within the range of $10^{2}-10^{4}$ and $10-10^{3} \mathrm{cfu} \mathrm{g}^{-1}$, respectively (Shamsuddeen, 2015). The aim of the study is therefore, to assess the total viable bacterial counts of tsire marketed locally within Garko town, and to isolate and identify the organisms at the point of consumption with the intention of promoting public health and food hygiene habits in the Nigerian populace.

\section{MATERIALS AND METHODS Study Area and Population}

Garko is one of the existing 44 local government areas located in Kano south west zone of Kano state with its capital administrative headquarters in the Garko town. It has coordinates $11^{\circ} 39^{\prime} \mathrm{N}$ $8^{\circ} 54^{\prime} \mathrm{E}$, and an area of $450 \mathrm{~km}^{2}$. The projected population of Garko local Government was 225,300 according to the National Population Census report (2018). Garko is known for agricultural activities both farming and animal husbandry. It is popularly known for large scale rice production. Other food crops include sweet potatoes, cassava, onions, sorghum, millet and sugarcane. Cows, sheep and goats are major groups of animals reared by majority of the populace. Meat products processed, retailed and consumed in Garko include roasted meat (Balangu), dried roasted meat (Kilishi), stick meat (Tsire), hide and skin pepper soup (Ragadada) and minced fried meat (Danbunnama).

\section{Samples Collection}

Five samples of Tsire products were collected from 6 different identified locations within Garko town in a sterile foil paper and immediately analyzed for the presence of bacteria.

\section{Sample Preparation}

Sample preparation for the bacteriological analysis was carried out in accordance with the method described by Atlas (1997). Twenty five grams $(25 \mathrm{~g})$ of the sample was homogenized in $225 \mathrm{ml}$ peptone water using Kenwood blender machine to obtain a $10^{1}$ homogenate. The homogenate was thoroughly shaken and $1 \mathrm{ml}$ pipetted into test tubes containing $9 \mathrm{ml}$ of peptone water $\left(10^{2}\right)$. The test tubes were further serially diluted to $10^{5}$.

Total Aerobic Mesophilic Bacterial Count

Total Aerobic mesophilic bacterial count was determined using the method described by Abdullahi et al. (2004) where $1 \mathrm{ml}$ of inoculums from $10^{1}$ to $10^{5}$ dilutions were transferred into duplicate Petri dishes and labeled accordingly. This was followed by pouring aseptically about $15 \mathrm{ml}$ of molten nutrient agar. The culture was homogenized by gentle spinning of the plates and allowed to solidify. The plates were incubated at $37^{\circ} \mathrm{C}$ for 24 hours. Plates containing 30-300 colonies were counted. The number of colony forming units per gram of a sample (cfu/g) was obtained by multiplying the average colony number with the inverse of the dilution factor.

\section{Enumeration and Detection of Coliform bacteria}

Detection and enumeration of coliform was carried out according to method described by Atlas, (1977). A set of 9 test tubes each containing $9 \mathrm{ml}$ of lactose broth and an inverted Durham tubes were autoclaved to expel air and to sterilize. Similarly, $1 \mathrm{ml}$ from the diluents $10^{1}$ was transferred to the first 3 test tubes, followed by $1 \mathrm{ml}$ from the diluents $10^{2}$ to the second set of 3 test tubes and finally the third diluents $10^{3}$ to the $3^{\text {rd }}$ set of 3 test tubes. All the 9 test tubes were incubated at $37^{\circ} \mathrm{C}$ for 24 hours. Tubes that showed gas and acid production after 24 hours were recorded as positive for the presence of Coliform. Negative tubes were further reincubated for 24 hours. Positive tubes were recorded. Estimate of most probable number of Coliform per gram of sample (MPN/g) was determined by comparing the number of gas positive tubes with the most probable number table. 
BAJOPAS Volume 13 Number 1, June, 2020 Identification of Coliform

A loop full of inoculum from gas positive tubes was streaked on to Eosine methylene blue (EMB) agar plate and incubated at $37^{\circ} \mathrm{C}$ for $24 \mathrm{hrs}$. Colonies which formed bluish black color with green metallic sheen, and reddish colonies were isolated on agar slants. Those colonies showing metallic sheen on EMB were sub cultured into tubes of lactose broth and incubated at $45^{\circ} \mathrm{C}$. The tubes were observed after $24 \mathrm{hrs}$ for gas production. This is the completed test for fecal coliform. Gram stain and other biochemical tests such as Indole, Methyl red, Voges-Proskauer and Citrate Utilization tests (IMVIC), Coagulase and Catalase tests were carried out for the Identification and confirmation of isolates.

\section{Procedure for Indole Test}

Indole test was carried out by preparing a Tryptone broth drawn in to test tubes, sterilized by autoclaving, inoculated with loopful of suspension and incubated at $37^{\circ} \mathrm{C}$ for 24 hours. Three drops of xylene was added in tubes, shaken vigorously and kept for the separation of two layers. One millilitre of Kovac's reagent was added and the formation of pink colour ring indicates positive Indole test.

\section{Procedure for Methyl Red Test}

Methyl red test was carried out by preparing Glucose phosphate broth, dispensed in test tubes, sterilized, inoculated with test culture and incubated at $37^{\circ} \mathrm{C}$ for 24 hours. Five drops of methyl-red indicator was added to the medium for the formation of red colour.

\section{Procedure for Voges-Proskauer Test}

Voges-Proskauer test was carried out by inoculating tubes with the bacterial culture followed by incubation for 48 hours at $37^{\circ} \mathrm{C}$. Separate pipettes were used to pipette $1 \mathrm{ml}$ from each culture tube into clean separate tubes. Eighteen drops $(0.5 \mathrm{ml})$ of Barrit's solution A (a-naphthol) was added to each tube containing glucose phosphate broth followed by the addition of an equal amount of solution $B$ into the same tube. The tubes were shaken at 30 seconds interval. A positive reaction was indicated by the development of a pink color, which turns red in 1-2 hours, after vigorous shaking.

\section{Procedure for Citrate Utilization Test}

Citrate Utilization Test was carried out by distributing melted agar (Simmon Citrate Agar) in to test tubes followed by sterilization at $121.5^{\circ} \mathrm{C}$ for 15 minutes. The test tubes were afterward held in slanted position, inoculated with the given bacterial culture and incubated at $37^{\circ} \mathrm{C}$ for $24 \mathrm{hrs}$. Positive test was indicated by color change of the media from green to blue.

\section{RESULTS AND DISCUSSIONS}

The results of this study are presented in tables $1,2,3$ and 4. Among the sampling areas Kofar Kudu had the highest aerobic mesophilic bacteria counts $4.0 \times 10^{5} \mathrm{cfu} / \mathrm{g}$ followed by Rinji $2.72 \times 10^{5} \mathrm{cfu} / \mathrm{g}$, while Tosaro had the least Aerobic mesophilic bacteria counts of $1.02 \times 10^{5}$ $\mathrm{cfu} / \mathrm{g}$ as indicated in Table 1.Makwalla had the highest coliform count $68 \mathrm{MPN} / \mathrm{g}$ followed by Rinji $37 \mathrm{MPN} / \mathrm{g}$. Tsohuwar Kasuwa had the least coliform counts $8 \mathrm{MPN} / \mathrm{g}$, (Table 2). Result from table 1 shows variation in the microbial contents among the samples which suggest variation in their sources, poor handling procedures and contamination from the processing environment. High coliform count and their differences within sampling areas is an indication of poor microbiological quality of the product. Ndahi et al. (2013) reported microbial load to be a function of the handling personnel and the environment. The results indicated that the samples were contaminated with bacteria as the counts exceeded the minimum safety level $\left(10^{4} \mathrm{cfu} / \mathrm{g}\right)$ for members of the Enterobacteriaceae family. However, it might be a reflection of poor hygienic practices which may contribute to health hazard to the potential consumers. Similarly, Inusa and Sa'id (2017); Osimani et al. (2015) reported that, the initial microbial content of the raw material play significant role in influencing the final microbial load of the finished product. Isolation of members of the Enterobacteriaceae such as $E$. coli, Klebsiella pneumoniae, Salmonella and Shigella signifies danger to the public health. These organisms are capable of producing endotoxins which trigger high fevers in infected individuals, and the enterotoxins which colonize the small intestines and lead to extreme dehydration as a result of vomiting and diarrhea sometimes with severe and fatal outcomes (Amaeze et al., 2016). From the 16 isolated organisms $E$. coli had the highest isolation rate $6(37.5 \%)$ (Table 3), this suggest faecal contamination of the products. $E$. coli is a common flora in the gastrointestinal tract responsible for diarrhea and extra-intestinal infections (CDC, 2011). The result is in conformity with the findings of Ndahi et al. (2013) and Shamsuddeen (2009). Also presence of campylobacter might be due to cross contamination from raw meat to finished product (Tsire). Staphylococcus aureus is a normal flora of the skin, nasal, genital, mouth or anal area in both humans and animals without any symptom of an infection (Matthew et al., 2013). Isolation of $S$. aureus in these study concords with the findings of Lucretia et al. (2018) from Suya sold in Rivers State. 
BAJOPAS Volume 13 Number 1, June, 2020

It is also in agreement with the findings of Yousafzai et al. (2018); Onuorah et al. (2015) and Tijjani and Jumare (2014) from tsire samples in different countries. Presence of $S$. aureus in foods is most of the time an indication of poor human handling, poor environment, unhygienic utensils and equipments used during processing (Igene et al., 2016; Okonko et al., 2013). Infections caused by $S$. aureus are difficult to treat leading to long hospitalization with consequent economic loss (Udobi et al., 2013). These include soft tissue infections, pneumonia, hospital-acquired postoperative wound infections, Staphylococcal food poisoning, impetigo and cellulitis (Charlene et al., 2013). Samples obtained from Dausai and Kofar Kudu had the highest isolation rate $4(80 \%)$ (Table 4 ) probably because of the much commercial activities taking place in the area which can lead to environmental contamination.

Table 1: Total Aerobic Mesophilic Bacterial Count of Tsire sold in Garko Town

\begin{tabular}{lll}
\hline Sampling Area & APC cfu/g & Mean \pm STD \\
\hline Dausai & $2.20 \times 10^{5}$ & $110000 \pm 14142.14$ \\
Kofar Kudu & $4.00 \times 10^{5}$ & $133333.3 \pm 23094.01$ \\
Makwalla & $1.30 \times 10^{5}$ & $32500 \pm 7187.953$ \\
Rinji & $2.72 \times 10^{5}$ & $90666.67 \pm 94769.90$ \\
Tosaro & $1.02 \times 10^{5}$ & $51000 \pm 15556.35$ \\
Tsohuwar Kasuwa & $1.75 \times 10^{5}$ & $35000 \pm 11357.82$ \\
\hline
\end{tabular}

Key: APC: Aerobic Mesophilic Counts

STD: Standard Deviation

Table 2: Total Coliform Count of Tsire sold in Garko Town

\begin{tabular}{lcc}
\hline \multicolumn{1}{c}{ Sampling Area } & TCC MPN/g & Mean \pm STD \\
\hline Dausai & 20 & $6.67 \pm 2.5166$ \\
Kofar Kudu & 32 & $16.00 \pm 5.6569$ \\
Makwalla & 68 & $13.60 \pm 8.7062$ \\
Rinji & 37 & $9.25 \pm 4.7871$ \\
Tosaro & 10 & $5.00 \pm 2.8284$ \\
Tsohuwar Kasuwa & 8 & $4.00 \pm 0.0000$ \\
\hline
\end{tabular}

Table 3: Organisms Isolated from Tsire Sold in Garko

\begin{tabular}{lcl}
\hline Isolated Organism & Frequency & Percentage (\%) \\
\hline Campylobacter & 2 & 06.66 \\
Escherichia coli & 6 & 20.00 \\
Klebsiella pneumoniae & 2 & 06.66 \\
Salmonella species & 1 & 03.33 \\
Shigella & 3 & 10.00 \\
Staphylococcus aureus & 2 & 06.66 \\
Total & 16 & \\
\hline
\end{tabular}

Table 4: Distribution of Organisms within Sampling Area

\begin{tabular}{lcc}
\hline \multicolumn{1}{c}{ Sampling Area } & No. Isolated & Percentage (\%) \\
\hline Dausai & 4 & 80 \\
Kofar Kudu & 4 & 80 \\
Makwalla & 2 & 40 \\
Rinji & 3 & 60 \\
Tosaro & 2 & 40 \\
Tsohuwar Kasuwa & 1 & 20 \\
Total & 16 & \\
\hline
\end{tabular}

\section{CONCLUSION}

Results indicated $4.00 \times 10^{5} \mathrm{CFU} / \mathrm{g}$ as the highest APCs count; while $68 \mathrm{MPN} / \mathrm{g}$ was the highest TCCs from the 30 samples analyzed. Among the isolates, $E$. coli has the highest isolation rate of $6(20 \%)$. Dausai and Kofar kudu were having the highest bacteria count of $4(80 \%)$, each, indicating higher contamination in those locations. 
BAJOPAS Volume 13 Number 1, June, 2020 RECOMMENDATIONS

The following recommendations are tenable:

1. Hygienic practices at all stages of production should be improved to safe guard the consumers against potential health hazard.

2. Monitoring of microbiological contamination of Tsire during preparations, packaging and marketing is essential to ensure product of good microbiological quality for consumers' health.

\section{REFERENCES}

Abdullahi, I. O., Umoh, V. J. and Galadima, M. (2004). Hazards Associated with Kilishi Preparations in Zaria. Nigerian Journal of Microbiology, 18 (1-2): $339-345$.

Ahmadu, J. and Ibrahim E. J., (2013): Determinants of Revenue in Suya Production in BeninCity, Edo State, Nigeria. Nigerian journal of agriculture, food and environment.9(3):1-5

Amaeze, N. Aboh, M. Itohan, A. Felix, E. Olatunji, T. and Oladosu, P. (2016) Microbial Profile, Antibiotic Sensitivity and Heat Resistance of Bacterial Isolates from Commercial Roasted Beef (Suya) in Abuja, Nigeria. JOPAT, 15(2): $22-30$.

Apata, E.S., Kuku1, I.A., Apata, O.C. and Adeyemi, K.O. (2013). Evaluation of Suya(Tsire) - An Intermediate Moisture Meat Product in Ogun State, Nigeria. J. Food Res 2 (1): 87.

Atlas, R. M. (1997) Principles of Microbiology Second Edition. C. Brown Publishers. Pp 802-803.

Borch, E. Kant-Muermans, M. L., Blixt, Y. (1996) Bacterial Spoilage of Meat and Cured Meat Products. Int $\mathrm{J}$ Food Microbiol .33(1): 103-20.

Centre for Disease Control, CDC (2011). "Escherichia coli 0157:H7" Division of Bacterial and Mycotic Diseasesht://www.cdc.gov/nczved/divisi ons/dfbmd/diseases/ecoli_0157h7/.

Charlene, R. J., Johnnie, A. D., and John, B. B., (2013) Prevalence and Characterization of Methicillin-Resistant Staphylococcus aureus Isolates from Retail Meat and Humans in Georgia. American society for Microbiology. J. of clinical microbiology. 12(1):123-6 doi:10.1128/JCM.0316612JCM.03166-12

Egbebi, A.O and Seidu, K., T. (2011). Microbiological Evaluation of Suya (dried smoked

meat) Sold in Ado and Akure, South West Nigeria.European Journal of Experinmental Biology, 1(4):1-5
3. Government should establish regulatory bodies responsible for inculcating hygiene habits to the local producers and vendors in order to prevent instant, cross and post processing contaminations by microbial pathogens.

4. Awareness and sensitization of local food producers about good hygienic practices in food handling and processing.

Falegan, C, R., Akoja, S. D., and Oyarekua, M. A., (2017) Microbiological Assessment of Suya (Sliced Roasted Beef) in Ado-Ekiti Metropolis, Ekiti State, Nigeria. MOJ Biology andMedicine.

Fonkem, D., N. Tanya, V., N. and Ebangi, A., L. (2010). Effect of Season on the Microbiological Quality of Kilishi, a Traditional Cameroonian Dried Beef Product. Tropicultura, 28(1): 10-15.

Food and Agricultural Organization of the United Nations (F A O, 1979). Manual of food quality control 4. Microbiological analysis.

Food and Agriculture Organisation of the United Nation (FAO), 2019. Nigeria at a glance.

Igene J.O., Uwadia, O.E., Ebabhamiegbebho, P.A. and Evivie, S.E., (2016) Shelf life Stability Studies of University of Benin (UNIBEN) Proff's Kilishi Product Asian Journal of Science and Technology 7(1): 2268-2274.

Inusa, S. K. and Said, I. S. (2017) Evaluation of the Chemical and Microbiological Properties Of Kilishi Sold in Kano Metropolis. Journal of Dry land Agriculture, 3 (1): $59-69$.

Lucretia, I. B, Patience, C. Obinna-Echem, Sophia, C. A. (2018) Microbiological quality andantibiotic sensitivity of potential pathogens isolated from meat product (Suya) sold in Rivers State University and its environs. International Journal of Biotechnology and Food Science, 6(4): 67-76.

Matthew, E., Drosos, E., John, L. and Ioanna, P. (2013) MRSA in Africa: Filling the Global Map of Antimicrobial Resistance PLOS One. 8(7): e68024 doi: 10.1371/journal.pone.0068024

Mgbemere, V.N., Akpapunam, M. A. and Igene, J. O., (2011). Effect of Groundnut FlourSubstitution on Yield, Quality and Storage Stability of Kilishi - a Nigerian Indigenous Dried Meat Product. African Journal of Food, Agriculture, Nutrition and Development, $\quad \mathbf{1 1}(2)$ : 4718-4738. 
BAJOPAS Volume 13 Number 1, June, 2020

Mubarak, A. A., Azeez, M. L., Amos A. O., Opeyemi, O. O. (2016) Assessment of Animal Protein Consumption and Food Security Among Rural Households in Kwara State, Nigeria American Journal of Business and Society, 1(4): 233245.

Ndahi, M., D. Kwaga, J., K. P. Bello, M. Kabir J., V. Umoh, .J. Yakubu, S., E. and Nok, A., J. (2013) Prevalence and Antimicrobial Susceptibility of Listeria Monocytogenes and Methicillin-Resistant Staphylococcus aureus Strains from Raw Meat and Meat Products in Zaria, Nigeria. Applied Journal of Microbiology, 58(3):262-9.

Okonko, I.O., Odu, N.N. and Igboh, I.E. (2013). Microbiological Analysis of Kilishi Sold In Port Harcourt, Nigeria. New York Science Journal, 6 (7):37-43.

Osimani, A., Aquilanti, L. and Clementi, F. (2015) Microbiological Quality of Meatbased Meals and Operation of Control Systems within a Food Service Environment. International Food Research Journal 22(4): 1692-1698.

Onuorah, S. Obika, I. Odibo, F. Orji, M. (2015)An Assessment of the Bacteriological Quality of Tsire-Suya (Grilled Beef) sold in Awka, Nigeria. American. J. Life. Sci. Res. 3(4):287292.

Razavilar, V, Khandaghi, J. Barzgari, A. (2010); Isolation of Eschericia coli 0157:H7 from manure fertilized farms and raw vegetables grown on it, in Tabriz city in
Iran. African Journal of Microbiology Research, 4(9): 891-895.

Scallan, E. Hoekstra, R. M. Angulo, F. J.Tauxe, R. V, Widdowson, M. Roy, S. L et al., (2011).Food borne illness acquired in the United States- Major Pathogens. Emerg. Infec Dis, 17(1): 7-15.

Shamsuddeen U (2009). Microbiological quality of spice used in the production of Kilishi a traditionally dried and grilled meat product. Bayero Journal of Pure andApplied Sciences, 2(2): 66-69.

Shamsuddeen, U. (2015) Microbiological Hazard and Critical control point Analysis of Dried and Minced Meat Snacks Produced in Kano Nigeria. Lambert Academic Publishing; Pp 1-36.

Tijani, O.and Jumare, S. (2014). Microblological Quality Assessment of Meat

Sold in KauraNamoda. International Conference on Earth, Environment and Life sciences (EELS) Dubai (UAE).

Udobi, C. E., Obajuluwa, A. F., and Onaolapo, J. A., (2013) Prevalence and Antibiotic Resistance Pattern of MethicillinResistant Staphylococcus aureus from an Orthopaedic Hospital in Nigeria BioMed Research International; 26(6); 6-7.

WHO, 2015 Foodborne diseases in the WHO African Region.

Yousafzai HA, Rind R, Khan MA, Abro SH, Korejo NA, Ejaz M, Kabir A, Shahid M, Memon S. (2019). Microbiological Contamination of Cattle and Meat in Peshawar, Pakistan. J. Anim. Health Prod. 7(1): 1116. 


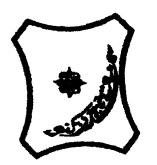

Bayero Journal of Pure and Applied Sciences, 13(1); 40 - 45

Received: September, 2019

Accepted: April, 2020

ISSN $2006-6996$

\title{
BACTERIOLOGICAL QUALITY OF STICK MEAT (Tsire) SOLD IN GARKO LOCAL GOVERNMENT AREA OF KANO STATE, NIGERIA
}

\author{
$*^{1}$ Dahiru A. T. and ${ }^{2}$ Maigari A. K. \\ ${ }^{1}$ Department of Hospitality Management, School of Technology, Kano State Polytechnic, PMB 3348, \\ Kano Nigeria. \\ ${ }^{2}$ Departmnt of Biological Sciences, Bayero University, Kano \\ Corresponding Author: dturajo61@gmail.com; GSM: 08087508262.
}

ABSTRACT

Stick meat, locally called Tsire in Hausa Language, is a significant portion of the diet of a large active population of Northern Nigeria. However, because of the handling and processing methods by the manufacturers as well as the hawking system of stick meat, the meat product may be exposed to both pre- and post-processed product contamination, and thus may poses danger to public health. Therefore, considering the role of Tsire in improving nutrition and increase household income to the populace, the need to improve the processing, distribution and overall quality of the product is simply indispensable. A total of 30 samples (5 samples from each of the 6 sampling points) of Tsire were collected randomly in Garko Town. Aerobic plate counts (APCs) and Total coliform counts (TCCS) of Tsire samples were determined using standard microbiological methods. APCs ranged from $1.02 \times 10^{5}$ to $4.00 \times 10^{5} \mathrm{CFU} / \mathrm{g}$; while TCCs ranged from $8 \mathrm{MPN} / \mathrm{g}$ to $68 \mathrm{MPN} / \mathrm{g}$. From the 30 samples screened, 16(53.33\%) bacteria namely, Campylobacter 2(6.66\%), Escherichia coli 6(20\%), Klebsiella pneumoniae 2(6.66\%), Salmonella spp. 1(3.33\%), Shigella 3(10\%) and Staphylococcus aureus 2(6.66\%) were detected. $E$. coli has the highest isolation rate of 6(20\%), while Salmonella spp. had the least frequency of 1(3.33\%). The distribution of isolated organisms within the study area were as follows: Dausai, 4(80\%), Kofar kudu, 4(80\%), Makwalla, 2(40\%), Rinji, 3(60\%), Tosaro, 2(40\%), and Tsohuwar Kasuwa, 1(20\%). The results have indicated that the Tsire was contaminated with bacteria thus exposing the product to fast deterioration, spoilage and also a vehicle for food borne illness, suggesting for adequate hygienic practices at all the stages, prior to consumption, to ensure safety of the meat product.

Key words: APCs, TCCs, Contamination, Microorganisms, Garko

\section{INTRODUCTION}

Nigeria is one of the developing nations with inadequate food supply and most often deficient in protein content (FAO, 2019). Nigerian's average animal protein intake per head per day is estimated at $7.9 \mathrm{~g}$ as against $35 \mathrm{~g}$ recommended value by Food and Agricultural Organization (Mubarak et al., 2016). These low levels of animal protein intake create great concern as it affects the nutritional status of Nigerians. Hence, there is the need for sufficient supply of animal protein from energy rich animal products to satisfy the nutritional requirements for Nigerians.

Meat is one major source of animal protein largely composed of water, protein and fats which can make it susceptible to microbial contamination within short time leading to spoilage (Apata et al., 2013; Mgbemere et al., 2011). Meat is mostly eaten after it has been cooked or processed in a variety of ways such as sun drying; smoking and roasting with or without fortifications (Borch et al., 1996). In Nigeria meat products such as Tsire, Kilishi and Balangu are locally produced using one or more of these methods in order to meet the nutritional requirements of the teeming Nigerians (Egbebi, 2011).

Tsire is a popular Nigerian traditional processed ready-to-eat roasted stick meat product (Shamsuddeen, 2015). It is sold in public places, along roads, in hotels, parks, quarters and even offices (Falegan et al., 2017). It is prepared from boneless healthy animal flesh such as beef and mutton, spiced with peanut cake, salt, vegetable oil and other flavorings followed by roasting (Shamsuddeen, 2015). Consumption of these products has extended to other parts of African countries such as Ghana, Somali, Cameroun and Chad (Ahmadu and Ibrahim, 2013). 
BAJOPAS Volume 13 Number 1, June, 2020

However, evidence of quality control sticking to procedural hygiene by the handlers during preparation and retailing of these products is poorly documented. Tsire is of great safety risk because of the fact that there are erratic cases of gastroenteritis and symptoms of food infection after consumption (WHO, 2015). Food borne illnesses are one of the major health problems in developing and developed countries (Razavilar, 2010). According to the World Health Organization, WHO (2015), $0.07 \%$ death of the 600 million global burdens of Foodborne illnesses have been reported to be caused by bacteria, viruses, fungi and chemicals. In America $0.27 \%$ of the estimated 48 million affected people is hospitalized and about $0.0063 \%$ deaths are recorded each year (Scallan et al., 2011). More than 91 million people in Africa fall ill and $0.15 \%$ dies each year, making Africa the highest burden bearer of Foodborne diseases per population (WHO, 2015).

Application of a Hazard Analysis Critical Control Point (HACCP) at all stages of meat products preparation is essential in order to ensure its safety. Thus, according to the guidelines of good manufacturing practice, the level of total aerobic bacterial contamination of thermally processed meat products should not exceed $10^{4}\left(\mathrm{cfu} \mathrm{g}^{-1}\right)$. Enterobacteriaceae and faecal coliform contamination in meat products should be within the range of $10^{2}-10^{4}$ and $10-10^{3} \mathrm{cfu} \mathrm{g}^{-1}$, respectively (Shamsuddeen, 2015). The aim of the study is therefore, to assess the total viable bacterial counts of tsire marketed locally within Garko town, and to isolate and identify the organisms at the point of consumption with the intention of promoting public health and food hygiene habits in the Nigerian populace.

\section{MATERIALS AND METHODS Study Area and Population}

Garko is one of the existing 44 local government areas located in Kano south west zone of Kano state with its capital administrative headquarters in the Garko town. It has coordinates $11^{\circ} 39^{\prime} \mathrm{N}$ $8^{\circ} 54^{\prime} \mathrm{E}$, and an area of $450 \mathrm{~km}^{2}$. The projected population of Garko local Government was 225,300 according to the National Population Census report (2018). Garko is known for agricultural activities both farming and animal husbandry. It is popularly known for large scale rice production. Other food crops include sweet potatoes, cassava, onions, sorghum, millet and sugarcane. Cows, sheep and goats are major groups of animals reared by majority of the populace. Meat products processed, retailed and consumed in Garko include roasted meat (Balangu), dried roasted meat (Kilishi), stick meat (Tsire), hide and skin pepper soup (Ragadada) and minced fried meat (Danbunnama).

\section{Samples Collection}

Five samples of Tsire products were collected from 6 different identified locations within Garko town in a sterile foil paper and immediately analyzed for the presence of bacteria.

\section{Sample Preparation}

Sample preparation for the bacteriological analysis was carried out in accordance with the method described by Atlas (1997). Twenty five grams $(25 \mathrm{~g})$ of the sample was homogenized in $225 \mathrm{ml}$ peptone water using Kenwood blender machine to obtain a $10^{1}$ homogenate. The homogenate was thoroughly shaken and $1 \mathrm{ml}$ pipetted into test tubes containing $9 \mathrm{ml}$ of peptone water $\left(10^{2}\right)$. The test tubes were further serially diluted to $10^{5}$.

Total Aerobic Mesophilic Bacterial Count

Total Aerobic mesophilic bacterial count was determined using the method described by Abdullahi et al. (2004) where $1 \mathrm{ml}$ of inoculums from $10^{1}$ to $10^{5}$ dilutions were transferred into duplicate Petri dishes and labeled accordingly. This was followed by pouring aseptically about $15 \mathrm{ml}$ of molten nutrient agar. The culture was homogenized by gentle spinning of the plates and allowed to solidify. The plates were incubated at $37^{\circ} \mathrm{C}$ for 24 hours. Plates containing 30-300 colonies were counted. The number of colony forming units per gram of a sample (cfu/g) was obtained by multiplying the average colony number with the inverse of the dilution factor.

\section{Enumeration and Detection of Coliform bacteria}

Detection and enumeration of coliform was carried out according to method described by Atlas, (1977). A set of 9 test tubes each containing $9 \mathrm{ml}$ of lactose broth and an inverted Durham tubes were autoclaved to expel air and to sterilize. Similarly, $1 \mathrm{ml}$ from the diluents $10^{1}$ was transferred to the first 3 test tubes, followed by $1 \mathrm{ml}$ from the diluents $10^{2}$ to the second set of 3 test tubes and finally the third diluents $10^{3}$ to the $3^{\text {rd }}$ set of 3 test tubes. All the 9 test tubes were incubated at $37^{\circ} \mathrm{C}$ for 24 hours. Tubes that showed gas and acid production after 24 hours were recorded as positive for the presence of Coliform. Negative tubes were further reincubated for 24 hours. Positive tubes were recorded. Estimate of most probable number of Coliform per gram of sample (MPN/g) was determined by comparing the number of gas positive tubes with the most probable number table. 
BAJOPAS Volume 13 Number 1, June, 2020 Identification of Coliform

A loop full of inoculum from gas positive tubes was streaked on to Eosine methylene blue (EMB) agar plate and incubated at $37^{\circ} \mathrm{C}$ for $24 \mathrm{hrs}$. Colonies which formed bluish black color with green metallic sheen, and reddish colonies were isolated on agar slants. Those colonies showing metallic sheen on EMB were sub cultured into tubes of lactose broth and incubated at $45^{\circ} \mathrm{C}$. The tubes were observed after $24 \mathrm{hrs}$ for gas production. This is the completed test for fecal coliform. Gram stain and other biochemical tests such as Indole, Methyl red, Voges-Proskauer and Citrate Utilization tests (IMVIC), Coagulase and Catalase tests were carried out for the Identification and confirmation of isolates.

\section{Procedure for Indole Test}

Indole test was carried out by preparing a Tryptone broth drawn in to test tubes, sterilized by autoclaving, inoculated with loopful of suspension and incubated at $37^{\circ} \mathrm{C}$ for 24 hours. Three drops of xylene was added in tubes, shaken vigorously and kept for the separation of two layers. One millilitre of Kovac's reagent was added and the formation of pink colour ring indicates positive Indole test.

\section{Procedure for Methyl Red Test}

Methyl red test was carried out by preparing Glucose phosphate broth, dispensed in test tubes, sterilized, inoculated with test culture and incubated at $37^{\circ} \mathrm{C}$ for 24 hours. Five drops of methyl-red indicator was added to the medium for the formation of red colour.

\section{Procedure for Voges-Proskauer Test}

Voges-Proskauer test was carried out by inoculating tubes with the bacterial culture followed by incubation for 48 hours at $37^{\circ} \mathrm{C}$. Separate pipettes were used to pipette $1 \mathrm{ml}$ from each culture tube into clean separate tubes. Eighteen drops $(0.5 \mathrm{ml})$ of Barrit's solution A (a-naphthol) was added to each tube containing glucose phosphate broth followed by the addition of an equal amount of solution $B$ into the same tube. The tubes were shaken at 30 seconds interval. A positive reaction was indicated by the development of a pink color, which turns red in 1-2 hours, after vigorous shaking.

\section{Procedure for Citrate Utilization Test}

Citrate Utilization Test was carried out by distributing melted agar (Simmon Citrate Agar) in to test tubes followed by sterilization at $121.5^{\circ} \mathrm{C}$ for 15 minutes. The test tubes were afterward held in slanted position, inoculated with the given bacterial culture and incubated at $37^{\circ} \mathrm{C}$ for $24 \mathrm{hrs}$. Positive test was indicated by color change of the media from green to blue.

\section{RESULTS AND DISCUSSIONS}

The results of this study are presented in tables $1,2,3$ and 4. Among the sampling areas Kofar Kudu had the highest aerobic mesophilic bacteria counts $4.0 \times 10^{5} \mathrm{cfu} / \mathrm{g}$ followed by Rinji $2.72 \times 10^{5} \mathrm{cfu} / \mathrm{g}$, while Tosaro had the least Aerobic mesophilic bacteria counts of $1.02 \times 10^{5}$ $\mathrm{cfu} / \mathrm{g}$ as indicated in Table 1.Makwalla had the highest coliform count $68 \mathrm{MPN} / \mathrm{g}$ followed by Rinji $37 \mathrm{MPN} / \mathrm{g}$. Tsohuwar Kasuwa had the least coliform counts $8 \mathrm{MPN} / \mathrm{g}$, (Table 2). Result from table 1 shows variation in the microbial contents among the samples which suggest variation in their sources, poor handling procedures and contamination from the processing environment. High coliform count and their differences within sampling areas is an indication of poor microbiological quality of the product. Ndahi et al. (2013) reported microbial load to be a function of the handling personnel and the environment. The results indicated that the samples were contaminated with bacteria as the counts exceeded the minimum safety level $\left(10^{4} \mathrm{cfu} / \mathrm{g}\right)$ for members of the Enterobacteriaceae family. However, it might be a reflection of poor hygienic practices which may contribute to health hazard to the potential consumers. Similarly, Inusa and Sa'id (2017); Osimani et al. (2015) reported that, the initial microbial content of the raw material play significant role in influencing the final microbial load of the finished product. Isolation of members of the Enterobacteriaceae such as $E$. coli, Klebsiella pneumoniae, Salmonella and Shigella signifies danger to the public health. These organisms are capable of producing endotoxins which trigger high fevers in infected individuals, and the enterotoxins which colonize the small intestines and lead to extreme dehydration as a result of vomiting and diarrhea sometimes with severe and fatal outcomes (Amaeze et al., 2016). From the 16 isolated organisms $E$. coli had the highest isolation rate $6(37.5 \%)$ (Table 3), this suggest faecal contamination of the products. $E$. coli is a common flora in the gastrointestinal tract responsible for diarrhea and extra-intestinal infections (CDC, 2011). The result is in conformity with the findings of Ndahi et al. (2013) and Shamsuddeen (2009). Also presence of campylobacter might be due to cross contamination from raw meat to finished product (Tsire). Staphylococcus aureus is a normal flora of the skin, nasal, genital, mouth or anal area in both humans and animals without any symptom of an infection (Matthew et al., 2013). Isolation of $S$. aureus in these study concords with the findings of Lucretia et al. (2018) from Suya sold in Rivers State. 
BAJOPAS Volume 13 Number 1, June, 2020

It is also in agreement with the findings of Yousafzai et al. (2018); Onuorah et al. (2015) and Tijjani and Jumare (2014) from tsire samples in different countries. Presence of $S$. aureus in foods is most of the time an indication of poor human handling, poor environment, unhygienic utensils and equipments used during processing (Igene et al., 2016; Okonko et al., 2013). Infections caused by $S$. aureus are difficult to treat leading to long hospitalization with consequent economic loss (Udobi et al., 2013). These include soft tissue infections, pneumonia, hospital-acquired postoperative wound infections, Staphylococcal food poisoning, impetigo and cellulitis (Charlene et al., 2013). Samples obtained from Dausai and Kofar Kudu had the highest isolation rate $4(80 \%)$ (Table 4 ) probably because of the much commercial activities taking place in the area which can lead to environmental contamination.

Table 1: Total Aerobic Mesophilic Bacterial Count of Tsire sold in Garko Town

\begin{tabular}{lll}
\hline Sampling Area & APC cfu/g & Mean \pm STD \\
\hline Dausai & $2.20 \times 10^{5}$ & $110000 \pm 14142.14$ \\
Kofar Kudu & $4.00 \times 10^{5}$ & $133333.3 \pm 23094.01$ \\
Makwalla & $1.30 \times 10^{5}$ & $32500 \pm 7187.953$ \\
Rinji & $2.72 \times 10^{5}$ & $90666.67 \pm 94769.90$ \\
Tosaro & $1.02 \times 10^{5}$ & $51000 \pm 15556.35$ \\
Tsohuwar Kasuwa & $1.75 \times 10^{5}$ & $35000 \pm 11357.82$ \\
\hline
\end{tabular}

Key: APC: Aerobic Mesophilic Counts

STD: Standard Deviation

Table 2: Total Coliform Count of Tsire sold in Garko Town

\begin{tabular}{lcc}
\hline \multicolumn{1}{c}{ Sampling Area } & TCC MPN/g & Mean \pm STD \\
\hline Dausai & 20 & $6.67 \pm 2.5166$ \\
Kofar Kudu & 32 & $16.00 \pm 5.6569$ \\
Makwalla & 68 & $13.60 \pm 8.7062$ \\
Rinji & 37 & $9.25 \pm 4.7871$ \\
Tosaro & 10 & $5.00 \pm 2.8284$ \\
Tsohuwar Kasuwa & 8 & $4.00 \pm 0.0000$ \\
\hline
\end{tabular}

Table 3: Organisms Isolated from Tsire Sold in Garko

\begin{tabular}{lcl}
\hline Isolated Organism & Frequency & Percentage (\%) \\
\hline Campylobacter & 2 & 06.66 \\
Escherichia coli & 6 & 20.00 \\
Klebsiella pneumoniae & 2 & 06.66 \\
Salmonella species & 1 & 03.33 \\
Shigella & 3 & 10.00 \\
Staphylococcus aureus & 2 & 06.66 \\
Total & 16 & \\
\hline
\end{tabular}

Table 4: Distribution of Organisms within Sampling Area

\begin{tabular}{lcc}
\hline \multicolumn{1}{c}{ Sampling Area } & No. Isolated & Percentage (\%) \\
\hline Dausai & 4 & 80 \\
Kofar Kudu & 4 & 80 \\
Makwalla & 2 & 40 \\
Rinji & 3 & 60 \\
Tosaro & 2 & 40 \\
Tsohuwar Kasuwa & 1 & 20 \\
Total & 16 & \\
\hline
\end{tabular}

\section{CONCLUSION}

Results indicated $4.00 \times 10^{5} \mathrm{CFU} / \mathrm{g}$ as the highest APCs count; while $68 \mathrm{MPN} / \mathrm{g}$ was the highest TCCs from the 30 samples analyzed. Among the isolates, $E$. coli has the highest isolation rate of $6(20 \%)$. Dausai and Kofar kudu were having the highest bacteria count of $4(80 \%)$, each, indicating higher contamination in those locations. 
BAJOPAS Volume 13 Number 1, June, 2020 RECOMMENDATIONS

The following recommendations are tenable:

1. Hygienic practices at all stages of production should be improved to safe guard the consumers against potential health hazard.

2. Monitoring of microbiological contamination of Tsire during preparations, packaging and marketing is essential to ensure product of good microbiological quality for consumers' health.

\section{REFERENCES}

Abdullahi, I. O., Umoh, V. J. and Galadima, M. (2004). Hazards Associated with Kilishi Preparations in Zaria. Nigerian Journal of Microbiology, 18 (1-2): $339-345$.

Ahmadu, J. and Ibrahim E. J., (2013): Determinants of Revenue in Suya Production in BeninCity, Edo State, Nigeria. Nigerian journal of agriculture, food and environment.9(3):1-5

Amaeze, N. Aboh, M. Itohan, A. Felix, E. Olatunji, T. and Oladosu, P. (2016) Microbial Profile, Antibiotic Sensitivity and Heat Resistance of Bacterial Isolates from Commercial Roasted Beef (Suya) in Abuja, Nigeria. JOPAT, 15(2): $22-30$.

Apata, E.S., Kuku1, I.A., Apata, O.C. and Adeyemi, K.O. (2013). Evaluation of Suya(Tsire) - An Intermediate Moisture Meat Product in Ogun State, Nigeria. J. Food Res 2 (1): 87.

Atlas, R. M. (1997) Principles of Microbiology Second Edition. C. Brown Publishers. Pp 802-803.

Borch, E. Kant-Muermans, M. L., Blixt, Y. (1996) Bacterial Spoilage of Meat and Cured Meat Products. Int $\mathrm{J}$ Food Microbiol .33(1): 103-20.

Centre for Disease Control, CDC (2011). "Escherichia coli 0157:H7" Division of Bacterial and Mycotic Diseasesht://www.cdc.gov/nczved/divisi ons/dfbmd/diseases/ecoli_0157h7/.

Charlene, R. J., Johnnie, A. D., and John, B. B., (2013) Prevalence and Characterization of Methicillin-Resistant Staphylococcus aureus Isolates from Retail Meat and Humans in Georgia. American society for Microbiology. J. of clinical microbiology. 12(1):123-6 doi:10.1128/JCM.0316612JCM.03166-12

Egbebi, A.O and Seidu, K., T. (2011). Microbiological Evaluation of Suya (dried smoked

meat) Sold in Ado and Akure, South West Nigeria.European Journal of Experinmental Biology, 1(4):1-5
3. Government should establish regulatory bodies responsible for inculcating hygiene habits to the local producers and vendors in order to prevent instant, cross and post processing contaminations by microbial pathogens.

4. Awareness and sensitization of local food producers about good hygienic practices in food handling and processing.

Falegan, C, R., Akoja, S. D., and Oyarekua, M. A., (2017) Microbiological Assessment of Suya (Sliced Roasted Beef) in Ado-Ekiti Metropolis, Ekiti State, Nigeria. MOJ Biology andMedicine.

Fonkem, D., N. Tanya, V., N. and Ebangi, A., L. (2010). Effect of Season on the Microbiological Quality of Kilishi, a Traditional Cameroonian Dried Beef Product. Tropicultura, 28(1): 10-15.

Food and Agricultural Organization of the United Nations (F A O, 1979). Manual of food quality control 4. Microbiological analysis.

Food and Agriculture Organisation of the United Nation (FAO), 2019. Nigeria at a glance.

Igene J.O., Uwadia, O.E., Ebabhamiegbebho, P.A. and Evivie, S.E., (2016) Shelf life Stability Studies of University of Benin (UNIBEN) Proff's Kilishi Product Asian Journal of Science and Technology 7(1): 2268-2274.

Inusa, S. K. and Said, I. S. (2017) Evaluation of the Chemical and Microbiological Properties Of Kilishi Sold in Kano Metropolis. Journal of Dry land Agriculture, 3 (1): $59-69$.

Lucretia, I. B, Patience, C. Obinna-Echem, Sophia, C. A. (2018) Microbiological quality andantibiotic sensitivity of potential pathogens isolated from meat product (Suya) sold in Rivers State University and its environs. International Journal of Biotechnology and Food Science, 6(4): 67-76.

Matthew, E., Drosos, E., John, L. and Ioanna, P. (2013) MRSA in Africa: Filling the Global Map of Antimicrobial Resistance PLOS One. 8(7): e68024 doi: 10.1371/journal.pone.0068024

Mgbemere, V.N., Akpapunam, M. A. and Igene, J. O., (2011). Effect of Groundnut FlourSubstitution on Yield, Quality and Storage Stability of Kilishi - a Nigerian Indigenous Dried Meat Product. African Journal of Food, Agriculture, Nutrition and Development, $\quad \mathbf{1 1}(2)$ : 4718-4738. 
BAJOPAS Volume 13 Number 1, June, 2020

Mubarak, A. A., Azeez, M. L., Amos A. O., Opeyemi, O. O. (2016) Assessment of Animal Protein Consumption and Food Security Among Rural Households in Kwara State, Nigeria American Journal of Business and Society, 1(4): 233245.

Ndahi, M., D. Kwaga, J., K. P. Bello, M. Kabir J., V. Umoh, .J. Yakubu, S., E. and Nok, A., J. (2013) Prevalence and Antimicrobial Susceptibility of Listeria Monocytogenes and Methicillin-Resistant Staphylococcus aureus Strains from Raw Meat and Meat Products in Zaria, Nigeria. Applied Journal of Microbiology, 58(3):262-9.

Okonko, I.O., Odu, N.N. and Igboh, I.E. (2013). Microbiological Analysis of Kilishi Sold In Port Harcourt, Nigeria. New York Science Journal, 6 (7):37-43.

Osimani, A., Aquilanti, L. and Clementi, F. (2015) Microbiological Quality of Meatbased Meals and Operation of Control Systems within a Food Service Environment. International Food Research Journal 22(4): 1692-1698.

Onuorah, S. Obika, I. Odibo, F. Orji, M. (2015)An Assessment of the Bacteriological Quality of Tsire-Suya (Grilled Beef) sold in Awka, Nigeria. American. J. Life. Sci. Res. 3(4):287292.

Razavilar, V, Khandaghi, J. Barzgari, A. (2010); Isolation of Eschericia coli 0157:H7 from manure fertilized farms and raw vegetables grown on it, in Tabriz city in
Iran. African Journal of Microbiology Research, 4(9): 891-895.

Scallan, E. Hoekstra, R. M. Angulo, F. J.Tauxe, R. V, Widdowson, M. Roy, S. L et al., (2011).Food borne illness acquired in the United States- Major Pathogens. Emerg. Infec Dis, 17(1): 7-15.

Shamsuddeen U (2009). Microbiological quality of spice used in the production of Kilishi a traditionally dried and grilled meat product. Bayero Journal of Pure andApplied Sciences, 2(2): 66-69.

Shamsuddeen, U. (2015) Microbiological Hazard and Critical control point Analysis of Dried and Minced Meat Snacks Produced in Kano Nigeria. Lambert Academic Publishing; Pp 1-36.

Tijani, O.and Jumare, S. (2014). Microblological Quality Assessment of Meat

Sold in KauraNamoda. International Conference on Earth, Environment and Life sciences (EELS) Dubai (UAE).

Udobi, C. E., Obajuluwa, A. F., and Onaolapo, J. A., (2013) Prevalence and Antibiotic Resistance Pattern of MethicillinResistant Staphylococcus aureus from an Orthopaedic Hospital in Nigeria BioMed Research International; 26(6); 6-7.

WHO, 2015 Foodborne diseases in the WHO African Region.

Yousafzai HA, Rind R, Khan MA, Abro SH, Korejo NA, Ejaz M, Kabir A, Shahid M, Memon S. (2019). Microbiological Contamination of Cattle and Meat in Peshawar, Pakistan. J. Anim. Health Prod. 7(1): 1116. 


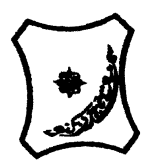

Bayero Journal of Pure and Applied Sciences, 13(1); 40 - 45

Received: September, 2019

Accepted: April, 2020

ISSN $2006-6996$

\title{
BACTERIOLOGICAL QUALITY OF STICK MEAT (Tsire) SOLD IN GARKO LOCAL GOVERNMENT AREA OF KANO STATE, NIGERIA
}

\author{
$*^{1}$ Dahiru A. T. and ${ }^{2}$ Maigari A. K. \\ ${ }^{1}$ Department of Hospitality Management, School of Technology, Kano State Polytechnic, PMB 3348, \\ Kano Nigeria. \\ ${ }^{2}$ Departmnt of Biological Sciences, Bayero University, Kano \\ Corresponding Author: dturajo61@gmail.com; GSM: 08087508262.
}

ABSTRACT

Stick meat, locally called Tsire in Hausa Language, is a significant portion of the diet of a large active population of Northern Nigeria. However, because of the handling and processing methods by the manufacturers as well as the hawking system of stick meat, the meat product may be exposed to both pre- and post-processed product contamination, and thus may poses danger to public health. Therefore, considering the role of Tsire in improving nutrition and increase household income to the populace, the need to improve the processing, distribution and overall quality of the product is simply indispensable. A total of 30 samples (5 samples from each of the 6 sampling points) of Tsire were collected randomly in Garko Town. Aerobic plate counts (APCs) and Total coliform counts (TCCS) of Tsire samples were determined using standard microbiological methods. APCs ranged from $1.02 \times 10^{5}$ to $4.00 \times 10^{5} \mathrm{CFU} / \mathrm{g}$; while TCCs ranged from $8 \mathrm{MPN} / \mathrm{g}$ to $68 \mathrm{MPN} / \mathrm{g}$. From the 30 samples screened, 16(53.33\%) bacteria namely, Campylobacter 2(6.66\%), Escherichia coli 6(20\%), Klebsiella pneumoniae 2(6.66\%), Salmonella spp. 1(3.33\%), Shigella 3(10\%) and Staphylococcus aureus 2(6.66\%) were detected. $E$. coli has the highest isolation rate of 6(20\%), while Salmonella spp. had the least frequency of 1(3.33\%). The distribution of isolated organisms within the study area were as follows: Dausai, 4(80\%), Kofar kudu, 4(80\%), Makwalla, 2(40\%), Rinji, 3(60\%), Tosaro, 2(40\%), and Tsohuwar Kasuwa, 1(20\%). The results have indicated that the Tsire was contaminated with bacteria thus exposing the product to fast deterioration, spoilage and also a vehicle for food borne illness, suggesting for adequate hygienic practices at all the stages, prior to consumption, to ensure safety of the meat product.

Key words: APCs, TCCs, Contamination, Microorganisms, Garko

\section{INTRODUCTION}

Nigeria is one of the developing nations with inadequate food supply and most often deficient in protein content (FAO, 2019). Nigerian's average animal protein intake per head per day is estimated at $7.9 \mathrm{~g}$ as against $35 \mathrm{~g}$ recommended value by Food and Agricultural Organization (Mubarak et al., 2016). These low levels of animal protein intake create great concern as it affects the nutritional status of Nigerians. Hence, there is the need for sufficient supply of animal protein from energy rich animal products to satisfy the nutritional requirements for Nigerians.

Meat is one major source of animal protein largely composed of water, protein and fats which can make it susceptible to microbial contamination within short time leading to spoilage (Apata et al., 2013; Mgbemere et al., 2011). Meat is mostly eaten after it has been cooked or processed in a variety of ways such as sun drying; smoking and roasting with or without fortifications (Borch et al., 1996). In Nigeria meat products such as Tsire, Kilishi and Balangu are locally produced using one or more of these methods in order to meet the nutritional requirements of the teeming Nigerians (Egbebi, 2011).

Tsire is a popular Nigerian traditional processed ready-to-eat roasted stick meat product (Shamsuddeen, 2015). It is sold in public places, along roads, in hotels, parks, quarters and even offices (Falegan et al., 2017). It is prepared from boneless healthy animal flesh such as beef and mutton, spiced with peanut cake, salt, vegetable oil and other flavorings followed by roasting (Shamsuddeen, 2015). Consumption of these products has extended to other parts of African countries such as Ghana, Somali, Cameroun and Chad (Ahmadu and Ibrahim, 2013). 
BAJOPAS Volume 13 Number 1, June, 2020

However, evidence of quality control sticking to procedural hygiene by the handlers during preparation and retailing of these products is poorly documented. Tsire is of great safety risk because of the fact that there are erratic cases of gastroenteritis and symptoms of food infection after consumption (WHO, 2015). Food borne illnesses are one of the major health problems in developing and developed countries (Razavilar, 2010). According to the World Health Organization, WHO (2015), $0.07 \%$ death of the 600 million global burdens of Foodborne illnesses have been reported to be caused by bacteria, viruses, fungi and chemicals. In America $0.27 \%$ of the estimated 48 million affected people is hospitalized and about $0.0063 \%$ deaths are recorded each year (Scallan et al., 2011). More than 91 million people in Africa fall ill and $0.15 \%$ dies each year, making Africa the highest burden bearer of Foodborne diseases per population (WHO, 2015).

Application of a Hazard Analysis Critical Control Point (HACCP) at all stages of meat products preparation is essential in order to ensure its safety. Thus, according to the guidelines of good manufacturing practice, the level of total aerobic bacterial contamination of thermally processed meat products should not exceed $10^{4}\left(\mathrm{cfu} \mathrm{g}^{-1}\right)$. Enterobacteriaceae and faecal coliform contamination in meat products should be within the range of $10^{2}-10^{4}$ and $10-10^{3} \mathrm{cfu} \mathrm{g}^{-1}$, respectively (Shamsuddeen, 2015). The aim of the study is therefore, to assess the total viable bacterial counts of tsire marketed locally within Garko town, and to isolate and identify the organisms at the point of consumption with the intention of promoting public health and food hygiene habits in the Nigerian populace.

\section{MATERIALS AND METHODS Study Area and Population}

Garko is one of the existing 44 local government areas located in Kano south west zone of Kano state with its capital administrative headquarters in the Garko town. It has coordinates $11^{\circ} 39^{\prime} \mathrm{N}$ $8^{\circ} 54^{\prime} \mathrm{E}$, and an area of $450 \mathrm{~km}^{2}$. The projected population of Garko local Government was 225,300 according to the National Population Census report (2018). Garko is known for agricultural activities both farming and animal husbandry. It is popularly known for large scale rice production. Other food crops include sweet potatoes, cassava, onions, sorghum, millet and sugarcane. Cows, sheep and goats are major groups of animals reared by majority of the populace. Meat products processed, retailed and consumed in Garko include roasted meat (Balangu), dried roasted meat (Kilishi), stick meat (Tsire), hide and skin pepper soup (Ragadada) and minced fried meat (Danbunnama).

\section{Samples Collection}

Five samples of Tsire products were collected from 6 different identified locations within Garko town in a sterile foil paper and immediately analyzed for the presence of bacteria.

\section{Sample Preparation}

Sample preparation for the bacteriological analysis was carried out in accordance with the method described by Atlas (1997). Twenty five grams $(25 \mathrm{~g})$ of the sample was homogenized in $225 \mathrm{ml}$ peptone water using Kenwood blender machine to obtain a $10^{1}$ homogenate. The homogenate was thoroughly shaken and $1 \mathrm{ml}$ pipetted into test tubes containing $9 \mathrm{ml}$ of peptone water $\left(10^{2}\right)$. The test tubes were further serially diluted to $10^{5}$.

Total Aerobic Mesophilic Bacterial Count

Total Aerobic mesophilic bacterial count was determined using the method described by Abdullahi et al. (2004) where $1 \mathrm{ml}$ of inoculums from $10^{1}$ to $10^{5}$ dilutions were transferred into duplicate Petri dishes and labeled accordingly. This was followed by pouring aseptically about $15 \mathrm{ml}$ of molten nutrient agar. The culture was homogenized by gentle spinning of the plates and allowed to solidify. The plates were incubated at $37^{\circ} \mathrm{C}$ for 24 hours. Plates containing 30-300 colonies were counted. The number of colony forming units per gram of a sample (cfu/g) was obtained by multiplying the average colony number with the inverse of the dilution factor.

\section{Enumeration and Detection of Coliform bacteria}

Detection and enumeration of coliform was carried out according to method described by Atlas, (1977). A set of 9 test tubes each containing $9 \mathrm{ml}$ of lactose broth and an inverted Durham tubes were autoclaved to expel air and to sterilize. Similarly, $1 \mathrm{ml}$ from the diluents $10^{1}$ was transferred to the first 3 test tubes, followed by $1 \mathrm{ml}$ from the diluents $10^{2}$ to the second set of 3 test tubes and finally the third diluents $10^{3}$ to the $3^{\text {rd }}$ set of 3 test tubes. All the 9 test tubes were incubated at $37^{\circ} \mathrm{C}$ for 24 hours. Tubes that showed gas and acid production after 24 hours were recorded as positive for the presence of Coliform. Negative tubes were further reincubated for 24 hours. Positive tubes were recorded. Estimate of most probable number of Coliform per gram of sample (MPN/g) was determined by comparing the number of gas positive tubes with the most probable number table. 
BAJOPAS Volume 13 Number 1, June, 2020 Identification of Coliform

A loop full of inoculum from gas positive tubes was streaked on to Eosine methylene blue (EMB) agar plate and incubated at $37^{\circ} \mathrm{C}$ for $24 \mathrm{hrs}$. Colonies which formed bluish black color with green metallic sheen, and reddish colonies were isolated on agar slants. Those colonies showing metallic sheen on EMB were sub cultured into tubes of lactose broth and incubated at $45^{\circ} \mathrm{C}$. The tubes were observed after $24 \mathrm{hrs}$ for gas production. This is the completed test for fecal coliform. Gram stain and other biochemical tests such as Indole, Methyl red, Voges-Proskauer and Citrate Utilization tests (IMVIC), Coagulase and Catalase tests were carried out for the Identification and confirmation of isolates.

\section{Procedure for Indole Test}

Indole test was carried out by preparing a Tryptone broth drawn in to test tubes, sterilized by autoclaving, inoculated with loopful of suspension and incubated at $37^{\circ} \mathrm{C}$ for 24 hours. Three drops of xylene was added in tubes, shaken vigorously and kept for the separation of two layers. One millilitre of Kovac's reagent was added and the formation of pink colour ring indicates positive Indole test.

\section{Procedure for Methyl Red Test}

Methyl red test was carried out by preparing Glucose phosphate broth, dispensed in test tubes, sterilized, inoculated with test culture and incubated at $37^{\circ} \mathrm{C}$ for 24 hours. Five drops of methyl-red indicator was added to the medium for the formation of red colour.

\section{Procedure for Voges-Proskauer Test}

Voges-Proskauer test was carried out by inoculating tubes with the bacterial culture followed by incubation for 48 hours at $37^{\circ} \mathrm{C}$. Separate pipettes were used to pipette $1 \mathrm{ml}$ from each culture tube into clean separate tubes. Eighteen drops $(0.5 \mathrm{ml})$ of Barrit's solution A (a-naphthol) was added to each tube containing glucose phosphate broth followed by the addition of an equal amount of solution $B$ into the same tube. The tubes were shaken at 30 seconds interval. A positive reaction was indicated by the development of a pink color, which turns red in 1-2 hours, after vigorous shaking.

\section{Procedure for Citrate Utilization Test}

Citrate Utilization Test was carried out by distributing melted agar (Simmon Citrate Agar) in to test tubes followed by sterilization at $121.5^{\circ} \mathrm{C}$ for 15 minutes. The test tubes were afterward held in slanted position, inoculated with the given bacterial culture and incubated at $37^{\circ} \mathrm{C}$ for $24 \mathrm{hrs}$. Positive test was indicated by color change of the media from green to blue.

\section{RESULTS AND DISCUSSIONS}

The results of this study are presented in tables $1,2,3$ and 4. Among the sampling areas Kofar Kudu had the highest aerobic mesophilic bacteria counts $4.0 \times 10^{5} \mathrm{cfu} / \mathrm{g}$ followed by Rinji $2.72 \times 10^{5} \mathrm{cfu} / \mathrm{g}$, while Tosaro had the least Aerobic mesophilic bacteria counts of $1.02 \times 10^{5}$ $\mathrm{cfu} / \mathrm{g}$ as indicated in Table 1.Makwalla had the highest coliform count $68 \mathrm{MPN} / \mathrm{g}$ followed by Rinji $37 \mathrm{MPN} / \mathrm{g}$. Tsohuwar Kasuwa had the least coliform counts $8 \mathrm{MPN} / \mathrm{g}$, (Table 2). Result from table 1 shows variation in the microbial contents among the samples which suggest variation in their sources, poor handling procedures and contamination from the processing environment. High coliform count and their differences within sampling areas is an indication of poor microbiological quality of the product. Ndahi et al. (2013) reported microbial load to be a function of the handling personnel and the environment. The results indicated that the samples were contaminated with bacteria as the counts exceeded the minimum safety level $\left(10^{4} \mathrm{cfu} / \mathrm{g}\right)$ for members of the Enterobacteriaceae family. However, it might be a reflection of poor hygienic practices which may contribute to health hazard to the potential consumers. Similarly, Inusa and Sa'id (2017); Osimani et al. (2015) reported that, the initial microbial content of the raw material play significant role in influencing the final microbial load of the finished product. Isolation of members of the Enterobacteriaceae such as $E$. coli, Klebsiella pneumoniae, Salmonella and Shigella signifies danger to the public health. These organisms are capable of producing endotoxins which trigger high fevers in infected individuals, and the enterotoxins which colonize the small intestines and lead to extreme dehydration as a result of vomiting and diarrhea sometimes with severe and fatal outcomes (Amaeze et al., 2016). From the 16 isolated organisms $E$. coli had the highest isolation rate $6(37.5 \%)$ (Table 3), this suggest faecal contamination of the products. $E$. coli is a common flora in the gastrointestinal tract responsible for diarrhea and extra-intestinal infections (CDC, 2011). The result is in conformity with the findings of Ndahi et al. (2013) and Shamsuddeen (2009). Also presence of campylobacter might be due to cross contamination from raw meat to finished product (Tsire). Staphylococcus aureus is a normal flora of the skin, nasal, genital, mouth or anal area in both humans and animals without any symptom of an infection (Matthew et al., 2013). Isolation of $S$. aureus in these study concords with the findings of Lucretia et al. (2018) from Suya sold in Rivers State. 
BAJOPAS Volume 13 Number 1, June, 2020

It is also in agreement with the findings of Yousafzai et al. (2018); Onuorah et al. (2015) and Tijjani and Jumare (2014) from tsire samples in different countries. Presence of $S$. aureus in foods is most of the time an indication of poor human handling, poor environment, unhygienic utensils and equipments used during processing (Igene et al., 2016; Okonko et al., 2013). Infections caused by $S$. aureus are difficult to treat leading to long hospitalization with consequent economic loss (Udobi et al., 2013). These include soft tissue infections, pneumonia, hospital-acquired postoperative wound infections, Staphylococcal food poisoning, impetigo and cellulitis (Charlene et al., 2013). Samples obtained from Dausai and Kofar Kudu had the highest isolation rate $4(80 \%)$ (Table 4 ) probably because of the much commercial activities taking place in the area which can lead to environmental contamination.

Table 1: Total Aerobic Mesophilic Bacterial Count of Tsire sold in Garko Town

\begin{tabular}{lll}
\hline Sampling Area & APC cfu/g & Mean \pm STD \\
\hline Dausai & $2.20 \times 10^{5}$ & $110000 \pm 14142.14$ \\
Kofar Kudu & $4.00 \times 10^{5}$ & $133333.3 \pm 23094.01$ \\
Makwalla & $1.30 \times 10^{5}$ & $32500 \pm 7187.953$ \\
Rinji & $2.72 \times 10^{5}$ & $90666.67 \pm 94769.90$ \\
Tosaro & $1.02 \times 10^{5}$ & $51000 \pm 15556.35$ \\
Tsohuwar Kasuwa & $1.75 \times 10^{5}$ & $35000 \pm 11357.82$ \\
\hline
\end{tabular}

Key: APC: Aerobic Mesophilic Counts

STD: Standard Deviation

Table 2: Total Coliform Count of Tsire sold in Garko Town

\begin{tabular}{lcc}
\hline \multicolumn{1}{c}{ Sampling Area } & TCC MPN/g & Mean \pm STD \\
\hline Dausai & 20 & $6.67 \pm 2.5166$ \\
Kofar Kudu & 32 & $16.00 \pm 5.6569$ \\
Makwalla & 68 & $13.60 \pm 8.7062$ \\
Rinji & 37 & $9.25 \pm 4.7871$ \\
Tosaro & 10 & $5.00 \pm 2.8284$ \\
Tsohuwar Kasuwa & 8 & $4.00 \pm 0.0000$ \\
\hline
\end{tabular}

Table 3: Organisms Isolated from Tsire Sold in Garko

\begin{tabular}{lcl}
\hline Isolated Organism & Frequency & Percentage (\%) \\
\hline Campylobacter & 2 & 06.66 \\
Escherichia coli & 6 & 20.00 \\
Klebsiella pneumoniae & 2 & 06.66 \\
Salmonella species & 1 & 03.33 \\
Shigella & 3 & 10.00 \\
Staphylococcus aureus & 2 & 06.66 \\
Total & 16 & \\
\hline
\end{tabular}

Table 4: Distribution of Organisms within Sampling Area

\begin{tabular}{lcc}
\hline \multicolumn{1}{c}{ Sampling Area } & No. Isolated & Percentage (\%) \\
\hline Dausai & 4 & 80 \\
Kofar Kudu & 4 & 80 \\
Makwalla & 2 & 40 \\
Rinji & 3 & 60 \\
Tosaro & 2 & 40 \\
Tsohuwar Kasuwa & 1 & 20 \\
Total & 16 & \\
\hline
\end{tabular}

\section{CONCLUSION}

Results indicated $4.00 \times 10^{5} \mathrm{CFU} / \mathrm{g}$ as the highest APCs count; while $68 \mathrm{MPN} / \mathrm{g}$ was the highest TCCs from the 30 samples analyzed. Among the isolates, $E$. coli has the highest isolation rate of $6(20 \%)$. Dausai and Kofar kudu were having the highest bacteria count of $4(80 \%)$, each, indicating higher contamination in those locations. 
BAJOPAS Volume 13 Number 1, June, 2020 RECOMMENDATIONS

The following recommendations are tenable:

1. Hygienic practices at all stages of production should be improved to safe guard the consumers against potential health hazard.

2. Monitoring of microbiological contamination of Tsire during preparations, packaging and marketing is essential to ensure product of good microbiological quality for consumers' health.

\section{REFERENCES}

Abdullahi, I. O., Umoh, V. J. and Galadima, M. (2004). Hazards Associated with Kilishi Preparations in Zaria. Nigerian Journal of Microbiology, 18 (1-2): $339-345$.

Ahmadu, J. and Ibrahim E. J., (2013): Determinants of Revenue in Suya Production in BeninCity, Edo State, Nigeria. Nigerian journal of agriculture, food and environment.9(3):1-5

Amaeze, N. Aboh, M. Itohan, A. Felix, E. Olatunji, T. and Oladosu, P. (2016) Microbial Profile, Antibiotic Sensitivity and Heat Resistance of Bacterial Isolates from Commercial Roasted Beef (Suya) in Abuja, Nigeria. JOPAT, 15(2): $22-30$.

Apata, E.S., Kuku1, I.A., Apata, O.C. and Adeyemi, K.O. (2013). Evaluation of Suya(Tsire) - An Intermediate Moisture Meat Product in Ogun State, Nigeria. J. Food Res 2 (1): 87.

Atlas, R. M. (1997) Principles of Microbiology Second Edition. C. Brown Publishers. Pp 802-803.

Borch, E. Kant-Muermans, M. L., Blixt, Y. (1996) Bacterial Spoilage of Meat and Cured Meat Products. Int $\mathrm{J}$ Food Microbiol .33(1): 103-20.

Centre for Disease Control, CDC (2011). "Escherichia coli 0157:H7" Division of Bacterial and Mycotic Diseasesht://www.cdc.gov/nczved/divisi ons/dfbmd/diseases/ecoli_0157h7/.

Charlene, R. J., Johnnie, A. D., and John, B. B., (2013) Prevalence and Characterization of Methicillin-Resistant Staphylococcus aureus Isolates from Retail Meat and Humans in Georgia. American society for Microbiology. J. of clinical microbiology. 12(1):123-6 doi:10.1128/JCM.0316612JCM.03166-12

Egbebi, A.O and Seidu, K., T. (2011). Microbiological Evaluation of Suya (dried smoked

meat) Sold in Ado and Akure, South West Nigeria.European Journal of Experinmental Biology, 1(4):1-5
3. Government should establish regulatory bodies responsible for inculcating hygiene habits to the local producers and vendors in order to prevent instant, cross and post processing contaminations by microbial pathogens.

4. Awareness and sensitization of local food producers about good hygienic practices in food handling and processing.

Falegan, C, R., Akoja, S. D., and Oyarekua, M. A., (2017) Microbiological Assessment of Suya (Sliced Roasted Beef) in Ado-Ekiti Metropolis, Ekiti State, Nigeria. MOJ Biology andMedicine.

Fonkem, D., N. Tanya, V., N. and Ebangi, A., L. (2010). Effect of Season on the Microbiological Quality of Kilishi, a Traditional Cameroonian Dried Beef Product. Tropicultura, 28(1): 10-15.

Food and Agricultural Organization of the United Nations (F A O, 1979). Manual of food quality control 4. Microbiological analysis.

Food and Agriculture Organisation of the United Nation (FAO), 2019. Nigeria at a glance.

Igene J.O., Uwadia, O.E., Ebabhamiegbebho, P.A. and Evivie, S.E., (2016) Shelf life Stability Studies of University of Benin (UNIBEN) Proff's Kilishi Product Asian Journal of Science and Technology 7(1): 2268-2274.

Inusa, S. K. and Said, I. S. (2017) Evaluation of the Chemical and Microbiological Properties Of Kilishi Sold in Kano Metropolis. Journal of Dry land Agriculture, 3 (1): $59-69$.

Lucretia, I. B, Patience, C. Obinna-Echem, Sophia, C. A. (2018) Microbiological quality andantibiotic sensitivity of potential pathogens isolated from meat product (Suya) sold in Rivers State University and its environs. International Journal of Biotechnology and Food Science, 6(4): 67-76.

Matthew, E., Drosos, E., John, L. and Ioanna, P. (2013) MRSA in Africa: Filling the Global Map of Antimicrobial Resistance PLOS One. 8(7): e68024 doi: 10.1371/journal.pone.0068024

Mgbemere, V.N., Akpapunam, M. A. and Igene, J. O., (2011). Effect of Groundnut FlourSubstitution on Yield, Quality and Storage Stability of Kilishi - a Nigerian Indigenous Dried Meat Product. African Journal of Food, Agriculture, Nutrition and Development, $\quad \mathbf{1 1}(2)$ : 4718-4738. 
BAJOPAS Volume 13 Number 1, June, 2020

Mubarak, A. A., Azeez, M. L., Amos A. O., Opeyemi, O. O. (2016) Assessment of Animal Protein Consumption and Food Security Among Rural Households in Kwara State, Nigeria American Journal of Business and Society, 1(4): 233245.

Ndahi, M., D. Kwaga, J., K. P. Bello, M. Kabir J., V. Umoh, .J. Yakubu, S., E. and Nok, A., J. (2013) Prevalence and Antimicrobial Susceptibility of Listeria Monocytogenes and Methicillin-Resistant Staphylococcus aureus Strains from Raw Meat and Meat Products in Zaria, Nigeria. Applied Journal of Microbiology, 58(3):262-9.

Okonko, I.O., Odu, N.N. and Igboh, I.E. (2013). Microbiological Analysis of Kilishi Sold In Port Harcourt, Nigeria. New York Science Journal, 6 (7):37-43.

Osimani, A., Aquilanti, L. and Clementi, F. (2015) Microbiological Quality of Meatbased Meals and Operation of Control Systems within a Food Service Environment. International Food Research Journal 22(4): 1692-1698.

Onuorah, S. Obika, I. Odibo, F. Orji, M. (2015)An Assessment of the Bacteriological Quality of Tsire-Suya (Grilled Beef) sold in Awka, Nigeria. American. J. Life. Sci. Res. 3(4):287292.

Razavilar, V, Khandaghi, J. Barzgari, A. (2010); Isolation of Eschericia coli 0157:H7 from manure fertilized farms and raw vegetables grown on it, in Tabriz city in
Iran. African Journal of Microbiology Research, 4(9): 891-895.

Scallan, E. Hoekstra, R. M. Angulo, F. J.Tauxe, R. V, Widdowson, M. Roy, S. L et al., (2011).Food borne illness acquired in the United States- Major Pathogens. Emerg. Infec Dis, 17(1): 7-15.

Shamsuddeen U (2009). Microbiological quality of spice used in the production of Kilishi a traditionally dried and grilled meat product. Bayero Journal of Pure andApplied Sciences, 2(2): 66-69.

Shamsuddeen, U. (2015) Microbiological Hazard and Critical control point Analysis of Dried and Minced Meat Snacks Produced in Kano Nigeria. Lambert Academic Publishing; Pp 1-36.

Tijani, O.and Jumare, S. (2014). Microblological Quality Assessment of Meat

Sold in KauraNamoda. International Conference on Earth, Environment and Life sciences (EELS) Dubai (UAE).

Udobi, C. E., Obajuluwa, A. F., and Onaolapo, J. A., (2013) Prevalence and Antibiotic Resistance Pattern of MethicillinResistant Staphylococcus aureus from an Orthopaedic Hospital in Nigeria BioMed Research International; 26(6); 6-7.

WHO, 2015 Foodborne diseases in the WHO African Region.

Yousafzai HA, Rind R, Khan MA, Abro SH, Korejo NA, Ejaz M, Kabir A, Shahid M, Memon S. (2019). Microbiological Contamination of Cattle and Meat in Peshawar, Pakistan. J. Anim. Health Prod. 7(1): 1116. 


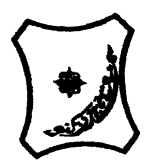

Bayero Journal of Pure and Applied Sciences, 13(1); 40 - 45

Received: September, 2019

Accepted: April, 2020

ISSN $2006-6996$

\title{
BACTERIOLOGICAL QUALITY OF STICK MEAT (Tsire) SOLD IN GARKO LOCAL GOVERNMENT AREA OF KANO STATE, NIGERIA
}

\author{
$*^{1}$ Dahiru A. T. and ${ }^{2}$ Maigari A. K. \\ ${ }^{1}$ Department of Hospitality Management, School of Technology, Kano State Polytechnic, PMB 3348, \\ Kano Nigeria. \\ ${ }^{2}$ Departmnt of Biological Sciences, Bayero University, Kano \\ Corresponding Author: dturajo61@gmail.com; GSM: 08087508262.
}

ABSTRACT

Stick meat, locally called Tsire in Hausa Language, is a significant portion of the diet of a large active population of Northern Nigeria. However, because of the handling and processing methods by the manufacturers as well as the hawking system of stick meat, the meat product may be exposed to both pre- and post-processed product contamination, and thus may poses danger to public health. Therefore, considering the role of Tsire in improving nutrition and increase household income to the populace, the need to improve the processing, distribution and overall quality of the product is simply indispensable. A total of 30 samples (5 samples from each of the 6 sampling points) of Tsire were collected randomly in Garko Town. Aerobic plate counts (APCs) and Total coliform counts (TCCS) of Tsire samples were determined using standard microbiological methods. APCs ranged from $1.02 \times 10^{5}$ to $4.00 \times 10^{5} \mathrm{CFU} / \mathrm{g}$; while TCCs ranged from $8 \mathrm{MPN} / \mathrm{g}$ to $68 \mathrm{MPN} / \mathrm{g}$. From the 30 samples screened, 16(53.33\%) bacteria namely, Campylobacter 2(6.66\%), Escherichia coli 6(20\%), Klebsiella pneumoniae 2(6.66\%), Salmonella spp. 1(3.33\%), Shigella 3(10\%) and Staphylococcus aureus 2(6.66\%) were detected. $E$. coli has the highest isolation rate of 6(20\%), while Salmonella spp. had the least frequency of 1(3.33\%). The distribution of isolated organisms within the study area were as follows: Dausai, 4(80\%), Kofar kudu, 4(80\%), Makwalla, 2(40\%), Rinji, 3(60\%), Tosaro, 2(40\%), and Tsohuwar Kasuwa, 1(20\%). The results have indicated that the Tsire was contaminated with bacteria thus exposing the product to fast deterioration, spoilage and also a vehicle for food borne illness, suggesting for adequate hygienic practices at all the stages, prior to consumption, to ensure safety of the meat product.

Key words: APCs, TCCs, Contamination, Microorganisms, Garko

\section{INTRODUCTION}

Nigeria is one of the developing nations with inadequate food supply and most often deficient in protein content (FAO, 2019). Nigerian's average animal protein intake per head per day is estimated at $7.9 \mathrm{~g}$ as against $35 \mathrm{~g}$ recommended value by Food and Agricultural Organization (Mubarak et al., 2016). These low levels of animal protein intake create great concern as it affects the nutritional status of Nigerians. Hence, there is the need for sufficient supply of animal protein from energy rich animal products to satisfy the nutritional requirements for Nigerians.

Meat is one major source of animal protein largely composed of water, protein and fats which can make it susceptible to microbial contamination within short time leading to spoilage (Apata et al., 2013; Mgbemere et al., 2011). Meat is mostly eaten after it has been cooked or processed in a variety of ways such as sun drying; smoking and roasting with or without fortifications (Borch et al., 1996). In Nigeria meat products such as Tsire, Kilishi and Balangu are locally produced using one or more of these methods in order to meet the nutritional requirements of the teeming Nigerians (Egbebi, 2011).

Tsire is a popular Nigerian traditional processed ready-to-eat roasted stick meat product (Shamsuddeen, 2015). It is sold in public places, along roads, in hotels, parks, quarters and even offices (Falegan et al., 2017). It is prepared from boneless healthy animal flesh such as beef and mutton, spiced with peanut cake, salt, vegetable oil and other flavorings followed by roasting (Shamsuddeen, 2015). Consumption of these products has extended to other parts of African countries such as Ghana, Somali, Cameroun and Chad (Ahmadu and Ibrahim, 2013). 
BAJOPAS Volume 13 Number 1, June, 2020

However, evidence of quality control sticking to procedural hygiene by the handlers during preparation and retailing of these products is poorly documented. Tsire is of great safety risk because of the fact that there are erratic cases of gastroenteritis and symptoms of food infection after consumption (WHO, 2015). Food borne illnesses are one of the major health problems in developing and developed countries (Razavilar, 2010). According to the World Health Organization, WHO (2015), $0.07 \%$ death of the 600 million global burdens of Foodborne illnesses have been reported to be caused by bacteria, viruses, fungi and chemicals. In America $0.27 \%$ of the estimated 48 million affected people is hospitalized and about $0.0063 \%$ deaths are recorded each year (Scallan et al., 2011). More than 91 million people in Africa fall ill and $0.15 \%$ dies each year, making Africa the highest burden bearer of Foodborne diseases per population (WHO, 2015).

Application of a Hazard Analysis Critical Control Point (HACCP) at all stages of meat products preparation is essential in order to ensure its safety. Thus, according to the guidelines of good manufacturing practice, the level of total aerobic bacterial contamination of thermally processed meat products should not exceed $10^{4}\left(\mathrm{cfu} \mathrm{g}^{-1}\right)$. Enterobacteriaceae and faecal coliform contamination in meat products should be within the range of $10^{2}-10^{4}$ and $10-10^{3} \mathrm{cfu} \mathrm{g}^{-1}$, respectively (Shamsuddeen, 2015). The aim of the study is therefore, to assess the total viable bacterial counts of tsire marketed locally within Garko town, and to isolate and identify the organisms at the point of consumption with the intention of promoting public health and food hygiene habits in the Nigerian populace.

\section{MATERIALS AND METHODS Study Area and Population}

Garko is one of the existing 44 local government areas located in Kano south west zone of Kano state with its capital administrative headquarters in the Garko town. It has coordinates $11^{\circ} 39^{\prime} \mathrm{N}$ $8^{\circ} 54^{\prime} \mathrm{E}$, and an area of $450 \mathrm{~km}^{2}$. The projected population of Garko local Government was 225,300 according to the National Population Census report (2018). Garko is known for agricultural activities both farming and animal husbandry. It is popularly known for large scale rice production. Other food crops include sweet potatoes, cassava, onions, sorghum, millet and sugarcane. Cows, sheep and goats are major groups of animals reared by majority of the populace. Meat products processed, retailed and consumed in Garko include roasted meat (Balangu), dried roasted meat (Kilishi), stick meat (Tsire), hide and skin pepper soup (Ragadada) and minced fried meat (Danbunnama).

\section{Samples Collection}

Five samples of Tsire products were collected from 6 different identified locations within Garko town in a sterile foil paper and immediately analyzed for the presence of bacteria.

\section{Sample Preparation}

Sample preparation for the bacteriological analysis was carried out in accordance with the method described by Atlas (1997). Twenty five grams $(25 \mathrm{~g})$ of the sample was homogenized in $225 \mathrm{ml}$ peptone water using Kenwood blender machine to obtain a $10^{1}$ homogenate. The homogenate was thoroughly shaken and $1 \mathrm{ml}$ pipetted into test tubes containing $9 \mathrm{ml}$ of peptone water $\left(10^{2}\right)$. The test tubes were further serially diluted to $10^{5}$.

Total Aerobic Mesophilic Bacterial Count

Total Aerobic mesophilic bacterial count was determined using the method described by Abdullahi et al. (2004) where $1 \mathrm{ml}$ of inoculums from $10^{1}$ to $10^{5}$ dilutions were transferred into duplicate Petri dishes and labeled accordingly. This was followed by pouring aseptically about $15 \mathrm{ml}$ of molten nutrient agar. The culture was homogenized by gentle spinning of the plates and allowed to solidify. The plates were incubated at $37^{\circ} \mathrm{C}$ for 24 hours. Plates containing 30-300 colonies were counted. The number of colony forming units per gram of a sample (cfu/g) was obtained by multiplying the average colony number with the inverse of the dilution factor.

\section{Enumeration and Detection of Coliform bacteria}

Detection and enumeration of coliform was carried out according to method described by Atlas, (1977). A set of 9 test tubes each containing $9 \mathrm{ml}$ of lactose broth and an inverted Durham tubes were autoclaved to expel air and to sterilize. Similarly, $1 \mathrm{ml}$ from the diluents $10^{1}$ was transferred to the first 3 test tubes, followed by $1 \mathrm{ml}$ from the diluents $10^{2}$ to the second set of 3 test tubes and finally the third diluents $10^{3}$ to the $3^{\text {rd }}$ set of 3 test tubes. All the 9 test tubes were incubated at $37^{\circ} \mathrm{C}$ for 24 hours. Tubes that showed gas and acid production after 24 hours were recorded as positive for the presence of Coliform. Negative tubes were further reincubated for 24 hours. Positive tubes were recorded. Estimate of most probable number of Coliform per gram of sample (MPN/g) was determined by comparing the number of gas positive tubes with the most probable number table. 
BAJOPAS Volume 13 Number 1, June, 2020 Identification of Coliform

A loop full of inoculum from gas positive tubes was streaked on to Eosine methylene blue (EMB) agar plate and incubated at $37^{\circ} \mathrm{C}$ for $24 \mathrm{hrs}$. Colonies which formed bluish black color with green metallic sheen, and reddish colonies were isolated on agar slants. Those colonies showing metallic sheen on EMB were sub cultured into tubes of lactose broth and incubated at $45^{\circ} \mathrm{C}$. The tubes were observed after $24 \mathrm{hrs}$ for gas production. This is the completed test for fecal coliform. Gram stain and other biochemical tests such as Indole, Methyl red, Voges-Proskauer and Citrate Utilization tests (IMVIC), Coagulase and Catalase tests were carried out for the Identification and confirmation of isolates.

\section{Procedure for Indole Test}

Indole test was carried out by preparing a Tryptone broth drawn in to test tubes, sterilized by autoclaving, inoculated with loopful of suspension and incubated at $37^{\circ} \mathrm{C}$ for 24 hours. Three drops of xylene was added in tubes, shaken vigorously and kept for the separation of two layers. One millilitre of Kovac's reagent was added and the formation of pink colour ring indicates positive Indole test.

\section{Procedure for Methyl Red Test}

Methyl red test was carried out by preparing Glucose phosphate broth, dispensed in test tubes, sterilized, inoculated with test culture and incubated at $37^{\circ} \mathrm{C}$ for 24 hours. Five drops of methyl-red indicator was added to the medium for the formation of red colour.

\section{Procedure for Voges-Proskauer Test}

Voges-Proskauer test was carried out by inoculating tubes with the bacterial culture followed by incubation for 48 hours at $37^{\circ} \mathrm{C}$. Separate pipettes were used to pipette $1 \mathrm{ml}$ from each culture tube into clean separate tubes. Eighteen drops $(0.5 \mathrm{ml})$ of Barrit's solution A (a-naphthol) was added to each tube containing glucose phosphate broth followed by the addition of an equal amount of solution $B$ into the same tube. The tubes were shaken at 30 seconds interval. A positive reaction was indicated by the development of a pink color, which turns red in 1-2 hours, after vigorous shaking.

\section{Procedure for Citrate Utilization Test}

Citrate Utilization Test was carried out by distributing melted agar (Simmon Citrate Agar) in to test tubes followed by sterilization at $121.5^{\circ} \mathrm{C}$ for 15 minutes. The test tubes were afterward held in slanted position, inoculated with the given bacterial culture and incubated at $37^{\circ} \mathrm{C}$ for $24 \mathrm{hrs}$. Positive test was indicated by color change of the media from green to blue.

\section{RESULTS AND DISCUSSIONS}

The results of this study are presented in tables $1,2,3$ and 4. Among the sampling areas Kofar Kudu had the highest aerobic mesophilic bacteria counts $4.0 \times 10^{5} \mathrm{cfu} / \mathrm{g}$ followed by Rinji $2.72 \times 10^{5} \mathrm{cfu} / \mathrm{g}$, while Tosaro had the least Aerobic mesophilic bacteria counts of $1.02 \times 10^{5}$ $\mathrm{cfu} / \mathrm{g}$ as indicated in Table 1.Makwalla had the highest coliform count $68 \mathrm{MPN} / \mathrm{g}$ followed by Rinji $37 \mathrm{MPN} / \mathrm{g}$. Tsohuwar Kasuwa had the least coliform counts $8 \mathrm{MPN} / \mathrm{g}$, (Table 2). Result from table 1 shows variation in the microbial contents among the samples which suggest variation in their sources, poor handling procedures and contamination from the processing environment. High coliform count and their differences within sampling areas is an indication of poor microbiological quality of the product. Ndahi et al. (2013) reported microbial load to be a function of the handling personnel and the environment. The results indicated that the samples were contaminated with bacteria as the counts exceeded the minimum safety level $\left(10^{4} \mathrm{cfu} / \mathrm{g}\right)$ for members of the Enterobacteriaceae family. However, it might be a reflection of poor hygienic practices which may contribute to health hazard to the potential consumers. Similarly, Inusa and Sa'id (2017); Osimani et al. (2015) reported that, the initial microbial content of the raw material play significant role in influencing the final microbial load of the finished product. Isolation of members of the Enterobacteriaceae such as $E$. coli, Klebsiella pneumoniae, Salmonella and Shigella signifies danger to the public health. These organisms are capable of producing endotoxins which trigger high fevers in infected individuals, and the enterotoxins which colonize the small intestines and lead to extreme dehydration as a result of vomiting and diarrhea sometimes with severe and fatal outcomes (Amaeze et al., 2016). From the 16 isolated organisms $E$. coli had the highest isolation rate $6(37.5 \%)$ (Table 3), this suggest faecal contamination of the products. $E$. coli is a common flora in the gastrointestinal tract responsible for diarrhea and extra-intestinal infections (CDC, 2011). The result is in conformity with the findings of Ndahi et al. (2013) and Shamsuddeen (2009). Also presence of campylobacter might be due to cross contamination from raw meat to finished product (Tsire). Staphylococcus aureus is a normal flora of the skin, nasal, genital, mouth or anal area in both humans and animals without any symptom of an infection (Matthew et al., 2013). Isolation of $S$. aureus in these study concords with the findings of Lucretia et al. (2018) from Suya sold in Rivers State. 
BAJOPAS Volume 13 Number 1, June, 2020

It is also in agreement with the findings of Yousafzai et al. (2018); Onuorah et al. (2015) and Tijjani and Jumare (2014) from tsire samples in different countries. Presence of $S$. aureus in foods is most of the time an indication of poor human handling, poor environment, unhygienic utensils and equipments used during processing (Igene et al., 2016; Okonko et al., 2013). Infections caused by $S$. aureus are difficult to treat leading to long hospitalization with consequent economic loss (Udobi et al., 2013). These include soft tissue infections, pneumonia, hospital-acquired postoperative wound infections, Staphylococcal food poisoning, impetigo and cellulitis (Charlene et al., 2013). Samples obtained from Dausai and Kofar Kudu had the highest isolation rate $4(80 \%)$ (Table 4 ) probably because of the much commercial activities taking place in the area which can lead to environmental contamination.

Table 1: Total Aerobic Mesophilic Bacterial Count of Tsire sold in Garko Town

\begin{tabular}{lll}
\hline Sampling Area & APC cfu/g & Mean \pm STD \\
\hline Dausai & $2.20 \times 10^{5}$ & $110000 \pm 14142.14$ \\
Kofar Kudu & $4.00 \times 10^{5}$ & $133333.3 \pm 23094.01$ \\
Makwalla & $1.30 \times 10^{5}$ & $32500 \pm 7187.953$ \\
Rinji & $2.72 \times 10^{5}$ & $90666.67 \pm 94769.90$ \\
Tosaro & $1.02 \times 10^{5}$ & $51000 \pm 15556.35$ \\
Tsohuwar Kasuwa & $1.75 \times 10^{5}$ & $35000 \pm 11357.82$ \\
\hline
\end{tabular}

Key: APC: Aerobic Mesophilic Counts

STD: Standard Deviation

Table 2: Total Coliform Count of Tsire sold in Garko Town

\begin{tabular}{lcc}
\hline \multicolumn{1}{c}{ Sampling Area } & TCC MPN/g & Mean \pm STD \\
\hline Dausai & 20 & $6.67 \pm 2.5166$ \\
Kofar Kudu & 32 & $16.00 \pm 5.6569$ \\
Makwalla & 68 & $13.60 \pm 8.7062$ \\
Rinji & 37 & $9.25 \pm 4.7871$ \\
Tosaro & 10 & $5.00 \pm 2.8284$ \\
Tsohuwar Kasuwa & 8 & $4.00 \pm 0.0000$ \\
\hline
\end{tabular}

Table 3: Organisms Isolated from Tsire Sold in Garko

\begin{tabular}{lcl}
\hline Isolated Organism & Frequency & Percentage (\%) \\
\hline Campylobacter & 2 & 06.66 \\
Escherichia coli & 6 & 20.00 \\
Klebsiella pneumoniae & 2 & 06.66 \\
Salmonella species & 1 & 03.33 \\
Shigella & 3 & 10.00 \\
Staphylococcus aureus & 2 & 06.66 \\
Total & 16 & \\
\hline
\end{tabular}

Table 4: Distribution of Organisms within Sampling Area

\begin{tabular}{lcc}
\hline \multicolumn{1}{c}{ Sampling Area } & No. Isolated & Percentage (\%) \\
\hline Dausai & 4 & 80 \\
Kofar Kudu & 4 & 80 \\
Makwalla & 2 & 40 \\
Rinji & 3 & 60 \\
Tosaro & 2 & 40 \\
Tsohuwar Kasuwa & 1 & 20 \\
Total & 16 & \\
\hline
\end{tabular}

\section{CONCLUSION}

Results indicated $4.00 \times 10^{5} \mathrm{CFU} / \mathrm{g}$ as the highest APCs count; while $68 \mathrm{MPN} / \mathrm{g}$ was the highest TCCs from the 30 samples analyzed. Among the isolates, $E$. coli has the highest isolation rate of $6(20 \%)$. Dausai and Kofar kudu were having the highest bacteria count of $4(80 \%)$, each, indicating higher contamination in those locations. 
BAJOPAS Volume 13 Number 1, June, 2020 RECOMMENDATIONS

The following recommendations are tenable:

1. Hygienic practices at all stages of production should be improved to safe guard the consumers against potential health hazard.

2. Monitoring of microbiological contamination of Tsire during preparations, packaging and marketing is essential to ensure product of good microbiological quality for consumers' health.

\section{REFERENCES}

Abdullahi, I. O., Umoh, V. J. and Galadima, M. (2004). Hazards Associated with Kilishi Preparations in Zaria. Nigerian Journal of Microbiology, 18 (1-2): $339-345$.

Ahmadu, J. and Ibrahim E. J., (2013): Determinants of Revenue in Suya Production in BeninCity, Edo State, Nigeria. Nigerian journal of agriculture, food and environment.9(3):1-5

Amaeze, N. Aboh, M. Itohan, A. Felix, E. Olatunji, T. and Oladosu, P. (2016) Microbial Profile, Antibiotic Sensitivity and Heat Resistance of Bacterial Isolates from Commercial Roasted Beef (Suya) in Abuja, Nigeria. JOPAT, 15(2): $22-30$.

Apata, E.S., Kuku1, I.A., Apata, O.C. and Adeyemi, K.O. (2013). Evaluation of Suya(Tsire) - An Intermediate Moisture Meat Product in Ogun State, Nigeria. J. Food Res 2 (1): 87.

Atlas, R. M. (1997) Principles of Microbiology Second Edition. C. Brown Publishers. Pp 802-803.

Borch, E. Kant-Muermans, M. L., Blixt, Y. (1996) Bacterial Spoilage of Meat and Cured Meat Products. Int $\mathrm{J}$ Food Microbiol .33(1): 103-20.

Centre for Disease Control, CDC (2011). "Escherichia coli 0157:H7" Division of Bacterial and Mycotic Diseasesht://www.cdc.gov/nczved/divisi ons/dfbmd/diseases/ecoli_0157h7/.

Charlene, R. J., Johnnie, A. D., and John, B. B., (2013) Prevalence and Characterization of Methicillin-Resistant Staphylococcus aureus Isolates from Retail Meat and Humans in Georgia. American society for Microbiology. J. of clinical microbiology. 12(1):123-6 doi:10.1128/JCM.0316612JCM.03166-12

Egbebi, A.O and Seidu, K., T. (2011). Microbiological Evaluation of Suya (dried smoked

meat) Sold in Ado and Akure, South West Nigeria.European Journal of Experinmental Biology, 1(4):1-5
3. Government should establish regulatory bodies responsible for inculcating hygiene habits to the local producers and vendors in order to prevent instant, cross and post processing contaminations by microbial pathogens.

4. Awareness and sensitization of local food producers about good hygienic practices in food handling and processing.

Falegan, C, R., Akoja, S. D., and Oyarekua, M. A., (2017) Microbiological Assessment of Suya (Sliced Roasted Beef) in Ado-Ekiti Metropolis, Ekiti State, Nigeria. MOJ Biology andMedicine.

Fonkem, D., N. Tanya, V., N. and Ebangi, A., L. (2010). Effect of Season on the Microbiological Quality of Kilishi, a Traditional Cameroonian Dried Beef Product. Tropicultura, 28(1): 10-15.

Food and Agricultural Organization of the United Nations (F A O, 1979). Manual of food quality control 4. Microbiological analysis.

Food and Agriculture Organisation of the United Nation (FAO), 2019. Nigeria at a glance.

Igene J.O., Uwadia, O.E., Ebabhamiegbebho, P.A. and Evivie, S.E., (2016) Shelf life Stability Studies of University of Benin (UNIBEN) Proff's Kilishi Product Asian Journal of Science and Technology 7(1): 2268-2274.

Inusa, S. K. and Said, I. S. (2017) Evaluation of the Chemical and Microbiological Properties Of Kilishi Sold in Kano Metropolis. Journal of Dry land Agriculture, 3 (1): $59-69$.

Lucretia, I. B, Patience, C. Obinna-Echem, Sophia, C. A. (2018) Microbiological quality andantibiotic sensitivity of potential pathogens isolated from meat product (Suya) sold in Rivers State University and its environs. International Journal of Biotechnology and Food Science, 6(4): 67-76.

Matthew, E., Drosos, E., John, L. and Ioanna, P. (2013) MRSA in Africa: Filling the Global Map of Antimicrobial Resistance PLOS One. 8(7): e68024 doi: 10.1371/journal.pone.0068024

Mgbemere, V.N., Akpapunam, M. A. and Igene, J. O., (2011). Effect of Groundnut FlourSubstitution on Yield, Quality and Storage Stability of Kilishi - a Nigerian Indigenous Dried Meat Product. African Journal of Food, Agriculture, Nutrition and Development, $\quad \mathbf{1 1}(2)$ : 4718-4738. 
BAJOPAS Volume 13 Number 1, June, 2020

Mubarak, A. A., Azeez, M. L., Amos A. O., Opeyemi, O. O. (2016) Assessment of Animal Protein Consumption and Food Security Among Rural Households in Kwara State, Nigeria American Journal of Business and Society, 1(4): 233245.

Ndahi, M., D. Kwaga, J., K. P. Bello, M. Kabir J., V. Umoh, .J. Yakubu, S., E. and Nok, A., J. (2013) Prevalence and Antimicrobial Susceptibility of Listeria Monocytogenes and Methicillin-Resistant Staphylococcus aureus Strains from Raw Meat and Meat Products in Zaria, Nigeria. Applied Journal of Microbiology, 58(3):262-9.

Okonko, I.O., Odu, N.N. and Igboh, I.E. (2013). Microbiological Analysis of Kilishi Sold In Port Harcourt, Nigeria. New York Science Journal, 6 (7):37-43.

Osimani, A., Aquilanti, L. and Clementi, F. (2015) Microbiological Quality of Meatbased Meals and Operation of Control Systems within a Food Service Environment. International Food Research Journal 22(4): 1692-1698.

Onuorah, S. Obika, I. Odibo, F. Orji, M. (2015)An Assessment of the Bacteriological Quality of Tsire-Suya (Grilled Beef) sold in Awka, Nigeria. American. J. Life. Sci. Res. 3(4):287292.

Razavilar, V, Khandaghi, J. Barzgari, A. (2010); Isolation of Eschericia coli 0157:H7 from manure fertilized farms and raw vegetables grown on it, in Tabriz city in
Iran. African Journal of Microbiology Research, 4(9): 891-895.

Scallan, E. Hoekstra, R. M. Angulo, F. J.Tauxe, R. V, Widdowson, M. Roy, S. L et al., (2011).Food borne illness acquired in the United States- Major Pathogens. Emerg. Infec Dis, 17(1): 7-15.

Shamsuddeen U (2009). Microbiological quality of spice used in the production of Kilishi a traditionally dried and grilled meat product. Bayero Journal of Pure andApplied Sciences, 2(2): 66-69.

Shamsuddeen, U. (2015) Microbiological Hazard and Critical control point Analysis of Dried and Minced Meat Snacks Produced in Kano Nigeria. Lambert Academic Publishing; Pp 1-36.

Tijani, O.and Jumare, S. (2014). Microblological Quality Assessment of Meat

Sold in KauraNamoda. International Conference on Earth, Environment and Life sciences (EELS) Dubai (UAE).

Udobi, C. E., Obajuluwa, A. F., and Onaolapo, J. A., (2013) Prevalence and Antibiotic Resistance Pattern of MethicillinResistant Staphylococcus aureus from an Orthopaedic Hospital in Nigeria BioMed Research International; 26(6); 6-7.

WHO, 2015 Foodborne diseases in the WHO African Region.

Yousafzai HA, Rind R, Khan MA, Abro SH, Korejo NA, Ejaz M, Kabir A, Shahid M, Memon S. (2019). Microbiological Contamination of Cattle and Meat in Peshawar, Pakistan. J. Anim. Health Prod. 7(1): 1116. 


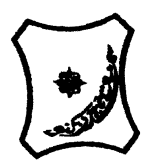

Bayero Journal of Pure and Applied Sciences, 13(1); 40 - 45

Received: September, 2019

Accepted: April, 2020

ISSN $2006-6996$

\title{
BACTERIOLOGICAL QUALITY OF STICK MEAT (Tsire) SOLD IN GARKO LOCAL GOVERNMENT AREA OF KANO STATE, NIGERIA
}

\author{
$*^{1}$ Dahiru A. T. and ${ }^{2}$ Maigari A. K. \\ ${ }^{1}$ Department of Hospitality Management, School of Technology, Kano State Polytechnic, PMB 3348, \\ Kano Nigeria. \\ ${ }^{2}$ Departmnt of Biological Sciences, Bayero University, Kano \\ Corresponding Author: dturajo61@gmail.com; GSM: 08087508262.
}

ABSTRACT

Stick meat, locally called Tsire in Hausa Language, is a significant portion of the diet of a large active population of Northern Nigeria. However, because of the handling and processing methods by the manufacturers as well as the hawking system of stick meat, the meat product may be exposed to both pre- and post-processed product contamination, and thus may poses danger to public health. Therefore, considering the role of Tsire in improving nutrition and increase household income to the populace, the need to improve the processing, distribution and overall quality of the product is simply indispensable. A total of 30 samples (5 samples from each of the 6 sampling points) of Tsire were collected randomly in Garko Town. Aerobic plate counts (APCs) and Total coliform counts (TCCS) of Tsire samples were determined using standard microbiological methods. APCs ranged from $1.02 \times 10^{5}$ to $4.00 \times 10^{5} \mathrm{CFU} / \mathrm{g}$; while TCCs ranged from $8 \mathrm{MPN} / \mathrm{g}$ to $68 \mathrm{MPN} / \mathrm{g}$. From the 30 samples screened, 16(53.33\%) bacteria namely, Campylobacter 2(6.66\%), Escherichia coli 6(20\%), Klebsiella pneumoniae 2(6.66\%), Salmonella spp. 1(3.33\%), Shigella 3(10\%) and Staphylococcus aureus 2(6.66\%) were detected. $E$. coli has the highest isolation rate of 6(20\%), while Salmonella spp. had the least frequency of 1(3.33\%). The distribution of isolated organisms within the study area were as follows: Dausai, 4(80\%), Kofar kudu, 4(80\%), Makwalla, 2(40\%), Rinji, 3(60\%), Tosaro, 2(40\%), and Tsohuwar Kasuwa, 1(20\%). The results have indicated that the Tsire was contaminated with bacteria thus exposing the product to fast deterioration, spoilage and also a vehicle for food borne illness, suggesting for adequate hygienic practices at all the stages, prior to consumption, to ensure safety of the meat product.

Key words: APCs, TCCs, Contamination, Microorganisms, Garko

\section{INTRODUCTION}

Nigeria is one of the developing nations with inadequate food supply and most often deficient in protein content (FAO, 2019). Nigerian's average animal protein intake per head per day is estimated at $7.9 \mathrm{~g}$ as against $35 \mathrm{~g}$ recommended value by Food and Agricultural Organization (Mubarak et al., 2016). These low levels of animal protein intake create great concern as it affects the nutritional status of Nigerians. Hence, there is the need for sufficient supply of animal protein from energy rich animal products to satisfy the nutritional requirements for Nigerians.

Meat is one major source of animal protein largely composed of water, protein and fats which can make it susceptible to microbial contamination within short time leading to spoilage (Apata et al., 2013; Mgbemere et al., 2011). Meat is mostly eaten after it has been cooked or processed in a variety of ways such as sun drying; smoking and roasting with or without fortifications (Borch et al., 1996). In Nigeria meat products such as Tsire, Kilishi and Balangu are locally produced using one or more of these methods in order to meet the nutritional requirements of the teeming Nigerians (Egbebi, 2011).

Tsire is a popular Nigerian traditional processed ready-to-eat roasted stick meat product (Shamsuddeen, 2015). It is sold in public places, along roads, in hotels, parks, quarters and even offices (Falegan et al., 2017). It is prepared from boneless healthy animal flesh such as beef and mutton, spiced with peanut cake, salt, vegetable oil and other flavorings followed by roasting (Shamsuddeen, 2015). Consumption of these products has extended to other parts of African countries such as Ghana, Somali, Cameroun and Chad (Ahmadu and Ibrahim, 2013). 
BAJOPAS Volume 13 Number 1, June, 2020

However, evidence of quality control sticking to procedural hygiene by the handlers during preparation and retailing of these products is poorly documented. Tsire is of great safety risk because of the fact that there are erratic cases of gastroenteritis and symptoms of food infection after consumption (WHO, 2015). Food borne illnesses are one of the major health problems in developing and developed countries (Razavilar, 2010). According to the World Health Organization, WHO (2015), $0.07 \%$ death of the 600 million global burdens of Foodborne illnesses have been reported to be caused by bacteria, viruses, fungi and chemicals. In America $0.27 \%$ of the estimated 48 million affected people is hospitalized and about $0.0063 \%$ deaths are recorded each year (Scallan et al., 2011). More than 91 million people in Africa fall ill and $0.15 \%$ dies each year, making Africa the highest burden bearer of Foodborne diseases per population (WHO, 2015).

Application of a Hazard Analysis Critical Control Point (HACCP) at all stages of meat products preparation is essential in order to ensure its safety. Thus, according to the guidelines of good manufacturing practice, the level of total aerobic bacterial contamination of thermally processed meat products should not exceed $10^{4}\left(\mathrm{cfu} \mathrm{g}^{-1}\right)$. Enterobacteriaceae and faecal coliform contamination in meat products should be within the range of $10^{2}-10^{4}$ and $10-10^{3} \mathrm{cfu} \mathrm{g}^{-1}$, respectively (Shamsuddeen, 2015). The aim of the study is therefore, to assess the total viable bacterial counts of tsire marketed locally within Garko town, and to isolate and identify the organisms at the point of consumption with the intention of promoting public health and food hygiene habits in the Nigerian populace.

\section{MATERIALS AND METHODS Study Area and Population}

Garko is one of the existing 44 local government areas located in Kano south west zone of Kano state with its capital administrative headquarters in the Garko town. It has coordinates $11^{\circ} 39^{\prime} \mathrm{N}$ $8^{\circ} 54^{\prime} \mathrm{E}$, and an area of $450 \mathrm{~km}^{2}$. The projected population of Garko local Government was 225,300 according to the National Population Census report (2018). Garko is known for agricultural activities both farming and animal husbandry. It is popularly known for large scale rice production. Other food crops include sweet potatoes, cassava, onions, sorghum, millet and sugarcane. Cows, sheep and goats are major groups of animals reared by majority of the populace. Meat products processed, retailed and consumed in Garko include roasted meat (Balangu), dried roasted meat (Kilishi), stick meat (Tsire), hide and skin pepper soup (Ragadada) and minced fried meat (Danbunnama).

\section{Samples Collection}

Five samples of Tsire products were collected from 6 different identified locations within Garko town in a sterile foil paper and immediately analyzed for the presence of bacteria.

\section{Sample Preparation}

Sample preparation for the bacteriological analysis was carried out in accordance with the method described by Atlas (1997). Twenty five grams $(25 \mathrm{~g})$ of the sample was homogenized in $225 \mathrm{ml}$ peptone water using Kenwood blender machine to obtain a $10^{1}$ homogenate. The homogenate was thoroughly shaken and $1 \mathrm{ml}$ pipetted into test tubes containing $9 \mathrm{ml}$ of peptone water $\left(10^{2}\right)$. The test tubes were further serially diluted to $10^{5}$.

Total Aerobic Mesophilic Bacterial Count

Total Aerobic mesophilic bacterial count was determined using the method described by Abdullahi et al. (2004) where $1 \mathrm{ml}$ of inoculums from $10^{1}$ to $10^{5}$ dilutions were transferred into duplicate Petri dishes and labeled accordingly. This was followed by pouring aseptically about $15 \mathrm{ml}$ of molten nutrient agar. The culture was homogenized by gentle spinning of the plates and allowed to solidify. The plates were incubated at $37^{\circ} \mathrm{C}$ for 24 hours. Plates containing 30-300 colonies were counted. The number of colony forming units per gram of a sample (cfu/g) was obtained by multiplying the average colony number with the inverse of the dilution factor.

\section{Enumeration and Detection of Coliform bacteria}

Detection and enumeration of coliform was carried out according to method described by Atlas, (1977). A set of 9 test tubes each containing $9 \mathrm{ml}$ of lactose broth and an inverted Durham tubes were autoclaved to expel air and to sterilize. Similarly, $1 \mathrm{ml}$ from the diluents $10^{1}$ was transferred to the first 3 test tubes, followed by $1 \mathrm{ml}$ from the diluents $10^{2}$ to the second set of 3 test tubes and finally the third diluents $10^{3}$ to the $3^{\text {rd }}$ set of 3 test tubes. All the 9 test tubes were incubated at $37^{\circ} \mathrm{C}$ for 24 hours. Tubes that showed gas and acid production after 24 hours were recorded as positive for the presence of Coliform. Negative tubes were further reincubated for 24 hours. Positive tubes were recorded. Estimate of most probable number of Coliform per gram of sample (MPN/g) was determined by comparing the number of gas positive tubes with the most probable number table. 
BAJOPAS Volume 13 Number 1, June, 2020 Identification of Coliform

A loop full of inoculum from gas positive tubes was streaked on to Eosine methylene blue (EMB) agar plate and incubated at $37^{\circ} \mathrm{C}$ for $24 \mathrm{hrs}$. Colonies which formed bluish black color with green metallic sheen, and reddish colonies were isolated on agar slants. Those colonies showing metallic sheen on EMB were sub cultured into tubes of lactose broth and incubated at $45^{\circ} \mathrm{C}$. The tubes were observed after $24 \mathrm{hrs}$ for gas production. This is the completed test for fecal coliform. Gram stain and other biochemical tests such as Indole, Methyl red, Voges-Proskauer and Citrate Utilization tests (IMVIC), Coagulase and Catalase tests were carried out for the Identification and confirmation of isolates.

\section{Procedure for Indole Test}

Indole test was carried out by preparing a Tryptone broth drawn in to test tubes, sterilized by autoclaving, inoculated with loopful of suspension and incubated at $37^{\circ} \mathrm{C}$ for 24 hours. Three drops of xylene was added in tubes, shaken vigorously and kept for the separation of two layers. One millilitre of Kovac's reagent was added and the formation of pink colour ring indicates positive Indole test.

\section{Procedure for Methyl Red Test}

Methyl red test was carried out by preparing Glucose phosphate broth, dispensed in test tubes, sterilized, inoculated with test culture and incubated at $37^{\circ} \mathrm{C}$ for 24 hours. Five drops of methyl-red indicator was added to the medium for the formation of red colour.

\section{Procedure for Voges-Proskauer Test}

Voges-Proskauer test was carried out by inoculating tubes with the bacterial culture followed by incubation for 48 hours at $37^{\circ} \mathrm{C}$. Separate pipettes were used to pipette $1 \mathrm{ml}$ from each culture tube into clean separate tubes. Eighteen drops $(0.5 \mathrm{ml})$ of Barrit's solution A (a-naphthol) was added to each tube containing glucose phosphate broth followed by the addition of an equal amount of solution $B$ into the same tube. The tubes were shaken at 30 seconds interval. A positive reaction was indicated by the development of a pink color, which turns red in 1-2 hours, after vigorous shaking.

\section{Procedure for Citrate Utilization Test}

Citrate Utilization Test was carried out by distributing melted agar (Simmon Citrate Agar) in to test tubes followed by sterilization at $121.5^{\circ} \mathrm{C}$ for 15 minutes. The test tubes were afterward held in slanted position, inoculated with the given bacterial culture and incubated at $37^{\circ} \mathrm{C}$ for $24 \mathrm{hrs}$. Positive test was indicated by color change of the media from green to blue.

\section{RESULTS AND DISCUSSIONS}

The results of this study are presented in tables $1,2,3$ and 4. Among the sampling areas Kofar Kudu had the highest aerobic mesophilic bacteria counts $4.0 \times 10^{5} \mathrm{cfu} / \mathrm{g}$ followed by Rinji $2.72 \times 10^{5} \mathrm{cfu} / \mathrm{g}$, while Tosaro had the least Aerobic mesophilic bacteria counts of $1.02 \times 10^{5}$ $\mathrm{cfu} / \mathrm{g}$ as indicated in Table 1.Makwalla had the highest coliform count $68 \mathrm{MPN} / \mathrm{g}$ followed by Rinji $37 \mathrm{MPN} / \mathrm{g}$. Tsohuwar Kasuwa had the least coliform counts $8 \mathrm{MPN} / \mathrm{g}$, (Table 2). Result from table 1 shows variation in the microbial contents among the samples which suggest variation in their sources, poor handling procedures and contamination from the processing environment. High coliform count and their differences within sampling areas is an indication of poor microbiological quality of the product. Ndahi et al. (2013) reported microbial load to be a function of the handling personnel and the environment. The results indicated that the samples were contaminated with bacteria as the counts exceeded the minimum safety level $\left(10^{4} \mathrm{cfu} / \mathrm{g}\right)$ for members of the Enterobacteriaceae family. However, it might be a reflection of poor hygienic practices which may contribute to health hazard to the potential consumers. Similarly, Inusa and Sa'id (2017); Osimani et al. (2015) reported that, the initial microbial content of the raw material play significant role in influencing the final microbial load of the finished product. Isolation of members of the Enterobacteriaceae such as $E$. coli, Klebsiella pneumoniae, Salmonella and Shigella signifies danger to the public health. These organisms are capable of producing endotoxins which trigger high fevers in infected individuals, and the enterotoxins which colonize the small intestines and lead to extreme dehydration as a result of vomiting and diarrhea sometimes with severe and fatal outcomes (Amaeze et al., 2016). From the 16 isolated organisms $E$. coli had the highest isolation rate $6(37.5 \%)$ (Table 3), this suggest faecal contamination of the products. $E$. coli is a common flora in the gastrointestinal tract responsible for diarrhea and extra-intestinal infections (CDC, 2011). The result is in conformity with the findings of Ndahi et al. (2013) and Shamsuddeen (2009). Also presence of campylobacter might be due to cross contamination from raw meat to finished product (Tsire). Staphylococcus aureus is a normal flora of the skin, nasal, genital, mouth or anal area in both humans and animals without any symptom of an infection (Matthew et al., 2013). Isolation of $S$. aureus in these study concords with the findings of Lucretia et al. (2018) from Suya sold in Rivers State. 
BAJOPAS Volume 13 Number 1, June, 2020

It is also in agreement with the findings of Yousafzai et al. (2018); Onuorah et al. (2015) and Tijjani and Jumare (2014) from tsire samples in different countries. Presence of $S$. aureus in foods is most of the time an indication of poor human handling, poor environment, unhygienic utensils and equipments used during processing (Igene et al., 2016; Okonko et al., 2013). Infections caused by $S$. aureus are difficult to treat leading to long hospitalization with consequent economic loss (Udobi et al., 2013). These include soft tissue infections, pneumonia, hospital-acquired postoperative wound infections, Staphylococcal food poisoning, impetigo and cellulitis (Charlene et al., 2013). Samples obtained from Dausai and Kofar Kudu had the highest isolation rate $4(80 \%)$ (Table 4 ) probably because of the much commercial activities taking place in the area which can lead to environmental contamination.

Table 1: Total Aerobic Mesophilic Bacterial Count of Tsire sold in Garko Town

\begin{tabular}{lll}
\hline Sampling Area & APC cfu/g & Mean \pm STD \\
\hline Dausai & $2.20 \times 10^{5}$ & $110000 \pm 14142.14$ \\
Kofar Kudu & $4.00 \times 10^{5}$ & $133333.3 \pm 23094.01$ \\
Makwalla & $1.30 \times 10^{5}$ & $32500 \pm 7187.953$ \\
Rinji & $2.72 \times 10^{5}$ & $90666.67 \pm 94769.90$ \\
Tosaro & $1.02 \times 10^{5}$ & $51000 \pm 15556.35$ \\
Tsohuwar Kasuwa & $1.75 \times 10^{5}$ & $35000 \pm 11357.82$ \\
\hline
\end{tabular}

Key: APC: Aerobic Mesophilic Counts

STD: Standard Deviation

Table 2: Total Coliform Count of Tsire sold in Garko Town

\begin{tabular}{lcc}
\hline \multicolumn{1}{c}{ Sampling Area } & TCC MPN/g & Mean \pm STD \\
\hline Dausai & 20 & $6.67 \pm 2.5166$ \\
Kofar Kudu & 32 & $16.00 \pm 5.6569$ \\
Makwalla & 68 & $13.60 \pm 8.7062$ \\
Rinji & 37 & $9.25 \pm 4.7871$ \\
Tosaro & 10 & $5.00 \pm 2.8284$ \\
Tsohuwar Kasuwa & 8 & $4.00 \pm 0.0000$ \\
\hline
\end{tabular}

Table 3: Organisms Isolated from Tsire Sold in Garko

\begin{tabular}{lcl}
\hline Isolated Organism & Frequency & Percentage (\%) \\
\hline Campylobacter & 2 & 06.66 \\
Escherichia coli & 6 & 20.00 \\
Klebsiella pneumoniae & 2 & 06.66 \\
Salmonella species & 1 & 03.33 \\
Shigella & 3 & 10.00 \\
Staphylococcus aureus & 2 & 06.66 \\
Total & 16 & \\
\hline
\end{tabular}

Table 4: Distribution of Organisms within Sampling Area

\begin{tabular}{lcc}
\hline \multicolumn{1}{c}{ Sampling Area } & No. Isolated & Percentage (\%) \\
\hline Dausai & 4 & 80 \\
Kofar Kudu & 4 & 80 \\
Makwalla & 2 & 40 \\
Rinji & 3 & 60 \\
Tosaro & 2 & 40 \\
Tsohuwar Kasuwa & 1 & 20 \\
Total & 16 & \\
\hline
\end{tabular}

\section{CONCLUSION}

Results indicated $4.00 \times 10^{5} \mathrm{CFU} / \mathrm{g}$ as the highest APCs count; while $68 \mathrm{MPN} / \mathrm{g}$ was the highest TCCs from the 30 samples analyzed. Among the isolates, $E$. coli has the highest isolation rate of $6(20 \%)$. Dausai and Kofar kudu were having the highest bacteria count of $4(80 \%)$, each, indicating higher contamination in those locations. 
BAJOPAS Volume 13 Number 1, June, 2020 RECOMMENDATIONS

The following recommendations are tenable:

1. Hygienic practices at all stages of production should be improved to safe guard the consumers against potential health hazard.

2. Monitoring of microbiological contamination of Tsire during preparations, packaging and marketing is essential to ensure product of good microbiological quality for consumers' health.

\section{REFERENCES}

Abdullahi, I. O., Umoh, V. J. and Galadima, M. (2004). Hazards Associated with Kilishi Preparations in Zaria. Nigerian Journal of Microbiology, 18 (1-2): $339-345$.

Ahmadu, J. and Ibrahim E. J., (2013): Determinants of Revenue in Suya Production in BeninCity, Edo State, Nigeria. Nigerian journal of agriculture, food and environment.9(3):1-5

Amaeze, N. Aboh, M. Itohan, A. Felix, E. Olatunji, T. and Oladosu, P. (2016) Microbial Profile, Antibiotic Sensitivity and Heat Resistance of Bacterial Isolates from Commercial Roasted Beef (Suya) in Abuja, Nigeria. JOPAT, 15(2): $22-30$.

Apata, E.S., Kuku1, I.A., Apata, O.C. and Adeyemi, K.O. (2013). Evaluation of Suya(Tsire) - An Intermediate Moisture Meat Product in Ogun State, Nigeria. J. Food Res 2 (1): 87.

Atlas, R. M. (1997) Principles of Microbiology Second Edition. C. Brown Publishers. Pp 802-803.

Borch, E. Kant-Muermans, M. L., Blixt, Y. (1996) Bacterial Spoilage of Meat and Cured Meat Products. Int $\mathrm{J}$ Food Microbiol .33(1): 103-20.

Centre for Disease Control, CDC (2011). "Escherichia coli 0157:H7" Division of Bacterial and Mycotic Diseasesht://www.cdc.gov/nczved/divisi ons/dfbmd/diseases/ecoli_0157h7/.

Charlene, R. J., Johnnie, A. D., and John, B. B., (2013) Prevalence and Characterization of Methicillin-Resistant Staphylococcus aureus Isolates from Retail Meat and Humans in Georgia. American society for Microbiology. J. of clinical microbiology. 12(1):123-6 doi:10.1128/JCM.0316612JCM.03166-12

Egbebi, A.O and Seidu, K., T. (2011). Microbiological Evaluation of Suya (dried smoked

meat) Sold in Ado and Akure, South West Nigeria.European Journal of Experinmental Biology, 1(4):1-5
3. Government should establish regulatory bodies responsible for inculcating hygiene habits to the local producers and vendors in order to prevent instant, cross and post processing contaminations by microbial pathogens.

4. Awareness and sensitization of local food producers about good hygienic practices in food handling and processing.

Falegan, C, R., Akoja, S. D., and Oyarekua, M. A., (2017) Microbiological Assessment of Suya (Sliced Roasted Beef) in Ado-Ekiti Metropolis, Ekiti State, Nigeria. MOJ Biology andMedicine.

Fonkem, D., N. Tanya, V., N. and Ebangi, A., L. (2010). Effect of Season on the Microbiological Quality of Kilishi, a Traditional Cameroonian Dried Beef Product. Tropicultura, 28(1): 10-15.

Food and Agricultural Organization of the United Nations (F A O, 1979). Manual of food quality control 4. Microbiological analysis.

Food and Agriculture Organisation of the United Nation (FAO), 2019. Nigeria at a glance.

Igene J.O., Uwadia, O.E., Ebabhamiegbebho, P.A. and Evivie, S.E., (2016) Shelf life Stability Studies of University of Benin (UNIBEN) Proff's Kilishi Product Asian Journal of Science and Technology 7(1): 2268-2274.

Inusa, S. K. and Said, I. S. (2017) Evaluation of the Chemical and Microbiological Properties Of Kilishi Sold in Kano Metropolis. Journal of Dry land Agriculture, 3 (1): $59-69$.

Lucretia, I. B, Patience, C. Obinna-Echem, Sophia, C. A. (2018) Microbiological quality andantibiotic sensitivity of potential pathogens isolated from meat product (Suya) sold in Rivers State University and its environs. International Journal of Biotechnology and Food Science, 6(4): 67-76.

Matthew, E., Drosos, E., John, L. and Ioanna, P. (2013) MRSA in Africa: Filling the Global Map of Antimicrobial Resistance PLOS One. 8(7): e68024 doi: 10.1371/journal.pone.0068024

Mgbemere, V.N., Akpapunam, M. A. and Igene, J. O., (2011). Effect of Groundnut FlourSubstitution on Yield, Quality and Storage Stability of Kilishi - a Nigerian Indigenous Dried Meat Product. African Journal of Food, Agriculture, Nutrition and Development, $\quad \mathbf{1 1}(2)$ : 4718-4738. 
BAJOPAS Volume 13 Number 1, June, 2020

Mubarak, A. A., Azeez, M. L., Amos A. O., Opeyemi, O. O. (2016) Assessment of Animal Protein Consumption and Food Security Among Rural Households in Kwara State, Nigeria American Journal of Business and Society, 1(4): 233245.

Ndahi, M., D. Kwaga, J., K. P. Bello, M. Kabir J., V. Umoh, .J. Yakubu, S., E. and Nok, A., J. (2013) Prevalence and Antimicrobial Susceptibility of Listeria Monocytogenes and Methicillin-Resistant Staphylococcus aureus Strains from Raw Meat and Meat Products in Zaria, Nigeria. Applied Journal of Microbiology, 58(3):262-9.

Okonko, I.O., Odu, N.N. and Igboh, I.E. (2013). Microbiological Analysis of Kilishi Sold In Port Harcourt, Nigeria. New York Science Journal, 6 (7):37-43.

Osimani, A., Aquilanti, L. and Clementi, F. (2015) Microbiological Quality of Meatbased Meals and Operation of Control Systems within a Food Service Environment. International Food Research Journal 22(4): 1692-1698.

Onuorah, S. Obika, I. Odibo, F. Orji, M. (2015)An Assessment of the Bacteriological Quality of Tsire-Suya (Grilled Beef) sold in Awka, Nigeria. American. J. Life. Sci. Res. 3(4):287292.

Razavilar, V, Khandaghi, J. Barzgari, A. (2010); Isolation of Eschericia coli 0157:H7 from manure fertilized farms and raw vegetables grown on it, in Tabriz city in
Iran. African Journal of Microbiology Research, 4(9): 891-895.

Scallan, E. Hoekstra, R. M. Angulo, F. J.Tauxe, R. V, Widdowson, M. Roy, S. L et al., (2011).Food borne illness acquired in the United States- Major Pathogens. Emerg. Infec Dis, 17(1): 7-15.

Shamsuddeen U (2009). Microbiological quality of spice used in the production of Kilishi a traditionally dried and grilled meat product. Bayero Journal of Pure andApplied Sciences, 2(2): 66-69.

Shamsuddeen, U. (2015) Microbiological Hazard and Critical control point Analysis of Dried and Minced Meat Snacks Produced in Kano Nigeria. Lambert Academic Publishing; Pp 1-36.

Tijani, O.and Jumare, S. (2014). Microblological Quality Assessment of Meat

Sold in KauraNamoda. International Conference on Earth, Environment and Life sciences (EELS) Dubai (UAE).

Udobi, C. E., Obajuluwa, A. F., and Onaolapo, J. A., (2013) Prevalence and Antibiotic Resistance Pattern of MethicillinResistant Staphylococcus aureus from an Orthopaedic Hospital in Nigeria BioMed Research International; 26(6); 6-7.

WHO, 2015 Foodborne diseases in the WHO African Region.

Yousafzai HA, Rind R, Khan MA, Abro SH, Korejo NA, Ejaz M, Kabir A, Shahid M, Memon S. (2019). Microbiological Contamination of Cattle and Meat in Peshawar, Pakistan. J. Anim. Health Prod. 7(1): 1116. 


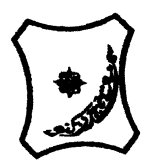

Bayero Journal of Pure and Applied Sciences, 13(1); 40 - 45

Received: September, 2019

Accepted: April, 2020

ISSN $2006-6996$

\title{
BACTERIOLOGICAL QUALITY OF STICK MEAT (Tsire) SOLD IN GARKO LOCAL GOVERNMENT AREA OF KANO STATE, NIGERIA
}

\author{
$*^{1}$ Dahiru A. T. and ${ }^{2}$ Maigari A. K. \\ ${ }^{1}$ Department of Hospitality Management, School of Technology, Kano State Polytechnic, PMB 3348, \\ Kano Nigeria. \\ ${ }^{2}$ Departmnt of Biological Sciences, Bayero University, Kano \\ Corresponding Author: dturajo61@gmail.com; GSM: 08087508262.
}

ABSTRACT

Stick meat, locally called Tsire in Hausa Language, is a significant portion of the diet of a large active population of Northern Nigeria. However, because of the handling and processing methods by the manufacturers as well as the hawking system of stick meat, the meat product may be exposed to both pre- and post-processed product contamination, and thus may poses danger to public health. Therefore, considering the role of Tsire in improving nutrition and increase household income to the populace, the need to improve the processing, distribution and overall quality of the product is simply indispensable. A total of 30 samples (5 samples from each of the 6 sampling points) of Tsire were collected randomly in Garko Town. Aerobic plate counts (APCs) and Total coliform counts (TCCS) of Tsire samples were determined using standard microbiological methods. APCs ranged from $1.02 \times 10^{5}$ to $4.00 \times 10^{5} \mathrm{CFU} / \mathrm{g}$; while TCCs ranged from $8 \mathrm{MPN} / \mathrm{g}$ to $68 \mathrm{MPN} / \mathrm{g}$. From the 30 samples screened, 16(53.33\%) bacteria namely, Campylobacter 2(6.66\%), Escherichia coli 6(20\%), Klebsiella pneumoniae 2(6.66\%), Salmonella spp. 1(3.33\%), Shigella 3(10\%) and Staphylococcus aureus 2(6.66\%) were detected. $E$. coli has the highest isolation rate of 6(20\%), while Salmonella spp. had the least frequency of 1(3.33\%). The distribution of isolated organisms within the study area were as follows: Dausai, 4(80\%), Kofar kudu, 4(80\%), Makwalla, 2(40\%), Rinji, 3(60\%), Tosaro, 2(40\%), and Tsohuwar Kasuwa, 1(20\%). The results have indicated that the Tsire was contaminated with bacteria thus exposing the product to fast deterioration, spoilage and also a vehicle for food borne illness, suggesting for adequate hygienic practices at all the stages, prior to consumption, to ensure safety of the meat product.

Key words: APCs, TCCs, Contamination, Microorganisms, Garko

\section{INTRODUCTION}

Nigeria is one of the developing nations with inadequate food supply and most often deficient in protein content (FAO, 2019). Nigerian's average animal protein intake per head per day is estimated at $7.9 \mathrm{~g}$ as against $35 \mathrm{~g}$ recommended value by Food and Agricultural Organization (Mubarak et al., 2016). These low levels of animal protein intake create great concern as it affects the nutritional status of Nigerians. Hence, there is the need for sufficient supply of animal protein from energy rich animal products to satisfy the nutritional requirements for Nigerians.

Meat is one major source of animal protein largely composed of water, protein and fats which can make it susceptible to microbial contamination within short time leading to spoilage (Apata et al., 2013; Mgbemere et al., 2011). Meat is mostly eaten after it has been cooked or processed in a variety of ways such as sun drying; smoking and roasting with or without fortifications (Borch et al., 1996). In Nigeria meat products such as Tsire, Kilishi and Balangu are locally produced using one or more of these methods in order to meet the nutritional requirements of the teeming Nigerians (Egbebi, 2011).

Tsire is a popular Nigerian traditional processed ready-to-eat roasted stick meat product (Shamsuddeen, 2015). It is sold in public places, along roads, in hotels, parks, quarters and even offices (Falegan et al., 2017). It is prepared from boneless healthy animal flesh such as beef and mutton, spiced with peanut cake, salt, vegetable oil and other flavorings followed by roasting (Shamsuddeen, 2015). Consumption of these products has extended to other parts of African countries such as Ghana, Somali, Cameroun and Chad (Ahmadu and Ibrahim, 2013). 
BAJOPAS Volume 13 Number 1, June, 2020

However, evidence of quality control sticking to procedural hygiene by the handlers during preparation and retailing of these products is poorly documented. Tsire is of great safety risk because of the fact that there are erratic cases of gastroenteritis and symptoms of food infection after consumption (WHO, 2015). Food borne illnesses are one of the major health problems in developing and developed countries (Razavilar, 2010). According to the World Health Organization, WHO (2015), $0.07 \%$ death of the 600 million global burdens of Foodborne illnesses have been reported to be caused by bacteria, viruses, fungi and chemicals. In America $0.27 \%$ of the estimated 48 million affected people is hospitalized and about $0.0063 \%$ deaths are recorded each year (Scallan et al., 2011). More than 91 million people in Africa fall ill and $0.15 \%$ dies each year, making Africa the highest burden bearer of Foodborne diseases per population (WHO, 2015).

Application of a Hazard Analysis Critical Control Point (HACCP) at all stages of meat products preparation is essential in order to ensure its safety. Thus, according to the guidelines of good manufacturing practice, the level of total aerobic bacterial contamination of thermally processed meat products should not exceed $10^{4}\left(\mathrm{cfu} \mathrm{g}^{-1}\right)$. Enterobacteriaceae and faecal coliform contamination in meat products should be within the range of $10^{2}-10^{4}$ and $10-10^{3} \mathrm{cfu} \mathrm{g}^{-1}$, respectively (Shamsuddeen, 2015). The aim of the study is therefore, to assess the total viable bacterial counts of tsire marketed locally within Garko town, and to isolate and identify the organisms at the point of consumption with the intention of promoting public health and food hygiene habits in the Nigerian populace.

\section{MATERIALS AND METHODS Study Area and Population}

Garko is one of the existing 44 local government areas located in Kano south west zone of Kano state with its capital administrative headquarters in the Garko town. It has coordinates $11^{\circ} 39^{\prime} \mathrm{N}$ $8^{\circ} 54^{\prime} \mathrm{E}$, and an area of $450 \mathrm{~km}^{2}$. The projected population of Garko local Government was 225,300 according to the National Population Census report (2018). Garko is known for agricultural activities both farming and animal husbandry. It is popularly known for large scale rice production. Other food crops include sweet potatoes, cassava, onions, sorghum, millet and sugarcane. Cows, sheep and goats are major groups of animals reared by majority of the populace. Meat products processed, retailed and consumed in Garko include roasted meat (Balangu), dried roasted meat (Kilishi), stick meat (Tsire), hide and skin pepper soup (Ragadada) and minced fried meat (Danbunnama).

\section{Samples Collection}

Five samples of Tsire products were collected from 6 different identified locations within Garko town in a sterile foil paper and immediately analyzed for the presence of bacteria.

\section{Sample Preparation}

Sample preparation for the bacteriological analysis was carried out in accordance with the method described by Atlas (1997). Twenty five grams $(25 \mathrm{~g})$ of the sample was homogenized in $225 \mathrm{ml}$ peptone water using Kenwood blender machine to obtain a $10^{1}$ homogenate. The homogenate was thoroughly shaken and $1 \mathrm{ml}$ pipetted into test tubes containing $9 \mathrm{ml}$ of peptone water $\left(10^{2}\right)$. The test tubes were further serially diluted to $10^{5}$.

Total Aerobic Mesophilic Bacterial Count

Total Aerobic mesophilic bacterial count was determined using the method described by Abdullahi et al. (2004) where $1 \mathrm{ml}$ of inoculums from $10^{1}$ to $10^{5}$ dilutions were transferred into duplicate Petri dishes and labeled accordingly. This was followed by pouring aseptically about $15 \mathrm{ml}$ of molten nutrient agar. The culture was homogenized by gentle spinning of the plates and allowed to solidify. The plates were incubated at $37^{\circ} \mathrm{C}$ for 24 hours. Plates containing 30-300 colonies were counted. The number of colony forming units per gram of a sample (cfu/g) was obtained by multiplying the average colony number with the inverse of the dilution factor.

\section{Enumeration and Detection of Coliform bacteria}

Detection and enumeration of coliform was carried out according to method described by Atlas, (1977). A set of 9 test tubes each containing $9 \mathrm{ml}$ of lactose broth and an inverted Durham tubes were autoclaved to expel air and to sterilize. Similarly, $1 \mathrm{ml}$ from the diluents $10^{1}$ was transferred to the first 3 test tubes, followed by $1 \mathrm{ml}$ from the diluents $10^{2}$ to the second set of 3 test tubes and finally the third diluents $10^{3}$ to the $3^{\text {rd }}$ set of 3 test tubes. All the 9 test tubes were incubated at $37^{\circ} \mathrm{C}$ for 24 hours. Tubes that showed gas and acid production after 24 hours were recorded as positive for the presence of Coliform. Negative tubes were further reincubated for 24 hours. Positive tubes were recorded. Estimate of most probable number of Coliform per gram of sample (MPN/g) was determined by comparing the number of gas positive tubes with the most probable number table. 
BAJOPAS Volume 13 Number 1, June, 2020 Identification of Coliform

A loop full of inoculum from gas positive tubes was streaked on to Eosine methylene blue (EMB) agar plate and incubated at $37^{\circ} \mathrm{C}$ for $24 \mathrm{hrs}$. Colonies which formed bluish black color with green metallic sheen, and reddish colonies were isolated on agar slants. Those colonies showing metallic sheen on EMB were sub cultured into tubes of lactose broth and incubated at $45^{\circ} \mathrm{C}$. The tubes were observed after $24 \mathrm{hrs}$ for gas production. This is the completed test for fecal coliform. Gram stain and other biochemical tests such as Indole, Methyl red, Voges-Proskauer and Citrate Utilization tests (IMVIC), Coagulase and Catalase tests were carried out for the Identification and confirmation of isolates.

\section{Procedure for Indole Test}

Indole test was carried out by preparing a Tryptone broth drawn in to test tubes, sterilized by autoclaving, inoculated with loopful of suspension and incubated at $37^{\circ} \mathrm{C}$ for 24 hours. Three drops of xylene was added in tubes, shaken vigorously and kept for the separation of two layers. One millilitre of Kovac's reagent was added and the formation of pink colour ring indicates positive Indole test.

\section{Procedure for Methyl Red Test}

Methyl red test was carried out by preparing Glucose phosphate broth, dispensed in test tubes, sterilized, inoculated with test culture and incubated at $37^{\circ} \mathrm{C}$ for 24 hours. Five drops of methyl-red indicator was added to the medium for the formation of red colour.

\section{Procedure for Voges-Proskauer Test}

Voges-Proskauer test was carried out by inoculating tubes with the bacterial culture followed by incubation for 48 hours at $37^{\circ} \mathrm{C}$. Separate pipettes were used to pipette $1 \mathrm{ml}$ from each culture tube into clean separate tubes. Eighteen drops $(0.5 \mathrm{ml})$ of Barrit's solution A (a-naphthol) was added to each tube containing glucose phosphate broth followed by the addition of an equal amount of solution $B$ into the same tube. The tubes were shaken at 30 seconds interval. A positive reaction was indicated by the development of a pink color, which turns red in 1-2 hours, after vigorous shaking.

\section{Procedure for Citrate Utilization Test}

Citrate Utilization Test was carried out by distributing melted agar (Simmon Citrate Agar) in to test tubes followed by sterilization at $121.5^{\circ} \mathrm{C}$ for 15 minutes. The test tubes were afterward held in slanted position, inoculated with the given bacterial culture and incubated at $37^{\circ} \mathrm{C}$ for $24 \mathrm{hrs}$. Positive test was indicated by color change of the media from green to blue.

\section{RESULTS AND DISCUSSIONS}

The results of this study are presented in tables $1,2,3$ and 4. Among the sampling areas Kofar Kudu had the highest aerobic mesophilic bacteria counts $4.0 \times 10^{5} \mathrm{cfu} / \mathrm{g}$ followed by Rinji $2.72 \times 10^{5} \mathrm{cfu} / \mathrm{g}$, while Tosaro had the least Aerobic mesophilic bacteria counts of $1.02 \times 10^{5}$ $\mathrm{cfu} / \mathrm{g}$ as indicated in Table 1.Makwalla had the highest coliform count $68 \mathrm{MPN} / \mathrm{g}$ followed by Rinji $37 \mathrm{MPN} / \mathrm{g}$. Tsohuwar Kasuwa had the least coliform counts $8 \mathrm{MPN} / \mathrm{g}$, (Table 2). Result from table 1 shows variation in the microbial contents among the samples which suggest variation in their sources, poor handling procedures and contamination from the processing environment. High coliform count and their differences within sampling areas is an indication of poor microbiological quality of the product. Ndahi et al. (2013) reported microbial load to be a function of the handling personnel and the environment. The results indicated that the samples were contaminated with bacteria as the counts exceeded the minimum safety level $\left(10^{4} \mathrm{cfu} / \mathrm{g}\right)$ for members of the Enterobacteriaceae family. However, it might be a reflection of poor hygienic practices which may contribute to health hazard to the potential consumers. Similarly, Inusa and Sa'id (2017); Osimani et al. (2015) reported that, the initial microbial content of the raw material play significant role in influencing the final microbial load of the finished product. Isolation of members of the Enterobacteriaceae such as $E$. coli, Klebsiella pneumoniae, Salmonella and Shigella signifies danger to the public health. These organisms are capable of producing endotoxins which trigger high fevers in infected individuals, and the enterotoxins which colonize the small intestines and lead to extreme dehydration as a result of vomiting and diarrhea sometimes with severe and fatal outcomes (Amaeze et al., 2016). From the 16 isolated organisms $E$. coli had the highest isolation rate $6(37.5 \%)$ (Table 3), this suggest faecal contamination of the products. $E$. coli is a common flora in the gastrointestinal tract responsible for diarrhea and extra-intestinal infections (CDC, 2011). The result is in conformity with the findings of Ndahi et al. (2013) and Shamsuddeen (2009). Also presence of campylobacter might be due to cross contamination from raw meat to finished product (Tsire). Staphylococcus aureus is a normal flora of the skin, nasal, genital, mouth or anal area in both humans and animals without any symptom of an infection (Matthew et al., 2013). Isolation of $S$. aureus in these study concords with the findings of Lucretia et al. (2018) from Suya sold in Rivers State. 
BAJOPAS Volume 13 Number 1, June, 2020

It is also in agreement with the findings of Yousafzai et al. (2018); Onuorah et al. (2015) and Tijjani and Jumare (2014) from tsire samples in different countries. Presence of $S$. aureus in foods is most of the time an indication of poor human handling, poor environment, unhygienic utensils and equipments used during processing (Igene et al., 2016; Okonko et al., 2013). Infections caused by $S$. aureus are difficult to treat leading to long hospitalization with consequent economic loss (Udobi et al., 2013). These include soft tissue infections, pneumonia, hospital-acquired postoperative wound infections, Staphylococcal food poisoning, impetigo and cellulitis (Charlene et al., 2013). Samples obtained from Dausai and Kofar Kudu had the highest isolation rate $4(80 \%)$ (Table 4 ) probably because of the much commercial activities taking place in the area which can lead to environmental contamination.

Table 1: Total Aerobic Mesophilic Bacterial Count of Tsire sold in Garko Town

\begin{tabular}{lll}
\hline Sampling Area & APC cfu/g & Mean \pm STD \\
\hline Dausai & $2.20 \times 10^{5}$ & $110000 \pm 14142.14$ \\
Kofar Kudu & $4.00 \times 10^{5}$ & $133333.3 \pm 23094.01$ \\
Makwalla & $1.30 \times 10^{5}$ & $32500 \pm 7187.953$ \\
Rinji & $2.72 \times 10^{5}$ & $90666.67 \pm 94769.90$ \\
Tosaro & $1.02 \times 10^{5}$ & $51000 \pm 15556.35$ \\
Tsohuwar Kasuwa & $1.75 \times 10^{5}$ & $35000 \pm 11357.82$ \\
\hline
\end{tabular}

Key: APC: Aerobic Mesophilic Counts

STD: Standard Deviation

Table 2: Total Coliform Count of Tsire sold in Garko Town

\begin{tabular}{lcc}
\hline \multicolumn{1}{c}{ Sampling Area } & TCC MPN/g & Mean \pm STD \\
\hline Dausai & 20 & $6.67 \pm 2.5166$ \\
Kofar Kudu & 32 & $16.00 \pm 5.6569$ \\
Makwalla & 68 & $13.60 \pm 8.7062$ \\
Rinji & 37 & $9.25 \pm 4.7871$ \\
Tosaro & 10 & $5.00 \pm 2.8284$ \\
Tsohuwar Kasuwa & 8 & $4.00 \pm 0.0000$ \\
\hline
\end{tabular}

Table 3: Organisms Isolated from Tsire Sold in Garko

\begin{tabular}{lcl}
\hline Isolated Organism & Frequency & Percentage (\%) \\
\hline Campylobacter & 2 & 06.66 \\
Escherichia coli & 6 & 20.00 \\
Klebsiella pneumoniae & 2 & 06.66 \\
Salmonella species & 1 & 03.33 \\
Shigella & 3 & 10.00 \\
Staphylococcus aureus & 2 & 06.66 \\
Total & 16 & \\
\hline
\end{tabular}

Table 4: Distribution of Organisms within Sampling Area

\begin{tabular}{lcc}
\hline \multicolumn{1}{c}{ Sampling Area } & No. Isolated & Percentage (\%) \\
\hline Dausai & 4 & 80 \\
Kofar Kudu & 4 & 80 \\
Makwalla & 2 & 40 \\
Rinji & 3 & 60 \\
Tosaro & 2 & 40 \\
Tsohuwar Kasuwa & 1 & 20 \\
Total & 16 & \\
\hline
\end{tabular}

\section{CONCLUSION}

Results indicated $4.00 \times 10^{5} \mathrm{CFU} / \mathrm{g}$ as the highest APCs count; while $68 \mathrm{MPN} / \mathrm{g}$ was the highest TCCs from the 30 samples analyzed. Among the isolates, $E$. coli has the highest isolation rate of $6(20 \%)$. Dausai and Kofar kudu were having the highest bacteria count of $4(80 \%)$, each, indicating higher contamination in those locations. 
BAJOPAS Volume 13 Number 1, June, 2020 RECOMMENDATIONS

The following recommendations are tenable:

1. Hygienic practices at all stages of production should be improved to safe guard the consumers against potential health hazard.

2. Monitoring of microbiological contamination of Tsire during preparations, packaging and marketing is essential to ensure product of good microbiological quality for consumers' health.

\section{REFERENCES}

Abdullahi, I. O., Umoh, V. J. and Galadima, M. (2004). Hazards Associated with Kilishi Preparations in Zaria. Nigerian Journal of Microbiology, 18 (1-2): $339-345$.

Ahmadu, J. and Ibrahim E. J., (2013): Determinants of Revenue in Suya Production in BeninCity, Edo State, Nigeria. Nigerian journal of agriculture, food and environment.9(3):1-5

Amaeze, N. Aboh, M. Itohan, A. Felix, E. Olatunji, T. and Oladosu, P. (2016) Microbial Profile, Antibiotic Sensitivity and Heat Resistance of Bacterial Isolates from Commercial Roasted Beef (Suya) in Abuja, Nigeria. JOPAT, 15(2): $22-30$.

Apata, E.S., Kuku1, I.A., Apata, O.C. and Adeyemi, K.O. (2013). Evaluation of Suya(Tsire) - An Intermediate Moisture Meat Product in Ogun State, Nigeria. J. Food Res 2 (1): 87.

Atlas, R. M. (1997) Principles of Microbiology Second Edition. C. Brown Publishers. Pp 802-803.

Borch, E. Kant-Muermans, M. L., Blixt, Y. (1996) Bacterial Spoilage of Meat and Cured Meat Products. Int $\mathrm{J}$ Food Microbiol .33(1): 103-20.

Centre for Disease Control, CDC (2011). "Escherichia coli 0157:H7" Division of Bacterial and Mycotic Diseasesht://www.cdc.gov/nczved/divisi ons/dfbmd/diseases/ecoli_0157h7/.

Charlene, R. J., Johnnie, A. D., and John, B. B., (2013) Prevalence and Characterization of Methicillin-Resistant Staphylococcus aureus Isolates from Retail Meat and Humans in Georgia. American society for Microbiology. J. of clinical microbiology. 12(1):123-6 doi:10.1128/JCM.0316612JCM.03166-12

Egbebi, A.O and Seidu, K., T. (2011). Microbiological Evaluation of Suya (dried smoked

meat) Sold in Ado and Akure, South West Nigeria.European Journal of Experinmental Biology, 1(4):1-5
3. Government should establish regulatory bodies responsible for inculcating hygiene habits to the local producers and vendors in order to prevent instant, cross and post processing contaminations by microbial pathogens.

4. Awareness and sensitization of local food producers about good hygienic practices in food handling and processing.

Falegan, C, R., Akoja, S. D., and Oyarekua, M. A., (2017) Microbiological Assessment of Suya (Sliced Roasted Beef) in Ado-Ekiti Metropolis, Ekiti State, Nigeria. MOJ Biology andMedicine.

Fonkem, D., N. Tanya, V., N. and Ebangi, A., L. (2010). Effect of Season on the Microbiological Quality of Kilishi, a Traditional Cameroonian Dried Beef Product. Tropicultura, 28(1): 10-15.

Food and Agricultural Organization of the United Nations (F A O, 1979). Manual of food quality control 4. Microbiological analysis.

Food and Agriculture Organisation of the United Nation (FAO), 2019. Nigeria at a glance.

Igene J.O., Uwadia, O.E., Ebabhamiegbebho, P.A. and Evivie, S.E., (2016) Shelf life Stability Studies of University of Benin (UNIBEN) Proff's Kilishi Product Asian Journal of Science and Technology 7(1): 2268-2274.

Inusa, S. K. and Said, I. S. (2017) Evaluation of the Chemical and Microbiological Properties Of Kilishi Sold in Kano Metropolis. Journal of Dry land Agriculture, 3 (1): $59-69$.

Lucretia, I. B, Patience, C. Obinna-Echem, Sophia, C. A. (2018) Microbiological quality andantibiotic sensitivity of potential pathogens isolated from meat product (Suya) sold in Rivers State University and its environs. International Journal of Biotechnology and Food Science, 6(4): 67-76.

Matthew, E., Drosos, E., John, L. and Ioanna, P. (2013) MRSA in Africa: Filling the Global Map of Antimicrobial Resistance PLOS One. 8(7): e68024 doi: 10.1371/journal.pone.0068024

Mgbemere, V.N., Akpapunam, M. A. and Igene, J. O., (2011). Effect of Groundnut FlourSubstitution on Yield, Quality and Storage Stability of Kilishi - a Nigerian Indigenous Dried Meat Product. African Journal of Food, Agriculture, Nutrition and Development, $\quad \mathbf{1 1}(2)$ : 4718-4738. 
BAJOPAS Volume 13 Number 1, June, 2020

Mubarak, A. A., Azeez, M. L., Amos A. O., Opeyemi, O. O. (2016) Assessment of Animal Protein Consumption and Food Security Among Rural Households in Kwara State, Nigeria American Journal of Business and Society, 1(4): 233245.

Ndahi, M., D. Kwaga, J., K. P. Bello, M. Kabir J., V. Umoh, .J. Yakubu, S., E. and Nok, A., J. (2013) Prevalence and Antimicrobial Susceptibility of Listeria Monocytogenes and Methicillin-Resistant Staphylococcus aureus Strains from Raw Meat and Meat Products in Zaria, Nigeria. Applied Journal of Microbiology, 58(3):262-9.

Okonko, I.O., Odu, N.N. and Igboh, I.E. (2013). Microbiological Analysis of Kilishi Sold In Port Harcourt, Nigeria. New York Science Journal, 6 (7):37-43.

Osimani, A., Aquilanti, L. and Clementi, F. (2015) Microbiological Quality of Meatbased Meals and Operation of Control Systems within a Food Service Environment. International Food Research Journal 22(4): 1692-1698.

Onuorah, S. Obika, I. Odibo, F. Orji, M. (2015)An Assessment of the Bacteriological Quality of Tsire-Suya (Grilled Beef) sold in Awka, Nigeria. American. J. Life. Sci. Res. 3(4):287292.

Razavilar, V, Khandaghi, J. Barzgari, A. (2010); Isolation of Eschericia coli 0157:H7 from manure fertilized farms and raw vegetables grown on it, in Tabriz city in
Iran. African Journal of Microbiology Research, 4(9): 891-895.

Scallan, E. Hoekstra, R. M. Angulo, F. J.Tauxe, R. V, Widdowson, M. Roy, S. L et al., (2011).Food borne illness acquired in the United States- Major Pathogens. Emerg. Infec Dis, 17(1): 7-15.

Shamsuddeen U (2009). Microbiological quality of spice used in the production of Kilishi a traditionally dried and grilled meat product. Bayero Journal of Pure andApplied Sciences, 2(2): 66-69.

Shamsuddeen, U. (2015) Microbiological Hazard and Critical control point Analysis of Dried and Minced Meat Snacks Produced in Kano Nigeria. Lambert Academic Publishing; Pp 1-36.

Tijani, O.and Jumare, S. (2014). Microblological Quality Assessment of Meat

Sold in KauraNamoda. International Conference on Earth, Environment and Life sciences (EELS) Dubai (UAE).

Udobi, C. E., Obajuluwa, A. F., and Onaolapo, J. A., (2013) Prevalence and Antibiotic Resistance Pattern of MethicillinResistant Staphylococcus aureus from an Orthopaedic Hospital in Nigeria BioMed Research International; 26(6); 6-7.

WHO, 2015 Foodborne diseases in the WHO African Region.

Yousafzai HA, Rind R, Khan MA, Abro SH, Korejo NA, Ejaz M, Kabir A, Shahid M, Memon S. (2019). Microbiological Contamination of Cattle and Meat in Peshawar, Pakistan. J. Anim. Health Prod. 7(1): 1116. 


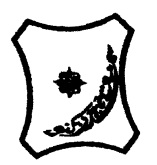

Bayero Journal of Pure and Applied Sciences, 13(1); 40 - 45

Received: September, 2019

Accepted: April, 2020

ISSN $2006-6996$

\title{
BACTERIOLOGICAL QUALITY OF STICK MEAT (Tsire) SOLD IN GARKO LOCAL GOVERNMENT AREA OF KANO STATE, NIGERIA
}

\author{
$*^{1}$ Dahiru A. T. and ${ }^{2}$ Maigari A. K. \\ ${ }^{1}$ Department of Hospitality Management, School of Technology, Kano State Polytechnic, PMB 3348, \\ Kano Nigeria. \\ ${ }^{2}$ Departmnt of Biological Sciences, Bayero University, Kano \\ Corresponding Author: dturajo61@gmail.com; GSM: 08087508262.
}

ABSTRACT

Stick meat, locally called Tsire in Hausa Language, is a significant portion of the diet of a large active population of Northern Nigeria. However, because of the handling and processing methods by the manufacturers as well as the hawking system of stick meat, the meat product may be exposed to both pre- and post-processed product contamination, and thus may poses danger to public health. Therefore, considering the role of Tsire in improving nutrition and increase household income to the populace, the need to improve the processing, distribution and overall quality of the product is simply indispensable. A total of 30 samples (5 samples from each of the 6 sampling points) of Tsire were collected randomly in Garko Town. Aerobic plate counts (APCs) and Total coliform counts (TCCS) of Tsire samples were determined using standard microbiological methods. APCs ranged from $1.02 \times 10^{5}$ to $4.00 \times 10^{5} \mathrm{CFU} / \mathrm{g}$; while TCCs ranged from $8 \mathrm{MPN} / \mathrm{g}$ to $68 \mathrm{MPN} / \mathrm{g}$. From the 30 samples screened, 16(53.33\%) bacteria namely, Campylobacter 2(6.66\%), Escherichia coli 6(20\%), Klebsiella pneumoniae 2(6.66\%), Salmonella spp. 1(3.33\%), Shigella 3(10\%) and Staphylococcus aureus 2(6.66\%) were detected. $E$. coli has the highest isolation rate of 6(20\%), while Salmonella spp. had the least frequency of 1(3.33\%). The distribution of isolated organisms within the study area were as follows: Dausai, 4(80\%), Kofar kudu, 4(80\%), Makwalla, 2(40\%), Rinji, 3(60\%), Tosaro, 2(40\%), and Tsohuwar Kasuwa, 1(20\%). The results have indicated that the Tsire was contaminated with bacteria thus exposing the product to fast deterioration, spoilage and also a vehicle for food borne illness, suggesting for adequate hygienic practices at all the stages, prior to consumption, to ensure safety of the meat product.

Key words: APCs, TCCs, Contamination, Microorganisms, Garko

\section{INTRODUCTION}

Nigeria is one of the developing nations with inadequate food supply and most often deficient in protein content (FAO, 2019). Nigerian's average animal protein intake per head per day is estimated at $7.9 \mathrm{~g}$ as against $35 \mathrm{~g}$ recommended value by Food and Agricultural Organization (Mubarak et al., 2016). These low levels of animal protein intake create great concern as it affects the nutritional status of Nigerians. Hence, there is the need for sufficient supply of animal protein from energy rich animal products to satisfy the nutritional requirements for Nigerians.

Meat is one major source of animal protein largely composed of water, protein and fats which can make it susceptible to microbial contamination within short time leading to spoilage (Apata et al., 2013; Mgbemere et al., 2011). Meat is mostly eaten after it has been cooked or processed in a variety of ways such as sun drying; smoking and roasting with or without fortifications (Borch et al., 1996). In Nigeria meat products such as Tsire, Kilishi and Balangu are locally produced using one or more of these methods in order to meet the nutritional requirements of the teeming Nigerians (Egbebi, 2011).

Tsire is a popular Nigerian traditional processed ready-to-eat roasted stick meat product (Shamsuddeen, 2015). It is sold in public places, along roads, in hotels, parks, quarters and even offices (Falegan et al., 2017). It is prepared from boneless healthy animal flesh such as beef and mutton, spiced with peanut cake, salt, vegetable oil and other flavorings followed by roasting (Shamsuddeen, 2015). Consumption of these products has extended to other parts of African countries such as Ghana, Somali, Cameroun and Chad (Ahmadu and Ibrahim, 2013). 
BAJOPAS Volume 13 Number 1, June, 2020

However, evidence of quality control sticking to procedural hygiene by the handlers during preparation and retailing of these products is poorly documented. Tsire is of great safety risk because of the fact that there are erratic cases of gastroenteritis and symptoms of food infection after consumption (WHO, 2015). Food borne illnesses are one of the major health problems in developing and developed countries (Razavilar, 2010). According to the World Health Organization, WHO (2015), $0.07 \%$ death of the 600 million global burdens of Foodborne illnesses have been reported to be caused by bacteria, viruses, fungi and chemicals. In America $0.27 \%$ of the estimated 48 million affected people is hospitalized and about $0.0063 \%$ deaths are recorded each year (Scallan et al., 2011). More than 91 million people in Africa fall ill and $0.15 \%$ dies each year, making Africa the highest burden bearer of Foodborne diseases per population (WHO, 2015).

Application of a Hazard Analysis Critical Control Point (HACCP) at all stages of meat products preparation is essential in order to ensure its safety. Thus, according to the guidelines of good manufacturing practice, the level of total aerobic bacterial contamination of thermally processed meat products should not exceed $10^{4}\left(\mathrm{cfu} \mathrm{g}^{-1}\right)$. Enterobacteriaceae and faecal coliform contamination in meat products should be within the range of $10^{2}-10^{4}$ and $10-10^{3} \mathrm{cfu} \mathrm{g}^{-1}$, respectively (Shamsuddeen, 2015). The aim of the study is therefore, to assess the total viable bacterial counts of tsire marketed locally within Garko town, and to isolate and identify the organisms at the point of consumption with the intention of promoting public health and food hygiene habits in the Nigerian populace.

\section{MATERIALS AND METHODS Study Area and Population}

Garko is one of the existing 44 local government areas located in Kano south west zone of Kano state with its capital administrative headquarters in the Garko town. It has coordinates $11^{\circ} 39^{\prime} \mathrm{N}$ $8^{\circ} 54^{\prime} \mathrm{E}$, and an area of $450 \mathrm{~km}^{2}$. The projected population of Garko local Government was 225,300 according to the National Population Census report (2018). Garko is known for agricultural activities both farming and animal husbandry. It is popularly known for large scale rice production. Other food crops include sweet potatoes, cassava, onions, sorghum, millet and sugarcane. Cows, sheep and goats are major groups of animals reared by majority of the populace. Meat products processed, retailed and consumed in Garko include roasted meat (Balangu), dried roasted meat (Kilishi), stick meat (Tsire), hide and skin pepper soup (Ragadada) and minced fried meat (Danbunnama).

\section{Samples Collection}

Five samples of Tsire products were collected from 6 different identified locations within Garko town in a sterile foil paper and immediately analyzed for the presence of bacteria.

\section{Sample Preparation}

Sample preparation for the bacteriological analysis was carried out in accordance with the method described by Atlas (1997). Twenty five grams $(25 \mathrm{~g})$ of the sample was homogenized in $225 \mathrm{ml}$ peptone water using Kenwood blender machine to obtain a $10^{1}$ homogenate. The homogenate was thoroughly shaken and $1 \mathrm{ml}$ pipetted into test tubes containing $9 \mathrm{ml}$ of peptone water $\left(10^{2}\right)$. The test tubes were further serially diluted to $10^{5}$.

Total Aerobic Mesophilic Bacterial Count

Total Aerobic mesophilic bacterial count was determined using the method described by Abdullahi et al. (2004) where $1 \mathrm{ml}$ of inoculums from $10^{1}$ to $10^{5}$ dilutions were transferred into duplicate Petri dishes and labeled accordingly. This was followed by pouring aseptically about $15 \mathrm{ml}$ of molten nutrient agar. The culture was homogenized by gentle spinning of the plates and allowed to solidify. The plates were incubated at $37^{\circ} \mathrm{C}$ for 24 hours. Plates containing 30-300 colonies were counted. The number of colony forming units per gram of a sample (cfu/g) was obtained by multiplying the average colony number with the inverse of the dilution factor.

\section{Enumeration and Detection of Coliform bacteria}

Detection and enumeration of coliform was carried out according to method described by Atlas, (1977). A set of 9 test tubes each containing $9 \mathrm{ml}$ of lactose broth and an inverted Durham tubes were autoclaved to expel air and to sterilize. Similarly, $1 \mathrm{ml}$ from the diluents $10^{1}$ was transferred to the first 3 test tubes, followed by $1 \mathrm{ml}$ from the diluents $10^{2}$ to the second set of 3 test tubes and finally the third diluents $10^{3}$ to the $3^{\text {rd }}$ set of 3 test tubes. All the 9 test tubes were incubated at $37^{\circ} \mathrm{C}$ for 24 hours. Tubes that showed gas and acid production after 24 hours were recorded as positive for the presence of Coliform. Negative tubes were further reincubated for 24 hours. Positive tubes were recorded. Estimate of most probable number of Coliform per gram of sample (MPN/g) was determined by comparing the number of gas positive tubes with the most probable number table. 
BAJOPAS Volume 13 Number 1, June, 2020 Identification of Coliform

A loop full of inoculum from gas positive tubes was streaked on to Eosine methylene blue (EMB) agar plate and incubated at $37^{\circ} \mathrm{C}$ for $24 \mathrm{hrs}$. Colonies which formed bluish black color with green metallic sheen, and reddish colonies were isolated on agar slants. Those colonies showing metallic sheen on EMB were sub cultured into tubes of lactose broth and incubated at $45^{\circ} \mathrm{C}$. The tubes were observed after $24 \mathrm{hrs}$ for gas production. This is the completed test for fecal coliform. Gram stain and other biochemical tests such as Indole, Methyl red, Voges-Proskauer and Citrate Utilization tests (IMVIC), Coagulase and Catalase tests were carried out for the Identification and confirmation of isolates.

\section{Procedure for Indole Test}

Indole test was carried out by preparing a Tryptone broth drawn in to test tubes, sterilized by autoclaving, inoculated with loopful of suspension and incubated at $37^{\circ} \mathrm{C}$ for 24 hours. Three drops of xylene was added in tubes, shaken vigorously and kept for the separation of two layers. One millilitre of Kovac's reagent was added and the formation of pink colour ring indicates positive Indole test.

\section{Procedure for Methyl Red Test}

Methyl red test was carried out by preparing Glucose phosphate broth, dispensed in test tubes, sterilized, inoculated with test culture and incubated at $37^{\circ} \mathrm{C}$ for 24 hours. Five drops of methyl-red indicator was added to the medium for the formation of red colour.

\section{Procedure for Voges-Proskauer Test}

Voges-Proskauer test was carried out by inoculating tubes with the bacterial culture followed by incubation for 48 hours at $37^{\circ} \mathrm{C}$. Separate pipettes were used to pipette $1 \mathrm{ml}$ from each culture tube into clean separate tubes. Eighteen drops $(0.5 \mathrm{ml})$ of Barrit's solution A (a-naphthol) was added to each tube containing glucose phosphate broth followed by the addition of an equal amount of solution $B$ into the same tube. The tubes were shaken at 30 seconds interval. A positive reaction was indicated by the development of a pink color, which turns red in 1-2 hours, after vigorous shaking.

\section{Procedure for Citrate Utilization Test}

Citrate Utilization Test was carried out by distributing melted agar (Simmon Citrate Agar) in to test tubes followed by sterilization at $121.5^{\circ} \mathrm{C}$ for 15 minutes. The test tubes were afterward held in slanted position, inoculated with the given bacterial culture and incubated at $37^{\circ} \mathrm{C}$ for $24 \mathrm{hrs}$. Positive test was indicated by color change of the media from green to blue.

\section{RESULTS AND DISCUSSIONS}

The results of this study are presented in tables $1,2,3$ and 4. Among the sampling areas Kofar Kudu had the highest aerobic mesophilic bacteria counts $4.0 \times 10^{5} \mathrm{cfu} / \mathrm{g}$ followed by Rinji $2.72 \times 10^{5} \mathrm{cfu} / \mathrm{g}$, while Tosaro had the least Aerobic mesophilic bacteria counts of $1.02 \times 10^{5}$ $\mathrm{cfu} / \mathrm{g}$ as indicated in Table 1.Makwalla had the highest coliform count $68 \mathrm{MPN} / \mathrm{g}$ followed by Rinji $37 \mathrm{MPN} / \mathrm{g}$. Tsohuwar Kasuwa had the least coliform counts $8 \mathrm{MPN} / \mathrm{g}$, (Table 2). Result from table 1 shows variation in the microbial contents among the samples which suggest variation in their sources, poor handling procedures and contamination from the processing environment. High coliform count and their differences within sampling areas is an indication of poor microbiological quality of the product. Ndahi et al. (2013) reported microbial load to be a function of the handling personnel and the environment. The results indicated that the samples were contaminated with bacteria as the counts exceeded the minimum safety level $\left(10^{4} \mathrm{cfu} / \mathrm{g}\right)$ for members of the Enterobacteriaceae family. However, it might be a reflection of poor hygienic practices which may contribute to health hazard to the potential consumers. Similarly, Inusa and Sa'id (2017); Osimani et al. (2015) reported that, the initial microbial content of the raw material play significant role in influencing the final microbial load of the finished product. Isolation of members of the Enterobacteriaceae such as $E$. coli, Klebsiella pneumoniae, Salmonella and Shigella signifies danger to the public health. These organisms are capable of producing endotoxins which trigger high fevers in infected individuals, and the enterotoxins which colonize the small intestines and lead to extreme dehydration as a result of vomiting and diarrhea sometimes with severe and fatal outcomes (Amaeze et al., 2016). From the 16 isolated organisms $E$. coli had the highest isolation rate $6(37.5 \%)$ (Table 3), this suggest faecal contamination of the products. $E$. coli is a common flora in the gastrointestinal tract responsible for diarrhea and extra-intestinal infections (CDC, 2011). The result is in conformity with the findings of Ndahi et al. (2013) and Shamsuddeen (2009). Also presence of campylobacter might be due to cross contamination from raw meat to finished product (Tsire). Staphylococcus aureus is a normal flora of the skin, nasal, genital, mouth or anal area in both humans and animals without any symptom of an infection (Matthew et al., 2013). Isolation of $S$. aureus in these study concords with the findings of Lucretia et al. (2018) from Suya sold in Rivers State. 
BAJOPAS Volume 13 Number 1, June, 2020

It is also in agreement with the findings of Yousafzai et al. (2018); Onuorah et al. (2015) and Tijjani and Jumare (2014) from tsire samples in different countries. Presence of $S$. aureus in foods is most of the time an indication of poor human handling, poor environment, unhygienic utensils and equipments used during processing (Igene et al., 2016; Okonko et al., 2013). Infections caused by $S$. aureus are difficult to treat leading to long hospitalization with consequent economic loss (Udobi et al., 2013). These include soft tissue infections, pneumonia, hospital-acquired postoperative wound infections, Staphylococcal food poisoning, impetigo and cellulitis (Charlene et al., 2013). Samples obtained from Dausai and Kofar Kudu had the highest isolation rate $4(80 \%)$ (Table 4 ) probably because of the much commercial activities taking place in the area which can lead to environmental contamination.

Table 1: Total Aerobic Mesophilic Bacterial Count of Tsire sold in Garko Town

\begin{tabular}{lll}
\hline Sampling Area & APC cfu/g & Mean \pm STD \\
\hline Dausai & $2.20 \times 10^{5}$ & $110000 \pm 14142.14$ \\
Kofar Kudu & $4.00 \times 10^{5}$ & $133333.3 \pm 23094.01$ \\
Makwalla & $1.30 \times 10^{5}$ & $32500 \pm 7187.953$ \\
Rinji & $2.72 \times 10^{5}$ & $90666.67 \pm 94769.90$ \\
Tosaro & $1.02 \times 10^{5}$ & $51000 \pm 15556.35$ \\
Tsohuwar Kasuwa & $1.75 \times 10^{5}$ & $35000 \pm 11357.82$ \\
\hline
\end{tabular}

Key: APC: Aerobic Mesophilic Counts

STD: Standard Deviation

Table 2: Total Coliform Count of Tsire sold in Garko Town

\begin{tabular}{lcc}
\hline \multicolumn{1}{c}{ Sampling Area } & TCC MPN/g & Mean \pm STD \\
\hline Dausai & 20 & $6.67 \pm 2.5166$ \\
Kofar Kudu & 32 & $16.00 \pm 5.6569$ \\
Makwalla & 68 & $13.60 \pm 8.7062$ \\
Rinji & 37 & $9.25 \pm 4.7871$ \\
Tosaro & 10 & $5.00 \pm 2.8284$ \\
Tsohuwar Kasuwa & 8 & $4.00 \pm 0.0000$ \\
\hline
\end{tabular}

Table 3: Organisms Isolated from Tsire Sold in Garko

\begin{tabular}{lcl}
\hline Isolated Organism & Frequency & Percentage (\%) \\
\hline Campylobacter & 2 & 06.66 \\
Escherichia coli & 6 & 20.00 \\
Klebsiella pneumoniae & 2 & 06.66 \\
Salmonella species & 1 & 03.33 \\
Shigella & 3 & 10.00 \\
Staphylococcus aureus & 2 & 06.66 \\
Total & 16 & \\
\hline
\end{tabular}

Table 4: Distribution of Organisms within Sampling Area

\begin{tabular}{lcc}
\hline \multicolumn{1}{c}{ Sampling Area } & No. Isolated & Percentage (\%) \\
\hline Dausai & 4 & 80 \\
Kofar Kudu & 4 & 80 \\
Makwalla & 2 & 40 \\
Rinji & 3 & 60 \\
Tosaro & 2 & 40 \\
Tsohuwar Kasuwa & 1 & 20 \\
Total & 16 & \\
\hline
\end{tabular}

\section{CONCLUSION}

Results indicated $4.00 \times 10^{5} \mathrm{CFU} / \mathrm{g}$ as the highest APCs count; while $68 \mathrm{MPN} / \mathrm{g}$ was the highest TCCs from the 30 samples analyzed. Among the isolates, $E$. coli has the highest isolation rate of $6(20 \%)$. Dausai and Kofar kudu were having the highest bacteria count of $4(80 \%)$, each, indicating higher contamination in those locations. 
BAJOPAS Volume 13 Number 1, June, 2020 RECOMMENDATIONS

The following recommendations are tenable:

1. Hygienic practices at all stages of production should be improved to safe guard the consumers against potential health hazard.

2. Monitoring of microbiological contamination of Tsire during preparations, packaging and marketing is essential to ensure product of good microbiological quality for consumers' health.

\section{REFERENCES}

Abdullahi, I. O., Umoh, V. J. and Galadima, M. (2004). Hazards Associated with Kilishi Preparations in Zaria. Nigerian Journal of Microbiology, 18 (1-2): $339-345$.

Ahmadu, J. and Ibrahim E. J., (2013): Determinants of Revenue in Suya Production in BeninCity, Edo State, Nigeria. Nigerian journal of agriculture, food and environment.9(3):1-5

Amaeze, N. Aboh, M. Itohan, A. Felix, E. Olatunji, T. and Oladosu, P. (2016) Microbial Profile, Antibiotic Sensitivity and Heat Resistance of Bacterial Isolates from Commercial Roasted Beef (Suya) in Abuja, Nigeria. JOPAT, 15(2): $22-30$.

Apata, E.S., Kuku1, I.A., Apata, O.C. and Adeyemi, K.O. (2013). Evaluation of Suya(Tsire) - An Intermediate Moisture Meat Product in Ogun State, Nigeria. J. Food Res 2 (1): 87.

Atlas, R. M. (1997) Principles of Microbiology Second Edition. C. Brown Publishers. Pp 802-803.

Borch, E. Kant-Muermans, M. L., Blixt, Y. (1996) Bacterial Spoilage of Meat and Cured Meat Products. Int $\mathrm{J}$ Food Microbiol .33(1): 103-20.

Centre for Disease Control, CDC (2011). "Escherichia coli 0157:H7" Division of Bacterial and Mycotic Diseasesht://www.cdc.gov/nczved/divisi ons/dfbmd/diseases/ecoli_0157h7/.

Charlene, R. J., Johnnie, A. D., and John, B. B., (2013) Prevalence and Characterization of Methicillin-Resistant Staphylococcus aureus Isolates from Retail Meat and Humans in Georgia. American society for Microbiology. J. of clinical microbiology. 12(1):123-6 doi:10.1128/JCM.0316612JCM.03166-12

Egbebi, A.O and Seidu, K., T. (2011). Microbiological Evaluation of Suya (dried smoked

meat) Sold in Ado and Akure, South West Nigeria.European Journal of Experinmental Biology, 1(4):1-5
3. Government should establish regulatory bodies responsible for inculcating hygiene habits to the local producers and vendors in order to prevent instant, cross and post processing contaminations by microbial pathogens.

4. Awareness and sensitization of local food producers about good hygienic practices in food handling and processing.

Falegan, C, R., Akoja, S. D., and Oyarekua, M. A., (2017) Microbiological Assessment of Suya (Sliced Roasted Beef) in Ado-Ekiti Metropolis, Ekiti State, Nigeria. MOJ Biology andMedicine.

Fonkem, D., N. Tanya, V., N. and Ebangi, A., L. (2010). Effect of Season on the Microbiological Quality of Kilishi, a Traditional Cameroonian Dried Beef Product. Tropicultura, 28(1): 10-15.

Food and Agricultural Organization of the United Nations (F A O, 1979). Manual of food quality control 4. Microbiological analysis.

Food and Agriculture Organisation of the United Nation (FAO), 2019. Nigeria at a glance.

Igene J.O., Uwadia, O.E., Ebabhamiegbebho, P.A. and Evivie, S.E., (2016) Shelf life Stability Studies of University of Benin (UNIBEN) Proff's Kilishi Product Asian Journal of Science and Technology 7(1): 2268-2274.

Inusa, S. K. and Said, I. S. (2017) Evaluation of the Chemical and Microbiological Properties Of Kilishi Sold in Kano Metropolis. Journal of Dry land Agriculture, 3 (1): $59-69$.

Lucretia, I. B, Patience, C. Obinna-Echem, Sophia, C. A. (2018) Microbiological quality andantibiotic sensitivity of potential pathogens isolated from meat product (Suya) sold in Rivers State University and its environs. International Journal of Biotechnology and Food Science, 6(4): 67-76.

Matthew, E., Drosos, E., John, L. and Ioanna, P. (2013) MRSA in Africa: Filling the Global Map of Antimicrobial Resistance PLOS One. 8(7): e68024 doi: 10.1371/journal.pone.0068024

Mgbemere, V.N., Akpapunam, M. A. and Igene, J. O., (2011). Effect of Groundnut FlourSubstitution on Yield, Quality and Storage Stability of Kilishi - a Nigerian Indigenous Dried Meat Product. African Journal of Food, Agriculture, Nutrition and Development, $\quad \mathbf{1 1}(2)$ : 4718-4738. 
BAJOPAS Volume 13 Number 1, June, 2020

Mubarak, A. A., Azeez, M. L., Amos A. O., Opeyemi, O. O. (2016) Assessment of Animal Protein Consumption and Food Security Among Rural Households in Kwara State, Nigeria American Journal of Business and Society, 1(4): 233245.

Ndahi, M., D. Kwaga, J., K. P. Bello, M. Kabir J., V. Umoh, .J. Yakubu, S., E. and Nok, A., J. (2013) Prevalence and Antimicrobial Susceptibility of Listeria Monocytogenes and Methicillin-Resistant Staphylococcus aureus Strains from Raw Meat and Meat Products in Zaria, Nigeria. Applied Journal of Microbiology, 58(3):262-9.

Okonko, I.O., Odu, N.N. and Igboh, I.E. (2013). Microbiological Analysis of Kilishi Sold In Port Harcourt, Nigeria. New York Science Journal, 6 (7):37-43.

Osimani, A., Aquilanti, L. and Clementi, F. (2015) Microbiological Quality of Meatbased Meals and Operation of Control Systems within a Food Service Environment. International Food Research Journal 22(4): 1692-1698.

Onuorah, S. Obika, I. Odibo, F. Orji, M. (2015)An Assessment of the Bacteriological Quality of Tsire-Suya (Grilled Beef) sold in Awka, Nigeria. American. J. Life. Sci. Res. 3(4):287292.

Razavilar, V, Khandaghi, J. Barzgari, A. (2010); Isolation of Eschericia coli 0157:H7 from manure fertilized farms and raw vegetables grown on it, in Tabriz city in
Iran. African Journal of Microbiology Research, 4(9): 891-895.

Scallan, E. Hoekstra, R. M. Angulo, F. J.Tauxe, R. V, Widdowson, M. Roy, S. L et al., (2011).Food borne illness acquired in the United States- Major Pathogens. Emerg. Infec Dis, 17(1): 7-15.

Shamsuddeen U (2009). Microbiological quality of spice used in the production of Kilishi a traditionally dried and grilled meat product. Bayero Journal of Pure andApplied Sciences, 2(2): 66-69.

Shamsuddeen, U. (2015) Microbiological Hazard and Critical control point Analysis of Dried and Minced Meat Snacks Produced in Kano Nigeria. Lambert Academic Publishing; Pp 1-36.

Tijani, O.and Jumare, S. (2014). Microblological Quality Assessment of Meat

Sold in KauraNamoda. International Conference on Earth, Environment and Life sciences (EELS) Dubai (UAE).

Udobi, C. E., Obajuluwa, A. F., and Onaolapo, J. A., (2013) Prevalence and Antibiotic Resistance Pattern of MethicillinResistant Staphylococcus aureus from an Orthopaedic Hospital in Nigeria BioMed Research International; 26(6); 6-7.

WHO, 2015 Foodborne diseases in the WHO African Region.

Yousafzai HA, Rind R, Khan MA, Abro SH, Korejo NA, Ejaz M, Kabir A, Shahid M, Memon S. (2019). Microbiological Contamination of Cattle and Meat in Peshawar, Pakistan. J. Anim. Health Prod. 7(1): 1116. 


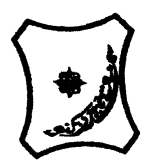

Bayero Journal of Pure and Applied Sciences, 13(1); 40 - 45

Received: September, 2019

Accepted: April, 2020

ISSN $2006-6996$

\title{
BACTERIOLOGICAL QUALITY OF STICK MEAT (Tsire) SOLD IN GARKO LOCAL GOVERNMENT AREA OF KANO STATE, NIGERIA
}

\author{
$*^{1}$ Dahiru A. T. and ${ }^{2}$ Maigari A. K. \\ ${ }^{1}$ Department of Hospitality Management, School of Technology, Kano State Polytechnic, PMB 3348, \\ Kano Nigeria. \\ ${ }^{2}$ Departmnt of Biological Sciences, Bayero University, Kano \\ Corresponding Author: dturajo61@gmail.com; GSM: 08087508262.
}

ABSTRACT

Stick meat, locally called Tsire in Hausa Language, is a significant portion of the diet of a large active population of Northern Nigeria. However, because of the handling and processing methods by the manufacturers as well as the hawking system of stick meat, the meat product may be exposed to both pre- and post-processed product contamination, and thus may poses danger to public health. Therefore, considering the role of Tsire in improving nutrition and increase household income to the populace, the need to improve the processing, distribution and overall quality of the product is simply indispensable. A total of 30 samples (5 samples from each of the 6 sampling points) of Tsire were collected randomly in Garko Town. Aerobic plate counts (APCs) and Total coliform counts (TCCS) of Tsire samples were determined using standard microbiological methods. APCs ranged from $1.02 \times 10^{5}$ to $4.00 \times 10^{5} \mathrm{CFU} / \mathrm{g}$; while TCCs ranged from $8 \mathrm{MPN} / \mathrm{g}$ to $68 \mathrm{MPN} / \mathrm{g}$. From the 30 samples screened, 16(53.33\%) bacteria namely, Campylobacter 2(6.66\%), Escherichia coli 6(20\%), Klebsiella pneumoniae 2(6.66\%), Salmonella spp. 1(3.33\%), Shigella 3(10\%) and Staphylococcus aureus 2(6.66\%) were detected. $E$. coli has the highest isolation rate of 6(20\%), while Salmonella spp. had the least frequency of 1(3.33\%). The distribution of isolated organisms within the study area were as follows: Dausai, 4(80\%), Kofar kudu, 4(80\%), Makwalla, 2(40\%), Rinji, 3(60\%), Tosaro, 2(40\%), and Tsohuwar Kasuwa, 1(20\%). The results have indicated that the Tsire was contaminated with bacteria thus exposing the product to fast deterioration, spoilage and also a vehicle for food borne illness, suggesting for adequate hygienic practices at all the stages, prior to consumption, to ensure safety of the meat product.

Key words: APCs, TCCs, Contamination, Microorganisms, Garko

\section{INTRODUCTION}

Nigeria is one of the developing nations with inadequate food supply and most often deficient in protein content (FAO, 2019). Nigerian's average animal protein intake per head per day is estimated at $7.9 \mathrm{~g}$ as against $35 \mathrm{~g}$ recommended value by Food and Agricultural Organization (Mubarak et al., 2016). These low levels of animal protein intake create great concern as it affects the nutritional status of Nigerians. Hence, there is the need for sufficient supply of animal protein from energy rich animal products to satisfy the nutritional requirements for Nigerians.

Meat is one major source of animal protein largely composed of water, protein and fats which can make it susceptible to microbial contamination within short time leading to spoilage (Apata et al., 2013; Mgbemere et al., 2011). Meat is mostly eaten after it has been cooked or processed in a variety of ways such as sun drying; smoking and roasting with or without fortifications (Borch et al., 1996). In Nigeria meat products such as Tsire, Kilishi and Balangu are locally produced using one or more of these methods in order to meet the nutritional requirements of the teeming Nigerians (Egbebi, 2011).

Tsire is a popular Nigerian traditional processed ready-to-eat roasted stick meat product (Shamsuddeen, 2015). It is sold in public places, along roads, in hotels, parks, quarters and even offices (Falegan et al., 2017). It is prepared from boneless healthy animal flesh such as beef and mutton, spiced with peanut cake, salt, vegetable oil and other flavorings followed by roasting (Shamsuddeen, 2015). Consumption of these products has extended to other parts of African countries such as Ghana, Somali, Cameroun and Chad (Ahmadu and Ibrahim, 2013). 
BAJOPAS Volume 13 Number 1, June, 2020

However, evidence of quality control sticking to procedural hygiene by the handlers during preparation and retailing of these products is poorly documented. Tsire is of great safety risk because of the fact that there are erratic cases of gastroenteritis and symptoms of food infection after consumption (WHO, 2015). Food borne illnesses are one of the major health problems in developing and developed countries (Razavilar, 2010). According to the World Health Organization, WHO (2015), $0.07 \%$ death of the 600 million global burdens of Foodborne illnesses have been reported to be caused by bacteria, viruses, fungi and chemicals. In America $0.27 \%$ of the estimated 48 million affected people is hospitalized and about $0.0063 \%$ deaths are recorded each year (Scallan et al., 2011). More than 91 million people in Africa fall ill and $0.15 \%$ dies each year, making Africa the highest burden bearer of Foodborne diseases per population (WHO, 2015).

Application of a Hazard Analysis Critical Control Point (HACCP) at all stages of meat products preparation is essential in order to ensure its safety. Thus, according to the guidelines of good manufacturing practice, the level of total aerobic bacterial contamination of thermally processed meat products should not exceed $10^{4}\left(\mathrm{cfu} \mathrm{g}^{-1}\right)$. Enterobacteriaceae and faecal coliform contamination in meat products should be within the range of $10^{2}-10^{4}$ and $10-10^{3} \mathrm{cfu} \mathrm{g}^{-1}$, respectively (Shamsuddeen, 2015). The aim of the study is therefore, to assess the total viable bacterial counts of tsire marketed locally within Garko town, and to isolate and identify the organisms at the point of consumption with the intention of promoting public health and food hygiene habits in the Nigerian populace.

\section{MATERIALS AND METHODS Study Area and Population}

Garko is one of the existing 44 local government areas located in Kano south west zone of Kano state with its capital administrative headquarters in the Garko town. It has coordinates $11^{\circ} 39^{\prime} \mathrm{N}$ $8^{\circ} 54^{\prime} \mathrm{E}$, and an area of $450 \mathrm{~km}^{2}$. The projected population of Garko local Government was 225,300 according to the National Population Census report (2018). Garko is known for agricultural activities both farming and animal husbandry. It is popularly known for large scale rice production. Other food crops include sweet potatoes, cassava, onions, sorghum, millet and sugarcane. Cows, sheep and goats are major groups of animals reared by majority of the populace. Meat products processed, retailed and consumed in Garko include roasted meat (Balangu), dried roasted meat (Kilishi), stick meat (Tsire), hide and skin pepper soup (Ragadada) and minced fried meat (Danbunnama).

\section{Samples Collection}

Five samples of Tsire products were collected from 6 different identified locations within Garko town in a sterile foil paper and immediately analyzed for the presence of bacteria.

\section{Sample Preparation}

Sample preparation for the bacteriological analysis was carried out in accordance with the method described by Atlas (1997). Twenty five grams $(25 \mathrm{~g})$ of the sample was homogenized in $225 \mathrm{ml}$ peptone water using Kenwood blender machine to obtain a $10^{1}$ homogenate. The homogenate was thoroughly shaken and $1 \mathrm{ml}$ pipetted into test tubes containing $9 \mathrm{ml}$ of peptone water $\left(10^{2}\right)$. The test tubes were further serially diluted to $10^{5}$.

Total Aerobic Mesophilic Bacterial Count

Total Aerobic mesophilic bacterial count was determined using the method described by Abdullahi et al. (2004) where $1 \mathrm{ml}$ of inoculums from $10^{1}$ to $10^{5}$ dilutions were transferred into duplicate Petri dishes and labeled accordingly. This was followed by pouring aseptically about $15 \mathrm{ml}$ of molten nutrient agar. The culture was homogenized by gentle spinning of the plates and allowed to solidify. The plates were incubated at $37^{\circ} \mathrm{C}$ for 24 hours. Plates containing 30-300 colonies were counted. The number of colony forming units per gram of a sample (cfu/g) was obtained by multiplying the average colony number with the inverse of the dilution factor.

\section{Enumeration and Detection of Coliform bacteria}

Detection and enumeration of coliform was carried out according to method described by Atlas, (1977). A set of 9 test tubes each containing $9 \mathrm{ml}$ of lactose broth and an inverted Durham tubes were autoclaved to expel air and to sterilize. Similarly, $1 \mathrm{ml}$ from the diluents $10^{1}$ was transferred to the first 3 test tubes, followed by $1 \mathrm{ml}$ from the diluents $10^{2}$ to the second set of 3 test tubes and finally the third diluents $10^{3}$ to the $3^{\text {rd }}$ set of 3 test tubes. All the 9 test tubes were incubated at $37^{\circ} \mathrm{C}$ for 24 hours. Tubes that showed gas and acid production after 24 hours were recorded as positive for the presence of Coliform. Negative tubes were further reincubated for 24 hours. Positive tubes were recorded. Estimate of most probable number of Coliform per gram of sample (MPN/g) was determined by comparing the number of gas positive tubes with the most probable number table. 
BAJOPAS Volume 13 Number 1, June, 2020 Identification of Coliform

A loop full of inoculum from gas positive tubes was streaked on to Eosine methylene blue (EMB) agar plate and incubated at $37^{\circ} \mathrm{C}$ for $24 \mathrm{hrs}$. Colonies which formed bluish black color with green metallic sheen, and reddish colonies were isolated on agar slants. Those colonies showing metallic sheen on EMB were sub cultured into tubes of lactose broth and incubated at $45^{\circ} \mathrm{C}$. The tubes were observed after $24 \mathrm{hrs}$ for gas production. This is the completed test for fecal coliform. Gram stain and other biochemical tests such as Indole, Methyl red, Voges-Proskauer and Citrate Utilization tests (IMVIC), Coagulase and Catalase tests were carried out for the Identification and confirmation of isolates.

\section{Procedure for Indole Test}

Indole test was carried out by preparing a Tryptone broth drawn in to test tubes, sterilized by autoclaving, inoculated with loopful of suspension and incubated at $37^{\circ} \mathrm{C}$ for 24 hours. Three drops of xylene was added in tubes, shaken vigorously and kept for the separation of two layers. One millilitre of Kovac's reagent was added and the formation of pink colour ring indicates positive Indole test.

\section{Procedure for Methyl Red Test}

Methyl red test was carried out by preparing Glucose phosphate broth, dispensed in test tubes, sterilized, inoculated with test culture and incubated at $37^{\circ} \mathrm{C}$ for 24 hours. Five drops of methyl-red indicator was added to the medium for the formation of red colour.

\section{Procedure for Voges-Proskauer Test}

Voges-Proskauer test was carried out by inoculating tubes with the bacterial culture followed by incubation for 48 hours at $37^{\circ} \mathrm{C}$. Separate pipettes were used to pipette $1 \mathrm{ml}$ from each culture tube into clean separate tubes. Eighteen drops $(0.5 \mathrm{ml})$ of Barrit's solution A (a-naphthol) was added to each tube containing glucose phosphate broth followed by the addition of an equal amount of solution $B$ into the same tube. The tubes were shaken at 30 seconds interval. A positive reaction was indicated by the development of a pink color, which turns red in 1-2 hours, after vigorous shaking.

\section{Procedure for Citrate Utilization Test}

Citrate Utilization Test was carried out by distributing melted agar (Simmon Citrate Agar) in to test tubes followed by sterilization at $121.5^{\circ} \mathrm{C}$ for 15 minutes. The test tubes were afterward held in slanted position, inoculated with the given bacterial culture and incubated at $37^{\circ} \mathrm{C}$ for $24 \mathrm{hrs}$. Positive test was indicated by color change of the media from green to blue.

\section{RESULTS AND DISCUSSIONS}

The results of this study are presented in tables $1,2,3$ and 4. Among the sampling areas Kofar Kudu had the highest aerobic mesophilic bacteria counts $4.0 \times 10^{5} \mathrm{cfu} / \mathrm{g}$ followed by Rinji $2.72 \times 10^{5} \mathrm{cfu} / \mathrm{g}$, while Tosaro had the least Aerobic mesophilic bacteria counts of $1.02 \times 10^{5}$ $\mathrm{cfu} / \mathrm{g}$ as indicated in Table 1.Makwalla had the highest coliform count $68 \mathrm{MPN} / \mathrm{g}$ followed by Rinji $37 \mathrm{MPN} / \mathrm{g}$. Tsohuwar Kasuwa had the least coliform counts $8 \mathrm{MPN} / \mathrm{g}$, (Table 2). Result from table 1 shows variation in the microbial contents among the samples which suggest variation in their sources, poor handling procedures and contamination from the processing environment. High coliform count and their differences within sampling areas is an indication of poor microbiological quality of the product. Ndahi et al. (2013) reported microbial load to be a function of the handling personnel and the environment. The results indicated that the samples were contaminated with bacteria as the counts exceeded the minimum safety level $\left(10^{4} \mathrm{cfu} / \mathrm{g}\right)$ for members of the Enterobacteriaceae family. However, it might be a reflection of poor hygienic practices which may contribute to health hazard to the potential consumers. Similarly, Inusa and Sa'id (2017); Osimani et al. (2015) reported that, the initial microbial content of the raw material play significant role in influencing the final microbial load of the finished product. Isolation of members of the Enterobacteriaceae such as $E$. coli, Klebsiella pneumoniae, Salmonella and Shigella signifies danger to the public health. These organisms are capable of producing endotoxins which trigger high fevers in infected individuals, and the enterotoxins which colonize the small intestines and lead to extreme dehydration as a result of vomiting and diarrhea sometimes with severe and fatal outcomes (Amaeze et al., 2016). From the 16 isolated organisms $E$. coli had the highest isolation rate $6(37.5 \%)$ (Table 3), this suggest faecal contamination of the products. $E$. coli is a common flora in the gastrointestinal tract responsible for diarrhea and extra-intestinal infections (CDC, 2011). The result is in conformity with the findings of Ndahi et al. (2013) and Shamsuddeen (2009). Also presence of campylobacter might be due to cross contamination from raw meat to finished product (Tsire). Staphylococcus aureus is a normal flora of the skin, nasal, genital, mouth or anal area in both humans and animals without any symptom of an infection (Matthew et al., 2013). Isolation of $S$. aureus in these study concords with the findings of Lucretia et al. (2018) from Suya sold in Rivers State. 
BAJOPAS Volume 13 Number 1, June, 2020

It is also in agreement with the findings of Yousafzai et al. (2018); Onuorah et al. (2015) and Tijjani and Jumare (2014) from tsire samples in different countries. Presence of $S$. aureus in foods is most of the time an indication of poor human handling, poor environment, unhygienic utensils and equipments used during processing (Igene et al., 2016; Okonko et al., 2013). Infections caused by $S$. aureus are difficult to treat leading to long hospitalization with consequent economic loss (Udobi et al., 2013). These include soft tissue infections, pneumonia, hospital-acquired postoperative wound infections, Staphylococcal food poisoning, impetigo and cellulitis (Charlene et al., 2013). Samples obtained from Dausai and Kofar Kudu had the highest isolation rate $4(80 \%)$ (Table 4 ) probably because of the much commercial activities taking place in the area which can lead to environmental contamination.

Table 1: Total Aerobic Mesophilic Bacterial Count of Tsire sold in Garko Town

\begin{tabular}{lll}
\hline Sampling Area & APC cfu/g & Mean \pm STD \\
\hline Dausai & $2.20 \times 10^{5}$ & $110000 \pm 14142.14$ \\
Kofar Kudu & $4.00 \times 10^{5}$ & $133333.3 \pm 23094.01$ \\
Makwalla & $1.30 \times 10^{5}$ & $32500 \pm 7187.953$ \\
Rinji & $2.72 \times 10^{5}$ & $90666.67 \pm 94769.90$ \\
Tosaro & $1.02 \times 10^{5}$ & $51000 \pm 15556.35$ \\
Tsohuwar Kasuwa & $1.75 \times 10^{5}$ & $35000 \pm 11357.82$ \\
\hline
\end{tabular}

Key: APC: Aerobic Mesophilic Counts

STD: Standard Deviation

Table 2: Total Coliform Count of Tsire sold in Garko Town

\begin{tabular}{lcc}
\hline \multicolumn{1}{c}{ Sampling Area } & TCC MPN/g & Mean \pm STD \\
\hline Dausai & 20 & $6.67 \pm 2.5166$ \\
Kofar Kudu & 32 & $16.00 \pm 5.6569$ \\
Makwalla & 68 & $13.60 \pm 8.7062$ \\
Rinji & 37 & $9.25 \pm 4.7871$ \\
Tosaro & 10 & $5.00 \pm 2.8284$ \\
Tsohuwar Kasuwa & 8 & $4.00 \pm 0.0000$ \\
\hline
\end{tabular}

Table 3: Organisms Isolated from Tsire Sold in Garko

\begin{tabular}{lcl}
\hline Isolated Organism & Frequency & Percentage (\%) \\
\hline Campylobacter & 2 & 06.66 \\
Escherichia coli & 6 & 20.00 \\
Klebsiella pneumoniae & 2 & 06.66 \\
Salmonella species & 1 & 03.33 \\
Shigella & 3 & 10.00 \\
Staphylococcus aureus & 2 & 06.66 \\
Total & 16 & \\
\hline
\end{tabular}

Table 4: Distribution of Organisms within Sampling Area

\begin{tabular}{lcc}
\hline \multicolumn{1}{c}{ Sampling Area } & No. Isolated & Percentage (\%) \\
\hline Dausai & 4 & 80 \\
Kofar Kudu & 4 & 80 \\
Makwalla & 2 & 40 \\
Rinji & 3 & 60 \\
Tosaro & 2 & 40 \\
Tsohuwar Kasuwa & 1 & 20 \\
Total & 16 & \\
\hline
\end{tabular}

\section{CONCLUSION}

Results indicated $4.00 \times 10^{5} \mathrm{CFU} / \mathrm{g}$ as the highest APCs count; while $68 \mathrm{MPN} / \mathrm{g}$ was the highest TCCs from the 30 samples analyzed. Among the isolates, $E$. coli has the highest isolation rate of $6(20 \%)$. Dausai and Kofar kudu were having the highest bacteria count of $4(80 \%)$, each, indicating higher contamination in those locations. 
BAJOPAS Volume 13 Number 1, June, 2020 RECOMMENDATIONS

The following recommendations are tenable:

1. Hygienic practices at all stages of production should be improved to safe guard the consumers against potential health hazard.

2. Monitoring of microbiological contamination of Tsire during preparations, packaging and marketing is essential to ensure product of good microbiological quality for consumers' health.

\section{REFERENCES}

Abdullahi, I. O., Umoh, V. J. and Galadima, M. (2004). Hazards Associated with Kilishi Preparations in Zaria. Nigerian Journal of Microbiology, 18 (1-2): $339-345$.

Ahmadu, J. and Ibrahim E. J., (2013): Determinants of Revenue in Suya Production in BeninCity, Edo State, Nigeria. Nigerian journal of agriculture, food and environment.9(3):1-5

Amaeze, N. Aboh, M. Itohan, A. Felix, E. Olatunji, T. and Oladosu, P. (2016) Microbial Profile, Antibiotic Sensitivity and Heat Resistance of Bacterial Isolates from Commercial Roasted Beef (Suya) in Abuja, Nigeria. JOPAT, 15(2): $22-30$.

Apata, E.S., Kuku1, I.A., Apata, O.C. and Adeyemi, K.O. (2013). Evaluation of Suya(Tsire) - An Intermediate Moisture Meat Product in Ogun State, Nigeria. J. Food Res 2 (1): 87.

Atlas, R. M. (1997) Principles of Microbiology Second Edition. C. Brown Publishers. Pp 802-803.

Borch, E. Kant-Muermans, M. L., Blixt, Y. (1996) Bacterial Spoilage of Meat and Cured Meat Products. Int $\mathrm{J}$ Food Microbiol .33(1): 103-20.

Centre for Disease Control, CDC (2011). "Escherichia coli 0157:H7" Division of Bacterial and Mycotic Diseasesht://www.cdc.gov/nczved/divisi ons/dfbmd/diseases/ecoli_0157h7/.

Charlene, R. J., Johnnie, A. D., and John, B. B., (2013) Prevalence and Characterization of Methicillin-Resistant Staphylococcus aureus Isolates from Retail Meat and Humans in Georgia. American society for Microbiology. J. of clinical microbiology. 12(1):123-6 doi:10.1128/JCM.0316612JCM.03166-12

Egbebi, A.O and Seidu, K., T. (2011). Microbiological Evaluation of Suya (dried smoked

meat) Sold in Ado and Akure, South West Nigeria.European Journal of Experinmental Biology, 1(4):1-5
3. Government should establish regulatory bodies responsible for inculcating hygiene habits to the local producers and vendors in order to prevent instant, cross and post processing contaminations by microbial pathogens.

4. Awareness and sensitization of local food producers about good hygienic practices in food handling and processing.

Falegan, C, R., Akoja, S. D., and Oyarekua, M. A., (2017) Microbiological Assessment of Suya (Sliced Roasted Beef) in Ado-Ekiti Metropolis, Ekiti State, Nigeria. MOJ Biology andMedicine.

Fonkem, D., N. Tanya, V., N. and Ebangi, A., L. (2010). Effect of Season on the Microbiological Quality of Kilishi, a Traditional Cameroonian Dried Beef Product. Tropicultura, 28(1): 10-15.

Food and Agricultural Organization of the United Nations (F A O, 1979). Manual of food quality control 4. Microbiological analysis.

Food and Agriculture Organisation of the United Nation (FAO), 2019. Nigeria at a glance.

Igene J.O., Uwadia, O.E., Ebabhamiegbebho, P.A. and Evivie, S.E., (2016) Shelf life Stability Studies of University of Benin (UNIBEN) Proff's Kilishi Product Asian Journal of Science and Technology 7(1): 2268-2274.

Inusa, S. K. and Said, I. S. (2017) Evaluation of the Chemical and Microbiological Properties Of Kilishi Sold in Kano Metropolis. Journal of Dry land Agriculture, 3 (1): $59-69$.

Lucretia, I. B, Patience, C. Obinna-Echem, Sophia, C. A. (2018) Microbiological quality andantibiotic sensitivity of potential pathogens isolated from meat product (Suya) sold in Rivers State University and its environs. International Journal of Biotechnology and Food Science, 6(4): 67-76.

Matthew, E., Drosos, E., John, L. and Ioanna, P. (2013) MRSA in Africa: Filling the Global Map of Antimicrobial Resistance PLOS One. 8(7): e68024 doi: 10.1371/journal.pone.0068024

Mgbemere, V.N., Akpapunam, M. A. and Igene, J. O., (2011). Effect of Groundnut FlourSubstitution on Yield, Quality and Storage Stability of Kilishi - a Nigerian Indigenous Dried Meat Product. African Journal of Food, Agriculture, Nutrition and Development, $\quad \mathbf{1 1}(2)$ : 4718-4738. 
BAJOPAS Volume 13 Number 1, June, 2020

Mubarak, A. A., Azeez, M. L., Amos A. O., Opeyemi, O. O. (2016) Assessment of Animal Protein Consumption and Food Security Among Rural Households in Kwara State, Nigeria American Journal of Business and Society, 1(4): 233245.

Ndahi, M., D. Kwaga, J., K. P. Bello, M. Kabir J., V. Umoh, .J. Yakubu, S., E. and Nok, A., J. (2013) Prevalence and Antimicrobial Susceptibility of Listeria Monocytogenes and Methicillin-Resistant Staphylococcus aureus Strains from Raw Meat and Meat Products in Zaria, Nigeria. Applied Journal of Microbiology, 58(3):262-9.

Okonko, I.O., Odu, N.N. and Igboh, I.E. (2013). Microbiological Analysis of Kilishi Sold In Port Harcourt, Nigeria. New York Science Journal, 6 (7):37-43.

Osimani, A., Aquilanti, L. and Clementi, F. (2015) Microbiological Quality of Meatbased Meals and Operation of Control Systems within a Food Service Environment. International Food Research Journal 22(4): 1692-1698.

Onuorah, S. Obika, I. Odibo, F. Orji, M. (2015)An Assessment of the Bacteriological Quality of Tsire-Suya (Grilled Beef) sold in Awka, Nigeria. American. J. Life. Sci. Res. 3(4):287292.

Razavilar, V, Khandaghi, J. Barzgari, A. (2010); Isolation of Eschericia coli 0157:H7 from manure fertilized farms and raw vegetables grown on it, in Tabriz city in
Iran. African Journal of Microbiology Research, 4(9): 891-895.

Scallan, E. Hoekstra, R. M. Angulo, F. J.Tauxe, R. V, Widdowson, M. Roy, S. L et al., (2011).Food borne illness acquired in the United States- Major Pathogens. Emerg. Infec Dis, 17(1): 7-15.

Shamsuddeen U (2009). Microbiological quality of spice used in the production of Kilishi a traditionally dried and grilled meat product. Bayero Journal of Pure andApplied Sciences, 2(2): 66-69.

Shamsuddeen, U. (2015) Microbiological Hazard and Critical control point Analysis of Dried and Minced Meat Snacks Produced in Kano Nigeria. Lambert Academic Publishing; Pp 1-36.

Tijani, O.and Jumare, S. (2014). Microblological Quality Assessment of Meat

Sold in KauraNamoda. International Conference on Earth, Environment and Life sciences (EELS) Dubai (UAE).

Udobi, C. E., Obajuluwa, A. F., and Onaolapo, J. A., (2013) Prevalence and Antibiotic Resistance Pattern of MethicillinResistant Staphylococcus aureus from an Orthopaedic Hospital in Nigeria BioMed Research International; 26(6); 6-7.

WHO, 2015 Foodborne diseases in the WHO African Region.

Yousafzai HA, Rind R, Khan MA, Abro SH, Korejo NA, Ejaz M, Kabir A, Shahid M, Memon S. (2019). Microbiological Contamination of Cattle and Meat in Peshawar, Pakistan. J. Anim. Health Prod. 7(1): 1116. 


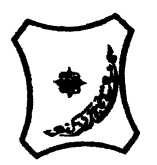

Bayero Journal of Pure and Applied Sciences, 13(1); 40 - 45

Received: September, 2019

Accepted: April, 2020

ISSN $2006-6996$

\title{
BACTERIOLOGICAL QUALITY OF STICK MEAT (Tsire) SOLD IN GARKO LOCAL GOVERNMENT AREA OF KANO STATE, NIGERIA
}

\author{
$*^{1}$ Dahiru A. T. and ${ }^{2}$ Maigari A. K. \\ ${ }^{1}$ Department of Hospitality Management, School of Technology, Kano State Polytechnic, PMB 3348, \\ Kano Nigeria. \\ ${ }^{2}$ Departmnt of Biological Sciences, Bayero University, Kano \\ Corresponding Author: dturajo61@gmail.com; GSM: 08087508262.
}

ABSTRACT

Stick meat, locally called Tsire in Hausa Language, is a significant portion of the diet of a large active population of Northern Nigeria. However, because of the handling and processing methods by the manufacturers as well as the hawking system of stick meat, the meat product may be exposed to both pre- and post-processed product contamination, and thus may poses danger to public health. Therefore, considering the role of Tsire in improving nutrition and increase household income to the populace, the need to improve the processing, distribution and overall quality of the product is simply indispensable. A total of 30 samples (5 samples from each of the 6 sampling points) of Tsire were collected randomly in Garko Town. Aerobic plate counts (APCs) and Total coliform counts (TCCS) of Tsire samples were determined using standard microbiological methods. APCs ranged from $1.02 \times 10^{5}$ to $4.00 \times 10^{5} \mathrm{CFU} / \mathrm{g}$; while TCCs ranged from $8 \mathrm{MPN} / \mathrm{g}$ to $68 \mathrm{MPN} / \mathrm{g}$. From the 30 samples screened, 16(53.33\%) bacteria namely, Campylobacter 2(6.66\%), Escherichia coli 6(20\%), Klebsiella pneumoniae 2(6.66\%), Salmonella spp. 1(3.33\%), Shigella 3(10\%) and Staphylococcus aureus 2(6.66\%) were detected. $E$. coli has the highest isolation rate of 6(20\%), while Salmonella spp. had the least frequency of 1(3.33\%). The distribution of isolated organisms within the study area were as follows: Dausai, 4(80\%), Kofar kudu, 4(80\%), Makwalla, 2(40\%), Rinji, 3(60\%), Tosaro, 2(40\%), and Tsohuwar Kasuwa, 1(20\%). The results have indicated that the Tsire was contaminated with bacteria thus exposing the product to fast deterioration, spoilage and also a vehicle for food borne illness, suggesting for adequate hygienic practices at all the stages, prior to consumption, to ensure safety of the meat product.

Key words: APCs, TCCs, Contamination, Microorganisms, Garko

\section{INTRODUCTION}

Nigeria is one of the developing nations with inadequate food supply and most often deficient in protein content (FAO, 2019). Nigerian's average animal protein intake per head per day is estimated at $7.9 \mathrm{~g}$ as against $35 \mathrm{~g}$ recommended value by Food and Agricultural Organization (Mubarak et al., 2016). These low levels of animal protein intake create great concern as it affects the nutritional status of Nigerians. Hence, there is the need for sufficient supply of animal protein from energy rich animal products to satisfy the nutritional requirements for Nigerians.

Meat is one major source of animal protein largely composed of water, protein and fats which can make it susceptible to microbial contamination within short time leading to spoilage (Apata et al., 2013; Mgbemere et al., 2011). Meat is mostly eaten after it has been cooked or processed in a variety of ways such as sun drying; smoking and roasting with or without fortifications (Borch et al., 1996). In Nigeria meat products such as Tsire, Kilishi and Balangu are locally produced using one or more of these methods in order to meet the nutritional requirements of the teeming Nigerians (Egbebi, 2011).

Tsire is a popular Nigerian traditional processed ready-to-eat roasted stick meat product (Shamsuddeen, 2015). It is sold in public places, along roads, in hotels, parks, quarters and even offices (Falegan et al., 2017). It is prepared from boneless healthy animal flesh such as beef and mutton, spiced with peanut cake, salt, vegetable oil and other flavorings followed by roasting (Shamsuddeen, 2015). Consumption of these products has extended to other parts of African countries such as Ghana, Somali, Cameroun and Chad (Ahmadu and Ibrahim, 2013). 
BAJOPAS Volume 13 Number 1, June, 2020

However, evidence of quality control sticking to procedural hygiene by the handlers during preparation and retailing of these products is poorly documented. Tsire is of great safety risk because of the fact that there are erratic cases of gastroenteritis and symptoms of food infection after consumption (WHO, 2015). Food borne illnesses are one of the major health problems in developing and developed countries (Razavilar, 2010). According to the World Health Organization, WHO (2015), $0.07 \%$ death of the 600 million global burdens of Foodborne illnesses have been reported to be caused by bacteria, viruses, fungi and chemicals. In America $0.27 \%$ of the estimated 48 million affected people is hospitalized and about $0.0063 \%$ deaths are recorded each year (Scallan et al., 2011). More than 91 million people in Africa fall ill and $0.15 \%$ dies each year, making Africa the highest burden bearer of Foodborne diseases per population (WHO, 2015).

Application of a Hazard Analysis Critical Control Point (HACCP) at all stages of meat products preparation is essential in order to ensure its safety. Thus, according to the guidelines of good manufacturing practice, the level of total aerobic bacterial contamination of thermally processed meat products should not exceed $10^{4}\left(\mathrm{cfu} \mathrm{g}^{-1}\right)$. Enterobacteriaceae and faecal coliform contamination in meat products should be within the range of $10^{2}-10^{4}$ and $10-10^{3} \mathrm{cfu} \mathrm{g}^{-1}$, respectively (Shamsuddeen, 2015). The aim of the study is therefore, to assess the total viable bacterial counts of tsire marketed locally within Garko town, and to isolate and identify the organisms at the point of consumption with the intention of promoting public health and food hygiene habits in the Nigerian populace.

\section{MATERIALS AND METHODS Study Area and Population}

Garko is one of the existing 44 local government areas located in Kano south west zone of Kano state with its capital administrative headquarters in the Garko town. It has coordinates $11^{\circ} 39^{\prime} \mathrm{N}$ $8^{\circ} 54^{\prime} \mathrm{E}$, and an area of $450 \mathrm{~km}^{2}$. The projected population of Garko local Government was 225,300 according to the National Population Census report (2018). Garko is known for agricultural activities both farming and animal husbandry. It is popularly known for large scale rice production. Other food crops include sweet potatoes, cassava, onions, sorghum, millet and sugarcane. Cows, sheep and goats are major groups of animals reared by majority of the populace. Meat products processed, retailed and consumed in Garko include roasted meat (Balangu), dried roasted meat (Kilishi), stick meat (Tsire), hide and skin pepper soup (Ragadada) and minced fried meat (Danbunnama).

\section{Samples Collection}

Five samples of Tsire products were collected from 6 different identified locations within Garko town in a sterile foil paper and immediately analyzed for the presence of bacteria.

\section{Sample Preparation}

Sample preparation for the bacteriological analysis was carried out in accordance with the method described by Atlas (1997). Twenty five grams $(25 \mathrm{~g})$ of the sample was homogenized in $225 \mathrm{ml}$ peptone water using Kenwood blender machine to obtain a $10^{1}$ homogenate. The homogenate was thoroughly shaken and $1 \mathrm{ml}$ pipetted into test tubes containing $9 \mathrm{ml}$ of peptone water $\left(10^{2}\right)$. The test tubes were further serially diluted to $10^{5}$.

Total Aerobic Mesophilic Bacterial Count

Total Aerobic mesophilic bacterial count was determined using the method described by Abdullahi et al. (2004) where $1 \mathrm{ml}$ of inoculums from $10^{1}$ to $10^{5}$ dilutions were transferred into duplicate Petri dishes and labeled accordingly. This was followed by pouring aseptically about $15 \mathrm{ml}$ of molten nutrient agar. The culture was homogenized by gentle spinning of the plates and allowed to solidify. The plates were incubated at $37^{\circ} \mathrm{C}$ for 24 hours. Plates containing 30-300 colonies were counted. The number of colony forming units per gram of a sample (cfu/g) was obtained by multiplying the average colony number with the inverse of the dilution factor.

\section{Enumeration and Detection of Coliform bacteria}

Detection and enumeration of coliform was carried out according to method described by Atlas, (1977). A set of 9 test tubes each containing $9 \mathrm{ml}$ of lactose broth and an inverted Durham tubes were autoclaved to expel air and to sterilize. Similarly, $1 \mathrm{ml}$ from the diluents $10^{1}$ was transferred to the first 3 test tubes, followed by $1 \mathrm{ml}$ from the diluents $10^{2}$ to the second set of 3 test tubes and finally the third diluents $10^{3}$ to the $3^{\text {rd }}$ set of 3 test tubes. All the 9 test tubes were incubated at $37^{\circ} \mathrm{C}$ for 24 hours. Tubes that showed gas and acid production after 24 hours were recorded as positive for the presence of Coliform. Negative tubes were further reincubated for 24 hours. Positive tubes were recorded. Estimate of most probable number of Coliform per gram of sample (MPN/g) was determined by comparing the number of gas positive tubes with the most probable number table. 
BAJOPAS Volume 13 Number 1, June, 2020 Identification of Coliform

A loop full of inoculum from gas positive tubes was streaked on to Eosine methylene blue (EMB) agar plate and incubated at $37^{\circ} \mathrm{C}$ for $24 \mathrm{hrs}$. Colonies which formed bluish black color with green metallic sheen, and reddish colonies were isolated on agar slants. Those colonies showing metallic sheen on EMB were sub cultured into tubes of lactose broth and incubated at $45^{\circ} \mathrm{C}$. The tubes were observed after $24 \mathrm{hrs}$ for gas production. This is the completed test for fecal coliform. Gram stain and other biochemical tests such as Indole, Methyl red, Voges-Proskauer and Citrate Utilization tests (IMVIC), Coagulase and Catalase tests were carried out for the Identification and confirmation of isolates.

\section{Procedure for Indole Test}

Indole test was carried out by preparing a Tryptone broth drawn in to test tubes, sterilized by autoclaving, inoculated with loopful of suspension and incubated at $37^{\circ} \mathrm{C}$ for 24 hours. Three drops of xylene was added in tubes, shaken vigorously and kept for the separation of two layers. One millilitre of Kovac's reagent was added and the formation of pink colour ring indicates positive Indole test.

\section{Procedure for Methyl Red Test}

Methyl red test was carried out by preparing Glucose phosphate broth, dispensed in test tubes, sterilized, inoculated with test culture and incubated at $37^{\circ} \mathrm{C}$ for 24 hours. Five drops of methyl-red indicator was added to the medium for the formation of red colour.

\section{Procedure for Voges-Proskauer Test}

Voges-Proskauer test was carried out by inoculating tubes with the bacterial culture followed by incubation for 48 hours at $37^{\circ} \mathrm{C}$. Separate pipettes were used to pipette $1 \mathrm{ml}$ from each culture tube into clean separate tubes. Eighteen drops $(0.5 \mathrm{ml})$ of Barrit's solution A (a-naphthol) was added to each tube containing glucose phosphate broth followed by the addition of an equal amount of solution $B$ into the same tube. The tubes were shaken at 30 seconds interval. A positive reaction was indicated by the development of a pink color, which turns red in 1-2 hours, after vigorous shaking.

\section{Procedure for Citrate Utilization Test}

Citrate Utilization Test was carried out by distributing melted agar (Simmon Citrate Agar) in to test tubes followed by sterilization at $121.5^{\circ} \mathrm{C}$ for 15 minutes. The test tubes were afterward held in slanted position, inoculated with the given bacterial culture and incubated at $37^{\circ} \mathrm{C}$ for $24 \mathrm{hrs}$. Positive test was indicated by color change of the media from green to blue.

\section{RESULTS AND DISCUSSIONS}

The results of this study are presented in tables $1,2,3$ and 4. Among the sampling areas Kofar Kudu had the highest aerobic mesophilic bacteria counts $4.0 \times 10^{5} \mathrm{cfu} / \mathrm{g}$ followed by Rinji $2.72 \times 10^{5} \mathrm{cfu} / \mathrm{g}$, while Tosaro had the least Aerobic mesophilic bacteria counts of $1.02 \times 10^{5}$ $\mathrm{cfu} / \mathrm{g}$ as indicated in Table 1.Makwalla had the highest coliform count $68 \mathrm{MPN} / \mathrm{g}$ followed by Rinji $37 \mathrm{MPN} / \mathrm{g}$. Tsohuwar Kasuwa had the least coliform counts $8 \mathrm{MPN} / \mathrm{g}$, (Table 2). Result from table 1 shows variation in the microbial contents among the samples which suggest variation in their sources, poor handling procedures and contamination from the processing environment. High coliform count and their differences within sampling areas is an indication of poor microbiological quality of the product. Ndahi et al. (2013) reported microbial load to be a function of the handling personnel and the environment. The results indicated that the samples were contaminated with bacteria as the counts exceeded the minimum safety level $\left(10^{4} \mathrm{cfu} / \mathrm{g}\right)$ for members of the Enterobacteriaceae family. However, it might be a reflection of poor hygienic practices which may contribute to health hazard to the potential consumers. Similarly, Inusa and Sa'id (2017); Osimani et al. (2015) reported that, the initial microbial content of the raw material play significant role in influencing the final microbial load of the finished product. Isolation of members of the Enterobacteriaceae such as $E$. coli, Klebsiella pneumoniae, Salmonella and Shigella signifies danger to the public health. These organisms are capable of producing endotoxins which trigger high fevers in infected individuals, and the enterotoxins which colonize the small intestines and lead to extreme dehydration as a result of vomiting and diarrhea sometimes with severe and fatal outcomes (Amaeze et al., 2016). From the 16 isolated organisms $E$. coli had the highest isolation rate $6(37.5 \%)$ (Table 3), this suggest faecal contamination of the products. $E$. coli is a common flora in the gastrointestinal tract responsible for diarrhea and extra-intestinal infections (CDC, 2011). The result is in conformity with the findings of Ndahi et al. (2013) and Shamsuddeen (2009). Also presence of campylobacter might be due to cross contamination from raw meat to finished product (Tsire). Staphylococcus aureus is a normal flora of the skin, nasal, genital, mouth or anal area in both humans and animals without any symptom of an infection (Matthew et al., 2013). Isolation of $S$. aureus in these study concords with the findings of Lucretia et al. (2018) from Suya sold in Rivers State. 
BAJOPAS Volume 13 Number 1, June, 2020

It is also in agreement with the findings of Yousafzai et al. (2018); Onuorah et al. (2015) and Tijjani and Jumare (2014) from tsire samples in different countries. Presence of $S$. aureus in foods is most of the time an indication of poor human handling, poor environment, unhygienic utensils and equipments used during processing (Igene et al., 2016; Okonko et al., 2013). Infections caused by $S$. aureus are difficult to treat leading to long hospitalization with consequent economic loss (Udobi et al., 2013). These include soft tissue infections, pneumonia, hospital-acquired postoperative wound infections, Staphylococcal food poisoning, impetigo and cellulitis (Charlene et al., 2013). Samples obtained from Dausai and Kofar Kudu had the highest isolation rate $4(80 \%)$ (Table 4 ) probably because of the much commercial activities taking place in the area which can lead to environmental contamination.

Table 1: Total Aerobic Mesophilic Bacterial Count of Tsire sold in Garko Town

\begin{tabular}{lll}
\hline Sampling Area & APC cfu/g & Mean \pm STD \\
\hline Dausai & $2.20 \times 10^{5}$ & $110000 \pm 14142.14$ \\
Kofar Kudu & $4.00 \times 10^{5}$ & $133333.3 \pm 23094.01$ \\
Makwalla & $1.30 \times 10^{5}$ & $32500 \pm 7187.953$ \\
Rinji & $2.72 \times 10^{5}$ & $90666.67 \pm 94769.90$ \\
Tosaro & $1.02 \times 10^{5}$ & $51000 \pm 15556.35$ \\
Tsohuwar Kasuwa & $1.75 \times 10^{5}$ & $35000 \pm 11357.82$ \\
\hline
\end{tabular}

Key: APC: Aerobic Mesophilic Counts

STD: Standard Deviation

Table 2: Total Coliform Count of Tsire sold in Garko Town

\begin{tabular}{lcc}
\hline \multicolumn{1}{c}{ Sampling Area } & TCC MPN/g & Mean \pm STD \\
\hline Dausai & 20 & $6.67 \pm 2.5166$ \\
Kofar Kudu & 32 & $16.00 \pm 5.6569$ \\
Makwalla & 68 & $13.60 \pm 8.7062$ \\
Rinji & 37 & $9.25 \pm 4.7871$ \\
Tosaro & 10 & $5.00 \pm 2.8284$ \\
Tsohuwar Kasuwa & 8 & $4.00 \pm 0.0000$ \\
\hline
\end{tabular}

Table 3: Organisms Isolated from Tsire Sold in Garko

\begin{tabular}{lcl}
\hline Isolated Organism & Frequency & Percentage (\%) \\
\hline Campylobacter & 2 & 06.66 \\
Escherichia coli & 6 & 20.00 \\
Klebsiella pneumoniae & 2 & 06.66 \\
Salmonella species & 1 & 03.33 \\
Shigella & 3 & 10.00 \\
Staphylococcus aureus & 2 & 06.66 \\
Total & 16 & \\
\hline
\end{tabular}

Table 4: Distribution of Organisms within Sampling Area

\begin{tabular}{lcc}
\hline \multicolumn{1}{c}{ Sampling Area } & No. Isolated & Percentage (\%) \\
\hline Dausai & 4 & 80 \\
Kofar Kudu & 4 & 80 \\
Makwalla & 2 & 40 \\
Rinji & 3 & 60 \\
Tosaro & 2 & 40 \\
Tsohuwar Kasuwa & 1 & 20 \\
Total & 16 & \\
\hline
\end{tabular}

\section{CONCLUSION}

Results indicated $4.00 \times 10^{5} \mathrm{CFU} / \mathrm{g}$ as the highest APCs count; while $68 \mathrm{MPN} / \mathrm{g}$ was the highest TCCs from the 30 samples analyzed. Among the isolates, $E$. coli has the highest isolation rate of $6(20 \%)$. Dausai and Kofar kudu were having the highest bacteria count of $4(80 \%)$, each, indicating higher contamination in those locations. 
BAJOPAS Volume 13 Number 1, June, 2020 RECOMMENDATIONS

The following recommendations are tenable:

1. Hygienic practices at all stages of production should be improved to safe guard the consumers against potential health hazard.

2. Monitoring of microbiological contamination of Tsire during preparations, packaging and marketing is essential to ensure product of good microbiological quality for consumers' health.

\section{REFERENCES}

Abdullahi, I. O., Umoh, V. J. and Galadima, M. (2004). Hazards Associated with Kilishi Preparations in Zaria. Nigerian Journal of Microbiology, 18 (1-2): $339-345$.

Ahmadu, J. and Ibrahim E. J., (2013): Determinants of Revenue in Suya Production in BeninCity, Edo State, Nigeria. Nigerian journal of agriculture, food and environment.9(3):1-5

Amaeze, N. Aboh, M. Itohan, A. Felix, E. Olatunji, T. and Oladosu, P. (2016) Microbial Profile, Antibiotic Sensitivity and Heat Resistance of Bacterial Isolates from Commercial Roasted Beef (Suya) in Abuja, Nigeria. JOPAT, 15(2): $22-30$.

Apata, E.S., Kuku1, I.A., Apata, O.C. and Adeyemi, K.O. (2013). Evaluation of Suya(Tsire) - An Intermediate Moisture Meat Product in Ogun State, Nigeria. J. Food Res 2 (1): 87.

Atlas, R. M. (1997) Principles of Microbiology Second Edition. C. Brown Publishers. Pp 802-803.

Borch, E. Kant-Muermans, M. L., Blixt, Y. (1996) Bacterial Spoilage of Meat and Cured Meat Products. Int $\mathrm{J}$ Food Microbiol .33(1): 103-20.

Centre for Disease Control, CDC (2011). "Escherichia coli 0157:H7" Division of Bacterial and Mycotic Diseasesht://www.cdc.gov/nczved/divisi ons/dfbmd/diseases/ecoli_0157h7/.

Charlene, R. J., Johnnie, A. D., and John, B. B., (2013) Prevalence and Characterization of Methicillin-Resistant Staphylococcus aureus Isolates from Retail Meat and Humans in Georgia. American society for Microbiology. J. of clinical microbiology. 12(1):123-6 doi:10.1128/JCM.0316612JCM.03166-12

Egbebi, A.O and Seidu, K., T. (2011). Microbiological Evaluation of Suya (dried smoked

meat) Sold in Ado and Akure, South West Nigeria.European Journal of Experinmental Biology, 1(4):1-5
3. Government should establish regulatory bodies responsible for inculcating hygiene habits to the local producers and vendors in order to prevent instant, cross and post processing contaminations by microbial pathogens.

4. Awareness and sensitization of local food producers about good hygienic practices in food handling and processing.

Falegan, C, R., Akoja, S. D., and Oyarekua, M. A., (2017) Microbiological Assessment of Suya (Sliced Roasted Beef) in Ado-Ekiti Metropolis, Ekiti State, Nigeria. MOJ Biology andMedicine.

Fonkem, D., N. Tanya, V., N. and Ebangi, A., L. (2010). Effect of Season on the Microbiological Quality of Kilishi, a Traditional Cameroonian Dried Beef Product. Tropicultura, 28(1): 10-15.

Food and Agricultural Organization of the United Nations (F A O, 1979). Manual of food quality control 4. Microbiological analysis.

Food and Agriculture Organisation of the United Nation (FAO), 2019. Nigeria at a glance.

Igene J.O., Uwadia, O.E., Ebabhamiegbebho, P.A. and Evivie, S.E., (2016) Shelf life Stability Studies of University of Benin (UNIBEN) Proff's Kilishi Product Asian Journal of Science and Technology 7(1): 2268-2274.

Inusa, S. K. and Said, I. S. (2017) Evaluation of the Chemical and Microbiological Properties Of Kilishi Sold in Kano Metropolis. Journal of Dry land Agriculture, 3 (1): $59-69$.

Lucretia, I. B, Patience, C. Obinna-Echem, Sophia, C. A. (2018) Microbiological quality andantibiotic sensitivity of potential pathogens isolated from meat product (Suya) sold in Rivers State University and its environs. International Journal of Biotechnology and Food Science, 6(4): 67-76.

Matthew, E., Drosos, E., John, L. and Ioanna, P. (2013) MRSA in Africa: Filling the Global Map of Antimicrobial Resistance PLOS One. 8(7): e68024 doi: 10.1371/journal.pone.0068024

Mgbemere, V.N., Akpapunam, M. A. and Igene, J. O., (2011). Effect of Groundnut FlourSubstitution on Yield, Quality and Storage Stability of Kilishi - a Nigerian Indigenous Dried Meat Product. African Journal of Food, Agriculture, Nutrition and Development, $\quad \mathbf{1 1}(2)$ : 4718-4738. 
BAJOPAS Volume 13 Number 1, June, 2020

Mubarak, A. A., Azeez, M. L., Amos A. O., Opeyemi, O. O. (2016) Assessment of Animal Protein Consumption and Food Security Among Rural Households in Kwara State, Nigeria American Journal of Business and Society, 1(4): 233245.

Ndahi, M., D. Kwaga, J., K. P. Bello, M. Kabir J., V. Umoh, .J. Yakubu, S., E. and Nok, A., J. (2013) Prevalence and Antimicrobial Susceptibility of Listeria Monocytogenes and Methicillin-Resistant Staphylococcus aureus Strains from Raw Meat and Meat Products in Zaria, Nigeria. Applied Journal of Microbiology, 58(3):262-9.

Okonko, I.O., Odu, N.N. and Igboh, I.E. (2013). Microbiological Analysis of Kilishi Sold In Port Harcourt, Nigeria. New York Science Journal, 6 (7):37-43.

Osimani, A., Aquilanti, L. and Clementi, F. (2015) Microbiological Quality of Meatbased Meals and Operation of Control Systems within a Food Service Environment. International Food Research Journal 22(4): 1692-1698.

Onuorah, S. Obika, I. Odibo, F. Orji, M. (2015)An Assessment of the Bacteriological Quality of Tsire-Suya (Grilled Beef) sold in Awka, Nigeria. American. J. Life. Sci. Res. 3(4):287292.

Razavilar, V, Khandaghi, J. Barzgari, A. (2010); Isolation of Eschericia coli 0157:H7 from manure fertilized farms and raw vegetables grown on it, in Tabriz city in
Iran. African Journal of Microbiology Research, 4(9): 891-895.

Scallan, E. Hoekstra, R. M. Angulo, F. J.Tauxe, R. V, Widdowson, M. Roy, S. L et al., (2011).Food borne illness acquired in the United States- Major Pathogens. Emerg. Infec Dis, 17(1): 7-15.

Shamsuddeen U (2009). Microbiological quality of spice used in the production of Kilishi a traditionally dried and grilled meat product. Bayero Journal of Pure andApplied Sciences, 2(2): 66-69.

Shamsuddeen, U. (2015) Microbiological Hazard and Critical control point Analysis of Dried and Minced Meat Snacks Produced in Kano Nigeria. Lambert Academic Publishing; Pp 1-36.

Tijani, O.and Jumare, S. (2014). Microblological Quality Assessment of Meat

Sold in KauraNamoda. International Conference on Earth, Environment and Life sciences (EELS) Dubai (UAE).

Udobi, C. E., Obajuluwa, A. F., and Onaolapo, J. A., (2013) Prevalence and Antibiotic Resistance Pattern of MethicillinResistant Staphylococcus aureus from an Orthopaedic Hospital in Nigeria BioMed Research International; 26(6); 6-7.

WHO, 2015 Foodborne diseases in the WHO African Region.

Yousafzai HA, Rind R, Khan MA, Abro SH, Korejo NA, Ejaz M, Kabir A, Shahid M, Memon S. (2019). Microbiological Contamination of Cattle and Meat in Peshawar, Pakistan. J. Anim. Health Prod. 7(1): 1116. 


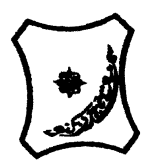

Bayero Journal of Pure and Applied Sciences, 13(1); 40 - 45

Received: September, 2019

Accepted: April, 2020

ISSN $2006-6996$

\title{
BACTERIOLOGICAL QUALITY OF STICK MEAT (Tsire) SOLD IN GARKO LOCAL GOVERNMENT AREA OF KANO STATE, NIGERIA
}

\author{
$*^{1}$ Dahiru A. T. and ${ }^{2}$ Maigari A. K. \\ ${ }^{1}$ Department of Hospitality Management, School of Technology, Kano State Polytechnic, PMB 3348, \\ Kano Nigeria. \\ ${ }^{2}$ Departmnt of Biological Sciences, Bayero University, Kano \\ Corresponding Author: dturajo61@gmail.com; GSM: 08087508262.
}

ABSTRACT

Stick meat, locally called Tsire in Hausa Language, is a significant portion of the diet of a large active population of Northern Nigeria. However, because of the handling and processing methods by the manufacturers as well as the hawking system of stick meat, the meat product may be exposed to both pre- and post-processed product contamination, and thus may poses danger to public health. Therefore, considering the role of Tsire in improving nutrition and increase household income to the populace, the need to improve the processing, distribution and overall quality of the product is simply indispensable. A total of 30 samples (5 samples from each of the 6 sampling points) of Tsire were collected randomly in Garko Town. Aerobic plate counts (APCs) and Total coliform counts (TCCS) of Tsire samples were determined using standard microbiological methods. APCs ranged from $1.02 \times 10^{5}$ to $4.00 \times 10^{5} \mathrm{CFU} / \mathrm{g}$; while TCCs ranged from $8 \mathrm{MPN} / \mathrm{g}$ to $68 \mathrm{MPN} / \mathrm{g}$. From the 30 samples screened, 16(53.33\%) bacteria namely, Campylobacter 2(6.66\%), Escherichia coli 6(20\%), Klebsiella pneumoniae 2(6.66\%), Salmonella spp. 1(3.33\%), Shigella 3(10\%) and Staphylococcus aureus 2(6.66\%) were detected. $E$. coli has the highest isolation rate of 6(20\%), while Salmonella spp. had the least frequency of 1(3.33\%). The distribution of isolated organisms within the study area were as follows: Dausai, 4(80\%), Kofar kudu, 4(80\%), Makwalla, 2(40\%), Rinji, 3(60\%), Tosaro, 2(40\%), and Tsohuwar Kasuwa, 1(20\%). The results have indicated that the Tsire was contaminated with bacteria thus exposing the product to fast deterioration, spoilage and also a vehicle for food borne illness, suggesting for adequate hygienic practices at all the stages, prior to consumption, to ensure safety of the meat product.

Key words: APCs, TCCs, Contamination, Microorganisms, Garko

\section{INTRODUCTION}

Nigeria is one of the developing nations with inadequate food supply and most often deficient in protein content (FAO, 2019). Nigerian's average animal protein intake per head per day is estimated at $7.9 \mathrm{~g}$ as against $35 \mathrm{~g}$ recommended value by Food and Agricultural Organization (Mubarak et al., 2016). These low levels of animal protein intake create great concern as it affects the nutritional status of Nigerians. Hence, there is the need for sufficient supply of animal protein from energy rich animal products to satisfy the nutritional requirements for Nigerians.

Meat is one major source of animal protein largely composed of water, protein and fats which can make it susceptible to microbial contamination within short time leading to spoilage (Apata et al., 2013; Mgbemere et al., 2011). Meat is mostly eaten after it has been cooked or processed in a variety of ways such as sun drying; smoking and roasting with or without fortifications (Borch et al., 1996). In Nigeria meat products such as Tsire, Kilishi and Balangu are locally produced using one or more of these methods in order to meet the nutritional requirements of the teeming Nigerians (Egbebi, 2011).

Tsire is a popular Nigerian traditional processed ready-to-eat roasted stick meat product (Shamsuddeen, 2015). It is sold in public places, along roads, in hotels, parks, quarters and even offices (Falegan et al., 2017). It is prepared from boneless healthy animal flesh such as beef and mutton, spiced with peanut cake, salt, vegetable oil and other flavorings followed by roasting (Shamsuddeen, 2015). Consumption of these products has extended to other parts of African countries such as Ghana, Somali, Cameroun and Chad (Ahmadu and Ibrahim, 2013). 
BAJOPAS Volume 13 Number 1, June, 2020

However, evidence of quality control sticking to procedural hygiene by the handlers during preparation and retailing of these products is poorly documented. Tsire is of great safety risk because of the fact that there are erratic cases of gastroenteritis and symptoms of food infection after consumption (WHO, 2015). Food borne illnesses are one of the major health problems in developing and developed countries (Razavilar, 2010). According to the World Health Organization, WHO (2015), $0.07 \%$ death of the 600 million global burdens of Foodborne illnesses have been reported to be caused by bacteria, viruses, fungi and chemicals. In America $0.27 \%$ of the estimated 48 million affected people is hospitalized and about $0.0063 \%$ deaths are recorded each year (Scallan et al., 2011). More than 91 million people in Africa fall ill and $0.15 \%$ dies each year, making Africa the highest burden bearer of Foodborne diseases per population (WHO, 2015).

Application of a Hazard Analysis Critical Control Point (HACCP) at all stages of meat products preparation is essential in order to ensure its safety. Thus, according to the guidelines of good manufacturing practice, the level of total aerobic bacterial contamination of thermally processed meat products should not exceed $10^{4}\left(\mathrm{cfu} \mathrm{g}^{-1}\right)$. Enterobacteriaceae and faecal coliform contamination in meat products should be within the range of $10^{2}-10^{4}$ and $10-10^{3} \mathrm{cfu} \mathrm{g}^{-1}$, respectively (Shamsuddeen, 2015). The aim of the study is therefore, to assess the total viable bacterial counts of tsire marketed locally within Garko town, and to isolate and identify the organisms at the point of consumption with the intention of promoting public health and food hygiene habits in the Nigerian populace.

\section{MATERIALS AND METHODS Study Area and Population}

Garko is one of the existing 44 local government areas located in Kano south west zone of Kano state with its capital administrative headquarters in the Garko town. It has coordinates $11^{\circ} 39^{\prime} \mathrm{N}$ $8^{\circ} 54^{\prime} \mathrm{E}$, and an area of $450 \mathrm{~km}^{2}$. The projected population of Garko local Government was 225,300 according to the National Population Census report (2018). Garko is known for agricultural activities both farming and animal husbandry. It is popularly known for large scale rice production. Other food crops include sweet potatoes, cassava, onions, sorghum, millet and sugarcane. Cows, sheep and goats are major groups of animals reared by majority of the populace. Meat products processed, retailed and consumed in Garko include roasted meat (Balangu), dried roasted meat (Kilishi), stick meat (Tsire), hide and skin pepper soup (Ragadada) and minced fried meat (Danbunnama).

\section{Samples Collection}

Five samples of Tsire products were collected from 6 different identified locations within Garko town in a sterile foil paper and immediately analyzed for the presence of bacteria.

\section{Sample Preparation}

Sample preparation for the bacteriological analysis was carried out in accordance with the method described by Atlas (1997). Twenty five grams $(25 \mathrm{~g})$ of the sample was homogenized in $225 \mathrm{ml}$ peptone water using Kenwood blender machine to obtain a $10^{1}$ homogenate. The homogenate was thoroughly shaken and $1 \mathrm{ml}$ pipetted into test tubes containing $9 \mathrm{ml}$ of peptone water $\left(10^{2}\right)$. The test tubes were further serially diluted to $10^{5}$.

Total Aerobic Mesophilic Bacterial Count

Total Aerobic mesophilic bacterial count was determined using the method described by Abdullahi et al. (2004) where $1 \mathrm{ml}$ of inoculums from $10^{1}$ to $10^{5}$ dilutions were transferred into duplicate Petri dishes and labeled accordingly. This was followed by pouring aseptically about $15 \mathrm{ml}$ of molten nutrient agar. The culture was homogenized by gentle spinning of the plates and allowed to solidify. The plates were incubated at $37^{\circ} \mathrm{C}$ for 24 hours. Plates containing 30-300 colonies were counted. The number of colony forming units per gram of a sample (cfu/g) was obtained by multiplying the average colony number with the inverse of the dilution factor.

\section{Enumeration and Detection of Coliform bacteria}

Detection and enumeration of coliform was carried out according to method described by Atlas, (1977). A set of 9 test tubes each containing $9 \mathrm{ml}$ of lactose broth and an inverted Durham tubes were autoclaved to expel air and to sterilize. Similarly, $1 \mathrm{ml}$ from the diluents $10^{1}$ was transferred to the first 3 test tubes, followed by $1 \mathrm{ml}$ from the diluents $10^{2}$ to the second set of 3 test tubes and finally the third diluents $10^{3}$ to the $3^{\text {rd }}$ set of 3 test tubes. All the 9 test tubes were incubated at $37^{\circ} \mathrm{C}$ for 24 hours. Tubes that showed gas and acid production after 24 hours were recorded as positive for the presence of Coliform. Negative tubes were further reincubated for 24 hours. Positive tubes were recorded. Estimate of most probable number of Coliform per gram of sample (MPN/g) was determined by comparing the number of gas positive tubes with the most probable number table. 
BAJOPAS Volume 13 Number 1, June, 2020 Identification of Coliform

A loop full of inoculum from gas positive tubes was streaked on to Eosine methylene blue (EMB) agar plate and incubated at $37^{\circ} \mathrm{C}$ for $24 \mathrm{hrs}$. Colonies which formed bluish black color with green metallic sheen, and reddish colonies were isolated on agar slants. Those colonies showing metallic sheen on EMB were sub cultured into tubes of lactose broth and incubated at $45^{\circ} \mathrm{C}$. The tubes were observed after $24 \mathrm{hrs}$ for gas production. This is the completed test for fecal coliform. Gram stain and other biochemical tests such as Indole, Methyl red, Voges-Proskauer and Citrate Utilization tests (IMVIC), Coagulase and Catalase tests were carried out for the Identification and confirmation of isolates.

\section{Procedure for Indole Test}

Indole test was carried out by preparing a Tryptone broth drawn in to test tubes, sterilized by autoclaving, inoculated with loopful of suspension and incubated at $37^{\circ} \mathrm{C}$ for 24 hours. Three drops of xylene was added in tubes, shaken vigorously and kept for the separation of two layers. One millilitre of Kovac's reagent was added and the formation of pink colour ring indicates positive Indole test.

\section{Procedure for Methyl Red Test}

Methyl red test was carried out by preparing Glucose phosphate broth, dispensed in test tubes, sterilized, inoculated with test culture and incubated at $37^{\circ} \mathrm{C}$ for 24 hours. Five drops of methyl-red indicator was added to the medium for the formation of red colour.

\section{Procedure for Voges-Proskauer Test}

Voges-Proskauer test was carried out by inoculating tubes with the bacterial culture followed by incubation for 48 hours at $37^{\circ} \mathrm{C}$. Separate pipettes were used to pipette $1 \mathrm{ml}$ from each culture tube into clean separate tubes. Eighteen drops $(0.5 \mathrm{ml})$ of Barrit's solution A (a-naphthol) was added to each tube containing glucose phosphate broth followed by the addition of an equal amount of solution $B$ into the same tube. The tubes were shaken at 30 seconds interval. A positive reaction was indicated by the development of a pink color, which turns red in 1-2 hours, after vigorous shaking.

\section{Procedure for Citrate Utilization Test}

Citrate Utilization Test was carried out by distributing melted agar (Simmon Citrate Agar) in to test tubes followed by sterilization at $121.5^{\circ} \mathrm{C}$ for 15 minutes. The test tubes were afterward held in slanted position, inoculated with the given bacterial culture and incubated at $37^{\circ} \mathrm{C}$ for $24 \mathrm{hrs}$. Positive test was indicated by color change of the media from green to blue.

\section{RESULTS AND DISCUSSIONS}

The results of this study are presented in tables $1,2,3$ and 4. Among the sampling areas Kofar Kudu had the highest aerobic mesophilic bacteria counts $4.0 \times 10^{5} \mathrm{cfu} / \mathrm{g}$ followed by Rinji $2.72 \times 10^{5} \mathrm{cfu} / \mathrm{g}$, while Tosaro had the least Aerobic mesophilic bacteria counts of $1.02 \times 10^{5}$ $\mathrm{cfu} / \mathrm{g}$ as indicated in Table 1.Makwalla had the highest coliform count $68 \mathrm{MPN} / \mathrm{g}$ followed by Rinji $37 \mathrm{MPN} / \mathrm{g}$. Tsohuwar Kasuwa had the least coliform counts $8 \mathrm{MPN} / \mathrm{g}$, (Table 2). Result from table 1 shows variation in the microbial contents among the samples which suggest variation in their sources, poor handling procedures and contamination from the processing environment. High coliform count and their differences within sampling areas is an indication of poor microbiological quality of the product. Ndahi et al. (2013) reported microbial load to be a function of the handling personnel and the environment. The results indicated that the samples were contaminated with bacteria as the counts exceeded the minimum safety level $\left(10^{4} \mathrm{cfu} / \mathrm{g}\right)$ for members of the Enterobacteriaceae family. However, it might be a reflection of poor hygienic practices which may contribute to health hazard to the potential consumers. Similarly, Inusa and Sa'id (2017); Osimani et al. (2015) reported that, the initial microbial content of the raw material play significant role in influencing the final microbial load of the finished product. Isolation of members of the Enterobacteriaceae such as $E$. coli, Klebsiella pneumoniae, Salmonella and Shigella signifies danger to the public health. These organisms are capable of producing endotoxins which trigger high fevers in infected individuals, and the enterotoxins which colonize the small intestines and lead to extreme dehydration as a result of vomiting and diarrhea sometimes with severe and fatal outcomes (Amaeze et al., 2016). From the 16 isolated organisms $E$. coli had the highest isolation rate $6(37.5 \%)$ (Table 3), this suggest faecal contamination of the products. $E$. coli is a common flora in the gastrointestinal tract responsible for diarrhea and extra-intestinal infections (CDC, 2011). The result is in conformity with the findings of Ndahi et al. (2013) and Shamsuddeen (2009). Also presence of campylobacter might be due to cross contamination from raw meat to finished product (Tsire). Staphylococcus aureus is a normal flora of the skin, nasal, genital, mouth or anal area in both humans and animals without any symptom of an infection (Matthew et al., 2013). Isolation of $S$. aureus in these study concords with the findings of Lucretia et al. (2018) from Suya sold in Rivers State. 
BAJOPAS Volume 13 Number 1, June, 2020

It is also in agreement with the findings of Yousafzai et al. (2018); Onuorah et al. (2015) and Tijjani and Jumare (2014) from tsire samples in different countries. Presence of $S$. aureus in foods is most of the time an indication of poor human handling, poor environment, unhygienic utensils and equipments used during processing (Igene et al., 2016; Okonko et al., 2013). Infections caused by $S$. aureus are difficult to treat leading to long hospitalization with consequent economic loss (Udobi et al., 2013). These include soft tissue infections, pneumonia, hospital-acquired postoperative wound infections, Staphylococcal food poisoning, impetigo and cellulitis (Charlene et al., 2013). Samples obtained from Dausai and Kofar Kudu had the highest isolation rate $4(80 \%)$ (Table 4 ) probably because of the much commercial activities taking place in the area which can lead to environmental contamination.

Table 1: Total Aerobic Mesophilic Bacterial Count of Tsire sold in Garko Town

\begin{tabular}{lll}
\hline Sampling Area & APC cfu/g & Mean \pm STD \\
\hline Dausai & $2.20 \times 10^{5}$ & $110000 \pm 14142.14$ \\
Kofar Kudu & $4.00 \times 10^{5}$ & $133333.3 \pm 23094.01$ \\
Makwalla & $1.30 \times 10^{5}$ & $32500 \pm 7187.953$ \\
Rinji & $2.72 \times 10^{5}$ & $90666.67 \pm 94769.90$ \\
Tosaro & $1.02 \times 10^{5}$ & $51000 \pm 15556.35$ \\
Tsohuwar Kasuwa & $1.75 \times 10^{5}$ & $35000 \pm 11357.82$ \\
\hline
\end{tabular}

Key: APC: Aerobic Mesophilic Counts

STD: Standard Deviation

Table 2: Total Coliform Count of Tsire sold in Garko Town

\begin{tabular}{lcc}
\hline \multicolumn{1}{c}{ Sampling Area } & TCC MPN/g & Mean \pm STD \\
\hline Dausai & 20 & $6.67 \pm 2.5166$ \\
Kofar Kudu & 32 & $16.00 \pm 5.6569$ \\
Makwalla & 68 & $13.60 \pm 8.7062$ \\
Rinji & 37 & $9.25 \pm 4.7871$ \\
Tosaro & 10 & $5.00 \pm 2.8284$ \\
Tsohuwar Kasuwa & 8 & $4.00 \pm 0.0000$ \\
\hline
\end{tabular}

Table 3: Organisms Isolated from Tsire Sold in Garko

\begin{tabular}{lcl}
\hline Isolated Organism & Frequency & Percentage (\%) \\
\hline Campylobacter & 2 & 06.66 \\
Escherichia coli & 6 & 20.00 \\
Klebsiella pneumoniae & 2 & 06.66 \\
Salmonella species & 1 & 03.33 \\
Shigella & 3 & 10.00 \\
Staphylococcus aureus & 2 & 06.66 \\
Total & 16 & \\
\hline
\end{tabular}

Table 4: Distribution of Organisms within Sampling Area

\begin{tabular}{lcc}
\hline \multicolumn{1}{c}{ Sampling Area } & No. Isolated & Percentage (\%) \\
\hline Dausai & 4 & 80 \\
Kofar Kudu & 4 & 80 \\
Makwalla & 2 & 40 \\
Rinji & 3 & 60 \\
Tosaro & 2 & 40 \\
Tsohuwar Kasuwa & 1 & 20 \\
Total & 16 & \\
\hline
\end{tabular}

\section{CONCLUSION}

Results indicated $4.00 \times 10^{5} \mathrm{CFU} / \mathrm{g}$ as the highest APCs count; while $68 \mathrm{MPN} / \mathrm{g}$ was the highest TCCs from the 30 samples analyzed. Among the isolates, $E$. coli has the highest isolation rate of $6(20 \%)$. Dausai and Kofar kudu were having the highest bacteria count of $4(80 \%)$, each, indicating higher contamination in those locations. 
BAJOPAS Volume 13 Number 1, June, 2020 RECOMMENDATIONS

The following recommendations are tenable:

1. Hygienic practices at all stages of production should be improved to safe guard the consumers against potential health hazard.

2. Monitoring of microbiological contamination of Tsire during preparations, packaging and marketing is essential to ensure product of good microbiological quality for consumers' health.

\section{REFERENCES}

Abdullahi, I. O., Umoh, V. J. and Galadima, M. (2004). Hazards Associated with Kilishi Preparations in Zaria. Nigerian Journal of Microbiology, 18 (1-2): $339-345$.

Ahmadu, J. and Ibrahim E. J., (2013): Determinants of Revenue in Suya Production in BeninCity, Edo State, Nigeria. Nigerian journal of agriculture, food and environment.9(3):1-5

Amaeze, N. Aboh, M. Itohan, A. Felix, E. Olatunji, T. and Oladosu, P. (2016) Microbial Profile, Antibiotic Sensitivity and Heat Resistance of Bacterial Isolates from Commercial Roasted Beef (Suya) in Abuja, Nigeria. JOPAT, 15(2): $22-30$.

Apata, E.S., Kuku1, I.A., Apata, O.C. and Adeyemi, K.O. (2013). Evaluation of Suya(Tsire) - An Intermediate Moisture Meat Product in Ogun State, Nigeria. J. Food Res 2 (1): 87.

Atlas, R. M. (1997) Principles of Microbiology Second Edition. C. Brown Publishers. Pp 802-803.

Borch, E. Kant-Muermans, M. L., Blixt, Y. (1996) Bacterial Spoilage of Meat and Cured Meat Products. Int $\mathrm{J}$ Food Microbiol .33(1): 103-20.

Centre for Disease Control, CDC (2011). "Escherichia coli 0157:H7" Division of Bacterial and Mycotic Diseasesht://www.cdc.gov/nczved/divisi ons/dfbmd/diseases/ecoli_0157h7/.

Charlene, R. J., Johnnie, A. D., and John, B. B., (2013) Prevalence and Characterization of Methicillin-Resistant Staphylococcus aureus Isolates from Retail Meat and Humans in Georgia. American society for Microbiology. J. of clinical microbiology. 12(1):123-6 doi:10.1128/JCM.0316612JCM.03166-12

Egbebi, A.O and Seidu, K., T. (2011). Microbiological Evaluation of Suya (dried smoked

meat) Sold in Ado and Akure, South West Nigeria.European Journal of Experinmental Biology, 1(4):1-5
3. Government should establish regulatory bodies responsible for inculcating hygiene habits to the local producers and vendors in order to prevent instant, cross and post processing contaminations by microbial pathogens.

4. Awareness and sensitization of local food producers about good hygienic practices in food handling and processing.

Falegan, C, R., Akoja, S. D., and Oyarekua, M. A., (2017) Microbiological Assessment of Suya (Sliced Roasted Beef) in Ado-Ekiti Metropolis, Ekiti State, Nigeria. MOJ Biology andMedicine.

Fonkem, D., N. Tanya, V., N. and Ebangi, A., L. (2010). Effect of Season on the Microbiological Quality of Kilishi, a Traditional Cameroonian Dried Beef Product. Tropicultura, 28(1): 10-15.

Food and Agricultural Organization of the United Nations (F A O, 1979). Manual of food quality control 4. Microbiological analysis.

Food and Agriculture Organisation of the United Nation (FAO), 2019. Nigeria at a glance.

Igene J.O., Uwadia, O.E., Ebabhamiegbebho, P.A. and Evivie, S.E., (2016) Shelf life Stability Studies of University of Benin (UNIBEN) Proff's Kilishi Product Asian Journal of Science and Technology 7(1): 2268-2274.

Inusa, S. K. and Said, I. S. (2017) Evaluation of the Chemical and Microbiological Properties Of Kilishi Sold in Kano Metropolis. Journal of Dry land Agriculture, 3 (1): $59-69$.

Lucretia, I. B, Patience, C. Obinna-Echem, Sophia, C. A. (2018) Microbiological quality andantibiotic sensitivity of potential pathogens isolated from meat product (Suya) sold in Rivers State University and its environs. International Journal of Biotechnology and Food Science, 6(4): 67-76.

Matthew, E., Drosos, E., John, L. and Ioanna, P. (2013) MRSA in Africa: Filling the Global Map of Antimicrobial Resistance PLOS One. 8(7): e68024 doi: 10.1371/journal.pone.0068024

Mgbemere, V.N., Akpapunam, M. A. and Igene, J. O., (2011). Effect of Groundnut FlourSubstitution on Yield, Quality and Storage Stability of Kilishi - a Nigerian Indigenous Dried Meat Product. African Journal of Food, Agriculture, Nutrition and Development, $\quad \mathbf{1 1}(2)$ : 4718-4738. 
BAJOPAS Volume 13 Number 1, June, 2020

Mubarak, A. A., Azeez, M. L., Amos A. O., Opeyemi, O. O. (2016) Assessment of Animal Protein Consumption and Food Security Among Rural Households in Kwara State, Nigeria American Journal of Business and Society, 1(4): 233245.

Ndahi, M., D. Kwaga, J., K. P. Bello, M. Kabir J., V. Umoh, .J. Yakubu, S., E. and Nok, A., J. (2013) Prevalence and Antimicrobial Susceptibility of Listeria Monocytogenes and Methicillin-Resistant Staphylococcus aureus Strains from Raw Meat and Meat Products in Zaria, Nigeria. Applied Journal of Microbiology, 58(3):262-9.

Okonko, I.O., Odu, N.N. and Igboh, I.E. (2013). Microbiological Analysis of Kilishi Sold In Port Harcourt, Nigeria. New York Science Journal, 6 (7):37-43.

Osimani, A., Aquilanti, L. and Clementi, F. (2015) Microbiological Quality of Meatbased Meals and Operation of Control Systems within a Food Service Environment. International Food Research Journal 22(4): 1692-1698.

Onuorah, S. Obika, I. Odibo, F. Orji, M. (2015)An Assessment of the Bacteriological Quality of Tsire-Suya (Grilled Beef) sold in Awka, Nigeria. American. J. Life. Sci. Res. 3(4):287292.

Razavilar, V, Khandaghi, J. Barzgari, A. (2010); Isolation of Eschericia coli 0157:H7 from manure fertilized farms and raw vegetables grown on it, in Tabriz city in
Iran. African Journal of Microbiology Research, 4(9): 891-895.

Scallan, E. Hoekstra, R. M. Angulo, F. J.Tauxe, R. V, Widdowson, M. Roy, S. L et al., (2011).Food borne illness acquired in the United States- Major Pathogens. Emerg. Infec Dis, 17(1): 7-15.

Shamsuddeen U (2009). Microbiological quality of spice used in the production of Kilishi a traditionally dried and grilled meat product. Bayero Journal of Pure andApplied Sciences, 2(2): 66-69.

Shamsuddeen, U. (2015) Microbiological Hazard and Critical control point Analysis of Dried and Minced Meat Snacks Produced in Kano Nigeria. Lambert Academic Publishing; Pp 1-36.

Tijani, O.and Jumare, S. (2014). Microblological Quality Assessment of Meat

Sold in KauraNamoda. International Conference on Earth, Environment and Life sciences (EELS) Dubai (UAE).

Udobi, C. E., Obajuluwa, A. F., and Onaolapo, J. A., (2013) Prevalence and Antibiotic Resistance Pattern of MethicillinResistant Staphylococcus aureus from an Orthopaedic Hospital in Nigeria BioMed Research International; 26(6); 6-7.

WHO, 2015 Foodborne diseases in the WHO African Region.

Yousafzai HA, Rind R, Khan MA, Abro SH, Korejo NA, Ejaz M, Kabir A, Shahid M, Memon S. (2019). Microbiological Contamination of Cattle and Meat in Peshawar, Pakistan. J. Anim. Health Prod. 7(1): 1116. 


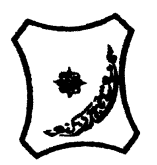

Bayero Journal of Pure and Applied Sciences, 13(1); 40 - 45

Received: September, 2019

Accepted: April, 2020

ISSN $2006-6996$

\title{
BACTERIOLOGICAL QUALITY OF STICK MEAT (Tsire) SOLD IN GARKO LOCAL GOVERNMENT AREA OF KANO STATE, NIGERIA
}

\author{
$*^{1}$ Dahiru A. T. and ${ }^{2}$ Maigari A. K. \\ ${ }^{1}$ Department of Hospitality Management, School of Technology, Kano State Polytechnic, PMB 3348, \\ Kano Nigeria. \\ ${ }^{2}$ Departmnt of Biological Sciences, Bayero University, Kano \\ Corresponding Author: dturajo61@gmail.com; GSM: 08087508262.
}

ABSTRACT

Stick meat, locally called Tsire in Hausa Language, is a significant portion of the diet of a large active population of Northern Nigeria. However, because of the handling and processing methods by the manufacturers as well as the hawking system of stick meat, the meat product may be exposed to both pre- and post-processed product contamination, and thus may poses danger to public health. Therefore, considering the role of Tsire in improving nutrition and increase household income to the populace, the need to improve the processing, distribution and overall quality of the product is simply indispensable. A total of 30 samples (5 samples from each of the 6 sampling points) of Tsire were collected randomly in Garko Town. Aerobic plate counts (APCs) and Total coliform counts (TCCS) of Tsire samples were determined using standard microbiological methods. APCs ranged from $1.02 \times 10^{5}$ to $4.00 \times 10^{5} \mathrm{CFU} / \mathrm{g}$; while TCCs ranged from $8 \mathrm{MPN} / \mathrm{g}$ to $68 \mathrm{MPN} / \mathrm{g}$. From the 30 samples screened, 16(53.33\%) bacteria namely, Campylobacter 2(6.66\%), Escherichia coli 6(20\%), Klebsiella pneumoniae 2(6.66\%), Salmonella spp. 1(3.33\%), Shigella 3(10\%) and Staphylococcus aureus 2(6.66\%) were detected. $E$. coli has the highest isolation rate of 6(20\%), while Salmonella spp. had the least frequency of 1(3.33\%). The distribution of isolated organisms within the study area were as follows: Dausai, 4(80\%), Kofar kudu, 4(80\%), Makwalla, 2(40\%), Rinji, 3(60\%), Tosaro, 2(40\%), and Tsohuwar Kasuwa, 1(20\%). The results have indicated that the Tsire was contaminated with bacteria thus exposing the product to fast deterioration, spoilage and also a vehicle for food borne illness, suggesting for adequate hygienic practices at all the stages, prior to consumption, to ensure safety of the meat product.

Key words: APCs, TCCs, Contamination, Microorganisms, Garko

\section{INTRODUCTION}

Nigeria is one of the developing nations with inadequate food supply and most often deficient in protein content (FAO, 2019). Nigerian's average animal protein intake per head per day is estimated at $7.9 \mathrm{~g}$ as against $35 \mathrm{~g}$ recommended value by Food and Agricultural Organization (Mubarak et al., 2016). These low levels of animal protein intake create great concern as it affects the nutritional status of Nigerians. Hence, there is the need for sufficient supply of animal protein from energy rich animal products to satisfy the nutritional requirements for Nigerians.

Meat is one major source of animal protein largely composed of water, protein and fats which can make it susceptible to microbial contamination within short time leading to spoilage (Apata et al., 2013; Mgbemere et al., 2011). Meat is mostly eaten after it has been cooked or processed in a variety of ways such as sun drying; smoking and roasting with or without fortifications (Borch et al., 1996). In Nigeria meat products such as Tsire, Kilishi and Balangu are locally produced using one or more of these methods in order to meet the nutritional requirements of the teeming Nigerians (Egbebi, 2011).

Tsire is a popular Nigerian traditional processed ready-to-eat roasted stick meat product (Shamsuddeen, 2015). It is sold in public places, along roads, in hotels, parks, quarters and even offices (Falegan et al., 2017). It is prepared from boneless healthy animal flesh such as beef and mutton, spiced with peanut cake, salt, vegetable oil and other flavorings followed by roasting (Shamsuddeen, 2015). Consumption of these products has extended to other parts of African countries such as Ghana, Somali, Cameroun and Chad (Ahmadu and Ibrahim, 2013). 
BAJOPAS Volume 13 Number 1, June, 2020

However, evidence of quality control sticking to procedural hygiene by the handlers during preparation and retailing of these products is poorly documented. Tsire is of great safety risk because of the fact that there are erratic cases of gastroenteritis and symptoms of food infection after consumption (WHO, 2015). Food borne illnesses are one of the major health problems in developing and developed countries (Razavilar, 2010). According to the World Health Organization, WHO (2015), $0.07 \%$ death of the 600 million global burdens of Foodborne illnesses have been reported to be caused by bacteria, viruses, fungi and chemicals. In America $0.27 \%$ of the estimated 48 million affected people is hospitalized and about $0.0063 \%$ deaths are recorded each year (Scallan et al., 2011). More than 91 million people in Africa fall ill and $0.15 \%$ dies each year, making Africa the highest burden bearer of Foodborne diseases per population (WHO, 2015).

Application of a Hazard Analysis Critical Control Point (HACCP) at all stages of meat products preparation is essential in order to ensure its safety. Thus, according to the guidelines of good manufacturing practice, the level of total aerobic bacterial contamination of thermally processed meat products should not exceed $10^{4}\left(\mathrm{cfu} \mathrm{g}^{-1}\right)$. Enterobacteriaceae and faecal coliform contamination in meat products should be within the range of $10^{2}-10^{4}$ and $10-10^{3} \mathrm{cfu} \mathrm{g}^{-1}$, respectively (Shamsuddeen, 2015). The aim of the study is therefore, to assess the total viable bacterial counts of tsire marketed locally within Garko town, and to isolate and identify the organisms at the point of consumption with the intention of promoting public health and food hygiene habits in the Nigerian populace.

\section{MATERIALS AND METHODS Study Area and Population}

Garko is one of the existing 44 local government areas located in Kano south west zone of Kano state with its capital administrative headquarters in the Garko town. It has coordinates $11^{\circ} 39^{\prime} \mathrm{N}$ $8^{\circ} 54^{\prime} \mathrm{E}$, and an area of $450 \mathrm{~km}^{2}$. The projected population of Garko local Government was 225,300 according to the National Population Census report (2018). Garko is known for agricultural activities both farming and animal husbandry. It is popularly known for large scale rice production. Other food crops include sweet potatoes, cassava, onions, sorghum, millet and sugarcane. Cows, sheep and goats are major groups of animals reared by majority of the populace. Meat products processed, retailed and consumed in Garko include roasted meat (Balangu), dried roasted meat (Kilishi), stick meat (Tsire), hide and skin pepper soup (Ragadada) and minced fried meat (Danbunnama).

\section{Samples Collection}

Five samples of Tsire products were collected from 6 different identified locations within Garko town in a sterile foil paper and immediately analyzed for the presence of bacteria.

\section{Sample Preparation}

Sample preparation for the bacteriological analysis was carried out in accordance with the method described by Atlas (1997). Twenty five grams $(25 \mathrm{~g})$ of the sample was homogenized in $225 \mathrm{ml}$ peptone water using Kenwood blender machine to obtain a $10^{1}$ homogenate. The homogenate was thoroughly shaken and $1 \mathrm{ml}$ pipetted into test tubes containing $9 \mathrm{ml}$ of peptone water $\left(10^{2}\right)$. The test tubes were further serially diluted to $10^{5}$.

Total Aerobic Mesophilic Bacterial Count

Total Aerobic mesophilic bacterial count was determined using the method described by Abdullahi et al. (2004) where $1 \mathrm{ml}$ of inoculums from $10^{1}$ to $10^{5}$ dilutions were transferred into duplicate Petri dishes and labeled accordingly. This was followed by pouring aseptically about $15 \mathrm{ml}$ of molten nutrient agar. The culture was homogenized by gentle spinning of the plates and allowed to solidify. The plates were incubated at $37^{\circ} \mathrm{C}$ for 24 hours. Plates containing 30-300 colonies were counted. The number of colony forming units per gram of a sample (cfu/g) was obtained by multiplying the average colony number with the inverse of the dilution factor.

\section{Enumeration and Detection of Coliform bacteria}

Detection and enumeration of coliform was carried out according to method described by Atlas, (1977). A set of 9 test tubes each containing $9 \mathrm{ml}$ of lactose broth and an inverted Durham tubes were autoclaved to expel air and to sterilize. Similarly, $1 \mathrm{ml}$ from the diluents $10^{1}$ was transferred to the first 3 test tubes, followed by $1 \mathrm{ml}$ from the diluents $10^{2}$ to the second set of 3 test tubes and finally the third diluents $10^{3}$ to the $3^{\text {rd }}$ set of 3 test tubes. All the 9 test tubes were incubated at $37^{\circ} \mathrm{C}$ for 24 hours. Tubes that showed gas and acid production after 24 hours were recorded as positive for the presence of Coliform. Negative tubes were further reincubated for 24 hours. Positive tubes were recorded. Estimate of most probable number of Coliform per gram of sample (MPN/g) was determined by comparing the number of gas positive tubes with the most probable number table. 
BAJOPAS Volume 13 Number 1, June, 2020 Identification of Coliform

A loop full of inoculum from gas positive tubes was streaked on to Eosine methylene blue (EMB) agar plate and incubated at $37^{\circ} \mathrm{C}$ for $24 \mathrm{hrs}$. Colonies which formed bluish black color with green metallic sheen, and reddish colonies were isolated on agar slants. Those colonies showing metallic sheen on EMB were sub cultured into tubes of lactose broth and incubated at $45^{\circ} \mathrm{C}$. The tubes were observed after $24 \mathrm{hrs}$ for gas production. This is the completed test for fecal coliform. Gram stain and other biochemical tests such as Indole, Methyl red, Voges-Proskauer and Citrate Utilization tests (IMVIC), Coagulase and Catalase tests were carried out for the Identification and confirmation of isolates.

\section{Procedure for Indole Test}

Indole test was carried out by preparing a Tryptone broth drawn in to test tubes, sterilized by autoclaving, inoculated with loopful of suspension and incubated at $37^{\circ} \mathrm{C}$ for 24 hours. Three drops of xylene was added in tubes, shaken vigorously and kept for the separation of two layers. One millilitre of Kovac's reagent was added and the formation of pink colour ring indicates positive Indole test.

\section{Procedure for Methyl Red Test}

Methyl red test was carried out by preparing Glucose phosphate broth, dispensed in test tubes, sterilized, inoculated with test culture and incubated at $37^{\circ} \mathrm{C}$ for 24 hours. Five drops of methyl-red indicator was added to the medium for the formation of red colour.

\section{Procedure for Voges-Proskauer Test}

Voges-Proskauer test was carried out by inoculating tubes with the bacterial culture followed by incubation for 48 hours at $37^{\circ} \mathrm{C}$. Separate pipettes were used to pipette $1 \mathrm{ml}$ from each culture tube into clean separate tubes. Eighteen drops $(0.5 \mathrm{ml})$ of Barrit's solution A (a-naphthol) was added to each tube containing glucose phosphate broth followed by the addition of an equal amount of solution $B$ into the same tube. The tubes were shaken at 30 seconds interval. A positive reaction was indicated by the development of a pink color, which turns red in 1-2 hours, after vigorous shaking.

\section{Procedure for Citrate Utilization Test}

Citrate Utilization Test was carried out by distributing melted agar (Simmon Citrate Agar) in to test tubes followed by sterilization at $121.5^{\circ} \mathrm{C}$ for 15 minutes. The test tubes were afterward held in slanted position, inoculated with the given bacterial culture and incubated at $37^{\circ} \mathrm{C}$ for $24 \mathrm{hrs}$. Positive test was indicated by color change of the media from green to blue.

\section{RESULTS AND DISCUSSIONS}

The results of this study are presented in tables $1,2,3$ and 4. Among the sampling areas Kofar Kudu had the highest aerobic mesophilic bacteria counts $4.0 \times 10^{5} \mathrm{cfu} / \mathrm{g}$ followed by Rinji $2.72 \times 10^{5} \mathrm{cfu} / \mathrm{g}$, while Tosaro had the least Aerobic mesophilic bacteria counts of $1.02 \times 10^{5}$ $\mathrm{cfu} / \mathrm{g}$ as indicated in Table 1.Makwalla had the highest coliform count $68 \mathrm{MPN} / \mathrm{g}$ followed by Rinji $37 \mathrm{MPN} / \mathrm{g}$. Tsohuwar Kasuwa had the least coliform counts $8 \mathrm{MPN} / \mathrm{g}$, (Table 2). Result from table 1 shows variation in the microbial contents among the samples which suggest variation in their sources, poor handling procedures and contamination from the processing environment. High coliform count and their differences within sampling areas is an indication of poor microbiological quality of the product. Ndahi et al. (2013) reported microbial load to be a function of the handling personnel and the environment. The results indicated that the samples were contaminated with bacteria as the counts exceeded the minimum safety level $\left(10^{4} \mathrm{cfu} / \mathrm{g}\right)$ for members of the Enterobacteriaceae family. However, it might be a reflection of poor hygienic practices which may contribute to health hazard to the potential consumers. Similarly, Inusa and Sa'id (2017); Osimani et al. (2015) reported that, the initial microbial content of the raw material play significant role in influencing the final microbial load of the finished product. Isolation of members of the Enterobacteriaceae such as $E$. coli, Klebsiella pneumoniae, Salmonella and Shigella signifies danger to the public health. These organisms are capable of producing endotoxins which trigger high fevers in infected individuals, and the enterotoxins which colonize the small intestines and lead to extreme dehydration as a result of vomiting and diarrhea sometimes with severe and fatal outcomes (Amaeze et al., 2016). From the 16 isolated organisms $E$. coli had the highest isolation rate $6(37.5 \%)$ (Table 3), this suggest faecal contamination of the products. $E$. coli is a common flora in the gastrointestinal tract responsible for diarrhea and extra-intestinal infections (CDC, 2011). The result is in conformity with the findings of Ndahi et al. (2013) and Shamsuddeen (2009). Also presence of campylobacter might be due to cross contamination from raw meat to finished product (Tsire). Staphylococcus aureus is a normal flora of the skin, nasal, genital, mouth or anal area in both humans and animals without any symptom of an infection (Matthew et al., 2013). Isolation of $S$. aureus in these study concords with the findings of Lucretia et al. (2018) from Suya sold in Rivers State. 
BAJOPAS Volume 13 Number 1, June, 2020

It is also in agreement with the findings of Yousafzai et al. (2018); Onuorah et al. (2015) and Tijjani and Jumare (2014) from tsire samples in different countries. Presence of $S$. aureus in foods is most of the time an indication of poor human handling, poor environment, unhygienic utensils and equipments used during processing (Igene et al., 2016; Okonko et al., 2013). Infections caused by $S$. aureus are difficult to treat leading to long hospitalization with consequent economic loss (Udobi et al., 2013). These include soft tissue infections, pneumonia, hospital-acquired postoperative wound infections, Staphylococcal food poisoning, impetigo and cellulitis (Charlene et al., 2013). Samples obtained from Dausai and Kofar Kudu had the highest isolation rate $4(80 \%)$ (Table 4 ) probably because of the much commercial activities taking place in the area which can lead to environmental contamination.

Table 1: Total Aerobic Mesophilic Bacterial Count of Tsire sold in Garko Town

\begin{tabular}{lll}
\hline Sampling Area & APC cfu/g & Mean \pm STD \\
\hline Dausai & $2.20 \times 10^{5}$ & $110000 \pm 14142.14$ \\
Kofar Kudu & $4.00 \times 10^{5}$ & $133333.3 \pm 23094.01$ \\
Makwalla & $1.30 \times 10^{5}$ & $32500 \pm 7187.953$ \\
Rinji & $2.72 \times 10^{5}$ & $90666.67 \pm 94769.90$ \\
Tosaro & $1.02 \times 10^{5}$ & $51000 \pm 15556.35$ \\
Tsohuwar Kasuwa & $1.75 \times 10^{5}$ & $35000 \pm 11357.82$ \\
\hline
\end{tabular}

Key: APC: Aerobic Mesophilic Counts

STD: Standard Deviation

Table 2: Total Coliform Count of Tsire sold in Garko Town

\begin{tabular}{lcc}
\hline \multicolumn{1}{c}{ Sampling Area } & TCC MPN/g & Mean \pm STD \\
\hline Dausai & 20 & $6.67 \pm 2.5166$ \\
Kofar Kudu & 32 & $16.00 \pm 5.6569$ \\
Makwalla & 68 & $13.60 \pm 8.7062$ \\
Rinji & 37 & $9.25 \pm 4.7871$ \\
Tosaro & 10 & $5.00 \pm 2.8284$ \\
Tsohuwar Kasuwa & 8 & $4.00 \pm 0.0000$ \\
\hline
\end{tabular}

Table 3: Organisms Isolated from Tsire Sold in Garko

\begin{tabular}{lcl}
\hline Isolated Organism & Frequency & Percentage (\%) \\
\hline Campylobacter & 2 & 06.66 \\
Escherichia coli & 6 & 20.00 \\
Klebsiella pneumoniae & 2 & 06.66 \\
Salmonella species & 1 & 03.33 \\
Shigella & 3 & 10.00 \\
Staphylococcus aureus & 2 & 06.66 \\
Total & 16 & \\
\hline
\end{tabular}

Table 4: Distribution of Organisms within Sampling Area

\begin{tabular}{lcc}
\hline \multicolumn{1}{c}{ Sampling Area } & No. Isolated & Percentage (\%) \\
\hline Dausai & 4 & 80 \\
Kofar Kudu & 4 & 80 \\
Makwalla & 2 & 40 \\
Rinji & 3 & 60 \\
Tosaro & 2 & 40 \\
Tsohuwar Kasuwa & 1 & 20 \\
Total & 16 & \\
\hline
\end{tabular}

\section{CONCLUSION}

Results indicated $4.00 \times 10^{5} \mathrm{CFU} / \mathrm{g}$ as the highest APCs count; while $68 \mathrm{MPN} / \mathrm{g}$ was the highest TCCs from the 30 samples analyzed. Among the isolates, $E$. coli has the highest isolation rate of $6(20 \%)$. Dausai and Kofar kudu were having the highest bacteria count of $4(80 \%)$, each, indicating higher contamination in those locations. 
BAJOPAS Volume 13 Number 1, June, 2020 RECOMMENDATIONS

The following recommendations are tenable:

1. Hygienic practices at all stages of production should be improved to safe guard the consumers against potential health hazard.

2. Monitoring of microbiological contamination of Tsire during preparations, packaging and marketing is essential to ensure product of good microbiological quality for consumers' health.

\section{REFERENCES}

Abdullahi, I. O., Umoh, V. J. and Galadima, M. (2004). Hazards Associated with Kilishi Preparations in Zaria. Nigerian Journal of Microbiology, 18 (1-2): $339-345$.

Ahmadu, J. and Ibrahim E. J., (2013): Determinants of Revenue in Suya Production in BeninCity, Edo State, Nigeria. Nigerian journal of agriculture, food and environment.9(3):1-5

Amaeze, N. Aboh, M. Itohan, A. Felix, E. Olatunji, T. and Oladosu, P. (2016) Microbial Profile, Antibiotic Sensitivity and Heat Resistance of Bacterial Isolates from Commercial Roasted Beef (Suya) in Abuja, Nigeria. JOPAT, 15(2): $22-30$.

Apata, E.S., Kuku1, I.A., Apata, O.C. and Adeyemi, K.O. (2013). Evaluation of Suya(Tsire) - An Intermediate Moisture Meat Product in Ogun State, Nigeria. J. Food Res 2 (1): 87.

Atlas, R. M. (1997) Principles of Microbiology Second Edition. C. Brown Publishers. Pp 802-803.

Borch, E. Kant-Muermans, M. L., Blixt, Y. (1996) Bacterial Spoilage of Meat and Cured Meat Products. Int $\mathrm{J}$ Food Microbiol .33(1): 103-20.

Centre for Disease Control, CDC (2011). "Escherichia coli 0157:H7" Division of Bacterial and Mycotic Diseasesht://www.cdc.gov/nczved/divisi ons/dfbmd/diseases/ecoli_0157h7/.

Charlene, R. J., Johnnie, A. D., and John, B. B., (2013) Prevalence and Characterization of Methicillin-Resistant Staphylococcus aureus Isolates from Retail Meat and Humans in Georgia. American society for Microbiology. J. of clinical microbiology. 12(1):123-6 doi:10.1128/JCM.0316612JCM.03166-12

Egbebi, A.O and Seidu, K., T. (2011). Microbiological Evaluation of Suya (dried smoked

meat) Sold in Ado and Akure, South West Nigeria.European Journal of Experinmental Biology, 1(4):1-5
3. Government should establish regulatory bodies responsible for inculcating hygiene habits to the local producers and vendors in order to prevent instant, cross and post processing contaminations by microbial pathogens.

4. Awareness and sensitization of local food producers about good hygienic practices in food handling and processing.

Falegan, C, R., Akoja, S. D., and Oyarekua, M. A., (2017) Microbiological Assessment of Suya (Sliced Roasted Beef) in Ado-Ekiti Metropolis, Ekiti State, Nigeria. MOJ Biology andMedicine.

Fonkem, D., N. Tanya, V., N. and Ebangi, A., L. (2010). Effect of Season on the Microbiological Quality of Kilishi, a Traditional Cameroonian Dried Beef Product. Tropicultura, 28(1): 10-15.

Food and Agricultural Organization of the United Nations (F A O, 1979). Manual of food quality control 4. Microbiological analysis.

Food and Agriculture Organisation of the United Nation (FAO), 2019. Nigeria at a glance.

Igene J.O., Uwadia, O.E., Ebabhamiegbebho, P.A. and Evivie, S.E., (2016) Shelf life Stability Studies of University of Benin (UNIBEN) Proff's Kilishi Product Asian Journal of Science and Technology 7(1): 2268-2274.

Inusa, S. K. and Said, I. S. (2017) Evaluation of the Chemical and Microbiological Properties Of Kilishi Sold in Kano Metropolis. Journal of Dry land Agriculture, 3 (1): $59-69$.

Lucretia, I. B, Patience, C. Obinna-Echem, Sophia, C. A. (2018) Microbiological quality andantibiotic sensitivity of potential pathogens isolated from meat product (Suya) sold in Rivers State University and its environs. International Journal of Biotechnology and Food Science, 6(4): 67-76.

Matthew, E., Drosos, E., John, L. and Ioanna, P. (2013) MRSA in Africa: Filling the Global Map of Antimicrobial Resistance PLOS One. 8(7): e68024 doi: 10.1371/journal.pone.0068024

Mgbemere, V.N., Akpapunam, M. A. and Igene, J. O., (2011). Effect of Groundnut FlourSubstitution on Yield, Quality and Storage Stability of Kilishi - a Nigerian Indigenous Dried Meat Product. African Journal of Food, Agriculture, Nutrition and Development, $\quad \mathbf{1 1}(2)$ : 4718-4738. 
BAJOPAS Volume 13 Number 1, June, 2020

Mubarak, A. A., Azeez, M. L., Amos A. O., Opeyemi, O. O. (2016) Assessment of Animal Protein Consumption and Food Security Among Rural Households in Kwara State, Nigeria American Journal of Business and Society, 1(4): 233245.

Ndahi, M., D. Kwaga, J., K. P. Bello, M. Kabir J., V. Umoh, .J. Yakubu, S., E. and Nok, A., J. (2013) Prevalence and Antimicrobial Susceptibility of Listeria Monocytogenes and Methicillin-Resistant Staphylococcus aureus Strains from Raw Meat and Meat Products in Zaria, Nigeria. Applied Journal of Microbiology, 58(3):262-9.

Okonko, I.O., Odu, N.N. and Igboh, I.E. (2013). Microbiological Analysis of Kilishi Sold In Port Harcourt, Nigeria. New York Science Journal, 6 (7):37-43.

Osimani, A., Aquilanti, L. and Clementi, F. (2015) Microbiological Quality of Meatbased Meals and Operation of Control Systems within a Food Service Environment. International Food Research Journal 22(4): 1692-1698.

Onuorah, S. Obika, I. Odibo, F. Orji, M. (2015)An Assessment of the Bacteriological Quality of Tsire-Suya (Grilled Beef) sold in Awka, Nigeria. American. J. Life. Sci. Res. 3(4):287292.

Razavilar, V, Khandaghi, J. Barzgari, A. (2010); Isolation of Eschericia coli 0157:H7 from manure fertilized farms and raw vegetables grown on it, in Tabriz city in
Iran. African Journal of Microbiology Research, 4(9): 891-895.

Scallan, E. Hoekstra, R. M. Angulo, F. J.Tauxe, R. V, Widdowson, M. Roy, S. L et al., (2011).Food borne illness acquired in the United States- Major Pathogens. Emerg. Infec Dis, 17(1): 7-15.

Shamsuddeen U (2009). Microbiological quality of spice used in the production of Kilishi a traditionally dried and grilled meat product. Bayero Journal of Pure andApplied Sciences, 2(2): 66-69.

Shamsuddeen, U. (2015) Microbiological Hazard and Critical control point Analysis of Dried and Minced Meat Snacks Produced in Kano Nigeria. Lambert Academic Publishing; Pp 1-36.

Tijani, O.and Jumare, S. (2014). Microblological Quality Assessment of Meat

Sold in KauraNamoda. International Conference on Earth, Environment and Life sciences (EELS) Dubai (UAE).

Udobi, C. E., Obajuluwa, A. F., and Onaolapo, J. A., (2013) Prevalence and Antibiotic Resistance Pattern of MethicillinResistant Staphylococcus aureus from an Orthopaedic Hospital in Nigeria BioMed Research International; 26(6); 6-7.

WHO, 2015 Foodborne diseases in the WHO African Region.

Yousafzai HA, Rind R, Khan MA, Abro SH, Korejo NA, Ejaz M, Kabir A, Shahid M, Memon S. (2019). Microbiological Contamination of Cattle and Meat in Peshawar, Pakistan. J. Anim. Health Prod. 7(1): 1116. 


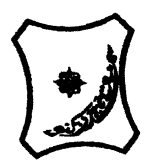

Bayero Journal of Pure and Applied Sciences, 13(1); 40 - 45

Received: September, 2019

Accepted: April, 2020

ISSN $2006-6996$

\title{
BACTERIOLOGICAL QUALITY OF STICK MEAT (Tsire) SOLD IN GARKO LOCAL GOVERNMENT AREA OF KANO STATE, NIGERIA
}

\author{
$*^{1}$ Dahiru A. T. and ${ }^{2}$ Maigari A. K. \\ ${ }^{1}$ Department of Hospitality Management, School of Technology, Kano State Polytechnic, PMB 3348, \\ Kano Nigeria. \\ ${ }^{2}$ Departmnt of Biological Sciences, Bayero University, Kano \\ Corresponding Author: dturajo61@gmail.com; GSM: 08087508262.
}

ABSTRACT

Stick meat, locally called Tsire in Hausa Language, is a significant portion of the diet of a large active population of Northern Nigeria. However, because of the handling and processing methods by the manufacturers as well as the hawking system of stick meat, the meat product may be exposed to both pre- and post-processed product contamination, and thus may poses danger to public health. Therefore, considering the role of Tsire in improving nutrition and increase household income to the populace, the need to improve the processing, distribution and overall quality of the product is simply indispensable. A total of 30 samples (5 samples from each of the 6 sampling points) of Tsire were collected randomly in Garko Town. Aerobic plate counts (APCs) and Total coliform counts (TCCS) of Tsire samples were determined using standard microbiological methods. APCs ranged from $1.02 \times 10^{5}$ to $4.00 \times 10^{5} \mathrm{CFU} / \mathrm{g}$; while TCCs ranged from $8 \mathrm{MPN} / \mathrm{g}$ to $68 \mathrm{MPN} / \mathrm{g}$. From the 30 samples screened, 16(53.33\%) bacteria namely, Campylobacter 2(6.66\%), Escherichia coli 6(20\%), Klebsiella pneumoniae 2(6.66\%), Salmonella spp. 1(3.33\%), Shigella 3(10\%) and Staphylococcus aureus 2(6.66\%) were detected. $E$. coli has the highest isolation rate of 6(20\%), while Salmonella spp. had the least frequency of 1(3.33\%). The distribution of isolated organisms within the study area were as follows: Dausai, 4(80\%), Kofar kudu, 4(80\%), Makwalla, 2(40\%), Rinji, 3(60\%), Tosaro, 2(40\%), and Tsohuwar Kasuwa, 1(20\%). The results have indicated that the Tsire was contaminated with bacteria thus exposing the product to fast deterioration, spoilage and also a vehicle for food borne illness, suggesting for adequate hygienic practices at all the stages, prior to consumption, to ensure safety of the meat product.

Key words: APCs, TCCs, Contamination, Microorganisms, Garko

\section{INTRODUCTION}

Nigeria is one of the developing nations with inadequate food supply and most often deficient in protein content (FAO, 2019). Nigerian's average animal protein intake per head per day is estimated at $7.9 \mathrm{~g}$ as against $35 \mathrm{~g}$ recommended value by Food and Agricultural Organization (Mubarak et al., 2016). These low levels of animal protein intake create great concern as it affects the nutritional status of Nigerians. Hence, there is the need for sufficient supply of animal protein from energy rich animal products to satisfy the nutritional requirements for Nigerians.

Meat is one major source of animal protein largely composed of water, protein and fats which can make it susceptible to microbial contamination within short time leading to spoilage (Apata et al., 2013; Mgbemere et al., 2011). Meat is mostly eaten after it has been cooked or processed in a variety of ways such as sun drying; smoking and roasting with or without fortifications (Borch et al., 1996). In Nigeria meat products such as Tsire, Kilishi and Balangu are locally produced using one or more of these methods in order to meet the nutritional requirements of the teeming Nigerians (Egbebi, 2011).

Tsire is a popular Nigerian traditional processed ready-to-eat roasted stick meat product (Shamsuddeen, 2015). It is sold in public places, along roads, in hotels, parks, quarters and even offices (Falegan et al., 2017). It is prepared from boneless healthy animal flesh such as beef and mutton, spiced with peanut cake, salt, vegetable oil and other flavorings followed by roasting (Shamsuddeen, 2015). Consumption of these products has extended to other parts of African countries such as Ghana, Somali, Cameroun and Chad (Ahmadu and Ibrahim, 2013). 
BAJOPAS Volume 13 Number 1, June, 2020

However, evidence of quality control sticking to procedural hygiene by the handlers during preparation and retailing of these products is poorly documented. Tsire is of great safety risk because of the fact that there are erratic cases of gastroenteritis and symptoms of food infection after consumption (WHO, 2015). Food borne illnesses are one of the major health problems in developing and developed countries (Razavilar, 2010). According to the World Health Organization, WHO (2015), $0.07 \%$ death of the 600 million global burdens of Foodborne illnesses have been reported to be caused by bacteria, viruses, fungi and chemicals. In America $0.27 \%$ of the estimated 48 million affected people is hospitalized and about $0.0063 \%$ deaths are recorded each year (Scallan et al., 2011). More than 91 million people in Africa fall ill and $0.15 \%$ dies each year, making Africa the highest burden bearer of Foodborne diseases per population (WHO, 2015).

Application of a Hazard Analysis Critical Control Point (HACCP) at all stages of meat products preparation is essential in order to ensure its safety. Thus, according to the guidelines of good manufacturing practice, the level of total aerobic bacterial contamination of thermally processed meat products should not exceed $10^{4}\left(\mathrm{cfu} \mathrm{g}^{-1}\right)$. Enterobacteriaceae and faecal coliform contamination in meat products should be within the range of $10^{2}-10^{4}$ and $10-10^{3} \mathrm{cfu} \mathrm{g}^{-1}$, respectively (Shamsuddeen, 2015). The aim of the study is therefore, to assess the total viable bacterial counts of tsire marketed locally within Garko town, and to isolate and identify the organisms at the point of consumption with the intention of promoting public health and food hygiene habits in the Nigerian populace.

\section{MATERIALS AND METHODS Study Area and Population}

Garko is one of the existing 44 local government areas located in Kano south west zone of Kano state with its capital administrative headquarters in the Garko town. It has coordinates $11^{\circ} 39^{\prime} \mathrm{N}$ $8^{\circ} 54^{\prime} \mathrm{E}$, and an area of $450 \mathrm{~km}^{2}$. The projected population of Garko local Government was 225,300 according to the National Population Census report (2018). Garko is known for agricultural activities both farming and animal husbandry. It is popularly known for large scale rice production. Other food crops include sweet potatoes, cassava, onions, sorghum, millet and sugarcane. Cows, sheep and goats are major groups of animals reared by majority of the populace. Meat products processed, retailed and consumed in Garko include roasted meat (Balangu), dried roasted meat (Kilishi), stick meat (Tsire), hide and skin pepper soup (Ragadada) and minced fried meat (Danbunnama).

\section{Samples Collection}

Five samples of Tsire products were collected from 6 different identified locations within Garko town in a sterile foil paper and immediately analyzed for the presence of bacteria.

\section{Sample Preparation}

Sample preparation for the bacteriological analysis was carried out in accordance with the method described by Atlas (1997). Twenty five grams $(25 \mathrm{~g})$ of the sample was homogenized in $225 \mathrm{ml}$ peptone water using Kenwood blender machine to obtain a $10^{1}$ homogenate. The homogenate was thoroughly shaken and $1 \mathrm{ml}$ pipetted into test tubes containing $9 \mathrm{ml}$ of peptone water $\left(10^{2}\right)$. The test tubes were further serially diluted to $10^{5}$.

Total Aerobic Mesophilic Bacterial Count

Total Aerobic mesophilic bacterial count was determined using the method described by Abdullahi et al. (2004) where $1 \mathrm{ml}$ of inoculums from $10^{1}$ to $10^{5}$ dilutions were transferred into duplicate Petri dishes and labeled accordingly. This was followed by pouring aseptically about $15 \mathrm{ml}$ of molten nutrient agar. The culture was homogenized by gentle spinning of the plates and allowed to solidify. The plates were incubated at $37^{\circ} \mathrm{C}$ for 24 hours. Plates containing 30-300 colonies were counted. The number of colony forming units per gram of a sample (cfu/g) was obtained by multiplying the average colony number with the inverse of the dilution factor.

\section{Enumeration and Detection of Coliform bacteria}

Detection and enumeration of coliform was carried out according to method described by Atlas, (1977). A set of 9 test tubes each containing $9 \mathrm{ml}$ of lactose broth and an inverted Durham tubes were autoclaved to expel air and to sterilize. Similarly, $1 \mathrm{ml}$ from the diluents $10^{1}$ was transferred to the first 3 test tubes, followed by $1 \mathrm{ml}$ from the diluents $10^{2}$ to the second set of 3 test tubes and finally the third diluents $10^{3}$ to the $3^{\text {rd }}$ set of 3 test tubes. All the 9 test tubes were incubated at $37^{\circ} \mathrm{C}$ for 24 hours. Tubes that showed gas and acid production after 24 hours were recorded as positive for the presence of Coliform. Negative tubes were further reincubated for 24 hours. Positive tubes were recorded. Estimate of most probable number of Coliform per gram of sample (MPN/g) was determined by comparing the number of gas positive tubes with the most probable number table. 
BAJOPAS Volume 13 Number 1, June, 2020 Identification of Coliform

A loop full of inoculum from gas positive tubes was streaked on to Eosine methylene blue (EMB) agar plate and incubated at $37^{\circ} \mathrm{C}$ for $24 \mathrm{hrs}$. Colonies which formed bluish black color with green metallic sheen, and reddish colonies were isolated on agar slants. Those colonies showing metallic sheen on EMB were sub cultured into tubes of lactose broth and incubated at $45^{\circ} \mathrm{C}$. The tubes were observed after $24 \mathrm{hrs}$ for gas production. This is the completed test for fecal coliform. Gram stain and other biochemical tests such as Indole, Methyl red, Voges-Proskauer and Citrate Utilization tests (IMVIC), Coagulase and Catalase tests were carried out for the Identification and confirmation of isolates.

\section{Procedure for Indole Test}

Indole test was carried out by preparing a Tryptone broth drawn in to test tubes, sterilized by autoclaving, inoculated with loopful of suspension and incubated at $37^{\circ} \mathrm{C}$ for 24 hours. Three drops of xylene was added in tubes, shaken vigorously and kept for the separation of two layers. One millilitre of Kovac's reagent was added and the formation of pink colour ring indicates positive Indole test.

\section{Procedure for Methyl Red Test}

Methyl red test was carried out by preparing Glucose phosphate broth, dispensed in test tubes, sterilized, inoculated with test culture and incubated at $37^{\circ} \mathrm{C}$ for 24 hours. Five drops of methyl-red indicator was added to the medium for the formation of red colour.

\section{Procedure for Voges-Proskauer Test}

Voges-Proskauer test was carried out by inoculating tubes with the bacterial culture followed by incubation for 48 hours at $37^{\circ} \mathrm{C}$. Separate pipettes were used to pipette $1 \mathrm{ml}$ from each culture tube into clean separate tubes. Eighteen drops $(0.5 \mathrm{ml})$ of Barrit's solution A (a-naphthol) was added to each tube containing glucose phosphate broth followed by the addition of an equal amount of solution $B$ into the same tube. The tubes were shaken at 30 seconds interval. A positive reaction was indicated by the development of a pink color, which turns red in 1-2 hours, after vigorous shaking.

\section{Procedure for Citrate Utilization Test}

Citrate Utilization Test was carried out by distributing melted agar (Simmon Citrate Agar) in to test tubes followed by sterilization at $121.5^{\circ} \mathrm{C}$ for 15 minutes. The test tubes were afterward held in slanted position, inoculated with the given bacterial culture and incubated at $37^{\circ} \mathrm{C}$ for $24 \mathrm{hrs}$. Positive test was indicated by color change of the media from green to blue.

\section{RESULTS AND DISCUSSIONS}

The results of this study are presented in tables $1,2,3$ and 4. Among the sampling areas Kofar Kudu had the highest aerobic mesophilic bacteria counts $4.0 \times 10^{5} \mathrm{cfu} / \mathrm{g}$ followed by Rinji $2.72 \times 10^{5} \mathrm{cfu} / \mathrm{g}$, while Tosaro had the least Aerobic mesophilic bacteria counts of $1.02 \times 10^{5}$ $\mathrm{cfu} / \mathrm{g}$ as indicated in Table 1.Makwalla had the highest coliform count $68 \mathrm{MPN} / \mathrm{g}$ followed by Rinji $37 \mathrm{MPN} / \mathrm{g}$. Tsohuwar Kasuwa had the least coliform counts $8 \mathrm{MPN} / \mathrm{g}$, (Table 2). Result from table 1 shows variation in the microbial contents among the samples which suggest variation in their sources, poor handling procedures and contamination from the processing environment. High coliform count and their differences within sampling areas is an indication of poor microbiological quality of the product. Ndahi et al. (2013) reported microbial load to be a function of the handling personnel and the environment. The results indicated that the samples were contaminated with bacteria as the counts exceeded the minimum safety level $\left(10^{4} \mathrm{cfu} / \mathrm{g}\right)$ for members of the Enterobacteriaceae family. However, it might be a reflection of poor hygienic practices which may contribute to health hazard to the potential consumers. Similarly, Inusa and Sa'id (2017); Osimani et al. (2015) reported that, the initial microbial content of the raw material play significant role in influencing the final microbial load of the finished product. Isolation of members of the Enterobacteriaceae such as $E$. coli, Klebsiella pneumoniae, Salmonella and Shigella signifies danger to the public health. These organisms are capable of producing endotoxins which trigger high fevers in infected individuals, and the enterotoxins which colonize the small intestines and lead to extreme dehydration as a result of vomiting and diarrhea sometimes with severe and fatal outcomes (Amaeze et al., 2016). From the 16 isolated organisms $E$. coli had the highest isolation rate $6(37.5 \%)$ (Table 3), this suggest faecal contamination of the products. $E$. coli is a common flora in the gastrointestinal tract responsible for diarrhea and extra-intestinal infections (CDC, 2011). The result is in conformity with the findings of Ndahi et al. (2013) and Shamsuddeen (2009). Also presence of campylobacter might be due to cross contamination from raw meat to finished product (Tsire). Staphylococcus aureus is a normal flora of the skin, nasal, genital, mouth or anal area in both humans and animals without any symptom of an infection (Matthew et al., 2013). Isolation of $S$. aureus in these study concords with the findings of Lucretia et al. (2018) from Suya sold in Rivers State. 
BAJOPAS Volume 13 Number 1, June, 2020

It is also in agreement with the findings of Yousafzai et al. (2018); Onuorah et al. (2015) and Tijjani and Jumare (2014) from tsire samples in different countries. Presence of $S$. aureus in foods is most of the time an indication of poor human handling, poor environment, unhygienic utensils and equipments used during processing (Igene et al., 2016; Okonko et al., 2013). Infections caused by $S$. aureus are difficult to treat leading to long hospitalization with consequent economic loss (Udobi et al., 2013). These include soft tissue infections, pneumonia, hospital-acquired postoperative wound infections, Staphylococcal food poisoning, impetigo and cellulitis (Charlene et al., 2013). Samples obtained from Dausai and Kofar Kudu had the highest isolation rate $4(80 \%)$ (Table 4 ) probably because of the much commercial activities taking place in the area which can lead to environmental contamination.

Table 1: Total Aerobic Mesophilic Bacterial Count of Tsire sold in Garko Town

\begin{tabular}{lll}
\hline Sampling Area & APC cfu/g & Mean \pm STD \\
\hline Dausai & $2.20 \times 10^{5}$ & $110000 \pm 14142.14$ \\
Kofar Kudu & $4.00 \times 10^{5}$ & $133333.3 \pm 23094.01$ \\
Makwalla & $1.30 \times 10^{5}$ & $32500 \pm 7187.953$ \\
Rinji & $2.72 \times 10^{5}$ & $90666.67 \pm 94769.90$ \\
Tosaro & $1.02 \times 10^{5}$ & $51000 \pm 15556.35$ \\
Tsohuwar Kasuwa & $1.75 \times 10^{5}$ & $35000 \pm 11357.82$ \\
\hline
\end{tabular}

Key: APC: Aerobic Mesophilic Counts

STD: Standard Deviation

Table 2: Total Coliform Count of Tsire sold in Garko Town

\begin{tabular}{lcc}
\hline \multicolumn{1}{c}{ Sampling Area } & TCC MPN/g & Mean \pm STD \\
\hline Dausai & 20 & $6.67 \pm 2.5166$ \\
Kofar Kudu & 32 & $16.00 \pm 5.6569$ \\
Makwalla & 68 & $13.60 \pm 8.7062$ \\
Rinji & 37 & $9.25 \pm 4.7871$ \\
Tosaro & 10 & $5.00 \pm 2.8284$ \\
Tsohuwar Kasuwa & 8 & $4.00 \pm 0.0000$ \\
\hline
\end{tabular}

Table 3: Organisms Isolated from Tsire Sold in Garko

\begin{tabular}{lcl}
\hline Isolated Organism & Frequency & Percentage (\%) \\
\hline Campylobacter & 2 & 06.66 \\
Escherichia coli & 6 & 20.00 \\
Klebsiella pneumoniae & 2 & 06.66 \\
Salmonella species & 1 & 03.33 \\
Shigella & 3 & 10.00 \\
Staphylococcus aureus & 2 & 06.66 \\
Total & 16 & \\
\hline
\end{tabular}

Table 4: Distribution of Organisms within Sampling Area

\begin{tabular}{lcc}
\hline \multicolumn{1}{c}{ Sampling Area } & No. Isolated & Percentage (\%) \\
\hline Dausai & 4 & 80 \\
Kofar Kudu & 4 & 80 \\
Makwalla & 2 & 40 \\
Rinji & 3 & 60 \\
Tosaro & 2 & 40 \\
Tsohuwar Kasuwa & 1 & 20 \\
Total & 16 & \\
\hline
\end{tabular}

\section{CONCLUSION}

Results indicated $4.00 \times 10^{5} \mathrm{CFU} / \mathrm{g}$ as the highest APCs count; while $68 \mathrm{MPN} / \mathrm{g}$ was the highest TCCs from the 30 samples analyzed. Among the isolates, $E$. coli has the highest isolation rate of $6(20 \%)$. Dausai and Kofar kudu were having the highest bacteria count of $4(80 \%)$, each, indicating higher contamination in those locations. 
BAJOPAS Volume 13 Number 1, June, 2020 RECOMMENDATIONS

The following recommendations are tenable:

1. Hygienic practices at all stages of production should be improved to safe guard the consumers against potential health hazard.

2. Monitoring of microbiological contamination of Tsire during preparations, packaging and marketing is essential to ensure product of good microbiological quality for consumers' health.

\section{REFERENCES}

Abdullahi, I. O., Umoh, V. J. and Galadima, M. (2004). Hazards Associated with Kilishi Preparations in Zaria. Nigerian Journal of Microbiology, 18 (1-2): $339-345$.

Ahmadu, J. and Ibrahim E. J., (2013): Determinants of Revenue in Suya Production in BeninCity, Edo State, Nigeria. Nigerian journal of agriculture, food and environment.9(3):1-5

Amaeze, N. Aboh, M. Itohan, A. Felix, E. Olatunji, T. and Oladosu, P. (2016) Microbial Profile, Antibiotic Sensitivity and Heat Resistance of Bacterial Isolates from Commercial Roasted Beef (Suya) in Abuja, Nigeria. JOPAT, 15(2): $22-30$.

Apata, E.S., Kuku1, I.A., Apata, O.C. and Adeyemi, K.O. (2013). Evaluation of Suya(Tsire) - An Intermediate Moisture Meat Product in Ogun State, Nigeria. J. Food Res 2 (1): 87.

Atlas, R. M. (1997) Principles of Microbiology Second Edition. C. Brown Publishers. Pp 802-803.

Borch, E. Kant-Muermans, M. L., Blixt, Y. (1996) Bacterial Spoilage of Meat and Cured Meat Products. Int $\mathrm{J}$ Food Microbiol .33(1): 103-20.

Centre for Disease Control, CDC (2011). "Escherichia coli 0157:H7" Division of Bacterial and Mycotic Diseasesht://www.cdc.gov/nczved/divisi ons/dfbmd/diseases/ecoli_0157h7/.

Charlene, R. J., Johnnie, A. D., and John, B. B., (2013) Prevalence and Characterization of Methicillin-Resistant Staphylococcus aureus Isolates from Retail Meat and Humans in Georgia. American society for Microbiology. J. of clinical microbiology. 12(1):123-6 doi:10.1128/JCM.0316612JCM.03166-12

Egbebi, A.O and Seidu, K., T. (2011). Microbiological Evaluation of Suya (dried smoked

meat) Sold in Ado and Akure, South West Nigeria.European Journal of Experinmental Biology, 1(4):1-5
3. Government should establish regulatory bodies responsible for inculcating hygiene habits to the local producers and vendors in order to prevent instant, cross and post processing contaminations by microbial pathogens.

4. Awareness and sensitization of local food producers about good hygienic practices in food handling and processing.

Falegan, C, R., Akoja, S. D., and Oyarekua, M. A., (2017) Microbiological Assessment of Suya (Sliced Roasted Beef) in Ado-Ekiti Metropolis, Ekiti State, Nigeria. MOJ Biology andMedicine.

Fonkem, D., N. Tanya, V., N. and Ebangi, A., L. (2010). Effect of Season on the Microbiological Quality of Kilishi, a Traditional Cameroonian Dried Beef Product. Tropicultura, 28(1): 10-15.

Food and Agricultural Organization of the United Nations (F A O, 1979). Manual of food quality control 4. Microbiological analysis.

Food and Agriculture Organisation of the United Nation (FAO), 2019. Nigeria at a glance.

Igene J.O., Uwadia, O.E., Ebabhamiegbebho, P.A. and Evivie, S.E., (2016) Shelf life Stability Studies of University of Benin (UNIBEN) Proff's Kilishi Product Asian Journal of Science and Technology 7(1): 2268-2274.

Inusa, S. K. and Said, I. S. (2017) Evaluation of the Chemical and Microbiological Properties Of Kilishi Sold in Kano Metropolis. Journal of Dry land Agriculture, 3 (1): $59-69$.

Lucretia, I. B, Patience, C. Obinna-Echem, Sophia, C. A. (2018) Microbiological quality andantibiotic sensitivity of potential pathogens isolated from meat product (Suya) sold in Rivers State University and its environs. International Journal of Biotechnology and Food Science, 6(4): 67-76.

Matthew, E., Drosos, E., John, L. and Ioanna, P. (2013) MRSA in Africa: Filling the Global Map of Antimicrobial Resistance PLOS One. 8(7): e68024 doi: 10.1371/journal.pone.0068024

Mgbemere, V.N., Akpapunam, M. A. and Igene, J. O., (2011). Effect of Groundnut FlourSubstitution on Yield, Quality and Storage Stability of Kilishi - a Nigerian Indigenous Dried Meat Product. African Journal of Food, Agriculture, Nutrition and Development, $\quad \mathbf{1 1}(2)$ : 4718-4738. 
BAJOPAS Volume 13 Number 1, June, 2020

Mubarak, A. A., Azeez, M. L., Amos A. O., Opeyemi, O. O. (2016) Assessment of Animal Protein Consumption and Food Security Among Rural Households in Kwara State, Nigeria American Journal of Business and Society, 1(4): 233245.

Ndahi, M., D. Kwaga, J., K. P. Bello, M. Kabir J., V. Umoh, .J. Yakubu, S., E. and Nok, A., J. (2013) Prevalence and Antimicrobial Susceptibility of Listeria Monocytogenes and Methicillin-Resistant Staphylococcus aureus Strains from Raw Meat and Meat Products in Zaria, Nigeria. Applied Journal of Microbiology, 58(3):262-9.

Okonko, I.O., Odu, N.N. and Igboh, I.E. (2013). Microbiological Analysis of Kilishi Sold In Port Harcourt, Nigeria. New York Science Journal, 6 (7):37-43.

Osimani, A., Aquilanti, L. and Clementi, F. (2015) Microbiological Quality of Meatbased Meals and Operation of Control Systems within a Food Service Environment. International Food Research Journal 22(4): 1692-1698.

Onuorah, S. Obika, I. Odibo, F. Orji, M. (2015)An Assessment of the Bacteriological Quality of Tsire-Suya (Grilled Beef) sold in Awka, Nigeria. American. J. Life. Sci. Res. 3(4):287292.

Razavilar, V, Khandaghi, J. Barzgari, A. (2010); Isolation of Eschericia coli 0157:H7 from manure fertilized farms and raw vegetables grown on it, in Tabriz city in
Iran. African Journal of Microbiology Research, 4(9): 891-895.

Scallan, E. Hoekstra, R. M. Angulo, F. J.Tauxe, R. V, Widdowson, M. Roy, S. L et al., (2011).Food borne illness acquired in the United States- Major Pathogens. Emerg. Infec Dis, 17(1): 7-15.

Shamsuddeen U (2009). Microbiological quality of spice used in the production of Kilishi a traditionally dried and grilled meat product. Bayero Journal of Pure andApplied Sciences, 2(2): 66-69.

Shamsuddeen, U. (2015) Microbiological Hazard and Critical control point Analysis of Dried and Minced Meat Snacks Produced in Kano Nigeria. Lambert Academic Publishing; Pp 1-36.

Tijani, O.and Jumare, S. (2014). Microblological Quality Assessment of Meat

Sold in KauraNamoda. International Conference on Earth, Environment and Life sciences (EELS) Dubai (UAE).

Udobi, C. E., Obajuluwa, A. F., and Onaolapo, J. A., (2013) Prevalence and Antibiotic Resistance Pattern of MethicillinResistant Staphylococcus aureus from an Orthopaedic Hospital in Nigeria BioMed Research International; 26(6); 6-7.

WHO, 2015 Foodborne diseases in the WHO African Region.

Yousafzai HA, Rind R, Khan MA, Abro SH, Korejo NA, Ejaz M, Kabir A, Shahid M, Memon S. (2019). Microbiological Contamination of Cattle and Meat in Peshawar, Pakistan. J. Anim. Health Prod. 7(1): 1116. 


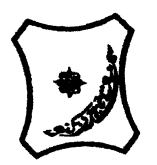

Bayero Journal of Pure and Applied Sciences, 13(1); 40 - 45

Received: September, 2019

Accepted: April, 2020

ISSN $2006-6996$

\title{
BACTERIOLOGICAL QUALITY OF STICK MEAT (Tsire) SOLD IN GARKO LOCAL GOVERNMENT AREA OF KANO STATE, NIGERIA
}

\author{
$*^{1}$ Dahiru A. T. and ${ }^{2}$ Maigari A. K. \\ ${ }^{1}$ Department of Hospitality Management, School of Technology, Kano State Polytechnic, PMB 3348, \\ Kano Nigeria. \\ ${ }^{2}$ Departmnt of Biological Sciences, Bayero University, Kano \\ Corresponding Author: dturajo61@gmail.com; GSM: 08087508262.
}

ABSTRACT

Stick meat, locally called Tsire in Hausa Language, is a significant portion of the diet of a large active population of Northern Nigeria. However, because of the handling and processing methods by the manufacturers as well as the hawking system of stick meat, the meat product may be exposed to both pre- and post-processed product contamination, and thus may poses danger to public health. Therefore, considering the role of Tsire in improving nutrition and increase household income to the populace, the need to improve the processing, distribution and overall quality of the product is simply indispensable. A total of 30 samples (5 samples from each of the 6 sampling points) of Tsire were collected randomly in Garko Town. Aerobic plate counts (APCs) and Total coliform counts (TCCS) of Tsire samples were determined using standard microbiological methods. APCs ranged from $1.02 \times 10^{5}$ to $4.00 \times 10^{5} \mathrm{CFU} / \mathrm{g}$; while TCCs ranged from $8 \mathrm{MPN} / \mathrm{g}$ to $68 \mathrm{MPN} / \mathrm{g}$. From the 30 samples screened, 16(53.33\%) bacteria namely, Campylobacter 2(6.66\%), Escherichia coli 6(20\%), Klebsiella pneumoniae 2(6.66\%), Salmonella spp. 1(3.33\%), Shigella 3(10\%) and Staphylococcus aureus 2(6.66\%) were detected. $E$. coli has the highest isolation rate of 6(20\%), while Salmonella spp. had the least frequency of 1(3.33\%). The distribution of isolated organisms within the study area were as follows: Dausai, 4(80\%), Kofar kudu, 4(80\%), Makwalla, 2(40\%), Rinji, 3(60\%), Tosaro, 2(40\%), and Tsohuwar Kasuwa, 1(20\%). The results have indicated that the Tsire was contaminated with bacteria thus exposing the product to fast deterioration, spoilage and also a vehicle for food borne illness, suggesting for adequate hygienic practices at all the stages, prior to consumption, to ensure safety of the meat product.

Key words: APCs, TCCs, Contamination, Microorganisms, Garko

\section{INTRODUCTION}

Nigeria is one of the developing nations with inadequate food supply and most often deficient in protein content (FAO, 2019). Nigerian's average animal protein intake per head per day is estimated at $7.9 \mathrm{~g}$ as against $35 \mathrm{~g}$ recommended value by Food and Agricultural Organization (Mubarak et al., 2016). These low levels of animal protein intake create great concern as it affects the nutritional status of Nigerians. Hence, there is the need for sufficient supply of animal protein from energy rich animal products to satisfy the nutritional requirements for Nigerians.

Meat is one major source of animal protein largely composed of water, protein and fats which can make it susceptible to microbial contamination within short time leading to spoilage (Apata et al., 2013; Mgbemere et al., 2011). Meat is mostly eaten after it has been cooked or processed in a variety of ways such as sun drying; smoking and roasting with or without fortifications (Borch et al., 1996). In Nigeria meat products such as Tsire, Kilishi and Balangu are locally produced using one or more of these methods in order to meet the nutritional requirements of the teeming Nigerians (Egbebi, 2011).

Tsire is a popular Nigerian traditional processed ready-to-eat roasted stick meat product (Shamsuddeen, 2015). It is sold in public places, along roads, in hotels, parks, quarters and even offices (Falegan et al., 2017). It is prepared from boneless healthy animal flesh such as beef and mutton, spiced with peanut cake, salt, vegetable oil and other flavorings followed by roasting (Shamsuddeen, 2015). Consumption of these products has extended to other parts of African countries such as Ghana, Somali, Cameroun and Chad (Ahmadu and Ibrahim, 2013). 
BAJOPAS Volume 13 Number 1, June, 2020

However, evidence of quality control sticking to procedural hygiene by the handlers during preparation and retailing of these products is poorly documented. Tsire is of great safety risk because of the fact that there are erratic cases of gastroenteritis and symptoms of food infection after consumption (WHO, 2015). Food borne illnesses are one of the major health problems in developing and developed countries (Razavilar, 2010). According to the World Health Organization, WHO (2015), $0.07 \%$ death of the 600 million global burdens of Foodborne illnesses have been reported to be caused by bacteria, viruses, fungi and chemicals. In America $0.27 \%$ of the estimated 48 million affected people is hospitalized and about $0.0063 \%$ deaths are recorded each year (Scallan et al., 2011). More than 91 million people in Africa fall ill and $0.15 \%$ dies each year, making Africa the highest burden bearer of Foodborne diseases per population (WHO, 2015).

Application of a Hazard Analysis Critical Control Point (HACCP) at all stages of meat products preparation is essential in order to ensure its safety. Thus, according to the guidelines of good manufacturing practice, the level of total aerobic bacterial contamination of thermally processed meat products should not exceed $10^{4}\left(\mathrm{cfu} \mathrm{g}^{-1}\right)$. Enterobacteriaceae and faecal coliform contamination in meat products should be within the range of $10^{2}-10^{4}$ and $10-10^{3} \mathrm{cfu} \mathrm{g}^{-1}$, respectively (Shamsuddeen, 2015). The aim of the study is therefore, to assess the total viable bacterial counts of tsire marketed locally within Garko town, and to isolate and identify the organisms at the point of consumption with the intention of promoting public health and food hygiene habits in the Nigerian populace.

\section{MATERIALS AND METHODS Study Area and Population}

Garko is one of the existing 44 local government areas located in Kano south west zone of Kano state with its capital administrative headquarters in the Garko town. It has coordinates $11^{\circ} 39^{\prime} \mathrm{N}$ $8^{\circ} 54^{\prime} \mathrm{E}$, and an area of $450 \mathrm{~km}^{2}$. The projected population of Garko local Government was 225,300 according to the National Population Census report (2018). Garko is known for agricultural activities both farming and animal husbandry. It is popularly known for large scale rice production. Other food crops include sweet potatoes, cassava, onions, sorghum, millet and sugarcane. Cows, sheep and goats are major groups of animals reared by majority of the populace. Meat products processed, retailed and consumed in Garko include roasted meat (Balangu), dried roasted meat (Kilishi), stick meat (Tsire), hide and skin pepper soup (Ragadada) and minced fried meat (Danbunnama).

\section{Samples Collection}

Five samples of Tsire products were collected from 6 different identified locations within Garko town in a sterile foil paper and immediately analyzed for the presence of bacteria.

\section{Sample Preparation}

Sample preparation for the bacteriological analysis was carried out in accordance with the method described by Atlas (1997). Twenty five grams $(25 \mathrm{~g})$ of the sample was homogenized in $225 \mathrm{ml}$ peptone water using Kenwood blender machine to obtain a $10^{1}$ homogenate. The homogenate was thoroughly shaken and $1 \mathrm{ml}$ pipetted into test tubes containing $9 \mathrm{ml}$ of peptone water $\left(10^{2}\right)$. The test tubes were further serially diluted to $10^{5}$.

Total Aerobic Mesophilic Bacterial Count

Total Aerobic mesophilic bacterial count was determined using the method described by Abdullahi et al. (2004) where $1 \mathrm{ml}$ of inoculums from $10^{1}$ to $10^{5}$ dilutions were transferred into duplicate Petri dishes and labeled accordingly. This was followed by pouring aseptically about $15 \mathrm{ml}$ of molten nutrient agar. The culture was homogenized by gentle spinning of the plates and allowed to solidify. The plates were incubated at $37^{\circ} \mathrm{C}$ for 24 hours. Plates containing 30-300 colonies were counted. The number of colony forming units per gram of a sample (cfu/g) was obtained by multiplying the average colony number with the inverse of the dilution factor.

\section{Enumeration and Detection of Coliform bacteria}

Detection and enumeration of coliform was carried out according to method described by Atlas, (1977). A set of 9 test tubes each containing $9 \mathrm{ml}$ of lactose broth and an inverted Durham tubes were autoclaved to expel air and to sterilize. Similarly, $1 \mathrm{ml}$ from the diluents $10^{1}$ was transferred to the first 3 test tubes, followed by $1 \mathrm{ml}$ from the diluents $10^{2}$ to the second set of 3 test tubes and finally the third diluents $10^{3}$ to the $3^{\text {rd }}$ set of 3 test tubes. All the 9 test tubes were incubated at $37^{\circ} \mathrm{C}$ for 24 hours. Tubes that showed gas and acid production after 24 hours were recorded as positive for the presence of Coliform. Negative tubes were further reincubated for 24 hours. Positive tubes were recorded. Estimate of most probable number of Coliform per gram of sample (MPN/g) was determined by comparing the number of gas positive tubes with the most probable number table. 
BAJOPAS Volume 13 Number 1, June, 2020 Identification of Coliform

A loop full of inoculum from gas positive tubes was streaked on to Eosine methylene blue (EMB) agar plate and incubated at $37^{\circ} \mathrm{C}$ for $24 \mathrm{hrs}$. Colonies which formed bluish black color with green metallic sheen, and reddish colonies were isolated on agar slants. Those colonies showing metallic sheen on EMB were sub cultured into tubes of lactose broth and incubated at $45^{\circ} \mathrm{C}$. The tubes were observed after $24 \mathrm{hrs}$ for gas production. This is the completed test for fecal coliform. Gram stain and other biochemical tests such as Indole, Methyl red, Voges-Proskauer and Citrate Utilization tests (IMVIC), Coagulase and Catalase tests were carried out for the Identification and confirmation of isolates.

\section{Procedure for Indole Test}

Indole test was carried out by preparing a Tryptone broth drawn in to test tubes, sterilized by autoclaving, inoculated with loopful of suspension and incubated at $37^{\circ} \mathrm{C}$ for 24 hours. Three drops of xylene was added in tubes, shaken vigorously and kept for the separation of two layers. One millilitre of Kovac's reagent was added and the formation of pink colour ring indicates positive Indole test.

\section{Procedure for Methyl Red Test}

Methyl red test was carried out by preparing Glucose phosphate broth, dispensed in test tubes, sterilized, inoculated with test culture and incubated at $37^{\circ} \mathrm{C}$ for 24 hours. Five drops of methyl-red indicator was added to the medium for the formation of red colour.

\section{Procedure for Voges-Proskauer Test}

Voges-Proskauer test was carried out by inoculating tubes with the bacterial culture followed by incubation for 48 hours at $37^{\circ} \mathrm{C}$. Separate pipettes were used to pipette $1 \mathrm{ml}$ from each culture tube into clean separate tubes. Eighteen drops $(0.5 \mathrm{ml})$ of Barrit's solution A (a-naphthol) was added to each tube containing glucose phosphate broth followed by the addition of an equal amount of solution $B$ into the same tube. The tubes were shaken at 30 seconds interval. A positive reaction was indicated by the development of a pink color, which turns red in 1-2 hours, after vigorous shaking.

\section{Procedure for Citrate Utilization Test}

Citrate Utilization Test was carried out by distributing melted agar (Simmon Citrate Agar) in to test tubes followed by sterilization at $121.5^{\circ} \mathrm{C}$ for 15 minutes. The test tubes were afterward held in slanted position, inoculated with the given bacterial culture and incubated at $37^{\circ} \mathrm{C}$ for $24 \mathrm{hrs}$. Positive test was indicated by color change of the media from green to blue.

\section{RESULTS AND DISCUSSIONS}

The results of this study are presented in tables $1,2,3$ and 4. Among the sampling areas Kofar Kudu had the highest aerobic mesophilic bacteria counts $4.0 \times 10^{5} \mathrm{cfu} / \mathrm{g}$ followed by Rinji $2.72 \times 10^{5} \mathrm{cfu} / \mathrm{g}$, while Tosaro had the least Aerobic mesophilic bacteria counts of $1.02 \times 10^{5}$ $\mathrm{cfu} / \mathrm{g}$ as indicated in Table 1.Makwalla had the highest coliform count $68 \mathrm{MPN} / \mathrm{g}$ followed by Rinji $37 \mathrm{MPN} / \mathrm{g}$. Tsohuwar Kasuwa had the least coliform counts $8 \mathrm{MPN} / \mathrm{g}$, (Table 2). Result from table 1 shows variation in the microbial contents among the samples which suggest variation in their sources, poor handling procedures and contamination from the processing environment. High coliform count and their differences within sampling areas is an indication of poor microbiological quality of the product. Ndahi et al. (2013) reported microbial load to be a function of the handling personnel and the environment. The results indicated that the samples were contaminated with bacteria as the counts exceeded the minimum safety level $\left(10^{4} \mathrm{cfu} / \mathrm{g}\right)$ for members of the Enterobacteriaceae family. However, it might be a reflection of poor hygienic practices which may contribute to health hazard to the potential consumers. Similarly, Inusa and Sa'id (2017); Osimani et al. (2015) reported that, the initial microbial content of the raw material play significant role in influencing the final microbial load of the finished product. Isolation of members of the Enterobacteriaceae such as $E$. coli, Klebsiella pneumoniae, Salmonella and Shigella signifies danger to the public health. These organisms are capable of producing endotoxins which trigger high fevers in infected individuals, and the enterotoxins which colonize the small intestines and lead to extreme dehydration as a result of vomiting and diarrhea sometimes with severe and fatal outcomes (Amaeze et al., 2016). From the 16 isolated organisms $E$. coli had the highest isolation rate $6(37.5 \%)$ (Table 3), this suggest faecal contamination of the products. $E$. coli is a common flora in the gastrointestinal tract responsible for diarrhea and extra-intestinal infections (CDC, 2011). The result is in conformity with the findings of Ndahi et al. (2013) and Shamsuddeen (2009). Also presence of campylobacter might be due to cross contamination from raw meat to finished product (Tsire). Staphylococcus aureus is a normal flora of the skin, nasal, genital, mouth or anal area in both humans and animals without any symptom of an infection (Matthew et al., 2013). Isolation of $S$. aureus in these study concords with the findings of Lucretia et al. (2018) from Suya sold in Rivers State. 
BAJOPAS Volume 13 Number 1, June, 2020

It is also in agreement with the findings of Yousafzai et al. (2018); Onuorah et al. (2015) and Tijjani and Jumare (2014) from tsire samples in different countries. Presence of $S$. aureus in foods is most of the time an indication of poor human handling, poor environment, unhygienic utensils and equipments used during processing (Igene et al., 2016; Okonko et al., 2013). Infections caused by $S$. aureus are difficult to treat leading to long hospitalization with consequent economic loss (Udobi et al., 2013). These include soft tissue infections, pneumonia, hospital-acquired postoperative wound infections, Staphylococcal food poisoning, impetigo and cellulitis (Charlene et al., 2013). Samples obtained from Dausai and Kofar Kudu had the highest isolation rate $4(80 \%)$ (Table 4 ) probably because of the much commercial activities taking place in the area which can lead to environmental contamination.

Table 1: Total Aerobic Mesophilic Bacterial Count of Tsire sold in Garko Town

\begin{tabular}{lll}
\hline Sampling Area & APC cfu/g & Mean \pm STD \\
\hline Dausai & $2.20 \times 10^{5}$ & $110000 \pm 14142.14$ \\
Kofar Kudu & $4.00 \times 10^{5}$ & $133333.3 \pm 23094.01$ \\
Makwalla & $1.30 \times 10^{5}$ & $32500 \pm 7187.953$ \\
Rinji & $2.72 \times 10^{5}$ & $90666.67 \pm 94769.90$ \\
Tosaro & $1.02 \times 10^{5}$ & $51000 \pm 15556.35$ \\
Tsohuwar Kasuwa & $1.75 \times 10^{5}$ & $35000 \pm 11357.82$ \\
\hline
\end{tabular}

Key: APC: Aerobic Mesophilic Counts

STD: Standard Deviation

Table 2: Total Coliform Count of Tsire sold in Garko Town

\begin{tabular}{lcc}
\hline \multicolumn{1}{c}{ Sampling Area } & TCC MPN/g & Mean \pm STD \\
\hline Dausai & 20 & $6.67 \pm 2.5166$ \\
Kofar Kudu & 32 & $16.00 \pm 5.6569$ \\
Makwalla & 68 & $13.60 \pm 8.7062$ \\
Rinji & 37 & $9.25 \pm 4.7871$ \\
Tosaro & 10 & $5.00 \pm 2.8284$ \\
Tsohuwar Kasuwa & 8 & $4.00 \pm 0.0000$ \\
\hline
\end{tabular}

Table 3: Organisms Isolated from Tsire Sold in Garko

\begin{tabular}{lcl}
\hline Isolated Organism & Frequency & Percentage (\%) \\
\hline Campylobacter & 2 & 06.66 \\
Escherichia coli & 6 & 20.00 \\
Klebsiella pneumoniae & 2 & 06.66 \\
Salmonella species & 1 & 03.33 \\
Shigella & 3 & 10.00 \\
Staphylococcus aureus & 2 & 06.66 \\
Total & 16 & \\
\hline
\end{tabular}

Table 4: Distribution of Organisms within Sampling Area

\begin{tabular}{lcc}
\hline \multicolumn{1}{c}{ Sampling Area } & No. Isolated & Percentage (\%) \\
\hline Dausai & 4 & 80 \\
Kofar Kudu & 4 & 80 \\
Makwalla & 2 & 40 \\
Rinji & 3 & 60 \\
Tosaro & 2 & 40 \\
Tsohuwar Kasuwa & 1 & 20 \\
Total & 16 & \\
\hline
\end{tabular}

\section{CONCLUSION}

Results indicated $4.00 \times 10^{5} \mathrm{CFU} / \mathrm{g}$ as the highest APCs count; while $68 \mathrm{MPN} / \mathrm{g}$ was the highest TCCs from the 30 samples analyzed. Among the isolates, $E$. coli has the highest isolation rate of $6(20 \%)$. Dausai and Kofar kudu were having the highest bacteria count of $4(80 \%)$, each, indicating higher contamination in those locations. 
BAJOPAS Volume 13 Number 1, June, 2020 RECOMMENDATIONS

The following recommendations are tenable:

1. Hygienic practices at all stages of production should be improved to safe guard the consumers against potential health hazard.

2. Monitoring of microbiological contamination of Tsire during preparations, packaging and marketing is essential to ensure product of good microbiological quality for consumers' health.

\section{REFERENCES}

Abdullahi, I. O., Umoh, V. J. and Galadima, M. (2004). Hazards Associated with Kilishi Preparations in Zaria. Nigerian Journal of Microbiology, 18 (1-2): $339-345$.

Ahmadu, J. and Ibrahim E. J., (2013): Determinants of Revenue in Suya Production in BeninCity, Edo State, Nigeria. Nigerian journal of agriculture, food and environment.9(3):1-5

Amaeze, N. Aboh, M. Itohan, A. Felix, E. Olatunji, T. and Oladosu, P. (2016) Microbial Profile, Antibiotic Sensitivity and Heat Resistance of Bacterial Isolates from Commercial Roasted Beef (Suya) in Abuja, Nigeria. JOPAT, 15(2): $22-30$.

Apata, E.S., Kuku1, I.A., Apata, O.C. and Adeyemi, K.O. (2013). Evaluation of Suya(Tsire) - An Intermediate Moisture Meat Product in Ogun State, Nigeria. J. Food Res 2 (1): 87.

Atlas, R. M. (1997) Principles of Microbiology Second Edition. C. Brown Publishers. Pp 802-803.

Borch, E. Kant-Muermans, M. L., Blixt, Y. (1996) Bacterial Spoilage of Meat and Cured Meat Products. Int $\mathrm{J}$ Food Microbiol .33(1): 103-20.

Centre for Disease Control, CDC (2011). "Escherichia coli 0157:H7" Division of Bacterial and Mycotic Diseasesht://www.cdc.gov/nczved/divisi ons/dfbmd/diseases/ecoli_0157h7/.

Charlene, R. J., Johnnie, A. D., and John, B. B., (2013) Prevalence and Characterization of Methicillin-Resistant Staphylococcus aureus Isolates from Retail Meat and Humans in Georgia. American society for Microbiology. J. of clinical microbiology. 12(1):123-6 doi:10.1128/JCM.0316612JCM.03166-12

Egbebi, A.O and Seidu, K., T. (2011). Microbiological Evaluation of Suya (dried smoked

meat) Sold in Ado and Akure, South West Nigeria.European Journal of Experinmental Biology, 1(4):1-5
3. Government should establish regulatory bodies responsible for inculcating hygiene habits to the local producers and vendors in order to prevent instant, cross and post processing contaminations by microbial pathogens.

4. Awareness and sensitization of local food producers about good hygienic practices in food handling and processing.

Falegan, C, R., Akoja, S. D., and Oyarekua, M. A., (2017) Microbiological Assessment of Suya (Sliced Roasted Beef) in Ado-Ekiti Metropolis, Ekiti State, Nigeria. MOJ Biology andMedicine.

Fonkem, D., N. Tanya, V., N. and Ebangi, A., L. (2010). Effect of Season on the Microbiological Quality of Kilishi, a Traditional Cameroonian Dried Beef Product. Tropicultura, 28(1): 10-15.

Food and Agricultural Organization of the United Nations (F A O, 1979). Manual of food quality control 4. Microbiological analysis.

Food and Agriculture Organisation of the United Nation (FAO), 2019. Nigeria at a glance.

Igene J.O., Uwadia, O.E., Ebabhamiegbebho, P.A. and Evivie, S.E., (2016) Shelf life Stability Studies of University of Benin (UNIBEN) Proff's Kilishi Product Asian Journal of Science and Technology 7(1): 2268-2274.

Inusa, S. K. and Said, I. S. (2017) Evaluation of the Chemical and Microbiological Properties Of Kilishi Sold in Kano Metropolis. Journal of Dry land Agriculture, 3 (1): $59-69$.

Lucretia, I. B, Patience, C. Obinna-Echem, Sophia, C. A. (2018) Microbiological quality andantibiotic sensitivity of potential pathogens isolated from meat product (Suya) sold in Rivers State University and its environs. International Journal of Biotechnology and Food Science, 6(4): 67-76.

Matthew, E., Drosos, E., John, L. and Ioanna, P. (2013) MRSA in Africa: Filling the Global Map of Antimicrobial Resistance PLOS One. 8(7): e68024 doi: 10.1371/journal.pone.0068024

Mgbemere, V.N., Akpapunam, M. A. and Igene, J. O., (2011). Effect of Groundnut FlourSubstitution on Yield, Quality and Storage Stability of Kilishi - a Nigerian Indigenous Dried Meat Product. African Journal of Food, Agriculture, Nutrition and Development, $\quad \mathbf{1 1}(2)$ : 4718-4738. 
BAJOPAS Volume 13 Number 1, June, 2020

Mubarak, A. A., Azeez, M. L., Amos A. O., Opeyemi, O. O. (2016) Assessment of Animal Protein Consumption and Food Security Among Rural Households in Kwara State, Nigeria American Journal of Business and Society, 1(4): 233245.

Ndahi, M., D. Kwaga, J., K. P. Bello, M. Kabir J., V. Umoh, .J. Yakubu, S., E. and Nok, A., J. (2013) Prevalence and Antimicrobial Susceptibility of Listeria Monocytogenes and Methicillin-Resistant Staphylococcus aureus Strains from Raw Meat and Meat Products in Zaria, Nigeria. Applied Journal of Microbiology, 58(3):262-9.

Okonko, I.O., Odu, N.N. and Igboh, I.E. (2013). Microbiological Analysis of Kilishi Sold In Port Harcourt, Nigeria. New York Science Journal, 6 (7):37-43.

Osimani, A., Aquilanti, L. and Clementi, F. (2015) Microbiological Quality of Meatbased Meals and Operation of Control Systems within a Food Service Environment. International Food Research Journal 22(4): 1692-1698.

Onuorah, S. Obika, I. Odibo, F. Orji, M. (2015)An Assessment of the Bacteriological Quality of Tsire-Suya (Grilled Beef) sold in Awka, Nigeria. American. J. Life. Sci. Res. 3(4):287292.

Razavilar, V, Khandaghi, J. Barzgari, A. (2010); Isolation of Eschericia coli 0157:H7 from manure fertilized farms and raw vegetables grown on it, in Tabriz city in
Iran. African Journal of Microbiology Research, 4(9): 891-895.

Scallan, E. Hoekstra, R. M. Angulo, F. J.Tauxe, R. V, Widdowson, M. Roy, S. L et al., (2011).Food borne illness acquired in the United States- Major Pathogens. Emerg. Infec Dis, 17(1): 7-15.

Shamsuddeen U (2009). Microbiological quality of spice used in the production of Kilishi a traditionally dried and grilled meat product. Bayero Journal of Pure andApplied Sciences, 2(2): 66-69.

Shamsuddeen, U. (2015) Microbiological Hazard and Critical control point Analysis of Dried and Minced Meat Snacks Produced in Kano Nigeria. Lambert Academic Publishing; Pp 1-36.

Tijani, O.and Jumare, S. (2014). Microblological Quality Assessment of Meat

Sold in KauraNamoda. International Conference on Earth, Environment and Life sciences (EELS) Dubai (UAE).

Udobi, C. E., Obajuluwa, A. F., and Onaolapo, J. A., (2013) Prevalence and Antibiotic Resistance Pattern of MethicillinResistant Staphylococcus aureus from an Orthopaedic Hospital in Nigeria BioMed Research International; 26(6); 6-7.

WHO, 2015 Foodborne diseases in the WHO African Region.

Yousafzai HA, Rind R, Khan MA, Abro SH, Korejo NA, Ejaz M, Kabir A, Shahid M, Memon S. (2019). Microbiological Contamination of Cattle and Meat in Peshawar, Pakistan. J. Anim. Health Prod. 7(1): 1116. 


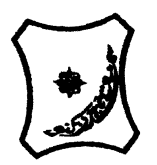

Bayero Journal of Pure and Applied Sciences, 13(1); 40 - 45

Received: September, 2019

Accepted: April, 2020

ISSN $2006-6996$

\title{
BACTERIOLOGICAL QUALITY OF STICK MEAT (Tsire) SOLD IN GARKO LOCAL GOVERNMENT AREA OF KANO STATE, NIGERIA
}

\author{
$*^{1}$ Dahiru A. T. and ${ }^{2}$ Maigari A. K. \\ ${ }^{1}$ Department of Hospitality Management, School of Technology, Kano State Polytechnic, PMB 3348, \\ Kano Nigeria. \\ ${ }^{2}$ Departmnt of Biological Sciences, Bayero University, Kano \\ Corresponding Author: dturajo61@gmail.com; GSM: 08087508262.
}

ABSTRACT

Stick meat, locally called Tsire in Hausa Language, is a significant portion of the diet of a large active population of Northern Nigeria. However, because of the handling and processing methods by the manufacturers as well as the hawking system of stick meat, the meat product may be exposed to both pre- and post-processed product contamination, and thus may poses danger to public health. Therefore, considering the role of Tsire in improving nutrition and increase household income to the populace, the need to improve the processing, distribution and overall quality of the product is simply indispensable. A total of 30 samples (5 samples from each of the 6 sampling points) of Tsire were collected randomly in Garko Town. Aerobic plate counts (APCs) and Total coliform counts (TCCS) of Tsire samples were determined using standard microbiological methods. APCs ranged from $1.02 \times 10^{5}$ to $4.00 \times 10^{5} \mathrm{CFU} / \mathrm{g}$; while TCCs ranged from $8 \mathrm{MPN} / \mathrm{g}$ to $68 \mathrm{MPN} / \mathrm{g}$. From the 30 samples screened, 16(53.33\%) bacteria namely, Campylobacter 2(6.66\%), Escherichia coli 6(20\%), Klebsiella pneumoniae 2(6.66\%), Salmonella spp. 1(3.33\%), Shigella 3(10\%) and Staphylococcus aureus 2(6.66\%) were detected. $E$. coli has the highest isolation rate of 6(20\%), while Salmonella spp. had the least frequency of 1(3.33\%). The distribution of isolated organisms within the study area were as follows: Dausai, 4(80\%), Kofar kudu, 4(80\%), Makwalla, 2(40\%), Rinji, 3(60\%), Tosaro, 2(40\%), and Tsohuwar Kasuwa, 1(20\%). The results have indicated that the Tsire was contaminated with bacteria thus exposing the product to fast deterioration, spoilage and also a vehicle for food borne illness, suggesting for adequate hygienic practices at all the stages, prior to consumption, to ensure safety of the meat product.

Key words: APCs, TCCs, Contamination, Microorganisms, Garko

\section{INTRODUCTION}

Nigeria is one of the developing nations with inadequate food supply and most often deficient in protein content (FAO, 2019). Nigerian's average animal protein intake per head per day is estimated at $7.9 \mathrm{~g}$ as against $35 \mathrm{~g}$ recommended value by Food and Agricultural Organization (Mubarak et al., 2016). These low levels of animal protein intake create great concern as it affects the nutritional status of Nigerians. Hence, there is the need for sufficient supply of animal protein from energy rich animal products to satisfy the nutritional requirements for Nigerians.

Meat is one major source of animal protein largely composed of water, protein and fats which can make it susceptible to microbial contamination within short time leading to spoilage (Apata et al., 2013; Mgbemere et al., 2011). Meat is mostly eaten after it has been cooked or processed in a variety of ways such as sun drying; smoking and roasting with or without fortifications (Borch et al., 1996). In Nigeria meat products such as Tsire, Kilishi and Balangu are locally produced using one or more of these methods in order to meet the nutritional requirements of the teeming Nigerians (Egbebi, 2011).

Tsire is a popular Nigerian traditional processed ready-to-eat roasted stick meat product (Shamsuddeen, 2015). It is sold in public places, along roads, in hotels, parks, quarters and even offices (Falegan et al., 2017). It is prepared from boneless healthy animal flesh such as beef and mutton, spiced with peanut cake, salt, vegetable oil and other flavorings followed by roasting (Shamsuddeen, 2015). Consumption of these products has extended to other parts of African countries such as Ghana, Somali, Cameroun and Chad (Ahmadu and Ibrahim, 2013). 
BAJOPAS Volume 13 Number 1, June, 2020

However, evidence of quality control sticking to procedural hygiene by the handlers during preparation and retailing of these products is poorly documented. Tsire is of great safety risk because of the fact that there are erratic cases of gastroenteritis and symptoms of food infection after consumption (WHO, 2015). Food borne illnesses are one of the major health problems in developing and developed countries (Razavilar, 2010). According to the World Health Organization, WHO (2015), $0.07 \%$ death of the 600 million global burdens of Foodborne illnesses have been reported to be caused by bacteria, viruses, fungi and chemicals. In America $0.27 \%$ of the estimated 48 million affected people is hospitalized and about $0.0063 \%$ deaths are recorded each year (Scallan et al., 2011). More than 91 million people in Africa fall ill and $0.15 \%$ dies each year, making Africa the highest burden bearer of Foodborne diseases per population (WHO, 2015).

Application of a Hazard Analysis Critical Control Point (HACCP) at all stages of meat products preparation is essential in order to ensure its safety. Thus, according to the guidelines of good manufacturing practice, the level of total aerobic bacterial contamination of thermally processed meat products should not exceed $10^{4}\left(\mathrm{cfu} \mathrm{g}^{-1}\right)$. Enterobacteriaceae and faecal coliform contamination in meat products should be within the range of $10^{2}-10^{4}$ and $10-10^{3} \mathrm{cfu} \mathrm{g}^{-1}$, respectively (Shamsuddeen, 2015). The aim of the study is therefore, to assess the total viable bacterial counts of tsire marketed locally within Garko town, and to isolate and identify the organisms at the point of consumption with the intention of promoting public health and food hygiene habits in the Nigerian populace.

\section{MATERIALS AND METHODS Study Area and Population}

Garko is one of the existing 44 local government areas located in Kano south west zone of Kano state with its capital administrative headquarters in the Garko town. It has coordinates $11^{\circ} 39^{\prime} \mathrm{N}$ $8^{\circ} 54^{\prime} \mathrm{E}$, and an area of $450 \mathrm{~km}^{2}$. The projected population of Garko local Government was 225,300 according to the National Population Census report (2018). Garko is known for agricultural activities both farming and animal husbandry. It is popularly known for large scale rice production. Other food crops include sweet potatoes, cassava, onions, sorghum, millet and sugarcane. Cows, sheep and goats are major groups of animals reared by majority of the populace. Meat products processed, retailed and consumed in Garko include roasted meat (Balangu), dried roasted meat (Kilishi), stick meat (Tsire), hide and skin pepper soup (Ragadada) and minced fried meat (Danbunnama).

\section{Samples Collection}

Five samples of Tsire products were collected from 6 different identified locations within Garko town in a sterile foil paper and immediately analyzed for the presence of bacteria.

\section{Sample Preparation}

Sample preparation for the bacteriological analysis was carried out in accordance with the method described by Atlas (1997). Twenty five grams $(25 \mathrm{~g})$ of the sample was homogenized in $225 \mathrm{ml}$ peptone water using Kenwood blender machine to obtain a $10^{1}$ homogenate. The homogenate was thoroughly shaken and $1 \mathrm{ml}$ pipetted into test tubes containing $9 \mathrm{ml}$ of peptone water $\left(10^{2}\right)$. The test tubes were further serially diluted to $10^{5}$.

Total Aerobic Mesophilic Bacterial Count

Total Aerobic mesophilic bacterial count was determined using the method described by Abdullahi et al. (2004) where $1 \mathrm{ml}$ of inoculums from $10^{1}$ to $10^{5}$ dilutions were transferred into duplicate Petri dishes and labeled accordingly. This was followed by pouring aseptically about $15 \mathrm{ml}$ of molten nutrient agar. The culture was homogenized by gentle spinning of the plates and allowed to solidify. The plates were incubated at $37^{\circ} \mathrm{C}$ for 24 hours. Plates containing 30-300 colonies were counted. The number of colony forming units per gram of a sample (cfu/g) was obtained by multiplying the average colony number with the inverse of the dilution factor.

\section{Enumeration and Detection of Coliform bacteria}

Detection and enumeration of coliform was carried out according to method described by Atlas, (1977). A set of 9 test tubes each containing $9 \mathrm{ml}$ of lactose broth and an inverted Durham tubes were autoclaved to expel air and to sterilize. Similarly, $1 \mathrm{ml}$ from the diluents $10^{1}$ was transferred to the first 3 test tubes, followed by $1 \mathrm{ml}$ from the diluents $10^{2}$ to the second set of 3 test tubes and finally the third diluents $10^{3}$ to the $3^{\text {rd }}$ set of 3 test tubes. All the 9 test tubes were incubated at $37^{\circ} \mathrm{C}$ for 24 hours. Tubes that showed gas and acid production after 24 hours were recorded as positive for the presence of Coliform. Negative tubes were further reincubated for 24 hours. Positive tubes were recorded. Estimate of most probable number of Coliform per gram of sample (MPN/g) was determined by comparing the number of gas positive tubes with the most probable number table. 
BAJOPAS Volume 13 Number 1, June, 2020 Identification of Coliform

A loop full of inoculum from gas positive tubes was streaked on to Eosine methylene blue (EMB) agar plate and incubated at $37^{\circ} \mathrm{C}$ for $24 \mathrm{hrs}$. Colonies which formed bluish black color with green metallic sheen, and reddish colonies were isolated on agar slants. Those colonies showing metallic sheen on EMB were sub cultured into tubes of lactose broth and incubated at $45^{\circ} \mathrm{C}$. The tubes were observed after $24 \mathrm{hrs}$ for gas production. This is the completed test for fecal coliform. Gram stain and other biochemical tests such as Indole, Methyl red, Voges-Proskauer and Citrate Utilization tests (IMVIC), Coagulase and Catalase tests were carried out for the Identification and confirmation of isolates.

\section{Procedure for Indole Test}

Indole test was carried out by preparing a Tryptone broth drawn in to test tubes, sterilized by autoclaving, inoculated with loopful of suspension and incubated at $37^{\circ} \mathrm{C}$ for 24 hours. Three drops of xylene was added in tubes, shaken vigorously and kept for the separation of two layers. One millilitre of Kovac's reagent was added and the formation of pink colour ring indicates positive Indole test.

\section{Procedure for Methyl Red Test}

Methyl red test was carried out by preparing Glucose phosphate broth, dispensed in test tubes, sterilized, inoculated with test culture and incubated at $37^{\circ} \mathrm{C}$ for 24 hours. Five drops of methyl-red indicator was added to the medium for the formation of red colour.

\section{Procedure for Voges-Proskauer Test}

Voges-Proskauer test was carried out by inoculating tubes with the bacterial culture followed by incubation for 48 hours at $37^{\circ} \mathrm{C}$. Separate pipettes were used to pipette $1 \mathrm{ml}$ from each culture tube into clean separate tubes. Eighteen drops $(0.5 \mathrm{ml})$ of Barrit's solution A (a-naphthol) was added to each tube containing glucose phosphate broth followed by the addition of an equal amount of solution $B$ into the same tube. The tubes were shaken at 30 seconds interval. A positive reaction was indicated by the development of a pink color, which turns red in 1-2 hours, after vigorous shaking.

\section{Procedure for Citrate Utilization Test}

Citrate Utilization Test was carried out by distributing melted agar (Simmon Citrate Agar) in to test tubes followed by sterilization at $121.5^{\circ} \mathrm{C}$ for 15 minutes. The test tubes were afterward held in slanted position, inoculated with the given bacterial culture and incubated at $37^{\circ} \mathrm{C}$ for $24 \mathrm{hrs}$. Positive test was indicated by color change of the media from green to blue.

\section{RESULTS AND DISCUSSIONS}

The results of this study are presented in tables $1,2,3$ and 4. Among the sampling areas Kofar Kudu had the highest aerobic mesophilic bacteria counts $4.0 \times 10^{5} \mathrm{cfu} / \mathrm{g}$ followed by Rinji $2.72 \times 10^{5} \mathrm{cfu} / \mathrm{g}$, while Tosaro had the least Aerobic mesophilic bacteria counts of $1.02 \times 10^{5}$ $\mathrm{cfu} / \mathrm{g}$ as indicated in Table 1.Makwalla had the highest coliform count $68 \mathrm{MPN} / \mathrm{g}$ followed by Rinji $37 \mathrm{MPN} / \mathrm{g}$. Tsohuwar Kasuwa had the least coliform counts $8 \mathrm{MPN} / \mathrm{g}$, (Table 2). Result from table 1 shows variation in the microbial contents among the samples which suggest variation in their sources, poor handling procedures and contamination from the processing environment. High coliform count and their differences within sampling areas is an indication of poor microbiological quality of the product. Ndahi et al. (2013) reported microbial load to be a function of the handling personnel and the environment. The results indicated that the samples were contaminated with bacteria as the counts exceeded the minimum safety level $\left(10^{4} \mathrm{cfu} / \mathrm{g}\right)$ for members of the Enterobacteriaceae family. However, it might be a reflection of poor hygienic practices which may contribute to health hazard to the potential consumers. Similarly, Inusa and Sa'id (2017); Osimani et al. (2015) reported that, the initial microbial content of the raw material play significant role in influencing the final microbial load of the finished product. Isolation of members of the Enterobacteriaceae such as $E$. coli, Klebsiella pneumoniae, Salmonella and Shigella signifies danger to the public health. These organisms are capable of producing endotoxins which trigger high fevers in infected individuals, and the enterotoxins which colonize the small intestines and lead to extreme dehydration as a result of vomiting and diarrhea sometimes with severe and fatal outcomes (Amaeze et al., 2016). From the 16 isolated organisms $E$. coli had the highest isolation rate $6(37.5 \%)$ (Table 3), this suggest faecal contamination of the products. $E$. coli is a common flora in the gastrointestinal tract responsible for diarrhea and extra-intestinal infections (CDC, 2011). The result is in conformity with the findings of Ndahi et al. (2013) and Shamsuddeen (2009). Also presence of campylobacter might be due to cross contamination from raw meat to finished product (Tsire). Staphylococcus aureus is a normal flora of the skin, nasal, genital, mouth or anal area in both humans and animals without any symptom of an infection (Matthew et al., 2013). Isolation of $S$. aureus in these study concords with the findings of Lucretia et al. (2018) from Suya sold in Rivers State. 
BAJOPAS Volume 13 Number 1, June, 2020

It is also in agreement with the findings of Yousafzai et al. (2018); Onuorah et al. (2015) and Tijjani and Jumare (2014) from tsire samples in different countries. Presence of $S$. aureus in foods is most of the time an indication of poor human handling, poor environment, unhygienic utensils and equipments used during processing (Igene et al., 2016; Okonko et al., 2013). Infections caused by $S$. aureus are difficult to treat leading to long hospitalization with consequent economic loss (Udobi et al., 2013). These include soft tissue infections, pneumonia, hospital-acquired postoperative wound infections, Staphylococcal food poisoning, impetigo and cellulitis (Charlene et al., 2013). Samples obtained from Dausai and Kofar Kudu had the highest isolation rate $4(80 \%)$ (Table 4 ) probably because of the much commercial activities taking place in the area which can lead to environmental contamination.

Table 1: Total Aerobic Mesophilic Bacterial Count of Tsire sold in Garko Town

\begin{tabular}{lll}
\hline Sampling Area & APC cfu/g & Mean \pm STD \\
\hline Dausai & $2.20 \times 10^{5}$ & $110000 \pm 14142.14$ \\
Kofar Kudu & $4.00 \times 10^{5}$ & $133333.3 \pm 23094.01$ \\
Makwalla & $1.30 \times 10^{5}$ & $32500 \pm 7187.953$ \\
Rinji & $2.72 \times 10^{5}$ & $90666.67 \pm 94769.90$ \\
Tosaro & $1.02 \times 10^{5}$ & $51000 \pm 15556.35$ \\
Tsohuwar Kasuwa & $1.75 \times 10^{5}$ & $35000 \pm 11357.82$ \\
\hline
\end{tabular}

Key: APC: Aerobic Mesophilic Counts

STD: Standard Deviation

Table 2: Total Coliform Count of Tsire sold in Garko Town

\begin{tabular}{lcc}
\hline \multicolumn{1}{c}{ Sampling Area } & TCC MPN/g & Mean \pm STD \\
\hline Dausai & 20 & $6.67 \pm 2.5166$ \\
Kofar Kudu & 32 & $16.00 \pm 5.6569$ \\
Makwalla & 68 & $13.60 \pm 8.7062$ \\
Rinji & 37 & $9.25 \pm 4.7871$ \\
Tosaro & 10 & $5.00 \pm 2.8284$ \\
Tsohuwar Kasuwa & 8 & $4.00 \pm 0.0000$ \\
\hline
\end{tabular}

Table 3: Organisms Isolated from Tsire Sold in Garko

\begin{tabular}{lcl}
\hline Isolated Organism & Frequency & Percentage (\%) \\
\hline Campylobacter & 2 & 06.66 \\
Escherichia coli & 6 & 20.00 \\
Klebsiella pneumoniae & 2 & 06.66 \\
Salmonella species & 1 & 03.33 \\
Shigella & 3 & 10.00 \\
Staphylococcus aureus & 2 & 06.66 \\
Total & 16 & \\
\hline
\end{tabular}

Table 4: Distribution of Organisms within Sampling Area

\begin{tabular}{lcc}
\hline \multicolumn{1}{c}{ Sampling Area } & No. Isolated & Percentage (\%) \\
\hline Dausai & 4 & 80 \\
Kofar Kudu & 4 & 80 \\
Makwalla & 2 & 40 \\
Rinji & 3 & 60 \\
Tosaro & 2 & 40 \\
Tsohuwar Kasuwa & 1 & 20 \\
Total & 16 & \\
\hline
\end{tabular}

\section{CONCLUSION}

Results indicated $4.00 \times 10^{5} \mathrm{CFU} / \mathrm{g}$ as the highest APCs count; while $68 \mathrm{MPN} / \mathrm{g}$ was the highest TCCs from the 30 samples analyzed. Among the isolates, $E$. coli has the highest isolation rate of $6(20 \%)$. Dausai and Kofar kudu were having the highest bacteria count of $4(80 \%)$, each, indicating higher contamination in those locations. 
BAJOPAS Volume 13 Number 1, June, 2020 RECOMMENDATIONS

The following recommendations are tenable:

1. Hygienic practices at all stages of production should be improved to safe guard the consumers against potential health hazard.

2. Monitoring of microbiological contamination of Tsire during preparations, packaging and marketing is essential to ensure product of good microbiological quality for consumers' health.

\section{REFERENCES}

Abdullahi, I. O., Umoh, V. J. and Galadima, M. (2004). Hazards Associated with Kilishi Preparations in Zaria. Nigerian Journal of Microbiology, 18 (1-2): $339-345$.

Ahmadu, J. and Ibrahim E. J., (2013): Determinants of Revenue in Suya Production in BeninCity, Edo State, Nigeria. Nigerian journal of agriculture, food and environment.9(3):1-5

Amaeze, N. Aboh, M. Itohan, A. Felix, E. Olatunji, T. and Oladosu, P. (2016) Microbial Profile, Antibiotic Sensitivity and Heat Resistance of Bacterial Isolates from Commercial Roasted Beef (Suya) in Abuja, Nigeria. JOPAT, 15(2): $22-30$.

Apata, E.S., Kuku1, I.A., Apata, O.C. and Adeyemi, K.O. (2013). Evaluation of Suya(Tsire) - An Intermediate Moisture Meat Product in Ogun State, Nigeria. J. Food Res 2 (1): 87.

Atlas, R. M. (1997) Principles of Microbiology Second Edition. C. Brown Publishers. Pp 802-803.

Borch, E. Kant-Muermans, M. L., Blixt, Y. (1996) Bacterial Spoilage of Meat and Cured Meat Products. Int $\mathrm{J}$ Food Microbiol .33(1): 103-20.

Centre for Disease Control, CDC (2011). "Escherichia coli 0157:H7" Division of Bacterial and Mycotic Diseasesht://www.cdc.gov/nczved/divisi ons/dfbmd/diseases/ecoli_0157h7/.

Charlene, R. J., Johnnie, A. D., and John, B. B., (2013) Prevalence and Characterization of Methicillin-Resistant Staphylococcus aureus Isolates from Retail Meat and Humans in Georgia. American society for Microbiology. J. of clinical microbiology. 12(1):123-6 doi:10.1128/JCM.0316612JCM.03166-12

Egbebi, A.O and Seidu, K., T. (2011). Microbiological Evaluation of Suya (dried smoked

meat) Sold in Ado and Akure, South West Nigeria.European Journal of Experinmental Biology, 1(4):1-5
3. Government should establish regulatory bodies responsible for inculcating hygiene habits to the local producers and vendors in order to prevent instant, cross and post processing contaminations by microbial pathogens.

4. Awareness and sensitization of local food producers about good hygienic practices in food handling and processing.

Falegan, C, R., Akoja, S. D., and Oyarekua, M. A., (2017) Microbiological Assessment of Suya (Sliced Roasted Beef) in Ado-Ekiti Metropolis, Ekiti State, Nigeria. MOJ Biology andMedicine.

Fonkem, D., N. Tanya, V., N. and Ebangi, A., L. (2010). Effect of Season on the Microbiological Quality of Kilishi, a Traditional Cameroonian Dried Beef Product. Tropicultura, 28(1): 10-15.

Food and Agricultural Organization of the United Nations (F A O, 1979). Manual of food quality control 4. Microbiological analysis.

Food and Agriculture Organisation of the United Nation (FAO), 2019. Nigeria at a glance.

Igene J.O., Uwadia, O.E., Ebabhamiegbebho, P.A. and Evivie, S.E., (2016) Shelf life Stability Studies of University of Benin (UNIBEN) Proff's Kilishi Product Asian Journal of Science and Technology 7(1): 2268-2274.

Inusa, S. K. and Said, I. S. (2017) Evaluation of the Chemical and Microbiological Properties Of Kilishi Sold in Kano Metropolis. Journal of Dry land Agriculture, 3 (1): $59-69$.

Lucretia, I. B, Patience, C. Obinna-Echem, Sophia, C. A. (2018) Microbiological quality andantibiotic sensitivity of potential pathogens isolated from meat product (Suya) sold in Rivers State University and its environs. International Journal of Biotechnology and Food Science, 6(4): 67-76.

Matthew, E., Drosos, E., John, L. and Ioanna, P. (2013) MRSA in Africa: Filling the Global Map of Antimicrobial Resistance PLOS One. 8(7): e68024 doi: 10.1371/journal.pone.0068024

Mgbemere, V.N., Akpapunam, M. A. and Igene, J. O., (2011). Effect of Groundnut FlourSubstitution on Yield, Quality and Storage Stability of Kilishi - a Nigerian Indigenous Dried Meat Product. African Journal of Food, Agriculture, Nutrition and Development, $\quad \mathbf{1 1}(2)$ : 4718-4738. 
BAJOPAS Volume 13 Number 1, June, 2020

Mubarak, A. A., Azeez, M. L., Amos A. O., Opeyemi, O. O. (2016) Assessment of Animal Protein Consumption and Food Security Among Rural Households in Kwara State, Nigeria American Journal of Business and Society, 1(4): 233245.

Ndahi, M., D. Kwaga, J., K. P. Bello, M. Kabir J., V. Umoh, .J. Yakubu, S., E. and Nok, A., J. (2013) Prevalence and Antimicrobial Susceptibility of Listeria Monocytogenes and Methicillin-Resistant Staphylococcus aureus Strains from Raw Meat and Meat Products in Zaria, Nigeria. Applied Journal of Microbiology, 58(3):262-9.

Okonko, I.O., Odu, N.N. and Igboh, I.E. (2013). Microbiological Analysis of Kilishi Sold In Port Harcourt, Nigeria. New York Science Journal, 6 (7):37-43.

Osimani, A., Aquilanti, L. and Clementi, F. (2015) Microbiological Quality of Meatbased Meals and Operation of Control Systems within a Food Service Environment. International Food Research Journal 22(4): 1692-1698.

Onuorah, S. Obika, I. Odibo, F. Orji, M. (2015)An Assessment of the Bacteriological Quality of Tsire-Suya (Grilled Beef) sold in Awka, Nigeria. American. J. Life. Sci. Res. 3(4):287292.

Razavilar, V, Khandaghi, J. Barzgari, A. (2010); Isolation of Eschericia coli 0157:H7 from manure fertilized farms and raw vegetables grown on it, in Tabriz city in
Iran. African Journal of Microbiology Research, 4(9): 891-895.

Scallan, E. Hoekstra, R. M. Angulo, F. J.Tauxe, R. V, Widdowson, M. Roy, S. L et al., (2011).Food borne illness acquired in the United States- Major Pathogens. Emerg. Infec Dis, 17(1): 7-15.

Shamsuddeen U (2009). Microbiological quality of spice used in the production of Kilishi a traditionally dried and grilled meat product. Bayero Journal of Pure andApplied Sciences, 2(2): 66-69.

Shamsuddeen, U. (2015) Microbiological Hazard and Critical control point Analysis of Dried and Minced Meat Snacks Produced in Kano Nigeria. Lambert Academic Publishing; Pp 1-36.

Tijani, O.and Jumare, S. (2014). Microblological Quality Assessment of Meat

Sold in KauraNamoda. International Conference on Earth, Environment and Life sciences (EELS) Dubai (UAE).

Udobi, C. E., Obajuluwa, A. F., and Onaolapo, J. A., (2013) Prevalence and Antibiotic Resistance Pattern of MethicillinResistant Staphylococcus aureus from an Orthopaedic Hospital in Nigeria BioMed Research International; 26(6); 6-7.

WHO, 2015 Foodborne diseases in the WHO African Region.

Yousafzai HA, Rind R, Khan MA, Abro SH, Korejo NA, Ejaz M, Kabir A, Shahid M, Memon S. (2019). Microbiological Contamination of Cattle and Meat in Peshawar, Pakistan. J. Anim. Health Prod. 7(1): 1116. 


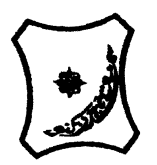

Bayero Journal of Pure and Applied Sciences, 13(1); 40 - 45

Received: September, 2019

Accepted: April, 2020

ISSN $2006-6996$

\title{
BACTERIOLOGICAL QUALITY OF STICK MEAT (Tsire) SOLD IN GARKO LOCAL GOVERNMENT AREA OF KANO STATE, NIGERIA
}

\author{
$*^{1}$ Dahiru A. T. and ${ }^{2}$ Maigari A. K. \\ ${ }^{1}$ Department of Hospitality Management, School of Technology, Kano State Polytechnic, PMB 3348, \\ Kano Nigeria. \\ ${ }^{2}$ Departmnt of Biological Sciences, Bayero University, Kano \\ Corresponding Author: dturajo61@gmail.com; GSM: 08087508262.
}

ABSTRACT

Stick meat, locally called Tsire in Hausa Language, is a significant portion of the diet of a large active population of Northern Nigeria. However, because of the handling and processing methods by the manufacturers as well as the hawking system of stick meat, the meat product may be exposed to both pre- and post-processed product contamination, and thus may poses danger to public health. Therefore, considering the role of Tsire in improving nutrition and increase household income to the populace, the need to improve the processing, distribution and overall quality of the product is simply indispensable. A total of 30 samples (5 samples from each of the 6 sampling points) of Tsire were collected randomly in Garko Town. Aerobic plate counts (APCs) and Total coliform counts (TCCS) of Tsire samples were determined using standard microbiological methods. APCs ranged from $1.02 \times 10^{5}$ to $4.00 \times 10^{5} \mathrm{CFU} / \mathrm{g}$; while TCCs ranged from $8 \mathrm{MPN} / \mathrm{g}$ to $68 \mathrm{MPN} / \mathrm{g}$. From the 30 samples screened, 16(53.33\%) bacteria namely, Campylobacter 2(6.66\%), Escherichia coli 6(20\%), Klebsiella pneumoniae 2(6.66\%), Salmonella spp. 1(3.33\%), Shigella 3(10\%) and Staphylococcus aureus 2(6.66\%) were detected. $E$. coli has the highest isolation rate of 6(20\%), while Salmonella spp. had the least frequency of 1(3.33\%). The distribution of isolated organisms within the study area were as follows: Dausai, 4(80\%), Kofar kudu, 4(80\%), Makwalla, 2(40\%), Rinji, 3(60\%), Tosaro, 2(40\%), and Tsohuwar Kasuwa, 1(20\%). The results have indicated that the Tsire was contaminated with bacteria thus exposing the product to fast deterioration, spoilage and also a vehicle for food borne illness, suggesting for adequate hygienic practices at all the stages, prior to consumption, to ensure safety of the meat product.

Key words: APCs, TCCs, Contamination, Microorganisms, Garko

\section{INTRODUCTION}

Nigeria is one of the developing nations with inadequate food supply and most often deficient in protein content (FAO, 2019). Nigerian's average animal protein intake per head per day is estimated at $7.9 \mathrm{~g}$ as against $35 \mathrm{~g}$ recommended value by Food and Agricultural Organization (Mubarak et al., 2016). These low levels of animal protein intake create great concern as it affects the nutritional status of Nigerians. Hence, there is the need for sufficient supply of animal protein from energy rich animal products to satisfy the nutritional requirements for Nigerians.

Meat is one major source of animal protein largely composed of water, protein and fats which can make it susceptible to microbial contamination within short time leading to spoilage (Apata et al., 2013; Mgbemere et al., 2011). Meat is mostly eaten after it has been cooked or processed in a variety of ways such as sun drying; smoking and roasting with or without fortifications (Borch et al., 1996). In Nigeria meat products such as Tsire, Kilishi and Balangu are locally produced using one or more of these methods in order to meet the nutritional requirements of the teeming Nigerians (Egbebi, 2011).

Tsire is a popular Nigerian traditional processed ready-to-eat roasted stick meat product (Shamsuddeen, 2015). It is sold in public places, along roads, in hotels, parks, quarters and even offices (Falegan et al., 2017). It is prepared from boneless healthy animal flesh such as beef and mutton, spiced with peanut cake, salt, vegetable oil and other flavorings followed by roasting (Shamsuddeen, 2015). Consumption of these products has extended to other parts of African countries such as Ghana, Somali, Cameroun and Chad (Ahmadu and Ibrahim, 2013). 
BAJOPAS Volume 13 Number 1, June, 2020

However, evidence of quality control sticking to procedural hygiene by the handlers during preparation and retailing of these products is poorly documented. Tsire is of great safety risk because of the fact that there are erratic cases of gastroenteritis and symptoms of food infection after consumption (WHO, 2015). Food borne illnesses are one of the major health problems in developing and developed countries (Razavilar, 2010). According to the World Health Organization, WHO (2015), $0.07 \%$ death of the 600 million global burdens of Foodborne illnesses have been reported to be caused by bacteria, viruses, fungi and chemicals. In America $0.27 \%$ of the estimated 48 million affected people is hospitalized and about $0.0063 \%$ deaths are recorded each year (Scallan et al., 2011). More than 91 million people in Africa fall ill and $0.15 \%$ dies each year, making Africa the highest burden bearer of Foodborne diseases per population (WHO, 2015).

Application of a Hazard Analysis Critical Control Point (HACCP) at all stages of meat products preparation is essential in order to ensure its safety. Thus, according to the guidelines of good manufacturing practice, the level of total aerobic bacterial contamination of thermally processed meat products should not exceed $10^{4}\left(\mathrm{cfu} \mathrm{g}^{-1}\right)$. Enterobacteriaceae and faecal coliform contamination in meat products should be within the range of $10^{2}-10^{4}$ and $10-10^{3} \mathrm{cfu} \mathrm{g}^{-1}$, respectively (Shamsuddeen, 2015). The aim of the study is therefore, to assess the total viable bacterial counts of tsire marketed locally within Garko town, and to isolate and identify the organisms at the point of consumption with the intention of promoting public health and food hygiene habits in the Nigerian populace.

\section{MATERIALS AND METHODS Study Area and Population}

Garko is one of the existing 44 local government areas located in Kano south west zone of Kano state with its capital administrative headquarters in the Garko town. It has coordinates $11^{\circ} 39^{\prime} \mathrm{N}$ $8^{\circ} 54^{\prime} \mathrm{E}$, and an area of $450 \mathrm{~km}^{2}$. The projected population of Garko local Government was 225,300 according to the National Population Census report (2018). Garko is known for agricultural activities both farming and animal husbandry. It is popularly known for large scale rice production. Other food crops include sweet potatoes, cassava, onions, sorghum, millet and sugarcane. Cows, sheep and goats are major groups of animals reared by majority of the populace. Meat products processed, retailed and consumed in Garko include roasted meat (Balangu), dried roasted meat (Kilishi), stick meat (Tsire), hide and skin pepper soup (Ragadada) and minced fried meat (Danbunnama).

\section{Samples Collection}

Five samples of Tsire products were collected from 6 different identified locations within Garko town in a sterile foil paper and immediately analyzed for the presence of bacteria.

\section{Sample Preparation}

Sample preparation for the bacteriological analysis was carried out in accordance with the method described by Atlas (1997). Twenty five grams $(25 \mathrm{~g})$ of the sample was homogenized in $225 \mathrm{ml}$ peptone water using Kenwood blender machine to obtain a $10^{1}$ homogenate. The homogenate was thoroughly shaken and $1 \mathrm{ml}$ pipetted into test tubes containing $9 \mathrm{ml}$ of peptone water $\left(10^{2}\right)$. The test tubes were further serially diluted to $10^{5}$.

Total Aerobic Mesophilic Bacterial Count

Total Aerobic mesophilic bacterial count was determined using the method described by Abdullahi et al. (2004) where $1 \mathrm{ml}$ of inoculums from $10^{1}$ to $10^{5}$ dilutions were transferred into duplicate Petri dishes and labeled accordingly. This was followed by pouring aseptically about $15 \mathrm{ml}$ of molten nutrient agar. The culture was homogenized by gentle spinning of the plates and allowed to solidify. The plates were incubated at $37^{\circ} \mathrm{C}$ for 24 hours. Plates containing 30-300 colonies were counted. The number of colony forming units per gram of a sample (cfu/g) was obtained by multiplying the average colony number with the inverse of the dilution factor.

\section{Enumeration and Detection of Coliform bacteria}

Detection and enumeration of coliform was carried out according to method described by Atlas, (1977). A set of 9 test tubes each containing $9 \mathrm{ml}$ of lactose broth and an inverted Durham tubes were autoclaved to expel air and to sterilize. Similarly, $1 \mathrm{ml}$ from the diluents $10^{1}$ was transferred to the first 3 test tubes, followed by $1 \mathrm{ml}$ from the diluents $10^{2}$ to the second set of 3 test tubes and finally the third diluents $10^{3}$ to the $3^{\text {rd }}$ set of 3 test tubes. All the 9 test tubes were incubated at $37^{\circ} \mathrm{C}$ for 24 hours. Tubes that showed gas and acid production after 24 hours were recorded as positive for the presence of Coliform. Negative tubes were further reincubated for 24 hours. Positive tubes were recorded. Estimate of most probable number of Coliform per gram of sample (MPN/g) was determined by comparing the number of gas positive tubes with the most probable number table. 
BAJOPAS Volume 13 Number 1, June, 2020 Identification of Coliform

A loop full of inoculum from gas positive tubes was streaked on to Eosine methylene blue (EMB) agar plate and incubated at $37^{\circ} \mathrm{C}$ for $24 \mathrm{hrs}$. Colonies which formed bluish black color with green metallic sheen, and reddish colonies were isolated on agar slants. Those colonies showing metallic sheen on EMB were sub cultured into tubes of lactose broth and incubated at $45^{\circ} \mathrm{C}$. The tubes were observed after $24 \mathrm{hrs}$ for gas production. This is the completed test for fecal coliform. Gram stain and other biochemical tests such as Indole, Methyl red, Voges-Proskauer and Citrate Utilization tests (IMVIC), Coagulase and Catalase tests were carried out for the Identification and confirmation of isolates.

\section{Procedure for Indole Test}

Indole test was carried out by preparing a Tryptone broth drawn in to test tubes, sterilized by autoclaving, inoculated with loopful of suspension and incubated at $37^{\circ} \mathrm{C}$ for 24 hours. Three drops of xylene was added in tubes, shaken vigorously and kept for the separation of two layers. One millilitre of Kovac's reagent was added and the formation of pink colour ring indicates positive Indole test.

\section{Procedure for Methyl Red Test}

Methyl red test was carried out by preparing Glucose phosphate broth, dispensed in test tubes, sterilized, inoculated with test culture and incubated at $37^{\circ} \mathrm{C}$ for 24 hours. Five drops of methyl-red indicator was added to the medium for the formation of red colour.

\section{Procedure for Voges-Proskauer Test}

Voges-Proskauer test was carried out by inoculating tubes with the bacterial culture followed by incubation for 48 hours at $37^{\circ} \mathrm{C}$. Separate pipettes were used to pipette $1 \mathrm{ml}$ from each culture tube into clean separate tubes. Eighteen drops $(0.5 \mathrm{ml})$ of Barrit's solution A (a-naphthol) was added to each tube containing glucose phosphate broth followed by the addition of an equal amount of solution $B$ into the same tube. The tubes were shaken at 30 seconds interval. A positive reaction was indicated by the development of a pink color, which turns red in 1-2 hours, after vigorous shaking.

\section{Procedure for Citrate Utilization Test}

Citrate Utilization Test was carried out by distributing melted agar (Simmon Citrate Agar) in to test tubes followed by sterilization at $121.5^{\circ} \mathrm{C}$ for 15 minutes. The test tubes were afterward held in slanted position, inoculated with the given bacterial culture and incubated at $37^{\circ} \mathrm{C}$ for $24 \mathrm{hrs}$. Positive test was indicated by color change of the media from green to blue.

\section{RESULTS AND DISCUSSIONS}

The results of this study are presented in tables $1,2,3$ and 4. Among the sampling areas Kofar Kudu had the highest aerobic mesophilic bacteria counts $4.0 \times 10^{5} \mathrm{cfu} / \mathrm{g}$ followed by Rinji $2.72 \times 10^{5} \mathrm{cfu} / \mathrm{g}$, while Tosaro had the least Aerobic mesophilic bacteria counts of $1.02 \times 10^{5}$ $\mathrm{cfu} / \mathrm{g}$ as indicated in Table 1.Makwalla had the highest coliform count $68 \mathrm{MPN} / \mathrm{g}$ followed by Rinji $37 \mathrm{MPN} / \mathrm{g}$. Tsohuwar Kasuwa had the least coliform counts $8 \mathrm{MPN} / \mathrm{g}$, (Table 2). Result from table 1 shows variation in the microbial contents among the samples which suggest variation in their sources, poor handling procedures and contamination from the processing environment. High coliform count and their differences within sampling areas is an indication of poor microbiological quality of the product. Ndahi et al. (2013) reported microbial load to be a function of the handling personnel and the environment. The results indicated that the samples were contaminated with bacteria as the counts exceeded the minimum safety level $\left(10^{4} \mathrm{cfu} / \mathrm{g}\right)$ for members of the Enterobacteriaceae family. However, it might be a reflection of poor hygienic practices which may contribute to health hazard to the potential consumers. Similarly, Inusa and Sa'id (2017); Osimani et al. (2015) reported that, the initial microbial content of the raw material play significant role in influencing the final microbial load of the finished product. Isolation of members of the Enterobacteriaceae such as $E$. coli, Klebsiella pneumoniae, Salmonella and Shigella signifies danger to the public health. These organisms are capable of producing endotoxins which trigger high fevers in infected individuals, and the enterotoxins which colonize the small intestines and lead to extreme dehydration as a result of vomiting and diarrhea sometimes with severe and fatal outcomes (Amaeze et al., 2016). From the 16 isolated organisms $E$. coli had the highest isolation rate $6(37.5 \%)$ (Table 3), this suggest faecal contamination of the products. $E$. coli is a common flora in the gastrointestinal tract responsible for diarrhea and extra-intestinal infections (CDC, 2011). The result is in conformity with the findings of Ndahi et al. (2013) and Shamsuddeen (2009). Also presence of campylobacter might be due to cross contamination from raw meat to finished product (Tsire). Staphylococcus aureus is a normal flora of the skin, nasal, genital, mouth or anal area in both humans and animals without any symptom of an infection (Matthew et al., 2013). Isolation of $S$. aureus in these study concords with the findings of Lucretia et al. (2018) from Suya sold in Rivers State. 
BAJOPAS Volume 13 Number 1, June, 2020

It is also in agreement with the findings of Yousafzai et al. (2018); Onuorah et al. (2015) and Tijjani and Jumare (2014) from tsire samples in different countries. Presence of $S$. aureus in foods is most of the time an indication of poor human handling, poor environment, unhygienic utensils and equipments used during processing (Igene et al., 2016; Okonko et al., 2013). Infections caused by $S$. aureus are difficult to treat leading to long hospitalization with consequent economic loss (Udobi et al., 2013). These include soft tissue infections, pneumonia, hospital-acquired postoperative wound infections, Staphylococcal food poisoning, impetigo and cellulitis (Charlene et al., 2013). Samples obtained from Dausai and Kofar Kudu had the highest isolation rate $4(80 \%)$ (Table 4 ) probably because of the much commercial activities taking place in the area which can lead to environmental contamination.

Table 1: Total Aerobic Mesophilic Bacterial Count of Tsire sold in Garko Town

\begin{tabular}{lll}
\hline Sampling Area & APC cfu/g & Mean \pm STD \\
\hline Dausai & $2.20 \times 10^{5}$ & $110000 \pm 14142.14$ \\
Kofar Kudu & $4.00 \times 10^{5}$ & $133333.3 \pm 23094.01$ \\
Makwalla & $1.30 \times 10^{5}$ & $32500 \pm 7187.953$ \\
Rinji & $2.72 \times 10^{5}$ & $90666.67 \pm 94769.90$ \\
Tosaro & $1.02 \times 10^{5}$ & $51000 \pm 15556.35$ \\
Tsohuwar Kasuwa & $1.75 \times 10^{5}$ & $35000 \pm 11357.82$ \\
\hline
\end{tabular}

Key: APC: Aerobic Mesophilic Counts

STD: Standard Deviation

Table 2: Total Coliform Count of Tsire sold in Garko Town

\begin{tabular}{lcc}
\hline \multicolumn{1}{c}{ Sampling Area } & TCC MPN/g & Mean \pm STD \\
\hline Dausai & 20 & $6.67 \pm 2.5166$ \\
Kofar Kudu & 32 & $16.00 \pm 5.6569$ \\
Makwalla & 68 & $13.60 \pm 8.7062$ \\
Rinji & 37 & $9.25 \pm 4.7871$ \\
Tosaro & 10 & $5.00 \pm 2.8284$ \\
Tsohuwar Kasuwa & 8 & $4.00 \pm 0.0000$ \\
\hline
\end{tabular}

Table 3: Organisms Isolated from Tsire Sold in Garko

\begin{tabular}{lcl}
\hline Isolated Organism & Frequency & Percentage (\%) \\
\hline Campylobacter & 2 & 06.66 \\
Escherichia coli & 6 & 20.00 \\
Klebsiella pneumoniae & 2 & 06.66 \\
Salmonella species & 1 & 03.33 \\
Shigella & 3 & 10.00 \\
Staphylococcus aureus & 2 & 06.66 \\
Total & 16 & \\
\hline
\end{tabular}

Table 4: Distribution of Organisms within Sampling Area

\begin{tabular}{lcc}
\hline \multicolumn{1}{c}{ Sampling Area } & No. Isolated & Percentage (\%) \\
\hline Dausai & 4 & 80 \\
Kofar Kudu & 4 & 80 \\
Makwalla & 2 & 40 \\
Rinji & 3 & 60 \\
Tosaro & 2 & 40 \\
Tsohuwar Kasuwa & 1 & 20 \\
Total & 16 & \\
\hline
\end{tabular}

\section{CONCLUSION}

Results indicated $4.00 \times 10^{5} \mathrm{CFU} / \mathrm{g}$ as the highest APCs count; while $68 \mathrm{MPN} / \mathrm{g}$ was the highest TCCs from the 30 samples analyzed. Among the isolates, $E$. coli has the highest isolation rate of $6(20 \%)$. Dausai and Kofar kudu were having the highest bacteria count of $4(80 \%)$, each, indicating higher contamination in those locations. 
BAJOPAS Volume 13 Number 1, June, 2020 RECOMMENDATIONS

The following recommendations are tenable:

1. Hygienic practices at all stages of production should be improved to safe guard the consumers against potential health hazard.

2. Monitoring of microbiological contamination of Tsire during preparations, packaging and marketing is essential to ensure product of good microbiological quality for consumers' health.

\section{REFERENCES}

Abdullahi, I. O., Umoh, V. J. and Galadima, M. (2004). Hazards Associated with Kilishi Preparations in Zaria. Nigerian Journal of Microbiology, 18 (1-2): $339-345$.

Ahmadu, J. and Ibrahim E. J., (2013): Determinants of Revenue in Suya Production in BeninCity, Edo State, Nigeria. Nigerian journal of agriculture, food and environment.9(3):1-5

Amaeze, N. Aboh, M. Itohan, A. Felix, E. Olatunji, T. and Oladosu, P. (2016) Microbial Profile, Antibiotic Sensitivity and Heat Resistance of Bacterial Isolates from Commercial Roasted Beef (Suya) in Abuja, Nigeria. JOPAT, 15(2): $22-30$.

Apata, E.S., Kuku1, I.A., Apata, O.C. and Adeyemi, K.O. (2013). Evaluation of Suya(Tsire) - An Intermediate Moisture Meat Product in Ogun State, Nigeria. J. Food Res 2 (1): 87.

Atlas, R. M. (1997) Principles of Microbiology Second Edition. C. Brown Publishers. Pp 802-803.

Borch, E. Kant-Muermans, M. L., Blixt, Y. (1996) Bacterial Spoilage of Meat and Cured Meat Products. Int $\mathrm{J}$ Food Microbiol .33(1): 103-20.

Centre for Disease Control, CDC (2011). "Escherichia coli 0157:H7" Division of Bacterial and Mycotic Diseasesht://www.cdc.gov/nczved/divisi ons/dfbmd/diseases/ecoli_0157h7/.

Charlene, R. J., Johnnie, A. D., and John, B. B., (2013) Prevalence and Characterization of Methicillin-Resistant Staphylococcus aureus Isolates from Retail Meat and Humans in Georgia. American society for Microbiology. J. of clinical microbiology. 12(1):123-6 doi:10.1128/JCM.0316612JCM.03166-12

Egbebi, A.O and Seidu, K., T. (2011). Microbiological Evaluation of Suya (dried smoked

meat) Sold in Ado and Akure, South West Nigeria.European Journal of Experinmental Biology, 1(4):1-5
3. Government should establish regulatory bodies responsible for inculcating hygiene habits to the local producers and vendors in order to prevent instant, cross and post processing contaminations by microbial pathogens.

4. Awareness and sensitization of local food producers about good hygienic practices in food handling and processing.

Falegan, C, R., Akoja, S. D., and Oyarekua, M. A., (2017) Microbiological Assessment of Suya (Sliced Roasted Beef) in Ado-Ekiti Metropolis, Ekiti State, Nigeria. MOJ Biology andMedicine.

Fonkem, D., N. Tanya, V., N. and Ebangi, A., L. (2010). Effect of Season on the Microbiological Quality of Kilishi, a Traditional Cameroonian Dried Beef Product. Tropicultura, 28(1): 10-15.

Food and Agricultural Organization of the United Nations (F A O, 1979). Manual of food quality control 4. Microbiological analysis.

Food and Agriculture Organisation of the United Nation (FAO), 2019. Nigeria at a glance.

Igene J.O., Uwadia, O.E., Ebabhamiegbebho, P.A. and Evivie, S.E., (2016) Shelf life Stability Studies of University of Benin (UNIBEN) Proff's Kilishi Product Asian Journal of Science and Technology 7(1): 2268-2274.

Inusa, S. K. and Said, I. S. (2017) Evaluation of the Chemical and Microbiological Properties Of Kilishi Sold in Kano Metropolis. Journal of Dry land Agriculture, 3 (1): $59-69$.

Lucretia, I. B, Patience, C. Obinna-Echem, Sophia, C. A. (2018) Microbiological quality andantibiotic sensitivity of potential pathogens isolated from meat product (Suya) sold in Rivers State University and its environs. International Journal of Biotechnology and Food Science, 6(4): 67-76.

Matthew, E., Drosos, E., John, L. and Ioanna, P. (2013) MRSA in Africa: Filling the Global Map of Antimicrobial Resistance PLOS One. 8(7): e68024 doi: 10.1371/journal.pone.0068024

Mgbemere, V.N., Akpapunam, M. A. and Igene, J. O., (2011). Effect of Groundnut FlourSubstitution on Yield, Quality and Storage Stability of Kilishi - a Nigerian Indigenous Dried Meat Product. African Journal of Food, Agriculture, Nutrition and Development, $\quad \mathbf{1 1}(2)$ : 4718-4738. 
BAJOPAS Volume 13 Number 1, June, 2020

Mubarak, A. A., Azeez, M. L., Amos A. O., Opeyemi, O. O. (2016) Assessment of Animal Protein Consumption and Food Security Among Rural Households in Kwara State, Nigeria American Journal of Business and Society, 1(4): 233245.

Ndahi, M., D. Kwaga, J., K. P. Bello, M. Kabir J., V. Umoh, .J. Yakubu, S., E. and Nok, A., J. (2013) Prevalence and Antimicrobial Susceptibility of Listeria Monocytogenes and Methicillin-Resistant Staphylococcus aureus Strains from Raw Meat and Meat Products in Zaria, Nigeria. Applied Journal of Microbiology, 58(3):262-9.

Okonko, I.O., Odu, N.N. and Igboh, I.E. (2013). Microbiological Analysis of Kilishi Sold In Port Harcourt, Nigeria. New York Science Journal, 6 (7):37-43.

Osimani, A., Aquilanti, L. and Clementi, F. (2015) Microbiological Quality of Meatbased Meals and Operation of Control Systems within a Food Service Environment. International Food Research Journal 22(4): 1692-1698.

Onuorah, S. Obika, I. Odibo, F. Orji, M. (2015)An Assessment of the Bacteriological Quality of Tsire-Suya (Grilled Beef) sold in Awka, Nigeria. American. J. Life. Sci. Res. 3(4):287292.

Razavilar, V, Khandaghi, J. Barzgari, A. (2010); Isolation of Eschericia coli 0157:H7 from manure fertilized farms and raw vegetables grown on it, in Tabriz city in
Iran. African Journal of Microbiology Research, 4(9): 891-895.

Scallan, E. Hoekstra, R. M. Angulo, F. J.Tauxe, R. V, Widdowson, M. Roy, S. L et al., (2011).Food borne illness acquired in the United States- Major Pathogens. Emerg. Infec Dis, 17(1): 7-15.

Shamsuddeen U (2009). Microbiological quality of spice used in the production of Kilishi a traditionally dried and grilled meat product. Bayero Journal of Pure andApplied Sciences, 2(2): 66-69.

Shamsuddeen, U. (2015) Microbiological Hazard and Critical control point Analysis of Dried and Minced Meat Snacks Produced in Kano Nigeria. Lambert Academic Publishing; Pp 1-36.

Tijani, O.and Jumare, S. (2014). Microblological Quality Assessment of Meat

Sold in KauraNamoda. International Conference on Earth, Environment and Life sciences (EELS) Dubai (UAE).

Udobi, C. E., Obajuluwa, A. F., and Onaolapo, J. A., (2013) Prevalence and Antibiotic Resistance Pattern of MethicillinResistant Staphylococcus aureus from an Orthopaedic Hospital in Nigeria BioMed Research International; 26(6); 6-7.

WHO, 2015 Foodborne diseases in the WHO African Region.

Yousafzai HA, Rind R, Khan MA, Abro SH, Korejo NA, Ejaz M, Kabir A, Shahid M, Memon S. (2019). Microbiological Contamination of Cattle and Meat in Peshawar, Pakistan. J. Anim. Health Prod. 7(1): 1116. 


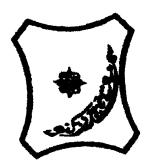

Bayero Journal of Pure and Applied Sciences, 13(1); 40 - 45

Received: September, 2019

Accepted: April, 2020

ISSN $2006-6996$

\title{
BACTERIOLOGICAL QUALITY OF STICK MEAT (Tsire) SOLD IN GARKO LOCAL GOVERNMENT AREA OF KANO STATE, NIGERIA
}

\author{
$*^{1}$ Dahiru A. T. and ${ }^{2}$ Maigari A. K. \\ ${ }^{1}$ Department of Hospitality Management, School of Technology, Kano State Polytechnic, PMB 3348, \\ Kano Nigeria. \\ ${ }^{2}$ Departmnt of Biological Sciences, Bayero University, Kano \\ Corresponding Author: dturajo61@gmail.com; GSM: 08087508262.
}

ABSTRACT

Stick meat, locally called Tsire in Hausa Language, is a significant portion of the diet of a large active population of Northern Nigeria. However, because of the handling and processing methods by the manufacturers as well as the hawking system of stick meat, the meat product may be exposed to both pre- and post-processed product contamination, and thus may poses danger to public health. Therefore, considering the role of Tsire in improving nutrition and increase household income to the populace, the need to improve the processing, distribution and overall quality of the product is simply indispensable. A total of 30 samples (5 samples from each of the 6 sampling points) of Tsire were collected randomly in Garko Town. Aerobic plate counts (APCs) and Total coliform counts (TCCS) of Tsire samples were determined using standard microbiological methods. APCs ranged from $1.02 \times 10^{5}$ to $4.00 \times 10^{5} \mathrm{CFU} / \mathrm{g}$; while TCCs ranged from $8 \mathrm{MPN} / \mathrm{g}$ to $68 \mathrm{MPN} / \mathrm{g}$. From the 30 samples screened, 16(53.33\%) bacteria namely, Campylobacter 2(6.66\%), Escherichia coli 6(20\%), Klebsiella pneumoniae 2(6.66\%), Salmonella spp. 1(3.33\%), Shigella 3(10\%) and Staphylococcus aureus 2(6.66\%) were detected. $E$. coli has the highest isolation rate of 6(20\%), while Salmonella spp. had the least frequency of 1(3.33\%). The distribution of isolated organisms within the study area were as follows: Dausai, 4(80\%), Kofar kudu, 4(80\%), Makwalla, 2(40\%), Rinji, 3(60\%), Tosaro, 2(40\%), and Tsohuwar Kasuwa, 1(20\%). The results have indicated that the Tsire was contaminated with bacteria thus exposing the product to fast deterioration, spoilage and also a vehicle for food borne illness, suggesting for adequate hygienic practices at all the stages, prior to consumption, to ensure safety of the meat product.

Key words: APCs, TCCs, Contamination, Microorganisms, Garko

\section{INTRODUCTION}

Nigeria is one of the developing nations with inadequate food supply and most often deficient in protein content (FAO, 2019). Nigerian's average animal protein intake per head per day is estimated at $7.9 \mathrm{~g}$ as against $35 \mathrm{~g}$ recommended value by Food and Agricultural Organization (Mubarak et al., 2016). These low levels of animal protein intake create great concern as it affects the nutritional status of Nigerians. Hence, there is the need for sufficient supply of animal protein from energy rich animal products to satisfy the nutritional requirements for Nigerians.

Meat is one major source of animal protein largely composed of water, protein and fats which can make it susceptible to microbial contamination within short time leading to spoilage (Apata et al., 2013; Mgbemere et al., 2011). Meat is mostly eaten after it has been cooked or processed in a variety of ways such as sun drying; smoking and roasting with or without fortifications (Borch et al., 1996). In Nigeria meat products such as Tsire, Kilishi and Balangu are locally produced using one or more of these methods in order to meet the nutritional requirements of the teeming Nigerians (Egbebi, 2011).

Tsire is a popular Nigerian traditional processed ready-to-eat roasted stick meat product (Shamsuddeen, 2015). It is sold in public places, along roads, in hotels, parks, quarters and even offices (Falegan et al., 2017). It is prepared from boneless healthy animal flesh such as beef and mutton, spiced with peanut cake, salt, vegetable oil and other flavorings followed by roasting (Shamsuddeen, 2015). Consumption of these products has extended to other parts of African countries such as Ghana, Somali, Cameroun and Chad (Ahmadu and Ibrahim, 2013). 
BAJOPAS Volume 13 Number 1, June, 2020

However, evidence of quality control sticking to procedural hygiene by the handlers during preparation and retailing of these products is poorly documented. Tsire is of great safety risk because of the fact that there are erratic cases of gastroenteritis and symptoms of food infection after consumption (WHO, 2015). Food borne illnesses are one of the major health problems in developing and developed countries (Razavilar, 2010). According to the World Health Organization, WHO (2015), $0.07 \%$ death of the 600 million global burdens of Foodborne illnesses have been reported to be caused by bacteria, viruses, fungi and chemicals. In America $0.27 \%$ of the estimated 48 million affected people is hospitalized and about $0.0063 \%$ deaths are recorded each year (Scallan et al., 2011). More than 91 million people in Africa fall ill and $0.15 \%$ dies each year, making Africa the highest burden bearer of Foodborne diseases per population (WHO, 2015).

Application of a Hazard Analysis Critical Control Point (HACCP) at all stages of meat products preparation is essential in order to ensure its safety. Thus, according to the guidelines of good manufacturing practice, the level of total aerobic bacterial contamination of thermally processed meat products should not exceed $10^{4}\left(\mathrm{cfu} \mathrm{g}^{-1}\right)$. Enterobacteriaceae and faecal coliform contamination in meat products should be within the range of $10^{2}-10^{4}$ and $10-10^{3} \mathrm{cfu} \mathrm{g}^{-1}$, respectively (Shamsuddeen, 2015). The aim of the study is therefore, to assess the total viable bacterial counts of tsire marketed locally within Garko town, and to isolate and identify the organisms at the point of consumption with the intention of promoting public health and food hygiene habits in the Nigerian populace.

\section{MATERIALS AND METHODS Study Area and Population}

Garko is one of the existing 44 local government areas located in Kano south west zone of Kano state with its capital administrative headquarters in the Garko town. It has coordinates $11^{\circ} 39^{\prime} \mathrm{N}$ $8^{\circ} 54^{\prime} \mathrm{E}$, and an area of $450 \mathrm{~km}^{2}$. The projected population of Garko local Government was 225,300 according to the National Population Census report (2018). Garko is known for agricultural activities both farming and animal husbandry. It is popularly known for large scale rice production. Other food crops include sweet potatoes, cassava, onions, sorghum, millet and sugarcane. Cows, sheep and goats are major groups of animals reared by majority of the populace. Meat products processed, retailed and consumed in Garko include roasted meat (Balangu), dried roasted meat (Kilishi), stick meat (Tsire), hide and skin pepper soup (Ragadada) and minced fried meat (Danbunnama).

\section{Samples Collection}

Five samples of Tsire products were collected from 6 different identified locations within Garko town in a sterile foil paper and immediately analyzed for the presence of bacteria.

\section{Sample Preparation}

Sample preparation for the bacteriological analysis was carried out in accordance with the method described by Atlas (1997). Twenty five grams $(25 \mathrm{~g})$ of the sample was homogenized in $225 \mathrm{ml}$ peptone water using Kenwood blender machine to obtain a $10^{1}$ homogenate. The homogenate was thoroughly shaken and $1 \mathrm{ml}$ pipetted into test tubes containing $9 \mathrm{ml}$ of peptone water $\left(10^{2}\right)$. The test tubes were further serially diluted to $10^{5}$.

Total Aerobic Mesophilic Bacterial Count

Total Aerobic mesophilic bacterial count was determined using the method described by Abdullahi et al. (2004) where $1 \mathrm{ml}$ of inoculums from $10^{1}$ to $10^{5}$ dilutions were transferred into duplicate Petri dishes and labeled accordingly. This was followed by pouring aseptically about $15 \mathrm{ml}$ of molten nutrient agar. The culture was homogenized by gentle spinning of the plates and allowed to solidify. The plates were incubated at $37^{\circ} \mathrm{C}$ for 24 hours. Plates containing 30-300 colonies were counted. The number of colony forming units per gram of a sample (cfu/g) was obtained by multiplying the average colony number with the inverse of the dilution factor.

\section{Enumeration and Detection of Coliform bacteria}

Detection and enumeration of coliform was carried out according to method described by Atlas, (1977). A set of 9 test tubes each containing $9 \mathrm{ml}$ of lactose broth and an inverted Durham tubes were autoclaved to expel air and to sterilize. Similarly, $1 \mathrm{ml}$ from the diluents $10^{1}$ was transferred to the first 3 test tubes, followed by $1 \mathrm{ml}$ from the diluents $10^{2}$ to the second set of 3 test tubes and finally the third diluents $10^{3}$ to the $3^{\text {rd }}$ set of 3 test tubes. All the 9 test tubes were incubated at $37^{\circ} \mathrm{C}$ for 24 hours. Tubes that showed gas and acid production after 24 hours were recorded as positive for the presence of Coliform. Negative tubes were further reincubated for 24 hours. Positive tubes were recorded. Estimate of most probable number of Coliform per gram of sample (MPN/g) was determined by comparing the number of gas positive tubes with the most probable number table. 
BAJOPAS Volume 13 Number 1, June, 2020 Identification of Coliform

A loop full of inoculum from gas positive tubes was streaked on to Eosine methylene blue (EMB) agar plate and incubated at $37^{\circ} \mathrm{C}$ for $24 \mathrm{hrs}$. Colonies which formed bluish black color with green metallic sheen, and reddish colonies were isolated on agar slants. Those colonies showing metallic sheen on EMB were sub cultured into tubes of lactose broth and incubated at $45^{\circ} \mathrm{C}$. The tubes were observed after $24 \mathrm{hrs}$ for gas production. This is the completed test for fecal coliform. Gram stain and other biochemical tests such as Indole, Methyl red, Voges-Proskauer and Citrate Utilization tests (IMVIC), Coagulase and Catalase tests were carried out for the Identification and confirmation of isolates.

\section{Procedure for Indole Test}

Indole test was carried out by preparing a Tryptone broth drawn in to test tubes, sterilized by autoclaving, inoculated with loopful of suspension and incubated at $37^{\circ} \mathrm{C}$ for 24 hours. Three drops of xylene was added in tubes, shaken vigorously and kept for the separation of two layers. One millilitre of Kovac's reagent was added and the formation of pink colour ring indicates positive Indole test.

\section{Procedure for Methyl Red Test}

Methyl red test was carried out by preparing Glucose phosphate broth, dispensed in test tubes, sterilized, inoculated with test culture and incubated at $37^{\circ} \mathrm{C}$ for 24 hours. Five drops of methyl-red indicator was added to the medium for the formation of red colour.

\section{Procedure for Voges-Proskauer Test}

Voges-Proskauer test was carried out by inoculating tubes with the bacterial culture followed by incubation for 48 hours at $37^{\circ} \mathrm{C}$. Separate pipettes were used to pipette $1 \mathrm{ml}$ from each culture tube into clean separate tubes. Eighteen drops $(0.5 \mathrm{ml})$ of Barrit's solution A (a-naphthol) was added to each tube containing glucose phosphate broth followed by the addition of an equal amount of solution $B$ into the same tube. The tubes were shaken at 30 seconds interval. A positive reaction was indicated by the development of a pink color, which turns red in 1-2 hours, after vigorous shaking.

\section{Procedure for Citrate Utilization Test}

Citrate Utilization Test was carried out by distributing melted agar (Simmon Citrate Agar) in to test tubes followed by sterilization at $121.5^{\circ} \mathrm{C}$ for 15 minutes. The test tubes were afterward held in slanted position, inoculated with the given bacterial culture and incubated at $37^{\circ} \mathrm{C}$ for $24 \mathrm{hrs}$. Positive test was indicated by color change of the media from green to blue.

\section{RESULTS AND DISCUSSIONS}

The results of this study are presented in tables $1,2,3$ and 4. Among the sampling areas Kofar Kudu had the highest aerobic mesophilic bacteria counts $4.0 \times 10^{5} \mathrm{cfu} / \mathrm{g}$ followed by Rinji $2.72 \times 10^{5} \mathrm{cfu} / \mathrm{g}$, while Tosaro had the least Aerobic mesophilic bacteria counts of $1.02 \times 10^{5}$ $\mathrm{cfu} / \mathrm{g}$ as indicated in Table 1.Makwalla had the highest coliform count $68 \mathrm{MPN} / \mathrm{g}$ followed by Rinji $37 \mathrm{MPN} / \mathrm{g}$. Tsohuwar Kasuwa had the least coliform counts $8 \mathrm{MPN} / \mathrm{g}$, (Table 2). Result from table 1 shows variation in the microbial contents among the samples which suggest variation in their sources, poor handling procedures and contamination from the processing environment. High coliform count and their differences within sampling areas is an indication of poor microbiological quality of the product. Ndahi et al. (2013) reported microbial load to be a function of the handling personnel and the environment. The results indicated that the samples were contaminated with bacteria as the counts exceeded the minimum safety level $\left(10^{4} \mathrm{cfu} / \mathrm{g}\right)$ for members of the Enterobacteriaceae family. However, it might be a reflection of poor hygienic practices which may contribute to health hazard to the potential consumers. Similarly, Inusa and Sa'id (2017); Osimani et al. (2015) reported that, the initial microbial content of the raw material play significant role in influencing the final microbial load of the finished product. Isolation of members of the Enterobacteriaceae such as $E$. coli, Klebsiella pneumoniae, Salmonella and Shigella signifies danger to the public health. These organisms are capable of producing endotoxins which trigger high fevers in infected individuals, and the enterotoxins which colonize the small intestines and lead to extreme dehydration as a result of vomiting and diarrhea sometimes with severe and fatal outcomes (Amaeze et al., 2016). From the 16 isolated organisms $E$. coli had the highest isolation rate $6(37.5 \%)$ (Table 3), this suggest faecal contamination of the products. $E$. coli is a common flora in the gastrointestinal tract responsible for diarrhea and extra-intestinal infections (CDC, 2011). The result is in conformity with the findings of Ndahi et al. (2013) and Shamsuddeen (2009). Also presence of campylobacter might be due to cross contamination from raw meat to finished product (Tsire). Staphylococcus aureus is a normal flora of the skin, nasal, genital, mouth or anal area in both humans and animals without any symptom of an infection (Matthew et al., 2013). Isolation of $S$. aureus in these study concords with the findings of Lucretia et al. (2018) from Suya sold in Rivers State. 
BAJOPAS Volume 13 Number 1, June, 2020

It is also in agreement with the findings of Yousafzai et al. (2018); Onuorah et al. (2015) and Tijjani and Jumare (2014) from tsire samples in different countries. Presence of $S$. aureus in foods is most of the time an indication of poor human handling, poor environment, unhygienic utensils and equipments used during processing (Igene et al., 2016; Okonko et al., 2013). Infections caused by $S$. aureus are difficult to treat leading to long hospitalization with consequent economic loss (Udobi et al., 2013). These include soft tissue infections, pneumonia, hospital-acquired postoperative wound infections, Staphylococcal food poisoning, impetigo and cellulitis (Charlene et al., 2013). Samples obtained from Dausai and Kofar Kudu had the highest isolation rate $4(80 \%)$ (Table 4 ) probably because of the much commercial activities taking place in the area which can lead to environmental contamination.

Table 1: Total Aerobic Mesophilic Bacterial Count of Tsire sold in Garko Town

\begin{tabular}{lll}
\hline Sampling Area & APC cfu/g & Mean \pm STD \\
\hline Dausai & $2.20 \times 10^{5}$ & $110000 \pm 14142.14$ \\
Kofar Kudu & $4.00 \times 10^{5}$ & $133333.3 \pm 23094.01$ \\
Makwalla & $1.30 \times 10^{5}$ & $32500 \pm 7187.953$ \\
Rinji & $2.72 \times 10^{5}$ & $90666.67 \pm 94769.90$ \\
Tosaro & $1.02 \times 10^{5}$ & $51000 \pm 15556.35$ \\
Tsohuwar Kasuwa & $1.75 \times 10^{5}$ & $35000 \pm 11357.82$ \\
\hline
\end{tabular}

Key: APC: Aerobic Mesophilic Counts

STD: Standard Deviation

Table 2: Total Coliform Count of Tsire sold in Garko Town

\begin{tabular}{lcc}
\hline \multicolumn{1}{c}{ Sampling Area } & TCC MPN/g & Mean \pm STD \\
\hline Dausai & 20 & $6.67 \pm 2.5166$ \\
Kofar Kudu & 32 & $16.00 \pm 5.6569$ \\
Makwalla & 68 & $13.60 \pm 8.7062$ \\
Rinji & 37 & $9.25 \pm 4.7871$ \\
Tosaro & 10 & $5.00 \pm 2.8284$ \\
Tsohuwar Kasuwa & 8 & $4.00 \pm 0.0000$ \\
\hline
\end{tabular}

Table 3: Organisms Isolated from Tsire Sold in Garko

\begin{tabular}{lcl}
\hline Isolated Organism & Frequency & Percentage (\%) \\
\hline Campylobacter & 2 & 06.66 \\
Escherichia coli & 6 & 20.00 \\
Klebsiella pneumoniae & 2 & 06.66 \\
Salmonella species & 1 & 03.33 \\
Shigella & 3 & 10.00 \\
Staphylococcus aureus & 2 & 06.66 \\
Total & 16 & \\
\hline
\end{tabular}

Table 4: Distribution of Organisms within Sampling Area

\begin{tabular}{lcc}
\hline \multicolumn{1}{c}{ Sampling Area } & No. Isolated & Percentage (\%) \\
\hline Dausai & 4 & 80 \\
Kofar Kudu & 4 & 80 \\
Makwalla & 2 & 40 \\
Rinji & 3 & 60 \\
Tosaro & 2 & 40 \\
Tsohuwar Kasuwa & 1 & 20 \\
Total & 16 & \\
\hline
\end{tabular}

\section{CONCLUSION}

Results indicated $4.00 \times 10^{5} \mathrm{CFU} / \mathrm{g}$ as the highest APCs count; while $68 \mathrm{MPN} / \mathrm{g}$ was the highest TCCs from the 30 samples analyzed. Among the isolates, $E$. coli has the highest isolation rate of $6(20 \%)$. Dausai and Kofar kudu were having the highest bacteria count of $4(80 \%)$, each, indicating higher contamination in those locations. 
BAJOPAS Volume 13 Number 1, June, 2020 RECOMMENDATIONS

The following recommendations are tenable:

1. Hygienic practices at all stages of production should be improved to safe guard the consumers against potential health hazard.

2. Monitoring of microbiological contamination of Tsire during preparations, packaging and marketing is essential to ensure product of good microbiological quality for consumers' health.

\section{REFERENCES}

Abdullahi, I. O., Umoh, V. J. and Galadima, M. (2004). Hazards Associated with Kilishi Preparations in Zaria. Nigerian Journal of Microbiology, 18 (1-2): $339-345$.

Ahmadu, J. and Ibrahim E. J., (2013): Determinants of Revenue in Suya Production in BeninCity, Edo State, Nigeria. Nigerian journal of agriculture, food and environment.9(3):1-5

Amaeze, N. Aboh, M. Itohan, A. Felix, E. Olatunji, T. and Oladosu, P. (2016) Microbial Profile, Antibiotic Sensitivity and Heat Resistance of Bacterial Isolates from Commercial Roasted Beef (Suya) in Abuja, Nigeria. JOPAT, 15(2): $22-30$.

Apata, E.S., Kuku1, I.A., Apata, O.C. and Adeyemi, K.O. (2013). Evaluation of Suya(Tsire) - An Intermediate Moisture Meat Product in Ogun State, Nigeria. J. Food Res 2 (1): 87.

Atlas, R. M. (1997) Principles of Microbiology Second Edition. C. Brown Publishers. Pp 802-803.

Borch, E. Kant-Muermans, M. L., Blixt, Y. (1996) Bacterial Spoilage of Meat and Cured Meat Products. Int $\mathrm{J}$ Food Microbiol .33(1): 103-20.

Centre for Disease Control, CDC (2011). "Escherichia coli 0157:H7" Division of Bacterial and Mycotic Diseasesht://www.cdc.gov/nczved/divisi ons/dfbmd/diseases/ecoli_0157h7/.

Charlene, R. J., Johnnie, A. D., and John, B. B., (2013) Prevalence and Characterization of Methicillin-Resistant Staphylococcus aureus Isolates from Retail Meat and Humans in Georgia. American society for Microbiology. J. of clinical microbiology. 12(1):123-6 doi:10.1128/JCM.0316612JCM.03166-12

Egbebi, A.O and Seidu, K., T. (2011). Microbiological Evaluation of Suya (dried smoked

meat) Sold in Ado and Akure, South West Nigeria.European Journal of Experinmental Biology, 1(4):1-5
3. Government should establish regulatory bodies responsible for inculcating hygiene habits to the local producers and vendors in order to prevent instant, cross and post processing contaminations by microbial pathogens.

4. Awareness and sensitization of local food producers about good hygienic practices in food handling and processing.

Falegan, C, R., Akoja, S. D., and Oyarekua, M. A., (2017) Microbiological Assessment of Suya (Sliced Roasted Beef) in Ado-Ekiti Metropolis, Ekiti State, Nigeria. MOJ Biology andMedicine.

Fonkem, D., N. Tanya, V., N. and Ebangi, A., L. (2010). Effect of Season on the Microbiological Quality of Kilishi, a Traditional Cameroonian Dried Beef Product. Tropicultura, 28(1): 10-15.

Food and Agricultural Organization of the United Nations (F A O, 1979). Manual of food quality control 4. Microbiological analysis.

Food and Agriculture Organisation of the United Nation (FAO), 2019. Nigeria at a glance.

Igene J.O., Uwadia, O.E., Ebabhamiegbebho, P.A. and Evivie, S.E., (2016) Shelf life Stability Studies of University of Benin (UNIBEN) Proff's Kilishi Product Asian Journal of Science and Technology 7(1): 2268-2274.

Inusa, S. K. and Said, I. S. (2017) Evaluation of the Chemical and Microbiological Properties Of Kilishi Sold in Kano Metropolis. Journal of Dry land Agriculture, 3 (1): $59-69$.

Lucretia, I. B, Patience, C. Obinna-Echem, Sophia, C. A. (2018) Microbiological quality andantibiotic sensitivity of potential pathogens isolated from meat product (Suya) sold in Rivers State University and its environs. International Journal of Biotechnology and Food Science, 6(4): 67-76.

Matthew, E., Drosos, E., John, L. and Ioanna, P. (2013) MRSA in Africa: Filling the Global Map of Antimicrobial Resistance PLOS One. 8(7): e68024 doi: 10.1371/journal.pone.0068024

Mgbemere, V.N., Akpapunam, M. A. and Igene, J. O., (2011). Effect of Groundnut FlourSubstitution on Yield, Quality and Storage Stability of Kilishi - a Nigerian Indigenous Dried Meat Product. African Journal of Food, Agriculture, Nutrition and Development, $\quad \mathbf{1 1}(2)$ : 4718-4738. 
BAJOPAS Volume 13 Number 1, June, 2020

Mubarak, A. A., Azeez, M. L., Amos A. O., Opeyemi, O. O. (2016) Assessment of Animal Protein Consumption and Food Security Among Rural Households in Kwara State, Nigeria American Journal of Business and Society, 1(4): 233245.

Ndahi, M., D. Kwaga, J., K. P. Bello, M. Kabir J., V. Umoh, .J. Yakubu, S., E. and Nok, A., J. (2013) Prevalence and Antimicrobial Susceptibility of Listeria Monocytogenes and Methicillin-Resistant Staphylococcus aureus Strains from Raw Meat and Meat Products in Zaria, Nigeria. Applied Journal of Microbiology, 58(3):262-9.

Okonko, I.O., Odu, N.N. and Igboh, I.E. (2013). Microbiological Analysis of Kilishi Sold In Port Harcourt, Nigeria. New York Science Journal, 6 (7):37-43.

Osimani, A., Aquilanti, L. and Clementi, F. (2015) Microbiological Quality of Meatbased Meals and Operation of Control Systems within a Food Service Environment. International Food Research Journal 22(4): 1692-1698.

Onuorah, S. Obika, I. Odibo, F. Orji, M. (2015)An Assessment of the Bacteriological Quality of Tsire-Suya (Grilled Beef) sold in Awka, Nigeria. American. J. Life. Sci. Res. 3(4):287292.

Razavilar, V, Khandaghi, J. Barzgari, A. (2010); Isolation of Eschericia coli 0157:H7 from manure fertilized farms and raw vegetables grown on it, in Tabriz city in
Iran. African Journal of Microbiology Research, 4(9): 891-895.

Scallan, E. Hoekstra, R. M. Angulo, F. J.Tauxe, R. V, Widdowson, M. Roy, S. L et al., (2011).Food borne illness acquired in the United States- Major Pathogens. Emerg. Infec Dis, 17(1): 7-15.

Shamsuddeen U (2009). Microbiological quality of spice used in the production of Kilishi a traditionally dried and grilled meat product. Bayero Journal of Pure andApplied Sciences, 2(2): 66-69.

Shamsuddeen, U. (2015) Microbiological Hazard and Critical control point Analysis of Dried and Minced Meat Snacks Produced in Kano Nigeria. Lambert Academic Publishing; Pp 1-36.

Tijani, O.and Jumare, S. (2014). Microblological Quality Assessment of Meat

Sold in KauraNamoda. International Conference on Earth, Environment and Life sciences (EELS) Dubai (UAE).

Udobi, C. E., Obajuluwa, A. F., and Onaolapo, J. A., (2013) Prevalence and Antibiotic Resistance Pattern of MethicillinResistant Staphylococcus aureus from an Orthopaedic Hospital in Nigeria BioMed Research International; 26(6); 6-7.

WHO, 2015 Foodborne diseases in the WHO African Region.

Yousafzai HA, Rind R, Khan MA, Abro SH, Korejo NA, Ejaz M, Kabir A, Shahid M, Memon S. (2019). Microbiological Contamination of Cattle and Meat in Peshawar, Pakistan. J. Anim. Health Prod. 7(1): 1116. 


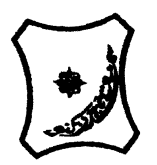

Bayero Journal of Pure and Applied Sciences, 13(1); 40 - 45

Received: September, 2019

Accepted: April, 2020

ISSN $2006-6996$

\title{
BACTERIOLOGICAL QUALITY OF STICK MEAT (Tsire) SOLD IN GARKO LOCAL GOVERNMENT AREA OF KANO STATE, NIGERIA
}

\author{
$*^{1}$ Dahiru A. T. and ${ }^{2}$ Maigari A. K. \\ ${ }^{1}$ Department of Hospitality Management, School of Technology, Kano State Polytechnic, PMB 3348, \\ Kano Nigeria. \\ ${ }^{2}$ Departmnt of Biological Sciences, Bayero University, Kano \\ Corresponding Author: dturajo61@gmail.com; GSM: 08087508262.
}

ABSTRACT

Stick meat, locally called Tsire in Hausa Language, is a significant portion of the diet of a large active population of Northern Nigeria. However, because of the handling and processing methods by the manufacturers as well as the hawking system of stick meat, the meat product may be exposed to both pre- and post-processed product contamination, and thus may poses danger to public health. Therefore, considering the role of Tsire in improving nutrition and increase household income to the populace, the need to improve the processing, distribution and overall quality of the product is simply indispensable. A total of 30 samples (5 samples from each of the 6 sampling points) of Tsire were collected randomly in Garko Town. Aerobic plate counts (APCs) and Total coliform counts (TCCS) of Tsire samples were determined using standard microbiological methods. APCs ranged from $1.02 \times 10^{5}$ to $4.00 \times 10^{5} \mathrm{CFU} / \mathrm{g}$; while TCCs ranged from $8 \mathrm{MPN} / \mathrm{g}$ to $68 \mathrm{MPN} / \mathrm{g}$. From the 30 samples screened, 16(53.33\%) bacteria namely, Campylobacter 2(6.66\%), Escherichia coli 6(20\%), Klebsiella pneumoniae 2(6.66\%), Salmonella spp. 1(3.33\%), Shigella 3(10\%) and Staphylococcus aureus 2(6.66\%) were detected. $E$. coli has the highest isolation rate of 6(20\%), while Salmonella spp. had the least frequency of 1(3.33\%). The distribution of isolated organisms within the study area were as follows: Dausai, 4(80\%), Kofar kudu, 4(80\%), Makwalla, 2(40\%), Rinji, 3(60\%), Tosaro, 2(40\%), and Tsohuwar Kasuwa, 1(20\%). The results have indicated that the Tsire was contaminated with bacteria thus exposing the product to fast deterioration, spoilage and also a vehicle for food borne illness, suggesting for adequate hygienic practices at all the stages, prior to consumption, to ensure safety of the meat product.

Key words: APCs, TCCs, Contamination, Microorganisms, Garko

\section{INTRODUCTION}

Nigeria is one of the developing nations with inadequate food supply and most often deficient in protein content (FAO, 2019). Nigerian's average animal protein intake per head per day is estimated at $7.9 \mathrm{~g}$ as against $35 \mathrm{~g}$ recommended value by Food and Agricultural Organization (Mubarak et al., 2016). These low levels of animal protein intake create great concern as it affects the nutritional status of Nigerians. Hence, there is the need for sufficient supply of animal protein from energy rich animal products to satisfy the nutritional requirements for Nigerians.

Meat is one major source of animal protein largely composed of water, protein and fats which can make it susceptible to microbial contamination within short time leading to spoilage (Apata et al., 2013; Mgbemere et al., 2011). Meat is mostly eaten after it has been cooked or processed in a variety of ways such as sun drying; smoking and roasting with or without fortifications (Borch et al., 1996). In Nigeria meat products such as Tsire, Kilishi and Balangu are locally produced using one or more of these methods in order to meet the nutritional requirements of the teeming Nigerians (Egbebi, 2011).

Tsire is a popular Nigerian traditional processed ready-to-eat roasted stick meat product (Shamsuddeen, 2015). It is sold in public places, along roads, in hotels, parks, quarters and even offices (Falegan et al., 2017). It is prepared from boneless healthy animal flesh such as beef and mutton, spiced with peanut cake, salt, vegetable oil and other flavorings followed by roasting (Shamsuddeen, 2015). Consumption of these products has extended to other parts of African countries such as Ghana, Somali, Cameroun and Chad (Ahmadu and Ibrahim, 2013). 
BAJOPAS Volume 13 Number 1, June, 2020

However, evidence of quality control sticking to procedural hygiene by the handlers during preparation and retailing of these products is poorly documented. Tsire is of great safety risk because of the fact that there are erratic cases of gastroenteritis and symptoms of food infection after consumption (WHO, 2015). Food borne illnesses are one of the major health problems in developing and developed countries (Razavilar, 2010). According to the World Health Organization, WHO (2015), $0.07 \%$ death of the 600 million global burdens of Foodborne illnesses have been reported to be caused by bacteria, viruses, fungi and chemicals. In America $0.27 \%$ of the estimated 48 million affected people is hospitalized and about $0.0063 \%$ deaths are recorded each year (Scallan et al., 2011). More than 91 million people in Africa fall ill and $0.15 \%$ dies each year, making Africa the highest burden bearer of Foodborne diseases per population (WHO, 2015).

Application of a Hazard Analysis Critical Control Point (HACCP) at all stages of meat products preparation is essential in order to ensure its safety. Thus, according to the guidelines of good manufacturing practice, the level of total aerobic bacterial contamination of thermally processed meat products should not exceed $10^{4}\left(\mathrm{cfu} \mathrm{g}^{-1}\right)$. Enterobacteriaceae and faecal coliform contamination in meat products should be within the range of $10^{2}-10^{4}$ and $10-10^{3} \mathrm{cfu} \mathrm{g}^{-1}$, respectively (Shamsuddeen, 2015). The aim of the study is therefore, to assess the total viable bacterial counts of tsire marketed locally within Garko town, and to isolate and identify the organisms at the point of consumption with the intention of promoting public health and food hygiene habits in the Nigerian populace.

\section{MATERIALS AND METHODS Study Area and Population}

Garko is one of the existing 44 local government areas located in Kano south west zone of Kano state with its capital administrative headquarters in the Garko town. It has coordinates $11^{\circ} 39^{\prime} \mathrm{N}$ $8^{\circ} 54^{\prime} \mathrm{E}$, and an area of $450 \mathrm{~km}^{2}$. The projected population of Garko local Government was 225,300 according to the National Population Census report (2018). Garko is known for agricultural activities both farming and animal husbandry. It is popularly known for large scale rice production. Other food crops include sweet potatoes, cassava, onions, sorghum, millet and sugarcane. Cows, sheep and goats are major groups of animals reared by majority of the populace. Meat products processed, retailed and consumed in Garko include roasted meat (Balangu), dried roasted meat (Kilishi), stick meat (Tsire), hide and skin pepper soup (Ragadada) and minced fried meat (Danbunnama).

\section{Samples Collection}

Five samples of Tsire products were collected from 6 different identified locations within Garko town in a sterile foil paper and immediately analyzed for the presence of bacteria.

\section{Sample Preparation}

Sample preparation for the bacteriological analysis was carried out in accordance with the method described by Atlas (1997). Twenty five grams $(25 \mathrm{~g})$ of the sample was homogenized in $225 \mathrm{ml}$ peptone water using Kenwood blender machine to obtain a $10^{1}$ homogenate. The homogenate was thoroughly shaken and $1 \mathrm{ml}$ pipetted into test tubes containing $9 \mathrm{ml}$ of peptone water $\left(10^{2}\right)$. The test tubes were further serially diluted to $10^{5}$.

Total Aerobic Mesophilic Bacterial Count

Total Aerobic mesophilic bacterial count was determined using the method described by Abdullahi et al. (2004) where $1 \mathrm{ml}$ of inoculums from $10^{1}$ to $10^{5}$ dilutions were transferred into duplicate Petri dishes and labeled accordingly. This was followed by pouring aseptically about $15 \mathrm{ml}$ of molten nutrient agar. The culture was homogenized by gentle spinning of the plates and allowed to solidify. The plates were incubated at $37^{\circ} \mathrm{C}$ for 24 hours. Plates containing 30-300 colonies were counted. The number of colony forming units per gram of a sample (cfu/g) was obtained by multiplying the average colony number with the inverse of the dilution factor.

\section{Enumeration and Detection of Coliform bacteria}

Detection and enumeration of coliform was carried out according to method described by Atlas, (1977). A set of 9 test tubes each containing $9 \mathrm{ml}$ of lactose broth and an inverted Durham tubes were autoclaved to expel air and to sterilize. Similarly, $1 \mathrm{ml}$ from the diluents $10^{1}$ was transferred to the first 3 test tubes, followed by $1 \mathrm{ml}$ from the diluents $10^{2}$ to the second set of 3 test tubes and finally the third diluents $10^{3}$ to the $3^{\text {rd }}$ set of 3 test tubes. All the 9 test tubes were incubated at $37^{\circ} \mathrm{C}$ for 24 hours. Tubes that showed gas and acid production after 24 hours were recorded as positive for the presence of Coliform. Negative tubes were further reincubated for 24 hours. Positive tubes were recorded. Estimate of most probable number of Coliform per gram of sample (MPN/g) was determined by comparing the number of gas positive tubes with the most probable number table. 
BAJOPAS Volume 13 Number 1, June, 2020 Identification of Coliform

A loop full of inoculum from gas positive tubes was streaked on to Eosine methylene blue (EMB) agar plate and incubated at $37^{\circ} \mathrm{C}$ for $24 \mathrm{hrs}$. Colonies which formed bluish black color with green metallic sheen, and reddish colonies were isolated on agar slants. Those colonies showing metallic sheen on EMB were sub cultured into tubes of lactose broth and incubated at $45^{\circ} \mathrm{C}$. The tubes were observed after $24 \mathrm{hrs}$ for gas production. This is the completed test for fecal coliform. Gram stain and other biochemical tests such as Indole, Methyl red, Voges-Proskauer and Citrate Utilization tests (IMVIC), Coagulase and Catalase tests were carried out for the Identification and confirmation of isolates.

\section{Procedure for Indole Test}

Indole test was carried out by preparing a Tryptone broth drawn in to test tubes, sterilized by autoclaving, inoculated with loopful of suspension and incubated at $37^{\circ} \mathrm{C}$ for 24 hours. Three drops of xylene was added in tubes, shaken vigorously and kept for the separation of two layers. One millilitre of Kovac's reagent was added and the formation of pink colour ring indicates positive Indole test.

\section{Procedure for Methyl Red Test}

Methyl red test was carried out by preparing Glucose phosphate broth, dispensed in test tubes, sterilized, inoculated with test culture and incubated at $37^{\circ} \mathrm{C}$ for 24 hours. Five drops of methyl-red indicator was added to the medium for the formation of red colour.

\section{Procedure for Voges-Proskauer Test}

Voges-Proskauer test was carried out by inoculating tubes with the bacterial culture followed by incubation for 48 hours at $37^{\circ} \mathrm{C}$. Separate pipettes were used to pipette $1 \mathrm{ml}$ from each culture tube into clean separate tubes. Eighteen drops $(0.5 \mathrm{ml})$ of Barrit's solution A (a-naphthol) was added to each tube containing glucose phosphate broth followed by the addition of an equal amount of solution $B$ into the same tube. The tubes were shaken at 30 seconds interval. A positive reaction was indicated by the development of a pink color, which turns red in 1-2 hours, after vigorous shaking.

\section{Procedure for Citrate Utilization Test}

Citrate Utilization Test was carried out by distributing melted agar (Simmon Citrate Agar) in to test tubes followed by sterilization at $121.5^{\circ} \mathrm{C}$ for 15 minutes. The test tubes were afterward held in slanted position, inoculated with the given bacterial culture and incubated at $37^{\circ} \mathrm{C}$ for $24 \mathrm{hrs}$. Positive test was indicated by color change of the media from green to blue.

\section{RESULTS AND DISCUSSIONS}

The results of this study are presented in tables $1,2,3$ and 4. Among the sampling areas Kofar Kudu had the highest aerobic mesophilic bacteria counts $4.0 \times 10^{5} \mathrm{cfu} / \mathrm{g}$ followed by Rinji $2.72 \times 10^{5} \mathrm{cfu} / \mathrm{g}$, while Tosaro had the least Aerobic mesophilic bacteria counts of $1.02 \times 10^{5}$ $\mathrm{cfu} / \mathrm{g}$ as indicated in Table 1.Makwalla had the highest coliform count $68 \mathrm{MPN} / \mathrm{g}$ followed by Rinji $37 \mathrm{MPN} / \mathrm{g}$. Tsohuwar Kasuwa had the least coliform counts $8 \mathrm{MPN} / \mathrm{g}$, (Table 2). Result from table 1 shows variation in the microbial contents among the samples which suggest variation in their sources, poor handling procedures and contamination from the processing environment. High coliform count and their differences within sampling areas is an indication of poor microbiological quality of the product. Ndahi et al. (2013) reported microbial load to be a function of the handling personnel and the environment. The results indicated that the samples were contaminated with bacteria as the counts exceeded the minimum safety level $\left(10^{4} \mathrm{cfu} / \mathrm{g}\right)$ for members of the Enterobacteriaceae family. However, it might be a reflection of poor hygienic practices which may contribute to health hazard to the potential consumers. Similarly, Inusa and Sa'id (2017); Osimani et al. (2015) reported that, the initial microbial content of the raw material play significant role in influencing the final microbial load of the finished product. Isolation of members of the Enterobacteriaceae such as $E$. coli, Klebsiella pneumoniae, Salmonella and Shigella signifies danger to the public health. These organisms are capable of producing endotoxins which trigger high fevers in infected individuals, and the enterotoxins which colonize the small intestines and lead to extreme dehydration as a result of vomiting and diarrhea sometimes with severe and fatal outcomes (Amaeze et al., 2016). From the 16 isolated organisms $E$. coli had the highest isolation rate $6(37.5 \%)$ (Table 3), this suggest faecal contamination of the products. $E$. coli is a common flora in the gastrointestinal tract responsible for diarrhea and extra-intestinal infections (CDC, 2011). The result is in conformity with the findings of Ndahi et al. (2013) and Shamsuddeen (2009). Also presence of campylobacter might be due to cross contamination from raw meat to finished product (Tsire). Staphylococcus aureus is a normal flora of the skin, nasal, genital, mouth or anal area in both humans and animals without any symptom of an infection (Matthew et al., 2013). Isolation of $S$. aureus in these study concords with the findings of Lucretia et al. (2018) from Suya sold in Rivers State. 
BAJOPAS Volume 13 Number 1, June, 2020

It is also in agreement with the findings of Yousafzai et al. (2018); Onuorah et al. (2015) and Tijjani and Jumare (2014) from tsire samples in different countries. Presence of $S$. aureus in foods is most of the time an indication of poor human handling, poor environment, unhygienic utensils and equipments used during processing (Igene et al., 2016; Okonko et al., 2013). Infections caused by $S$. aureus are difficult to treat leading to long hospitalization with consequent economic loss (Udobi et al., 2013). These include soft tissue infections, pneumonia, hospital-acquired postoperative wound infections, Staphylococcal food poisoning, impetigo and cellulitis (Charlene et al., 2013). Samples obtained from Dausai and Kofar Kudu had the highest isolation rate $4(80 \%)$ (Table 4 ) probably because of the much commercial activities taking place in the area which can lead to environmental contamination.

Table 1: Total Aerobic Mesophilic Bacterial Count of Tsire sold in Garko Town

\begin{tabular}{lll}
\hline Sampling Area & APC cfu/g & Mean \pm STD \\
\hline Dausai & $2.20 \times 10^{5}$ & $110000 \pm 14142.14$ \\
Kofar Kudu & $4.00 \times 10^{5}$ & $133333.3 \pm 23094.01$ \\
Makwalla & $1.30 \times 10^{5}$ & $32500 \pm 7187.953$ \\
Rinji & $2.72 \times 10^{5}$ & $90666.67 \pm 94769.90$ \\
Tosaro & $1.02 \times 10^{5}$ & $51000 \pm 15556.35$ \\
Tsohuwar Kasuwa & $1.75 \times 10^{5}$ & $35000 \pm 11357.82$ \\
\hline
\end{tabular}

Key: APC: Aerobic Mesophilic Counts

STD: Standard Deviation

Table 2: Total Coliform Count of Tsire sold in Garko Town

\begin{tabular}{lcc}
\hline \multicolumn{1}{c}{ Sampling Area } & TCC MPN/g & Mean \pm STD \\
\hline Dausai & 20 & $6.67 \pm 2.5166$ \\
Kofar Kudu & 32 & $16.00 \pm 5.6569$ \\
Makwalla & 68 & $13.60 \pm 8.7062$ \\
Rinji & 37 & $9.25 \pm 4.7871$ \\
Tosaro & 10 & $5.00 \pm 2.8284$ \\
Tsohuwar Kasuwa & 8 & $4.00 \pm 0.0000$ \\
\hline
\end{tabular}

Table 3: Organisms Isolated from Tsire Sold in Garko

\begin{tabular}{lcl}
\hline Isolated Organism & Frequency & Percentage (\%) \\
\hline Campylobacter & 2 & 06.66 \\
Escherichia coli & 6 & 20.00 \\
Klebsiella pneumoniae & 2 & 06.66 \\
Salmonella species & 1 & 03.33 \\
Shigella & 3 & 10.00 \\
Staphylococcus aureus & 2 & 06.66 \\
Total & 16 & \\
\hline
\end{tabular}

Table 4: Distribution of Organisms within Sampling Area

\begin{tabular}{lcc}
\hline \multicolumn{1}{c}{ Sampling Area } & No. Isolated & Percentage (\%) \\
\hline Dausai & 4 & 80 \\
Kofar Kudu & 4 & 80 \\
Makwalla & 2 & 40 \\
Rinji & 3 & 60 \\
Tosaro & 2 & 40 \\
Tsohuwar Kasuwa & 1 & 20 \\
Total & 16 & \\
\hline
\end{tabular}

\section{CONCLUSION}

Results indicated $4.00 \times 10^{5} \mathrm{CFU} / \mathrm{g}$ as the highest APCs count; while $68 \mathrm{MPN} / \mathrm{g}$ was the highest TCCs from the 30 samples analyzed. Among the isolates, $E$. coli has the highest isolation rate of $6(20 \%)$. Dausai and Kofar kudu were having the highest bacteria count of $4(80 \%)$, each, indicating higher contamination in those locations. 
BAJOPAS Volume 13 Number 1, June, 2020 RECOMMENDATIONS

The following recommendations are tenable:

1. Hygienic practices at all stages of production should be improved to safe guard the consumers against potential health hazard.

2. Monitoring of microbiological contamination of Tsire during preparations, packaging and marketing is essential to ensure product of good microbiological quality for consumers' health.

\section{REFERENCES}

Abdullahi, I. O., Umoh, V. J. and Galadima, M. (2004). Hazards Associated with Kilishi Preparations in Zaria. Nigerian Journal of Microbiology, 18 (1-2): $339-345$.

Ahmadu, J. and Ibrahim E. J., (2013): Determinants of Revenue in Suya Production in BeninCity, Edo State, Nigeria. Nigerian journal of agriculture, food and environment.9(3):1-5

Amaeze, N. Aboh, M. Itohan, A. Felix, E. Olatunji, T. and Oladosu, P. (2016) Microbial Profile, Antibiotic Sensitivity and Heat Resistance of Bacterial Isolates from Commercial Roasted Beef (Suya) in Abuja, Nigeria. JOPAT, 15(2): $22-30$.

Apata, E.S., Kuku1, I.A., Apata, O.C. and Adeyemi, K.O. (2013). Evaluation of Suya(Tsire) - An Intermediate Moisture Meat Product in Ogun State, Nigeria. J. Food Res 2 (1): 87.

Atlas, R. M. (1997) Principles of Microbiology Second Edition. C. Brown Publishers. Pp 802-803.

Borch, E. Kant-Muermans, M. L., Blixt, Y. (1996) Bacterial Spoilage of Meat and Cured Meat Products. Int $\mathrm{J}$ Food Microbiol .33(1): 103-20.

Centre for Disease Control, CDC (2011). "Escherichia coli 0157:H7" Division of Bacterial and Mycotic Diseasesht://www.cdc.gov/nczved/divisi ons/dfbmd/diseases/ecoli_0157h7/.

Charlene, R. J., Johnnie, A. D., and John, B. B., (2013) Prevalence and Characterization of Methicillin-Resistant Staphylococcus aureus Isolates from Retail Meat and Humans in Georgia. American society for Microbiology. J. of clinical microbiology. 12(1):123-6 doi:10.1128/JCM.0316612JCM.03166-12

Egbebi, A.O and Seidu, K., T. (2011). Microbiological Evaluation of Suya (dried smoked

meat) Sold in Ado and Akure, South West Nigeria.European Journal of Experinmental Biology, 1(4):1-5
3. Government should establish regulatory bodies responsible for inculcating hygiene habits to the local producers and vendors in order to prevent instant, cross and post processing contaminations by microbial pathogens.

4. Awareness and sensitization of local food producers about good hygienic practices in food handling and processing.

Falegan, C, R., Akoja, S. D., and Oyarekua, M. A., (2017) Microbiological Assessment of Suya (Sliced Roasted Beef) in Ado-Ekiti Metropolis, Ekiti State, Nigeria. MOJ Biology andMedicine.

Fonkem, D., N. Tanya, V., N. and Ebangi, A., L. (2010). Effect of Season on the Microbiological Quality of Kilishi, a Traditional Cameroonian Dried Beef Product. Tropicultura, 28(1): 10-15.

Food and Agricultural Organization of the United Nations (F A O, 1979). Manual of food quality control 4. Microbiological analysis.

Food and Agriculture Organisation of the United Nation (FAO), 2019. Nigeria at a glance.

Igene J.O., Uwadia, O.E., Ebabhamiegbebho, P.A. and Evivie, S.E., (2016) Shelf life Stability Studies of University of Benin (UNIBEN) Proff's Kilishi Product Asian Journal of Science and Technology 7(1): 2268-2274.

Inusa, S. K. and Said, I. S. (2017) Evaluation of the Chemical and Microbiological Properties Of Kilishi Sold in Kano Metropolis. Journal of Dry land Agriculture, 3 (1): $59-69$.

Lucretia, I. B, Patience, C. Obinna-Echem, Sophia, C. A. (2018) Microbiological quality andantibiotic sensitivity of potential pathogens isolated from meat product (Suya) sold in Rivers State University and its environs. International Journal of Biotechnology and Food Science, 6(4): 67-76.

Matthew, E., Drosos, E., John, L. and Ioanna, P. (2013) MRSA in Africa: Filling the Global Map of Antimicrobial Resistance PLOS One. 8(7): e68024 doi: 10.1371/journal.pone.0068024

Mgbemere, V.N., Akpapunam, M. A. and Igene, J. O., (2011). Effect of Groundnut FlourSubstitution on Yield, Quality and Storage Stability of Kilishi - a Nigerian Indigenous Dried Meat Product. African Journal of Food, Agriculture, Nutrition and Development, $\quad \mathbf{1 1}(2)$ : 4718-4738. 
BAJOPAS Volume 13 Number 1, June, 2020

Mubarak, A. A., Azeez, M. L., Amos A. O., Opeyemi, O. O. (2016) Assessment of Animal Protein Consumption and Food Security Among Rural Households in Kwara State, Nigeria American Journal of Business and Society, 1(4): 233245.

Ndahi, M., D. Kwaga, J., K. P. Bello, M. Kabir J., V. Umoh, .J. Yakubu, S., E. and Nok, A., J. (2013) Prevalence and Antimicrobial Susceptibility of Listeria Monocytogenes and Methicillin-Resistant Staphylococcus aureus Strains from Raw Meat and Meat Products in Zaria, Nigeria. Applied Journal of Microbiology, 58(3):262-9.

Okonko, I.O., Odu, N.N. and Igboh, I.E. (2013). Microbiological Analysis of Kilishi Sold In Port Harcourt, Nigeria. New York Science Journal, 6 (7):37-43.

Osimani, A., Aquilanti, L. and Clementi, F. (2015) Microbiological Quality of Meatbased Meals and Operation of Control Systems within a Food Service Environment. International Food Research Journal 22(4): 1692-1698.

Onuorah, S. Obika, I. Odibo, F. Orji, M. (2015)An Assessment of the Bacteriological Quality of Tsire-Suya (Grilled Beef) sold in Awka, Nigeria. American. J. Life. Sci. Res. 3(4):287292.

Razavilar, V, Khandaghi, J. Barzgari, A. (2010); Isolation of Eschericia coli 0157:H7 from manure fertilized farms and raw vegetables grown on it, in Tabriz city in
Iran. African Journal of Microbiology Research, 4(9): 891-895.

Scallan, E. Hoekstra, R. M. Angulo, F. J.Tauxe, R. V, Widdowson, M. Roy, S. L et al., (2011).Food borne illness acquired in the United States- Major Pathogens. Emerg. Infec Dis, 17(1): 7-15.

Shamsuddeen U (2009). Microbiological quality of spice used in the production of Kilishi a traditionally dried and grilled meat product. Bayero Journal of Pure andApplied Sciences, 2(2): 66-69.

Shamsuddeen, U. (2015) Microbiological Hazard and Critical control point Analysis of Dried and Minced Meat Snacks Produced in Kano Nigeria. Lambert Academic Publishing; Pp 1-36.

Tijani, O.and Jumare, S. (2014). Microblological Quality Assessment of Meat

Sold in KauraNamoda. International Conference on Earth, Environment and Life sciences (EELS) Dubai (UAE).

Udobi, C. E., Obajuluwa, A. F., and Onaolapo, J. A., (2013) Prevalence and Antibiotic Resistance Pattern of MethicillinResistant Staphylococcus aureus from an Orthopaedic Hospital in Nigeria BioMed Research International; 26(6); 6-7.

WHO, 2015 Foodborne diseases in the WHO African Region.

Yousafzai HA, Rind R, Khan MA, Abro SH, Korejo NA, Ejaz M, Kabir A, Shahid M, Memon S. (2019). Microbiological Contamination of Cattle and Meat in Peshawar, Pakistan. J. Anim. Health Prod. 7(1): 1116. 


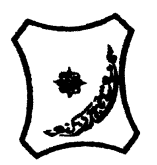

Bayero Journal of Pure and Applied Sciences, 13(1); 40 - 45

Received: September, 2019

Accepted: April, 2020

ISSN $2006-6996$

\title{
BACTERIOLOGICAL QUALITY OF STICK MEAT (Tsire) SOLD IN GARKO LOCAL GOVERNMENT AREA OF KANO STATE, NIGERIA
}

\author{
$*^{1}$ Dahiru A. T. and ${ }^{2}$ Maigari A. K. \\ ${ }^{1}$ Department of Hospitality Management, School of Technology, Kano State Polytechnic, PMB 3348, \\ Kano Nigeria. \\ ${ }^{2}$ Departmnt of Biological Sciences, Bayero University, Kano \\ Corresponding Author: dturajo61@gmail.com; GSM: 08087508262.
}

ABSTRACT

Stick meat, locally called Tsire in Hausa Language, is a significant portion of the diet of a large active population of Northern Nigeria. However, because of the handling and processing methods by the manufacturers as well as the hawking system of stick meat, the meat product may be exposed to both pre- and post-processed product contamination, and thus may poses danger to public health. Therefore, considering the role of Tsire in improving nutrition and increase household income to the populace, the need to improve the processing, distribution and overall quality of the product is simply indispensable. A total of 30 samples (5 samples from each of the 6 sampling points) of Tsire were collected randomly in Garko Town. Aerobic plate counts (APCs) and Total coliform counts (TCCS) of Tsire samples were determined using standard microbiological methods. APCs ranged from $1.02 \times 10^{5}$ to $4.00 \times 10^{5} \mathrm{CFU} / \mathrm{g}$; while TCCs ranged from $8 \mathrm{MPN} / \mathrm{g}$ to $68 \mathrm{MPN} / \mathrm{g}$. From the 30 samples screened, 16(53.33\%) bacteria namely, Campylobacter 2(6.66\%), Escherichia coli 6(20\%), Klebsiella pneumoniae 2(6.66\%), Salmonella spp. 1(3.33\%), Shigella 3(10\%) and Staphylococcus aureus 2(6.66\%) were detected. $E$. coli has the highest isolation rate of 6(20\%), while Salmonella spp. had the least frequency of 1(3.33\%). The distribution of isolated organisms within the study area were as follows: Dausai, 4(80\%), Kofar kudu, 4(80\%), Makwalla, 2(40\%), Rinji, 3(60\%), Tosaro, 2(40\%), and Tsohuwar Kasuwa, 1(20\%). The results have indicated that the Tsire was contaminated with bacteria thus exposing the product to fast deterioration, spoilage and also a vehicle for food borne illness, suggesting for adequate hygienic practices at all the stages, prior to consumption, to ensure safety of the meat product.

Key words: APCs, TCCs, Contamination, Microorganisms, Garko

\section{INTRODUCTION}

Nigeria is one of the developing nations with inadequate food supply and most often deficient in protein content (FAO, 2019). Nigerian's average animal protein intake per head per day is estimated at $7.9 \mathrm{~g}$ as against $35 \mathrm{~g}$ recommended value by Food and Agricultural Organization (Mubarak et al., 2016). These low levels of animal protein intake create great concern as it affects the nutritional status of Nigerians. Hence, there is the need for sufficient supply of animal protein from energy rich animal products to satisfy the nutritional requirements for Nigerians.

Meat is one major source of animal protein largely composed of water, protein and fats which can make it susceptible to microbial contamination within short time leading to spoilage (Apata et al., 2013; Mgbemere et al., 2011). Meat is mostly eaten after it has been cooked or processed in a variety of ways such as sun drying; smoking and roasting with or without fortifications (Borch et al., 1996). In Nigeria meat products such as Tsire, Kilishi and Balangu are locally produced using one or more of these methods in order to meet the nutritional requirements of the teeming Nigerians (Egbebi, 2011).

Tsire is a popular Nigerian traditional processed ready-to-eat roasted stick meat product (Shamsuddeen, 2015). It is sold in public places, along roads, in hotels, parks, quarters and even offices (Falegan et al., 2017). It is prepared from boneless healthy animal flesh such as beef and mutton, spiced with peanut cake, salt, vegetable oil and other flavorings followed by roasting (Shamsuddeen, 2015). Consumption of these products has extended to other parts of African countries such as Ghana, Somali, Cameroun and Chad (Ahmadu and Ibrahim, 2013). 
BAJOPAS Volume 13 Number 1, June, 2020

However, evidence of quality control sticking to procedural hygiene by the handlers during preparation and retailing of these products is poorly documented. Tsire is of great safety risk because of the fact that there are erratic cases of gastroenteritis and symptoms of food infection after consumption (WHO, 2015). Food borne illnesses are one of the major health problems in developing and developed countries (Razavilar, 2010). According to the World Health Organization, WHO (2015), $0.07 \%$ death of the 600 million global burdens of Foodborne illnesses have been reported to be caused by bacteria, viruses, fungi and chemicals. In America $0.27 \%$ of the estimated 48 million affected people is hospitalized and about $0.0063 \%$ deaths are recorded each year (Scallan et al., 2011). More than 91 million people in Africa fall ill and $0.15 \%$ dies each year, making Africa the highest burden bearer of Foodborne diseases per population (WHO, 2015).

Application of a Hazard Analysis Critical Control Point (HACCP) at all stages of meat products preparation is essential in order to ensure its safety. Thus, according to the guidelines of good manufacturing practice, the level of total aerobic bacterial contamination of thermally processed meat products should not exceed $10^{4}\left(\mathrm{cfu} \mathrm{g}^{-1}\right)$. Enterobacteriaceae and faecal coliform contamination in meat products should be within the range of $10^{2}-10^{4}$ and $10-10^{3} \mathrm{cfu} \mathrm{g}^{-1}$, respectively (Shamsuddeen, 2015). The aim of the study is therefore, to assess the total viable bacterial counts of tsire marketed locally within Garko town, and to isolate and identify the organisms at the point of consumption with the intention of promoting public health and food hygiene habits in the Nigerian populace.

\section{MATERIALS AND METHODS Study Area and Population}

Garko is one of the existing 44 local government areas located in Kano south west zone of Kano state with its capital administrative headquarters in the Garko town. It has coordinates $11^{\circ} 39^{\prime} \mathrm{N}$ $8^{\circ} 54^{\prime} \mathrm{E}$, and an area of $450 \mathrm{~km}^{2}$. The projected population of Garko local Government was 225,300 according to the National Population Census report (2018). Garko is known for agricultural activities both farming and animal husbandry. It is popularly known for large scale rice production. Other food crops include sweet potatoes, cassava, onions, sorghum, millet and sugarcane. Cows, sheep and goats are major groups of animals reared by majority of the populace. Meat products processed, retailed and consumed in Garko include roasted meat (Balangu), dried roasted meat (Kilishi), stick meat (Tsire), hide and skin pepper soup (Ragadada) and minced fried meat (Danbunnama).

\section{Samples Collection}

Five samples of Tsire products were collected from 6 different identified locations within Garko town in a sterile foil paper and immediately analyzed for the presence of bacteria.

\section{Sample Preparation}

Sample preparation for the bacteriological analysis was carried out in accordance with the method described by Atlas (1997). Twenty five grams $(25 \mathrm{~g})$ of the sample was homogenized in $225 \mathrm{ml}$ peptone water using Kenwood blender machine to obtain a $10^{1}$ homogenate. The homogenate was thoroughly shaken and $1 \mathrm{ml}$ pipetted into test tubes containing $9 \mathrm{ml}$ of peptone water $\left(10^{2}\right)$. The test tubes were further serially diluted to $10^{5}$.

Total Aerobic Mesophilic Bacterial Count

Total Aerobic mesophilic bacterial count was determined using the method described by Abdullahi et al. (2004) where $1 \mathrm{ml}$ of inoculums from $10^{1}$ to $10^{5}$ dilutions were transferred into duplicate Petri dishes and labeled accordingly. This was followed by pouring aseptically about $15 \mathrm{ml}$ of molten nutrient agar. The culture was homogenized by gentle spinning of the plates and allowed to solidify. The plates were incubated at $37^{\circ} \mathrm{C}$ for 24 hours. Plates containing 30-300 colonies were counted. The number of colony forming units per gram of a sample (cfu/g) was obtained by multiplying the average colony number with the inverse of the dilution factor.

\section{Enumeration and Detection of Coliform bacteria}

Detection and enumeration of coliform was carried out according to method described by Atlas, (1977). A set of 9 test tubes each containing $9 \mathrm{ml}$ of lactose broth and an inverted Durham tubes were autoclaved to expel air and to sterilize. Similarly, $1 \mathrm{ml}$ from the diluents $10^{1}$ was transferred to the first 3 test tubes, followed by $1 \mathrm{ml}$ from the diluents $10^{2}$ to the second set of 3 test tubes and finally the third diluents $10^{3}$ to the $3^{\text {rd }}$ set of 3 test tubes. All the 9 test tubes were incubated at $37^{\circ} \mathrm{C}$ for 24 hours. Tubes that showed gas and acid production after 24 hours were recorded as positive for the presence of Coliform. Negative tubes were further reincubated for 24 hours. Positive tubes were recorded. Estimate of most probable number of Coliform per gram of sample (MPN/g) was determined by comparing the number of gas positive tubes with the most probable number table. 
BAJOPAS Volume 13 Number 1, June, 2020 Identification of Coliform

A loop full of inoculum from gas positive tubes was streaked on to Eosine methylene blue (EMB) agar plate and incubated at $37^{\circ} \mathrm{C}$ for $24 \mathrm{hrs}$. Colonies which formed bluish black color with green metallic sheen, and reddish colonies were isolated on agar slants. Those colonies showing metallic sheen on EMB were sub cultured into tubes of lactose broth and incubated at $45^{\circ} \mathrm{C}$. The tubes were observed after $24 \mathrm{hrs}$ for gas production. This is the completed test for fecal coliform. Gram stain and other biochemical tests such as Indole, Methyl red, Voges-Proskauer and Citrate Utilization tests (IMVIC), Coagulase and Catalase tests were carried out for the Identification and confirmation of isolates.

\section{Procedure for Indole Test}

Indole test was carried out by preparing a Tryptone broth drawn in to test tubes, sterilized by autoclaving, inoculated with loopful of suspension and incubated at $37^{\circ} \mathrm{C}$ for 24 hours. Three drops of xylene was added in tubes, shaken vigorously and kept for the separation of two layers. One millilitre of Kovac's reagent was added and the formation of pink colour ring indicates positive Indole test.

\section{Procedure for Methyl Red Test}

Methyl red test was carried out by preparing Glucose phosphate broth, dispensed in test tubes, sterilized, inoculated with test culture and incubated at $37^{\circ} \mathrm{C}$ for 24 hours. Five drops of methyl-red indicator was added to the medium for the formation of red colour.

\section{Procedure for Voges-Proskauer Test}

Voges-Proskauer test was carried out by inoculating tubes with the bacterial culture followed by incubation for 48 hours at $37^{\circ} \mathrm{C}$. Separate pipettes were used to pipette $1 \mathrm{ml}$ from each culture tube into clean separate tubes. Eighteen drops $(0.5 \mathrm{ml})$ of Barrit's solution A (a-naphthol) was added to each tube containing glucose phosphate broth followed by the addition of an equal amount of solution $B$ into the same tube. The tubes were shaken at 30 seconds interval. A positive reaction was indicated by the development of a pink color, which turns red in 1-2 hours, after vigorous shaking.

\section{Procedure for Citrate Utilization Test}

Citrate Utilization Test was carried out by distributing melted agar (Simmon Citrate Agar) in to test tubes followed by sterilization at $121.5^{\circ} \mathrm{C}$ for 15 minutes. The test tubes were afterward held in slanted position, inoculated with the given bacterial culture and incubated at $37^{\circ} \mathrm{C}$ for $24 \mathrm{hrs}$. Positive test was indicated by color change of the media from green to blue.

\section{RESULTS AND DISCUSSIONS}

The results of this study are presented in tables $1,2,3$ and 4. Among the sampling areas Kofar Kudu had the highest aerobic mesophilic bacteria counts $4.0 \times 10^{5} \mathrm{cfu} / \mathrm{g}$ followed by Rinji $2.72 \times 10^{5} \mathrm{cfu} / \mathrm{g}$, while Tosaro had the least Aerobic mesophilic bacteria counts of $1.02 \times 10^{5}$ $\mathrm{cfu} / \mathrm{g}$ as indicated in Table 1.Makwalla had the highest coliform count $68 \mathrm{MPN} / \mathrm{g}$ followed by Rinji $37 \mathrm{MPN} / \mathrm{g}$. Tsohuwar Kasuwa had the least coliform counts $8 \mathrm{MPN} / \mathrm{g}$, (Table 2). Result from table 1 shows variation in the microbial contents among the samples which suggest variation in their sources, poor handling procedures and contamination from the processing environment. High coliform count and their differences within sampling areas is an indication of poor microbiological quality of the product. Ndahi et al. (2013) reported microbial load to be a function of the handling personnel and the environment. The results indicated that the samples were contaminated with bacteria as the counts exceeded the minimum safety level $\left(10^{4} \mathrm{cfu} / \mathrm{g}\right)$ for members of the Enterobacteriaceae family. However, it might be a reflection of poor hygienic practices which may contribute to health hazard to the potential consumers. Similarly, Inusa and Sa'id (2017); Osimani et al. (2015) reported that, the initial microbial content of the raw material play significant role in influencing the final microbial load of the finished product. Isolation of members of the Enterobacteriaceae such as $E$. coli, Klebsiella pneumoniae, Salmonella and Shigella signifies danger to the public health. These organisms are capable of producing endotoxins which trigger high fevers in infected individuals, and the enterotoxins which colonize the small intestines and lead to extreme dehydration as a result of vomiting and diarrhea sometimes with severe and fatal outcomes (Amaeze et al., 2016). From the 16 isolated organisms $E$. coli had the highest isolation rate $6(37.5 \%)$ (Table 3), this suggest faecal contamination of the products. $E$. coli is a common flora in the gastrointestinal tract responsible for diarrhea and extra-intestinal infections (CDC, 2011). The result is in conformity with the findings of Ndahi et al. (2013) and Shamsuddeen (2009). Also presence of campylobacter might be due to cross contamination from raw meat to finished product (Tsire). Staphylococcus aureus is a normal flora of the skin, nasal, genital, mouth or anal area in both humans and animals without any symptom of an infection (Matthew et al., 2013). Isolation of $S$. aureus in these study concords with the findings of Lucretia et al. (2018) from Suya sold in Rivers State. 
BAJOPAS Volume 13 Number 1, June, 2020

It is also in agreement with the findings of Yousafzai et al. (2018); Onuorah et al. (2015) and Tijjani and Jumare (2014) from tsire samples in different countries. Presence of $S$. aureus in foods is most of the time an indication of poor human handling, poor environment, unhygienic utensils and equipments used during processing (Igene et al., 2016; Okonko et al., 2013). Infections caused by $S$. aureus are difficult to treat leading to long hospitalization with consequent economic loss (Udobi et al., 2013). These include soft tissue infections, pneumonia, hospital-acquired postoperative wound infections, Staphylococcal food poisoning, impetigo and cellulitis (Charlene et al., 2013). Samples obtained from Dausai and Kofar Kudu had the highest isolation rate $4(80 \%)$ (Table 4 ) probably because of the much commercial activities taking place in the area which can lead to environmental contamination.

Table 1: Total Aerobic Mesophilic Bacterial Count of Tsire sold in Garko Town

\begin{tabular}{lll}
\hline Sampling Area & APC cfu/g & Mean \pm STD \\
\hline Dausai & $2.20 \times 10^{5}$ & $110000 \pm 14142.14$ \\
Kofar Kudu & $4.00 \times 10^{5}$ & $133333.3 \pm 23094.01$ \\
Makwalla & $1.30 \times 10^{5}$ & $32500 \pm 7187.953$ \\
Rinji & $2.72 \times 10^{5}$ & $90666.67 \pm 94769.90$ \\
Tosaro & $1.02 \times 10^{5}$ & $51000 \pm 15556.35$ \\
Tsohuwar Kasuwa & $1.75 \times 10^{5}$ & $35000 \pm 11357.82$ \\
\hline
\end{tabular}

Key: APC: Aerobic Mesophilic Counts

STD: Standard Deviation

Table 2: Total Coliform Count of Tsire sold in Garko Town

\begin{tabular}{lcc}
\hline \multicolumn{1}{c}{ Sampling Area } & TCC MPN/g & Mean \pm STD \\
\hline Dausai & 20 & $6.67 \pm 2.5166$ \\
Kofar Kudu & 32 & $16.00 \pm 5.6569$ \\
Makwalla & 68 & $13.60 \pm 8.7062$ \\
Rinji & 37 & $9.25 \pm 4.7871$ \\
Tosaro & 10 & $5.00 \pm 2.8284$ \\
Tsohuwar Kasuwa & 8 & $4.00 \pm 0.0000$ \\
\hline
\end{tabular}

Table 3: Organisms Isolated from Tsire Sold in Garko

\begin{tabular}{lcl}
\hline Isolated Organism & Frequency & Percentage (\%) \\
\hline Campylobacter & 2 & 06.66 \\
Escherichia coli & 6 & 20.00 \\
Klebsiella pneumoniae & 2 & 06.66 \\
Salmonella species & 1 & 03.33 \\
Shigella & 3 & 10.00 \\
Staphylococcus aureus & 2 & 06.66 \\
Total & 16 & \\
\hline
\end{tabular}

Table 4: Distribution of Organisms within Sampling Area

\begin{tabular}{lcc}
\hline \multicolumn{1}{c}{ Sampling Area } & No. Isolated & Percentage (\%) \\
\hline Dausai & 4 & 80 \\
Kofar Kudu & 4 & 80 \\
Makwalla & 2 & 40 \\
Rinji & 3 & 60 \\
Tosaro & 2 & 40 \\
Tsohuwar Kasuwa & 1 & 20 \\
Total & 16 & \\
\hline
\end{tabular}

\section{CONCLUSION}

Results indicated $4.00 \times 10^{5} \mathrm{CFU} / \mathrm{g}$ as the highest APCs count; while $68 \mathrm{MPN} / \mathrm{g}$ was the highest TCCs from the 30 samples analyzed. Among the isolates, $E$. coli has the highest isolation rate of $6(20 \%)$. Dausai and Kofar kudu were having the highest bacteria count of $4(80 \%)$, each, indicating higher contamination in those locations. 
BAJOPAS Volume 13 Number 1, June, 2020 RECOMMENDATIONS

The following recommendations are tenable:

1. Hygienic practices at all stages of production should be improved to safe guard the consumers against potential health hazard.

2. Monitoring of microbiological contamination of Tsire during preparations, packaging and marketing is essential to ensure product of good microbiological quality for consumers' health.

\section{REFERENCES}

Abdullahi, I. O., Umoh, V. J. and Galadima, M. (2004). Hazards Associated with Kilishi Preparations in Zaria. Nigerian Journal of Microbiology, 18 (1-2): $339-345$.

Ahmadu, J. and Ibrahim E. J., (2013): Determinants of Revenue in Suya Production in BeninCity, Edo State, Nigeria. Nigerian journal of agriculture, food and environment.9(3):1-5

Amaeze, N. Aboh, M. Itohan, A. Felix, E. Olatunji, T. and Oladosu, P. (2016) Microbial Profile, Antibiotic Sensitivity and Heat Resistance of Bacterial Isolates from Commercial Roasted Beef (Suya) in Abuja, Nigeria. JOPAT, 15(2): $22-30$.

Apata, E.S., Kuku1, I.A., Apata, O.C. and Adeyemi, K.O. (2013). Evaluation of Suya(Tsire) - An Intermediate Moisture Meat Product in Ogun State, Nigeria. J. Food Res 2 (1): 87.

Atlas, R. M. (1997) Principles of Microbiology Second Edition. C. Brown Publishers. Pp 802-803.

Borch, E. Kant-Muermans, M. L., Blixt, Y. (1996) Bacterial Spoilage of Meat and Cured Meat Products. Int $\mathrm{J}$ Food Microbiol .33(1): 103-20.

Centre for Disease Control, CDC (2011). "Escherichia coli 0157:H7" Division of Bacterial and Mycotic Diseasesht://www.cdc.gov/nczved/divisi ons/dfbmd/diseases/ecoli_0157h7/.

Charlene, R. J., Johnnie, A. D., and John, B. B., (2013) Prevalence and Characterization of Methicillin-Resistant Staphylococcus aureus Isolates from Retail Meat and Humans in Georgia. American society for Microbiology. J. of clinical microbiology. 12(1):123-6 doi:10.1128/JCM.0316612JCM.03166-12

Egbebi, A.O and Seidu, K., T. (2011). Microbiological Evaluation of Suya (dried smoked

meat) Sold in Ado and Akure, South West Nigeria.European Journal of Experinmental Biology, 1(4):1-5
3. Government should establish regulatory bodies responsible for inculcating hygiene habits to the local producers and vendors in order to prevent instant, cross and post processing contaminations by microbial pathogens.

4. Awareness and sensitization of local food producers about good hygienic practices in food handling and processing.

Falegan, C, R., Akoja, S. D., and Oyarekua, M. A., (2017) Microbiological Assessment of Suya (Sliced Roasted Beef) in Ado-Ekiti Metropolis, Ekiti State, Nigeria. MOJ Biology andMedicine.

Fonkem, D., N. Tanya, V., N. and Ebangi, A., L. (2010). Effect of Season on the Microbiological Quality of Kilishi, a Traditional Cameroonian Dried Beef Product. Tropicultura, 28(1): 10-15.

Food and Agricultural Organization of the United Nations (F A O, 1979). Manual of food quality control 4. Microbiological analysis.

Food and Agriculture Organisation of the United Nation (FAO), 2019. Nigeria at a glance.

Igene J.O., Uwadia, O.E., Ebabhamiegbebho, P.A. and Evivie, S.E., (2016) Shelf life Stability Studies of University of Benin (UNIBEN) Proff's Kilishi Product Asian Journal of Science and Technology 7(1): 2268-2274.

Inusa, S. K. and Said, I. S. (2017) Evaluation of the Chemical and Microbiological Properties Of Kilishi Sold in Kano Metropolis. Journal of Dry land Agriculture, 3 (1): $59-69$.

Lucretia, I. B, Patience, C. Obinna-Echem, Sophia, C. A. (2018) Microbiological quality andantibiotic sensitivity of potential pathogens isolated from meat product (Suya) sold in Rivers State University and its environs. International Journal of Biotechnology and Food Science, 6(4): 67-76.

Matthew, E., Drosos, E., John, L. and Ioanna, P. (2013) MRSA in Africa: Filling the Global Map of Antimicrobial Resistance PLOS One. 8(7): e68024 doi: 10.1371/journal.pone.0068024

Mgbemere, V.N., Akpapunam, M. A. and Igene, J. O., (2011). Effect of Groundnut FlourSubstitution on Yield, Quality and Storage Stability of Kilishi - a Nigerian Indigenous Dried Meat Product. African Journal of Food, Agriculture, Nutrition and Development, $\quad \mathbf{1 1}(2)$ : 4718-4738. 
BAJOPAS Volume 13 Number 1, June, 2020

Mubarak, A. A., Azeez, M. L., Amos A. O., Opeyemi, O. O. (2016) Assessment of Animal Protein Consumption and Food Security Among Rural Households in Kwara State, Nigeria American Journal of Business and Society, 1(4): 233245.

Ndahi, M., D. Kwaga, J., K. P. Bello, M. Kabir J., V. Umoh, .J. Yakubu, S., E. and Nok, A., J. (2013) Prevalence and Antimicrobial Susceptibility of Listeria Monocytogenes and Methicillin-Resistant Staphylococcus aureus Strains from Raw Meat and Meat Products in Zaria, Nigeria. Applied Journal of Microbiology, 58(3):262-9.

Okonko, I.O., Odu, N.N. and Igboh, I.E. (2013). Microbiological Analysis of Kilishi Sold In Port Harcourt, Nigeria. New York Science Journal, 6 (7):37-43.

Osimani, A., Aquilanti, L. and Clementi, F. (2015) Microbiological Quality of Meatbased Meals and Operation of Control Systems within a Food Service Environment. International Food Research Journal 22(4): 1692-1698.

Onuorah, S. Obika, I. Odibo, F. Orji, M. (2015)An Assessment of the Bacteriological Quality of Tsire-Suya (Grilled Beef) sold in Awka, Nigeria. American. J. Life. Sci. Res. 3(4):287292.

Razavilar, V, Khandaghi, J. Barzgari, A. (2010); Isolation of Eschericia coli 0157:H7 from manure fertilized farms and raw vegetables grown on it, in Tabriz city in
Iran. African Journal of Microbiology Research, 4(9): 891-895.

Scallan, E. Hoekstra, R. M. Angulo, F. J.Tauxe, R. V, Widdowson, M. Roy, S. L et al., (2011).Food borne illness acquired in the United States- Major Pathogens. Emerg. Infec Dis, 17(1): 7-15.

Shamsuddeen U (2009). Microbiological quality of spice used in the production of Kilishi a traditionally dried and grilled meat product. Bayero Journal of Pure andApplied Sciences, 2(2): 66-69.

Shamsuddeen, U. (2015) Microbiological Hazard and Critical control point Analysis of Dried and Minced Meat Snacks Produced in Kano Nigeria. Lambert Academic Publishing; Pp 1-36.

Tijani, O.and Jumare, S. (2014). Microblological Quality Assessment of Meat

Sold in KauraNamoda. International Conference on Earth, Environment and Life sciences (EELS) Dubai (UAE).

Udobi, C. E., Obajuluwa, A. F., and Onaolapo, J. A., (2013) Prevalence and Antibiotic Resistance Pattern of MethicillinResistant Staphylococcus aureus from an Orthopaedic Hospital in Nigeria BioMed Research International; 26(6); 6-7.

WHO, 2015 Foodborne diseases in the WHO African Region.

Yousafzai HA, Rind R, Khan MA, Abro SH, Korejo NA, Ejaz M, Kabir A, Shahid M, Memon S. (2019). Microbiological Contamination of Cattle and Meat in Peshawar, Pakistan. J. Anim. Health Prod. 7(1): 1116. 


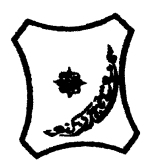

Bayero Journal of Pure and Applied Sciences, 13(1); 40 - 45

Received: September, 2019

Accepted: April, 2020

ISSN $2006-6996$

\title{
BACTERIOLOGICAL QUALITY OF STICK MEAT (Tsire) SOLD IN GARKO LOCAL GOVERNMENT AREA OF KANO STATE, NIGERIA
}

\author{
$*^{1}$ Dahiru A. T. and ${ }^{2}$ Maigari A. K. \\ ${ }^{1}$ Department of Hospitality Management, School of Technology, Kano State Polytechnic, PMB 3348, \\ Kano Nigeria. \\ ${ }^{2}$ Departmnt of Biological Sciences, Bayero University, Kano \\ Corresponding Author: dturajo61@gmail.com; GSM: 08087508262.
}

ABSTRACT

Stick meat, locally called Tsire in Hausa Language, is a significant portion of the diet of a large active population of Northern Nigeria. However, because of the handling and processing methods by the manufacturers as well as the hawking system of stick meat, the meat product may be exposed to both pre- and post-processed product contamination, and thus may poses danger to public health. Therefore, considering the role of Tsire in improving nutrition and increase household income to the populace, the need to improve the processing, distribution and overall quality of the product is simply indispensable. A total of 30 samples (5 samples from each of the 6 sampling points) of Tsire were collected randomly in Garko Town. Aerobic plate counts (APCs) and Total coliform counts (TCCS) of Tsire samples were determined using standard microbiological methods. APCs ranged from $1.02 \times 10^{5}$ to $4.00 \times 10^{5} \mathrm{CFU} / \mathrm{g}$; while TCCs ranged from $8 \mathrm{MPN} / \mathrm{g}$ to $68 \mathrm{MPN} / \mathrm{g}$. From the 30 samples screened, 16(53.33\%) bacteria namely, Campylobacter 2(6.66\%), Escherichia coli 6(20\%), Klebsiella pneumoniae 2(6.66\%), Salmonella spp. 1(3.33\%), Shigella 3(10\%) and Staphylococcus aureus 2(6.66\%) were detected. $E$. coli has the highest isolation rate of 6(20\%), while Salmonella spp. had the least frequency of 1(3.33\%). The distribution of isolated organisms within the study area were as follows: Dausai, 4(80\%), Kofar kudu, 4(80\%), Makwalla, 2(40\%), Rinji, 3(60\%), Tosaro, 2(40\%), and Tsohuwar Kasuwa, 1(20\%). The results have indicated that the Tsire was contaminated with bacteria thus exposing the product to fast deterioration, spoilage and also a vehicle for food borne illness, suggesting for adequate hygienic practices at all the stages, prior to consumption, to ensure safety of the meat product.

Key words: APCs, TCCs, Contamination, Microorganisms, Garko

\section{INTRODUCTION}

Nigeria is one of the developing nations with inadequate food supply and most often deficient in protein content (FAO, 2019). Nigerian's average animal protein intake per head per day is estimated at $7.9 \mathrm{~g}$ as against $35 \mathrm{~g}$ recommended value by Food and Agricultural Organization (Mubarak et al., 2016). These low levels of animal protein intake create great concern as it affects the nutritional status of Nigerians. Hence, there is the need for sufficient supply of animal protein from energy rich animal products to satisfy the nutritional requirements for Nigerians.

Meat is one major source of animal protein largely composed of water, protein and fats which can make it susceptible to microbial contamination within short time leading to spoilage (Apata et al., 2013; Mgbemere et al., 2011). Meat is mostly eaten after it has been cooked or processed in a variety of ways such as sun drying; smoking and roasting with or without fortifications (Borch et al., 1996). In Nigeria meat products such as Tsire, Kilishi and Balangu are locally produced using one or more of these methods in order to meet the nutritional requirements of the teeming Nigerians (Egbebi, 2011).

Tsire is a popular Nigerian traditional processed ready-to-eat roasted stick meat product (Shamsuddeen, 2015). It is sold in public places, along roads, in hotels, parks, quarters and even offices (Falegan et al., 2017). It is prepared from boneless healthy animal flesh such as beef and mutton, spiced with peanut cake, salt, vegetable oil and other flavorings followed by roasting (Shamsuddeen, 2015). Consumption of these products has extended to other parts of African countries such as Ghana, Somali, Cameroun and Chad (Ahmadu and Ibrahim, 2013). 
BAJOPAS Volume 13 Number 1, June, 2020

However, evidence of quality control sticking to procedural hygiene by the handlers during preparation and retailing of these products is poorly documented. Tsire is of great safety risk because of the fact that there are erratic cases of gastroenteritis and symptoms of food infection after consumption (WHO, 2015). Food borne illnesses are one of the major health problems in developing and developed countries (Razavilar, 2010). According to the World Health Organization, WHO (2015), $0.07 \%$ death of the 600 million global burdens of Foodborne illnesses have been reported to be caused by bacteria, viruses, fungi and chemicals. In America $0.27 \%$ of the estimated 48 million affected people is hospitalized and about $0.0063 \%$ deaths are recorded each year (Scallan et al., 2011). More than 91 million people in Africa fall ill and $0.15 \%$ dies each year, making Africa the highest burden bearer of Foodborne diseases per population (WHO, 2015).

Application of a Hazard Analysis Critical Control Point (HACCP) at all stages of meat products preparation is essential in order to ensure its safety. Thus, according to the guidelines of good manufacturing practice, the level of total aerobic bacterial contamination of thermally processed meat products should not exceed $10^{4}\left(\mathrm{cfu} \mathrm{g}^{-1}\right)$. Enterobacteriaceae and faecal coliform contamination in meat products should be within the range of $10^{2}-10^{4}$ and $10-10^{3} \mathrm{cfu} \mathrm{g}^{-1}$, respectively (Shamsuddeen, 2015). The aim of the study is therefore, to assess the total viable bacterial counts of tsire marketed locally within Garko town, and to isolate and identify the organisms at the point of consumption with the intention of promoting public health and food hygiene habits in the Nigerian populace.

\section{MATERIALS AND METHODS Study Area and Population}

Garko is one of the existing 44 local government areas located in Kano south west zone of Kano state with its capital administrative headquarters in the Garko town. It has coordinates $11^{\circ} 39^{\prime} \mathrm{N}$ $8^{\circ} 54^{\prime} \mathrm{E}$, and an area of $450 \mathrm{~km}^{2}$. The projected population of Garko local Government was 225,300 according to the National Population Census report (2018). Garko is known for agricultural activities both farming and animal husbandry. It is popularly known for large scale rice production. Other food crops include sweet potatoes, cassava, onions, sorghum, millet and sugarcane. Cows, sheep and goats are major groups of animals reared by majority of the populace. Meat products processed, retailed and consumed in Garko include roasted meat (Balangu), dried roasted meat (Kilishi), stick meat (Tsire), hide and skin pepper soup (Ragadada) and minced fried meat (Danbunnama).

\section{Samples Collection}

Five samples of Tsire products were collected from 6 different identified locations within Garko town in a sterile foil paper and immediately analyzed for the presence of bacteria.

\section{Sample Preparation}

Sample preparation for the bacteriological analysis was carried out in accordance with the method described by Atlas (1997). Twenty five grams $(25 \mathrm{~g})$ of the sample was homogenized in $225 \mathrm{ml}$ peptone water using Kenwood blender machine to obtain a $10^{1}$ homogenate. The homogenate was thoroughly shaken and $1 \mathrm{ml}$ pipetted into test tubes containing $9 \mathrm{ml}$ of peptone water $\left(10^{2}\right)$. The test tubes were further serially diluted to $10^{5}$.

Total Aerobic Mesophilic Bacterial Count

Total Aerobic mesophilic bacterial count was determined using the method described by Abdullahi et al. (2004) where $1 \mathrm{ml}$ of inoculums from $10^{1}$ to $10^{5}$ dilutions were transferred into duplicate Petri dishes and labeled accordingly. This was followed by pouring aseptically about $15 \mathrm{ml}$ of molten nutrient agar. The culture was homogenized by gentle spinning of the plates and allowed to solidify. The plates were incubated at $37^{\circ} \mathrm{C}$ for 24 hours. Plates containing 30-300 colonies were counted. The number of colony forming units per gram of a sample (cfu/g) was obtained by multiplying the average colony number with the inverse of the dilution factor.

\section{Enumeration and Detection of Coliform bacteria}

Detection and enumeration of coliform was carried out according to method described by Atlas, (1977). A set of 9 test tubes each containing $9 \mathrm{ml}$ of lactose broth and an inverted Durham tubes were autoclaved to expel air and to sterilize. Similarly, $1 \mathrm{ml}$ from the diluents $10^{1}$ was transferred to the first 3 test tubes, followed by $1 \mathrm{ml}$ from the diluents $10^{2}$ to the second set of 3 test tubes and finally the third diluents $10^{3}$ to the $3^{\text {rd }}$ set of 3 test tubes. All the 9 test tubes were incubated at $37^{\circ} \mathrm{C}$ for 24 hours. Tubes that showed gas and acid production after 24 hours were recorded as positive for the presence of Coliform. Negative tubes were further reincubated for 24 hours. Positive tubes were recorded. Estimate of most probable number of Coliform per gram of sample (MPN/g) was determined by comparing the number of gas positive tubes with the most probable number table. 
BAJOPAS Volume 13 Number 1, June, 2020 Identification of Coliform

A loop full of inoculum from gas positive tubes was streaked on to Eosine methylene blue (EMB) agar plate and incubated at $37^{\circ} \mathrm{C}$ for $24 \mathrm{hrs}$. Colonies which formed bluish black color with green metallic sheen, and reddish colonies were isolated on agar slants. Those colonies showing metallic sheen on EMB were sub cultured into tubes of lactose broth and incubated at $45^{\circ} \mathrm{C}$. The tubes were observed after $24 \mathrm{hrs}$ for gas production. This is the completed test for fecal coliform. Gram stain and other biochemical tests such as Indole, Methyl red, Voges-Proskauer and Citrate Utilization tests (IMVIC), Coagulase and Catalase tests were carried out for the Identification and confirmation of isolates.

\section{Procedure for Indole Test}

Indole test was carried out by preparing a Tryptone broth drawn in to test tubes, sterilized by autoclaving, inoculated with loopful of suspension and incubated at $37^{\circ} \mathrm{C}$ for 24 hours. Three drops of xylene was added in tubes, shaken vigorously and kept for the separation of two layers. One millilitre of Kovac's reagent was added and the formation of pink colour ring indicates positive Indole test.

\section{Procedure for Methyl Red Test}

Methyl red test was carried out by preparing Glucose phosphate broth, dispensed in test tubes, sterilized, inoculated with test culture and incubated at $37^{\circ} \mathrm{C}$ for 24 hours. Five drops of methyl-red indicator was added to the medium for the formation of red colour.

\section{Procedure for Voges-Proskauer Test}

Voges-Proskauer test was carried out by inoculating tubes with the bacterial culture followed by incubation for 48 hours at $37^{\circ} \mathrm{C}$. Separate pipettes were used to pipette $1 \mathrm{ml}$ from each culture tube into clean separate tubes. Eighteen drops $(0.5 \mathrm{ml})$ of Barrit's solution A (a-naphthol) was added to each tube containing glucose phosphate broth followed by the addition of an equal amount of solution $B$ into the same tube. The tubes were shaken at 30 seconds interval. A positive reaction was indicated by the development of a pink color, which turns red in 1-2 hours, after vigorous shaking.

\section{Procedure for Citrate Utilization Test}

Citrate Utilization Test was carried out by distributing melted agar (Simmon Citrate Agar) in to test tubes followed by sterilization at $121.5^{\circ} \mathrm{C}$ for 15 minutes. The test tubes were afterward held in slanted position, inoculated with the given bacterial culture and incubated at $37^{\circ} \mathrm{C}$ for $24 \mathrm{hrs}$. Positive test was indicated by color change of the media from green to blue.

\section{RESULTS AND DISCUSSIONS}

The results of this study are presented in tables $1,2,3$ and 4. Among the sampling areas Kofar Kudu had the highest aerobic mesophilic bacteria counts $4.0 \times 10^{5} \mathrm{cfu} / \mathrm{g}$ followed by Rinji $2.72 \times 10^{5} \mathrm{cfu} / \mathrm{g}$, while Tosaro had the least Aerobic mesophilic bacteria counts of $1.02 \times 10^{5}$ $\mathrm{cfu} / \mathrm{g}$ as indicated in Table 1.Makwalla had the highest coliform count $68 \mathrm{MPN} / \mathrm{g}$ followed by Rinji $37 \mathrm{MPN} / \mathrm{g}$. Tsohuwar Kasuwa had the least coliform counts $8 \mathrm{MPN} / \mathrm{g}$, (Table 2). Result from table 1 shows variation in the microbial contents among the samples which suggest variation in their sources, poor handling procedures and contamination from the processing environment. High coliform count and their differences within sampling areas is an indication of poor microbiological quality of the product. Ndahi et al. (2013) reported microbial load to be a function of the handling personnel and the environment. The results indicated that the samples were contaminated with bacteria as the counts exceeded the minimum safety level $\left(10^{4} \mathrm{cfu} / \mathrm{g}\right)$ for members of the Enterobacteriaceae family. However, it might be a reflection of poor hygienic practices which may contribute to health hazard to the potential consumers. Similarly, Inusa and Sa'id (2017); Osimani et al. (2015) reported that, the initial microbial content of the raw material play significant role in influencing the final microbial load of the finished product. Isolation of members of the Enterobacteriaceae such as $E$. coli, Klebsiella pneumoniae, Salmonella and Shigella signifies danger to the public health. These organisms are capable of producing endotoxins which trigger high fevers in infected individuals, and the enterotoxins which colonize the small intestines and lead to extreme dehydration as a result of vomiting and diarrhea sometimes with severe and fatal outcomes (Amaeze et al., 2016). From the 16 isolated organisms $E$. coli had the highest isolation rate $6(37.5 \%)$ (Table 3), this suggest faecal contamination of the products. $E$. coli is a common flora in the gastrointestinal tract responsible for diarrhea and extra-intestinal infections (CDC, 2011). The result is in conformity with the findings of Ndahi et al. (2013) and Shamsuddeen (2009). Also presence of campylobacter might be due to cross contamination from raw meat to finished product (Tsire). Staphylococcus aureus is a normal flora of the skin, nasal, genital, mouth or anal area in both humans and animals without any symptom of an infection (Matthew et al., 2013). Isolation of $S$. aureus in these study concords with the findings of Lucretia et al. (2018) from Suya sold in Rivers State. 
BAJOPAS Volume 13 Number 1, June, 2020

It is also in agreement with the findings of Yousafzai et al. (2018); Onuorah et al. (2015) and Tijjani and Jumare (2014) from tsire samples in different countries. Presence of $S$. aureus in foods is most of the time an indication of poor human handling, poor environment, unhygienic utensils and equipments used during processing (Igene et al., 2016; Okonko et al., 2013). Infections caused by $S$. aureus are difficult to treat leading to long hospitalization with consequent economic loss (Udobi et al., 2013). These include soft tissue infections, pneumonia, hospital-acquired postoperative wound infections, Staphylococcal food poisoning, impetigo and cellulitis (Charlene et al., 2013). Samples obtained from Dausai and Kofar Kudu had the highest isolation rate $4(80 \%)$ (Table 4 ) probably because of the much commercial activities taking place in the area which can lead to environmental contamination.

Table 1: Total Aerobic Mesophilic Bacterial Count of Tsire sold in Garko Town

\begin{tabular}{lll}
\hline Sampling Area & APC cfu/g & Mean \pm STD \\
\hline Dausai & $2.20 \times 10^{5}$ & $110000 \pm 14142.14$ \\
Kofar Kudu & $4.00 \times 10^{5}$ & $133333.3 \pm 23094.01$ \\
Makwalla & $1.30 \times 10^{5}$ & $32500 \pm 7187.953$ \\
Rinji & $2.72 \times 10^{5}$ & $90666.67 \pm 94769.90$ \\
Tosaro & $1.02 \times 10^{5}$ & $51000 \pm 15556.35$ \\
Tsohuwar Kasuwa & $1.75 \times 10^{5}$ & $35000 \pm 11357.82$ \\
\hline
\end{tabular}

Key: APC: Aerobic Mesophilic Counts

STD: Standard Deviation

Table 2: Total Coliform Count of Tsire sold in Garko Town

\begin{tabular}{lcc}
\hline \multicolumn{1}{c}{ Sampling Area } & TCC MPN/g & Mean \pm STD \\
\hline Dausai & 20 & $6.67 \pm 2.5166$ \\
Kofar Kudu & 32 & $16.00 \pm 5.6569$ \\
Makwalla & 68 & $13.60 \pm 8.7062$ \\
Rinji & 37 & $9.25 \pm 4.7871$ \\
Tosaro & 10 & $5.00 \pm 2.8284$ \\
Tsohuwar Kasuwa & 8 & $4.00 \pm 0.0000$ \\
\hline
\end{tabular}

Table 3: Organisms Isolated from Tsire Sold in Garko

\begin{tabular}{lcl}
\hline Isolated Organism & Frequency & Percentage (\%) \\
\hline Campylobacter & 2 & 06.66 \\
Escherichia coli & 6 & 20.00 \\
Klebsiella pneumoniae & 2 & 06.66 \\
Salmonella species & 1 & 03.33 \\
Shigella & 3 & 10.00 \\
Staphylococcus aureus & 2 & 06.66 \\
Total & 16 & \\
\hline
\end{tabular}

Table 4: Distribution of Organisms within Sampling Area

\begin{tabular}{lcc}
\hline \multicolumn{1}{c}{ Sampling Area } & No. Isolated & Percentage (\%) \\
\hline Dausai & 4 & 80 \\
Kofar Kudu & 4 & 80 \\
Makwalla & 2 & 40 \\
Rinji & 3 & 60 \\
Tosaro & 2 & 40 \\
Tsohuwar Kasuwa & 1 & 20 \\
Total & 16 & \\
\hline
\end{tabular}

\section{CONCLUSION}

Results indicated $4.00 \times 10^{5} \mathrm{CFU} / \mathrm{g}$ as the highest APCs count; while $68 \mathrm{MPN} / \mathrm{g}$ was the highest TCCs from the 30 samples analyzed. Among the isolates, $E$. coli has the highest isolation rate of $6(20 \%)$. Dausai and Kofar kudu were having the highest bacteria count of $4(80 \%)$, each, indicating higher contamination in those locations. 
BAJOPAS Volume 13 Number 1, June, 2020 RECOMMENDATIONS

The following recommendations are tenable:

1. Hygienic practices at all stages of production should be improved to safe guard the consumers against potential health hazard.

2. Monitoring of microbiological contamination of Tsire during preparations, packaging and marketing is essential to ensure product of good microbiological quality for consumers' health.

\section{REFERENCES}

Abdullahi, I. O., Umoh, V. J. and Galadima, M. (2004). Hazards Associated with Kilishi Preparations in Zaria. Nigerian Journal of Microbiology, 18 (1-2): $339-345$.

Ahmadu, J. and Ibrahim E. J., (2013): Determinants of Revenue in Suya Production in BeninCity, Edo State, Nigeria. Nigerian journal of agriculture, food and environment.9(3):1-5

Amaeze, N. Aboh, M. Itohan, A. Felix, E. Olatunji, T. and Oladosu, P. (2016) Microbial Profile, Antibiotic Sensitivity and Heat Resistance of Bacterial Isolates from Commercial Roasted Beef (Suya) in Abuja, Nigeria. JOPAT, 15(2): $22-30$.

Apata, E.S., Kuku1, I.A., Apata, O.C. and Adeyemi, K.O. (2013). Evaluation of Suya(Tsire) - An Intermediate Moisture Meat Product in Ogun State, Nigeria. J. Food Res 2 (1): 87.

Atlas, R. M. (1997) Principles of Microbiology Second Edition. C. Brown Publishers. Pp 802-803.

Borch, E. Kant-Muermans, M. L., Blixt, Y. (1996) Bacterial Spoilage of Meat and Cured Meat Products. Int $\mathrm{J}$ Food Microbiol .33(1): 103-20.

Centre for Disease Control, CDC (2011). "Escherichia coli 0157:H7" Division of Bacterial and Mycotic Diseasesht://www.cdc.gov/nczved/divisi ons/dfbmd/diseases/ecoli_0157h7/.

Charlene, R. J., Johnnie, A. D., and John, B. B., (2013) Prevalence and Characterization of Methicillin-Resistant Staphylococcus aureus Isolates from Retail Meat and Humans in Georgia. American society for Microbiology. J. of clinical microbiology. 12(1):123-6 doi:10.1128/JCM.0316612JCM.03166-12

Egbebi, A.O and Seidu, K., T. (2011). Microbiological Evaluation of Suya (dried smoked

meat) Sold in Ado and Akure, South West Nigeria.European Journal of Experinmental Biology, 1(4):1-5
3. Government should establish regulatory bodies responsible for inculcating hygiene habits to the local producers and vendors in order to prevent instant, cross and post processing contaminations by microbial pathogens.

4. Awareness and sensitization of local food producers about good hygienic practices in food handling and processing.

Falegan, C, R., Akoja, S. D., and Oyarekua, M. A., (2017) Microbiological Assessment of Suya (Sliced Roasted Beef) in Ado-Ekiti Metropolis, Ekiti State, Nigeria. MOJ Biology andMedicine.

Fonkem, D., N. Tanya, V., N. and Ebangi, A., L. (2010). Effect of Season on the Microbiological Quality of Kilishi, a Traditional Cameroonian Dried Beef Product. Tropicultura, 28(1): 10-15.

Food and Agricultural Organization of the United Nations (F A O, 1979). Manual of food quality control 4. Microbiological analysis.

Food and Agriculture Organisation of the United Nation (FAO), 2019. Nigeria at a glance.

Igene J.O., Uwadia, O.E., Ebabhamiegbebho, P.A. and Evivie, S.E., (2016) Shelf life Stability Studies of University of Benin (UNIBEN) Proff's Kilishi Product Asian Journal of Science and Technology 7(1): 2268-2274.

Inusa, S. K. and Said, I. S. (2017) Evaluation of the Chemical and Microbiological Properties Of Kilishi Sold in Kano Metropolis. Journal of Dry land Agriculture, 3 (1): $59-69$.

Lucretia, I. B, Patience, C. Obinna-Echem, Sophia, C. A. (2018) Microbiological quality andantibiotic sensitivity of potential pathogens isolated from meat product (Suya) sold in Rivers State University and its environs. International Journal of Biotechnology and Food Science, 6(4): 67-76.

Matthew, E., Drosos, E., John, L. and Ioanna, P. (2013) MRSA in Africa: Filling the Global Map of Antimicrobial Resistance PLOS One. 8(7): e68024 doi: 10.1371/journal.pone.0068024

Mgbemere, V.N., Akpapunam, M. A. and Igene, J. O., (2011). Effect of Groundnut FlourSubstitution on Yield, Quality and Storage Stability of Kilishi - a Nigerian Indigenous Dried Meat Product. African Journal of Food, Agriculture, Nutrition and Development, $\quad \mathbf{1 1}(2)$ : 4718-4738. 
BAJOPAS Volume 13 Number 1, June, 2020

Mubarak, A. A., Azeez, M. L., Amos A. O., Opeyemi, O. O. (2016) Assessment of Animal Protein Consumption and Food Security Among Rural Households in Kwara State, Nigeria American Journal of Business and Society, 1(4): 233245.

Ndahi, M., D. Kwaga, J., K. P. Bello, M. Kabir J., V. Umoh, .J. Yakubu, S., E. and Nok, A., J. (2013) Prevalence and Antimicrobial Susceptibility of Listeria Monocytogenes and Methicillin-Resistant Staphylococcus aureus Strains from Raw Meat and Meat Products in Zaria, Nigeria. Applied Journal of Microbiology, 58(3):262-9.

Okonko, I.O., Odu, N.N. and Igboh, I.E. (2013). Microbiological Analysis of Kilishi Sold In Port Harcourt, Nigeria. New York Science Journal, 6 (7):37-43.

Osimani, A., Aquilanti, L. and Clementi, F. (2015) Microbiological Quality of Meatbased Meals and Operation of Control Systems within a Food Service Environment. International Food Research Journal 22(4): 1692-1698.

Onuorah, S. Obika, I. Odibo, F. Orji, M. (2015)An Assessment of the Bacteriological Quality of Tsire-Suya (Grilled Beef) sold in Awka, Nigeria. American. J. Life. Sci. Res. 3(4):287292.

Razavilar, V, Khandaghi, J. Barzgari, A. (2010); Isolation of Eschericia coli 0157:H7 from manure fertilized farms and raw vegetables grown on it, in Tabriz city in
Iran. African Journal of Microbiology Research, 4(9): 891-895.

Scallan, E. Hoekstra, R. M. Angulo, F. J.Tauxe, R. V, Widdowson, M. Roy, S. L et al., (2011).Food borne illness acquired in the United States- Major Pathogens. Emerg. Infec Dis, 17(1): 7-15.

Shamsuddeen U (2009). Microbiological quality of spice used in the production of Kilishi a traditionally dried and grilled meat product. Bayero Journal of Pure andApplied Sciences, 2(2): 66-69.

Shamsuddeen, U. (2015) Microbiological Hazard and Critical control point Analysis of Dried and Minced Meat Snacks Produced in Kano Nigeria. Lambert Academic Publishing; Pp 1-36.

Tijani, O.and Jumare, S. (2014). Microblological Quality Assessment of Meat

Sold in KauraNamoda. International Conference on Earth, Environment and Life sciences (EELS) Dubai (UAE).

Udobi, C. E., Obajuluwa, A. F., and Onaolapo, J. A., (2013) Prevalence and Antibiotic Resistance Pattern of MethicillinResistant Staphylococcus aureus from an Orthopaedic Hospital in Nigeria BioMed Research International; 26(6); 6-7.

WHO, 2015 Foodborne diseases in the WHO African Region.

Yousafzai HA, Rind R, Khan MA, Abro SH, Korejo NA, Ejaz M, Kabir A, Shahid M, Memon S. (2019). Microbiological Contamination of Cattle and Meat in Peshawar, Pakistan. J. Anim. Health Prod. 7(1): 1116. 


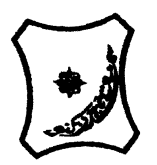

Bayero Journal of Pure and Applied Sciences, 13(1); 40 - 45

Received: September, 2019

Accepted: April, 2020

ISSN $2006-6996$

\title{
BACTERIOLOGICAL QUALITY OF STICK MEAT (Tsire) SOLD IN GARKO LOCAL GOVERNMENT AREA OF KANO STATE, NIGERIA
}

\author{
$*^{1}$ Dahiru A. T. and ${ }^{2}$ Maigari A. K. \\ ${ }^{1}$ Department of Hospitality Management, School of Technology, Kano State Polytechnic, PMB 3348, \\ Kano Nigeria. \\ ${ }^{2}$ Departmnt of Biological Sciences, Bayero University, Kano \\ Corresponding Author: dturajo61@gmail.com; GSM: 08087508262.
}

ABSTRACT

Stick meat, locally called Tsire in Hausa Language, is a significant portion of the diet of a large active population of Northern Nigeria. However, because of the handling and processing methods by the manufacturers as well as the hawking system of stick meat, the meat product may be exposed to both pre- and post-processed product contamination, and thus may poses danger to public health. Therefore, considering the role of Tsire in improving nutrition and increase household income to the populace, the need to improve the processing, distribution and overall quality of the product is simply indispensable. A total of 30 samples (5 samples from each of the 6 sampling points) of Tsire were collected randomly in Garko Town. Aerobic plate counts (APCs) and Total coliform counts (TCCS) of Tsire samples were determined using standard microbiological methods. APCs ranged from $1.02 \times 10^{5}$ to $4.00 \times 10^{5} \mathrm{CFU} / \mathrm{g}$; while TCCs ranged from $8 \mathrm{MPN} / \mathrm{g}$ to $68 \mathrm{MPN} / \mathrm{g}$. From the 30 samples screened, 16(53.33\%) bacteria namely, Campylobacter 2(6.66\%), Escherichia coli 6(20\%), Klebsiella pneumoniae 2(6.66\%), Salmonella spp. 1(3.33\%), Shigella 3(10\%) and Staphylococcus aureus 2(6.66\%) were detected. $E$. coli has the highest isolation rate of 6(20\%), while Salmonella spp. had the least frequency of 1(3.33\%). The distribution of isolated organisms within the study area were as follows: Dausai, 4(80\%), Kofar kudu, 4(80\%), Makwalla, 2(40\%), Rinji, 3(60\%), Tosaro, 2(40\%), and Tsohuwar Kasuwa, 1(20\%). The results have indicated that the Tsire was contaminated with bacteria thus exposing the product to fast deterioration, spoilage and also a vehicle for food borne illness, suggesting for adequate hygienic practices at all the stages, prior to consumption, to ensure safety of the meat product.

Key words: APCs, TCCs, Contamination, Microorganisms, Garko

\section{INTRODUCTION}

Nigeria is one of the developing nations with inadequate food supply and most often deficient in protein content (FAO, 2019). Nigerian's average animal protein intake per head per day is estimated at $7.9 \mathrm{~g}$ as against $35 \mathrm{~g}$ recommended value by Food and Agricultural Organization (Mubarak et al., 2016). These low levels of animal protein intake create great concern as it affects the nutritional status of Nigerians. Hence, there is the need for sufficient supply of animal protein from energy rich animal products to satisfy the nutritional requirements for Nigerians.

Meat is one major source of animal protein largely composed of water, protein and fats which can make it susceptible to microbial contamination within short time leading to spoilage (Apata et al., 2013; Mgbemere et al., 2011). Meat is mostly eaten after it has been cooked or processed in a variety of ways such as sun drying; smoking and roasting with or without fortifications (Borch et al., 1996). In Nigeria meat products such as Tsire, Kilishi and Balangu are locally produced using one or more of these methods in order to meet the nutritional requirements of the teeming Nigerians (Egbebi, 2011).

Tsire is a popular Nigerian traditional processed ready-to-eat roasted stick meat product (Shamsuddeen, 2015). It is sold in public places, along roads, in hotels, parks, quarters and even offices (Falegan et al., 2017). It is prepared from boneless healthy animal flesh such as beef and mutton, spiced with peanut cake, salt, vegetable oil and other flavorings followed by roasting (Shamsuddeen, 2015). Consumption of these products has extended to other parts of African countries such as Ghana, Somali, Cameroun and Chad (Ahmadu and Ibrahim, 2013). 
BAJOPAS Volume 13 Number 1, June, 2020

However, evidence of quality control sticking to procedural hygiene by the handlers during preparation and retailing of these products is poorly documented. Tsire is of great safety risk because of the fact that there are erratic cases of gastroenteritis and symptoms of food infection after consumption (WHO, 2015). Food borne illnesses are one of the major health problems in developing and developed countries (Razavilar, 2010). According to the World Health Organization, WHO (2015), $0.07 \%$ death of the 600 million global burdens of Foodborne illnesses have been reported to be caused by bacteria, viruses, fungi and chemicals. In America $0.27 \%$ of the estimated 48 million affected people is hospitalized and about $0.0063 \%$ deaths are recorded each year (Scallan et al., 2011). More than 91 million people in Africa fall ill and $0.15 \%$ dies each year, making Africa the highest burden bearer of Foodborne diseases per population (WHO, 2015).

Application of a Hazard Analysis Critical Control Point (HACCP) at all stages of meat products preparation is essential in order to ensure its safety. Thus, according to the guidelines of good manufacturing practice, the level of total aerobic bacterial contamination of thermally processed meat products should not exceed $10^{4}\left(\mathrm{cfu} \mathrm{g}^{-1}\right)$. Enterobacteriaceae and faecal coliform contamination in meat products should be within the range of $10^{2}-10^{4}$ and $10-10^{3} \mathrm{cfu} \mathrm{g}^{-1}$, respectively (Shamsuddeen, 2015). The aim of the study is therefore, to assess the total viable bacterial counts of tsire marketed locally within Garko town, and to isolate and identify the organisms at the point of consumption with the intention of promoting public health and food hygiene habits in the Nigerian populace.

\section{MATERIALS AND METHODS Study Area and Population}

Garko is one of the existing 44 local government areas located in Kano south west zone of Kano state with its capital administrative headquarters in the Garko town. It has coordinates $11^{\circ} 39^{\prime} \mathrm{N}$ $8^{\circ} 54^{\prime} \mathrm{E}$, and an area of $450 \mathrm{~km}^{2}$. The projected population of Garko local Government was 225,300 according to the National Population Census report (2018). Garko is known for agricultural activities both farming and animal husbandry. It is popularly known for large scale rice production. Other food crops include sweet potatoes, cassava, onions, sorghum, millet and sugarcane. Cows, sheep and goats are major groups of animals reared by majority of the populace. Meat products processed, retailed and consumed in Garko include roasted meat (Balangu), dried roasted meat (Kilishi), stick meat (Tsire), hide and skin pepper soup (Ragadada) and minced fried meat (Danbunnama).

\section{Samples Collection}

Five samples of Tsire products were collected from 6 different identified locations within Garko town in a sterile foil paper and immediately analyzed for the presence of bacteria.

\section{Sample Preparation}

Sample preparation for the bacteriological analysis was carried out in accordance with the method described by Atlas (1997). Twenty five grams $(25 \mathrm{~g})$ of the sample was homogenized in $225 \mathrm{ml}$ peptone water using Kenwood blender machine to obtain a $10^{1}$ homogenate. The homogenate was thoroughly shaken and $1 \mathrm{ml}$ pipetted into test tubes containing $9 \mathrm{ml}$ of peptone water $\left(10^{2}\right)$. The test tubes were further serially diluted to $10^{5}$.

Total Aerobic Mesophilic Bacterial Count

Total Aerobic mesophilic bacterial count was determined using the method described by Abdullahi et al. (2004) where $1 \mathrm{ml}$ of inoculums from $10^{1}$ to $10^{5}$ dilutions were transferred into duplicate Petri dishes and labeled accordingly. This was followed by pouring aseptically about $15 \mathrm{ml}$ of molten nutrient agar. The culture was homogenized by gentle spinning of the plates and allowed to solidify. The plates were incubated at $37^{\circ} \mathrm{C}$ for 24 hours. Plates containing 30-300 colonies were counted. The number of colony forming units per gram of a sample (cfu/g) was obtained by multiplying the average colony number with the inverse of the dilution factor.

\section{Enumeration and Detection of Coliform bacteria}

Detection and enumeration of coliform was carried out according to method described by Atlas, (1977). A set of 9 test tubes each containing $9 \mathrm{ml}$ of lactose broth and an inverted Durham tubes were autoclaved to expel air and to sterilize. Similarly, $1 \mathrm{ml}$ from the diluents $10^{1}$ was transferred to the first 3 test tubes, followed by $1 \mathrm{ml}$ from the diluents $10^{2}$ to the second set of 3 test tubes and finally the third diluents $10^{3}$ to the $3^{\text {rd }}$ set of 3 test tubes. All the 9 test tubes were incubated at $37^{\circ} \mathrm{C}$ for 24 hours. Tubes that showed gas and acid production after 24 hours were recorded as positive for the presence of Coliform. Negative tubes were further reincubated for 24 hours. Positive tubes were recorded. Estimate of most probable number of Coliform per gram of sample (MPN/g) was determined by comparing the number of gas positive tubes with the most probable number table. 
BAJOPAS Volume 13 Number 1, June, 2020 Identification of Coliform

A loop full of inoculum from gas positive tubes was streaked on to Eosine methylene blue (EMB) agar plate and incubated at $37^{\circ} \mathrm{C}$ for $24 \mathrm{hrs}$. Colonies which formed bluish black color with green metallic sheen, and reddish colonies were isolated on agar slants. Those colonies showing metallic sheen on EMB were sub cultured into tubes of lactose broth and incubated at $45^{\circ} \mathrm{C}$. The tubes were observed after $24 \mathrm{hrs}$ for gas production. This is the completed test for fecal coliform. Gram stain and other biochemical tests such as Indole, Methyl red, Voges-Proskauer and Citrate Utilization tests (IMVIC), Coagulase and Catalase tests were carried out for the Identification and confirmation of isolates.

\section{Procedure for Indole Test}

Indole test was carried out by preparing a Tryptone broth drawn in to test tubes, sterilized by autoclaving, inoculated with loopful of suspension and incubated at $37^{\circ} \mathrm{C}$ for 24 hours. Three drops of xylene was added in tubes, shaken vigorously and kept for the separation of two layers. One millilitre of Kovac's reagent was added and the formation of pink colour ring indicates positive Indole test.

\section{Procedure for Methyl Red Test}

Methyl red test was carried out by preparing Glucose phosphate broth, dispensed in test tubes, sterilized, inoculated with test culture and incubated at $37^{\circ} \mathrm{C}$ for 24 hours. Five drops of methyl-red indicator was added to the medium for the formation of red colour.

\section{Procedure for Voges-Proskauer Test}

Voges-Proskauer test was carried out by inoculating tubes with the bacterial culture followed by incubation for 48 hours at $37^{\circ} \mathrm{C}$. Separate pipettes were used to pipette $1 \mathrm{ml}$ from each culture tube into clean separate tubes. Eighteen drops $(0.5 \mathrm{ml})$ of Barrit's solution A (a-naphthol) was added to each tube containing glucose phosphate broth followed by the addition of an equal amount of solution $B$ into the same tube. The tubes were shaken at 30 seconds interval. A positive reaction was indicated by the development of a pink color, which turns red in 1-2 hours, after vigorous shaking.

\section{Procedure for Citrate Utilization Test}

Citrate Utilization Test was carried out by distributing melted agar (Simmon Citrate Agar) in to test tubes followed by sterilization at $121.5^{\circ} \mathrm{C}$ for 15 minutes. The test tubes were afterward held in slanted position, inoculated with the given bacterial culture and incubated at $37^{\circ} \mathrm{C}$ for $24 \mathrm{hrs}$. Positive test was indicated by color change of the media from green to blue.

\section{RESULTS AND DISCUSSIONS}

The results of this study are presented in tables $1,2,3$ and 4. Among the sampling areas Kofar Kudu had the highest aerobic mesophilic bacteria counts $4.0 \times 10^{5} \mathrm{cfu} / \mathrm{g}$ followed by Rinji $2.72 \times 10^{5} \mathrm{cfu} / \mathrm{g}$, while Tosaro had the least Aerobic mesophilic bacteria counts of $1.02 \times 10^{5}$ $\mathrm{cfu} / \mathrm{g}$ as indicated in Table 1.Makwalla had the highest coliform count $68 \mathrm{MPN} / \mathrm{g}$ followed by Rinji $37 \mathrm{MPN} / \mathrm{g}$. Tsohuwar Kasuwa had the least coliform counts $8 \mathrm{MPN} / \mathrm{g}$, (Table 2). Result from table 1 shows variation in the microbial contents among the samples which suggest variation in their sources, poor handling procedures and contamination from the processing environment. High coliform count and their differences within sampling areas is an indication of poor microbiological quality of the product. Ndahi et al. (2013) reported microbial load to be a function of the handling personnel and the environment. The results indicated that the samples were contaminated with bacteria as the counts exceeded the minimum safety level $\left(10^{4} \mathrm{cfu} / \mathrm{g}\right)$ for members of the Enterobacteriaceae family. However, it might be a reflection of poor hygienic practices which may contribute to health hazard to the potential consumers. Similarly, Inusa and Sa'id (2017); Osimani et al. (2015) reported that, the initial microbial content of the raw material play significant role in influencing the final microbial load of the finished product. Isolation of members of the Enterobacteriaceae such as $E$. coli, Klebsiella pneumoniae, Salmonella and Shigella signifies danger to the public health. These organisms are capable of producing endotoxins which trigger high fevers in infected individuals, and the enterotoxins which colonize the small intestines and lead to extreme dehydration as a result of vomiting and diarrhea sometimes with severe and fatal outcomes (Amaeze et al., 2016). From the 16 isolated organisms $E$. coli had the highest isolation rate $6(37.5 \%)$ (Table 3), this suggest faecal contamination of the products. $E$. coli is a common flora in the gastrointestinal tract responsible for diarrhea and extra-intestinal infections (CDC, 2011). The result is in conformity with the findings of Ndahi et al. (2013) and Shamsuddeen (2009). Also presence of campylobacter might be due to cross contamination from raw meat to finished product (Tsire). Staphylococcus aureus is a normal flora of the skin, nasal, genital, mouth or anal area in both humans and animals without any symptom of an infection (Matthew et al., 2013). Isolation of $S$. aureus in these study concords with the findings of Lucretia et al. (2018) from Suya sold in Rivers State. 
BAJOPAS Volume 13 Number 1, June, 2020

It is also in agreement with the findings of Yousafzai et al. (2018); Onuorah et al. (2015) and Tijjani and Jumare (2014) from tsire samples in different countries. Presence of $S$. aureus in foods is most of the time an indication of poor human handling, poor environment, unhygienic utensils and equipments used during processing (Igene et al., 2016; Okonko et al., 2013). Infections caused by $S$. aureus are difficult to treat leading to long hospitalization with consequent economic loss (Udobi et al., 2013). These include soft tissue infections, pneumonia, hospital-acquired postoperative wound infections, Staphylococcal food poisoning, impetigo and cellulitis (Charlene et al., 2013). Samples obtained from Dausai and Kofar Kudu had the highest isolation rate $4(80 \%)$ (Table 4 ) probably because of the much commercial activities taking place in the area which can lead to environmental contamination.

Table 1: Total Aerobic Mesophilic Bacterial Count of Tsire sold in Garko Town

\begin{tabular}{lll}
\hline Sampling Area & APC cfu/g & Mean \pm STD \\
\hline Dausai & $2.20 \times 10^{5}$ & $110000 \pm 14142.14$ \\
Kofar Kudu & $4.00 \times 10^{5}$ & $133333.3 \pm 23094.01$ \\
Makwalla & $1.30 \times 10^{5}$ & $32500 \pm 7187.953$ \\
Rinji & $2.72 \times 10^{5}$ & $90666.67 \pm 94769.90$ \\
Tosaro & $1.02 \times 10^{5}$ & $51000 \pm 15556.35$ \\
Tsohuwar Kasuwa & $1.75 \times 10^{5}$ & $35000 \pm 11357.82$ \\
\hline
\end{tabular}

Key: APC: Aerobic Mesophilic Counts

STD: Standard Deviation

Table 2: Total Coliform Count of Tsire sold in Garko Town

\begin{tabular}{lcc}
\hline \multicolumn{1}{c}{ Sampling Area } & TCC MPN/g & Mean \pm STD \\
\hline Dausai & 20 & $6.67 \pm 2.5166$ \\
Kofar Kudu & 32 & $16.00 \pm 5.6569$ \\
Makwalla & 68 & $13.60 \pm 8.7062$ \\
Rinji & 37 & $9.25 \pm 4.7871$ \\
Tosaro & 10 & $5.00 \pm 2.8284$ \\
Tsohuwar Kasuwa & 8 & $4.00 \pm 0.0000$ \\
\hline
\end{tabular}

Table 3: Organisms Isolated from Tsire Sold in Garko

\begin{tabular}{lcl}
\hline Isolated Organism & Frequency & Percentage (\%) \\
\hline Campylobacter & 2 & 06.66 \\
Escherichia coli & 6 & 20.00 \\
Klebsiella pneumoniae & 2 & 06.66 \\
Salmonella species & 1 & 03.33 \\
Shigella & 3 & 10.00 \\
Staphylococcus aureus & 2 & 06.66 \\
Total & 16 & \\
\hline
\end{tabular}

Table 4: Distribution of Organisms within Sampling Area

\begin{tabular}{lcc}
\hline \multicolumn{1}{c}{ Sampling Area } & No. Isolated & Percentage (\%) \\
\hline Dausai & 4 & 80 \\
Kofar Kudu & 4 & 80 \\
Makwalla & 2 & 40 \\
Rinji & 3 & 60 \\
Tosaro & 2 & 40 \\
Tsohuwar Kasuwa & 1 & 20 \\
Total & 16 & \\
\hline
\end{tabular}

\section{CONCLUSION}

Results indicated $4.00 \times 10^{5} \mathrm{CFU} / \mathrm{g}$ as the highest APCs count; while $68 \mathrm{MPN} / \mathrm{g}$ was the highest TCCs from the 30 samples analyzed. Among the isolates, $E$. coli has the highest isolation rate of $6(20 \%)$. Dausai and Kofar kudu were having the highest bacteria count of $4(80 \%)$, each, indicating higher contamination in those locations. 
BAJOPAS Volume 13 Number 1, June, 2020 RECOMMENDATIONS

The following recommendations are tenable:

1. Hygienic practices at all stages of production should be improved to safe guard the consumers against potential health hazard.

2. Monitoring of microbiological contamination of Tsire during preparations, packaging and marketing is essential to ensure product of good microbiological quality for consumers' health.

\section{REFERENCES}

Abdullahi, I. O., Umoh, V. J. and Galadima, M. (2004). Hazards Associated with Kilishi Preparations in Zaria. Nigerian Journal of Microbiology, 18 (1-2): $339-345$.

Ahmadu, J. and Ibrahim E. J., (2013): Determinants of Revenue in Suya Production in BeninCity, Edo State, Nigeria. Nigerian journal of agriculture, food and environment.9(3):1-5

Amaeze, N. Aboh, M. Itohan, A. Felix, E. Olatunji, T. and Oladosu, P. (2016) Microbial Profile, Antibiotic Sensitivity and Heat Resistance of Bacterial Isolates from Commercial Roasted Beef (Suya) in Abuja, Nigeria. JOPAT, 15(2): $22-30$.

Apata, E.S., Kuku1, I.A., Apata, O.C. and Adeyemi, K.O. (2013). Evaluation of Suya(Tsire) - An Intermediate Moisture Meat Product in Ogun State, Nigeria. J. Food Res 2 (1): 87.

Atlas, R. M. (1997) Principles of Microbiology Second Edition. C. Brown Publishers. Pp 802-803.

Borch, E. Kant-Muermans, M. L., Blixt, Y. (1996) Bacterial Spoilage of Meat and Cured Meat Products. Int $\mathrm{J}$ Food Microbiol .33(1): 103-20.

Centre for Disease Control, CDC (2011). "Escherichia coli 0157:H7" Division of Bacterial and Mycotic Diseasesht://www.cdc.gov/nczved/divisi ons/dfbmd/diseases/ecoli_0157h7/.

Charlene, R. J., Johnnie, A. D., and John, B. B., (2013) Prevalence and Characterization of Methicillin-Resistant Staphylococcus aureus Isolates from Retail Meat and Humans in Georgia. American society for Microbiology. J. of clinical microbiology. 12(1):123-6 doi:10.1128/JCM.0316612JCM.03166-12

Egbebi, A.O and Seidu, K., T. (2011). Microbiological Evaluation of Suya (dried smoked

meat) Sold in Ado and Akure, South West Nigeria.European Journal of Experinmental Biology, 1(4):1-5
3. Government should establish regulatory bodies responsible for inculcating hygiene habits to the local producers and vendors in order to prevent instant, cross and post processing contaminations by microbial pathogens.

4. Awareness and sensitization of local food producers about good hygienic practices in food handling and processing.

Falegan, C, R., Akoja, S. D., and Oyarekua, M. A., (2017) Microbiological Assessment of Suya (Sliced Roasted Beef) in Ado-Ekiti Metropolis, Ekiti State, Nigeria. MOJ Biology andMedicine.

Fonkem, D., N. Tanya, V., N. and Ebangi, A., L. (2010). Effect of Season on the Microbiological Quality of Kilishi, a Traditional Cameroonian Dried Beef Product. Tropicultura, 28(1): 10-15.

Food and Agricultural Organization of the United Nations (F A O, 1979). Manual of food quality control 4. Microbiological analysis.

Food and Agriculture Organisation of the United Nation (FAO), 2019. Nigeria at a glance.

Igene J.O., Uwadia, O.E., Ebabhamiegbebho, P.A. and Evivie, S.E., (2016) Shelf life Stability Studies of University of Benin (UNIBEN) Proff's Kilishi Product Asian Journal of Science and Technology 7(1): 2268-2274.

Inusa, S. K. and Said, I. S. (2017) Evaluation of the Chemical and Microbiological Properties Of Kilishi Sold in Kano Metropolis. Journal of Dry land Agriculture, 3 (1): $59-69$.

Lucretia, I. B, Patience, C. Obinna-Echem, Sophia, C. A. (2018) Microbiological quality andantibiotic sensitivity of potential pathogens isolated from meat product (Suya) sold in Rivers State University and its environs. International Journal of Biotechnology and Food Science, 6(4): 67-76.

Matthew, E., Drosos, E., John, L. and Ioanna, P. (2013) MRSA in Africa: Filling the Global Map of Antimicrobial Resistance PLOS One. 8(7): e68024 doi: 10.1371/journal.pone.0068024

Mgbemere, V.N., Akpapunam, M. A. and Igene, J. O., (2011). Effect of Groundnut FlourSubstitution on Yield, Quality and Storage Stability of Kilishi - a Nigerian Indigenous Dried Meat Product. African Journal of Food, Agriculture, Nutrition and Development, $\quad \mathbf{1 1}(2)$ : 4718-4738. 
BAJOPAS Volume 13 Number 1, June, 2020

Mubarak, A. A., Azeez, M. L., Amos A. O., Opeyemi, O. O. (2016) Assessment of Animal Protein Consumption and Food Security Among Rural Households in Kwara State, Nigeria American Journal of Business and Society, 1(4): 233245.

Ndahi, M., D. Kwaga, J., K. P. Bello, M. Kabir J., V. Umoh, .J. Yakubu, S., E. and Nok, A., J. (2013) Prevalence and Antimicrobial Susceptibility of Listeria Monocytogenes and Methicillin-Resistant Staphylococcus aureus Strains from Raw Meat and Meat Products in Zaria, Nigeria. Applied Journal of Microbiology, 58(3):262-9.

Okonko, I.O., Odu, N.N. and Igboh, I.E. (2013). Microbiological Analysis of Kilishi Sold In Port Harcourt, Nigeria. New York Science Journal, 6 (7):37-43.

Osimani, A., Aquilanti, L. and Clementi, F. (2015) Microbiological Quality of Meatbased Meals and Operation of Control Systems within a Food Service Environment. International Food Research Journal 22(4): 1692-1698.

Onuorah, S. Obika, I. Odibo, F. Orji, M. (2015)An Assessment of the Bacteriological Quality of Tsire-Suya (Grilled Beef) sold in Awka, Nigeria. American. J. Life. Sci. Res. 3(4):287292.

Razavilar, V, Khandaghi, J. Barzgari, A. (2010); Isolation of Eschericia coli 0157:H7 from manure fertilized farms and raw vegetables grown on it, in Tabriz city in
Iran. African Journal of Microbiology Research, 4(9): 891-895.

Scallan, E. Hoekstra, R. M. Angulo, F. J.Tauxe, R. V, Widdowson, M. Roy, S. L et al., (2011).Food borne illness acquired in the United States- Major Pathogens. Emerg. Infec Dis, 17(1): 7-15.

Shamsuddeen U (2009). Microbiological quality of spice used in the production of Kilishi a traditionally dried and grilled meat product. Bayero Journal of Pure andApplied Sciences, 2(2): 66-69.

Shamsuddeen, U. (2015) Microbiological Hazard and Critical control point Analysis of Dried and Minced Meat Snacks Produced in Kano Nigeria. Lambert Academic Publishing; Pp 1-36.

Tijani, O.and Jumare, S. (2014). Microblological Quality Assessment of Meat

Sold in KauraNamoda. International Conference on Earth, Environment and Life sciences (EELS) Dubai (UAE).

Udobi, C. E., Obajuluwa, A. F., and Onaolapo, J. A., (2013) Prevalence and Antibiotic Resistance Pattern of MethicillinResistant Staphylococcus aureus from an Orthopaedic Hospital in Nigeria BioMed Research International; 26(6); 6-7.

WHO, 2015 Foodborne diseases in the WHO African Region.

Yousafzai HA, Rind R, Khan MA, Abro SH, Korejo NA, Ejaz M, Kabir A, Shahid M, Memon S. (2019). Microbiological Contamination of Cattle and Meat in Peshawar, Pakistan. J. Anim. Health Prod. 7(1): 1116. 


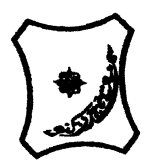

Bayero Journal of Pure and Applied Sciences, 13(1); 40 - 45

Received: September, 2019

Accepted: April, 2020

ISSN $2006-6996$

\title{
BACTERIOLOGICAL QUALITY OF STICK MEAT (Tsire) SOLD IN GARKO LOCAL GOVERNMENT AREA OF KANO STATE, NIGERIA
}

\author{
$*^{1}$ Dahiru A. T. and ${ }^{2}$ Maigari A. K. \\ ${ }^{1}$ Department of Hospitality Management, School of Technology, Kano State Polytechnic, PMB 3348, \\ Kano Nigeria. \\ ${ }^{2}$ Departmnt of Biological Sciences, Bayero University, Kano \\ Corresponding Author: dturajo61@gmail.com; GSM: 08087508262.
}

ABSTRACT

Stick meat, locally called Tsire in Hausa Language, is a significant portion of the diet of a large active population of Northern Nigeria. However, because of the handling and processing methods by the manufacturers as well as the hawking system of stick meat, the meat product may be exposed to both pre- and post-processed product contamination, and thus may poses danger to public health. Therefore, considering the role of Tsire in improving nutrition and increase household income to the populace, the need to improve the processing, distribution and overall quality of the product is simply indispensable. A total of 30 samples (5 samples from each of the 6 sampling points) of Tsire were collected randomly in Garko Town. Aerobic plate counts (APCs) and Total coliform counts (TCCS) of Tsire samples were determined using standard microbiological methods. APCs ranged from $1.02 \times 10^{5}$ to $4.00 \times 10^{5} \mathrm{CFU} / \mathrm{g}$; while TCCs ranged from $8 \mathrm{MPN} / \mathrm{g}$ to $68 \mathrm{MPN} / \mathrm{g}$. From the 30 samples screened, 16(53.33\%) bacteria namely, Campylobacter 2(6.66\%), Escherichia coli 6(20\%), Klebsiella pneumoniae 2(6.66\%), Salmonella spp. 1(3.33\%), Shigella 3(10\%) and Staphylococcus aureus 2(6.66\%) were detected. $E$. coli has the highest isolation rate of 6(20\%), while Salmonella spp. had the least frequency of 1(3.33\%). The distribution of isolated organisms within the study area were as follows: Dausai, 4(80\%), Kofar kudu, 4(80\%), Makwalla, 2(40\%), Rinji, 3(60\%), Tosaro, 2(40\%), and Tsohuwar Kasuwa, 1(20\%). The results have indicated that the Tsire was contaminated with bacteria thus exposing the product to fast deterioration, spoilage and also a vehicle for food borne illness, suggesting for adequate hygienic practices at all the stages, prior to consumption, to ensure safety of the meat product.

Key words: APCs, TCCs, Contamination, Microorganisms, Garko

\section{INTRODUCTION}

Nigeria is one of the developing nations with inadequate food supply and most often deficient in protein content (FAO, 2019). Nigerian's average animal protein intake per head per day is estimated at $7.9 \mathrm{~g}$ as against $35 \mathrm{~g}$ recommended value by Food and Agricultural Organization (Mubarak et al., 2016). These low levels of animal protein intake create great concern as it affects the nutritional status of Nigerians. Hence, there is the need for sufficient supply of animal protein from energy rich animal products to satisfy the nutritional requirements for Nigerians.

Meat is one major source of animal protein largely composed of water, protein and fats which can make it susceptible to microbial contamination within short time leading to spoilage (Apata et al., 2013; Mgbemere et al., 2011). Meat is mostly eaten after it has been cooked or processed in a variety of ways such as sun drying; smoking and roasting with or without fortifications (Borch et al., 1996). In Nigeria meat products such as Tsire, Kilishi and Balangu are locally produced using one or more of these methods in order to meet the nutritional requirements of the teeming Nigerians (Egbebi, 2011).

Tsire is a popular Nigerian traditional processed ready-to-eat roasted stick meat product (Shamsuddeen, 2015). It is sold in public places, along roads, in hotels, parks, quarters and even offices (Falegan et al., 2017). It is prepared from boneless healthy animal flesh such as beef and mutton, spiced with peanut cake, salt, vegetable oil and other flavorings followed by roasting (Shamsuddeen, 2015). Consumption of these products has extended to other parts of African countries such as Ghana, Somali, Cameroun and Chad (Ahmadu and Ibrahim, 2013). 
BAJOPAS Volume 13 Number 1, June, 2020

However, evidence of quality control sticking to procedural hygiene by the handlers during preparation and retailing of these products is poorly documented. Tsire is of great safety risk because of the fact that there are erratic cases of gastroenteritis and symptoms of food infection after consumption (WHO, 2015). Food borne illnesses are one of the major health problems in developing and developed countries (Razavilar, 2010). According to the World Health Organization, WHO (2015), $0.07 \%$ death of the 600 million global burdens of Foodborne illnesses have been reported to be caused by bacteria, viruses, fungi and chemicals. In America $0.27 \%$ of the estimated 48 million affected people is hospitalized and about $0.0063 \%$ deaths are recorded each year (Scallan et al., 2011). More than 91 million people in Africa fall ill and $0.15 \%$ dies each year, making Africa the highest burden bearer of Foodborne diseases per population (WHO, 2015).

Application of a Hazard Analysis Critical Control Point (HACCP) at all stages of meat products preparation is essential in order to ensure its safety. Thus, according to the guidelines of good manufacturing practice, the level of total aerobic bacterial contamination of thermally processed meat products should not exceed $10^{4}\left(\mathrm{cfu} \mathrm{g}^{-1}\right)$. Enterobacteriaceae and faecal coliform contamination in meat products should be within the range of $10^{2}-10^{4}$ and $10-10^{3} \mathrm{cfu} \mathrm{g}^{-1}$, respectively (Shamsuddeen, 2015). The aim of the study is therefore, to assess the total viable bacterial counts of tsire marketed locally within Garko town, and to isolate and identify the organisms at the point of consumption with the intention of promoting public health and food hygiene habits in the Nigerian populace.

\section{MATERIALS AND METHODS Study Area and Population}

Garko is one of the existing 44 local government areas located in Kano south west zone of Kano state with its capital administrative headquarters in the Garko town. It has coordinates $11^{\circ} 39^{\prime} \mathrm{N}$ $8^{\circ} 54^{\prime} \mathrm{E}$, and an area of $450 \mathrm{~km}^{2}$. The projected population of Garko local Government was 225,300 according to the National Population Census report (2018). Garko is known for agricultural activities both farming and animal husbandry. It is popularly known for large scale rice production. Other food crops include sweet potatoes, cassava, onions, sorghum, millet and sugarcane. Cows, sheep and goats are major groups of animals reared by majority of the populace. Meat products processed, retailed and consumed in Garko include roasted meat (Balangu), dried roasted meat (Kilishi), stick meat (Tsire), hide and skin pepper soup (Ragadada) and minced fried meat (Danbunnama).

\section{Samples Collection}

Five samples of Tsire products were collected from 6 different identified locations within Garko town in a sterile foil paper and immediately analyzed for the presence of bacteria.

\section{Sample Preparation}

Sample preparation for the bacteriological analysis was carried out in accordance with the method described by Atlas (1997). Twenty five grams $(25 \mathrm{~g})$ of the sample was homogenized in $225 \mathrm{ml}$ peptone water using Kenwood blender machine to obtain a $10^{1}$ homogenate. The homogenate was thoroughly shaken and $1 \mathrm{ml}$ pipetted into test tubes containing $9 \mathrm{ml}$ of peptone water $\left(10^{2}\right)$. The test tubes were further serially diluted to $10^{5}$.

Total Aerobic Mesophilic Bacterial Count

Total Aerobic mesophilic bacterial count was determined using the method described by Abdullahi et al. (2004) where $1 \mathrm{ml}$ of inoculums from $10^{1}$ to $10^{5}$ dilutions were transferred into duplicate Petri dishes and labeled accordingly. This was followed by pouring aseptically about $15 \mathrm{ml}$ of molten nutrient agar. The culture was homogenized by gentle spinning of the plates and allowed to solidify. The plates were incubated at $37^{\circ} \mathrm{C}$ for 24 hours. Plates containing 30-300 colonies were counted. The number of colony forming units per gram of a sample (cfu/g) was obtained by multiplying the average colony number with the inverse of the dilution factor.

\section{Enumeration and Detection of Coliform bacteria}

Detection and enumeration of coliform was carried out according to method described by Atlas, (1977). A set of 9 test tubes each containing $9 \mathrm{ml}$ of lactose broth and an inverted Durham tubes were autoclaved to expel air and to sterilize. Similarly, $1 \mathrm{ml}$ from the diluents $10^{1}$ was transferred to the first 3 test tubes, followed by $1 \mathrm{ml}$ from the diluents $10^{2}$ to the second set of 3 test tubes and finally the third diluents $10^{3}$ to the $3^{\text {rd }}$ set of 3 test tubes. All the 9 test tubes were incubated at $37^{\circ} \mathrm{C}$ for 24 hours. Tubes that showed gas and acid production after 24 hours were recorded as positive for the presence of Coliform. Negative tubes were further reincubated for 24 hours. Positive tubes were recorded. Estimate of most probable number of Coliform per gram of sample (MPN/g) was determined by comparing the number of gas positive tubes with the most probable number table. 
BAJOPAS Volume 13 Number 1, June, 2020 Identification of Coliform

A loop full of inoculum from gas positive tubes was streaked on to Eosine methylene blue (EMB) agar plate and incubated at $37^{\circ} \mathrm{C}$ for $24 \mathrm{hrs}$. Colonies which formed bluish black color with green metallic sheen, and reddish colonies were isolated on agar slants. Those colonies showing metallic sheen on EMB were sub cultured into tubes of lactose broth and incubated at $45^{\circ} \mathrm{C}$. The tubes were observed after $24 \mathrm{hrs}$ for gas production. This is the completed test for fecal coliform. Gram stain and other biochemical tests such as Indole, Methyl red, Voges-Proskauer and Citrate Utilization tests (IMVIC), Coagulase and Catalase tests were carried out for the Identification and confirmation of isolates.

\section{Procedure for Indole Test}

Indole test was carried out by preparing a Tryptone broth drawn in to test tubes, sterilized by autoclaving, inoculated with loopful of suspension and incubated at $37^{\circ} \mathrm{C}$ for 24 hours. Three drops of xylene was added in tubes, shaken vigorously and kept for the separation of two layers. One millilitre of Kovac's reagent was added and the formation of pink colour ring indicates positive Indole test.

\section{Procedure for Methyl Red Test}

Methyl red test was carried out by preparing Glucose phosphate broth, dispensed in test tubes, sterilized, inoculated with test culture and incubated at $37^{\circ} \mathrm{C}$ for 24 hours. Five drops of methyl-red indicator was added to the medium for the formation of red colour.

\section{Procedure for Voges-Proskauer Test}

Voges-Proskauer test was carried out by inoculating tubes with the bacterial culture followed by incubation for 48 hours at $37^{\circ} \mathrm{C}$. Separate pipettes were used to pipette $1 \mathrm{ml}$ from each culture tube into clean separate tubes. Eighteen drops $(0.5 \mathrm{ml})$ of Barrit's solution A (a-naphthol) was added to each tube containing glucose phosphate broth followed by the addition of an equal amount of solution $B$ into the same tube. The tubes were shaken at 30 seconds interval. A positive reaction was indicated by the development of a pink color, which turns red in 1-2 hours, after vigorous shaking.

\section{Procedure for Citrate Utilization Test}

Citrate Utilization Test was carried out by distributing melted agar (Simmon Citrate Agar) in to test tubes followed by sterilization at $121.5^{\circ} \mathrm{C}$ for 15 minutes. The test tubes were afterward held in slanted position, inoculated with the given bacterial culture and incubated at $37^{\circ} \mathrm{C}$ for $24 \mathrm{hrs}$. Positive test was indicated by color change of the media from green to blue.

\section{RESULTS AND DISCUSSIONS}

The results of this study are presented in tables $1,2,3$ and 4. Among the sampling areas Kofar Kudu had the highest aerobic mesophilic bacteria counts $4.0 \times 10^{5} \mathrm{cfu} / \mathrm{g}$ followed by Rinji $2.72 \times 10^{5} \mathrm{cfu} / \mathrm{g}$, while Tosaro had the least Aerobic mesophilic bacteria counts of $1.02 \times 10^{5}$ $\mathrm{cfu} / \mathrm{g}$ as indicated in Table 1.Makwalla had the highest coliform count $68 \mathrm{MPN} / \mathrm{g}$ followed by Rinji $37 \mathrm{MPN} / \mathrm{g}$. Tsohuwar Kasuwa had the least coliform counts $8 \mathrm{MPN} / \mathrm{g}$, (Table 2). Result from table 1 shows variation in the microbial contents among the samples which suggest variation in their sources, poor handling procedures and contamination from the processing environment. High coliform count and their differences within sampling areas is an indication of poor microbiological quality of the product. Ndahi et al. (2013) reported microbial load to be a function of the handling personnel and the environment. The results indicated that the samples were contaminated with bacteria as the counts exceeded the minimum safety level $\left(10^{4} \mathrm{cfu} / \mathrm{g}\right)$ for members of the Enterobacteriaceae family. However, it might be a reflection of poor hygienic practices which may contribute to health hazard to the potential consumers. Similarly, Inusa and Sa'id (2017); Osimani et al. (2015) reported that, the initial microbial content of the raw material play significant role in influencing the final microbial load of the finished product. Isolation of members of the Enterobacteriaceae such as $E$. coli, Klebsiella pneumoniae, Salmonella and Shigella signifies danger to the public health. These organisms are capable of producing endotoxins which trigger high fevers in infected individuals, and the enterotoxins which colonize the small intestines and lead to extreme dehydration as a result of vomiting and diarrhea sometimes with severe and fatal outcomes (Amaeze et al., 2016). From the 16 isolated organisms $E$. coli had the highest isolation rate $6(37.5 \%)$ (Table 3), this suggest faecal contamination of the products. $E$. coli is a common flora in the gastrointestinal tract responsible for diarrhea and extra-intestinal infections (CDC, 2011). The result is in conformity with the findings of Ndahi et al. (2013) and Shamsuddeen (2009). Also presence of campylobacter might be due to cross contamination from raw meat to finished product (Tsire). Staphylococcus aureus is a normal flora of the skin, nasal, genital, mouth or anal area in both humans and animals without any symptom of an infection (Matthew et al., 2013). Isolation of $S$. aureus in these study concords with the findings of Lucretia et al. (2018) from Suya sold in Rivers State. 
BAJOPAS Volume 13 Number 1, June, 2020

It is also in agreement with the findings of Yousafzai et al. (2018); Onuorah et al. (2015) and Tijjani and Jumare (2014) from tsire samples in different countries. Presence of $S$. aureus in foods is most of the time an indication of poor human handling, poor environment, unhygienic utensils and equipments used during processing (Igene et al., 2016; Okonko et al., 2013). Infections caused by $S$. aureus are difficult to treat leading to long hospitalization with consequent economic loss (Udobi et al., 2013). These include soft tissue infections, pneumonia, hospital-acquired postoperative wound infections, Staphylococcal food poisoning, impetigo and cellulitis (Charlene et al., 2013). Samples obtained from Dausai and Kofar Kudu had the highest isolation rate $4(80 \%)$ (Table 4 ) probably because of the much commercial activities taking place in the area which can lead to environmental contamination.

Table 1: Total Aerobic Mesophilic Bacterial Count of Tsire sold in Garko Town

\begin{tabular}{lll}
\hline Sampling Area & APC cfu/g & Mean \pm STD \\
\hline Dausai & $2.20 \times 10^{5}$ & $110000 \pm 14142.14$ \\
Kofar Kudu & $4.00 \times 10^{5}$ & $133333.3 \pm 23094.01$ \\
Makwalla & $1.30 \times 10^{5}$ & $32500 \pm 7187.953$ \\
Rinji & $2.72 \times 10^{5}$ & $90666.67 \pm 94769.90$ \\
Tosaro & $1.02 \times 10^{5}$ & $51000 \pm 15556.35$ \\
Tsohuwar Kasuwa & $1.75 \times 10^{5}$ & $35000 \pm 11357.82$ \\
\hline
\end{tabular}

Key: APC: Aerobic Mesophilic Counts

STD: Standard Deviation

Table 2: Total Coliform Count of Tsire sold in Garko Town

\begin{tabular}{lcc}
\hline \multicolumn{1}{c}{ Sampling Area } & TCC MPN/g & Mean \pm STD \\
\hline Dausai & 20 & $6.67 \pm 2.5166$ \\
Kofar Kudu & 32 & $16.00 \pm 5.6569$ \\
Makwalla & 68 & $13.60 \pm 8.7062$ \\
Rinji & 37 & $9.25 \pm 4.7871$ \\
Tosaro & 10 & $5.00 \pm 2.8284$ \\
Tsohuwar Kasuwa & 8 & $4.00 \pm 0.0000$ \\
\hline
\end{tabular}

Table 3: Organisms Isolated from Tsire Sold in Garko

\begin{tabular}{lcl}
\hline Isolated Organism & Frequency & Percentage (\%) \\
\hline Campylobacter & 2 & 06.66 \\
Escherichia coli & 6 & 20.00 \\
Klebsiella pneumoniae & 2 & 06.66 \\
Salmonella species & 1 & 03.33 \\
Shigella & 3 & 10.00 \\
Staphylococcus aureus & 2 & 06.66 \\
Total & 16 & \\
\hline
\end{tabular}

Table 4: Distribution of Organisms within Sampling Area

\begin{tabular}{lcc}
\hline \multicolumn{1}{c}{ Sampling Area } & No. Isolated & Percentage (\%) \\
\hline Dausai & 4 & 80 \\
Kofar Kudu & 4 & 80 \\
Makwalla & 2 & 40 \\
Rinji & 3 & 60 \\
Tosaro & 2 & 40 \\
Tsohuwar Kasuwa & 1 & 20 \\
Total & 16 & \\
\hline
\end{tabular}

\section{CONCLUSION}

Results indicated $4.00 \times 10^{5} \mathrm{CFU} / \mathrm{g}$ as the highest APCs count; while $68 \mathrm{MPN} / \mathrm{g}$ was the highest TCCs from the 30 samples analyzed. Among the isolates, $E$. coli has the highest isolation rate of $6(20 \%)$. Dausai and Kofar kudu were having the highest bacteria count of $4(80 \%)$, each, indicating higher contamination in those locations. 
BAJOPAS Volume 13 Number 1, June, 2020 RECOMMENDATIONS

The following recommendations are tenable:

1. Hygienic practices at all stages of production should be improved to safe guard the consumers against potential health hazard.

2. Monitoring of microbiological contamination of Tsire during preparations, packaging and marketing is essential to ensure product of good microbiological quality for consumers' health.

\section{REFERENCES}

Abdullahi, I. O., Umoh, V. J. and Galadima, M. (2004). Hazards Associated with Kilishi Preparations in Zaria. Nigerian Journal of Microbiology, 18 (1-2): $339-345$.

Ahmadu, J. and Ibrahim E. J., (2013): Determinants of Revenue in Suya Production in BeninCity, Edo State, Nigeria. Nigerian journal of agriculture, food and environment.9(3):1-5

Amaeze, N. Aboh, M. Itohan, A. Felix, E. Olatunji, T. and Oladosu, P. (2016) Microbial Profile, Antibiotic Sensitivity and Heat Resistance of Bacterial Isolates from Commercial Roasted Beef (Suya) in Abuja, Nigeria. JOPAT, 15(2): $22-30$.

Apata, E.S., Kuku1, I.A., Apata, O.C. and Adeyemi, K.O. (2013). Evaluation of Suya(Tsire) - An Intermediate Moisture Meat Product in Ogun State, Nigeria. J. Food Res 2 (1): 87.

Atlas, R. M. (1997) Principles of Microbiology Second Edition. C. Brown Publishers. Pp 802-803.

Borch, E. Kant-Muermans, M. L., Blixt, Y. (1996) Bacterial Spoilage of Meat and Cured Meat Products. Int $\mathrm{J}$ Food Microbiol .33(1): 103-20.

Centre for Disease Control, CDC (2011). "Escherichia coli 0157:H7" Division of Bacterial and Mycotic Diseasesht://www.cdc.gov/nczved/divisi ons/dfbmd/diseases/ecoli_0157h7/.

Charlene, R. J., Johnnie, A. D., and John, B. B., (2013) Prevalence and Characterization of Methicillin-Resistant Staphylococcus aureus Isolates from Retail Meat and Humans in Georgia. American society for Microbiology. J. of clinical microbiology. 12(1):123-6 doi:10.1128/JCM.0316612JCM.03166-12

Egbebi, A.O and Seidu, K., T. (2011). Microbiological Evaluation of Suya (dried smoked

meat) Sold in Ado and Akure, South West Nigeria.European Journal of Experinmental Biology, 1(4):1-5
3. Government should establish regulatory bodies responsible for inculcating hygiene habits to the local producers and vendors in order to prevent instant, cross and post processing contaminations by microbial pathogens.

4. Awareness and sensitization of local food producers about good hygienic practices in food handling and processing.

Falegan, C, R., Akoja, S. D., and Oyarekua, M. A., (2017) Microbiological Assessment of Suya (Sliced Roasted Beef) in Ado-Ekiti Metropolis, Ekiti State, Nigeria. MOJ Biology andMedicine.

Fonkem, D., N. Tanya, V., N. and Ebangi, A., L. (2010). Effect of Season on the Microbiological Quality of Kilishi, a Traditional Cameroonian Dried Beef Product. Tropicultura, 28(1): 10-15.

Food and Agricultural Organization of the United Nations (F A O, 1979). Manual of food quality control 4. Microbiological analysis.

Food and Agriculture Organisation of the United Nation (FAO), 2019. Nigeria at a glance.

Igene J.O., Uwadia, O.E., Ebabhamiegbebho, P.A. and Evivie, S.E., (2016) Shelf life Stability Studies of University of Benin (UNIBEN) Proff's Kilishi Product Asian Journal of Science and Technology 7(1): 2268-2274.

Inusa, S. K. and Said, I. S. (2017) Evaluation of the Chemical and Microbiological Properties Of Kilishi Sold in Kano Metropolis. Journal of Dry land Agriculture, 3 (1): $59-69$.

Lucretia, I. B, Patience, C. Obinna-Echem, Sophia, C. A. (2018) Microbiological quality andantibiotic sensitivity of potential pathogens isolated from meat product (Suya) sold in Rivers State University and its environs. International Journal of Biotechnology and Food Science, 6(4): 67-76.

Matthew, E., Drosos, E., John, L. and Ioanna, P. (2013) MRSA in Africa: Filling the Global Map of Antimicrobial Resistance PLOS One. 8(7): e68024 doi: 10.1371/journal.pone.0068024

Mgbemere, V.N., Akpapunam, M. A. and Igene, J. O., (2011). Effect of Groundnut FlourSubstitution on Yield, Quality and Storage Stability of Kilishi - a Nigerian Indigenous Dried Meat Product. African Journal of Food, Agriculture, Nutrition and Development, $\quad \mathbf{1 1}(2)$ : 4718-4738. 
BAJOPAS Volume 13 Number 1, June, 2020

Mubarak, A. A., Azeez, M. L., Amos A. O., Opeyemi, O. O. (2016) Assessment of Animal Protein Consumption and Food Security Among Rural Households in Kwara State, Nigeria American Journal of Business and Society, 1(4): 233245.

Ndahi, M., D. Kwaga, J., K. P. Bello, M. Kabir J., V. Umoh, .J. Yakubu, S., E. and Nok, A., J. (2013) Prevalence and Antimicrobial Susceptibility of Listeria Monocytogenes and Methicillin-Resistant Staphylococcus aureus Strains from Raw Meat and Meat Products in Zaria, Nigeria. Applied Journal of Microbiology, 58(3):262-9.

Okonko, I.O., Odu, N.N. and Igboh, I.E. (2013). Microbiological Analysis of Kilishi Sold In Port Harcourt, Nigeria. New York Science Journal, 6 (7):37-43.

Osimani, A., Aquilanti, L. and Clementi, F. (2015) Microbiological Quality of Meatbased Meals and Operation of Control Systems within a Food Service Environment. International Food Research Journal 22(4): 1692-1698.

Onuorah, S. Obika, I. Odibo, F. Orji, M. (2015)An Assessment of the Bacteriological Quality of Tsire-Suya (Grilled Beef) sold in Awka, Nigeria. American. J. Life. Sci. Res. 3(4):287292.

Razavilar, V, Khandaghi, J. Barzgari, A. (2010); Isolation of Eschericia coli 0157:H7 from manure fertilized farms and raw vegetables grown on it, in Tabriz city in
Iran. African Journal of Microbiology Research, 4(9): 891-895.

Scallan, E. Hoekstra, R. M. Angulo, F. J.Tauxe, R. V, Widdowson, M. Roy, S. L et al., (2011).Food borne illness acquired in the United States- Major Pathogens. Emerg. Infec Dis, 17(1): 7-15.

Shamsuddeen U (2009). Microbiological quality of spice used in the production of Kilishi a traditionally dried and grilled meat product. Bayero Journal of Pure andApplied Sciences, 2(2): 66-69.

Shamsuddeen, U. (2015) Microbiological Hazard and Critical control point Analysis of Dried and Minced Meat Snacks Produced in Kano Nigeria. Lambert Academic Publishing; Pp 1-36.

Tijani, O.and Jumare, S. (2014). Microblological Quality Assessment of Meat

Sold in KauraNamoda. International Conference on Earth, Environment and Life sciences (EELS) Dubai (UAE).

Udobi, C. E., Obajuluwa, A. F., and Onaolapo, J. A., (2013) Prevalence and Antibiotic Resistance Pattern of MethicillinResistant Staphylococcus aureus from an Orthopaedic Hospital in Nigeria BioMed Research International; 26(6); 6-7.

WHO, 2015 Foodborne diseases in the WHO African Region.

Yousafzai HA, Rind R, Khan MA, Abro SH, Korejo NA, Ejaz M, Kabir A, Shahid M, Memon S. (2019). Microbiological Contamination of Cattle and Meat in Peshawar, Pakistan. J. Anim. Health Prod. 7(1): 1116. 


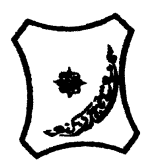

Bayero Journal of Pure and Applied Sciences, 13(1); 40 - 45

Received: September, 2019

Accepted: April, 2020

ISSN $2006-6996$

\title{
BACTERIOLOGICAL QUALITY OF STICK MEAT (Tsire) SOLD IN GARKO LOCAL GOVERNMENT AREA OF KANO STATE, NIGERIA
}

\author{
$*^{1}$ Dahiru A. T. and ${ }^{2}$ Maigari A. K. \\ ${ }^{1}$ Department of Hospitality Management, School of Technology, Kano State Polytechnic, PMB 3348, \\ Kano Nigeria. \\ ${ }^{2}$ Departmnt of Biological Sciences, Bayero University, Kano \\ Corresponding Author: dturajo61@gmail.com; GSM: 08087508262.
}

ABSTRACT

Stick meat, locally called Tsire in Hausa Language, is a significant portion of the diet of a large active population of Northern Nigeria. However, because of the handling and processing methods by the manufacturers as well as the hawking system of stick meat, the meat product may be exposed to both pre- and post-processed product contamination, and thus may poses danger to public health. Therefore, considering the role of Tsire in improving nutrition and increase household income to the populace, the need to improve the processing, distribution and overall quality of the product is simply indispensable. A total of 30 samples (5 samples from each of the 6 sampling points) of Tsire were collected randomly in Garko Town. Aerobic plate counts (APCs) and Total coliform counts (TCCS) of Tsire samples were determined using standard microbiological methods. APCs ranged from $1.02 \times 10^{5}$ to $4.00 \times 10^{5} \mathrm{CFU} / \mathrm{g}$; while TCCs ranged from $8 \mathrm{MPN} / \mathrm{g}$ to $68 \mathrm{MPN} / \mathrm{g}$. From the 30 samples screened, 16(53.33\%) bacteria namely, Campylobacter 2(6.66\%), Escherichia coli 6(20\%), Klebsiella pneumoniae 2(6.66\%), Salmonella spp. 1(3.33\%), Shigella 3(10\%) and Staphylococcus aureus 2(6.66\%) were detected. $E$. coli has the highest isolation rate of 6(20\%), while Salmonella spp. had the least frequency of 1(3.33\%). The distribution of isolated organisms within the study area were as follows: Dausai, 4(80\%), Kofar kudu, 4(80\%), Makwalla, 2(40\%), Rinji, 3(60\%), Tosaro, 2(40\%), and Tsohuwar Kasuwa, 1(20\%). The results have indicated that the Tsire was contaminated with bacteria thus exposing the product to fast deterioration, spoilage and also a vehicle for food borne illness, suggesting for adequate hygienic practices at all the stages, prior to consumption, to ensure safety of the meat product.

Key words: APCs, TCCs, Contamination, Microorganisms, Garko

\section{INTRODUCTION}

Nigeria is one of the developing nations with inadequate food supply and most often deficient in protein content (FAO, 2019). Nigerian's average animal protein intake per head per day is estimated at $7.9 \mathrm{~g}$ as against $35 \mathrm{~g}$ recommended value by Food and Agricultural Organization (Mubarak et al., 2016). These low levels of animal protein intake create great concern as it affects the nutritional status of Nigerians. Hence, there is the need for sufficient supply of animal protein from energy rich animal products to satisfy the nutritional requirements for Nigerians.

Meat is one major source of animal protein largely composed of water, protein and fats which can make it susceptible to microbial contamination within short time leading to spoilage (Apata et al., 2013; Mgbemere et al., 2011). Meat is mostly eaten after it has been cooked or processed in a variety of ways such as sun drying; smoking and roasting with or without fortifications (Borch et al., 1996). In Nigeria meat products such as Tsire, Kilishi and Balangu are locally produced using one or more of these methods in order to meet the nutritional requirements of the teeming Nigerians (Egbebi, 2011).

Tsire is a popular Nigerian traditional processed ready-to-eat roasted stick meat product (Shamsuddeen, 2015). It is sold in public places, along roads, in hotels, parks, quarters and even offices (Falegan et al., 2017). It is prepared from boneless healthy animal flesh such as beef and mutton, spiced with peanut cake, salt, vegetable oil and other flavorings followed by roasting (Shamsuddeen, 2015). Consumption of these products has extended to other parts of African countries such as Ghana, Somali, Cameroun and Chad (Ahmadu and Ibrahim, 2013). 
BAJOPAS Volume 13 Number 1, June, 2020

However, evidence of quality control sticking to procedural hygiene by the handlers during preparation and retailing of these products is poorly documented. Tsire is of great safety risk because of the fact that there are erratic cases of gastroenteritis and symptoms of food infection after consumption (WHO, 2015). Food borne illnesses are one of the major health problems in developing and developed countries (Razavilar, 2010). According to the World Health Organization, WHO (2015), $0.07 \%$ death of the 600 million global burdens of Foodborne illnesses have been reported to be caused by bacteria, viruses, fungi and chemicals. In America $0.27 \%$ of the estimated 48 million affected people is hospitalized and about $0.0063 \%$ deaths are recorded each year (Scallan et al., 2011). More than 91 million people in Africa fall ill and $0.15 \%$ dies each year, making Africa the highest burden bearer of Foodborne diseases per population (WHO, 2015).

Application of a Hazard Analysis Critical Control Point (HACCP) at all stages of meat products preparation is essential in order to ensure its safety. Thus, according to the guidelines of good manufacturing practice, the level of total aerobic bacterial contamination of thermally processed meat products should not exceed $10^{4}\left(\mathrm{cfu} \mathrm{g}^{-1}\right)$. Enterobacteriaceae and faecal coliform contamination in meat products should be within the range of $10^{2}-10^{4}$ and $10-10^{3} \mathrm{cfu} \mathrm{g}^{-1}$, respectively (Shamsuddeen, 2015). The aim of the study is therefore, to assess the total viable bacterial counts of tsire marketed locally within Garko town, and to isolate and identify the organisms at the point of consumption with the intention of promoting public health and food hygiene habits in the Nigerian populace.

\section{MATERIALS AND METHODS Study Area and Population}

Garko is one of the existing 44 local government areas located in Kano south west zone of Kano state with its capital administrative headquarters in the Garko town. It has coordinates $11^{\circ} 39^{\prime} \mathrm{N}$ $8^{\circ} 54^{\prime} \mathrm{E}$, and an area of $450 \mathrm{~km}^{2}$. The projected population of Garko local Government was 225,300 according to the National Population Census report (2018). Garko is known for agricultural activities both farming and animal husbandry. It is popularly known for large scale rice production. Other food crops include sweet potatoes, cassava, onions, sorghum, millet and sugarcane. Cows, sheep and goats are major groups of animals reared by majority of the populace. Meat products processed, retailed and consumed in Garko include roasted meat (Balangu), dried roasted meat (Kilishi), stick meat (Tsire), hide and skin pepper soup (Ragadada) and minced fried meat (Danbunnama).

\section{Samples Collection}

Five samples of Tsire products were collected from 6 different identified locations within Garko town in a sterile foil paper and immediately analyzed for the presence of bacteria.

\section{Sample Preparation}

Sample preparation for the bacteriological analysis was carried out in accordance with the method described by Atlas (1997). Twenty five grams $(25 \mathrm{~g})$ of the sample was homogenized in $225 \mathrm{ml}$ peptone water using Kenwood blender machine to obtain a $10^{1}$ homogenate. The homogenate was thoroughly shaken and $1 \mathrm{ml}$ pipetted into test tubes containing $9 \mathrm{ml}$ of peptone water $\left(10^{2}\right)$. The test tubes were further serially diluted to $10^{5}$.

Total Aerobic Mesophilic Bacterial Count

Total Aerobic mesophilic bacterial count was determined using the method described by Abdullahi et al. (2004) where $1 \mathrm{ml}$ of inoculums from $10^{1}$ to $10^{5}$ dilutions were transferred into duplicate Petri dishes and labeled accordingly. This was followed by pouring aseptically about $15 \mathrm{ml}$ of molten nutrient agar. The culture was homogenized by gentle spinning of the plates and allowed to solidify. The plates were incubated at $37^{\circ} \mathrm{C}$ for 24 hours. Plates containing 30-300 colonies were counted. The number of colony forming units per gram of a sample (cfu/g) was obtained by multiplying the average colony number with the inverse of the dilution factor.

\section{Enumeration and Detection of Coliform bacteria}

Detection and enumeration of coliform was carried out according to method described by Atlas, (1977). A set of 9 test tubes each containing $9 \mathrm{ml}$ of lactose broth and an inverted Durham tubes were autoclaved to expel air and to sterilize. Similarly, $1 \mathrm{ml}$ from the diluents $10^{1}$ was transferred to the first 3 test tubes, followed by $1 \mathrm{ml}$ from the diluents $10^{2}$ to the second set of 3 test tubes and finally the third diluents $10^{3}$ to the $3^{\text {rd }}$ set of 3 test tubes. All the 9 test tubes were incubated at $37^{\circ} \mathrm{C}$ for 24 hours. Tubes that showed gas and acid production after 24 hours were recorded as positive for the presence of Coliform. Negative tubes were further reincubated for 24 hours. Positive tubes were recorded. Estimate of most probable number of Coliform per gram of sample (MPN/g) was determined by comparing the number of gas positive tubes with the most probable number table. 
BAJOPAS Volume 13 Number 1, June, 2020 Identification of Coliform

A loop full of inoculum from gas positive tubes was streaked on to Eosine methylene blue (EMB) agar plate and incubated at $37^{\circ} \mathrm{C}$ for $24 \mathrm{hrs}$. Colonies which formed bluish black color with green metallic sheen, and reddish colonies were isolated on agar slants. Those colonies showing metallic sheen on EMB were sub cultured into tubes of lactose broth and incubated at $45^{\circ} \mathrm{C}$. The tubes were observed after $24 \mathrm{hrs}$ for gas production. This is the completed test for fecal coliform. Gram stain and other biochemical tests such as Indole, Methyl red, Voges-Proskauer and Citrate Utilization tests (IMVIC), Coagulase and Catalase tests were carried out for the Identification and confirmation of isolates.

\section{Procedure for Indole Test}

Indole test was carried out by preparing a Tryptone broth drawn in to test tubes, sterilized by autoclaving, inoculated with loopful of suspension and incubated at $37^{\circ} \mathrm{C}$ for 24 hours. Three drops of xylene was added in tubes, shaken vigorously and kept for the separation of two layers. One millilitre of Kovac's reagent was added and the formation of pink colour ring indicates positive Indole test.

\section{Procedure for Methyl Red Test}

Methyl red test was carried out by preparing Glucose phosphate broth, dispensed in test tubes, sterilized, inoculated with test culture and incubated at $37^{\circ} \mathrm{C}$ for 24 hours. Five drops of methyl-red indicator was added to the medium for the formation of red colour.

\section{Procedure for Voges-Proskauer Test}

Voges-Proskauer test was carried out by inoculating tubes with the bacterial culture followed by incubation for 48 hours at $37^{\circ} \mathrm{C}$. Separate pipettes were used to pipette $1 \mathrm{ml}$ from each culture tube into clean separate tubes. Eighteen drops $(0.5 \mathrm{ml})$ of Barrit's solution A (a-naphthol) was added to each tube containing glucose phosphate broth followed by the addition of an equal amount of solution $B$ into the same tube. The tubes were shaken at 30 seconds interval. A positive reaction was indicated by the development of a pink color, which turns red in 1-2 hours, after vigorous shaking.

\section{Procedure for Citrate Utilization Test}

Citrate Utilization Test was carried out by distributing melted agar (Simmon Citrate Agar) in to test tubes followed by sterilization at $121.5^{\circ} \mathrm{C}$ for 15 minutes. The test tubes were afterward held in slanted position, inoculated with the given bacterial culture and incubated at $37^{\circ} \mathrm{C}$ for $24 \mathrm{hrs}$. Positive test was indicated by color change of the media from green to blue.

\section{RESULTS AND DISCUSSIONS}

The results of this study are presented in tables $1,2,3$ and 4. Among the sampling areas Kofar Kudu had the highest aerobic mesophilic bacteria counts $4.0 \times 10^{5} \mathrm{cfu} / \mathrm{g}$ followed by Rinji $2.72 \times 10^{5} \mathrm{cfu} / \mathrm{g}$, while Tosaro had the least Aerobic mesophilic bacteria counts of $1.02 \times 10^{5}$ $\mathrm{cfu} / \mathrm{g}$ as indicated in Table 1.Makwalla had the highest coliform count $68 \mathrm{MPN} / \mathrm{g}$ followed by Rinji $37 \mathrm{MPN} / \mathrm{g}$. Tsohuwar Kasuwa had the least coliform counts $8 \mathrm{MPN} / \mathrm{g}$, (Table 2). Result from table 1 shows variation in the microbial contents among the samples which suggest variation in their sources, poor handling procedures and contamination from the processing environment. High coliform count and their differences within sampling areas is an indication of poor microbiological quality of the product. Ndahi et al. (2013) reported microbial load to be a function of the handling personnel and the environment. The results indicated that the samples were contaminated with bacteria as the counts exceeded the minimum safety level $\left(10^{4} \mathrm{cfu} / \mathrm{g}\right)$ for members of the Enterobacteriaceae family. However, it might be a reflection of poor hygienic practices which may contribute to health hazard to the potential consumers. Similarly, Inusa and Sa'id (2017); Osimani et al. (2015) reported that, the initial microbial content of the raw material play significant role in influencing the final microbial load of the finished product. Isolation of members of the Enterobacteriaceae such as $E$. coli, Klebsiella pneumoniae, Salmonella and Shigella signifies danger to the public health. These organisms are capable of producing endotoxins which trigger high fevers in infected individuals, and the enterotoxins which colonize the small intestines and lead to extreme dehydration as a result of vomiting and diarrhea sometimes with severe and fatal outcomes (Amaeze et al., 2016). From the 16 isolated organisms $E$. coli had the highest isolation rate $6(37.5 \%)$ (Table 3), this suggest faecal contamination of the products. $E$. coli is a common flora in the gastrointestinal tract responsible for diarrhea and extra-intestinal infections (CDC, 2011). The result is in conformity with the findings of Ndahi et al. (2013) and Shamsuddeen (2009). Also presence of campylobacter might be due to cross contamination from raw meat to finished product (Tsire). Staphylococcus aureus is a normal flora of the skin, nasal, genital, mouth or anal area in both humans and animals without any symptom of an infection (Matthew et al., 2013). Isolation of $S$. aureus in these study concords with the findings of Lucretia et al. (2018) from Suya sold in Rivers State. 
BAJOPAS Volume 13 Number 1, June, 2020

It is also in agreement with the findings of Yousafzai et al. (2018); Onuorah et al. (2015) and Tijjani and Jumare (2014) from tsire samples in different countries. Presence of $S$. aureus in foods is most of the time an indication of poor human handling, poor environment, unhygienic utensils and equipments used during processing (Igene et al., 2016; Okonko et al., 2013). Infections caused by $S$. aureus are difficult to treat leading to long hospitalization with consequent economic loss (Udobi et al., 2013). These include soft tissue infections, pneumonia, hospital-acquired postoperative wound infections, Staphylococcal food poisoning, impetigo and cellulitis (Charlene et al., 2013). Samples obtained from Dausai and Kofar Kudu had the highest isolation rate $4(80 \%)$ (Table 4 ) probably because of the much commercial activities taking place in the area which can lead to environmental contamination.

Table 1: Total Aerobic Mesophilic Bacterial Count of Tsire sold in Garko Town

\begin{tabular}{lll}
\hline Sampling Area & APC cfu/g & Mean \pm STD \\
\hline Dausai & $2.20 \times 10^{5}$ & $110000 \pm 14142.14$ \\
Kofar Kudu & $4.00 \times 10^{5}$ & $133333.3 \pm 23094.01$ \\
Makwalla & $1.30 \times 10^{5}$ & $32500 \pm 7187.953$ \\
Rinji & $2.72 \times 10^{5}$ & $90666.67 \pm 94769.90$ \\
Tosaro & $1.02 \times 10^{5}$ & $51000 \pm 15556.35$ \\
Tsohuwar Kasuwa & $1.75 \times 10^{5}$ & $35000 \pm 11357.82$ \\
\hline
\end{tabular}

Key: APC: Aerobic Mesophilic Counts

STD: Standard Deviation

Table 2: Total Coliform Count of Tsire sold in Garko Town

\begin{tabular}{lcc}
\hline \multicolumn{1}{c}{ Sampling Area } & TCC MPN/g & Mean \pm STD \\
\hline Dausai & 20 & $6.67 \pm 2.5166$ \\
Kofar Kudu & 32 & $16.00 \pm 5.6569$ \\
Makwalla & 68 & $13.60 \pm 8.7062$ \\
Rinji & 37 & $9.25 \pm 4.7871$ \\
Tosaro & 10 & $5.00 \pm 2.8284$ \\
Tsohuwar Kasuwa & 8 & $4.00 \pm 0.0000$ \\
\hline
\end{tabular}

Table 3: Organisms Isolated from Tsire Sold in Garko

\begin{tabular}{lcl}
\hline Isolated Organism & Frequency & Percentage (\%) \\
\hline Campylobacter & 2 & 06.66 \\
Escherichia coli & 6 & 20.00 \\
Klebsiella pneumoniae & 2 & 06.66 \\
Salmonella species & 1 & 03.33 \\
Shigella & 3 & 10.00 \\
Staphylococcus aureus & 2 & 06.66 \\
Total & 16 & \\
\hline
\end{tabular}

Table 4: Distribution of Organisms within Sampling Area

\begin{tabular}{lcc}
\hline \multicolumn{1}{c}{ Sampling Area } & No. Isolated & Percentage (\%) \\
\hline Dausai & 4 & 80 \\
Kofar Kudu & 4 & 80 \\
Makwalla & 2 & 40 \\
Rinji & 3 & 60 \\
Tosaro & 2 & 40 \\
Tsohuwar Kasuwa & 1 & 20 \\
Total & 16 & \\
\hline
\end{tabular}

\section{CONCLUSION}

Results indicated $4.00 \times 10^{5} \mathrm{CFU} / \mathrm{g}$ as the highest APCs count; while $68 \mathrm{MPN} / \mathrm{g}$ was the highest TCCs from the 30 samples analyzed. Among the isolates, $E$. coli has the highest isolation rate of $6(20 \%)$. Dausai and Kofar kudu were having the highest bacteria count of $4(80 \%)$, each, indicating higher contamination in those locations. 
BAJOPAS Volume 13 Number 1, June, 2020 RECOMMENDATIONS

The following recommendations are tenable:

1. Hygienic practices at all stages of production should be improved to safe guard the consumers against potential health hazard.

2. Monitoring of microbiological contamination of Tsire during preparations, packaging and marketing is essential to ensure product of good microbiological quality for consumers' health.

\section{REFERENCES}

Abdullahi, I. O., Umoh, V. J. and Galadima, M. (2004). Hazards Associated with Kilishi Preparations in Zaria. Nigerian Journal of Microbiology, 18 (1-2): $339-345$.

Ahmadu, J. and Ibrahim E. J., (2013): Determinants of Revenue in Suya Production in BeninCity, Edo State, Nigeria. Nigerian journal of agriculture, food and environment.9(3):1-5

Amaeze, N. Aboh, M. Itohan, A. Felix, E. Olatunji, T. and Oladosu, P. (2016) Microbial Profile, Antibiotic Sensitivity and Heat Resistance of Bacterial Isolates from Commercial Roasted Beef (Suya) in Abuja, Nigeria. JOPAT, 15(2): $22-30$.

Apata, E.S., Kuku1, I.A., Apata, O.C. and Adeyemi, K.O. (2013). Evaluation of Suya(Tsire) - An Intermediate Moisture Meat Product in Ogun State, Nigeria. J. Food Res 2 (1): 87.

Atlas, R. M. (1997) Principles of Microbiology Second Edition. C. Brown Publishers. Pp 802-803.

Borch, E. Kant-Muermans, M. L., Blixt, Y. (1996) Bacterial Spoilage of Meat and Cured Meat Products. Int $\mathrm{J}$ Food Microbiol .33(1): 103-20.

Centre for Disease Control, CDC (2011). "Escherichia coli 0157:H7" Division of Bacterial and Mycotic Diseasesht://www.cdc.gov/nczved/divisi ons/dfbmd/diseases/ecoli_0157h7/.

Charlene, R. J., Johnnie, A. D., and John, B. B., (2013) Prevalence and Characterization of Methicillin-Resistant Staphylococcus aureus Isolates from Retail Meat and Humans in Georgia. American society for Microbiology. J. of clinical microbiology. 12(1):123-6 doi:10.1128/JCM.0316612JCM.03166-12

Egbebi, A.O and Seidu, K., T. (2011). Microbiological Evaluation of Suya (dried smoked

meat) Sold in Ado and Akure, South West Nigeria.European Journal of Experinmental Biology, 1(4):1-5
3. Government should establish regulatory bodies responsible for inculcating hygiene habits to the local producers and vendors in order to prevent instant, cross and post processing contaminations by microbial pathogens.

4. Awareness and sensitization of local food producers about good hygienic practices in food handling and processing.

Falegan, C, R., Akoja, S. D., and Oyarekua, M. A., (2017) Microbiological Assessment of Suya (Sliced Roasted Beef) in Ado-Ekiti Metropolis, Ekiti State, Nigeria. MOJ Biology andMedicine.

Fonkem, D., N. Tanya, V., N. and Ebangi, A., L. (2010). Effect of Season on the Microbiological Quality of Kilishi, a Traditional Cameroonian Dried Beef Product. Tropicultura, 28(1): 10-15.

Food and Agricultural Organization of the United Nations (F A O, 1979). Manual of food quality control 4. Microbiological analysis.

Food and Agriculture Organisation of the United Nation (FAO), 2019. Nigeria at a glance.

Igene J.O., Uwadia, O.E., Ebabhamiegbebho, P.A. and Evivie, S.E., (2016) Shelf life Stability Studies of University of Benin (UNIBEN) Proff's Kilishi Product Asian Journal of Science and Technology 7(1): 2268-2274.

Inusa, S. K. and Said, I. S. (2017) Evaluation of the Chemical and Microbiological Properties Of Kilishi Sold in Kano Metropolis. Journal of Dry land Agriculture, 3 (1): $59-69$.

Lucretia, I. B, Patience, C. Obinna-Echem, Sophia, C. A. (2018) Microbiological quality andantibiotic sensitivity of potential pathogens isolated from meat product (Suya) sold in Rivers State University and its environs. International Journal of Biotechnology and Food Science, 6(4): 67-76.

Matthew, E., Drosos, E., John, L. and Ioanna, P. (2013) MRSA in Africa: Filling the Global Map of Antimicrobial Resistance PLOS One. 8(7): e68024 doi: 10.1371/journal.pone.0068024

Mgbemere, V.N., Akpapunam, M. A. and Igene, J. O., (2011). Effect of Groundnut FlourSubstitution on Yield, Quality and Storage Stability of Kilishi - a Nigerian Indigenous Dried Meat Product. African Journal of Food, Agriculture, Nutrition and Development, $\quad \mathbf{1 1}(2)$ : 4718-4738. 
BAJOPAS Volume 13 Number 1, June, 2020

Mubarak, A. A., Azeez, M. L., Amos A. O., Opeyemi, O. O. (2016) Assessment of Animal Protein Consumption and Food Security Among Rural Households in Kwara State, Nigeria American Journal of Business and Society, 1(4): 233245.

Ndahi, M., D. Kwaga, J., K. P. Bello, M. Kabir J., V. Umoh, .J. Yakubu, S., E. and Nok, A., J. (2013) Prevalence and Antimicrobial Susceptibility of Listeria Monocytogenes and Methicillin-Resistant Staphylococcus aureus Strains from Raw Meat and Meat Products in Zaria, Nigeria. Applied Journal of Microbiology, 58(3):262-9.

Okonko, I.O., Odu, N.N. and Igboh, I.E. (2013). Microbiological Analysis of Kilishi Sold In Port Harcourt, Nigeria. New York Science Journal, 6 (7):37-43.

Osimani, A., Aquilanti, L. and Clementi, F. (2015) Microbiological Quality of Meatbased Meals and Operation of Control Systems within a Food Service Environment. International Food Research Journal 22(4): 1692-1698.

Onuorah, S. Obika, I. Odibo, F. Orji, M. (2015)An Assessment of the Bacteriological Quality of Tsire-Suya (Grilled Beef) sold in Awka, Nigeria. American. J. Life. Sci. Res. 3(4):287292.

Razavilar, V, Khandaghi, J. Barzgari, A. (2010); Isolation of Eschericia coli 0157:H7 from manure fertilized farms and raw vegetables grown on it, in Tabriz city in
Iran. African Journal of Microbiology Research, 4(9): 891-895.

Scallan, E. Hoekstra, R. M. Angulo, F. J.Tauxe, R. V, Widdowson, M. Roy, S. L et al., (2011).Food borne illness acquired in the United States- Major Pathogens. Emerg. Infec Dis, 17(1): 7-15.

Shamsuddeen U (2009). Microbiological quality of spice used in the production of Kilishi a traditionally dried and grilled meat product. Bayero Journal of Pure andApplied Sciences, 2(2): 66-69.

Shamsuddeen, U. (2015) Microbiological Hazard and Critical control point Analysis of Dried and Minced Meat Snacks Produced in Kano Nigeria. Lambert Academic Publishing; Pp 1-36.

Tijani, O.and Jumare, S. (2014). Microblological Quality Assessment of Meat

Sold in KauraNamoda. International Conference on Earth, Environment and Life sciences (EELS) Dubai (UAE).

Udobi, C. E., Obajuluwa, A. F., and Onaolapo, J. A., (2013) Prevalence and Antibiotic Resistance Pattern of MethicillinResistant Staphylococcus aureus from an Orthopaedic Hospital in Nigeria BioMed Research International; 26(6); 6-7.

WHO, 2015 Foodborne diseases in the WHO African Region.

Yousafzai HA, Rind R, Khan MA, Abro SH, Korejo NA, Ejaz M, Kabir A, Shahid M, Memon S. (2019). Microbiological Contamination of Cattle and Meat in Peshawar, Pakistan. J. Anim. Health Prod. 7(1): 1116. 


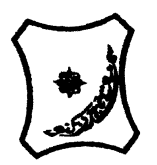

Bayero Journal of Pure and Applied Sciences, 13(1); 40 - 45

Received: September, 2019

Accepted: April, 2020

ISSN $2006-6996$

\title{
BACTERIOLOGICAL QUALITY OF STICK MEAT (Tsire) SOLD IN GARKO LOCAL GOVERNMENT AREA OF KANO STATE, NIGERIA
}

\author{
$*^{1}$ Dahiru A. T. and ${ }^{2}$ Maigari A. K. \\ ${ }^{1}$ Department of Hospitality Management, School of Technology, Kano State Polytechnic, PMB 3348, \\ Kano Nigeria. \\ ${ }^{2}$ Departmnt of Biological Sciences, Bayero University, Kano \\ Corresponding Author: dturajo61@gmail.com; GSM: 08087508262.
}

ABSTRACT

Stick meat, locally called Tsire in Hausa Language, is a significant portion of the diet of a large active population of Northern Nigeria. However, because of the handling and processing methods by the manufacturers as well as the hawking system of stick meat, the meat product may be exposed to both pre- and post-processed product contamination, and thus may poses danger to public health. Therefore, considering the role of Tsire in improving nutrition and increase household income to the populace, the need to improve the processing, distribution and overall quality of the product is simply indispensable. A total of 30 samples (5 samples from each of the 6 sampling points) of Tsire were collected randomly in Garko Town. Aerobic plate counts (APCs) and Total coliform counts (TCCS) of Tsire samples were determined using standard microbiological methods. APCs ranged from $1.02 \times 10^{5}$ to $4.00 \times 10^{5} \mathrm{CFU} / \mathrm{g}$; while TCCs ranged from $8 \mathrm{MPN} / \mathrm{g}$ to $68 \mathrm{MPN} / \mathrm{g}$. From the 30 samples screened, 16(53.33\%) bacteria namely, Campylobacter 2(6.66\%), Escherichia coli 6(20\%), Klebsiella pneumoniae 2(6.66\%), Salmonella spp. 1(3.33\%), Shigella 3(10\%) and Staphylococcus aureus 2(6.66\%) were detected. $E$. coli has the highest isolation rate of 6(20\%), while Salmonella spp. had the least frequency of 1(3.33\%). The distribution of isolated organisms within the study area were as follows: Dausai, 4(80\%), Kofar kudu, 4(80\%), Makwalla, 2(40\%), Rinji, 3(60\%), Tosaro, 2(40\%), and Tsohuwar Kasuwa, 1(20\%). The results have indicated that the Tsire was contaminated with bacteria thus exposing the product to fast deterioration, spoilage and also a vehicle for food borne illness, suggesting for adequate hygienic practices at all the stages, prior to consumption, to ensure safety of the meat product.

Key words: APCs, TCCs, Contamination, Microorganisms, Garko

\section{INTRODUCTION}

Nigeria is one of the developing nations with inadequate food supply and most often deficient in protein content (FAO, 2019). Nigerian's average animal protein intake per head per day is estimated at $7.9 \mathrm{~g}$ as against $35 \mathrm{~g}$ recommended value by Food and Agricultural Organization (Mubarak et al., 2016). These low levels of animal protein intake create great concern as it affects the nutritional status of Nigerians. Hence, there is the need for sufficient supply of animal protein from energy rich animal products to satisfy the nutritional requirements for Nigerians.

Meat is one major source of animal protein largely composed of water, protein and fats which can make it susceptible to microbial contamination within short time leading to spoilage (Apata et al., 2013; Mgbemere et al., 2011). Meat is mostly eaten after it has been cooked or processed in a variety of ways such as sun drying; smoking and roasting with or without fortifications (Borch et al., 1996). In Nigeria meat products such as Tsire, Kilishi and Balangu are locally produced using one or more of these methods in order to meet the nutritional requirements of the teeming Nigerians (Egbebi, 2011).

Tsire is a popular Nigerian traditional processed ready-to-eat roasted stick meat product (Shamsuddeen, 2015). It is sold in public places, along roads, in hotels, parks, quarters and even offices (Falegan et al., 2017). It is prepared from boneless healthy animal flesh such as beef and mutton, spiced with peanut cake, salt, vegetable oil and other flavorings followed by roasting (Shamsuddeen, 2015). Consumption of these products has extended to other parts of African countries such as Ghana, Somali, Cameroun and Chad (Ahmadu and Ibrahim, 2013). 
BAJOPAS Volume 13 Number 1, June, 2020

However, evidence of quality control sticking to procedural hygiene by the handlers during preparation and retailing of these products is poorly documented. Tsire is of great safety risk because of the fact that there are erratic cases of gastroenteritis and symptoms of food infection after consumption (WHO, 2015). Food borne illnesses are one of the major health problems in developing and developed countries (Razavilar, 2010). According to the World Health Organization, WHO (2015), $0.07 \%$ death of the 600 million global burdens of Foodborne illnesses have been reported to be caused by bacteria, viruses, fungi and chemicals. In America $0.27 \%$ of the estimated 48 million affected people is hospitalized and about $0.0063 \%$ deaths are recorded each year (Scallan et al., 2011). More than 91 million people in Africa fall ill and $0.15 \%$ dies each year, making Africa the highest burden bearer of Foodborne diseases per population (WHO, 2015).

Application of a Hazard Analysis Critical Control Point (HACCP) at all stages of meat products preparation is essential in order to ensure its safety. Thus, according to the guidelines of good manufacturing practice, the level of total aerobic bacterial contamination of thermally processed meat products should not exceed $10^{4}\left(\mathrm{cfu} \mathrm{g}^{-1}\right)$. Enterobacteriaceae and faecal coliform contamination in meat products should be within the range of $10^{2}-10^{4}$ and $10-10^{3} \mathrm{cfu} \mathrm{g}^{-1}$, respectively (Shamsuddeen, 2015). The aim of the study is therefore, to assess the total viable bacterial counts of tsire marketed locally within Garko town, and to isolate and identify the organisms at the point of consumption with the intention of promoting public health and food hygiene habits in the Nigerian populace.

\section{MATERIALS AND METHODS Study Area and Population}

Garko is one of the existing 44 local government areas located in Kano south west zone of Kano state with its capital administrative headquarters in the Garko town. It has coordinates $11^{\circ} 39^{\prime} \mathrm{N}$ $8^{\circ} 54^{\prime} \mathrm{E}$, and an area of $450 \mathrm{~km}^{2}$. The projected population of Garko local Government was 225,300 according to the National Population Census report (2018). Garko is known for agricultural activities both farming and animal husbandry. It is popularly known for large scale rice production. Other food crops include sweet potatoes, cassava, onions, sorghum, millet and sugarcane. Cows, sheep and goats are major groups of animals reared by majority of the populace. Meat products processed, retailed and consumed in Garko include roasted meat (Balangu), dried roasted meat (Kilishi), stick meat (Tsire), hide and skin pepper soup (Ragadada) and minced fried meat (Danbunnama).

\section{Samples Collection}

Five samples of Tsire products were collected from 6 different identified locations within Garko town in a sterile foil paper and immediately analyzed for the presence of bacteria.

\section{Sample Preparation}

Sample preparation for the bacteriological analysis was carried out in accordance with the method described by Atlas (1997). Twenty five grams $(25 \mathrm{~g})$ of the sample was homogenized in $225 \mathrm{ml}$ peptone water using Kenwood blender machine to obtain a $10^{1}$ homogenate. The homogenate was thoroughly shaken and $1 \mathrm{ml}$ pipetted into test tubes containing $9 \mathrm{ml}$ of peptone water $\left(10^{2}\right)$. The test tubes were further serially diluted to $10^{5}$.

Total Aerobic Mesophilic Bacterial Count

Total Aerobic mesophilic bacterial count was determined using the method described by Abdullahi et al. (2004) where $1 \mathrm{ml}$ of inoculums from $10^{1}$ to $10^{5}$ dilutions were transferred into duplicate Petri dishes and labeled accordingly. This was followed by pouring aseptically about $15 \mathrm{ml}$ of molten nutrient agar. The culture was homogenized by gentle spinning of the plates and allowed to solidify. The plates were incubated at $37^{\circ} \mathrm{C}$ for 24 hours. Plates containing 30-300 colonies were counted. The number of colony forming units per gram of a sample (cfu/g) was obtained by multiplying the average colony number with the inverse of the dilution factor.

\section{Enumeration and Detection of Coliform bacteria}

Detection and enumeration of coliform was carried out according to method described by Atlas, (1977). A set of 9 test tubes each containing $9 \mathrm{ml}$ of lactose broth and an inverted Durham tubes were autoclaved to expel air and to sterilize. Similarly, $1 \mathrm{ml}$ from the diluents $10^{1}$ was transferred to the first 3 test tubes, followed by $1 \mathrm{ml}$ from the diluents $10^{2}$ to the second set of 3 test tubes and finally the third diluents $10^{3}$ to the $3^{\text {rd }}$ set of 3 test tubes. All the 9 test tubes were incubated at $37^{\circ} \mathrm{C}$ for 24 hours. Tubes that showed gas and acid production after 24 hours were recorded as positive for the presence of Coliform. Negative tubes were further reincubated for 24 hours. Positive tubes were recorded. Estimate of most probable number of Coliform per gram of sample (MPN/g) was determined by comparing the number of gas positive tubes with the most probable number table. 
BAJOPAS Volume 13 Number 1, June, 2020 Identification of Coliform

A loop full of inoculum from gas positive tubes was streaked on to Eosine methylene blue (EMB) agar plate and incubated at $37^{\circ} \mathrm{C}$ for $24 \mathrm{hrs}$. Colonies which formed bluish black color with green metallic sheen, and reddish colonies were isolated on agar slants. Those colonies showing metallic sheen on EMB were sub cultured into tubes of lactose broth and incubated at $45^{\circ} \mathrm{C}$. The tubes were observed after $24 \mathrm{hrs}$ for gas production. This is the completed test for fecal coliform. Gram stain and other biochemical tests such as Indole, Methyl red, Voges-Proskauer and Citrate Utilization tests (IMVIC), Coagulase and Catalase tests were carried out for the Identification and confirmation of isolates.

\section{Procedure for Indole Test}

Indole test was carried out by preparing a Tryptone broth drawn in to test tubes, sterilized by autoclaving, inoculated with loopful of suspension and incubated at $37^{\circ} \mathrm{C}$ for 24 hours. Three drops of xylene was added in tubes, shaken vigorously and kept for the separation of two layers. One millilitre of Kovac's reagent was added and the formation of pink colour ring indicates positive Indole test.

\section{Procedure for Methyl Red Test}

Methyl red test was carried out by preparing Glucose phosphate broth, dispensed in test tubes, sterilized, inoculated with test culture and incubated at $37^{\circ} \mathrm{C}$ for 24 hours. Five drops of methyl-red indicator was added to the medium for the formation of red colour.

\section{Procedure for Voges-Proskauer Test}

Voges-Proskauer test was carried out by inoculating tubes with the bacterial culture followed by incubation for 48 hours at $37^{\circ} \mathrm{C}$. Separate pipettes were used to pipette $1 \mathrm{ml}$ from each culture tube into clean separate tubes. Eighteen drops $(0.5 \mathrm{ml})$ of Barrit's solution A (a-naphthol) was added to each tube containing glucose phosphate broth followed by the addition of an equal amount of solution $B$ into the same tube. The tubes were shaken at 30 seconds interval. A positive reaction was indicated by the development of a pink color, which turns red in 1-2 hours, after vigorous shaking.

\section{Procedure for Citrate Utilization Test}

Citrate Utilization Test was carried out by distributing melted agar (Simmon Citrate Agar) in to test tubes followed by sterilization at $121.5^{\circ} \mathrm{C}$ for 15 minutes. The test tubes were afterward held in slanted position, inoculated with the given bacterial culture and incubated at $37^{\circ} \mathrm{C}$ for $24 \mathrm{hrs}$. Positive test was indicated by color change of the media from green to blue.

\section{RESULTS AND DISCUSSIONS}

The results of this study are presented in tables $1,2,3$ and 4. Among the sampling areas Kofar Kudu had the highest aerobic mesophilic bacteria counts $4.0 \times 10^{5} \mathrm{cfu} / \mathrm{g}$ followed by Rinji $2.72 \times 10^{5} \mathrm{cfu} / \mathrm{g}$, while Tosaro had the least Aerobic mesophilic bacteria counts of $1.02 \times 10^{5}$ $\mathrm{cfu} / \mathrm{g}$ as indicated in Table 1.Makwalla had the highest coliform count $68 \mathrm{MPN} / \mathrm{g}$ followed by Rinji $37 \mathrm{MPN} / \mathrm{g}$. Tsohuwar Kasuwa had the least coliform counts $8 \mathrm{MPN} / \mathrm{g}$, (Table 2). Result from table 1 shows variation in the microbial contents among the samples which suggest variation in their sources, poor handling procedures and contamination from the processing environment. High coliform count and their differences within sampling areas is an indication of poor microbiological quality of the product. Ndahi et al. (2013) reported microbial load to be a function of the handling personnel and the environment. The results indicated that the samples were contaminated with bacteria as the counts exceeded the minimum safety level $\left(10^{4} \mathrm{cfu} / \mathrm{g}\right)$ for members of the Enterobacteriaceae family. However, it might be a reflection of poor hygienic practices which may contribute to health hazard to the potential consumers. Similarly, Inusa and Sa'id (2017); Osimani et al. (2015) reported that, the initial microbial content of the raw material play significant role in influencing the final microbial load of the finished product. Isolation of members of the Enterobacteriaceae such as $E$. coli, Klebsiella pneumoniae, Salmonella and Shigella signifies danger to the public health. These organisms are capable of producing endotoxins which trigger high fevers in infected individuals, and the enterotoxins which colonize the small intestines and lead to extreme dehydration as a result of vomiting and diarrhea sometimes with severe and fatal outcomes (Amaeze et al., 2016). From the 16 isolated organisms $E$. coli had the highest isolation rate $6(37.5 \%)$ (Table 3), this suggest faecal contamination of the products. $E$. coli is a common flora in the gastrointestinal tract responsible for diarrhea and extra-intestinal infections (CDC, 2011). The result is in conformity with the findings of Ndahi et al. (2013) and Shamsuddeen (2009). Also presence of campylobacter might be due to cross contamination from raw meat to finished product (Tsire). Staphylococcus aureus is a normal flora of the skin, nasal, genital, mouth or anal area in both humans and animals without any symptom of an infection (Matthew et al., 2013). Isolation of $S$. aureus in these study concords with the findings of Lucretia et al. (2018) from Suya sold in Rivers State. 
BAJOPAS Volume 13 Number 1, June, 2020

It is also in agreement with the findings of Yousafzai et al. (2018); Onuorah et al. (2015) and Tijjani and Jumare (2014) from tsire samples in different countries. Presence of $S$. aureus in foods is most of the time an indication of poor human handling, poor environment, unhygienic utensils and equipments used during processing (Igene et al., 2016; Okonko et al., 2013). Infections caused by $S$. aureus are difficult to treat leading to long hospitalization with consequent economic loss (Udobi et al., 2013). These include soft tissue infections, pneumonia, hospital-acquired postoperative wound infections, Staphylococcal food poisoning, impetigo and cellulitis (Charlene et al., 2013). Samples obtained from Dausai and Kofar Kudu had the highest isolation rate $4(80 \%)$ (Table 4 ) probably because of the much commercial activities taking place in the area which can lead to environmental contamination.

Table 1: Total Aerobic Mesophilic Bacterial Count of Tsire sold in Garko Town

\begin{tabular}{lll}
\hline Sampling Area & APC cfu/g & Mean \pm STD \\
\hline Dausai & $2.20 \times 10^{5}$ & $110000 \pm 14142.14$ \\
Kofar Kudu & $4.00 \times 10^{5}$ & $133333.3 \pm 23094.01$ \\
Makwalla & $1.30 \times 10^{5}$ & $32500 \pm 7187.953$ \\
Rinji & $2.72 \times 10^{5}$ & $90666.67 \pm 94769.90$ \\
Tosaro & $1.02 \times 10^{5}$ & $51000 \pm 15556.35$ \\
Tsohuwar Kasuwa & $1.75 \times 10^{5}$ & $35000 \pm 11357.82$ \\
\hline
\end{tabular}

Key: APC: Aerobic Mesophilic Counts

STD: Standard Deviation

Table 2: Total Coliform Count of Tsire sold in Garko Town

\begin{tabular}{lcc}
\hline \multicolumn{1}{c}{ Sampling Area } & TCC MPN/g & Mean \pm STD \\
\hline Dausai & 20 & $6.67 \pm 2.5166$ \\
Kofar Kudu & 32 & $16.00 \pm 5.6569$ \\
Makwalla & 68 & $13.60 \pm 8.7062$ \\
Rinji & 37 & $9.25 \pm 4.7871$ \\
Tosaro & 10 & $5.00 \pm 2.8284$ \\
Tsohuwar Kasuwa & 8 & $4.00 \pm 0.0000$ \\
\hline
\end{tabular}

Table 3: Organisms Isolated from Tsire Sold in Garko

\begin{tabular}{lcl}
\hline Isolated Organism & Frequency & Percentage (\%) \\
\hline Campylobacter & 2 & 06.66 \\
Escherichia coli & 6 & 20.00 \\
Klebsiella pneumoniae & 2 & 06.66 \\
Salmonella species & 1 & 03.33 \\
Shigella & 3 & 10.00 \\
Staphylococcus aureus & 2 & 06.66 \\
Total & 16 & \\
\hline
\end{tabular}

Table 4: Distribution of Organisms within Sampling Area

\begin{tabular}{lcc}
\hline \multicolumn{1}{c}{ Sampling Area } & No. Isolated & Percentage (\%) \\
\hline Dausai & 4 & 80 \\
Kofar Kudu & 4 & 80 \\
Makwalla & 2 & 40 \\
Rinji & 3 & 60 \\
Tosaro & 2 & 40 \\
Tsohuwar Kasuwa & 1 & 20 \\
Total & 16 & \\
\hline
\end{tabular}

\section{CONCLUSION}

Results indicated $4.00 \times 10^{5} \mathrm{CFU} / \mathrm{g}$ as the highest APCs count; while $68 \mathrm{MPN} / \mathrm{g}$ was the highest TCCs from the 30 samples analyzed. Among the isolates, $E$. coli has the highest isolation rate of $6(20 \%)$. Dausai and Kofar kudu were having the highest bacteria count of $4(80 \%)$, each, indicating higher contamination in those locations. 
BAJOPAS Volume 13 Number 1, June, 2020 RECOMMENDATIONS

The following recommendations are tenable:

1. Hygienic practices at all stages of production should be improved to safe guard the consumers against potential health hazard.

2. Monitoring of microbiological contamination of Tsire during preparations, packaging and marketing is essential to ensure product of good microbiological quality for consumers' health.

\section{REFERENCES}

Abdullahi, I. O., Umoh, V. J. and Galadima, M. (2004). Hazards Associated with Kilishi Preparations in Zaria. Nigerian Journal of Microbiology, 18 (1-2): $339-345$.

Ahmadu, J. and Ibrahim E. J., (2013): Determinants of Revenue in Suya Production in BeninCity, Edo State, Nigeria. Nigerian journal of agriculture, food and environment.9(3):1-5

Amaeze, N. Aboh, M. Itohan, A. Felix, E. Olatunji, T. and Oladosu, P. (2016) Microbial Profile, Antibiotic Sensitivity and Heat Resistance of Bacterial Isolates from Commercial Roasted Beef (Suya) in Abuja, Nigeria. JOPAT, 15(2): $22-30$.

Apata, E.S., Kuku1, I.A., Apata, O.C. and Adeyemi, K.O. (2013). Evaluation of Suya(Tsire) - An Intermediate Moisture Meat Product in Ogun State, Nigeria. J. Food Res 2 (1): 87.

Atlas, R. M. (1997) Principles of Microbiology Second Edition. C. Brown Publishers. Pp 802-803.

Borch, E. Kant-Muermans, M. L., Blixt, Y. (1996) Bacterial Spoilage of Meat and Cured Meat Products. Int $\mathrm{J}$ Food Microbiol .33(1): 103-20.

Centre for Disease Control, CDC (2011). "Escherichia coli 0157:H7" Division of Bacterial and Mycotic Diseasesht://www.cdc.gov/nczved/divisi ons/dfbmd/diseases/ecoli_0157h7/.

Charlene, R. J., Johnnie, A. D., and John, B. B., (2013) Prevalence and Characterization of Methicillin-Resistant Staphylococcus aureus Isolates from Retail Meat and Humans in Georgia. American society for Microbiology. J. of clinical microbiology. 12(1):123-6 doi:10.1128/JCM.0316612JCM.03166-12

Egbebi, A.O and Seidu, K., T. (2011). Microbiological Evaluation of Suya (dried smoked

meat) Sold in Ado and Akure, South West Nigeria.European Journal of Experinmental Biology, 1(4):1-5
3. Government should establish regulatory bodies responsible for inculcating hygiene habits to the local producers and vendors in order to prevent instant, cross and post processing contaminations by microbial pathogens.

4. Awareness and sensitization of local food producers about good hygienic practices in food handling and processing.

Falegan, C, R., Akoja, S. D., and Oyarekua, M. A., (2017) Microbiological Assessment of Suya (Sliced Roasted Beef) in Ado-Ekiti Metropolis, Ekiti State, Nigeria. MOJ Biology andMedicine.

Fonkem, D., N. Tanya, V., N. and Ebangi, A., L. (2010). Effect of Season on the Microbiological Quality of Kilishi, a Traditional Cameroonian Dried Beef Product. Tropicultura, 28(1): 10-15.

Food and Agricultural Organization of the United Nations (F A O, 1979). Manual of food quality control 4. Microbiological analysis.

Food and Agriculture Organisation of the United Nation (FAO), 2019. Nigeria at a glance.

Igene J.O., Uwadia, O.E., Ebabhamiegbebho, P.A. and Evivie, S.E., (2016) Shelf life Stability Studies of University of Benin (UNIBEN) Proff's Kilishi Product Asian Journal of Science and Technology 7(1): 2268-2274.

Inusa, S. K. and Said, I. S. (2017) Evaluation of the Chemical and Microbiological Properties Of Kilishi Sold in Kano Metropolis. Journal of Dry land Agriculture, 3 (1): $59-69$.

Lucretia, I. B, Patience, C. Obinna-Echem, Sophia, C. A. (2018) Microbiological quality andantibiotic sensitivity of potential pathogens isolated from meat product (Suya) sold in Rivers State University and its environs. International Journal of Biotechnology and Food Science, 6(4): 67-76.

Matthew, E., Drosos, E., John, L. and Ioanna, P. (2013) MRSA in Africa: Filling the Global Map of Antimicrobial Resistance PLOS One. 8(7): e68024 doi: 10.1371/journal.pone.0068024

Mgbemere, V.N., Akpapunam, M. A. and Igene, J. O., (2011). Effect of Groundnut FlourSubstitution on Yield, Quality and Storage Stability of Kilishi - a Nigerian Indigenous Dried Meat Product. African Journal of Food, Agriculture, Nutrition and Development, $\quad \mathbf{1 1}(2)$ : 4718-4738. 
BAJOPAS Volume 13 Number 1, June, 2020

Mubarak, A. A., Azeez, M. L., Amos A. O., Opeyemi, O. O. (2016) Assessment of Animal Protein Consumption and Food Security Among Rural Households in Kwara State, Nigeria American Journal of Business and Society, 1(4): 233245.

Ndahi, M., D. Kwaga, J., K. P. Bello, M. Kabir J., V. Umoh, .J. Yakubu, S., E. and Nok, A., J. (2013) Prevalence and Antimicrobial Susceptibility of Listeria Monocytogenes and Methicillin-Resistant Staphylococcus aureus Strains from Raw Meat and Meat Products in Zaria, Nigeria. Applied Journal of Microbiology, 58(3):262-9.

Okonko, I.O., Odu, N.N. and Igboh, I.E. (2013). Microbiological Analysis of Kilishi Sold In Port Harcourt, Nigeria. New York Science Journal, 6 (7):37-43.

Osimani, A., Aquilanti, L. and Clementi, F. (2015) Microbiological Quality of Meatbased Meals and Operation of Control Systems within a Food Service Environment. International Food Research Journal 22(4): 1692-1698.

Onuorah, S. Obika, I. Odibo, F. Orji, M. (2015)An Assessment of the Bacteriological Quality of Tsire-Suya (Grilled Beef) sold in Awka, Nigeria. American. J. Life. Sci. Res. 3(4):287292.

Razavilar, V, Khandaghi, J. Barzgari, A. (2010); Isolation of Eschericia coli 0157:H7 from manure fertilized farms and raw vegetables grown on it, in Tabriz city in
Iran. African Journal of Microbiology Research, 4(9): 891-895.

Scallan, E. Hoekstra, R. M. Angulo, F. J.Tauxe, R. V, Widdowson, M. Roy, S. L et al., (2011).Food borne illness acquired in the United States- Major Pathogens. Emerg. Infec Dis, 17(1): 7-15.

Shamsuddeen U (2009). Microbiological quality of spice used in the production of Kilishi a traditionally dried and grilled meat product. Bayero Journal of Pure andApplied Sciences, 2(2): 66-69.

Shamsuddeen, U. (2015) Microbiological Hazard and Critical control point Analysis of Dried and Minced Meat Snacks Produced in Kano Nigeria. Lambert Academic Publishing; Pp 1-36.

Tijani, O.and Jumare, S. (2014). Microblological Quality Assessment of Meat

Sold in KauraNamoda. International Conference on Earth, Environment and Life sciences (EELS) Dubai (UAE).

Udobi, C. E., Obajuluwa, A. F., and Onaolapo, J. A., (2013) Prevalence and Antibiotic Resistance Pattern of MethicillinResistant Staphylococcus aureus from an Orthopaedic Hospital in Nigeria BioMed Research International; 26(6); 6-7.

WHO, 2015 Foodborne diseases in the WHO African Region.

Yousafzai HA, Rind R, Khan MA, Abro SH, Korejo NA, Ejaz M, Kabir A, Shahid M, Memon S. (2019). Microbiological Contamination of Cattle and Meat in Peshawar, Pakistan. J. Anim. Health Prod. 7(1): 1116. 


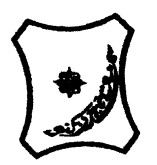

Bayero Journal of Pure and Applied Sciences, 13(1); 40 - 45

Received: September, 2019

Accepted: April, 2020

ISSN $2006-6996$

\title{
BACTERIOLOGICAL QUALITY OF STICK MEAT (Tsire) SOLD IN GARKO LOCAL GOVERNMENT AREA OF KANO STATE, NIGERIA
}

\author{
$*^{1}$ Dahiru A. T. and ${ }^{2}$ Maigari A. K. \\ ${ }^{1}$ Department of Hospitality Management, School of Technology, Kano State Polytechnic, PMB 3348, \\ Kano Nigeria. \\ ${ }^{2}$ Departmnt of Biological Sciences, Bayero University, Kano \\ Corresponding Author: dturajo61@gmail.com; GSM: 08087508262.
}

ABSTRACT

Stick meat, locally called Tsire in Hausa Language, is a significant portion of the diet of a large active population of Northern Nigeria. However, because of the handling and processing methods by the manufacturers as well as the hawking system of stick meat, the meat product may be exposed to both pre- and post-processed product contamination, and thus may poses danger to public health. Therefore, considering the role of Tsire in improving nutrition and increase household income to the populace, the need to improve the processing, distribution and overall quality of the product is simply indispensable. A total of 30 samples (5 samples from each of the 6 sampling points) of Tsire were collected randomly in Garko Town. Aerobic plate counts (APCs) and Total coliform counts (TCCS) of Tsire samples were determined using standard microbiological methods. APCs ranged from $1.02 \times 10^{5}$ to $4.00 \times 10^{5} \mathrm{CFU} / \mathrm{g}$; while TCCs ranged from $8 \mathrm{MPN} / \mathrm{g}$ to $68 \mathrm{MPN} / \mathrm{g}$. From the 30 samples screened, 16(53.33\%) bacteria namely, Campylobacter 2(6.66\%), Escherichia coli 6(20\%), Klebsiella pneumoniae 2(6.66\%), Salmonella spp. 1(3.33\%), Shigella 3(10\%) and Staphylococcus aureus 2(6.66\%) were detected. $E$. coli has the highest isolation rate of 6(20\%), while Salmonella spp. had the least frequency of 1(3.33\%). The distribution of isolated organisms within the study area were as follows: Dausai, 4(80\%), Kofar kudu, 4(80\%), Makwalla, 2(40\%), Rinji, 3(60\%), Tosaro, 2(40\%), and Tsohuwar Kasuwa, 1(20\%). The results have indicated that the Tsire was contaminated with bacteria thus exposing the product to fast deterioration, spoilage and also a vehicle for food borne illness, suggesting for adequate hygienic practices at all the stages, prior to consumption, to ensure safety of the meat product.

Key words: APCs, TCCs, Contamination, Microorganisms, Garko

\section{INTRODUCTION}

Nigeria is one of the developing nations with inadequate food supply and most often deficient in protein content (FAO, 2019). Nigerian's average animal protein intake per head per day is estimated at $7.9 \mathrm{~g}$ as against $35 \mathrm{~g}$ recommended value by Food and Agricultural Organization (Mubarak et al., 2016). These low levels of animal protein intake create great concern as it affects the nutritional status of Nigerians. Hence, there is the need for sufficient supply of animal protein from energy rich animal products to satisfy the nutritional requirements for Nigerians.

Meat is one major source of animal protein largely composed of water, protein and fats which can make it susceptible to microbial contamination within short time leading to spoilage (Apata et al., 2013; Mgbemere et al., 2011). Meat is mostly eaten after it has been cooked or processed in a variety of ways such as sun drying; smoking and roasting with or without fortifications (Borch et al., 1996). In Nigeria meat products such as Tsire, Kilishi and Balangu are locally produced using one or more of these methods in order to meet the nutritional requirements of the teeming Nigerians (Egbebi, 2011).

Tsire is a popular Nigerian traditional processed ready-to-eat roasted stick meat product (Shamsuddeen, 2015). It is sold in public places, along roads, in hotels, parks, quarters and even offices (Falegan et al., 2017). It is prepared from boneless healthy animal flesh such as beef and mutton, spiced with peanut cake, salt, vegetable oil and other flavorings followed by roasting (Shamsuddeen, 2015). Consumption of these products has extended to other parts of African countries such as Ghana, Somali, Cameroun and Chad (Ahmadu and Ibrahim, 2013). 
BAJOPAS Volume 13 Number 1, June, 2020

However, evidence of quality control sticking to procedural hygiene by the handlers during preparation and retailing of these products is poorly documented. Tsire is of great safety risk because of the fact that there are erratic cases of gastroenteritis and symptoms of food infection after consumption (WHO, 2015). Food borne illnesses are one of the major health problems in developing and developed countries (Razavilar, 2010). According to the World Health Organization, WHO (2015), $0.07 \%$ death of the 600 million global burdens of Foodborne illnesses have been reported to be caused by bacteria, viruses, fungi and chemicals. In America $0.27 \%$ of the estimated 48 million affected people is hospitalized and about $0.0063 \%$ deaths are recorded each year (Scallan et al., 2011). More than 91 million people in Africa fall ill and $0.15 \%$ dies each year, making Africa the highest burden bearer of Foodborne diseases per population (WHO, 2015).

Application of a Hazard Analysis Critical Control Point (HACCP) at all stages of meat products preparation is essential in order to ensure its safety. Thus, according to the guidelines of good manufacturing practice, the level of total aerobic bacterial contamination of thermally processed meat products should not exceed $10^{4}\left(\mathrm{cfu} \mathrm{g}^{-1}\right)$. Enterobacteriaceae and faecal coliform contamination in meat products should be within the range of $10^{2}-10^{4}$ and $10-10^{3} \mathrm{cfu} \mathrm{g}^{-1}$, respectively (Shamsuddeen, 2015). The aim of the study is therefore, to assess the total viable bacterial counts of tsire marketed locally within Garko town, and to isolate and identify the organisms at the point of consumption with the intention of promoting public health and food hygiene habits in the Nigerian populace.

\section{MATERIALS AND METHODS Study Area and Population}

Garko is one of the existing 44 local government areas located in Kano south west zone of Kano state with its capital administrative headquarters in the Garko town. It has coordinates $11^{\circ} 39^{\prime} \mathrm{N}$ $8^{\circ} 54^{\prime} \mathrm{E}$, and an area of $450 \mathrm{~km}^{2}$. The projected population of Garko local Government was 225,300 according to the National Population Census report (2018). Garko is known for agricultural activities both farming and animal husbandry. It is popularly known for large scale rice production. Other food crops include sweet potatoes, cassava, onions, sorghum, millet and sugarcane. Cows, sheep and goats are major groups of animals reared by majority of the populace. Meat products processed, retailed and consumed in Garko include roasted meat (Balangu), dried roasted meat (Kilishi), stick meat (Tsire), hide and skin pepper soup (Ragadada) and minced fried meat (Danbunnama).

\section{Samples Collection}

Five samples of Tsire products were collected from 6 different identified locations within Garko town in a sterile foil paper and immediately analyzed for the presence of bacteria.

\section{Sample Preparation}

Sample preparation for the bacteriological analysis was carried out in accordance with the method described by Atlas (1997). Twenty five grams $(25 \mathrm{~g})$ of the sample was homogenized in $225 \mathrm{ml}$ peptone water using Kenwood blender machine to obtain a $10^{1}$ homogenate. The homogenate was thoroughly shaken and $1 \mathrm{ml}$ pipetted into test tubes containing $9 \mathrm{ml}$ of peptone water $\left(10^{2}\right)$. The test tubes were further serially diluted to $10^{5}$.

Total Aerobic Mesophilic Bacterial Count

Total Aerobic mesophilic bacterial count was determined using the method described by Abdullahi et al. (2004) where $1 \mathrm{ml}$ of inoculums from $10^{1}$ to $10^{5}$ dilutions were transferred into duplicate Petri dishes and labeled accordingly. This was followed by pouring aseptically about $15 \mathrm{ml}$ of molten nutrient agar. The culture was homogenized by gentle spinning of the plates and allowed to solidify. The plates were incubated at $37^{\circ} \mathrm{C}$ for 24 hours. Plates containing 30-300 colonies were counted. The number of colony forming units per gram of a sample (cfu/g) was obtained by multiplying the average colony number with the inverse of the dilution factor.

\section{Enumeration and Detection of Coliform bacteria}

Detection and enumeration of coliform was carried out according to method described by Atlas, (1977). A set of 9 test tubes each containing $9 \mathrm{ml}$ of lactose broth and an inverted Durham tubes were autoclaved to expel air and to sterilize. Similarly, $1 \mathrm{ml}$ from the diluents $10^{1}$ was transferred to the first 3 test tubes, followed by $1 \mathrm{ml}$ from the diluents $10^{2}$ to the second set of 3 test tubes and finally the third diluents $10^{3}$ to the $3^{\text {rd }}$ set of 3 test tubes. All the 9 test tubes were incubated at $37^{\circ} \mathrm{C}$ for 24 hours. Tubes that showed gas and acid production after 24 hours were recorded as positive for the presence of Coliform. Negative tubes were further reincubated for 24 hours. Positive tubes were recorded. Estimate of most probable number of Coliform per gram of sample (MPN/g) was determined by comparing the number of gas positive tubes with the most probable number table. 
BAJOPAS Volume 13 Number 1, June, 2020 Identification of Coliform

A loop full of inoculum from gas positive tubes was streaked on to Eosine methylene blue (EMB) agar plate and incubated at $37^{\circ} \mathrm{C}$ for $24 \mathrm{hrs}$. Colonies which formed bluish black color with green metallic sheen, and reddish colonies were isolated on agar slants. Those colonies showing metallic sheen on EMB were sub cultured into tubes of lactose broth and incubated at $45^{\circ} \mathrm{C}$. The tubes were observed after $24 \mathrm{hrs}$ for gas production. This is the completed test for fecal coliform. Gram stain and other biochemical tests such as Indole, Methyl red, Voges-Proskauer and Citrate Utilization tests (IMVIC), Coagulase and Catalase tests were carried out for the Identification and confirmation of isolates.

\section{Procedure for Indole Test}

Indole test was carried out by preparing a Tryptone broth drawn in to test tubes, sterilized by autoclaving, inoculated with loopful of suspension and incubated at $37^{\circ} \mathrm{C}$ for 24 hours. Three drops of xylene was added in tubes, shaken vigorously and kept for the separation of two layers. One millilitre of Kovac's reagent was added and the formation of pink colour ring indicates positive Indole test.

\section{Procedure for Methyl Red Test}

Methyl red test was carried out by preparing Glucose phosphate broth, dispensed in test tubes, sterilized, inoculated with test culture and incubated at $37^{\circ} \mathrm{C}$ for 24 hours. Five drops of methyl-red indicator was added to the medium for the formation of red colour.

\section{Procedure for Voges-Proskauer Test}

Voges-Proskauer test was carried out by inoculating tubes with the bacterial culture followed by incubation for 48 hours at $37^{\circ} \mathrm{C}$. Separate pipettes were used to pipette $1 \mathrm{ml}$ from each culture tube into clean separate tubes. Eighteen drops $(0.5 \mathrm{ml})$ of Barrit's solution A (a-naphthol) was added to each tube containing glucose phosphate broth followed by the addition of an equal amount of solution $B$ into the same tube. The tubes were shaken at 30 seconds interval. A positive reaction was indicated by the development of a pink color, which turns red in 1-2 hours, after vigorous shaking.

\section{Procedure for Citrate Utilization Test}

Citrate Utilization Test was carried out by distributing melted agar (Simmon Citrate Agar) in to test tubes followed by sterilization at $121.5^{\circ} \mathrm{C}$ for 15 minutes. The test tubes were afterward held in slanted position, inoculated with the given bacterial culture and incubated at $37^{\circ} \mathrm{C}$ for $24 \mathrm{hrs}$. Positive test was indicated by color change of the media from green to blue.

\section{RESULTS AND DISCUSSIONS}

The results of this study are presented in tables $1,2,3$ and 4. Among the sampling areas Kofar Kudu had the highest aerobic mesophilic bacteria counts $4.0 \times 10^{5} \mathrm{cfu} / \mathrm{g}$ followed by Rinji $2.72 \times 10^{5} \mathrm{cfu} / \mathrm{g}$, while Tosaro had the least Aerobic mesophilic bacteria counts of $1.02 \times 10^{5}$ $\mathrm{cfu} / \mathrm{g}$ as indicated in Table 1.Makwalla had the highest coliform count $68 \mathrm{MPN} / \mathrm{g}$ followed by Rinji $37 \mathrm{MPN} / \mathrm{g}$. Tsohuwar Kasuwa had the least coliform counts $8 \mathrm{MPN} / \mathrm{g}$, (Table 2). Result from table 1 shows variation in the microbial contents among the samples which suggest variation in their sources, poor handling procedures and contamination from the processing environment. High coliform count and their differences within sampling areas is an indication of poor microbiological quality of the product. Ndahi et al. (2013) reported microbial load to be a function of the handling personnel and the environment. The results indicated that the samples were contaminated with bacteria as the counts exceeded the minimum safety level $\left(10^{4} \mathrm{cfu} / \mathrm{g}\right)$ for members of the Enterobacteriaceae family. However, it might be a reflection of poor hygienic practices which may contribute to health hazard to the potential consumers. Similarly, Inusa and Sa'id (2017); Osimani et al. (2015) reported that, the initial microbial content of the raw material play significant role in influencing the final microbial load of the finished product. Isolation of members of the Enterobacteriaceae such as $E$. coli, Klebsiella pneumoniae, Salmonella and Shigella signifies danger to the public health. These organisms are capable of producing endotoxins which trigger high fevers in infected individuals, and the enterotoxins which colonize the small intestines and lead to extreme dehydration as a result of vomiting and diarrhea sometimes with severe and fatal outcomes (Amaeze et al., 2016). From the 16 isolated organisms $E$. coli had the highest isolation rate $6(37.5 \%)$ (Table 3), this suggest faecal contamination of the products. $E$. coli is a common flora in the gastrointestinal tract responsible for diarrhea and extra-intestinal infections (CDC, 2011). The result is in conformity with the findings of Ndahi et al. (2013) and Shamsuddeen (2009). Also presence of campylobacter might be due to cross contamination from raw meat to finished product (Tsire). Staphylococcus aureus is a normal flora of the skin, nasal, genital, mouth or anal area in both humans and animals without any symptom of an infection (Matthew et al., 2013). Isolation of $S$. aureus in these study concords with the findings of Lucretia et al. (2018) from Suya sold in Rivers State. 
BAJOPAS Volume 13 Number 1, June, 2020

It is also in agreement with the findings of Yousafzai et al. (2018); Onuorah et al. (2015) and Tijjani and Jumare (2014) from tsire samples in different countries. Presence of $S$. aureus in foods is most of the time an indication of poor human handling, poor environment, unhygienic utensils and equipments used during processing (Igene et al., 2016; Okonko et al., 2013). Infections caused by $S$. aureus are difficult to treat leading to long hospitalization with consequent economic loss (Udobi et al., 2013). These include soft tissue infections, pneumonia, hospital-acquired postoperative wound infections, Staphylococcal food poisoning, impetigo and cellulitis (Charlene et al., 2013). Samples obtained from Dausai and Kofar Kudu had the highest isolation rate $4(80 \%)$ (Table 4 ) probably because of the much commercial activities taking place in the area which can lead to environmental contamination.

Table 1: Total Aerobic Mesophilic Bacterial Count of Tsire sold in Garko Town

\begin{tabular}{lll}
\hline Sampling Area & APC cfu/g & Mean \pm STD \\
\hline Dausai & $2.20 \times 10^{5}$ & $110000 \pm 14142.14$ \\
Kofar Kudu & $4.00 \times 10^{5}$ & $133333.3 \pm 23094.01$ \\
Makwalla & $1.30 \times 10^{5}$ & $32500 \pm 7187.953$ \\
Rinji & $2.72 \times 10^{5}$ & $90666.67 \pm 94769.90$ \\
Tosaro & $1.02 \times 10^{5}$ & $51000 \pm 15556.35$ \\
Tsohuwar Kasuwa & $1.75 \times 10^{5}$ & $35000 \pm 11357.82$ \\
\hline
\end{tabular}

Key: APC: Aerobic Mesophilic Counts

STD: Standard Deviation

Table 2: Total Coliform Count of Tsire sold in Garko Town

\begin{tabular}{lcc}
\hline \multicolumn{1}{c}{ Sampling Area } & TCC MPN/g & Mean \pm STD \\
\hline Dausai & 20 & $6.67 \pm 2.5166$ \\
Kofar Kudu & 32 & $16.00 \pm 5.6569$ \\
Makwalla & 68 & $13.60 \pm 8.7062$ \\
Rinji & 37 & $9.25 \pm 4.7871$ \\
Tosaro & 10 & $5.00 \pm 2.8284$ \\
Tsohuwar Kasuwa & 8 & $4.00 \pm 0.0000$ \\
\hline
\end{tabular}

Table 3: Organisms Isolated from Tsire Sold in Garko

\begin{tabular}{lcl}
\hline Isolated Organism & Frequency & Percentage (\%) \\
\hline Campylobacter & 2 & 06.66 \\
Escherichia coli & 6 & 20.00 \\
Klebsiella pneumoniae & 2 & 06.66 \\
Salmonella species & 1 & 03.33 \\
Shigella & 3 & 10.00 \\
Staphylococcus aureus & 2 & 06.66 \\
Total & 16 & \\
\hline
\end{tabular}

Table 4: Distribution of Organisms within Sampling Area

\begin{tabular}{lcc}
\hline \multicolumn{1}{c}{ Sampling Area } & No. Isolated & Percentage (\%) \\
\hline Dausai & 4 & 80 \\
Kofar Kudu & 4 & 80 \\
Makwalla & 2 & 40 \\
Rinji & 3 & 60 \\
Tosaro & 2 & 40 \\
Tsohuwar Kasuwa & 1 & 20 \\
Total & 16 & \\
\hline
\end{tabular}

\section{CONCLUSION}

Results indicated $4.00 \times 10^{5} \mathrm{CFU} / \mathrm{g}$ as the highest APCs count; while $68 \mathrm{MPN} / \mathrm{g}$ was the highest TCCs from the 30 samples analyzed. Among the isolates, $E$. coli has the highest isolation rate of $6(20 \%)$. Dausai and Kofar kudu were having the highest bacteria count of $4(80 \%)$, each, indicating higher contamination in those locations. 
BAJOPAS Volume 13 Number 1, June, 2020 RECOMMENDATIONS

The following recommendations are tenable:

1. Hygienic practices at all stages of production should be improved to safe guard the consumers against potential health hazard.

2. Monitoring of microbiological contamination of Tsire during preparations, packaging and marketing is essential to ensure product of good microbiological quality for consumers' health.

\section{REFERENCES}

Abdullahi, I. O., Umoh, V. J. and Galadima, M. (2004). Hazards Associated with Kilishi Preparations in Zaria. Nigerian Journal of Microbiology, 18 (1-2): $339-345$.

Ahmadu, J. and Ibrahim E. J., (2013): Determinants of Revenue in Suya Production in BeninCity, Edo State, Nigeria. Nigerian journal of agriculture, food and environment.9(3):1-5

Amaeze, N. Aboh, M. Itohan, A. Felix, E. Olatunji, T. and Oladosu, P. (2016) Microbial Profile, Antibiotic Sensitivity and Heat Resistance of Bacterial Isolates from Commercial Roasted Beef (Suya) in Abuja, Nigeria. JOPAT, 15(2): $22-30$.

Apata, E.S., Kuku1, I.A., Apata, O.C. and Adeyemi, K.O. (2013). Evaluation of Suya(Tsire) - An Intermediate Moisture Meat Product in Ogun State, Nigeria. J. Food Res 2 (1): 87.

Atlas, R. M. (1997) Principles of Microbiology Second Edition. C. Brown Publishers. Pp 802-803.

Borch, E. Kant-Muermans, M. L., Blixt, Y. (1996) Bacterial Spoilage of Meat and Cured Meat Products. Int $\mathrm{J}$ Food Microbiol .33(1): 103-20.

Centre for Disease Control, CDC (2011). "Escherichia coli 0157:H7" Division of Bacterial and Mycotic Diseasesht://www.cdc.gov/nczved/divisi ons/dfbmd/diseases/ecoli_0157h7/.

Charlene, R. J., Johnnie, A. D., and John, B. B., (2013) Prevalence and Characterization of Methicillin-Resistant Staphylococcus aureus Isolates from Retail Meat and Humans in Georgia. American society for Microbiology. J. of clinical microbiology. 12(1):123-6 doi:10.1128/JCM.0316612JCM.03166-12

Egbebi, A.O and Seidu, K., T. (2011). Microbiological Evaluation of Suya (dried smoked

meat) Sold in Ado and Akure, South West Nigeria.European Journal of Experinmental Biology, 1(4):1-5
3. Government should establish regulatory bodies responsible for inculcating hygiene habits to the local producers and vendors in order to prevent instant, cross and post processing contaminations by microbial pathogens.

4. Awareness and sensitization of local food producers about good hygienic practices in food handling and processing.

Falegan, C, R., Akoja, S. D., and Oyarekua, M. A., (2017) Microbiological Assessment of Suya (Sliced Roasted Beef) in Ado-Ekiti Metropolis, Ekiti State, Nigeria. MOJ Biology andMedicine.

Fonkem, D., N. Tanya, V., N. and Ebangi, A., L. (2010). Effect of Season on the Microbiological Quality of Kilishi, a Traditional Cameroonian Dried Beef Product. Tropicultura, 28(1): 10-15.

Food and Agricultural Organization of the United Nations (F A O, 1979). Manual of food quality control 4. Microbiological analysis.

Food and Agriculture Organisation of the United Nation (FAO), 2019. Nigeria at a glance.

Igene J.O., Uwadia, O.E., Ebabhamiegbebho, P.A. and Evivie, S.E., (2016) Shelf life Stability Studies of University of Benin (UNIBEN) Proff's Kilishi Product Asian Journal of Science and Technology 7(1): 2268-2274.

Inusa, S. K. and Said, I. S. (2017) Evaluation of the Chemical and Microbiological Properties Of Kilishi Sold in Kano Metropolis. Journal of Dry land Agriculture, 3 (1): $59-69$.

Lucretia, I. B, Patience, C. Obinna-Echem, Sophia, C. A. (2018) Microbiological quality andantibiotic sensitivity of potential pathogens isolated from meat product (Suya) sold in Rivers State University and its environs. International Journal of Biotechnology and Food Science, 6(4): 67-76.

Matthew, E., Drosos, E., John, L. and Ioanna, P. (2013) MRSA in Africa: Filling the Global Map of Antimicrobial Resistance PLOS One. 8(7): e68024 doi: 10.1371/journal.pone.0068024

Mgbemere, V.N., Akpapunam, M. A. and Igene, J. O., (2011). Effect of Groundnut FlourSubstitution on Yield, Quality and Storage Stability of Kilishi - a Nigerian Indigenous Dried Meat Product. African Journal of Food, Agriculture, Nutrition and Development, $\quad \mathbf{1 1}(2)$ : 4718-4738. 
BAJOPAS Volume 13 Number 1, June, 2020

Mubarak, A. A., Azeez, M. L., Amos A. O., Opeyemi, O. O. (2016) Assessment of Animal Protein Consumption and Food Security Among Rural Households in Kwara State, Nigeria American Journal of Business and Society, 1(4): 233245.

Ndahi, M., D. Kwaga, J., K. P. Bello, M. Kabir J., V. Umoh, .J. Yakubu, S., E. and Nok, A., J. (2013) Prevalence and Antimicrobial Susceptibility of Listeria Monocytogenes and Methicillin-Resistant Staphylococcus aureus Strains from Raw Meat and Meat Products in Zaria, Nigeria. Applied Journal of Microbiology, 58(3):262-9.

Okonko, I.O., Odu, N.N. and Igboh, I.E. (2013). Microbiological Analysis of Kilishi Sold In Port Harcourt, Nigeria. New York Science Journal, 6 (7):37-43.

Osimani, A., Aquilanti, L. and Clementi, F. (2015) Microbiological Quality of Meatbased Meals and Operation of Control Systems within a Food Service Environment. International Food Research Journal 22(4): 1692-1698.

Onuorah, S. Obika, I. Odibo, F. Orji, M. (2015)An Assessment of the Bacteriological Quality of Tsire-Suya (Grilled Beef) sold in Awka, Nigeria. American. J. Life. Sci. Res. 3(4):287292.

Razavilar, V, Khandaghi, J. Barzgari, A. (2010); Isolation of Eschericia coli 0157:H7 from manure fertilized farms and raw vegetables grown on it, in Tabriz city in
Iran. African Journal of Microbiology Research, 4(9): 891-895.

Scallan, E. Hoekstra, R. M. Angulo, F. J.Tauxe, R. V, Widdowson, M. Roy, S. L et al., (2011).Food borne illness acquired in the United States- Major Pathogens. Emerg. Infec Dis, 17(1): 7-15.

Shamsuddeen U (2009). Microbiological quality of spice used in the production of Kilishi a traditionally dried and grilled meat product. Bayero Journal of Pure andApplied Sciences, 2(2): 66-69.

Shamsuddeen, U. (2015) Microbiological Hazard and Critical control point Analysis of Dried and Minced Meat Snacks Produced in Kano Nigeria. Lambert Academic Publishing; Pp 1-36.

Tijani, O.and Jumare, S. (2014). Microblological Quality Assessment of Meat

Sold in KauraNamoda. International Conference on Earth, Environment and Life sciences (EELS) Dubai (UAE).

Udobi, C. E., Obajuluwa, A. F., and Onaolapo, J. A., (2013) Prevalence and Antibiotic Resistance Pattern of MethicillinResistant Staphylococcus aureus from an Orthopaedic Hospital in Nigeria BioMed Research International; 26(6); 6-7.

WHO, 2015 Foodborne diseases in the WHO African Region.

Yousafzai HA, Rind R, Khan MA, Abro SH, Korejo NA, Ejaz M, Kabir A, Shahid M, Memon S. (2019). Microbiological Contamination of Cattle and Meat in Peshawar, Pakistan. J. Anim. Health Prod. 7(1): 1116. 


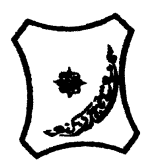

Bayero Journal of Pure and Applied Sciences, 13(1); 40 - 45

Received: September, 2019

Accepted: April, 2020

ISSN $2006-6996$

\title{
BACTERIOLOGICAL QUALITY OF STICK MEAT (Tsire) SOLD IN GARKO LOCAL GOVERNMENT AREA OF KANO STATE, NIGERIA
}

\author{
$*^{1}$ Dahiru A. T. and ${ }^{2}$ Maigari A. K. \\ ${ }^{1}$ Department of Hospitality Management, School of Technology, Kano State Polytechnic, PMB 3348, \\ Kano Nigeria. \\ ${ }^{2}$ Departmnt of Biological Sciences, Bayero University, Kano \\ Corresponding Author: dturajo61@gmail.com; GSM: 08087508262.
}

ABSTRACT

Stick meat, locally called Tsire in Hausa Language, is a significant portion of the diet of a large active population of Northern Nigeria. However, because of the handling and processing methods by the manufacturers as well as the hawking system of stick meat, the meat product may be exposed to both pre- and post-processed product contamination, and thus may poses danger to public health. Therefore, considering the role of Tsire in improving nutrition and increase household income to the populace, the need to improve the processing, distribution and overall quality of the product is simply indispensable. A total of 30 samples (5 samples from each of the 6 sampling points) of Tsire were collected randomly in Garko Town. Aerobic plate counts (APCs) and Total coliform counts (TCCS) of Tsire samples were determined using standard microbiological methods. APCs ranged from $1.02 \times 10^{5}$ to $4.00 \times 10^{5} \mathrm{CFU} / \mathrm{g}$; while TCCs ranged from $8 \mathrm{MPN} / \mathrm{g}$ to $68 \mathrm{MPN} / \mathrm{g}$. From the 30 samples screened, 16(53.33\%) bacteria namely, Campylobacter 2(6.66\%), Escherichia coli 6(20\%), Klebsiella pneumoniae 2(6.66\%), Salmonella spp. 1(3.33\%), Shigella 3(10\%) and Staphylococcus aureus 2(6.66\%) were detected. $E$. coli has the highest isolation rate of 6(20\%), while Salmonella spp. had the least frequency of 1(3.33\%). The distribution of isolated organisms within the study area were as follows: Dausai, 4(80\%), Kofar kudu, 4(80\%), Makwalla, 2(40\%), Rinji, 3(60\%), Tosaro, 2(40\%), and Tsohuwar Kasuwa, 1(20\%). The results have indicated that the Tsire was contaminated with bacteria thus exposing the product to fast deterioration, spoilage and also a vehicle for food borne illness, suggesting for adequate hygienic practices at all the stages, prior to consumption, to ensure safety of the meat product.

Key words: APCs, TCCs, Contamination, Microorganisms, Garko

\section{INTRODUCTION}

Nigeria is one of the developing nations with inadequate food supply and most often deficient in protein content (FAO, 2019). Nigerian's average animal protein intake per head per day is estimated at $7.9 \mathrm{~g}$ as against $35 \mathrm{~g}$ recommended value by Food and Agricultural Organization (Mubarak et al., 2016). These low levels of animal protein intake create great concern as it affects the nutritional status of Nigerians. Hence, there is the need for sufficient supply of animal protein from energy rich animal products to satisfy the nutritional requirements for Nigerians.

Meat is one major source of animal protein largely composed of water, protein and fats which can make it susceptible to microbial contamination within short time leading to spoilage (Apata et al., 2013; Mgbemere et al., 2011). Meat is mostly eaten after it has been cooked or processed in a variety of ways such as sun drying; smoking and roasting with or without fortifications (Borch et al., 1996). In Nigeria meat products such as Tsire, Kilishi and Balangu are locally produced using one or more of these methods in order to meet the nutritional requirements of the teeming Nigerians (Egbebi, 2011).

Tsire is a popular Nigerian traditional processed ready-to-eat roasted stick meat product (Shamsuddeen, 2015). It is sold in public places, along roads, in hotels, parks, quarters and even offices (Falegan et al., 2017). It is prepared from boneless healthy animal flesh such as beef and mutton, spiced with peanut cake, salt, vegetable oil and other flavorings followed by roasting (Shamsuddeen, 2015). Consumption of these products has extended to other parts of African countries such as Ghana, Somali, Cameroun and Chad (Ahmadu and Ibrahim, 2013). 
BAJOPAS Volume 13 Number 1, June, 2020

However, evidence of quality control sticking to procedural hygiene by the handlers during preparation and retailing of these products is poorly documented. Tsire is of great safety risk because of the fact that there are erratic cases of gastroenteritis and symptoms of food infection after consumption (WHO, 2015). Food borne illnesses are one of the major health problems in developing and developed countries (Razavilar, 2010). According to the World Health Organization, WHO (2015), $0.07 \%$ death of the 600 million global burdens of Foodborne illnesses have been reported to be caused by bacteria, viruses, fungi and chemicals. In America $0.27 \%$ of the estimated 48 million affected people is hospitalized and about $0.0063 \%$ deaths are recorded each year (Scallan et al., 2011). More than 91 million people in Africa fall ill and $0.15 \%$ dies each year, making Africa the highest burden bearer of Foodborne diseases per population (WHO, 2015).

Application of a Hazard Analysis Critical Control Point (HACCP) at all stages of meat products preparation is essential in order to ensure its safety. Thus, according to the guidelines of good manufacturing practice, the level of total aerobic bacterial contamination of thermally processed meat products should not exceed $10^{4}\left(\mathrm{cfu} \mathrm{g}^{-1}\right)$. Enterobacteriaceae and faecal coliform contamination in meat products should be within the range of $10^{2}-10^{4}$ and $10-10^{3} \mathrm{cfu} \mathrm{g}^{-1}$, respectively (Shamsuddeen, 2015). The aim of the study is therefore, to assess the total viable bacterial counts of tsire marketed locally within Garko town, and to isolate and identify the organisms at the point of consumption with the intention of promoting public health and food hygiene habits in the Nigerian populace.

\section{MATERIALS AND METHODS Study Area and Population}

Garko is one of the existing 44 local government areas located in Kano south west zone of Kano state with its capital administrative headquarters in the Garko town. It has coordinates $11^{\circ} 39^{\prime} \mathrm{N}$ $8^{\circ} 54^{\prime} \mathrm{E}$, and an area of $450 \mathrm{~km}^{2}$. The projected population of Garko local Government was 225,300 according to the National Population Census report (2018). Garko is known for agricultural activities both farming and animal husbandry. It is popularly known for large scale rice production. Other food crops include sweet potatoes, cassava, onions, sorghum, millet and sugarcane. Cows, sheep and goats are major groups of animals reared by majority of the populace. Meat products processed, retailed and consumed in Garko include roasted meat (Balangu), dried roasted meat (Kilishi), stick meat (Tsire), hide and skin pepper soup (Ragadada) and minced fried meat (Danbunnama).

\section{Samples Collection}

Five samples of Tsire products were collected from 6 different identified locations within Garko town in a sterile foil paper and immediately analyzed for the presence of bacteria.

\section{Sample Preparation}

Sample preparation for the bacteriological analysis was carried out in accordance with the method described by Atlas (1997). Twenty five grams $(25 \mathrm{~g})$ of the sample was homogenized in $225 \mathrm{ml}$ peptone water using Kenwood blender machine to obtain a $10^{1}$ homogenate. The homogenate was thoroughly shaken and $1 \mathrm{ml}$ pipetted into test tubes containing $9 \mathrm{ml}$ of peptone water $\left(10^{2}\right)$. The test tubes were further serially diluted to $10^{5}$.

Total Aerobic Mesophilic Bacterial Count

Total Aerobic mesophilic bacterial count was determined using the method described by Abdullahi et al. (2004) where $1 \mathrm{ml}$ of inoculums from $10^{1}$ to $10^{5}$ dilutions were transferred into duplicate Petri dishes and labeled accordingly. This was followed by pouring aseptically about $15 \mathrm{ml}$ of molten nutrient agar. The culture was homogenized by gentle spinning of the plates and allowed to solidify. The plates were incubated at $37^{\circ} \mathrm{C}$ for 24 hours. Plates containing 30-300 colonies were counted. The number of colony forming units per gram of a sample (cfu/g) was obtained by multiplying the average colony number with the inverse of the dilution factor.

\section{Enumeration and Detection of Coliform bacteria}

Detection and enumeration of coliform was carried out according to method described by Atlas, (1977). A set of 9 test tubes each containing $9 \mathrm{ml}$ of lactose broth and an inverted Durham tubes were autoclaved to expel air and to sterilize. Similarly, $1 \mathrm{ml}$ from the diluents $10^{1}$ was transferred to the first 3 test tubes, followed by $1 \mathrm{ml}$ from the diluents $10^{2}$ to the second set of 3 test tubes and finally the third diluents $10^{3}$ to the $3^{\text {rd }}$ set of 3 test tubes. All the 9 test tubes were incubated at $37^{\circ} \mathrm{C}$ for 24 hours. Tubes that showed gas and acid production after 24 hours were recorded as positive for the presence of Coliform. Negative tubes were further reincubated for 24 hours. Positive tubes were recorded. Estimate of most probable number of Coliform per gram of sample (MPN/g) was determined by comparing the number of gas positive tubes with the most probable number table. 
BAJOPAS Volume 13 Number 1, June, 2020 Identification of Coliform

A loop full of inoculum from gas positive tubes was streaked on to Eosine methylene blue (EMB) agar plate and incubated at $37^{\circ} \mathrm{C}$ for $24 \mathrm{hrs}$. Colonies which formed bluish black color with green metallic sheen, and reddish colonies were isolated on agar slants. Those colonies showing metallic sheen on EMB were sub cultured into tubes of lactose broth and incubated at $45^{\circ} \mathrm{C}$. The tubes were observed after $24 \mathrm{hrs}$ for gas production. This is the completed test for fecal coliform. Gram stain and other biochemical tests such as Indole, Methyl red, Voges-Proskauer and Citrate Utilization tests (IMVIC), Coagulase and Catalase tests were carried out for the Identification and confirmation of isolates.

\section{Procedure for Indole Test}

Indole test was carried out by preparing a Tryptone broth drawn in to test tubes, sterilized by autoclaving, inoculated with loopful of suspension and incubated at $37^{\circ} \mathrm{C}$ for 24 hours. Three drops of xylene was added in tubes, shaken vigorously and kept for the separation of two layers. One millilitre of Kovac's reagent was added and the formation of pink colour ring indicates positive Indole test.

\section{Procedure for Methyl Red Test}

Methyl red test was carried out by preparing Glucose phosphate broth, dispensed in test tubes, sterilized, inoculated with test culture and incubated at $37^{\circ} \mathrm{C}$ for 24 hours. Five drops of methyl-red indicator was added to the medium for the formation of red colour.

\section{Procedure for Voges-Proskauer Test}

Voges-Proskauer test was carried out by inoculating tubes with the bacterial culture followed by incubation for 48 hours at $37^{\circ} \mathrm{C}$. Separate pipettes were used to pipette $1 \mathrm{ml}$ from each culture tube into clean separate tubes. Eighteen drops $(0.5 \mathrm{ml})$ of Barrit's solution A (a-naphthol) was added to each tube containing glucose phosphate broth followed by the addition of an equal amount of solution $B$ into the same tube. The tubes were shaken at 30 seconds interval. A positive reaction was indicated by the development of a pink color, which turns red in 1-2 hours, after vigorous shaking.

\section{Procedure for Citrate Utilization Test}

Citrate Utilization Test was carried out by distributing melted agar (Simmon Citrate Agar) in to test tubes followed by sterilization at $121.5^{\circ} \mathrm{C}$ for 15 minutes. The test tubes were afterward held in slanted position, inoculated with the given bacterial culture and incubated at $37^{\circ} \mathrm{C}$ for $24 \mathrm{hrs}$. Positive test was indicated by color change of the media from green to blue.

\section{RESULTS AND DISCUSSIONS}

The results of this study are presented in tables $1,2,3$ and 4. Among the sampling areas Kofar Kudu had the highest aerobic mesophilic bacteria counts $4.0 \times 10^{5} \mathrm{cfu} / \mathrm{g}$ followed by Rinji $2.72 \times 10^{5} \mathrm{cfu} / \mathrm{g}$, while Tosaro had the least Aerobic mesophilic bacteria counts of $1.02 \times 10^{5}$ $\mathrm{cfu} / \mathrm{g}$ as indicated in Table 1.Makwalla had the highest coliform count $68 \mathrm{MPN} / \mathrm{g}$ followed by Rinji $37 \mathrm{MPN} / \mathrm{g}$. Tsohuwar Kasuwa had the least coliform counts $8 \mathrm{MPN} / \mathrm{g}$, (Table 2). Result from table 1 shows variation in the microbial contents among the samples which suggest variation in their sources, poor handling procedures and contamination from the processing environment. High coliform count and their differences within sampling areas is an indication of poor microbiological quality of the product. Ndahi et al. (2013) reported microbial load to be a function of the handling personnel and the environment. The results indicated that the samples were contaminated with bacteria as the counts exceeded the minimum safety level $\left(10^{4} \mathrm{cfu} / \mathrm{g}\right)$ for members of the Enterobacteriaceae family. However, it might be a reflection of poor hygienic practices which may contribute to health hazard to the potential consumers. Similarly, Inusa and Sa'id (2017); Osimani et al. (2015) reported that, the initial microbial content of the raw material play significant role in influencing the final microbial load of the finished product. Isolation of members of the Enterobacteriaceae such as $E$. coli, Klebsiella pneumoniae, Salmonella and Shigella signifies danger to the public health. These organisms are capable of producing endotoxins which trigger high fevers in infected individuals, and the enterotoxins which colonize the small intestines and lead to extreme dehydration as a result of vomiting and diarrhea sometimes with severe and fatal outcomes (Amaeze et al., 2016). From the 16 isolated organisms $E$. coli had the highest isolation rate $6(37.5 \%)$ (Table 3), this suggest faecal contamination of the products. $E$. coli is a common flora in the gastrointestinal tract responsible for diarrhea and extra-intestinal infections (CDC, 2011). The result is in conformity with the findings of Ndahi et al. (2013) and Shamsuddeen (2009). Also presence of campylobacter might be due to cross contamination from raw meat to finished product (Tsire). Staphylococcus aureus is a normal flora of the skin, nasal, genital, mouth or anal area in both humans and animals without any symptom of an infection (Matthew et al., 2013). Isolation of $S$. aureus in these study concords with the findings of Lucretia et al. (2018) from Suya sold in Rivers State. 
BAJOPAS Volume 13 Number 1, June, 2020

It is also in agreement with the findings of Yousafzai et al. (2018); Onuorah et al. (2015) and Tijjani and Jumare (2014) from tsire samples in different countries. Presence of $S$. aureus in foods is most of the time an indication of poor human handling, poor environment, unhygienic utensils and equipments used during processing (Igene et al., 2016; Okonko et al., 2013). Infections caused by $S$. aureus are difficult to treat leading to long hospitalization with consequent economic loss (Udobi et al., 2013). These include soft tissue infections, pneumonia, hospital-acquired postoperative wound infections, Staphylococcal food poisoning, impetigo and cellulitis (Charlene et al., 2013). Samples obtained from Dausai and Kofar Kudu had the highest isolation rate $4(80 \%)$ (Table 4 ) probably because of the much commercial activities taking place in the area which can lead to environmental contamination.

Table 1: Total Aerobic Mesophilic Bacterial Count of Tsire sold in Garko Town

\begin{tabular}{lll}
\hline Sampling Area & APC cfu/g & Mean \pm STD \\
\hline Dausai & $2.20 \times 10^{5}$ & $110000 \pm 14142.14$ \\
Kofar Kudu & $4.00 \times 10^{5}$ & $133333.3 \pm 23094.01$ \\
Makwalla & $1.30 \times 10^{5}$ & $32500 \pm 7187.953$ \\
Rinji & $2.72 \times 10^{5}$ & $90666.67 \pm 94769.90$ \\
Tosaro & $1.02 \times 10^{5}$ & $51000 \pm 15556.35$ \\
Tsohuwar Kasuwa & $1.75 \times 10^{5}$ & $35000 \pm 11357.82$ \\
\hline
\end{tabular}

Key: APC: Aerobic Mesophilic Counts

STD: Standard Deviation

Table 2: Total Coliform Count of Tsire sold in Garko Town

\begin{tabular}{lcc}
\hline \multicolumn{1}{c}{ Sampling Area } & TCC MPN/g & Mean \pm STD \\
\hline Dausai & 20 & $6.67 \pm 2.5166$ \\
Kofar Kudu & 32 & $16.00 \pm 5.6569$ \\
Makwalla & 68 & $13.60 \pm 8.7062$ \\
Rinji & 37 & $9.25 \pm 4.7871$ \\
Tosaro & 10 & $5.00 \pm 2.8284$ \\
Tsohuwar Kasuwa & 8 & $4.00 \pm 0.0000$ \\
\hline
\end{tabular}

Table 3: Organisms Isolated from Tsire Sold in Garko

\begin{tabular}{lcl}
\hline Isolated Organism & Frequency & Percentage (\%) \\
\hline Campylobacter & 2 & 06.66 \\
Escherichia coli & 6 & 20.00 \\
Klebsiella pneumoniae & 2 & 06.66 \\
Salmonella species & 1 & 03.33 \\
Shigella & 3 & 10.00 \\
Staphylococcus aureus & 2 & 06.66 \\
Total & 16 & \\
\hline
\end{tabular}

Table 4: Distribution of Organisms within Sampling Area

\begin{tabular}{lcc}
\hline \multicolumn{1}{c}{ Sampling Area } & No. Isolated & Percentage (\%) \\
\hline Dausai & 4 & 80 \\
Kofar Kudu & 4 & 80 \\
Makwalla & 2 & 40 \\
Rinji & 3 & 60 \\
Tosaro & 2 & 40 \\
Tsohuwar Kasuwa & 1 & 20 \\
Total & 16 & \\
\hline
\end{tabular}

\section{CONCLUSION}

Results indicated $4.00 \times 10^{5} \mathrm{CFU} / \mathrm{g}$ as the highest APCs count; while $68 \mathrm{MPN} / \mathrm{g}$ was the highest TCCs from the 30 samples analyzed. Among the isolates, $E$. coli has the highest isolation rate of $6(20 \%)$. Dausai and Kofar kudu were having the highest bacteria count of $4(80 \%)$, each, indicating higher contamination in those locations. 
BAJOPAS Volume 13 Number 1, June, 2020 RECOMMENDATIONS

The following recommendations are tenable:

1. Hygienic practices at all stages of production should be improved to safe guard the consumers against potential health hazard.

2. Monitoring of microbiological contamination of Tsire during preparations, packaging and marketing is essential to ensure product of good microbiological quality for consumers' health.

\section{REFERENCES}

Abdullahi, I. O., Umoh, V. J. and Galadima, M. (2004). Hazards Associated with Kilishi Preparations in Zaria. Nigerian Journal of Microbiology, 18 (1-2): $339-345$.

Ahmadu, J. and Ibrahim E. J., (2013): Determinants of Revenue in Suya Production in BeninCity, Edo State, Nigeria. Nigerian journal of agriculture, food and environment.9(3):1-5

Amaeze, N. Aboh, M. Itohan, A. Felix, E. Olatunji, T. and Oladosu, P. (2016) Microbial Profile, Antibiotic Sensitivity and Heat Resistance of Bacterial Isolates from Commercial Roasted Beef (Suya) in Abuja, Nigeria. JOPAT, 15(2): $22-30$.

Apata, E.S., Kuku1, I.A., Apata, O.C. and Adeyemi, K.O. (2013). Evaluation of Suya(Tsire) - An Intermediate Moisture Meat Product in Ogun State, Nigeria. J. Food Res 2 (1): 87.

Atlas, R. M. (1997) Principles of Microbiology Second Edition. C. Brown Publishers. Pp 802-803.

Borch, E. Kant-Muermans, M. L., Blixt, Y. (1996) Bacterial Spoilage of Meat and Cured Meat Products. Int $\mathrm{J}$ Food Microbiol .33(1): 103-20.

Centre for Disease Control, CDC (2011). "Escherichia coli 0157:H7" Division of Bacterial and Mycotic Diseasesht://www.cdc.gov/nczved/divisi ons/dfbmd/diseases/ecoli_0157h7/.

Charlene, R. J., Johnnie, A. D., and John, B. B., (2013) Prevalence and Characterization of Methicillin-Resistant Staphylococcus aureus Isolates from Retail Meat and Humans in Georgia. American society for Microbiology. J. of clinical microbiology. 12(1):123-6 doi:10.1128/JCM.0316612JCM.03166-12

Egbebi, A.O and Seidu, K., T. (2011). Microbiological Evaluation of Suya (dried smoked

meat) Sold in Ado and Akure, South West Nigeria.European Journal of Experinmental Biology, 1(4):1-5
3. Government should establish regulatory bodies responsible for inculcating hygiene habits to the local producers and vendors in order to prevent instant, cross and post processing contaminations by microbial pathogens.

4. Awareness and sensitization of local food producers about good hygienic practices in food handling and processing.

Falegan, C, R., Akoja, S. D., and Oyarekua, M. A., (2017) Microbiological Assessment of Suya (Sliced Roasted Beef) in Ado-Ekiti Metropolis, Ekiti State, Nigeria. MOJ Biology andMedicine.

Fonkem, D., N. Tanya, V., N. and Ebangi, A., L. (2010). Effect of Season on the Microbiological Quality of Kilishi, a Traditional Cameroonian Dried Beef Product. Tropicultura, 28(1): 10-15.

Food and Agricultural Organization of the United Nations (F A O, 1979). Manual of food quality control 4. Microbiological analysis.

Food and Agriculture Organisation of the United Nation (FAO), 2019. Nigeria at a glance.

Igene J.O., Uwadia, O.E., Ebabhamiegbebho, P.A. and Evivie, S.E., (2016) Shelf life Stability Studies of University of Benin (UNIBEN) Proff's Kilishi Product Asian Journal of Science and Technology 7(1): 2268-2274.

Inusa, S. K. and Said, I. S. (2017) Evaluation of the Chemical and Microbiological Properties Of Kilishi Sold in Kano Metropolis. Journal of Dry land Agriculture, 3 (1): $59-69$.

Lucretia, I. B, Patience, C. Obinna-Echem, Sophia, C. A. (2018) Microbiological quality andantibiotic sensitivity of potential pathogens isolated from meat product (Suya) sold in Rivers State University and its environs. International Journal of Biotechnology and Food Science, 6(4): 67-76.

Matthew, E., Drosos, E., John, L. and Ioanna, P. (2013) MRSA in Africa: Filling the Global Map of Antimicrobial Resistance PLOS One. 8(7): e68024 doi: 10.1371/journal.pone.0068024

Mgbemere, V.N., Akpapunam, M. A. and Igene, J. O., (2011). Effect of Groundnut FlourSubstitution on Yield, Quality and Storage Stability of Kilishi - a Nigerian Indigenous Dried Meat Product. African Journal of Food, Agriculture, Nutrition and Development, $\quad \mathbf{1 1}(2)$ : 4718-4738. 
BAJOPAS Volume 13 Number 1, June, 2020

Mubarak, A. A., Azeez, M. L., Amos A. O., Opeyemi, O. O. (2016) Assessment of Animal Protein Consumption and Food Security Among Rural Households in Kwara State, Nigeria American Journal of Business and Society, 1(4): 233245.

Ndahi, M., D. Kwaga, J., K. P. Bello, M. Kabir J., V. Umoh, .J. Yakubu, S., E. and Nok, A., J. (2013) Prevalence and Antimicrobial Susceptibility of Listeria Monocytogenes and Methicillin-Resistant Staphylococcus aureus Strains from Raw Meat and Meat Products in Zaria, Nigeria. Applied Journal of Microbiology, 58(3):262-9.

Okonko, I.O., Odu, N.N. and Igboh, I.E. (2013). Microbiological Analysis of Kilishi Sold In Port Harcourt, Nigeria. New York Science Journal, 6 (7):37-43.

Osimani, A., Aquilanti, L. and Clementi, F. (2015) Microbiological Quality of Meatbased Meals and Operation of Control Systems within a Food Service Environment. International Food Research Journal 22(4): 1692-1698.

Onuorah, S. Obika, I. Odibo, F. Orji, M. (2015)An Assessment of the Bacteriological Quality of Tsire-Suya (Grilled Beef) sold in Awka, Nigeria. American. J. Life. Sci. Res. 3(4):287292.

Razavilar, V, Khandaghi, J. Barzgari, A. (2010); Isolation of Eschericia coli 0157:H7 from manure fertilized farms and raw vegetables grown on it, in Tabriz city in
Iran. African Journal of Microbiology Research, 4(9): 891-895.

Scallan, E. Hoekstra, R. M. Angulo, F. J.Tauxe, R. V, Widdowson, M. Roy, S. L et al., (2011).Food borne illness acquired in the United States- Major Pathogens. Emerg. Infec Dis, 17(1): 7-15.

Shamsuddeen U (2009). Microbiological quality of spice used in the production of Kilishi a traditionally dried and grilled meat product. Bayero Journal of Pure andApplied Sciences, 2(2): 66-69.

Shamsuddeen, U. (2015) Microbiological Hazard and Critical control point Analysis of Dried and Minced Meat Snacks Produced in Kano Nigeria. Lambert Academic Publishing; Pp 1-36.

Tijani, O.and Jumare, S. (2014). Microblological Quality Assessment of Meat

Sold in KauraNamoda. International Conference on Earth, Environment and Life sciences (EELS) Dubai (UAE).

Udobi, C. E., Obajuluwa, A. F., and Onaolapo, J. A., (2013) Prevalence and Antibiotic Resistance Pattern of MethicillinResistant Staphylococcus aureus from an Orthopaedic Hospital in Nigeria BioMed Research International; 26(6); 6-7.

WHO, 2015 Foodborne diseases in the WHO African Region.

Yousafzai HA, Rind R, Khan MA, Abro SH, Korejo NA, Ejaz M, Kabir A, Shahid M, Memon S. (2019). Microbiological Contamination of Cattle and Meat in Peshawar, Pakistan. J. Anim. Health Prod. 7(1): 1116. 


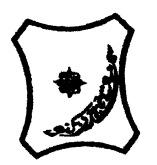

Bayero Journal of Pure and Applied Sciences, 13(1); 40 - 45

Received: September, 2019

Accepted: April, 2020

ISSN $2006-6996$

\title{
BACTERIOLOGICAL QUALITY OF STICK MEAT (Tsire) SOLD IN GARKO LOCAL GOVERNMENT AREA OF KANO STATE, NIGERIA
}

\author{
$*^{1}$ Dahiru A. T. and ${ }^{2}$ Maigari A. K. \\ ${ }^{1}$ Department of Hospitality Management, School of Technology, Kano State Polytechnic, PMB 3348, \\ Kano Nigeria. \\ ${ }^{2}$ Departmnt of Biological Sciences, Bayero University, Kano \\ Corresponding Author: dturajo61@gmail.com; GSM: 08087508262.
}

ABSTRACT

Stick meat, locally called Tsire in Hausa Language, is a significant portion of the diet of a large active population of Northern Nigeria. However, because of the handling and processing methods by the manufacturers as well as the hawking system of stick meat, the meat product may be exposed to both pre- and post-processed product contamination, and thus may poses danger to public health. Therefore, considering the role of Tsire in improving nutrition and increase household income to the populace, the need to improve the processing, distribution and overall quality of the product is simply indispensable. A total of 30 samples (5 samples from each of the 6 sampling points) of Tsire were collected randomly in Garko Town. Aerobic plate counts (APCs) and Total coliform counts (TCCS) of Tsire samples were determined using standard microbiological methods. APCs ranged from $1.02 \times 10^{5}$ to $4.00 \times 10^{5} \mathrm{CFU} / \mathrm{g}$; while TCCs ranged from $8 \mathrm{MPN} / \mathrm{g}$ to $68 \mathrm{MPN} / \mathrm{g}$. From the 30 samples screened, 16(53.33\%) bacteria namely, Campylobacter 2(6.66\%), Escherichia coli 6(20\%), Klebsiella pneumoniae 2(6.66\%), Salmonella spp. 1(3.33\%), Shigella 3(10\%) and Staphylococcus aureus 2(6.66\%) were detected. $E$. coli has the highest isolation rate of 6(20\%), while Salmonella spp. had the least frequency of 1(3.33\%). The distribution of isolated organisms within the study area were as follows: Dausai, 4(80\%), Kofar kudu, 4(80\%), Makwalla, 2(40\%), Rinji, 3(60\%), Tosaro, 2(40\%), and Tsohuwar Kasuwa, 1(20\%). The results have indicated that the Tsire was contaminated with bacteria thus exposing the product to fast deterioration, spoilage and also a vehicle for food borne illness, suggesting for adequate hygienic practices at all the stages, prior to consumption, to ensure safety of the meat product.

Key words: APCs, TCCs, Contamination, Microorganisms, Garko

\section{INTRODUCTION}

Nigeria is one of the developing nations with inadequate food supply and most often deficient in protein content (FAO, 2019). Nigerian's average animal protein intake per head per day is estimated at $7.9 \mathrm{~g}$ as against $35 \mathrm{~g}$ recommended value by Food and Agricultural Organization (Mubarak et al., 2016). These low levels of animal protein intake create great concern as it affects the nutritional status of Nigerians. Hence, there is the need for sufficient supply of animal protein from energy rich animal products to satisfy the nutritional requirements for Nigerians.

Meat is one major source of animal protein largely composed of water, protein and fats which can make it susceptible to microbial contamination within short time leading to spoilage (Apata et al., 2013; Mgbemere et al., 2011). Meat is mostly eaten after it has been cooked or processed in a variety of ways such as sun drying; smoking and roasting with or without fortifications (Borch et al., 1996). In Nigeria meat products such as Tsire, Kilishi and Balangu are locally produced using one or more of these methods in order to meet the nutritional requirements of the teeming Nigerians (Egbebi, 2011).

Tsire is a popular Nigerian traditional processed ready-to-eat roasted stick meat product (Shamsuddeen, 2015). It is sold in public places, along roads, in hotels, parks, quarters and even offices (Falegan et al., 2017). It is prepared from boneless healthy animal flesh such as beef and mutton, spiced with peanut cake, salt, vegetable oil and other flavorings followed by roasting (Shamsuddeen, 2015). Consumption of these products has extended to other parts of African countries such as Ghana, Somali, Cameroun and Chad (Ahmadu and Ibrahim, 2013). 
BAJOPAS Volume 13 Number 1, June, 2020

However, evidence of quality control sticking to procedural hygiene by the handlers during preparation and retailing of these products is poorly documented. Tsire is of great safety risk because of the fact that there are erratic cases of gastroenteritis and symptoms of food infection after consumption (WHO, 2015). Food borne illnesses are one of the major health problems in developing and developed countries (Razavilar, 2010). According to the World Health Organization, WHO (2015), $0.07 \%$ death of the 600 million global burdens of Foodborne illnesses have been reported to be caused by bacteria, viruses, fungi and chemicals. In America $0.27 \%$ of the estimated 48 million affected people is hospitalized and about $0.0063 \%$ deaths are recorded each year (Scallan et al., 2011). More than 91 million people in Africa fall ill and $0.15 \%$ dies each year, making Africa the highest burden bearer of Foodborne diseases per population (WHO, 2015).

Application of a Hazard Analysis Critical Control Point (HACCP) at all stages of meat products preparation is essential in order to ensure its safety. Thus, according to the guidelines of good manufacturing practice, the level of total aerobic bacterial contamination of thermally processed meat products should not exceed $10^{4}\left(\mathrm{cfu} \mathrm{g}^{-1}\right)$. Enterobacteriaceae and faecal coliform contamination in meat products should be within the range of $10^{2}-10^{4}$ and $10-10^{3} \mathrm{cfu} \mathrm{g}^{-1}$, respectively (Shamsuddeen, 2015). The aim of the study is therefore, to assess the total viable bacterial counts of tsire marketed locally within Garko town, and to isolate and identify the organisms at the point of consumption with the intention of promoting public health and food hygiene habits in the Nigerian populace.

\section{MATERIALS AND METHODS Study Area and Population}

Garko is one of the existing 44 local government areas located in Kano south west zone of Kano state with its capital administrative headquarters in the Garko town. It has coordinates $11^{\circ} 39^{\prime} \mathrm{N}$ $8^{\circ} 54^{\prime} \mathrm{E}$, and an area of $450 \mathrm{~km}^{2}$. The projected population of Garko local Government was 225,300 according to the National Population Census report (2018). Garko is known for agricultural activities both farming and animal husbandry. It is popularly known for large scale rice production. Other food crops include sweet potatoes, cassava, onions, sorghum, millet and sugarcane. Cows, sheep and goats are major groups of animals reared by majority of the populace. Meat products processed, retailed and consumed in Garko include roasted meat (Balangu), dried roasted meat (Kilishi), stick meat (Tsire), hide and skin pepper soup (Ragadada) and minced fried meat (Danbunnama).

\section{Samples Collection}

Five samples of Tsire products were collected from 6 different identified locations within Garko town in a sterile foil paper and immediately analyzed for the presence of bacteria.

\section{Sample Preparation}

Sample preparation for the bacteriological analysis was carried out in accordance with the method described by Atlas (1997). Twenty five grams $(25 \mathrm{~g})$ of the sample was homogenized in $225 \mathrm{ml}$ peptone water using Kenwood blender machine to obtain a $10^{1}$ homogenate. The homogenate was thoroughly shaken and $1 \mathrm{ml}$ pipetted into test tubes containing $9 \mathrm{ml}$ of peptone water $\left(10^{2}\right)$. The test tubes were further serially diluted to $10^{5}$.

Total Aerobic Mesophilic Bacterial Count

Total Aerobic mesophilic bacterial count was determined using the method described by Abdullahi et al. (2004) where $1 \mathrm{ml}$ of inoculums from $10^{1}$ to $10^{5}$ dilutions were transferred into duplicate Petri dishes and labeled accordingly. This was followed by pouring aseptically about $15 \mathrm{ml}$ of molten nutrient agar. The culture was homogenized by gentle spinning of the plates and allowed to solidify. The plates were incubated at $37^{\circ} \mathrm{C}$ for 24 hours. Plates containing 30-300 colonies were counted. The number of colony forming units per gram of a sample (cfu/g) was obtained by multiplying the average colony number with the inverse of the dilution factor.

\section{Enumeration and Detection of Coliform bacteria}

Detection and enumeration of coliform was carried out according to method described by Atlas, (1977). A set of 9 test tubes each containing $9 \mathrm{ml}$ of lactose broth and an inverted Durham tubes were autoclaved to expel air and to sterilize. Similarly, $1 \mathrm{ml}$ from the diluents $10^{1}$ was transferred to the first 3 test tubes, followed by $1 \mathrm{ml}$ from the diluents $10^{2}$ to the second set of 3 test tubes and finally the third diluents $10^{3}$ to the $3^{\text {rd }}$ set of 3 test tubes. All the 9 test tubes were incubated at $37^{\circ} \mathrm{C}$ for 24 hours. Tubes that showed gas and acid production after 24 hours were recorded as positive for the presence of Coliform. Negative tubes were further reincubated for 24 hours. Positive tubes were recorded. Estimate of most probable number of Coliform per gram of sample (MPN/g) was determined by comparing the number of gas positive tubes with the most probable number table. 
BAJOPAS Volume 13 Number 1, June, 2020 Identification of Coliform

A loop full of inoculum from gas positive tubes was streaked on to Eosine methylene blue (EMB) agar plate and incubated at $37^{\circ} \mathrm{C}$ for $24 \mathrm{hrs}$. Colonies which formed bluish black color with green metallic sheen, and reddish colonies were isolated on agar slants. Those colonies showing metallic sheen on EMB were sub cultured into tubes of lactose broth and incubated at $45^{\circ} \mathrm{C}$. The tubes were observed after $24 \mathrm{hrs}$ for gas production. This is the completed test for fecal coliform. Gram stain and other biochemical tests such as Indole, Methyl red, Voges-Proskauer and Citrate Utilization tests (IMVIC), Coagulase and Catalase tests were carried out for the Identification and confirmation of isolates.

\section{Procedure for Indole Test}

Indole test was carried out by preparing a Tryptone broth drawn in to test tubes, sterilized by autoclaving, inoculated with loopful of suspension and incubated at $37^{\circ} \mathrm{C}$ for 24 hours. Three drops of xylene was added in tubes, shaken vigorously and kept for the separation of two layers. One millilitre of Kovac's reagent was added and the formation of pink colour ring indicates positive Indole test.

\section{Procedure for Methyl Red Test}

Methyl red test was carried out by preparing Glucose phosphate broth, dispensed in test tubes, sterilized, inoculated with test culture and incubated at $37^{\circ} \mathrm{C}$ for 24 hours. Five drops of methyl-red indicator was added to the medium for the formation of red colour.

\section{Procedure for Voges-Proskauer Test}

Voges-Proskauer test was carried out by inoculating tubes with the bacterial culture followed by incubation for 48 hours at $37^{\circ} \mathrm{C}$. Separate pipettes were used to pipette $1 \mathrm{ml}$ from each culture tube into clean separate tubes. Eighteen drops $(0.5 \mathrm{ml})$ of Barrit's solution A (a-naphthol) was added to each tube containing glucose phosphate broth followed by the addition of an equal amount of solution $B$ into the same tube. The tubes were shaken at 30 seconds interval. A positive reaction was indicated by the development of a pink color, which turns red in 1-2 hours, after vigorous shaking.

\section{Procedure for Citrate Utilization Test}

Citrate Utilization Test was carried out by distributing melted agar (Simmon Citrate Agar) in to test tubes followed by sterilization at $121.5^{\circ} \mathrm{C}$ for 15 minutes. The test tubes were afterward held in slanted position, inoculated with the given bacterial culture and incubated at $37^{\circ} \mathrm{C}$ for $24 \mathrm{hrs}$. Positive test was indicated by color change of the media from green to blue.

\section{RESULTS AND DISCUSSIONS}

The results of this study are presented in tables $1,2,3$ and 4. Among the sampling areas Kofar Kudu had the highest aerobic mesophilic bacteria counts $4.0 \times 10^{5} \mathrm{cfu} / \mathrm{g}$ followed by Rinji $2.72 \times 10^{5} \mathrm{cfu} / \mathrm{g}$, while Tosaro had the least Aerobic mesophilic bacteria counts of $1.02 \times 10^{5}$ $\mathrm{cfu} / \mathrm{g}$ as indicated in Table 1.Makwalla had the highest coliform count $68 \mathrm{MPN} / \mathrm{g}$ followed by Rinji $37 \mathrm{MPN} / \mathrm{g}$. Tsohuwar Kasuwa had the least coliform counts $8 \mathrm{MPN} / \mathrm{g}$, (Table 2). Result from table 1 shows variation in the microbial contents among the samples which suggest variation in their sources, poor handling procedures and contamination from the processing environment. High coliform count and their differences within sampling areas is an indication of poor microbiological quality of the product. Ndahi et al. (2013) reported microbial load to be a function of the handling personnel and the environment. The results indicated that the samples were contaminated with bacteria as the counts exceeded the minimum safety level $\left(10^{4} \mathrm{cfu} / \mathrm{g}\right)$ for members of the Enterobacteriaceae family. However, it might be a reflection of poor hygienic practices which may contribute to health hazard to the potential consumers. Similarly, Inusa and Sa'id (2017); Osimani et al. (2015) reported that, the initial microbial content of the raw material play significant role in influencing the final microbial load of the finished product. Isolation of members of the Enterobacteriaceae such as $E$. coli, Klebsiella pneumoniae, Salmonella and Shigella signifies danger to the public health. These organisms are capable of producing endotoxins which trigger high fevers in infected individuals, and the enterotoxins which colonize the small intestines and lead to extreme dehydration as a result of vomiting and diarrhea sometimes with severe and fatal outcomes (Amaeze et al., 2016). From the 16 isolated organisms $E$. coli had the highest isolation rate $6(37.5 \%)$ (Table 3), this suggest faecal contamination of the products. $E$. coli is a common flora in the gastrointestinal tract responsible for diarrhea and extra-intestinal infections (CDC, 2011). The result is in conformity with the findings of Ndahi et al. (2013) and Shamsuddeen (2009). Also presence of campylobacter might be due to cross contamination from raw meat to finished product (Tsire). Staphylococcus aureus is a normal flora of the skin, nasal, genital, mouth or anal area in both humans and animals without any symptom of an infection (Matthew et al., 2013). Isolation of $S$. aureus in these study concords with the findings of Lucretia et al. (2018) from Suya sold in Rivers State. 
BAJOPAS Volume 13 Number 1, June, 2020

It is also in agreement with the findings of Yousafzai et al. (2018); Onuorah et al. (2015) and Tijjani and Jumare (2014) from tsire samples in different countries. Presence of $S$. aureus in foods is most of the time an indication of poor human handling, poor environment, unhygienic utensils and equipments used during processing (Igene et al., 2016; Okonko et al., 2013). Infections caused by $S$. aureus are difficult to treat leading to long hospitalization with consequent economic loss (Udobi et al., 2013). These include soft tissue infections, pneumonia, hospital-acquired postoperative wound infections, Staphylococcal food poisoning, impetigo and cellulitis (Charlene et al., 2013). Samples obtained from Dausai and Kofar Kudu had the highest isolation rate $4(80 \%)$ (Table 4 ) probably because of the much commercial activities taking place in the area which can lead to environmental contamination.

Table 1: Total Aerobic Mesophilic Bacterial Count of Tsire sold in Garko Town

\begin{tabular}{lll}
\hline Sampling Area & APC cfu/g & Mean \pm STD \\
\hline Dausai & $2.20 \times 10^{5}$ & $110000 \pm 14142.14$ \\
Kofar Kudu & $4.00 \times 10^{5}$ & $133333.3 \pm 23094.01$ \\
Makwalla & $1.30 \times 10^{5}$ & $32500 \pm 7187.953$ \\
Rinji & $2.72 \times 10^{5}$ & $90666.67 \pm 94769.90$ \\
Tosaro & $1.02 \times 10^{5}$ & $51000 \pm 15556.35$ \\
Tsohuwar Kasuwa & $1.75 \times 10^{5}$ & $35000 \pm 11357.82$ \\
\hline
\end{tabular}

Key: APC: Aerobic Mesophilic Counts

STD: Standard Deviation

Table 2: Total Coliform Count of Tsire sold in Garko Town

\begin{tabular}{lcc}
\hline \multicolumn{1}{c}{ Sampling Area } & TCC MPN/g & Mean \pm STD \\
\hline Dausai & 20 & $6.67 \pm 2.5166$ \\
Kofar Kudu & 32 & $16.00 \pm 5.6569$ \\
Makwalla & 68 & $13.60 \pm 8.7062$ \\
Rinji & 37 & $9.25 \pm 4.7871$ \\
Tosaro & 10 & $5.00 \pm 2.8284$ \\
Tsohuwar Kasuwa & 8 & $4.00 \pm 0.0000$ \\
\hline
\end{tabular}

Table 3: Organisms Isolated from Tsire Sold in Garko

\begin{tabular}{lcl}
\hline Isolated Organism & Frequency & Percentage (\%) \\
\hline Campylobacter & 2 & 06.66 \\
Escherichia coli & 6 & 20.00 \\
Klebsiella pneumoniae & 2 & 06.66 \\
Salmonella species & 1 & 03.33 \\
Shigella & 3 & 10.00 \\
Staphylococcus aureus & 2 & 06.66 \\
Total & 16 & \\
\hline
\end{tabular}

Table 4: Distribution of Organisms within Sampling Area

\begin{tabular}{lcc}
\hline \multicolumn{1}{c}{ Sampling Area } & No. Isolated & Percentage (\%) \\
\hline Dausai & 4 & 80 \\
Kofar Kudu & 4 & 80 \\
Makwalla & 2 & 40 \\
Rinji & 3 & 60 \\
Tosaro & 2 & 40 \\
Tsohuwar Kasuwa & 1 & 20 \\
Total & 16 & \\
\hline
\end{tabular}

\section{CONCLUSION}

Results indicated $4.00 \times 10^{5} \mathrm{CFU} / \mathrm{g}$ as the highest APCs count; while $68 \mathrm{MPN} / \mathrm{g}$ was the highest TCCs from the 30 samples analyzed. Among the isolates, $E$. coli has the highest isolation rate of $6(20 \%)$. Dausai and Kofar kudu were having the highest bacteria count of $4(80 \%)$, each, indicating higher contamination in those locations. 
BAJOPAS Volume 13 Number 1, June, 2020 RECOMMENDATIONS

The following recommendations are tenable:

1. Hygienic practices at all stages of production should be improved to safe guard the consumers against potential health hazard.

2. Monitoring of microbiological contamination of Tsire during preparations, packaging and marketing is essential to ensure product of good microbiological quality for consumers' health.

\section{REFERENCES}

Abdullahi, I. O., Umoh, V. J. and Galadima, M. (2004). Hazards Associated with Kilishi Preparations in Zaria. Nigerian Journal of Microbiology, 18 (1-2): $339-345$.

Ahmadu, J. and Ibrahim E. J., (2013): Determinants of Revenue in Suya Production in BeninCity, Edo State, Nigeria. Nigerian journal of agriculture, food and environment.9(3):1-5

Amaeze, N. Aboh, M. Itohan, A. Felix, E. Olatunji, T. and Oladosu, P. (2016) Microbial Profile, Antibiotic Sensitivity and Heat Resistance of Bacterial Isolates from Commercial Roasted Beef (Suya) in Abuja, Nigeria. JOPAT, 15(2): $22-30$.

Apata, E.S., Kuku1, I.A., Apata, O.C. and Adeyemi, K.O. (2013). Evaluation of Suya(Tsire) - An Intermediate Moisture Meat Product in Ogun State, Nigeria. J. Food Res 2 (1): 87.

Atlas, R. M. (1997) Principles of Microbiology Second Edition. C. Brown Publishers. Pp 802-803.

Borch, E. Kant-Muermans, M. L., Blixt, Y. (1996) Bacterial Spoilage of Meat and Cured Meat Products. Int $\mathrm{J}$ Food Microbiol .33(1): 103-20.

Centre for Disease Control, CDC (2011). "Escherichia coli 0157:H7" Division of Bacterial and Mycotic Diseasesht://www.cdc.gov/nczved/divisi ons/dfbmd/diseases/ecoli_0157h7/.

Charlene, R. J., Johnnie, A. D., and John, B. B., (2013) Prevalence and Characterization of Methicillin-Resistant Staphylococcus aureus Isolates from Retail Meat and Humans in Georgia. American society for Microbiology. J. of clinical microbiology. 12(1):123-6 doi:10.1128/JCM.0316612JCM.03166-12

Egbebi, A.O and Seidu, K., T. (2011). Microbiological Evaluation of Suya (dried smoked

meat) Sold in Ado and Akure, South West Nigeria.European Journal of Experinmental Biology, 1(4):1-5
3. Government should establish regulatory bodies responsible for inculcating hygiene habits to the local producers and vendors in order to prevent instant, cross and post processing contaminations by microbial pathogens.

4. Awareness and sensitization of local food producers about good hygienic practices in food handling and processing.

Falegan, C, R., Akoja, S. D., and Oyarekua, M. A., (2017) Microbiological Assessment of Suya (Sliced Roasted Beef) in Ado-Ekiti Metropolis, Ekiti State, Nigeria. MOJ Biology andMedicine.

Fonkem, D., N. Tanya, V., N. and Ebangi, A., L. (2010). Effect of Season on the Microbiological Quality of Kilishi, a Traditional Cameroonian Dried Beef Product. Tropicultura, 28(1): 10-15.

Food and Agricultural Organization of the United Nations (F A O, 1979). Manual of food quality control 4. Microbiological analysis.

Food and Agriculture Organisation of the United Nation (FAO), 2019. Nigeria at a glance.

Igene J.O., Uwadia, O.E., Ebabhamiegbebho, P.A. and Evivie, S.E., (2016) Shelf life Stability Studies of University of Benin (UNIBEN) Proff's Kilishi Product Asian Journal of Science and Technology 7(1): 2268-2274.

Inusa, S. K. and Said, I. S. (2017) Evaluation of the Chemical and Microbiological Properties Of Kilishi Sold in Kano Metropolis. Journal of Dry land Agriculture, 3 (1): $59-69$.

Lucretia, I. B, Patience, C. Obinna-Echem, Sophia, C. A. (2018) Microbiological quality andantibiotic sensitivity of potential pathogens isolated from meat product (Suya) sold in Rivers State University and its environs. International Journal of Biotechnology and Food Science, 6(4): 67-76.

Matthew, E., Drosos, E., John, L. and Ioanna, P. (2013) MRSA in Africa: Filling the Global Map of Antimicrobial Resistance PLOS One. 8(7): e68024 doi: 10.1371/journal.pone.0068024

Mgbemere, V.N., Akpapunam, M. A. and Igene, J. O., (2011). Effect of Groundnut FlourSubstitution on Yield, Quality and Storage Stability of Kilishi - a Nigerian Indigenous Dried Meat Product. African Journal of Food, Agriculture, Nutrition and Development, $\quad \mathbf{1 1}(2)$ : 4718-4738. 
BAJOPAS Volume 13 Number 1, June, 2020

Mubarak, A. A., Azeez, M. L., Amos A. O., Opeyemi, O. O. (2016) Assessment of Animal Protein Consumption and Food Security Among Rural Households in Kwara State, Nigeria American Journal of Business and Society, 1(4): 233245.

Ndahi, M., D. Kwaga, J., K. P. Bello, M. Kabir J., V. Umoh, .J. Yakubu, S., E. and Nok, A., J. (2013) Prevalence and Antimicrobial Susceptibility of Listeria Monocytogenes and Methicillin-Resistant Staphylococcus aureus Strains from Raw Meat and Meat Products in Zaria, Nigeria. Applied Journal of Microbiology, 58(3):262-9.

Okonko, I.O., Odu, N.N. and Igboh, I.E. (2013). Microbiological Analysis of Kilishi Sold In Port Harcourt, Nigeria. New York Science Journal, 6 (7):37-43.

Osimani, A., Aquilanti, L. and Clementi, F. (2015) Microbiological Quality of Meatbased Meals and Operation of Control Systems within a Food Service Environment. International Food Research Journal 22(4): 1692-1698.

Onuorah, S. Obika, I. Odibo, F. Orji, M. (2015)An Assessment of the Bacteriological Quality of Tsire-Suya (Grilled Beef) sold in Awka, Nigeria. American. J. Life. Sci. Res. 3(4):287292.

Razavilar, V, Khandaghi, J. Barzgari, A. (2010); Isolation of Eschericia coli 0157:H7 from manure fertilized farms and raw vegetables grown on it, in Tabriz city in
Iran. African Journal of Microbiology Research, 4(9): 891-895.

Scallan, E. Hoekstra, R. M. Angulo, F. J.Tauxe, R. V, Widdowson, M. Roy, S. L et al., (2011).Food borne illness acquired in the United States- Major Pathogens. Emerg. Infec Dis, 17(1): 7-15.

Shamsuddeen U (2009). Microbiological quality of spice used in the production of Kilishi a traditionally dried and grilled meat product. Bayero Journal of Pure andApplied Sciences, 2(2): 66-69.

Shamsuddeen, U. (2015) Microbiological Hazard and Critical control point Analysis of Dried and Minced Meat Snacks Produced in Kano Nigeria. Lambert Academic Publishing; Pp 1-36.

Tijani, O.and Jumare, S. (2014). Microblological Quality Assessment of Meat

Sold in KauraNamoda. International Conference on Earth, Environment and Life sciences (EELS) Dubai (UAE).

Udobi, C. E., Obajuluwa, A. F., and Onaolapo, J. A., (2013) Prevalence and Antibiotic Resistance Pattern of MethicillinResistant Staphylococcus aureus from an Orthopaedic Hospital in Nigeria BioMed Research International; 26(6); 6-7.

WHO, 2015 Foodborne diseases in the WHO African Region.

Yousafzai HA, Rind R, Khan MA, Abro SH, Korejo NA, Ejaz M, Kabir A, Shahid M, Memon S. (2019). Microbiological Contamination of Cattle and Meat in Peshawar, Pakistan. J. Anim. Health Prod. 7(1): 1116. 


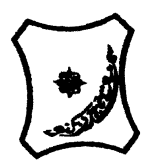

Bayero Journal of Pure and Applied Sciences, 13(1); 40 - 45

Received: September, 2019

Accepted: April, 2020

ISSN $2006-6996$

\title{
BACTERIOLOGICAL QUALITY OF STICK MEAT (Tsire) SOLD IN GARKO LOCAL GOVERNMENT AREA OF KANO STATE, NIGERIA
}

\author{
$*^{1}$ Dahiru A. T. and ${ }^{2}$ Maigari A. K. \\ ${ }^{1}$ Department of Hospitality Management, School of Technology, Kano State Polytechnic, PMB 3348, \\ Kano Nigeria. \\ ${ }^{2}$ Departmnt of Biological Sciences, Bayero University, Kano \\ Corresponding Author: dturajo61@gmail.com; GSM: 08087508262.
}

ABSTRACT

Stick meat, locally called Tsire in Hausa Language, is a significant portion of the diet of a large active population of Northern Nigeria. However, because of the handling and processing methods by the manufacturers as well as the hawking system of stick meat, the meat product may be exposed to both pre- and post-processed product contamination, and thus may poses danger to public health. Therefore, considering the role of Tsire in improving nutrition and increase household income to the populace, the need to improve the processing, distribution and overall quality of the product is simply indispensable. A total of 30 samples (5 samples from each of the 6 sampling points) of Tsire were collected randomly in Garko Town. Aerobic plate counts (APCs) and Total coliform counts (TCCS) of Tsire samples were determined using standard microbiological methods. APCs ranged from $1.02 \times 10^{5}$ to $4.00 \times 10^{5} \mathrm{CFU} / \mathrm{g}$; while TCCs ranged from $8 \mathrm{MPN} / \mathrm{g}$ to $68 \mathrm{MPN} / \mathrm{g}$. From the 30 samples screened, 16(53.33\%) bacteria namely, Campylobacter 2(6.66\%), Escherichia coli 6(20\%), Klebsiella pneumoniae 2(6.66\%), Salmonella spp. 1(3.33\%), Shigella 3(10\%) and Staphylococcus aureus 2(6.66\%) were detected. $E$. coli has the highest isolation rate of 6(20\%), while Salmonella spp. had the least frequency of 1(3.33\%). The distribution of isolated organisms within the study area were as follows: Dausai, 4(80\%), Kofar kudu, 4(80\%), Makwalla, 2(40\%), Rinji, 3(60\%), Tosaro, 2(40\%), and Tsohuwar Kasuwa, 1(20\%). The results have indicated that the Tsire was contaminated with bacteria thus exposing the product to fast deterioration, spoilage and also a vehicle for food borne illness, suggesting for adequate hygienic practices at all the stages, prior to consumption, to ensure safety of the meat product.

Key words: APCs, TCCs, Contamination, Microorganisms, Garko

\section{INTRODUCTION}

Nigeria is one of the developing nations with inadequate food supply and most often deficient in protein content (FAO, 2019). Nigerian's average animal protein intake per head per day is estimated at $7.9 \mathrm{~g}$ as against $35 \mathrm{~g}$ recommended value by Food and Agricultural Organization (Mubarak et al., 2016). These low levels of animal protein intake create great concern as it affects the nutritional status of Nigerians. Hence, there is the need for sufficient supply of animal protein from energy rich animal products to satisfy the nutritional requirements for Nigerians.

Meat is one major source of animal protein largely composed of water, protein and fats which can make it susceptible to microbial contamination within short time leading to spoilage (Apata et al., 2013; Mgbemere et al., 2011). Meat is mostly eaten after it has been cooked or processed in a variety of ways such as sun drying; smoking and roasting with or without fortifications (Borch et al., 1996). In Nigeria meat products such as Tsire, Kilishi and Balangu are locally produced using one or more of these methods in order to meet the nutritional requirements of the teeming Nigerians (Egbebi, 2011).

Tsire is a popular Nigerian traditional processed ready-to-eat roasted stick meat product (Shamsuddeen, 2015). It is sold in public places, along roads, in hotels, parks, quarters and even offices (Falegan et al., 2017). It is prepared from boneless healthy animal flesh such as beef and mutton, spiced with peanut cake, salt, vegetable oil and other flavorings followed by roasting (Shamsuddeen, 2015). Consumption of these products has extended to other parts of African countries such as Ghana, Somali, Cameroun and Chad (Ahmadu and Ibrahim, 2013). 
BAJOPAS Volume 13 Number 1, June, 2020

However, evidence of quality control sticking to procedural hygiene by the handlers during preparation and retailing of these products is poorly documented. Tsire is of great safety risk because of the fact that there are erratic cases of gastroenteritis and symptoms of food infection after consumption (WHO, 2015). Food borne illnesses are one of the major health problems in developing and developed countries (Razavilar, 2010). According to the World Health Organization, WHO (2015), $0.07 \%$ death of the 600 million global burdens of Foodborne illnesses have been reported to be caused by bacteria, viruses, fungi and chemicals. In America $0.27 \%$ of the estimated 48 million affected people is hospitalized and about $0.0063 \%$ deaths are recorded each year (Scallan et al., 2011). More than 91 million people in Africa fall ill and $0.15 \%$ dies each year, making Africa the highest burden bearer of Foodborne diseases per population (WHO, 2015).

Application of a Hazard Analysis Critical Control Point (HACCP) at all stages of meat products preparation is essential in order to ensure its safety. Thus, according to the guidelines of good manufacturing practice, the level of total aerobic bacterial contamination of thermally processed meat products should not exceed $10^{4}\left(\mathrm{cfu} \mathrm{g}^{-1}\right)$. Enterobacteriaceae and faecal coliform contamination in meat products should be within the range of $10^{2}-10^{4}$ and $10-10^{3} \mathrm{cfu} \mathrm{g}^{-1}$, respectively (Shamsuddeen, 2015). The aim of the study is therefore, to assess the total viable bacterial counts of tsire marketed locally within Garko town, and to isolate and identify the organisms at the point of consumption with the intention of promoting public health and food hygiene habits in the Nigerian populace.

\section{MATERIALS AND METHODS Study Area and Population}

Garko is one of the existing 44 local government areas located in Kano south west zone of Kano state with its capital administrative headquarters in the Garko town. It has coordinates $11^{\circ} 39^{\prime} \mathrm{N}$ $8^{\circ} 54^{\prime} \mathrm{E}$, and an area of $450 \mathrm{~km}^{2}$. The projected population of Garko local Government was 225,300 according to the National Population Census report (2018). Garko is known for agricultural activities both farming and animal husbandry. It is popularly known for large scale rice production. Other food crops include sweet potatoes, cassava, onions, sorghum, millet and sugarcane. Cows, sheep and goats are major groups of animals reared by majority of the populace. Meat products processed, retailed and consumed in Garko include roasted meat (Balangu), dried roasted meat (Kilishi), stick meat (Tsire), hide and skin pepper soup (Ragadada) and minced fried meat (Danbunnama).

\section{Samples Collection}

Five samples of Tsire products were collected from 6 different identified locations within Garko town in a sterile foil paper and immediately analyzed for the presence of bacteria.

\section{Sample Preparation}

Sample preparation for the bacteriological analysis was carried out in accordance with the method described by Atlas (1997). Twenty five grams $(25 \mathrm{~g})$ of the sample was homogenized in $225 \mathrm{ml}$ peptone water using Kenwood blender machine to obtain a $10^{1}$ homogenate. The homogenate was thoroughly shaken and $1 \mathrm{ml}$ pipetted into test tubes containing $9 \mathrm{ml}$ of peptone water $\left(10^{2}\right)$. The test tubes were further serially diluted to $10^{5}$.

Total Aerobic Mesophilic Bacterial Count

Total Aerobic mesophilic bacterial count was determined using the method described by Abdullahi et al. (2004) where $1 \mathrm{ml}$ of inoculums from $10^{1}$ to $10^{5}$ dilutions were transferred into duplicate Petri dishes and labeled accordingly. This was followed by pouring aseptically about $15 \mathrm{ml}$ of molten nutrient agar. The culture was homogenized by gentle spinning of the plates and allowed to solidify. The plates were incubated at $37^{\circ} \mathrm{C}$ for 24 hours. Plates containing 30-300 colonies were counted. The number of colony forming units per gram of a sample (cfu/g) was obtained by multiplying the average colony number with the inverse of the dilution factor.

\section{Enumeration and Detection of Coliform bacteria}

Detection and enumeration of coliform was carried out according to method described by Atlas, (1977). A set of 9 test tubes each containing $9 \mathrm{ml}$ of lactose broth and an inverted Durham tubes were autoclaved to expel air and to sterilize. Similarly, $1 \mathrm{ml}$ from the diluents $10^{1}$ was transferred to the first 3 test tubes, followed by $1 \mathrm{ml}$ from the diluents $10^{2}$ to the second set of 3 test tubes and finally the third diluents $10^{3}$ to the $3^{\text {rd }}$ set of 3 test tubes. All the 9 test tubes were incubated at $37^{\circ} \mathrm{C}$ for 24 hours. Tubes that showed gas and acid production after 24 hours were recorded as positive for the presence of Coliform. Negative tubes were further reincubated for 24 hours. Positive tubes were recorded. Estimate of most probable number of Coliform per gram of sample (MPN/g) was determined by comparing the number of gas positive tubes with the most probable number table. 
BAJOPAS Volume 13 Number 1, June, 2020 Identification of Coliform

A loop full of inoculum from gas positive tubes was streaked on to Eosine methylene blue (EMB) agar plate and incubated at $37^{\circ} \mathrm{C}$ for $24 \mathrm{hrs}$. Colonies which formed bluish black color with green metallic sheen, and reddish colonies were isolated on agar slants. Those colonies showing metallic sheen on EMB were sub cultured into tubes of lactose broth and incubated at $45^{\circ} \mathrm{C}$. The tubes were observed after $24 \mathrm{hrs}$ for gas production. This is the completed test for fecal coliform. Gram stain and other biochemical tests such as Indole, Methyl red, Voges-Proskauer and Citrate Utilization tests (IMVIC), Coagulase and Catalase tests were carried out for the Identification and confirmation of isolates.

\section{Procedure for Indole Test}

Indole test was carried out by preparing a Tryptone broth drawn in to test tubes, sterilized by autoclaving, inoculated with loopful of suspension and incubated at $37^{\circ} \mathrm{C}$ for 24 hours. Three drops of xylene was added in tubes, shaken vigorously and kept for the separation of two layers. One millilitre of Kovac's reagent was added and the formation of pink colour ring indicates positive Indole test.

\section{Procedure for Methyl Red Test}

Methyl red test was carried out by preparing Glucose phosphate broth, dispensed in test tubes, sterilized, inoculated with test culture and incubated at $37^{\circ} \mathrm{C}$ for 24 hours. Five drops of methyl-red indicator was added to the medium for the formation of red colour.

\section{Procedure for Voges-Proskauer Test}

Voges-Proskauer test was carried out by inoculating tubes with the bacterial culture followed by incubation for 48 hours at $37^{\circ} \mathrm{C}$. Separate pipettes were used to pipette $1 \mathrm{ml}$ from each culture tube into clean separate tubes. Eighteen drops $(0.5 \mathrm{ml})$ of Barrit's solution A (a-naphthol) was added to each tube containing glucose phosphate broth followed by the addition of an equal amount of solution $B$ into the same tube. The tubes were shaken at 30 seconds interval. A positive reaction was indicated by the development of a pink color, which turns red in 1-2 hours, after vigorous shaking.

\section{Procedure for Citrate Utilization Test}

Citrate Utilization Test was carried out by distributing melted agar (Simmon Citrate Agar) in to test tubes followed by sterilization at $121.5^{\circ} \mathrm{C}$ for 15 minutes. The test tubes were afterward held in slanted position, inoculated with the given bacterial culture and incubated at $37^{\circ} \mathrm{C}$ for $24 \mathrm{hrs}$. Positive test was indicated by color change of the media from green to blue.

\section{RESULTS AND DISCUSSIONS}

The results of this study are presented in tables $1,2,3$ and 4. Among the sampling areas Kofar Kudu had the highest aerobic mesophilic bacteria counts $4.0 \times 10^{5} \mathrm{cfu} / \mathrm{g}$ followed by Rinji $2.72 \times 10^{5} \mathrm{cfu} / \mathrm{g}$, while Tosaro had the least Aerobic mesophilic bacteria counts of $1.02 \times 10^{5}$ $\mathrm{cfu} / \mathrm{g}$ as indicated in Table 1.Makwalla had the highest coliform count $68 \mathrm{MPN} / \mathrm{g}$ followed by Rinji $37 \mathrm{MPN} / \mathrm{g}$. Tsohuwar Kasuwa had the least coliform counts $8 \mathrm{MPN} / \mathrm{g}$, (Table 2). Result from table 1 shows variation in the microbial contents among the samples which suggest variation in their sources, poor handling procedures and contamination from the processing environment. High coliform count and their differences within sampling areas is an indication of poor microbiological quality of the product. Ndahi et al. (2013) reported microbial load to be a function of the handling personnel and the environment. The results indicated that the samples were contaminated with bacteria as the counts exceeded the minimum safety level $\left(10^{4} \mathrm{cfu} / \mathrm{g}\right)$ for members of the Enterobacteriaceae family. However, it might be a reflection of poor hygienic practices which may contribute to health hazard to the potential consumers. Similarly, Inusa and Sa'id (2017); Osimani et al. (2015) reported that, the initial microbial content of the raw material play significant role in influencing the final microbial load of the finished product. Isolation of members of the Enterobacteriaceae such as $E$. coli, Klebsiella pneumoniae, Salmonella and Shigella signifies danger to the public health. These organisms are capable of producing endotoxins which trigger high fevers in infected individuals, and the enterotoxins which colonize the small intestines and lead to extreme dehydration as a result of vomiting and diarrhea sometimes with severe and fatal outcomes (Amaeze et al., 2016). From the 16 isolated organisms $E$. coli had the highest isolation rate $6(37.5 \%)$ (Table 3), this suggest faecal contamination of the products. $E$. coli is a common flora in the gastrointestinal tract responsible for diarrhea and extra-intestinal infections (CDC, 2011). The result is in conformity with the findings of Ndahi et al. (2013) and Shamsuddeen (2009). Also presence of campylobacter might be due to cross contamination from raw meat to finished product (Tsire). Staphylococcus aureus is a normal flora of the skin, nasal, genital, mouth or anal area in both humans and animals without any symptom of an infection (Matthew et al., 2013). Isolation of $S$. aureus in these study concords with the findings of Lucretia et al. (2018) from Suya sold in Rivers State. 
BAJOPAS Volume 13 Number 1, June, 2020

It is also in agreement with the findings of Yousafzai et al. (2018); Onuorah et al. (2015) and Tijjani and Jumare (2014) from tsire samples in different countries. Presence of $S$. aureus in foods is most of the time an indication of poor human handling, poor environment, unhygienic utensils and equipments used during processing (Igene et al., 2016; Okonko et al., 2013). Infections caused by $S$. aureus are difficult to treat leading to long hospitalization with consequent economic loss (Udobi et al., 2013). These include soft tissue infections, pneumonia, hospital-acquired postoperative wound infections, Staphylococcal food poisoning, impetigo and cellulitis (Charlene et al., 2013). Samples obtained from Dausai and Kofar Kudu had the highest isolation rate $4(80 \%)$ (Table 4 ) probably because of the much commercial activities taking place in the area which can lead to environmental contamination.

Table 1: Total Aerobic Mesophilic Bacterial Count of Tsire sold in Garko Town

\begin{tabular}{lll}
\hline Sampling Area & APC cfu/g & Mean \pm STD \\
\hline Dausai & $2.20 \times 10^{5}$ & $110000 \pm 14142.14$ \\
Kofar Kudu & $4.00 \times 10^{5}$ & $133333.3 \pm 23094.01$ \\
Makwalla & $1.30 \times 10^{5}$ & $32500 \pm 7187.953$ \\
Rinji & $2.72 \times 10^{5}$ & $90666.67 \pm 94769.90$ \\
Tosaro & $1.02 \times 10^{5}$ & $51000 \pm 15556.35$ \\
Tsohuwar Kasuwa & $1.75 \times 10^{5}$ & $35000 \pm 11357.82$ \\
\hline
\end{tabular}

Key: APC: Aerobic Mesophilic Counts

STD: Standard Deviation

Table 2: Total Coliform Count of Tsire sold in Garko Town

\begin{tabular}{lcc}
\hline \multicolumn{1}{c}{ Sampling Area } & TCC MPN/g & Mean \pm STD \\
\hline Dausai & 20 & $6.67 \pm 2.5166$ \\
Kofar Kudu & 32 & $16.00 \pm 5.6569$ \\
Makwalla & 68 & $13.60 \pm 8.7062$ \\
Rinji & 37 & $9.25 \pm 4.7871$ \\
Tosaro & 10 & $5.00 \pm 2.8284$ \\
Tsohuwar Kasuwa & 8 & $4.00 \pm 0.0000$ \\
\hline
\end{tabular}

Table 3: Organisms Isolated from Tsire Sold in Garko

\begin{tabular}{lcl}
\hline Isolated Organism & Frequency & Percentage (\%) \\
\hline Campylobacter & 2 & 06.66 \\
Escherichia coli & 6 & 20.00 \\
Klebsiella pneumoniae & 2 & 06.66 \\
Salmonella species & 1 & 03.33 \\
Shigella & 3 & 10.00 \\
Staphylococcus aureus & 2 & 06.66 \\
Total & 16 & \\
\hline
\end{tabular}

Table 4: Distribution of Organisms within Sampling Area

\begin{tabular}{lcc}
\hline \multicolumn{1}{c}{ Sampling Area } & No. Isolated & Percentage (\%) \\
\hline Dausai & 4 & 80 \\
Kofar Kudu & 4 & 80 \\
Makwalla & 2 & 40 \\
Rinji & 3 & 60 \\
Tosaro & 2 & 40 \\
Tsohuwar Kasuwa & 1 & 20 \\
Total & 16 & \\
\hline
\end{tabular}

\section{CONCLUSION}

Results indicated $4.00 \times 10^{5} \mathrm{CFU} / \mathrm{g}$ as the highest APCs count; while $68 \mathrm{MPN} / \mathrm{g}$ was the highest TCCs from the 30 samples analyzed. Among the isolates, $E$. coli has the highest isolation rate of $6(20 \%)$. Dausai and Kofar kudu were having the highest bacteria count of $4(80 \%)$, each, indicating higher contamination in those locations. 
BAJOPAS Volume 13 Number 1, June, 2020 RECOMMENDATIONS

The following recommendations are tenable:

1. Hygienic practices at all stages of production should be improved to safe guard the consumers against potential health hazard.

2. Monitoring of microbiological contamination of Tsire during preparations, packaging and marketing is essential to ensure product of good microbiological quality for consumers' health.

\section{REFERENCES}

Abdullahi, I. O., Umoh, V. J. and Galadima, M. (2004). Hazards Associated with Kilishi Preparations in Zaria. Nigerian Journal of Microbiology, 18 (1-2): $339-345$.

Ahmadu, J. and Ibrahim E. J., (2013): Determinants of Revenue in Suya Production in BeninCity, Edo State, Nigeria. Nigerian journal of agriculture, food and environment.9(3):1-5

Amaeze, N. Aboh, M. Itohan, A. Felix, E. Olatunji, T. and Oladosu, P. (2016) Microbial Profile, Antibiotic Sensitivity and Heat Resistance of Bacterial Isolates from Commercial Roasted Beef (Suya) in Abuja, Nigeria. JOPAT, 15(2): $22-30$.

Apata, E.S., Kuku1, I.A., Apata, O.C. and Adeyemi, K.O. (2013). Evaluation of Suya(Tsire) - An Intermediate Moisture Meat Product in Ogun State, Nigeria. J. Food Res 2 (1): 87.

Atlas, R. M. (1997) Principles of Microbiology Second Edition. C. Brown Publishers. Pp 802-803.

Borch, E. Kant-Muermans, M. L., Blixt, Y. (1996) Bacterial Spoilage of Meat and Cured Meat Products. Int $\mathrm{J}$ Food Microbiol .33(1): 103-20.

Centre for Disease Control, CDC (2011). "Escherichia coli 0157:H7" Division of Bacterial and Mycotic Diseasesht://www.cdc.gov/nczved/divisi ons/dfbmd/diseases/ecoli_0157h7/.

Charlene, R. J., Johnnie, A. D., and John, B. B., (2013) Prevalence and Characterization of Methicillin-Resistant Staphylococcus aureus Isolates from Retail Meat and Humans in Georgia. American society for Microbiology. J. of clinical microbiology. 12(1):123-6 doi:10.1128/JCM.0316612JCM.03166-12

Egbebi, A.O and Seidu, K., T. (2011). Microbiological Evaluation of Suya (dried smoked

meat) Sold in Ado and Akure, South West Nigeria.European Journal of Experinmental Biology, 1(4):1-5
3. Government should establish regulatory bodies responsible for inculcating hygiene habits to the local producers and vendors in order to prevent instant, cross and post processing contaminations by microbial pathogens.

4. Awareness and sensitization of local food producers about good hygienic practices in food handling and processing.

Falegan, C, R., Akoja, S. D., and Oyarekua, M. A., (2017) Microbiological Assessment of Suya (Sliced Roasted Beef) in Ado-Ekiti Metropolis, Ekiti State, Nigeria. MOJ Biology andMedicine.

Fonkem, D., N. Tanya, V., N. and Ebangi, A., L. (2010). Effect of Season on the Microbiological Quality of Kilishi, a Traditional Cameroonian Dried Beef Product. Tropicultura, 28(1): 10-15.

Food and Agricultural Organization of the United Nations (F A O, 1979). Manual of food quality control 4. Microbiological analysis.

Food and Agriculture Organisation of the United Nation (FAO), 2019. Nigeria at a glance.

Igene J.O., Uwadia, O.E., Ebabhamiegbebho, P.A. and Evivie, S.E., (2016) Shelf life Stability Studies of University of Benin (UNIBEN) Proff's Kilishi Product Asian Journal of Science and Technology 7(1): 2268-2274.

Inusa, S. K. and Said, I. S. (2017) Evaluation of the Chemical and Microbiological Properties Of Kilishi Sold in Kano Metropolis. Journal of Dry land Agriculture, 3 (1): $59-69$.

Lucretia, I. B, Patience, C. Obinna-Echem, Sophia, C. A. (2018) Microbiological quality andantibiotic sensitivity of potential pathogens isolated from meat product (Suya) sold in Rivers State University and its environs. International Journal of Biotechnology and Food Science, 6(4): 67-76.

Matthew, E., Drosos, E., John, L. and Ioanna, P. (2013) MRSA in Africa: Filling the Global Map of Antimicrobial Resistance PLOS One. 8(7): e68024 doi: 10.1371/journal.pone.0068024

Mgbemere, V.N., Akpapunam, M. A. and Igene, J. O., (2011). Effect of Groundnut FlourSubstitution on Yield, Quality and Storage Stability of Kilishi - a Nigerian Indigenous Dried Meat Product. African Journal of Food, Agriculture, Nutrition and Development, $\quad \mathbf{1 1}(2)$ : 4718-4738. 
BAJOPAS Volume 13 Number 1, June, 2020

Mubarak, A. A., Azeez, M. L., Amos A. O., Opeyemi, O. O. (2016) Assessment of Animal Protein Consumption and Food Security Among Rural Households in Kwara State, Nigeria American Journal of Business and Society, 1(4): 233245.

Ndahi, M., D. Kwaga, J., K. P. Bello, M. Kabir J., V. Umoh, .J. Yakubu, S., E. and Nok, A., J. (2013) Prevalence and Antimicrobial Susceptibility of Listeria Monocytogenes and Methicillin-Resistant Staphylococcus aureus Strains from Raw Meat and Meat Products in Zaria, Nigeria. Applied Journal of Microbiology, 58(3):262-9.

Okonko, I.O., Odu, N.N. and Igboh, I.E. (2013). Microbiological Analysis of Kilishi Sold In Port Harcourt, Nigeria. New York Science Journal, 6 (7):37-43.

Osimani, A., Aquilanti, L. and Clementi, F. (2015) Microbiological Quality of Meatbased Meals and Operation of Control Systems within a Food Service Environment. International Food Research Journal 22(4): 1692-1698.

Onuorah, S. Obika, I. Odibo, F. Orji, M. (2015)An Assessment of the Bacteriological Quality of Tsire-Suya (Grilled Beef) sold in Awka, Nigeria. American. J. Life. Sci. Res. 3(4):287292.

Razavilar, V, Khandaghi, J. Barzgari, A. (2010); Isolation of Eschericia coli 0157:H7 from manure fertilized farms and raw vegetables grown on it, in Tabriz city in
Iran. African Journal of Microbiology Research, 4(9): 891-895.

Scallan, E. Hoekstra, R. M. Angulo, F. J.Tauxe, R. V, Widdowson, M. Roy, S. L et al., (2011).Food borne illness acquired in the United States- Major Pathogens. Emerg. Infec Dis, 17(1): 7-15.

Shamsuddeen U (2009). Microbiological quality of spice used in the production of Kilishi a traditionally dried and grilled meat product. Bayero Journal of Pure andApplied Sciences, 2(2): 66-69.

Shamsuddeen, U. (2015) Microbiological Hazard and Critical control point Analysis of Dried and Minced Meat Snacks Produced in Kano Nigeria. Lambert Academic Publishing; Pp 1-36.

Tijani, O.and Jumare, S. (2014). Microblological Quality Assessment of Meat

Sold in KauraNamoda. International Conference on Earth, Environment and Life sciences (EELS) Dubai (UAE).

Udobi, C. E., Obajuluwa, A. F., and Onaolapo, J. A., (2013) Prevalence and Antibiotic Resistance Pattern of MethicillinResistant Staphylococcus aureus from an Orthopaedic Hospital in Nigeria BioMed Research International; 26(6); 6-7.

WHO, 2015 Foodborne diseases in the WHO African Region.

Yousafzai HA, Rind R, Khan MA, Abro SH, Korejo NA, Ejaz M, Kabir A, Shahid M, Memon S. (2019). Microbiological Contamination of Cattle and Meat in Peshawar, Pakistan. J. Anim. Health Prod. 7(1): 1116. 


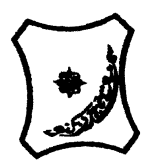

Bayero Journal of Pure and Applied Sciences, 13(1); 40 - 45

Received: September, 2019

Accepted: April, 2020

ISSN $2006-6996$

\title{
BACTERIOLOGICAL QUALITY OF STICK MEAT (Tsire) SOLD IN GARKO LOCAL GOVERNMENT AREA OF KANO STATE, NIGERIA
}

\author{
$*^{1}$ Dahiru A. T. and ${ }^{2}$ Maigari A. K. \\ ${ }^{1}$ Department of Hospitality Management, School of Technology, Kano State Polytechnic, PMB 3348, \\ Kano Nigeria. \\ ${ }^{2}$ Departmnt of Biological Sciences, Bayero University, Kano \\ Corresponding Author: dturajo61@gmail.com; GSM: 08087508262.
}

ABSTRACT

Stick meat, locally called Tsire in Hausa Language, is a significant portion of the diet of a large active population of Northern Nigeria. However, because of the handling and processing methods by the manufacturers as well as the hawking system of stick meat, the meat product may be exposed to both pre- and post-processed product contamination, and thus may poses danger to public health. Therefore, considering the role of Tsire in improving nutrition and increase household income to the populace, the need to improve the processing, distribution and overall quality of the product is simply indispensable. A total of 30 samples (5 samples from each of the 6 sampling points) of Tsire were collected randomly in Garko Town. Aerobic plate counts (APCs) and Total coliform counts (TCCS) of Tsire samples were determined using standard microbiological methods. APCs ranged from $1.02 \times 10^{5}$ to $4.00 \times 10^{5} \mathrm{CFU} / \mathrm{g}$; while TCCs ranged from $8 \mathrm{MPN} / \mathrm{g}$ to $68 \mathrm{MPN} / \mathrm{g}$. From the 30 samples screened, 16(53.33\%) bacteria namely, Campylobacter 2(6.66\%), Escherichia coli 6(20\%), Klebsiella pneumoniae 2(6.66\%), Salmonella spp. 1(3.33\%), Shigella 3(10\%) and Staphylococcus aureus 2(6.66\%) were detected. $E$. coli has the highest isolation rate of 6(20\%), while Salmonella spp. had the least frequency of 1(3.33\%). The distribution of isolated organisms within the study area were as follows: Dausai, 4(80\%), Kofar kudu, 4(80\%), Makwalla, 2(40\%), Rinji, 3(60\%), Tosaro, 2(40\%), and Tsohuwar Kasuwa, 1(20\%). The results have indicated that the Tsire was contaminated with bacteria thus exposing the product to fast deterioration, spoilage and also a vehicle for food borne illness, suggesting for adequate hygienic practices at all the stages, prior to consumption, to ensure safety of the meat product.

Key words: APCs, TCCs, Contamination, Microorganisms, Garko

\section{INTRODUCTION}

Nigeria is one of the developing nations with inadequate food supply and most often deficient in protein content (FAO, 2019). Nigerian's average animal protein intake per head per day is estimated at $7.9 \mathrm{~g}$ as against $35 \mathrm{~g}$ recommended value by Food and Agricultural Organization (Mubarak et al., 2016). These low levels of animal protein intake create great concern as it affects the nutritional status of Nigerians. Hence, there is the need for sufficient supply of animal protein from energy rich animal products to satisfy the nutritional requirements for Nigerians.

Meat is one major source of animal protein largely composed of water, protein and fats which can make it susceptible to microbial contamination within short time leading to spoilage (Apata et al., 2013; Mgbemere et al., 2011). Meat is mostly eaten after it has been cooked or processed in a variety of ways such as sun drying; smoking and roasting with or without fortifications (Borch et al., 1996). In Nigeria meat products such as Tsire, Kilishi and Balangu are locally produced using one or more of these methods in order to meet the nutritional requirements of the teeming Nigerians (Egbebi, 2011).

Tsire is a popular Nigerian traditional processed ready-to-eat roasted stick meat product (Shamsuddeen, 2015). It is sold in public places, along roads, in hotels, parks, quarters and even offices (Falegan et al., 2017). It is prepared from boneless healthy animal flesh such as beef and mutton, spiced with peanut cake, salt, vegetable oil and other flavorings followed by roasting (Shamsuddeen, 2015). Consumption of these products has extended to other parts of African countries such as Ghana, Somali, Cameroun and Chad (Ahmadu and Ibrahim, 2013). 
BAJOPAS Volume 13 Number 1, June, 2020

However, evidence of quality control sticking to procedural hygiene by the handlers during preparation and retailing of these products is poorly documented. Tsire is of great safety risk because of the fact that there are erratic cases of gastroenteritis and symptoms of food infection after consumption (WHO, 2015). Food borne illnesses are one of the major health problems in developing and developed countries (Razavilar, 2010). According to the World Health Organization, WHO (2015), $0.07 \%$ death of the 600 million global burdens of Foodborne illnesses have been reported to be caused by bacteria, viruses, fungi and chemicals. In America $0.27 \%$ of the estimated 48 million affected people is hospitalized and about $0.0063 \%$ deaths are recorded each year (Scallan et al., 2011). More than 91 million people in Africa fall ill and $0.15 \%$ dies each year, making Africa the highest burden bearer of Foodborne diseases per population (WHO, 2015).

Application of a Hazard Analysis Critical Control Point (HACCP) at all stages of meat products preparation is essential in order to ensure its safety. Thus, according to the guidelines of good manufacturing practice, the level of total aerobic bacterial contamination of thermally processed meat products should not exceed $10^{4}\left(\mathrm{cfu} \mathrm{g}^{-1}\right)$. Enterobacteriaceae and faecal coliform contamination in meat products should be within the range of $10^{2}-10^{4}$ and $10-10^{3} \mathrm{cfu} \mathrm{g}^{-1}$, respectively (Shamsuddeen, 2015). The aim of the study is therefore, to assess the total viable bacterial counts of tsire marketed locally within Garko town, and to isolate and identify the organisms at the point of consumption with the intention of promoting public health and food hygiene habits in the Nigerian populace.

\section{MATERIALS AND METHODS Study Area and Population}

Garko is one of the existing 44 local government areas located in Kano south west zone of Kano state with its capital administrative headquarters in the Garko town. It has coordinates $11^{\circ} 39^{\prime} \mathrm{N}$ $8^{\circ} 54^{\prime} \mathrm{E}$, and an area of $450 \mathrm{~km}^{2}$. The projected population of Garko local Government was 225,300 according to the National Population Census report (2018). Garko is known for agricultural activities both farming and animal husbandry. It is popularly known for large scale rice production. Other food crops include sweet potatoes, cassava, onions, sorghum, millet and sugarcane. Cows, sheep and goats are major groups of animals reared by majority of the populace. Meat products processed, retailed and consumed in Garko include roasted meat (Balangu), dried roasted meat (Kilishi), stick meat (Tsire), hide and skin pepper soup (Ragadada) and minced fried meat (Danbunnama).

\section{Samples Collection}

Five samples of Tsire products were collected from 6 different identified locations within Garko town in a sterile foil paper and immediately analyzed for the presence of bacteria.

\section{Sample Preparation}

Sample preparation for the bacteriological analysis was carried out in accordance with the method described by Atlas (1997). Twenty five grams $(25 \mathrm{~g})$ of the sample was homogenized in $225 \mathrm{ml}$ peptone water using Kenwood blender machine to obtain a $10^{1}$ homogenate. The homogenate was thoroughly shaken and $1 \mathrm{ml}$ pipetted into test tubes containing $9 \mathrm{ml}$ of peptone water $\left(10^{2}\right)$. The test tubes were further serially diluted to $10^{5}$.

Total Aerobic Mesophilic Bacterial Count

Total Aerobic mesophilic bacterial count was determined using the method described by Abdullahi et al. (2004) where $1 \mathrm{ml}$ of inoculums from $10^{1}$ to $10^{5}$ dilutions were transferred into duplicate Petri dishes and labeled accordingly. This was followed by pouring aseptically about $15 \mathrm{ml}$ of molten nutrient agar. The culture was homogenized by gentle spinning of the plates and allowed to solidify. The plates were incubated at $37^{\circ} \mathrm{C}$ for 24 hours. Plates containing 30-300 colonies were counted. The number of colony forming units per gram of a sample (cfu/g) was obtained by multiplying the average colony number with the inverse of the dilution factor.

\section{Enumeration and Detection of Coliform bacteria}

Detection and enumeration of coliform was carried out according to method described by Atlas, (1977). A set of 9 test tubes each containing $9 \mathrm{ml}$ of lactose broth and an inverted Durham tubes were autoclaved to expel air and to sterilize. Similarly, $1 \mathrm{ml}$ from the diluents $10^{1}$ was transferred to the first 3 test tubes, followed by $1 \mathrm{ml}$ from the diluents $10^{2}$ to the second set of 3 test tubes and finally the third diluents $10^{3}$ to the $3^{\text {rd }}$ set of 3 test tubes. All the 9 test tubes were incubated at $37^{\circ} \mathrm{C}$ for 24 hours. Tubes that showed gas and acid production after 24 hours were recorded as positive for the presence of Coliform. Negative tubes were further reincubated for 24 hours. Positive tubes were recorded. Estimate of most probable number of Coliform per gram of sample (MPN/g) was determined by comparing the number of gas positive tubes with the most probable number table. 
BAJOPAS Volume 13 Number 1, June, 2020 Identification of Coliform

A loop full of inoculum from gas positive tubes was streaked on to Eosine methylene blue (EMB) agar plate and incubated at $37^{\circ} \mathrm{C}$ for $24 \mathrm{hrs}$. Colonies which formed bluish black color with green metallic sheen, and reddish colonies were isolated on agar slants. Those colonies showing metallic sheen on EMB were sub cultured into tubes of lactose broth and incubated at $45^{\circ} \mathrm{C}$. The tubes were observed after $24 \mathrm{hrs}$ for gas production. This is the completed test for fecal coliform. Gram stain and other biochemical tests such as Indole, Methyl red, Voges-Proskauer and Citrate Utilization tests (IMVIC), Coagulase and Catalase tests were carried out for the Identification and confirmation of isolates.

\section{Procedure for Indole Test}

Indole test was carried out by preparing a Tryptone broth drawn in to test tubes, sterilized by autoclaving, inoculated with loopful of suspension and incubated at $37^{\circ} \mathrm{C}$ for 24 hours. Three drops of xylene was added in tubes, shaken vigorously and kept for the separation of two layers. One millilitre of Kovac's reagent was added and the formation of pink colour ring indicates positive Indole test.

\section{Procedure for Methyl Red Test}

Methyl red test was carried out by preparing Glucose phosphate broth, dispensed in test tubes, sterilized, inoculated with test culture and incubated at $37^{\circ} \mathrm{C}$ for 24 hours. Five drops of methyl-red indicator was added to the medium for the formation of red colour.

\section{Procedure for Voges-Proskauer Test}

Voges-Proskauer test was carried out by inoculating tubes with the bacterial culture followed by incubation for 48 hours at $37^{\circ} \mathrm{C}$. Separate pipettes were used to pipette $1 \mathrm{ml}$ from each culture tube into clean separate tubes. Eighteen drops $(0.5 \mathrm{ml})$ of Barrit's solution A (a-naphthol) was added to each tube containing glucose phosphate broth followed by the addition of an equal amount of solution $B$ into the same tube. The tubes were shaken at 30 seconds interval. A positive reaction was indicated by the development of a pink color, which turns red in 1-2 hours, after vigorous shaking.

\section{Procedure for Citrate Utilization Test}

Citrate Utilization Test was carried out by distributing melted agar (Simmon Citrate Agar) in to test tubes followed by sterilization at $121.5^{\circ} \mathrm{C}$ for 15 minutes. The test tubes were afterward held in slanted position, inoculated with the given bacterial culture and incubated at $37^{\circ} \mathrm{C}$ for $24 \mathrm{hrs}$. Positive test was indicated by color change of the media from green to blue.

\section{RESULTS AND DISCUSSIONS}

The results of this study are presented in tables $1,2,3$ and 4. Among the sampling areas Kofar Kudu had the highest aerobic mesophilic bacteria counts $4.0 \times 10^{5} \mathrm{cfu} / \mathrm{g}$ followed by Rinji $2.72 \times 10^{5} \mathrm{cfu} / \mathrm{g}$, while Tosaro had the least Aerobic mesophilic bacteria counts of $1.02 \times 10^{5}$ $\mathrm{cfu} / \mathrm{g}$ as indicated in Table 1.Makwalla had the highest coliform count $68 \mathrm{MPN} / \mathrm{g}$ followed by Rinji $37 \mathrm{MPN} / \mathrm{g}$. Tsohuwar Kasuwa had the least coliform counts $8 \mathrm{MPN} / \mathrm{g}$, (Table 2). Result from table 1 shows variation in the microbial contents among the samples which suggest variation in their sources, poor handling procedures and contamination from the processing environment. High coliform count and their differences within sampling areas is an indication of poor microbiological quality of the product. Ndahi et al. (2013) reported microbial load to be a function of the handling personnel and the environment. The results indicated that the samples were contaminated with bacteria as the counts exceeded the minimum safety level $\left(10^{4} \mathrm{cfu} / \mathrm{g}\right)$ for members of the Enterobacteriaceae family. However, it might be a reflection of poor hygienic practices which may contribute to health hazard to the potential consumers. Similarly, Inusa and Sa'id (2017); Osimani et al. (2015) reported that, the initial microbial content of the raw material play significant role in influencing the final microbial load of the finished product. Isolation of members of the Enterobacteriaceae such as $E$. coli, Klebsiella pneumoniae, Salmonella and Shigella signifies danger to the public health. These organisms are capable of producing endotoxins which trigger high fevers in infected individuals, and the enterotoxins which colonize the small intestines and lead to extreme dehydration as a result of vomiting and diarrhea sometimes with severe and fatal outcomes (Amaeze et al., 2016). From the 16 isolated organisms $E$. coli had the highest isolation rate $6(37.5 \%)$ (Table 3), this suggest faecal contamination of the products. $E$. coli is a common flora in the gastrointestinal tract responsible for diarrhea and extra-intestinal infections (CDC, 2011). The result is in conformity with the findings of Ndahi et al. (2013) and Shamsuddeen (2009). Also presence of campylobacter might be due to cross contamination from raw meat to finished product (Tsire). Staphylococcus aureus is a normal flora of the skin, nasal, genital, mouth or anal area in both humans and animals without any symptom of an infection (Matthew et al., 2013). Isolation of $S$. aureus in these study concords with the findings of Lucretia et al. (2018) from Suya sold in Rivers State. 
BAJOPAS Volume 13 Number 1, June, 2020

It is also in agreement with the findings of Yousafzai et al. (2018); Onuorah et al. (2015) and Tijjani and Jumare (2014) from tsire samples in different countries. Presence of $S$. aureus in foods is most of the time an indication of poor human handling, poor environment, unhygienic utensils and equipments used during processing (Igene et al., 2016; Okonko et al., 2013). Infections caused by $S$. aureus are difficult to treat leading to long hospitalization with consequent economic loss (Udobi et al., 2013). These include soft tissue infections, pneumonia, hospital-acquired postoperative wound infections, Staphylococcal food poisoning, impetigo and cellulitis (Charlene et al., 2013). Samples obtained from Dausai and Kofar Kudu had the highest isolation rate $4(80 \%)$ (Table 4 ) probably because of the much commercial activities taking place in the area which can lead to environmental contamination.

Table 1: Total Aerobic Mesophilic Bacterial Count of Tsire sold in Garko Town

\begin{tabular}{lll}
\hline Sampling Area & APC cfu/g & Mean \pm STD \\
\hline Dausai & $2.20 \times 10^{5}$ & $110000 \pm 14142.14$ \\
Kofar Kudu & $4.00 \times 10^{5}$ & $133333.3 \pm 23094.01$ \\
Makwalla & $1.30 \times 10^{5}$ & $32500 \pm 7187.953$ \\
Rinji & $2.72 \times 10^{5}$ & $90666.67 \pm 94769.90$ \\
Tosaro & $1.02 \times 10^{5}$ & $51000 \pm 15556.35$ \\
Tsohuwar Kasuwa & $1.75 \times 10^{5}$ & $35000 \pm 11357.82$ \\
\hline
\end{tabular}

Key: APC: Aerobic Mesophilic Counts

STD: Standard Deviation

Table 2: Total Coliform Count of Tsire sold in Garko Town

\begin{tabular}{lcc}
\hline \multicolumn{1}{c}{ Sampling Area } & TCC MPN/g & Mean \pm STD \\
\hline Dausai & 20 & $6.67 \pm 2.5166$ \\
Kofar Kudu & 32 & $16.00 \pm 5.6569$ \\
Makwalla & 68 & $13.60 \pm 8.7062$ \\
Rinji & 37 & $9.25 \pm 4.7871$ \\
Tosaro & 10 & $5.00 \pm 2.8284$ \\
Tsohuwar Kasuwa & 8 & $4.00 \pm 0.0000$ \\
\hline
\end{tabular}

Table 3: Organisms Isolated from Tsire Sold in Garko

\begin{tabular}{lcl}
\hline Isolated Organism & Frequency & Percentage (\%) \\
\hline Campylobacter & 2 & 06.66 \\
Escherichia coli & 6 & 20.00 \\
Klebsiella pneumoniae & 2 & 06.66 \\
Salmonella species & 1 & 03.33 \\
Shigella & 3 & 10.00 \\
Staphylococcus aureus & 2 & 06.66 \\
Total & 16 & \\
\hline
\end{tabular}

Table 4: Distribution of Organisms within Sampling Area

\begin{tabular}{lcc}
\hline \multicolumn{1}{c}{ Sampling Area } & No. Isolated & Percentage (\%) \\
\hline Dausai & 4 & 80 \\
Kofar Kudu & 4 & 80 \\
Makwalla & 2 & 40 \\
Rinji & 3 & 60 \\
Tosaro & 2 & 40 \\
Tsohuwar Kasuwa & 1 & 20 \\
Total & 16 & \\
\hline
\end{tabular}

\section{CONCLUSION}

Results indicated $4.00 \times 10^{5} \mathrm{CFU} / \mathrm{g}$ as the highest APCs count; while $68 \mathrm{MPN} / \mathrm{g}$ was the highest TCCs from the 30 samples analyzed. Among the isolates, $E$. coli has the highest isolation rate of $6(20 \%)$. Dausai and Kofar kudu were having the highest bacteria count of $4(80 \%)$, each, indicating higher contamination in those locations. 
BAJOPAS Volume 13 Number 1, June, 2020 RECOMMENDATIONS

The following recommendations are tenable:

1. Hygienic practices at all stages of production should be improved to safe guard the consumers against potential health hazard.

2. Monitoring of microbiological contamination of Tsire during preparations, packaging and marketing is essential to ensure product of good microbiological quality for consumers' health.

\section{REFERENCES}

Abdullahi, I. O., Umoh, V. J. and Galadima, M. (2004). Hazards Associated with Kilishi Preparations in Zaria. Nigerian Journal of Microbiology, 18 (1-2): $339-345$.

Ahmadu, J. and Ibrahim E. J., (2013): Determinants of Revenue in Suya Production in BeninCity, Edo State, Nigeria. Nigerian journal of agriculture, food and environment.9(3):1-5

Amaeze, N. Aboh, M. Itohan, A. Felix, E. Olatunji, T. and Oladosu, P. (2016) Microbial Profile, Antibiotic Sensitivity and Heat Resistance of Bacterial Isolates from Commercial Roasted Beef (Suya) in Abuja, Nigeria. JOPAT, 15(2): $22-30$.

Apata, E.S., Kuku1, I.A., Apata, O.C. and Adeyemi, K.O. (2013). Evaluation of Suya(Tsire) - An Intermediate Moisture Meat Product in Ogun State, Nigeria. J. Food Res 2 (1): 87.

Atlas, R. M. (1997) Principles of Microbiology Second Edition. C. Brown Publishers. Pp 802-803.

Borch, E. Kant-Muermans, M. L., Blixt, Y. (1996) Bacterial Spoilage of Meat and Cured Meat Products. Int $\mathrm{J}$ Food Microbiol .33(1): 103-20.

Centre for Disease Control, CDC (2011). "Escherichia coli 0157:H7" Division of Bacterial and Mycotic Diseasesht://www.cdc.gov/nczved/divisi ons/dfbmd/diseases/ecoli_0157h7/.

Charlene, R. J., Johnnie, A. D., and John, B. B., (2013) Prevalence and Characterization of Methicillin-Resistant Staphylococcus aureus Isolates from Retail Meat and Humans in Georgia. American society for Microbiology. J. of clinical microbiology. 12(1):123-6 doi:10.1128/JCM.0316612JCM.03166-12

Egbebi, A.O and Seidu, K., T. (2011). Microbiological Evaluation of Suya (dried smoked

meat) Sold in Ado and Akure, South West Nigeria.European Journal of Experinmental Biology, 1(4):1-5
3. Government should establish regulatory bodies responsible for inculcating hygiene habits to the local producers and vendors in order to prevent instant, cross and post processing contaminations by microbial pathogens.

4. Awareness and sensitization of local food producers about good hygienic practices in food handling and processing.

Falegan, C, R., Akoja, S. D., and Oyarekua, M. A., (2017) Microbiological Assessment of Suya (Sliced Roasted Beef) in Ado-Ekiti Metropolis, Ekiti State, Nigeria. MOJ Biology andMedicine.

Fonkem, D., N. Tanya, V., N. and Ebangi, A., L. (2010). Effect of Season on the Microbiological Quality of Kilishi, a Traditional Cameroonian Dried Beef Product. Tropicultura, 28(1): 10-15.

Food and Agricultural Organization of the United Nations (F A O, 1979). Manual of food quality control 4. Microbiological analysis.

Food and Agriculture Organisation of the United Nation (FAO), 2019. Nigeria at a glance.

Igene J.O., Uwadia, O.E., Ebabhamiegbebho, P.A. and Evivie, S.E., (2016) Shelf life Stability Studies of University of Benin (UNIBEN) Proff's Kilishi Product Asian Journal of Science and Technology 7(1): 2268-2274.

Inusa, S. K. and Said, I. S. (2017) Evaluation of the Chemical and Microbiological Properties Of Kilishi Sold in Kano Metropolis. Journal of Dry land Agriculture, 3 (1): $59-69$.

Lucretia, I. B, Patience, C. Obinna-Echem, Sophia, C. A. (2018) Microbiological quality andantibiotic sensitivity of potential pathogens isolated from meat product (Suya) sold in Rivers State University and its environs. International Journal of Biotechnology and Food Science, 6(4): 67-76.

Matthew, E., Drosos, E., John, L. and Ioanna, P. (2013) MRSA in Africa: Filling the Global Map of Antimicrobial Resistance PLOS One. 8(7): e68024 doi: 10.1371/journal.pone.0068024

Mgbemere, V.N., Akpapunam, M. A. and Igene, J. O., (2011). Effect of Groundnut FlourSubstitution on Yield, Quality and Storage Stability of Kilishi - a Nigerian Indigenous Dried Meat Product. African Journal of Food, Agriculture, Nutrition and Development, $\quad \mathbf{1 1}(2)$ : 4718-4738. 
BAJOPAS Volume 13 Number 1, June, 2020

Mubarak, A. A., Azeez, M. L., Amos A. O., Opeyemi, O. O. (2016) Assessment of Animal Protein Consumption and Food Security Among Rural Households in Kwara State, Nigeria American Journal of Business and Society, 1(4): 233245.

Ndahi, M., D. Kwaga, J., K. P. Bello, M. Kabir J., V. Umoh, .J. Yakubu, S., E. and Nok, A., J. (2013) Prevalence and Antimicrobial Susceptibility of Listeria Monocytogenes and Methicillin-Resistant Staphylococcus aureus Strains from Raw Meat and Meat Products in Zaria, Nigeria. Applied Journal of Microbiology, 58(3):262-9.

Okonko, I.O., Odu, N.N. and Igboh, I.E. (2013). Microbiological Analysis of Kilishi Sold In Port Harcourt, Nigeria. New York Science Journal, 6 (7):37-43.

Osimani, A., Aquilanti, L. and Clementi, F. (2015) Microbiological Quality of Meatbased Meals and Operation of Control Systems within a Food Service Environment. International Food Research Journal 22(4): 1692-1698.

Onuorah, S. Obika, I. Odibo, F. Orji, M. (2015)An Assessment of the Bacteriological Quality of Tsire-Suya (Grilled Beef) sold in Awka, Nigeria. American. J. Life. Sci. Res. 3(4):287292.

Razavilar, V, Khandaghi, J. Barzgari, A. (2010); Isolation of Eschericia coli 0157:H7 from manure fertilized farms and raw vegetables grown on it, in Tabriz city in
Iran. African Journal of Microbiology Research, 4(9): 891-895.

Scallan, E. Hoekstra, R. M. Angulo, F. J.Tauxe, R. V, Widdowson, M. Roy, S. L et al., (2011).Food borne illness acquired in the United States- Major Pathogens. Emerg. Infec Dis, 17(1): 7-15.

Shamsuddeen U (2009). Microbiological quality of spice used in the production of Kilishi a traditionally dried and grilled meat product. Bayero Journal of Pure andApplied Sciences, 2(2): 66-69.

Shamsuddeen, U. (2015) Microbiological Hazard and Critical control point Analysis of Dried and Minced Meat Snacks Produced in Kano Nigeria. Lambert Academic Publishing; Pp 1-36.

Tijani, O.and Jumare, S. (2014). Microblological Quality Assessment of Meat

Sold in KauraNamoda. International Conference on Earth, Environment and Life sciences (EELS) Dubai (UAE).

Udobi, C. E., Obajuluwa, A. F., and Onaolapo, J. A., (2013) Prevalence and Antibiotic Resistance Pattern of MethicillinResistant Staphylococcus aureus from an Orthopaedic Hospital in Nigeria BioMed Research International; 26(6); 6-7.

WHO, 2015 Foodborne diseases in the WHO African Region.

Yousafzai HA, Rind R, Khan MA, Abro SH, Korejo NA, Ejaz M, Kabir A, Shahid M, Memon S. (2019). Microbiological Contamination of Cattle and Meat in Peshawar, Pakistan. J. Anim. Health Prod. 7(1): 1116. 


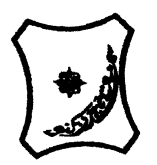

Bayero Journal of Pure and Applied Sciences, 13(1); 40 - 45

Received: September, 2019

Accepted: April, 2020

ISSN $2006-6996$

\title{
BACTERIOLOGICAL QUALITY OF STICK MEAT (Tsire) SOLD IN GARKO LOCAL GOVERNMENT AREA OF KANO STATE, NIGERIA
}

\author{
$*^{1}$ Dahiru A. T. and ${ }^{2}$ Maigari A. K. \\ ${ }^{1}$ Department of Hospitality Management, School of Technology, Kano State Polytechnic, PMB 3348, \\ Kano Nigeria. \\ ${ }^{2}$ Departmnt of Biological Sciences, Bayero University, Kano \\ Corresponding Author: dturajo61@gmail.com; GSM: 08087508262.
}

ABSTRACT

Stick meat, locally called Tsire in Hausa Language, is a significant portion of the diet of a large active population of Northern Nigeria. However, because of the handling and processing methods by the manufacturers as well as the hawking system of stick meat, the meat product may be exposed to both pre- and post-processed product contamination, and thus may poses danger to public health. Therefore, considering the role of Tsire in improving nutrition and increase household income to the populace, the need to improve the processing, distribution and overall quality of the product is simply indispensable. A total of 30 samples (5 samples from each of the 6 sampling points) of Tsire were collected randomly in Garko Town. Aerobic plate counts (APCs) and Total coliform counts (TCCS) of Tsire samples were determined using standard microbiological methods. APCs ranged from $1.02 \times 10^{5}$ to $4.00 \times 10^{5} \mathrm{CFU} / \mathrm{g}$; while TCCs ranged from $8 \mathrm{MPN} / \mathrm{g}$ to $68 \mathrm{MPN} / \mathrm{g}$. From the 30 samples screened, 16(53.33\%) bacteria namely, Campylobacter 2(6.66\%), Escherichia coli 6(20\%), Klebsiella pneumoniae 2(6.66\%), Salmonella spp. 1(3.33\%), Shigella 3(10\%) and Staphylococcus aureus 2(6.66\%) were detected. $E$. coli has the highest isolation rate of 6(20\%), while Salmonella spp. had the least frequency of 1(3.33\%). The distribution of isolated organisms within the study area were as follows: Dausai, 4(80\%), Kofar kudu, 4(80\%), Makwalla, 2(40\%), Rinji, 3(60\%), Tosaro, 2(40\%), and Tsohuwar Kasuwa, 1(20\%). The results have indicated that the Tsire was contaminated with bacteria thus exposing the product to fast deterioration, spoilage and also a vehicle for food borne illness, suggesting for adequate hygienic practices at all the stages, prior to consumption, to ensure safety of the meat product.

Key words: APCs, TCCs, Contamination, Microorganisms, Garko

\section{INTRODUCTION}

Nigeria is one of the developing nations with inadequate food supply and most often deficient in protein content (FAO, 2019). Nigerian's average animal protein intake per head per day is estimated at $7.9 \mathrm{~g}$ as against $35 \mathrm{~g}$ recommended value by Food and Agricultural Organization (Mubarak et al., 2016). These low levels of animal protein intake create great concern as it affects the nutritional status of Nigerians. Hence, there is the need for sufficient supply of animal protein from energy rich animal products to satisfy the nutritional requirements for Nigerians.

Meat is one major source of animal protein largely composed of water, protein and fats which can make it susceptible to microbial contamination within short time leading to spoilage (Apata et al., 2013; Mgbemere et al., 2011). Meat is mostly eaten after it has been cooked or processed in a variety of ways such as sun drying; smoking and roasting with or without fortifications (Borch et al., 1996). In Nigeria meat products such as Tsire, Kilishi and Balangu are locally produced using one or more of these methods in order to meet the nutritional requirements of the teeming Nigerians (Egbebi, 2011).

Tsire is a popular Nigerian traditional processed ready-to-eat roasted stick meat product (Shamsuddeen, 2015). It is sold in public places, along roads, in hotels, parks, quarters and even offices (Falegan et al., 2017). It is prepared from boneless healthy animal flesh such as beef and mutton, spiced with peanut cake, salt, vegetable oil and other flavorings followed by roasting (Shamsuddeen, 2015). Consumption of these products has extended to other parts of African countries such as Ghana, Somali, Cameroun and Chad (Ahmadu and Ibrahim, 2013). 
BAJOPAS Volume 13 Number 1, June, 2020

However, evidence of quality control sticking to procedural hygiene by the handlers during preparation and retailing of these products is poorly documented. Tsire is of great safety risk because of the fact that there are erratic cases of gastroenteritis and symptoms of food infection after consumption (WHO, 2015). Food borne illnesses are one of the major health problems in developing and developed countries (Razavilar, 2010). According to the World Health Organization, WHO (2015), $0.07 \%$ death of the 600 million global burdens of Foodborne illnesses have been reported to be caused by bacteria, viruses, fungi and chemicals. In America $0.27 \%$ of the estimated 48 million affected people is hospitalized and about $0.0063 \%$ deaths are recorded each year (Scallan et al., 2011). More than 91 million people in Africa fall ill and $0.15 \%$ dies each year, making Africa the highest burden bearer of Foodborne diseases per population (WHO, 2015).

Application of a Hazard Analysis Critical Control Point (HACCP) at all stages of meat products preparation is essential in order to ensure its safety. Thus, according to the guidelines of good manufacturing practice, the level of total aerobic bacterial contamination of thermally processed meat products should not exceed $10^{4}\left(\mathrm{cfu} \mathrm{g}^{-1}\right)$. Enterobacteriaceae and faecal coliform contamination in meat products should be within the range of $10^{2}-10^{4}$ and $10-10^{3} \mathrm{cfu} \mathrm{g}^{-1}$, respectively (Shamsuddeen, 2015). The aim of the study is therefore, to assess the total viable bacterial counts of tsire marketed locally within Garko town, and to isolate and identify the organisms at the point of consumption with the intention of promoting public health and food hygiene habits in the Nigerian populace.

\section{MATERIALS AND METHODS Study Area and Population}

Garko is one of the existing 44 local government areas located in Kano south west zone of Kano state with its capital administrative headquarters in the Garko town. It has coordinates $11^{\circ} 39^{\prime} \mathrm{N}$ $8^{\circ} 54^{\prime} \mathrm{E}$, and an area of $450 \mathrm{~km}^{2}$. The projected population of Garko local Government was 225,300 according to the National Population Census report (2018). Garko is known for agricultural activities both farming and animal husbandry. It is popularly known for large scale rice production. Other food crops include sweet potatoes, cassava, onions, sorghum, millet and sugarcane. Cows, sheep and goats are major groups of animals reared by majority of the populace. Meat products processed, retailed and consumed in Garko include roasted meat (Balangu), dried roasted meat (Kilishi), stick meat (Tsire), hide and skin pepper soup (Ragadada) and minced fried meat (Danbunnama).

\section{Samples Collection}

Five samples of Tsire products were collected from 6 different identified locations within Garko town in a sterile foil paper and immediately analyzed for the presence of bacteria.

\section{Sample Preparation}

Sample preparation for the bacteriological analysis was carried out in accordance with the method described by Atlas (1997). Twenty five grams $(25 \mathrm{~g})$ of the sample was homogenized in $225 \mathrm{ml}$ peptone water using Kenwood blender machine to obtain a $10^{1}$ homogenate. The homogenate was thoroughly shaken and $1 \mathrm{ml}$ pipetted into test tubes containing $9 \mathrm{ml}$ of peptone water $\left(10^{2}\right)$. The test tubes were further serially diluted to $10^{5}$.

Total Aerobic Mesophilic Bacterial Count

Total Aerobic mesophilic bacterial count was determined using the method described by Abdullahi et al. (2004) where $1 \mathrm{ml}$ of inoculums from $10^{1}$ to $10^{5}$ dilutions were transferred into duplicate Petri dishes and labeled accordingly. This was followed by pouring aseptically about $15 \mathrm{ml}$ of molten nutrient agar. The culture was homogenized by gentle spinning of the plates and allowed to solidify. The plates were incubated at $37^{\circ} \mathrm{C}$ for 24 hours. Plates containing 30-300 colonies were counted. The number of colony forming units per gram of a sample (cfu/g) was obtained by multiplying the average colony number with the inverse of the dilution factor.

\section{Enumeration and Detection of Coliform bacteria}

Detection and enumeration of coliform was carried out according to method described by Atlas, (1977). A set of 9 test tubes each containing $9 \mathrm{ml}$ of lactose broth and an inverted Durham tubes were autoclaved to expel air and to sterilize. Similarly, $1 \mathrm{ml}$ from the diluents $10^{1}$ was transferred to the first 3 test tubes, followed by $1 \mathrm{ml}$ from the diluents $10^{2}$ to the second set of 3 test tubes and finally the third diluents $10^{3}$ to the $3^{\text {rd }}$ set of 3 test tubes. All the 9 test tubes were incubated at $37^{\circ} \mathrm{C}$ for 24 hours. Tubes that showed gas and acid production after 24 hours were recorded as positive for the presence of Coliform. Negative tubes were further reincubated for 24 hours. Positive tubes were recorded. Estimate of most probable number of Coliform per gram of sample (MPN/g) was determined by comparing the number of gas positive tubes with the most probable number table. 
BAJOPAS Volume 13 Number 1, June, 2020 Identification of Coliform

A loop full of inoculum from gas positive tubes was streaked on to Eosine methylene blue (EMB) agar plate and incubated at $37^{\circ} \mathrm{C}$ for $24 \mathrm{hrs}$. Colonies which formed bluish black color with green metallic sheen, and reddish colonies were isolated on agar slants. Those colonies showing metallic sheen on EMB were sub cultured into tubes of lactose broth and incubated at $45^{\circ} \mathrm{C}$. The tubes were observed after $24 \mathrm{hrs}$ for gas production. This is the completed test for fecal coliform. Gram stain and other biochemical tests such as Indole, Methyl red, Voges-Proskauer and Citrate Utilization tests (IMVIC), Coagulase and Catalase tests were carried out for the Identification and confirmation of isolates.

\section{Procedure for Indole Test}

Indole test was carried out by preparing a Tryptone broth drawn in to test tubes, sterilized by autoclaving, inoculated with loopful of suspension and incubated at $37^{\circ} \mathrm{C}$ for 24 hours. Three drops of xylene was added in tubes, shaken vigorously and kept for the separation of two layers. One millilitre of Kovac's reagent was added and the formation of pink colour ring indicates positive Indole test.

\section{Procedure for Methyl Red Test}

Methyl red test was carried out by preparing Glucose phosphate broth, dispensed in test tubes, sterilized, inoculated with test culture and incubated at $37^{\circ} \mathrm{C}$ for 24 hours. Five drops of methyl-red indicator was added to the medium for the formation of red colour.

\section{Procedure for Voges-Proskauer Test}

Voges-Proskauer test was carried out by inoculating tubes with the bacterial culture followed by incubation for 48 hours at $37^{\circ} \mathrm{C}$. Separate pipettes were used to pipette $1 \mathrm{ml}$ from each culture tube into clean separate tubes. Eighteen drops $(0.5 \mathrm{ml})$ of Barrit's solution A (a-naphthol) was added to each tube containing glucose phosphate broth followed by the addition of an equal amount of solution $B$ into the same tube. The tubes were shaken at 30 seconds interval. A positive reaction was indicated by the development of a pink color, which turns red in 1-2 hours, after vigorous shaking.

\section{Procedure for Citrate Utilization Test}

Citrate Utilization Test was carried out by distributing melted agar (Simmon Citrate Agar) in to test tubes followed by sterilization at $121.5^{\circ} \mathrm{C}$ for 15 minutes. The test tubes were afterward held in slanted position, inoculated with the given bacterial culture and incubated at $37^{\circ} \mathrm{C}$ for $24 \mathrm{hrs}$. Positive test was indicated by color change of the media from green to blue.

\section{RESULTS AND DISCUSSIONS}

The results of this study are presented in tables $1,2,3$ and 4. Among the sampling areas Kofar Kudu had the highest aerobic mesophilic bacteria counts $4.0 \times 10^{5} \mathrm{cfu} / \mathrm{g}$ followed by Rinji $2.72 \times 10^{5} \mathrm{cfu} / \mathrm{g}$, while Tosaro had the least Aerobic mesophilic bacteria counts of $1.02 \times 10^{5}$ $\mathrm{cfu} / \mathrm{g}$ as indicated in Table 1.Makwalla had the highest coliform count $68 \mathrm{MPN} / \mathrm{g}$ followed by Rinji $37 \mathrm{MPN} / \mathrm{g}$. Tsohuwar Kasuwa had the least coliform counts $8 \mathrm{MPN} / \mathrm{g}$, (Table 2). Result from table 1 shows variation in the microbial contents among the samples which suggest variation in their sources, poor handling procedures and contamination from the processing environment. High coliform count and their differences within sampling areas is an indication of poor microbiological quality of the product. Ndahi et al. (2013) reported microbial load to be a function of the handling personnel and the environment. The results indicated that the samples were contaminated with bacteria as the counts exceeded the minimum safety level $\left(10^{4} \mathrm{cfu} / \mathrm{g}\right)$ for members of the Enterobacteriaceae family. However, it might be a reflection of poor hygienic practices which may contribute to health hazard to the potential consumers. Similarly, Inusa and Sa'id (2017); Osimani et al. (2015) reported that, the initial microbial content of the raw material play significant role in influencing the final microbial load of the finished product. Isolation of members of the Enterobacteriaceae such as $E$. coli, Klebsiella pneumoniae, Salmonella and Shigella signifies danger to the public health. These organisms are capable of producing endotoxins which trigger high fevers in infected individuals, and the enterotoxins which colonize the small intestines and lead to extreme dehydration as a result of vomiting and diarrhea sometimes with severe and fatal outcomes (Amaeze et al., 2016). From the 16 isolated organisms $E$. coli had the highest isolation rate $6(37.5 \%)$ (Table 3), this suggest faecal contamination of the products. $E$. coli is a common flora in the gastrointestinal tract responsible for diarrhea and extra-intestinal infections (CDC, 2011). The result is in conformity with the findings of Ndahi et al. (2013) and Shamsuddeen (2009). Also presence of campylobacter might be due to cross contamination from raw meat to finished product (Tsire). Staphylococcus aureus is a normal flora of the skin, nasal, genital, mouth or anal area in both humans and animals without any symptom of an infection (Matthew et al., 2013). Isolation of $S$. aureus in these study concords with the findings of Lucretia et al. (2018) from Suya sold in Rivers State. 
BAJOPAS Volume 13 Number 1, June, 2020

It is also in agreement with the findings of Yousafzai et al. (2018); Onuorah et al. (2015) and Tijjani and Jumare (2014) from tsire samples in different countries. Presence of $S$. aureus in foods is most of the time an indication of poor human handling, poor environment, unhygienic utensils and equipments used during processing (Igene et al., 2016; Okonko et al., 2013). Infections caused by $S$. aureus are difficult to treat leading to long hospitalization with consequent economic loss (Udobi et al., 2013). These include soft tissue infections, pneumonia, hospital-acquired postoperative wound infections, Staphylococcal food poisoning, impetigo and cellulitis (Charlene et al., 2013). Samples obtained from Dausai and Kofar Kudu had the highest isolation rate $4(80 \%)$ (Table 4 ) probably because of the much commercial activities taking place in the area which can lead to environmental contamination.

Table 1: Total Aerobic Mesophilic Bacterial Count of Tsire sold in Garko Town

\begin{tabular}{lll}
\hline Sampling Area & APC cfu/g & Mean \pm STD \\
\hline Dausai & $2.20 \times 10^{5}$ & $110000 \pm 14142.14$ \\
Kofar Kudu & $4.00 \times 10^{5}$ & $133333.3 \pm 23094.01$ \\
Makwalla & $1.30 \times 10^{5}$ & $32500 \pm 7187.953$ \\
Rinji & $2.72 \times 10^{5}$ & $90666.67 \pm 94769.90$ \\
Tosaro & $1.02 \times 10^{5}$ & $51000 \pm 15556.35$ \\
Tsohuwar Kasuwa & $1.75 \times 10^{5}$ & $35000 \pm 11357.82$ \\
\hline
\end{tabular}

Key: APC: Aerobic Mesophilic Counts

STD: Standard Deviation

Table 2: Total Coliform Count of Tsire sold in Garko Town

\begin{tabular}{lcc}
\hline \multicolumn{1}{c}{ Sampling Area } & TCC MPN/g & Mean \pm STD \\
\hline Dausai & 20 & $6.67 \pm 2.5166$ \\
Kofar Kudu & 32 & $16.00 \pm 5.6569$ \\
Makwalla & 68 & $13.60 \pm 8.7062$ \\
Rinji & 37 & $9.25 \pm 4.7871$ \\
Tosaro & 10 & $5.00 \pm 2.8284$ \\
Tsohuwar Kasuwa & 8 & $4.00 \pm 0.0000$ \\
\hline
\end{tabular}

Table 3: Organisms Isolated from Tsire Sold in Garko

\begin{tabular}{lcl}
\hline Isolated Organism & Frequency & Percentage (\%) \\
\hline Campylobacter & 2 & 06.66 \\
Escherichia coli & 6 & 20.00 \\
Klebsiella pneumoniae & 2 & 06.66 \\
Salmonella species & 1 & 03.33 \\
Shigella & 3 & 10.00 \\
Staphylococcus aureus & 2 & 06.66 \\
Total & 16 & \\
\hline
\end{tabular}

Table 4: Distribution of Organisms within Sampling Area

\begin{tabular}{lcc}
\hline \multicolumn{1}{c}{ Sampling Area } & No. Isolated & Percentage (\%) \\
\hline Dausai & 4 & 80 \\
Kofar Kudu & 4 & 80 \\
Makwalla & 2 & 40 \\
Rinji & 3 & 60 \\
Tosaro & 2 & 40 \\
Tsohuwar Kasuwa & 1 & 20 \\
Total & 16 & \\
\hline
\end{tabular}

\section{CONCLUSION}

Results indicated $4.00 \times 10^{5} \mathrm{CFU} / \mathrm{g}$ as the highest APCs count; while $68 \mathrm{MPN} / \mathrm{g}$ was the highest TCCs from the 30 samples analyzed. Among the isolates, $E$. coli has the highest isolation rate of $6(20 \%)$. Dausai and Kofar kudu were having the highest bacteria count of $4(80 \%)$, each, indicating higher contamination in those locations. 
BAJOPAS Volume 13 Number 1, June, 2020 RECOMMENDATIONS

The following recommendations are tenable:

1. Hygienic practices at all stages of production should be improved to safe guard the consumers against potential health hazard.

2. Monitoring of microbiological contamination of Tsire during preparations, packaging and marketing is essential to ensure product of good microbiological quality for consumers' health.

\section{REFERENCES}

Abdullahi, I. O., Umoh, V. J. and Galadima, M. (2004). Hazards Associated with Kilishi Preparations in Zaria. Nigerian Journal of Microbiology, 18 (1-2): $339-345$.

Ahmadu, J. and Ibrahim E. J., (2013): Determinants of Revenue in Suya Production in BeninCity, Edo State, Nigeria. Nigerian journal of agriculture, food and environment.9(3):1-5

Amaeze, N. Aboh, M. Itohan, A. Felix, E. Olatunji, T. and Oladosu, P. (2016) Microbial Profile, Antibiotic Sensitivity and Heat Resistance of Bacterial Isolates from Commercial Roasted Beef (Suya) in Abuja, Nigeria. JOPAT, 15(2): $22-30$.

Apata, E.S., Kuku1, I.A., Apata, O.C. and Adeyemi, K.O. (2013). Evaluation of Suya(Tsire) - An Intermediate Moisture Meat Product in Ogun State, Nigeria. J. Food Res 2 (1): 87.

Atlas, R. M. (1997) Principles of Microbiology Second Edition. C. Brown Publishers. Pp 802-803.

Borch, E. Kant-Muermans, M. L., Blixt, Y. (1996) Bacterial Spoilage of Meat and Cured Meat Products. Int $\mathrm{J}$ Food Microbiol .33(1): 103-20.

Centre for Disease Control, CDC (2011). "Escherichia coli 0157:H7" Division of Bacterial and Mycotic Diseasesht://www.cdc.gov/nczved/divisi ons/dfbmd/diseases/ecoli_0157h7/.

Charlene, R. J., Johnnie, A. D., and John, B. B., (2013) Prevalence and Characterization of Methicillin-Resistant Staphylococcus aureus Isolates from Retail Meat and Humans in Georgia. American society for Microbiology. J. of clinical microbiology. 12(1):123-6 doi:10.1128/JCM.0316612JCM.03166-12

Egbebi, A.O and Seidu, K., T. (2011). Microbiological Evaluation of Suya (dried smoked

meat) Sold in Ado and Akure, South West Nigeria.European Journal of Experinmental Biology, 1(4):1-5
3. Government should establish regulatory bodies responsible for inculcating hygiene habits to the local producers and vendors in order to prevent instant, cross and post processing contaminations by microbial pathogens.

4. Awareness and sensitization of local food producers about good hygienic practices in food handling and processing.

Falegan, C, R., Akoja, S. D., and Oyarekua, M. A., (2017) Microbiological Assessment of Suya (Sliced Roasted Beef) in Ado-Ekiti Metropolis, Ekiti State, Nigeria. MOJ Biology andMedicine.

Fonkem, D., N. Tanya, V., N. and Ebangi, A., L. (2010). Effect of Season on the Microbiological Quality of Kilishi, a Traditional Cameroonian Dried Beef Product. Tropicultura, 28(1): 10-15.

Food and Agricultural Organization of the United Nations (F A O, 1979). Manual of food quality control 4. Microbiological analysis.

Food and Agriculture Organisation of the United Nation (FAO), 2019. Nigeria at a glance.

Igene J.O., Uwadia, O.E., Ebabhamiegbebho, P.A. and Evivie, S.E., (2016) Shelf life Stability Studies of University of Benin (UNIBEN) Proff's Kilishi Product Asian Journal of Science and Technology 7(1): 2268-2274.

Inusa, S. K. and Said, I. S. (2017) Evaluation of the Chemical and Microbiological Properties Of Kilishi Sold in Kano Metropolis. Journal of Dry land Agriculture, 3 (1): $59-69$.

Lucretia, I. B, Patience, C. Obinna-Echem, Sophia, C. A. (2018) Microbiological quality andantibiotic sensitivity of potential pathogens isolated from meat product (Suya) sold in Rivers State University and its environs. International Journal of Biotechnology and Food Science, 6(4): 67-76.

Matthew, E., Drosos, E., John, L. and Ioanna, P. (2013) MRSA in Africa: Filling the Global Map of Antimicrobial Resistance PLOS One. 8(7): e68024 doi: 10.1371/journal.pone.0068024

Mgbemere, V.N., Akpapunam, M. A. and Igene, J. O., (2011). Effect of Groundnut FlourSubstitution on Yield, Quality and Storage Stability of Kilishi - a Nigerian Indigenous Dried Meat Product. African Journal of Food, Agriculture, Nutrition and Development, $\quad \mathbf{1 1}(2)$ : 4718-4738. 
BAJOPAS Volume 13 Number 1, June, 2020

Mubarak, A. A., Azeez, M. L., Amos A. O., Opeyemi, O. O. (2016) Assessment of Animal Protein Consumption and Food Security Among Rural Households in Kwara State, Nigeria American Journal of Business and Society, 1(4): 233245.

Ndahi, M., D. Kwaga, J., K. P. Bello, M. Kabir J., V. Umoh, .J. Yakubu, S., E. and Nok, A., J. (2013) Prevalence and Antimicrobial Susceptibility of Listeria Monocytogenes and Methicillin-Resistant Staphylococcus aureus Strains from Raw Meat and Meat Products in Zaria, Nigeria. Applied Journal of Microbiology, 58(3):262-9.

Okonko, I.O., Odu, N.N. and Igboh, I.E. (2013). Microbiological Analysis of Kilishi Sold In Port Harcourt, Nigeria. New York Science Journal, 6 (7):37-43.

Osimani, A., Aquilanti, L. and Clementi, F. (2015) Microbiological Quality of Meatbased Meals and Operation of Control Systems within a Food Service Environment. International Food Research Journal 22(4): 1692-1698.

Onuorah, S. Obika, I. Odibo, F. Orji, M. (2015)An Assessment of the Bacteriological Quality of Tsire-Suya (Grilled Beef) sold in Awka, Nigeria. American. J. Life. Sci. Res. 3(4):287292.

Razavilar, V, Khandaghi, J. Barzgari, A. (2010); Isolation of Eschericia coli 0157:H7 from manure fertilized farms and raw vegetables grown on it, in Tabriz city in
Iran. African Journal of Microbiology Research, 4(9): 891-895.

Scallan, E. Hoekstra, R. M. Angulo, F. J.Tauxe, R. V, Widdowson, M. Roy, S. L et al., (2011).Food borne illness acquired in the United States- Major Pathogens. Emerg. Infec Dis, 17(1): 7-15.

Shamsuddeen U (2009). Microbiological quality of spice used in the production of Kilishi a traditionally dried and grilled meat product. Bayero Journal of Pure andApplied Sciences, 2(2): 66-69.

Shamsuddeen, U. (2015) Microbiological Hazard and Critical control point Analysis of Dried and Minced Meat Snacks Produced in Kano Nigeria. Lambert Academic Publishing; Pp 1-36.

Tijani, O.and Jumare, S. (2014). Microblological Quality Assessment of Meat

Sold in KauraNamoda. International Conference on Earth, Environment and Life sciences (EELS) Dubai (UAE).

Udobi, C. E., Obajuluwa, A. F., and Onaolapo, J. A., (2013) Prevalence and Antibiotic Resistance Pattern of MethicillinResistant Staphylococcus aureus from an Orthopaedic Hospital in Nigeria BioMed Research International; 26(6); 6-7.

WHO, 2015 Foodborne diseases in the WHO African Region.

Yousafzai HA, Rind R, Khan MA, Abro SH, Korejo NA, Ejaz M, Kabir A, Shahid M, Memon S. (2019). Microbiological Contamination of Cattle and Meat in Peshawar, Pakistan. J. Anim. Health Prod. 7(1): 1116. 


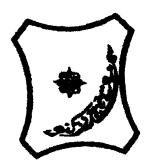

Bayero Journal of Pure and Applied Sciences, 13(1); 40 - 45

Received: September, 2019

Accepted: April, 2020

ISSN $2006-6996$

\title{
BACTERIOLOGICAL QUALITY OF STICK MEAT (Tsire) SOLD IN GARKO LOCAL GOVERNMENT AREA OF KANO STATE, NIGERIA
}

\author{
$*^{1}$ Dahiru A. T. and ${ }^{2}$ Maigari A. K. \\ ${ }^{1}$ Department of Hospitality Management, School of Technology, Kano State Polytechnic, PMB 3348, \\ Kano Nigeria. \\ ${ }^{2}$ Departmnt of Biological Sciences, Bayero University, Kano \\ Corresponding Author: dturajo61@gmail.com; GSM: 08087508262.
}

ABSTRACT

Stick meat, locally called Tsire in Hausa Language, is a significant portion of the diet of a large active population of Northern Nigeria. However, because of the handling and processing methods by the manufacturers as well as the hawking system of stick meat, the meat product may be exposed to both pre- and post-processed product contamination, and thus may poses danger to public health. Therefore, considering the role of Tsire in improving nutrition and increase household income to the populace, the need to improve the processing, distribution and overall quality of the product is simply indispensable. A total of 30 samples (5 samples from each of the 6 sampling points) of Tsire were collected randomly in Garko Town. Aerobic plate counts (APCs) and Total coliform counts (TCCS) of Tsire samples were determined using standard microbiological methods. APCs ranged from $1.02 \times 10^{5}$ to $4.00 \times 10^{5} \mathrm{CFU} / \mathrm{g}$; while TCCs ranged from $8 \mathrm{MPN} / \mathrm{g}$ to $68 \mathrm{MPN} / \mathrm{g}$. From the 30 samples screened, 16(53.33\%) bacteria namely, Campylobacter 2(6.66\%), Escherichia coli 6(20\%), Klebsiella pneumoniae 2(6.66\%), Salmonella spp. 1(3.33\%), Shigella 3(10\%) and Staphylococcus aureus 2(6.66\%) were detected. $E$. coli has the highest isolation rate of 6(20\%), while Salmonella spp. had the least frequency of 1(3.33\%). The distribution of isolated organisms within the study area were as follows: Dausai, 4(80\%), Kofar kudu, 4(80\%), Makwalla, 2(40\%), Rinji, 3(60\%), Tosaro, 2(40\%), and Tsohuwar Kasuwa, 1(20\%). The results have indicated that the Tsire was contaminated with bacteria thus exposing the product to fast deterioration, spoilage and also a vehicle for food borne illness, suggesting for adequate hygienic practices at all the stages, prior to consumption, to ensure safety of the meat product.

Key words: APCs, TCCs, Contamination, Microorganisms, Garko

\section{INTRODUCTION}

Nigeria is one of the developing nations with inadequate food supply and most often deficient in protein content (FAO, 2019). Nigerian's average animal protein intake per head per day is estimated at $7.9 \mathrm{~g}$ as against $35 \mathrm{~g}$ recommended value by Food and Agricultural Organization (Mubarak et al., 2016). These low levels of animal protein intake create great concern as it affects the nutritional status of Nigerians. Hence, there is the need for sufficient supply of animal protein from energy rich animal products to satisfy the nutritional requirements for Nigerians.

Meat is one major source of animal protein largely composed of water, protein and fats which can make it susceptible to microbial contamination within short time leading to spoilage (Apata et al., 2013; Mgbemere et al., 2011). Meat is mostly eaten after it has been cooked or processed in a variety of ways such as sun drying; smoking and roasting with or without fortifications (Borch et al., 1996). In Nigeria meat products such as Tsire, Kilishi and Balangu are locally produced using one or more of these methods in order to meet the nutritional requirements of the teeming Nigerians (Egbebi, 2011).

Tsire is a popular Nigerian traditional processed ready-to-eat roasted stick meat product (Shamsuddeen, 2015). It is sold in public places, along roads, in hotels, parks, quarters and even offices (Falegan et al., 2017). It is prepared from boneless healthy animal flesh such as beef and mutton, spiced with peanut cake, salt, vegetable oil and other flavorings followed by roasting (Shamsuddeen, 2015). Consumption of these products has extended to other parts of African countries such as Ghana, Somali, Cameroun and Chad (Ahmadu and Ibrahim, 2013). 
BAJOPAS Volume 13 Number 1, June, 2020

However, evidence of quality control sticking to procedural hygiene by the handlers during preparation and retailing of these products is poorly documented. Tsire is of great safety risk because of the fact that there are erratic cases of gastroenteritis and symptoms of food infection after consumption (WHO, 2015). Food borne illnesses are one of the major health problems in developing and developed countries (Razavilar, 2010). According to the World Health Organization, WHO (2015), $0.07 \%$ death of the 600 million global burdens of Foodborne illnesses have been reported to be caused by bacteria, viruses, fungi and chemicals. In America $0.27 \%$ of the estimated 48 million affected people is hospitalized and about $0.0063 \%$ deaths are recorded each year (Scallan et al., 2011). More than 91 million people in Africa fall ill and $0.15 \%$ dies each year, making Africa the highest burden bearer of Foodborne diseases per population (WHO, 2015).

Application of a Hazard Analysis Critical Control Point (HACCP) at all stages of meat products preparation is essential in order to ensure its safety. Thus, according to the guidelines of good manufacturing practice, the level of total aerobic bacterial contamination of thermally processed meat products should not exceed $10^{4}\left(\mathrm{cfu} \mathrm{g}^{-1}\right)$. Enterobacteriaceae and faecal coliform contamination in meat products should be within the range of $10^{2}-10^{4}$ and $10-10^{3} \mathrm{cfu} \mathrm{g}^{-1}$, respectively (Shamsuddeen, 2015). The aim of the study is therefore, to assess the total viable bacterial counts of tsire marketed locally within Garko town, and to isolate and identify the organisms at the point of consumption with the intention of promoting public health and food hygiene habits in the Nigerian populace.

\section{MATERIALS AND METHODS Study Area and Population}

Garko is one of the existing 44 local government areas located in Kano south west zone of Kano state with its capital administrative headquarters in the Garko town. It has coordinates $11^{\circ} 39^{\prime} \mathrm{N}$ $8^{\circ} 54^{\prime} \mathrm{E}$, and an area of $450 \mathrm{~km}^{2}$. The projected population of Garko local Government was 225,300 according to the National Population Census report (2018). Garko is known for agricultural activities both farming and animal husbandry. It is popularly known for large scale rice production. Other food crops include sweet potatoes, cassava, onions, sorghum, millet and sugarcane. Cows, sheep and goats are major groups of animals reared by majority of the populace. Meat products processed, retailed and consumed in Garko include roasted meat (Balangu), dried roasted meat (Kilishi), stick meat (Tsire), hide and skin pepper soup (Ragadada) and minced fried meat (Danbunnama).

\section{Samples Collection}

Five samples of Tsire products were collected from 6 different identified locations within Garko town in a sterile foil paper and immediately analyzed for the presence of bacteria.

\section{Sample Preparation}

Sample preparation for the bacteriological analysis was carried out in accordance with the method described by Atlas (1997). Twenty five grams $(25 \mathrm{~g})$ of the sample was homogenized in $225 \mathrm{ml}$ peptone water using Kenwood blender machine to obtain a $10^{1}$ homogenate. The homogenate was thoroughly shaken and $1 \mathrm{ml}$ pipetted into test tubes containing $9 \mathrm{ml}$ of peptone water $\left(10^{2}\right)$. The test tubes were further serially diluted to $10^{5}$.

Total Aerobic Mesophilic Bacterial Count

Total Aerobic mesophilic bacterial count was determined using the method described by Abdullahi et al. (2004) where $1 \mathrm{ml}$ of inoculums from $10^{1}$ to $10^{5}$ dilutions were transferred into duplicate Petri dishes and labeled accordingly. This was followed by pouring aseptically about $15 \mathrm{ml}$ of molten nutrient agar. The culture was homogenized by gentle spinning of the plates and allowed to solidify. The plates were incubated at $37^{\circ} \mathrm{C}$ for 24 hours. Plates containing 30-300 colonies were counted. The number of colony forming units per gram of a sample (cfu/g) was obtained by multiplying the average colony number with the inverse of the dilution factor.

\section{Enumeration and Detection of Coliform bacteria}

Detection and enumeration of coliform was carried out according to method described by Atlas, (1977). A set of 9 test tubes each containing $9 \mathrm{ml}$ of lactose broth and an inverted Durham tubes were autoclaved to expel air and to sterilize. Similarly, $1 \mathrm{ml}$ from the diluents $10^{1}$ was transferred to the first 3 test tubes, followed by $1 \mathrm{ml}$ from the diluents $10^{2}$ to the second set of 3 test tubes and finally the third diluents $10^{3}$ to the $3^{\text {rd }}$ set of 3 test tubes. All the 9 test tubes were incubated at $37^{\circ} \mathrm{C}$ for 24 hours. Tubes that showed gas and acid production after 24 hours were recorded as positive for the presence of Coliform. Negative tubes were further reincubated for 24 hours. Positive tubes were recorded. Estimate of most probable number of Coliform per gram of sample (MPN/g) was determined by comparing the number of gas positive tubes with the most probable number table. 
BAJOPAS Volume 13 Number 1, June, 2020 Identification of Coliform

A loop full of inoculum from gas positive tubes was streaked on to Eosine methylene blue (EMB) agar plate and incubated at $37^{\circ} \mathrm{C}$ for $24 \mathrm{hrs}$. Colonies which formed bluish black color with green metallic sheen, and reddish colonies were isolated on agar slants. Those colonies showing metallic sheen on EMB were sub cultured into tubes of lactose broth and incubated at $45^{\circ} \mathrm{C}$. The tubes were observed after $24 \mathrm{hrs}$ for gas production. This is the completed test for fecal coliform. Gram stain and other biochemical tests such as Indole, Methyl red, Voges-Proskauer and Citrate Utilization tests (IMVIC), Coagulase and Catalase tests were carried out for the Identification and confirmation of isolates.

\section{Procedure for Indole Test}

Indole test was carried out by preparing a Tryptone broth drawn in to test tubes, sterilized by autoclaving, inoculated with loopful of suspension and incubated at $37^{\circ} \mathrm{C}$ for 24 hours. Three drops of xylene was added in tubes, shaken vigorously and kept for the separation of two layers. One millilitre of Kovac's reagent was added and the formation of pink colour ring indicates positive Indole test.

\section{Procedure for Methyl Red Test}

Methyl red test was carried out by preparing Glucose phosphate broth, dispensed in test tubes, sterilized, inoculated with test culture and incubated at $37^{\circ} \mathrm{C}$ for 24 hours. Five drops of methyl-red indicator was added to the medium for the formation of red colour.

\section{Procedure for Voges-Proskauer Test}

Voges-Proskauer test was carried out by inoculating tubes with the bacterial culture followed by incubation for 48 hours at $37^{\circ} \mathrm{C}$. Separate pipettes were used to pipette $1 \mathrm{ml}$ from each culture tube into clean separate tubes. Eighteen drops $(0.5 \mathrm{ml})$ of Barrit's solution A (a-naphthol) was added to each tube containing glucose phosphate broth followed by the addition of an equal amount of solution $B$ into the same tube. The tubes were shaken at 30 seconds interval. A positive reaction was indicated by the development of a pink color, which turns red in 1-2 hours, after vigorous shaking.

\section{Procedure for Citrate Utilization Test}

Citrate Utilization Test was carried out by distributing melted agar (Simmon Citrate Agar) in to test tubes followed by sterilization at $121.5^{\circ} \mathrm{C}$ for 15 minutes. The test tubes were afterward held in slanted position, inoculated with the given bacterial culture and incubated at $37^{\circ} \mathrm{C}$ for $24 \mathrm{hrs}$. Positive test was indicated by color change of the media from green to blue.

\section{RESULTS AND DISCUSSIONS}

The results of this study are presented in tables $1,2,3$ and 4. Among the sampling areas Kofar Kudu had the highest aerobic mesophilic bacteria counts $4.0 \times 10^{5} \mathrm{cfu} / \mathrm{g}$ followed by Rinji $2.72 \times 10^{5} \mathrm{cfu} / \mathrm{g}$, while Tosaro had the least Aerobic mesophilic bacteria counts of $1.02 \times 10^{5}$ $\mathrm{cfu} / \mathrm{g}$ as indicated in Table 1.Makwalla had the highest coliform count $68 \mathrm{MPN} / \mathrm{g}$ followed by Rinji $37 \mathrm{MPN} / \mathrm{g}$. Tsohuwar Kasuwa had the least coliform counts $8 \mathrm{MPN} / \mathrm{g}$, (Table 2). Result from table 1 shows variation in the microbial contents among the samples which suggest variation in their sources, poor handling procedures and contamination from the processing environment. High coliform count and their differences within sampling areas is an indication of poor microbiological quality of the product. Ndahi et al. (2013) reported microbial load to be a function of the handling personnel and the environment. The results indicated that the samples were contaminated with bacteria as the counts exceeded the minimum safety level $\left(10^{4} \mathrm{cfu} / \mathrm{g}\right)$ for members of the Enterobacteriaceae family. However, it might be a reflection of poor hygienic practices which may contribute to health hazard to the potential consumers. Similarly, Inusa and Sa'id (2017); Osimani et al. (2015) reported that, the initial microbial content of the raw material play significant role in influencing the final microbial load of the finished product. Isolation of members of the Enterobacteriaceae such as $E$. coli, Klebsiella pneumoniae, Salmonella and Shigella signifies danger to the public health. These organisms are capable of producing endotoxins which trigger high fevers in infected individuals, and the enterotoxins which colonize the small intestines and lead to extreme dehydration as a result of vomiting and diarrhea sometimes with severe and fatal outcomes (Amaeze et al., 2016). From the 16 isolated organisms $E$. coli had the highest isolation rate $6(37.5 \%)$ (Table 3), this suggest faecal contamination of the products. $E$. coli is a common flora in the gastrointestinal tract responsible for diarrhea and extra-intestinal infections (CDC, 2011). The result is in conformity with the findings of Ndahi et al. (2013) and Shamsuddeen (2009). Also presence of campylobacter might be due to cross contamination from raw meat to finished product (Tsire). Staphylococcus aureus is a normal flora of the skin, nasal, genital, mouth or anal area in both humans and animals without any symptom of an infection (Matthew et al., 2013). Isolation of $S$. aureus in these study concords with the findings of Lucretia et al. (2018) from Suya sold in Rivers State. 
BAJOPAS Volume 13 Number 1, June, 2020

It is also in agreement with the findings of Yousafzai et al. (2018); Onuorah et al. (2015) and Tijjani and Jumare (2014) from tsire samples in different countries. Presence of $S$. aureus in foods is most of the time an indication of poor human handling, poor environment, unhygienic utensils and equipments used during processing (Igene et al., 2016; Okonko et al., 2013). Infections caused by $S$. aureus are difficult to treat leading to long hospitalization with consequent economic loss (Udobi et al., 2013). These include soft tissue infections, pneumonia, hospital-acquired postoperative wound infections, Staphylococcal food poisoning, impetigo and cellulitis (Charlene et al., 2013). Samples obtained from Dausai and Kofar Kudu had the highest isolation rate $4(80 \%)$ (Table 4 ) probably because of the much commercial activities taking place in the area which can lead to environmental contamination.

Table 1: Total Aerobic Mesophilic Bacterial Count of Tsire sold in Garko Town

\begin{tabular}{lll}
\hline Sampling Area & APC cfu/g & Mean \pm STD \\
\hline Dausai & $2.20 \times 10^{5}$ & $110000 \pm 14142.14$ \\
Kofar Kudu & $4.00 \times 10^{5}$ & $133333.3 \pm 23094.01$ \\
Makwalla & $1.30 \times 10^{5}$ & $32500 \pm 7187.953$ \\
Rinji & $2.72 \times 10^{5}$ & $90666.67 \pm 94769.90$ \\
Tosaro & $1.02 \times 10^{5}$ & $51000 \pm 15556.35$ \\
Tsohuwar Kasuwa & $1.75 \times 10^{5}$ & $35000 \pm 11357.82$ \\
\hline
\end{tabular}

Key: APC: Aerobic Mesophilic Counts

STD: Standard Deviation

Table 2: Total Coliform Count of Tsire sold in Garko Town

\begin{tabular}{lcc}
\hline \multicolumn{1}{c}{ Sampling Area } & TCC MPN/g & Mean \pm STD \\
\hline Dausai & 20 & $6.67 \pm 2.5166$ \\
Kofar Kudu & 32 & $16.00 \pm 5.6569$ \\
Makwalla & 68 & $13.60 \pm 8.7062$ \\
Rinji & 37 & $9.25 \pm 4.7871$ \\
Tosaro & 10 & $5.00 \pm 2.8284$ \\
Tsohuwar Kasuwa & 8 & $4.00 \pm 0.0000$ \\
\hline
\end{tabular}

Table 3: Organisms Isolated from Tsire Sold in Garko

\begin{tabular}{lcl}
\hline Isolated Organism & Frequency & Percentage (\%) \\
\hline Campylobacter & 2 & 06.66 \\
Escherichia coli & 6 & 20.00 \\
Klebsiella pneumoniae & 2 & 06.66 \\
Salmonella species & 1 & 03.33 \\
Shigella & 3 & 10.00 \\
Staphylococcus aureus & 2 & 06.66 \\
Total & 16 & \\
\hline
\end{tabular}

Table 4: Distribution of Organisms within Sampling Area

\begin{tabular}{lcc}
\hline \multicolumn{1}{c}{ Sampling Area } & No. Isolated & Percentage (\%) \\
\hline Dausai & 4 & 80 \\
Kofar Kudu & 4 & 80 \\
Makwalla & 2 & 40 \\
Rinji & 3 & 60 \\
Tosaro & 2 & 40 \\
Tsohuwar Kasuwa & 1 & 20 \\
Total & 16 & \\
\hline
\end{tabular}

\section{CONCLUSION}

Results indicated $4.00 \times 10^{5} \mathrm{CFU} / \mathrm{g}$ as the highest APCs count; while $68 \mathrm{MPN} / \mathrm{g}$ was the highest TCCs from the 30 samples analyzed. Among the isolates, $E$. coli has the highest isolation rate of $6(20 \%)$. Dausai and Kofar kudu were having the highest bacteria count of $4(80 \%)$, each, indicating higher contamination in those locations. 
BAJOPAS Volume 13 Number 1, June, 2020 RECOMMENDATIONS

The following recommendations are tenable:

1. Hygienic practices at all stages of production should be improved to safe guard the consumers against potential health hazard.

2. Monitoring of microbiological contamination of Tsire during preparations, packaging and marketing is essential to ensure product of good microbiological quality for consumers' health.

\section{REFERENCES}

Abdullahi, I. O., Umoh, V. J. and Galadima, M. (2004). Hazards Associated with Kilishi Preparations in Zaria. Nigerian Journal of Microbiology, 18 (1-2): $339-345$.

Ahmadu, J. and Ibrahim E. J., (2013): Determinants of Revenue in Suya Production in BeninCity, Edo State, Nigeria. Nigerian journal of agriculture, food and environment.9(3):1-5

Amaeze, N. Aboh, M. Itohan, A. Felix, E. Olatunji, T. and Oladosu, P. (2016) Microbial Profile, Antibiotic Sensitivity and Heat Resistance of Bacterial Isolates from Commercial Roasted Beef (Suya) in Abuja, Nigeria. JOPAT, 15(2): $22-30$.

Apata, E.S., Kuku1, I.A., Apata, O.C. and Adeyemi, K.O. (2013). Evaluation of Suya(Tsire) - An Intermediate Moisture Meat Product in Ogun State, Nigeria. J. Food Res 2 (1): 87.

Atlas, R. M. (1997) Principles of Microbiology Second Edition. C. Brown Publishers. Pp 802-803.

Borch, E. Kant-Muermans, M. L., Blixt, Y. (1996) Bacterial Spoilage of Meat and Cured Meat Products. Int $\mathrm{J}$ Food Microbiol .33(1): 103-20.

Centre for Disease Control, CDC (2011). "Escherichia coli 0157:H7" Division of Bacterial and Mycotic Diseasesht://www.cdc.gov/nczved/divisi ons/dfbmd/diseases/ecoli_0157h7/.

Charlene, R. J., Johnnie, A. D., and John, B. B., (2013) Prevalence and Characterization of Methicillin-Resistant Staphylococcus aureus Isolates from Retail Meat and Humans in Georgia. American society for Microbiology. J. of clinical microbiology. 12(1):123-6 doi:10.1128/JCM.0316612JCM.03166-12

Egbebi, A.O and Seidu, K., T. (2011). Microbiological Evaluation of Suya (dried smoked

meat) Sold in Ado and Akure, South West Nigeria.European Journal of Experinmental Biology, 1(4):1-5
3. Government should establish regulatory bodies responsible for inculcating hygiene habits to the local producers and vendors in order to prevent instant, cross and post processing contaminations by microbial pathogens.

4. Awareness and sensitization of local food producers about good hygienic practices in food handling and processing.

Falegan, C, R., Akoja, S. D., and Oyarekua, M. A., (2017) Microbiological Assessment of Suya (Sliced Roasted Beef) in Ado-Ekiti Metropolis, Ekiti State, Nigeria. MOJ Biology andMedicine.

Fonkem, D., N. Tanya, V., N. and Ebangi, A., L. (2010). Effect of Season on the Microbiological Quality of Kilishi, a Traditional Cameroonian Dried Beef Product. Tropicultura, 28(1): 10-15.

Food and Agricultural Organization of the United Nations (F A O, 1979). Manual of food quality control 4. Microbiological analysis.

Food and Agriculture Organisation of the United Nation (FAO), 2019. Nigeria at a glance.

Igene J.O., Uwadia, O.E., Ebabhamiegbebho, P.A. and Evivie, S.E., (2016) Shelf life Stability Studies of University of Benin (UNIBEN) Proff's Kilishi Product Asian Journal of Science and Technology 7(1): 2268-2274.

Inusa, S. K. and Said, I. S. (2017) Evaluation of the Chemical and Microbiological Properties Of Kilishi Sold in Kano Metropolis. Journal of Dry land Agriculture, 3 (1): $59-69$.

Lucretia, I. B, Patience, C. Obinna-Echem, Sophia, C. A. (2018) Microbiological quality andantibiotic sensitivity of potential pathogens isolated from meat product (Suya) sold in Rivers State University and its environs. International Journal of Biotechnology and Food Science, 6(4): 67-76.

Matthew, E., Drosos, E., John, L. and Ioanna, P. (2013) MRSA in Africa: Filling the Global Map of Antimicrobial Resistance PLOS One. 8(7): e68024 doi: 10.1371/journal.pone.0068024

Mgbemere, V.N., Akpapunam, M. A. and Igene, J. O., (2011). Effect of Groundnut FlourSubstitution on Yield, Quality and Storage Stability of Kilishi - a Nigerian Indigenous Dried Meat Product. African Journal of Food, Agriculture, Nutrition and Development, $\quad \mathbf{1 1}(2)$ : 4718-4738. 
BAJOPAS Volume 13 Number 1, June, 2020

Mubarak, A. A., Azeez, M. L., Amos A. O., Opeyemi, O. O. (2016) Assessment of Animal Protein Consumption and Food Security Among Rural Households in Kwara State, Nigeria American Journal of Business and Society, 1(4): 233245.

Ndahi, M., D. Kwaga, J., K. P. Bello, M. Kabir J., V. Umoh, .J. Yakubu, S., E. and Nok, A., J. (2013) Prevalence and Antimicrobial Susceptibility of Listeria Monocytogenes and Methicillin-Resistant Staphylococcus aureus Strains from Raw Meat and Meat Products in Zaria, Nigeria. Applied Journal of Microbiology, 58(3):262-9.

Okonko, I.O., Odu, N.N. and Igboh, I.E. (2013). Microbiological Analysis of Kilishi Sold In Port Harcourt, Nigeria. New York Science Journal, 6 (7):37-43.

Osimani, A., Aquilanti, L. and Clementi, F. (2015) Microbiological Quality of Meatbased Meals and Operation of Control Systems within a Food Service Environment. International Food Research Journal 22(4): 1692-1698.

Onuorah, S. Obika, I. Odibo, F. Orji, M. (2015)An Assessment of the Bacteriological Quality of Tsire-Suya (Grilled Beef) sold in Awka, Nigeria. American. J. Life. Sci. Res. 3(4):287292.

Razavilar, V, Khandaghi, J. Barzgari, A. (2010); Isolation of Eschericia coli 0157:H7 from manure fertilized farms and raw vegetables grown on it, in Tabriz city in
Iran. African Journal of Microbiology Research, 4(9): 891-895.

Scallan, E. Hoekstra, R. M. Angulo, F. J.Tauxe, R. V, Widdowson, M. Roy, S. L et al., (2011).Food borne illness acquired in the United States- Major Pathogens. Emerg. Infec Dis, 17(1): 7-15.

Shamsuddeen U (2009). Microbiological quality of spice used in the production of Kilishi a traditionally dried and grilled meat product. Bayero Journal of Pure andApplied Sciences, 2(2): 66-69.

Shamsuddeen, U. (2015) Microbiological Hazard and Critical control point Analysis of Dried and Minced Meat Snacks Produced in Kano Nigeria. Lambert Academic Publishing; Pp 1-36.

Tijani, O.and Jumare, S. (2014). Microblological Quality Assessment of Meat

Sold in KauraNamoda. International Conference on Earth, Environment and Life sciences (EELS) Dubai (UAE).

Udobi, C. E., Obajuluwa, A. F., and Onaolapo, J. A., (2013) Prevalence and Antibiotic Resistance Pattern of MethicillinResistant Staphylococcus aureus from an Orthopaedic Hospital in Nigeria BioMed Research International; 26(6); 6-7.

WHO, 2015 Foodborne diseases in the WHO African Region.

Yousafzai HA, Rind R, Khan MA, Abro SH, Korejo NA, Ejaz M, Kabir A, Shahid M, Memon S. (2019). Microbiological Contamination of Cattle and Meat in Peshawar, Pakistan. J. Anim. Health Prod. 7(1): 1116. 


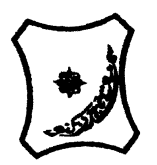

Bayero Journal of Pure and Applied Sciences, 13(1); 40 - 45

Received: September, 2019

Accepted: April, 2020

ISSN $2006-6996$

\title{
BACTERIOLOGICAL QUALITY OF STICK MEAT (Tsire) SOLD IN GARKO LOCAL GOVERNMENT AREA OF KANO STATE, NIGERIA
}

\author{
$*^{1}$ Dahiru A. T. and ${ }^{2}$ Maigari A. K. \\ ${ }^{1}$ Department of Hospitality Management, School of Technology, Kano State Polytechnic, PMB 3348, \\ Kano Nigeria. \\ ${ }^{2}$ Departmnt of Biological Sciences, Bayero University, Kano \\ Corresponding Author: dturajo61@gmail.com; GSM: 08087508262.
}

ABSTRACT

Stick meat, locally called Tsire in Hausa Language, is a significant portion of the diet of a large active population of Northern Nigeria. However, because of the handling and processing methods by the manufacturers as well as the hawking system of stick meat, the meat product may be exposed to both pre- and post-processed product contamination, and thus may poses danger to public health. Therefore, considering the role of Tsire in improving nutrition and increase household income to the populace, the need to improve the processing, distribution and overall quality of the product is simply indispensable. A total of 30 samples (5 samples from each of the 6 sampling points) of Tsire were collected randomly in Garko Town. Aerobic plate counts (APCs) and Total coliform counts (TCCS) of Tsire samples were determined using standard microbiological methods. APCs ranged from $1.02 \times 10^{5}$ to $4.00 \times 10^{5} \mathrm{CFU} / \mathrm{g}$; while TCCs ranged from $8 \mathrm{MPN} / \mathrm{g}$ to $68 \mathrm{MPN} / \mathrm{g}$. From the 30 samples screened, 16(53.33\%) bacteria namely, Campylobacter 2(6.66\%), Escherichia coli 6(20\%), Klebsiella pneumoniae 2(6.66\%), Salmonella spp. 1(3.33\%), Shigella 3(10\%) and Staphylococcus aureus 2(6.66\%) were detected. $E$. coli has the highest isolation rate of 6(20\%), while Salmonella spp. had the least frequency of 1(3.33\%). The distribution of isolated organisms within the study area were as follows: Dausai, 4(80\%), Kofar kudu, 4(80\%), Makwalla, 2(40\%), Rinji, 3(60\%), Tosaro, 2(40\%), and Tsohuwar Kasuwa, 1(20\%). The results have indicated that the Tsire was contaminated with bacteria thus exposing the product to fast deterioration, spoilage and also a vehicle for food borne illness, suggesting for adequate hygienic practices at all the stages, prior to consumption, to ensure safety of the meat product.

Key words: APCs, TCCs, Contamination, Microorganisms, Garko

\section{INTRODUCTION}

Nigeria is one of the developing nations with inadequate food supply and most often deficient in protein content (FAO, 2019). Nigerian's average animal protein intake per head per day is estimated at $7.9 \mathrm{~g}$ as against $35 \mathrm{~g}$ recommended value by Food and Agricultural Organization (Mubarak et al., 2016). These low levels of animal protein intake create great concern as it affects the nutritional status of Nigerians. Hence, there is the need for sufficient supply of animal protein from energy rich animal products to satisfy the nutritional requirements for Nigerians.

Meat is one major source of animal protein largely composed of water, protein and fats which can make it susceptible to microbial contamination within short time leading to spoilage (Apata et al., 2013; Mgbemere et al., 2011). Meat is mostly eaten after it has been cooked or processed in a variety of ways such as sun drying; smoking and roasting with or without fortifications (Borch et al., 1996). In Nigeria meat products such as Tsire, Kilishi and Balangu are locally produced using one or more of these methods in order to meet the nutritional requirements of the teeming Nigerians (Egbebi, 2011).

Tsire is a popular Nigerian traditional processed ready-to-eat roasted stick meat product (Shamsuddeen, 2015). It is sold in public places, along roads, in hotels, parks, quarters and even offices (Falegan et al., 2017). It is prepared from boneless healthy animal flesh such as beef and mutton, spiced with peanut cake, salt, vegetable oil and other flavorings followed by roasting (Shamsuddeen, 2015). Consumption of these products has extended to other parts of African countries such as Ghana, Somali, Cameroun and Chad (Ahmadu and Ibrahim, 2013). 
BAJOPAS Volume 13 Number 1, June, 2020

However, evidence of quality control sticking to procedural hygiene by the handlers during preparation and retailing of these products is poorly documented. Tsire is of great safety risk because of the fact that there are erratic cases of gastroenteritis and symptoms of food infection after consumption (WHO, 2015). Food borne illnesses are one of the major health problems in developing and developed countries (Razavilar, 2010). According to the World Health Organization, WHO (2015), $0.07 \%$ death of the 600 million global burdens of Foodborne illnesses have been reported to be caused by bacteria, viruses, fungi and chemicals. In America $0.27 \%$ of the estimated 48 million affected people is hospitalized and about $0.0063 \%$ deaths are recorded each year (Scallan et al., 2011). More than 91 million people in Africa fall ill and $0.15 \%$ dies each year, making Africa the highest burden bearer of Foodborne diseases per population (WHO, 2015).

Application of a Hazard Analysis Critical Control Point (HACCP) at all stages of meat products preparation is essential in order to ensure its safety. Thus, according to the guidelines of good manufacturing practice, the level of total aerobic bacterial contamination of thermally processed meat products should not exceed $10^{4}\left(\mathrm{cfu} \mathrm{g}^{-1}\right)$. Enterobacteriaceae and faecal coliform contamination in meat products should be within the range of $10^{2}-10^{4}$ and $10-10^{3} \mathrm{cfu} \mathrm{g}^{-1}$, respectively (Shamsuddeen, 2015). The aim of the study is therefore, to assess the total viable bacterial counts of tsire marketed locally within Garko town, and to isolate and identify the organisms at the point of consumption with the intention of promoting public health and food hygiene habits in the Nigerian populace.

\section{MATERIALS AND METHODS Study Area and Population}

Garko is one of the existing 44 local government areas located in Kano south west zone of Kano state with its capital administrative headquarters in the Garko town. It has coordinates $11^{\circ} 39^{\prime} \mathrm{N}$ $8^{\circ} 54^{\prime} \mathrm{E}$, and an area of $450 \mathrm{~km}^{2}$. The projected population of Garko local Government was 225,300 according to the National Population Census report (2018). Garko is known for agricultural activities both farming and animal husbandry. It is popularly known for large scale rice production. Other food crops include sweet potatoes, cassava, onions, sorghum, millet and sugarcane. Cows, sheep and goats are major groups of animals reared by majority of the populace. Meat products processed, retailed and consumed in Garko include roasted meat (Balangu), dried roasted meat (Kilishi), stick meat (Tsire), hide and skin pepper soup (Ragadada) and minced fried meat (Danbunnama).

\section{Samples Collection}

Five samples of Tsire products were collected from 6 different identified locations within Garko town in a sterile foil paper and immediately analyzed for the presence of bacteria.

\section{Sample Preparation}

Sample preparation for the bacteriological analysis was carried out in accordance with the method described by Atlas (1997). Twenty five grams $(25 \mathrm{~g})$ of the sample was homogenized in $225 \mathrm{ml}$ peptone water using Kenwood blender machine to obtain a $10^{1}$ homogenate. The homogenate was thoroughly shaken and $1 \mathrm{ml}$ pipetted into test tubes containing $9 \mathrm{ml}$ of peptone water $\left(10^{2}\right)$. The test tubes were further serially diluted to $10^{5}$.

Total Aerobic Mesophilic Bacterial Count

Total Aerobic mesophilic bacterial count was determined using the method described by Abdullahi et al. (2004) where $1 \mathrm{ml}$ of inoculums from $10^{1}$ to $10^{5}$ dilutions were transferred into duplicate Petri dishes and labeled accordingly. This was followed by pouring aseptically about $15 \mathrm{ml}$ of molten nutrient agar. The culture was homogenized by gentle spinning of the plates and allowed to solidify. The plates were incubated at $37^{\circ} \mathrm{C}$ for 24 hours. Plates containing 30-300 colonies were counted. The number of colony forming units per gram of a sample (cfu/g) was obtained by multiplying the average colony number with the inverse of the dilution factor.

\section{Enumeration and Detection of Coliform bacteria}

Detection and enumeration of coliform was carried out according to method described by Atlas, (1977). A set of 9 test tubes each containing $9 \mathrm{ml}$ of lactose broth and an inverted Durham tubes were autoclaved to expel air and to sterilize. Similarly, $1 \mathrm{ml}$ from the diluents $10^{1}$ was transferred to the first 3 test tubes, followed by $1 \mathrm{ml}$ from the diluents $10^{2}$ to the second set of 3 test tubes and finally the third diluents $10^{3}$ to the $3^{\text {rd }}$ set of 3 test tubes. All the 9 test tubes were incubated at $37^{\circ} \mathrm{C}$ for 24 hours. Tubes that showed gas and acid production after 24 hours were recorded as positive for the presence of Coliform. Negative tubes were further reincubated for 24 hours. Positive tubes were recorded. Estimate of most probable number of Coliform per gram of sample (MPN/g) was determined by comparing the number of gas positive tubes with the most probable number table. 
BAJOPAS Volume 13 Number 1, June, 2020 Identification of Coliform

A loop full of inoculum from gas positive tubes was streaked on to Eosine methylene blue (EMB) agar plate and incubated at $37^{\circ} \mathrm{C}$ for $24 \mathrm{hrs}$. Colonies which formed bluish black color with green metallic sheen, and reddish colonies were isolated on agar slants. Those colonies showing metallic sheen on EMB were sub cultured into tubes of lactose broth and incubated at $45^{\circ} \mathrm{C}$. The tubes were observed after $24 \mathrm{hrs}$ for gas production. This is the completed test for fecal coliform. Gram stain and other biochemical tests such as Indole, Methyl red, Voges-Proskauer and Citrate Utilization tests (IMVIC), Coagulase and Catalase tests were carried out for the Identification and confirmation of isolates.

\section{Procedure for Indole Test}

Indole test was carried out by preparing a Tryptone broth drawn in to test tubes, sterilized by autoclaving, inoculated with loopful of suspension and incubated at $37^{\circ} \mathrm{C}$ for 24 hours. Three drops of xylene was added in tubes, shaken vigorously and kept for the separation of two layers. One millilitre of Kovac's reagent was added and the formation of pink colour ring indicates positive Indole test.

\section{Procedure for Methyl Red Test}

Methyl red test was carried out by preparing Glucose phosphate broth, dispensed in test tubes, sterilized, inoculated with test culture and incubated at $37^{\circ} \mathrm{C}$ for 24 hours. Five drops of methyl-red indicator was added to the medium for the formation of red colour.

\section{Procedure for Voges-Proskauer Test}

Voges-Proskauer test was carried out by inoculating tubes with the bacterial culture followed by incubation for 48 hours at $37^{\circ} \mathrm{C}$. Separate pipettes were used to pipette $1 \mathrm{ml}$ from each culture tube into clean separate tubes. Eighteen drops $(0.5 \mathrm{ml})$ of Barrit's solution A (a-naphthol) was added to each tube containing glucose phosphate broth followed by the addition of an equal amount of solution $B$ into the same tube. The tubes were shaken at 30 seconds interval. A positive reaction was indicated by the development of a pink color, which turns red in 1-2 hours, after vigorous shaking.

\section{Procedure for Citrate Utilization Test}

Citrate Utilization Test was carried out by distributing melted agar (Simmon Citrate Agar) in to test tubes followed by sterilization at $121.5^{\circ} \mathrm{C}$ for 15 minutes. The test tubes were afterward held in slanted position, inoculated with the given bacterial culture and incubated at $37^{\circ} \mathrm{C}$ for $24 \mathrm{hrs}$. Positive test was indicated by color change of the media from green to blue.

\section{RESULTS AND DISCUSSIONS}

The results of this study are presented in tables $1,2,3$ and 4. Among the sampling areas Kofar Kudu had the highest aerobic mesophilic bacteria counts $4.0 \times 10^{5} \mathrm{cfu} / \mathrm{g}$ followed by Rinji $2.72 \times 10^{5} \mathrm{cfu} / \mathrm{g}$, while Tosaro had the least Aerobic mesophilic bacteria counts of $1.02 \times 10^{5}$ $\mathrm{cfu} / \mathrm{g}$ as indicated in Table 1.Makwalla had the highest coliform count $68 \mathrm{MPN} / \mathrm{g}$ followed by Rinji $37 \mathrm{MPN} / \mathrm{g}$. Tsohuwar Kasuwa had the least coliform counts $8 \mathrm{MPN} / \mathrm{g}$, (Table 2). Result from table 1 shows variation in the microbial contents among the samples which suggest variation in their sources, poor handling procedures and contamination from the processing environment. High coliform count and their differences within sampling areas is an indication of poor microbiological quality of the product. Ndahi et al. (2013) reported microbial load to be a function of the handling personnel and the environment. The results indicated that the samples were contaminated with bacteria as the counts exceeded the minimum safety level $\left(10^{4} \mathrm{cfu} / \mathrm{g}\right)$ for members of the Enterobacteriaceae family. However, it might be a reflection of poor hygienic practices which may contribute to health hazard to the potential consumers. Similarly, Inusa and Sa'id (2017); Osimani et al. (2015) reported that, the initial microbial content of the raw material play significant role in influencing the final microbial load of the finished product. Isolation of members of the Enterobacteriaceae such as $E$. coli, Klebsiella pneumoniae, Salmonella and Shigella signifies danger to the public health. These organisms are capable of producing endotoxins which trigger high fevers in infected individuals, and the enterotoxins which colonize the small intestines and lead to extreme dehydration as a result of vomiting and diarrhea sometimes with severe and fatal outcomes (Amaeze et al., 2016). From the 16 isolated organisms $E$. coli had the highest isolation rate $6(37.5 \%)$ (Table 3), this suggest faecal contamination of the products. $E$. coli is a common flora in the gastrointestinal tract responsible for diarrhea and extra-intestinal infections (CDC, 2011). The result is in conformity with the findings of Ndahi et al. (2013) and Shamsuddeen (2009). Also presence of campylobacter might be due to cross contamination from raw meat to finished product (Tsire). Staphylococcus aureus is a normal flora of the skin, nasal, genital, mouth or anal area in both humans and animals without any symptom of an infection (Matthew et al., 2013). Isolation of $S$. aureus in these study concords with the findings of Lucretia et al. (2018) from Suya sold in Rivers State. 
BAJOPAS Volume 13 Number 1, June, 2020

It is also in agreement with the findings of Yousafzai et al. (2018); Onuorah et al. (2015) and Tijjani and Jumare (2014) from tsire samples in different countries. Presence of $S$. aureus in foods is most of the time an indication of poor human handling, poor environment, unhygienic utensils and equipments used during processing (Igene et al., 2016; Okonko et al., 2013). Infections caused by $S$. aureus are difficult to treat leading to long hospitalization with consequent economic loss (Udobi et al., 2013). These include soft tissue infections, pneumonia, hospital-acquired postoperative wound infections, Staphylococcal food poisoning, impetigo and cellulitis (Charlene et al., 2013). Samples obtained from Dausai and Kofar Kudu had the highest isolation rate $4(80 \%)$ (Table 4 ) probably because of the much commercial activities taking place in the area which can lead to environmental contamination.

Table 1: Total Aerobic Mesophilic Bacterial Count of Tsire sold in Garko Town

\begin{tabular}{lll}
\hline Sampling Area & APC cfu/g & Mean \pm STD \\
\hline Dausai & $2.20 \times 10^{5}$ & $110000 \pm 14142.14$ \\
Kofar Kudu & $4.00 \times 10^{5}$ & $133333.3 \pm 23094.01$ \\
Makwalla & $1.30 \times 10^{5}$ & $32500 \pm 7187.953$ \\
Rinji & $2.72 \times 10^{5}$ & $90666.67 \pm 94769.90$ \\
Tosaro & $1.02 \times 10^{5}$ & $51000 \pm 15556.35$ \\
Tsohuwar Kasuwa & $1.75 \times 10^{5}$ & $35000 \pm 11357.82$ \\
\hline
\end{tabular}

Key: APC: Aerobic Mesophilic Counts

STD: Standard Deviation

Table 2: Total Coliform Count of Tsire sold in Garko Town

\begin{tabular}{lcc}
\hline \multicolumn{1}{c}{ Sampling Area } & TCC MPN/g & Mean \pm STD \\
\hline Dausai & 20 & $6.67 \pm 2.5166$ \\
Kofar Kudu & 32 & $16.00 \pm 5.6569$ \\
Makwalla & 68 & $13.60 \pm 8.7062$ \\
Rinji & 37 & $9.25 \pm 4.7871$ \\
Tosaro & 10 & $5.00 \pm 2.8284$ \\
Tsohuwar Kasuwa & 8 & $4.00 \pm 0.0000$ \\
\hline
\end{tabular}

Table 3: Organisms Isolated from Tsire Sold in Garko

\begin{tabular}{lcl}
\hline Isolated Organism & Frequency & Percentage (\%) \\
\hline Campylobacter & 2 & 06.66 \\
Escherichia coli & 6 & 20.00 \\
Klebsiella pneumoniae & 2 & 06.66 \\
Salmonella species & 1 & 03.33 \\
Shigella & 3 & 10.00 \\
Staphylococcus aureus & 2 & 06.66 \\
Total & 16 & \\
\hline
\end{tabular}

Table 4: Distribution of Organisms within Sampling Area

\begin{tabular}{lcc}
\hline \multicolumn{1}{c}{ Sampling Area } & No. Isolated & Percentage (\%) \\
\hline Dausai & 4 & 80 \\
Kofar Kudu & 4 & 80 \\
Makwalla & 2 & 40 \\
Rinji & 3 & 60 \\
Tosaro & 2 & 40 \\
Tsohuwar Kasuwa & 1 & 20 \\
Total & 16 & \\
\hline
\end{tabular}

\section{CONCLUSION}

Results indicated $4.00 \times 10^{5} \mathrm{CFU} / \mathrm{g}$ as the highest APCs count; while $68 \mathrm{MPN} / \mathrm{g}$ was the highest TCCs from the 30 samples analyzed. Among the isolates, $E$. coli has the highest isolation rate of $6(20 \%)$. Dausai and Kofar kudu were having the highest bacteria count of $4(80 \%)$, each, indicating higher contamination in those locations. 
BAJOPAS Volume 13 Number 1, June, 2020 RECOMMENDATIONS

The following recommendations are tenable:

1. Hygienic practices at all stages of production should be improved to safe guard the consumers against potential health hazard.

2. Monitoring of microbiological contamination of Tsire during preparations, packaging and marketing is essential to ensure product of good microbiological quality for consumers' health.

\section{REFERENCES}

Abdullahi, I. O., Umoh, V. J. and Galadima, M. (2004). Hazards Associated with Kilishi Preparations in Zaria. Nigerian Journal of Microbiology, 18 (1-2): $339-345$.

Ahmadu, J. and Ibrahim E. J., (2013): Determinants of Revenue in Suya Production in BeninCity, Edo State, Nigeria. Nigerian journal of agriculture, food and environment.9(3):1-5

Amaeze, N. Aboh, M. Itohan, A. Felix, E. Olatunji, T. and Oladosu, P. (2016) Microbial Profile, Antibiotic Sensitivity and Heat Resistance of Bacterial Isolates from Commercial Roasted Beef (Suya) in Abuja, Nigeria. JOPAT, 15(2): $22-30$.

Apata, E.S., Kuku1, I.A., Apata, O.C. and Adeyemi, K.O. (2013). Evaluation of Suya(Tsire) - An Intermediate Moisture Meat Product in Ogun State, Nigeria. J. Food Res 2 (1): 87.

Atlas, R. M. (1997) Principles of Microbiology Second Edition. C. Brown Publishers. Pp 802-803.

Borch, E. Kant-Muermans, M. L., Blixt, Y. (1996) Bacterial Spoilage of Meat and Cured Meat Products. Int $\mathrm{J}$ Food Microbiol .33(1): 103-20.

Centre for Disease Control, CDC (2011). "Escherichia coli 0157:H7" Division of Bacterial and Mycotic Diseasesht://www.cdc.gov/nczved/divisi ons/dfbmd/diseases/ecoli_0157h7/.

Charlene, R. J., Johnnie, A. D., and John, B. B., (2013) Prevalence and Characterization of Methicillin-Resistant Staphylococcus aureus Isolates from Retail Meat and Humans in Georgia. American society for Microbiology. J. of clinical microbiology. 12(1):123-6 doi:10.1128/JCM.0316612JCM.03166-12

Egbebi, A.O and Seidu, K., T. (2011). Microbiological Evaluation of Suya (dried smoked

meat) Sold in Ado and Akure, South West Nigeria.European Journal of Experinmental Biology, 1(4):1-5
3. Government should establish regulatory bodies responsible for inculcating hygiene habits to the local producers and vendors in order to prevent instant, cross and post processing contaminations by microbial pathogens.

4. Awareness and sensitization of local food producers about good hygienic practices in food handling and processing.

Falegan, C, R., Akoja, S. D., and Oyarekua, M. A., (2017) Microbiological Assessment of Suya (Sliced Roasted Beef) in Ado-Ekiti Metropolis, Ekiti State, Nigeria. MOJ Biology andMedicine.

Fonkem, D., N. Tanya, V., N. and Ebangi, A., L. (2010). Effect of Season on the Microbiological Quality of Kilishi, a Traditional Cameroonian Dried Beef Product. Tropicultura, 28(1): 10-15.

Food and Agricultural Organization of the United Nations (F A O, 1979). Manual of food quality control 4. Microbiological analysis.

Food and Agriculture Organisation of the United Nation (FAO), 2019. Nigeria at a glance.

Igene J.O., Uwadia, O.E., Ebabhamiegbebho, P.A. and Evivie, S.E., (2016) Shelf life Stability Studies of University of Benin (UNIBEN) Proff's Kilishi Product Asian Journal of Science and Technology 7(1): 2268-2274.

Inusa, S. K. and Said, I. S. (2017) Evaluation of the Chemical and Microbiological Properties Of Kilishi Sold in Kano Metropolis. Journal of Dry land Agriculture, 3 (1): $59-69$.

Lucretia, I. B, Patience, C. Obinna-Echem, Sophia, C. A. (2018) Microbiological quality andantibiotic sensitivity of potential pathogens isolated from meat product (Suya) sold in Rivers State University and its environs. International Journal of Biotechnology and Food Science, 6(4): 67-76.

Matthew, E., Drosos, E., John, L. and Ioanna, P. (2013) MRSA in Africa: Filling the Global Map of Antimicrobial Resistance PLOS One. 8(7): e68024 doi: 10.1371/journal.pone.0068024

Mgbemere, V.N., Akpapunam, M. A. and Igene, J. O., (2011). Effect of Groundnut FlourSubstitution on Yield, Quality and Storage Stability of Kilishi - a Nigerian Indigenous Dried Meat Product. African Journal of Food, Agriculture, Nutrition and Development, $\quad \mathbf{1 1}(2)$ : 4718-4738. 
BAJOPAS Volume 13 Number 1, June, 2020

Mubarak, A. A., Azeez, M. L., Amos A. O., Opeyemi, O. O. (2016) Assessment of Animal Protein Consumption and Food Security Among Rural Households in Kwara State, Nigeria American Journal of Business and Society, 1(4): 233245.

Ndahi, M., D. Kwaga, J., K. P. Bello, M. Kabir J., V. Umoh, .J. Yakubu, S., E. and Nok, A., J. (2013) Prevalence and Antimicrobial Susceptibility of Listeria Monocytogenes and Methicillin-Resistant Staphylococcus aureus Strains from Raw Meat and Meat Products in Zaria, Nigeria. Applied Journal of Microbiology, 58(3):262-9.

Okonko, I.O., Odu, N.N. and Igboh, I.E. (2013). Microbiological Analysis of Kilishi Sold In Port Harcourt, Nigeria. New York Science Journal, 6 (7):37-43.

Osimani, A., Aquilanti, L. and Clementi, F. (2015) Microbiological Quality of Meatbased Meals and Operation of Control Systems within a Food Service Environment. International Food Research Journal 22(4): 1692-1698.

Onuorah, S. Obika, I. Odibo, F. Orji, M. (2015)An Assessment of the Bacteriological Quality of Tsire-Suya (Grilled Beef) sold in Awka, Nigeria. American. J. Life. Sci. Res. 3(4):287292.

Razavilar, V, Khandaghi, J. Barzgari, A. (2010); Isolation of Eschericia coli 0157:H7 from manure fertilized farms and raw vegetables grown on it, in Tabriz city in
Iran. African Journal of Microbiology Research, 4(9): 891-895.

Scallan, E. Hoekstra, R. M. Angulo, F. J.Tauxe, R. V, Widdowson, M. Roy, S. L et al., (2011).Food borne illness acquired in the United States- Major Pathogens. Emerg. Infec Dis, 17(1): 7-15.

Shamsuddeen U (2009). Microbiological quality of spice used in the production of Kilishi a traditionally dried and grilled meat product. Bayero Journal of Pure andApplied Sciences, 2(2): 66-69.

Shamsuddeen, U. (2015) Microbiological Hazard and Critical control point Analysis of Dried and Minced Meat Snacks Produced in Kano Nigeria. Lambert Academic Publishing; Pp 1-36.

Tijani, O.and Jumare, S. (2014). Microblological Quality Assessment of Meat

Sold in KauraNamoda. International Conference on Earth, Environment and Life sciences (EELS) Dubai (UAE).

Udobi, C. E., Obajuluwa, A. F., and Onaolapo, J. A., (2013) Prevalence and Antibiotic Resistance Pattern of MethicillinResistant Staphylococcus aureus from an Orthopaedic Hospital in Nigeria BioMed Research International; 26(6); 6-7.

WHO, 2015 Foodborne diseases in the WHO African Region.

Yousafzai HA, Rind R, Khan MA, Abro SH, Korejo NA, Ejaz M, Kabir A, Shahid M, Memon S. (2019). Microbiological Contamination of Cattle and Meat in Peshawar, Pakistan. J. Anim. Health Prod. 7(1): 1116. 


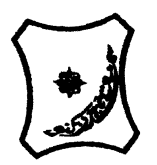

Bayero Journal of Pure and Applied Sciences, 13(1); 40 - 45

Received: September, 2019

Accepted: April, 2020

ISSN $2006-6996$

\title{
BACTERIOLOGICAL QUALITY OF STICK MEAT (Tsire) SOLD IN GARKO LOCAL GOVERNMENT AREA OF KANO STATE, NIGERIA
}

\author{
$*^{1}$ Dahiru A. T. and ${ }^{2}$ Maigari A. K. \\ ${ }^{1}$ Department of Hospitality Management, School of Technology, Kano State Polytechnic, PMB 3348, \\ Kano Nigeria. \\ ${ }^{2}$ Departmnt of Biological Sciences, Bayero University, Kano \\ Corresponding Author: dturajo61@gmail.com; GSM: 08087508262.
}

ABSTRACT

Stick meat, locally called Tsire in Hausa Language, is a significant portion of the diet of a large active population of Northern Nigeria. However, because of the handling and processing methods by the manufacturers as well as the hawking system of stick meat, the meat product may be exposed to both pre- and post-processed product contamination, and thus may poses danger to public health. Therefore, considering the role of Tsire in improving nutrition and increase household income to the populace, the need to improve the processing, distribution and overall quality of the product is simply indispensable. A total of 30 samples (5 samples from each of the 6 sampling points) of Tsire were collected randomly in Garko Town. Aerobic plate counts (APCs) and Total coliform counts (TCCS) of Tsire samples were determined using standard microbiological methods. APCs ranged from $1.02 \times 10^{5}$ to $4.00 \times 10^{5} \mathrm{CFU} / \mathrm{g}$; while TCCs ranged from $8 \mathrm{MPN} / \mathrm{g}$ to $68 \mathrm{MPN} / \mathrm{g}$. From the 30 samples screened, 16(53.33\%) bacteria namely, Campylobacter 2(6.66\%), Escherichia coli 6(20\%), Klebsiella pneumoniae 2(6.66\%), Salmonella spp. 1(3.33\%), Shigella 3(10\%) and Staphylococcus aureus 2(6.66\%) were detected. $E$. coli has the highest isolation rate of 6(20\%), while Salmonella spp. had the least frequency of 1(3.33\%). The distribution of isolated organisms within the study area were as follows: Dausai, 4(80\%), Kofar kudu, 4(80\%), Makwalla, 2(40\%), Rinji, 3(60\%), Tosaro, 2(40\%), and Tsohuwar Kasuwa, 1(20\%). The results have indicated that the Tsire was contaminated with bacteria thus exposing the product to fast deterioration, spoilage and also a vehicle for food borne illness, suggesting for adequate hygienic practices at all the stages, prior to consumption, to ensure safety of the meat product.

Key words: APCs, TCCs, Contamination, Microorganisms, Garko

\section{INTRODUCTION}

Nigeria is one of the developing nations with inadequate food supply and most often deficient in protein content (FAO, 2019). Nigerian's average animal protein intake per head per day is estimated at $7.9 \mathrm{~g}$ as against $35 \mathrm{~g}$ recommended value by Food and Agricultural Organization (Mubarak et al., 2016). These low levels of animal protein intake create great concern as it affects the nutritional status of Nigerians. Hence, there is the need for sufficient supply of animal protein from energy rich animal products to satisfy the nutritional requirements for Nigerians.

Meat is one major source of animal protein largely composed of water, protein and fats which can make it susceptible to microbial contamination within short time leading to spoilage (Apata et al., 2013; Mgbemere et al., 2011). Meat is mostly eaten after it has been cooked or processed in a variety of ways such as sun drying; smoking and roasting with or without fortifications (Borch et al., 1996). In Nigeria meat products such as Tsire, Kilishi and Balangu are locally produced using one or more of these methods in order to meet the nutritional requirements of the teeming Nigerians (Egbebi, 2011).

Tsire is a popular Nigerian traditional processed ready-to-eat roasted stick meat product (Shamsuddeen, 2015). It is sold in public places, along roads, in hotels, parks, quarters and even offices (Falegan et al., 2017). It is prepared from boneless healthy animal flesh such as beef and mutton, spiced with peanut cake, salt, vegetable oil and other flavorings followed by roasting (Shamsuddeen, 2015). Consumption of these products has extended to other parts of African countries such as Ghana, Somali, Cameroun and Chad (Ahmadu and Ibrahim, 2013). 
BAJOPAS Volume 13 Number 1, June, 2020

However, evidence of quality control sticking to procedural hygiene by the handlers during preparation and retailing of these products is poorly documented. Tsire is of great safety risk because of the fact that there are erratic cases of gastroenteritis and symptoms of food infection after consumption (WHO, 2015). Food borne illnesses are one of the major health problems in developing and developed countries (Razavilar, 2010). According to the World Health Organization, WHO (2015), $0.07 \%$ death of the 600 million global burdens of Foodborne illnesses have been reported to be caused by bacteria, viruses, fungi and chemicals. In America $0.27 \%$ of the estimated 48 million affected people is hospitalized and about $0.0063 \%$ deaths are recorded each year (Scallan et al., 2011). More than 91 million people in Africa fall ill and $0.15 \%$ dies each year, making Africa the highest burden bearer of Foodborne diseases per population (WHO, 2015).

Application of a Hazard Analysis Critical Control Point (HACCP) at all stages of meat products preparation is essential in order to ensure its safety. Thus, according to the guidelines of good manufacturing practice, the level of total aerobic bacterial contamination of thermally processed meat products should not exceed $10^{4}\left(\mathrm{cfu} \mathrm{g}^{-1}\right)$. Enterobacteriaceae and faecal coliform contamination in meat products should be within the range of $10^{2}-10^{4}$ and $10-10^{3} \mathrm{cfu} \mathrm{g}^{-1}$, respectively (Shamsuddeen, 2015). The aim of the study is therefore, to assess the total viable bacterial counts of tsire marketed locally within Garko town, and to isolate and identify the organisms at the point of consumption with the intention of promoting public health and food hygiene habits in the Nigerian populace.

\section{MATERIALS AND METHODS Study Area and Population}

Garko is one of the existing 44 local government areas located in Kano south west zone of Kano state with its capital administrative headquarters in the Garko town. It has coordinates $11^{\circ} 39^{\prime} \mathrm{N}$ $8^{\circ} 54^{\prime} \mathrm{E}$, and an area of $450 \mathrm{~km}^{2}$. The projected population of Garko local Government was 225,300 according to the National Population Census report (2018). Garko is known for agricultural activities both farming and animal husbandry. It is popularly known for large scale rice production. Other food crops include sweet potatoes, cassava, onions, sorghum, millet and sugarcane. Cows, sheep and goats are major groups of animals reared by majority of the populace. Meat products processed, retailed and consumed in Garko include roasted meat (Balangu), dried roasted meat (Kilishi), stick meat (Tsire), hide and skin pepper soup (Ragadada) and minced fried meat (Danbunnama).

\section{Samples Collection}

Five samples of Tsire products were collected from 6 different identified locations within Garko town in a sterile foil paper and immediately analyzed for the presence of bacteria.

\section{Sample Preparation}

Sample preparation for the bacteriological analysis was carried out in accordance with the method described by Atlas (1997). Twenty five grams $(25 \mathrm{~g})$ of the sample was homogenized in $225 \mathrm{ml}$ peptone water using Kenwood blender machine to obtain a $10^{1}$ homogenate. The homogenate was thoroughly shaken and $1 \mathrm{ml}$ pipetted into test tubes containing $9 \mathrm{ml}$ of peptone water $\left(10^{2}\right)$. The test tubes were further serially diluted to $10^{5}$.

Total Aerobic Mesophilic Bacterial Count

Total Aerobic mesophilic bacterial count was determined using the method described by Abdullahi et al. (2004) where $1 \mathrm{ml}$ of inoculums from $10^{1}$ to $10^{5}$ dilutions were transferred into duplicate Petri dishes and labeled accordingly. This was followed by pouring aseptically about $15 \mathrm{ml}$ of molten nutrient agar. The culture was homogenized by gentle spinning of the plates and allowed to solidify. The plates were incubated at $37^{\circ} \mathrm{C}$ for 24 hours. Plates containing 30-300 colonies were counted. The number of colony forming units per gram of a sample (cfu/g) was obtained by multiplying the average colony number with the inverse of the dilution factor.

\section{Enumeration and Detection of Coliform bacteria}

Detection and enumeration of coliform was carried out according to method described by Atlas, (1977). A set of 9 test tubes each containing $9 \mathrm{ml}$ of lactose broth and an inverted Durham tubes were autoclaved to expel air and to sterilize. Similarly, $1 \mathrm{ml}$ from the diluents $10^{1}$ was transferred to the first 3 test tubes, followed by $1 \mathrm{ml}$ from the diluents $10^{2}$ to the second set of 3 test tubes and finally the third diluents $10^{3}$ to the $3^{\text {rd }}$ set of 3 test tubes. All the 9 test tubes were incubated at $37^{\circ} \mathrm{C}$ for 24 hours. Tubes that showed gas and acid production after 24 hours were recorded as positive for the presence of Coliform. Negative tubes were further reincubated for 24 hours. Positive tubes were recorded. Estimate of most probable number of Coliform per gram of sample (MPN/g) was determined by comparing the number of gas positive tubes with the most probable number table. 
BAJOPAS Volume 13 Number 1, June, 2020 Identification of Coliform

A loop full of inoculum from gas positive tubes was streaked on to Eosine methylene blue (EMB) agar plate and incubated at $37^{\circ} \mathrm{C}$ for $24 \mathrm{hrs}$. Colonies which formed bluish black color with green metallic sheen, and reddish colonies were isolated on agar slants. Those colonies showing metallic sheen on EMB were sub cultured into tubes of lactose broth and incubated at $45^{\circ} \mathrm{C}$. The tubes were observed after $24 \mathrm{hrs}$ for gas production. This is the completed test for fecal coliform. Gram stain and other biochemical tests such as Indole, Methyl red, Voges-Proskauer and Citrate Utilization tests (IMVIC), Coagulase and Catalase tests were carried out for the Identification and confirmation of isolates.

\section{Procedure for Indole Test}

Indole test was carried out by preparing a Tryptone broth drawn in to test tubes, sterilized by autoclaving, inoculated with loopful of suspension and incubated at $37^{\circ} \mathrm{C}$ for 24 hours. Three drops of xylene was added in tubes, shaken vigorously and kept for the separation of two layers. One millilitre of Kovac's reagent was added and the formation of pink colour ring indicates positive Indole test.

\section{Procedure for Methyl Red Test}

Methyl red test was carried out by preparing Glucose phosphate broth, dispensed in test tubes, sterilized, inoculated with test culture and incubated at $37^{\circ} \mathrm{C}$ for 24 hours. Five drops of methyl-red indicator was added to the medium for the formation of red colour.

\section{Procedure for Voges-Proskauer Test}

Voges-Proskauer test was carried out by inoculating tubes with the bacterial culture followed by incubation for 48 hours at $37^{\circ} \mathrm{C}$. Separate pipettes were used to pipette $1 \mathrm{ml}$ from each culture tube into clean separate tubes. Eighteen drops $(0.5 \mathrm{ml})$ of Barrit's solution A (a-naphthol) was added to each tube containing glucose phosphate broth followed by the addition of an equal amount of solution $B$ into the same tube. The tubes were shaken at 30 seconds interval. A positive reaction was indicated by the development of a pink color, which turns red in 1-2 hours, after vigorous shaking.

\section{Procedure for Citrate Utilization Test}

Citrate Utilization Test was carried out by distributing melted agar (Simmon Citrate Agar) in to test tubes followed by sterilization at $121.5^{\circ} \mathrm{C}$ for 15 minutes. The test tubes were afterward held in slanted position, inoculated with the given bacterial culture and incubated at $37^{\circ} \mathrm{C}$ for $24 \mathrm{hrs}$. Positive test was indicated by color change of the media from green to blue.

\section{RESULTS AND DISCUSSIONS}

The results of this study are presented in tables $1,2,3$ and 4. Among the sampling areas Kofar Kudu had the highest aerobic mesophilic bacteria counts $4.0 \times 10^{5} \mathrm{cfu} / \mathrm{g}$ followed by Rinji $2.72 \times 10^{5} \mathrm{cfu} / \mathrm{g}$, while Tosaro had the least Aerobic mesophilic bacteria counts of $1.02 \times 10^{5}$ $\mathrm{cfu} / \mathrm{g}$ as indicated in Table 1.Makwalla had the highest coliform count $68 \mathrm{MPN} / \mathrm{g}$ followed by Rinji $37 \mathrm{MPN} / \mathrm{g}$. Tsohuwar Kasuwa had the least coliform counts $8 \mathrm{MPN} / \mathrm{g}$, (Table 2). Result from table 1 shows variation in the microbial contents among the samples which suggest variation in their sources, poor handling procedures and contamination from the processing environment. High coliform count and their differences within sampling areas is an indication of poor microbiological quality of the product. Ndahi et al. (2013) reported microbial load to be a function of the handling personnel and the environment. The results indicated that the samples were contaminated with bacteria as the counts exceeded the minimum safety level $\left(10^{4} \mathrm{cfu} / \mathrm{g}\right)$ for members of the Enterobacteriaceae family. However, it might be a reflection of poor hygienic practices which may contribute to health hazard to the potential consumers. Similarly, Inusa and Sa'id (2017); Osimani et al. (2015) reported that, the initial microbial content of the raw material play significant role in influencing the final microbial load of the finished product. Isolation of members of the Enterobacteriaceae such as $E$. coli, Klebsiella pneumoniae, Salmonella and Shigella signifies danger to the public health. These organisms are capable of producing endotoxins which trigger high fevers in infected individuals, and the enterotoxins which colonize the small intestines and lead to extreme dehydration as a result of vomiting and diarrhea sometimes with severe and fatal outcomes (Amaeze et al., 2016). From the 16 isolated organisms $E$. coli had the highest isolation rate $6(37.5 \%)$ (Table 3), this suggest faecal contamination of the products. $E$. coli is a common flora in the gastrointestinal tract responsible for diarrhea and extra-intestinal infections (CDC, 2011). The result is in conformity with the findings of Ndahi et al. (2013) and Shamsuddeen (2009). Also presence of campylobacter might be due to cross contamination from raw meat to finished product (Tsire). Staphylococcus aureus is a normal flora of the skin, nasal, genital, mouth or anal area in both humans and animals without any symptom of an infection (Matthew et al., 2013). Isolation of $S$. aureus in these study concords with the findings of Lucretia et al. (2018) from Suya sold in Rivers State. 
BAJOPAS Volume 13 Number 1, June, 2020

It is also in agreement with the findings of Yousafzai et al. (2018); Onuorah et al. (2015) and Tijjani and Jumare (2014) from tsire samples in different countries. Presence of $S$. aureus in foods is most of the time an indication of poor human handling, poor environment, unhygienic utensils and equipments used during processing (Igene et al., 2016; Okonko et al., 2013). Infections caused by $S$. aureus are difficult to treat leading to long hospitalization with consequent economic loss (Udobi et al., 2013). These include soft tissue infections, pneumonia, hospital-acquired postoperative wound infections, Staphylococcal food poisoning, impetigo and cellulitis (Charlene et al., 2013). Samples obtained from Dausai and Kofar Kudu had the highest isolation rate $4(80 \%)$ (Table 4 ) probably because of the much commercial activities taking place in the area which can lead to environmental contamination.

Table 1: Total Aerobic Mesophilic Bacterial Count of Tsire sold in Garko Town

\begin{tabular}{lll}
\hline Sampling Area & APC cfu/g & Mean \pm STD \\
\hline Dausai & $2.20 \times 10^{5}$ & $110000 \pm 14142.14$ \\
Kofar Kudu & $4.00 \times 10^{5}$ & $133333.3 \pm 23094.01$ \\
Makwalla & $1.30 \times 10^{5}$ & $32500 \pm 7187.953$ \\
Rinji & $2.72 \times 10^{5}$ & $90666.67 \pm 94769.90$ \\
Tosaro & $1.02 \times 10^{5}$ & $51000 \pm 15556.35$ \\
Tsohuwar Kasuwa & $1.75 \times 10^{5}$ & $35000 \pm 11357.82$ \\
\hline
\end{tabular}

Key: APC: Aerobic Mesophilic Counts

STD: Standard Deviation

Table 2: Total Coliform Count of Tsire sold in Garko Town

\begin{tabular}{lcc}
\hline \multicolumn{1}{c}{ Sampling Area } & TCC MPN/g & Mean \pm STD \\
\hline Dausai & 20 & $6.67 \pm 2.5166$ \\
Kofar Kudu & 32 & $16.00 \pm 5.6569$ \\
Makwalla & 68 & $13.60 \pm 8.7062$ \\
Rinji & 37 & $9.25 \pm 4.7871$ \\
Tosaro & 10 & $5.00 \pm 2.8284$ \\
Tsohuwar Kasuwa & 8 & $4.00 \pm 0.0000$ \\
\hline
\end{tabular}

Table 3: Organisms Isolated from Tsire Sold in Garko

\begin{tabular}{lcl}
\hline Isolated Organism & Frequency & Percentage (\%) \\
\hline Campylobacter & 2 & 06.66 \\
Escherichia coli & 6 & 20.00 \\
Klebsiella pneumoniae & 2 & 06.66 \\
Salmonella species & 1 & 03.33 \\
Shigella & 3 & 10.00 \\
Staphylococcus aureus & 2 & 06.66 \\
Total & 16 & \\
\hline
\end{tabular}

Table 4: Distribution of Organisms within Sampling Area

\begin{tabular}{lcc}
\hline \multicolumn{1}{c}{ Sampling Area } & No. Isolated & Percentage (\%) \\
\hline Dausai & 4 & 80 \\
Kofar Kudu & 4 & 80 \\
Makwalla & 2 & 40 \\
Rinji & 3 & 60 \\
Tosaro & 2 & 40 \\
Tsohuwar Kasuwa & 1 & 20 \\
Total & 16 & \\
\hline
\end{tabular}

\section{CONCLUSION}

Results indicated $4.00 \times 10^{5} \mathrm{CFU} / \mathrm{g}$ as the highest APCs count; while $68 \mathrm{MPN} / \mathrm{g}$ was the highest TCCs from the 30 samples analyzed. Among the isolates, $E$. coli has the highest isolation rate of $6(20 \%)$. Dausai and Kofar kudu were having the highest bacteria count of $4(80 \%)$, each, indicating higher contamination in those locations. 
BAJOPAS Volume 13 Number 1, June, 2020 RECOMMENDATIONS

The following recommendations are tenable:

1. Hygienic practices at all stages of production should be improved to safe guard the consumers against potential health hazard.

2. Monitoring of microbiological contamination of Tsire during preparations, packaging and marketing is essential to ensure product of good microbiological quality for consumers' health.

\section{REFERENCES}

Abdullahi, I. O., Umoh, V. J. and Galadima, M. (2004). Hazards Associated with Kilishi Preparations in Zaria. Nigerian Journal of Microbiology, 18 (1-2): $339-345$.

Ahmadu, J. and Ibrahim E. J., (2013): Determinants of Revenue in Suya Production in BeninCity, Edo State, Nigeria. Nigerian journal of agriculture, food and environment.9(3):1-5

Amaeze, N. Aboh, M. Itohan, A. Felix, E. Olatunji, T. and Oladosu, P. (2016) Microbial Profile, Antibiotic Sensitivity and Heat Resistance of Bacterial Isolates from Commercial Roasted Beef (Suya) in Abuja, Nigeria. JOPAT, 15(2): $22-30$.

Apata, E.S., Kuku1, I.A., Apata, O.C. and Adeyemi, K.O. (2013). Evaluation of Suya(Tsire) - An Intermediate Moisture Meat Product in Ogun State, Nigeria. J. Food Res 2 (1): 87.

Atlas, R. M. (1997) Principles of Microbiology Second Edition. C. Brown Publishers. Pp 802-803.

Borch, E. Kant-Muermans, M. L., Blixt, Y. (1996) Bacterial Spoilage of Meat and Cured Meat Products. Int $\mathrm{J}$ Food Microbiol .33(1): 103-20.

Centre for Disease Control, CDC (2011). "Escherichia coli 0157:H7" Division of Bacterial and Mycotic Diseasesht://www.cdc.gov/nczved/divisi ons/dfbmd/diseases/ecoli_0157h7/.

Charlene, R. J., Johnnie, A. D., and John, B. B., (2013) Prevalence and Characterization of Methicillin-Resistant Staphylococcus aureus Isolates from Retail Meat and Humans in Georgia. American society for Microbiology. J. of clinical microbiology. 12(1):123-6 doi:10.1128/JCM.0316612JCM.03166-12

Egbebi, A.O and Seidu, K., T. (2011). Microbiological Evaluation of Suya (dried smoked

meat) Sold in Ado and Akure, South West Nigeria.European Journal of Experinmental Biology, 1(4):1-5
3. Government should establish regulatory bodies responsible for inculcating hygiene habits to the local producers and vendors in order to prevent instant, cross and post processing contaminations by microbial pathogens.

4. Awareness and sensitization of local food producers about good hygienic practices in food handling and processing.

Falegan, C, R., Akoja, S. D., and Oyarekua, M. A., (2017) Microbiological Assessment of Suya (Sliced Roasted Beef) in Ado-Ekiti Metropolis, Ekiti State, Nigeria. MOJ Biology andMedicine.

Fonkem, D., N. Tanya, V., N. and Ebangi, A., L. (2010). Effect of Season on the Microbiological Quality of Kilishi, a Traditional Cameroonian Dried Beef Product. Tropicultura, 28(1): 10-15.

Food and Agricultural Organization of the United Nations (F A O, 1979). Manual of food quality control 4. Microbiological analysis.

Food and Agriculture Organisation of the United Nation (FAO), 2019. Nigeria at a glance.

Igene J.O., Uwadia, O.E., Ebabhamiegbebho, P.A. and Evivie, S.E., (2016) Shelf life Stability Studies of University of Benin (UNIBEN) Proff's Kilishi Product Asian Journal of Science and Technology 7(1): 2268-2274.

Inusa, S. K. and Said, I. S. (2017) Evaluation of the Chemical and Microbiological Properties Of Kilishi Sold in Kano Metropolis. Journal of Dry land Agriculture, 3 (1): $59-69$.

Lucretia, I. B, Patience, C. Obinna-Echem, Sophia, C. A. (2018) Microbiological quality andantibiotic sensitivity of potential pathogens isolated from meat product (Suya) sold in Rivers State University and its environs. International Journal of Biotechnology and Food Science, 6(4): 67-76.

Matthew, E., Drosos, E., John, L. and Ioanna, P. (2013) MRSA in Africa: Filling the Global Map of Antimicrobial Resistance PLOS One. 8(7): e68024 doi: 10.1371/journal.pone.0068024

Mgbemere, V.N., Akpapunam, M. A. and Igene, J. O., (2011). Effect of Groundnut FlourSubstitution on Yield, Quality and Storage Stability of Kilishi - a Nigerian Indigenous Dried Meat Product. African Journal of Food, Agriculture, Nutrition and Development, $\quad \mathbf{1 1}(2)$ : 4718-4738. 
BAJOPAS Volume 13 Number 1, June, 2020

Mubarak, A. A., Azeez, M. L., Amos A. O., Opeyemi, O. O. (2016) Assessment of Animal Protein Consumption and Food Security Among Rural Households in Kwara State, Nigeria American Journal of Business and Society, 1(4): 233245.

Ndahi, M., D. Kwaga, J., K. P. Bello, M. Kabir J., V. Umoh, .J. Yakubu, S., E. and Nok, A., J. (2013) Prevalence and Antimicrobial Susceptibility of Listeria Monocytogenes and Methicillin-Resistant Staphylococcus aureus Strains from Raw Meat and Meat Products in Zaria, Nigeria. Applied Journal of Microbiology, 58(3):262-9.

Okonko, I.O., Odu, N.N. and Igboh, I.E. (2013). Microbiological Analysis of Kilishi Sold In Port Harcourt, Nigeria. New York Science Journal, 6 (7):37-43.

Osimani, A., Aquilanti, L. and Clementi, F. (2015) Microbiological Quality of Meatbased Meals and Operation of Control Systems within a Food Service Environment. International Food Research Journal 22(4): 1692-1698.

Onuorah, S. Obika, I. Odibo, F. Orji, M. (2015)An Assessment of the Bacteriological Quality of Tsire-Suya (Grilled Beef) sold in Awka, Nigeria. American. J. Life. Sci. Res. 3(4):287292.

Razavilar, V, Khandaghi, J. Barzgari, A. (2010); Isolation of Eschericia coli 0157:H7 from manure fertilized farms and raw vegetables grown on it, in Tabriz city in
Iran. African Journal of Microbiology Research, 4(9): 891-895.

Scallan, E. Hoekstra, R. M. Angulo, F. J.Tauxe, R. V, Widdowson, M. Roy, S. L et al., (2011).Food borne illness acquired in the United States- Major Pathogens. Emerg. Infec Dis, 17(1): 7-15.

Shamsuddeen U (2009). Microbiological quality of spice used in the production of Kilishi a traditionally dried and grilled meat product. Bayero Journal of Pure andApplied Sciences, 2(2): 66-69.

Shamsuddeen, U. (2015) Microbiological Hazard and Critical control point Analysis of Dried and Minced Meat Snacks Produced in Kano Nigeria. Lambert Academic Publishing; Pp 1-36.

Tijani, O.and Jumare, S. (2014). Microblological Quality Assessment of Meat

Sold in KauraNamoda. International Conference on Earth, Environment and Life sciences (EELS) Dubai (UAE).

Udobi, C. E., Obajuluwa, A. F., and Onaolapo, J. A., (2013) Prevalence and Antibiotic Resistance Pattern of MethicillinResistant Staphylococcus aureus from an Orthopaedic Hospital in Nigeria BioMed Research International; 26(6); 6-7.

WHO, 2015 Foodborne diseases in the WHO African Region.

Yousafzai HA, Rind R, Khan MA, Abro SH, Korejo NA, Ejaz M, Kabir A, Shahid M, Memon S. (2019). Microbiological Contamination of Cattle and Meat in Peshawar, Pakistan. J. Anim. Health Prod. 7(1): 1116. 


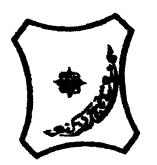

Bayero Journal of Pure and Applied Sciences, 13(1); 40 - 45

Received: September, 2019

Accepted: April, 2020

ISSN $2006-6996$

\title{
BACTERIOLOGICAL QUALITY OF STICK MEAT (Tsire) SOLD IN GARKO LOCAL GOVERNMENT AREA OF KANO STATE, NIGERIA
}

\author{
$*^{1}$ Dahiru A. T. and ${ }^{2}$ Maigari A. K. \\ ${ }^{1}$ Department of Hospitality Management, School of Technology, Kano State Polytechnic, PMB 3348, \\ Kano Nigeria. \\ ${ }^{2}$ Departmnt of Biological Sciences, Bayero University, Kano \\ Corresponding Author: dturajo61@gmail.com; GSM: 08087508262.
}

ABSTRACT

Stick meat, locally called Tsire in Hausa Language, is a significant portion of the diet of a large active population of Northern Nigeria. However, because of the handling and processing methods by the manufacturers as well as the hawking system of stick meat, the meat product may be exposed to both pre- and post-processed product contamination, and thus may poses danger to public health. Therefore, considering the role of Tsire in improving nutrition and increase household income to the populace, the need to improve the processing, distribution and overall quality of the product is simply indispensable. A total of 30 samples (5 samples from each of the 6 sampling points) of Tsire were collected randomly in Garko Town. Aerobic plate counts (APCs) and Total coliform counts (TCCS) of Tsire samples were determined using standard microbiological methods. APCs ranged from $1.02 \times 10^{5}$ to $4.00 \times 10^{5} \mathrm{CFU} / \mathrm{g}$; while TCCs ranged from $8 \mathrm{MPN} / \mathrm{g}$ to $68 \mathrm{MPN} / \mathrm{g}$. From the 30 samples screened, 16(53.33\%) bacteria namely, Campylobacter 2(6.66\%), Escherichia coli 6(20\%), Klebsiella pneumoniae 2(6.66\%), Salmonella spp. 1(3.33\%), Shigella 3(10\%) and Staphylococcus aureus 2(6.66\%) were detected. $E$. coli has the highest isolation rate of 6(20\%), while Salmonella spp. had the least frequency of 1(3.33\%). The distribution of isolated organisms within the study area were as follows: Dausai, 4(80\%), Kofar kudu, 4(80\%), Makwalla, 2(40\%), Rinji, 3(60\%), Tosaro, 2(40\%), and Tsohuwar Kasuwa, 1(20\%). The results have indicated that the Tsire was contaminated with bacteria thus exposing the product to fast deterioration, spoilage and also a vehicle for food borne illness, suggesting for adequate hygienic practices at all the stages, prior to consumption, to ensure safety of the meat product.

Key words: APCs, TCCs, Contamination, Microorganisms, Garko

\section{INTRODUCTION}

Nigeria is one of the developing nations with inadequate food supply and most often deficient in protein content (FAO, 2019). Nigerian's average animal protein intake per head per day is estimated at $7.9 \mathrm{~g}$ as against $35 \mathrm{~g}$ recommended value by Food and Agricultural Organization (Mubarak et al., 2016). These low levels of animal protein intake create great concern as it affects the nutritional status of Nigerians. Hence, there is the need for sufficient supply of animal protein from energy rich animal products to satisfy the nutritional requirements for Nigerians.

Meat is one major source of animal protein largely composed of water, protein and fats which can make it susceptible to microbial contamination within short time leading to spoilage (Apata et al., 2013; Mgbemere et al., 2011). Meat is mostly eaten after it has been cooked or processed in a variety of ways such as sun drying; smoking and roasting with or without fortifications (Borch et al., 1996). In Nigeria meat products such as Tsire, Kilishi and Balangu are locally produced using one or more of these methods in order to meet the nutritional requirements of the teeming Nigerians (Egbebi, 2011).

Tsire is a popular Nigerian traditional processed ready-to-eat roasted stick meat product (Shamsuddeen, 2015). It is sold in public places, along roads, in hotels, parks, quarters and even offices (Falegan et al., 2017). It is prepared from boneless healthy animal flesh such as beef and mutton, spiced with peanut cake, salt, vegetable oil and other flavorings followed by roasting (Shamsuddeen, 2015). Consumption of these products has extended to other parts of African countries such as Ghana, Somali, Cameroun and Chad (Ahmadu and Ibrahim, 2013). 
BAJOPAS Volume 13 Number 1, June, 2020

However, evidence of quality control sticking to procedural hygiene by the handlers during preparation and retailing of these products is poorly documented. Tsire is of great safety risk because of the fact that there are erratic cases of gastroenteritis and symptoms of food infection after consumption (WHO, 2015). Food borne illnesses are one of the major health problems in developing and developed countries (Razavilar, 2010). According to the World Health Organization, WHO (2015), $0.07 \%$ death of the 600 million global burdens of Foodborne illnesses have been reported to be caused by bacteria, viruses, fungi and chemicals. In America $0.27 \%$ of the estimated 48 million affected people is hospitalized and about $0.0063 \%$ deaths are recorded each year (Scallan et al., 2011). More than 91 million people in Africa fall ill and $0.15 \%$ dies each year, making Africa the highest burden bearer of Foodborne diseases per population (WHO, 2015).

Application of a Hazard Analysis Critical Control Point (HACCP) at all stages of meat products preparation is essential in order to ensure its safety. Thus, according to the guidelines of good manufacturing practice, the level of total aerobic bacterial contamination of thermally processed meat products should not exceed $10^{4}\left(\mathrm{cfu} \mathrm{g}^{-1}\right)$. Enterobacteriaceae and faecal coliform contamination in meat products should be within the range of $10^{2}-10^{4}$ and $10-10^{3} \mathrm{cfu} \mathrm{g}^{-1}$, respectively (Shamsuddeen, 2015). The aim of the study is therefore, to assess the total viable bacterial counts of tsire marketed locally within Garko town, and to isolate and identify the organisms at the point of consumption with the intention of promoting public health and food hygiene habits in the Nigerian populace.

\section{MATERIALS AND METHODS Study Area and Population}

Garko is one of the existing 44 local government areas located in Kano south west zone of Kano state with its capital administrative headquarters in the Garko town. It has coordinates $11^{\circ} 39^{\prime} \mathrm{N}$ $8^{\circ} 54^{\prime} \mathrm{E}$, and an area of $450 \mathrm{~km}^{2}$. The projected population of Garko local Government was 225,300 according to the National Population Census report (2018). Garko is known for agricultural activities both farming and animal husbandry. It is popularly known for large scale rice production. Other food crops include sweet potatoes, cassava, onions, sorghum, millet and sugarcane. Cows, sheep and goats are major groups of animals reared by majority of the populace. Meat products processed, retailed and consumed in Garko include roasted meat (Balangu), dried roasted meat (Kilishi), stick meat (Tsire), hide and skin pepper soup (Ragadada) and minced fried meat (Danbunnama).

\section{Samples Collection}

Five samples of Tsire products were collected from 6 different identified locations within Garko town in a sterile foil paper and immediately analyzed for the presence of bacteria.

\section{Sample Preparation}

Sample preparation for the bacteriological analysis was carried out in accordance with the method described by Atlas (1997). Twenty five grams $(25 \mathrm{~g})$ of the sample was homogenized in $225 \mathrm{ml}$ peptone water using Kenwood blender machine to obtain a $10^{1}$ homogenate. The homogenate was thoroughly shaken and $1 \mathrm{ml}$ pipetted into test tubes containing $9 \mathrm{ml}$ of peptone water $\left(10^{2}\right)$. The test tubes were further serially diluted to $10^{5}$.

Total Aerobic Mesophilic Bacterial Count

Total Aerobic mesophilic bacterial count was determined using the method described by Abdullahi et al. (2004) where $1 \mathrm{ml}$ of inoculums from $10^{1}$ to $10^{5}$ dilutions were transferred into duplicate Petri dishes and labeled accordingly. This was followed by pouring aseptically about $15 \mathrm{ml}$ of molten nutrient agar. The culture was homogenized by gentle spinning of the plates and allowed to solidify. The plates were incubated at $37^{\circ} \mathrm{C}$ for 24 hours. Plates containing 30-300 colonies were counted. The number of colony forming units per gram of a sample (cfu/g) was obtained by multiplying the average colony number with the inverse of the dilution factor.

\section{Enumeration and Detection of Coliform bacteria}

Detection and enumeration of coliform was carried out according to method described by Atlas, (1977). A set of 9 test tubes each containing $9 \mathrm{ml}$ of lactose broth and an inverted Durham tubes were autoclaved to expel air and to sterilize. Similarly, $1 \mathrm{ml}$ from the diluents $10^{1}$ was transferred to the first 3 test tubes, followed by $1 \mathrm{ml}$ from the diluents $10^{2}$ to the second set of 3 test tubes and finally the third diluents $10^{3}$ to the $3^{\text {rd }}$ set of 3 test tubes. All the 9 test tubes were incubated at $37^{\circ} \mathrm{C}$ for 24 hours. Tubes that showed gas and acid production after 24 hours were recorded as positive for the presence of Coliform. Negative tubes were further reincubated for 24 hours. Positive tubes were recorded. Estimate of most probable number of Coliform per gram of sample (MPN/g) was determined by comparing the number of gas positive tubes with the most probable number table. 
BAJOPAS Volume 13 Number 1, June, 2020 Identification of Coliform

A loop full of inoculum from gas positive tubes was streaked on to Eosine methylene blue (EMB) agar plate and incubated at $37^{\circ} \mathrm{C}$ for $24 \mathrm{hrs}$. Colonies which formed bluish black color with green metallic sheen, and reddish colonies were isolated on agar slants. Those colonies showing metallic sheen on EMB were sub cultured into tubes of lactose broth and incubated at $45^{\circ} \mathrm{C}$. The tubes were observed after $24 \mathrm{hrs}$ for gas production. This is the completed test for fecal coliform. Gram stain and other biochemical tests such as Indole, Methyl red, Voges-Proskauer and Citrate Utilization tests (IMVIC), Coagulase and Catalase tests were carried out for the Identification and confirmation of isolates.

\section{Procedure for Indole Test}

Indole test was carried out by preparing a Tryptone broth drawn in to test tubes, sterilized by autoclaving, inoculated with loopful of suspension and incubated at $37^{\circ} \mathrm{C}$ for 24 hours. Three drops of xylene was added in tubes, shaken vigorously and kept for the separation of two layers. One millilitre of Kovac's reagent was added and the formation of pink colour ring indicates positive Indole test.

\section{Procedure for Methyl Red Test}

Methyl red test was carried out by preparing Glucose phosphate broth, dispensed in test tubes, sterilized, inoculated with test culture and incubated at $37^{\circ} \mathrm{C}$ for 24 hours. Five drops of methyl-red indicator was added to the medium for the formation of red colour.

\section{Procedure for Voges-Proskauer Test}

Voges-Proskauer test was carried out by inoculating tubes with the bacterial culture followed by incubation for 48 hours at $37^{\circ} \mathrm{C}$. Separate pipettes were used to pipette $1 \mathrm{ml}$ from each culture tube into clean separate tubes. Eighteen drops $(0.5 \mathrm{ml})$ of Barrit's solution A (a-naphthol) was added to each tube containing glucose phosphate broth followed by the addition of an equal amount of solution $B$ into the same tube. The tubes were shaken at 30 seconds interval. A positive reaction was indicated by the development of a pink color, which turns red in 1-2 hours, after vigorous shaking.

\section{Procedure for Citrate Utilization Test}

Citrate Utilization Test was carried out by distributing melted agar (Simmon Citrate Agar) in to test tubes followed by sterilization at $121.5^{\circ} \mathrm{C}$ for 15 minutes. The test tubes were afterward held in slanted position, inoculated with the given bacterial culture and incubated at $37^{\circ} \mathrm{C}$ for $24 \mathrm{hrs}$. Positive test was indicated by color change of the media from green to blue.

\section{RESULTS AND DISCUSSIONS}

The results of this study are presented in tables $1,2,3$ and 4. Among the sampling areas Kofar Kudu had the highest aerobic mesophilic bacteria counts $4.0 \times 10^{5} \mathrm{cfu} / \mathrm{g}$ followed by Rinji $2.72 \times 10^{5} \mathrm{cfu} / \mathrm{g}$, while Tosaro had the least Aerobic mesophilic bacteria counts of $1.02 \times 10^{5}$ $\mathrm{cfu} / \mathrm{g}$ as indicated in Table 1.Makwalla had the highest coliform count $68 \mathrm{MPN} / \mathrm{g}$ followed by Rinji $37 \mathrm{MPN} / \mathrm{g}$. Tsohuwar Kasuwa had the least coliform counts $8 \mathrm{MPN} / \mathrm{g}$, (Table 2). Result from table 1 shows variation in the microbial contents among the samples which suggest variation in their sources, poor handling procedures and contamination from the processing environment. High coliform count and their differences within sampling areas is an indication of poor microbiological quality of the product. Ndahi et al. (2013) reported microbial load to be a function of the handling personnel and the environment. The results indicated that the samples were contaminated with bacteria as the counts exceeded the minimum safety level $\left(10^{4} \mathrm{cfu} / \mathrm{g}\right)$ for members of the Enterobacteriaceae family. However, it might be a reflection of poor hygienic practices which may contribute to health hazard to the potential consumers. Similarly, Inusa and Sa'id (2017); Osimani et al. (2015) reported that, the initial microbial content of the raw material play significant role in influencing the final microbial load of the finished product. Isolation of members of the Enterobacteriaceae such as $E$. coli, Klebsiella pneumoniae, Salmonella and Shigella signifies danger to the public health. These organisms are capable of producing endotoxins which trigger high fevers in infected individuals, and the enterotoxins which colonize the small intestines and lead to extreme dehydration as a result of vomiting and diarrhea sometimes with severe and fatal outcomes (Amaeze et al., 2016). From the 16 isolated organisms $E$. coli had the highest isolation rate $6(37.5 \%)$ (Table 3), this suggest faecal contamination of the products. $E$. coli is a common flora in the gastrointestinal tract responsible for diarrhea and extra-intestinal infections (CDC, 2011). The result is in conformity with the findings of Ndahi et al. (2013) and Shamsuddeen (2009). Also presence of campylobacter might be due to cross contamination from raw meat to finished product (Tsire). Staphylococcus aureus is a normal flora of the skin, nasal, genital, mouth or anal area in both humans and animals without any symptom of an infection (Matthew et al., 2013). Isolation of $S$. aureus in these study concords with the findings of Lucretia et al. (2018) from Suya sold in Rivers State. 
BAJOPAS Volume 13 Number 1, June, 2020

It is also in agreement with the findings of Yousafzai et al. (2018); Onuorah et al. (2015) and Tijjani and Jumare (2014) from tsire samples in different countries. Presence of $S$. aureus in foods is most of the time an indication of poor human handling, poor environment, unhygienic utensils and equipments used during processing (Igene et al., 2016; Okonko et al., 2013). Infections caused by $S$. aureus are difficult to treat leading to long hospitalization with consequent economic loss (Udobi et al., 2013). These include soft tissue infections, pneumonia, hospital-acquired postoperative wound infections, Staphylococcal food poisoning, impetigo and cellulitis (Charlene et al., 2013). Samples obtained from Dausai and Kofar Kudu had the highest isolation rate $4(80 \%)$ (Table 4 ) probably because of the much commercial activities taking place in the area which can lead to environmental contamination.

Table 1: Total Aerobic Mesophilic Bacterial Count of Tsire sold in Garko Town

\begin{tabular}{lll}
\hline Sampling Area & APC cfu/g & Mean \pm STD \\
\hline Dausai & $2.20 \times 10^{5}$ & $110000 \pm 14142.14$ \\
Kofar Kudu & $4.00 \times 10^{5}$ & $133333.3 \pm 23094.01$ \\
Makwalla & $1.30 \times 10^{5}$ & $32500 \pm 7187.953$ \\
Rinji & $2.72 \times 10^{5}$ & $90666.67 \pm 94769.90$ \\
Tosaro & $1.02 \times 10^{5}$ & $51000 \pm 15556.35$ \\
Tsohuwar Kasuwa & $1.75 \times 10^{5}$ & $35000 \pm 11357.82$ \\
\hline
\end{tabular}

Key: APC: Aerobic Mesophilic Counts

STD: Standard Deviation

Table 2: Total Coliform Count of Tsire sold in Garko Town

\begin{tabular}{lcc}
\hline \multicolumn{1}{c}{ Sampling Area } & TCC MPN/g & Mean \pm STD \\
\hline Dausai & 20 & $6.67 \pm 2.5166$ \\
Kofar Kudu & 32 & $16.00 \pm 5.6569$ \\
Makwalla & 68 & $13.60 \pm 8.7062$ \\
Rinji & 37 & $9.25 \pm 4.7871$ \\
Tosaro & 10 & $5.00 \pm 2.8284$ \\
Tsohuwar Kasuwa & 8 & $4.00 \pm 0.0000$ \\
\hline
\end{tabular}

Table 3: Organisms Isolated from Tsire Sold in Garko

\begin{tabular}{lcl}
\hline Isolated Organism & Frequency & Percentage (\%) \\
\hline Campylobacter & 2 & 06.66 \\
Escherichia coli & 6 & 20.00 \\
Klebsiella pneumoniae & 2 & 06.66 \\
Salmonella species & 1 & 03.33 \\
Shigella & 3 & 10.00 \\
Staphylococcus aureus & 2 & 06.66 \\
Total & 16 & \\
\hline
\end{tabular}

Table 4: Distribution of Organisms within Sampling Area

\begin{tabular}{lcc}
\hline \multicolumn{1}{c}{ Sampling Area } & No. Isolated & Percentage (\%) \\
\hline Dausai & 4 & 80 \\
Kofar Kudu & 4 & 80 \\
Makwalla & 2 & 40 \\
Rinji & 3 & 60 \\
Tosaro & 2 & 40 \\
Tsohuwar Kasuwa & 1 & 20 \\
Total & 16 & \\
\hline
\end{tabular}

\section{CONCLUSION}

Results indicated $4.00 \times 10^{5} \mathrm{CFU} / \mathrm{g}$ as the highest APCs count; while $68 \mathrm{MPN} / \mathrm{g}$ was the highest TCCs from the 30 samples analyzed. Among the isolates, $E$. coli has the highest isolation rate of $6(20 \%)$. Dausai and Kofar kudu were having the highest bacteria count of $4(80 \%)$, each, indicating higher contamination in those locations. 
BAJOPAS Volume 13 Number 1, June, 2020 RECOMMENDATIONS

The following recommendations are tenable:

1. Hygienic practices at all stages of production should be improved to safe guard the consumers against potential health hazard.

2. Monitoring of microbiological contamination of Tsire during preparations, packaging and marketing is essential to ensure product of good microbiological quality for consumers' health.

\section{REFERENCES}

Abdullahi, I. O., Umoh, V. J. and Galadima, M. (2004). Hazards Associated with Kilishi Preparations in Zaria. Nigerian Journal of Microbiology, 18 (1-2): $339-345$.

Ahmadu, J. and Ibrahim E. J., (2013): Determinants of Revenue in Suya Production in BeninCity, Edo State, Nigeria. Nigerian journal of agriculture, food and environment.9(3):1-5

Amaeze, N. Aboh, M. Itohan, A. Felix, E. Olatunji, T. and Oladosu, P. (2016) Microbial Profile, Antibiotic Sensitivity and Heat Resistance of Bacterial Isolates from Commercial Roasted Beef (Suya) in Abuja, Nigeria. JOPAT, 15(2): $22-30$.

Apata, E.S., Kuku1, I.A., Apata, O.C. and Adeyemi, K.O. (2013). Evaluation of Suya(Tsire) - An Intermediate Moisture Meat Product in Ogun State, Nigeria. J. Food Res 2 (1): 87.

Atlas, R. M. (1997) Principles of Microbiology Second Edition. C. Brown Publishers. Pp 802-803.

Borch, E. Kant-Muermans, M. L., Blixt, Y. (1996) Bacterial Spoilage of Meat and Cured Meat Products. Int $\mathrm{J}$ Food Microbiol .33(1): 103-20.

Centre for Disease Control, CDC (2011). "Escherichia coli 0157:H7" Division of Bacterial and Mycotic Diseasesht://www.cdc.gov/nczved/divisi ons/dfbmd/diseases/ecoli_0157h7/.

Charlene, R. J., Johnnie, A. D., and John, B. B., (2013) Prevalence and Characterization of Methicillin-Resistant Staphylococcus aureus Isolates from Retail Meat and Humans in Georgia. American society for Microbiology. J. of clinical microbiology. 12(1):123-6 doi:10.1128/JCM.0316612JCM.03166-12

Egbebi, A.O and Seidu, K., T. (2011). Microbiological Evaluation of Suya (dried smoked

meat) Sold in Ado and Akure, South West Nigeria.European Journal of Experinmental Biology, 1(4):1-5
3. Government should establish regulatory bodies responsible for inculcating hygiene habits to the local producers and vendors in order to prevent instant, cross and post processing contaminations by microbial pathogens.

4. Awareness and sensitization of local food producers about good hygienic practices in food handling and processing.

Falegan, C, R., Akoja, S. D., and Oyarekua, M. A., (2017) Microbiological Assessment of Suya (Sliced Roasted Beef) in Ado-Ekiti Metropolis, Ekiti State, Nigeria. MOJ Biology andMedicine.

Fonkem, D., N. Tanya, V., N. and Ebangi, A., L. (2010). Effect of Season on the Microbiological Quality of Kilishi, a Traditional Cameroonian Dried Beef Product. Tropicultura, 28(1): 10-15.

Food and Agricultural Organization of the United Nations (F A O, 1979). Manual of food quality control 4. Microbiological analysis.

Food and Agriculture Organisation of the United Nation (FAO), 2019. Nigeria at a glance.

Igene J.O., Uwadia, O.E., Ebabhamiegbebho, P.A. and Evivie, S.E., (2016) Shelf life Stability Studies of University of Benin (UNIBEN) Proff's Kilishi Product Asian Journal of Science and Technology 7(1): 2268-2274.

Inusa, S. K. and Said, I. S. (2017) Evaluation of the Chemical and Microbiological Properties Of Kilishi Sold in Kano Metropolis. Journal of Dry land Agriculture, 3 (1): $59-69$.

Lucretia, I. B, Patience, C. Obinna-Echem, Sophia, C. A. (2018) Microbiological quality andantibiotic sensitivity of potential pathogens isolated from meat product (Suya) sold in Rivers State University and its environs. International Journal of Biotechnology and Food Science, 6(4): 67-76.

Matthew, E., Drosos, E., John, L. and Ioanna, P. (2013) MRSA in Africa: Filling the Global Map of Antimicrobial Resistance PLOS One. 8(7): e68024 doi: 10.1371/journal.pone.0068024

Mgbemere, V.N., Akpapunam, M. A. and Igene, J. O., (2011). Effect of Groundnut FlourSubstitution on Yield, Quality and Storage Stability of Kilishi - a Nigerian Indigenous Dried Meat Product. African Journal of Food, Agriculture, Nutrition and Development, $\quad \mathbf{1 1}(2)$ : 4718-4738. 
BAJOPAS Volume 13 Number 1, June, 2020

Mubarak, A. A., Azeez, M. L., Amos A. O., Opeyemi, O. O. (2016) Assessment of Animal Protein Consumption and Food Security Among Rural Households in Kwara State, Nigeria American Journal of Business and Society, 1(4): 233245.

Ndahi, M., D. Kwaga, J., K. P. Bello, M. Kabir J., V. Umoh, .J. Yakubu, S., E. and Nok, A., J. (2013) Prevalence and Antimicrobial Susceptibility of Listeria Monocytogenes and Methicillin-Resistant Staphylococcus aureus Strains from Raw Meat and Meat Products in Zaria, Nigeria. Applied Journal of Microbiology, 58(3):262-9.

Okonko, I.O., Odu, N.N. and Igboh, I.E. (2013). Microbiological Analysis of Kilishi Sold In Port Harcourt, Nigeria. New York Science Journal, 6 (7):37-43.

Osimani, A., Aquilanti, L. and Clementi, F. (2015) Microbiological Quality of Meatbased Meals and Operation of Control Systems within a Food Service Environment. International Food Research Journal 22(4): 1692-1698.

Onuorah, S. Obika, I. Odibo, F. Orji, M. (2015)An Assessment of the Bacteriological Quality of Tsire-Suya (Grilled Beef) sold in Awka, Nigeria. American. J. Life. Sci. Res. 3(4):287292.

Razavilar, V, Khandaghi, J. Barzgari, A. (2010); Isolation of Eschericia coli 0157:H7 from manure fertilized farms and raw vegetables grown on it, in Tabriz city in
Iran. African Journal of Microbiology Research, 4(9): 891-895.

Scallan, E. Hoekstra, R. M. Angulo, F. J.Tauxe, R. V, Widdowson, M. Roy, S. L et al., (2011).Food borne illness acquired in the United States- Major Pathogens. Emerg. Infec Dis, 17(1): 7-15.

Shamsuddeen U (2009). Microbiological quality of spice used in the production of Kilishi a traditionally dried and grilled meat product. Bayero Journal of Pure andApplied Sciences, 2(2): 66-69.

Shamsuddeen, U. (2015) Microbiological Hazard and Critical control point Analysis of Dried and Minced Meat Snacks Produced in Kano Nigeria. Lambert Academic Publishing; Pp 1-36.

Tijani, O.and Jumare, S. (2014). Microblological Quality Assessment of Meat

Sold in KauraNamoda. International Conference on Earth, Environment and Life sciences (EELS) Dubai (UAE).

Udobi, C. E., Obajuluwa, A. F., and Onaolapo, J. A., (2013) Prevalence and Antibiotic Resistance Pattern of MethicillinResistant Staphylococcus aureus from an Orthopaedic Hospital in Nigeria BioMed Research International; 26(6); 6-7.

WHO, 2015 Foodborne diseases in the WHO African Region.

Yousafzai HA, Rind R, Khan MA, Abro SH, Korejo NA, Ejaz M, Kabir A, Shahid M, Memon S. (2019). Microbiological Contamination of Cattle and Meat in Peshawar, Pakistan. J. Anim. Health Prod. 7(1): 1116. 


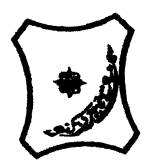

Bayero Journal of Pure and Applied Sciences, 13(1); 40 - 45

Received: September, 2019

Accepted: April, 2020

ISSN $2006-6996$

\title{
BACTERIOLOGICAL QUALITY OF STICK MEAT (Tsire) SOLD IN GARKO LOCAL GOVERNMENT AREA OF KANO STATE, NIGERIA
}

\author{
$*^{1}$ Dahiru A. T. and ${ }^{2}$ Maigari A. K. \\ ${ }^{1}$ Department of Hospitality Management, School of Technology, Kano State Polytechnic, PMB 3348, \\ Kano Nigeria. \\ ${ }^{2}$ Departmnt of Biological Sciences, Bayero University, Kano \\ Corresponding Author: dturajo61@gmail.com; GSM: 08087508262.
}

ABSTRACT

Stick meat, locally called Tsire in Hausa Language, is a significant portion of the diet of a large active population of Northern Nigeria. However, because of the handling and processing methods by the manufacturers as well as the hawking system of stick meat, the meat product may be exposed to both pre- and post-processed product contamination, and thus may poses danger to public health. Therefore, considering the role of Tsire in improving nutrition and increase household income to the populace, the need to improve the processing, distribution and overall quality of the product is simply indispensable. A total of 30 samples (5 samples from each of the 6 sampling points) of Tsire were collected randomly in Garko Town. Aerobic plate counts (APCs) and Total coliform counts (TCCS) of Tsire samples were determined using standard microbiological methods. APCs ranged from $1.02 \times 10^{5}$ to $4.00 \times 10^{5} \mathrm{CFU} / \mathrm{g}$; while TCCs ranged from $8 \mathrm{MPN} / \mathrm{g}$ to $68 \mathrm{MPN} / \mathrm{g}$. From the 30 samples screened, 16(53.33\%) bacteria namely, Campylobacter 2(6.66\%), Escherichia coli 6(20\%), Klebsiella pneumoniae 2(6.66\%), Salmonella spp. 1(3.33\%), Shigella 3(10\%) and Staphylococcus aureus 2(6.66\%) were detected. $E$. coli has the highest isolation rate of 6(20\%), while Salmonella spp. had the least frequency of 1(3.33\%). The distribution of isolated organisms within the study area were as follows: Dausai, 4(80\%), Kofar kudu, 4(80\%), Makwalla, 2(40\%), Rinji, 3(60\%), Tosaro, 2(40\%), and Tsohuwar Kasuwa, 1(20\%). The results have indicated that the Tsire was contaminated with bacteria thus exposing the product to fast deterioration, spoilage and also a vehicle for food borne illness, suggesting for adequate hygienic practices at all the stages, prior to consumption, to ensure safety of the meat product.

Key words: APCs, TCCs, Contamination, Microorganisms, Garko

\section{INTRODUCTION}

Nigeria is one of the developing nations with inadequate food supply and most often deficient in protein content (FAO, 2019). Nigerian's average animal protein intake per head per day is estimated at $7.9 \mathrm{~g}$ as against $35 \mathrm{~g}$ recommended value by Food and Agricultural Organization (Mubarak et al., 2016). These low levels of animal protein intake create great concern as it affects the nutritional status of Nigerians. Hence, there is the need for sufficient supply of animal protein from energy rich animal products to satisfy the nutritional requirements for Nigerians.

Meat is one major source of animal protein largely composed of water, protein and fats which can make it susceptible to microbial contamination within short time leading to spoilage (Apata et al., 2013; Mgbemere et al., 2011). Meat is mostly eaten after it has been cooked or processed in a variety of ways such as sun drying; smoking and roasting with or without fortifications (Borch et al., 1996). In Nigeria meat products such as Tsire, Kilishi and Balangu are locally produced using one or more of these methods in order to meet the nutritional requirements of the teeming Nigerians (Egbebi, 2011).

Tsire is a popular Nigerian traditional processed ready-to-eat roasted stick meat product (Shamsuddeen, 2015). It is sold in public places, along roads, in hotels, parks, quarters and even offices (Falegan et al., 2017). It is prepared from boneless healthy animal flesh such as beef and mutton, spiced with peanut cake, salt, vegetable oil and other flavorings followed by roasting (Shamsuddeen, 2015). Consumption of these products has extended to other parts of African countries such as Ghana, Somali, Cameroun and Chad (Ahmadu and Ibrahim, 2013). 
BAJOPAS Volume 13 Number 1, June, 2020

However, evidence of quality control sticking to procedural hygiene by the handlers during preparation and retailing of these products is poorly documented. Tsire is of great safety risk because of the fact that there are erratic cases of gastroenteritis and symptoms of food infection after consumption (WHO, 2015). Food borne illnesses are one of the major health problems in developing and developed countries (Razavilar, 2010). According to the World Health Organization, WHO (2015), $0.07 \%$ death of the 600 million global burdens of Foodborne illnesses have been reported to be caused by bacteria, viruses, fungi and chemicals. In America $0.27 \%$ of the estimated 48 million affected people is hospitalized and about $0.0063 \%$ deaths are recorded each year (Scallan et al., 2011). More than 91 million people in Africa fall ill and $0.15 \%$ dies each year, making Africa the highest burden bearer of Foodborne diseases per population (WHO, 2015).

Application of a Hazard Analysis Critical Control Point (HACCP) at all stages of meat products preparation is essential in order to ensure its safety. Thus, according to the guidelines of good manufacturing practice, the level of total aerobic bacterial contamination of thermally processed meat products should not exceed $10^{4}\left(\mathrm{cfu} \mathrm{g}^{-1}\right)$. Enterobacteriaceae and faecal coliform contamination in meat products should be within the range of $10^{2}-10^{4}$ and $10-10^{3} \mathrm{cfu} \mathrm{g}^{-1}$, respectively (Shamsuddeen, 2015). The aim of the study is therefore, to assess the total viable bacterial counts of tsire marketed locally within Garko town, and to isolate and identify the organisms at the point of consumption with the intention of promoting public health and food hygiene habits in the Nigerian populace.

\section{MATERIALS AND METHODS Study Area and Population}

Garko is one of the existing 44 local government areas located in Kano south west zone of Kano state with its capital administrative headquarters in the Garko town. It has coordinates $11^{\circ} 39^{\prime} \mathrm{N}$ $8^{\circ} 54^{\prime} \mathrm{E}$, and an area of $450 \mathrm{~km}^{2}$. The projected population of Garko local Government was 225,300 according to the National Population Census report (2018). Garko is known for agricultural activities both farming and animal husbandry. It is popularly known for large scale rice production. Other food crops include sweet potatoes, cassava, onions, sorghum, millet and sugarcane. Cows, sheep and goats are major groups of animals reared by majority of the populace. Meat products processed, retailed and consumed in Garko include roasted meat (Balangu), dried roasted meat (Kilishi), stick meat (Tsire), hide and skin pepper soup (Ragadada) and minced fried meat (Danbunnama).

\section{Samples Collection}

Five samples of Tsire products were collected from 6 different identified locations within Garko town in a sterile foil paper and immediately analyzed for the presence of bacteria.

\section{Sample Preparation}

Sample preparation for the bacteriological analysis was carried out in accordance with the method described by Atlas (1997). Twenty five grams $(25 \mathrm{~g})$ of the sample was homogenized in $225 \mathrm{ml}$ peptone water using Kenwood blender machine to obtain a $10^{1}$ homogenate. The homogenate was thoroughly shaken and $1 \mathrm{ml}$ pipetted into test tubes containing $9 \mathrm{ml}$ of peptone water $\left(10^{2}\right)$. The test tubes were further serially diluted to $10^{5}$.

Total Aerobic Mesophilic Bacterial Count

Total Aerobic mesophilic bacterial count was determined using the method described by Abdullahi et al. (2004) where $1 \mathrm{ml}$ of inoculums from $10^{1}$ to $10^{5}$ dilutions were transferred into duplicate Petri dishes and labeled accordingly. This was followed by pouring aseptically about $15 \mathrm{ml}$ of molten nutrient agar. The culture was homogenized by gentle spinning of the plates and allowed to solidify. The plates were incubated at $37^{\circ} \mathrm{C}$ for 24 hours. Plates containing 30-300 colonies were counted. The number of colony forming units per gram of a sample (cfu/g) was obtained by multiplying the average colony number with the inverse of the dilution factor.

\section{Enumeration and Detection of Coliform bacteria}

Detection and enumeration of coliform was carried out according to method described by Atlas, (1977). A set of 9 test tubes each containing $9 \mathrm{ml}$ of lactose broth and an inverted Durham tubes were autoclaved to expel air and to sterilize. Similarly, $1 \mathrm{ml}$ from the diluents $10^{1}$ was transferred to the first 3 test tubes, followed by $1 \mathrm{ml}$ from the diluents $10^{2}$ to the second set of 3 test tubes and finally the third diluents $10^{3}$ to the $3^{\text {rd }}$ set of 3 test tubes. All the 9 test tubes were incubated at $37^{\circ} \mathrm{C}$ for 24 hours. Tubes that showed gas and acid production after 24 hours were recorded as positive for the presence of Coliform. Negative tubes were further reincubated for 24 hours. Positive tubes were recorded. Estimate of most probable number of Coliform per gram of sample (MPN/g) was determined by comparing the number of gas positive tubes with the most probable number table. 
BAJOPAS Volume 13 Number 1, June, 2020 Identification of Coliform

A loop full of inoculum from gas positive tubes was streaked on to Eosine methylene blue (EMB) agar plate and incubated at $37^{\circ} \mathrm{C}$ for $24 \mathrm{hrs}$. Colonies which formed bluish black color with green metallic sheen, and reddish colonies were isolated on agar slants. Those colonies showing metallic sheen on EMB were sub cultured into tubes of lactose broth and incubated at $45^{\circ} \mathrm{C}$. The tubes were observed after $24 \mathrm{hrs}$ for gas production. This is the completed test for fecal coliform. Gram stain and other biochemical tests such as Indole, Methyl red, Voges-Proskauer and Citrate Utilization tests (IMVIC), Coagulase and Catalase tests were carried out for the Identification and confirmation of isolates.

\section{Procedure for Indole Test}

Indole test was carried out by preparing a Tryptone broth drawn in to test tubes, sterilized by autoclaving, inoculated with loopful of suspension and incubated at $37^{\circ} \mathrm{C}$ for 24 hours. Three drops of xylene was added in tubes, shaken vigorously and kept for the separation of two layers. One millilitre of Kovac's reagent was added and the formation of pink colour ring indicates positive Indole test.

\section{Procedure for Methyl Red Test}

Methyl red test was carried out by preparing Glucose phosphate broth, dispensed in test tubes, sterilized, inoculated with test culture and incubated at $37^{\circ} \mathrm{C}$ for 24 hours. Five drops of methyl-red indicator was added to the medium for the formation of red colour.

\section{Procedure for Voges-Proskauer Test}

Voges-Proskauer test was carried out by inoculating tubes with the bacterial culture followed by incubation for 48 hours at $37^{\circ} \mathrm{C}$. Separate pipettes were used to pipette $1 \mathrm{ml}$ from each culture tube into clean separate tubes. Eighteen drops $(0.5 \mathrm{ml})$ of Barrit's solution A (a-naphthol) was added to each tube containing glucose phosphate broth followed by the addition of an equal amount of solution $B$ into the same tube. The tubes were shaken at 30 seconds interval. A positive reaction was indicated by the development of a pink color, which turns red in 1-2 hours, after vigorous shaking.

\section{Procedure for Citrate Utilization Test}

Citrate Utilization Test was carried out by distributing melted agar (Simmon Citrate Agar) in to test tubes followed by sterilization at $121.5^{\circ} \mathrm{C}$ for 15 minutes. The test tubes were afterward held in slanted position, inoculated with the given bacterial culture and incubated at $37^{\circ} \mathrm{C}$ for $24 \mathrm{hrs}$. Positive test was indicated by color change of the media from green to blue.

\section{RESULTS AND DISCUSSIONS}

The results of this study are presented in tables $1,2,3$ and 4. Among the sampling areas Kofar Kudu had the highest aerobic mesophilic bacteria counts $4.0 \times 10^{5} \mathrm{cfu} / \mathrm{g}$ followed by Rinji $2.72 \times 10^{5} \mathrm{cfu} / \mathrm{g}$, while Tosaro had the least Aerobic mesophilic bacteria counts of $1.02 \times 10^{5}$ $\mathrm{cfu} / \mathrm{g}$ as indicated in Table 1.Makwalla had the highest coliform count $68 \mathrm{MPN} / \mathrm{g}$ followed by Rinji $37 \mathrm{MPN} / \mathrm{g}$. Tsohuwar Kasuwa had the least coliform counts $8 \mathrm{MPN} / \mathrm{g}$, (Table 2). Result from table 1 shows variation in the microbial contents among the samples which suggest variation in their sources, poor handling procedures and contamination from the processing environment. High coliform count and their differences within sampling areas is an indication of poor microbiological quality of the product. Ndahi et al. (2013) reported microbial load to be a function of the handling personnel and the environment. The results indicated that the samples were contaminated with bacteria as the counts exceeded the minimum safety level $\left(10^{4} \mathrm{cfu} / \mathrm{g}\right)$ for members of the Enterobacteriaceae family. However, it might be a reflection of poor hygienic practices which may contribute to health hazard to the potential consumers. Similarly, Inusa and Sa'id (2017); Osimani et al. (2015) reported that, the initial microbial content of the raw material play significant role in influencing the final microbial load of the finished product. Isolation of members of the Enterobacteriaceae such as $E$. coli, Klebsiella pneumoniae, Salmonella and Shigella signifies danger to the public health. These organisms are capable of producing endotoxins which trigger high fevers in infected individuals, and the enterotoxins which colonize the small intestines and lead to extreme dehydration as a result of vomiting and diarrhea sometimes with severe and fatal outcomes (Amaeze et al., 2016). From the 16 isolated organisms $E$. coli had the highest isolation rate $6(37.5 \%)$ (Table 3), this suggest faecal contamination of the products. $E$. coli is a common flora in the gastrointestinal tract responsible for diarrhea and extra-intestinal infections (CDC, 2011). The result is in conformity with the findings of Ndahi et al. (2013) and Shamsuddeen (2009). Also presence of campylobacter might be due to cross contamination from raw meat to finished product (Tsire). Staphylococcus aureus is a normal flora of the skin, nasal, genital, mouth or anal area in both humans and animals without any symptom of an infection (Matthew et al., 2013). Isolation of $S$. aureus in these study concords with the findings of Lucretia et al. (2018) from Suya sold in Rivers State. 
BAJOPAS Volume 13 Number 1, June, 2020

It is also in agreement with the findings of Yousafzai et al. (2018); Onuorah et al. (2015) and Tijjani and Jumare (2014) from tsire samples in different countries. Presence of $S$. aureus in foods is most of the time an indication of poor human handling, poor environment, unhygienic utensils and equipments used during processing (Igene et al., 2016; Okonko et al., 2013). Infections caused by $S$. aureus are difficult to treat leading to long hospitalization with consequent economic loss (Udobi et al., 2013). These include soft tissue infections, pneumonia, hospital-acquired postoperative wound infections, Staphylococcal food poisoning, impetigo and cellulitis (Charlene et al., 2013). Samples obtained from Dausai and Kofar Kudu had the highest isolation rate $4(80 \%)$ (Table 4 ) probably because of the much commercial activities taking place in the area which can lead to environmental contamination.

Table 1: Total Aerobic Mesophilic Bacterial Count of Tsire sold in Garko Town

\begin{tabular}{lll}
\hline Sampling Area & APC cfu/g & Mean \pm STD \\
\hline Dausai & $2.20 \times 10^{5}$ & $110000 \pm 14142.14$ \\
Kofar Kudu & $4.00 \times 10^{5}$ & $133333.3 \pm 23094.01$ \\
Makwalla & $1.30 \times 10^{5}$ & $32500 \pm 7187.953$ \\
Rinji & $2.72 \times 10^{5}$ & $90666.67 \pm 94769.90$ \\
Tosaro & $1.02 \times 10^{5}$ & $51000 \pm 15556.35$ \\
Tsohuwar Kasuwa & $1.75 \times 10^{5}$ & $35000 \pm 11357.82$ \\
\hline
\end{tabular}

Key: APC: Aerobic Mesophilic Counts

STD: Standard Deviation

Table 2: Total Coliform Count of Tsire sold in Garko Town

\begin{tabular}{lcc}
\hline \multicolumn{1}{c}{ Sampling Area } & TCC MPN/g & Mean \pm STD \\
\hline Dausai & 20 & $6.67 \pm 2.5166$ \\
Kofar Kudu & 32 & $16.00 \pm 5.6569$ \\
Makwalla & 68 & $13.60 \pm 8.7062$ \\
Rinji & 37 & $9.25 \pm 4.7871$ \\
Tosaro & 10 & $5.00 \pm 2.8284$ \\
Tsohuwar Kasuwa & 8 & $4.00 \pm 0.0000$ \\
\hline
\end{tabular}

Table 3: Organisms Isolated from Tsire Sold in Garko

\begin{tabular}{lcl}
\hline Isolated Organism & Frequency & Percentage (\%) \\
\hline Campylobacter & 2 & 06.66 \\
Escherichia coli & 6 & 20.00 \\
Klebsiella pneumoniae & 2 & 06.66 \\
Salmonella species & 1 & 03.33 \\
Shigella & 3 & 10.00 \\
Staphylococcus aureus & 2 & 06.66 \\
Total & 16 & \\
\hline
\end{tabular}

Table 4: Distribution of Organisms within Sampling Area

\begin{tabular}{lcc}
\hline \multicolumn{1}{c}{ Sampling Area } & No. Isolated & Percentage (\%) \\
\hline Dausai & 4 & 80 \\
Kofar Kudu & 4 & 80 \\
Makwalla & 2 & 40 \\
Rinji & 3 & 60 \\
Tosaro & 2 & 40 \\
Tsohuwar Kasuwa & 1 & 20 \\
Total & 16 & \\
\hline
\end{tabular}

\section{CONCLUSION}

Results indicated $4.00 \times 10^{5} \mathrm{CFU} / \mathrm{g}$ as the highest APCs count; while $68 \mathrm{MPN} / \mathrm{g}$ was the highest TCCs from the 30 samples analyzed. Among the isolates, $E$. coli has the highest isolation rate of $6(20 \%)$. Dausai and Kofar kudu were having the highest bacteria count of $4(80 \%)$, each, indicating higher contamination in those locations. 
BAJOPAS Volume 13 Number 1, June, 2020 RECOMMENDATIONS

The following recommendations are tenable:

1. Hygienic practices at all stages of production should be improved to safe guard the consumers against potential health hazard.

2. Monitoring of microbiological contamination of Tsire during preparations, packaging and marketing is essential to ensure product of good microbiological quality for consumers' health.

\section{REFERENCES}

Abdullahi, I. O., Umoh, V. J. and Galadima, M. (2004). Hazards Associated with Kilishi Preparations in Zaria. Nigerian Journal of Microbiology, 18 (1-2): $339-345$.

Ahmadu, J. and Ibrahim E. J., (2013): Determinants of Revenue in Suya Production in BeninCity, Edo State, Nigeria. Nigerian journal of agriculture, food and environment.9(3):1-5

Amaeze, N. Aboh, M. Itohan, A. Felix, E. Olatunji, T. and Oladosu, P. (2016) Microbial Profile, Antibiotic Sensitivity and Heat Resistance of Bacterial Isolates from Commercial Roasted Beef (Suya) in Abuja, Nigeria. JOPAT, 15(2): $22-30$.

Apata, E.S., Kuku1, I.A., Apata, O.C. and Adeyemi, K.O. (2013). Evaluation of Suya(Tsire) - An Intermediate Moisture Meat Product in Ogun State, Nigeria. J. Food Res 2 (1): 87.

Atlas, R. M. (1997) Principles of Microbiology Second Edition. C. Brown Publishers. Pp 802-803.

Borch, E. Kant-Muermans, M. L., Blixt, Y. (1996) Bacterial Spoilage of Meat and Cured Meat Products. Int $\mathrm{J}$ Food Microbiol .33(1): 103-20.

Centre for Disease Control, CDC (2011). "Escherichia coli 0157:H7" Division of Bacterial and Mycotic Diseasesht://www.cdc.gov/nczved/divisi ons/dfbmd/diseases/ecoli_0157h7/.

Charlene, R. J., Johnnie, A. D., and John, B. B., (2013) Prevalence and Characterization of Methicillin-Resistant Staphylococcus aureus Isolates from Retail Meat and Humans in Georgia. American society for Microbiology. J. of clinical microbiology. 12(1):123-6 doi:10.1128/JCM.0316612JCM.03166-12

Egbebi, A.O and Seidu, K., T. (2011). Microbiological Evaluation of Suya (dried smoked

meat) Sold in Ado and Akure, South West Nigeria.European Journal of Experinmental Biology, 1(4):1-5
3. Government should establish regulatory bodies responsible for inculcating hygiene habits to the local producers and vendors in order to prevent instant, cross and post processing contaminations by microbial pathogens.

4. Awareness and sensitization of local food producers about good hygienic practices in food handling and processing.

Falegan, C, R., Akoja, S. D., and Oyarekua, M. A., (2017) Microbiological Assessment of Suya (Sliced Roasted Beef) in Ado-Ekiti Metropolis, Ekiti State, Nigeria. MOJ Biology andMedicine.

Fonkem, D., N. Tanya, V., N. and Ebangi, A., L. (2010). Effect of Season on the Microbiological Quality of Kilishi, a Traditional Cameroonian Dried Beef Product. Tropicultura, 28(1): 10-15.

Food and Agricultural Organization of the United Nations (F A O, 1979). Manual of food quality control 4. Microbiological analysis.

Food and Agriculture Organisation of the United Nation (FAO), 2019. Nigeria at a glance.

Igene J.O., Uwadia, O.E., Ebabhamiegbebho, P.A. and Evivie, S.E., (2016) Shelf life Stability Studies of University of Benin (UNIBEN) Proff's Kilishi Product Asian Journal of Science and Technology 7(1): 2268-2274.

Inusa, S. K. and Said, I. S. (2017) Evaluation of the Chemical and Microbiological Properties Of Kilishi Sold in Kano Metropolis. Journal of Dry land Agriculture, 3 (1): $59-69$.

Lucretia, I. B, Patience, C. Obinna-Echem, Sophia, C. A. (2018) Microbiological quality andantibiotic sensitivity of potential pathogens isolated from meat product (Suya) sold in Rivers State University and its environs. International Journal of Biotechnology and Food Science, 6(4): 67-76.

Matthew, E., Drosos, E., John, L. and Ioanna, P. (2013) MRSA in Africa: Filling the Global Map of Antimicrobial Resistance PLOS One. 8(7): e68024 doi: 10.1371/journal.pone.0068024

Mgbemere, V.N., Akpapunam, M. A. and Igene, J. O., (2011). Effect of Groundnut FlourSubstitution on Yield, Quality and Storage Stability of Kilishi - a Nigerian Indigenous Dried Meat Product. African Journal of Food, Agriculture, Nutrition and Development, $\quad \mathbf{1 1}(2)$ : 4718-4738. 
BAJOPAS Volume 13 Number 1, June, 2020

Mubarak, A. A., Azeez, M. L., Amos A. O., Opeyemi, O. O. (2016) Assessment of Animal Protein Consumption and Food Security Among Rural Households in Kwara State, Nigeria American Journal of Business and Society, 1(4): 233245.

Ndahi, M., D. Kwaga, J., K. P. Bello, M. Kabir J., V. Umoh, .J. Yakubu, S., E. and Nok, A., J. (2013) Prevalence and Antimicrobial Susceptibility of Listeria Monocytogenes and Methicillin-Resistant Staphylococcus aureus Strains from Raw Meat and Meat Products in Zaria, Nigeria. Applied Journal of Microbiology, 58(3):262-9.

Okonko, I.O., Odu, N.N. and Igboh, I.E. (2013). Microbiological Analysis of Kilishi Sold In Port Harcourt, Nigeria. New York Science Journal, 6 (7):37-43.

Osimani, A., Aquilanti, L. and Clementi, F. (2015) Microbiological Quality of Meatbased Meals and Operation of Control Systems within a Food Service Environment. International Food Research Journal 22(4): 1692-1698.

Onuorah, S. Obika, I. Odibo, F. Orji, M. (2015)An Assessment of the Bacteriological Quality of Tsire-Suya (Grilled Beef) sold in Awka, Nigeria. American. J. Life. Sci. Res. 3(4):287292.

Razavilar, V, Khandaghi, J. Barzgari, A. (2010); Isolation of Eschericia coli 0157:H7 from manure fertilized farms and raw vegetables grown on it, in Tabriz city in
Iran. African Journal of Microbiology Research, 4(9): 891-895.

Scallan, E. Hoekstra, R. M. Angulo, F. J.Tauxe, R. V, Widdowson, M. Roy, S. L et al., (2011).Food borne illness acquired in the United States- Major Pathogens. Emerg. Infec Dis, 17(1): 7-15.

Shamsuddeen U (2009). Microbiological quality of spice used in the production of Kilishi a traditionally dried and grilled meat product. Bayero Journal of Pure andApplied Sciences, 2(2): 66-69.

Shamsuddeen, U. (2015) Microbiological Hazard and Critical control point Analysis of Dried and Minced Meat Snacks Produced in Kano Nigeria. Lambert Academic Publishing; Pp 1-36.

Tijani, O.and Jumare, S. (2014). Microblological Quality Assessment of Meat

Sold in KauraNamoda. International Conference on Earth, Environment and Life sciences (EELS) Dubai (UAE).

Udobi, C. E., Obajuluwa, A. F., and Onaolapo, J. A., (2013) Prevalence and Antibiotic Resistance Pattern of MethicillinResistant Staphylococcus aureus from an Orthopaedic Hospital in Nigeria BioMed Research International; 26(6); 6-7.

WHO, 2015 Foodborne diseases in the WHO African Region.

Yousafzai HA, Rind R, Khan MA, Abro SH, Korejo NA, Ejaz M, Kabir A, Shahid M, Memon S. (2019). Microbiological Contamination of Cattle and Meat in Peshawar, Pakistan. J. Anim. Health Prod. 7(1): 1116. 


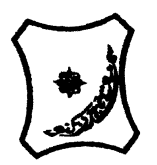

Bayero Journal of Pure and Applied Sciences, 13(1); 40 - 45

Received: September, 2019

Accepted: April, 2020

ISSN $2006-6996$

\title{
BACTERIOLOGICAL QUALITY OF STICK MEAT (Tsire) SOLD IN GARKO LOCAL GOVERNMENT AREA OF KANO STATE, NIGERIA
}

\author{
$*^{1}$ Dahiru A. T. and ${ }^{2}$ Maigari A. K. \\ ${ }^{1}$ Department of Hospitality Management, School of Technology, Kano State Polytechnic, PMB 3348, \\ Kano Nigeria. \\ ${ }^{2}$ Departmnt of Biological Sciences, Bayero University, Kano \\ Corresponding Author: dturajo61@gmail.com; GSM: 08087508262.
}

ABSTRACT

Stick meat, locally called Tsire in Hausa Language, is a significant portion of the diet of a large active population of Northern Nigeria. However, because of the handling and processing methods by the manufacturers as well as the hawking system of stick meat, the meat product may be exposed to both pre- and post-processed product contamination, and thus may poses danger to public health. Therefore, considering the role of Tsire in improving nutrition and increase household income to the populace, the need to improve the processing, distribution and overall quality of the product is simply indispensable. A total of 30 samples (5 samples from each of the 6 sampling points) of Tsire were collected randomly in Garko Town. Aerobic plate counts (APCs) and Total coliform counts (TCCS) of Tsire samples were determined using standard microbiological methods. APCs ranged from $1.02 \times 10^{5}$ to $4.00 \times 10^{5} \mathrm{CFU} / \mathrm{g}$; while TCCs ranged from $8 \mathrm{MPN} / \mathrm{g}$ to $68 \mathrm{MPN} / \mathrm{g}$. From the 30 samples screened, 16(53.33\%) bacteria namely, Campylobacter 2(6.66\%), Escherichia coli 6(20\%), Klebsiella pneumoniae 2(6.66\%), Salmonella spp. 1(3.33\%), Shigella 3(10\%) and Staphylococcus aureus 2(6.66\%) were detected. $E$. coli has the highest isolation rate of 6(20\%), while Salmonella spp. had the least frequency of 1(3.33\%). The distribution of isolated organisms within the study area were as follows: Dausai, 4(80\%), Kofar kudu, 4(80\%), Makwalla, 2(40\%), Rinji, 3(60\%), Tosaro, 2(40\%), and Tsohuwar Kasuwa, 1(20\%). The results have indicated that the Tsire was contaminated with bacteria thus exposing the product to fast deterioration, spoilage and also a vehicle for food borne illness, suggesting for adequate hygienic practices at all the stages, prior to consumption, to ensure safety of the meat product.

Key words: APCs, TCCs, Contamination, Microorganisms, Garko

\section{INTRODUCTION}

Nigeria is one of the developing nations with inadequate food supply and most often deficient in protein content (FAO, 2019). Nigerian's average animal protein intake per head per day is estimated at $7.9 \mathrm{~g}$ as against $35 \mathrm{~g}$ recommended value by Food and Agricultural Organization (Mubarak et al., 2016). These low levels of animal protein intake create great concern as it affects the nutritional status of Nigerians. Hence, there is the need for sufficient supply of animal protein from energy rich animal products to satisfy the nutritional requirements for Nigerians.

Meat is one major source of animal protein largely composed of water, protein and fats which can make it susceptible to microbial contamination within short time leading to spoilage (Apata et al., 2013; Mgbemere et al., 2011). Meat is mostly eaten after it has been cooked or processed in a variety of ways such as sun drying; smoking and roasting with or without fortifications (Borch et al., 1996). In Nigeria meat products such as Tsire, Kilishi and Balangu are locally produced using one or more of these methods in order to meet the nutritional requirements of the teeming Nigerians (Egbebi, 2011).

Tsire is a popular Nigerian traditional processed ready-to-eat roasted stick meat product (Shamsuddeen, 2015). It is sold in public places, along roads, in hotels, parks, quarters and even offices (Falegan et al., 2017). It is prepared from boneless healthy animal flesh such as beef and mutton, spiced with peanut cake, salt, vegetable oil and other flavorings followed by roasting (Shamsuddeen, 2015). Consumption of these products has extended to other parts of African countries such as Ghana, Somali, Cameroun and Chad (Ahmadu and Ibrahim, 2013). 
BAJOPAS Volume 13 Number 1, June, 2020

However, evidence of quality control sticking to procedural hygiene by the handlers during preparation and retailing of these products is poorly documented. Tsire is of great safety risk because of the fact that there are erratic cases of gastroenteritis and symptoms of food infection after consumption (WHO, 2015). Food borne illnesses are one of the major health problems in developing and developed countries (Razavilar, 2010). According to the World Health Organization, WHO (2015), $0.07 \%$ death of the 600 million global burdens of Foodborne illnesses have been reported to be caused by bacteria, viruses, fungi and chemicals. In America $0.27 \%$ of the estimated 48 million affected people is hospitalized and about $0.0063 \%$ deaths are recorded each year (Scallan et al., 2011). More than 91 million people in Africa fall ill and $0.15 \%$ dies each year, making Africa the highest burden bearer of Foodborne diseases per population (WHO, 2015).

Application of a Hazard Analysis Critical Control Point (HACCP) at all stages of meat products preparation is essential in order to ensure its safety. Thus, according to the guidelines of good manufacturing practice, the level of total aerobic bacterial contamination of thermally processed meat products should not exceed $10^{4}\left(\mathrm{cfu} \mathrm{g}^{-1}\right)$. Enterobacteriaceae and faecal coliform contamination in meat products should be within the range of $10^{2}-10^{4}$ and $10-10^{3} \mathrm{cfu} \mathrm{g}^{-1}$, respectively (Shamsuddeen, 2015). The aim of the study is therefore, to assess the total viable bacterial counts of tsire marketed locally within Garko town, and to isolate and identify the organisms at the point of consumption with the intention of promoting public health and food hygiene habits in the Nigerian populace.

\section{MATERIALS AND METHODS Study Area and Population}

Garko is one of the existing 44 local government areas located in Kano south west zone of Kano state with its capital administrative headquarters in the Garko town. It has coordinates $11^{\circ} 39^{\prime} \mathrm{N}$ $8^{\circ} 54^{\prime} \mathrm{E}$, and an area of $450 \mathrm{~km}^{2}$. The projected population of Garko local Government was 225,300 according to the National Population Census report (2018). Garko is known for agricultural activities both farming and animal husbandry. It is popularly known for large scale rice production. Other food crops include sweet potatoes, cassava, onions, sorghum, millet and sugarcane. Cows, sheep and goats are major groups of animals reared by majority of the populace. Meat products processed, retailed and consumed in Garko include roasted meat (Balangu), dried roasted meat (Kilishi), stick meat (Tsire), hide and skin pepper soup (Ragadada) and minced fried meat (Danbunnama).

\section{Samples Collection}

Five samples of Tsire products were collected from 6 different identified locations within Garko town in a sterile foil paper and immediately analyzed for the presence of bacteria.

\section{Sample Preparation}

Sample preparation for the bacteriological analysis was carried out in accordance with the method described by Atlas (1997). Twenty five grams $(25 \mathrm{~g})$ of the sample was homogenized in $225 \mathrm{ml}$ peptone water using Kenwood blender machine to obtain a $10^{1}$ homogenate. The homogenate was thoroughly shaken and $1 \mathrm{ml}$ pipetted into test tubes containing $9 \mathrm{ml}$ of peptone water $\left(10^{2}\right)$. The test tubes were further serially diluted to $10^{5}$.

Total Aerobic Mesophilic Bacterial Count

Total Aerobic mesophilic bacterial count was determined using the method described by Abdullahi et al. (2004) where $1 \mathrm{ml}$ of inoculums from $10^{1}$ to $10^{5}$ dilutions were transferred into duplicate Petri dishes and labeled accordingly. This was followed by pouring aseptically about $15 \mathrm{ml}$ of molten nutrient agar. The culture was homogenized by gentle spinning of the plates and allowed to solidify. The plates were incubated at $37^{\circ} \mathrm{C}$ for 24 hours. Plates containing 30-300 colonies were counted. The number of colony forming units per gram of a sample (cfu/g) was obtained by multiplying the average colony number with the inverse of the dilution factor.

\section{Enumeration and Detection of Coliform bacteria}

Detection and enumeration of coliform was carried out according to method described by Atlas, (1977). A set of 9 test tubes each containing $9 \mathrm{ml}$ of lactose broth and an inverted Durham tubes were autoclaved to expel air and to sterilize. Similarly, $1 \mathrm{ml}$ from the diluents $10^{1}$ was transferred to the first 3 test tubes, followed by $1 \mathrm{ml}$ from the diluents $10^{2}$ to the second set of 3 test tubes and finally the third diluents $10^{3}$ to the $3^{\text {rd }}$ set of 3 test tubes. All the 9 test tubes were incubated at $37^{\circ} \mathrm{C}$ for 24 hours. Tubes that showed gas and acid production after 24 hours were recorded as positive for the presence of Coliform. Negative tubes were further reincubated for 24 hours. Positive tubes were recorded. Estimate of most probable number of Coliform per gram of sample (MPN/g) was determined by comparing the number of gas positive tubes with the most probable number table. 
BAJOPAS Volume 13 Number 1, June, 2020 Identification of Coliform

A loop full of inoculum from gas positive tubes was streaked on to Eosine methylene blue (EMB) agar plate and incubated at $37^{\circ} \mathrm{C}$ for $24 \mathrm{hrs}$. Colonies which formed bluish black color with green metallic sheen, and reddish colonies were isolated on agar slants. Those colonies showing metallic sheen on EMB were sub cultured into tubes of lactose broth and incubated at $45^{\circ} \mathrm{C}$. The tubes were observed after $24 \mathrm{hrs}$ for gas production. This is the completed test for fecal coliform. Gram stain and other biochemical tests such as Indole, Methyl red, Voges-Proskauer and Citrate Utilization tests (IMVIC), Coagulase and Catalase tests were carried out for the Identification and confirmation of isolates.

\section{Procedure for Indole Test}

Indole test was carried out by preparing a Tryptone broth drawn in to test tubes, sterilized by autoclaving, inoculated with loopful of suspension and incubated at $37^{\circ} \mathrm{C}$ for 24 hours. Three drops of xylene was added in tubes, shaken vigorously and kept for the separation of two layers. One millilitre of Kovac's reagent was added and the formation of pink colour ring indicates positive Indole test.

\section{Procedure for Methyl Red Test}

Methyl red test was carried out by preparing Glucose phosphate broth, dispensed in test tubes, sterilized, inoculated with test culture and incubated at $37^{\circ} \mathrm{C}$ for 24 hours. Five drops of methyl-red indicator was added to the medium for the formation of red colour.

\section{Procedure for Voges-Proskauer Test}

Voges-Proskauer test was carried out by inoculating tubes with the bacterial culture followed by incubation for 48 hours at $37^{\circ} \mathrm{C}$. Separate pipettes were used to pipette $1 \mathrm{ml}$ from each culture tube into clean separate tubes. Eighteen drops $(0.5 \mathrm{ml})$ of Barrit's solution A (a-naphthol) was added to each tube containing glucose phosphate broth followed by the addition of an equal amount of solution $B$ into the same tube. The tubes were shaken at 30 seconds interval. A positive reaction was indicated by the development of a pink color, which turns red in 1-2 hours, after vigorous shaking.

\section{Procedure for Citrate Utilization Test}

Citrate Utilization Test was carried out by distributing melted agar (Simmon Citrate Agar) in to test tubes followed by sterilization at $121.5^{\circ} \mathrm{C}$ for 15 minutes. The test tubes were afterward held in slanted position, inoculated with the given bacterial culture and incubated at $37^{\circ} \mathrm{C}$ for $24 \mathrm{hrs}$. Positive test was indicated by color change of the media from green to blue.

\section{RESULTS AND DISCUSSIONS}

The results of this study are presented in tables $1,2,3$ and 4. Among the sampling areas Kofar Kudu had the highest aerobic mesophilic bacteria counts $4.0 \times 10^{5} \mathrm{cfu} / \mathrm{g}$ followed by Rinji $2.72 \times 10^{5} \mathrm{cfu} / \mathrm{g}$, while Tosaro had the least Aerobic mesophilic bacteria counts of $1.02 \times 10^{5}$ $\mathrm{cfu} / \mathrm{g}$ as indicated in Table 1.Makwalla had the highest coliform count $68 \mathrm{MPN} / \mathrm{g}$ followed by Rinji $37 \mathrm{MPN} / \mathrm{g}$. Tsohuwar Kasuwa had the least coliform counts $8 \mathrm{MPN} / \mathrm{g}$, (Table 2). Result from table 1 shows variation in the microbial contents among the samples which suggest variation in their sources, poor handling procedures and contamination from the processing environment. High coliform count and their differences within sampling areas is an indication of poor microbiological quality of the product. Ndahi et al. (2013) reported microbial load to be a function of the handling personnel and the environment. The results indicated that the samples were contaminated with bacteria as the counts exceeded the minimum safety level $\left(10^{4} \mathrm{cfu} / \mathrm{g}\right)$ for members of the Enterobacteriaceae family. However, it might be a reflection of poor hygienic practices which may contribute to health hazard to the potential consumers. Similarly, Inusa and Sa'id (2017); Osimani et al. (2015) reported that, the initial microbial content of the raw material play significant role in influencing the final microbial load of the finished product. Isolation of members of the Enterobacteriaceae such as $E$. coli, Klebsiella pneumoniae, Salmonella and Shigella signifies danger to the public health. These organisms are capable of producing endotoxins which trigger high fevers in infected individuals, and the enterotoxins which colonize the small intestines and lead to extreme dehydration as a result of vomiting and diarrhea sometimes with severe and fatal outcomes (Amaeze et al., 2016). From the 16 isolated organisms $E$. coli had the highest isolation rate $6(37.5 \%)$ (Table 3), this suggest faecal contamination of the products. $E$. coli is a common flora in the gastrointestinal tract responsible for diarrhea and extra-intestinal infections (CDC, 2011). The result is in conformity with the findings of Ndahi et al. (2013) and Shamsuddeen (2009). Also presence of campylobacter might be due to cross contamination from raw meat to finished product (Tsire). Staphylococcus aureus is a normal flora of the skin, nasal, genital, mouth or anal area in both humans and animals without any symptom of an infection (Matthew et al., 2013). Isolation of $S$. aureus in these study concords with the findings of Lucretia et al. (2018) from Suya sold in Rivers State. 
BAJOPAS Volume 13 Number 1, June, 2020

It is also in agreement with the findings of Yousafzai et al. (2018); Onuorah et al. (2015) and Tijjani and Jumare (2014) from tsire samples in different countries. Presence of $S$. aureus in foods is most of the time an indication of poor human handling, poor environment, unhygienic utensils and equipments used during processing (Igene et al., 2016; Okonko et al., 2013). Infections caused by $S$. aureus are difficult to treat leading to long hospitalization with consequent economic loss (Udobi et al., 2013). These include soft tissue infections, pneumonia, hospital-acquired postoperative wound infections, Staphylococcal food poisoning, impetigo and cellulitis (Charlene et al., 2013). Samples obtained from Dausai and Kofar Kudu had the highest isolation rate $4(80 \%)$ (Table 4 ) probably because of the much commercial activities taking place in the area which can lead to environmental contamination.

Table 1: Total Aerobic Mesophilic Bacterial Count of Tsire sold in Garko Town

\begin{tabular}{lll}
\hline Sampling Area & APC cfu/g & Mean \pm STD \\
\hline Dausai & $2.20 \times 10^{5}$ & $110000 \pm 14142.14$ \\
Kofar Kudu & $4.00 \times 10^{5}$ & $133333.3 \pm 23094.01$ \\
Makwalla & $1.30 \times 10^{5}$ & $32500 \pm 7187.953$ \\
Rinji & $2.72 \times 10^{5}$ & $90666.67 \pm 94769.90$ \\
Tosaro & $1.02 \times 10^{5}$ & $51000 \pm 15556.35$ \\
Tsohuwar Kasuwa & $1.75 \times 10^{5}$ & $35000 \pm 11357.82$ \\
\hline
\end{tabular}

Key: APC: Aerobic Mesophilic Counts

STD: Standard Deviation

Table 2: Total Coliform Count of Tsire sold in Garko Town

\begin{tabular}{lcc}
\hline \multicolumn{1}{c}{ Sampling Area } & TCC MPN/g & Mean \pm STD \\
\hline Dausai & 20 & $6.67 \pm 2.5166$ \\
Kofar Kudu & 32 & $16.00 \pm 5.6569$ \\
Makwalla & 68 & $13.60 \pm 8.7062$ \\
Rinji & 37 & $9.25 \pm 4.7871$ \\
Tosaro & 10 & $5.00 \pm 2.8284$ \\
Tsohuwar Kasuwa & 8 & $4.00 \pm 0.0000$ \\
\hline
\end{tabular}

Table 3: Organisms Isolated from Tsire Sold in Garko

\begin{tabular}{lcl}
\hline Isolated Organism & Frequency & Percentage (\%) \\
\hline Campylobacter & 2 & 06.66 \\
Escherichia coli & 6 & 20.00 \\
Klebsiella pneumoniae & 2 & 06.66 \\
Salmonella species & 1 & 03.33 \\
Shigella & 3 & 10.00 \\
Staphylococcus aureus & 2 & 06.66 \\
Total & 16 & \\
\hline
\end{tabular}

Table 4: Distribution of Organisms within Sampling Area

\begin{tabular}{lcc}
\hline \multicolumn{1}{c}{ Sampling Area } & No. Isolated & Percentage (\%) \\
\hline Dausai & 4 & 80 \\
Kofar Kudu & 4 & 80 \\
Makwalla & 2 & 40 \\
Rinji & 3 & 60 \\
Tosaro & 2 & 40 \\
Tsohuwar Kasuwa & 1 & 20 \\
Total & 16 & \\
\hline
\end{tabular}

\section{CONCLUSION}

Results indicated $4.00 \times 10^{5} \mathrm{CFU} / \mathrm{g}$ as the highest APCs count; while $68 \mathrm{MPN} / \mathrm{g}$ was the highest TCCs from the 30 samples analyzed. Among the isolates, $E$. coli has the highest isolation rate of $6(20 \%)$. Dausai and Kofar kudu were having the highest bacteria count of $4(80 \%)$, each, indicating higher contamination in those locations. 
BAJOPAS Volume 13 Number 1, June, 2020 RECOMMENDATIONS

The following recommendations are tenable:

1. Hygienic practices at all stages of production should be improved to safe guard the consumers against potential health hazard.

2. Monitoring of microbiological contamination of Tsire during preparations, packaging and marketing is essential to ensure product of good microbiological quality for consumers' health.

\section{REFERENCES}

Abdullahi, I. O., Umoh, V. J. and Galadima, M. (2004). Hazards Associated with Kilishi Preparations in Zaria. Nigerian Journal of Microbiology, 18 (1-2): $339-345$.

Ahmadu, J. and Ibrahim E. J., (2013): Determinants of Revenue in Suya Production in BeninCity, Edo State, Nigeria. Nigerian journal of agriculture, food and environment.9(3):1-5

Amaeze, N. Aboh, M. Itohan, A. Felix, E. Olatunji, T. and Oladosu, P. (2016) Microbial Profile, Antibiotic Sensitivity and Heat Resistance of Bacterial Isolates from Commercial Roasted Beef (Suya) in Abuja, Nigeria. JOPAT, 15(2): $22-30$.

Apata, E.S., Kuku1, I.A., Apata, O.C. and Adeyemi, K.O. (2013). Evaluation of Suya(Tsire) - An Intermediate Moisture Meat Product in Ogun State, Nigeria. J. Food Res 2 (1): 87.

Atlas, R. M. (1997) Principles of Microbiology Second Edition. C. Brown Publishers. Pp 802-803.

Borch, E. Kant-Muermans, M. L., Blixt, Y. (1996) Bacterial Spoilage of Meat and Cured Meat Products. Int $\mathrm{J}$ Food Microbiol .33(1): 103-20.

Centre for Disease Control, CDC (2011). "Escherichia coli 0157:H7" Division of Bacterial and Mycotic Diseasesht://www.cdc.gov/nczved/divisi ons/dfbmd/diseases/ecoli_0157h7/.

Charlene, R. J., Johnnie, A. D., and John, B. B., (2013) Prevalence and Characterization of Methicillin-Resistant Staphylococcus aureus Isolates from Retail Meat and Humans in Georgia. American society for Microbiology. J. of clinical microbiology. 12(1):123-6 doi:10.1128/JCM.0316612JCM.03166-12

Egbebi, A.O and Seidu, K., T. (2011). Microbiological Evaluation of Suya (dried smoked

meat) Sold in Ado and Akure, South West Nigeria.European Journal of Experinmental Biology, 1(4):1-5
3. Government should establish regulatory bodies responsible for inculcating hygiene habits to the local producers and vendors in order to prevent instant, cross and post processing contaminations by microbial pathogens.

4. Awareness and sensitization of local food producers about good hygienic practices in food handling and processing.

Falegan, C, R., Akoja, S. D., and Oyarekua, M. A., (2017) Microbiological Assessment of Suya (Sliced Roasted Beef) in Ado-Ekiti Metropolis, Ekiti State, Nigeria. MOJ Biology andMedicine.

Fonkem, D., N. Tanya, V., N. and Ebangi, A., L. (2010). Effect of Season on the Microbiological Quality of Kilishi, a Traditional Cameroonian Dried Beef Product. Tropicultura, 28(1): 10-15.

Food and Agricultural Organization of the United Nations (F A O, 1979). Manual of food quality control 4. Microbiological analysis.

Food and Agriculture Organisation of the United Nation (FAO), 2019. Nigeria at a glance.

Igene J.O., Uwadia, O.E., Ebabhamiegbebho, P.A. and Evivie, S.E., (2016) Shelf life Stability Studies of University of Benin (UNIBEN) Proff's Kilishi Product Asian Journal of Science and Technology 7(1): 2268-2274.

Inusa, S. K. and Said, I. S. (2017) Evaluation of the Chemical and Microbiological Properties Of Kilishi Sold in Kano Metropolis. Journal of Dry land Agriculture, 3 (1): $59-69$.

Lucretia, I. B, Patience, C. Obinna-Echem, Sophia, C. A. (2018) Microbiological quality andantibiotic sensitivity of potential pathogens isolated from meat product (Suya) sold in Rivers State University and its environs. International Journal of Biotechnology and Food Science, 6(4): 67-76.

Matthew, E., Drosos, E., John, L. and Ioanna, P. (2013) MRSA in Africa: Filling the Global Map of Antimicrobial Resistance PLOS One. 8(7): e68024 doi: 10.1371/journal.pone.0068024

Mgbemere, V.N., Akpapunam, M. A. and Igene, J. O., (2011). Effect of Groundnut FlourSubstitution on Yield, Quality and Storage Stability of Kilishi - a Nigerian Indigenous Dried Meat Product. African Journal of Food, Agriculture, Nutrition and Development, $\quad \mathbf{1 1}(2)$ : 4718-4738. 
BAJOPAS Volume 13 Number 1, June, 2020

Mubarak, A. A., Azeez, M. L., Amos A. O., Opeyemi, O. O. (2016) Assessment of Animal Protein Consumption and Food Security Among Rural Households in Kwara State, Nigeria American Journal of Business and Society, 1(4): 233245.

Ndahi, M., D. Kwaga, J., K. P. Bello, M. Kabir J., V. Umoh, .J. Yakubu, S., E. and Nok, A., J. (2013) Prevalence and Antimicrobial Susceptibility of Listeria Monocytogenes and Methicillin-Resistant Staphylococcus aureus Strains from Raw Meat and Meat Products in Zaria, Nigeria. Applied Journal of Microbiology, 58(3):262-9.

Okonko, I.O., Odu, N.N. and Igboh, I.E. (2013). Microbiological Analysis of Kilishi Sold In Port Harcourt, Nigeria. New York Science Journal, 6 (7):37-43.

Osimani, A., Aquilanti, L. and Clementi, F. (2015) Microbiological Quality of Meatbased Meals and Operation of Control Systems within a Food Service Environment. International Food Research Journal 22(4): 1692-1698.

Onuorah, S. Obika, I. Odibo, F. Orji, M. (2015)An Assessment of the Bacteriological Quality of Tsire-Suya (Grilled Beef) sold in Awka, Nigeria. American. J. Life. Sci. Res. 3(4):287292.

Razavilar, V, Khandaghi, J. Barzgari, A. (2010); Isolation of Eschericia coli 0157:H7 from manure fertilized farms and raw vegetables grown on it, in Tabriz city in
Iran. African Journal of Microbiology Research, 4(9): 891-895.

Scallan, E. Hoekstra, R. M. Angulo, F. J.Tauxe, R. V, Widdowson, M. Roy, S. L et al., (2011).Food borne illness acquired in the United States- Major Pathogens. Emerg. Infec Dis, 17(1): 7-15.

Shamsuddeen U (2009). Microbiological quality of spice used in the production of Kilishi a traditionally dried and grilled meat product. Bayero Journal of Pure andApplied Sciences, 2(2): 66-69.

Shamsuddeen, U. (2015) Microbiological Hazard and Critical control point Analysis of Dried and Minced Meat Snacks Produced in Kano Nigeria. Lambert Academic Publishing; Pp 1-36.

Tijani, O.and Jumare, S. (2014). Microblological Quality Assessment of Meat

Sold in KauraNamoda. International Conference on Earth, Environment and Life sciences (EELS) Dubai (UAE).

Udobi, C. E., Obajuluwa, A. F., and Onaolapo, J. A., (2013) Prevalence and Antibiotic Resistance Pattern of MethicillinResistant Staphylococcus aureus from an Orthopaedic Hospital in Nigeria BioMed Research International; 26(6); 6-7.

WHO, 2015 Foodborne diseases in the WHO African Region.

Yousafzai HA, Rind R, Khan MA, Abro SH, Korejo NA, Ejaz M, Kabir A, Shahid M, Memon S. (2019). Microbiological Contamination of Cattle and Meat in Peshawar, Pakistan. J. Anim. Health Prod. 7(1): 1116. 


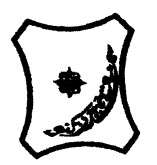

Bayero Journal of Pure and Applied Sciences, 13(1); 40 - 45

Received: September, 2019

Accepted: April, 2020

ISSN $2006-6996$

\title{
BACTERIOLOGICAL QUALITY OF STICK MEAT (Tsire) SOLD IN GARKO LOCAL GOVERNMENT AREA OF KANO STATE, NIGERIA
}

\author{
$*^{1}$ Dahiru A. T. and ${ }^{2}$ Maigari A. K. \\ ${ }^{1}$ Department of Hospitality Management, School of Technology, Kano State Polytechnic, PMB 3348, \\ Kano Nigeria. \\ ${ }^{2}$ Departmnt of Biological Sciences, Bayero University, Kano \\ Corresponding Author: dturajo61@gmail.com; GSM: 08087508262.
}

ABSTRACT

Stick meat, locally called Tsire in Hausa Language, is a significant portion of the diet of a large active population of Northern Nigeria. However, because of the handling and processing methods by the manufacturers as well as the hawking system of stick meat, the meat product may be exposed to both pre- and post-processed product contamination, and thus may poses danger to public health. Therefore, considering the role of Tsire in improving nutrition and increase household income to the populace, the need to improve the processing, distribution and overall quality of the product is simply indispensable. A total of 30 samples (5 samples from each of the 6 sampling points) of Tsire were collected randomly in Garko Town. Aerobic plate counts (APCs) and Total coliform counts (TCCS) of Tsire samples were determined using standard microbiological methods. APCs ranged from $1.02 \times 10^{5}$ to $4.00 \times 10^{5} \mathrm{CFU} / \mathrm{g}$; while TCCs ranged from $8 \mathrm{MPN} / \mathrm{g}$ to $68 \mathrm{MPN} / \mathrm{g}$. From the 30 samples screened, 16(53.33\%) bacteria namely, Campylobacter 2(6.66\%), Escherichia coli 6(20\%), Klebsiella pneumoniae 2(6.66\%), Salmonella spp. 1(3.33\%), Shigella 3(10\%) and Staphylococcus aureus 2(6.66\%) were detected. $E$. coli has the highest isolation rate of 6(20\%), while Salmonella spp. had the least frequency of 1(3.33\%). The distribution of isolated organisms within the study area were as follows: Dausai, 4(80\%), Kofar kudu, 4(80\%), Makwalla, 2(40\%), Rinji, 3(60\%), Tosaro, 2(40\%), and Tsohuwar Kasuwa, 1(20\%). The results have indicated that the Tsire was contaminated with bacteria thus exposing the product to fast deterioration, spoilage and also a vehicle for food borne illness, suggesting for adequate hygienic practices at all the stages, prior to consumption, to ensure safety of the meat product.

Key words: APCs, TCCs, Contamination, Microorganisms, Garko

\section{INTRODUCTION}

Nigeria is one of the developing nations with inadequate food supply and most often deficient in protein content (FAO, 2019). Nigerian's average animal protein intake per head per day is estimated at $7.9 \mathrm{~g}$ as against $35 \mathrm{~g}$ recommended value by Food and Agricultural Organization (Mubarak et al., 2016). These low levels of animal protein intake create great concern as it affects the nutritional status of Nigerians. Hence, there is the need for sufficient supply of animal protein from energy rich animal products to satisfy the nutritional requirements for Nigerians.

Meat is one major source of animal protein largely composed of water, protein and fats which can make it susceptible to microbial contamination within short time leading to spoilage (Apata et al., 2013; Mgbemere et al., 2011). Meat is mostly eaten after it has been cooked or processed in a variety of ways such as sun drying; smoking and roasting with or without fortifications (Borch et al., 1996). In Nigeria meat products such as Tsire, Kilishi and Balangu are locally produced using one or more of these methods in order to meet the nutritional requirements of the teeming Nigerians (Egbebi, 2011).

Tsire is a popular Nigerian traditional processed ready-to-eat roasted stick meat product (Shamsuddeen, 2015). It is sold in public places, along roads, in hotels, parks, quarters and even offices (Falegan et al., 2017). It is prepared from boneless healthy animal flesh such as beef and mutton, spiced with peanut cake, salt, vegetable oil and other flavorings followed by roasting (Shamsuddeen, 2015). Consumption of these products has extended to other parts of African countries such as Ghana, Somali, Cameroun and Chad (Ahmadu and Ibrahim, 2013). 
BAJOPAS Volume 13 Number 1, June, 2020

However, evidence of quality control sticking to procedural hygiene by the handlers during preparation and retailing of these products is poorly documented. Tsire is of great safety risk because of the fact that there are erratic cases of gastroenteritis and symptoms of food infection after consumption (WHO, 2015). Food borne illnesses are one of the major health problems in developing and developed countries (Razavilar, 2010). According to the World Health Organization, WHO (2015), $0.07 \%$ death of the 600 million global burdens of Foodborne illnesses have been reported to be caused by bacteria, viruses, fungi and chemicals. In America $0.27 \%$ of the estimated 48 million affected people is hospitalized and about $0.0063 \%$ deaths are recorded each year (Scallan et al., 2011). More than 91 million people in Africa fall ill and $0.15 \%$ dies each year, making Africa the highest burden bearer of Foodborne diseases per population (WHO, 2015).

Application of a Hazard Analysis Critical Control Point (HACCP) at all stages of meat products preparation is essential in order to ensure its safety. Thus, according to the guidelines of good manufacturing practice, the level of total aerobic bacterial contamination of thermally processed meat products should not exceed $10^{4}\left(\mathrm{cfu} \mathrm{g}^{-1}\right)$. Enterobacteriaceae and faecal coliform contamination in meat products should be within the range of $10^{2}-10^{4}$ and $10-10^{3} \mathrm{cfu} \mathrm{g}^{-1}$, respectively (Shamsuddeen, 2015). The aim of the study is therefore, to assess the total viable bacterial counts of tsire marketed locally within Garko town, and to isolate and identify the organisms at the point of consumption with the intention of promoting public health and food hygiene habits in the Nigerian populace.

\section{MATERIALS AND METHODS Study Area and Population}

Garko is one of the existing 44 local government areas located in Kano south west zone of Kano state with its capital administrative headquarters in the Garko town. It has coordinates $11^{\circ} 39^{\prime} \mathrm{N}$ $8^{\circ} 54^{\prime} \mathrm{E}$, and an area of $450 \mathrm{~km}^{2}$. The projected population of Garko local Government was 225,300 according to the National Population Census report (2018). Garko is known for agricultural activities both farming and animal husbandry. It is popularly known for large scale rice production. Other food crops include sweet potatoes, cassava, onions, sorghum, millet and sugarcane. Cows, sheep and goats are major groups of animals reared by majority of the populace. Meat products processed, retailed and consumed in Garko include roasted meat (Balangu), dried roasted meat (Kilishi), stick meat (Tsire), hide and skin pepper soup (Ragadada) and minced fried meat (Danbunnama).

\section{Samples Collection}

Five samples of Tsire products were collected from 6 different identified locations within Garko town in a sterile foil paper and immediately analyzed for the presence of bacteria.

\section{Sample Preparation}

Sample preparation for the bacteriological analysis was carried out in accordance with the method described by Atlas (1997). Twenty five grams $(25 \mathrm{~g})$ of the sample was homogenized in $225 \mathrm{ml}$ peptone water using Kenwood blender machine to obtain a $10^{1}$ homogenate. The homogenate was thoroughly shaken and $1 \mathrm{ml}$ pipetted into test tubes containing $9 \mathrm{ml}$ of peptone water $\left(10^{2}\right)$. The test tubes were further serially diluted to $10^{5}$.

Total Aerobic Mesophilic Bacterial Count

Total Aerobic mesophilic bacterial count was determined using the method described by Abdullahi et al. (2004) where $1 \mathrm{ml}$ of inoculums from $10^{1}$ to $10^{5}$ dilutions were transferred into duplicate Petri dishes and labeled accordingly. This was followed by pouring aseptically about $15 \mathrm{ml}$ of molten nutrient agar. The culture was homogenized by gentle spinning of the plates and allowed to solidify. The plates were incubated at $37^{\circ} \mathrm{C}$ for 24 hours. Plates containing 30-300 colonies were counted. The number of colony forming units per gram of a sample (cfu/g) was obtained by multiplying the average colony number with the inverse of the dilution factor.

\section{Enumeration and Detection of Coliform bacteria}

Detection and enumeration of coliform was carried out according to method described by Atlas, (1977). A set of 9 test tubes each containing $9 \mathrm{ml}$ of lactose broth and an inverted Durham tubes were autoclaved to expel air and to sterilize. Similarly, $1 \mathrm{ml}$ from the diluents $10^{1}$ was transferred to the first 3 test tubes, followed by $1 \mathrm{ml}$ from the diluents $10^{2}$ to the second set of 3 test tubes and finally the third diluents $10^{3}$ to the $3^{\text {rd }}$ set of 3 test tubes. All the 9 test tubes were incubated at $37^{\circ} \mathrm{C}$ for 24 hours. Tubes that showed gas and acid production after 24 hours were recorded as positive for the presence of Coliform. Negative tubes were further reincubated for 24 hours. Positive tubes were recorded. Estimate of most probable number of Coliform per gram of sample (MPN/g) was determined by comparing the number of gas positive tubes with the most probable number table. 
BAJOPAS Volume 13 Number 1, June, 2020 Identification of Coliform

A loop full of inoculum from gas positive tubes was streaked on to Eosine methylene blue (EMB) agar plate and incubated at $37^{\circ} \mathrm{C}$ for $24 \mathrm{hrs}$. Colonies which formed bluish black color with green metallic sheen, and reddish colonies were isolated on agar slants. Those colonies showing metallic sheen on EMB were sub cultured into tubes of lactose broth and incubated at $45^{\circ} \mathrm{C}$. The tubes were observed after $24 \mathrm{hrs}$ for gas production. This is the completed test for fecal coliform. Gram stain and other biochemical tests such as Indole, Methyl red, Voges-Proskauer and Citrate Utilization tests (IMVIC), Coagulase and Catalase tests were carried out for the Identification and confirmation of isolates.

\section{Procedure for Indole Test}

Indole test was carried out by preparing a Tryptone broth drawn in to test tubes, sterilized by autoclaving, inoculated with loopful of suspension and incubated at $37^{\circ} \mathrm{C}$ for 24 hours. Three drops of xylene was added in tubes, shaken vigorously and kept for the separation of two layers. One millilitre of Kovac's reagent was added and the formation of pink colour ring indicates positive Indole test.

\section{Procedure for Methyl Red Test}

Methyl red test was carried out by preparing Glucose phosphate broth, dispensed in test tubes, sterilized, inoculated with test culture and incubated at $37^{\circ} \mathrm{C}$ for 24 hours. Five drops of methyl-red indicator was added to the medium for the formation of red colour.

\section{Procedure for Voges-Proskauer Test}

Voges-Proskauer test was carried out by inoculating tubes with the bacterial culture followed by incubation for 48 hours at $37^{\circ} \mathrm{C}$. Separate pipettes were used to pipette $1 \mathrm{ml}$ from each culture tube into clean separate tubes. Eighteen drops $(0.5 \mathrm{ml})$ of Barrit's solution A (a-naphthol) was added to each tube containing glucose phosphate broth followed by the addition of an equal amount of solution $B$ into the same tube. The tubes were shaken at 30 seconds interval. A positive reaction was indicated by the development of a pink color, which turns red in 1-2 hours, after vigorous shaking.

\section{Procedure for Citrate Utilization Test}

Citrate Utilization Test was carried out by distributing melted agar (Simmon Citrate Agar) in to test tubes followed by sterilization at $121.5^{\circ} \mathrm{C}$ for 15 minutes. The test tubes were afterward held in slanted position, inoculated with the given bacterial culture and incubated at $37^{\circ} \mathrm{C}$ for $24 \mathrm{hrs}$. Positive test was indicated by color change of the media from green to blue.

\section{RESULTS AND DISCUSSIONS}

The results of this study are presented in tables $1,2,3$ and 4. Among the sampling areas Kofar Kudu had the highest aerobic mesophilic bacteria counts $4.0 \times 10^{5} \mathrm{cfu} / \mathrm{g}$ followed by Rinji $2.72 \times 10^{5} \mathrm{cfu} / \mathrm{g}$, while Tosaro had the least Aerobic mesophilic bacteria counts of $1.02 \times 10^{5}$ $\mathrm{cfu} / \mathrm{g}$ as indicated in Table 1.Makwalla had the highest coliform count $68 \mathrm{MPN} / \mathrm{g}$ followed by Rinji $37 \mathrm{MPN} / \mathrm{g}$. Tsohuwar Kasuwa had the least coliform counts $8 \mathrm{MPN} / \mathrm{g}$, (Table 2). Result from table 1 shows variation in the microbial contents among the samples which suggest variation in their sources, poor handling procedures and contamination from the processing environment. High coliform count and their differences within sampling areas is an indication of poor microbiological quality of the product. Ndahi et al. (2013) reported microbial load to be a function of the handling personnel and the environment. The results indicated that the samples were contaminated with bacteria as the counts exceeded the minimum safety level $\left(10^{4} \mathrm{cfu} / \mathrm{g}\right)$ for members of the Enterobacteriaceae family. However, it might be a reflection of poor hygienic practices which may contribute to health hazard to the potential consumers. Similarly, Inusa and Sa'id (2017); Osimani et al. (2015) reported that, the initial microbial content of the raw material play significant role in influencing the final microbial load of the finished product. Isolation of members of the Enterobacteriaceae such as $E$. coli, Klebsiella pneumoniae, Salmonella and Shigella signifies danger to the public health. These organisms are capable of producing endotoxins which trigger high fevers in infected individuals, and the enterotoxins which colonize the small intestines and lead to extreme dehydration as a result of vomiting and diarrhea sometimes with severe and fatal outcomes (Amaeze et al., 2016). From the 16 isolated organisms $E$. coli had the highest isolation rate $6(37.5 \%)$ (Table 3), this suggest faecal contamination of the products. $E$. coli is a common flora in the gastrointestinal tract responsible for diarrhea and extra-intestinal infections (CDC, 2011). The result is in conformity with the findings of Ndahi et al. (2013) and Shamsuddeen (2009). Also presence of campylobacter might be due to cross contamination from raw meat to finished product (Tsire). Staphylococcus aureus is a normal flora of the skin, nasal, genital, mouth or anal area in both humans and animals without any symptom of an infection (Matthew et al., 2013). Isolation of $S$. aureus in these study concords with the findings of Lucretia et al. (2018) from Suya sold in Rivers State. 
BAJOPAS Volume 13 Number 1, June, 2020

It is also in agreement with the findings of Yousafzai et al. (2018); Onuorah et al. (2015) and Tijjani and Jumare (2014) from tsire samples in different countries. Presence of $S$. aureus in foods is most of the time an indication of poor human handling, poor environment, unhygienic utensils and equipments used during processing (Igene et al., 2016; Okonko et al., 2013). Infections caused by $S$. aureus are difficult to treat leading to long hospitalization with consequent economic loss (Udobi et al., 2013). These include soft tissue infections, pneumonia, hospital-acquired postoperative wound infections, Staphylococcal food poisoning, impetigo and cellulitis (Charlene et al., 2013). Samples obtained from Dausai and Kofar Kudu had the highest isolation rate $4(80 \%)$ (Table 4 ) probably because of the much commercial activities taking place in the area which can lead to environmental contamination.

Table 1: Total Aerobic Mesophilic Bacterial Count of Tsire sold in Garko Town

\begin{tabular}{lll}
\hline Sampling Area & APC cfu/g & Mean \pm STD \\
\hline Dausai & $2.20 \times 10^{5}$ & $110000 \pm 14142.14$ \\
Kofar Kudu & $4.00 \times 10^{5}$ & $133333.3 \pm 23094.01$ \\
Makwalla & $1.30 \times 10^{5}$ & $32500 \pm 7187.953$ \\
Rinji & $2.72 \times 10^{5}$ & $90666.67 \pm 94769.90$ \\
Tosaro & $1.02 \times 10^{5}$ & $51000 \pm 15556.35$ \\
Tsohuwar Kasuwa & $1.75 \times 10^{5}$ & $35000 \pm 11357.82$ \\
\hline
\end{tabular}

Key: APC: Aerobic Mesophilic Counts

STD: Standard Deviation

Table 2: Total Coliform Count of Tsire sold in Garko Town

\begin{tabular}{lcc}
\hline \multicolumn{1}{c}{ Sampling Area } & TCC MPN/g & Mean \pm STD \\
\hline Dausai & 20 & $6.67 \pm 2.5166$ \\
Kofar Kudu & 32 & $16.00 \pm 5.6569$ \\
Makwalla & 68 & $13.60 \pm 8.7062$ \\
Rinji & 37 & $9.25 \pm 4.7871$ \\
Tosaro & 10 & $5.00 \pm 2.8284$ \\
Tsohuwar Kasuwa & 8 & $4.00 \pm 0.0000$ \\
\hline
\end{tabular}

Table 3: Organisms Isolated from Tsire Sold in Garko

\begin{tabular}{lcl}
\hline Isolated Organism & Frequency & Percentage (\%) \\
\hline Campylobacter & 2 & 06.66 \\
Escherichia coli & 6 & 20.00 \\
Klebsiella pneumoniae & 2 & 06.66 \\
Salmonella species & 1 & 03.33 \\
Shigella & 3 & 10.00 \\
Staphylococcus aureus & 2 & 06.66 \\
Total & 16 & \\
\hline
\end{tabular}

Table 4: Distribution of Organisms within Sampling Area

\begin{tabular}{lcc}
\hline \multicolumn{1}{c}{ Sampling Area } & No. Isolated & Percentage (\%) \\
\hline Dausai & 4 & 80 \\
Kofar Kudu & 4 & 80 \\
Makwalla & 2 & 40 \\
Rinji & 3 & 60 \\
Tosaro & 2 & 40 \\
Tsohuwar Kasuwa & 1 & 20 \\
Total & 16 & \\
\hline
\end{tabular}

\section{CONCLUSION}

Results indicated $4.00 \times 10^{5} \mathrm{CFU} / \mathrm{g}$ as the highest APCs count; while $68 \mathrm{MPN} / \mathrm{g}$ was the highest TCCs from the 30 samples analyzed. Among the isolates, $E$. coli has the highest isolation rate of $6(20 \%)$. Dausai and Kofar kudu were having the highest bacteria count of $4(80 \%)$, each, indicating higher contamination in those locations. 
BAJOPAS Volume 13 Number 1, June, 2020 RECOMMENDATIONS

The following recommendations are tenable:

1. Hygienic practices at all stages of production should be improved to safe guard the consumers against potential health hazard.

2. Monitoring of microbiological contamination of Tsire during preparations, packaging and marketing is essential to ensure product of good microbiological quality for consumers' health.

\section{REFERENCES}

Abdullahi, I. O., Umoh, V. J. and Galadima, M. (2004). Hazards Associated with Kilishi Preparations in Zaria. Nigerian Journal of Microbiology, 18 (1-2): $339-345$.

Ahmadu, J. and Ibrahim E. J., (2013): Determinants of Revenue in Suya Production in BeninCity, Edo State, Nigeria. Nigerian journal of agriculture, food and environment.9(3):1-5

Amaeze, N. Aboh, M. Itohan, A. Felix, E. Olatunji, T. and Oladosu, P. (2016) Microbial Profile, Antibiotic Sensitivity and Heat Resistance of Bacterial Isolates from Commercial Roasted Beef (Suya) in Abuja, Nigeria. JOPAT, 15(2): $22-30$.

Apata, E.S., Kuku1, I.A., Apata, O.C. and Adeyemi, K.O. (2013). Evaluation of Suya(Tsire) - An Intermediate Moisture Meat Product in Ogun State, Nigeria. J. Food Res 2 (1): 87.

Atlas, R. M. (1997) Principles of Microbiology Second Edition. C. Brown Publishers. Pp 802-803.

Borch, E. Kant-Muermans, M. L., Blixt, Y. (1996) Bacterial Spoilage of Meat and Cured Meat Products. Int $\mathrm{J}$ Food Microbiol .33(1): 103-20.

Centre for Disease Control, CDC (2011). "Escherichia coli 0157:H7" Division of Bacterial and Mycotic Diseasesht://www.cdc.gov/nczved/divisi ons/dfbmd/diseases/ecoli_0157h7/.

Charlene, R. J., Johnnie, A. D., and John, B. B., (2013) Prevalence and Characterization of Methicillin-Resistant Staphylococcus aureus Isolates from Retail Meat and Humans in Georgia. American society for Microbiology. J. of clinical microbiology. 12(1):123-6 doi:10.1128/JCM.0316612JCM.03166-12

Egbebi, A.O and Seidu, K., T. (2011). Microbiological Evaluation of Suya (dried smoked

meat) Sold in Ado and Akure, South West Nigeria.European Journal of Experinmental Biology, 1(4):1-5
3. Government should establish regulatory bodies responsible for inculcating hygiene habits to the local producers and vendors in order to prevent instant, cross and post processing contaminations by microbial pathogens.

4. Awareness and sensitization of local food producers about good hygienic practices in food handling and processing.

Falegan, C, R., Akoja, S. D., and Oyarekua, M. A., (2017) Microbiological Assessment of Suya (Sliced Roasted Beef) in Ado-Ekiti Metropolis, Ekiti State, Nigeria. MOJ Biology andMedicine.

Fonkem, D., N. Tanya, V., N. and Ebangi, A., L. (2010). Effect of Season on the Microbiological Quality of Kilishi, a Traditional Cameroonian Dried Beef Product. Tropicultura, 28(1): 10-15.

Food and Agricultural Organization of the United Nations (F A O, 1979). Manual of food quality control 4. Microbiological analysis.

Food and Agriculture Organisation of the United Nation (FAO), 2019. Nigeria at a glance.

Igene J.O., Uwadia, O.E., Ebabhamiegbebho, P.A. and Evivie, S.E., (2016) Shelf life Stability Studies of University of Benin (UNIBEN) Proff's Kilishi Product Asian Journal of Science and Technology 7(1): 2268-2274.

Inusa, S. K. and Said, I. S. (2017) Evaluation of the Chemical and Microbiological Properties Of Kilishi Sold in Kano Metropolis. Journal of Dry land Agriculture, 3 (1): $59-69$.

Lucretia, I. B, Patience, C. Obinna-Echem, Sophia, C. A. (2018) Microbiological quality andantibiotic sensitivity of potential pathogens isolated from meat product (Suya) sold in Rivers State University and its environs. International Journal of Biotechnology and Food Science, 6(4): 67-76.

Matthew, E., Drosos, E., John, L. and Ioanna, P. (2013) MRSA in Africa: Filling the Global Map of Antimicrobial Resistance PLOS One. 8(7): e68024 doi: 10.1371/journal.pone.0068024

Mgbemere, V.N., Akpapunam, M. A. and Igene, J. O., (2011). Effect of Groundnut FlourSubstitution on Yield, Quality and Storage Stability of Kilishi - a Nigerian Indigenous Dried Meat Product. African Journal of Food, Agriculture, Nutrition and Development, $\quad \mathbf{1 1}(2)$ : 4718-4738. 
BAJOPAS Volume 13 Number 1, June, 2020

Mubarak, A. A., Azeez, M. L., Amos A. O., Opeyemi, O. O. (2016) Assessment of Animal Protein Consumption and Food Security Among Rural Households in Kwara State, Nigeria American Journal of Business and Society, 1(4): 233245.

Ndahi, M., D. Kwaga, J., K. P. Bello, M. Kabir J., V. Umoh, .J. Yakubu, S., E. and Nok, A., J. (2013) Prevalence and Antimicrobial Susceptibility of Listeria Monocytogenes and Methicillin-Resistant Staphylococcus aureus Strains from Raw Meat and Meat Products in Zaria, Nigeria. Applied Journal of Microbiology, 58(3):262-9.

Okonko, I.O., Odu, N.N. and Igboh, I.E. (2013). Microbiological Analysis of Kilishi Sold In Port Harcourt, Nigeria. New York Science Journal, 6 (7):37-43.

Osimani, A., Aquilanti, L. and Clementi, F. (2015) Microbiological Quality of Meatbased Meals and Operation of Control Systems within a Food Service Environment. International Food Research Journal 22(4): 1692-1698.

Onuorah, S. Obika, I. Odibo, F. Orji, M. (2015)An Assessment of the Bacteriological Quality of Tsire-Suya (Grilled Beef) sold in Awka, Nigeria. American. J. Life. Sci. Res. 3(4):287292.

Razavilar, V, Khandaghi, J. Barzgari, A. (2010); Isolation of Eschericia coli 0157:H7 from manure fertilized farms and raw vegetables grown on it, in Tabriz city in
Iran. African Journal of Microbiology Research, 4(9): 891-895.

Scallan, E. Hoekstra, R. M. Angulo, F. J.Tauxe, R. V, Widdowson, M. Roy, S. L et al., (2011).Food borne illness acquired in the United States- Major Pathogens. Emerg. Infec Dis, 17(1): 7-15.

Shamsuddeen U (2009). Microbiological quality of spice used in the production of Kilishi a traditionally dried and grilled meat product. Bayero Journal of Pure andApplied Sciences, 2(2): 66-69.

Shamsuddeen, U. (2015) Microbiological Hazard and Critical control point Analysis of Dried and Minced Meat Snacks Produced in Kano Nigeria. Lambert Academic Publishing; Pp 1-36.

Tijani, O.and Jumare, S. (2014). Microblological Quality Assessment of Meat

Sold in KauraNamoda. International Conference on Earth, Environment and Life sciences (EELS) Dubai (UAE).

Udobi, C. E., Obajuluwa, A. F., and Onaolapo, J. A., (2013) Prevalence and Antibiotic Resistance Pattern of MethicillinResistant Staphylococcus aureus from an Orthopaedic Hospital in Nigeria BioMed Research International; 26(6); 6-7.

WHO, 2015 Foodborne diseases in the WHO African Region.

Yousafzai HA, Rind R, Khan MA, Abro SH, Korejo NA, Ejaz M, Kabir A, Shahid M, Memon S. (2019). Microbiological Contamination of Cattle and Meat in Peshawar, Pakistan. J. Anim. Health Prod. 7(1): 1116. 


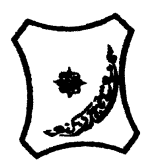

Bayero Journal of Pure and Applied Sciences, 13(1); 40 - 45

Received: September, 2019

Accepted: April, 2020

ISSN $2006-6996$

\title{
BACTERIOLOGICAL QUALITY OF STICK MEAT (Tsire) SOLD IN GARKO LOCAL GOVERNMENT AREA OF KANO STATE, NIGERIA
}

\author{
$*^{1}$ Dahiru A. T. and ${ }^{2}$ Maigari A. K. \\ ${ }^{1}$ Department of Hospitality Management, School of Technology, Kano State Polytechnic, PMB 3348, \\ Kano Nigeria. \\ ${ }^{2}$ Departmnt of Biological Sciences, Bayero University, Kano \\ Corresponding Author: dturajo61@gmail.com; GSM: 08087508262.
}

ABSTRACT

Stick meat, locally called Tsire in Hausa Language, is a significant portion of the diet of a large active population of Northern Nigeria. However, because of the handling and processing methods by the manufacturers as well as the hawking system of stick meat, the meat product may be exposed to both pre- and post-processed product contamination, and thus may poses danger to public health. Therefore, considering the role of Tsire in improving nutrition and increase household income to the populace, the need to improve the processing, distribution and overall quality of the product is simply indispensable. A total of 30 samples (5 samples from each of the 6 sampling points) of Tsire were collected randomly in Garko Town. Aerobic plate counts (APCs) and Total coliform counts (TCCS) of Tsire samples were determined using standard microbiological methods. APCs ranged from $1.02 \times 10^{5}$ to $4.00 \times 10^{5} \mathrm{CFU} / \mathrm{g}$; while TCCs ranged from $8 \mathrm{MPN} / \mathrm{g}$ to $68 \mathrm{MPN} / \mathrm{g}$. From the 30 samples screened, 16(53.33\%) bacteria namely, Campylobacter 2(6.66\%), Escherichia coli 6(20\%), Klebsiella pneumoniae 2(6.66\%), Salmonella spp. 1(3.33\%), Shigella 3(10\%) and Staphylococcus aureus 2(6.66\%) were detected. $E$. coli has the highest isolation rate of 6(20\%), while Salmonella spp. had the least frequency of 1(3.33\%). The distribution of isolated organisms within the study area were as follows: Dausai, 4(80\%), Kofar kudu, 4(80\%), Makwalla, 2(40\%), Rinji, 3(60\%), Tosaro, 2(40\%), and Tsohuwar Kasuwa, 1(20\%). The results have indicated that the Tsire was contaminated with bacteria thus exposing the product to fast deterioration, spoilage and also a vehicle for food borne illness, suggesting for adequate hygienic practices at all the stages, prior to consumption, to ensure safety of the meat product.

Key words: APCs, TCCs, Contamination, Microorganisms, Garko

\section{INTRODUCTION}

Nigeria is one of the developing nations with inadequate food supply and most often deficient in protein content (FAO, 2019). Nigerian's average animal protein intake per head per day is estimated at $7.9 \mathrm{~g}$ as against $35 \mathrm{~g}$ recommended value by Food and Agricultural Organization (Mubarak et al., 2016). These low levels of animal protein intake create great concern as it affects the nutritional status of Nigerians. Hence, there is the need for sufficient supply of animal protein from energy rich animal products to satisfy the nutritional requirements for Nigerians.

Meat is one major source of animal protein largely composed of water, protein and fats which can make it susceptible to microbial contamination within short time leading to spoilage (Apata et al., 2013; Mgbemere et al., 2011). Meat is mostly eaten after it has been cooked or processed in a variety of ways such as sun drying; smoking and roasting with or without fortifications (Borch et al., 1996). In Nigeria meat products such as Tsire, Kilishi and Balangu are locally produced using one or more of these methods in order to meet the nutritional requirements of the teeming Nigerians (Egbebi, 2011).

Tsire is a popular Nigerian traditional processed ready-to-eat roasted stick meat product (Shamsuddeen, 2015). It is sold in public places, along roads, in hotels, parks, quarters and even offices (Falegan et al., 2017). It is prepared from boneless healthy animal flesh such as beef and mutton, spiced with peanut cake, salt, vegetable oil and other flavorings followed by roasting (Shamsuddeen, 2015). Consumption of these products has extended to other parts of African countries such as Ghana, Somali, Cameroun and Chad (Ahmadu and Ibrahim, 2013). 
BAJOPAS Volume 13 Number 1, June, 2020

However, evidence of quality control sticking to procedural hygiene by the handlers during preparation and retailing of these products is poorly documented. Tsire is of great safety risk because of the fact that there are erratic cases of gastroenteritis and symptoms of food infection after consumption (WHO, 2015). Food borne illnesses are one of the major health problems in developing and developed countries (Razavilar, 2010). According to the World Health Organization, WHO (2015), $0.07 \%$ death of the 600 million global burdens of Foodborne illnesses have been reported to be caused by bacteria, viruses, fungi and chemicals. In America $0.27 \%$ of the estimated 48 million affected people is hospitalized and about $0.0063 \%$ deaths are recorded each year (Scallan et al., 2011). More than 91 million people in Africa fall ill and $0.15 \%$ dies each year, making Africa the highest burden bearer of Foodborne diseases per population (WHO, 2015).

Application of a Hazard Analysis Critical Control Point (HACCP) at all stages of meat products preparation is essential in order to ensure its safety. Thus, according to the guidelines of good manufacturing practice, the level of total aerobic bacterial contamination of thermally processed meat products should not exceed $10^{4}\left(\mathrm{cfu} \mathrm{g}^{-1}\right)$. Enterobacteriaceae and faecal coliform contamination in meat products should be within the range of $10^{2}-10^{4}$ and $10-10^{3} \mathrm{cfu} \mathrm{g}^{-1}$, respectively (Shamsuddeen, 2015). The aim of the study is therefore, to assess the total viable bacterial counts of tsire marketed locally within Garko town, and to isolate and identify the organisms at the point of consumption with the intention of promoting public health and food hygiene habits in the Nigerian populace.

\section{MATERIALS AND METHODS Study Area and Population}

Garko is one of the existing 44 local government areas located in Kano south west zone of Kano state with its capital administrative headquarters in the Garko town. It has coordinates $11^{\circ} 39^{\prime} \mathrm{N}$ $8^{\circ} 54^{\prime} \mathrm{E}$, and an area of $450 \mathrm{~km}^{2}$. The projected population of Garko local Government was 225,300 according to the National Population Census report (2018). Garko is known for agricultural activities both farming and animal husbandry. It is popularly known for large scale rice production. Other food crops include sweet potatoes, cassava, onions, sorghum, millet and sugarcane. Cows, sheep and goats are major groups of animals reared by majority of the populace. Meat products processed, retailed and consumed in Garko include roasted meat (Balangu), dried roasted meat (Kilishi), stick meat (Tsire), hide and skin pepper soup (Ragadada) and minced fried meat (Danbunnama).

\section{Samples Collection}

Five samples of Tsire products were collected from 6 different identified locations within Garko town in a sterile foil paper and immediately analyzed for the presence of bacteria.

\section{Sample Preparation}

Sample preparation for the bacteriological analysis was carried out in accordance with the method described by Atlas (1997). Twenty five grams $(25 \mathrm{~g})$ of the sample was homogenized in $225 \mathrm{ml}$ peptone water using Kenwood blender machine to obtain a $10^{1}$ homogenate. The homogenate was thoroughly shaken and $1 \mathrm{ml}$ pipetted into test tubes containing $9 \mathrm{ml}$ of peptone water $\left(10^{2}\right)$. The test tubes were further serially diluted to $10^{5}$.

Total Aerobic Mesophilic Bacterial Count

Total Aerobic mesophilic bacterial count was determined using the method described by Abdullahi et al. (2004) where $1 \mathrm{ml}$ of inoculums from $10^{1}$ to $10^{5}$ dilutions were transferred into duplicate Petri dishes and labeled accordingly. This was followed by pouring aseptically about $15 \mathrm{ml}$ of molten nutrient agar. The culture was homogenized by gentle spinning of the plates and allowed to solidify. The plates were incubated at $37^{\circ} \mathrm{C}$ for 24 hours. Plates containing 30-300 colonies were counted. The number of colony forming units per gram of a sample (cfu/g) was obtained by multiplying the average colony number with the inverse of the dilution factor.

\section{Enumeration and Detection of Coliform bacteria}

Detection and enumeration of coliform was carried out according to method described by Atlas, (1977). A set of 9 test tubes each containing $9 \mathrm{ml}$ of lactose broth and an inverted Durham tubes were autoclaved to expel air and to sterilize. Similarly, $1 \mathrm{ml}$ from the diluents $10^{1}$ was transferred to the first 3 test tubes, followed by $1 \mathrm{ml}$ from the diluents $10^{2}$ to the second set of 3 test tubes and finally the third diluents $10^{3}$ to the $3^{\text {rd }}$ set of 3 test tubes. All the 9 test tubes were incubated at $37^{\circ} \mathrm{C}$ for 24 hours. Tubes that showed gas and acid production after 24 hours were recorded as positive for the presence of Coliform. Negative tubes were further reincubated for 24 hours. Positive tubes were recorded. Estimate of most probable number of Coliform per gram of sample (MPN/g) was determined by comparing the number of gas positive tubes with the most probable number table. 
BAJOPAS Volume 13 Number 1, June, 2020 Identification of Coliform

A loop full of inoculum from gas positive tubes was streaked on to Eosine methylene blue (EMB) agar plate and incubated at $37^{\circ} \mathrm{C}$ for $24 \mathrm{hrs}$. Colonies which formed bluish black color with green metallic sheen, and reddish colonies were isolated on agar slants. Those colonies showing metallic sheen on EMB were sub cultured into tubes of lactose broth and incubated at $45^{\circ} \mathrm{C}$. The tubes were observed after $24 \mathrm{hrs}$ for gas production. This is the completed test for fecal coliform. Gram stain and other biochemical tests such as Indole, Methyl red, Voges-Proskauer and Citrate Utilization tests (IMVIC), Coagulase and Catalase tests were carried out for the Identification and confirmation of isolates.

\section{Procedure for Indole Test}

Indole test was carried out by preparing a Tryptone broth drawn in to test tubes, sterilized by autoclaving, inoculated with loopful of suspension and incubated at $37^{\circ} \mathrm{C}$ for 24 hours. Three drops of xylene was added in tubes, shaken vigorously and kept for the separation of two layers. One millilitre of Kovac's reagent was added and the formation of pink colour ring indicates positive Indole test.

\section{Procedure for Methyl Red Test}

Methyl red test was carried out by preparing Glucose phosphate broth, dispensed in test tubes, sterilized, inoculated with test culture and incubated at $37^{\circ} \mathrm{C}$ for 24 hours. Five drops of methyl-red indicator was added to the medium for the formation of red colour.

\section{Procedure for Voges-Proskauer Test}

Voges-Proskauer test was carried out by inoculating tubes with the bacterial culture followed by incubation for 48 hours at $37^{\circ} \mathrm{C}$. Separate pipettes were used to pipette $1 \mathrm{ml}$ from each culture tube into clean separate tubes. Eighteen drops $(0.5 \mathrm{ml})$ of Barrit's solution A (a-naphthol) was added to each tube containing glucose phosphate broth followed by the addition of an equal amount of solution $B$ into the same tube. The tubes were shaken at 30 seconds interval. A positive reaction was indicated by the development of a pink color, which turns red in 1-2 hours, after vigorous shaking.

\section{Procedure for Citrate Utilization Test}

Citrate Utilization Test was carried out by distributing melted agar (Simmon Citrate Agar) in to test tubes followed by sterilization at $121.5^{\circ} \mathrm{C}$ for 15 minutes. The test tubes were afterward held in slanted position, inoculated with the given bacterial culture and incubated at $37^{\circ} \mathrm{C}$ for $24 \mathrm{hrs}$. Positive test was indicated by color change of the media from green to blue.

\section{RESULTS AND DISCUSSIONS}

The results of this study are presented in tables $1,2,3$ and 4. Among the sampling areas Kofar Kudu had the highest aerobic mesophilic bacteria counts $4.0 \times 10^{5} \mathrm{cfu} / \mathrm{g}$ followed by Rinji $2.72 \times 10^{5} \mathrm{cfu} / \mathrm{g}$, while Tosaro had the least Aerobic mesophilic bacteria counts of $1.02 \times 10^{5}$ $\mathrm{cfu} / \mathrm{g}$ as indicated in Table 1.Makwalla had the highest coliform count $68 \mathrm{MPN} / \mathrm{g}$ followed by Rinji $37 \mathrm{MPN} / \mathrm{g}$. Tsohuwar Kasuwa had the least coliform counts $8 \mathrm{MPN} / \mathrm{g}$, (Table 2). Result from table 1 shows variation in the microbial contents among the samples which suggest variation in their sources, poor handling procedures and contamination from the processing environment. High coliform count and their differences within sampling areas is an indication of poor microbiological quality of the product. Ndahi et al. (2013) reported microbial load to be a function of the handling personnel and the environment. The results indicated that the samples were contaminated with bacteria as the counts exceeded the minimum safety level $\left(10^{4} \mathrm{cfu} / \mathrm{g}\right)$ for members of the Enterobacteriaceae family. However, it might be a reflection of poor hygienic practices which may contribute to health hazard to the potential consumers. Similarly, Inusa and Sa'id (2017); Osimani et al. (2015) reported that, the initial microbial content of the raw material play significant role in influencing the final microbial load of the finished product. Isolation of members of the Enterobacteriaceae such as $E$. coli, Klebsiella pneumoniae, Salmonella and Shigella signifies danger to the public health. These organisms are capable of producing endotoxins which trigger high fevers in infected individuals, and the enterotoxins which colonize the small intestines and lead to extreme dehydration as a result of vomiting and diarrhea sometimes with severe and fatal outcomes (Amaeze et al., 2016). From the 16 isolated organisms $E$. coli had the highest isolation rate $6(37.5 \%)$ (Table 3), this suggest faecal contamination of the products. $E$. coli is a common flora in the gastrointestinal tract responsible for diarrhea and extra-intestinal infections (CDC, 2011). The result is in conformity with the findings of Ndahi et al. (2013) and Shamsuddeen (2009). Also presence of campylobacter might be due to cross contamination from raw meat to finished product (Tsire). Staphylococcus aureus is a normal flora of the skin, nasal, genital, mouth or anal area in both humans and animals without any symptom of an infection (Matthew et al., 2013). Isolation of $S$. aureus in these study concords with the findings of Lucretia et al. (2018) from Suya sold in Rivers State. 
BAJOPAS Volume 13 Number 1, June, 2020

It is also in agreement with the findings of Yousafzai et al. (2018); Onuorah et al. (2015) and Tijjani and Jumare (2014) from tsire samples in different countries. Presence of $S$. aureus in foods is most of the time an indication of poor human handling, poor environment, unhygienic utensils and equipments used during processing (Igene et al., 2016; Okonko et al., 2013). Infections caused by $S$. aureus are difficult to treat leading to long hospitalization with consequent economic loss (Udobi et al., 2013). These include soft tissue infections, pneumonia, hospital-acquired postoperative wound infections, Staphylococcal food poisoning, impetigo and cellulitis (Charlene et al., 2013). Samples obtained from Dausai and Kofar Kudu had the highest isolation rate $4(80 \%)$ (Table 4 ) probably because of the much commercial activities taking place in the area which can lead to environmental contamination.

Table 1: Total Aerobic Mesophilic Bacterial Count of Tsire sold in Garko Town

\begin{tabular}{lll}
\hline Sampling Area & APC cfu/g & Mean \pm STD \\
\hline Dausai & $2.20 \times 10^{5}$ & $110000 \pm 14142.14$ \\
Kofar Kudu & $4.00 \times 10^{5}$ & $133333.3 \pm 23094.01$ \\
Makwalla & $1.30 \times 10^{5}$ & $32500 \pm 7187.953$ \\
Rinji & $2.72 \times 10^{5}$ & $90666.67 \pm 94769.90$ \\
Tosaro & $1.02 \times 10^{5}$ & $51000 \pm 15556.35$ \\
Tsohuwar Kasuwa & $1.75 \times 10^{5}$ & $35000 \pm 11357.82$ \\
\hline
\end{tabular}

Key: APC: Aerobic Mesophilic Counts

STD: Standard Deviation

Table 2: Total Coliform Count of Tsire sold in Garko Town

\begin{tabular}{lcc}
\hline \multicolumn{1}{c}{ Sampling Area } & TCC MPN/g & Mean \pm STD \\
\hline Dausai & 20 & $6.67 \pm 2.5166$ \\
Kofar Kudu & 32 & $16.00 \pm 5.6569$ \\
Makwalla & 68 & $13.60 \pm 8.7062$ \\
Rinji & 37 & $9.25 \pm 4.7871$ \\
Tosaro & 10 & $5.00 \pm 2.8284$ \\
Tsohuwar Kasuwa & 8 & $4.00 \pm 0.0000$ \\
\hline
\end{tabular}

Table 3: Organisms Isolated from Tsire Sold in Garko

\begin{tabular}{lcl}
\hline Isolated Organism & Frequency & Percentage (\%) \\
\hline Campylobacter & 2 & 06.66 \\
Escherichia coli & 6 & 20.00 \\
Klebsiella pneumoniae & 2 & 06.66 \\
Salmonella species & 1 & 03.33 \\
Shigella & 3 & 10.00 \\
Staphylococcus aureus & 2 & 06.66 \\
Total & 16 & \\
\hline
\end{tabular}

Table 4: Distribution of Organisms within Sampling Area

\begin{tabular}{lcc}
\hline \multicolumn{1}{c}{ Sampling Area } & No. Isolated & Percentage (\%) \\
\hline Dausai & 4 & 80 \\
Kofar Kudu & 4 & 80 \\
Makwalla & 2 & 40 \\
Rinji & 3 & 60 \\
Tosaro & 2 & 40 \\
Tsohuwar Kasuwa & 1 & 20 \\
Total & 16 & \\
\hline
\end{tabular}

\section{CONCLUSION}

Results indicated $4.00 \times 10^{5} \mathrm{CFU} / \mathrm{g}$ as the highest APCs count; while $68 \mathrm{MPN} / \mathrm{g}$ was the highest TCCs from the 30 samples analyzed. Among the isolates, $E$. coli has the highest isolation rate of $6(20 \%)$. Dausai and Kofar kudu were having the highest bacteria count of $4(80 \%)$, each, indicating higher contamination in those locations. 
BAJOPAS Volume 13 Number 1, June, 2020 RECOMMENDATIONS

The following recommendations are tenable:

1. Hygienic practices at all stages of production should be improved to safe guard the consumers against potential health hazard.

2. Monitoring of microbiological contamination of Tsire during preparations, packaging and marketing is essential to ensure product of good microbiological quality for consumers' health.

\section{REFERENCES}

Abdullahi, I. O., Umoh, V. J. and Galadima, M. (2004). Hazards Associated with Kilishi Preparations in Zaria. Nigerian Journal of Microbiology, 18 (1-2): $339-345$.

Ahmadu, J. and Ibrahim E. J., (2013): Determinants of Revenue in Suya Production in BeninCity, Edo State, Nigeria. Nigerian journal of agriculture, food and environment.9(3):1-5

Amaeze, N. Aboh, M. Itohan, A. Felix, E. Olatunji, T. and Oladosu, P. (2016) Microbial Profile, Antibiotic Sensitivity and Heat Resistance of Bacterial Isolates from Commercial Roasted Beef (Suya) in Abuja, Nigeria. JOPAT, 15(2): $22-30$.

Apata, E.S., Kuku1, I.A., Apata, O.C. and Adeyemi, K.O. (2013). Evaluation of Suya(Tsire) - An Intermediate Moisture Meat Product in Ogun State, Nigeria. J. Food Res 2 (1): 87.

Atlas, R. M. (1997) Principles of Microbiology Second Edition. C. Brown Publishers. Pp 802-803.

Borch, E. Kant-Muermans, M. L., Blixt, Y. (1996) Bacterial Spoilage of Meat and Cured Meat Products. Int $\mathrm{J}$ Food Microbiol .33(1): 103-20.

Centre for Disease Control, CDC (2011). "Escherichia coli 0157:H7" Division of Bacterial and Mycotic Diseasesht://www.cdc.gov/nczved/divisi ons/dfbmd/diseases/ecoli_0157h7/.

Charlene, R. J., Johnnie, A. D., and John, B. B., (2013) Prevalence and Characterization of Methicillin-Resistant Staphylococcus aureus Isolates from Retail Meat and Humans in Georgia. American society for Microbiology. J. of clinical microbiology. 12(1):123-6 doi:10.1128/JCM.0316612JCM.03166-12

Egbebi, A.O and Seidu, K., T. (2011). Microbiological Evaluation of Suya (dried smoked

meat) Sold in Ado and Akure, South West Nigeria.European Journal of Experinmental Biology, 1(4):1-5
3. Government should establish regulatory bodies responsible for inculcating hygiene habits to the local producers and vendors in order to prevent instant, cross and post processing contaminations by microbial pathogens.

4. Awareness and sensitization of local food producers about good hygienic practices in food handling and processing.

Falegan, C, R., Akoja, S. D., and Oyarekua, M. A., (2017) Microbiological Assessment of Suya (Sliced Roasted Beef) in Ado-Ekiti Metropolis, Ekiti State, Nigeria. MOJ Biology andMedicine.

Fonkem, D., N. Tanya, V., N. and Ebangi, A., L. (2010). Effect of Season on the Microbiological Quality of Kilishi, a Traditional Cameroonian Dried Beef Product. Tropicultura, 28(1): 10-15.

Food and Agricultural Organization of the United Nations (F A O, 1979). Manual of food quality control 4. Microbiological analysis.

Food and Agriculture Organisation of the United Nation (FAO), 2019. Nigeria at a glance.

Igene J.O., Uwadia, O.E., Ebabhamiegbebho, P.A. and Evivie, S.E., (2016) Shelf life Stability Studies of University of Benin (UNIBEN) Proff's Kilishi Product Asian Journal of Science and Technology 7(1): 2268-2274.

Inusa, S. K. and Said, I. S. (2017) Evaluation of the Chemical and Microbiological Properties Of Kilishi Sold in Kano Metropolis. Journal of Dry land Agriculture, 3 (1): $59-69$.

Lucretia, I. B, Patience, C. Obinna-Echem, Sophia, C. A. (2018) Microbiological quality andantibiotic sensitivity of potential pathogens isolated from meat product (Suya) sold in Rivers State University and its environs. International Journal of Biotechnology and Food Science, 6(4): 67-76.

Matthew, E., Drosos, E., John, L. and Ioanna, P. (2013) MRSA in Africa: Filling the Global Map of Antimicrobial Resistance PLOS One. 8(7): e68024 doi: 10.1371/journal.pone.0068024

Mgbemere, V.N., Akpapunam, M. A. and Igene, J. O., (2011). Effect of Groundnut FlourSubstitution on Yield, Quality and Storage Stability of Kilishi - a Nigerian Indigenous Dried Meat Product. African Journal of Food, Agriculture, Nutrition and Development, $\quad \mathbf{1 1}(2)$ : 4718-4738. 
BAJOPAS Volume 13 Number 1, June, 2020

Mubarak, A. A., Azeez, M. L., Amos A. O., Opeyemi, O. O. (2016) Assessment of Animal Protein Consumption and Food Security Among Rural Households in Kwara State, Nigeria American Journal of Business and Society, 1(4): 233245.

Ndahi, M., D. Kwaga, J., K. P. Bello, M. Kabir J., V. Umoh, .J. Yakubu, S., E. and Nok, A., J. (2013) Prevalence and Antimicrobial Susceptibility of Listeria Monocytogenes and Methicillin-Resistant Staphylococcus aureus Strains from Raw Meat and Meat Products in Zaria, Nigeria. Applied Journal of Microbiology, 58(3):262-9.

Okonko, I.O., Odu, N.N. and Igboh, I.E. (2013). Microbiological Analysis of Kilishi Sold In Port Harcourt, Nigeria. New York Science Journal, 6 (7):37-43.

Osimani, A., Aquilanti, L. and Clementi, F. (2015) Microbiological Quality of Meatbased Meals and Operation of Control Systems within a Food Service Environment. International Food Research Journal 22(4): 1692-1698.

Onuorah, S. Obika, I. Odibo, F. Orji, M. (2015)An Assessment of the Bacteriological Quality of Tsire-Suya (Grilled Beef) sold in Awka, Nigeria. American. J. Life. Sci. Res. 3(4):287292.

Razavilar, V, Khandaghi, J. Barzgari, A. (2010); Isolation of Eschericia coli 0157:H7 from manure fertilized farms and raw vegetables grown on it, in Tabriz city in
Iran. African Journal of Microbiology Research, 4(9): 891-895.

Scallan, E. Hoekstra, R. M. Angulo, F. J.Tauxe, R. V, Widdowson, M. Roy, S. L et al., (2011).Food borne illness acquired in the United States- Major Pathogens. Emerg. Infec Dis, 17(1): 7-15.

Shamsuddeen U (2009). Microbiological quality of spice used in the production of Kilishi a traditionally dried and grilled meat product. Bayero Journal of Pure andApplied Sciences, 2(2): 66-69.

Shamsuddeen, U. (2015) Microbiological Hazard and Critical control point Analysis of Dried and Minced Meat Snacks Produced in Kano Nigeria. Lambert Academic Publishing; Pp 1-36.

Tijani, O.and Jumare, S. (2014). Microblological Quality Assessment of Meat

Sold in KauraNamoda. International Conference on Earth, Environment and Life sciences (EELS) Dubai (UAE).

Udobi, C. E., Obajuluwa, A. F., and Onaolapo, J. A., (2013) Prevalence and Antibiotic Resistance Pattern of MethicillinResistant Staphylococcus aureus from an Orthopaedic Hospital in Nigeria BioMed Research International; 26(6); 6-7.

WHO, 2015 Foodborne diseases in the WHO African Region.

Yousafzai HA, Rind R, Khan MA, Abro SH, Korejo NA, Ejaz M, Kabir A, Shahid M, Memon S. (2019). Microbiological Contamination of Cattle and Meat in Peshawar, Pakistan. J. Anim. Health Prod. 7(1): 1116. 


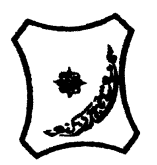

Bayero Journal of Pure and Applied Sciences, 13(1); 40 - 45

Received: September, 2019

Accepted: April, 2020

ISSN $2006-6996$

\title{
BACTERIOLOGICAL QUALITY OF STICK MEAT (Tsire) SOLD IN GARKO LOCAL GOVERNMENT AREA OF KANO STATE, NIGERIA
}

\author{
$*^{1}$ Dahiru A. T. and ${ }^{2}$ Maigari A. K. \\ ${ }^{1}$ Department of Hospitality Management, School of Technology, Kano State Polytechnic, PMB 3348, \\ Kano Nigeria. \\ ${ }^{2}$ Departmnt of Biological Sciences, Bayero University, Kano \\ Corresponding Author: dturajo61@gmail.com; GSM: 08087508262.
}

ABSTRACT

Stick meat, locally called Tsire in Hausa Language, is a significant portion of the diet of a large active population of Northern Nigeria. However, because of the handling and processing methods by the manufacturers as well as the hawking system of stick meat, the meat product may be exposed to both pre- and post-processed product contamination, and thus may poses danger to public health. Therefore, considering the role of Tsire in improving nutrition and increase household income to the populace, the need to improve the processing, distribution and overall quality of the product is simply indispensable. A total of 30 samples (5 samples from each of the 6 sampling points) of Tsire were collected randomly in Garko Town. Aerobic plate counts (APCs) and Total coliform counts (TCCS) of Tsire samples were determined using standard microbiological methods. APCs ranged from $1.02 \times 10^{5}$ to $4.00 \times 10^{5} \mathrm{CFU} / \mathrm{g}$; while TCCs ranged from $8 \mathrm{MPN} / \mathrm{g}$ to $68 \mathrm{MPN} / \mathrm{g}$. From the 30 samples screened, 16(53.33\%) bacteria namely, Campylobacter 2(6.66\%), Escherichia coli 6(20\%), Klebsiella pneumoniae 2(6.66\%), Salmonella spp. 1(3.33\%), Shigella 3(10\%) and Staphylococcus aureus 2(6.66\%) were detected. $E$. coli has the highest isolation rate of 6(20\%), while Salmonella spp. had the least frequency of 1(3.33\%). The distribution of isolated organisms within the study area were as follows: Dausai, 4(80\%), Kofar kudu, 4(80\%), Makwalla, 2(40\%), Rinji, 3(60\%), Tosaro, 2(40\%), and Tsohuwar Kasuwa, 1(20\%). The results have indicated that the Tsire was contaminated with bacteria thus exposing the product to fast deterioration, spoilage and also a vehicle for food borne illness, suggesting for adequate hygienic practices at all the stages, prior to consumption, to ensure safety of the meat product.

Key words: APCs, TCCs, Contamination, Microorganisms, Garko

\section{INTRODUCTION}

Nigeria is one of the developing nations with inadequate food supply and most often deficient in protein content (FAO, 2019). Nigerian's average animal protein intake per head per day is estimated at $7.9 \mathrm{~g}$ as against $35 \mathrm{~g}$ recommended value by Food and Agricultural Organization (Mubarak et al., 2016). These low levels of animal protein intake create great concern as it affects the nutritional status of Nigerians. Hence, there is the need for sufficient supply of animal protein from energy rich animal products to satisfy the nutritional requirements for Nigerians.

Meat is one major source of animal protein largely composed of water, protein and fats which can make it susceptible to microbial contamination within short time leading to spoilage (Apata et al., 2013; Mgbemere et al., 2011). Meat is mostly eaten after it has been cooked or processed in a variety of ways such as sun drying; smoking and roasting with or without fortifications (Borch et al., 1996). In Nigeria meat products such as Tsire, Kilishi and Balangu are locally produced using one or more of these methods in order to meet the nutritional requirements of the teeming Nigerians (Egbebi, 2011).

Tsire is a popular Nigerian traditional processed ready-to-eat roasted stick meat product (Shamsuddeen, 2015). It is sold in public places, along roads, in hotels, parks, quarters and even offices (Falegan et al., 2017). It is prepared from boneless healthy animal flesh such as beef and mutton, spiced with peanut cake, salt, vegetable oil and other flavorings followed by roasting (Shamsuddeen, 2015). Consumption of these products has extended to other parts of African countries such as Ghana, Somali, Cameroun and Chad (Ahmadu and Ibrahim, 2013). 
BAJOPAS Volume 13 Number 1, June, 2020

However, evidence of quality control sticking to procedural hygiene by the handlers during preparation and retailing of these products is poorly documented. Tsire is of great safety risk because of the fact that there are erratic cases of gastroenteritis and symptoms of food infection after consumption (WHO, 2015). Food borne illnesses are one of the major health problems in developing and developed countries (Razavilar, 2010). According to the World Health Organization, WHO (2015), $0.07 \%$ death of the 600 million global burdens of Foodborne illnesses have been reported to be caused by bacteria, viruses, fungi and chemicals. In America $0.27 \%$ of the estimated 48 million affected people is hospitalized and about $0.0063 \%$ deaths are recorded each year (Scallan et al., 2011). More than 91 million people in Africa fall ill and $0.15 \%$ dies each year, making Africa the highest burden bearer of Foodborne diseases per population (WHO, 2015).

Application of a Hazard Analysis Critical Control Point (HACCP) at all stages of meat products preparation is essential in order to ensure its safety. Thus, according to the guidelines of good manufacturing practice, the level of total aerobic bacterial contamination of thermally processed meat products should not exceed $10^{4}\left(\mathrm{cfu} \mathrm{g}^{-1}\right)$. Enterobacteriaceae and faecal coliform contamination in meat products should be within the range of $10^{2}-10^{4}$ and $10-10^{3} \mathrm{cfu} \mathrm{g}^{-1}$, respectively (Shamsuddeen, 2015). The aim of the study is therefore, to assess the total viable bacterial counts of tsire marketed locally within Garko town, and to isolate and identify the organisms at the point of consumption with the intention of promoting public health and food hygiene habits in the Nigerian populace.

\section{MATERIALS AND METHODS Study Area and Population}

Garko is one of the existing 44 local government areas located in Kano south west zone of Kano state with its capital administrative headquarters in the Garko town. It has coordinates $11^{\circ} 39^{\prime} \mathrm{N}$ $8^{\circ} 54^{\prime} \mathrm{E}$, and an area of $450 \mathrm{~km}^{2}$. The projected population of Garko local Government was 225,300 according to the National Population Census report (2018). Garko is known for agricultural activities both farming and animal husbandry. It is popularly known for large scale rice production. Other food crops include sweet potatoes, cassava, onions, sorghum, millet and sugarcane. Cows, sheep and goats are major groups of animals reared by majority of the populace. Meat products processed, retailed and consumed in Garko include roasted meat (Balangu), dried roasted meat (Kilishi), stick meat (Tsire), hide and skin pepper soup (Ragadada) and minced fried meat (Danbunnama).

\section{Samples Collection}

Five samples of Tsire products were collected from 6 different identified locations within Garko town in a sterile foil paper and immediately analyzed for the presence of bacteria.

\section{Sample Preparation}

Sample preparation for the bacteriological analysis was carried out in accordance with the method described by Atlas (1997). Twenty five grams $(25 \mathrm{~g})$ of the sample was homogenized in $225 \mathrm{ml}$ peptone water using Kenwood blender machine to obtain a $10^{1}$ homogenate. The homogenate was thoroughly shaken and $1 \mathrm{ml}$ pipetted into test tubes containing $9 \mathrm{ml}$ of peptone water $\left(10^{2}\right)$. The test tubes were further serially diluted to $10^{5}$.

Total Aerobic Mesophilic Bacterial Count

Total Aerobic mesophilic bacterial count was determined using the method described by Abdullahi et al. (2004) where $1 \mathrm{ml}$ of inoculums from $10^{1}$ to $10^{5}$ dilutions were transferred into duplicate Petri dishes and labeled accordingly. This was followed by pouring aseptically about $15 \mathrm{ml}$ of molten nutrient agar. The culture was homogenized by gentle spinning of the plates and allowed to solidify. The plates were incubated at $37^{\circ} \mathrm{C}$ for 24 hours. Plates containing 30-300 colonies were counted. The number of colony forming units per gram of a sample (cfu/g) was obtained by multiplying the average colony number with the inverse of the dilution factor.

\section{Enumeration and Detection of Coliform bacteria}

Detection and enumeration of coliform was carried out according to method described by Atlas, (1977). A set of 9 test tubes each containing $9 \mathrm{ml}$ of lactose broth and an inverted Durham tubes were autoclaved to expel air and to sterilize. Similarly, $1 \mathrm{ml}$ from the diluents $10^{1}$ was transferred to the first 3 test tubes, followed by $1 \mathrm{ml}$ from the diluents $10^{2}$ to the second set of 3 test tubes and finally the third diluents $10^{3}$ to the $3^{\text {rd }}$ set of 3 test tubes. All the 9 test tubes were incubated at $37^{\circ} \mathrm{C}$ for 24 hours. Tubes that showed gas and acid production after 24 hours were recorded as positive for the presence of Coliform. Negative tubes were further reincubated for 24 hours. Positive tubes were recorded. Estimate of most probable number of Coliform per gram of sample (MPN/g) was determined by comparing the number of gas positive tubes with the most probable number table. 
BAJOPAS Volume 13 Number 1, June, 2020 Identification of Coliform

A loop full of inoculum from gas positive tubes was streaked on to Eosine methylene blue (EMB) agar plate and incubated at $37^{\circ} \mathrm{C}$ for $24 \mathrm{hrs}$. Colonies which formed bluish black color with green metallic sheen, and reddish colonies were isolated on agar slants. Those colonies showing metallic sheen on EMB were sub cultured into tubes of lactose broth and incubated at $45^{\circ} \mathrm{C}$. The tubes were observed after $24 \mathrm{hrs}$ for gas production. This is the completed test for fecal coliform. Gram stain and other biochemical tests such as Indole, Methyl red, Voges-Proskauer and Citrate Utilization tests (IMVIC), Coagulase and Catalase tests were carried out for the Identification and confirmation of isolates.

\section{Procedure for Indole Test}

Indole test was carried out by preparing a Tryptone broth drawn in to test tubes, sterilized by autoclaving, inoculated with loopful of suspension and incubated at $37^{\circ} \mathrm{C}$ for 24 hours. Three drops of xylene was added in tubes, shaken vigorously and kept for the separation of two layers. One millilitre of Kovac's reagent was added and the formation of pink colour ring indicates positive Indole test.

\section{Procedure for Methyl Red Test}

Methyl red test was carried out by preparing Glucose phosphate broth, dispensed in test tubes, sterilized, inoculated with test culture and incubated at $37^{\circ} \mathrm{C}$ for 24 hours. Five drops of methyl-red indicator was added to the medium for the formation of red colour.

\section{Procedure for Voges-Proskauer Test}

Voges-Proskauer test was carried out by inoculating tubes with the bacterial culture followed by incubation for 48 hours at $37^{\circ} \mathrm{C}$. Separate pipettes were used to pipette $1 \mathrm{ml}$ from each culture tube into clean separate tubes. Eighteen drops $(0.5 \mathrm{ml})$ of Barrit's solution A (a-naphthol) was added to each tube containing glucose phosphate broth followed by the addition of an equal amount of solution $B$ into the same tube. The tubes were shaken at 30 seconds interval. A positive reaction was indicated by the development of a pink color, which turns red in 1-2 hours, after vigorous shaking.

\section{Procedure for Citrate Utilization Test}

Citrate Utilization Test was carried out by distributing melted agar (Simmon Citrate Agar) in to test tubes followed by sterilization at $121.5^{\circ} \mathrm{C}$ for 15 minutes. The test tubes were afterward held in slanted position, inoculated with the given bacterial culture and incubated at $37^{\circ} \mathrm{C}$ for $24 \mathrm{hrs}$. Positive test was indicated by color change of the media from green to blue.

\section{RESULTS AND DISCUSSIONS}

The results of this study are presented in tables $1,2,3$ and 4. Among the sampling areas Kofar Kudu had the highest aerobic mesophilic bacteria counts $4.0 \times 10^{5} \mathrm{cfu} / \mathrm{g}$ followed by Rinji $2.72 \times 10^{5} \mathrm{cfu} / \mathrm{g}$, while Tosaro had the least Aerobic mesophilic bacteria counts of $1.02 \times 10^{5}$ $\mathrm{cfu} / \mathrm{g}$ as indicated in Table 1.Makwalla had the highest coliform count $68 \mathrm{MPN} / \mathrm{g}$ followed by Rinji $37 \mathrm{MPN} / \mathrm{g}$. Tsohuwar Kasuwa had the least coliform counts $8 \mathrm{MPN} / \mathrm{g}$, (Table 2). Result from table 1 shows variation in the microbial contents among the samples which suggest variation in their sources, poor handling procedures and contamination from the processing environment. High coliform count and their differences within sampling areas is an indication of poor microbiological quality of the product. Ndahi et al. (2013) reported microbial load to be a function of the handling personnel and the environment. The results indicated that the samples were contaminated with bacteria as the counts exceeded the minimum safety level $\left(10^{4} \mathrm{cfu} / \mathrm{g}\right)$ for members of the Enterobacteriaceae family. However, it might be a reflection of poor hygienic practices which may contribute to health hazard to the potential consumers. Similarly, Inusa and Sa'id (2017); Osimani et al. (2015) reported that, the initial microbial content of the raw material play significant role in influencing the final microbial load of the finished product. Isolation of members of the Enterobacteriaceae such as $E$. coli, Klebsiella pneumoniae, Salmonella and Shigella signifies danger to the public health. These organisms are capable of producing endotoxins which trigger high fevers in infected individuals, and the enterotoxins which colonize the small intestines and lead to extreme dehydration as a result of vomiting and diarrhea sometimes with severe and fatal outcomes (Amaeze et al., 2016). From the 16 isolated organisms $E$. coli had the highest isolation rate $6(37.5 \%)$ (Table 3), this suggest faecal contamination of the products. $E$. coli is a common flora in the gastrointestinal tract responsible for diarrhea and extra-intestinal infections (CDC, 2011). The result is in conformity with the findings of Ndahi et al. (2013) and Shamsuddeen (2009). Also presence of campylobacter might be due to cross contamination from raw meat to finished product (Tsire). Staphylococcus aureus is a normal flora of the skin, nasal, genital, mouth or anal area in both humans and animals without any symptom of an infection (Matthew et al., 2013). Isolation of $S$. aureus in these study concords with the findings of Lucretia et al. (2018) from Suya sold in Rivers State. 
BAJOPAS Volume 13 Number 1, June, 2020

It is also in agreement with the findings of Yousafzai et al. (2018); Onuorah et al. (2015) and Tijjani and Jumare (2014) from tsire samples in different countries. Presence of $S$. aureus in foods is most of the time an indication of poor human handling, poor environment, unhygienic utensils and equipments used during processing (Igene et al., 2016; Okonko et al., 2013). Infections caused by $S$. aureus are difficult to treat leading to long hospitalization with consequent economic loss (Udobi et al., 2013). These include soft tissue infections, pneumonia, hospital-acquired postoperative wound infections, Staphylococcal food poisoning, impetigo and cellulitis (Charlene et al., 2013). Samples obtained from Dausai and Kofar Kudu had the highest isolation rate $4(80 \%)$ (Table 4 ) probably because of the much commercial activities taking place in the area which can lead to environmental contamination.

Table 1: Total Aerobic Mesophilic Bacterial Count of Tsire sold in Garko Town

\begin{tabular}{lll}
\hline Sampling Area & APC cfu/g & Mean \pm STD \\
\hline Dausai & $2.20 \times 10^{5}$ & $110000 \pm 14142.14$ \\
Kofar Kudu & $4.00 \times 10^{5}$ & $133333.3 \pm 23094.01$ \\
Makwalla & $1.30 \times 10^{5}$ & $32500 \pm 7187.953$ \\
Rinji & $2.72 \times 10^{5}$ & $90666.67 \pm 94769.90$ \\
Tosaro & $1.02 \times 10^{5}$ & $51000 \pm 15556.35$ \\
Tsohuwar Kasuwa & $1.75 \times 10^{5}$ & $35000 \pm 11357.82$ \\
\hline
\end{tabular}

Key: APC: Aerobic Mesophilic Counts

STD: Standard Deviation

Table 2: Total Coliform Count of Tsire sold in Garko Town

\begin{tabular}{lcc}
\hline \multicolumn{1}{c}{ Sampling Area } & TCC MPN/g & Mean \pm STD \\
\hline Dausai & 20 & $6.67 \pm 2.5166$ \\
Kofar Kudu & 32 & $16.00 \pm 5.6569$ \\
Makwalla & 68 & $13.60 \pm 8.7062$ \\
Rinji & 37 & $9.25 \pm 4.7871$ \\
Tosaro & 10 & $5.00 \pm 2.8284$ \\
Tsohuwar Kasuwa & 8 & $4.00 \pm 0.0000$ \\
\hline
\end{tabular}

Table 3: Organisms Isolated from Tsire Sold in Garko

\begin{tabular}{lcl}
\hline Isolated Organism & Frequency & Percentage (\%) \\
\hline Campylobacter & 2 & 06.66 \\
Escherichia coli & 6 & 20.00 \\
Klebsiella pneumoniae & 2 & 06.66 \\
Salmonella species & 1 & 03.33 \\
Shigella & 3 & 10.00 \\
Staphylococcus aureus & 2 & 06.66 \\
Total & 16 & \\
\hline
\end{tabular}

Table 4: Distribution of Organisms within Sampling Area

\begin{tabular}{lcc}
\hline \multicolumn{1}{c}{ Sampling Area } & No. Isolated & Percentage (\%) \\
\hline Dausai & 4 & 80 \\
Kofar Kudu & 4 & 80 \\
Makwalla & 2 & 40 \\
Rinji & 3 & 60 \\
Tosaro & 2 & 40 \\
Tsohuwar Kasuwa & 1 & 20 \\
Total & 16 & \\
\hline
\end{tabular}

\section{CONCLUSION}

Results indicated $4.00 \times 10^{5} \mathrm{CFU} / \mathrm{g}$ as the highest APCs count; while $68 \mathrm{MPN} / \mathrm{g}$ was the highest TCCs from the 30 samples analyzed. Among the isolates, $E$. coli has the highest isolation rate of $6(20 \%)$. Dausai and Kofar kudu were having the highest bacteria count of $4(80 \%)$, each, indicating higher contamination in those locations. 
BAJOPAS Volume 13 Number 1, June, 2020 RECOMMENDATIONS

The following recommendations are tenable:

1. Hygienic practices at all stages of production should be improved to safe guard the consumers against potential health hazard.

2. Monitoring of microbiological contamination of Tsire during preparations, packaging and marketing is essential to ensure product of good microbiological quality for consumers' health.

\section{REFERENCES}

Abdullahi, I. O., Umoh, V. J. and Galadima, M. (2004). Hazards Associated with Kilishi Preparations in Zaria. Nigerian Journal of Microbiology, 18 (1-2): $339-345$.

Ahmadu, J. and Ibrahim E. J., (2013): Determinants of Revenue in Suya Production in BeninCity, Edo State, Nigeria. Nigerian journal of agriculture, food and environment.9(3):1-5

Amaeze, N. Aboh, M. Itohan, A. Felix, E. Olatunji, T. and Oladosu, P. (2016) Microbial Profile, Antibiotic Sensitivity and Heat Resistance of Bacterial Isolates from Commercial Roasted Beef (Suya) in Abuja, Nigeria. JOPAT, 15(2): $22-30$.

Apata, E.S., Kuku1, I.A., Apata, O.C. and Adeyemi, K.O. (2013). Evaluation of Suya(Tsire) - An Intermediate Moisture Meat Product in Ogun State, Nigeria. J. Food Res 2 (1): 87.

Atlas, R. M. (1997) Principles of Microbiology Second Edition. C. Brown Publishers. Pp 802-803.

Borch, E. Kant-Muermans, M. L., Blixt, Y. (1996) Bacterial Spoilage of Meat and Cured Meat Products. Int $\mathrm{J}$ Food Microbiol .33(1): 103-20.

Centre for Disease Control, CDC (2011). "Escherichia coli 0157:H7" Division of Bacterial and Mycotic Diseasesht://www.cdc.gov/nczved/divisi ons/dfbmd/diseases/ecoli_0157h7/.

Charlene, R. J., Johnnie, A. D., and John, B. B., (2013) Prevalence and Characterization of Methicillin-Resistant Staphylococcus aureus Isolates from Retail Meat and Humans in Georgia. American society for Microbiology. J. of clinical microbiology. 12(1):123-6 doi:10.1128/JCM.0316612JCM.03166-12

Egbebi, A.O and Seidu, K., T. (2011). Microbiological Evaluation of Suya (dried smoked

meat) Sold in Ado and Akure, South West Nigeria.European Journal of Experinmental Biology, 1(4):1-5
3. Government should establish regulatory bodies responsible for inculcating hygiene habits to the local producers and vendors in order to prevent instant, cross and post processing contaminations by microbial pathogens.

4. Awareness and sensitization of local food producers about good hygienic practices in food handling and processing.

Falegan, C, R., Akoja, S. D., and Oyarekua, M. A., (2017) Microbiological Assessment of Suya (Sliced Roasted Beef) in Ado-Ekiti Metropolis, Ekiti State, Nigeria. MOJ Biology andMedicine.

Fonkem, D., N. Tanya, V., N. and Ebangi, A., L. (2010). Effect of Season on the Microbiological Quality of Kilishi, a Traditional Cameroonian Dried Beef Product. Tropicultura, 28(1): 10-15.

Food and Agricultural Organization of the United Nations (F A O, 1979). Manual of food quality control 4. Microbiological analysis.

Food and Agriculture Organisation of the United Nation (FAO), 2019. Nigeria at a glance.

Igene J.O., Uwadia, O.E., Ebabhamiegbebho, P.A. and Evivie, S.E., (2016) Shelf life Stability Studies of University of Benin (UNIBEN) Proff's Kilishi Product Asian Journal of Science and Technology 7(1): 2268-2274.

Inusa, S. K. and Said, I. S. (2017) Evaluation of the Chemical and Microbiological Properties Of Kilishi Sold in Kano Metropolis. Journal of Dry land Agriculture, 3 (1): $59-69$.

Lucretia, I. B, Patience, C. Obinna-Echem, Sophia, C. A. (2018) Microbiological quality andantibiotic sensitivity of potential pathogens isolated from meat product (Suya) sold in Rivers State University and its environs. International Journal of Biotechnology and Food Science, 6(4): 67-76.

Matthew, E., Drosos, E., John, L. and Ioanna, P. (2013) MRSA in Africa: Filling the Global Map of Antimicrobial Resistance PLOS One. 8(7): e68024 doi: 10.1371/journal.pone.0068024

Mgbemere, V.N., Akpapunam, M. A. and Igene, J. O., (2011). Effect of Groundnut FlourSubstitution on Yield, Quality and Storage Stability of Kilishi - a Nigerian Indigenous Dried Meat Product. African Journal of Food, Agriculture, Nutrition and Development, $\quad \mathbf{1 1}(2)$ : 4718-4738. 
BAJOPAS Volume 13 Number 1, June, 2020

Mubarak, A. A., Azeez, M. L., Amos A. O., Opeyemi, O. O. (2016) Assessment of Animal Protein Consumption and Food Security Among Rural Households in Kwara State, Nigeria American Journal of Business and Society, 1(4): 233245.

Ndahi, M., D. Kwaga, J., K. P. Bello, M. Kabir J., V. Umoh, .J. Yakubu, S., E. and Nok, A., J. (2013) Prevalence and Antimicrobial Susceptibility of Listeria Monocytogenes and Methicillin-Resistant Staphylococcus aureus Strains from Raw Meat and Meat Products in Zaria, Nigeria. Applied Journal of Microbiology, 58(3):262-9.

Okonko, I.O., Odu, N.N. and Igboh, I.E. (2013). Microbiological Analysis of Kilishi Sold In Port Harcourt, Nigeria. New York Science Journal, 6 (7):37-43.

Osimani, A., Aquilanti, L. and Clementi, F. (2015) Microbiological Quality of Meatbased Meals and Operation of Control Systems within a Food Service Environment. International Food Research Journal 22(4): 1692-1698.

Onuorah, S. Obika, I. Odibo, F. Orji, M. (2015)An Assessment of the Bacteriological Quality of Tsire-Suya (Grilled Beef) sold in Awka, Nigeria. American. J. Life. Sci. Res. 3(4):287292.

Razavilar, V, Khandaghi, J. Barzgari, A. (2010); Isolation of Eschericia coli 0157:H7 from manure fertilized farms and raw vegetables grown on it, in Tabriz city in
Iran. African Journal of Microbiology Research, 4(9): 891-895.

Scallan, E. Hoekstra, R. M. Angulo, F. J.Tauxe, R. V, Widdowson, M. Roy, S. L et al., (2011).Food borne illness acquired in the United States- Major Pathogens. Emerg. Infec Dis, 17(1): 7-15.

Shamsuddeen U (2009). Microbiological quality of spice used in the production of Kilishi a traditionally dried and grilled meat product. Bayero Journal of Pure andApplied Sciences, 2(2): 66-69.

Shamsuddeen, U. (2015) Microbiological Hazard and Critical control point Analysis of Dried and Minced Meat Snacks Produced in Kano Nigeria. Lambert Academic Publishing; Pp 1-36.

Tijani, O.and Jumare, S. (2014). Microblological Quality Assessment of Meat

Sold in KauraNamoda. International Conference on Earth, Environment and Life sciences (EELS) Dubai (UAE).

Udobi, C. E., Obajuluwa, A. F., and Onaolapo, J. A., (2013) Prevalence and Antibiotic Resistance Pattern of MethicillinResistant Staphylococcus aureus from an Orthopaedic Hospital in Nigeria BioMed Research International; 26(6); 6-7.

WHO, 2015 Foodborne diseases in the WHO African Region.

Yousafzai HA, Rind R, Khan MA, Abro SH, Korejo NA, Ejaz M, Kabir A, Shahid M, Memon S. (2019). Microbiological Contamination of Cattle and Meat in Peshawar, Pakistan. J. Anim. Health Prod. 7(1): 1116. 


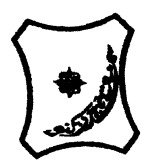

Bayero Journal of Pure and Applied Sciences, 13(1); 40 - 45

Received: September, 2019

Accepted: April, 2020

ISSN $2006-6996$

\title{
BACTERIOLOGICAL QUALITY OF STICK MEAT (Tsire) SOLD IN GARKO LOCAL GOVERNMENT AREA OF KANO STATE, NIGERIA
}

\author{
$*^{1}$ Dahiru A. T. and ${ }^{2}$ Maigari A. K. \\ ${ }^{1}$ Department of Hospitality Management, School of Technology, Kano State Polytechnic, PMB 3348, \\ Kano Nigeria. \\ ${ }^{2}$ Departmnt of Biological Sciences, Bayero University, Kano \\ Corresponding Author: dturajo61@gmail.com; GSM: 08087508262.
}

ABSTRACT

Stick meat, locally called Tsire in Hausa Language, is a significant portion of the diet of a large active population of Northern Nigeria. However, because of the handling and processing methods by the manufacturers as well as the hawking system of stick meat, the meat product may be exposed to both pre- and post-processed product contamination, and thus may poses danger to public health. Therefore, considering the role of Tsire in improving nutrition and increase household income to the populace, the need to improve the processing, distribution and overall quality of the product is simply indispensable. A total of 30 samples (5 samples from each of the 6 sampling points) of Tsire were collected randomly in Garko Town. Aerobic plate counts (APCs) and Total coliform counts (TCCS) of Tsire samples were determined using standard microbiological methods. APCs ranged from $1.02 \times 10^{5}$ to $4.00 \times 10^{5} \mathrm{CFU} / \mathrm{g}$; while TCCs ranged from $8 \mathrm{MPN} / \mathrm{g}$ to $68 \mathrm{MPN} / \mathrm{g}$. From the 30 samples screened, 16(53.33\%) bacteria namely, Campylobacter 2(6.66\%), Escherichia coli 6(20\%), Klebsiella pneumoniae 2(6.66\%), Salmonella spp. 1(3.33\%), Shigella 3(10\%) and Staphylococcus aureus 2(6.66\%) were detected. $E$. coli has the highest isolation rate of 6(20\%), while Salmonella spp. had the least frequency of 1(3.33\%). The distribution of isolated organisms within the study area were as follows: Dausai, 4(80\%), Kofar kudu, 4(80\%), Makwalla, 2(40\%), Rinji, 3(60\%), Tosaro, 2(40\%), and Tsohuwar Kasuwa, 1(20\%). The results have indicated that the Tsire was contaminated with bacteria thus exposing the product to fast deterioration, spoilage and also a vehicle for food borne illness, suggesting for adequate hygienic practices at all the stages, prior to consumption, to ensure safety of the meat product.

Key words: APCs, TCCs, Contamination, Microorganisms, Garko

\section{INTRODUCTION}

Nigeria is one of the developing nations with inadequate food supply and most often deficient in protein content (FAO, 2019). Nigerian's average animal protein intake per head per day is estimated at $7.9 \mathrm{~g}$ as against $35 \mathrm{~g}$ recommended value by Food and Agricultural Organization (Mubarak et al., 2016). These low levels of animal protein intake create great concern as it affects the nutritional status of Nigerians. Hence, there is the need for sufficient supply of animal protein from energy rich animal products to satisfy the nutritional requirements for Nigerians.

Meat is one major source of animal protein largely composed of water, protein and fats which can make it susceptible to microbial contamination within short time leading to spoilage (Apata et al., 2013; Mgbemere et al., 2011). Meat is mostly eaten after it has been cooked or processed in a variety of ways such as sun drying; smoking and roasting with or without fortifications (Borch et al., 1996). In Nigeria meat products such as Tsire, Kilishi and Balangu are locally produced using one or more of these methods in order to meet the nutritional requirements of the teeming Nigerians (Egbebi, 2011).

Tsire is a popular Nigerian traditional processed ready-to-eat roasted stick meat product (Shamsuddeen, 2015). It is sold in public places, along roads, in hotels, parks, quarters and even offices (Falegan et al., 2017). It is prepared from boneless healthy animal flesh such as beef and mutton, spiced with peanut cake, salt, vegetable oil and other flavorings followed by roasting (Shamsuddeen, 2015). Consumption of these products has extended to other parts of African countries such as Ghana, Somali, Cameroun and Chad (Ahmadu and Ibrahim, 2013). 
BAJOPAS Volume 13 Number 1, June, 2020

However, evidence of quality control sticking to procedural hygiene by the handlers during preparation and retailing of these products is poorly documented. Tsire is of great safety risk because of the fact that there are erratic cases of gastroenteritis and symptoms of food infection after consumption (WHO, 2015). Food borne illnesses are one of the major health problems in developing and developed countries (Razavilar, 2010). According to the World Health Organization, WHO (2015), $0.07 \%$ death of the 600 million global burdens of Foodborne illnesses have been reported to be caused by bacteria, viruses, fungi and chemicals. In America $0.27 \%$ of the estimated 48 million affected people is hospitalized and about $0.0063 \%$ deaths are recorded each year (Scallan et al., 2011). More than 91 million people in Africa fall ill and $0.15 \%$ dies each year, making Africa the highest burden bearer of Foodborne diseases per population (WHO, 2015).

Application of a Hazard Analysis Critical Control Point (HACCP) at all stages of meat products preparation is essential in order to ensure its safety. Thus, according to the guidelines of good manufacturing practice, the level of total aerobic bacterial contamination of thermally processed meat products should not exceed $10^{4}\left(\mathrm{cfu} \mathrm{g}^{-1}\right)$. Enterobacteriaceae and faecal coliform contamination in meat products should be within the range of $10^{2}-10^{4}$ and $10-10^{3} \mathrm{cfu} \mathrm{g}^{-1}$, respectively (Shamsuddeen, 2015). The aim of the study is therefore, to assess the total viable bacterial counts of tsire marketed locally within Garko town, and to isolate and identify the organisms at the point of consumption with the intention of promoting public health and food hygiene habits in the Nigerian populace.

\section{MATERIALS AND METHODS Study Area and Population}

Garko is one of the existing 44 local government areas located in Kano south west zone of Kano state with its capital administrative headquarters in the Garko town. It has coordinates $11^{\circ} 39^{\prime} \mathrm{N}$ $8^{\circ} 54^{\prime} \mathrm{E}$, and an area of $450 \mathrm{~km}^{2}$. The projected population of Garko local Government was 225,300 according to the National Population Census report (2018). Garko is known for agricultural activities both farming and animal husbandry. It is popularly known for large scale rice production. Other food crops include sweet potatoes, cassava, onions, sorghum, millet and sugarcane. Cows, sheep and goats are major groups of animals reared by majority of the populace. Meat products processed, retailed and consumed in Garko include roasted meat (Balangu), dried roasted meat (Kilishi), stick meat (Tsire), hide and skin pepper soup (Ragadada) and minced fried meat (Danbunnama).

\section{Samples Collection}

Five samples of Tsire products were collected from 6 different identified locations within Garko town in a sterile foil paper and immediately analyzed for the presence of bacteria.

\section{Sample Preparation}

Sample preparation for the bacteriological analysis was carried out in accordance with the method described by Atlas (1997). Twenty five grams $(25 \mathrm{~g})$ of the sample was homogenized in $225 \mathrm{ml}$ peptone water using Kenwood blender machine to obtain a $10^{1}$ homogenate. The homogenate was thoroughly shaken and $1 \mathrm{ml}$ pipetted into test tubes containing $9 \mathrm{ml}$ of peptone water $\left(10^{2}\right)$. The test tubes were further serially diluted to $10^{5}$.

Total Aerobic Mesophilic Bacterial Count

Total Aerobic mesophilic bacterial count was determined using the method described by Abdullahi et al. (2004) where $1 \mathrm{ml}$ of inoculums from $10^{1}$ to $10^{5}$ dilutions were transferred into duplicate Petri dishes and labeled accordingly. This was followed by pouring aseptically about $15 \mathrm{ml}$ of molten nutrient agar. The culture was homogenized by gentle spinning of the plates and allowed to solidify. The plates were incubated at $37^{\circ} \mathrm{C}$ for 24 hours. Plates containing 30-300 colonies were counted. The number of colony forming units per gram of a sample (cfu/g) was obtained by multiplying the average colony number with the inverse of the dilution factor.

\section{Enumeration and Detection of Coliform bacteria}

Detection and enumeration of coliform was carried out according to method described by Atlas, (1977). A set of 9 test tubes each containing $9 \mathrm{ml}$ of lactose broth and an inverted Durham tubes were autoclaved to expel air and to sterilize. Similarly, $1 \mathrm{ml}$ from the diluents $10^{1}$ was transferred to the first 3 test tubes, followed by $1 \mathrm{ml}$ from the diluents $10^{2}$ to the second set of 3 test tubes and finally the third diluents $10^{3}$ to the $3^{\text {rd }}$ set of 3 test tubes. All the 9 test tubes were incubated at $37^{\circ} \mathrm{C}$ for 24 hours. Tubes that showed gas and acid production after 24 hours were recorded as positive for the presence of Coliform. Negative tubes were further reincubated for 24 hours. Positive tubes were recorded. Estimate of most probable number of Coliform per gram of sample (MPN/g) was determined by comparing the number of gas positive tubes with the most probable number table. 
BAJOPAS Volume 13 Number 1, June, 2020 Identification of Coliform

A loop full of inoculum from gas positive tubes was streaked on to Eosine methylene blue (EMB) agar plate and incubated at $37^{\circ} \mathrm{C}$ for $24 \mathrm{hrs}$. Colonies which formed bluish black color with green metallic sheen, and reddish colonies were isolated on agar slants. Those colonies showing metallic sheen on EMB were sub cultured into tubes of lactose broth and incubated at $45^{\circ} \mathrm{C}$. The tubes were observed after $24 \mathrm{hrs}$ for gas production. This is the completed test for fecal coliform. Gram stain and other biochemical tests such as Indole, Methyl red, Voges-Proskauer and Citrate Utilization tests (IMVIC), Coagulase and Catalase tests were carried out for the Identification and confirmation of isolates.

\section{Procedure for Indole Test}

Indole test was carried out by preparing a Tryptone broth drawn in to test tubes, sterilized by autoclaving, inoculated with loopful of suspension and incubated at $37^{\circ} \mathrm{C}$ for 24 hours. Three drops of xylene was added in tubes, shaken vigorously and kept for the separation of two layers. One millilitre of Kovac's reagent was added and the formation of pink colour ring indicates positive Indole test.

\section{Procedure for Methyl Red Test}

Methyl red test was carried out by preparing Glucose phosphate broth, dispensed in test tubes, sterilized, inoculated with test culture and incubated at $37^{\circ} \mathrm{C}$ for 24 hours. Five drops of methyl-red indicator was added to the medium for the formation of red colour.

\section{Procedure for Voges-Proskauer Test}

Voges-Proskauer test was carried out by inoculating tubes with the bacterial culture followed by incubation for 48 hours at $37^{\circ} \mathrm{C}$. Separate pipettes were used to pipette $1 \mathrm{ml}$ from each culture tube into clean separate tubes. Eighteen drops $(0.5 \mathrm{ml})$ of Barrit's solution A (a-naphthol) was added to each tube containing glucose phosphate broth followed by the addition of an equal amount of solution $B$ into the same tube. The tubes were shaken at 30 seconds interval. A positive reaction was indicated by the development of a pink color, which turns red in 1-2 hours, after vigorous shaking.

\section{Procedure for Citrate Utilization Test}

Citrate Utilization Test was carried out by distributing melted agar (Simmon Citrate Agar) in to test tubes followed by sterilization at $121.5^{\circ} \mathrm{C}$ for 15 minutes. The test tubes were afterward held in slanted position, inoculated with the given bacterial culture and incubated at $37^{\circ} \mathrm{C}$ for $24 \mathrm{hrs}$. Positive test was indicated by color change of the media from green to blue.

\section{RESULTS AND DISCUSSIONS}

The results of this study are presented in tables $1,2,3$ and 4. Among the sampling areas Kofar Kudu had the highest aerobic mesophilic bacteria counts $4.0 \times 10^{5} \mathrm{cfu} / \mathrm{g}$ followed by Rinji $2.72 \times 10^{5} \mathrm{cfu} / \mathrm{g}$, while Tosaro had the least Aerobic mesophilic bacteria counts of $1.02 \times 10^{5}$ $\mathrm{cfu} / \mathrm{g}$ as indicated in Table 1.Makwalla had the highest coliform count $68 \mathrm{MPN} / \mathrm{g}$ followed by Rinji $37 \mathrm{MPN} / \mathrm{g}$. Tsohuwar Kasuwa had the least coliform counts $8 \mathrm{MPN} / \mathrm{g}$, (Table 2). Result from table 1 shows variation in the microbial contents among the samples which suggest variation in their sources, poor handling procedures and contamination from the processing environment. High coliform count and their differences within sampling areas is an indication of poor microbiological quality of the product. Ndahi et al. (2013) reported microbial load to be a function of the handling personnel and the environment. The results indicated that the samples were contaminated with bacteria as the counts exceeded the minimum safety level $\left(10^{4} \mathrm{cfu} / \mathrm{g}\right)$ for members of the Enterobacteriaceae family. However, it might be a reflection of poor hygienic practices which may contribute to health hazard to the potential consumers. Similarly, Inusa and Sa'id (2017); Osimani et al. (2015) reported that, the initial microbial content of the raw material play significant role in influencing the final microbial load of the finished product. Isolation of members of the Enterobacteriaceae such as $E$. coli, Klebsiella pneumoniae, Salmonella and Shigella signifies danger to the public health. These organisms are capable of producing endotoxins which trigger high fevers in infected individuals, and the enterotoxins which colonize the small intestines and lead to extreme dehydration as a result of vomiting and diarrhea sometimes with severe and fatal outcomes (Amaeze et al., 2016). From the 16 isolated organisms $E$. coli had the highest isolation rate $6(37.5 \%)$ (Table 3), this suggest faecal contamination of the products. $E$. coli is a common flora in the gastrointestinal tract responsible for diarrhea and extra-intestinal infections (CDC, 2011). The result is in conformity with the findings of Ndahi et al. (2013) and Shamsuddeen (2009). Also presence of campylobacter might be due to cross contamination from raw meat to finished product (Tsire). Staphylococcus aureus is a normal flora of the skin, nasal, genital, mouth or anal area in both humans and animals without any symptom of an infection (Matthew et al., 2013). Isolation of $S$. aureus in these study concords with the findings of Lucretia et al. (2018) from Suya sold in Rivers State. 
BAJOPAS Volume 13 Number 1, June, 2020

It is also in agreement with the findings of Yousafzai et al. (2018); Onuorah et al. (2015) and Tijjani and Jumare (2014) from tsire samples in different countries. Presence of $S$. aureus in foods is most of the time an indication of poor human handling, poor environment, unhygienic utensils and equipments used during processing (Igene et al., 2016; Okonko et al., 2013). Infections caused by $S$. aureus are difficult to treat leading to long hospitalization with consequent economic loss (Udobi et al., 2013). These include soft tissue infections, pneumonia, hospital-acquired postoperative wound infections, Staphylococcal food poisoning, impetigo and cellulitis (Charlene et al., 2013). Samples obtained from Dausai and Kofar Kudu had the highest isolation rate $4(80 \%)$ (Table 4 ) probably because of the much commercial activities taking place in the area which can lead to environmental contamination.

Table 1: Total Aerobic Mesophilic Bacterial Count of Tsire sold in Garko Town

\begin{tabular}{lll}
\hline Sampling Area & APC cfu/g & Mean \pm STD \\
\hline Dausai & $2.20 \times 10^{5}$ & $110000 \pm 14142.14$ \\
Kofar Kudu & $4.00 \times 10^{5}$ & $133333.3 \pm 23094.01$ \\
Makwalla & $1.30 \times 10^{5}$ & $32500 \pm 7187.953$ \\
Rinji & $2.72 \times 10^{5}$ & $90666.67 \pm 94769.90$ \\
Tosaro & $1.02 \times 10^{5}$ & $51000 \pm 15556.35$ \\
Tsohuwar Kasuwa & $1.75 \times 10^{5}$ & $35000 \pm 11357.82$ \\
\hline
\end{tabular}

Key: APC: Aerobic Mesophilic Counts

STD: Standard Deviation

Table 2: Total Coliform Count of Tsire sold in Garko Town

\begin{tabular}{lcc}
\hline \multicolumn{1}{c}{ Sampling Area } & TCC MPN/g & Mean \pm STD \\
\hline Dausai & 20 & $6.67 \pm 2.5166$ \\
Kofar Kudu & 32 & $16.00 \pm 5.6569$ \\
Makwalla & 68 & $13.60 \pm 8.7062$ \\
Rinji & 37 & $9.25 \pm 4.7871$ \\
Tosaro & 10 & $5.00 \pm 2.8284$ \\
Tsohuwar Kasuwa & 8 & $4.00 \pm 0.0000$ \\
\hline
\end{tabular}

Table 3: Organisms Isolated from Tsire Sold in Garko

\begin{tabular}{lcl}
\hline Isolated Organism & Frequency & Percentage (\%) \\
\hline Campylobacter & 2 & 06.66 \\
Escherichia coli & 6 & 20.00 \\
Klebsiella pneumoniae & 2 & 06.66 \\
Salmonella species & 1 & 03.33 \\
Shigella & 3 & 10.00 \\
Staphylococcus aureus & 2 & 06.66 \\
Total & 16 & \\
\hline
\end{tabular}

Table 4: Distribution of Organisms within Sampling Area

\begin{tabular}{lcc}
\hline \multicolumn{1}{c}{ Sampling Area } & No. Isolated & Percentage (\%) \\
\hline Dausai & 4 & 80 \\
Kofar Kudu & 4 & 80 \\
Makwalla & 2 & 40 \\
Rinji & 3 & 60 \\
Tosaro & 2 & 40 \\
Tsohuwar Kasuwa & 1 & 20 \\
Total & 16 & \\
\hline
\end{tabular}

\section{CONCLUSION}

Results indicated $4.00 \times 10^{5} \mathrm{CFU} / \mathrm{g}$ as the highest APCs count; while $68 \mathrm{MPN} / \mathrm{g}$ was the highest TCCs from the 30 samples analyzed. Among the isolates, $E$. coli has the highest isolation rate of $6(20 \%)$. Dausai and Kofar kudu were having the highest bacteria count of $4(80 \%)$, each, indicating higher contamination in those locations. 
BAJOPAS Volume 13 Number 1, June, 2020 RECOMMENDATIONS

The following recommendations are tenable:

1. Hygienic practices at all stages of production should be improved to safe guard the consumers against potential health hazard.

2. Monitoring of microbiological contamination of Tsire during preparations, packaging and marketing is essential to ensure product of good microbiological quality for consumers' health.

\section{REFERENCES}

Abdullahi, I. O., Umoh, V. J. and Galadima, M. (2004). Hazards Associated with Kilishi Preparations in Zaria. Nigerian Journal of Microbiology, 18 (1-2): $339-345$.

Ahmadu, J. and Ibrahim E. J., (2013): Determinants of Revenue in Suya Production in BeninCity, Edo State, Nigeria. Nigerian journal of agriculture, food and environment.9(3):1-5

Amaeze, N. Aboh, M. Itohan, A. Felix, E. Olatunji, T. and Oladosu, P. (2016) Microbial Profile, Antibiotic Sensitivity and Heat Resistance of Bacterial Isolates from Commercial Roasted Beef (Suya) in Abuja, Nigeria. JOPAT, 15(2): $22-30$.

Apata, E.S., Kuku1, I.A., Apata, O.C. and Adeyemi, K.O. (2013). Evaluation of Suya(Tsire) - An Intermediate Moisture Meat Product in Ogun State, Nigeria. J. Food Res 2 (1): 87.

Atlas, R. M. (1997) Principles of Microbiology Second Edition. C. Brown Publishers. Pp 802-803.

Borch, E. Kant-Muermans, M. L., Blixt, Y. (1996) Bacterial Spoilage of Meat and Cured Meat Products. Int $\mathrm{J}$ Food Microbiol .33(1): 103-20.

Centre for Disease Control, CDC (2011). "Escherichia coli 0157:H7" Division of Bacterial and Mycotic Diseasesht://www.cdc.gov/nczved/divisi ons/dfbmd/diseases/ecoli_0157h7/.

Charlene, R. J., Johnnie, A. D., and John, B. B., (2013) Prevalence and Characterization of Methicillin-Resistant Staphylococcus aureus Isolates from Retail Meat and Humans in Georgia. American society for Microbiology. J. of clinical microbiology. 12(1):123-6 doi:10.1128/JCM.0316612JCM.03166-12

Egbebi, A.O and Seidu, K., T. (2011). Microbiological Evaluation of Suya (dried smoked

meat) Sold in Ado and Akure, South West Nigeria.European Journal of Experinmental Biology, 1(4):1-5
3. Government should establish regulatory bodies responsible for inculcating hygiene habits to the local producers and vendors in order to prevent instant, cross and post processing contaminations by microbial pathogens.

4. Awareness and sensitization of local food producers about good hygienic practices in food handling and processing.

Falegan, C, R., Akoja, S. D., and Oyarekua, M. A., (2017) Microbiological Assessment of Suya (Sliced Roasted Beef) in Ado-Ekiti Metropolis, Ekiti State, Nigeria. MOJ Biology andMedicine.

Fonkem, D., N. Tanya, V., N. and Ebangi, A., L. (2010). Effect of Season on the Microbiological Quality of Kilishi, a Traditional Cameroonian Dried Beef Product. Tropicultura, 28(1): 10-15.

Food and Agricultural Organization of the United Nations (F A O, 1979). Manual of food quality control 4. Microbiological analysis.

Food and Agriculture Organisation of the United Nation (FAO), 2019. Nigeria at a glance.

Igene J.O., Uwadia, O.E., Ebabhamiegbebho, P.A. and Evivie, S.E., (2016) Shelf life Stability Studies of University of Benin (UNIBEN) Proff's Kilishi Product Asian Journal of Science and Technology 7(1): 2268-2274.

Inusa, S. K. and Said, I. S. (2017) Evaluation of the Chemical and Microbiological Properties Of Kilishi Sold in Kano Metropolis. Journal of Dry land Agriculture, 3 (1): $59-69$.

Lucretia, I. B, Patience, C. Obinna-Echem, Sophia, C. A. (2018) Microbiological quality andantibiotic sensitivity of potential pathogens isolated from meat product (Suya) sold in Rivers State University and its environs. International Journal of Biotechnology and Food Science, 6(4): 67-76.

Matthew, E., Drosos, E., John, L. and Ioanna, P. (2013) MRSA in Africa: Filling the Global Map of Antimicrobial Resistance PLOS One. 8(7): e68024 doi: 10.1371/journal.pone.0068024

Mgbemere, V.N., Akpapunam, M. A. and Igene, J. O., (2011). Effect of Groundnut FlourSubstitution on Yield, Quality and Storage Stability of Kilishi - a Nigerian Indigenous Dried Meat Product. African Journal of Food, Agriculture, Nutrition and Development, $\quad \mathbf{1 1}(2)$ : 4718-4738. 
BAJOPAS Volume 13 Number 1, June, 2020

Mubarak, A. A., Azeez, M. L., Amos A. O., Opeyemi, O. O. (2016) Assessment of Animal Protein Consumption and Food Security Among Rural Households in Kwara State, Nigeria American Journal of Business and Society, 1(4): 233245.

Ndahi, M., D. Kwaga, J., K. P. Bello, M. Kabir J., V. Umoh, .J. Yakubu, S., E. and Nok, A., J. (2013) Prevalence and Antimicrobial Susceptibility of Listeria Monocytogenes and Methicillin-Resistant Staphylococcus aureus Strains from Raw Meat and Meat Products in Zaria, Nigeria. Applied Journal of Microbiology, 58(3):262-9.

Okonko, I.O., Odu, N.N. and Igboh, I.E. (2013). Microbiological Analysis of Kilishi Sold In Port Harcourt, Nigeria. New York Science Journal, 6 (7):37-43.

Osimani, A., Aquilanti, L. and Clementi, F. (2015) Microbiological Quality of Meatbased Meals and Operation of Control Systems within a Food Service Environment. International Food Research Journal 22(4): 1692-1698.

Onuorah, S. Obika, I. Odibo, F. Orji, M. (2015)An Assessment of the Bacteriological Quality of Tsire-Suya (Grilled Beef) sold in Awka, Nigeria. American. J. Life. Sci. Res. 3(4):287292.

Razavilar, V, Khandaghi, J. Barzgari, A. (2010); Isolation of Eschericia coli 0157:H7 from manure fertilized farms and raw vegetables grown on it, in Tabriz city in
Iran. African Journal of Microbiology Research, 4(9): 891-895.

Scallan, E. Hoekstra, R. M. Angulo, F. J.Tauxe, R. V, Widdowson, M. Roy, S. L et al., (2011).Food borne illness acquired in the United States- Major Pathogens. Emerg. Infec Dis, 17(1): 7-15.

Shamsuddeen U (2009). Microbiological quality of spice used in the production of Kilishi a traditionally dried and grilled meat product. Bayero Journal of Pure andApplied Sciences, 2(2): 66-69.

Shamsuddeen, U. (2015) Microbiological Hazard and Critical control point Analysis of Dried and Minced Meat Snacks Produced in Kano Nigeria. Lambert Academic Publishing; Pp 1-36.

Tijani, O.and Jumare, S. (2014). Microblological Quality Assessment of Meat

Sold in KauraNamoda. International Conference on Earth, Environment and Life sciences (EELS) Dubai (UAE).

Udobi, C. E., Obajuluwa, A. F., and Onaolapo, J. A., (2013) Prevalence and Antibiotic Resistance Pattern of MethicillinResistant Staphylococcus aureus from an Orthopaedic Hospital in Nigeria BioMed Research International; 26(6); 6-7.

WHO, 2015 Foodborne diseases in the WHO African Region.

Yousafzai HA, Rind R, Khan MA, Abro SH, Korejo NA, Ejaz M, Kabir A, Shahid M, Memon S. (2019). Microbiological Contamination of Cattle and Meat in Peshawar, Pakistan. J. Anim. Health Prod. 7(1): 1116. 


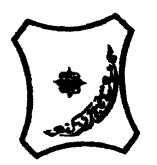

Bayero Journal of Pure and Applied Sciences, 13(1); 40 - 45

Received: September, 2019

Accepted: April, 2020

ISSN $2006-6996$

\title{
BACTERIOLOGICAL QUALITY OF STICK MEAT (Tsire) SOLD IN GARKO LOCAL GOVERNMENT AREA OF KANO STATE, NIGERIA
}

\author{
$*^{1}$ Dahiru A. T. and ${ }^{2}$ Maigari A. K. \\ ${ }^{1}$ Department of Hospitality Management, School of Technology, Kano State Polytechnic, PMB 3348, \\ Kano Nigeria. \\ ${ }^{2}$ Departmnt of Biological Sciences, Bayero University, Kano \\ Corresponding Author: dturajo61@gmail.com; GSM: 08087508262.
}

ABSTRACT

Stick meat, locally called Tsire in Hausa Language, is a significant portion of the diet of a large active population of Northern Nigeria. However, because of the handling and processing methods by the manufacturers as well as the hawking system of stick meat, the meat product may be exposed to both pre- and post-processed product contamination, and thus may poses danger to public health. Therefore, considering the role of Tsire in improving nutrition and increase household income to the populace, the need to improve the processing, distribution and overall quality of the product is simply indispensable. A total of 30 samples (5 samples from each of the 6 sampling points) of Tsire were collected randomly in Garko Town. Aerobic plate counts (APCs) and Total coliform counts (TCCS) of Tsire samples were determined using standard microbiological methods. APCs ranged from $1.02 \times 10^{5}$ to $4.00 \times 10^{5} \mathrm{CFU} / \mathrm{g}$; while TCCs ranged from $8 \mathrm{MPN} / \mathrm{g}$ to $68 \mathrm{MPN} / \mathrm{g}$. From the 30 samples screened, 16(53.33\%) bacteria namely, Campylobacter 2(6.66\%), Escherichia coli 6(20\%), Klebsiella pneumoniae 2(6.66\%), Salmonella spp. 1(3.33\%), Shigella 3(10\%) and Staphylococcus aureus 2(6.66\%) were detected. $E$. coli has the highest isolation rate of 6(20\%), while Salmonella spp. had the least frequency of 1(3.33\%). The distribution of isolated organisms within the study area were as follows: Dausai, 4(80\%), Kofar kudu, 4(80\%), Makwalla, 2(40\%), Rinji, 3(60\%), Tosaro, 2(40\%), and Tsohuwar Kasuwa, 1(20\%). The results have indicated that the Tsire was contaminated with bacteria thus exposing the product to fast deterioration, spoilage and also a vehicle for food borne illness, suggesting for adequate hygienic practices at all the stages, prior to consumption, to ensure safety of the meat product.

Key words: APCs, TCCs, Contamination, Microorganisms, Garko

\section{INTRODUCTION}

Nigeria is one of the developing nations with inadequate food supply and most often deficient in protein content (FAO, 2019). Nigerian's average animal protein intake per head per day is estimated at $7.9 \mathrm{~g}$ as against $35 \mathrm{~g}$ recommended value by Food and Agricultural Organization (Mubarak et al., 2016). These low levels of animal protein intake create great concern as it affects the nutritional status of Nigerians. Hence, there is the need for sufficient supply of animal protein from energy rich animal products to satisfy the nutritional requirements for Nigerians.

Meat is one major source of animal protein largely composed of water, protein and fats which can make it susceptible to microbial contamination within short time leading to spoilage (Apata et al., 2013; Mgbemere et al., 2011). Meat is mostly eaten after it has been cooked or processed in a variety of ways such as sun drying; smoking and roasting with or without fortifications (Borch et al., 1996). In Nigeria meat products such as Tsire, Kilishi and Balangu are locally produced using one or more of these methods in order to meet the nutritional requirements of the teeming Nigerians (Egbebi, 2011).

Tsire is a popular Nigerian traditional processed ready-to-eat roasted stick meat product (Shamsuddeen, 2015). It is sold in public places, along roads, in hotels, parks, quarters and even offices (Falegan et al., 2017). It is prepared from boneless healthy animal flesh such as beef and mutton, spiced with peanut cake, salt, vegetable oil and other flavorings followed by roasting (Shamsuddeen, 2015). Consumption of these products has extended to other parts of African countries such as Ghana, Somali, Cameroun and Chad (Ahmadu and Ibrahim, 2013). 
BAJOPAS Volume 13 Number 1, June, 2020

However, evidence of quality control sticking to procedural hygiene by the handlers during preparation and retailing of these products is poorly documented. Tsire is of great safety risk because of the fact that there are erratic cases of gastroenteritis and symptoms of food infection after consumption (WHO, 2015). Food borne illnesses are one of the major health problems in developing and developed countries (Razavilar, 2010). According to the World Health Organization, WHO (2015), $0.07 \%$ death of the 600 million global burdens of Foodborne illnesses have been reported to be caused by bacteria, viruses, fungi and chemicals. In America $0.27 \%$ of the estimated 48 million affected people is hospitalized and about $0.0063 \%$ deaths are recorded each year (Scallan et al., 2011). More than 91 million people in Africa fall ill and $0.15 \%$ dies each year, making Africa the highest burden bearer of Foodborne diseases per population (WHO, 2015).

Application of a Hazard Analysis Critical Control Point (HACCP) at all stages of meat products preparation is essential in order to ensure its safety. Thus, according to the guidelines of good manufacturing practice, the level of total aerobic bacterial contamination of thermally processed meat products should not exceed $10^{4}\left(\mathrm{cfu} \mathrm{g}^{-1}\right)$. Enterobacteriaceae and faecal coliform contamination in meat products should be within the range of $10^{2}-10^{4}$ and $10-10^{3} \mathrm{cfu} \mathrm{g}^{-1}$, respectively (Shamsuddeen, 2015). The aim of the study is therefore, to assess the total viable bacterial counts of tsire marketed locally within Garko town, and to isolate and identify the organisms at the point of consumption with the intention of promoting public health and food hygiene habits in the Nigerian populace.

\section{MATERIALS AND METHODS Study Area and Population}

Garko is one of the existing 44 local government areas located in Kano south west zone of Kano state with its capital administrative headquarters in the Garko town. It has coordinates $11^{\circ} 39^{\prime} \mathrm{N}$ $8^{\circ} 54^{\prime} \mathrm{E}$, and an area of $450 \mathrm{~km}^{2}$. The projected population of Garko local Government was 225,300 according to the National Population Census report (2018). Garko is known for agricultural activities both farming and animal husbandry. It is popularly known for large scale rice production. Other food crops include sweet potatoes, cassava, onions, sorghum, millet and sugarcane. Cows, sheep and goats are major groups of animals reared by majority of the populace. Meat products processed, retailed and consumed in Garko include roasted meat (Balangu), dried roasted meat (Kilishi), stick meat (Tsire), hide and skin pepper soup (Ragadada) and minced fried meat (Danbunnama).

\section{Samples Collection}

Five samples of Tsire products were collected from 6 different identified locations within Garko town in a sterile foil paper and immediately analyzed for the presence of bacteria.

\section{Sample Preparation}

Sample preparation for the bacteriological analysis was carried out in accordance with the method described by Atlas (1997). Twenty five grams $(25 \mathrm{~g})$ of the sample was homogenized in $225 \mathrm{ml}$ peptone water using Kenwood blender machine to obtain a $10^{1}$ homogenate. The homogenate was thoroughly shaken and $1 \mathrm{ml}$ pipetted into test tubes containing $9 \mathrm{ml}$ of peptone water $\left(10^{2}\right)$. The test tubes were further serially diluted to $10^{5}$.

Total Aerobic Mesophilic Bacterial Count

Total Aerobic mesophilic bacterial count was determined using the method described by Abdullahi et al. (2004) where $1 \mathrm{ml}$ of inoculums from $10^{1}$ to $10^{5}$ dilutions were transferred into duplicate Petri dishes and labeled accordingly. This was followed by pouring aseptically about $15 \mathrm{ml}$ of molten nutrient agar. The culture was homogenized by gentle spinning of the plates and allowed to solidify. The plates were incubated at $37^{\circ} \mathrm{C}$ for 24 hours. Plates containing 30-300 colonies were counted. The number of colony forming units per gram of a sample (cfu/g) was obtained by multiplying the average colony number with the inverse of the dilution factor.

\section{Enumeration and Detection of Coliform bacteria}

Detection and enumeration of coliform was carried out according to method described by Atlas, (1977). A set of 9 test tubes each containing $9 \mathrm{ml}$ of lactose broth and an inverted Durham tubes were autoclaved to expel air and to sterilize. Similarly, $1 \mathrm{ml}$ from the diluents $10^{1}$ was transferred to the first 3 test tubes, followed by $1 \mathrm{ml}$ from the diluents $10^{2}$ to the second set of 3 test tubes and finally the third diluents $10^{3}$ to the $3^{\text {rd }}$ set of 3 test tubes. All the 9 test tubes were incubated at $37^{\circ} \mathrm{C}$ for 24 hours. Tubes that showed gas and acid production after 24 hours were recorded as positive for the presence of Coliform. Negative tubes were further reincubated for 24 hours. Positive tubes were recorded. Estimate of most probable number of Coliform per gram of sample (MPN/g) was determined by comparing the number of gas positive tubes with the most probable number table. 
BAJOPAS Volume 13 Number 1, June, 2020 Identification of Coliform

A loop full of inoculum from gas positive tubes was streaked on to Eosine methylene blue (EMB) agar plate and incubated at $37^{\circ} \mathrm{C}$ for $24 \mathrm{hrs}$. Colonies which formed bluish black color with green metallic sheen, and reddish colonies were isolated on agar slants. Those colonies showing metallic sheen on EMB were sub cultured into tubes of lactose broth and incubated at $45^{\circ} \mathrm{C}$. The tubes were observed after $24 \mathrm{hrs}$ for gas production. This is the completed test for fecal coliform. Gram stain and other biochemical tests such as Indole, Methyl red, Voges-Proskauer and Citrate Utilization tests (IMVIC), Coagulase and Catalase tests were carried out for the Identification and confirmation of isolates.

\section{Procedure for Indole Test}

Indole test was carried out by preparing a Tryptone broth drawn in to test tubes, sterilized by autoclaving, inoculated with loopful of suspension and incubated at $37^{\circ} \mathrm{C}$ for 24 hours. Three drops of xylene was added in tubes, shaken vigorously and kept for the separation of two layers. One millilitre of Kovac's reagent was added and the formation of pink colour ring indicates positive Indole test.

\section{Procedure for Methyl Red Test}

Methyl red test was carried out by preparing Glucose phosphate broth, dispensed in test tubes, sterilized, inoculated with test culture and incubated at $37^{\circ} \mathrm{C}$ for 24 hours. Five drops of methyl-red indicator was added to the medium for the formation of red colour.

\section{Procedure for Voges-Proskauer Test}

Voges-Proskauer test was carried out by inoculating tubes with the bacterial culture followed by incubation for 48 hours at $37^{\circ} \mathrm{C}$. Separate pipettes were used to pipette $1 \mathrm{ml}$ from each culture tube into clean separate tubes. Eighteen drops $(0.5 \mathrm{ml})$ of Barrit's solution A (a-naphthol) was added to each tube containing glucose phosphate broth followed by the addition of an equal amount of solution $B$ into the same tube. The tubes were shaken at 30 seconds interval. A positive reaction was indicated by the development of a pink color, which turns red in 1-2 hours, after vigorous shaking.

\section{Procedure for Citrate Utilization Test}

Citrate Utilization Test was carried out by distributing melted agar (Simmon Citrate Agar) in to test tubes followed by sterilization at $121.5^{\circ} \mathrm{C}$ for 15 minutes. The test tubes were afterward held in slanted position, inoculated with the given bacterial culture and incubated at $37^{\circ} \mathrm{C}$ for $24 \mathrm{hrs}$. Positive test was indicated by color change of the media from green to blue.

\section{RESULTS AND DISCUSSIONS}

The results of this study are presented in tables $1,2,3$ and 4. Among the sampling areas Kofar Kudu had the highest aerobic mesophilic bacteria counts $4.0 \times 10^{5} \mathrm{cfu} / \mathrm{g}$ followed by Rinji $2.72 \times 10^{5} \mathrm{cfu} / \mathrm{g}$, while Tosaro had the least Aerobic mesophilic bacteria counts of $1.02 \times 10^{5}$ $\mathrm{cfu} / \mathrm{g}$ as indicated in Table 1.Makwalla had the highest coliform count $68 \mathrm{MPN} / \mathrm{g}$ followed by Rinji $37 \mathrm{MPN} / \mathrm{g}$. Tsohuwar Kasuwa had the least coliform counts $8 \mathrm{MPN} / \mathrm{g}$, (Table 2). Result from table 1 shows variation in the microbial contents among the samples which suggest variation in their sources, poor handling procedures and contamination from the processing environment. High coliform count and their differences within sampling areas is an indication of poor microbiological quality of the product. Ndahi et al. (2013) reported microbial load to be a function of the handling personnel and the environment. The results indicated that the samples were contaminated with bacteria as the counts exceeded the minimum safety level $\left(10^{4} \mathrm{cfu} / \mathrm{g}\right)$ for members of the Enterobacteriaceae family. However, it might be a reflection of poor hygienic practices which may contribute to health hazard to the potential consumers. Similarly, Inusa and Sa'id (2017); Osimani et al. (2015) reported that, the initial microbial content of the raw material play significant role in influencing the final microbial load of the finished product. Isolation of members of the Enterobacteriaceae such as $E$. coli, Klebsiella pneumoniae, Salmonella and Shigella signifies danger to the public health. These organisms are capable of producing endotoxins which trigger high fevers in infected individuals, and the enterotoxins which colonize the small intestines and lead to extreme dehydration as a result of vomiting and diarrhea sometimes with severe and fatal outcomes (Amaeze et al., 2016). From the 16 isolated organisms $E$. coli had the highest isolation rate $6(37.5 \%)$ (Table 3), this suggest faecal contamination of the products. $E$. coli is a common flora in the gastrointestinal tract responsible for diarrhea and extra-intestinal infections (CDC, 2011). The result is in conformity with the findings of Ndahi et al. (2013) and Shamsuddeen (2009). Also presence of campylobacter might be due to cross contamination from raw meat to finished product (Tsire). Staphylococcus aureus is a normal flora of the skin, nasal, genital, mouth or anal area in both humans and animals without any symptom of an infection (Matthew et al., 2013). Isolation of $S$. aureus in these study concords with the findings of Lucretia et al. (2018) from Suya sold in Rivers State. 
BAJOPAS Volume 13 Number 1, June, 2020

It is also in agreement with the findings of Yousafzai et al. (2018); Onuorah et al. (2015) and Tijjani and Jumare (2014) from tsire samples in different countries. Presence of $S$. aureus in foods is most of the time an indication of poor human handling, poor environment, unhygienic utensils and equipments used during processing (Igene et al., 2016; Okonko et al., 2013). Infections caused by $S$. aureus are difficult to treat leading to long hospitalization with consequent economic loss (Udobi et al., 2013). These include soft tissue infections, pneumonia, hospital-acquired postoperative wound infections, Staphylococcal food poisoning, impetigo and cellulitis (Charlene et al., 2013). Samples obtained from Dausai and Kofar Kudu had the highest isolation rate $4(80 \%)$ (Table 4 ) probably because of the much commercial activities taking place in the area which can lead to environmental contamination.

Table 1: Total Aerobic Mesophilic Bacterial Count of Tsire sold in Garko Town

\begin{tabular}{lll}
\hline Sampling Area & APC cfu/g & Mean \pm STD \\
\hline Dausai & $2.20 \times 10^{5}$ & $110000 \pm 14142.14$ \\
Kofar Kudu & $4.00 \times 10^{5}$ & $133333.3 \pm 23094.01$ \\
Makwalla & $1.30 \times 10^{5}$ & $32500 \pm 7187.953$ \\
Rinji & $2.72 \times 10^{5}$ & $90666.67 \pm 94769.90$ \\
Tosaro & $1.02 \times 10^{5}$ & $51000 \pm 15556.35$ \\
Tsohuwar Kasuwa & $1.75 \times 10^{5}$ & $35000 \pm 11357.82$ \\
\hline
\end{tabular}

Key: APC: Aerobic Mesophilic Counts

STD: Standard Deviation

Table 2: Total Coliform Count of Tsire sold in Garko Town

\begin{tabular}{lcc}
\hline \multicolumn{1}{c}{ Sampling Area } & TCC MPN/g & Mean \pm STD \\
\hline Dausai & 20 & $6.67 \pm 2.5166$ \\
Kofar Kudu & 32 & $16.00 \pm 5.6569$ \\
Makwalla & 68 & $13.60 \pm 8.7062$ \\
Rinji & 37 & $9.25 \pm 4.7871$ \\
Tosaro & 10 & $5.00 \pm 2.8284$ \\
Tsohuwar Kasuwa & 8 & $4.00 \pm 0.0000$ \\
\hline
\end{tabular}

Table 3: Organisms Isolated from Tsire Sold in Garko

\begin{tabular}{lcl}
\hline Isolated Organism & Frequency & Percentage (\%) \\
\hline Campylobacter & 2 & 06.66 \\
Escherichia coli & 6 & 20.00 \\
Klebsiella pneumoniae & 2 & 06.66 \\
Salmonella species & 1 & 03.33 \\
Shigella & 3 & 10.00 \\
Staphylococcus aureus & 2 & 06.66 \\
Total & 16 & \\
\hline
\end{tabular}

Table 4: Distribution of Organisms within Sampling Area

\begin{tabular}{lcc}
\hline \multicolumn{1}{c}{ Sampling Area } & No. Isolated & Percentage (\%) \\
\hline Dausai & 4 & 80 \\
Kofar Kudu & 4 & 80 \\
Makwalla & 2 & 40 \\
Rinji & 3 & 60 \\
Tosaro & 2 & 40 \\
Tsohuwar Kasuwa & 1 & 20 \\
Total & 16 & \\
\hline
\end{tabular}

\section{CONCLUSION}

Results indicated $4.00 \times 10^{5} \mathrm{CFU} / \mathrm{g}$ as the highest APCs count; while $68 \mathrm{MPN} / \mathrm{g}$ was the highest TCCs from the 30 samples analyzed. Among the isolates, $E$. coli has the highest isolation rate of $6(20 \%)$. Dausai and Kofar kudu were having the highest bacteria count of $4(80 \%)$, each, indicating higher contamination in those locations. 
BAJOPAS Volume 13 Number 1, June, 2020 RECOMMENDATIONS

The following recommendations are tenable:

1. Hygienic practices at all stages of production should be improved to safe guard the consumers against potential health hazard.

2. Monitoring of microbiological contamination of Tsire during preparations, packaging and marketing is essential to ensure product of good microbiological quality for consumers' health.

\section{REFERENCES}

Abdullahi, I. O., Umoh, V. J. and Galadima, M. (2004). Hazards Associated with Kilishi Preparations in Zaria. Nigerian Journal of Microbiology, 18 (1-2): $339-345$.

Ahmadu, J. and Ibrahim E. J., (2013): Determinants of Revenue in Suya Production in BeninCity, Edo State, Nigeria. Nigerian journal of agriculture, food and environment.9(3):1-5

Amaeze, N. Aboh, M. Itohan, A. Felix, E. Olatunji, T. and Oladosu, P. (2016) Microbial Profile, Antibiotic Sensitivity and Heat Resistance of Bacterial Isolates from Commercial Roasted Beef (Suya) in Abuja, Nigeria. JOPAT, 15(2): $22-30$.

Apata, E.S., Kuku1, I.A., Apata, O.C. and Adeyemi, K.O. (2013). Evaluation of Suya(Tsire) - An Intermediate Moisture Meat Product in Ogun State, Nigeria. J. Food Res 2 (1): 87.

Atlas, R. M. (1997) Principles of Microbiology Second Edition. C. Brown Publishers. Pp 802-803.

Borch, E. Kant-Muermans, M. L., Blixt, Y. (1996) Bacterial Spoilage of Meat and Cured Meat Products. Int $\mathrm{J}$ Food Microbiol .33(1): 103-20.

Centre for Disease Control, CDC (2011). "Escherichia coli 0157:H7" Division of Bacterial and Mycotic Diseasesht://www.cdc.gov/nczved/divisi ons/dfbmd/diseases/ecoli_0157h7/.

Charlene, R. J., Johnnie, A. D., and John, B. B., (2013) Prevalence and Characterization of Methicillin-Resistant Staphylococcus aureus Isolates from Retail Meat and Humans in Georgia. American society for Microbiology. J. of clinical microbiology. 12(1):123-6 doi:10.1128/JCM.0316612JCM.03166-12

Egbebi, A.O and Seidu, K., T. (2011). Microbiological Evaluation of Suya (dried smoked

meat) Sold in Ado and Akure, South West Nigeria.European Journal of Experinmental Biology, 1(4):1-5
3. Government should establish regulatory bodies responsible for inculcating hygiene habits to the local producers and vendors in order to prevent instant, cross and post processing contaminations by microbial pathogens.

4. Awareness and sensitization of local food producers about good hygienic practices in food handling and processing.

Falegan, C, R., Akoja, S. D., and Oyarekua, M. A., (2017) Microbiological Assessment of Suya (Sliced Roasted Beef) in Ado-Ekiti Metropolis, Ekiti State, Nigeria. MOJ Biology andMedicine.

Fonkem, D., N. Tanya, V., N. and Ebangi, A., L. (2010). Effect of Season on the Microbiological Quality of Kilishi, a Traditional Cameroonian Dried Beef Product. Tropicultura, 28(1): 10-15.

Food and Agricultural Organization of the United Nations (F A O, 1979). Manual of food quality control 4. Microbiological analysis.

Food and Agriculture Organisation of the United Nation (FAO), 2019. Nigeria at a glance.

Igene J.O., Uwadia, O.E., Ebabhamiegbebho, P.A. and Evivie, S.E., (2016) Shelf life Stability Studies of University of Benin (UNIBEN) Proff's Kilishi Product Asian Journal of Science and Technology 7(1): 2268-2274.

Inusa, S. K. and Said, I. S. (2017) Evaluation of the Chemical and Microbiological Properties Of Kilishi Sold in Kano Metropolis. Journal of Dry land Agriculture, 3 (1): $59-69$.

Lucretia, I. B, Patience, C. Obinna-Echem, Sophia, C. A. (2018) Microbiological quality andantibiotic sensitivity of potential pathogens isolated from meat product (Suya) sold in Rivers State University and its environs. International Journal of Biotechnology and Food Science, 6(4): 67-76.

Matthew, E., Drosos, E., John, L. and Ioanna, P. (2013) MRSA in Africa: Filling the Global Map of Antimicrobial Resistance PLOS One. 8(7): e68024 doi: 10.1371/journal.pone.0068024

Mgbemere, V.N., Akpapunam, M. A. and Igene, J. O., (2011). Effect of Groundnut FlourSubstitution on Yield, Quality and Storage Stability of Kilishi - a Nigerian Indigenous Dried Meat Product. African Journal of Food, Agriculture, Nutrition and Development, $\quad \mathbf{1 1}(2)$ : 4718-4738. 
BAJOPAS Volume 13 Number 1, June, 2020

Mubarak, A. A., Azeez, M. L., Amos A. O., Opeyemi, O. O. (2016) Assessment of Animal Protein Consumption and Food Security Among Rural Households in Kwara State, Nigeria American Journal of Business and Society, 1(4): 233245.

Ndahi, M., D. Kwaga, J., K. P. Bello, M. Kabir J., V. Umoh, .J. Yakubu, S., E. and Nok, A., J. (2013) Prevalence and Antimicrobial Susceptibility of Listeria Monocytogenes and Methicillin-Resistant Staphylococcus aureus Strains from Raw Meat and Meat Products in Zaria, Nigeria. Applied Journal of Microbiology, 58(3):262-9.

Okonko, I.O., Odu, N.N. and Igboh, I.E. (2013). Microbiological Analysis of Kilishi Sold In Port Harcourt, Nigeria. New York Science Journal, 6 (7):37-43.

Osimani, A., Aquilanti, L. and Clementi, F. (2015) Microbiological Quality of Meatbased Meals and Operation of Control Systems within a Food Service Environment. International Food Research Journal 22(4): 1692-1698.

Onuorah, S. Obika, I. Odibo, F. Orji, M. (2015)An Assessment of the Bacteriological Quality of Tsire-Suya (Grilled Beef) sold in Awka, Nigeria. American. J. Life. Sci. Res. 3(4):287292.

Razavilar, V, Khandaghi, J. Barzgari, A. (2010); Isolation of Eschericia coli 0157:H7 from manure fertilized farms and raw vegetables grown on it, in Tabriz city in
Iran. African Journal of Microbiology Research, 4(9): 891-895.

Scallan, E. Hoekstra, R. M. Angulo, F. J.Tauxe, R. V, Widdowson, M. Roy, S. L et al., (2011).Food borne illness acquired in the United States- Major Pathogens. Emerg. Infec Dis, 17(1): 7-15.

Shamsuddeen U (2009). Microbiological quality of spice used in the production of Kilishi a traditionally dried and grilled meat product. Bayero Journal of Pure andApplied Sciences, 2(2): 66-69.

Shamsuddeen, U. (2015) Microbiological Hazard and Critical control point Analysis of Dried and Minced Meat Snacks Produced in Kano Nigeria. Lambert Academic Publishing; Pp 1-36.

Tijani, O.and Jumare, S. (2014). Microblological Quality Assessment of Meat

Sold in KauraNamoda. International Conference on Earth, Environment and Life sciences (EELS) Dubai (UAE).

Udobi, C. E., Obajuluwa, A. F., and Onaolapo, J. A., (2013) Prevalence and Antibiotic Resistance Pattern of MethicillinResistant Staphylococcus aureus from an Orthopaedic Hospital in Nigeria BioMed Research International; 26(6); 6-7.

WHO, 2015 Foodborne diseases in the WHO African Region.

Yousafzai HA, Rind R, Khan MA, Abro SH, Korejo NA, Ejaz M, Kabir A, Shahid M, Memon S. (2019). Microbiological Contamination of Cattle and Meat in Peshawar, Pakistan. J. Anim. Health Prod. 7(1): 1116. 


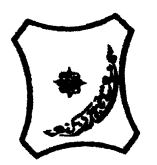

Bayero Journal of Pure and Applied Sciences, 13(1); 40 - 45

Received: September, 2019

Accepted: April, 2020

ISSN $2006-6996$

\title{
BACTERIOLOGICAL QUALITY OF STICK MEAT (Tsire) SOLD IN GARKO LOCAL GOVERNMENT AREA OF KANO STATE, NIGERIA
}

\author{
$*^{1}$ Dahiru A. T. and ${ }^{2}$ Maigari A. K. \\ ${ }^{1}$ Department of Hospitality Management, School of Technology, Kano State Polytechnic, PMB 3348, \\ Kano Nigeria. \\ ${ }^{2}$ Departmnt of Biological Sciences, Bayero University, Kano \\ Corresponding Author: dturajo61@gmail.com; GSM: 08087508262.
}

ABSTRACT

Stick meat, locally called Tsire in Hausa Language, is a significant portion of the diet of a large active population of Northern Nigeria. However, because of the handling and processing methods by the manufacturers as well as the hawking system of stick meat, the meat product may be exposed to both pre- and post-processed product contamination, and thus may poses danger to public health. Therefore, considering the role of Tsire in improving nutrition and increase household income to the populace, the need to improve the processing, distribution and overall quality of the product is simply indispensable. A total of 30 samples (5 samples from each of the 6 sampling points) of Tsire were collected randomly in Garko Town. Aerobic plate counts (APCs) and Total coliform counts (TCCS) of Tsire samples were determined using standard microbiological methods. APCs ranged from $1.02 \times 10^{5}$ to $4.00 \times 10^{5} \mathrm{CFU} / \mathrm{g}$; while TCCs ranged from $8 \mathrm{MPN} / \mathrm{g}$ to $68 \mathrm{MPN} / \mathrm{g}$. From the 30 samples screened, 16(53.33\%) bacteria namely, Campylobacter 2(6.66\%), Escherichia coli 6(20\%), Klebsiella pneumoniae 2(6.66\%), Salmonella spp. 1(3.33\%), Shigella 3(10\%) and Staphylococcus aureus 2(6.66\%) were detected. $E$. coli has the highest isolation rate of 6(20\%), while Salmonella spp. had the least frequency of 1(3.33\%). The distribution of isolated organisms within the study area were as follows: Dausai, 4(80\%), Kofar kudu, 4(80\%), Makwalla, 2(40\%), Rinji, 3(60\%), Tosaro, 2(40\%), and Tsohuwar Kasuwa, 1(20\%). The results have indicated that the Tsire was contaminated with bacteria thus exposing the product to fast deterioration, spoilage and also a vehicle for food borne illness, suggesting for adequate hygienic practices at all the stages, prior to consumption, to ensure safety of the meat product.

Key words: APCs, TCCs, Contamination, Microorganisms, Garko

\section{INTRODUCTION}

Nigeria is one of the developing nations with inadequate food supply and most often deficient in protein content (FAO, 2019). Nigerian's average animal protein intake per head per day is estimated at $7.9 \mathrm{~g}$ as against $35 \mathrm{~g}$ recommended value by Food and Agricultural Organization (Mubarak et al., 2016). These low levels of animal protein intake create great concern as it affects the nutritional status of Nigerians. Hence, there is the need for sufficient supply of animal protein from energy rich animal products to satisfy the nutritional requirements for Nigerians.

Meat is one major source of animal protein largely composed of water, protein and fats which can make it susceptible to microbial contamination within short time leading to spoilage (Apata et al., 2013; Mgbemere et al., 2011). Meat is mostly eaten after it has been cooked or processed in a variety of ways such as sun drying; smoking and roasting with or without fortifications (Borch et al., 1996). In Nigeria meat products such as Tsire, Kilishi and Balangu are locally produced using one or more of these methods in order to meet the nutritional requirements of the teeming Nigerians (Egbebi, 2011).

Tsire is a popular Nigerian traditional processed ready-to-eat roasted stick meat product (Shamsuddeen, 2015). It is sold in public places, along roads, in hotels, parks, quarters and even offices (Falegan et al., 2017). It is prepared from boneless healthy animal flesh such as beef and mutton, spiced with peanut cake, salt, vegetable oil and other flavorings followed by roasting (Shamsuddeen, 2015). Consumption of these products has extended to other parts of African countries such as Ghana, Somali, Cameroun and Chad (Ahmadu and Ibrahim, 2013). 
BAJOPAS Volume 13 Number 1, June, 2020

However, evidence of quality control sticking to procedural hygiene by the handlers during preparation and retailing of these products is poorly documented. Tsire is of great safety risk because of the fact that there are erratic cases of gastroenteritis and symptoms of food infection after consumption (WHO, 2015). Food borne illnesses are one of the major health problems in developing and developed countries (Razavilar, 2010). According to the World Health Organization, WHO (2015), $0.07 \%$ death of the 600 million global burdens of Foodborne illnesses have been reported to be caused by bacteria, viruses, fungi and chemicals. In America $0.27 \%$ of the estimated 48 million affected people is hospitalized and about $0.0063 \%$ deaths are recorded each year (Scallan et al., 2011). More than 91 million people in Africa fall ill and $0.15 \%$ dies each year, making Africa the highest burden bearer of Foodborne diseases per population (WHO, 2015).

Application of a Hazard Analysis Critical Control Point (HACCP) at all stages of meat products preparation is essential in order to ensure its safety. Thus, according to the guidelines of good manufacturing practice, the level of total aerobic bacterial contamination of thermally processed meat products should not exceed $10^{4}\left(\mathrm{cfu} \mathrm{g}^{-1}\right)$. Enterobacteriaceae and faecal coliform contamination in meat products should be within the range of $10^{2}-10^{4}$ and $10-10^{3} \mathrm{cfu} \mathrm{g}^{-1}$, respectively (Shamsuddeen, 2015). The aim of the study is therefore, to assess the total viable bacterial counts of tsire marketed locally within Garko town, and to isolate and identify the organisms at the point of consumption with the intention of promoting public health and food hygiene habits in the Nigerian populace.

\section{MATERIALS AND METHODS Study Area and Population}

Garko is one of the existing 44 local government areas located in Kano south west zone of Kano state with its capital administrative headquarters in the Garko town. It has coordinates $11^{\circ} 39^{\prime} \mathrm{N}$ $8^{\circ} 54^{\prime} \mathrm{E}$, and an area of $450 \mathrm{~km}^{2}$. The projected population of Garko local Government was 225,300 according to the National Population Census report (2018). Garko is known for agricultural activities both farming and animal husbandry. It is popularly known for large scale rice production. Other food crops include sweet potatoes, cassava, onions, sorghum, millet and sugarcane. Cows, sheep and goats are major groups of animals reared by majority of the populace. Meat products processed, retailed and consumed in Garko include roasted meat (Balangu), dried roasted meat (Kilishi), stick meat (Tsire), hide and skin pepper soup (Ragadada) and minced fried meat (Danbunnama).

\section{Samples Collection}

Five samples of Tsire products were collected from 6 different identified locations within Garko town in a sterile foil paper and immediately analyzed for the presence of bacteria.

\section{Sample Preparation}

Sample preparation for the bacteriological analysis was carried out in accordance with the method described by Atlas (1997). Twenty five grams $(25 \mathrm{~g})$ of the sample was homogenized in $225 \mathrm{ml}$ peptone water using Kenwood blender machine to obtain a $10^{1}$ homogenate. The homogenate was thoroughly shaken and $1 \mathrm{ml}$ pipetted into test tubes containing $9 \mathrm{ml}$ of peptone water $\left(10^{2}\right)$. The test tubes were further serially diluted to $10^{5}$.

Total Aerobic Mesophilic Bacterial Count

Total Aerobic mesophilic bacterial count was determined using the method described by Abdullahi et al. (2004) where $1 \mathrm{ml}$ of inoculums from $10^{1}$ to $10^{5}$ dilutions were transferred into duplicate Petri dishes and labeled accordingly. This was followed by pouring aseptically about $15 \mathrm{ml}$ of molten nutrient agar. The culture was homogenized by gentle spinning of the plates and allowed to solidify. The plates were incubated at $37^{\circ} \mathrm{C}$ for 24 hours. Plates containing 30-300 colonies were counted. The number of colony forming units per gram of a sample (cfu/g) was obtained by multiplying the average colony number with the inverse of the dilution factor.

\section{Enumeration and Detection of Coliform bacteria}

Detection and enumeration of coliform was carried out according to method described by Atlas, (1977). A set of 9 test tubes each containing $9 \mathrm{ml}$ of lactose broth and an inverted Durham tubes were autoclaved to expel air and to sterilize. Similarly, $1 \mathrm{ml}$ from the diluents $10^{1}$ was transferred to the first 3 test tubes, followed by $1 \mathrm{ml}$ from the diluents $10^{2}$ to the second set of 3 test tubes and finally the third diluents $10^{3}$ to the $3^{\text {rd }}$ set of 3 test tubes. All the 9 test tubes were incubated at $37^{\circ} \mathrm{C}$ for 24 hours. Tubes that showed gas and acid production after 24 hours were recorded as positive for the presence of Coliform. Negative tubes were further reincubated for 24 hours. Positive tubes were recorded. Estimate of most probable number of Coliform per gram of sample (MPN/g) was determined by comparing the number of gas positive tubes with the most probable number table. 
BAJOPAS Volume 13 Number 1, June, 2020 Identification of Coliform

A loop full of inoculum from gas positive tubes was streaked on to Eosine methylene blue (EMB) agar plate and incubated at $37^{\circ} \mathrm{C}$ for $24 \mathrm{hrs}$. Colonies which formed bluish black color with green metallic sheen, and reddish colonies were isolated on agar slants. Those colonies showing metallic sheen on EMB were sub cultured into tubes of lactose broth and incubated at $45^{\circ} \mathrm{C}$. The tubes were observed after $24 \mathrm{hrs}$ for gas production. This is the completed test for fecal coliform. Gram stain and other biochemical tests such as Indole, Methyl red, Voges-Proskauer and Citrate Utilization tests (IMVIC), Coagulase and Catalase tests were carried out for the Identification and confirmation of isolates.

\section{Procedure for Indole Test}

Indole test was carried out by preparing a Tryptone broth drawn in to test tubes, sterilized by autoclaving, inoculated with loopful of suspension and incubated at $37^{\circ} \mathrm{C}$ for 24 hours. Three drops of xylene was added in tubes, shaken vigorously and kept for the separation of two layers. One millilitre of Kovac's reagent was added and the formation of pink colour ring indicates positive Indole test.

\section{Procedure for Methyl Red Test}

Methyl red test was carried out by preparing Glucose phosphate broth, dispensed in test tubes, sterilized, inoculated with test culture and incubated at $37^{\circ} \mathrm{C}$ for 24 hours. Five drops of methyl-red indicator was added to the medium for the formation of red colour.

\section{Procedure for Voges-Proskauer Test}

Voges-Proskauer test was carried out by inoculating tubes with the bacterial culture followed by incubation for 48 hours at $37^{\circ} \mathrm{C}$. Separate pipettes were used to pipette $1 \mathrm{ml}$ from each culture tube into clean separate tubes. Eighteen drops $(0.5 \mathrm{ml})$ of Barrit's solution A (a-naphthol) was added to each tube containing glucose phosphate broth followed by the addition of an equal amount of solution $B$ into the same tube. The tubes were shaken at 30 seconds interval. A positive reaction was indicated by the development of a pink color, which turns red in 1-2 hours, after vigorous shaking.

\section{Procedure for Citrate Utilization Test}

Citrate Utilization Test was carried out by distributing melted agar (Simmon Citrate Agar) in to test tubes followed by sterilization at $121.5^{\circ} \mathrm{C}$ for 15 minutes. The test tubes were afterward held in slanted position, inoculated with the given bacterial culture and incubated at $37^{\circ} \mathrm{C}$ for $24 \mathrm{hrs}$. Positive test was indicated by color change of the media from green to blue.

\section{RESULTS AND DISCUSSIONS}

The results of this study are presented in tables $1,2,3$ and 4. Among the sampling areas Kofar Kudu had the highest aerobic mesophilic bacteria counts $4.0 \times 10^{5} \mathrm{cfu} / \mathrm{g}$ followed by Rinji $2.72 \times 10^{5} \mathrm{cfu} / \mathrm{g}$, while Tosaro had the least Aerobic mesophilic bacteria counts of $1.02 \times 10^{5}$ $\mathrm{cfu} / \mathrm{g}$ as indicated in Table 1.Makwalla had the highest coliform count $68 \mathrm{MPN} / \mathrm{g}$ followed by Rinji $37 \mathrm{MPN} / \mathrm{g}$. Tsohuwar Kasuwa had the least coliform counts $8 \mathrm{MPN} / \mathrm{g}$, (Table 2). Result from table 1 shows variation in the microbial contents among the samples which suggest variation in their sources, poor handling procedures and contamination from the processing environment. High coliform count and their differences within sampling areas is an indication of poor microbiological quality of the product. Ndahi et al. (2013) reported microbial load to be a function of the handling personnel and the environment. The results indicated that the samples were contaminated with bacteria as the counts exceeded the minimum safety level $\left(10^{4} \mathrm{cfu} / \mathrm{g}\right)$ for members of the Enterobacteriaceae family. However, it might be a reflection of poor hygienic practices which may contribute to health hazard to the potential consumers. Similarly, Inusa and Sa'id (2017); Osimani et al. (2015) reported that, the initial microbial content of the raw material play significant role in influencing the final microbial load of the finished product. Isolation of members of the Enterobacteriaceae such as $E$. coli, Klebsiella pneumoniae, Salmonella and Shigella signifies danger to the public health. These organisms are capable of producing endotoxins which trigger high fevers in infected individuals, and the enterotoxins which colonize the small intestines and lead to extreme dehydration as a result of vomiting and diarrhea sometimes with severe and fatal outcomes (Amaeze et al., 2016). From the 16 isolated organisms $E$. coli had the highest isolation rate $6(37.5 \%)$ (Table 3), this suggest faecal contamination of the products. $E$. coli is a common flora in the gastrointestinal tract responsible for diarrhea and extra-intestinal infections (CDC, 2011). The result is in conformity with the findings of Ndahi et al. (2013) and Shamsuddeen (2009). Also presence of campylobacter might be due to cross contamination from raw meat to finished product (Tsire). Staphylococcus aureus is a normal flora of the skin, nasal, genital, mouth or anal area in both humans and animals without any symptom of an infection (Matthew et al., 2013). Isolation of $S$. aureus in these study concords with the findings of Lucretia et al. (2018) from Suya sold in Rivers State. 
BAJOPAS Volume 13 Number 1, June, 2020

It is also in agreement with the findings of Yousafzai et al. (2018); Onuorah et al. (2015) and Tijjani and Jumare (2014) from tsire samples in different countries. Presence of $S$. aureus in foods is most of the time an indication of poor human handling, poor environment, unhygienic utensils and equipments used during processing (Igene et al., 2016; Okonko et al., 2013). Infections caused by $S$. aureus are difficult to treat leading to long hospitalization with consequent economic loss (Udobi et al., 2013). These include soft tissue infections, pneumonia, hospital-acquired postoperative wound infections, Staphylococcal food poisoning, impetigo and cellulitis (Charlene et al., 2013). Samples obtained from Dausai and Kofar Kudu had the highest isolation rate $4(80 \%)$ (Table 4 ) probably because of the much commercial activities taking place in the area which can lead to environmental contamination.

Table 1: Total Aerobic Mesophilic Bacterial Count of Tsire sold in Garko Town

\begin{tabular}{lll}
\hline Sampling Area & APC cfu/g & Mean \pm STD \\
\hline Dausai & $2.20 \times 10^{5}$ & $110000 \pm 14142.14$ \\
Kofar Kudu & $4.00 \times 10^{5}$ & $133333.3 \pm 23094.01$ \\
Makwalla & $1.30 \times 10^{5}$ & $32500 \pm 7187.953$ \\
Rinji & $2.72 \times 10^{5}$ & $90666.67 \pm 94769.90$ \\
Tosaro & $1.02 \times 10^{5}$ & $51000 \pm 15556.35$ \\
Tsohuwar Kasuwa & $1.75 \times 10^{5}$ & $35000 \pm 11357.82$ \\
\hline
\end{tabular}

Key: APC: Aerobic Mesophilic Counts

STD: Standard Deviation

Table 2: Total Coliform Count of Tsire sold in Garko Town

\begin{tabular}{lcc}
\hline \multicolumn{1}{c}{ Sampling Area } & TCC MPN/g & Mean \pm STD \\
\hline Dausai & 20 & $6.67 \pm 2.5166$ \\
Kofar Kudu & 32 & $16.00 \pm 5.6569$ \\
Makwalla & 68 & $13.60 \pm 8.7062$ \\
Rinji & 37 & $9.25 \pm 4.7871$ \\
Tosaro & 10 & $5.00 \pm 2.8284$ \\
Tsohuwar Kasuwa & 8 & $4.00 \pm 0.0000$ \\
\hline
\end{tabular}

Table 3: Organisms Isolated from Tsire Sold in Garko

\begin{tabular}{lcl}
\hline Isolated Organism & Frequency & Percentage (\%) \\
\hline Campylobacter & 2 & 06.66 \\
Escherichia coli & 6 & 20.00 \\
Klebsiella pneumoniae & 2 & 06.66 \\
Salmonella species & 1 & 03.33 \\
Shigella & 3 & 10.00 \\
Staphylococcus aureus & 2 & 06.66 \\
Total & 16 & \\
\hline
\end{tabular}

Table 4: Distribution of Organisms within Sampling Area

\begin{tabular}{lcc}
\hline \multicolumn{1}{c}{ Sampling Area } & No. Isolated & Percentage (\%) \\
\hline Dausai & 4 & 80 \\
Kofar Kudu & 4 & 80 \\
Makwalla & 2 & 40 \\
Rinji & 3 & 60 \\
Tosaro & 2 & 40 \\
Tsohuwar Kasuwa & 1 & 20 \\
Total & 16 & \\
\hline
\end{tabular}

\section{CONCLUSION}

Results indicated $4.00 \times 10^{5} \mathrm{CFU} / \mathrm{g}$ as the highest APCs count; while $68 \mathrm{MPN} / \mathrm{g}$ was the highest TCCs from the 30 samples analyzed. Among the isolates, $E$. coli has the highest isolation rate of $6(20 \%)$. Dausai and Kofar kudu were having the highest bacteria count of $4(80 \%)$, each, indicating higher contamination in those locations. 
BAJOPAS Volume 13 Number 1, June, 2020 RECOMMENDATIONS

The following recommendations are tenable:

1. Hygienic practices at all stages of production should be improved to safe guard the consumers against potential health hazard.

2. Monitoring of microbiological contamination of Tsire during preparations, packaging and marketing is essential to ensure product of good microbiological quality for consumers' health.

\section{REFERENCES}

Abdullahi, I. O., Umoh, V. J. and Galadima, M. (2004). Hazards Associated with Kilishi Preparations in Zaria. Nigerian Journal of Microbiology, 18 (1-2): $339-345$.

Ahmadu, J. and Ibrahim E. J., (2013): Determinants of Revenue in Suya Production in BeninCity, Edo State, Nigeria. Nigerian journal of agriculture, food and environment.9(3):1-5

Amaeze, N. Aboh, M. Itohan, A. Felix, E. Olatunji, T. and Oladosu, P. (2016) Microbial Profile, Antibiotic Sensitivity and Heat Resistance of Bacterial Isolates from Commercial Roasted Beef (Suya) in Abuja, Nigeria. JOPAT, 15(2): $22-30$.

Apata, E.S., Kuku1, I.A., Apata, O.C. and Adeyemi, K.O. (2013). Evaluation of Suya(Tsire) - An Intermediate Moisture Meat Product in Ogun State, Nigeria. J. Food Res 2 (1): 87.

Atlas, R. M. (1997) Principles of Microbiology Second Edition. C. Brown Publishers. Pp 802-803.

Borch, E. Kant-Muermans, M. L., Blixt, Y. (1996) Bacterial Spoilage of Meat and Cured Meat Products. Int $\mathrm{J}$ Food Microbiol .33(1): 103-20.

Centre for Disease Control, CDC (2011). "Escherichia coli 0157:H7" Division of Bacterial and Mycotic Diseasesht://www.cdc.gov/nczved/divisi ons/dfbmd/diseases/ecoli_0157h7/.

Charlene, R. J., Johnnie, A. D., and John, B. B., (2013) Prevalence and Characterization of Methicillin-Resistant Staphylococcus aureus Isolates from Retail Meat and Humans in Georgia. American society for Microbiology. J. of clinical microbiology. 12(1):123-6 doi:10.1128/JCM.0316612JCM.03166-12

Egbebi, A.O and Seidu, K., T. (2011). Microbiological Evaluation of Suya (dried smoked

meat) Sold in Ado and Akure, South West Nigeria.European Journal of Experinmental Biology, 1(4):1-5
3. Government should establish regulatory bodies responsible for inculcating hygiene habits to the local producers and vendors in order to prevent instant, cross and post processing contaminations by microbial pathogens.

4. Awareness and sensitization of local food producers about good hygienic practices in food handling and processing.

Falegan, C, R., Akoja, S. D., and Oyarekua, M. A., (2017) Microbiological Assessment of Suya (Sliced Roasted Beef) in Ado-Ekiti Metropolis, Ekiti State, Nigeria. MOJ Biology andMedicine.

Fonkem, D., N. Tanya, V., N. and Ebangi, A., L. (2010). Effect of Season on the Microbiological Quality of Kilishi, a Traditional Cameroonian Dried Beef Product. Tropicultura, 28(1): 10-15.

Food and Agricultural Organization of the United Nations (F A O, 1979). Manual of food quality control 4. Microbiological analysis.

Food and Agriculture Organisation of the United Nation (FAO), 2019. Nigeria at a glance.

Igene J.O., Uwadia, O.E., Ebabhamiegbebho, P.A. and Evivie, S.E., (2016) Shelf life Stability Studies of University of Benin (UNIBEN) Proff's Kilishi Product Asian Journal of Science and Technology 7(1): 2268-2274.

Inusa, S. K. and Said, I. S. (2017) Evaluation of the Chemical and Microbiological Properties Of Kilishi Sold in Kano Metropolis. Journal of Dry land Agriculture, 3 (1): $59-69$.

Lucretia, I. B, Patience, C. Obinna-Echem, Sophia, C. A. (2018) Microbiological quality andantibiotic sensitivity of potential pathogens isolated from meat product (Suya) sold in Rivers State University and its environs. International Journal of Biotechnology and Food Science, 6(4): 67-76.

Matthew, E., Drosos, E., John, L. and Ioanna, P. (2013) MRSA in Africa: Filling the Global Map of Antimicrobial Resistance PLOS One. 8(7): e68024 doi: 10.1371/journal.pone.0068024

Mgbemere, V.N., Akpapunam, M. A. and Igene, J. O., (2011). Effect of Groundnut FlourSubstitution on Yield, Quality and Storage Stability of Kilishi - a Nigerian Indigenous Dried Meat Product. African Journal of Food, Agriculture, Nutrition and Development, $\quad \mathbf{1 1}(2)$ : 4718-4738. 
BAJOPAS Volume 13 Number 1, June, 2020

Mubarak, A. A., Azeez, M. L., Amos A. O., Opeyemi, O. O. (2016) Assessment of Animal Protein Consumption and Food Security Among Rural Households in Kwara State, Nigeria American Journal of Business and Society, 1(4): 233245.

Ndahi, M., D. Kwaga, J., K. P. Bello, M. Kabir J., V. Umoh, .J. Yakubu, S., E. and Nok, A., J. (2013) Prevalence and Antimicrobial Susceptibility of Listeria Monocytogenes and Methicillin-Resistant Staphylococcus aureus Strains from Raw Meat and Meat Products in Zaria, Nigeria. Applied Journal of Microbiology, 58(3):262-9.

Okonko, I.O., Odu, N.N. and Igboh, I.E. (2013). Microbiological Analysis of Kilishi Sold In Port Harcourt, Nigeria. New York Science Journal, 6 (7):37-43.

Osimani, A., Aquilanti, L. and Clementi, F. (2015) Microbiological Quality of Meatbased Meals and Operation of Control Systems within a Food Service Environment. International Food Research Journal 22(4): 1692-1698.

Onuorah, S. Obika, I. Odibo, F. Orji, M. (2015)An Assessment of the Bacteriological Quality of Tsire-Suya (Grilled Beef) sold in Awka, Nigeria. American. J. Life. Sci. Res. 3(4):287292.

Razavilar, V, Khandaghi, J. Barzgari, A. (2010); Isolation of Eschericia coli 0157:H7 from manure fertilized farms and raw vegetables grown on it, in Tabriz city in
Iran. African Journal of Microbiology Research, 4(9): 891-895.

Scallan, E. Hoekstra, R. M. Angulo, F. J.Tauxe, R. V, Widdowson, M. Roy, S. L et al., (2011).Food borne illness acquired in the United States- Major Pathogens. Emerg. Infec Dis, 17(1): 7-15.

Shamsuddeen U (2009). Microbiological quality of spice used in the production of Kilishi a traditionally dried and grilled meat product. Bayero Journal of Pure andApplied Sciences, 2(2): 66-69.

Shamsuddeen, U. (2015) Microbiological Hazard and Critical control point Analysis of Dried and Minced Meat Snacks Produced in Kano Nigeria. Lambert Academic Publishing; Pp 1-36.

Tijani, O.and Jumare, S. (2014). Microblological Quality Assessment of Meat

Sold in KauraNamoda. International Conference on Earth, Environment and Life sciences (EELS) Dubai (UAE).

Udobi, C. E., Obajuluwa, A. F., and Onaolapo, J. A., (2013) Prevalence and Antibiotic Resistance Pattern of MethicillinResistant Staphylococcus aureus from an Orthopaedic Hospital in Nigeria BioMed Research International; 26(6); 6-7.

WHO, 2015 Foodborne diseases in the WHO African Region.

Yousafzai HA, Rind R, Khan MA, Abro SH, Korejo NA, Ejaz M, Kabir A, Shahid M, Memon S. (2019). Microbiological Contamination of Cattle and Meat in Peshawar, Pakistan. J. Anim. Health Prod. 7(1): 1116. 


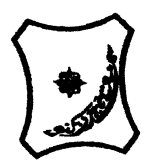

Bayero Journal of Pure and Applied Sciences, 13(1); 40 - 45

Received: September, 2019

Accepted: April, 2020

ISSN $2006-6996$

\title{
BACTERIOLOGICAL QUALITY OF STICK MEAT (Tsire) SOLD IN GARKO LOCAL GOVERNMENT AREA OF KANO STATE, NIGERIA
}

\author{
$*^{1}$ Dahiru A. T. and ${ }^{2}$ Maigari A. K. \\ ${ }^{1}$ Department of Hospitality Management, School of Technology, Kano State Polytechnic, PMB 3348, \\ Kano Nigeria. \\ ${ }^{2}$ Departmnt of Biological Sciences, Bayero University, Kano \\ Corresponding Author: dturajo61@gmail.com; GSM: 08087508262.
}

ABSTRACT

Stick meat, locally called Tsire in Hausa Language, is a significant portion of the diet of a large active population of Northern Nigeria. However, because of the handling and processing methods by the manufacturers as well as the hawking system of stick meat, the meat product may be exposed to both pre- and post-processed product contamination, and thus may poses danger to public health. Therefore, considering the role of Tsire in improving nutrition and increase household income to the populace, the need to improve the processing, distribution and overall quality of the product is simply indispensable. A total of 30 samples (5 samples from each of the 6 sampling points) of Tsire were collected randomly in Garko Town. Aerobic plate counts (APCs) and Total coliform counts (TCCS) of Tsire samples were determined using standard microbiological methods. APCs ranged from $1.02 \times 10^{5}$ to $4.00 \times 10^{5} \mathrm{CFU} / \mathrm{g}$; while TCCs ranged from $8 \mathrm{MPN} / \mathrm{g}$ to $68 \mathrm{MPN} / \mathrm{g}$. From the 30 samples screened, 16(53.33\%) bacteria namely, Campylobacter 2(6.66\%), Escherichia coli 6(20\%), Klebsiella pneumoniae 2(6.66\%), Salmonella spp. 1(3.33\%), Shigella 3(10\%) and Staphylococcus aureus 2(6.66\%) were detected. $E$. coli has the highest isolation rate of 6(20\%), while Salmonella spp. had the least frequency of 1(3.33\%). The distribution of isolated organisms within the study area were as follows: Dausai, 4(80\%), Kofar kudu, 4(80\%), Makwalla, 2(40\%), Rinji, 3(60\%), Tosaro, 2(40\%), and Tsohuwar Kasuwa, 1(20\%). The results have indicated that the Tsire was contaminated with bacteria thus exposing the product to fast deterioration, spoilage and also a vehicle for food borne illness, suggesting for adequate hygienic practices at all the stages, prior to consumption, to ensure safety of the meat product.

Key words: APCs, TCCs, Contamination, Microorganisms, Garko

\section{INTRODUCTION}

Nigeria is one of the developing nations with inadequate food supply and most often deficient in protein content (FAO, 2019). Nigerian's average animal protein intake per head per day is estimated at $7.9 \mathrm{~g}$ as against $35 \mathrm{~g}$ recommended value by Food and Agricultural Organization (Mubarak et al., 2016). These low levels of animal protein intake create great concern as it affects the nutritional status of Nigerians. Hence, there is the need for sufficient supply of animal protein from energy rich animal products to satisfy the nutritional requirements for Nigerians.

Meat is one major source of animal protein largely composed of water, protein and fats which can make it susceptible to microbial contamination within short time leading to spoilage (Apata et al., 2013; Mgbemere et al., 2011). Meat is mostly eaten after it has been cooked or processed in a variety of ways such as sun drying; smoking and roasting with or without fortifications (Borch et al., 1996). In Nigeria meat products such as Tsire, Kilishi and Balangu are locally produced using one or more of these methods in order to meet the nutritional requirements of the teeming Nigerians (Egbebi, 2011).

Tsire is a popular Nigerian traditional processed ready-to-eat roasted stick meat product (Shamsuddeen, 2015). It is sold in public places, along roads, in hotels, parks, quarters and even offices (Falegan et al., 2017). It is prepared from boneless healthy animal flesh such as beef and mutton, spiced with peanut cake, salt, vegetable oil and other flavorings followed by roasting (Shamsuddeen, 2015). Consumption of these products has extended to other parts of African countries such as Ghana, Somali, Cameroun and Chad (Ahmadu and Ibrahim, 2013). 
BAJOPAS Volume 13 Number 1, June, 2020

However, evidence of quality control sticking to procedural hygiene by the handlers during preparation and retailing of these products is poorly documented. Tsire is of great safety risk because of the fact that there are erratic cases of gastroenteritis and symptoms of food infection after consumption (WHO, 2015). Food borne illnesses are one of the major health problems in developing and developed countries (Razavilar, 2010). According to the World Health Organization, WHO (2015), $0.07 \%$ death of the 600 million global burdens of Foodborne illnesses have been reported to be caused by bacteria, viruses, fungi and chemicals. In America $0.27 \%$ of the estimated 48 million affected people is hospitalized and about $0.0063 \%$ deaths are recorded each year (Scallan et al., 2011). More than 91 million people in Africa fall ill and $0.15 \%$ dies each year, making Africa the highest burden bearer of Foodborne diseases per population (WHO, 2015).

Application of a Hazard Analysis Critical Control Point (HACCP) at all stages of meat products preparation is essential in order to ensure its safety. Thus, according to the guidelines of good manufacturing practice, the level of total aerobic bacterial contamination of thermally processed meat products should not exceed $10^{4}\left(\mathrm{cfu} \mathrm{g}^{-1}\right)$. Enterobacteriaceae and faecal coliform contamination in meat products should be within the range of $10^{2}-10^{4}$ and $10-10^{3} \mathrm{cfu} \mathrm{g}^{-1}$, respectively (Shamsuddeen, 2015). The aim of the study is therefore, to assess the total viable bacterial counts of tsire marketed locally within Garko town, and to isolate and identify the organisms at the point of consumption with the intention of promoting public health and food hygiene habits in the Nigerian populace.

\section{MATERIALS AND METHODS Study Area and Population}

Garko is one of the existing 44 local government areas located in Kano south west zone of Kano state with its capital administrative headquarters in the Garko town. It has coordinates $11^{\circ} 39^{\prime} \mathrm{N}$ $8^{\circ} 54^{\prime} \mathrm{E}$, and an area of $450 \mathrm{~km}^{2}$. The projected population of Garko local Government was 225,300 according to the National Population Census report (2018). Garko is known for agricultural activities both farming and animal husbandry. It is popularly known for large scale rice production. Other food crops include sweet potatoes, cassava, onions, sorghum, millet and sugarcane. Cows, sheep and goats are major groups of animals reared by majority of the populace. Meat products processed, retailed and consumed in Garko include roasted meat (Balangu), dried roasted meat (Kilishi), stick meat (Tsire), hide and skin pepper soup (Ragadada) and minced fried meat (Danbunnama).

\section{Samples Collection}

Five samples of Tsire products were collected from 6 different identified locations within Garko town in a sterile foil paper and immediately analyzed for the presence of bacteria.

\section{Sample Preparation}

Sample preparation for the bacteriological analysis was carried out in accordance with the method described by Atlas (1997). Twenty five grams $(25 \mathrm{~g})$ of the sample was homogenized in $225 \mathrm{ml}$ peptone water using Kenwood blender machine to obtain a $10^{1}$ homogenate. The homogenate was thoroughly shaken and $1 \mathrm{ml}$ pipetted into test tubes containing $9 \mathrm{ml}$ of peptone water $\left(10^{2}\right)$. The test tubes were further serially diluted to $10^{5}$.

Total Aerobic Mesophilic Bacterial Count

Total Aerobic mesophilic bacterial count was determined using the method described by Abdullahi et al. (2004) where $1 \mathrm{ml}$ of inoculums from $10^{1}$ to $10^{5}$ dilutions were transferred into duplicate Petri dishes and labeled accordingly. This was followed by pouring aseptically about $15 \mathrm{ml}$ of molten nutrient agar. The culture was homogenized by gentle spinning of the plates and allowed to solidify. The plates were incubated at $37^{\circ} \mathrm{C}$ for 24 hours. Plates containing 30-300 colonies were counted. The number of colony forming units per gram of a sample (cfu/g) was obtained by multiplying the average colony number with the inverse of the dilution factor.

\section{Enumeration and Detection of Coliform bacteria}

Detection and enumeration of coliform was carried out according to method described by Atlas, (1977). A set of 9 test tubes each containing $9 \mathrm{ml}$ of lactose broth and an inverted Durham tubes were autoclaved to expel air and to sterilize. Similarly, $1 \mathrm{ml}$ from the diluents $10^{1}$ was transferred to the first 3 test tubes, followed by $1 \mathrm{ml}$ from the diluents $10^{2}$ to the second set of 3 test tubes and finally the third diluents $10^{3}$ to the $3^{\text {rd }}$ set of 3 test tubes. All the 9 test tubes were incubated at $37^{\circ} \mathrm{C}$ for 24 hours. Tubes that showed gas and acid production after 24 hours were recorded as positive for the presence of Coliform. Negative tubes were further reincubated for 24 hours. Positive tubes were recorded. Estimate of most probable number of Coliform per gram of sample (MPN/g) was determined by comparing the number of gas positive tubes with the most probable number table. 
BAJOPAS Volume 13 Number 1, June, 2020 Identification of Coliform

A loop full of inoculum from gas positive tubes was streaked on to Eosine methylene blue (EMB) agar plate and incubated at $37^{\circ} \mathrm{C}$ for $24 \mathrm{hrs}$. Colonies which formed bluish black color with green metallic sheen, and reddish colonies were isolated on agar slants. Those colonies showing metallic sheen on EMB were sub cultured into tubes of lactose broth and incubated at $45^{\circ} \mathrm{C}$. The tubes were observed after $24 \mathrm{hrs}$ for gas production. This is the completed test for fecal coliform. Gram stain and other biochemical tests such as Indole, Methyl red, Voges-Proskauer and Citrate Utilization tests (IMVIC), Coagulase and Catalase tests were carried out for the Identification and confirmation of isolates.

\section{Procedure for Indole Test}

Indole test was carried out by preparing a Tryptone broth drawn in to test tubes, sterilized by autoclaving, inoculated with loopful of suspension and incubated at $37^{\circ} \mathrm{C}$ for 24 hours. Three drops of xylene was added in tubes, shaken vigorously and kept for the separation of two layers. One millilitre of Kovac's reagent was added and the formation of pink colour ring indicates positive Indole test.

\section{Procedure for Methyl Red Test}

Methyl red test was carried out by preparing Glucose phosphate broth, dispensed in test tubes, sterilized, inoculated with test culture and incubated at $37^{\circ} \mathrm{C}$ for 24 hours. Five drops of methyl-red indicator was added to the medium for the formation of red colour.

\section{Procedure for Voges-Proskauer Test}

Voges-Proskauer test was carried out by inoculating tubes with the bacterial culture followed by incubation for 48 hours at $37^{\circ} \mathrm{C}$. Separate pipettes were used to pipette $1 \mathrm{ml}$ from each culture tube into clean separate tubes. Eighteen drops $(0.5 \mathrm{ml})$ of Barrit's solution A (a-naphthol) was added to each tube containing glucose phosphate broth followed by the addition of an equal amount of solution $B$ into the same tube. The tubes were shaken at 30 seconds interval. A positive reaction was indicated by the development of a pink color, which turns red in 1-2 hours, after vigorous shaking.

\section{Procedure for Citrate Utilization Test}

Citrate Utilization Test was carried out by distributing melted agar (Simmon Citrate Agar) in to test tubes followed by sterilization at $121.5^{\circ} \mathrm{C}$ for 15 minutes. The test tubes were afterward held in slanted position, inoculated with the given bacterial culture and incubated at $37^{\circ} \mathrm{C}$ for $24 \mathrm{hrs}$. Positive test was indicated by color change of the media from green to blue.

\section{RESULTS AND DISCUSSIONS}

The results of this study are presented in tables $1,2,3$ and 4. Among the sampling areas Kofar Kudu had the highest aerobic mesophilic bacteria counts $4.0 \times 10^{5} \mathrm{cfu} / \mathrm{g}$ followed by Rinji $2.72 \times 10^{5} \mathrm{cfu} / \mathrm{g}$, while Tosaro had the least Aerobic mesophilic bacteria counts of $1.02 \times 10^{5}$ $\mathrm{cfu} / \mathrm{g}$ as indicated in Table 1.Makwalla had the highest coliform count $68 \mathrm{MPN} / \mathrm{g}$ followed by Rinji $37 \mathrm{MPN} / \mathrm{g}$. Tsohuwar Kasuwa had the least coliform counts $8 \mathrm{MPN} / \mathrm{g}$, (Table 2). Result from table 1 shows variation in the microbial contents among the samples which suggest variation in their sources, poor handling procedures and contamination from the processing environment. High coliform count and their differences within sampling areas is an indication of poor microbiological quality of the product. Ndahi et al. (2013) reported microbial load to be a function of the handling personnel and the environment. The results indicated that the samples were contaminated with bacteria as the counts exceeded the minimum safety level $\left(10^{4} \mathrm{cfu} / \mathrm{g}\right)$ for members of the Enterobacteriaceae family. However, it might be a reflection of poor hygienic practices which may contribute to health hazard to the potential consumers. Similarly, Inusa and Sa'id (2017); Osimani et al. (2015) reported that, the initial microbial content of the raw material play significant role in influencing the final microbial load of the finished product. Isolation of members of the Enterobacteriaceae such as $E$. coli, Klebsiella pneumoniae, Salmonella and Shigella signifies danger to the public health. These organisms are capable of producing endotoxins which trigger high fevers in infected individuals, and the enterotoxins which colonize the small intestines and lead to extreme dehydration as a result of vomiting and diarrhea sometimes with severe and fatal outcomes (Amaeze et al., 2016). From the 16 isolated organisms $E$. coli had the highest isolation rate $6(37.5 \%)$ (Table 3), this suggest faecal contamination of the products. $E$. coli is a common flora in the gastrointestinal tract responsible for diarrhea and extra-intestinal infections (CDC, 2011). The result is in conformity with the findings of Ndahi et al. (2013) and Shamsuddeen (2009). Also presence of campylobacter might be due to cross contamination from raw meat to finished product (Tsire). Staphylococcus aureus is a normal flora of the skin, nasal, genital, mouth or anal area in both humans and animals without any symptom of an infection (Matthew et al., 2013). Isolation of $S$. aureus in these study concords with the findings of Lucretia et al. (2018) from Suya sold in Rivers State. 
BAJOPAS Volume 13 Number 1, June, 2020

It is also in agreement with the findings of Yousafzai et al. (2018); Onuorah et al. (2015) and Tijjani and Jumare (2014) from tsire samples in different countries. Presence of $S$. aureus in foods is most of the time an indication of poor human handling, poor environment, unhygienic utensils and equipments used during processing (Igene et al., 2016; Okonko et al., 2013). Infections caused by $S$. aureus are difficult to treat leading to long hospitalization with consequent economic loss (Udobi et al., 2013). These include soft tissue infections, pneumonia, hospital-acquired postoperative wound infections, Staphylococcal food poisoning, impetigo and cellulitis (Charlene et al., 2013). Samples obtained from Dausai and Kofar Kudu had the highest isolation rate $4(80 \%)$ (Table 4 ) probably because of the much commercial activities taking place in the area which can lead to environmental contamination.

Table 1: Total Aerobic Mesophilic Bacterial Count of Tsire sold in Garko Town

\begin{tabular}{lll}
\hline Sampling Area & APC cfu/g & Mean \pm STD \\
\hline Dausai & $2.20 \times 10^{5}$ & $110000 \pm 14142.14$ \\
Kofar Kudu & $4.00 \times 10^{5}$ & $133333.3 \pm 23094.01$ \\
Makwalla & $1.30 \times 10^{5}$ & $32500 \pm 7187.953$ \\
Rinji & $2.72 \times 10^{5}$ & $90666.67 \pm 94769.90$ \\
Tosaro & $1.02 \times 10^{5}$ & $51000 \pm 15556.35$ \\
Tsohuwar Kasuwa & $1.75 \times 10^{5}$ & $35000 \pm 11357.82$ \\
\hline
\end{tabular}

Key: APC: Aerobic Mesophilic Counts

STD: Standard Deviation

Table 2: Total Coliform Count of Tsire sold in Garko Town

\begin{tabular}{lcc}
\hline \multicolumn{1}{c}{ Sampling Area } & TCC MPN/g & Mean \pm STD \\
\hline Dausai & 20 & $6.67 \pm 2.5166$ \\
Kofar Kudu & 32 & $16.00 \pm 5.6569$ \\
Makwalla & 68 & $13.60 \pm 8.7062$ \\
Rinji & 37 & $9.25 \pm 4.7871$ \\
Tosaro & 10 & $5.00 \pm 2.8284$ \\
Tsohuwar Kasuwa & 8 & $4.00 \pm 0.0000$ \\
\hline
\end{tabular}

Table 3: Organisms Isolated from Tsire Sold in Garko

\begin{tabular}{lcl}
\hline Isolated Organism & Frequency & Percentage (\%) \\
\hline Campylobacter & 2 & 06.66 \\
Escherichia coli & 6 & 20.00 \\
Klebsiella pneumoniae & 2 & 06.66 \\
Salmonella species & 1 & 03.33 \\
Shigella & 3 & 10.00 \\
Staphylococcus aureus & 2 & 06.66 \\
Total & 16 & \\
\hline
\end{tabular}

Table 4: Distribution of Organisms within Sampling Area

\begin{tabular}{lcc}
\hline \multicolumn{1}{c}{ Sampling Area } & No. Isolated & Percentage (\%) \\
\hline Dausai & 4 & 80 \\
Kofar Kudu & 4 & 80 \\
Makwalla & 2 & 40 \\
Rinji & 3 & 60 \\
Tosaro & 2 & 40 \\
Tsohuwar Kasuwa & 1 & 20 \\
Total & 16 & \\
\hline
\end{tabular}

\section{CONCLUSION}

Results indicated $4.00 \times 10^{5} \mathrm{CFU} / \mathrm{g}$ as the highest APCs count; while $68 \mathrm{MPN} / \mathrm{g}$ was the highest TCCs from the 30 samples analyzed. Among the isolates, $E$. coli has the highest isolation rate of $6(20 \%)$. Dausai and Kofar kudu were having the highest bacteria count of $4(80 \%)$, each, indicating higher contamination in those locations. 
BAJOPAS Volume 13 Number 1, June, 2020 RECOMMENDATIONS

The following recommendations are tenable:

1. Hygienic practices at all stages of production should be improved to safe guard the consumers against potential health hazard.

2. Monitoring of microbiological contamination of Tsire during preparations, packaging and marketing is essential to ensure product of good microbiological quality for consumers' health.

\section{REFERENCES}

Abdullahi, I. O., Umoh, V. J. and Galadima, M. (2004). Hazards Associated with Kilishi Preparations in Zaria. Nigerian Journal of Microbiology, 18 (1-2): $339-345$.

Ahmadu, J. and Ibrahim E. J., (2013): Determinants of Revenue in Suya Production in BeninCity, Edo State, Nigeria. Nigerian journal of agriculture, food and environment.9(3):1-5

Amaeze, N. Aboh, M. Itohan, A. Felix, E. Olatunji, T. and Oladosu, P. (2016) Microbial Profile, Antibiotic Sensitivity and Heat Resistance of Bacterial Isolates from Commercial Roasted Beef (Suya) in Abuja, Nigeria. JOPAT, 15(2): $22-30$.

Apata, E.S., Kuku1, I.A., Apata, O.C. and Adeyemi, K.O. (2013). Evaluation of Suya(Tsire) - An Intermediate Moisture Meat Product in Ogun State, Nigeria. J. Food Res 2 (1): 87.

Atlas, R. M. (1997) Principles of Microbiology Second Edition. C. Brown Publishers. Pp 802-803.

Borch, E. Kant-Muermans, M. L., Blixt, Y. (1996) Bacterial Spoilage of Meat and Cured Meat Products. Int $\mathrm{J}$ Food Microbiol .33(1): 103-20.

Centre for Disease Control, CDC (2011). "Escherichia coli 0157:H7" Division of Bacterial and Mycotic Diseasesht://www.cdc.gov/nczved/divisi ons/dfbmd/diseases/ecoli_0157h7/.

Charlene, R. J., Johnnie, A. D., and John, B. B., (2013) Prevalence and Characterization of Methicillin-Resistant Staphylococcus aureus Isolates from Retail Meat and Humans in Georgia. American society for Microbiology. J. of clinical microbiology. 12(1):123-6 doi:10.1128/JCM.0316612JCM.03166-12

Egbebi, A.O and Seidu, K., T. (2011). Microbiological Evaluation of Suya (dried smoked

meat) Sold in Ado and Akure, South West Nigeria.European Journal of Experinmental Biology, 1(4):1-5
3. Government should establish regulatory bodies responsible for inculcating hygiene habits to the local producers and vendors in order to prevent instant, cross and post processing contaminations by microbial pathogens.

4. Awareness and sensitization of local food producers about good hygienic practices in food handling and processing.

Falegan, C, R., Akoja, S. D., and Oyarekua, M. A., (2017) Microbiological Assessment of Suya (Sliced Roasted Beef) in Ado-Ekiti Metropolis, Ekiti State, Nigeria. MOJ Biology andMedicine.

Fonkem, D., N. Tanya, V., N. and Ebangi, A., L. (2010). Effect of Season on the Microbiological Quality of Kilishi, a Traditional Cameroonian Dried Beef Product. Tropicultura, 28(1): 10-15.

Food and Agricultural Organization of the United Nations (F A O, 1979). Manual of food quality control 4. Microbiological analysis.

Food and Agriculture Organisation of the United Nation (FAO), 2019. Nigeria at a glance.

Igene J.O., Uwadia, O.E., Ebabhamiegbebho, P.A. and Evivie, S.E., (2016) Shelf life Stability Studies of University of Benin (UNIBEN) Proff's Kilishi Product Asian Journal of Science and Technology 7(1): 2268-2274.

Inusa, S. K. and Said, I. S. (2017) Evaluation of the Chemical and Microbiological Properties Of Kilishi Sold in Kano Metropolis. Journal of Dry land Agriculture, 3 (1): $59-69$.

Lucretia, I. B, Patience, C. Obinna-Echem, Sophia, C. A. (2018) Microbiological quality andantibiotic sensitivity of potential pathogens isolated from meat product (Suya) sold in Rivers State University and its environs. International Journal of Biotechnology and Food Science, 6(4): 67-76.

Matthew, E., Drosos, E., John, L. and Ioanna, P. (2013) MRSA in Africa: Filling the Global Map of Antimicrobial Resistance PLOS One. 8(7): e68024 doi: 10.1371/journal.pone.0068024

Mgbemere, V.N., Akpapunam, M. A. and Igene, J. O., (2011). Effect of Groundnut FlourSubstitution on Yield, Quality and Storage Stability of Kilishi - a Nigerian Indigenous Dried Meat Product. African Journal of Food, Agriculture, Nutrition and Development, $\quad \mathbf{1 1}(2)$ : 4718-4738. 
BAJOPAS Volume 13 Number 1, June, 2020

Mubarak, A. A., Azeez, M. L., Amos A. O., Opeyemi, O. O. (2016) Assessment of Animal Protein Consumption and Food Security Among Rural Households in Kwara State, Nigeria American Journal of Business and Society, 1(4): 233245.

Ndahi, M., D. Kwaga, J., K. P. Bello, M. Kabir J., V. Umoh, .J. Yakubu, S., E. and Nok, A., J. (2013) Prevalence and Antimicrobial Susceptibility of Listeria Monocytogenes and Methicillin-Resistant Staphylococcus aureus Strains from Raw Meat and Meat Products in Zaria, Nigeria. Applied Journal of Microbiology, 58(3):262-9.

Okonko, I.O., Odu, N.N. and Igboh, I.E. (2013). Microbiological Analysis of Kilishi Sold In Port Harcourt, Nigeria. New York Science Journal, 6 (7):37-43.

Osimani, A., Aquilanti, L. and Clementi, F. (2015) Microbiological Quality of Meatbased Meals and Operation of Control Systems within a Food Service Environment. International Food Research Journal 22(4): 1692-1698.

Onuorah, S. Obika, I. Odibo, F. Orji, M. (2015)An Assessment of the Bacteriological Quality of Tsire-Suya (Grilled Beef) sold in Awka, Nigeria. American. J. Life. Sci. Res. 3(4):287292.

Razavilar, V, Khandaghi, J. Barzgari, A. (2010); Isolation of Eschericia coli 0157:H7 from manure fertilized farms and raw vegetables grown on it, in Tabriz city in
Iran. African Journal of Microbiology Research, 4(9): 891-895.

Scallan, E. Hoekstra, R. M. Angulo, F. J.Tauxe, R. V, Widdowson, M. Roy, S. L et al., (2011).Food borne illness acquired in the United States- Major Pathogens. Emerg. Infec Dis, 17(1): 7-15.

Shamsuddeen U (2009). Microbiological quality of spice used in the production of Kilishi a traditionally dried and grilled meat product. Bayero Journal of Pure andApplied Sciences, 2(2): 66-69.

Shamsuddeen, U. (2015) Microbiological Hazard and Critical control point Analysis of Dried and Minced Meat Snacks Produced in Kano Nigeria. Lambert Academic Publishing; Pp 1-36.

Tijani, O.and Jumare, S. (2014). Microblological Quality Assessment of Meat

Sold in KauraNamoda. International Conference on Earth, Environment and Life sciences (EELS) Dubai (UAE).

Udobi, C. E., Obajuluwa, A. F., and Onaolapo, J. A., (2013) Prevalence and Antibiotic Resistance Pattern of MethicillinResistant Staphylococcus aureus from an Orthopaedic Hospital in Nigeria BioMed Research International; 26(6); 6-7.

WHO, 2015 Foodborne diseases in the WHO African Region.

Yousafzai HA, Rind R, Khan MA, Abro SH, Korejo NA, Ejaz M, Kabir A, Shahid M, Memon S. (2019). Microbiological Contamination of Cattle and Meat in Peshawar, Pakistan. J. Anim. Health Prod. 7(1): 1116. 


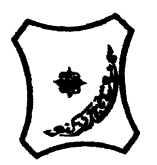

Bayero Journal of Pure and Applied Sciences, 13(1); 40 - 45

Received: September, 2019

Accepted: April, 2020

ISSN $2006-6996$

\title{
BACTERIOLOGICAL QUALITY OF STICK MEAT (Tsire) SOLD IN GARKO LOCAL GOVERNMENT AREA OF KANO STATE, NIGERIA
}

\author{
$*^{1}$ Dahiru A. T. and ${ }^{2}$ Maigari A. K. \\ ${ }^{1}$ Department of Hospitality Management, School of Technology, Kano State Polytechnic, PMB 3348, \\ Kano Nigeria. \\ ${ }^{2}$ Departmnt of Biological Sciences, Bayero University, Kano \\ Corresponding Author: dturajo61@gmail.com; GSM: 08087508262.
}

ABSTRACT

Stick meat, locally called Tsire in Hausa Language, is a significant portion of the diet of a large active population of Northern Nigeria. However, because of the handling and processing methods by the manufacturers as well as the hawking system of stick meat, the meat product may be exposed to both pre- and post-processed product contamination, and thus may poses danger to public health. Therefore, considering the role of Tsire in improving nutrition and increase household income to the populace, the need to improve the processing, distribution and overall quality of the product is simply indispensable. A total of 30 samples (5 samples from each of the 6 sampling points) of Tsire were collected randomly in Garko Town. Aerobic plate counts (APCs) and Total coliform counts (TCCS) of Tsire samples were determined using standard microbiological methods. APCs ranged from $1.02 \times 10^{5}$ to $4.00 \times 10^{5} \mathrm{CFU} / \mathrm{g}$; while TCCs ranged from $8 \mathrm{MPN} / \mathrm{g}$ to $68 \mathrm{MPN} / \mathrm{g}$. From the 30 samples screened, 16(53.33\%) bacteria namely, Campylobacter 2(6.66\%), Escherichia coli 6(20\%), Klebsiella pneumoniae 2(6.66\%), Salmonella spp. 1(3.33\%), Shigella 3(10\%) and Staphylococcus aureus 2(6.66\%) were detected. $E$. coli has the highest isolation rate of 6(20\%), while Salmonella spp. had the least frequency of 1(3.33\%). The distribution of isolated organisms within the study area were as follows: Dausai, 4(80\%), Kofar kudu, 4(80\%), Makwalla, 2(40\%), Rinji, 3(60\%), Tosaro, 2(40\%), and Tsohuwar Kasuwa, 1(20\%). The results have indicated that the Tsire was contaminated with bacteria thus exposing the product to fast deterioration, spoilage and also a vehicle for food borne illness, suggesting for adequate hygienic practices at all the stages, prior to consumption, to ensure safety of the meat product.

Key words: APCs, TCCs, Contamination, Microorganisms, Garko

\section{INTRODUCTION}

Nigeria is one of the developing nations with inadequate food supply and most often deficient in protein content (FAO, 2019). Nigerian's average animal protein intake per head per day is estimated at $7.9 \mathrm{~g}$ as against $35 \mathrm{~g}$ recommended value by Food and Agricultural Organization (Mubarak et al., 2016). These low levels of animal protein intake create great concern as it affects the nutritional status of Nigerians. Hence, there is the need for sufficient supply of animal protein from energy rich animal products to satisfy the nutritional requirements for Nigerians.

Meat is one major source of animal protein largely composed of water, protein and fats which can make it susceptible to microbial contamination within short time leading to spoilage (Apata et al., 2013; Mgbemere et al., 2011). Meat is mostly eaten after it has been cooked or processed in a variety of ways such as sun drying; smoking and roasting with or without fortifications (Borch et al., 1996). In Nigeria meat products such as Tsire, Kilishi and Balangu are locally produced using one or more of these methods in order to meet the nutritional requirements of the teeming Nigerians (Egbebi, 2011).

Tsire is a popular Nigerian traditional processed ready-to-eat roasted stick meat product (Shamsuddeen, 2015). It is sold in public places, along roads, in hotels, parks, quarters and even offices (Falegan et al., 2017). It is prepared from boneless healthy animal flesh such as beef and mutton, spiced with peanut cake, salt, vegetable oil and other flavorings followed by roasting (Shamsuddeen, 2015). Consumption of these products has extended to other parts of African countries such as Ghana, Somali, Cameroun and Chad (Ahmadu and Ibrahim, 2013). 
BAJOPAS Volume 13 Number 1, June, 2020

However, evidence of quality control sticking to procedural hygiene by the handlers during preparation and retailing of these products is poorly documented. Tsire is of great safety risk because of the fact that there are erratic cases of gastroenteritis and symptoms of food infection after consumption (WHO, 2015). Food borne illnesses are one of the major health problems in developing and developed countries (Razavilar, 2010). According to the World Health Organization, WHO (2015), $0.07 \%$ death of the 600 million global burdens of Foodborne illnesses have been reported to be caused by bacteria, viruses, fungi and chemicals. In America $0.27 \%$ of the estimated 48 million affected people is hospitalized and about $0.0063 \%$ deaths are recorded each year (Scallan et al., 2011). More than 91 million people in Africa fall ill and $0.15 \%$ dies each year, making Africa the highest burden bearer of Foodborne diseases per population (WHO, 2015).

Application of a Hazard Analysis Critical Control Point (HACCP) at all stages of meat products preparation is essential in order to ensure its safety. Thus, according to the guidelines of good manufacturing practice, the level of total aerobic bacterial contamination of thermally processed meat products should not exceed $10^{4}\left(\mathrm{cfu} \mathrm{g}^{-1}\right)$. Enterobacteriaceae and faecal coliform contamination in meat products should be within the range of $10^{2}-10^{4}$ and $10-10^{3} \mathrm{cfu} \mathrm{g}^{-1}$, respectively (Shamsuddeen, 2015). The aim of the study is therefore, to assess the total viable bacterial counts of tsire marketed locally within Garko town, and to isolate and identify the organisms at the point of consumption with the intention of promoting public health and food hygiene habits in the Nigerian populace.

\section{MATERIALS AND METHODS Study Area and Population}

Garko is one of the existing 44 local government areas located in Kano south west zone of Kano state with its capital administrative headquarters in the Garko town. It has coordinates $11^{\circ} 39^{\prime} \mathrm{N}$ $8^{\circ} 54^{\prime} \mathrm{E}$, and an area of $450 \mathrm{~km}^{2}$. The projected population of Garko local Government was 225,300 according to the National Population Census report (2018). Garko is known for agricultural activities both farming and animal husbandry. It is popularly known for large scale rice production. Other food crops include sweet potatoes, cassava, onions, sorghum, millet and sugarcane. Cows, sheep and goats are major groups of animals reared by majority of the populace. Meat products processed, retailed and consumed in Garko include roasted meat (Balangu), dried roasted meat (Kilishi), stick meat (Tsire), hide and skin pepper soup (Ragadada) and minced fried meat (Danbunnama).

\section{Samples Collection}

Five samples of Tsire products were collected from 6 different identified locations within Garko town in a sterile foil paper and immediately analyzed for the presence of bacteria.

\section{Sample Preparation}

Sample preparation for the bacteriological analysis was carried out in accordance with the method described by Atlas (1997). Twenty five grams $(25 \mathrm{~g})$ of the sample was homogenized in $225 \mathrm{ml}$ peptone water using Kenwood blender machine to obtain a $10^{1}$ homogenate. The homogenate was thoroughly shaken and $1 \mathrm{ml}$ pipetted into test tubes containing $9 \mathrm{ml}$ of peptone water $\left(10^{2}\right)$. The test tubes were further serially diluted to $10^{5}$.

Total Aerobic Mesophilic Bacterial Count

Total Aerobic mesophilic bacterial count was determined using the method described by Abdullahi et al. (2004) where $1 \mathrm{ml}$ of inoculums from $10^{1}$ to $10^{5}$ dilutions were transferred into duplicate Petri dishes and labeled accordingly. This was followed by pouring aseptically about $15 \mathrm{ml}$ of molten nutrient agar. The culture was homogenized by gentle spinning of the plates and allowed to solidify. The plates were incubated at $37^{\circ} \mathrm{C}$ for 24 hours. Plates containing 30-300 colonies were counted. The number of colony forming units per gram of a sample (cfu/g) was obtained by multiplying the average colony number with the inverse of the dilution factor.

\section{Enumeration and Detection of Coliform bacteria}

Detection and enumeration of coliform was carried out according to method described by Atlas, (1977). A set of 9 test tubes each containing $9 \mathrm{ml}$ of lactose broth and an inverted Durham tubes were autoclaved to expel air and to sterilize. Similarly, $1 \mathrm{ml}$ from the diluents $10^{1}$ was transferred to the first 3 test tubes, followed by $1 \mathrm{ml}$ from the diluents $10^{2}$ to the second set of 3 test tubes and finally the third diluents $10^{3}$ to the $3^{\text {rd }}$ set of 3 test tubes. All the 9 test tubes were incubated at $37^{\circ} \mathrm{C}$ for 24 hours. Tubes that showed gas and acid production after 24 hours were recorded as positive for the presence of Coliform. Negative tubes were further reincubated for 24 hours. Positive tubes were recorded. Estimate of most probable number of Coliform per gram of sample (MPN/g) was determined by comparing the number of gas positive tubes with the most probable number table. 
BAJOPAS Volume 13 Number 1, June, 2020 Identification of Coliform

A loop full of inoculum from gas positive tubes was streaked on to Eosine methylene blue (EMB) agar plate and incubated at $37^{\circ} \mathrm{C}$ for $24 \mathrm{hrs}$. Colonies which formed bluish black color with green metallic sheen, and reddish colonies were isolated on agar slants. Those colonies showing metallic sheen on EMB were sub cultured into tubes of lactose broth and incubated at $45^{\circ} \mathrm{C}$. The tubes were observed after $24 \mathrm{hrs}$ for gas production. This is the completed test for fecal coliform. Gram stain and other biochemical tests such as Indole, Methyl red, Voges-Proskauer and Citrate Utilization tests (IMVIC), Coagulase and Catalase tests were carried out for the Identification and confirmation of isolates.

\section{Procedure for Indole Test}

Indole test was carried out by preparing a Tryptone broth drawn in to test tubes, sterilized by autoclaving, inoculated with loopful of suspension and incubated at $37^{\circ} \mathrm{C}$ for 24 hours. Three drops of xylene was added in tubes, shaken vigorously and kept for the separation of two layers. One millilitre of Kovac's reagent was added and the formation of pink colour ring indicates positive Indole test.

\section{Procedure for Methyl Red Test}

Methyl red test was carried out by preparing Glucose phosphate broth, dispensed in test tubes, sterilized, inoculated with test culture and incubated at $37^{\circ} \mathrm{C}$ for 24 hours. Five drops of methyl-red indicator was added to the medium for the formation of red colour.

\section{Procedure for Voges-Proskauer Test}

Voges-Proskauer test was carried out by inoculating tubes with the bacterial culture followed by incubation for 48 hours at $37^{\circ} \mathrm{C}$. Separate pipettes were used to pipette $1 \mathrm{ml}$ from each culture tube into clean separate tubes. Eighteen drops $(0.5 \mathrm{ml})$ of Barrit's solution A (a-naphthol) was added to each tube containing glucose phosphate broth followed by the addition of an equal amount of solution $B$ into the same tube. The tubes were shaken at 30 seconds interval. A positive reaction was indicated by the development of a pink color, which turns red in 1-2 hours, after vigorous shaking.

\section{Procedure for Citrate Utilization Test}

Citrate Utilization Test was carried out by distributing melted agar (Simmon Citrate Agar) in to test tubes followed by sterilization at $121.5^{\circ} \mathrm{C}$ for 15 minutes. The test tubes were afterward held in slanted position, inoculated with the given bacterial culture and incubated at $37^{\circ} \mathrm{C}$ for $24 \mathrm{hrs}$. Positive test was indicated by color change of the media from green to blue.

\section{RESULTS AND DISCUSSIONS}

The results of this study are presented in tables $1,2,3$ and 4. Among the sampling areas Kofar Kudu had the highest aerobic mesophilic bacteria counts $4.0 \times 10^{5} \mathrm{cfu} / \mathrm{g}$ followed by Rinji $2.72 \times 10^{5} \mathrm{cfu} / \mathrm{g}$, while Tosaro had the least Aerobic mesophilic bacteria counts of $1.02 \times 10^{5}$ $\mathrm{cfu} / \mathrm{g}$ as indicated in Table 1.Makwalla had the highest coliform count $68 \mathrm{MPN} / \mathrm{g}$ followed by Rinji $37 \mathrm{MPN} / \mathrm{g}$. Tsohuwar Kasuwa had the least coliform counts $8 \mathrm{MPN} / \mathrm{g}$, (Table 2). Result from table 1 shows variation in the microbial contents among the samples which suggest variation in their sources, poor handling procedures and contamination from the processing environment. High coliform count and their differences within sampling areas is an indication of poor microbiological quality of the product. Ndahi et al. (2013) reported microbial load to be a function of the handling personnel and the environment. The results indicated that the samples were contaminated with bacteria as the counts exceeded the minimum safety level $\left(10^{4} \mathrm{cfu} / \mathrm{g}\right)$ for members of the Enterobacteriaceae family. However, it might be a reflection of poor hygienic practices which may contribute to health hazard to the potential consumers. Similarly, Inusa and Sa'id (2017); Osimani et al. (2015) reported that, the initial microbial content of the raw material play significant role in influencing the final microbial load of the finished product. Isolation of members of the Enterobacteriaceae such as $E$. coli, Klebsiella pneumoniae, Salmonella and Shigella signifies danger to the public health. These organisms are capable of producing endotoxins which trigger high fevers in infected individuals, and the enterotoxins which colonize the small intestines and lead to extreme dehydration as a result of vomiting and diarrhea sometimes with severe and fatal outcomes (Amaeze et al., 2016). From the 16 isolated organisms $E$. coli had the highest isolation rate $6(37.5 \%)$ (Table 3), this suggest faecal contamination of the products. $E$. coli is a common flora in the gastrointestinal tract responsible for diarrhea and extra-intestinal infections (CDC, 2011). The result is in conformity with the findings of Ndahi et al. (2013) and Shamsuddeen (2009). Also presence of campylobacter might be due to cross contamination from raw meat to finished product (Tsire). Staphylococcus aureus is a normal flora of the skin, nasal, genital, mouth or anal area in both humans and animals without any symptom of an infection (Matthew et al., 2013). Isolation of $S$. aureus in these study concords with the findings of Lucretia et al. (2018) from Suya sold in Rivers State. 
BAJOPAS Volume 13 Number 1, June, 2020

It is also in agreement with the findings of Yousafzai et al. (2018); Onuorah et al. (2015) and Tijjani and Jumare (2014) from tsire samples in different countries. Presence of $S$. aureus in foods is most of the time an indication of poor human handling, poor environment, unhygienic utensils and equipments used during processing (Igene et al., 2016; Okonko et al., 2013). Infections caused by $S$. aureus are difficult to treat leading to long hospitalization with consequent economic loss (Udobi et al., 2013). These include soft tissue infections, pneumonia, hospital-acquired postoperative wound infections, Staphylococcal food poisoning, impetigo and cellulitis (Charlene et al., 2013). Samples obtained from Dausai and Kofar Kudu had the highest isolation rate $4(80 \%)$ (Table 4 ) probably because of the much commercial activities taking place in the area which can lead to environmental contamination.

Table 1: Total Aerobic Mesophilic Bacterial Count of Tsire sold in Garko Town

\begin{tabular}{lll}
\hline Sampling Area & APC cfu/g & Mean \pm STD \\
\hline Dausai & $2.20 \times 10^{5}$ & $110000 \pm 14142.14$ \\
Kofar Kudu & $4.00 \times 10^{5}$ & $133333.3 \pm 23094.01$ \\
Makwalla & $1.30 \times 10^{5}$ & $32500 \pm 7187.953$ \\
Rinji & $2.72 \times 10^{5}$ & $90666.67 \pm 94769.90$ \\
Tosaro & $1.02 \times 10^{5}$ & $51000 \pm 15556.35$ \\
Tsohuwar Kasuwa & $1.75 \times 10^{5}$ & $35000 \pm 11357.82$ \\
\hline
\end{tabular}

Key: APC: Aerobic Mesophilic Counts

STD: Standard Deviation

Table 2: Total Coliform Count of Tsire sold in Garko Town

\begin{tabular}{lcc}
\hline \multicolumn{1}{c}{ Sampling Area } & TCC MPN/g & Mean \pm STD \\
\hline Dausai & 20 & $6.67 \pm 2.5166$ \\
Kofar Kudu & 32 & $16.00 \pm 5.6569$ \\
Makwalla & 68 & $13.60 \pm 8.7062$ \\
Rinji & 37 & $9.25 \pm 4.7871$ \\
Tosaro & 10 & $5.00 \pm 2.8284$ \\
Tsohuwar Kasuwa & 8 & $4.00 \pm 0.0000$ \\
\hline
\end{tabular}

Table 3: Organisms Isolated from Tsire Sold in Garko

\begin{tabular}{lcl}
\hline Isolated Organism & Frequency & Percentage (\%) \\
\hline Campylobacter & 2 & 06.66 \\
Escherichia coli & 6 & 20.00 \\
Klebsiella pneumoniae & 2 & 06.66 \\
Salmonella species & 1 & 03.33 \\
Shigella & 3 & 10.00 \\
Staphylococcus aureus & 2 & 06.66 \\
Total & 16 & \\
\hline
\end{tabular}

Table 4: Distribution of Organisms within Sampling Area

\begin{tabular}{lcc}
\hline \multicolumn{1}{c}{ Sampling Area } & No. Isolated & Percentage (\%) \\
\hline Dausai & 4 & 80 \\
Kofar Kudu & 4 & 80 \\
Makwalla & 2 & 40 \\
Rinji & 3 & 60 \\
Tosaro & 2 & 40 \\
Tsohuwar Kasuwa & 1 & 20 \\
Total & 16 & \\
\hline
\end{tabular}

\section{CONCLUSION}

Results indicated $4.00 \times 10^{5} \mathrm{CFU} / \mathrm{g}$ as the highest APCs count; while $68 \mathrm{MPN} / \mathrm{g}$ was the highest TCCs from the 30 samples analyzed. Among the isolates, $E$. coli has the highest isolation rate of $6(20 \%)$. Dausai and Kofar kudu were having the highest bacteria count of $4(80 \%)$, each, indicating higher contamination in those locations. 
BAJOPAS Volume 13 Number 1, June, 2020 RECOMMENDATIONS

The following recommendations are tenable:

1. Hygienic practices at all stages of production should be improved to safe guard the consumers against potential health hazard.

2. Monitoring of microbiological contamination of Tsire during preparations, packaging and marketing is essential to ensure product of good microbiological quality for consumers' health.

\section{REFERENCES}

Abdullahi, I. O., Umoh, V. J. and Galadima, M. (2004). Hazards Associated with Kilishi Preparations in Zaria. Nigerian Journal of Microbiology, 18 (1-2): $339-345$.

Ahmadu, J. and Ibrahim E. J., (2013): Determinants of Revenue in Suya Production in BeninCity, Edo State, Nigeria. Nigerian journal of agriculture, food and environment.9(3):1-5

Amaeze, N. Aboh, M. Itohan, A. Felix, E. Olatunji, T. and Oladosu, P. (2016) Microbial Profile, Antibiotic Sensitivity and Heat Resistance of Bacterial Isolates from Commercial Roasted Beef (Suya) in Abuja, Nigeria. JOPAT, 15(2): $22-30$.

Apata, E.S., Kuku1, I.A., Apata, O.C. and Adeyemi, K.O. (2013). Evaluation of Suya(Tsire) - An Intermediate Moisture Meat Product in Ogun State, Nigeria. J. Food Res 2 (1): 87.

Atlas, R. M. (1997) Principles of Microbiology Second Edition. C. Brown Publishers. Pp 802-803.

Borch, E. Kant-Muermans, M. L., Blixt, Y. (1996) Bacterial Spoilage of Meat and Cured Meat Products. Int $\mathrm{J}$ Food Microbiol .33(1): 103-20.

Centre for Disease Control, CDC (2011). "Escherichia coli 0157:H7" Division of Bacterial and Mycotic Diseasesht://www.cdc.gov/nczved/divisi ons/dfbmd/diseases/ecoli_0157h7/.

Charlene, R. J., Johnnie, A. D., and John, B. B., (2013) Prevalence and Characterization of Methicillin-Resistant Staphylococcus aureus Isolates from Retail Meat and Humans in Georgia. American society for Microbiology. J. of clinical microbiology. 12(1):123-6 doi:10.1128/JCM.0316612JCM.03166-12

Egbebi, A.O and Seidu, K., T. (2011). Microbiological Evaluation of Suya (dried smoked

meat) Sold in Ado and Akure, South West Nigeria.European Journal of Experinmental Biology, 1(4):1-5
3. Government should establish regulatory bodies responsible for inculcating hygiene habits to the local producers and vendors in order to prevent instant, cross and post processing contaminations by microbial pathogens.

4. Awareness and sensitization of local food producers about good hygienic practices in food handling and processing.

Falegan, C, R., Akoja, S. D., and Oyarekua, M. A., (2017) Microbiological Assessment of Suya (Sliced Roasted Beef) in Ado-Ekiti Metropolis, Ekiti State, Nigeria. MOJ Biology andMedicine.

Fonkem, D., N. Tanya, V., N. and Ebangi, A., L. (2010). Effect of Season on the Microbiological Quality of Kilishi, a Traditional Cameroonian Dried Beef Product. Tropicultura, 28(1): 10-15.

Food and Agricultural Organization of the United Nations (F A O, 1979). Manual of food quality control 4. Microbiological analysis.

Food and Agriculture Organisation of the United Nation (FAO), 2019. Nigeria at a glance.

Igene J.O., Uwadia, O.E., Ebabhamiegbebho, P.A. and Evivie, S.E., (2016) Shelf life Stability Studies of University of Benin (UNIBEN) Proff's Kilishi Product Asian Journal of Science and Technology 7(1): 2268-2274.

Inusa, S. K. and Said, I. S. (2017) Evaluation of the Chemical and Microbiological Properties Of Kilishi Sold in Kano Metropolis. Journal of Dry land Agriculture, 3 (1): $59-69$.

Lucretia, I. B, Patience, C. Obinna-Echem, Sophia, C. A. (2018) Microbiological quality andantibiotic sensitivity of potential pathogens isolated from meat product (Suya) sold in Rivers State University and its environs. International Journal of Biotechnology and Food Science, 6(4): 67-76.

Matthew, E., Drosos, E., John, L. and Ioanna, P. (2013) MRSA in Africa: Filling the Global Map of Antimicrobial Resistance PLOS One. 8(7): e68024 doi: 10.1371/journal.pone.0068024

Mgbemere, V.N., Akpapunam, M. A. and Igene, J. O., (2011). Effect of Groundnut FlourSubstitution on Yield, Quality and Storage Stability of Kilishi - a Nigerian Indigenous Dried Meat Product. African Journal of Food, Agriculture, Nutrition and Development, $\quad \mathbf{1 1}(2)$ : 4718-4738. 
BAJOPAS Volume 13 Number 1, June, 2020

Mubarak, A. A., Azeez, M. L., Amos A. O., Opeyemi, O. O. (2016) Assessment of Animal Protein Consumption and Food Security Among Rural Households in Kwara State, Nigeria American Journal of Business and Society, 1(4): 233245.

Ndahi, M., D. Kwaga, J., K. P. Bello, M. Kabir J., V. Umoh, .J. Yakubu, S., E. and Nok, A., J. (2013) Prevalence and Antimicrobial Susceptibility of Listeria Monocytogenes and Methicillin-Resistant Staphylococcus aureus Strains from Raw Meat and Meat Products in Zaria, Nigeria. Applied Journal of Microbiology, 58(3):262-9.

Okonko, I.O., Odu, N.N. and Igboh, I.E. (2013). Microbiological Analysis of Kilishi Sold In Port Harcourt, Nigeria. New York Science Journal, 6 (7):37-43.

Osimani, A., Aquilanti, L. and Clementi, F. (2015) Microbiological Quality of Meatbased Meals and Operation of Control Systems within a Food Service Environment. International Food Research Journal 22(4): 1692-1698.

Onuorah, S. Obika, I. Odibo, F. Orji, M. (2015)An Assessment of the Bacteriological Quality of Tsire-Suya (Grilled Beef) sold in Awka, Nigeria. American. J. Life. Sci. Res. 3(4):287292.

Razavilar, V, Khandaghi, J. Barzgari, A. (2010); Isolation of Eschericia coli 0157:H7 from manure fertilized farms and raw vegetables grown on it, in Tabriz city in
Iran. African Journal of Microbiology Research, 4(9): 891-895.

Scallan, E. Hoekstra, R. M. Angulo, F. J.Tauxe, R. V, Widdowson, M. Roy, S. L et al., (2011).Food borne illness acquired in the United States- Major Pathogens. Emerg. Infec Dis, 17(1): 7-15.

Shamsuddeen U (2009). Microbiological quality of spice used in the production of Kilishi a traditionally dried and grilled meat product. Bayero Journal of Pure andApplied Sciences, 2(2): 66-69.

Shamsuddeen, U. (2015) Microbiological Hazard and Critical control point Analysis of Dried and Minced Meat Snacks Produced in Kano Nigeria. Lambert Academic Publishing; Pp 1-36.

Tijani, O.and Jumare, S. (2014). Microblological Quality Assessment of Meat

Sold in KauraNamoda. International Conference on Earth, Environment and Life sciences (EELS) Dubai (UAE).

Udobi, C. E., Obajuluwa, A. F., and Onaolapo, J. A., (2013) Prevalence and Antibiotic Resistance Pattern of MethicillinResistant Staphylococcus aureus from an Orthopaedic Hospital in Nigeria BioMed Research International; 26(6); 6-7.

WHO, 2015 Foodborne diseases in the WHO African Region.

Yousafzai HA, Rind R, Khan MA, Abro SH, Korejo NA, Ejaz M, Kabir A, Shahid M, Memon S. (2019). Microbiological Contamination of Cattle and Meat in Peshawar, Pakistan. J. Anim. Health Prod. 7(1): 1116. 


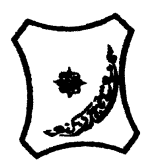

Bayero Journal of Pure and Applied Sciences, 13(1); 40 - 45

Received: September, 2019

Accepted: April, 2020

ISSN $2006-6996$

\title{
BACTERIOLOGICAL QUALITY OF STICK MEAT (Tsire) SOLD IN GARKO LOCAL GOVERNMENT AREA OF KANO STATE, NIGERIA
}

\author{
$*^{1}$ Dahiru A. T. and ${ }^{2}$ Maigari A. K. \\ ${ }^{1}$ Department of Hospitality Management, School of Technology, Kano State Polytechnic, PMB 3348, \\ Kano Nigeria. \\ ${ }^{2}$ Departmnt of Biological Sciences, Bayero University, Kano \\ Corresponding Author: dturajo61@gmail.com; GSM: 08087508262.
}

ABSTRACT

Stick meat, locally called Tsire in Hausa Language, is a significant portion of the diet of a large active population of Northern Nigeria. However, because of the handling and processing methods by the manufacturers as well as the hawking system of stick meat, the meat product may be exposed to both pre- and post-processed product contamination, and thus may poses danger to public health. Therefore, considering the role of Tsire in improving nutrition and increase household income to the populace, the need to improve the processing, distribution and overall quality of the product is simply indispensable. A total of 30 samples (5 samples from each of the 6 sampling points) of Tsire were collected randomly in Garko Town. Aerobic plate counts (APCs) and Total coliform counts (TCCS) of Tsire samples were determined using standard microbiological methods. APCs ranged from $1.02 \times 10^{5}$ to $4.00 \times 10^{5} \mathrm{CFU} / \mathrm{g}$; while TCCs ranged from $8 \mathrm{MPN} / \mathrm{g}$ to $68 \mathrm{MPN} / \mathrm{g}$. From the 30 samples screened, 16(53.33\%) bacteria namely, Campylobacter 2(6.66\%), Escherichia coli 6(20\%), Klebsiella pneumoniae 2(6.66\%), Salmonella spp. 1(3.33\%), Shigella 3(10\%) and Staphylococcus aureus 2(6.66\%) were detected. $E$. coli has the highest isolation rate of 6(20\%), while Salmonella spp. had the least frequency of 1(3.33\%). The distribution of isolated organisms within the study area were as follows: Dausai, 4(80\%), Kofar kudu, 4(80\%), Makwalla, 2(40\%), Rinji, 3(60\%), Tosaro, 2(40\%), and Tsohuwar Kasuwa, 1(20\%). The results have indicated that the Tsire was contaminated with bacteria thus exposing the product to fast deterioration, spoilage and also a vehicle for food borne illness, suggesting for adequate hygienic practices at all the stages, prior to consumption, to ensure safety of the meat product.

Key words: APCs, TCCs, Contamination, Microorganisms, Garko

\section{INTRODUCTION}

Nigeria is one of the developing nations with inadequate food supply and most often deficient in protein content (FAO, 2019). Nigerian's average animal protein intake per head per day is estimated at $7.9 \mathrm{~g}$ as against $35 \mathrm{~g}$ recommended value by Food and Agricultural Organization (Mubarak et al., 2016). These low levels of animal protein intake create great concern as it affects the nutritional status of Nigerians. Hence, there is the need for sufficient supply of animal protein from energy rich animal products to satisfy the nutritional requirements for Nigerians.

Meat is one major source of animal protein largely composed of water, protein and fats which can make it susceptible to microbial contamination within short time leading to spoilage (Apata et al., 2013; Mgbemere et al., 2011). Meat is mostly eaten after it has been cooked or processed in a variety of ways such as sun drying; smoking and roasting with or without fortifications (Borch et al., 1996). In Nigeria meat products such as Tsire, Kilishi and Balangu are locally produced using one or more of these methods in order to meet the nutritional requirements of the teeming Nigerians (Egbebi, 2011).

Tsire is a popular Nigerian traditional processed ready-to-eat roasted stick meat product (Shamsuddeen, 2015). It is sold in public places, along roads, in hotels, parks, quarters and even offices (Falegan et al., 2017). It is prepared from boneless healthy animal flesh such as beef and mutton, spiced with peanut cake, salt, vegetable oil and other flavorings followed by roasting (Shamsuddeen, 2015). Consumption of these products has extended to other parts of African countries such as Ghana, Somali, Cameroun and Chad (Ahmadu and Ibrahim, 2013). 
BAJOPAS Volume 13 Number 1, June, 2020

However, evidence of quality control sticking to procedural hygiene by the handlers during preparation and retailing of these products is poorly documented. Tsire is of great safety risk because of the fact that there are erratic cases of gastroenteritis and symptoms of food infection after consumption (WHO, 2015). Food borne illnesses are one of the major health problems in developing and developed countries (Razavilar, 2010). According to the World Health Organization, WHO (2015), $0.07 \%$ death of the 600 million global burdens of Foodborne illnesses have been reported to be caused by bacteria, viruses, fungi and chemicals. In America $0.27 \%$ of the estimated 48 million affected people is hospitalized and about $0.0063 \%$ deaths are recorded each year (Scallan et al., 2011). More than 91 million people in Africa fall ill and $0.15 \%$ dies each year, making Africa the highest burden bearer of Foodborne diseases per population (WHO, 2015).

Application of a Hazard Analysis Critical Control Point (HACCP) at all stages of meat products preparation is essential in order to ensure its safety. Thus, according to the guidelines of good manufacturing practice, the level of total aerobic bacterial contamination of thermally processed meat products should not exceed $10^{4}\left(\mathrm{cfu} \mathrm{g}^{-1}\right)$. Enterobacteriaceae and faecal coliform contamination in meat products should be within the range of $10^{2}-10^{4}$ and $10-10^{3} \mathrm{cfu} \mathrm{g}^{-1}$, respectively (Shamsuddeen, 2015). The aim of the study is therefore, to assess the total viable bacterial counts of tsire marketed locally within Garko town, and to isolate and identify the organisms at the point of consumption with the intention of promoting public health and food hygiene habits in the Nigerian populace.

\section{MATERIALS AND METHODS Study Area and Population}

Garko is one of the existing 44 local government areas located in Kano south west zone of Kano state with its capital administrative headquarters in the Garko town. It has coordinates $11^{\circ} 39^{\prime} \mathrm{N}$ $8^{\circ} 54^{\prime} \mathrm{E}$, and an area of $450 \mathrm{~km}^{2}$. The projected population of Garko local Government was 225,300 according to the National Population Census report (2018). Garko is known for agricultural activities both farming and animal husbandry. It is popularly known for large scale rice production. Other food crops include sweet potatoes, cassava, onions, sorghum, millet and sugarcane. Cows, sheep and goats are major groups of animals reared by majority of the populace. Meat products processed, retailed and consumed in Garko include roasted meat (Balangu), dried roasted meat (Kilishi), stick meat (Tsire), hide and skin pepper soup (Ragadada) and minced fried meat (Danbunnama).

\section{Samples Collection}

Five samples of Tsire products were collected from 6 different identified locations within Garko town in a sterile foil paper and immediately analyzed for the presence of bacteria.

\section{Sample Preparation}

Sample preparation for the bacteriological analysis was carried out in accordance with the method described by Atlas (1997). Twenty five grams $(25 \mathrm{~g})$ of the sample was homogenized in $225 \mathrm{ml}$ peptone water using Kenwood blender machine to obtain a $10^{1}$ homogenate. The homogenate was thoroughly shaken and $1 \mathrm{ml}$ pipetted into test tubes containing $9 \mathrm{ml}$ of peptone water $\left(10^{2}\right)$. The test tubes were further serially diluted to $10^{5}$.

Total Aerobic Mesophilic Bacterial Count

Total Aerobic mesophilic bacterial count was determined using the method described by Abdullahi et al. (2004) where $1 \mathrm{ml}$ of inoculums from $10^{1}$ to $10^{5}$ dilutions were transferred into duplicate Petri dishes and labeled accordingly. This was followed by pouring aseptically about $15 \mathrm{ml}$ of molten nutrient agar. The culture was homogenized by gentle spinning of the plates and allowed to solidify. The plates were incubated at $37^{\circ} \mathrm{C}$ for 24 hours. Plates containing 30-300 colonies were counted. The number of colony forming units per gram of a sample (cfu/g) was obtained by multiplying the average colony number with the inverse of the dilution factor.

\section{Enumeration and Detection of Coliform bacteria}

Detection and enumeration of coliform was carried out according to method described by Atlas, (1977). A set of 9 test tubes each containing $9 \mathrm{ml}$ of lactose broth and an inverted Durham tubes were autoclaved to expel air and to sterilize. Similarly, $1 \mathrm{ml}$ from the diluents $10^{1}$ was transferred to the first 3 test tubes, followed by $1 \mathrm{ml}$ from the diluents $10^{2}$ to the second set of 3 test tubes and finally the third diluents $10^{3}$ to the $3^{\text {rd }}$ set of 3 test tubes. All the 9 test tubes were incubated at $37^{\circ} \mathrm{C}$ for 24 hours. Tubes that showed gas and acid production after 24 hours were recorded as positive for the presence of Coliform. Negative tubes were further reincubated for 24 hours. Positive tubes were recorded. Estimate of most probable number of Coliform per gram of sample (MPN/g) was determined by comparing the number of gas positive tubes with the most probable number table. 
BAJOPAS Volume 13 Number 1, June, 2020 Identification of Coliform

A loop full of inoculum from gas positive tubes was streaked on to Eosine methylene blue (EMB) agar plate and incubated at $37^{\circ} \mathrm{C}$ for $24 \mathrm{hrs}$. Colonies which formed bluish black color with green metallic sheen, and reddish colonies were isolated on agar slants. Those colonies showing metallic sheen on EMB were sub cultured into tubes of lactose broth and incubated at $45^{\circ} \mathrm{C}$. The tubes were observed after $24 \mathrm{hrs}$ for gas production. This is the completed test for fecal coliform. Gram stain and other biochemical tests such as Indole, Methyl red, Voges-Proskauer and Citrate Utilization tests (IMVIC), Coagulase and Catalase tests were carried out for the Identification and confirmation of isolates.

\section{Procedure for Indole Test}

Indole test was carried out by preparing a Tryptone broth drawn in to test tubes, sterilized by autoclaving, inoculated with loopful of suspension and incubated at $37^{\circ} \mathrm{C}$ for 24 hours. Three drops of xylene was added in tubes, shaken vigorously and kept for the separation of two layers. One millilitre of Kovac's reagent was added and the formation of pink colour ring indicates positive Indole test.

\section{Procedure for Methyl Red Test}

Methyl red test was carried out by preparing Glucose phosphate broth, dispensed in test tubes, sterilized, inoculated with test culture and incubated at $37^{\circ} \mathrm{C}$ for 24 hours. Five drops of methyl-red indicator was added to the medium for the formation of red colour.

\section{Procedure for Voges-Proskauer Test}

Voges-Proskauer test was carried out by inoculating tubes with the bacterial culture followed by incubation for 48 hours at $37^{\circ} \mathrm{C}$. Separate pipettes were used to pipette $1 \mathrm{ml}$ from each culture tube into clean separate tubes. Eighteen drops $(0.5 \mathrm{ml})$ of Barrit's solution A (a-naphthol) was added to each tube containing glucose phosphate broth followed by the addition of an equal amount of solution $B$ into the same tube. The tubes were shaken at 30 seconds interval. A positive reaction was indicated by the development of a pink color, which turns red in 1-2 hours, after vigorous shaking.

\section{Procedure for Citrate Utilization Test}

Citrate Utilization Test was carried out by distributing melted agar (Simmon Citrate Agar) in to test tubes followed by sterilization at $121.5^{\circ} \mathrm{C}$ for 15 minutes. The test tubes were afterward held in slanted position, inoculated with the given bacterial culture and incubated at $37^{\circ} \mathrm{C}$ for $24 \mathrm{hrs}$. Positive test was indicated by color change of the media from green to blue.

\section{RESULTS AND DISCUSSIONS}

The results of this study are presented in tables $1,2,3$ and 4. Among the sampling areas Kofar Kudu had the highest aerobic mesophilic bacteria counts $4.0 \times 10^{5} \mathrm{cfu} / \mathrm{g}$ followed by Rinji $2.72 \times 10^{5} \mathrm{cfu} / \mathrm{g}$, while Tosaro had the least Aerobic mesophilic bacteria counts of $1.02 \times 10^{5}$ $\mathrm{cfu} / \mathrm{g}$ as indicated in Table 1.Makwalla had the highest coliform count $68 \mathrm{MPN} / \mathrm{g}$ followed by Rinji $37 \mathrm{MPN} / \mathrm{g}$. Tsohuwar Kasuwa had the least coliform counts $8 \mathrm{MPN} / \mathrm{g}$, (Table 2). Result from table 1 shows variation in the microbial contents among the samples which suggest variation in their sources, poor handling procedures and contamination from the processing environment. High coliform count and their differences within sampling areas is an indication of poor microbiological quality of the product. Ndahi et al. (2013) reported microbial load to be a function of the handling personnel and the environment. The results indicated that the samples were contaminated with bacteria as the counts exceeded the minimum safety level $\left(10^{4} \mathrm{cfu} / \mathrm{g}\right)$ for members of the Enterobacteriaceae family. However, it might be a reflection of poor hygienic practices which may contribute to health hazard to the potential consumers. Similarly, Inusa and Sa'id (2017); Osimani et al. (2015) reported that, the initial microbial content of the raw material play significant role in influencing the final microbial load of the finished product. Isolation of members of the Enterobacteriaceae such as $E$. coli, Klebsiella pneumoniae, Salmonella and Shigella signifies danger to the public health. These organisms are capable of producing endotoxins which trigger high fevers in infected individuals, and the enterotoxins which colonize the small intestines and lead to extreme dehydration as a result of vomiting and diarrhea sometimes with severe and fatal outcomes (Amaeze et al., 2016). From the 16 isolated organisms $E$. coli had the highest isolation rate $6(37.5 \%)$ (Table 3), this suggest faecal contamination of the products. $E$. coli is a common flora in the gastrointestinal tract responsible for diarrhea and extra-intestinal infections (CDC, 2011). The result is in conformity with the findings of Ndahi et al. (2013) and Shamsuddeen (2009). Also presence of campylobacter might be due to cross contamination from raw meat to finished product (Tsire). Staphylococcus aureus is a normal flora of the skin, nasal, genital, mouth or anal area in both humans and animals without any symptom of an infection (Matthew et al., 2013). Isolation of $S$. aureus in these study concords with the findings of Lucretia et al. (2018) from Suya sold in Rivers State. 
BAJOPAS Volume 13 Number 1, June, 2020

It is also in agreement with the findings of Yousafzai et al. (2018); Onuorah et al. (2015) and Tijjani and Jumare (2014) from tsire samples in different countries. Presence of $S$. aureus in foods is most of the time an indication of poor human handling, poor environment, unhygienic utensils and equipments used during processing (Igene et al., 2016; Okonko et al., 2013). Infections caused by $S$. aureus are difficult to treat leading to long hospitalization with consequent economic loss (Udobi et al., 2013). These include soft tissue infections, pneumonia, hospital-acquired postoperative wound infections, Staphylococcal food poisoning, impetigo and cellulitis (Charlene et al., 2013). Samples obtained from Dausai and Kofar Kudu had the highest isolation rate $4(80 \%)$ (Table 4 ) probably because of the much commercial activities taking place in the area which can lead to environmental contamination.

Table 1: Total Aerobic Mesophilic Bacterial Count of Tsire sold in Garko Town

\begin{tabular}{lll}
\hline Sampling Area & APC cfu/g & Mean \pm STD \\
\hline Dausai & $2.20 \times 10^{5}$ & $110000 \pm 14142.14$ \\
Kofar Kudu & $4.00 \times 10^{5}$ & $133333.3 \pm 23094.01$ \\
Makwalla & $1.30 \times 10^{5}$ & $32500 \pm 7187.953$ \\
Rinji & $2.72 \times 10^{5}$ & $90666.67 \pm 94769.90$ \\
Tosaro & $1.02 \times 10^{5}$ & $51000 \pm 15556.35$ \\
Tsohuwar Kasuwa & $1.75 \times 10^{5}$ & $35000 \pm 11357.82$ \\
\hline
\end{tabular}

Key: APC: Aerobic Mesophilic Counts

STD: Standard Deviation

Table 2: Total Coliform Count of Tsire sold in Garko Town

\begin{tabular}{lcc}
\hline \multicolumn{1}{c}{ Sampling Area } & TCC MPN/g & Mean \pm STD \\
\hline Dausai & 20 & $6.67 \pm 2.5166$ \\
Kofar Kudu & 32 & $16.00 \pm 5.6569$ \\
Makwalla & 68 & $13.60 \pm 8.7062$ \\
Rinji & 37 & $9.25 \pm 4.7871$ \\
Tosaro & 10 & $5.00 \pm 2.8284$ \\
Tsohuwar Kasuwa & 8 & $4.00 \pm 0.0000$ \\
\hline
\end{tabular}

Table 3: Organisms Isolated from Tsire Sold in Garko

\begin{tabular}{lcl}
\hline Isolated Organism & Frequency & Percentage (\%) \\
\hline Campylobacter & 2 & 06.66 \\
Escherichia coli & 6 & 20.00 \\
Klebsiella pneumoniae & 2 & 06.66 \\
Salmonella species & 1 & 03.33 \\
Shigella & 3 & 10.00 \\
Staphylococcus aureus & 2 & 06.66 \\
Total & 16 & \\
\hline
\end{tabular}

Table 4: Distribution of Organisms within Sampling Area

\begin{tabular}{lcc}
\hline \multicolumn{1}{c}{ Sampling Area } & No. Isolated & Percentage (\%) \\
\hline Dausai & 4 & 80 \\
Kofar Kudu & 4 & 80 \\
Makwalla & 2 & 40 \\
Rinji & 3 & 60 \\
Tosaro & 2 & 40 \\
Tsohuwar Kasuwa & 1 & 20 \\
Total & 16 & \\
\hline
\end{tabular}

\section{CONCLUSION}

Results indicated $4.00 \times 10^{5} \mathrm{CFU} / \mathrm{g}$ as the highest APCs count; while $68 \mathrm{MPN} / \mathrm{g}$ was the highest TCCs from the 30 samples analyzed. Among the isolates, $E$. coli has the highest isolation rate of $6(20 \%)$. Dausai and Kofar kudu were having the highest bacteria count of $4(80 \%)$, each, indicating higher contamination in those locations. 
BAJOPAS Volume 13 Number 1, June, 2020 RECOMMENDATIONS

The following recommendations are tenable:

1. Hygienic practices at all stages of production should be improved to safe guard the consumers against potential health hazard.

2. Monitoring of microbiological contamination of Tsire during preparations, packaging and marketing is essential to ensure product of good microbiological quality for consumers' health.

\section{REFERENCES}

Abdullahi, I. O., Umoh, V. J. and Galadima, M. (2004). Hazards Associated with Kilishi Preparations in Zaria. Nigerian Journal of Microbiology, 18 (1-2): $339-345$.

Ahmadu, J. and Ibrahim E. J., (2013): Determinants of Revenue in Suya Production in BeninCity, Edo State, Nigeria. Nigerian journal of agriculture, food and environment.9(3):1-5

Amaeze, N. Aboh, M. Itohan, A. Felix, E. Olatunji, T. and Oladosu, P. (2016) Microbial Profile, Antibiotic Sensitivity and Heat Resistance of Bacterial Isolates from Commercial Roasted Beef (Suya) in Abuja, Nigeria. JOPAT, 15(2): $22-30$.

Apata, E.S., Kuku1, I.A., Apata, O.C. and Adeyemi, K.O. (2013). Evaluation of Suya(Tsire) - An Intermediate Moisture Meat Product in Ogun State, Nigeria. J. Food Res 2 (1): 87.

Atlas, R. M. (1997) Principles of Microbiology Second Edition. C. Brown Publishers. Pp 802-803.

Borch, E. Kant-Muermans, M. L., Blixt, Y. (1996) Bacterial Spoilage of Meat and Cured Meat Products. Int $\mathrm{J}$ Food Microbiol .33(1): 103-20.

Centre for Disease Control, CDC (2011). "Escherichia coli 0157:H7" Division of Bacterial and Mycotic Diseasesht://www.cdc.gov/nczved/divisi ons/dfbmd/diseases/ecoli_0157h7/.

Charlene, R. J., Johnnie, A. D., and John, B. B., (2013) Prevalence and Characterization of Methicillin-Resistant Staphylococcus aureus Isolates from Retail Meat and Humans in Georgia. American society for Microbiology. J. of clinical microbiology. 12(1):123-6 doi:10.1128/JCM.0316612JCM.03166-12

Egbebi, A.O and Seidu, K., T. (2011). Microbiological Evaluation of Suya (dried smoked

meat) Sold in Ado and Akure, South West Nigeria.European Journal of Experinmental Biology, 1(4):1-5
3. Government should establish regulatory bodies responsible for inculcating hygiene habits to the local producers and vendors in order to prevent instant, cross and post processing contaminations by microbial pathogens.

4. Awareness and sensitization of local food producers about good hygienic practices in food handling and processing.

Falegan, C, R., Akoja, S. D., and Oyarekua, M. A., (2017) Microbiological Assessment of Suya (Sliced Roasted Beef) in Ado-Ekiti Metropolis, Ekiti State, Nigeria. MOJ Biology andMedicine.

Fonkem, D., N. Tanya, V., N. and Ebangi, A., L. (2010). Effect of Season on the Microbiological Quality of Kilishi, a Traditional Cameroonian Dried Beef Product. Tropicultura, 28(1): 10-15.

Food and Agricultural Organization of the United Nations (F A O, 1979). Manual of food quality control 4. Microbiological analysis.

Food and Agriculture Organisation of the United Nation (FAO), 2019. Nigeria at a glance.

Igene J.O., Uwadia, O.E., Ebabhamiegbebho, P.A. and Evivie, S.E., (2016) Shelf life Stability Studies of University of Benin (UNIBEN) Proff's Kilishi Product Asian Journal of Science and Technology 7(1): 2268-2274.

Inusa, S. K. and Said, I. S. (2017) Evaluation of the Chemical and Microbiological Properties Of Kilishi Sold in Kano Metropolis. Journal of Dry land Agriculture, 3 (1): $59-69$.

Lucretia, I. B, Patience, C. Obinna-Echem, Sophia, C. A. (2018) Microbiological quality andantibiotic sensitivity of potential pathogens isolated from meat product (Suya) sold in Rivers State University and its environs. International Journal of Biotechnology and Food Science, 6(4): 67-76.

Matthew, E., Drosos, E., John, L. and Ioanna, P. (2013) MRSA in Africa: Filling the Global Map of Antimicrobial Resistance PLOS One. 8(7): e68024 doi: 10.1371/journal.pone.0068024

Mgbemere, V.N., Akpapunam, M. A. and Igene, J. O., (2011). Effect of Groundnut FlourSubstitution on Yield, Quality and Storage Stability of Kilishi - a Nigerian Indigenous Dried Meat Product. African Journal of Food, Agriculture, Nutrition and Development, $\quad \mathbf{1 1}(2)$ : 4718-4738. 
BAJOPAS Volume 13 Number 1, June, 2020

Mubarak, A. A., Azeez, M. L., Amos A. O., Opeyemi, O. O. (2016) Assessment of Animal Protein Consumption and Food Security Among Rural Households in Kwara State, Nigeria American Journal of Business and Society, 1(4): 233245.

Ndahi, M., D. Kwaga, J., K. P. Bello, M. Kabir J., V. Umoh, .J. Yakubu, S., E. and Nok, A., J. (2013) Prevalence and Antimicrobial Susceptibility of Listeria Monocytogenes and Methicillin-Resistant Staphylococcus aureus Strains from Raw Meat and Meat Products in Zaria, Nigeria. Applied Journal of Microbiology, 58(3):262-9.

Okonko, I.O., Odu, N.N. and Igboh, I.E. (2013). Microbiological Analysis of Kilishi Sold In Port Harcourt, Nigeria. New York Science Journal, 6 (7):37-43.

Osimani, A., Aquilanti, L. and Clementi, F. (2015) Microbiological Quality of Meatbased Meals and Operation of Control Systems within a Food Service Environment. International Food Research Journal 22(4): 1692-1698.

Onuorah, S. Obika, I. Odibo, F. Orji, M. (2015)An Assessment of the Bacteriological Quality of Tsire-Suya (Grilled Beef) sold in Awka, Nigeria. American. J. Life. Sci. Res. 3(4):287292.

Razavilar, V, Khandaghi, J. Barzgari, A. (2010); Isolation of Eschericia coli 0157:H7 from manure fertilized farms and raw vegetables grown on it, in Tabriz city in
Iran. African Journal of Microbiology Research, 4(9): 891-895.

Scallan, E. Hoekstra, R. M. Angulo, F. J.Tauxe, R. V, Widdowson, M. Roy, S. L et al., (2011).Food borne illness acquired in the United States- Major Pathogens. Emerg. Infec Dis, 17(1): 7-15.

Shamsuddeen U (2009). Microbiological quality of spice used in the production of Kilishi a traditionally dried and grilled meat product. Bayero Journal of Pure andApplied Sciences, 2(2): 66-69.

Shamsuddeen, U. (2015) Microbiological Hazard and Critical control point Analysis of Dried and Minced Meat Snacks Produced in Kano Nigeria. Lambert Academic Publishing; Pp 1-36.

Tijani, O.and Jumare, S. (2014). Microblological Quality Assessment of Meat

Sold in KauraNamoda. International Conference on Earth, Environment and Life sciences (EELS) Dubai (UAE).

Udobi, C. E., Obajuluwa, A. F., and Onaolapo, J. A., (2013) Prevalence and Antibiotic Resistance Pattern of MethicillinResistant Staphylococcus aureus from an Orthopaedic Hospital in Nigeria BioMed Research International; 26(6); 6-7.

WHO, 2015 Foodborne diseases in the WHO African Region.

Yousafzai HA, Rind R, Khan MA, Abro SH, Korejo NA, Ejaz M, Kabir A, Shahid M, Memon S. (2019). Microbiological Contamination of Cattle and Meat in Peshawar, Pakistan. J. Anim. Health Prod. 7(1): 1116. 


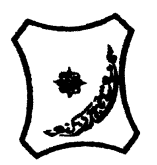

Bayero Journal of Pure and Applied Sciences, 13(1); 40 - 45

Received: September, 2019

Accepted: April, 2020

ISSN $2006-6996$

\title{
BACTERIOLOGICAL QUALITY OF STICK MEAT (Tsire) SOLD IN GARKO LOCAL GOVERNMENT AREA OF KANO STATE, NIGERIA
}

\author{
$*^{1}$ Dahiru A. T. and ${ }^{2}$ Maigari A. K. \\ ${ }^{1}$ Department of Hospitality Management, School of Technology, Kano State Polytechnic, PMB 3348, \\ Kano Nigeria. \\ ${ }^{2}$ Departmnt of Biological Sciences, Bayero University, Kano \\ Corresponding Author: dturajo61@gmail.com; GSM: 08087508262.
}

ABSTRACT

Stick meat, locally called Tsire in Hausa Language, is a significant portion of the diet of a large active population of Northern Nigeria. However, because of the handling and processing methods by the manufacturers as well as the hawking system of stick meat, the meat product may be exposed to both pre- and post-processed product contamination, and thus may poses danger to public health. Therefore, considering the role of Tsire in improving nutrition and increase household income to the populace, the need to improve the processing, distribution and overall quality of the product is simply indispensable. A total of 30 samples (5 samples from each of the 6 sampling points) of Tsire were collected randomly in Garko Town. Aerobic plate counts (APCs) and Total coliform counts (TCCS) of Tsire samples were determined using standard microbiological methods. APCs ranged from $1.02 \times 10^{5}$ to $4.00 \times 10^{5} \mathrm{CFU} / \mathrm{g}$; while TCCs ranged from $8 \mathrm{MPN} / \mathrm{g}$ to $68 \mathrm{MPN} / \mathrm{g}$. From the 30 samples screened, 16(53.33\%) bacteria namely, Campylobacter 2(6.66\%), Escherichia coli 6(20\%), Klebsiella pneumoniae 2(6.66\%), Salmonella spp. 1(3.33\%), Shigella 3(10\%) and Staphylococcus aureus 2(6.66\%) were detected. $E$. coli has the highest isolation rate of 6(20\%), while Salmonella spp. had the least frequency of 1(3.33\%). The distribution of isolated organisms within the study area were as follows: Dausai, 4(80\%), Kofar kudu, 4(80\%), Makwalla, 2(40\%), Rinji, 3(60\%), Tosaro, 2(40\%), and Tsohuwar Kasuwa, 1(20\%). The results have indicated that the Tsire was contaminated with bacteria thus exposing the product to fast deterioration, spoilage and also a vehicle for food borne illness, suggesting for adequate hygienic practices at all the stages, prior to consumption, to ensure safety of the meat product.

Key words: APCs, TCCs, Contamination, Microorganisms, Garko

\section{INTRODUCTION}

Nigeria is one of the developing nations with inadequate food supply and most often deficient in protein content (FAO, 2019). Nigerian's average animal protein intake per head per day is estimated at $7.9 \mathrm{~g}$ as against $35 \mathrm{~g}$ recommended value by Food and Agricultural Organization (Mubarak et al., 2016). These low levels of animal protein intake create great concern as it affects the nutritional status of Nigerians. Hence, there is the need for sufficient supply of animal protein from energy rich animal products to satisfy the nutritional requirements for Nigerians.

Meat is one major source of animal protein largely composed of water, protein and fats which can make it susceptible to microbial contamination within short time leading to spoilage (Apata et al., 2013; Mgbemere et al., 2011). Meat is mostly eaten after it has been cooked or processed in a variety of ways such as sun drying; smoking and roasting with or without fortifications (Borch et al., 1996). In Nigeria meat products such as Tsire, Kilishi and Balangu are locally produced using one or more of these methods in order to meet the nutritional requirements of the teeming Nigerians (Egbebi, 2011).

Tsire is a popular Nigerian traditional processed ready-to-eat roasted stick meat product (Shamsuddeen, 2015). It is sold in public places, along roads, in hotels, parks, quarters and even offices (Falegan et al., 2017). It is prepared from boneless healthy animal flesh such as beef and mutton, spiced with peanut cake, salt, vegetable oil and other flavorings followed by roasting (Shamsuddeen, 2015). Consumption of these products has extended to other parts of African countries such as Ghana, Somali, Cameroun and Chad (Ahmadu and Ibrahim, 2013). 
BAJOPAS Volume 13 Number 1, June, 2020

However, evidence of quality control sticking to procedural hygiene by the handlers during preparation and retailing of these products is poorly documented. Tsire is of great safety risk because of the fact that there are erratic cases of gastroenteritis and symptoms of food infection after consumption (WHO, 2015). Food borne illnesses are one of the major health problems in developing and developed countries (Razavilar, 2010). According to the World Health Organization, WHO (2015), $0.07 \%$ death of the 600 million global burdens of Foodborne illnesses have been reported to be caused by bacteria, viruses, fungi and chemicals. In America $0.27 \%$ of the estimated 48 million affected people is hospitalized and about $0.0063 \%$ deaths are recorded each year (Scallan et al., 2011). More than 91 million people in Africa fall ill and $0.15 \%$ dies each year, making Africa the highest burden bearer of Foodborne diseases per population (WHO, 2015).

Application of a Hazard Analysis Critical Control Point (HACCP) at all stages of meat products preparation is essential in order to ensure its safety. Thus, according to the guidelines of good manufacturing practice, the level of total aerobic bacterial contamination of thermally processed meat products should not exceed $10^{4}\left(\mathrm{cfu} \mathrm{g}^{-1}\right)$. Enterobacteriaceae and faecal coliform contamination in meat products should be within the range of $10^{2}-10^{4}$ and $10-10^{3} \mathrm{cfu} \mathrm{g}^{-1}$, respectively (Shamsuddeen, 2015). The aim of the study is therefore, to assess the total viable bacterial counts of tsire marketed locally within Garko town, and to isolate and identify the organisms at the point of consumption with the intention of promoting public health and food hygiene habits in the Nigerian populace.

\section{MATERIALS AND METHODS Study Area and Population}

Garko is one of the existing 44 local government areas located in Kano south west zone of Kano state with its capital administrative headquarters in the Garko town. It has coordinates $11^{\circ} 39^{\prime} \mathrm{N}$ $8^{\circ} 54^{\prime} \mathrm{E}$, and an area of $450 \mathrm{~km}^{2}$. The projected population of Garko local Government was 225,300 according to the National Population Census report (2018). Garko is known for agricultural activities both farming and animal husbandry. It is popularly known for large scale rice production. Other food crops include sweet potatoes, cassava, onions, sorghum, millet and sugarcane. Cows, sheep and goats are major groups of animals reared by majority of the populace. Meat products processed, retailed and consumed in Garko include roasted meat (Balangu), dried roasted meat (Kilishi), stick meat (Tsire), hide and skin pepper soup (Ragadada) and minced fried meat (Danbunnama).

\section{Samples Collection}

Five samples of Tsire products were collected from 6 different identified locations within Garko town in a sterile foil paper and immediately analyzed for the presence of bacteria.

\section{Sample Preparation}

Sample preparation for the bacteriological analysis was carried out in accordance with the method described by Atlas (1997). Twenty five grams $(25 \mathrm{~g})$ of the sample was homogenized in $225 \mathrm{ml}$ peptone water using Kenwood blender machine to obtain a $10^{1}$ homogenate. The homogenate was thoroughly shaken and $1 \mathrm{ml}$ pipetted into test tubes containing $9 \mathrm{ml}$ of peptone water $\left(10^{2}\right)$. The test tubes were further serially diluted to $10^{5}$.

Total Aerobic Mesophilic Bacterial Count

Total Aerobic mesophilic bacterial count was determined using the method described by Abdullahi et al. (2004) where $1 \mathrm{ml}$ of inoculums from $10^{1}$ to $10^{5}$ dilutions were transferred into duplicate Petri dishes and labeled accordingly. This was followed by pouring aseptically about $15 \mathrm{ml}$ of molten nutrient agar. The culture was homogenized by gentle spinning of the plates and allowed to solidify. The plates were incubated at $37^{\circ} \mathrm{C}$ for 24 hours. Plates containing 30-300 colonies were counted. The number of colony forming units per gram of a sample (cfu/g) was obtained by multiplying the average colony number with the inverse of the dilution factor.

\section{Enumeration and Detection of Coliform bacteria}

Detection and enumeration of coliform was carried out according to method described by Atlas, (1977). A set of 9 test tubes each containing $9 \mathrm{ml}$ of lactose broth and an inverted Durham tubes were autoclaved to expel air and to sterilize. Similarly, $1 \mathrm{ml}$ from the diluents $10^{1}$ was transferred to the first 3 test tubes, followed by $1 \mathrm{ml}$ from the diluents $10^{2}$ to the second set of 3 test tubes and finally the third diluents $10^{3}$ to the $3^{\text {rd }}$ set of 3 test tubes. All the 9 test tubes were incubated at $37^{\circ} \mathrm{C}$ for 24 hours. Tubes that showed gas and acid production after 24 hours were recorded as positive for the presence of Coliform. Negative tubes were further reincubated for 24 hours. Positive tubes were recorded. Estimate of most probable number of Coliform per gram of sample (MPN/g) was determined by comparing the number of gas positive tubes with the most probable number table. 
BAJOPAS Volume 13 Number 1, June, 2020 Identification of Coliform

A loop full of inoculum from gas positive tubes was streaked on to Eosine methylene blue (EMB) agar plate and incubated at $37^{\circ} \mathrm{C}$ for $24 \mathrm{hrs}$. Colonies which formed bluish black color with green metallic sheen, and reddish colonies were isolated on agar slants. Those colonies showing metallic sheen on EMB were sub cultured into tubes of lactose broth and incubated at $45^{\circ} \mathrm{C}$. The tubes were observed after $24 \mathrm{hrs}$ for gas production. This is the completed test for fecal coliform. Gram stain and other biochemical tests such as Indole, Methyl red, Voges-Proskauer and Citrate Utilization tests (IMVIC), Coagulase and Catalase tests were carried out for the Identification and confirmation of isolates.

\section{Procedure for Indole Test}

Indole test was carried out by preparing a Tryptone broth drawn in to test tubes, sterilized by autoclaving, inoculated with loopful of suspension and incubated at $37^{\circ} \mathrm{C}$ for 24 hours. Three drops of xylene was added in tubes, shaken vigorously and kept for the separation of two layers. One millilitre of Kovac's reagent was added and the formation of pink colour ring indicates positive Indole test.

\section{Procedure for Methyl Red Test}

Methyl red test was carried out by preparing Glucose phosphate broth, dispensed in test tubes, sterilized, inoculated with test culture and incubated at $37^{\circ} \mathrm{C}$ for 24 hours. Five drops of methyl-red indicator was added to the medium for the formation of red colour.

\section{Procedure for Voges-Proskauer Test}

Voges-Proskauer test was carried out by inoculating tubes with the bacterial culture followed by incubation for 48 hours at $37^{\circ} \mathrm{C}$. Separate pipettes were used to pipette $1 \mathrm{ml}$ from each culture tube into clean separate tubes. Eighteen drops $(0.5 \mathrm{ml})$ of Barrit's solution A (a-naphthol) was added to each tube containing glucose phosphate broth followed by the addition of an equal amount of solution $B$ into the same tube. The tubes were shaken at 30 seconds interval. A positive reaction was indicated by the development of a pink color, which turns red in 1-2 hours, after vigorous shaking.

\section{Procedure for Citrate Utilization Test}

Citrate Utilization Test was carried out by distributing melted agar (Simmon Citrate Agar) in to test tubes followed by sterilization at $121.5^{\circ} \mathrm{C}$ for 15 minutes. The test tubes were afterward held in slanted position, inoculated with the given bacterial culture and incubated at $37^{\circ} \mathrm{C}$ for $24 \mathrm{hrs}$. Positive test was indicated by color change of the media from green to blue.

\section{RESULTS AND DISCUSSIONS}

The results of this study are presented in tables $1,2,3$ and 4. Among the sampling areas Kofar Kudu had the highest aerobic mesophilic bacteria counts $4.0 \times 10^{5} \mathrm{cfu} / \mathrm{g}$ followed by Rinji $2.72 \times 10^{5} \mathrm{cfu} / \mathrm{g}$, while Tosaro had the least Aerobic mesophilic bacteria counts of $1.02 \times 10^{5}$ $\mathrm{cfu} / \mathrm{g}$ as indicated in Table 1.Makwalla had the highest coliform count $68 \mathrm{MPN} / \mathrm{g}$ followed by Rinji $37 \mathrm{MPN} / \mathrm{g}$. Tsohuwar Kasuwa had the least coliform counts $8 \mathrm{MPN} / \mathrm{g}$, (Table 2). Result from table 1 shows variation in the microbial contents among the samples which suggest variation in their sources, poor handling procedures and contamination from the processing environment. High coliform count and their differences within sampling areas is an indication of poor microbiological quality of the product. Ndahi et al. (2013) reported microbial load to be a function of the handling personnel and the environment. The results indicated that the samples were contaminated with bacteria as the counts exceeded the minimum safety level $\left(10^{4} \mathrm{cfu} / \mathrm{g}\right)$ for members of the Enterobacteriaceae family. However, it might be a reflection of poor hygienic practices which may contribute to health hazard to the potential consumers. Similarly, Inusa and Sa'id (2017); Osimani et al. (2015) reported that, the initial microbial content of the raw material play significant role in influencing the final microbial load of the finished product. Isolation of members of the Enterobacteriaceae such as $E$. coli, Klebsiella pneumoniae, Salmonella and Shigella signifies danger to the public health. These organisms are capable of producing endotoxins which trigger high fevers in infected individuals, and the enterotoxins which colonize the small intestines and lead to extreme dehydration as a result of vomiting and diarrhea sometimes with severe and fatal outcomes (Amaeze et al., 2016). From the 16 isolated organisms $E$. coli had the highest isolation rate $6(37.5 \%)$ (Table 3), this suggest faecal contamination of the products. $E$. coli is a common flora in the gastrointestinal tract responsible for diarrhea and extra-intestinal infections (CDC, 2011). The result is in conformity with the findings of Ndahi et al. (2013) and Shamsuddeen (2009). Also presence of campylobacter might be due to cross contamination from raw meat to finished product (Tsire). Staphylococcus aureus is a normal flora of the skin, nasal, genital, mouth or anal area in both humans and animals without any symptom of an infection (Matthew et al., 2013). Isolation of $S$. aureus in these study concords with the findings of Lucretia et al. (2018) from Suya sold in Rivers State. 
BAJOPAS Volume 13 Number 1, June, 2020

It is also in agreement with the findings of Yousafzai et al. (2018); Onuorah et al. (2015) and Tijjani and Jumare (2014) from tsire samples in different countries. Presence of $S$. aureus in foods is most of the time an indication of poor human handling, poor environment, unhygienic utensils and equipments used during processing (Igene et al., 2016; Okonko et al., 2013). Infections caused by $S$. aureus are difficult to treat leading to long hospitalization with consequent economic loss (Udobi et al., 2013). These include soft tissue infections, pneumonia, hospital-acquired postoperative wound infections, Staphylococcal food poisoning, impetigo and cellulitis (Charlene et al., 2013). Samples obtained from Dausai and Kofar Kudu had the highest isolation rate $4(80 \%)$ (Table 4 ) probably because of the much commercial activities taking place in the area which can lead to environmental contamination.

Table 1: Total Aerobic Mesophilic Bacterial Count of Tsire sold in Garko Town

\begin{tabular}{lll}
\hline Sampling Area & APC cfu/g & Mean \pm STD \\
\hline Dausai & $2.20 \times 10^{5}$ & $110000 \pm 14142.14$ \\
Kofar Kudu & $4.00 \times 10^{5}$ & $133333.3 \pm 23094.01$ \\
Makwalla & $1.30 \times 10^{5}$ & $32500 \pm 7187.953$ \\
Rinji & $2.72 \times 10^{5}$ & $90666.67 \pm 94769.90$ \\
Tosaro & $1.02 \times 10^{5}$ & $51000 \pm 15556.35$ \\
Tsohuwar Kasuwa & $1.75 \times 10^{5}$ & $35000 \pm 11357.82$ \\
\hline
\end{tabular}

Key: APC: Aerobic Mesophilic Counts

STD: Standard Deviation

Table 2: Total Coliform Count of Tsire sold in Garko Town

\begin{tabular}{lcc}
\hline \multicolumn{1}{c}{ Sampling Area } & TCC MPN/g & Mean \pm STD \\
\hline Dausai & 20 & $6.67 \pm 2.5166$ \\
Kofar Kudu & 32 & $16.00 \pm 5.6569$ \\
Makwalla & 68 & $13.60 \pm 8.7062$ \\
Rinji & 37 & $9.25 \pm 4.7871$ \\
Tosaro & 10 & $5.00 \pm 2.8284$ \\
Tsohuwar Kasuwa & 8 & $4.00 \pm 0.0000$ \\
\hline
\end{tabular}

Table 3: Organisms Isolated from Tsire Sold in Garko

\begin{tabular}{lcl}
\hline Isolated Organism & Frequency & Percentage (\%) \\
\hline Campylobacter & 2 & 06.66 \\
Escherichia coli & 6 & 20.00 \\
Klebsiella pneumoniae & 2 & 06.66 \\
Salmonella species & 1 & 03.33 \\
Shigella & 3 & 10.00 \\
Staphylococcus aureus & 2 & 06.66 \\
Total & 16 & \\
\hline
\end{tabular}

Table 4: Distribution of Organisms within Sampling Area

\begin{tabular}{lcc}
\hline \multicolumn{1}{c}{ Sampling Area } & No. Isolated & Percentage (\%) \\
\hline Dausai & 4 & 80 \\
Kofar Kudu & 4 & 80 \\
Makwalla & 2 & 40 \\
Rinji & 3 & 60 \\
Tosaro & 2 & 40 \\
Tsohuwar Kasuwa & 1 & 20 \\
Total & 16 & \\
\hline
\end{tabular}

\section{CONCLUSION}

Results indicated $4.00 \times 10^{5} \mathrm{CFU} / \mathrm{g}$ as the highest APCs count; while $68 \mathrm{MPN} / \mathrm{g}$ was the highest TCCs from the 30 samples analyzed. Among the isolates, $E$. coli has the highest isolation rate of $6(20 \%)$. Dausai and Kofar kudu were having the highest bacteria count of $4(80 \%)$, each, indicating higher contamination in those locations. 
BAJOPAS Volume 13 Number 1, June, 2020 RECOMMENDATIONS

The following recommendations are tenable:

1. Hygienic practices at all stages of production should be improved to safe guard the consumers against potential health hazard.

2. Monitoring of microbiological contamination of Tsire during preparations, packaging and marketing is essential to ensure product of good microbiological quality for consumers' health.

\section{REFERENCES}

Abdullahi, I. O., Umoh, V. J. and Galadima, M. (2004). Hazards Associated with Kilishi Preparations in Zaria. Nigerian Journal of Microbiology, 18 (1-2): $339-345$.

Ahmadu, J. and Ibrahim E. J., (2013): Determinants of Revenue in Suya Production in BeninCity, Edo State, Nigeria. Nigerian journal of agriculture, food and environment.9(3):1-5

Amaeze, N. Aboh, M. Itohan, A. Felix, E. Olatunji, T. and Oladosu, P. (2016) Microbial Profile, Antibiotic Sensitivity and Heat Resistance of Bacterial Isolates from Commercial Roasted Beef (Suya) in Abuja, Nigeria. JOPAT, 15(2): $22-30$.

Apata, E.S., Kuku1, I.A., Apata, O.C. and Adeyemi, K.O. (2013). Evaluation of Suya(Tsire) - An Intermediate Moisture Meat Product in Ogun State, Nigeria. J. Food Res 2 (1): 87.

Atlas, R. M. (1997) Principles of Microbiology Second Edition. C. Brown Publishers. Pp 802-803.

Borch, E. Kant-Muermans, M. L., Blixt, Y. (1996) Bacterial Spoilage of Meat and Cured Meat Products. Int $\mathrm{J}$ Food Microbiol .33(1): 103-20.

Centre for Disease Control, CDC (2011). "Escherichia coli 0157:H7" Division of Bacterial and Mycotic Diseasesht://www.cdc.gov/nczved/divisi ons/dfbmd/diseases/ecoli_0157h7/.

Charlene, R. J., Johnnie, A. D., and John, B. B., (2013) Prevalence and Characterization of Methicillin-Resistant Staphylococcus aureus Isolates from Retail Meat and Humans in Georgia. American society for Microbiology. J. of clinical microbiology. 12(1):123-6 doi:10.1128/JCM.0316612JCM.03166-12

Egbebi, A.O and Seidu, K., T. (2011). Microbiological Evaluation of Suya (dried smoked

meat) Sold in Ado and Akure, South West Nigeria.European Journal of Experinmental Biology, 1(4):1-5
3. Government should establish regulatory bodies responsible for inculcating hygiene habits to the local producers and vendors in order to prevent instant, cross and post processing contaminations by microbial pathogens.

4. Awareness and sensitization of local food producers about good hygienic practices in food handling and processing.

Falegan, C, R., Akoja, S. D., and Oyarekua, M. A., (2017) Microbiological Assessment of Suya (Sliced Roasted Beef) in Ado-Ekiti Metropolis, Ekiti State, Nigeria. MOJ Biology andMedicine.

Fonkem, D., N. Tanya, V., N. and Ebangi, A., L. (2010). Effect of Season on the Microbiological Quality of Kilishi, a Traditional Cameroonian Dried Beef Product. Tropicultura, 28(1): 10-15.

Food and Agricultural Organization of the United Nations (F A O, 1979). Manual of food quality control 4. Microbiological analysis.

Food and Agriculture Organisation of the United Nation (FAO), 2019. Nigeria at a glance.

Igene J.O., Uwadia, O.E., Ebabhamiegbebho, P.A. and Evivie, S.E., (2016) Shelf life Stability Studies of University of Benin (UNIBEN) Proff's Kilishi Product Asian Journal of Science and Technology 7(1): 2268-2274.

Inusa, S. K. and Said, I. S. (2017) Evaluation of the Chemical and Microbiological Properties Of Kilishi Sold in Kano Metropolis. Journal of Dry land Agriculture, 3 (1): $59-69$.

Lucretia, I. B, Patience, C. Obinna-Echem, Sophia, C. A. (2018) Microbiological quality andantibiotic sensitivity of potential pathogens isolated from meat product (Suya) sold in Rivers State University and its environs. International Journal of Biotechnology and Food Science, 6(4): 67-76.

Matthew, E., Drosos, E., John, L. and Ioanna, P. (2013) MRSA in Africa: Filling the Global Map of Antimicrobial Resistance PLOS One. 8(7): e68024 doi: 10.1371/journal.pone.0068024

Mgbemere, V.N., Akpapunam, M. A. and Igene, J. O., (2011). Effect of Groundnut FlourSubstitution on Yield, Quality and Storage Stability of Kilishi - a Nigerian Indigenous Dried Meat Product. African Journal of Food, Agriculture, Nutrition and Development, $\quad \mathbf{1 1}(2)$ : 4718-4738. 
BAJOPAS Volume 13 Number 1, June, 2020

Mubarak, A. A., Azeez, M. L., Amos A. O., Opeyemi, O. O. (2016) Assessment of Animal Protein Consumption and Food Security Among Rural Households in Kwara State, Nigeria American Journal of Business and Society, 1(4): 233245.

Ndahi, M., D. Kwaga, J., K. P. Bello, M. Kabir J., V. Umoh, .J. Yakubu, S., E. and Nok, A., J. (2013) Prevalence and Antimicrobial Susceptibility of Listeria Monocytogenes and Methicillin-Resistant Staphylococcus aureus Strains from Raw Meat and Meat Products in Zaria, Nigeria. Applied Journal of Microbiology, 58(3):262-9.

Okonko, I.O., Odu, N.N. and Igboh, I.E. (2013). Microbiological Analysis of Kilishi Sold In Port Harcourt, Nigeria. New York Science Journal, 6 (7):37-43.

Osimani, A., Aquilanti, L. and Clementi, F. (2015) Microbiological Quality of Meatbased Meals and Operation of Control Systems within a Food Service Environment. International Food Research Journal 22(4): 1692-1698.

Onuorah, S. Obika, I. Odibo, F. Orji, M. (2015)An Assessment of the Bacteriological Quality of Tsire-Suya (Grilled Beef) sold in Awka, Nigeria. American. J. Life. Sci. Res. 3(4):287292.

Razavilar, V, Khandaghi, J. Barzgari, A. (2010); Isolation of Eschericia coli 0157:H7 from manure fertilized farms and raw vegetables grown on it, in Tabriz city in
Iran. African Journal of Microbiology Research, 4(9): 891-895.

Scallan, E. Hoekstra, R. M. Angulo, F. J.Tauxe, R. V, Widdowson, M. Roy, S. L et al., (2011).Food borne illness acquired in the United States- Major Pathogens. Emerg. Infec Dis, 17(1): 7-15.

Shamsuddeen U (2009). Microbiological quality of spice used in the production of Kilishi a traditionally dried and grilled meat product. Bayero Journal of Pure andApplied Sciences, 2(2): 66-69.

Shamsuddeen, U. (2015) Microbiological Hazard and Critical control point Analysis of Dried and Minced Meat Snacks Produced in Kano Nigeria. Lambert Academic Publishing; Pp 1-36.

Tijani, O.and Jumare, S. (2014). Microblological Quality Assessment of Meat

Sold in KauraNamoda. International Conference on Earth, Environment and Life sciences (EELS) Dubai (UAE).

Udobi, C. E., Obajuluwa, A. F., and Onaolapo, J. A., (2013) Prevalence and Antibiotic Resistance Pattern of MethicillinResistant Staphylococcus aureus from an Orthopaedic Hospital in Nigeria BioMed Research International; 26(6); 6-7.

WHO, 2015 Foodborne diseases in the WHO African Region.

Yousafzai HA, Rind R, Khan MA, Abro SH, Korejo NA, Ejaz M, Kabir A, Shahid M, Memon S. (2019). Microbiological Contamination of Cattle and Meat in Peshawar, Pakistan. J. Anim. Health Prod. 7(1): 1116. 


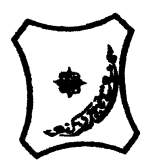

Bayero Journal of Pure and Applied Sciences, 13(1); 40 - 45

Received: September, 2019

Accepted: April, 2020

ISSN $2006-6996$

\title{
BACTERIOLOGICAL QUALITY OF STICK MEAT (Tsire) SOLD IN GARKO LOCAL GOVERNMENT AREA OF KANO STATE, NIGERIA
}

\author{
$*^{1}$ Dahiru A. T. and ${ }^{2}$ Maigari A. K. \\ ${ }^{1}$ Department of Hospitality Management, School of Technology, Kano State Polytechnic, PMB 3348, \\ Kano Nigeria. \\ ${ }^{2}$ Departmnt of Biological Sciences, Bayero University, Kano \\ Corresponding Author: dturajo61@gmail.com; GSM: 08087508262.
}

ABSTRACT

Stick meat, locally called Tsire in Hausa Language, is a significant portion of the diet of a large active population of Northern Nigeria. However, because of the handling and processing methods by the manufacturers as well as the hawking system of stick meat, the meat product may be exposed to both pre- and post-processed product contamination, and thus may poses danger to public health. Therefore, considering the role of Tsire in improving nutrition and increase household income to the populace, the need to improve the processing, distribution and overall quality of the product is simply indispensable. A total of 30 samples (5 samples from each of the 6 sampling points) of Tsire were collected randomly in Garko Town. Aerobic plate counts (APCs) and Total coliform counts (TCCS) of Tsire samples were determined using standard microbiological methods. APCs ranged from $1.02 \times 10^{5}$ to $4.00 \times 10^{5} \mathrm{CFU} / \mathrm{g}$; while TCCs ranged from $8 \mathrm{MPN} / \mathrm{g}$ to $68 \mathrm{MPN} / \mathrm{g}$. From the 30 samples screened, 16(53.33\%) bacteria namely, Campylobacter 2(6.66\%), Escherichia coli 6(20\%), Klebsiella pneumoniae 2(6.66\%), Salmonella spp. 1(3.33\%), Shigella 3(10\%) and Staphylococcus aureus 2(6.66\%) were detected. $E$. coli has the highest isolation rate of 6(20\%), while Salmonella spp. had the least frequency of 1(3.33\%). The distribution of isolated organisms within the study area were as follows: Dausai, 4(80\%), Kofar kudu, 4(80\%), Makwalla, 2(40\%), Rinji, 3(60\%), Tosaro, 2(40\%), and Tsohuwar Kasuwa, 1(20\%). The results have indicated that the Tsire was contaminated with bacteria thus exposing the product to fast deterioration, spoilage and also a vehicle for food borne illness, suggesting for adequate hygienic practices at all the stages, prior to consumption, to ensure safety of the meat product.

Key words: APCs, TCCs, Contamination, Microorganisms, Garko

\section{INTRODUCTION}

Nigeria is one of the developing nations with inadequate food supply and most often deficient in protein content (FAO, 2019). Nigerian's average animal protein intake per head per day is estimated at $7.9 \mathrm{~g}$ as against $35 \mathrm{~g}$ recommended value by Food and Agricultural Organization (Mubarak et al., 2016). These low levels of animal protein intake create great concern as it affects the nutritional status of Nigerians. Hence, there is the need for sufficient supply of animal protein from energy rich animal products to satisfy the nutritional requirements for Nigerians.

Meat is one major source of animal protein largely composed of water, protein and fats which can make it susceptible to microbial contamination within short time leading to spoilage (Apata et al., 2013; Mgbemere et al., 2011). Meat is mostly eaten after it has been cooked or processed in a variety of ways such as sun drying; smoking and roasting with or without fortifications (Borch et al., 1996). In Nigeria meat products such as Tsire, Kilishi and Balangu are locally produced using one or more of these methods in order to meet the nutritional requirements of the teeming Nigerians (Egbebi, 2011).

Tsire is a popular Nigerian traditional processed ready-to-eat roasted stick meat product (Shamsuddeen, 2015). It is sold in public places, along roads, in hotels, parks, quarters and even offices (Falegan et al., 2017). It is prepared from boneless healthy animal flesh such as beef and mutton, spiced with peanut cake, salt, vegetable oil and other flavorings followed by roasting (Shamsuddeen, 2015). Consumption of these products has extended to other parts of African countries such as Ghana, Somali, Cameroun and Chad (Ahmadu and Ibrahim, 2013). 
BAJOPAS Volume 13 Number 1, June, 2020

However, evidence of quality control sticking to procedural hygiene by the handlers during preparation and retailing of these products is poorly documented. Tsire is of great safety risk because of the fact that there are erratic cases of gastroenteritis and symptoms of food infection after consumption (WHO, 2015). Food borne illnesses are one of the major health problems in developing and developed countries (Razavilar, 2010). According to the World Health Organization, WHO (2015), $0.07 \%$ death of the 600 million global burdens of Foodborne illnesses have been reported to be caused by bacteria, viruses, fungi and chemicals. In America $0.27 \%$ of the estimated 48 million affected people is hospitalized and about $0.0063 \%$ deaths are recorded each year (Scallan et al., 2011). More than 91 million people in Africa fall ill and $0.15 \%$ dies each year, making Africa the highest burden bearer of Foodborne diseases per population (WHO, 2015).

Application of a Hazard Analysis Critical Control Point (HACCP) at all stages of meat products preparation is essential in order to ensure its safety. Thus, according to the guidelines of good manufacturing practice, the level of total aerobic bacterial contamination of thermally processed meat products should not exceed $10^{4}\left(\mathrm{cfu} \mathrm{g}^{-1}\right)$. Enterobacteriaceae and faecal coliform contamination in meat products should be within the range of $10^{2}-10^{4}$ and $10-10^{3} \mathrm{cfu} \mathrm{g}^{-1}$, respectively (Shamsuddeen, 2015). The aim of the study is therefore, to assess the total viable bacterial counts of tsire marketed locally within Garko town, and to isolate and identify the organisms at the point of consumption with the intention of promoting public health and food hygiene habits in the Nigerian populace.

\section{MATERIALS AND METHODS Study Area and Population}

Garko is one of the existing 44 local government areas located in Kano south west zone of Kano state with its capital administrative headquarters in the Garko town. It has coordinates $11^{\circ} 39^{\prime} \mathrm{N}$ $8^{\circ} 54^{\prime} \mathrm{E}$, and an area of $450 \mathrm{~km}^{2}$. The projected population of Garko local Government was 225,300 according to the National Population Census report (2018). Garko is known for agricultural activities both farming and animal husbandry. It is popularly known for large scale rice production. Other food crops include sweet potatoes, cassava, onions, sorghum, millet and sugarcane. Cows, sheep and goats are major groups of animals reared by majority of the populace. Meat products processed, retailed and consumed in Garko include roasted meat (Balangu), dried roasted meat (Kilishi), stick meat (Tsire), hide and skin pepper soup (Ragadada) and minced fried meat (Danbunnama).

\section{Samples Collection}

Five samples of Tsire products were collected from 6 different identified locations within Garko town in a sterile foil paper and immediately analyzed for the presence of bacteria.

\section{Sample Preparation}

Sample preparation for the bacteriological analysis was carried out in accordance with the method described by Atlas (1997). Twenty five grams $(25 \mathrm{~g})$ of the sample was homogenized in $225 \mathrm{ml}$ peptone water using Kenwood blender machine to obtain a $10^{1}$ homogenate. The homogenate was thoroughly shaken and $1 \mathrm{ml}$ pipetted into test tubes containing $9 \mathrm{ml}$ of peptone water $\left(10^{2}\right)$. The test tubes were further serially diluted to $10^{5}$.

Total Aerobic Mesophilic Bacterial Count

Total Aerobic mesophilic bacterial count was determined using the method described by Abdullahi et al. (2004) where $1 \mathrm{ml}$ of inoculums from $10^{1}$ to $10^{5}$ dilutions were transferred into duplicate Petri dishes and labeled accordingly. This was followed by pouring aseptically about $15 \mathrm{ml}$ of molten nutrient agar. The culture was homogenized by gentle spinning of the plates and allowed to solidify. The plates were incubated at $37^{\circ} \mathrm{C}$ for 24 hours. Plates containing 30-300 colonies were counted. The number of colony forming units per gram of a sample (cfu/g) was obtained by multiplying the average colony number with the inverse of the dilution factor.

\section{Enumeration and Detection of Coliform bacteria}

Detection and enumeration of coliform was carried out according to method described by Atlas, (1977). A set of 9 test tubes each containing $9 \mathrm{ml}$ of lactose broth and an inverted Durham tubes were autoclaved to expel air and to sterilize. Similarly, $1 \mathrm{ml}$ from the diluents $10^{1}$ was transferred to the first 3 test tubes, followed by $1 \mathrm{ml}$ from the diluents $10^{2}$ to the second set of 3 test tubes and finally the third diluents $10^{3}$ to the $3^{\text {rd }}$ set of 3 test tubes. All the 9 test tubes were incubated at $37^{\circ} \mathrm{C}$ for 24 hours. Tubes that showed gas and acid production after 24 hours were recorded as positive for the presence of Coliform. Negative tubes were further reincubated for 24 hours. Positive tubes were recorded. Estimate of most probable number of Coliform per gram of sample (MPN/g) was determined by comparing the number of gas positive tubes with the most probable number table. 
BAJOPAS Volume 13 Number 1, June, 2020 Identification of Coliform

A loop full of inoculum from gas positive tubes was streaked on to Eosine methylene blue (EMB) agar plate and incubated at $37^{\circ} \mathrm{C}$ for $24 \mathrm{hrs}$. Colonies which formed bluish black color with green metallic sheen, and reddish colonies were isolated on agar slants. Those colonies showing metallic sheen on EMB were sub cultured into tubes of lactose broth and incubated at $45^{\circ} \mathrm{C}$. The tubes were observed after $24 \mathrm{hrs}$ for gas production. This is the completed test for fecal coliform. Gram stain and other biochemical tests such as Indole, Methyl red, Voges-Proskauer and Citrate Utilization tests (IMVIC), Coagulase and Catalase tests were carried out for the Identification and confirmation of isolates.

\section{Procedure for Indole Test}

Indole test was carried out by preparing a Tryptone broth drawn in to test tubes, sterilized by autoclaving, inoculated with loopful of suspension and incubated at $37^{\circ} \mathrm{C}$ for 24 hours. Three drops of xylene was added in tubes, shaken vigorously and kept for the separation of two layers. One millilitre of Kovac's reagent was added and the formation of pink colour ring indicates positive Indole test.

\section{Procedure for Methyl Red Test}

Methyl red test was carried out by preparing Glucose phosphate broth, dispensed in test tubes, sterilized, inoculated with test culture and incubated at $37^{\circ} \mathrm{C}$ for 24 hours. Five drops of methyl-red indicator was added to the medium for the formation of red colour.

\section{Procedure for Voges-Proskauer Test}

Voges-Proskauer test was carried out by inoculating tubes with the bacterial culture followed by incubation for 48 hours at $37^{\circ} \mathrm{C}$. Separate pipettes were used to pipette $1 \mathrm{ml}$ from each culture tube into clean separate tubes. Eighteen drops $(0.5 \mathrm{ml})$ of Barrit's solution A (a-naphthol) was added to each tube containing glucose phosphate broth followed by the addition of an equal amount of solution $B$ into the same tube. The tubes were shaken at 30 seconds interval. A positive reaction was indicated by the development of a pink color, which turns red in 1-2 hours, after vigorous shaking.

\section{Procedure for Citrate Utilization Test}

Citrate Utilization Test was carried out by distributing melted agar (Simmon Citrate Agar) in to test tubes followed by sterilization at $121.5^{\circ} \mathrm{C}$ for 15 minutes. The test tubes were afterward held in slanted position, inoculated with the given bacterial culture and incubated at $37^{\circ} \mathrm{C}$ for $24 \mathrm{hrs}$. Positive test was indicated by color change of the media from green to blue.

\section{RESULTS AND DISCUSSIONS}

The results of this study are presented in tables $1,2,3$ and 4. Among the sampling areas Kofar Kudu had the highest aerobic mesophilic bacteria counts $4.0 \times 10^{5} \mathrm{cfu} / \mathrm{g}$ followed by Rinji $2.72 \times 10^{5} \mathrm{cfu} / \mathrm{g}$, while Tosaro had the least Aerobic mesophilic bacteria counts of $1.02 \times 10^{5}$ $\mathrm{cfu} / \mathrm{g}$ as indicated in Table 1.Makwalla had the highest coliform count $68 \mathrm{MPN} / \mathrm{g}$ followed by Rinji $37 \mathrm{MPN} / \mathrm{g}$. Tsohuwar Kasuwa had the least coliform counts $8 \mathrm{MPN} / \mathrm{g}$, (Table 2). Result from table 1 shows variation in the microbial contents among the samples which suggest variation in their sources, poor handling procedures and contamination from the processing environment. High coliform count and their differences within sampling areas is an indication of poor microbiological quality of the product. Ndahi et al. (2013) reported microbial load to be a function of the handling personnel and the environment. The results indicated that the samples were contaminated with bacteria as the counts exceeded the minimum safety level $\left(10^{4} \mathrm{cfu} / \mathrm{g}\right)$ for members of the Enterobacteriaceae family. However, it might be a reflection of poor hygienic practices which may contribute to health hazard to the potential consumers. Similarly, Inusa and Sa'id (2017); Osimani et al. (2015) reported that, the initial microbial content of the raw material play significant role in influencing the final microbial load of the finished product. Isolation of members of the Enterobacteriaceae such as $E$. coli, Klebsiella pneumoniae, Salmonella and Shigella signifies danger to the public health. These organisms are capable of producing endotoxins which trigger high fevers in infected individuals, and the enterotoxins which colonize the small intestines and lead to extreme dehydration as a result of vomiting and diarrhea sometimes with severe and fatal outcomes (Amaeze et al., 2016). From the 16 isolated organisms $E$. coli had the highest isolation rate $6(37.5 \%)$ (Table 3), this suggest faecal contamination of the products. $E$. coli is a common flora in the gastrointestinal tract responsible for diarrhea and extra-intestinal infections (CDC, 2011). The result is in conformity with the findings of Ndahi et al. (2013) and Shamsuddeen (2009). Also presence of campylobacter might be due to cross contamination from raw meat to finished product (Tsire). Staphylococcus aureus is a normal flora of the skin, nasal, genital, mouth or anal area in both humans and animals without any symptom of an infection (Matthew et al., 2013). Isolation of $S$. aureus in these study concords with the findings of Lucretia et al. (2018) from Suya sold in Rivers State. 
BAJOPAS Volume 13 Number 1, June, 2020

It is also in agreement with the findings of Yousafzai et al. (2018); Onuorah et al. (2015) and Tijjani and Jumare (2014) from tsire samples in different countries. Presence of $S$. aureus in foods is most of the time an indication of poor human handling, poor environment, unhygienic utensils and equipments used during processing (Igene et al., 2016; Okonko et al., 2013). Infections caused by $S$. aureus are difficult to treat leading to long hospitalization with consequent economic loss (Udobi et al., 2013). These include soft tissue infections, pneumonia, hospital-acquired postoperative wound infections, Staphylococcal food poisoning, impetigo and cellulitis (Charlene et al., 2013). Samples obtained from Dausai and Kofar Kudu had the highest isolation rate $4(80 \%)$ (Table 4 ) probably because of the much commercial activities taking place in the area which can lead to environmental contamination.

Table 1: Total Aerobic Mesophilic Bacterial Count of Tsire sold in Garko Town

\begin{tabular}{lll}
\hline Sampling Area & APC cfu/g & Mean \pm STD \\
\hline Dausai & $2.20 \times 10^{5}$ & $110000 \pm 14142.14$ \\
Kofar Kudu & $4.00 \times 10^{5}$ & $133333.3 \pm 23094.01$ \\
Makwalla & $1.30 \times 10^{5}$ & $32500 \pm 7187.953$ \\
Rinji & $2.72 \times 10^{5}$ & $90666.67 \pm 94769.90$ \\
Tosaro & $1.02 \times 10^{5}$ & $51000 \pm 15556.35$ \\
Tsohuwar Kasuwa & $1.75 \times 10^{5}$ & $35000 \pm 11357.82$ \\
\hline
\end{tabular}

Key: APC: Aerobic Mesophilic Counts

STD: Standard Deviation

Table 2: Total Coliform Count of Tsire sold in Garko Town

\begin{tabular}{lcc}
\hline \multicolumn{1}{c}{ Sampling Area } & TCC MPN/g & Mean \pm STD \\
\hline Dausai & 20 & $6.67 \pm 2.5166$ \\
Kofar Kudu & 32 & $16.00 \pm 5.6569$ \\
Makwalla & 68 & $13.60 \pm 8.7062$ \\
Rinji & 37 & $9.25 \pm 4.7871$ \\
Tosaro & 10 & $5.00 \pm 2.8284$ \\
Tsohuwar Kasuwa & 8 & $4.00 \pm 0.0000$ \\
\hline
\end{tabular}

Table 3: Organisms Isolated from Tsire Sold in Garko

\begin{tabular}{lcl}
\hline Isolated Organism & Frequency & Percentage (\%) \\
\hline Campylobacter & 2 & 06.66 \\
Escherichia coli & 6 & 20.00 \\
Klebsiella pneumoniae & 2 & 06.66 \\
Salmonella species & 1 & 03.33 \\
Shigella & 3 & 10.00 \\
Staphylococcus aureus & 2 & 06.66 \\
Total & 16 & \\
\hline
\end{tabular}

Table 4: Distribution of Organisms within Sampling Area

\begin{tabular}{lcc}
\hline \multicolumn{1}{c}{ Sampling Area } & No. Isolated & Percentage (\%) \\
\hline Dausai & 4 & 80 \\
Kofar Kudu & 4 & 80 \\
Makwalla & 2 & 40 \\
Rinji & 3 & 60 \\
Tosaro & 2 & 40 \\
Tsohuwar Kasuwa & 1 & 20 \\
Total & 16 & \\
\hline
\end{tabular}

\section{CONCLUSION}

Results indicated $4.00 \times 10^{5} \mathrm{CFU} / \mathrm{g}$ as the highest APCs count; while $68 \mathrm{MPN} / \mathrm{g}$ was the highest TCCs from the 30 samples analyzed. Among the isolates, $E$. coli has the highest isolation rate of $6(20 \%)$. Dausai and Kofar kudu were having the highest bacteria count of $4(80 \%)$, each, indicating higher contamination in those locations. 
BAJOPAS Volume 13 Number 1, June, 2020 RECOMMENDATIONS

The following recommendations are tenable:

1. Hygienic practices at all stages of production should be improved to safe guard the consumers against potential health hazard.

2. Monitoring of microbiological contamination of Tsire during preparations, packaging and marketing is essential to ensure product of good microbiological quality for consumers' health.

\section{REFERENCES}

Abdullahi, I. O., Umoh, V. J. and Galadima, M. (2004). Hazards Associated with Kilishi Preparations in Zaria. Nigerian Journal of Microbiology, 18 (1-2): $339-345$.

Ahmadu, J. and Ibrahim E. J., (2013): Determinants of Revenue in Suya Production in BeninCity, Edo State, Nigeria. Nigerian journal of agriculture, food and environment.9(3):1-5

Amaeze, N. Aboh, M. Itohan, A. Felix, E. Olatunji, T. and Oladosu, P. (2016) Microbial Profile, Antibiotic Sensitivity and Heat Resistance of Bacterial Isolates from Commercial Roasted Beef (Suya) in Abuja, Nigeria. JOPAT, 15(2): $22-30$.

Apata, E.S., Kuku1, I.A., Apata, O.C. and Adeyemi, K.O. (2013). Evaluation of Suya(Tsire) - An Intermediate Moisture Meat Product in Ogun State, Nigeria. J. Food Res 2 (1): 87.

Atlas, R. M. (1997) Principles of Microbiology Second Edition. C. Brown Publishers. Pp 802-803.

Borch, E. Kant-Muermans, M. L., Blixt, Y. (1996) Bacterial Spoilage of Meat and Cured Meat Products. Int $\mathrm{J}$ Food Microbiol .33(1): 103-20.

Centre for Disease Control, CDC (2011). "Escherichia coli 0157:H7" Division of Bacterial and Mycotic Diseasesht://www.cdc.gov/nczved/divisi ons/dfbmd/diseases/ecoli_0157h7/.

Charlene, R. J., Johnnie, A. D., and John, B. B., (2013) Prevalence and Characterization of Methicillin-Resistant Staphylococcus aureus Isolates from Retail Meat and Humans in Georgia. American society for Microbiology. J. of clinical microbiology. 12(1):123-6 doi:10.1128/JCM.0316612JCM.03166-12

Egbebi, A.O and Seidu, K., T. (2011). Microbiological Evaluation of Suya (dried smoked

meat) Sold in Ado and Akure, South West Nigeria.European Journal of Experinmental Biology, 1(4):1-5
3. Government should establish regulatory bodies responsible for inculcating hygiene habits to the local producers and vendors in order to prevent instant, cross and post processing contaminations by microbial pathogens.

4. Awareness and sensitization of local food producers about good hygienic practices in food handling and processing.

Falegan, C, R., Akoja, S. D., and Oyarekua, M. A., (2017) Microbiological Assessment of Suya (Sliced Roasted Beef) in Ado-Ekiti Metropolis, Ekiti State, Nigeria. MOJ Biology andMedicine.

Fonkem, D., N. Tanya, V., N. and Ebangi, A., L. (2010). Effect of Season on the Microbiological Quality of Kilishi, a Traditional Cameroonian Dried Beef Product. Tropicultura, 28(1): 10-15.

Food and Agricultural Organization of the United Nations (F A O, 1979). Manual of food quality control 4. Microbiological analysis.

Food and Agriculture Organisation of the United Nation (FAO), 2019. Nigeria at a glance.

Igene J.O., Uwadia, O.E., Ebabhamiegbebho, P.A. and Evivie, S.E., (2016) Shelf life Stability Studies of University of Benin (UNIBEN) Proff's Kilishi Product Asian Journal of Science and Technology 7(1): 2268-2274.

Inusa, S. K. and Said, I. S. (2017) Evaluation of the Chemical and Microbiological Properties Of Kilishi Sold in Kano Metropolis. Journal of Dry land Agriculture, 3 (1): $59-69$.

Lucretia, I. B, Patience, C. Obinna-Echem, Sophia, C. A. (2018) Microbiological quality andantibiotic sensitivity of potential pathogens isolated from meat product (Suya) sold in Rivers State University and its environs. International Journal of Biotechnology and Food Science, 6(4): 67-76.

Matthew, E., Drosos, E., John, L. and Ioanna, P. (2013) MRSA in Africa: Filling the Global Map of Antimicrobial Resistance PLOS One. 8(7): e68024 doi: 10.1371/journal.pone.0068024

Mgbemere, V.N., Akpapunam, M. A. and Igene, J. O., (2011). Effect of Groundnut FlourSubstitution on Yield, Quality and Storage Stability of Kilishi - a Nigerian Indigenous Dried Meat Product. African Journal of Food, Agriculture, Nutrition and Development, $\quad \mathbf{1 1}(2)$ : 4718-4738. 
BAJOPAS Volume 13 Number 1, June, 2020

Mubarak, A. A., Azeez, M. L., Amos A. O., Opeyemi, O. O. (2016) Assessment of Animal Protein Consumption and Food Security Among Rural Households in Kwara State, Nigeria American Journal of Business and Society, 1(4): 233245.

Ndahi, M., D. Kwaga, J., K. P. Bello, M. Kabir J., V. Umoh, .J. Yakubu, S., E. and Nok, A., J. (2013) Prevalence and Antimicrobial Susceptibility of Listeria Monocytogenes and Methicillin-Resistant Staphylococcus aureus Strains from Raw Meat and Meat Products in Zaria, Nigeria. Applied Journal of Microbiology, 58(3):262-9.

Okonko, I.O., Odu, N.N. and Igboh, I.E. (2013). Microbiological Analysis of Kilishi Sold In Port Harcourt, Nigeria. New York Science Journal, 6 (7):37-43.

Osimani, A., Aquilanti, L. and Clementi, F. (2015) Microbiological Quality of Meatbased Meals and Operation of Control Systems within a Food Service Environment. International Food Research Journal 22(4): 1692-1698.

Onuorah, S. Obika, I. Odibo, F. Orji, M. (2015)An Assessment of the Bacteriological Quality of Tsire-Suya (Grilled Beef) sold in Awka, Nigeria. American. J. Life. Sci. Res. 3(4):287292.

Razavilar, V, Khandaghi, J. Barzgari, A. (2010); Isolation of Eschericia coli 0157:H7 from manure fertilized farms and raw vegetables grown on it, in Tabriz city in
Iran. African Journal of Microbiology Research, 4(9): 891-895.

Scallan, E. Hoekstra, R. M. Angulo, F. J.Tauxe, R. V, Widdowson, M. Roy, S. L et al., (2011).Food borne illness acquired in the United States- Major Pathogens. Emerg. Infec Dis, 17(1): 7-15.

Shamsuddeen U (2009). Microbiological quality of spice used in the production of Kilishi a traditionally dried and grilled meat product. Bayero Journal of Pure andApplied Sciences, 2(2): 66-69.

Shamsuddeen, U. (2015) Microbiological Hazard and Critical control point Analysis of Dried and Minced Meat Snacks Produced in Kano Nigeria. Lambert Academic Publishing; Pp 1-36.

Tijani, O.and Jumare, S. (2014). Microblological Quality Assessment of Meat

Sold in KauraNamoda. International Conference on Earth, Environment and Life sciences (EELS) Dubai (UAE).

Udobi, C. E., Obajuluwa, A. F., and Onaolapo, J. A., (2013) Prevalence and Antibiotic Resistance Pattern of MethicillinResistant Staphylococcus aureus from an Orthopaedic Hospital in Nigeria BioMed Research International; 26(6); 6-7.

WHO, 2015 Foodborne diseases in the WHO African Region.

Yousafzai HA, Rind R, Khan MA, Abro SH, Korejo NA, Ejaz M, Kabir A, Shahid M, Memon S. (2019). Microbiological Contamination of Cattle and Meat in Peshawar, Pakistan. J. Anim. Health Prod. 7(1): 1116. 


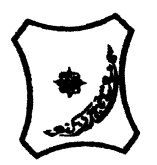

Bayero Journal of Pure and Applied Sciences, 13(1); 40 - 45

Received: September, 2019

Accepted: April, 2020

ISSN $2006-6996$

\title{
BACTERIOLOGICAL QUALITY OF STICK MEAT (Tsire) SOLD IN GARKO LOCAL GOVERNMENT AREA OF KANO STATE, NIGERIA
}

\author{
$*^{1}$ Dahiru A. T. and ${ }^{2}$ Maigari A. K. \\ ${ }^{1}$ Department of Hospitality Management, School of Technology, Kano State Polytechnic, PMB 3348, \\ Kano Nigeria. \\ ${ }^{2}$ Departmnt of Biological Sciences, Bayero University, Kano \\ Corresponding Author: dturajo61@gmail.com; GSM: 08087508262.
}

ABSTRACT

Stick meat, locally called Tsire in Hausa Language, is a significant portion of the diet of a large active population of Northern Nigeria. However, because of the handling and processing methods by the manufacturers as well as the hawking system of stick meat, the meat product may be exposed to both pre- and post-processed product contamination, and thus may poses danger to public health. Therefore, considering the role of Tsire in improving nutrition and increase household income to the populace, the need to improve the processing, distribution and overall quality of the product is simply indispensable. A total of 30 samples (5 samples from each of the 6 sampling points) of Tsire were collected randomly in Garko Town. Aerobic plate counts (APCs) and Total coliform counts (TCCS) of Tsire samples were determined using standard microbiological methods. APCs ranged from $1.02 \times 10^{5}$ to $4.00 \times 10^{5} \mathrm{CFU} / \mathrm{g}$; while TCCs ranged from $8 \mathrm{MPN} / \mathrm{g}$ to $68 \mathrm{MPN} / \mathrm{g}$. From the 30 samples screened, 16(53.33\%) bacteria namely, Campylobacter 2(6.66\%), Escherichia coli 6(20\%), Klebsiella pneumoniae 2(6.66\%), Salmonella spp. 1(3.33\%), Shigella 3(10\%) and Staphylococcus aureus 2(6.66\%) were detected. $E$. coli has the highest isolation rate of 6(20\%), while Salmonella spp. had the least frequency of 1(3.33\%). The distribution of isolated organisms within the study area were as follows: Dausai, 4(80\%), Kofar kudu, 4(80\%), Makwalla, 2(40\%), Rinji, 3(60\%), Tosaro, 2(40\%), and Tsohuwar Kasuwa, 1(20\%). The results have indicated that the Tsire was contaminated with bacteria thus exposing the product to fast deterioration, spoilage and also a vehicle for food borne illness, suggesting for adequate hygienic practices at all the stages, prior to consumption, to ensure safety of the meat product.

Key words: APCs, TCCs, Contamination, Microorganisms, Garko

\section{INTRODUCTION}

Nigeria is one of the developing nations with inadequate food supply and most often deficient in protein content (FAO, 2019). Nigerian's average animal protein intake per head per day is estimated at $7.9 \mathrm{~g}$ as against $35 \mathrm{~g}$ recommended value by Food and Agricultural Organization (Mubarak et al., 2016). These low levels of animal protein intake create great concern as it affects the nutritional status of Nigerians. Hence, there is the need for sufficient supply of animal protein from energy rich animal products to satisfy the nutritional requirements for Nigerians.

Meat is one major source of animal protein largely composed of water, protein and fats which can make it susceptible to microbial contamination within short time leading to spoilage (Apata et al., 2013; Mgbemere et al., 2011). Meat is mostly eaten after it has been cooked or processed in a variety of ways such as sun drying; smoking and roasting with or without fortifications (Borch et al., 1996). In Nigeria meat products such as Tsire, Kilishi and Balangu are locally produced using one or more of these methods in order to meet the nutritional requirements of the teeming Nigerians (Egbebi, 2011).

Tsire is a popular Nigerian traditional processed ready-to-eat roasted stick meat product (Shamsuddeen, 2015). It is sold in public places, along roads, in hotels, parks, quarters and even offices (Falegan et al., 2017). It is prepared from boneless healthy animal flesh such as beef and mutton, spiced with peanut cake, salt, vegetable oil and other flavorings followed by roasting (Shamsuddeen, 2015). Consumption of these products has extended to other parts of African countries such as Ghana, Somali, Cameroun and Chad (Ahmadu and Ibrahim, 2013). 
BAJOPAS Volume 13 Number 1, June, 2020

However, evidence of quality control sticking to procedural hygiene by the handlers during preparation and retailing of these products is poorly documented. Tsire is of great safety risk because of the fact that there are erratic cases of gastroenteritis and symptoms of food infection after consumption (WHO, 2015). Food borne illnesses are one of the major health problems in developing and developed countries (Razavilar, 2010). According to the World Health Organization, WHO (2015), $0.07 \%$ death of the 600 million global burdens of Foodborne illnesses have been reported to be caused by bacteria, viruses, fungi and chemicals. In America $0.27 \%$ of the estimated 48 million affected people is hospitalized and about $0.0063 \%$ deaths are recorded each year (Scallan et al., 2011). More than 91 million people in Africa fall ill and $0.15 \%$ dies each year, making Africa the highest burden bearer of Foodborne diseases per population (WHO, 2015).

Application of a Hazard Analysis Critical Control Point (HACCP) at all stages of meat products preparation is essential in order to ensure its safety. Thus, according to the guidelines of good manufacturing practice, the level of total aerobic bacterial contamination of thermally processed meat products should not exceed $10^{4}\left(\mathrm{cfu} \mathrm{g}^{-1}\right)$. Enterobacteriaceae and faecal coliform contamination in meat products should be within the range of $10^{2}-10^{4}$ and $10-10^{3} \mathrm{cfu} \mathrm{g}^{-1}$, respectively (Shamsuddeen, 2015). The aim of the study is therefore, to assess the total viable bacterial counts of tsire marketed locally within Garko town, and to isolate and identify the organisms at the point of consumption with the intention of promoting public health and food hygiene habits in the Nigerian populace.

\section{MATERIALS AND METHODS Study Area and Population}

Garko is one of the existing 44 local government areas located in Kano south west zone of Kano state with its capital administrative headquarters in the Garko town. It has coordinates $11^{\circ} 39^{\prime} \mathrm{N}$ $8^{\circ} 54^{\prime} \mathrm{E}$, and an area of $450 \mathrm{~km}^{2}$. The projected population of Garko local Government was 225,300 according to the National Population Census report (2018). Garko is known for agricultural activities both farming and animal husbandry. It is popularly known for large scale rice production. Other food crops include sweet potatoes, cassava, onions, sorghum, millet and sugarcane. Cows, sheep and goats are major groups of animals reared by majority of the populace. Meat products processed, retailed and consumed in Garko include roasted meat (Balangu), dried roasted meat (Kilishi), stick meat (Tsire), hide and skin pepper soup (Ragadada) and minced fried meat (Danbunnama).

\section{Samples Collection}

Five samples of Tsire products were collected from 6 different identified locations within Garko town in a sterile foil paper and immediately analyzed for the presence of bacteria.

\section{Sample Preparation}

Sample preparation for the bacteriological analysis was carried out in accordance with the method described by Atlas (1997). Twenty five grams $(25 \mathrm{~g})$ of the sample was homogenized in $225 \mathrm{ml}$ peptone water using Kenwood blender machine to obtain a $10^{1}$ homogenate. The homogenate was thoroughly shaken and $1 \mathrm{ml}$ pipetted into test tubes containing $9 \mathrm{ml}$ of peptone water $\left(10^{2}\right)$. The test tubes were further serially diluted to $10^{5}$.

Total Aerobic Mesophilic Bacterial Count

Total Aerobic mesophilic bacterial count was determined using the method described by Abdullahi et al. (2004) where $1 \mathrm{ml}$ of inoculums from $10^{1}$ to $10^{5}$ dilutions were transferred into duplicate Petri dishes and labeled accordingly. This was followed by pouring aseptically about $15 \mathrm{ml}$ of molten nutrient agar. The culture was homogenized by gentle spinning of the plates and allowed to solidify. The plates were incubated at $37^{\circ} \mathrm{C}$ for 24 hours. Plates containing 30-300 colonies were counted. The number of colony forming units per gram of a sample (cfu/g) was obtained by multiplying the average colony number with the inverse of the dilution factor.

\section{Enumeration and Detection of Coliform bacteria}

Detection and enumeration of coliform was carried out according to method described by Atlas, (1977). A set of 9 test tubes each containing $9 \mathrm{ml}$ of lactose broth and an inverted Durham tubes were autoclaved to expel air and to sterilize. Similarly, $1 \mathrm{ml}$ from the diluents $10^{1}$ was transferred to the first 3 test tubes, followed by $1 \mathrm{ml}$ from the diluents $10^{2}$ to the second set of 3 test tubes and finally the third diluents $10^{3}$ to the $3^{\text {rd }}$ set of 3 test tubes. All the 9 test tubes were incubated at $37^{\circ} \mathrm{C}$ for 24 hours. Tubes that showed gas and acid production after 24 hours were recorded as positive for the presence of Coliform. Negative tubes were further reincubated for 24 hours. Positive tubes were recorded. Estimate of most probable number of Coliform per gram of sample (MPN/g) was determined by comparing the number of gas positive tubes with the most probable number table. 
BAJOPAS Volume 13 Number 1, June, 2020 Identification of Coliform

A loop full of inoculum from gas positive tubes was streaked on to Eosine methylene blue (EMB) agar plate and incubated at $37^{\circ} \mathrm{C}$ for $24 \mathrm{hrs}$. Colonies which formed bluish black color with green metallic sheen, and reddish colonies were isolated on agar slants. Those colonies showing metallic sheen on EMB were sub cultured into tubes of lactose broth and incubated at $45^{\circ} \mathrm{C}$. The tubes were observed after $24 \mathrm{hrs}$ for gas production. This is the completed test for fecal coliform. Gram stain and other biochemical tests such as Indole, Methyl red, Voges-Proskauer and Citrate Utilization tests (IMVIC), Coagulase and Catalase tests were carried out for the Identification and confirmation of isolates.

\section{Procedure for Indole Test}

Indole test was carried out by preparing a Tryptone broth drawn in to test tubes, sterilized by autoclaving, inoculated with loopful of suspension and incubated at $37^{\circ} \mathrm{C}$ for 24 hours. Three drops of xylene was added in tubes, shaken vigorously and kept for the separation of two layers. One millilitre of Kovac's reagent was added and the formation of pink colour ring indicates positive Indole test.

\section{Procedure for Methyl Red Test}

Methyl red test was carried out by preparing Glucose phosphate broth, dispensed in test tubes, sterilized, inoculated with test culture and incubated at $37^{\circ} \mathrm{C}$ for 24 hours. Five drops of methyl-red indicator was added to the medium for the formation of red colour.

\section{Procedure for Voges-Proskauer Test}

Voges-Proskauer test was carried out by inoculating tubes with the bacterial culture followed by incubation for 48 hours at $37^{\circ} \mathrm{C}$. Separate pipettes were used to pipette $1 \mathrm{ml}$ from each culture tube into clean separate tubes. Eighteen drops $(0.5 \mathrm{ml})$ of Barrit's solution A (a-naphthol) was added to each tube containing glucose phosphate broth followed by the addition of an equal amount of solution $B$ into the same tube. The tubes were shaken at 30 seconds interval. A positive reaction was indicated by the development of a pink color, which turns red in 1-2 hours, after vigorous shaking.

\section{Procedure for Citrate Utilization Test}

Citrate Utilization Test was carried out by distributing melted agar (Simmon Citrate Agar) in to test tubes followed by sterilization at $121.5^{\circ} \mathrm{C}$ for 15 minutes. The test tubes were afterward held in slanted position, inoculated with the given bacterial culture and incubated at $37^{\circ} \mathrm{C}$ for $24 \mathrm{hrs}$. Positive test was indicated by color change of the media from green to blue.

\section{RESULTS AND DISCUSSIONS}

The results of this study are presented in tables $1,2,3$ and 4. Among the sampling areas Kofar Kudu had the highest aerobic mesophilic bacteria counts $4.0 \times 10^{5} \mathrm{cfu} / \mathrm{g}$ followed by Rinji $2.72 \times 10^{5} \mathrm{cfu} / \mathrm{g}$, while Tosaro had the least Aerobic mesophilic bacteria counts of $1.02 \times 10^{5}$ $\mathrm{cfu} / \mathrm{g}$ as indicated in Table 1.Makwalla had the highest coliform count $68 \mathrm{MPN} / \mathrm{g}$ followed by Rinji $37 \mathrm{MPN} / \mathrm{g}$. Tsohuwar Kasuwa had the least coliform counts $8 \mathrm{MPN} / \mathrm{g}$, (Table 2). Result from table 1 shows variation in the microbial contents among the samples which suggest variation in their sources, poor handling procedures and contamination from the processing environment. High coliform count and their differences within sampling areas is an indication of poor microbiological quality of the product. Ndahi et al. (2013) reported microbial load to be a function of the handling personnel and the environment. The results indicated that the samples were contaminated with bacteria as the counts exceeded the minimum safety level $\left(10^{4} \mathrm{cfu} / \mathrm{g}\right)$ for members of the Enterobacteriaceae family. However, it might be a reflection of poor hygienic practices which may contribute to health hazard to the potential consumers. Similarly, Inusa and Sa'id (2017); Osimani et al. (2015) reported that, the initial microbial content of the raw material play significant role in influencing the final microbial load of the finished product. Isolation of members of the Enterobacteriaceae such as $E$. coli, Klebsiella pneumoniae, Salmonella and Shigella signifies danger to the public health. These organisms are capable of producing endotoxins which trigger high fevers in infected individuals, and the enterotoxins which colonize the small intestines and lead to extreme dehydration as a result of vomiting and diarrhea sometimes with severe and fatal outcomes (Amaeze et al., 2016). From the 16 isolated organisms $E$. coli had the highest isolation rate $6(37.5 \%)$ (Table 3), this suggest faecal contamination of the products. $E$. coli is a common flora in the gastrointestinal tract responsible for diarrhea and extra-intestinal infections (CDC, 2011). The result is in conformity with the findings of Ndahi et al. (2013) and Shamsuddeen (2009). Also presence of campylobacter might be due to cross contamination from raw meat to finished product (Tsire). Staphylococcus aureus is a normal flora of the skin, nasal, genital, mouth or anal area in both humans and animals without any symptom of an infection (Matthew et al., 2013). Isolation of $S$. aureus in these study concords with the findings of Lucretia et al. (2018) from Suya sold in Rivers State. 
BAJOPAS Volume 13 Number 1, June, 2020

It is also in agreement with the findings of Yousafzai et al. (2018); Onuorah et al. (2015) and Tijjani and Jumare (2014) from tsire samples in different countries. Presence of $S$. aureus in foods is most of the time an indication of poor human handling, poor environment, unhygienic utensils and equipments used during processing (Igene et al., 2016; Okonko et al., 2013). Infections caused by $S$. aureus are difficult to treat leading to long hospitalization with consequent economic loss (Udobi et al., 2013). These include soft tissue infections, pneumonia, hospital-acquired postoperative wound infections, Staphylococcal food poisoning, impetigo and cellulitis (Charlene et al., 2013). Samples obtained from Dausai and Kofar Kudu had the highest isolation rate $4(80 \%)$ (Table 4 ) probably because of the much commercial activities taking place in the area which can lead to environmental contamination.

Table 1: Total Aerobic Mesophilic Bacterial Count of Tsire sold in Garko Town

\begin{tabular}{lll}
\hline Sampling Area & APC cfu/g & Mean \pm STD \\
\hline Dausai & $2.20 \times 10^{5}$ & $110000 \pm 14142.14$ \\
Kofar Kudu & $4.00 \times 10^{5}$ & $133333.3 \pm 23094.01$ \\
Makwalla & $1.30 \times 10^{5}$ & $32500 \pm 7187.953$ \\
Rinji & $2.72 \times 10^{5}$ & $90666.67 \pm 94769.90$ \\
Tosaro & $1.02 \times 10^{5}$ & $51000 \pm 15556.35$ \\
Tsohuwar Kasuwa & $1.75 \times 10^{5}$ & $35000 \pm 11357.82$ \\
\hline
\end{tabular}

Key: APC: Aerobic Mesophilic Counts

STD: Standard Deviation

Table 2: Total Coliform Count of Tsire sold in Garko Town

\begin{tabular}{lcc}
\hline \multicolumn{1}{c}{ Sampling Area } & TCC MPN/g & Mean \pm STD \\
\hline Dausai & 20 & $6.67 \pm 2.5166$ \\
Kofar Kudu & 32 & $16.00 \pm 5.6569$ \\
Makwalla & 68 & $13.60 \pm 8.7062$ \\
Rinji & 37 & $9.25 \pm 4.7871$ \\
Tosaro & 10 & $5.00 \pm 2.8284$ \\
Tsohuwar Kasuwa & 8 & $4.00 \pm 0.0000$ \\
\hline
\end{tabular}

Table 3: Organisms Isolated from Tsire Sold in Garko

\begin{tabular}{lcl}
\hline Isolated Organism & Frequency & Percentage (\%) \\
\hline Campylobacter & 2 & 06.66 \\
Escherichia coli & 6 & 20.00 \\
Klebsiella pneumoniae & 2 & 06.66 \\
Salmonella species & 1 & 03.33 \\
Shigella & 3 & 10.00 \\
Staphylococcus aureus & 2 & 06.66 \\
Total & 16 & \\
\hline
\end{tabular}

Table 4: Distribution of Organisms within Sampling Area

\begin{tabular}{lcc}
\hline \multicolumn{1}{c}{ Sampling Area } & No. Isolated & Percentage (\%) \\
\hline Dausai & 4 & 80 \\
Kofar Kudu & 4 & 80 \\
Makwalla & 2 & 40 \\
Rinji & 3 & 60 \\
Tosaro & 2 & 40 \\
Tsohuwar Kasuwa & 1 & 20 \\
Total & 16 & \\
\hline
\end{tabular}

\section{CONCLUSION}

Results indicated $4.00 \times 10^{5} \mathrm{CFU} / \mathrm{g}$ as the highest APCs count; while $68 \mathrm{MPN} / \mathrm{g}$ was the highest TCCs from the 30 samples analyzed. Among the isolates, $E$. coli has the highest isolation rate of $6(20 \%)$. Dausai and Kofar kudu were having the highest bacteria count of $4(80 \%)$, each, indicating higher contamination in those locations. 
BAJOPAS Volume 13 Number 1, June, 2020 RECOMMENDATIONS

The following recommendations are tenable:

1. Hygienic practices at all stages of production should be improved to safe guard the consumers against potential health hazard.

2. Monitoring of microbiological contamination of Tsire during preparations, packaging and marketing is essential to ensure product of good microbiological quality for consumers' health.

\section{REFERENCES}

Abdullahi, I. O., Umoh, V. J. and Galadima, M. (2004). Hazards Associated with Kilishi Preparations in Zaria. Nigerian Journal of Microbiology, 18 (1-2): $339-345$.

Ahmadu, J. and Ibrahim E. J., (2013): Determinants of Revenue in Suya Production in BeninCity, Edo State, Nigeria. Nigerian journal of agriculture, food and environment.9(3):1-5

Amaeze, N. Aboh, M. Itohan, A. Felix, E. Olatunji, T. and Oladosu, P. (2016) Microbial Profile, Antibiotic Sensitivity and Heat Resistance of Bacterial Isolates from Commercial Roasted Beef (Suya) in Abuja, Nigeria. JOPAT, 15(2): $22-30$.

Apata, E.S., Kuku1, I.A., Apata, O.C. and Adeyemi, K.O. (2013). Evaluation of Suya(Tsire) - An Intermediate Moisture Meat Product in Ogun State, Nigeria. J. Food Res 2 (1): 87.

Atlas, R. M. (1997) Principles of Microbiology Second Edition. C. Brown Publishers. Pp 802-803.

Borch, E. Kant-Muermans, M. L., Blixt, Y. (1996) Bacterial Spoilage of Meat and Cured Meat Products. Int $\mathrm{J}$ Food Microbiol .33(1): 103-20.

Centre for Disease Control, CDC (2011). "Escherichia coli 0157:H7" Division of Bacterial and Mycotic Diseasesht://www.cdc.gov/nczved/divisi ons/dfbmd/diseases/ecoli_0157h7/.

Charlene, R. J., Johnnie, A. D., and John, B. B., (2013) Prevalence and Characterization of Methicillin-Resistant Staphylococcus aureus Isolates from Retail Meat and Humans in Georgia. American society for Microbiology. J. of clinical microbiology. 12(1):123-6 doi:10.1128/JCM.0316612JCM.03166-12

Egbebi, A.O and Seidu, K., T. (2011). Microbiological Evaluation of Suya (dried smoked

meat) Sold in Ado and Akure, South West Nigeria.European Journal of Experinmental Biology, 1(4):1-5
3. Government should establish regulatory bodies responsible for inculcating hygiene habits to the local producers and vendors in order to prevent instant, cross and post processing contaminations by microbial pathogens.

4. Awareness and sensitization of local food producers about good hygienic practices in food handling and processing.

Falegan, C, R., Akoja, S. D., and Oyarekua, M. A., (2017) Microbiological Assessment of Suya (Sliced Roasted Beef) in Ado-Ekiti Metropolis, Ekiti State, Nigeria. MOJ Biology andMedicine.

Fonkem, D., N. Tanya, V., N. and Ebangi, A., L. (2010). Effect of Season on the Microbiological Quality of Kilishi, a Traditional Cameroonian Dried Beef Product. Tropicultura, 28(1): 10-15.

Food and Agricultural Organization of the United Nations (F A O, 1979). Manual of food quality control 4. Microbiological analysis.

Food and Agriculture Organisation of the United Nation (FAO), 2019. Nigeria at a glance.

Igene J.O., Uwadia, O.E., Ebabhamiegbebho, P.A. and Evivie, S.E., (2016) Shelf life Stability Studies of University of Benin (UNIBEN) Proff's Kilishi Product Asian Journal of Science and Technology 7(1): 2268-2274.

Inusa, S. K. and Said, I. S. (2017) Evaluation of the Chemical and Microbiological Properties Of Kilishi Sold in Kano Metropolis. Journal of Dry land Agriculture, 3 (1): $59-69$.

Lucretia, I. B, Patience, C. Obinna-Echem, Sophia, C. A. (2018) Microbiological quality andantibiotic sensitivity of potential pathogens isolated from meat product (Suya) sold in Rivers State University and its environs. International Journal of Biotechnology and Food Science, 6(4): 67-76.

Matthew, E., Drosos, E., John, L. and Ioanna, P. (2013) MRSA in Africa: Filling the Global Map of Antimicrobial Resistance PLOS One. 8(7): e68024 doi: 10.1371/journal.pone.0068024

Mgbemere, V.N., Akpapunam, M. A. and Igene, J. O., (2011). Effect of Groundnut FlourSubstitution on Yield, Quality and Storage Stability of Kilishi - a Nigerian Indigenous Dried Meat Product. African Journal of Food, Agriculture, Nutrition and Development, $\quad \mathbf{1 1}(2)$ : 4718-4738. 
BAJOPAS Volume 13 Number 1, June, 2020

Mubarak, A. A., Azeez, M. L., Amos A. O., Opeyemi, O. O. (2016) Assessment of Animal Protein Consumption and Food Security Among Rural Households in Kwara State, Nigeria American Journal of Business and Society, 1(4): 233245.

Ndahi, M., D. Kwaga, J., K. P. Bello, M. Kabir J., V. Umoh, .J. Yakubu, S., E. and Nok, A., J. (2013) Prevalence and Antimicrobial Susceptibility of Listeria Monocytogenes and Methicillin-Resistant Staphylococcus aureus Strains from Raw Meat and Meat Products in Zaria, Nigeria. Applied Journal of Microbiology, 58(3):262-9.

Okonko, I.O., Odu, N.N. and Igboh, I.E. (2013). Microbiological Analysis of Kilishi Sold In Port Harcourt, Nigeria. New York Science Journal, 6 (7):37-43.

Osimani, A., Aquilanti, L. and Clementi, F. (2015) Microbiological Quality of Meatbased Meals and Operation of Control Systems within a Food Service Environment. International Food Research Journal 22(4): 1692-1698.

Onuorah, S. Obika, I. Odibo, F. Orji, M. (2015)An Assessment of the Bacteriological Quality of Tsire-Suya (Grilled Beef) sold in Awka, Nigeria. American. J. Life. Sci. Res. 3(4):287292.

Razavilar, V, Khandaghi, J. Barzgari, A. (2010); Isolation of Eschericia coli 0157:H7 from manure fertilized farms and raw vegetables grown on it, in Tabriz city in
Iran. African Journal of Microbiology Research, 4(9): 891-895.

Scallan, E. Hoekstra, R. M. Angulo, F. J.Tauxe, R. V, Widdowson, M. Roy, S. L et al., (2011).Food borne illness acquired in the United States- Major Pathogens. Emerg. Infec Dis, 17(1): 7-15.

Shamsuddeen U (2009). Microbiological quality of spice used in the production of Kilishi a traditionally dried and grilled meat product. Bayero Journal of Pure andApplied Sciences, 2(2): 66-69.

Shamsuddeen, U. (2015) Microbiological Hazard and Critical control point Analysis of Dried and Minced Meat Snacks Produced in Kano Nigeria. Lambert Academic Publishing; Pp 1-36.

Tijani, O.and Jumare, S. (2014). Microblological Quality Assessment of Meat

Sold in KauraNamoda. International Conference on Earth, Environment and Life sciences (EELS) Dubai (UAE).

Udobi, C. E., Obajuluwa, A. F., and Onaolapo, J. A., (2013) Prevalence and Antibiotic Resistance Pattern of MethicillinResistant Staphylococcus aureus from an Orthopaedic Hospital in Nigeria BioMed Research International; 26(6); 6-7.

WHO, 2015 Foodborne diseases in the WHO African Region.

Yousafzai HA, Rind R, Khan MA, Abro SH, Korejo NA, Ejaz M, Kabir A, Shahid M, Memon S. (2019). Microbiological Contamination of Cattle and Meat in Peshawar, Pakistan. J. Anim. Health Prod. 7(1): 1116. 


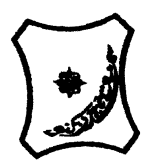

Bayero Journal of Pure and Applied Sciences, 13(1); 40 - 45

Received: September, 2019

Accepted: April, 2020

ISSN $2006-6996$

\title{
BACTERIOLOGICAL QUALITY OF STICK MEAT (Tsire) SOLD IN GARKO LOCAL GOVERNMENT AREA OF KANO STATE, NIGERIA
}

\author{
$*^{1}$ Dahiru A. T. and ${ }^{2}$ Maigari A. K. \\ ${ }^{1}$ Department of Hospitality Management, School of Technology, Kano State Polytechnic, PMB 3348, \\ Kano Nigeria. \\ ${ }^{2}$ Departmnt of Biological Sciences, Bayero University, Kano \\ Corresponding Author: dturajo61@gmail.com; GSM: 08087508262.
}

ABSTRACT

Stick meat, locally called Tsire in Hausa Language, is a significant portion of the diet of a large active population of Northern Nigeria. However, because of the handling and processing methods by the manufacturers as well as the hawking system of stick meat, the meat product may be exposed to both pre- and post-processed product contamination, and thus may poses danger to public health. Therefore, considering the role of Tsire in improving nutrition and increase household income to the populace, the need to improve the processing, distribution and overall quality of the product is simply indispensable. A total of 30 samples (5 samples from each of the 6 sampling points) of Tsire were collected randomly in Garko Town. Aerobic plate counts (APCs) and Total coliform counts (TCCS) of Tsire samples were determined using standard microbiological methods. APCs ranged from $1.02 \times 10^{5}$ to $4.00 \times 10^{5} \mathrm{CFU} / \mathrm{g}$; while TCCs ranged from $8 \mathrm{MPN} / \mathrm{g}$ to $68 \mathrm{MPN} / \mathrm{g}$. From the 30 samples screened, 16(53.33\%) bacteria namely, Campylobacter 2(6.66\%), Escherichia coli 6(20\%), Klebsiella pneumoniae 2(6.66\%), Salmonella spp. 1(3.33\%), Shigella 3(10\%) and Staphylococcus aureus 2(6.66\%) were detected. $E$. coli has the highest isolation rate of 6(20\%), while Salmonella spp. had the least frequency of 1(3.33\%). The distribution of isolated organisms within the study area were as follows: Dausai, 4(80\%), Kofar kudu, 4(80\%), Makwalla, 2(40\%), Rinji, 3(60\%), Tosaro, 2(40\%), and Tsohuwar Kasuwa, 1(20\%). The results have indicated that the Tsire was contaminated with bacteria thus exposing the product to fast deterioration, spoilage and also a vehicle for food borne illness, suggesting for adequate hygienic practices at all the stages, prior to consumption, to ensure safety of the meat product.

Key words: APCs, TCCs, Contamination, Microorganisms, Garko

\section{INTRODUCTION}

Nigeria is one of the developing nations with inadequate food supply and most often deficient in protein content (FAO, 2019). Nigerian's average animal protein intake per head per day is estimated at $7.9 \mathrm{~g}$ as against $35 \mathrm{~g}$ recommended value by Food and Agricultural Organization (Mubarak et al., 2016). These low levels of animal protein intake create great concern as it affects the nutritional status of Nigerians. Hence, there is the need for sufficient supply of animal protein from energy rich animal products to satisfy the nutritional requirements for Nigerians.

Meat is one major source of animal protein largely composed of water, protein and fats which can make it susceptible to microbial contamination within short time leading to spoilage (Apata et al., 2013; Mgbemere et al., 2011). Meat is mostly eaten after it has been cooked or processed in a variety of ways such as sun drying; smoking and roasting with or without fortifications (Borch et al., 1996). In Nigeria meat products such as Tsire, Kilishi and Balangu are locally produced using one or more of these methods in order to meet the nutritional requirements of the teeming Nigerians (Egbebi, 2011).

Tsire is a popular Nigerian traditional processed ready-to-eat roasted stick meat product (Shamsuddeen, 2015). It is sold in public places, along roads, in hotels, parks, quarters and even offices (Falegan et al., 2017). It is prepared from boneless healthy animal flesh such as beef and mutton, spiced with peanut cake, salt, vegetable oil and other flavorings followed by roasting (Shamsuddeen, 2015). Consumption of these products has extended to other parts of African countries such as Ghana, Somali, Cameroun and Chad (Ahmadu and Ibrahim, 2013). 
BAJOPAS Volume 13 Number 1, June, 2020

However, evidence of quality control sticking to procedural hygiene by the handlers during preparation and retailing of these products is poorly documented. Tsire is of great safety risk because of the fact that there are erratic cases of gastroenteritis and symptoms of food infection after consumption (WHO, 2015). Food borne illnesses are one of the major health problems in developing and developed countries (Razavilar, 2010). According to the World Health Organization, WHO (2015), $0.07 \%$ death of the 600 million global burdens of Foodborne illnesses have been reported to be caused by bacteria, viruses, fungi and chemicals. In America $0.27 \%$ of the estimated 48 million affected people is hospitalized and about $0.0063 \%$ deaths are recorded each year (Scallan et al., 2011). More than 91 million people in Africa fall ill and $0.15 \%$ dies each year, making Africa the highest burden bearer of Foodborne diseases per population (WHO, 2015).

Application of a Hazard Analysis Critical Control Point (HACCP) at all stages of meat products preparation is essential in order to ensure its safety. Thus, according to the guidelines of good manufacturing practice, the level of total aerobic bacterial contamination of thermally processed meat products should not exceed $10^{4}\left(\mathrm{cfu} \mathrm{g}^{-1}\right)$. Enterobacteriaceae and faecal coliform contamination in meat products should be within the range of $10^{2}-10^{4}$ and $10-10^{3} \mathrm{cfu} \mathrm{g}^{-1}$, respectively (Shamsuddeen, 2015). The aim of the study is therefore, to assess the total viable bacterial counts of tsire marketed locally within Garko town, and to isolate and identify the organisms at the point of consumption with the intention of promoting public health and food hygiene habits in the Nigerian populace.

\section{MATERIALS AND METHODS Study Area and Population}

Garko is one of the existing 44 local government areas located in Kano south west zone of Kano state with its capital administrative headquarters in the Garko town. It has coordinates $11^{\circ} 39^{\prime} \mathrm{N}$ $8^{\circ} 54^{\prime} \mathrm{E}$, and an area of $450 \mathrm{~km}^{2}$. The projected population of Garko local Government was 225,300 according to the National Population Census report (2018). Garko is known for agricultural activities both farming and animal husbandry. It is popularly known for large scale rice production. Other food crops include sweet potatoes, cassava, onions, sorghum, millet and sugarcane. Cows, sheep and goats are major groups of animals reared by majority of the populace. Meat products processed, retailed and consumed in Garko include roasted meat (Balangu), dried roasted meat (Kilishi), stick meat (Tsire), hide and skin pepper soup (Ragadada) and minced fried meat (Danbunnama).

\section{Samples Collection}

Five samples of Tsire products were collected from 6 different identified locations within Garko town in a sterile foil paper and immediately analyzed for the presence of bacteria.

\section{Sample Preparation}

Sample preparation for the bacteriological analysis was carried out in accordance with the method described by Atlas (1997). Twenty five grams $(25 \mathrm{~g})$ of the sample was homogenized in $225 \mathrm{ml}$ peptone water using Kenwood blender machine to obtain a $10^{1}$ homogenate. The homogenate was thoroughly shaken and $1 \mathrm{ml}$ pipetted into test tubes containing $9 \mathrm{ml}$ of peptone water $\left(10^{2}\right)$. The test tubes were further serially diluted to $10^{5}$.

Total Aerobic Mesophilic Bacterial Count

Total Aerobic mesophilic bacterial count was determined using the method described by Abdullahi et al. (2004) where $1 \mathrm{ml}$ of inoculums from $10^{1}$ to $10^{5}$ dilutions were transferred into duplicate Petri dishes and labeled accordingly. This was followed by pouring aseptically about $15 \mathrm{ml}$ of molten nutrient agar. The culture was homogenized by gentle spinning of the plates and allowed to solidify. The plates were incubated at $37^{\circ} \mathrm{C}$ for 24 hours. Plates containing 30-300 colonies were counted. The number of colony forming units per gram of a sample (cfu/g) was obtained by multiplying the average colony number with the inverse of the dilution factor.

\section{Enumeration and Detection of Coliform bacteria}

Detection and enumeration of coliform was carried out according to method described by Atlas, (1977). A set of 9 test tubes each containing $9 \mathrm{ml}$ of lactose broth and an inverted Durham tubes were autoclaved to expel air and to sterilize. Similarly, $1 \mathrm{ml}$ from the diluents $10^{1}$ was transferred to the first 3 test tubes, followed by $1 \mathrm{ml}$ from the diluents $10^{2}$ to the second set of 3 test tubes and finally the third diluents $10^{3}$ to the $3^{\text {rd }}$ set of 3 test tubes. All the 9 test tubes were incubated at $37^{\circ} \mathrm{C}$ for 24 hours. Tubes that showed gas and acid production after 24 hours were recorded as positive for the presence of Coliform. Negative tubes were further reincubated for 24 hours. Positive tubes were recorded. Estimate of most probable number of Coliform per gram of sample (MPN/g) was determined by comparing the number of gas positive tubes with the most probable number table. 
BAJOPAS Volume 13 Number 1, June, 2020 Identification of Coliform

A loop full of inoculum from gas positive tubes was streaked on to Eosine methylene blue (EMB) agar plate and incubated at $37^{\circ} \mathrm{C}$ for $24 \mathrm{hrs}$. Colonies which formed bluish black color with green metallic sheen, and reddish colonies were isolated on agar slants. Those colonies showing metallic sheen on EMB were sub cultured into tubes of lactose broth and incubated at $45^{\circ} \mathrm{C}$. The tubes were observed after $24 \mathrm{hrs}$ for gas production. This is the completed test for fecal coliform. Gram stain and other biochemical tests such as Indole, Methyl red, Voges-Proskauer and Citrate Utilization tests (IMVIC), Coagulase and Catalase tests were carried out for the Identification and confirmation of isolates.

\section{Procedure for Indole Test}

Indole test was carried out by preparing a Tryptone broth drawn in to test tubes, sterilized by autoclaving, inoculated with loopful of suspension and incubated at $37^{\circ} \mathrm{C}$ for 24 hours. Three drops of xylene was added in tubes, shaken vigorously and kept for the separation of two layers. One millilitre of Kovac's reagent was added and the formation of pink colour ring indicates positive Indole test.

\section{Procedure for Methyl Red Test}

Methyl red test was carried out by preparing Glucose phosphate broth, dispensed in test tubes, sterilized, inoculated with test culture and incubated at $37^{\circ} \mathrm{C}$ for 24 hours. Five drops of methyl-red indicator was added to the medium for the formation of red colour.

\section{Procedure for Voges-Proskauer Test}

Voges-Proskauer test was carried out by inoculating tubes with the bacterial culture followed by incubation for 48 hours at $37^{\circ} \mathrm{C}$. Separate pipettes were used to pipette $1 \mathrm{ml}$ from each culture tube into clean separate tubes. Eighteen drops $(0.5 \mathrm{ml})$ of Barrit's solution A (a-naphthol) was added to each tube containing glucose phosphate broth followed by the addition of an equal amount of solution $B$ into the same tube. The tubes were shaken at 30 seconds interval. A positive reaction was indicated by the development of a pink color, which turns red in 1-2 hours, after vigorous shaking.

\section{Procedure for Citrate Utilization Test}

Citrate Utilization Test was carried out by distributing melted agar (Simmon Citrate Agar) in to test tubes followed by sterilization at $121.5^{\circ} \mathrm{C}$ for 15 minutes. The test tubes were afterward held in slanted position, inoculated with the given bacterial culture and incubated at $37^{\circ} \mathrm{C}$ for $24 \mathrm{hrs}$. Positive test was indicated by color change of the media from green to blue.

\section{RESULTS AND DISCUSSIONS}

The results of this study are presented in tables $1,2,3$ and 4. Among the sampling areas Kofar Kudu had the highest aerobic mesophilic bacteria counts $4.0 \times 10^{5} \mathrm{cfu} / \mathrm{g}$ followed by Rinji $2.72 \times 10^{5} \mathrm{cfu} / \mathrm{g}$, while Tosaro had the least Aerobic mesophilic bacteria counts of $1.02 \times 10^{5}$ $\mathrm{cfu} / \mathrm{g}$ as indicated in Table 1.Makwalla had the highest coliform count $68 \mathrm{MPN} / \mathrm{g}$ followed by Rinji $37 \mathrm{MPN} / \mathrm{g}$. Tsohuwar Kasuwa had the least coliform counts $8 \mathrm{MPN} / \mathrm{g}$, (Table 2). Result from table 1 shows variation in the microbial contents among the samples which suggest variation in their sources, poor handling procedures and contamination from the processing environment. High coliform count and their differences within sampling areas is an indication of poor microbiological quality of the product. Ndahi et al. (2013) reported microbial load to be a function of the handling personnel and the environment. The results indicated that the samples were contaminated with bacteria as the counts exceeded the minimum safety level $\left(10^{4} \mathrm{cfu} / \mathrm{g}\right)$ for members of the Enterobacteriaceae family. However, it might be a reflection of poor hygienic practices which may contribute to health hazard to the potential consumers. Similarly, Inusa and Sa'id (2017); Osimani et al. (2015) reported that, the initial microbial content of the raw material play significant role in influencing the final microbial load of the finished product. Isolation of members of the Enterobacteriaceae such as $E$. coli, Klebsiella pneumoniae, Salmonella and Shigella signifies danger to the public health. These organisms are capable of producing endotoxins which trigger high fevers in infected individuals, and the enterotoxins which colonize the small intestines and lead to extreme dehydration as a result of vomiting and diarrhea sometimes with severe and fatal outcomes (Amaeze et al., 2016). From the 16 isolated organisms $E$. coli had the highest isolation rate $6(37.5 \%)$ (Table 3), this suggest faecal contamination of the products. $E$. coli is a common flora in the gastrointestinal tract responsible for diarrhea and extra-intestinal infections (CDC, 2011). The result is in conformity with the findings of Ndahi et al. (2013) and Shamsuddeen (2009). Also presence of campylobacter might be due to cross contamination from raw meat to finished product (Tsire). Staphylococcus aureus is a normal flora of the skin, nasal, genital, mouth or anal area in both humans and animals without any symptom of an infection (Matthew et al., 2013). Isolation of $S$. aureus in these study concords with the findings of Lucretia et al. (2018) from Suya sold in Rivers State. 
BAJOPAS Volume 13 Number 1, June, 2020

It is also in agreement with the findings of Yousafzai et al. (2018); Onuorah et al. (2015) and Tijjani and Jumare (2014) from tsire samples in different countries. Presence of $S$. aureus in foods is most of the time an indication of poor human handling, poor environment, unhygienic utensils and equipments used during processing (Igene et al., 2016; Okonko et al., 2013). Infections caused by $S$. aureus are difficult to treat leading to long hospitalization with consequent economic loss (Udobi et al., 2013). These include soft tissue infections, pneumonia, hospital-acquired postoperative wound infections, Staphylococcal food poisoning, impetigo and cellulitis (Charlene et al., 2013). Samples obtained from Dausai and Kofar Kudu had the highest isolation rate $4(80 \%)$ (Table 4 ) probably because of the much commercial activities taking place in the area which can lead to environmental contamination.

Table 1: Total Aerobic Mesophilic Bacterial Count of Tsire sold in Garko Town

\begin{tabular}{lll}
\hline Sampling Area & APC cfu/g & Mean \pm STD \\
\hline Dausai & $2.20 \times 10^{5}$ & $110000 \pm 14142.14$ \\
Kofar Kudu & $4.00 \times 10^{5}$ & $133333.3 \pm 23094.01$ \\
Makwalla & $1.30 \times 10^{5}$ & $32500 \pm 7187.953$ \\
Rinji & $2.72 \times 10^{5}$ & $90666.67 \pm 94769.90$ \\
Tosaro & $1.02 \times 10^{5}$ & $51000 \pm 15556.35$ \\
Tsohuwar Kasuwa & $1.75 \times 10^{5}$ & $35000 \pm 11357.82$ \\
\hline
\end{tabular}

Key: APC: Aerobic Mesophilic Counts

STD: Standard Deviation

Table 2: Total Coliform Count of Tsire sold in Garko Town

\begin{tabular}{lcc}
\hline \multicolumn{1}{c}{ Sampling Area } & TCC MPN/g & Mean \pm STD \\
\hline Dausai & 20 & $6.67 \pm 2.5166$ \\
Kofar Kudu & 32 & $16.00 \pm 5.6569$ \\
Makwalla & 68 & $13.60 \pm 8.7062$ \\
Rinji & 37 & $9.25 \pm 4.7871$ \\
Tosaro & 10 & $5.00 \pm 2.8284$ \\
Tsohuwar Kasuwa & 8 & $4.00 \pm 0.0000$ \\
\hline
\end{tabular}

Table 3: Organisms Isolated from Tsire Sold in Garko

\begin{tabular}{lcl}
\hline Isolated Organism & Frequency & Percentage (\%) \\
\hline Campylobacter & 2 & 06.66 \\
Escherichia coli & 6 & 20.00 \\
Klebsiella pneumoniae & 2 & 06.66 \\
Salmonella species & 1 & 03.33 \\
Shigella & 3 & 10.00 \\
Staphylococcus aureus & 2 & 06.66 \\
Total & 16 & \\
\hline
\end{tabular}

Table 4: Distribution of Organisms within Sampling Area

\begin{tabular}{lcc}
\hline \multicolumn{1}{c}{ Sampling Area } & No. Isolated & Percentage (\%) \\
\hline Dausai & 4 & 80 \\
Kofar Kudu & 4 & 80 \\
Makwalla & 2 & 40 \\
Rinji & 3 & 60 \\
Tosaro & 2 & 40 \\
Tsohuwar Kasuwa & 1 & 20 \\
Total & 16 & \\
\hline
\end{tabular}

\section{CONCLUSION}

Results indicated $4.00 \times 10^{5} \mathrm{CFU} / \mathrm{g}$ as the highest APCs count; while $68 \mathrm{MPN} / \mathrm{g}$ was the highest TCCs from the 30 samples analyzed. Among the isolates, $E$. coli has the highest isolation rate of $6(20 \%)$. Dausai and Kofar kudu were having the highest bacteria count of $4(80 \%)$, each, indicating higher contamination in those locations. 
BAJOPAS Volume 13 Number 1, June, 2020 RECOMMENDATIONS

The following recommendations are tenable:

1. Hygienic practices at all stages of production should be improved to safe guard the consumers against potential health hazard.

2. Monitoring of microbiological contamination of Tsire during preparations, packaging and marketing is essential to ensure product of good microbiological quality for consumers' health.

\section{REFERENCES}

Abdullahi, I. O., Umoh, V. J. and Galadima, M. (2004). Hazards Associated with Kilishi Preparations in Zaria. Nigerian Journal of Microbiology, 18 (1-2): $339-345$.

Ahmadu, J. and Ibrahim E. J., (2013): Determinants of Revenue in Suya Production in BeninCity, Edo State, Nigeria. Nigerian journal of agriculture, food and environment.9(3):1-5

Amaeze, N. Aboh, M. Itohan, A. Felix, E. Olatunji, T. and Oladosu, P. (2016) Microbial Profile, Antibiotic Sensitivity and Heat Resistance of Bacterial Isolates from Commercial Roasted Beef (Suya) in Abuja, Nigeria. JOPAT, 15(2): $22-30$.

Apata, E.S., Kuku1, I.A., Apata, O.C. and Adeyemi, K.O. (2013). Evaluation of Suya(Tsire) - An Intermediate Moisture Meat Product in Ogun State, Nigeria. J. Food Res 2 (1): 87.

Atlas, R. M. (1997) Principles of Microbiology Second Edition. C. Brown Publishers. Pp 802-803.

Borch, E. Kant-Muermans, M. L., Blixt, Y. (1996) Bacterial Spoilage of Meat and Cured Meat Products. Int $\mathrm{J}$ Food Microbiol .33(1): 103-20.

Centre for Disease Control, CDC (2011). "Escherichia coli 0157:H7" Division of Bacterial and Mycotic Diseasesht://www.cdc.gov/nczved/divisi ons/dfbmd/diseases/ecoli_0157h7/.

Charlene, R. J., Johnnie, A. D., and John, B. B., (2013) Prevalence and Characterization of Methicillin-Resistant Staphylococcus aureus Isolates from Retail Meat and Humans in Georgia. American society for Microbiology. J. of clinical microbiology. 12(1):123-6 doi:10.1128/JCM.0316612JCM.03166-12

Egbebi, A.O and Seidu, K., T. (2011). Microbiological Evaluation of Suya (dried smoked

meat) Sold in Ado and Akure, South West Nigeria.European Journal of Experinmental Biology, 1(4):1-5
3. Government should establish regulatory bodies responsible for inculcating hygiene habits to the local producers and vendors in order to prevent instant, cross and post processing contaminations by microbial pathogens.

4. Awareness and sensitization of local food producers about good hygienic practices in food handling and processing.

Falegan, C, R., Akoja, S. D., and Oyarekua, M. A., (2017) Microbiological Assessment of Suya (Sliced Roasted Beef) in Ado-Ekiti Metropolis, Ekiti State, Nigeria. MOJ Biology andMedicine.

Fonkem, D., N. Tanya, V., N. and Ebangi, A., L. (2010). Effect of Season on the Microbiological Quality of Kilishi, a Traditional Cameroonian Dried Beef Product. Tropicultura, 28(1): 10-15.

Food and Agricultural Organization of the United Nations (F A O, 1979). Manual of food quality control 4. Microbiological analysis.

Food and Agriculture Organisation of the United Nation (FAO), 2019. Nigeria at a glance.

Igene J.O., Uwadia, O.E., Ebabhamiegbebho, P.A. and Evivie, S.E., (2016) Shelf life Stability Studies of University of Benin (UNIBEN) Proff's Kilishi Product Asian Journal of Science and Technology 7(1): 2268-2274.

Inusa, S. K. and Said, I. S. (2017) Evaluation of the Chemical and Microbiological Properties Of Kilishi Sold in Kano Metropolis. Journal of Dry land Agriculture, 3 (1): $59-69$.

Lucretia, I. B, Patience, C. Obinna-Echem, Sophia, C. A. (2018) Microbiological quality andantibiotic sensitivity of potential pathogens isolated from meat product (Suya) sold in Rivers State University and its environs. International Journal of Biotechnology and Food Science, 6(4): 67-76.

Matthew, E., Drosos, E., John, L. and Ioanna, P. (2013) MRSA in Africa: Filling the Global Map of Antimicrobial Resistance PLOS One. 8(7): e68024 doi: 10.1371/journal.pone.0068024

Mgbemere, V.N., Akpapunam, M. A. and Igene, J. O., (2011). Effect of Groundnut FlourSubstitution on Yield, Quality and Storage Stability of Kilishi - a Nigerian Indigenous Dried Meat Product. African Journal of Food, Agriculture, Nutrition and Development, $\quad \mathbf{1 1}(2)$ : 4718-4738. 
BAJOPAS Volume 13 Number 1, June, 2020

Mubarak, A. A., Azeez, M. L., Amos A. O., Opeyemi, O. O. (2016) Assessment of Animal Protein Consumption and Food Security Among Rural Households in Kwara State, Nigeria American Journal of Business and Society, 1(4): 233245.

Ndahi, M., D. Kwaga, J., K. P. Bello, M. Kabir J., V. Umoh, .J. Yakubu, S., E. and Nok, A., J. (2013) Prevalence and Antimicrobial Susceptibility of Listeria Monocytogenes and Methicillin-Resistant Staphylococcus aureus Strains from Raw Meat and Meat Products in Zaria, Nigeria. Applied Journal of Microbiology, 58(3):262-9.

Okonko, I.O., Odu, N.N. and Igboh, I.E. (2013). Microbiological Analysis of Kilishi Sold In Port Harcourt, Nigeria. New York Science Journal, 6 (7):37-43.

Osimani, A., Aquilanti, L. and Clementi, F. (2015) Microbiological Quality of Meatbased Meals and Operation of Control Systems within a Food Service Environment. International Food Research Journal 22(4): 1692-1698.

Onuorah, S. Obika, I. Odibo, F. Orji, M. (2015)An Assessment of the Bacteriological Quality of Tsire-Suya (Grilled Beef) sold in Awka, Nigeria. American. J. Life. Sci. Res. 3(4):287292.

Razavilar, V, Khandaghi, J. Barzgari, A. (2010); Isolation of Eschericia coli 0157:H7 from manure fertilized farms and raw vegetables grown on it, in Tabriz city in
Iran. African Journal of Microbiology Research, 4(9): 891-895.

Scallan, E. Hoekstra, R. M. Angulo, F. J.Tauxe, R. V, Widdowson, M. Roy, S. L et al., (2011).Food borne illness acquired in the United States- Major Pathogens. Emerg. Infec Dis, 17(1): 7-15.

Shamsuddeen U (2009). Microbiological quality of spice used in the production of Kilishi a traditionally dried and grilled meat product. Bayero Journal of Pure andApplied Sciences, 2(2): 66-69.

Shamsuddeen, U. (2015) Microbiological Hazard and Critical control point Analysis of Dried and Minced Meat Snacks Produced in Kano Nigeria. Lambert Academic Publishing; Pp 1-36.

Tijani, O.and Jumare, S. (2014). Microblological Quality Assessment of Meat

Sold in KauraNamoda. International Conference on Earth, Environment and Life sciences (EELS) Dubai (UAE).

Udobi, C. E., Obajuluwa, A. F., and Onaolapo, J. A., (2013) Prevalence and Antibiotic Resistance Pattern of MethicillinResistant Staphylococcus aureus from an Orthopaedic Hospital in Nigeria BioMed Research International; 26(6); 6-7.

WHO, 2015 Foodborne diseases in the WHO African Region.

Yousafzai HA, Rind R, Khan MA, Abro SH, Korejo NA, Ejaz M, Kabir A, Shahid M, Memon S. (2019). Microbiological Contamination of Cattle and Meat in Peshawar, Pakistan. J. Anim. Health Prod. 7(1): 1116. 


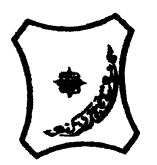

Bayero Journal of Pure and Applied Sciences, 13(1); 40 - 45

Received: September, 2019

Accepted: April, 2020

ISSN $2006-6996$

\title{
BACTERIOLOGICAL QUALITY OF STICK MEAT (Tsire) SOLD IN GARKO LOCAL GOVERNMENT AREA OF KANO STATE, NIGERIA
}

\author{
$*^{1}$ Dahiru A. T. and ${ }^{2}$ Maigari A. K. \\ ${ }^{1}$ Department of Hospitality Management, School of Technology, Kano State Polytechnic, PMB 3348, \\ Kano Nigeria. \\ ${ }^{2}$ Departmnt of Biological Sciences, Bayero University, Kano \\ Corresponding Author: dturajo61@gmail.com; GSM: 08087508262.
}

ABSTRACT

Stick meat, locally called Tsire in Hausa Language, is a significant portion of the diet of a large active population of Northern Nigeria. However, because of the handling and processing methods by the manufacturers as well as the hawking system of stick meat, the meat product may be exposed to both pre- and post-processed product contamination, and thus may poses danger to public health. Therefore, considering the role of Tsire in improving nutrition and increase household income to the populace, the need to improve the processing, distribution and overall quality of the product is simply indispensable. A total of 30 samples (5 samples from each of the 6 sampling points) of Tsire were collected randomly in Garko Town. Aerobic plate counts (APCs) and Total coliform counts (TCCS) of Tsire samples were determined using standard microbiological methods. APCs ranged from $1.02 \times 10^{5}$ to $4.00 \times 10^{5} \mathrm{CFU} / \mathrm{g}$; while TCCs ranged from $8 \mathrm{MPN} / \mathrm{g}$ to $68 \mathrm{MPN} / \mathrm{g}$. From the 30 samples screened, 16(53.33\%) bacteria namely, Campylobacter 2(6.66\%), Escherichia coli 6(20\%), Klebsiella pneumoniae 2(6.66\%), Salmonella spp. 1(3.33\%), Shigella 3(10\%) and Staphylococcus aureus 2(6.66\%) were detected. $E$. coli has the highest isolation rate of 6(20\%), while Salmonella spp. had the least frequency of 1(3.33\%). The distribution of isolated organisms within the study area were as follows: Dausai, 4(80\%), Kofar kudu, 4(80\%), Makwalla, 2(40\%), Rinji, 3(60\%), Tosaro, 2(40\%), and Tsohuwar Kasuwa, 1(20\%). The results have indicated that the Tsire was contaminated with bacteria thus exposing the product to fast deterioration, spoilage and also a vehicle for food borne illness, suggesting for adequate hygienic practices at all the stages, prior to consumption, to ensure safety of the meat product.

Key words: APCs, TCCs, Contamination, Microorganisms, Garko

\section{INTRODUCTION}

Nigeria is one of the developing nations with inadequate food supply and most often deficient in protein content (FAO, 2019). Nigerian's average animal protein intake per head per day is estimated at $7.9 \mathrm{~g}$ as against $35 \mathrm{~g}$ recommended value by Food and Agricultural Organization (Mubarak et al., 2016). These low levels of animal protein intake create great concern as it affects the nutritional status of Nigerians. Hence, there is the need for sufficient supply of animal protein from energy rich animal products to satisfy the nutritional requirements for Nigerians.

Meat is one major source of animal protein largely composed of water, protein and fats which can make it susceptible to microbial contamination within short time leading to spoilage (Apata et al., 2013; Mgbemere et al., 2011). Meat is mostly eaten after it has been cooked or processed in a variety of ways such as sun drying; smoking and roasting with or without fortifications (Borch et al., 1996). In Nigeria meat products such as Tsire, Kilishi and Balangu are locally produced using one or more of these methods in order to meet the nutritional requirements of the teeming Nigerians (Egbebi, 2011).

Tsire is a popular Nigerian traditional processed ready-to-eat roasted stick meat product (Shamsuddeen, 2015). It is sold in public places, along roads, in hotels, parks, quarters and even offices (Falegan et al., 2017). It is prepared from boneless healthy animal flesh such as beef and mutton, spiced with peanut cake, salt, vegetable oil and other flavorings followed by roasting (Shamsuddeen, 2015). Consumption of these products has extended to other parts of African countries such as Ghana, Somali, Cameroun and Chad (Ahmadu and Ibrahim, 2013). 
BAJOPAS Volume 13 Number 1, June, 2020

However, evidence of quality control sticking to procedural hygiene by the handlers during preparation and retailing of these products is poorly documented. Tsire is of great safety risk because of the fact that there are erratic cases of gastroenteritis and symptoms of food infection after consumption (WHO, 2015). Food borne illnesses are one of the major health problems in developing and developed countries (Razavilar, 2010). According to the World Health Organization, WHO (2015), $0.07 \%$ death of the 600 million global burdens of Foodborne illnesses have been reported to be caused by bacteria, viruses, fungi and chemicals. In America $0.27 \%$ of the estimated 48 million affected people is hospitalized and about $0.0063 \%$ deaths are recorded each year (Scallan et al., 2011). More than 91 million people in Africa fall ill and $0.15 \%$ dies each year, making Africa the highest burden bearer of Foodborne diseases per population (WHO, 2015).

Application of a Hazard Analysis Critical Control Point (HACCP) at all stages of meat products preparation is essential in order to ensure its safety. Thus, according to the guidelines of good manufacturing practice, the level of total aerobic bacterial contamination of thermally processed meat products should not exceed $10^{4}\left(\mathrm{cfu} \mathrm{g}^{-1}\right)$. Enterobacteriaceae and faecal coliform contamination in meat products should be within the range of $10^{2}-10^{4}$ and $10-10^{3} \mathrm{cfu} \mathrm{g}^{-1}$, respectively (Shamsuddeen, 2015). The aim of the study is therefore, to assess the total viable bacterial counts of tsire marketed locally within Garko town, and to isolate and identify the organisms at the point of consumption with the intention of promoting public health and food hygiene habits in the Nigerian populace.

\section{MATERIALS AND METHODS Study Area and Population}

Garko is one of the existing 44 local government areas located in Kano south west zone of Kano state with its capital administrative headquarters in the Garko town. It has coordinates $11^{\circ} 39^{\prime} \mathrm{N}$ $8^{\circ} 54^{\prime} \mathrm{E}$, and an area of $450 \mathrm{~km}^{2}$. The projected population of Garko local Government was 225,300 according to the National Population Census report (2018). Garko is known for agricultural activities both farming and animal husbandry. It is popularly known for large scale rice production. Other food crops include sweet potatoes, cassava, onions, sorghum, millet and sugarcane. Cows, sheep and goats are major groups of animals reared by majority of the populace. Meat products processed, retailed and consumed in Garko include roasted meat (Balangu), dried roasted meat (Kilishi), stick meat (Tsire), hide and skin pepper soup (Ragadada) and minced fried meat (Danbunnama).

\section{Samples Collection}

Five samples of Tsire products were collected from 6 different identified locations within Garko town in a sterile foil paper and immediately analyzed for the presence of bacteria.

\section{Sample Preparation}

Sample preparation for the bacteriological analysis was carried out in accordance with the method described by Atlas (1997). Twenty five grams $(25 \mathrm{~g})$ of the sample was homogenized in $225 \mathrm{ml}$ peptone water using Kenwood blender machine to obtain a $10^{1}$ homogenate. The homogenate was thoroughly shaken and $1 \mathrm{ml}$ pipetted into test tubes containing $9 \mathrm{ml}$ of peptone water $\left(10^{2}\right)$. The test tubes were further serially diluted to $10^{5}$.

Total Aerobic Mesophilic Bacterial Count

Total Aerobic mesophilic bacterial count was determined using the method described by Abdullahi et al. (2004) where $1 \mathrm{ml}$ of inoculums from $10^{1}$ to $10^{5}$ dilutions were transferred into duplicate Petri dishes and labeled accordingly. This was followed by pouring aseptically about $15 \mathrm{ml}$ of molten nutrient agar. The culture was homogenized by gentle spinning of the plates and allowed to solidify. The plates were incubated at $37^{\circ} \mathrm{C}$ for 24 hours. Plates containing 30-300 colonies were counted. The number of colony forming units per gram of a sample (cfu/g) was obtained by multiplying the average colony number with the inverse of the dilution factor.

\section{Enumeration and Detection of Coliform bacteria}

Detection and enumeration of coliform was carried out according to method described by Atlas, (1977). A set of 9 test tubes each containing $9 \mathrm{ml}$ of lactose broth and an inverted Durham tubes were autoclaved to expel air and to sterilize. Similarly, $1 \mathrm{ml}$ from the diluents $10^{1}$ was transferred to the first 3 test tubes, followed by $1 \mathrm{ml}$ from the diluents $10^{2}$ to the second set of 3 test tubes and finally the third diluents $10^{3}$ to the $3^{\text {rd }}$ set of 3 test tubes. All the 9 test tubes were incubated at $37^{\circ} \mathrm{C}$ for 24 hours. Tubes that showed gas and acid production after 24 hours were recorded as positive for the presence of Coliform. Negative tubes were further reincubated for 24 hours. Positive tubes were recorded. Estimate of most probable number of Coliform per gram of sample (MPN/g) was determined by comparing the number of gas positive tubes with the most probable number table. 
BAJOPAS Volume 13 Number 1, June, 2020 Identification of Coliform

A loop full of inoculum from gas positive tubes was streaked on to Eosine methylene blue (EMB) agar plate and incubated at $37^{\circ} \mathrm{C}$ for $24 \mathrm{hrs}$. Colonies which formed bluish black color with green metallic sheen, and reddish colonies were isolated on agar slants. Those colonies showing metallic sheen on EMB were sub cultured into tubes of lactose broth and incubated at $45^{\circ} \mathrm{C}$. The tubes were observed after $24 \mathrm{hrs}$ for gas production. This is the completed test for fecal coliform. Gram stain and other biochemical tests such as Indole, Methyl red, Voges-Proskauer and Citrate Utilization tests (IMVIC), Coagulase and Catalase tests were carried out for the Identification and confirmation of isolates.

\section{Procedure for Indole Test}

Indole test was carried out by preparing a Tryptone broth drawn in to test tubes, sterilized by autoclaving, inoculated with loopful of suspension and incubated at $37^{\circ} \mathrm{C}$ for 24 hours. Three drops of xylene was added in tubes, shaken vigorously and kept for the separation of two layers. One millilitre of Kovac's reagent was added and the formation of pink colour ring indicates positive Indole test.

\section{Procedure for Methyl Red Test}

Methyl red test was carried out by preparing Glucose phosphate broth, dispensed in test tubes, sterilized, inoculated with test culture and incubated at $37^{\circ} \mathrm{C}$ for 24 hours. Five drops of methyl-red indicator was added to the medium for the formation of red colour.

\section{Procedure for Voges-Proskauer Test}

Voges-Proskauer test was carried out by inoculating tubes with the bacterial culture followed by incubation for 48 hours at $37^{\circ} \mathrm{C}$. Separate pipettes were used to pipette $1 \mathrm{ml}$ from each culture tube into clean separate tubes. Eighteen drops $(0.5 \mathrm{ml})$ of Barrit's solution A (a-naphthol) was added to each tube containing glucose phosphate broth followed by the addition of an equal amount of solution $B$ into the same tube. The tubes were shaken at 30 seconds interval. A positive reaction was indicated by the development of a pink color, which turns red in 1-2 hours, after vigorous shaking.

\section{Procedure for Citrate Utilization Test}

Citrate Utilization Test was carried out by distributing melted agar (Simmon Citrate Agar) in to test tubes followed by sterilization at $121.5^{\circ} \mathrm{C}$ for 15 minutes. The test tubes were afterward held in slanted position, inoculated with the given bacterial culture and incubated at $37^{\circ} \mathrm{C}$ for $24 \mathrm{hrs}$. Positive test was indicated by color change of the media from green to blue.

\section{RESULTS AND DISCUSSIONS}

The results of this study are presented in tables $1,2,3$ and 4. Among the sampling areas Kofar Kudu had the highest aerobic mesophilic bacteria counts $4.0 \times 10^{5} \mathrm{cfu} / \mathrm{g}$ followed by Rinji $2.72 \times 10^{5} \mathrm{cfu} / \mathrm{g}$, while Tosaro had the least Aerobic mesophilic bacteria counts of $1.02 \times 10^{5}$ $\mathrm{cfu} / \mathrm{g}$ as indicated in Table 1.Makwalla had the highest coliform count $68 \mathrm{MPN} / \mathrm{g}$ followed by Rinji $37 \mathrm{MPN} / \mathrm{g}$. Tsohuwar Kasuwa had the least coliform counts $8 \mathrm{MPN} / \mathrm{g}$, (Table 2). Result from table 1 shows variation in the microbial contents among the samples which suggest variation in their sources, poor handling procedures and contamination from the processing environment. High coliform count and their differences within sampling areas is an indication of poor microbiological quality of the product. Ndahi et al. (2013) reported microbial load to be a function of the handling personnel and the environment. The results indicated that the samples were contaminated with bacteria as the counts exceeded the minimum safety level $\left(10^{4} \mathrm{cfu} / \mathrm{g}\right)$ for members of the Enterobacteriaceae family. However, it might be a reflection of poor hygienic practices which may contribute to health hazard to the potential consumers. Similarly, Inusa and Sa'id (2017); Osimani et al. (2015) reported that, the initial microbial content of the raw material play significant role in influencing the final microbial load of the finished product. Isolation of members of the Enterobacteriaceae such as $E$. coli, Klebsiella pneumoniae, Salmonella and Shigella signifies danger to the public health. These organisms are capable of producing endotoxins which trigger high fevers in infected individuals, and the enterotoxins which colonize the small intestines and lead to extreme dehydration as a result of vomiting and diarrhea sometimes with severe and fatal outcomes (Amaeze et al., 2016). From the 16 isolated organisms $E$. coli had the highest isolation rate $6(37.5 \%)$ (Table 3), this suggest faecal contamination of the products. $E$. coli is a common flora in the gastrointestinal tract responsible for diarrhea and extra-intestinal infections (CDC, 2011). The result is in conformity with the findings of Ndahi et al. (2013) and Shamsuddeen (2009). Also presence of campylobacter might be due to cross contamination from raw meat to finished product (Tsire). Staphylococcus aureus is a normal flora of the skin, nasal, genital, mouth or anal area in both humans and animals without any symptom of an infection (Matthew et al., 2013). Isolation of $S$. aureus in these study concords with the findings of Lucretia et al. (2018) from Suya sold in Rivers State. 
BAJOPAS Volume 13 Number 1, June, 2020

It is also in agreement with the findings of Yousafzai et al. (2018); Onuorah et al. (2015) and Tijjani and Jumare (2014) from tsire samples in different countries. Presence of $S$. aureus in foods is most of the time an indication of poor human handling, poor environment, unhygienic utensils and equipments used during processing (Igene et al., 2016; Okonko et al., 2013). Infections caused by $S$. aureus are difficult to treat leading to long hospitalization with consequent economic loss (Udobi et al., 2013). These include soft tissue infections, pneumonia, hospital-acquired postoperative wound infections, Staphylococcal food poisoning, impetigo and cellulitis (Charlene et al., 2013). Samples obtained from Dausai and Kofar Kudu had the highest isolation rate $4(80 \%)$ (Table 4 ) probably because of the much commercial activities taking place in the area which can lead to environmental contamination.

Table 1: Total Aerobic Mesophilic Bacterial Count of Tsire sold in Garko Town

\begin{tabular}{lll}
\hline Sampling Area & APC cfu/g & Mean \pm STD \\
\hline Dausai & $2.20 \times 10^{5}$ & $110000 \pm 14142.14$ \\
Kofar Kudu & $4.00 \times 10^{5}$ & $133333.3 \pm 23094.01$ \\
Makwalla & $1.30 \times 10^{5}$ & $32500 \pm 7187.953$ \\
Rinji & $2.72 \times 10^{5}$ & $90666.67 \pm 94769.90$ \\
Tosaro & $1.02 \times 10^{5}$ & $51000 \pm 15556.35$ \\
Tsohuwar Kasuwa & $1.75 \times 10^{5}$ & $35000 \pm 11357.82$ \\
\hline
\end{tabular}

Key: APC: Aerobic Mesophilic Counts

STD: Standard Deviation

Table 2: Total Coliform Count of Tsire sold in Garko Town

\begin{tabular}{lcc}
\hline \multicolumn{1}{c}{ Sampling Area } & TCC MPN/g & Mean \pm STD \\
\hline Dausai & 20 & $6.67 \pm 2.5166$ \\
Kofar Kudu & 32 & $16.00 \pm 5.6569$ \\
Makwalla & 68 & $13.60 \pm 8.7062$ \\
Rinji & 37 & $9.25 \pm 4.7871$ \\
Tosaro & 10 & $5.00 \pm 2.8284$ \\
Tsohuwar Kasuwa & 8 & $4.00 \pm 0.0000$ \\
\hline
\end{tabular}

Table 3: Organisms Isolated from Tsire Sold in Garko

\begin{tabular}{lcl}
\hline Isolated Organism & Frequency & Percentage (\%) \\
\hline Campylobacter & 2 & 06.66 \\
Escherichia coli & 6 & 20.00 \\
Klebsiella pneumoniae & 2 & 06.66 \\
Salmonella species & 1 & 03.33 \\
Shigella & 3 & 10.00 \\
Staphylococcus aureus & 2 & 06.66 \\
Total & 16 & \\
\hline
\end{tabular}

Table 4: Distribution of Organisms within Sampling Area

\begin{tabular}{lcc}
\hline \multicolumn{1}{c}{ Sampling Area } & No. Isolated & Percentage (\%) \\
\hline Dausai & 4 & 80 \\
Kofar Kudu & 4 & 80 \\
Makwalla & 2 & 40 \\
Rinji & 3 & 60 \\
Tosaro & 2 & 40 \\
Tsohuwar Kasuwa & 1 & 20 \\
Total & 16 & \\
\hline
\end{tabular}

\section{CONCLUSION}

Results indicated $4.00 \times 10^{5} \mathrm{CFU} / \mathrm{g}$ as the highest APCs count; while $68 \mathrm{MPN} / \mathrm{g}$ was the highest TCCs from the 30 samples analyzed. Among the isolates, $E$. coli has the highest isolation rate of $6(20 \%)$. Dausai and Kofar kudu were having the highest bacteria count of $4(80 \%)$, each, indicating higher contamination in those locations. 
BAJOPAS Volume 13 Number 1, June, 2020 RECOMMENDATIONS

The following recommendations are tenable:

1. Hygienic practices at all stages of production should be improved to safe guard the consumers against potential health hazard.

2. Monitoring of microbiological contamination of Tsire during preparations, packaging and marketing is essential to ensure product of good microbiological quality for consumers' health.

\section{REFERENCES}

Abdullahi, I. O., Umoh, V. J. and Galadima, M. (2004). Hazards Associated with Kilishi Preparations in Zaria. Nigerian Journal of Microbiology, 18 (1-2): $339-345$.

Ahmadu, J. and Ibrahim E. J., (2013): Determinants of Revenue in Suya Production in BeninCity, Edo State, Nigeria. Nigerian journal of agriculture, food and environment.9(3):1-5

Amaeze, N. Aboh, M. Itohan, A. Felix, E. Olatunji, T. and Oladosu, P. (2016) Microbial Profile, Antibiotic Sensitivity and Heat Resistance of Bacterial Isolates from Commercial Roasted Beef (Suya) in Abuja, Nigeria. JOPAT, 15(2): $22-30$.

Apata, E.S., Kuku1, I.A., Apata, O.C. and Adeyemi, K.O. (2013). Evaluation of Suya(Tsire) - An Intermediate Moisture Meat Product in Ogun State, Nigeria. J. Food Res 2 (1): 87.

Atlas, R. M. (1997) Principles of Microbiology Second Edition. C. Brown Publishers. Pp 802-803.

Borch, E. Kant-Muermans, M. L., Blixt, Y. (1996) Bacterial Spoilage of Meat and Cured Meat Products. Int $\mathrm{J}$ Food Microbiol .33(1): 103-20.

Centre for Disease Control, CDC (2011). "Escherichia coli 0157:H7" Division of Bacterial and Mycotic Diseasesht://www.cdc.gov/nczved/divisi ons/dfbmd/diseases/ecoli_0157h7/.

Charlene, R. J., Johnnie, A. D., and John, B. B., (2013) Prevalence and Characterization of Methicillin-Resistant Staphylococcus aureus Isolates from Retail Meat and Humans in Georgia. American society for Microbiology. J. of clinical microbiology. 12(1):123-6 doi:10.1128/JCM.0316612JCM.03166-12

Egbebi, A.O and Seidu, K., T. (2011). Microbiological Evaluation of Suya (dried smoked

meat) Sold in Ado and Akure, South West Nigeria.European Journal of Experinmental Biology, 1(4):1-5
3. Government should establish regulatory bodies responsible for inculcating hygiene habits to the local producers and vendors in order to prevent instant, cross and post processing contaminations by microbial pathogens.

4. Awareness and sensitization of local food producers about good hygienic practices in food handling and processing.

Falegan, C, R., Akoja, S. D., and Oyarekua, M. A., (2017) Microbiological Assessment of Suya (Sliced Roasted Beef) in Ado-Ekiti Metropolis, Ekiti State, Nigeria. MOJ Biology andMedicine.

Fonkem, D., N. Tanya, V., N. and Ebangi, A., L. (2010). Effect of Season on the Microbiological Quality of Kilishi, a Traditional Cameroonian Dried Beef Product. Tropicultura, 28(1): 10-15.

Food and Agricultural Organization of the United Nations (F A O, 1979). Manual of food quality control 4. Microbiological analysis.

Food and Agriculture Organisation of the United Nation (FAO), 2019. Nigeria at a glance.

Igene J.O., Uwadia, O.E., Ebabhamiegbebho, P.A. and Evivie, S.E., (2016) Shelf life Stability Studies of University of Benin (UNIBEN) Proff's Kilishi Product Asian Journal of Science and Technology 7(1): 2268-2274.

Inusa, S. K. and Said, I. S. (2017) Evaluation of the Chemical and Microbiological Properties Of Kilishi Sold in Kano Metropolis. Journal of Dry land Agriculture, 3 (1): $59-69$.

Lucretia, I. B, Patience, C. Obinna-Echem, Sophia, C. A. (2018) Microbiological quality andantibiotic sensitivity of potential pathogens isolated from meat product (Suya) sold in Rivers State University and its environs. International Journal of Biotechnology and Food Science, 6(4): 67-76.

Matthew, E., Drosos, E., John, L. and Ioanna, P. (2013) MRSA in Africa: Filling the Global Map of Antimicrobial Resistance PLOS One. 8(7): e68024 doi: 10.1371/journal.pone.0068024

Mgbemere, V.N., Akpapunam, M. A. and Igene, J. O., (2011). Effect of Groundnut FlourSubstitution on Yield, Quality and Storage Stability of Kilishi - a Nigerian Indigenous Dried Meat Product. African Journal of Food, Agriculture, Nutrition and Development, $\quad \mathbf{1 1}(2)$ : 4718-4738. 
BAJOPAS Volume 13 Number 1, June, 2020

Mubarak, A. A., Azeez, M. L., Amos A. O., Opeyemi, O. O. (2016) Assessment of Animal Protein Consumption and Food Security Among Rural Households in Kwara State, Nigeria American Journal of Business and Society, 1(4): 233245.

Ndahi, M., D. Kwaga, J., K. P. Bello, M. Kabir J., V. Umoh, .J. Yakubu, S., E. and Nok, A., J. (2013) Prevalence and Antimicrobial Susceptibility of Listeria Monocytogenes and Methicillin-Resistant Staphylococcus aureus Strains from Raw Meat and Meat Products in Zaria, Nigeria. Applied Journal of Microbiology, 58(3):262-9.

Okonko, I.O., Odu, N.N. and Igboh, I.E. (2013). Microbiological Analysis of Kilishi Sold In Port Harcourt, Nigeria. New York Science Journal, 6 (7):37-43.

Osimani, A., Aquilanti, L. and Clementi, F. (2015) Microbiological Quality of Meatbased Meals and Operation of Control Systems within a Food Service Environment. International Food Research Journal 22(4): 1692-1698.

Onuorah, S. Obika, I. Odibo, F. Orji, M. (2015)An Assessment of the Bacteriological Quality of Tsire-Suya (Grilled Beef) sold in Awka, Nigeria. American. J. Life. Sci. Res. 3(4):287292.

Razavilar, V, Khandaghi, J. Barzgari, A. (2010); Isolation of Eschericia coli 0157:H7 from manure fertilized farms and raw vegetables grown on it, in Tabriz city in
Iran. African Journal of Microbiology Research, 4(9): 891-895.

Scallan, E. Hoekstra, R. M. Angulo, F. J.Tauxe, R. V, Widdowson, M. Roy, S. L et al., (2011).Food borne illness acquired in the United States- Major Pathogens. Emerg. Infec Dis, 17(1): 7-15.

Shamsuddeen U (2009). Microbiological quality of spice used in the production of Kilishi a traditionally dried and grilled meat product. Bayero Journal of Pure andApplied Sciences, 2(2): 66-69.

Shamsuddeen, U. (2015) Microbiological Hazard and Critical control point Analysis of Dried and Minced Meat Snacks Produced in Kano Nigeria. Lambert Academic Publishing; Pp 1-36.

Tijani, O.and Jumare, S. (2014). Microblological Quality Assessment of Meat

Sold in KauraNamoda. International Conference on Earth, Environment and Life sciences (EELS) Dubai (UAE).

Udobi, C. E., Obajuluwa, A. F., and Onaolapo, J. A., (2013) Prevalence and Antibiotic Resistance Pattern of MethicillinResistant Staphylococcus aureus from an Orthopaedic Hospital in Nigeria BioMed Research International; 26(6); 6-7.

WHO, 2015 Foodborne diseases in the WHO African Region.

Yousafzai HA, Rind R, Khan MA, Abro SH, Korejo NA, Ejaz M, Kabir A, Shahid M, Memon S. (2019). Microbiological Contamination of Cattle and Meat in Peshawar, Pakistan. J. Anim. Health Prod. 7(1): 1116. 


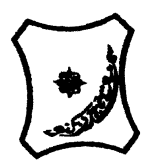

Bayero Journal of Pure and Applied Sciences, 13(1); 40 - 45

Received: September, 2019

Accepted: April, 2020

ISSN $2006-6996$

\title{
BACTERIOLOGICAL QUALITY OF STICK MEAT (Tsire) SOLD IN GARKO LOCAL GOVERNMENT AREA OF KANO STATE, NIGERIA
}

\author{
$*^{1}$ Dahiru A. T. and ${ }^{2}$ Maigari A. K. \\ ${ }^{1}$ Department of Hospitality Management, School of Technology, Kano State Polytechnic, PMB 3348, \\ Kano Nigeria. \\ ${ }^{2}$ Departmnt of Biological Sciences, Bayero University, Kano \\ Corresponding Author: dturajo61@gmail.com; GSM: 08087508262.
}

ABSTRACT

Stick meat, locally called Tsire in Hausa Language, is a significant portion of the diet of a large active population of Northern Nigeria. However, because of the handling and processing methods by the manufacturers as well as the hawking system of stick meat, the meat product may be exposed to both pre- and post-processed product contamination, and thus may poses danger to public health. Therefore, considering the role of Tsire in improving nutrition and increase household income to the populace, the need to improve the processing, distribution and overall quality of the product is simply indispensable. A total of 30 samples (5 samples from each of the 6 sampling points) of Tsire were collected randomly in Garko Town. Aerobic plate counts (APCs) and Total coliform counts (TCCS) of Tsire samples were determined using standard microbiological methods. APCs ranged from $1.02 \times 10^{5}$ to $4.00 \times 10^{5} \mathrm{CFU} / \mathrm{g}$; while TCCs ranged from $8 \mathrm{MPN} / \mathrm{g}$ to $68 \mathrm{MPN} / \mathrm{g}$. From the 30 samples screened, 16(53.33\%) bacteria namely, Campylobacter 2(6.66\%), Escherichia coli 6(20\%), Klebsiella pneumoniae 2(6.66\%), Salmonella spp. 1(3.33\%), Shigella 3(10\%) and Staphylococcus aureus 2(6.66\%) were detected. $E$. coli has the highest isolation rate of 6(20\%), while Salmonella spp. had the least frequency of 1(3.33\%). The distribution of isolated organisms within the study area were as follows: Dausai, 4(80\%), Kofar kudu, 4(80\%), Makwalla, 2(40\%), Rinji, 3(60\%), Tosaro, 2(40\%), and Tsohuwar Kasuwa, 1(20\%). The results have indicated that the Tsire was contaminated with bacteria thus exposing the product to fast deterioration, spoilage and also a vehicle for food borne illness, suggesting for adequate hygienic practices at all the stages, prior to consumption, to ensure safety of the meat product.

Key words: APCs, TCCs, Contamination, Microorganisms, Garko

\section{INTRODUCTION}

Nigeria is one of the developing nations with inadequate food supply and most often deficient in protein content (FAO, 2019). Nigerian's average animal protein intake per head per day is estimated at $7.9 \mathrm{~g}$ as against $35 \mathrm{~g}$ recommended value by Food and Agricultural Organization (Mubarak et al., 2016). These low levels of animal protein intake create great concern as it affects the nutritional status of Nigerians. Hence, there is the need for sufficient supply of animal protein from energy rich animal products to satisfy the nutritional requirements for Nigerians.

Meat is one major source of animal protein largely composed of water, protein and fats which can make it susceptible to microbial contamination within short time leading to spoilage (Apata et al., 2013; Mgbemere et al., 2011). Meat is mostly eaten after it has been cooked or processed in a variety of ways such as sun drying; smoking and roasting with or without fortifications (Borch et al., 1996). In Nigeria meat products such as Tsire, Kilishi and Balangu are locally produced using one or more of these methods in order to meet the nutritional requirements of the teeming Nigerians (Egbebi, 2011).

Tsire is a popular Nigerian traditional processed ready-to-eat roasted stick meat product (Shamsuddeen, 2015). It is sold in public places, along roads, in hotels, parks, quarters and even offices (Falegan et al., 2017). It is prepared from boneless healthy animal flesh such as beef and mutton, spiced with peanut cake, salt, vegetable oil and other flavorings followed by roasting (Shamsuddeen, 2015). Consumption of these products has extended to other parts of African countries such as Ghana, Somali, Cameroun and Chad (Ahmadu and Ibrahim, 2013). 
BAJOPAS Volume 13 Number 1, June, 2020

However, evidence of quality control sticking to procedural hygiene by the handlers during preparation and retailing of these products is poorly documented. Tsire is of great safety risk because of the fact that there are erratic cases of gastroenteritis and symptoms of food infection after consumption (WHO, 2015). Food borne illnesses are one of the major health problems in developing and developed countries (Razavilar, 2010). According to the World Health Organization, WHO (2015), $0.07 \%$ death of the 600 million global burdens of Foodborne illnesses have been reported to be caused by bacteria, viruses, fungi and chemicals. In America $0.27 \%$ of the estimated 48 million affected people is hospitalized and about $0.0063 \%$ deaths are recorded each year (Scallan et al., 2011). More than 91 million people in Africa fall ill and $0.15 \%$ dies each year, making Africa the highest burden bearer of Foodborne diseases per population (WHO, 2015).

Application of a Hazard Analysis Critical Control Point (HACCP) at all stages of meat products preparation is essential in order to ensure its safety. Thus, according to the guidelines of good manufacturing practice, the level of total aerobic bacterial contamination of thermally processed meat products should not exceed $10^{4}\left(\mathrm{cfu} \mathrm{g}^{-1}\right)$. Enterobacteriaceae and faecal coliform contamination in meat products should be within the range of $10^{2}-10^{4}$ and $10-10^{3} \mathrm{cfu} \mathrm{g}^{-1}$, respectively (Shamsuddeen, 2015). The aim of the study is therefore, to assess the total viable bacterial counts of tsire marketed locally within Garko town, and to isolate and identify the organisms at the point of consumption with the intention of promoting public health and food hygiene habits in the Nigerian populace.

\section{MATERIALS AND METHODS Study Area and Population}

Garko is one of the existing 44 local government areas located in Kano south west zone of Kano state with its capital administrative headquarters in the Garko town. It has coordinates $11^{\circ} 39^{\prime} \mathrm{N}$ $8^{\circ} 54^{\prime} \mathrm{E}$, and an area of $450 \mathrm{~km}^{2}$. The projected population of Garko local Government was 225,300 according to the National Population Census report (2018). Garko is known for agricultural activities both farming and animal husbandry. It is popularly known for large scale rice production. Other food crops include sweet potatoes, cassava, onions, sorghum, millet and sugarcane. Cows, sheep and goats are major groups of animals reared by majority of the populace. Meat products processed, retailed and consumed in Garko include roasted meat (Balangu), dried roasted meat (Kilishi), stick meat (Tsire), hide and skin pepper soup (Ragadada) and minced fried meat (Danbunnama).

\section{Samples Collection}

Five samples of Tsire products were collected from 6 different identified locations within Garko town in a sterile foil paper and immediately analyzed for the presence of bacteria.

\section{Sample Preparation}

Sample preparation for the bacteriological analysis was carried out in accordance with the method described by Atlas (1997). Twenty five grams $(25 \mathrm{~g})$ of the sample was homogenized in $225 \mathrm{ml}$ peptone water using Kenwood blender machine to obtain a $10^{1}$ homogenate. The homogenate was thoroughly shaken and $1 \mathrm{ml}$ pipetted into test tubes containing $9 \mathrm{ml}$ of peptone water $\left(10^{2}\right)$. The test tubes were further serially diluted to $10^{5}$.

Total Aerobic Mesophilic Bacterial Count

Total Aerobic mesophilic bacterial count was determined using the method described by Abdullahi et al. (2004) where $1 \mathrm{ml}$ of inoculums from $10^{1}$ to $10^{5}$ dilutions were transferred into duplicate Petri dishes and labeled accordingly. This was followed by pouring aseptically about $15 \mathrm{ml}$ of molten nutrient agar. The culture was homogenized by gentle spinning of the plates and allowed to solidify. The plates were incubated at $37^{\circ} \mathrm{C}$ for 24 hours. Plates containing 30-300 colonies were counted. The number of colony forming units per gram of a sample (cfu/g) was obtained by multiplying the average colony number with the inverse of the dilution factor.

\section{Enumeration and Detection of Coliform bacteria}

Detection and enumeration of coliform was carried out according to method described by Atlas, (1977). A set of 9 test tubes each containing $9 \mathrm{ml}$ of lactose broth and an inverted Durham tubes were autoclaved to expel air and to sterilize. Similarly, $1 \mathrm{ml}$ from the diluents $10^{1}$ was transferred to the first 3 test tubes, followed by $1 \mathrm{ml}$ from the diluents $10^{2}$ to the second set of 3 test tubes and finally the third diluents $10^{3}$ to the $3^{\text {rd }}$ set of 3 test tubes. All the 9 test tubes were incubated at $37^{\circ} \mathrm{C}$ for 24 hours. Tubes that showed gas and acid production after 24 hours were recorded as positive for the presence of Coliform. Negative tubes were further reincubated for 24 hours. Positive tubes were recorded. Estimate of most probable number of Coliform per gram of sample (MPN/g) was determined by comparing the number of gas positive tubes with the most probable number table. 
BAJOPAS Volume 13 Number 1, June, 2020 Identification of Coliform

A loop full of inoculum from gas positive tubes was streaked on to Eosine methylene blue (EMB) agar plate and incubated at $37^{\circ} \mathrm{C}$ for $24 \mathrm{hrs}$. Colonies which formed bluish black color with green metallic sheen, and reddish colonies were isolated on agar slants. Those colonies showing metallic sheen on EMB were sub cultured into tubes of lactose broth and incubated at $45^{\circ} \mathrm{C}$. The tubes were observed after $24 \mathrm{hrs}$ for gas production. This is the completed test for fecal coliform. Gram stain and other biochemical tests such as Indole, Methyl red, Voges-Proskauer and Citrate Utilization tests (IMVIC), Coagulase and Catalase tests were carried out for the Identification and confirmation of isolates.

\section{Procedure for Indole Test}

Indole test was carried out by preparing a Tryptone broth drawn in to test tubes, sterilized by autoclaving, inoculated with loopful of suspension and incubated at $37^{\circ} \mathrm{C}$ for 24 hours. Three drops of xylene was added in tubes, shaken vigorously and kept for the separation of two layers. One millilitre of Kovac's reagent was added and the formation of pink colour ring indicates positive Indole test.

\section{Procedure for Methyl Red Test}

Methyl red test was carried out by preparing Glucose phosphate broth, dispensed in test tubes, sterilized, inoculated with test culture and incubated at $37^{\circ} \mathrm{C}$ for 24 hours. Five drops of methyl-red indicator was added to the medium for the formation of red colour.

\section{Procedure for Voges-Proskauer Test}

Voges-Proskauer test was carried out by inoculating tubes with the bacterial culture followed by incubation for 48 hours at $37^{\circ} \mathrm{C}$. Separate pipettes were used to pipette $1 \mathrm{ml}$ from each culture tube into clean separate tubes. Eighteen drops $(0.5 \mathrm{ml})$ of Barrit's solution A (a-naphthol) was added to each tube containing glucose phosphate broth followed by the addition of an equal amount of solution $B$ into the same tube. The tubes were shaken at 30 seconds interval. A positive reaction was indicated by the development of a pink color, which turns red in 1-2 hours, after vigorous shaking.

\section{Procedure for Citrate Utilization Test}

Citrate Utilization Test was carried out by distributing melted agar (Simmon Citrate Agar) in to test tubes followed by sterilization at $121.5^{\circ} \mathrm{C}$ for 15 minutes. The test tubes were afterward held in slanted position, inoculated with the given bacterial culture and incubated at $37^{\circ} \mathrm{C}$ for $24 \mathrm{hrs}$. Positive test was indicated by color change of the media from green to blue.

\section{RESULTS AND DISCUSSIONS}

The results of this study are presented in tables $1,2,3$ and 4. Among the sampling areas Kofar Kudu had the highest aerobic mesophilic bacteria counts $4.0 \times 10^{5} \mathrm{cfu} / \mathrm{g}$ followed by Rinji $2.72 \times 10^{5} \mathrm{cfu} / \mathrm{g}$, while Tosaro had the least Aerobic mesophilic bacteria counts of $1.02 \times 10^{5}$ $\mathrm{cfu} / \mathrm{g}$ as indicated in Table 1.Makwalla had the highest coliform count $68 \mathrm{MPN} / \mathrm{g}$ followed by Rinji $37 \mathrm{MPN} / \mathrm{g}$. Tsohuwar Kasuwa had the least coliform counts $8 \mathrm{MPN} / \mathrm{g}$, (Table 2). Result from table 1 shows variation in the microbial contents among the samples which suggest variation in their sources, poor handling procedures and contamination from the processing environment. High coliform count and their differences within sampling areas is an indication of poor microbiological quality of the product. Ndahi et al. (2013) reported microbial load to be a function of the handling personnel and the environment. The results indicated that the samples were contaminated with bacteria as the counts exceeded the minimum safety level $\left(10^{4} \mathrm{cfu} / \mathrm{g}\right)$ for members of the Enterobacteriaceae family. However, it might be a reflection of poor hygienic practices which may contribute to health hazard to the potential consumers. Similarly, Inusa and Sa'id (2017); Osimani et al. (2015) reported that, the initial microbial content of the raw material play significant role in influencing the final microbial load of the finished product. Isolation of members of the Enterobacteriaceae such as $E$. coli, Klebsiella pneumoniae, Salmonella and Shigella signifies danger to the public health. These organisms are capable of producing endotoxins which trigger high fevers in infected individuals, and the enterotoxins which colonize the small intestines and lead to extreme dehydration as a result of vomiting and diarrhea sometimes with severe and fatal outcomes (Amaeze et al., 2016). From the 16 isolated organisms $E$. coli had the highest isolation rate $6(37.5 \%)$ (Table 3), this suggest faecal contamination of the products. $E$. coli is a common flora in the gastrointestinal tract responsible for diarrhea and extra-intestinal infections (CDC, 2011). The result is in conformity with the findings of Ndahi et al. (2013) and Shamsuddeen (2009). Also presence of campylobacter might be due to cross contamination from raw meat to finished product (Tsire). Staphylococcus aureus is a normal flora of the skin, nasal, genital, mouth or anal area in both humans and animals without any symptom of an infection (Matthew et al., 2013). Isolation of $S$. aureus in these study concords with the findings of Lucretia et al. (2018) from Suya sold in Rivers State. 
BAJOPAS Volume 13 Number 1, June, 2020

It is also in agreement with the findings of Yousafzai et al. (2018); Onuorah et al. (2015) and Tijjani and Jumare (2014) from tsire samples in different countries. Presence of $S$. aureus in foods is most of the time an indication of poor human handling, poor environment, unhygienic utensils and equipments used during processing (Igene et al., 2016; Okonko et al., 2013). Infections caused by $S$. aureus are difficult to treat leading to long hospitalization with consequent economic loss (Udobi et al., 2013). These include soft tissue infections, pneumonia, hospital-acquired postoperative wound infections, Staphylococcal food poisoning, impetigo and cellulitis (Charlene et al., 2013). Samples obtained from Dausai and Kofar Kudu had the highest isolation rate $4(80 \%)$ (Table 4 ) probably because of the much commercial activities taking place in the area which can lead to environmental contamination.

Table 1: Total Aerobic Mesophilic Bacterial Count of Tsire sold in Garko Town

\begin{tabular}{lll}
\hline Sampling Area & APC cfu/g & Mean \pm STD \\
\hline Dausai & $2.20 \times 10^{5}$ & $110000 \pm 14142.14$ \\
Kofar Kudu & $4.00 \times 10^{5}$ & $133333.3 \pm 23094.01$ \\
Makwalla & $1.30 \times 10^{5}$ & $32500 \pm 7187.953$ \\
Rinji & $2.72 \times 10^{5}$ & $90666.67 \pm 94769.90$ \\
Tosaro & $1.02 \times 10^{5}$ & $51000 \pm 15556.35$ \\
Tsohuwar Kasuwa & $1.75 \times 10^{5}$ & $35000 \pm 11357.82$ \\
\hline
\end{tabular}

Key: APC: Aerobic Mesophilic Counts

STD: Standard Deviation

Table 2: Total Coliform Count of Tsire sold in Garko Town

\begin{tabular}{lcc}
\hline \multicolumn{1}{c}{ Sampling Area } & TCC MPN/g & Mean \pm STD \\
\hline Dausai & 20 & $6.67 \pm 2.5166$ \\
Kofar Kudu & 32 & $16.00 \pm 5.6569$ \\
Makwalla & 68 & $13.60 \pm 8.7062$ \\
Rinji & 37 & $9.25 \pm 4.7871$ \\
Tosaro & 10 & $5.00 \pm 2.8284$ \\
Tsohuwar Kasuwa & 8 & $4.00 \pm 0.0000$ \\
\hline
\end{tabular}

Table 3: Organisms Isolated from Tsire Sold in Garko

\begin{tabular}{lcl}
\hline Isolated Organism & Frequency & Percentage (\%) \\
\hline Campylobacter & 2 & 06.66 \\
Escherichia coli & 6 & 20.00 \\
Klebsiella pneumoniae & 2 & 06.66 \\
Salmonella species & 1 & 03.33 \\
Shigella & 3 & 10.00 \\
Staphylococcus aureus & 2 & 06.66 \\
Total & 16 & \\
\hline
\end{tabular}

Table 4: Distribution of Organisms within Sampling Area

\begin{tabular}{lcc}
\hline \multicolumn{1}{c}{ Sampling Area } & No. Isolated & Percentage (\%) \\
\hline Dausai & 4 & 80 \\
Kofar Kudu & 4 & 80 \\
Makwalla & 2 & 40 \\
Rinji & 3 & 60 \\
Tosaro & 2 & 40 \\
Tsohuwar Kasuwa & 1 & 20 \\
Total & 16 & \\
\hline
\end{tabular}

\section{CONCLUSION}

Results indicated $4.00 \times 10^{5} \mathrm{CFU} / \mathrm{g}$ as the highest APCs count; while $68 \mathrm{MPN} / \mathrm{g}$ was the highest TCCs from the 30 samples analyzed. Among the isolates, $E$. coli has the highest isolation rate of $6(20 \%)$. Dausai and Kofar kudu were having the highest bacteria count of $4(80 \%)$, each, indicating higher contamination in those locations. 
BAJOPAS Volume 13 Number 1, June, 2020 RECOMMENDATIONS

The following recommendations are tenable:

1. Hygienic practices at all stages of production should be improved to safe guard the consumers against potential health hazard.

2. Monitoring of microbiological contamination of Tsire during preparations, packaging and marketing is essential to ensure product of good microbiological quality for consumers' health.

\section{REFERENCES}

Abdullahi, I. O., Umoh, V. J. and Galadima, M. (2004). Hazards Associated with Kilishi Preparations in Zaria. Nigerian Journal of Microbiology, 18 (1-2): $339-345$.

Ahmadu, J. and Ibrahim E. J., (2013): Determinants of Revenue in Suya Production in BeninCity, Edo State, Nigeria. Nigerian journal of agriculture, food and environment.9(3):1-5

Amaeze, N. Aboh, M. Itohan, A. Felix, E. Olatunji, T. and Oladosu, P. (2016) Microbial Profile, Antibiotic Sensitivity and Heat Resistance of Bacterial Isolates from Commercial Roasted Beef (Suya) in Abuja, Nigeria. JOPAT, 15(2): $22-30$.

Apata, E.S., Kuku1, I.A., Apata, O.C. and Adeyemi, K.O. (2013). Evaluation of Suya(Tsire) - An Intermediate Moisture Meat Product in Ogun State, Nigeria. J. Food Res 2 (1): 87.

Atlas, R. M. (1997) Principles of Microbiology Second Edition. C. Brown Publishers. Pp 802-803.

Borch, E. Kant-Muermans, M. L., Blixt, Y. (1996) Bacterial Spoilage of Meat and Cured Meat Products. Int $\mathrm{J}$ Food Microbiol .33(1): 103-20.

Centre for Disease Control, CDC (2011). "Escherichia coli 0157:H7" Division of Bacterial and Mycotic Diseasesht://www.cdc.gov/nczved/divisi ons/dfbmd/diseases/ecoli_0157h7/.

Charlene, R. J., Johnnie, A. D., and John, B. B., (2013) Prevalence and Characterization of Methicillin-Resistant Staphylococcus aureus Isolates from Retail Meat and Humans in Georgia. American society for Microbiology. J. of clinical microbiology. 12(1):123-6 doi:10.1128/JCM.0316612JCM.03166-12

Egbebi, A.O and Seidu, K., T. (2011). Microbiological Evaluation of Suya (dried smoked

meat) Sold in Ado and Akure, South West Nigeria.European Journal of Experinmental Biology, 1(4):1-5
3. Government should establish regulatory bodies responsible for inculcating hygiene habits to the local producers and vendors in order to prevent instant, cross and post processing contaminations by microbial pathogens.

4. Awareness and sensitization of local food producers about good hygienic practices in food handling and processing.

Falegan, C, R., Akoja, S. D., and Oyarekua, M. A., (2017) Microbiological Assessment of Suya (Sliced Roasted Beef) in Ado-Ekiti Metropolis, Ekiti State, Nigeria. MOJ Biology andMedicine.

Fonkem, D., N. Tanya, V., N. and Ebangi, A., L. (2010). Effect of Season on the Microbiological Quality of Kilishi, a Traditional Cameroonian Dried Beef Product. Tropicultura, 28(1): 10-15.

Food and Agricultural Organization of the United Nations (F A O, 1979). Manual of food quality control 4. Microbiological analysis.

Food and Agriculture Organisation of the United Nation (FAO), 2019. Nigeria at a glance.

Igene J.O., Uwadia, O.E., Ebabhamiegbebho, P.A. and Evivie, S.E., (2016) Shelf life Stability Studies of University of Benin (UNIBEN) Proff's Kilishi Product Asian Journal of Science and Technology 7(1): 2268-2274.

Inusa, S. K. and Said, I. S. (2017) Evaluation of the Chemical and Microbiological Properties Of Kilishi Sold in Kano Metropolis. Journal of Dry land Agriculture, 3 (1): $59-69$.

Lucretia, I. B, Patience, C. Obinna-Echem, Sophia, C. A. (2018) Microbiological quality andantibiotic sensitivity of potential pathogens isolated from meat product (Suya) sold in Rivers State University and its environs. International Journal of Biotechnology and Food Science, 6(4): 67-76.

Matthew, E., Drosos, E., John, L. and Ioanna, P. (2013) MRSA in Africa: Filling the Global Map of Antimicrobial Resistance PLOS One. 8(7): e68024 doi: 10.1371/journal.pone.0068024

Mgbemere, V.N., Akpapunam, M. A. and Igene, J. O., (2011). Effect of Groundnut FlourSubstitution on Yield, Quality and Storage Stability of Kilishi - a Nigerian Indigenous Dried Meat Product. African Journal of Food, Agriculture, Nutrition and Development, $\quad \mathbf{1 1}(2)$ : 4718-4738. 
BAJOPAS Volume 13 Number 1, June, 2020

Mubarak, A. A., Azeez, M. L., Amos A. O., Opeyemi, O. O. (2016) Assessment of Animal Protein Consumption and Food Security Among Rural Households in Kwara State, Nigeria American Journal of Business and Society, 1(4): 233245.

Ndahi, M., D. Kwaga, J., K. P. Bello, M. Kabir J., V. Umoh, .J. Yakubu, S., E. and Nok, A., J. (2013) Prevalence and Antimicrobial Susceptibility of Listeria Monocytogenes and Methicillin-Resistant Staphylococcus aureus Strains from Raw Meat and Meat Products in Zaria, Nigeria. Applied Journal of Microbiology, 58(3):262-9.

Okonko, I.O., Odu, N.N. and Igboh, I.E. (2013). Microbiological Analysis of Kilishi Sold In Port Harcourt, Nigeria. New York Science Journal, 6 (7):37-43.

Osimani, A., Aquilanti, L. and Clementi, F. (2015) Microbiological Quality of Meatbased Meals and Operation of Control Systems within a Food Service Environment. International Food Research Journal 22(4): 1692-1698.

Onuorah, S. Obika, I. Odibo, F. Orji, M. (2015)An Assessment of the Bacteriological Quality of Tsire-Suya (Grilled Beef) sold in Awka, Nigeria. American. J. Life. Sci. Res. 3(4):287292.

Razavilar, V, Khandaghi, J. Barzgari, A. (2010); Isolation of Eschericia coli 0157:H7 from manure fertilized farms and raw vegetables grown on it, in Tabriz city in
Iran. African Journal of Microbiology Research, 4(9): 891-895.

Scallan, E. Hoekstra, R. M. Angulo, F. J.Tauxe, R. V, Widdowson, M. Roy, S. L et al., (2011).Food borne illness acquired in the United States- Major Pathogens. Emerg. Infec Dis, 17(1): 7-15.

Shamsuddeen U (2009). Microbiological quality of spice used in the production of Kilishi a traditionally dried and grilled meat product. Bayero Journal of Pure andApplied Sciences, 2(2): 66-69.

Shamsuddeen, U. (2015) Microbiological Hazard and Critical control point Analysis of Dried and Minced Meat Snacks Produced in Kano Nigeria. Lambert Academic Publishing; Pp 1-36.

Tijani, O.and Jumare, S. (2014). Microblological Quality Assessment of Meat

Sold in KauraNamoda. International Conference on Earth, Environment and Life sciences (EELS) Dubai (UAE).

Udobi, C. E., Obajuluwa, A. F., and Onaolapo, J. A., (2013) Prevalence and Antibiotic Resistance Pattern of MethicillinResistant Staphylococcus aureus from an Orthopaedic Hospital in Nigeria BioMed Research International; 26(6); 6-7.

WHO, 2015 Foodborne diseases in the WHO African Region.

Yousafzai HA, Rind R, Khan MA, Abro SH, Korejo NA, Ejaz M, Kabir A, Shahid M, Memon S. (2019). Microbiological Contamination of Cattle and Meat in Peshawar, Pakistan. J. Anim. Health Prod. 7(1): 1116. 


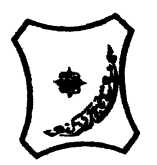

Bayero Journal of Pure and Applied Sciences, 13(1); 40 - 45

Received: September, 2019

Accepted: April, 2020

ISSN $2006-6996$

\title{
BACTERIOLOGICAL QUALITY OF STICK MEAT (Tsire) SOLD IN GARKO LOCAL GOVERNMENT AREA OF KANO STATE, NIGERIA
}

\author{
$*^{1}$ Dahiru A. T. and ${ }^{2}$ Maigari A. K. \\ ${ }^{1}$ Department of Hospitality Management, School of Technology, Kano State Polytechnic, PMB 3348, \\ Kano Nigeria. \\ ${ }^{2}$ Departmnt of Biological Sciences, Bayero University, Kano \\ Corresponding Author: dturajo61@gmail.com; GSM: 08087508262.
}

ABSTRACT

Stick meat, locally called Tsire in Hausa Language, is a significant portion of the diet of a large active population of Northern Nigeria. However, because of the handling and processing methods by the manufacturers as well as the hawking system of stick meat, the meat product may be exposed to both pre- and post-processed product contamination, and thus may poses danger to public health. Therefore, considering the role of Tsire in improving nutrition and increase household income to the populace, the need to improve the processing, distribution and overall quality of the product is simply indispensable. A total of 30 samples (5 samples from each of the 6 sampling points) of Tsire were collected randomly in Garko Town. Aerobic plate counts (APCs) and Total coliform counts (TCCS) of Tsire samples were determined using standard microbiological methods. APCs ranged from $1.02 \times 10^{5}$ to $4.00 \times 10^{5} \mathrm{CFU} / \mathrm{g}$; while TCCs ranged from $8 \mathrm{MPN} / \mathrm{g}$ to $68 \mathrm{MPN} / \mathrm{g}$. From the 30 samples screened, 16(53.33\%) bacteria namely, Campylobacter 2(6.66\%), Escherichia coli 6(20\%), Klebsiella pneumoniae 2(6.66\%), Salmonella spp. 1(3.33\%), Shigella 3(10\%) and Staphylococcus aureus 2(6.66\%) were detected. $E$. coli has the highest isolation rate of 6(20\%), while Salmonella spp. had the least frequency of 1(3.33\%). The distribution of isolated organisms within the study area were as follows: Dausai, 4(80\%), Kofar kudu, 4(80\%), Makwalla, 2(40\%), Rinji, 3(60\%), Tosaro, 2(40\%), and Tsohuwar Kasuwa, 1(20\%). The results have indicated that the Tsire was contaminated with bacteria thus exposing the product to fast deterioration, spoilage and also a vehicle for food borne illness, suggesting for adequate hygienic practices at all the stages, prior to consumption, to ensure safety of the meat product.

Key words: APCs, TCCs, Contamination, Microorganisms, Garko

\section{INTRODUCTION}

Nigeria is one of the developing nations with inadequate food supply and most often deficient in protein content (FAO, 2019). Nigerian's average animal protein intake per head per day is estimated at $7.9 \mathrm{~g}$ as against $35 \mathrm{~g}$ recommended value by Food and Agricultural Organization (Mubarak et al., 2016). These low levels of animal protein intake create great concern as it affects the nutritional status of Nigerians. Hence, there is the need for sufficient supply of animal protein from energy rich animal products to satisfy the nutritional requirements for Nigerians.

Meat is one major source of animal protein largely composed of water, protein and fats which can make it susceptible to microbial contamination within short time leading to spoilage (Apata et al., 2013; Mgbemere et al., 2011). Meat is mostly eaten after it has been cooked or processed in a variety of ways such as sun drying; smoking and roasting with or without fortifications (Borch et al., 1996). In Nigeria meat products such as Tsire, Kilishi and Balangu are locally produced using one or more of these methods in order to meet the nutritional requirements of the teeming Nigerians (Egbebi, 2011).

Tsire is a popular Nigerian traditional processed ready-to-eat roasted stick meat product (Shamsuddeen, 2015). It is sold in public places, along roads, in hotels, parks, quarters and even offices (Falegan et al., 2017). It is prepared from boneless healthy animal flesh such as beef and mutton, spiced with peanut cake, salt, vegetable oil and other flavorings followed by roasting (Shamsuddeen, 2015). Consumption of these products has extended to other parts of African countries such as Ghana, Somali, Cameroun and Chad (Ahmadu and Ibrahim, 2013). 
BAJOPAS Volume 13 Number 1, June, 2020

However, evidence of quality control sticking to procedural hygiene by the handlers during preparation and retailing of these products is poorly documented. Tsire is of great safety risk because of the fact that there are erratic cases of gastroenteritis and symptoms of food infection after consumption (WHO, 2015). Food borne illnesses are one of the major health problems in developing and developed countries (Razavilar, 2010). According to the World Health Organization, WHO (2015), $0.07 \%$ death of the 600 million global burdens of Foodborne illnesses have been reported to be caused by bacteria, viruses, fungi and chemicals. In America $0.27 \%$ of the estimated 48 million affected people is hospitalized and about $0.0063 \%$ deaths are recorded each year (Scallan et al., 2011). More than 91 million people in Africa fall ill and $0.15 \%$ dies each year, making Africa the highest burden bearer of Foodborne diseases per population (WHO, 2015).

Application of a Hazard Analysis Critical Control Point (HACCP) at all stages of meat products preparation is essential in order to ensure its safety. Thus, according to the guidelines of good manufacturing practice, the level of total aerobic bacterial contamination of thermally processed meat products should not exceed $10^{4}\left(\mathrm{cfu} \mathrm{g}^{-1}\right)$. Enterobacteriaceae and faecal coliform contamination in meat products should be within the range of $10^{2}-10^{4}$ and $10-10^{3} \mathrm{cfu} \mathrm{g}^{-1}$, respectively (Shamsuddeen, 2015). The aim of the study is therefore, to assess the total viable bacterial counts of tsire marketed locally within Garko town, and to isolate and identify the organisms at the point of consumption with the intention of promoting public health and food hygiene habits in the Nigerian populace.

\section{MATERIALS AND METHODS Study Area and Population}

Garko is one of the existing 44 local government areas located in Kano south west zone of Kano state with its capital administrative headquarters in the Garko town. It has coordinates $11^{\circ} 39^{\prime} \mathrm{N}$ $8^{\circ} 54^{\prime} \mathrm{E}$, and an area of $450 \mathrm{~km}^{2}$. The projected population of Garko local Government was 225,300 according to the National Population Census report (2018). Garko is known for agricultural activities both farming and animal husbandry. It is popularly known for large scale rice production. Other food crops include sweet potatoes, cassava, onions, sorghum, millet and sugarcane. Cows, sheep and goats are major groups of animals reared by majority of the populace. Meat products processed, retailed and consumed in Garko include roasted meat (Balangu), dried roasted meat (Kilishi), stick meat (Tsire), hide and skin pepper soup (Ragadada) and minced fried meat (Danbunnama).

\section{Samples Collection}

Five samples of Tsire products were collected from 6 different identified locations within Garko town in a sterile foil paper and immediately analyzed for the presence of bacteria.

\section{Sample Preparation}

Sample preparation for the bacteriological analysis was carried out in accordance with the method described by Atlas (1997). Twenty five grams $(25 \mathrm{~g})$ of the sample was homogenized in $225 \mathrm{ml}$ peptone water using Kenwood blender machine to obtain a $10^{1}$ homogenate. The homogenate was thoroughly shaken and $1 \mathrm{ml}$ pipetted into test tubes containing $9 \mathrm{ml}$ of peptone water $\left(10^{2}\right)$. The test tubes were further serially diluted to $10^{5}$.

Total Aerobic Mesophilic Bacterial Count

Total Aerobic mesophilic bacterial count was determined using the method described by Abdullahi et al. (2004) where $1 \mathrm{ml}$ of inoculums from $10^{1}$ to $10^{5}$ dilutions were transferred into duplicate Petri dishes and labeled accordingly. This was followed by pouring aseptically about $15 \mathrm{ml}$ of molten nutrient agar. The culture was homogenized by gentle spinning of the plates and allowed to solidify. The plates were incubated at $37^{\circ} \mathrm{C}$ for 24 hours. Plates containing 30-300 colonies were counted. The number of colony forming units per gram of a sample (cfu/g) was obtained by multiplying the average colony number with the inverse of the dilution factor.

\section{Enumeration and Detection of Coliform bacteria}

Detection and enumeration of coliform was carried out according to method described by Atlas, (1977). A set of 9 test tubes each containing $9 \mathrm{ml}$ of lactose broth and an inverted Durham tubes were autoclaved to expel air and to sterilize. Similarly, $1 \mathrm{ml}$ from the diluents $10^{1}$ was transferred to the first 3 test tubes, followed by $1 \mathrm{ml}$ from the diluents $10^{2}$ to the second set of 3 test tubes and finally the third diluents $10^{3}$ to the $3^{\text {rd }}$ set of 3 test tubes. All the 9 test tubes were incubated at $37^{\circ} \mathrm{C}$ for 24 hours. Tubes that showed gas and acid production after 24 hours were recorded as positive for the presence of Coliform. Negative tubes were further reincubated for 24 hours. Positive tubes were recorded. Estimate of most probable number of Coliform per gram of sample (MPN/g) was determined by comparing the number of gas positive tubes with the most probable number table. 
BAJOPAS Volume 13 Number 1, June, 2020 Identification of Coliform

A loop full of inoculum from gas positive tubes was streaked on to Eosine methylene blue (EMB) agar plate and incubated at $37^{\circ} \mathrm{C}$ for $24 \mathrm{hrs}$. Colonies which formed bluish black color with green metallic sheen, and reddish colonies were isolated on agar slants. Those colonies showing metallic sheen on EMB were sub cultured into tubes of lactose broth and incubated at $45^{\circ} \mathrm{C}$. The tubes were observed after $24 \mathrm{hrs}$ for gas production. This is the completed test for fecal coliform. Gram stain and other biochemical tests such as Indole, Methyl red, Voges-Proskauer and Citrate Utilization tests (IMVIC), Coagulase and Catalase tests were carried out for the Identification and confirmation of isolates.

\section{Procedure for Indole Test}

Indole test was carried out by preparing a Tryptone broth drawn in to test tubes, sterilized by autoclaving, inoculated with loopful of suspension and incubated at $37^{\circ} \mathrm{C}$ for 24 hours. Three drops of xylene was added in tubes, shaken vigorously and kept for the separation of two layers. One millilitre of Kovac's reagent was added and the formation of pink colour ring indicates positive Indole test.

\section{Procedure for Methyl Red Test}

Methyl red test was carried out by preparing Glucose phosphate broth, dispensed in test tubes, sterilized, inoculated with test culture and incubated at $37^{\circ} \mathrm{C}$ for 24 hours. Five drops of methyl-red indicator was added to the medium for the formation of red colour.

\section{Procedure for Voges-Proskauer Test}

Voges-Proskauer test was carried out by inoculating tubes with the bacterial culture followed by incubation for 48 hours at $37^{\circ} \mathrm{C}$. Separate pipettes were used to pipette $1 \mathrm{ml}$ from each culture tube into clean separate tubes. Eighteen drops $(0.5 \mathrm{ml})$ of Barrit's solution A (a-naphthol) was added to each tube containing glucose phosphate broth followed by the addition of an equal amount of solution $B$ into the same tube. The tubes were shaken at 30 seconds interval. A positive reaction was indicated by the development of a pink color, which turns red in 1-2 hours, after vigorous shaking.

\section{Procedure for Citrate Utilization Test}

Citrate Utilization Test was carried out by distributing melted agar (Simmon Citrate Agar) in to test tubes followed by sterilization at $121.5^{\circ} \mathrm{C}$ for 15 minutes. The test tubes were afterward held in slanted position, inoculated with the given bacterial culture and incubated at $37^{\circ} \mathrm{C}$ for $24 \mathrm{hrs}$. Positive test was indicated by color change of the media from green to blue.

\section{RESULTS AND DISCUSSIONS}

The results of this study are presented in tables $1,2,3$ and 4. Among the sampling areas Kofar Kudu had the highest aerobic mesophilic bacteria counts $4.0 \times 10^{5} \mathrm{cfu} / \mathrm{g}$ followed by Rinji $2.72 \times 10^{5} \mathrm{cfu} / \mathrm{g}$, while Tosaro had the least Aerobic mesophilic bacteria counts of $1.02 \times 10^{5}$ $\mathrm{cfu} / \mathrm{g}$ as indicated in Table 1.Makwalla had the highest coliform count $68 \mathrm{MPN} / \mathrm{g}$ followed by Rinji $37 \mathrm{MPN} / \mathrm{g}$. Tsohuwar Kasuwa had the least coliform counts $8 \mathrm{MPN} / \mathrm{g}$, (Table 2). Result from table 1 shows variation in the microbial contents among the samples which suggest variation in their sources, poor handling procedures and contamination from the processing environment. High coliform count and their differences within sampling areas is an indication of poor microbiological quality of the product. Ndahi et al. (2013) reported microbial load to be a function of the handling personnel and the environment. The results indicated that the samples were contaminated with bacteria as the counts exceeded the minimum safety level $\left(10^{4} \mathrm{cfu} / \mathrm{g}\right)$ for members of the Enterobacteriaceae family. However, it might be a reflection of poor hygienic practices which may contribute to health hazard to the potential consumers. Similarly, Inusa and Sa'id (2017); Osimani et al. (2015) reported that, the initial microbial content of the raw material play significant role in influencing the final microbial load of the finished product. Isolation of members of the Enterobacteriaceae such as $E$. coli, Klebsiella pneumoniae, Salmonella and Shigella signifies danger to the public health. These organisms are capable of producing endotoxins which trigger high fevers in infected individuals, and the enterotoxins which colonize the small intestines and lead to extreme dehydration as a result of vomiting and diarrhea sometimes with severe and fatal outcomes (Amaeze et al., 2016). From the 16 isolated organisms $E$. coli had the highest isolation rate $6(37.5 \%)$ (Table 3), this suggest faecal contamination of the products. $E$. coli is a common flora in the gastrointestinal tract responsible for diarrhea and extra-intestinal infections (CDC, 2011). The result is in conformity with the findings of Ndahi et al. (2013) and Shamsuddeen (2009). Also presence of campylobacter might be due to cross contamination from raw meat to finished product (Tsire). Staphylococcus aureus is a normal flora of the skin, nasal, genital, mouth or anal area in both humans and animals without any symptom of an infection (Matthew et al., 2013). Isolation of $S$. aureus in these study concords with the findings of Lucretia et al. (2018) from Suya sold in Rivers State. 
BAJOPAS Volume 13 Number 1, June, 2020

It is also in agreement with the findings of Yousafzai et al. (2018); Onuorah et al. (2015) and Tijjani and Jumare (2014) from tsire samples in different countries. Presence of $S$. aureus in foods is most of the time an indication of poor human handling, poor environment, unhygienic utensils and equipments used during processing (Igene et al., 2016; Okonko et al., 2013). Infections caused by $S$. aureus are difficult to treat leading to long hospitalization with consequent economic loss (Udobi et al., 2013). These include soft tissue infections, pneumonia, hospital-acquired postoperative wound infections, Staphylococcal food poisoning, impetigo and cellulitis (Charlene et al., 2013). Samples obtained from Dausai and Kofar Kudu had the highest isolation rate $4(80 \%)$ (Table 4 ) probably because of the much commercial activities taking place in the area which can lead to environmental contamination.

Table 1: Total Aerobic Mesophilic Bacterial Count of Tsire sold in Garko Town

\begin{tabular}{lll}
\hline Sampling Area & APC cfu/g & Mean \pm STD \\
\hline Dausai & $2.20 \times 10^{5}$ & $110000 \pm 14142.14$ \\
Kofar Kudu & $4.00 \times 10^{5}$ & $133333.3 \pm 23094.01$ \\
Makwalla & $1.30 \times 10^{5}$ & $32500 \pm 7187.953$ \\
Rinji & $2.72 \times 10^{5}$ & $90666.67 \pm 94769.90$ \\
Tosaro & $1.02 \times 10^{5}$ & $51000 \pm 15556.35$ \\
Tsohuwar Kasuwa & $1.75 \times 10^{5}$ & $35000 \pm 11357.82$ \\
\hline
\end{tabular}

Key: APC: Aerobic Mesophilic Counts

STD: Standard Deviation

Table 2: Total Coliform Count of Tsire sold in Garko Town

\begin{tabular}{lcc}
\hline \multicolumn{1}{c}{ Sampling Area } & TCC MPN/g & Mean \pm STD \\
\hline Dausai & 20 & $6.67 \pm 2.5166$ \\
Kofar Kudu & 32 & $16.00 \pm 5.6569$ \\
Makwalla & 68 & $13.60 \pm 8.7062$ \\
Rinji & 37 & $9.25 \pm 4.7871$ \\
Tosaro & 10 & $5.00 \pm 2.8284$ \\
Tsohuwar Kasuwa & 8 & $4.00 \pm 0.0000$ \\
\hline
\end{tabular}

Table 3: Organisms Isolated from Tsire Sold in Garko

\begin{tabular}{lcl}
\hline Isolated Organism & Frequency & Percentage (\%) \\
\hline Campylobacter & 2 & 06.66 \\
Escherichia coli & 6 & 20.00 \\
Klebsiella pneumoniae & 2 & 06.66 \\
Salmonella species & 1 & 03.33 \\
Shigella & 3 & 10.00 \\
Staphylococcus aureus & 2 & 06.66 \\
Total & 16 & \\
\hline
\end{tabular}

Table 4: Distribution of Organisms within Sampling Area

\begin{tabular}{lcc}
\hline \multicolumn{1}{c}{ Sampling Area } & No. Isolated & Percentage (\%) \\
\hline Dausai & 4 & 80 \\
Kofar Kudu & 4 & 80 \\
Makwalla & 2 & 40 \\
Rinji & 3 & 60 \\
Tosaro & 2 & 40 \\
Tsohuwar Kasuwa & 1 & 20 \\
Total & 16 & \\
\hline
\end{tabular}

\section{CONCLUSION}

Results indicated $4.00 \times 10^{5} \mathrm{CFU} / \mathrm{g}$ as the highest APCs count; while $68 \mathrm{MPN} / \mathrm{g}$ was the highest TCCs from the 30 samples analyzed. Among the isolates, $E$. coli has the highest isolation rate of $6(20 \%)$. Dausai and Kofar kudu were having the highest bacteria count of $4(80 \%)$, each, indicating higher contamination in those locations. 
BAJOPAS Volume 13 Number 1, June, 2020 RECOMMENDATIONS

The following recommendations are tenable:

1. Hygienic practices at all stages of production should be improved to safe guard the consumers against potential health hazard.

2. Monitoring of microbiological contamination of Tsire during preparations, packaging and marketing is essential to ensure product of good microbiological quality for consumers' health.

\section{REFERENCES}

Abdullahi, I. O., Umoh, V. J. and Galadima, M. (2004). Hazards Associated with Kilishi Preparations in Zaria. Nigerian Journal of Microbiology, 18 (1-2): $339-345$.

Ahmadu, J. and Ibrahim E. J., (2013): Determinants of Revenue in Suya Production in BeninCity, Edo State, Nigeria. Nigerian journal of agriculture, food and environment.9(3):1-5

Amaeze, N. Aboh, M. Itohan, A. Felix, E. Olatunji, T. and Oladosu, P. (2016) Microbial Profile, Antibiotic Sensitivity and Heat Resistance of Bacterial Isolates from Commercial Roasted Beef (Suya) in Abuja, Nigeria. JOPAT, 15(2): $22-30$.

Apata, E.S., Kuku1, I.A., Apata, O.C. and Adeyemi, K.O. (2013). Evaluation of Suya(Tsire) - An Intermediate Moisture Meat Product in Ogun State, Nigeria. J. Food Res 2 (1): 87.

Atlas, R. M. (1997) Principles of Microbiology Second Edition. C. Brown Publishers. Pp 802-803.

Borch, E. Kant-Muermans, M. L., Blixt, Y. (1996) Bacterial Spoilage of Meat and Cured Meat Products. Int $\mathrm{J}$ Food Microbiol .33(1): 103-20.

Centre for Disease Control, CDC (2011). "Escherichia coli 0157:H7" Division of Bacterial and Mycotic Diseasesht://www.cdc.gov/nczved/divisi ons/dfbmd/diseases/ecoli_0157h7/.

Charlene, R. J., Johnnie, A. D., and John, B. B., (2013) Prevalence and Characterization of Methicillin-Resistant Staphylococcus aureus Isolates from Retail Meat and Humans in Georgia. American society for Microbiology. J. of clinical microbiology. 12(1):123-6 doi:10.1128/JCM.0316612JCM.03166-12

Egbebi, A.O and Seidu, K., T. (2011). Microbiological Evaluation of Suya (dried smoked

meat) Sold in Ado and Akure, South West Nigeria.European Journal of Experinmental Biology, 1(4):1-5
3. Government should establish regulatory bodies responsible for inculcating hygiene habits to the local producers and vendors in order to prevent instant, cross and post processing contaminations by microbial pathogens.

4. Awareness and sensitization of local food producers about good hygienic practices in food handling and processing.

Falegan, C, R., Akoja, S. D., and Oyarekua, M. A., (2017) Microbiological Assessment of Suya (Sliced Roasted Beef) in Ado-Ekiti Metropolis, Ekiti State, Nigeria. MOJ Biology andMedicine.

Fonkem, D., N. Tanya, V., N. and Ebangi, A., L. (2010). Effect of Season on the Microbiological Quality of Kilishi, a Traditional Cameroonian Dried Beef Product. Tropicultura, 28(1): 10-15.

Food and Agricultural Organization of the United Nations (F A O, 1979). Manual of food quality control 4. Microbiological analysis.

Food and Agriculture Organisation of the United Nation (FAO), 2019. Nigeria at a glance.

Igene J.O., Uwadia, O.E., Ebabhamiegbebho, P.A. and Evivie, S.E., (2016) Shelf life Stability Studies of University of Benin (UNIBEN) Proff's Kilishi Product Asian Journal of Science and Technology 7(1): 2268-2274.

Inusa, S. K. and Said, I. S. (2017) Evaluation of the Chemical and Microbiological Properties Of Kilishi Sold in Kano Metropolis. Journal of Dry land Agriculture, 3 (1): $59-69$.

Lucretia, I. B, Patience, C. Obinna-Echem, Sophia, C. A. (2018) Microbiological quality andantibiotic sensitivity of potential pathogens isolated from meat product (Suya) sold in Rivers State University and its environs. International Journal of Biotechnology and Food Science, 6(4): 67-76.

Matthew, E., Drosos, E., John, L. and Ioanna, P. (2013) MRSA in Africa: Filling the Global Map of Antimicrobial Resistance PLOS One. 8(7): e68024 doi: 10.1371/journal.pone.0068024

Mgbemere, V.N., Akpapunam, M. A. and Igene, J. O., (2011). Effect of Groundnut FlourSubstitution on Yield, Quality and Storage Stability of Kilishi - a Nigerian Indigenous Dried Meat Product. African Journal of Food, Agriculture, Nutrition and Development, $\quad \mathbf{1 1}(2)$ : 4718-4738. 
BAJOPAS Volume 13 Number 1, June, 2020

Mubarak, A. A., Azeez, M. L., Amos A. O., Opeyemi, O. O. (2016) Assessment of Animal Protein Consumption and Food Security Among Rural Households in Kwara State, Nigeria American Journal of Business and Society, 1(4): 233245.

Ndahi, M., D. Kwaga, J., K. P. Bello, M. Kabir J., V. Umoh, .J. Yakubu, S., E. and Nok, A., J. (2013) Prevalence and Antimicrobial Susceptibility of Listeria Monocytogenes and Methicillin-Resistant Staphylococcus aureus Strains from Raw Meat and Meat Products in Zaria, Nigeria. Applied Journal of Microbiology, 58(3):262-9.

Okonko, I.O., Odu, N.N. and Igboh, I.E. (2013). Microbiological Analysis of Kilishi Sold In Port Harcourt, Nigeria. New York Science Journal, 6 (7):37-43.

Osimani, A., Aquilanti, L. and Clementi, F. (2015) Microbiological Quality of Meatbased Meals and Operation of Control Systems within a Food Service Environment. International Food Research Journal 22(4): 1692-1698.

Onuorah, S. Obika, I. Odibo, F. Orji, M. (2015)An Assessment of the Bacteriological Quality of Tsire-Suya (Grilled Beef) sold in Awka, Nigeria. American. J. Life. Sci. Res. 3(4):287292.

Razavilar, V, Khandaghi, J. Barzgari, A. (2010); Isolation of Eschericia coli 0157:H7 from manure fertilized farms and raw vegetables grown on it, in Tabriz city in
Iran. African Journal of Microbiology Research, 4(9): 891-895.

Scallan, E. Hoekstra, R. M. Angulo, F. J.Tauxe, R. V, Widdowson, M. Roy, S. L et al., (2011).Food borne illness acquired in the United States- Major Pathogens. Emerg. Infec Dis, 17(1): 7-15.

Shamsuddeen U (2009). Microbiological quality of spice used in the production of Kilishi a traditionally dried and grilled meat product. Bayero Journal of Pure andApplied Sciences, 2(2): 66-69.

Shamsuddeen, U. (2015) Microbiological Hazard and Critical control point Analysis of Dried and Minced Meat Snacks Produced in Kano Nigeria. Lambert Academic Publishing; Pp 1-36.

Tijani, O.and Jumare, S. (2014). Microblological Quality Assessment of Meat

Sold in KauraNamoda. International Conference on Earth, Environment and Life sciences (EELS) Dubai (UAE).

Udobi, C. E., Obajuluwa, A. F., and Onaolapo, J. A., (2013) Prevalence and Antibiotic Resistance Pattern of MethicillinResistant Staphylococcus aureus from an Orthopaedic Hospital in Nigeria BioMed Research International; 26(6); 6-7.

WHO, 2015 Foodborne diseases in the WHO African Region.

Yousafzai HA, Rind R, Khan MA, Abro SH, Korejo NA, Ejaz M, Kabir A, Shahid M, Memon S. (2019). Microbiological Contamination of Cattle and Meat in Peshawar, Pakistan. J. Anim. Health Prod. 7(1): 1116. 


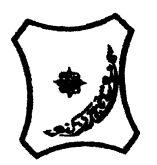

Bayero Journal of Pure and Applied Sciences, 13(1); 40 - 45

Received: September, 2019

Accepted: April, 2020

ISSN $2006-6996$

\title{
BACTERIOLOGICAL QUALITY OF STICK MEAT (Tsire) SOLD IN GARKO LOCAL GOVERNMENT AREA OF KANO STATE, NIGERIA
}

\author{
$*^{1}$ Dahiru A. T. and ${ }^{2}$ Maigari A. K. \\ ${ }^{1}$ Department of Hospitality Management, School of Technology, Kano State Polytechnic, PMB 3348, \\ Kano Nigeria. \\ ${ }^{2}$ Departmnt of Biological Sciences, Bayero University, Kano \\ Corresponding Author: dturajo61@gmail.com; GSM: 08087508262.
}

ABSTRACT

Stick meat, locally called Tsire in Hausa Language, is a significant portion of the diet of a large active population of Northern Nigeria. However, because of the handling and processing methods by the manufacturers as well as the hawking system of stick meat, the meat product may be exposed to both pre- and post-processed product contamination, and thus may poses danger to public health. Therefore, considering the role of Tsire in improving nutrition and increase household income to the populace, the need to improve the processing, distribution and overall quality of the product is simply indispensable. A total of 30 samples (5 samples from each of the 6 sampling points) of Tsire were collected randomly in Garko Town. Aerobic plate counts (APCs) and Total coliform counts (TCCS) of Tsire samples were determined using standard microbiological methods. APCs ranged from $1.02 \times 10^{5}$ to $4.00 \times 10^{5} \mathrm{CFU} / \mathrm{g}$; while TCCs ranged from $8 \mathrm{MPN} / \mathrm{g}$ to $68 \mathrm{MPN} / \mathrm{g}$. From the 30 samples screened, 16(53.33\%) bacteria namely, Campylobacter 2(6.66\%), Escherichia coli 6(20\%), Klebsiella pneumoniae 2(6.66\%), Salmonella spp. 1(3.33\%), Shigella 3(10\%) and Staphylococcus aureus 2(6.66\%) were detected. $E$. coli has the highest isolation rate of 6(20\%), while Salmonella spp. had the least frequency of 1(3.33\%). The distribution of isolated organisms within the study area were as follows: Dausai, 4(80\%), Kofar kudu, 4(80\%), Makwalla, 2(40\%), Rinji, 3(60\%), Tosaro, 2(40\%), and Tsohuwar Kasuwa, 1(20\%). The results have indicated that the Tsire was contaminated with bacteria thus exposing the product to fast deterioration, spoilage and also a vehicle for food borne illness, suggesting for adequate hygienic practices at all the stages, prior to consumption, to ensure safety of the meat product.

Key words: APCs, TCCs, Contamination, Microorganisms, Garko

\section{INTRODUCTION}

Nigeria is one of the developing nations with inadequate food supply and most often deficient in protein content (FAO, 2019). Nigerian's average animal protein intake per head per day is estimated at $7.9 \mathrm{~g}$ as against $35 \mathrm{~g}$ recommended value by Food and Agricultural Organization (Mubarak et al., 2016). These low levels of animal protein intake create great concern as it affects the nutritional status of Nigerians. Hence, there is the need for sufficient supply of animal protein from energy rich animal products to satisfy the nutritional requirements for Nigerians.

Meat is one major source of animal protein largely composed of water, protein and fats which can make it susceptible to microbial contamination within short time leading to spoilage (Apata et al., 2013; Mgbemere et al., 2011). Meat is mostly eaten after it has been cooked or processed in a variety of ways such as sun drying; smoking and roasting with or without fortifications (Borch et al., 1996). In Nigeria meat products such as Tsire, Kilishi and Balangu are locally produced using one or more of these methods in order to meet the nutritional requirements of the teeming Nigerians (Egbebi, 2011).

Tsire is a popular Nigerian traditional processed ready-to-eat roasted stick meat product (Shamsuddeen, 2015). It is sold in public places, along roads, in hotels, parks, quarters and even offices (Falegan et al., 2017). It is prepared from boneless healthy animal flesh such as beef and mutton, spiced with peanut cake, salt, vegetable oil and other flavorings followed by roasting (Shamsuddeen, 2015). Consumption of these products has extended to other parts of African countries such as Ghana, Somali, Cameroun and Chad (Ahmadu and Ibrahim, 2013). 
BAJOPAS Volume 13 Number 1, June, 2020

However, evidence of quality control sticking to procedural hygiene by the handlers during preparation and retailing of these products is poorly documented. Tsire is of great safety risk because of the fact that there are erratic cases of gastroenteritis and symptoms of food infection after consumption (WHO, 2015). Food borne illnesses are one of the major health problems in developing and developed countries (Razavilar, 2010). According to the World Health Organization, WHO (2015), $0.07 \%$ death of the 600 million global burdens of Foodborne illnesses have been reported to be caused by bacteria, viruses, fungi and chemicals. In America $0.27 \%$ of the estimated 48 million affected people is hospitalized and about $0.0063 \%$ deaths are recorded each year (Scallan et al., 2011). More than 91 million people in Africa fall ill and $0.15 \%$ dies each year, making Africa the highest burden bearer of Foodborne diseases per population (WHO, 2015).

Application of a Hazard Analysis Critical Control Point (HACCP) at all stages of meat products preparation is essential in order to ensure its safety. Thus, according to the guidelines of good manufacturing practice, the level of total aerobic bacterial contamination of thermally processed meat products should not exceed $10^{4}\left(\mathrm{cfu} \mathrm{g}^{-1}\right)$. Enterobacteriaceae and faecal coliform contamination in meat products should be within the range of $10^{2}-10^{4}$ and $10-10^{3} \mathrm{cfu} \mathrm{g}^{-1}$, respectively (Shamsuddeen, 2015). The aim of the study is therefore, to assess the total viable bacterial counts of tsire marketed locally within Garko town, and to isolate and identify the organisms at the point of consumption with the intention of promoting public health and food hygiene habits in the Nigerian populace.

\section{MATERIALS AND METHODS Study Area and Population}

Garko is one of the existing 44 local government areas located in Kano south west zone of Kano state with its capital administrative headquarters in the Garko town. It has coordinates $11^{\circ} 39^{\prime} \mathrm{N}$ $8^{\circ} 54^{\prime} \mathrm{E}$, and an area of $450 \mathrm{~km}^{2}$. The projected population of Garko local Government was 225,300 according to the National Population Census report (2018). Garko is known for agricultural activities both farming and animal husbandry. It is popularly known for large scale rice production. Other food crops include sweet potatoes, cassava, onions, sorghum, millet and sugarcane. Cows, sheep and goats are major groups of animals reared by majority of the populace. Meat products processed, retailed and consumed in Garko include roasted meat (Balangu), dried roasted meat (Kilishi), stick meat (Tsire), hide and skin pepper soup (Ragadada) and minced fried meat (Danbunnama).

\section{Samples Collection}

Five samples of Tsire products were collected from 6 different identified locations within Garko town in a sterile foil paper and immediately analyzed for the presence of bacteria.

\section{Sample Preparation}

Sample preparation for the bacteriological analysis was carried out in accordance with the method described by Atlas (1997). Twenty five grams $(25 \mathrm{~g})$ of the sample was homogenized in $225 \mathrm{ml}$ peptone water using Kenwood blender machine to obtain a $10^{1}$ homogenate. The homogenate was thoroughly shaken and $1 \mathrm{ml}$ pipetted into test tubes containing $9 \mathrm{ml}$ of peptone water $\left(10^{2}\right)$. The test tubes were further serially diluted to $10^{5}$.

Total Aerobic Mesophilic Bacterial Count

Total Aerobic mesophilic bacterial count was determined using the method described by Abdullahi et al. (2004) where $1 \mathrm{ml}$ of inoculums from $10^{1}$ to $10^{5}$ dilutions were transferred into duplicate Petri dishes and labeled accordingly. This was followed by pouring aseptically about $15 \mathrm{ml}$ of molten nutrient agar. The culture was homogenized by gentle spinning of the plates and allowed to solidify. The plates were incubated at $37^{\circ} \mathrm{C}$ for 24 hours. Plates containing 30-300 colonies were counted. The number of colony forming units per gram of a sample (cfu/g) was obtained by multiplying the average colony number with the inverse of the dilution factor.

\section{Enumeration and Detection of Coliform bacteria}

Detection and enumeration of coliform was carried out according to method described by Atlas, (1977). A set of 9 test tubes each containing $9 \mathrm{ml}$ of lactose broth and an inverted Durham tubes were autoclaved to expel air and to sterilize. Similarly, $1 \mathrm{ml}$ from the diluents $10^{1}$ was transferred to the first 3 test tubes, followed by $1 \mathrm{ml}$ from the diluents $10^{2}$ to the second set of 3 test tubes and finally the third diluents $10^{3}$ to the $3^{\text {rd }}$ set of 3 test tubes. All the 9 test tubes were incubated at $37^{\circ} \mathrm{C}$ for 24 hours. Tubes that showed gas and acid production after 24 hours were recorded as positive for the presence of Coliform. Negative tubes were further reincubated for 24 hours. Positive tubes were recorded. Estimate of most probable number of Coliform per gram of sample (MPN/g) was determined by comparing the number of gas positive tubes with the most probable number table. 
BAJOPAS Volume 13 Number 1, June, 2020 Identification of Coliform

A loop full of inoculum from gas positive tubes was streaked on to Eosine methylene blue (EMB) agar plate and incubated at $37^{\circ} \mathrm{C}$ for $24 \mathrm{hrs}$. Colonies which formed bluish black color with green metallic sheen, and reddish colonies were isolated on agar slants. Those colonies showing metallic sheen on EMB were sub cultured into tubes of lactose broth and incubated at $45^{\circ} \mathrm{C}$. The tubes were observed after $24 \mathrm{hrs}$ for gas production. This is the completed test for fecal coliform. Gram stain and other biochemical tests such as Indole, Methyl red, Voges-Proskauer and Citrate Utilization tests (IMVIC), Coagulase and Catalase tests were carried out for the Identification and confirmation of isolates.

\section{Procedure for Indole Test}

Indole test was carried out by preparing a Tryptone broth drawn in to test tubes, sterilized by autoclaving, inoculated with loopful of suspension and incubated at $37^{\circ} \mathrm{C}$ for 24 hours. Three drops of xylene was added in tubes, shaken vigorously and kept for the separation of two layers. One millilitre of Kovac's reagent was added and the formation of pink colour ring indicates positive Indole test.

\section{Procedure for Methyl Red Test}

Methyl red test was carried out by preparing Glucose phosphate broth, dispensed in test tubes, sterilized, inoculated with test culture and incubated at $37^{\circ} \mathrm{C}$ for 24 hours. Five drops of methyl-red indicator was added to the medium for the formation of red colour.

\section{Procedure for Voges-Proskauer Test}

Voges-Proskauer test was carried out by inoculating tubes with the bacterial culture followed by incubation for 48 hours at $37^{\circ} \mathrm{C}$. Separate pipettes were used to pipette $1 \mathrm{ml}$ from each culture tube into clean separate tubes. Eighteen drops $(0.5 \mathrm{ml})$ of Barrit's solution A (a-naphthol) was added to each tube containing glucose phosphate broth followed by the addition of an equal amount of solution $B$ into the same tube. The tubes were shaken at 30 seconds interval. A positive reaction was indicated by the development of a pink color, which turns red in 1-2 hours, after vigorous shaking.

\section{Procedure for Citrate Utilization Test}

Citrate Utilization Test was carried out by distributing melted agar (Simmon Citrate Agar) in to test tubes followed by sterilization at $121.5^{\circ} \mathrm{C}$ for 15 minutes. The test tubes were afterward held in slanted position, inoculated with the given bacterial culture and incubated at $37^{\circ} \mathrm{C}$ for $24 \mathrm{hrs}$. Positive test was indicated by color change of the media from green to blue.

\section{RESULTS AND DISCUSSIONS}

The results of this study are presented in tables $1,2,3$ and 4. Among the sampling areas Kofar Kudu had the highest aerobic mesophilic bacteria counts $4.0 \times 10^{5} \mathrm{cfu} / \mathrm{g}$ followed by Rinji $2.72 \times 10^{5} \mathrm{cfu} / \mathrm{g}$, while Tosaro had the least Aerobic mesophilic bacteria counts of $1.02 \times 10^{5}$ $\mathrm{cfu} / \mathrm{g}$ as indicated in Table 1.Makwalla had the highest coliform count $68 \mathrm{MPN} / \mathrm{g}$ followed by Rinji $37 \mathrm{MPN} / \mathrm{g}$. Tsohuwar Kasuwa had the least coliform counts $8 \mathrm{MPN} / \mathrm{g}$, (Table 2). Result from table 1 shows variation in the microbial contents among the samples which suggest variation in their sources, poor handling procedures and contamination from the processing environment. High coliform count and their differences within sampling areas is an indication of poor microbiological quality of the product. Ndahi et al. (2013) reported microbial load to be a function of the handling personnel and the environment. The results indicated that the samples were contaminated with bacteria as the counts exceeded the minimum safety level $\left(10^{4} \mathrm{cfu} / \mathrm{g}\right)$ for members of the Enterobacteriaceae family. However, it might be a reflection of poor hygienic practices which may contribute to health hazard to the potential consumers. Similarly, Inusa and Sa'id (2017); Osimani et al. (2015) reported that, the initial microbial content of the raw material play significant role in influencing the final microbial load of the finished product. Isolation of members of the Enterobacteriaceae such as $E$. coli, Klebsiella pneumoniae, Salmonella and Shigella signifies danger to the public health. These organisms are capable of producing endotoxins which trigger high fevers in infected individuals, and the enterotoxins which colonize the small intestines and lead to extreme dehydration as a result of vomiting and diarrhea sometimes with severe and fatal outcomes (Amaeze et al., 2016). From the 16 isolated organisms $E$. coli had the highest isolation rate $6(37.5 \%)$ (Table 3), this suggest faecal contamination of the products. $E$. coli is a common flora in the gastrointestinal tract responsible for diarrhea and extra-intestinal infections (CDC, 2011). The result is in conformity with the findings of Ndahi et al. (2013) and Shamsuddeen (2009). Also presence of campylobacter might be due to cross contamination from raw meat to finished product (Tsire). Staphylococcus aureus is a normal flora of the skin, nasal, genital, mouth or anal area in both humans and animals without any symptom of an infection (Matthew et al., 2013). Isolation of $S$. aureus in these study concords with the findings of Lucretia et al. (2018) from Suya sold in Rivers State. 
BAJOPAS Volume 13 Number 1, June, 2020

It is also in agreement with the findings of Yousafzai et al. (2018); Onuorah et al. (2015) and Tijjani and Jumare (2014) from tsire samples in different countries. Presence of $S$. aureus in foods is most of the time an indication of poor human handling, poor environment, unhygienic utensils and equipments used during processing (Igene et al., 2016; Okonko et al., 2013). Infections caused by $S$. aureus are difficult to treat leading to long hospitalization with consequent economic loss (Udobi et al., 2013). These include soft tissue infections, pneumonia, hospital-acquired postoperative wound infections, Staphylococcal food poisoning, impetigo and cellulitis (Charlene et al., 2013). Samples obtained from Dausai and Kofar Kudu had the highest isolation rate $4(80 \%)$ (Table 4 ) probably because of the much commercial activities taking place in the area which can lead to environmental contamination.

Table 1: Total Aerobic Mesophilic Bacterial Count of Tsire sold in Garko Town

\begin{tabular}{lll}
\hline Sampling Area & APC cfu/g & Mean \pm STD \\
\hline Dausai & $2.20 \times 10^{5}$ & $110000 \pm 14142.14$ \\
Kofar Kudu & $4.00 \times 10^{5}$ & $133333.3 \pm 23094.01$ \\
Makwalla & $1.30 \times 10^{5}$ & $32500 \pm 7187.953$ \\
Rinji & $2.72 \times 10^{5}$ & $90666.67 \pm 94769.90$ \\
Tosaro & $1.02 \times 10^{5}$ & $51000 \pm 15556.35$ \\
Tsohuwar Kasuwa & $1.75 \times 10^{5}$ & $35000 \pm 11357.82$ \\
\hline
\end{tabular}

Key: APC: Aerobic Mesophilic Counts

STD: Standard Deviation

Table 2: Total Coliform Count of Tsire sold in Garko Town

\begin{tabular}{lcc}
\hline \multicolumn{1}{c}{ Sampling Area } & TCC MPN/g & Mean \pm STD \\
\hline Dausai & 20 & $6.67 \pm 2.5166$ \\
Kofar Kudu & 32 & $16.00 \pm 5.6569$ \\
Makwalla & 68 & $13.60 \pm 8.7062$ \\
Rinji & 37 & $9.25 \pm 4.7871$ \\
Tosaro & 10 & $5.00 \pm 2.8284$ \\
Tsohuwar Kasuwa & 8 & $4.00 \pm 0.0000$ \\
\hline
\end{tabular}

Table 3: Organisms Isolated from Tsire Sold in Garko

\begin{tabular}{lcl}
\hline Isolated Organism & Frequency & Percentage (\%) \\
\hline Campylobacter & 2 & 06.66 \\
Escherichia coli & 6 & 20.00 \\
Klebsiella pneumoniae & 2 & 06.66 \\
Salmonella species & 1 & 03.33 \\
Shigella & 3 & 10.00 \\
Staphylococcus aureus & 2 & 06.66 \\
Total & 16 & \\
\hline
\end{tabular}

Table 4: Distribution of Organisms within Sampling Area

\begin{tabular}{lcc}
\hline \multicolumn{1}{c}{ Sampling Area } & No. Isolated & Percentage (\%) \\
\hline Dausai & 4 & 80 \\
Kofar Kudu & 4 & 80 \\
Makwalla & 2 & 40 \\
Rinji & 3 & 60 \\
Tosaro & 2 & 40 \\
Tsohuwar Kasuwa & 1 & 20 \\
Total & 16 & \\
\hline
\end{tabular}

\section{CONCLUSION}

Results indicated $4.00 \times 10^{5} \mathrm{CFU} / \mathrm{g}$ as the highest APCs count; while $68 \mathrm{MPN} / \mathrm{g}$ was the highest TCCs from the 30 samples analyzed. Among the isolates, $E$. coli has the highest isolation rate of $6(20 \%)$. Dausai and Kofar kudu were having the highest bacteria count of $4(80 \%)$, each, indicating higher contamination in those locations. 
BAJOPAS Volume 13 Number 1, June, 2020 RECOMMENDATIONS

The following recommendations are tenable:

1. Hygienic practices at all stages of production should be improved to safe guard the consumers against potential health hazard.

2. Monitoring of microbiological contamination of Tsire during preparations, packaging and marketing is essential to ensure product of good microbiological quality for consumers' health.

\section{REFERENCES}

Abdullahi, I. O., Umoh, V. J. and Galadima, M. (2004). Hazards Associated with Kilishi Preparations in Zaria. Nigerian Journal of Microbiology, 18 (1-2): $339-345$.

Ahmadu, J. and Ibrahim E. J., (2013): Determinants of Revenue in Suya Production in BeninCity, Edo State, Nigeria. Nigerian journal of agriculture, food and environment.9(3):1-5

Amaeze, N. Aboh, M. Itohan, A. Felix, E. Olatunji, T. and Oladosu, P. (2016) Microbial Profile, Antibiotic Sensitivity and Heat Resistance of Bacterial Isolates from Commercial Roasted Beef (Suya) in Abuja, Nigeria. JOPAT, 15(2): $22-30$.

Apata, E.S., Kuku1, I.A., Apata, O.C. and Adeyemi, K.O. (2013). Evaluation of Suya(Tsire) - An Intermediate Moisture Meat Product in Ogun State, Nigeria. J. Food Res 2 (1): 87.

Atlas, R. M. (1997) Principles of Microbiology Second Edition. C. Brown Publishers. Pp 802-803.

Borch, E. Kant-Muermans, M. L., Blixt, Y. (1996) Bacterial Spoilage of Meat and Cured Meat Products. Int $\mathrm{J}$ Food Microbiol .33(1): 103-20.

Centre for Disease Control, CDC (2011). "Escherichia coli 0157:H7" Division of Bacterial and Mycotic Diseasesht://www.cdc.gov/nczved/divisi ons/dfbmd/diseases/ecoli_0157h7/.

Charlene, R. J., Johnnie, A. D., and John, B. B., (2013) Prevalence and Characterization of Methicillin-Resistant Staphylococcus aureus Isolates from Retail Meat and Humans in Georgia. American society for Microbiology. J. of clinical microbiology. 12(1):123-6 doi:10.1128/JCM.0316612JCM.03166-12

Egbebi, A.O and Seidu, K., T. (2011). Microbiological Evaluation of Suya (dried smoked

meat) Sold in Ado and Akure, South West Nigeria.European Journal of Experinmental Biology, 1(4):1-5
3. Government should establish regulatory bodies responsible for inculcating hygiene habits to the local producers and vendors in order to prevent instant, cross and post processing contaminations by microbial pathogens.

4. Awareness and sensitization of local food producers about good hygienic practices in food handling and processing.

Falegan, C, R., Akoja, S. D., and Oyarekua, M. A., (2017) Microbiological Assessment of Suya (Sliced Roasted Beef) in Ado-Ekiti Metropolis, Ekiti State, Nigeria. MOJ Biology andMedicine.

Fonkem, D., N. Tanya, V., N. and Ebangi, A., L. (2010). Effect of Season on the Microbiological Quality of Kilishi, a Traditional Cameroonian Dried Beef Product. Tropicultura, 28(1): 10-15.

Food and Agricultural Organization of the United Nations (F A O, 1979). Manual of food quality control 4. Microbiological analysis.

Food and Agriculture Organisation of the United Nation (FAO), 2019. Nigeria at a glance.

Igene J.O., Uwadia, O.E., Ebabhamiegbebho, P.A. and Evivie, S.E., (2016) Shelf life Stability Studies of University of Benin (UNIBEN) Proff's Kilishi Product Asian Journal of Science and Technology 7(1): 2268-2274.

Inusa, S. K. and Said, I. S. (2017) Evaluation of the Chemical and Microbiological Properties Of Kilishi Sold in Kano Metropolis. Journal of Dry land Agriculture, 3 (1): $59-69$.

Lucretia, I. B, Patience, C. Obinna-Echem, Sophia, C. A. (2018) Microbiological quality andantibiotic sensitivity of potential pathogens isolated from meat product (Suya) sold in Rivers State University and its environs. International Journal of Biotechnology and Food Science, 6(4): 67-76.

Matthew, E., Drosos, E., John, L. and Ioanna, P. (2013) MRSA in Africa: Filling the Global Map of Antimicrobial Resistance PLOS One. 8(7): e68024 doi: 10.1371/journal.pone.0068024

Mgbemere, V.N., Akpapunam, M. A. and Igene, J. O., (2011). Effect of Groundnut FlourSubstitution on Yield, Quality and Storage Stability of Kilishi - a Nigerian Indigenous Dried Meat Product. African Journal of Food, Agriculture, Nutrition and Development, $\quad \mathbf{1 1}(2)$ : 4718-4738. 
BAJOPAS Volume 13 Number 1, June, 2020

Mubarak, A. A., Azeez, M. L., Amos A. O., Opeyemi, O. O. (2016) Assessment of Animal Protein Consumption and Food Security Among Rural Households in Kwara State, Nigeria American Journal of Business and Society, 1(4): 233245.

Ndahi, M., D. Kwaga, J., K. P. Bello, M. Kabir J., V. Umoh, .J. Yakubu, S., E. and Nok, A., J. (2013) Prevalence and Antimicrobial Susceptibility of Listeria Monocytogenes and Methicillin-Resistant Staphylococcus aureus Strains from Raw Meat and Meat Products in Zaria, Nigeria. Applied Journal of Microbiology, 58(3):262-9.

Okonko, I.O., Odu, N.N. and Igboh, I.E. (2013). Microbiological Analysis of Kilishi Sold In Port Harcourt, Nigeria. New York Science Journal, 6 (7):37-43.

Osimani, A., Aquilanti, L. and Clementi, F. (2015) Microbiological Quality of Meatbased Meals and Operation of Control Systems within a Food Service Environment. International Food Research Journal 22(4): 1692-1698.

Onuorah, S. Obika, I. Odibo, F. Orji, M. (2015)An Assessment of the Bacteriological Quality of Tsire-Suya (Grilled Beef) sold in Awka, Nigeria. American. J. Life. Sci. Res. 3(4):287292.

Razavilar, V, Khandaghi, J. Barzgari, A. (2010); Isolation of Eschericia coli 0157:H7 from manure fertilized farms and raw vegetables grown on it, in Tabriz city in
Iran. African Journal of Microbiology Research, 4(9): 891-895.

Scallan, E. Hoekstra, R. M. Angulo, F. J.Tauxe, R. V, Widdowson, M. Roy, S. L et al., (2011).Food borne illness acquired in the United States- Major Pathogens. Emerg. Infec Dis, 17(1): 7-15.

Shamsuddeen U (2009). Microbiological quality of spice used in the production of Kilishi a traditionally dried and grilled meat product. Bayero Journal of Pure andApplied Sciences, 2(2): 66-69.

Shamsuddeen, U. (2015) Microbiological Hazard and Critical control point Analysis of Dried and Minced Meat Snacks Produced in Kano Nigeria. Lambert Academic Publishing; Pp 1-36.

Tijani, O.and Jumare, S. (2014). Microblological Quality Assessment of Meat

Sold in KauraNamoda. International Conference on Earth, Environment and Life sciences (EELS) Dubai (UAE).

Udobi, C. E., Obajuluwa, A. F., and Onaolapo, J. A., (2013) Prevalence and Antibiotic Resistance Pattern of MethicillinResistant Staphylococcus aureus from an Orthopaedic Hospital in Nigeria BioMed Research International; 26(6); 6-7.

WHO, 2015 Foodborne diseases in the WHO African Region.

Yousafzai HA, Rind R, Khan MA, Abro SH, Korejo NA, Ejaz M, Kabir A, Shahid M, Memon S. (2019). Microbiological Contamination of Cattle and Meat in Peshawar, Pakistan. J. Anim. Health Prod. 7(1): 1116. 


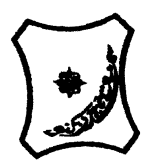

Bayero Journal of Pure and Applied Sciences, 13(1); 40 - 45

Received: September, 2019

Accepted: April, 2020

ISSN $2006-6996$

\title{
BACTERIOLOGICAL QUALITY OF STICK MEAT (Tsire) SOLD IN GARKO LOCAL GOVERNMENT AREA OF KANO STATE, NIGERIA
}

\author{
$*^{1}$ Dahiru A. T. and ${ }^{2}$ Maigari A. K. \\ ${ }^{1}$ Department of Hospitality Management, School of Technology, Kano State Polytechnic, PMB 3348, \\ Kano Nigeria. \\ ${ }^{2}$ Departmnt of Biological Sciences, Bayero University, Kano \\ Corresponding Author: dturajo61@gmail.com; GSM: 08087508262.
}

ABSTRACT

Stick meat, locally called Tsire in Hausa Language, is a significant portion of the diet of a large active population of Northern Nigeria. However, because of the handling and processing methods by the manufacturers as well as the hawking system of stick meat, the meat product may be exposed to both pre- and post-processed product contamination, and thus may poses danger to public health. Therefore, considering the role of Tsire in improving nutrition and increase household income to the populace, the need to improve the processing, distribution and overall quality of the product is simply indispensable. A total of 30 samples (5 samples from each of the 6 sampling points) of Tsire were collected randomly in Garko Town. Aerobic plate counts (APCs) and Total coliform counts (TCCS) of Tsire samples were determined using standard microbiological methods. APCs ranged from $1.02 \times 10^{5}$ to $4.00 \times 10^{5} \mathrm{CFU} / \mathrm{g}$; while TCCs ranged from $8 \mathrm{MPN} / \mathrm{g}$ to $68 \mathrm{MPN} / \mathrm{g}$. From the 30 samples screened, 16(53.33\%) bacteria namely, Campylobacter 2(6.66\%), Escherichia coli 6(20\%), Klebsiella pneumoniae 2(6.66\%), Salmonella spp. 1(3.33\%), Shigella 3(10\%) and Staphylococcus aureus 2(6.66\%) were detected. $E$. coli has the highest isolation rate of 6(20\%), while Salmonella spp. had the least frequency of 1(3.33\%). The distribution of isolated organisms within the study area were as follows: Dausai, 4(80\%), Kofar kudu, 4(80\%), Makwalla, 2(40\%), Rinji, 3(60\%), Tosaro, 2(40\%), and Tsohuwar Kasuwa, 1(20\%). The results have indicated that the Tsire was contaminated with bacteria thus exposing the product to fast deterioration, spoilage and also a vehicle for food borne illness, suggesting for adequate hygienic practices at all the stages, prior to consumption, to ensure safety of the meat product.

Key words: APCs, TCCs, Contamination, Microorganisms, Garko

\section{INTRODUCTION}

Nigeria is one of the developing nations with inadequate food supply and most often deficient in protein content (FAO, 2019). Nigerian's average animal protein intake per head per day is estimated at $7.9 \mathrm{~g}$ as against $35 \mathrm{~g}$ recommended value by Food and Agricultural Organization (Mubarak et al., 2016). These low levels of animal protein intake create great concern as it affects the nutritional status of Nigerians. Hence, there is the need for sufficient supply of animal protein from energy rich animal products to satisfy the nutritional requirements for Nigerians.

Meat is one major source of animal protein largely composed of water, protein and fats which can make it susceptible to microbial contamination within short time leading to spoilage (Apata et al., 2013; Mgbemere et al., 2011). Meat is mostly eaten after it has been cooked or processed in a variety of ways such as sun drying; smoking and roasting with or without fortifications (Borch et al., 1996). In Nigeria meat products such as Tsire, Kilishi and Balangu are locally produced using one or more of these methods in order to meet the nutritional requirements of the teeming Nigerians (Egbebi, 2011).

Tsire is a popular Nigerian traditional processed ready-to-eat roasted stick meat product (Shamsuddeen, 2015). It is sold in public places, along roads, in hotels, parks, quarters and even offices (Falegan et al., 2017). It is prepared from boneless healthy animal flesh such as beef and mutton, spiced with peanut cake, salt, vegetable oil and other flavorings followed by roasting (Shamsuddeen, 2015). Consumption of these products has extended to other parts of African countries such as Ghana, Somali, Cameroun and Chad (Ahmadu and Ibrahim, 2013). 
BAJOPAS Volume 13 Number 1, June, 2020

However, evidence of quality control sticking to procedural hygiene by the handlers during preparation and retailing of these products is poorly documented. Tsire is of great safety risk because of the fact that there are erratic cases of gastroenteritis and symptoms of food infection after consumption (WHO, 2015). Food borne illnesses are one of the major health problems in developing and developed countries (Razavilar, 2010). According to the World Health Organization, WHO (2015), $0.07 \%$ death of the 600 million global burdens of Foodborne illnesses have been reported to be caused by bacteria, viruses, fungi and chemicals. In America $0.27 \%$ of the estimated 48 million affected people is hospitalized and about $0.0063 \%$ deaths are recorded each year (Scallan et al., 2011). More than 91 million people in Africa fall ill and $0.15 \%$ dies each year, making Africa the highest burden bearer of Foodborne diseases per population (WHO, 2015).

Application of a Hazard Analysis Critical Control Point (HACCP) at all stages of meat products preparation is essential in order to ensure its safety. Thus, according to the guidelines of good manufacturing practice, the level of total aerobic bacterial contamination of thermally processed meat products should not exceed $10^{4}\left(\mathrm{cfu} \mathrm{g}^{-1}\right)$. Enterobacteriaceae and faecal coliform contamination in meat products should be within the range of $10^{2}-10^{4}$ and $10-10^{3} \mathrm{cfu} \mathrm{g}^{-1}$, respectively (Shamsuddeen, 2015). The aim of the study is therefore, to assess the total viable bacterial counts of tsire marketed locally within Garko town, and to isolate and identify the organisms at the point of consumption with the intention of promoting public health and food hygiene habits in the Nigerian populace.

\section{MATERIALS AND METHODS Study Area and Population}

Garko is one of the existing 44 local government areas located in Kano south west zone of Kano state with its capital administrative headquarters in the Garko town. It has coordinates $11^{\circ} 39^{\prime} \mathrm{N}$ $8^{\circ} 54^{\prime} \mathrm{E}$, and an area of $450 \mathrm{~km}^{2}$. The projected population of Garko local Government was 225,300 according to the National Population Census report (2018). Garko is known for agricultural activities both farming and animal husbandry. It is popularly known for large scale rice production. Other food crops include sweet potatoes, cassava, onions, sorghum, millet and sugarcane. Cows, sheep and goats are major groups of animals reared by majority of the populace. Meat products processed, retailed and consumed in Garko include roasted meat (Balangu), dried roasted meat (Kilishi), stick meat (Tsire), hide and skin pepper soup (Ragadada) and minced fried meat (Danbunnama).

\section{Samples Collection}

Five samples of Tsire products were collected from 6 different identified locations within Garko town in a sterile foil paper and immediately analyzed for the presence of bacteria.

\section{Sample Preparation}

Sample preparation for the bacteriological analysis was carried out in accordance with the method described by Atlas (1997). Twenty five grams $(25 \mathrm{~g})$ of the sample was homogenized in $225 \mathrm{ml}$ peptone water using Kenwood blender machine to obtain a $10^{1}$ homogenate. The homogenate was thoroughly shaken and $1 \mathrm{ml}$ pipetted into test tubes containing $9 \mathrm{ml}$ of peptone water $\left(10^{2}\right)$. The test tubes were further serially diluted to $10^{5}$.

Total Aerobic Mesophilic Bacterial Count

Total Aerobic mesophilic bacterial count was determined using the method described by Abdullahi et al. (2004) where $1 \mathrm{ml}$ of inoculums from $10^{1}$ to $10^{5}$ dilutions were transferred into duplicate Petri dishes and labeled accordingly. This was followed by pouring aseptically about $15 \mathrm{ml}$ of molten nutrient agar. The culture was homogenized by gentle spinning of the plates and allowed to solidify. The plates were incubated at $37^{\circ} \mathrm{C}$ for 24 hours. Plates containing 30-300 colonies were counted. The number of colony forming units per gram of a sample (cfu/g) was obtained by multiplying the average colony number with the inverse of the dilution factor.

\section{Enumeration and Detection of Coliform bacteria}

Detection and enumeration of coliform was carried out according to method described by Atlas, (1977). A set of 9 test tubes each containing $9 \mathrm{ml}$ of lactose broth and an inverted Durham tubes were autoclaved to expel air and to sterilize. Similarly, $1 \mathrm{ml}$ from the diluents $10^{1}$ was transferred to the first 3 test tubes, followed by $1 \mathrm{ml}$ from the diluents $10^{2}$ to the second set of 3 test tubes and finally the third diluents $10^{3}$ to the $3^{\text {rd }}$ set of 3 test tubes. All the 9 test tubes were incubated at $37^{\circ} \mathrm{C}$ for 24 hours. Tubes that showed gas and acid production after 24 hours were recorded as positive for the presence of Coliform. Negative tubes were further reincubated for 24 hours. Positive tubes were recorded. Estimate of most probable number of Coliform per gram of sample (MPN/g) was determined by comparing the number of gas positive tubes with the most probable number table. 
BAJOPAS Volume 13 Number 1, June, 2020 Identification of Coliform

A loop full of inoculum from gas positive tubes was streaked on to Eosine methylene blue (EMB) agar plate and incubated at $37^{\circ} \mathrm{C}$ for $24 \mathrm{hrs}$. Colonies which formed bluish black color with green metallic sheen, and reddish colonies were isolated on agar slants. Those colonies showing metallic sheen on EMB were sub cultured into tubes of lactose broth and incubated at $45^{\circ} \mathrm{C}$. The tubes were observed after $24 \mathrm{hrs}$ for gas production. This is the completed test for fecal coliform. Gram stain and other biochemical tests such as Indole, Methyl red, Voges-Proskauer and Citrate Utilization tests (IMVIC), Coagulase and Catalase tests were carried out for the Identification and confirmation of isolates.

\section{Procedure for Indole Test}

Indole test was carried out by preparing a Tryptone broth drawn in to test tubes, sterilized by autoclaving, inoculated with loopful of suspension and incubated at $37^{\circ} \mathrm{C}$ for 24 hours. Three drops of xylene was added in tubes, shaken vigorously and kept for the separation of two layers. One millilitre of Kovac's reagent was added and the formation of pink colour ring indicates positive Indole test.

\section{Procedure for Methyl Red Test}

Methyl red test was carried out by preparing Glucose phosphate broth, dispensed in test tubes, sterilized, inoculated with test culture and incubated at $37^{\circ} \mathrm{C}$ for 24 hours. Five drops of methyl-red indicator was added to the medium for the formation of red colour.

\section{Procedure for Voges-Proskauer Test}

Voges-Proskauer test was carried out by inoculating tubes with the bacterial culture followed by incubation for 48 hours at $37^{\circ} \mathrm{C}$. Separate pipettes were used to pipette $1 \mathrm{ml}$ from each culture tube into clean separate tubes. Eighteen drops $(0.5 \mathrm{ml})$ of Barrit's solution A (a-naphthol) was added to each tube containing glucose phosphate broth followed by the addition of an equal amount of solution $B$ into the same tube. The tubes were shaken at 30 seconds interval. A positive reaction was indicated by the development of a pink color, which turns red in 1-2 hours, after vigorous shaking.

\section{Procedure for Citrate Utilization Test}

Citrate Utilization Test was carried out by distributing melted agar (Simmon Citrate Agar) in to test tubes followed by sterilization at $121.5^{\circ} \mathrm{C}$ for 15 minutes. The test tubes were afterward held in slanted position, inoculated with the given bacterial culture and incubated at $37^{\circ} \mathrm{C}$ for $24 \mathrm{hrs}$. Positive test was indicated by color change of the media from green to blue.

\section{RESULTS AND DISCUSSIONS}

The results of this study are presented in tables $1,2,3$ and 4. Among the sampling areas Kofar Kudu had the highest aerobic mesophilic bacteria counts $4.0 \times 10^{5} \mathrm{cfu} / \mathrm{g}$ followed by Rinji $2.72 \times 10^{5} \mathrm{cfu} / \mathrm{g}$, while Tosaro had the least Aerobic mesophilic bacteria counts of $1.02 \times 10^{5}$ $\mathrm{cfu} / \mathrm{g}$ as indicated in Table 1.Makwalla had the highest coliform count $68 \mathrm{MPN} / \mathrm{g}$ followed by Rinji $37 \mathrm{MPN} / \mathrm{g}$. Tsohuwar Kasuwa had the least coliform counts $8 \mathrm{MPN} / \mathrm{g}$, (Table 2). Result from table 1 shows variation in the microbial contents among the samples which suggest variation in their sources, poor handling procedures and contamination from the processing environment. High coliform count and their differences within sampling areas is an indication of poor microbiological quality of the product. Ndahi et al. (2013) reported microbial load to be a function of the handling personnel and the environment. The results indicated that the samples were contaminated with bacteria as the counts exceeded the minimum safety level $\left(10^{4} \mathrm{cfu} / \mathrm{g}\right)$ for members of the Enterobacteriaceae family. However, it might be a reflection of poor hygienic practices which may contribute to health hazard to the potential consumers. Similarly, Inusa and Sa'id (2017); Osimani et al. (2015) reported that, the initial microbial content of the raw material play significant role in influencing the final microbial load of the finished product. Isolation of members of the Enterobacteriaceae such as $E$. coli, Klebsiella pneumoniae, Salmonella and Shigella signifies danger to the public health. These organisms are capable of producing endotoxins which trigger high fevers in infected individuals, and the enterotoxins which colonize the small intestines and lead to extreme dehydration as a result of vomiting and diarrhea sometimes with severe and fatal outcomes (Amaeze et al., 2016). From the 16 isolated organisms $E$. coli had the highest isolation rate $6(37.5 \%)$ (Table 3), this suggest faecal contamination of the products. $E$. coli is a common flora in the gastrointestinal tract responsible for diarrhea and extra-intestinal infections (CDC, 2011). The result is in conformity with the findings of Ndahi et al. (2013) and Shamsuddeen (2009). Also presence of campylobacter might be due to cross contamination from raw meat to finished product (Tsire). Staphylococcus aureus is a normal flora of the skin, nasal, genital, mouth or anal area in both humans and animals without any symptom of an infection (Matthew et al., 2013). Isolation of $S$. aureus in these study concords with the findings of Lucretia et al. (2018) from Suya sold in Rivers State. 
BAJOPAS Volume 13 Number 1, June, 2020

It is also in agreement with the findings of Yousafzai et al. (2018); Onuorah et al. (2015) and Tijjani and Jumare (2014) from tsire samples in different countries. Presence of $S$. aureus in foods is most of the time an indication of poor human handling, poor environment, unhygienic utensils and equipments used during processing (Igene et al., 2016; Okonko et al., 2013). Infections caused by $S$. aureus are difficult to treat leading to long hospitalization with consequent economic loss (Udobi et al., 2013). These include soft tissue infections, pneumonia, hospital-acquired postoperative wound infections, Staphylococcal food poisoning, impetigo and cellulitis (Charlene et al., 2013). Samples obtained from Dausai and Kofar Kudu had the highest isolation rate $4(80 \%)$ (Table 4 ) probably because of the much commercial activities taking place in the area which can lead to environmental contamination.

Table 1: Total Aerobic Mesophilic Bacterial Count of Tsire sold in Garko Town

\begin{tabular}{lll}
\hline Sampling Area & APC cfu/g & Mean \pm STD \\
\hline Dausai & $2.20 \times 10^{5}$ & $110000 \pm 14142.14$ \\
Kofar Kudu & $4.00 \times 10^{5}$ & $133333.3 \pm 23094.01$ \\
Makwalla & $1.30 \times 10^{5}$ & $32500 \pm 7187.953$ \\
Rinji & $2.72 \times 10^{5}$ & $90666.67 \pm 94769.90$ \\
Tosaro & $1.02 \times 10^{5}$ & $51000 \pm 15556.35$ \\
Tsohuwar Kasuwa & $1.75 \times 10^{5}$ & $35000 \pm 11357.82$ \\
\hline
\end{tabular}

Key: APC: Aerobic Mesophilic Counts

STD: Standard Deviation

Table 2: Total Coliform Count of Tsire sold in Garko Town

\begin{tabular}{lcc}
\hline \multicolumn{1}{c}{ Sampling Area } & TCC MPN/g & Mean \pm STD \\
\hline Dausai & 20 & $6.67 \pm 2.5166$ \\
Kofar Kudu & 32 & $16.00 \pm 5.6569$ \\
Makwalla & 68 & $13.60 \pm 8.7062$ \\
Rinji & 37 & $9.25 \pm 4.7871$ \\
Tosaro & 10 & $5.00 \pm 2.8284$ \\
Tsohuwar Kasuwa & 8 & $4.00 \pm 0.0000$ \\
\hline
\end{tabular}

Table 3: Organisms Isolated from Tsire Sold in Garko

\begin{tabular}{lcl}
\hline Isolated Organism & Frequency & Percentage (\%) \\
\hline Campylobacter & 2 & 06.66 \\
Escherichia coli & 6 & 20.00 \\
Klebsiella pneumoniae & 2 & 06.66 \\
Salmonella species & 1 & 03.33 \\
Shigella & 3 & 10.00 \\
Staphylococcus aureus & 2 & 06.66 \\
Total & 16 & \\
\hline
\end{tabular}

Table 4: Distribution of Organisms within Sampling Area

\begin{tabular}{lcc}
\hline \multicolumn{1}{c}{ Sampling Area } & No. Isolated & Percentage (\%) \\
\hline Dausai & 4 & 80 \\
Kofar Kudu & 4 & 80 \\
Makwalla & 2 & 40 \\
Rinji & 3 & 60 \\
Tosaro & 2 & 40 \\
Tsohuwar Kasuwa & 1 & 20 \\
Total & 16 & \\
\hline
\end{tabular}

\section{CONCLUSION}

Results indicated $4.00 \times 10^{5} \mathrm{CFU} / \mathrm{g}$ as the highest APCs count; while $68 \mathrm{MPN} / \mathrm{g}$ was the highest TCCs from the 30 samples analyzed. Among the isolates, $E$. coli has the highest isolation rate of $6(20 \%)$. Dausai and Kofar kudu were having the highest bacteria count of $4(80 \%)$, each, indicating higher contamination in those locations. 
BAJOPAS Volume 13 Number 1, June, 2020 RECOMMENDATIONS

The following recommendations are tenable:

1. Hygienic practices at all stages of production should be improved to safe guard the consumers against potential health hazard.

2. Monitoring of microbiological contamination of Tsire during preparations, packaging and marketing is essential to ensure product of good microbiological quality for consumers' health.

\section{REFERENCES}

Abdullahi, I. O., Umoh, V. J. and Galadima, M. (2004). Hazards Associated with Kilishi Preparations in Zaria. Nigerian Journal of Microbiology, 18 (1-2): $339-345$.

Ahmadu, J. and Ibrahim E. J., (2013): Determinants of Revenue in Suya Production in BeninCity, Edo State, Nigeria. Nigerian journal of agriculture, food and environment.9(3):1-5

Amaeze, N. Aboh, M. Itohan, A. Felix, E. Olatunji, T. and Oladosu, P. (2016) Microbial Profile, Antibiotic Sensitivity and Heat Resistance of Bacterial Isolates from Commercial Roasted Beef (Suya) in Abuja, Nigeria. JOPAT, 15(2): $22-30$.

Apata, E.S., Kuku1, I.A., Apata, O.C. and Adeyemi, K.O. (2013). Evaluation of Suya(Tsire) - An Intermediate Moisture Meat Product in Ogun State, Nigeria. J. Food Res 2 (1): 87.

Atlas, R. M. (1997) Principles of Microbiology Second Edition. C. Brown Publishers. Pp 802-803.

Borch, E. Kant-Muermans, M. L., Blixt, Y. (1996) Bacterial Spoilage of Meat and Cured Meat Products. Int $\mathrm{J}$ Food Microbiol .33(1): 103-20.

Centre for Disease Control, CDC (2011). "Escherichia coli 0157:H7" Division of Bacterial and Mycotic Diseasesht://www.cdc.gov/nczved/divisi ons/dfbmd/diseases/ecoli_0157h7/.

Charlene, R. J., Johnnie, A. D., and John, B. B., (2013) Prevalence and Characterization of Methicillin-Resistant Staphylococcus aureus Isolates from Retail Meat and Humans in Georgia. American society for Microbiology. J. of clinical microbiology. 12(1):123-6 doi:10.1128/JCM.0316612JCM.03166-12

Egbebi, A.O and Seidu, K., T. (2011). Microbiological Evaluation of Suya (dried smoked

meat) Sold in Ado and Akure, South West Nigeria.European Journal of Experinmental Biology, 1(4):1-5
3. Government should establish regulatory bodies responsible for inculcating hygiene habits to the local producers and vendors in order to prevent instant, cross and post processing contaminations by microbial pathogens.

4. Awareness and sensitization of local food producers about good hygienic practices in food handling and processing.

Falegan, C, R., Akoja, S. D., and Oyarekua, M. A., (2017) Microbiological Assessment of Suya (Sliced Roasted Beef) in Ado-Ekiti Metropolis, Ekiti State, Nigeria. MOJ Biology andMedicine.

Fonkem, D., N. Tanya, V., N. and Ebangi, A., L. (2010). Effect of Season on the Microbiological Quality of Kilishi, a Traditional Cameroonian Dried Beef Product. Tropicultura, 28(1): 10-15.

Food and Agricultural Organization of the United Nations (F A O, 1979). Manual of food quality control 4. Microbiological analysis.

Food and Agriculture Organisation of the United Nation (FAO), 2019. Nigeria at a glance.

Igene J.O., Uwadia, O.E., Ebabhamiegbebho, P.A. and Evivie, S.E., (2016) Shelf life Stability Studies of University of Benin (UNIBEN) Proff's Kilishi Product Asian Journal of Science and Technology 7(1): 2268-2274.

Inusa, S. K. and Said, I. S. (2017) Evaluation of the Chemical and Microbiological Properties Of Kilishi Sold in Kano Metropolis. Journal of Dry land Agriculture, 3 (1): $59-69$.

Lucretia, I. B, Patience, C. Obinna-Echem, Sophia, C. A. (2018) Microbiological quality andantibiotic sensitivity of potential pathogens isolated from meat product (Suya) sold in Rivers State University and its environs. International Journal of Biotechnology and Food Science, 6(4): 67-76.

Matthew, E., Drosos, E., John, L. and Ioanna, P. (2013) MRSA in Africa: Filling the Global Map of Antimicrobial Resistance PLOS One. 8(7): e68024 doi: 10.1371/journal.pone.0068024

Mgbemere, V.N., Akpapunam, M. A. and Igene, J. O., (2011). Effect of Groundnut FlourSubstitution on Yield, Quality and Storage Stability of Kilishi - a Nigerian Indigenous Dried Meat Product. African Journal of Food, Agriculture, Nutrition and Development, $\quad \mathbf{1 1}(2)$ : 4718-4738. 
BAJOPAS Volume 13 Number 1, June, 2020

Mubarak, A. A., Azeez, M. L., Amos A. O., Opeyemi, O. O. (2016) Assessment of Animal Protein Consumption and Food Security Among Rural Households in Kwara State, Nigeria American Journal of Business and Society, 1(4): 233245.

Ndahi, M., D. Kwaga, J., K. P. Bello, M. Kabir J., V. Umoh, .J. Yakubu, S., E. and Nok, A., J. (2013) Prevalence and Antimicrobial Susceptibility of Listeria Monocytogenes and Methicillin-Resistant Staphylococcus aureus Strains from Raw Meat and Meat Products in Zaria, Nigeria. Applied Journal of Microbiology, 58(3):262-9.

Okonko, I.O., Odu, N.N. and Igboh, I.E. (2013). Microbiological Analysis of Kilishi Sold In Port Harcourt, Nigeria. New York Science Journal, 6 (7):37-43.

Osimani, A., Aquilanti, L. and Clementi, F. (2015) Microbiological Quality of Meatbased Meals and Operation of Control Systems within a Food Service Environment. International Food Research Journal 22(4): 1692-1698.

Onuorah, S. Obika, I. Odibo, F. Orji, M. (2015)An Assessment of the Bacteriological Quality of Tsire-Suya (Grilled Beef) sold in Awka, Nigeria. American. J. Life. Sci. Res. 3(4):287292.

Razavilar, V, Khandaghi, J. Barzgari, A. (2010); Isolation of Eschericia coli 0157:H7 from manure fertilized farms and raw vegetables grown on it, in Tabriz city in
Iran. African Journal of Microbiology Research, 4(9): 891-895.

Scallan, E. Hoekstra, R. M. Angulo, F. J.Tauxe, R. V, Widdowson, M. Roy, S. L et al., (2011).Food borne illness acquired in the United States- Major Pathogens. Emerg. Infec Dis, 17(1): 7-15.

Shamsuddeen U (2009). Microbiological quality of spice used in the production of Kilishi a traditionally dried and grilled meat product. Bayero Journal of Pure andApplied Sciences, 2(2): 66-69.

Shamsuddeen, U. (2015) Microbiological Hazard and Critical control point Analysis of Dried and Minced Meat Snacks Produced in Kano Nigeria. Lambert Academic Publishing; Pp 1-36.

Tijani, O.and Jumare, S. (2014). Microblological Quality Assessment of Meat

Sold in KauraNamoda. International Conference on Earth, Environment and Life sciences (EELS) Dubai (UAE).

Udobi, C. E., Obajuluwa, A. F., and Onaolapo, J. A., (2013) Prevalence and Antibiotic Resistance Pattern of MethicillinResistant Staphylococcus aureus from an Orthopaedic Hospital in Nigeria BioMed Research International; 26(6); 6-7.

WHO, 2015 Foodborne diseases in the WHO African Region.

Yousafzai HA, Rind R, Khan MA, Abro SH, Korejo NA, Ejaz M, Kabir A, Shahid M, Memon S. (2019). Microbiological Contamination of Cattle and Meat in Peshawar, Pakistan. J. Anim. Health Prod. 7(1): 1116. 


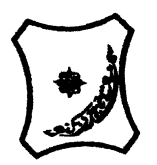

Bayero Journal of Pure and Applied Sciences, 13(1); 40 - 45

Received: September, 2019

Accepted: April, 2020

ISSN $2006-6996$

\title{
BACTERIOLOGICAL QUALITY OF STICK MEAT (Tsire) SOLD IN GARKO LOCAL GOVERNMENT AREA OF KANO STATE, NIGERIA
}

\author{
$*^{1}$ Dahiru A. T. and ${ }^{2}$ Maigari A. K. \\ ${ }^{1}$ Department of Hospitality Management, School of Technology, Kano State Polytechnic, PMB 3348, \\ Kano Nigeria. \\ ${ }^{2}$ Departmnt of Biological Sciences, Bayero University, Kano \\ Corresponding Author: dturajo61@gmail.com; GSM: 08087508262.
}

ABSTRACT

Stick meat, locally called Tsire in Hausa Language, is a significant portion of the diet of a large active population of Northern Nigeria. However, because of the handling and processing methods by the manufacturers as well as the hawking system of stick meat, the meat product may be exposed to both pre- and post-processed product contamination, and thus may poses danger to public health. Therefore, considering the role of Tsire in improving nutrition and increase household income to the populace, the need to improve the processing, distribution and overall quality of the product is simply indispensable. A total of 30 samples (5 samples from each of the 6 sampling points) of Tsire were collected randomly in Garko Town. Aerobic plate counts (APCs) and Total coliform counts (TCCS) of Tsire samples were determined using standard microbiological methods. APCs ranged from $1.02 \times 10^{5}$ to $4.00 \times 10^{5} \mathrm{CFU} / \mathrm{g}$; while TCCs ranged from $8 \mathrm{MPN} / \mathrm{g}$ to $68 \mathrm{MPN} / \mathrm{g}$. From the 30 samples screened, 16(53.33\%) bacteria namely, Campylobacter 2(6.66\%), Escherichia coli 6(20\%), Klebsiella pneumoniae 2(6.66\%), Salmonella spp. 1(3.33\%), Shigella 3(10\%) and Staphylococcus aureus 2(6.66\%) were detected. $E$. coli has the highest isolation rate of 6(20\%), while Salmonella spp. had the least frequency of 1(3.33\%). The distribution of isolated organisms within the study area were as follows: Dausai, 4(80\%), Kofar kudu, 4(80\%), Makwalla, 2(40\%), Rinji, 3(60\%), Tosaro, 2(40\%), and Tsohuwar Kasuwa, 1(20\%). The results have indicated that the Tsire was contaminated with bacteria thus exposing the product to fast deterioration, spoilage and also a vehicle for food borne illness, suggesting for adequate hygienic practices at all the stages, prior to consumption, to ensure safety of the meat product.

Key words: APCs, TCCs, Contamination, Microorganisms, Garko

\section{INTRODUCTION}

Nigeria is one of the developing nations with inadequate food supply and most often deficient in protein content (FAO, 2019). Nigerian's average animal protein intake per head per day is estimated at $7.9 \mathrm{~g}$ as against $35 \mathrm{~g}$ recommended value by Food and Agricultural Organization (Mubarak et al., 2016). These low levels of animal protein intake create great concern as it affects the nutritional status of Nigerians. Hence, there is the need for sufficient supply of animal protein from energy rich animal products to satisfy the nutritional requirements for Nigerians.

Meat is one major source of animal protein largely composed of water, protein and fats which can make it susceptible to microbial contamination within short time leading to spoilage (Apata et al., 2013; Mgbemere et al., 2011). Meat is mostly eaten after it has been cooked or processed in a variety of ways such as sun drying; smoking and roasting with or without fortifications (Borch et al., 1996). In Nigeria meat products such as Tsire, Kilishi and Balangu are locally produced using one or more of these methods in order to meet the nutritional requirements of the teeming Nigerians (Egbebi, 2011).

Tsire is a popular Nigerian traditional processed ready-to-eat roasted stick meat product (Shamsuddeen, 2015). It is sold in public places, along roads, in hotels, parks, quarters and even offices (Falegan et al., 2017). It is prepared from boneless healthy animal flesh such as beef and mutton, spiced with peanut cake, salt, vegetable oil and other flavorings followed by roasting (Shamsuddeen, 2015). Consumption of these products has extended to other parts of African countries such as Ghana, Somali, Cameroun and Chad (Ahmadu and Ibrahim, 2013). 
BAJOPAS Volume 13 Number 1, June, 2020

However, evidence of quality control sticking to procedural hygiene by the handlers during preparation and retailing of these products is poorly documented. Tsire is of great safety risk because of the fact that there are erratic cases of gastroenteritis and symptoms of food infection after consumption (WHO, 2015). Food borne illnesses are one of the major health problems in developing and developed countries (Razavilar, 2010). According to the World Health Organization, WHO (2015), $0.07 \%$ death of the 600 million global burdens of Foodborne illnesses have been reported to be caused by bacteria, viruses, fungi and chemicals. In America $0.27 \%$ of the estimated 48 million affected people is hospitalized and about $0.0063 \%$ deaths are recorded each year (Scallan et al., 2011). More than 91 million people in Africa fall ill and $0.15 \%$ dies each year, making Africa the highest burden bearer of Foodborne diseases per population (WHO, 2015).

Application of a Hazard Analysis Critical Control Point (HACCP) at all stages of meat products preparation is essential in order to ensure its safety. Thus, according to the guidelines of good manufacturing practice, the level of total aerobic bacterial contamination of thermally processed meat products should not exceed $10^{4}\left(\mathrm{cfu} \mathrm{g}^{-1}\right)$. Enterobacteriaceae and faecal coliform contamination in meat products should be within the range of $10^{2}-10^{4}$ and $10-10^{3} \mathrm{cfu} \mathrm{g}^{-1}$, respectively (Shamsuddeen, 2015). The aim of the study is therefore, to assess the total viable bacterial counts of tsire marketed locally within Garko town, and to isolate and identify the organisms at the point of consumption with the intention of promoting public health and food hygiene habits in the Nigerian populace.

\section{MATERIALS AND METHODS Study Area and Population}

Garko is one of the existing 44 local government areas located in Kano south west zone of Kano state with its capital administrative headquarters in the Garko town. It has coordinates $11^{\circ} 39^{\prime} \mathrm{N}$ $8^{\circ} 54^{\prime} \mathrm{E}$, and an area of $450 \mathrm{~km}^{2}$. The projected population of Garko local Government was 225,300 according to the National Population Census report (2018). Garko is known for agricultural activities both farming and animal husbandry. It is popularly known for large scale rice production. Other food crops include sweet potatoes, cassava, onions, sorghum, millet and sugarcane. Cows, sheep and goats are major groups of animals reared by majority of the populace. Meat products processed, retailed and consumed in Garko include roasted meat (Balangu), dried roasted meat (Kilishi), stick meat (Tsire), hide and skin pepper soup (Ragadada) and minced fried meat (Danbunnama).

\section{Samples Collection}

Five samples of Tsire products were collected from 6 different identified locations within Garko town in a sterile foil paper and immediately analyzed for the presence of bacteria.

\section{Sample Preparation}

Sample preparation for the bacteriological analysis was carried out in accordance with the method described by Atlas (1997). Twenty five grams $(25 \mathrm{~g})$ of the sample was homogenized in $225 \mathrm{ml}$ peptone water using Kenwood blender machine to obtain a $10^{1}$ homogenate. The homogenate was thoroughly shaken and $1 \mathrm{ml}$ pipetted into test tubes containing $9 \mathrm{ml}$ of peptone water $\left(10^{2}\right)$. The test tubes were further serially diluted to $10^{5}$.

Total Aerobic Mesophilic Bacterial Count

Total Aerobic mesophilic bacterial count was determined using the method described by Abdullahi et al. (2004) where $1 \mathrm{ml}$ of inoculums from $10^{1}$ to $10^{5}$ dilutions were transferred into duplicate Petri dishes and labeled accordingly. This was followed by pouring aseptically about $15 \mathrm{ml}$ of molten nutrient agar. The culture was homogenized by gentle spinning of the plates and allowed to solidify. The plates were incubated at $37^{\circ} \mathrm{C}$ for 24 hours. Plates containing 30-300 colonies were counted. The number of colony forming units per gram of a sample (cfu/g) was obtained by multiplying the average colony number with the inverse of the dilution factor.

\section{Enumeration and Detection of Coliform bacteria}

Detection and enumeration of coliform was carried out according to method described by Atlas, (1977). A set of 9 test tubes each containing $9 \mathrm{ml}$ of lactose broth and an inverted Durham tubes were autoclaved to expel air and to sterilize. Similarly, $1 \mathrm{ml}$ from the diluents $10^{1}$ was transferred to the first 3 test tubes, followed by $1 \mathrm{ml}$ from the diluents $10^{2}$ to the second set of 3 test tubes and finally the third diluents $10^{3}$ to the $3^{\text {rd }}$ set of 3 test tubes. All the 9 test tubes were incubated at $37^{\circ} \mathrm{C}$ for 24 hours. Tubes that showed gas and acid production after 24 hours were recorded as positive for the presence of Coliform. Negative tubes were further reincubated for 24 hours. Positive tubes were recorded. Estimate of most probable number of Coliform per gram of sample (MPN/g) was determined by comparing the number of gas positive tubes with the most probable number table. 
BAJOPAS Volume 13 Number 1, June, 2020 Identification of Coliform

A loop full of inoculum from gas positive tubes was streaked on to Eosine methylene blue (EMB) agar plate and incubated at $37^{\circ} \mathrm{C}$ for $24 \mathrm{hrs}$. Colonies which formed bluish black color with green metallic sheen, and reddish colonies were isolated on agar slants. Those colonies showing metallic sheen on EMB were sub cultured into tubes of lactose broth and incubated at $45^{\circ} \mathrm{C}$. The tubes were observed after $24 \mathrm{hrs}$ for gas production. This is the completed test for fecal coliform. Gram stain and other biochemical tests such as Indole, Methyl red, Voges-Proskauer and Citrate Utilization tests (IMVIC), Coagulase and Catalase tests were carried out for the Identification and confirmation of isolates.

\section{Procedure for Indole Test}

Indole test was carried out by preparing a Tryptone broth drawn in to test tubes, sterilized by autoclaving, inoculated with loopful of suspension and incubated at $37^{\circ} \mathrm{C}$ for 24 hours. Three drops of xylene was added in tubes, shaken vigorously and kept for the separation of two layers. One millilitre of Kovac's reagent was added and the formation of pink colour ring indicates positive Indole test.

\section{Procedure for Methyl Red Test}

Methyl red test was carried out by preparing Glucose phosphate broth, dispensed in test tubes, sterilized, inoculated with test culture and incubated at $37^{\circ} \mathrm{C}$ for 24 hours. Five drops of methyl-red indicator was added to the medium for the formation of red colour.

\section{Procedure for Voges-Proskauer Test}

Voges-Proskauer test was carried out by inoculating tubes with the bacterial culture followed by incubation for 48 hours at $37^{\circ} \mathrm{C}$. Separate pipettes were used to pipette $1 \mathrm{ml}$ from each culture tube into clean separate tubes. Eighteen drops $(0.5 \mathrm{ml})$ of Barrit's solution A (a-naphthol) was added to each tube containing glucose phosphate broth followed by the addition of an equal amount of solution $B$ into the same tube. The tubes were shaken at 30 seconds interval. A positive reaction was indicated by the development of a pink color, which turns red in 1-2 hours, after vigorous shaking.

\section{Procedure for Citrate Utilization Test}

Citrate Utilization Test was carried out by distributing melted agar (Simmon Citrate Agar) in to test tubes followed by sterilization at $121.5^{\circ} \mathrm{C}$ for 15 minutes. The test tubes were afterward held in slanted position, inoculated with the given bacterial culture and incubated at $37^{\circ} \mathrm{C}$ for $24 \mathrm{hrs}$. Positive test was indicated by color change of the media from green to blue.

\section{RESULTS AND DISCUSSIONS}

The results of this study are presented in tables $1,2,3$ and 4. Among the sampling areas Kofar Kudu had the highest aerobic mesophilic bacteria counts $4.0 \times 10^{5} \mathrm{cfu} / \mathrm{g}$ followed by Rinji $2.72 \times 10^{5} \mathrm{cfu} / \mathrm{g}$, while Tosaro had the least Aerobic mesophilic bacteria counts of $1.02 \times 10^{5}$ $\mathrm{cfu} / \mathrm{g}$ as indicated in Table 1.Makwalla had the highest coliform count $68 \mathrm{MPN} / \mathrm{g}$ followed by Rinji $37 \mathrm{MPN} / \mathrm{g}$. Tsohuwar Kasuwa had the least coliform counts $8 \mathrm{MPN} / \mathrm{g}$, (Table 2). Result from table 1 shows variation in the microbial contents among the samples which suggest variation in their sources, poor handling procedures and contamination from the processing environment. High coliform count and their differences within sampling areas is an indication of poor microbiological quality of the product. Ndahi et al. (2013) reported microbial load to be a function of the handling personnel and the environment. The results indicated that the samples were contaminated with bacteria as the counts exceeded the minimum safety level $\left(10^{4} \mathrm{cfu} / \mathrm{g}\right)$ for members of the Enterobacteriaceae family. However, it might be a reflection of poor hygienic practices which may contribute to health hazard to the potential consumers. Similarly, Inusa and Sa'id (2017); Osimani et al. (2015) reported that, the initial microbial content of the raw material play significant role in influencing the final microbial load of the finished product. Isolation of members of the Enterobacteriaceae such as $E$. coli, Klebsiella pneumoniae, Salmonella and Shigella signifies danger to the public health. These organisms are capable of producing endotoxins which trigger high fevers in infected individuals, and the enterotoxins which colonize the small intestines and lead to extreme dehydration as a result of vomiting and diarrhea sometimes with severe and fatal outcomes (Amaeze et al., 2016). From the 16 isolated organisms $E$. coli had the highest isolation rate $6(37.5 \%)$ (Table 3), this suggest faecal contamination of the products. $E$. coli is a common flora in the gastrointestinal tract responsible for diarrhea and extra-intestinal infections (CDC, 2011). The result is in conformity with the findings of Ndahi et al. (2013) and Shamsuddeen (2009). Also presence of campylobacter might be due to cross contamination from raw meat to finished product (Tsire). Staphylococcus aureus is a normal flora of the skin, nasal, genital, mouth or anal area in both humans and animals without any symptom of an infection (Matthew et al., 2013). Isolation of $S$. aureus in these study concords with the findings of Lucretia et al. (2018) from Suya sold in Rivers State. 
BAJOPAS Volume 13 Number 1, June, 2020

It is also in agreement with the findings of Yousafzai et al. (2018); Onuorah et al. (2015) and Tijjani and Jumare (2014) from tsire samples in different countries. Presence of $S$. aureus in foods is most of the time an indication of poor human handling, poor environment, unhygienic utensils and equipments used during processing (Igene et al., 2016; Okonko et al., 2013). Infections caused by $S$. aureus are difficult to treat leading to long hospitalization with consequent economic loss (Udobi et al., 2013). These include soft tissue infections, pneumonia, hospital-acquired postoperative wound infections, Staphylococcal food poisoning, impetigo and cellulitis (Charlene et al., 2013). Samples obtained from Dausai and Kofar Kudu had the highest isolation rate $4(80 \%)$ (Table 4 ) probably because of the much commercial activities taking place in the area which can lead to environmental contamination.

Table 1: Total Aerobic Mesophilic Bacterial Count of Tsire sold in Garko Town

\begin{tabular}{lll}
\hline Sampling Area & APC cfu/g & Mean \pm STD \\
\hline Dausai & $2.20 \times 10^{5}$ & $110000 \pm 14142.14$ \\
Kofar Kudu & $4.00 \times 10^{5}$ & $133333.3 \pm 23094.01$ \\
Makwalla & $1.30 \times 10^{5}$ & $32500 \pm 7187.953$ \\
Rinji & $2.72 \times 10^{5}$ & $90666.67 \pm 94769.90$ \\
Tosaro & $1.02 \times 10^{5}$ & $51000 \pm 15556.35$ \\
Tsohuwar Kasuwa & $1.75 \times 10^{5}$ & $35000 \pm 11357.82$ \\
\hline
\end{tabular}

Key: APC: Aerobic Mesophilic Counts

STD: Standard Deviation

Table 2: Total Coliform Count of Tsire sold in Garko Town

\begin{tabular}{lcc}
\hline \multicolumn{1}{c}{ Sampling Area } & TCC MPN/g & Mean \pm STD \\
\hline Dausai & 20 & $6.67 \pm 2.5166$ \\
Kofar Kudu & 32 & $16.00 \pm 5.6569$ \\
Makwalla & 68 & $13.60 \pm 8.7062$ \\
Rinji & 37 & $9.25 \pm 4.7871$ \\
Tosaro & 10 & $5.00 \pm 2.8284$ \\
Tsohuwar Kasuwa & 8 & $4.00 \pm 0.0000$ \\
\hline
\end{tabular}

Table 3: Organisms Isolated from Tsire Sold in Garko

\begin{tabular}{lcl}
\hline Isolated Organism & Frequency & Percentage (\%) \\
\hline Campylobacter & 2 & 06.66 \\
Escherichia coli & 6 & 20.00 \\
Klebsiella pneumoniae & 2 & 06.66 \\
Salmonella species & 1 & 03.33 \\
Shigella & 3 & 10.00 \\
Staphylococcus aureus & 2 & 06.66 \\
Total & 16 & \\
\hline
\end{tabular}

Table 4: Distribution of Organisms within Sampling Area

\begin{tabular}{lcc}
\hline \multicolumn{1}{c}{ Sampling Area } & No. Isolated & Percentage (\%) \\
\hline Dausai & 4 & 80 \\
Kofar Kudu & 4 & 80 \\
Makwalla & 2 & 40 \\
Rinji & 3 & 60 \\
Tosaro & 2 & 40 \\
Tsohuwar Kasuwa & 1 & 20 \\
Total & 16 & \\
\hline
\end{tabular}

\section{CONCLUSION}

Results indicated $4.00 \times 10^{5} \mathrm{CFU} / \mathrm{g}$ as the highest APCs count; while $68 \mathrm{MPN} / \mathrm{g}$ was the highest TCCs from the 30 samples analyzed. Among the isolates, $E$. coli has the highest isolation rate of $6(20 \%)$. Dausai and Kofar kudu were having the highest bacteria count of $4(80 \%)$, each, indicating higher contamination in those locations. 
BAJOPAS Volume 13 Number 1, June, 2020 RECOMMENDATIONS

The following recommendations are tenable:

1. Hygienic practices at all stages of production should be improved to safe guard the consumers against potential health hazard.

2. Monitoring of microbiological contamination of Tsire during preparations, packaging and marketing is essential to ensure product of good microbiological quality for consumers' health.

\section{REFERENCES}

Abdullahi, I. O., Umoh, V. J. and Galadima, M. (2004). Hazards Associated with Kilishi Preparations in Zaria. Nigerian Journal of Microbiology, 18 (1-2): $339-345$.

Ahmadu, J. and Ibrahim E. J., (2013): Determinants of Revenue in Suya Production in BeninCity, Edo State, Nigeria. Nigerian journal of agriculture, food and environment.9(3):1-5

Amaeze, N. Aboh, M. Itohan, A. Felix, E. Olatunji, T. and Oladosu, P. (2016) Microbial Profile, Antibiotic Sensitivity and Heat Resistance of Bacterial Isolates from Commercial Roasted Beef (Suya) in Abuja, Nigeria. JOPAT, 15(2): $22-30$.

Apata, E.S., Kuku1, I.A., Apata, O.C. and Adeyemi, K.O. (2013). Evaluation of Suya(Tsire) - An Intermediate Moisture Meat Product in Ogun State, Nigeria. J. Food Res 2 (1): 87.

Atlas, R. M. (1997) Principles of Microbiology Second Edition. C. Brown Publishers. Pp 802-803.

Borch, E. Kant-Muermans, M. L., Blixt, Y. (1996) Bacterial Spoilage of Meat and Cured Meat Products. Int $\mathrm{J}$ Food Microbiol .33(1): 103-20.

Centre for Disease Control, CDC (2011). "Escherichia coli 0157:H7" Division of Bacterial and Mycotic Diseasesht://www.cdc.gov/nczved/divisi ons/dfbmd/diseases/ecoli_0157h7/.

Charlene, R. J., Johnnie, A. D., and John, B. B., (2013) Prevalence and Characterization of Methicillin-Resistant Staphylococcus aureus Isolates from Retail Meat and Humans in Georgia. American society for Microbiology. J. of clinical microbiology. 12(1):123-6 doi:10.1128/JCM.0316612JCM.03166-12

Egbebi, A.O and Seidu, K., T. (2011). Microbiological Evaluation of Suya (dried smoked

meat) Sold in Ado and Akure, South West Nigeria.European Journal of Experinmental Biology, 1(4):1-5
3. Government should establish regulatory bodies responsible for inculcating hygiene habits to the local producers and vendors in order to prevent instant, cross and post processing contaminations by microbial pathogens.

4. Awareness and sensitization of local food producers about good hygienic practices in food handling and processing.

Falegan, C, R., Akoja, S. D., and Oyarekua, M. A., (2017) Microbiological Assessment of Suya (Sliced Roasted Beef) in Ado-Ekiti Metropolis, Ekiti State, Nigeria. MOJ Biology andMedicine.

Fonkem, D., N. Tanya, V., N. and Ebangi, A., L. (2010). Effect of Season on the Microbiological Quality of Kilishi, a Traditional Cameroonian Dried Beef Product. Tropicultura, 28(1): 10-15.

Food and Agricultural Organization of the United Nations (F A O, 1979). Manual of food quality control 4. Microbiological analysis.

Food and Agriculture Organisation of the United Nation (FAO), 2019. Nigeria at a glance.

Igene J.O., Uwadia, O.E., Ebabhamiegbebho, P.A. and Evivie, S.E., (2016) Shelf life Stability Studies of University of Benin (UNIBEN) Proff's Kilishi Product Asian Journal of Science and Technology 7(1): 2268-2274.

Inusa, S. K. and Said, I. S. (2017) Evaluation of the Chemical and Microbiological Properties Of Kilishi Sold in Kano Metropolis. Journal of Dry land Agriculture, 3 (1): $59-69$.

Lucretia, I. B, Patience, C. Obinna-Echem, Sophia, C. A. (2018) Microbiological quality andantibiotic sensitivity of potential pathogens isolated from meat product (Suya) sold in Rivers State University and its environs. International Journal of Biotechnology and Food Science, 6(4): 67-76.

Matthew, E., Drosos, E., John, L. and Ioanna, P. (2013) MRSA in Africa: Filling the Global Map of Antimicrobial Resistance PLOS One. 8(7): e68024 doi: 10.1371/journal.pone.0068024

Mgbemere, V.N., Akpapunam, M. A. and Igene, J. O., (2011). Effect of Groundnut FlourSubstitution on Yield, Quality and Storage Stability of Kilishi - a Nigerian Indigenous Dried Meat Product. African Journal of Food, Agriculture, Nutrition and Development, $\quad \mathbf{1 1}(2)$ : 4718-4738. 
BAJOPAS Volume 13 Number 1, June, 2020

Mubarak, A. A., Azeez, M. L., Amos A. O., Opeyemi, O. O. (2016) Assessment of Animal Protein Consumption and Food Security Among Rural Households in Kwara State, Nigeria American Journal of Business and Society, 1(4): 233245.

Ndahi, M., D. Kwaga, J., K. P. Bello, M. Kabir J., V. Umoh, .J. Yakubu, S., E. and Nok, A., J. (2013) Prevalence and Antimicrobial Susceptibility of Listeria Monocytogenes and Methicillin-Resistant Staphylococcus aureus Strains from Raw Meat and Meat Products in Zaria, Nigeria. Applied Journal of Microbiology, 58(3):262-9.

Okonko, I.O., Odu, N.N. and Igboh, I.E. (2013). Microbiological Analysis of Kilishi Sold In Port Harcourt, Nigeria. New York Science Journal, 6 (7):37-43.

Osimani, A., Aquilanti, L. and Clementi, F. (2015) Microbiological Quality of Meatbased Meals and Operation of Control Systems within a Food Service Environment. International Food Research Journal 22(4): 1692-1698.

Onuorah, S. Obika, I. Odibo, F. Orji, M. (2015)An Assessment of the Bacteriological Quality of Tsire-Suya (Grilled Beef) sold in Awka, Nigeria. American. J. Life. Sci. Res. 3(4):287292.

Razavilar, V, Khandaghi, J. Barzgari, A. (2010); Isolation of Eschericia coli 0157:H7 from manure fertilized farms and raw vegetables grown on it, in Tabriz city in
Iran. African Journal of Microbiology Research, 4(9): 891-895.

Scallan, E. Hoekstra, R. M. Angulo, F. J.Tauxe, R. V, Widdowson, M. Roy, S. L et al., (2011).Food borne illness acquired in the United States- Major Pathogens. Emerg. Infec Dis, 17(1): 7-15.

Shamsuddeen U (2009). Microbiological quality of spice used in the production of Kilishi a traditionally dried and grilled meat product. Bayero Journal of Pure andApplied Sciences, 2(2): 66-69.

Shamsuddeen, U. (2015) Microbiological Hazard and Critical control point Analysis of Dried and Minced Meat Snacks Produced in Kano Nigeria. Lambert Academic Publishing; Pp 1-36.

Tijani, O.and Jumare, S. (2014). Microblological Quality Assessment of Meat

Sold in KauraNamoda. International Conference on Earth, Environment and Life sciences (EELS) Dubai (UAE).

Udobi, C. E., Obajuluwa, A. F., and Onaolapo, J. A., (2013) Prevalence and Antibiotic Resistance Pattern of MethicillinResistant Staphylococcus aureus from an Orthopaedic Hospital in Nigeria BioMed Research International; 26(6); 6-7.

WHO, 2015 Foodborne diseases in the WHO African Region.

Yousafzai HA, Rind R, Khan MA, Abro SH, Korejo NA, Ejaz M, Kabir A, Shahid M, Memon S. (2019). Microbiological Contamination of Cattle and Meat in Peshawar, Pakistan. J. Anim. Health Prod. 7(1): 1116. 


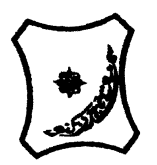

Bayero Journal of Pure and Applied Sciences, 13(1); 40 - 45

Received: September, 2019

Accepted: April, 2020

ISSN $2006-6996$

\title{
BACTERIOLOGICAL QUALITY OF STICK MEAT (Tsire) SOLD IN GARKO LOCAL GOVERNMENT AREA OF KANO STATE, NIGERIA
}

\author{
$*^{1}$ Dahiru A. T. and ${ }^{2}$ Maigari A. K. \\ ${ }^{1}$ Department of Hospitality Management, School of Technology, Kano State Polytechnic, PMB 3348, \\ Kano Nigeria. \\ ${ }^{2}$ Departmnt of Biological Sciences, Bayero University, Kano \\ Corresponding Author: dturajo61@gmail.com; GSM: 08087508262.
}

ABSTRACT

Stick meat, locally called Tsire in Hausa Language, is a significant portion of the diet of a large active population of Northern Nigeria. However, because of the handling and processing methods by the manufacturers as well as the hawking system of stick meat, the meat product may be exposed to both pre- and post-processed product contamination, and thus may poses danger to public health. Therefore, considering the role of Tsire in improving nutrition and increase household income to the populace, the need to improve the processing, distribution and overall quality of the product is simply indispensable. A total of 30 samples (5 samples from each of the 6 sampling points) of Tsire were collected randomly in Garko Town. Aerobic plate counts (APCs) and Total coliform counts (TCCS) of Tsire samples were determined using standard microbiological methods. APCs ranged from $1.02 \times 10^{5}$ to $4.00 \times 10^{5} \mathrm{CFU} / \mathrm{g}$; while TCCs ranged from $8 \mathrm{MPN} / \mathrm{g}$ to $68 \mathrm{MPN} / \mathrm{g}$. From the 30 samples screened, 16(53.33\%) bacteria namely, Campylobacter 2(6.66\%), Escherichia coli 6(20\%), Klebsiella pneumoniae 2(6.66\%), Salmonella spp. 1(3.33\%), Shigella 3(10\%) and Staphylococcus aureus 2(6.66\%) were detected. $E$. coli has the highest isolation rate of 6(20\%), while Salmonella spp. had the least frequency of 1(3.33\%). The distribution of isolated organisms within the study area were as follows: Dausai, 4(80\%), Kofar kudu, 4(80\%), Makwalla, 2(40\%), Rinji, 3(60\%), Tosaro, 2(40\%), and Tsohuwar Kasuwa, 1(20\%). The results have indicated that the Tsire was contaminated with bacteria thus exposing the product to fast deterioration, spoilage and also a vehicle for food borne illness, suggesting for adequate hygienic practices at all the stages, prior to consumption, to ensure safety of the meat product.

Key words: APCs, TCCs, Contamination, Microorganisms, Garko

\section{INTRODUCTION}

Nigeria is one of the developing nations with inadequate food supply and most often deficient in protein content (FAO, 2019). Nigerian's average animal protein intake per head per day is estimated at $7.9 \mathrm{~g}$ as against $35 \mathrm{~g}$ recommended value by Food and Agricultural Organization (Mubarak et al., 2016). These low levels of animal protein intake create great concern as it affects the nutritional status of Nigerians. Hence, there is the need for sufficient supply of animal protein from energy rich animal products to satisfy the nutritional requirements for Nigerians.

Meat is one major source of animal protein largely composed of water, protein and fats which can make it susceptible to microbial contamination within short time leading to spoilage (Apata et al., 2013; Mgbemere et al., 2011). Meat is mostly eaten after it has been cooked or processed in a variety of ways such as sun drying; smoking and roasting with or without fortifications (Borch et al., 1996). In Nigeria meat products such as Tsire, Kilishi and Balangu are locally produced using one or more of these methods in order to meet the nutritional requirements of the teeming Nigerians (Egbebi, 2011).

Tsire is a popular Nigerian traditional processed ready-to-eat roasted stick meat product (Shamsuddeen, 2015). It is sold in public places, along roads, in hotels, parks, quarters and even offices (Falegan et al., 2017). It is prepared from boneless healthy animal flesh such as beef and mutton, spiced with peanut cake, salt, vegetable oil and other flavorings followed by roasting (Shamsuddeen, 2015). Consumption of these products has extended to other parts of African countries such as Ghana, Somali, Cameroun and Chad (Ahmadu and Ibrahim, 2013). 
BAJOPAS Volume 13 Number 1, June, 2020

However, evidence of quality control sticking to procedural hygiene by the handlers during preparation and retailing of these products is poorly documented. Tsire is of great safety risk because of the fact that there are erratic cases of gastroenteritis and symptoms of food infection after consumption (WHO, 2015). Food borne illnesses are one of the major health problems in developing and developed countries (Razavilar, 2010). According to the World Health Organization, WHO (2015), $0.07 \%$ death of the 600 million global burdens of Foodborne illnesses have been reported to be caused by bacteria, viruses, fungi and chemicals. In America $0.27 \%$ of the estimated 48 million affected people is hospitalized and about $0.0063 \%$ deaths are recorded each year (Scallan et al., 2011). More than 91 million people in Africa fall ill and $0.15 \%$ dies each year, making Africa the highest burden bearer of Foodborne diseases per population (WHO, 2015).

Application of a Hazard Analysis Critical Control Point (HACCP) at all stages of meat products preparation is essential in order to ensure its safety. Thus, according to the guidelines of good manufacturing practice, the level of total aerobic bacterial contamination of thermally processed meat products should not exceed $10^{4}\left(\mathrm{cfu} \mathrm{g}^{-1}\right)$. Enterobacteriaceae and faecal coliform contamination in meat products should be within the range of $10^{2}-10^{4}$ and $10-10^{3} \mathrm{cfu} \mathrm{g}^{-1}$, respectively (Shamsuddeen, 2015). The aim of the study is therefore, to assess the total viable bacterial counts of tsire marketed locally within Garko town, and to isolate and identify the organisms at the point of consumption with the intention of promoting public health and food hygiene habits in the Nigerian populace.

\section{MATERIALS AND METHODS Study Area and Population}

Garko is one of the existing 44 local government areas located in Kano south west zone of Kano state with its capital administrative headquarters in the Garko town. It has coordinates $11^{\circ} 39^{\prime} \mathrm{N}$ $8^{\circ} 54^{\prime} \mathrm{E}$, and an area of $450 \mathrm{~km}^{2}$. The projected population of Garko local Government was 225,300 according to the National Population Census report (2018). Garko is known for agricultural activities both farming and animal husbandry. It is popularly known for large scale rice production. Other food crops include sweet potatoes, cassava, onions, sorghum, millet and sugarcane. Cows, sheep and goats are major groups of animals reared by majority of the populace. Meat products processed, retailed and consumed in Garko include roasted meat (Balangu), dried roasted meat (Kilishi), stick meat (Tsire), hide and skin pepper soup (Ragadada) and minced fried meat (Danbunnama).

\section{Samples Collection}

Five samples of Tsire products were collected from 6 different identified locations within Garko town in a sterile foil paper and immediately analyzed for the presence of bacteria.

\section{Sample Preparation}

Sample preparation for the bacteriological analysis was carried out in accordance with the method described by Atlas (1997). Twenty five grams $(25 \mathrm{~g})$ of the sample was homogenized in $225 \mathrm{ml}$ peptone water using Kenwood blender machine to obtain a $10^{1}$ homogenate. The homogenate was thoroughly shaken and $1 \mathrm{ml}$ pipetted into test tubes containing $9 \mathrm{ml}$ of peptone water $\left(10^{2}\right)$. The test tubes were further serially diluted to $10^{5}$.

Total Aerobic Mesophilic Bacterial Count

Total Aerobic mesophilic bacterial count was determined using the method described by Abdullahi et al. (2004) where $1 \mathrm{ml}$ of inoculums from $10^{1}$ to $10^{5}$ dilutions were transferred into duplicate Petri dishes and labeled accordingly. This was followed by pouring aseptically about $15 \mathrm{ml}$ of molten nutrient agar. The culture was homogenized by gentle spinning of the plates and allowed to solidify. The plates were incubated at $37^{\circ} \mathrm{C}$ for 24 hours. Plates containing 30-300 colonies were counted. The number of colony forming units per gram of a sample (cfu/g) was obtained by multiplying the average colony number with the inverse of the dilution factor.

\section{Enumeration and Detection of Coliform bacteria}

Detection and enumeration of coliform was carried out according to method described by Atlas, (1977). A set of 9 test tubes each containing $9 \mathrm{ml}$ of lactose broth and an inverted Durham tubes were autoclaved to expel air and to sterilize. Similarly, $1 \mathrm{ml}$ from the diluents $10^{1}$ was transferred to the first 3 test tubes, followed by $1 \mathrm{ml}$ from the diluents $10^{2}$ to the second set of 3 test tubes and finally the third diluents $10^{3}$ to the $3^{\text {rd }}$ set of 3 test tubes. All the 9 test tubes were incubated at $37^{\circ} \mathrm{C}$ for 24 hours. Tubes that showed gas and acid production after 24 hours were recorded as positive for the presence of Coliform. Negative tubes were further reincubated for 24 hours. Positive tubes were recorded. Estimate of most probable number of Coliform per gram of sample (MPN/g) was determined by comparing the number of gas positive tubes with the most probable number table. 
BAJOPAS Volume 13 Number 1, June, 2020 Identification of Coliform

A loop full of inoculum from gas positive tubes was streaked on to Eosine methylene blue (EMB) agar plate and incubated at $37^{\circ} \mathrm{C}$ for $24 \mathrm{hrs}$. Colonies which formed bluish black color with green metallic sheen, and reddish colonies were isolated on agar slants. Those colonies showing metallic sheen on EMB were sub cultured into tubes of lactose broth and incubated at $45^{\circ} \mathrm{C}$. The tubes were observed after $24 \mathrm{hrs}$ for gas production. This is the completed test for fecal coliform. Gram stain and other biochemical tests such as Indole, Methyl red, Voges-Proskauer and Citrate Utilization tests (IMVIC), Coagulase and Catalase tests were carried out for the Identification and confirmation of isolates.

\section{Procedure for Indole Test}

Indole test was carried out by preparing a Tryptone broth drawn in to test tubes, sterilized by autoclaving, inoculated with loopful of suspension and incubated at $37^{\circ} \mathrm{C}$ for 24 hours. Three drops of xylene was added in tubes, shaken vigorously and kept for the separation of two layers. One millilitre of Kovac's reagent was added and the formation of pink colour ring indicates positive Indole test.

\section{Procedure for Methyl Red Test}

Methyl red test was carried out by preparing Glucose phosphate broth, dispensed in test tubes, sterilized, inoculated with test culture and incubated at $37^{\circ} \mathrm{C}$ for 24 hours. Five drops of methyl-red indicator was added to the medium for the formation of red colour.

\section{Procedure for Voges-Proskauer Test}

Voges-Proskauer test was carried out by inoculating tubes with the bacterial culture followed by incubation for 48 hours at $37^{\circ} \mathrm{C}$. Separate pipettes were used to pipette $1 \mathrm{ml}$ from each culture tube into clean separate tubes. Eighteen drops $(0.5 \mathrm{ml})$ of Barrit's solution A (a-naphthol) was added to each tube containing glucose phosphate broth followed by the addition of an equal amount of solution $B$ into the same tube. The tubes were shaken at 30 seconds interval. A positive reaction was indicated by the development of a pink color, which turns red in 1-2 hours, after vigorous shaking.

\section{Procedure for Citrate Utilization Test}

Citrate Utilization Test was carried out by distributing melted agar (Simmon Citrate Agar) in to test tubes followed by sterilization at $121.5^{\circ} \mathrm{C}$ for 15 minutes. The test tubes were afterward held in slanted position, inoculated with the given bacterial culture and incubated at $37^{\circ} \mathrm{C}$ for $24 \mathrm{hrs}$. Positive test was indicated by color change of the media from green to blue.

\section{RESULTS AND DISCUSSIONS}

The results of this study are presented in tables $1,2,3$ and 4. Among the sampling areas Kofar Kudu had the highest aerobic mesophilic bacteria counts $4.0 \times 10^{5} \mathrm{cfu} / \mathrm{g}$ followed by Rinji $2.72 \times 10^{5} \mathrm{cfu} / \mathrm{g}$, while Tosaro had the least Aerobic mesophilic bacteria counts of $1.02 \times 10^{5}$ $\mathrm{cfu} / \mathrm{g}$ as indicated in Table 1.Makwalla had the highest coliform count $68 \mathrm{MPN} / \mathrm{g}$ followed by Rinji $37 \mathrm{MPN} / \mathrm{g}$. Tsohuwar Kasuwa had the least coliform counts $8 \mathrm{MPN} / \mathrm{g}$, (Table 2). Result from table 1 shows variation in the microbial contents among the samples which suggest variation in their sources, poor handling procedures and contamination from the processing environment. High coliform count and their differences within sampling areas is an indication of poor microbiological quality of the product. Ndahi et al. (2013) reported microbial load to be a function of the handling personnel and the environment. The results indicated that the samples were contaminated with bacteria as the counts exceeded the minimum safety level $\left(10^{4} \mathrm{cfu} / \mathrm{g}\right)$ for members of the Enterobacteriaceae family. However, it might be a reflection of poor hygienic practices which may contribute to health hazard to the potential consumers. Similarly, Inusa and Sa'id (2017); Osimani et al. (2015) reported that, the initial microbial content of the raw material play significant role in influencing the final microbial load of the finished product. Isolation of members of the Enterobacteriaceae such as $E$. coli, Klebsiella pneumoniae, Salmonella and Shigella signifies danger to the public health. These organisms are capable of producing endotoxins which trigger high fevers in infected individuals, and the enterotoxins which colonize the small intestines and lead to extreme dehydration as a result of vomiting and diarrhea sometimes with severe and fatal outcomes (Amaeze et al., 2016). From the 16 isolated organisms $E$. coli had the highest isolation rate $6(37.5 \%)$ (Table 3), this suggest faecal contamination of the products. $E$. coli is a common flora in the gastrointestinal tract responsible for diarrhea and extra-intestinal infections (CDC, 2011). The result is in conformity with the findings of Ndahi et al. (2013) and Shamsuddeen (2009). Also presence of campylobacter might be due to cross contamination from raw meat to finished product (Tsire). Staphylococcus aureus is a normal flora of the skin, nasal, genital, mouth or anal area in both humans and animals without any symptom of an infection (Matthew et al., 2013). Isolation of $S$. aureus in these study concords with the findings of Lucretia et al. (2018) from Suya sold in Rivers State. 
BAJOPAS Volume 13 Number 1, June, 2020

It is also in agreement with the findings of Yousafzai et al. (2018); Onuorah et al. (2015) and Tijjani and Jumare (2014) from tsire samples in different countries. Presence of $S$. aureus in foods is most of the time an indication of poor human handling, poor environment, unhygienic utensils and equipments used during processing (Igene et al., 2016; Okonko et al., 2013). Infections caused by $S$. aureus are difficult to treat leading to long hospitalization with consequent economic loss (Udobi et al., 2013). These include soft tissue infections, pneumonia, hospital-acquired postoperative wound infections, Staphylococcal food poisoning, impetigo and cellulitis (Charlene et al., 2013). Samples obtained from Dausai and Kofar Kudu had the highest isolation rate $4(80 \%)$ (Table 4 ) probably because of the much commercial activities taking place in the area which can lead to environmental contamination.

Table 1: Total Aerobic Mesophilic Bacterial Count of Tsire sold in Garko Town

\begin{tabular}{lll}
\hline Sampling Area & APC cfu/g & Mean \pm STD \\
\hline Dausai & $2.20 \times 10^{5}$ & $110000 \pm 14142.14$ \\
Kofar Kudu & $4.00 \times 10^{5}$ & $133333.3 \pm 23094.01$ \\
Makwalla & $1.30 \times 10^{5}$ & $32500 \pm 7187.953$ \\
Rinji & $2.72 \times 10^{5}$ & $90666.67 \pm 94769.90$ \\
Tosaro & $1.02 \times 10^{5}$ & $51000 \pm 15556.35$ \\
Tsohuwar Kasuwa & $1.75 \times 10^{5}$ & $35000 \pm 11357.82$ \\
\hline
\end{tabular}

Key: APC: Aerobic Mesophilic Counts

STD: Standard Deviation

Table 2: Total Coliform Count of Tsire sold in Garko Town

\begin{tabular}{lcc}
\hline \multicolumn{1}{c}{ Sampling Area } & TCC MPN/g & Mean \pm STD \\
\hline Dausai & 20 & $6.67 \pm 2.5166$ \\
Kofar Kudu & 32 & $16.00 \pm 5.6569$ \\
Makwalla & 68 & $13.60 \pm 8.7062$ \\
Rinji & 37 & $9.25 \pm 4.7871$ \\
Tosaro & 10 & $5.00 \pm 2.8284$ \\
Tsohuwar Kasuwa & 8 & $4.00 \pm 0.0000$ \\
\hline
\end{tabular}

Table 3: Organisms Isolated from Tsire Sold in Garko

\begin{tabular}{lcl}
\hline Isolated Organism & Frequency & Percentage (\%) \\
\hline Campylobacter & 2 & 06.66 \\
Escherichia coli & 6 & 20.00 \\
Klebsiella pneumoniae & 2 & 06.66 \\
Salmonella species & 1 & 03.33 \\
Shigella & 3 & 10.00 \\
Staphylococcus aureus & 2 & 06.66 \\
Total & 16 & \\
\hline
\end{tabular}

Table 4: Distribution of Organisms within Sampling Area

\begin{tabular}{lcc}
\hline \multicolumn{1}{c}{ Sampling Area } & No. Isolated & Percentage (\%) \\
\hline Dausai & 4 & 80 \\
Kofar Kudu & 4 & 80 \\
Makwalla & 2 & 40 \\
Rinji & 3 & 60 \\
Tosaro & 2 & 40 \\
Tsohuwar Kasuwa & 1 & 20 \\
Total & 16 & \\
\hline
\end{tabular}

\section{CONCLUSION}

Results indicated $4.00 \times 10^{5} \mathrm{CFU} / \mathrm{g}$ as the highest APCs count; while $68 \mathrm{MPN} / \mathrm{g}$ was the highest TCCs from the 30 samples analyzed. Among the isolates, $E$. coli has the highest isolation rate of $6(20 \%)$. Dausai and Kofar kudu were having the highest bacteria count of $4(80 \%)$, each, indicating higher contamination in those locations. 
BAJOPAS Volume 13 Number 1, June, 2020 RECOMMENDATIONS

The following recommendations are tenable:

1. Hygienic practices at all stages of production should be improved to safe guard the consumers against potential health hazard.

2. Monitoring of microbiological contamination of Tsire during preparations, packaging and marketing is essential to ensure product of good microbiological quality for consumers' health.

\section{REFERENCES}

Abdullahi, I. O., Umoh, V. J. and Galadima, M. (2004). Hazards Associated with Kilishi Preparations in Zaria. Nigerian Journal of Microbiology, 18 (1-2): $339-345$.

Ahmadu, J. and Ibrahim E. J., (2013): Determinants of Revenue in Suya Production in BeninCity, Edo State, Nigeria. Nigerian journal of agriculture, food and environment.9(3):1-5

Amaeze, N. Aboh, M. Itohan, A. Felix, E. Olatunji, T. and Oladosu, P. (2016) Microbial Profile, Antibiotic Sensitivity and Heat Resistance of Bacterial Isolates from Commercial Roasted Beef (Suya) in Abuja, Nigeria. JOPAT, 15(2): $22-30$.

Apata, E.S., Kuku1, I.A., Apata, O.C. and Adeyemi, K.O. (2013). Evaluation of Suya(Tsire) - An Intermediate Moisture Meat Product in Ogun State, Nigeria. J. Food Res 2 (1): 87.

Atlas, R. M. (1997) Principles of Microbiology Second Edition. C. Brown Publishers. Pp 802-803.

Borch, E. Kant-Muermans, M. L., Blixt, Y. (1996) Bacterial Spoilage of Meat and Cured Meat Products. Int $\mathrm{J}$ Food Microbiol .33(1): 103-20.

Centre for Disease Control, CDC (2011). "Escherichia coli 0157:H7" Division of Bacterial and Mycotic Diseasesht://www.cdc.gov/nczved/divisi ons/dfbmd/diseases/ecoli_0157h7/.

Charlene, R. J., Johnnie, A. D., and John, B. B., (2013) Prevalence and Characterization of Methicillin-Resistant Staphylococcus aureus Isolates from Retail Meat and Humans in Georgia. American society for Microbiology. J. of clinical microbiology. 12(1):123-6 doi:10.1128/JCM.0316612JCM.03166-12

Egbebi, A.O and Seidu, K., T. (2011). Microbiological Evaluation of Suya (dried smoked

meat) Sold in Ado and Akure, South West Nigeria.European Journal of Experinmental Biology, 1(4):1-5
3. Government should establish regulatory bodies responsible for inculcating hygiene habits to the local producers and vendors in order to prevent instant, cross and post processing contaminations by microbial pathogens.

4. Awareness and sensitization of local food producers about good hygienic practices in food handling and processing.

Falegan, C, R., Akoja, S. D., and Oyarekua, M. A., (2017) Microbiological Assessment of Suya (Sliced Roasted Beef) in Ado-Ekiti Metropolis, Ekiti State, Nigeria. MOJ Biology andMedicine.

Fonkem, D., N. Tanya, V., N. and Ebangi, A., L. (2010). Effect of Season on the Microbiological Quality of Kilishi, a Traditional Cameroonian Dried Beef Product. Tropicultura, 28(1): 10-15.

Food and Agricultural Organization of the United Nations (F A O, 1979). Manual of food quality control 4. Microbiological analysis.

Food and Agriculture Organisation of the United Nation (FAO), 2019. Nigeria at a glance.

Igene J.O., Uwadia, O.E., Ebabhamiegbebho, P.A. and Evivie, S.E., (2016) Shelf life Stability Studies of University of Benin (UNIBEN) Proff's Kilishi Product Asian Journal of Science and Technology 7(1): 2268-2274.

Inusa, S. K. and Said, I. S. (2017) Evaluation of the Chemical and Microbiological Properties Of Kilishi Sold in Kano Metropolis. Journal of Dry land Agriculture, 3 (1): $59-69$.

Lucretia, I. B, Patience, C. Obinna-Echem, Sophia, C. A. (2018) Microbiological quality andantibiotic sensitivity of potential pathogens isolated from meat product (Suya) sold in Rivers State University and its environs. International Journal of Biotechnology and Food Science, 6(4): 67-76.

Matthew, E., Drosos, E., John, L. and Ioanna, P. (2013) MRSA in Africa: Filling the Global Map of Antimicrobial Resistance PLOS One. 8(7): e68024 doi: 10.1371/journal.pone.0068024

Mgbemere, V.N., Akpapunam, M. A. and Igene, J. O., (2011). Effect of Groundnut FlourSubstitution on Yield, Quality and Storage Stability of Kilishi - a Nigerian Indigenous Dried Meat Product. African Journal of Food, Agriculture, Nutrition and Development, $\quad \mathbf{1 1}(2)$ : 4718-4738. 
BAJOPAS Volume 13 Number 1, June, 2020

Mubarak, A. A., Azeez, M. L., Amos A. O., Opeyemi, O. O. (2016) Assessment of Animal Protein Consumption and Food Security Among Rural Households in Kwara State, Nigeria American Journal of Business and Society, 1(4): 233245.

Ndahi, M., D. Kwaga, J., K. P. Bello, M. Kabir J., V. Umoh, .J. Yakubu, S., E. and Nok, A., J. (2013) Prevalence and Antimicrobial Susceptibility of Listeria Monocytogenes and Methicillin-Resistant Staphylococcus aureus Strains from Raw Meat and Meat Products in Zaria, Nigeria. Applied Journal of Microbiology, 58(3):262-9.

Okonko, I.O., Odu, N.N. and Igboh, I.E. (2013). Microbiological Analysis of Kilishi Sold In Port Harcourt, Nigeria. New York Science Journal, 6 (7):37-43.

Osimani, A., Aquilanti, L. and Clementi, F. (2015) Microbiological Quality of Meatbased Meals and Operation of Control Systems within a Food Service Environment. International Food Research Journal 22(4): 1692-1698.

Onuorah, S. Obika, I. Odibo, F. Orji, M. (2015)An Assessment of the Bacteriological Quality of Tsire-Suya (Grilled Beef) sold in Awka, Nigeria. American. J. Life. Sci. Res. 3(4):287292.

Razavilar, V, Khandaghi, J. Barzgari, A. (2010); Isolation of Eschericia coli 0157:H7 from manure fertilized farms and raw vegetables grown on it, in Tabriz city in
Iran. African Journal of Microbiology Research, 4(9): 891-895.

Scallan, E. Hoekstra, R. M. Angulo, F. J.Tauxe, R. V, Widdowson, M. Roy, S. L et al., (2011).Food borne illness acquired in the United States- Major Pathogens. Emerg. Infec Dis, 17(1): 7-15.

Shamsuddeen U (2009). Microbiological quality of spice used in the production of Kilishi a traditionally dried and grilled meat product. Bayero Journal of Pure andApplied Sciences, 2(2): 66-69.

Shamsuddeen, U. (2015) Microbiological Hazard and Critical control point Analysis of Dried and Minced Meat Snacks Produced in Kano Nigeria. Lambert Academic Publishing; Pp 1-36.

Tijani, O.and Jumare, S. (2014). Microblological Quality Assessment of Meat

Sold in KauraNamoda. International Conference on Earth, Environment and Life sciences (EELS) Dubai (UAE).

Udobi, C. E., Obajuluwa, A. F., and Onaolapo, J. A., (2013) Prevalence and Antibiotic Resistance Pattern of MethicillinResistant Staphylococcus aureus from an Orthopaedic Hospital in Nigeria BioMed Research International; 26(6); 6-7.

WHO, 2015 Foodborne diseases in the WHO African Region.

Yousafzai HA, Rind R, Khan MA, Abro SH, Korejo NA, Ejaz M, Kabir A, Shahid M, Memon S. (2019). Microbiological Contamination of Cattle and Meat in Peshawar, Pakistan. J. Anim. Health Prod. 7(1): 1116. 


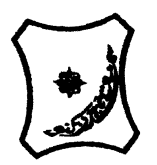

Bayero Journal of Pure and Applied Sciences, 13(1); 40 - 45

Received: September, 2019

Accepted: April, 2020

ISSN $2006-6996$

\title{
BACTERIOLOGICAL QUALITY OF STICK MEAT (Tsire) SOLD IN GARKO LOCAL GOVERNMENT AREA OF KANO STATE, NIGERIA
}

\author{
$*^{1}$ Dahiru A. T. and ${ }^{2}$ Maigari A. K. \\ ${ }^{1}$ Department of Hospitality Management, School of Technology, Kano State Polytechnic, PMB 3348, \\ Kano Nigeria. \\ ${ }^{2}$ Departmnt of Biological Sciences, Bayero University, Kano \\ Corresponding Author: dturajo61@gmail.com; GSM: 08087508262.
}

ABSTRACT

Stick meat, locally called Tsire in Hausa Language, is a significant portion of the diet of a large active population of Northern Nigeria. However, because of the handling and processing methods by the manufacturers as well as the hawking system of stick meat, the meat product may be exposed to both pre- and post-processed product contamination, and thus may poses danger to public health. Therefore, considering the role of Tsire in improving nutrition and increase household income to the populace, the need to improve the processing, distribution and overall quality of the product is simply indispensable. A total of 30 samples (5 samples from each of the 6 sampling points) of Tsire were collected randomly in Garko Town. Aerobic plate counts (APCs) and Total coliform counts (TCCS) of Tsire samples were determined using standard microbiological methods. APCs ranged from $1.02 \times 10^{5}$ to $4.00 \times 10^{5} \mathrm{CFU} / \mathrm{g}$; while TCCs ranged from $8 \mathrm{MPN} / \mathrm{g}$ to $68 \mathrm{MPN} / \mathrm{g}$. From the 30 samples screened, 16(53.33\%) bacteria namely, Campylobacter 2(6.66\%), Escherichia coli 6(20\%), Klebsiella pneumoniae 2(6.66\%), Salmonella spp. 1(3.33\%), Shigella 3(10\%) and Staphylococcus aureus 2(6.66\%) were detected. $E$. coli has the highest isolation rate of 6(20\%), while Salmonella spp. had the least frequency of 1(3.33\%). The distribution of isolated organisms within the study area were as follows: Dausai, 4(80\%), Kofar kudu, 4(80\%), Makwalla, 2(40\%), Rinji, 3(60\%), Tosaro, 2(40\%), and Tsohuwar Kasuwa, 1(20\%). The results have indicated that the Tsire was contaminated with bacteria thus exposing the product to fast deterioration, spoilage and also a vehicle for food borne illness, suggesting for adequate hygienic practices at all the stages, prior to consumption, to ensure safety of the meat product.

Key words: APCs, TCCs, Contamination, Microorganisms, Garko

\section{INTRODUCTION}

Nigeria is one of the developing nations with inadequate food supply and most often deficient in protein content (FAO, 2019). Nigerian's average animal protein intake per head per day is estimated at $7.9 \mathrm{~g}$ as against $35 \mathrm{~g}$ recommended value by Food and Agricultural Organization (Mubarak et al., 2016). These low levels of animal protein intake create great concern as it affects the nutritional status of Nigerians. Hence, there is the need for sufficient supply of animal protein from energy rich animal products to satisfy the nutritional requirements for Nigerians.

Meat is one major source of animal protein largely composed of water, protein and fats which can make it susceptible to microbial contamination within short time leading to spoilage (Apata et al., 2013; Mgbemere et al., 2011). Meat is mostly eaten after it has been cooked or processed in a variety of ways such as sun drying; smoking and roasting with or without fortifications (Borch et al., 1996). In Nigeria meat products such as Tsire, Kilishi and Balangu are locally produced using one or more of these methods in order to meet the nutritional requirements of the teeming Nigerians (Egbebi, 2011).

Tsire is a popular Nigerian traditional processed ready-to-eat roasted stick meat product (Shamsuddeen, 2015). It is sold in public places, along roads, in hotels, parks, quarters and even offices (Falegan et al., 2017). It is prepared from boneless healthy animal flesh such as beef and mutton, spiced with peanut cake, salt, vegetable oil and other flavorings followed by roasting (Shamsuddeen, 2015). Consumption of these products has extended to other parts of African countries such as Ghana, Somali, Cameroun and Chad (Ahmadu and Ibrahim, 2013). 
BAJOPAS Volume 13 Number 1, June, 2020

However, evidence of quality control sticking to procedural hygiene by the handlers during preparation and retailing of these products is poorly documented. Tsire is of great safety risk because of the fact that there are erratic cases of gastroenteritis and symptoms of food infection after consumption (WHO, 2015). Food borne illnesses are one of the major health problems in developing and developed countries (Razavilar, 2010). According to the World Health Organization, WHO (2015), $0.07 \%$ death of the 600 million global burdens of Foodborne illnesses have been reported to be caused by bacteria, viruses, fungi and chemicals. In America $0.27 \%$ of the estimated 48 million affected people is hospitalized and about $0.0063 \%$ deaths are recorded each year (Scallan et al., 2011). More than 91 million people in Africa fall ill and $0.15 \%$ dies each year, making Africa the highest burden bearer of Foodborne diseases per population (WHO, 2015).

Application of a Hazard Analysis Critical Control Point (HACCP) at all stages of meat products preparation is essential in order to ensure its safety. Thus, according to the guidelines of good manufacturing practice, the level of total aerobic bacterial contamination of thermally processed meat products should not exceed $10^{4}\left(\mathrm{cfu} \mathrm{g}^{-1}\right)$. Enterobacteriaceae and faecal coliform contamination in meat products should be within the range of $10^{2}-10^{4}$ and $10-10^{3} \mathrm{cfu} \mathrm{g}^{-1}$, respectively (Shamsuddeen, 2015). The aim of the study is therefore, to assess the total viable bacterial counts of tsire marketed locally within Garko town, and to isolate and identify the organisms at the point of consumption with the intention of promoting public health and food hygiene habits in the Nigerian populace.

\section{MATERIALS AND METHODS Study Area and Population}

Garko is one of the existing 44 local government areas located in Kano south west zone of Kano state with its capital administrative headquarters in the Garko town. It has coordinates $11^{\circ} 39^{\prime} \mathrm{N}$ $8^{\circ} 54^{\prime} \mathrm{E}$, and an area of $450 \mathrm{~km}^{2}$. The projected population of Garko local Government was 225,300 according to the National Population Census report (2018). Garko is known for agricultural activities both farming and animal husbandry. It is popularly known for large scale rice production. Other food crops include sweet potatoes, cassava, onions, sorghum, millet and sugarcane. Cows, sheep and goats are major groups of animals reared by majority of the populace. Meat products processed, retailed and consumed in Garko include roasted meat (Balangu), dried roasted meat (Kilishi), stick meat (Tsire), hide and skin pepper soup (Ragadada) and minced fried meat (Danbunnama).

\section{Samples Collection}

Five samples of Tsire products were collected from 6 different identified locations within Garko town in a sterile foil paper and immediately analyzed for the presence of bacteria.

\section{Sample Preparation}

Sample preparation for the bacteriological analysis was carried out in accordance with the method described by Atlas (1997). Twenty five grams $(25 \mathrm{~g})$ of the sample was homogenized in $225 \mathrm{ml}$ peptone water using Kenwood blender machine to obtain a $10^{1}$ homogenate. The homogenate was thoroughly shaken and $1 \mathrm{ml}$ pipetted into test tubes containing $9 \mathrm{ml}$ of peptone water $\left(10^{2}\right)$. The test tubes were further serially diluted to $10^{5}$.

Total Aerobic Mesophilic Bacterial Count

Total Aerobic mesophilic bacterial count was determined using the method described by Abdullahi et al. (2004) where $1 \mathrm{ml}$ of inoculums from $10^{1}$ to $10^{5}$ dilutions were transferred into duplicate Petri dishes and labeled accordingly. This was followed by pouring aseptically about $15 \mathrm{ml}$ of molten nutrient agar. The culture was homogenized by gentle spinning of the plates and allowed to solidify. The plates were incubated at $37^{\circ} \mathrm{C}$ for 24 hours. Plates containing 30-300 colonies were counted. The number of colony forming units per gram of a sample (cfu/g) was obtained by multiplying the average colony number with the inverse of the dilution factor.

\section{Enumeration and Detection of Coliform bacteria}

Detection and enumeration of coliform was carried out according to method described by Atlas, (1977). A set of 9 test tubes each containing $9 \mathrm{ml}$ of lactose broth and an inverted Durham tubes were autoclaved to expel air and to sterilize. Similarly, $1 \mathrm{ml}$ from the diluents $10^{1}$ was transferred to the first 3 test tubes, followed by $1 \mathrm{ml}$ from the diluents $10^{2}$ to the second set of 3 test tubes and finally the third diluents $10^{3}$ to the $3^{\text {rd }}$ set of 3 test tubes. All the 9 test tubes were incubated at $37^{\circ} \mathrm{C}$ for 24 hours. Tubes that showed gas and acid production after 24 hours were recorded as positive for the presence of Coliform. Negative tubes were further reincubated for 24 hours. Positive tubes were recorded. Estimate of most probable number of Coliform per gram of sample (MPN/g) was determined by comparing the number of gas positive tubes with the most probable number table. 
BAJOPAS Volume 13 Number 1, June, 2020 Identification of Coliform

A loop full of inoculum from gas positive tubes was streaked on to Eosine methylene blue (EMB) agar plate and incubated at $37^{\circ} \mathrm{C}$ for $24 \mathrm{hrs}$. Colonies which formed bluish black color with green metallic sheen, and reddish colonies were isolated on agar slants. Those colonies showing metallic sheen on EMB were sub cultured into tubes of lactose broth and incubated at $45^{\circ} \mathrm{C}$. The tubes were observed after $24 \mathrm{hrs}$ for gas production. This is the completed test for fecal coliform. Gram stain and other biochemical tests such as Indole, Methyl red, Voges-Proskauer and Citrate Utilization tests (IMVIC), Coagulase and Catalase tests were carried out for the Identification and confirmation of isolates.

\section{Procedure for Indole Test}

Indole test was carried out by preparing a Tryptone broth drawn in to test tubes, sterilized by autoclaving, inoculated with loopful of suspension and incubated at $37^{\circ} \mathrm{C}$ for 24 hours. Three drops of xylene was added in tubes, shaken vigorously and kept for the separation of two layers. One millilitre of Kovac's reagent was added and the formation of pink colour ring indicates positive Indole test.

\section{Procedure for Methyl Red Test}

Methyl red test was carried out by preparing Glucose phosphate broth, dispensed in test tubes, sterilized, inoculated with test culture and incubated at $37^{\circ} \mathrm{C}$ for 24 hours. Five drops of methyl-red indicator was added to the medium for the formation of red colour.

\section{Procedure for Voges-Proskauer Test}

Voges-Proskauer test was carried out by inoculating tubes with the bacterial culture followed by incubation for 48 hours at $37^{\circ} \mathrm{C}$. Separate pipettes were used to pipette $1 \mathrm{ml}$ from each culture tube into clean separate tubes. Eighteen drops $(0.5 \mathrm{ml})$ of Barrit's solution A (a-naphthol) was added to each tube containing glucose phosphate broth followed by the addition of an equal amount of solution $B$ into the same tube. The tubes were shaken at 30 seconds interval. A positive reaction was indicated by the development of a pink color, which turns red in 1-2 hours, after vigorous shaking.

\section{Procedure for Citrate Utilization Test}

Citrate Utilization Test was carried out by distributing melted agar (Simmon Citrate Agar) in to test tubes followed by sterilization at $121.5^{\circ} \mathrm{C}$ for 15 minutes. The test tubes were afterward held in slanted position, inoculated with the given bacterial culture and incubated at $37^{\circ} \mathrm{C}$ for $24 \mathrm{hrs}$. Positive test was indicated by color change of the media from green to blue.

\section{RESULTS AND DISCUSSIONS}

The results of this study are presented in tables $1,2,3$ and 4. Among the sampling areas Kofar Kudu had the highest aerobic mesophilic bacteria counts $4.0 \times 10^{5} \mathrm{cfu} / \mathrm{g}$ followed by Rinji $2.72 \times 10^{5} \mathrm{cfu} / \mathrm{g}$, while Tosaro had the least Aerobic mesophilic bacteria counts of $1.02 \times 10^{5}$ $\mathrm{cfu} / \mathrm{g}$ as indicated in Table 1.Makwalla had the highest coliform count $68 \mathrm{MPN} / \mathrm{g}$ followed by Rinji $37 \mathrm{MPN} / \mathrm{g}$. Tsohuwar Kasuwa had the least coliform counts $8 \mathrm{MPN} / \mathrm{g}$, (Table 2). Result from table 1 shows variation in the microbial contents among the samples which suggest variation in their sources, poor handling procedures and contamination from the processing environment. High coliform count and their differences within sampling areas is an indication of poor microbiological quality of the product. Ndahi et al. (2013) reported microbial load to be a function of the handling personnel and the environment. The results indicated that the samples were contaminated with bacteria as the counts exceeded the minimum safety level $\left(10^{4} \mathrm{cfu} / \mathrm{g}\right)$ for members of the Enterobacteriaceae family. However, it might be a reflection of poor hygienic practices which may contribute to health hazard to the potential consumers. Similarly, Inusa and Sa'id (2017); Osimani et al. (2015) reported that, the initial microbial content of the raw material play significant role in influencing the final microbial load of the finished product. Isolation of members of the Enterobacteriaceae such as $E$. coli, Klebsiella pneumoniae, Salmonella and Shigella signifies danger to the public health. These organisms are capable of producing endotoxins which trigger high fevers in infected individuals, and the enterotoxins which colonize the small intestines and lead to extreme dehydration as a result of vomiting and diarrhea sometimes with severe and fatal outcomes (Amaeze et al., 2016). From the 16 isolated organisms $E$. coli had the highest isolation rate $6(37.5 \%)$ (Table 3), this suggest faecal contamination of the products. $E$. coli is a common flora in the gastrointestinal tract responsible for diarrhea and extra-intestinal infections (CDC, 2011). The result is in conformity with the findings of Ndahi et al. (2013) and Shamsuddeen (2009). Also presence of campylobacter might be due to cross contamination from raw meat to finished product (Tsire). Staphylococcus aureus is a normal flora of the skin, nasal, genital, mouth or anal area in both humans and animals without any symptom of an infection (Matthew et al., 2013). Isolation of $S$. aureus in these study concords with the findings of Lucretia et al. (2018) from Suya sold in Rivers State. 
BAJOPAS Volume 13 Number 1, June, 2020

It is also in agreement with the findings of Yousafzai et al. (2018); Onuorah et al. (2015) and Tijjani and Jumare (2014) from tsire samples in different countries. Presence of $S$. aureus in foods is most of the time an indication of poor human handling, poor environment, unhygienic utensils and equipments used during processing (Igene et al., 2016; Okonko et al., 2013). Infections caused by $S$. aureus are difficult to treat leading to long hospitalization with consequent economic loss (Udobi et al., 2013). These include soft tissue infections, pneumonia, hospital-acquired postoperative wound infections, Staphylococcal food poisoning, impetigo and cellulitis (Charlene et al., 2013). Samples obtained from Dausai and Kofar Kudu had the highest isolation rate $4(80 \%)$ (Table 4 ) probably because of the much commercial activities taking place in the area which can lead to environmental contamination.

Table 1: Total Aerobic Mesophilic Bacterial Count of Tsire sold in Garko Town

\begin{tabular}{lll}
\hline Sampling Area & APC cfu/g & Mean \pm STD \\
\hline Dausai & $2.20 \times 10^{5}$ & $110000 \pm 14142.14$ \\
Kofar Kudu & $4.00 \times 10^{5}$ & $133333.3 \pm 23094.01$ \\
Makwalla & $1.30 \times 10^{5}$ & $32500 \pm 7187.953$ \\
Rinji & $2.72 \times 10^{5}$ & $90666.67 \pm 94769.90$ \\
Tosaro & $1.02 \times 10^{5}$ & $51000 \pm 15556.35$ \\
Tsohuwar Kasuwa & $1.75 \times 10^{5}$ & $35000 \pm 11357.82$ \\
\hline
\end{tabular}

Key: APC: Aerobic Mesophilic Counts

STD: Standard Deviation

Table 2: Total Coliform Count of Tsire sold in Garko Town

\begin{tabular}{lcc}
\hline \multicolumn{1}{c}{ Sampling Area } & TCC MPN/g & Mean \pm STD \\
\hline Dausai & 20 & $6.67 \pm 2.5166$ \\
Kofar Kudu & 32 & $16.00 \pm 5.6569$ \\
Makwalla & 68 & $13.60 \pm 8.7062$ \\
Rinji & 37 & $9.25 \pm 4.7871$ \\
Tosaro & 10 & $5.00 \pm 2.8284$ \\
Tsohuwar Kasuwa & 8 & $4.00 \pm 0.0000$ \\
\hline
\end{tabular}

Table 3: Organisms Isolated from Tsire Sold in Garko

\begin{tabular}{lcl}
\hline Isolated Organism & Frequency & Percentage (\%) \\
\hline Campylobacter & 2 & 06.66 \\
Escherichia coli & 6 & 20.00 \\
Klebsiella pneumoniae & 2 & 06.66 \\
Salmonella species & 1 & 03.33 \\
Shigella & 3 & 10.00 \\
Staphylococcus aureus & 2 & 06.66 \\
Total & 16 & \\
\hline
\end{tabular}

Table 4: Distribution of Organisms within Sampling Area

\begin{tabular}{lcc}
\hline \multicolumn{1}{c}{ Sampling Area } & No. Isolated & Percentage (\%) \\
\hline Dausai & 4 & 80 \\
Kofar Kudu & 4 & 80 \\
Makwalla & 2 & 40 \\
Rinji & 3 & 60 \\
Tosaro & 2 & 40 \\
Tsohuwar Kasuwa & 1 & 20 \\
Total & 16 & \\
\hline
\end{tabular}

\section{CONCLUSION}

Results indicated $4.00 \times 10^{5} \mathrm{CFU} / \mathrm{g}$ as the highest APCs count; while $68 \mathrm{MPN} / \mathrm{g}$ was the highest TCCs from the 30 samples analyzed. Among the isolates, $E$. coli has the highest isolation rate of $6(20 \%)$. Dausai and Kofar kudu were having the highest bacteria count of $4(80 \%)$, each, indicating higher contamination in those locations. 
BAJOPAS Volume 13 Number 1, June, 2020 RECOMMENDATIONS

The following recommendations are tenable:

1. Hygienic practices at all stages of production should be improved to safe guard the consumers against potential health hazard.

2. Monitoring of microbiological contamination of Tsire during preparations, packaging and marketing is essential to ensure product of good microbiological quality for consumers' health.

\section{REFERENCES}

Abdullahi, I. O., Umoh, V. J. and Galadima, M. (2004). Hazards Associated with Kilishi Preparations in Zaria. Nigerian Journal of Microbiology, 18 (1-2): $339-345$.

Ahmadu, J. and Ibrahim E. J., (2013): Determinants of Revenue in Suya Production in BeninCity, Edo State, Nigeria. Nigerian journal of agriculture, food and environment.9(3):1-5

Amaeze, N. Aboh, M. Itohan, A. Felix, E. Olatunji, T. and Oladosu, P. (2016) Microbial Profile, Antibiotic Sensitivity and Heat Resistance of Bacterial Isolates from Commercial Roasted Beef (Suya) in Abuja, Nigeria. JOPAT, 15(2): $22-30$.

Apata, E.S., Kuku1, I.A., Apata, O.C. and Adeyemi, K.O. (2013). Evaluation of Suya(Tsire) - An Intermediate Moisture Meat Product in Ogun State, Nigeria. J. Food Res 2 (1): 87.

Atlas, R. M. (1997) Principles of Microbiology Second Edition. C. Brown Publishers. Pp 802-803.

Borch, E. Kant-Muermans, M. L., Blixt, Y. (1996) Bacterial Spoilage of Meat and Cured Meat Products. Int $\mathrm{J}$ Food Microbiol .33(1): 103-20.

Centre for Disease Control, CDC (2011). "Escherichia coli 0157:H7" Division of Bacterial and Mycotic Diseasesht://www.cdc.gov/nczved/divisi ons/dfbmd/diseases/ecoli_0157h7/.

Charlene, R. J., Johnnie, A. D., and John, B. B., (2013) Prevalence and Characterization of Methicillin-Resistant Staphylococcus aureus Isolates from Retail Meat and Humans in Georgia. American society for Microbiology. J. of clinical microbiology. 12(1):123-6 doi:10.1128/JCM.0316612JCM.03166-12

Egbebi, A.O and Seidu, K., T. (2011). Microbiological Evaluation of Suya (dried smoked

meat) Sold in Ado and Akure, South West Nigeria.European Journal of Experinmental Biology, 1(4):1-5
3. Government should establish regulatory bodies responsible for inculcating hygiene habits to the local producers and vendors in order to prevent instant, cross and post processing contaminations by microbial pathogens.

4. Awareness and sensitization of local food producers about good hygienic practices in food handling and processing.

Falegan, C, R., Akoja, S. D., and Oyarekua, M. A., (2017) Microbiological Assessment of Suya (Sliced Roasted Beef) in Ado-Ekiti Metropolis, Ekiti State, Nigeria. MOJ Biology andMedicine.

Fonkem, D., N. Tanya, V., N. and Ebangi, A., L. (2010). Effect of Season on the Microbiological Quality of Kilishi, a Traditional Cameroonian Dried Beef Product. Tropicultura, 28(1): 10-15.

Food and Agricultural Organization of the United Nations (F A O, 1979). Manual of food quality control 4. Microbiological analysis.

Food and Agriculture Organisation of the United Nation (FAO), 2019. Nigeria at a glance.

Igene J.O., Uwadia, O.E., Ebabhamiegbebho, P.A. and Evivie, S.E., (2016) Shelf life Stability Studies of University of Benin (UNIBEN) Proff's Kilishi Product Asian Journal of Science and Technology 7(1): 2268-2274.

Inusa, S. K. and Said, I. S. (2017) Evaluation of the Chemical and Microbiological Properties Of Kilishi Sold in Kano Metropolis. Journal of Dry land Agriculture, 3 (1): $59-69$.

Lucretia, I. B, Patience, C. Obinna-Echem, Sophia, C. A. (2018) Microbiological quality andantibiotic sensitivity of potential pathogens isolated from meat product (Suya) sold in Rivers State University and its environs. International Journal of Biotechnology and Food Science, 6(4): 67-76.

Matthew, E., Drosos, E., John, L. and Ioanna, P. (2013) MRSA in Africa: Filling the Global Map of Antimicrobial Resistance PLOS One. 8(7): e68024 doi: 10.1371/journal.pone.0068024

Mgbemere, V.N., Akpapunam, M. A. and Igene, J. O., (2011). Effect of Groundnut FlourSubstitution on Yield, Quality and Storage Stability of Kilishi - a Nigerian Indigenous Dried Meat Product. African Journal of Food, Agriculture, Nutrition and Development, $\quad \mathbf{1 1}(2)$ : 4718-4738. 
BAJOPAS Volume 13 Number 1, June, 2020

Mubarak, A. A., Azeez, M. L., Amos A. O., Opeyemi, O. O. (2016) Assessment of Animal Protein Consumption and Food Security Among Rural Households in Kwara State, Nigeria American Journal of Business and Society, 1(4): 233245.

Ndahi, M., D. Kwaga, J., K. P. Bello, M. Kabir J., V. Umoh, .J. Yakubu, S., E. and Nok, A., J. (2013) Prevalence and Antimicrobial Susceptibility of Listeria Monocytogenes and Methicillin-Resistant Staphylococcus aureus Strains from Raw Meat and Meat Products in Zaria, Nigeria. Applied Journal of Microbiology, 58(3):262-9.

Okonko, I.O., Odu, N.N. and Igboh, I.E. (2013). Microbiological Analysis of Kilishi Sold In Port Harcourt, Nigeria. New York Science Journal, 6 (7):37-43.

Osimani, A., Aquilanti, L. and Clementi, F. (2015) Microbiological Quality of Meatbased Meals and Operation of Control Systems within a Food Service Environment. International Food Research Journal 22(4): 1692-1698.

Onuorah, S. Obika, I. Odibo, F. Orji, M. (2015)An Assessment of the Bacteriological Quality of Tsire-Suya (Grilled Beef) sold in Awka, Nigeria. American. J. Life. Sci. Res. 3(4):287292.

Razavilar, V, Khandaghi, J. Barzgari, A. (2010); Isolation of Eschericia coli 0157:H7 from manure fertilized farms and raw vegetables grown on it, in Tabriz city in
Iran. African Journal of Microbiology Research, 4(9): 891-895.

Scallan, E. Hoekstra, R. M. Angulo, F. J.Tauxe, R. V, Widdowson, M. Roy, S. L et al., (2011).Food borne illness acquired in the United States- Major Pathogens. Emerg. Infec Dis, 17(1): 7-15.

Shamsuddeen U (2009). Microbiological quality of spice used in the production of Kilishi a traditionally dried and grilled meat product. Bayero Journal of Pure andApplied Sciences, 2(2): 66-69.

Shamsuddeen, U. (2015) Microbiological Hazard and Critical control point Analysis of Dried and Minced Meat Snacks Produced in Kano Nigeria. Lambert Academic Publishing; Pp 1-36.

Tijani, O.and Jumare, S. (2014). Microblological Quality Assessment of Meat

Sold in KauraNamoda. International Conference on Earth, Environment and Life sciences (EELS) Dubai (UAE).

Udobi, C. E., Obajuluwa, A. F., and Onaolapo, J. A., (2013) Prevalence and Antibiotic Resistance Pattern of MethicillinResistant Staphylococcus aureus from an Orthopaedic Hospital in Nigeria BioMed Research International; 26(6); 6-7.

WHO, 2015 Foodborne diseases in the WHO African Region.

Yousafzai HA, Rind R, Khan MA, Abro SH, Korejo NA, Ejaz M, Kabir A, Shahid M, Memon S. (2019). Microbiological Contamination of Cattle and Meat in Peshawar, Pakistan. J. Anim. Health Prod. 7(1): 1116. 


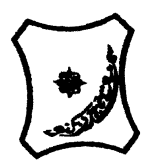

Bayero Journal of Pure and Applied Sciences, 13(1); 40 - 45

Received: September, 2019

Accepted: April, 2020

ISSN $2006-6996$

\title{
BACTERIOLOGICAL QUALITY OF STICK MEAT (Tsire) SOLD IN GARKO LOCAL GOVERNMENT AREA OF KANO STATE, NIGERIA
}

\author{
$*^{1}$ Dahiru A. T. and ${ }^{2}$ Maigari A. K. \\ ${ }^{1}$ Department of Hospitality Management, School of Technology, Kano State Polytechnic, PMB 3348, \\ Kano Nigeria. \\ ${ }^{2}$ Departmnt of Biological Sciences, Bayero University, Kano \\ Corresponding Author: dturajo61@gmail.com; GSM: 08087508262.
}

ABSTRACT

Stick meat, locally called Tsire in Hausa Language, is a significant portion of the diet of a large active population of Northern Nigeria. However, because of the handling and processing methods by the manufacturers as well as the hawking system of stick meat, the meat product may be exposed to both pre- and post-processed product contamination, and thus may poses danger to public health. Therefore, considering the role of Tsire in improving nutrition and increase household income to the populace, the need to improve the processing, distribution and overall quality of the product is simply indispensable. A total of 30 samples (5 samples from each of the 6 sampling points) of Tsire were collected randomly in Garko Town. Aerobic plate counts (APCs) and Total coliform counts (TCCS) of Tsire samples were determined using standard microbiological methods. APCs ranged from $1.02 \times 10^{5}$ to $4.00 \times 10^{5} \mathrm{CFU} / \mathrm{g}$; while TCCs ranged from $8 \mathrm{MPN} / \mathrm{g}$ to $68 \mathrm{MPN} / \mathrm{g}$. From the 30 samples screened, 16(53.33\%) bacteria namely, Campylobacter 2(6.66\%), Escherichia coli 6(20\%), Klebsiella pneumoniae 2(6.66\%), Salmonella spp. 1(3.33\%), Shigella 3(10\%) and Staphylococcus aureus 2(6.66\%) were detected. $E$. coli has the highest isolation rate of 6(20\%), while Salmonella spp. had the least frequency of 1(3.33\%). The distribution of isolated organisms within the study area were as follows: Dausai, 4(80\%), Kofar kudu, 4(80\%), Makwalla, 2(40\%), Rinji, 3(60\%), Tosaro, 2(40\%), and Tsohuwar Kasuwa, 1(20\%). The results have indicated that the Tsire was contaminated with bacteria thus exposing the product to fast deterioration, spoilage and also a vehicle for food borne illness, suggesting for adequate hygienic practices at all the stages, prior to consumption, to ensure safety of the meat product.

Key words: APCs, TCCs, Contamination, Microorganisms, Garko

\section{INTRODUCTION}

Nigeria is one of the developing nations with inadequate food supply and most often deficient in protein content (FAO, 2019). Nigerian's average animal protein intake per head per day is estimated at $7.9 \mathrm{~g}$ as against $35 \mathrm{~g}$ recommended value by Food and Agricultural Organization (Mubarak et al., 2016). These low levels of animal protein intake create great concern as it affects the nutritional status of Nigerians. Hence, there is the need for sufficient supply of animal protein from energy rich animal products to satisfy the nutritional requirements for Nigerians.

Meat is one major source of animal protein largely composed of water, protein and fats which can make it susceptible to microbial contamination within short time leading to spoilage (Apata et al., 2013; Mgbemere et al., 2011). Meat is mostly eaten after it has been cooked or processed in a variety of ways such as sun drying; smoking and roasting with or without fortifications (Borch et al., 1996). In Nigeria meat products such as Tsire, Kilishi and Balangu are locally produced using one or more of these methods in order to meet the nutritional requirements of the teeming Nigerians (Egbebi, 2011).

Tsire is a popular Nigerian traditional processed ready-to-eat roasted stick meat product (Shamsuddeen, 2015). It is sold in public places, along roads, in hotels, parks, quarters and even offices (Falegan et al., 2017). It is prepared from boneless healthy animal flesh such as beef and mutton, spiced with peanut cake, salt, vegetable oil and other flavorings followed by roasting (Shamsuddeen, 2015). Consumption of these products has extended to other parts of African countries such as Ghana, Somali, Cameroun and Chad (Ahmadu and Ibrahim, 2013). 
BAJOPAS Volume 13 Number 1, June, 2020

However, evidence of quality control sticking to procedural hygiene by the handlers during preparation and retailing of these products is poorly documented. Tsire is of great safety risk because of the fact that there are erratic cases of gastroenteritis and symptoms of food infection after consumption (WHO, 2015). Food borne illnesses are one of the major health problems in developing and developed countries (Razavilar, 2010). According to the World Health Organization, WHO (2015), $0.07 \%$ death of the 600 million global burdens of Foodborne illnesses have been reported to be caused by bacteria, viruses, fungi and chemicals. In America $0.27 \%$ of the estimated 48 million affected people is hospitalized and about $0.0063 \%$ deaths are recorded each year (Scallan et al., 2011). More than 91 million people in Africa fall ill and $0.15 \%$ dies each year, making Africa the highest burden bearer of Foodborne diseases per population (WHO, 2015).

Application of a Hazard Analysis Critical Control Point (HACCP) at all stages of meat products preparation is essential in order to ensure its safety. Thus, according to the guidelines of good manufacturing practice, the level of total aerobic bacterial contamination of thermally processed meat products should not exceed $10^{4}\left(\mathrm{cfu} \mathrm{g}^{-1}\right)$. Enterobacteriaceae and faecal coliform contamination in meat products should be within the range of $10^{2}-10^{4}$ and $10-10^{3} \mathrm{cfu} \mathrm{g}^{-1}$, respectively (Shamsuddeen, 2015). The aim of the study is therefore, to assess the total viable bacterial counts of tsire marketed locally within Garko town, and to isolate and identify the organisms at the point of consumption with the intention of promoting public health and food hygiene habits in the Nigerian populace.

\section{MATERIALS AND METHODS Study Area and Population}

Garko is one of the existing 44 local government areas located in Kano south west zone of Kano state with its capital administrative headquarters in the Garko town. It has coordinates $11^{\circ} 39^{\prime} \mathrm{N}$ $8^{\circ} 54^{\prime} \mathrm{E}$, and an area of $450 \mathrm{~km}^{2}$. The projected population of Garko local Government was 225,300 according to the National Population Census report (2018). Garko is known for agricultural activities both farming and animal husbandry. It is popularly known for large scale rice production. Other food crops include sweet potatoes, cassava, onions, sorghum, millet and sugarcane. Cows, sheep and goats are major groups of animals reared by majority of the populace. Meat products processed, retailed and consumed in Garko include roasted meat (Balangu), dried roasted meat (Kilishi), stick meat (Tsire), hide and skin pepper soup (Ragadada) and minced fried meat (Danbunnama).

\section{Samples Collection}

Five samples of Tsire products were collected from 6 different identified locations within Garko town in a sterile foil paper and immediately analyzed for the presence of bacteria.

\section{Sample Preparation}

Sample preparation for the bacteriological analysis was carried out in accordance with the method described by Atlas (1997). Twenty five grams $(25 \mathrm{~g})$ of the sample was homogenized in $225 \mathrm{ml}$ peptone water using Kenwood blender machine to obtain a $10^{1}$ homogenate. The homogenate was thoroughly shaken and $1 \mathrm{ml}$ pipetted into test tubes containing $9 \mathrm{ml}$ of peptone water $\left(10^{2}\right)$. The test tubes were further serially diluted to $10^{5}$.

Total Aerobic Mesophilic Bacterial Count

Total Aerobic mesophilic bacterial count was determined using the method described by Abdullahi et al. (2004) where $1 \mathrm{ml}$ of inoculums from $10^{1}$ to $10^{5}$ dilutions were transferred into duplicate Petri dishes and labeled accordingly. This was followed by pouring aseptically about $15 \mathrm{ml}$ of molten nutrient agar. The culture was homogenized by gentle spinning of the plates and allowed to solidify. The plates were incubated at $37^{\circ} \mathrm{C}$ for 24 hours. Plates containing 30-300 colonies were counted. The number of colony forming units per gram of a sample (cfu/g) was obtained by multiplying the average colony number with the inverse of the dilution factor.

\section{Enumeration and Detection of Coliform bacteria}

Detection and enumeration of coliform was carried out according to method described by Atlas, (1977). A set of 9 test tubes each containing $9 \mathrm{ml}$ of lactose broth and an inverted Durham tubes were autoclaved to expel air and to sterilize. Similarly, $1 \mathrm{ml}$ from the diluents $10^{1}$ was transferred to the first 3 test tubes, followed by $1 \mathrm{ml}$ from the diluents $10^{2}$ to the second set of 3 test tubes and finally the third diluents $10^{3}$ to the $3^{\text {rd }}$ set of 3 test tubes. All the 9 test tubes were incubated at $37^{\circ} \mathrm{C}$ for 24 hours. Tubes that showed gas and acid production after 24 hours were recorded as positive for the presence of Coliform. Negative tubes were further reincubated for 24 hours. Positive tubes were recorded. Estimate of most probable number of Coliform per gram of sample (MPN/g) was determined by comparing the number of gas positive tubes with the most probable number table. 
BAJOPAS Volume 13 Number 1, June, 2020 Identification of Coliform

A loop full of inoculum from gas positive tubes was streaked on to Eosine methylene blue (EMB) agar plate and incubated at $37^{\circ} \mathrm{C}$ for $24 \mathrm{hrs}$. Colonies which formed bluish black color with green metallic sheen, and reddish colonies were isolated on agar slants. Those colonies showing metallic sheen on EMB were sub cultured into tubes of lactose broth and incubated at $45^{\circ} \mathrm{C}$. The tubes were observed after $24 \mathrm{hrs}$ for gas production. This is the completed test for fecal coliform. Gram stain and other biochemical tests such as Indole, Methyl red, Voges-Proskauer and Citrate Utilization tests (IMVIC), Coagulase and Catalase tests were carried out for the Identification and confirmation of isolates.

\section{Procedure for Indole Test}

Indole test was carried out by preparing a Tryptone broth drawn in to test tubes, sterilized by autoclaving, inoculated with loopful of suspension and incubated at $37^{\circ} \mathrm{C}$ for 24 hours. Three drops of xylene was added in tubes, shaken vigorously and kept for the separation of two layers. One millilitre of Kovac's reagent was added and the formation of pink colour ring indicates positive Indole test.

\section{Procedure for Methyl Red Test}

Methyl red test was carried out by preparing Glucose phosphate broth, dispensed in test tubes, sterilized, inoculated with test culture and incubated at $37^{\circ} \mathrm{C}$ for 24 hours. Five drops of methyl-red indicator was added to the medium for the formation of red colour.

\section{Procedure for Voges-Proskauer Test}

Voges-Proskauer test was carried out by inoculating tubes with the bacterial culture followed by incubation for 48 hours at $37^{\circ} \mathrm{C}$. Separate pipettes were used to pipette $1 \mathrm{ml}$ from each culture tube into clean separate tubes. Eighteen drops $(0.5 \mathrm{ml})$ of Barrit's solution A (a-naphthol) was added to each tube containing glucose phosphate broth followed by the addition of an equal amount of solution $B$ into the same tube. The tubes were shaken at 30 seconds interval. A positive reaction was indicated by the development of a pink color, which turns red in 1-2 hours, after vigorous shaking.

\section{Procedure for Citrate Utilization Test}

Citrate Utilization Test was carried out by distributing melted agar (Simmon Citrate Agar) in to test tubes followed by sterilization at $121.5^{\circ} \mathrm{C}$ for 15 minutes. The test tubes were afterward held in slanted position, inoculated with the given bacterial culture and incubated at $37^{\circ} \mathrm{C}$ for $24 \mathrm{hrs}$. Positive test was indicated by color change of the media from green to blue.

\section{RESULTS AND DISCUSSIONS}

The results of this study are presented in tables $1,2,3$ and 4. Among the sampling areas Kofar Kudu had the highest aerobic mesophilic bacteria counts $4.0 \times 10^{5} \mathrm{cfu} / \mathrm{g}$ followed by Rinji $2.72 \times 10^{5} \mathrm{cfu} / \mathrm{g}$, while Tosaro had the least Aerobic mesophilic bacteria counts of $1.02 \times 10^{5}$ $\mathrm{cfu} / \mathrm{g}$ as indicated in Table 1.Makwalla had the highest coliform count $68 \mathrm{MPN} / \mathrm{g}$ followed by Rinji $37 \mathrm{MPN} / \mathrm{g}$. Tsohuwar Kasuwa had the least coliform counts $8 \mathrm{MPN} / \mathrm{g}$, (Table 2). Result from table 1 shows variation in the microbial contents among the samples which suggest variation in their sources, poor handling procedures and contamination from the processing environment. High coliform count and their differences within sampling areas is an indication of poor microbiological quality of the product. Ndahi et al. (2013) reported microbial load to be a function of the handling personnel and the environment. The results indicated that the samples were contaminated with bacteria as the counts exceeded the minimum safety level $\left(10^{4} \mathrm{cfu} / \mathrm{g}\right)$ for members of the Enterobacteriaceae family. However, it might be a reflection of poor hygienic practices which may contribute to health hazard to the potential consumers. Similarly, Inusa and Sa'id (2017); Osimani et al. (2015) reported that, the initial microbial content of the raw material play significant role in influencing the final microbial load of the finished product. Isolation of members of the Enterobacteriaceae such as $E$. coli, Klebsiella pneumoniae, Salmonella and Shigella signifies danger to the public health. These organisms are capable of producing endotoxins which trigger high fevers in infected individuals, and the enterotoxins which colonize the small intestines and lead to extreme dehydration as a result of vomiting and diarrhea sometimes with severe and fatal outcomes (Amaeze et al., 2016). From the 16 isolated organisms $E$. coli had the highest isolation rate $6(37.5 \%)$ (Table 3), this suggest faecal contamination of the products. $E$. coli is a common flora in the gastrointestinal tract responsible for diarrhea and extra-intestinal infections (CDC, 2011). The result is in conformity with the findings of Ndahi et al. (2013) and Shamsuddeen (2009). Also presence of campylobacter might be due to cross contamination from raw meat to finished product (Tsire). Staphylococcus aureus is a normal flora of the skin, nasal, genital, mouth or anal area in both humans and animals without any symptom of an infection (Matthew et al., 2013). Isolation of $S$. aureus in these study concords with the findings of Lucretia et al. (2018) from Suya sold in Rivers State. 
BAJOPAS Volume 13 Number 1, June, 2020

It is also in agreement with the findings of Yousafzai et al. (2018); Onuorah et al. (2015) and Tijjani and Jumare (2014) from tsire samples in different countries. Presence of $S$. aureus in foods is most of the time an indication of poor human handling, poor environment, unhygienic utensils and equipments used during processing (Igene et al., 2016; Okonko et al., 2013). Infections caused by $S$. aureus are difficult to treat leading to long hospitalization with consequent economic loss (Udobi et al., 2013). These include soft tissue infections, pneumonia, hospital-acquired postoperative wound infections, Staphylococcal food poisoning, impetigo and cellulitis (Charlene et al., 2013). Samples obtained from Dausai and Kofar Kudu had the highest isolation rate $4(80 \%)$ (Table 4 ) probably because of the much commercial activities taking place in the area which can lead to environmental contamination.

Table 1: Total Aerobic Mesophilic Bacterial Count of Tsire sold in Garko Town

\begin{tabular}{lll}
\hline Sampling Area & APC cfu/g & Mean \pm STD \\
\hline Dausai & $2.20 \times 10^{5}$ & $110000 \pm 14142.14$ \\
Kofar Kudu & $4.00 \times 10^{5}$ & $133333.3 \pm 23094.01$ \\
Makwalla & $1.30 \times 10^{5}$ & $32500 \pm 7187.953$ \\
Rinji & $2.72 \times 10^{5}$ & $90666.67 \pm 94769.90$ \\
Tosaro & $1.02 \times 10^{5}$ & $51000 \pm 15556.35$ \\
Tsohuwar Kasuwa & $1.75 \times 10^{5}$ & $35000 \pm 11357.82$ \\
\hline
\end{tabular}

Key: APC: Aerobic Mesophilic Counts

STD: Standard Deviation

Table 2: Total Coliform Count of Tsire sold in Garko Town

\begin{tabular}{lcc}
\hline \multicolumn{1}{c}{ Sampling Area } & TCC MPN/g & Mean \pm STD \\
\hline Dausai & 20 & $6.67 \pm 2.5166$ \\
Kofar Kudu & 32 & $16.00 \pm 5.6569$ \\
Makwalla & 68 & $13.60 \pm 8.7062$ \\
Rinji & 37 & $9.25 \pm 4.7871$ \\
Tosaro & 10 & $5.00 \pm 2.8284$ \\
Tsohuwar Kasuwa & 8 & $4.00 \pm 0.0000$ \\
\hline
\end{tabular}

Table 3: Organisms Isolated from Tsire Sold in Garko

\begin{tabular}{lcl}
\hline Isolated Organism & Frequency & Percentage (\%) \\
\hline Campylobacter & 2 & 06.66 \\
Escherichia coli & 6 & 20.00 \\
Klebsiella pneumoniae & 2 & 06.66 \\
Salmonella species & 1 & 03.33 \\
Shigella & 3 & 10.00 \\
Staphylococcus aureus & 2 & 06.66 \\
Total & 16 & \\
\hline
\end{tabular}

Table 4: Distribution of Organisms within Sampling Area

\begin{tabular}{lcc}
\hline \multicolumn{1}{c}{ Sampling Area } & No. Isolated & Percentage (\%) \\
\hline Dausai & 4 & 80 \\
Kofar Kudu & 4 & 80 \\
Makwalla & 2 & 40 \\
Rinji & 3 & 60 \\
Tosaro & 2 & 40 \\
Tsohuwar Kasuwa & 1 & 20 \\
Total & 16 & \\
\hline
\end{tabular}

\section{CONCLUSION}

Results indicated $4.00 \times 10^{5} \mathrm{CFU} / \mathrm{g}$ as the highest APCs count; while $68 \mathrm{MPN} / \mathrm{g}$ was the highest TCCs from the 30 samples analyzed. Among the isolates, $E$. coli has the highest isolation rate of $6(20 \%)$. Dausai and Kofar kudu were having the highest bacteria count of $4(80 \%)$, each, indicating higher contamination in those locations. 
BAJOPAS Volume 13 Number 1, June, 2020 RECOMMENDATIONS

The following recommendations are tenable:

1. Hygienic practices at all stages of production should be improved to safe guard the consumers against potential health hazard.

2. Monitoring of microbiological contamination of Tsire during preparations, packaging and marketing is essential to ensure product of good microbiological quality for consumers' health.

\section{REFERENCES}

Abdullahi, I. O., Umoh, V. J. and Galadima, M. (2004). Hazards Associated with Kilishi Preparations in Zaria. Nigerian Journal of Microbiology, 18 (1-2): $339-345$.

Ahmadu, J. and Ibrahim E. J., (2013): Determinants of Revenue in Suya Production in BeninCity, Edo State, Nigeria. Nigerian journal of agriculture, food and environment.9(3):1-5

Amaeze, N. Aboh, M. Itohan, A. Felix, E. Olatunji, T. and Oladosu, P. (2016) Microbial Profile, Antibiotic Sensitivity and Heat Resistance of Bacterial Isolates from Commercial Roasted Beef (Suya) in Abuja, Nigeria. JOPAT, 15(2): $22-30$.

Apata, E.S., Kuku1, I.A., Apata, O.C. and Adeyemi, K.O. (2013). Evaluation of Suya(Tsire) - An Intermediate Moisture Meat Product in Ogun State, Nigeria. J. Food Res 2 (1): 87.

Atlas, R. M. (1997) Principles of Microbiology Second Edition. C. Brown Publishers. Pp 802-803.

Borch, E. Kant-Muermans, M. L., Blixt, Y. (1996) Bacterial Spoilage of Meat and Cured Meat Products. Int $\mathrm{J}$ Food Microbiol .33(1): 103-20.

Centre for Disease Control, CDC (2011). "Escherichia coli 0157:H7" Division of Bacterial and Mycotic Diseasesht://www.cdc.gov/nczved/divisi ons/dfbmd/diseases/ecoli_0157h7/.

Charlene, R. J., Johnnie, A. D., and John, B. B., (2013) Prevalence and Characterization of Methicillin-Resistant Staphylococcus aureus Isolates from Retail Meat and Humans in Georgia. American society for Microbiology. J. of clinical microbiology. 12(1):123-6 doi:10.1128/JCM.0316612JCM.03166-12

Egbebi, A.O and Seidu, K., T. (2011). Microbiological Evaluation of Suya (dried smoked

meat) Sold in Ado and Akure, South West Nigeria.European Journal of Experinmental Biology, 1(4):1-5
3. Government should establish regulatory bodies responsible for inculcating hygiene habits to the local producers and vendors in order to prevent instant, cross and post processing contaminations by microbial pathogens.

4. Awareness and sensitization of local food producers about good hygienic practices in food handling and processing.

Falegan, C, R., Akoja, S. D., and Oyarekua, M. A., (2017) Microbiological Assessment of Suya (Sliced Roasted Beef) in Ado-Ekiti Metropolis, Ekiti State, Nigeria. MOJ Biology andMedicine.

Fonkem, D., N. Tanya, V., N. and Ebangi, A., L. (2010). Effect of Season on the Microbiological Quality of Kilishi, a Traditional Cameroonian Dried Beef Product. Tropicultura, 28(1): 10-15.

Food and Agricultural Organization of the United Nations (F A O, 1979). Manual of food quality control 4. Microbiological analysis.

Food and Agriculture Organisation of the United Nation (FAO), 2019. Nigeria at a glance.

Igene J.O., Uwadia, O.E., Ebabhamiegbebho, P.A. and Evivie, S.E., (2016) Shelf life Stability Studies of University of Benin (UNIBEN) Proff's Kilishi Product Asian Journal of Science and Technology 7(1): 2268-2274.

Inusa, S. K. and Said, I. S. (2017) Evaluation of the Chemical and Microbiological Properties Of Kilishi Sold in Kano Metropolis. Journal of Dry land Agriculture, 3 (1): $59-69$.

Lucretia, I. B, Patience, C. Obinna-Echem, Sophia, C. A. (2018) Microbiological quality andantibiotic sensitivity of potential pathogens isolated from meat product (Suya) sold in Rivers State University and its environs. International Journal of Biotechnology and Food Science, 6(4): 67-76.

Matthew, E., Drosos, E., John, L. and Ioanna, P. (2013) MRSA in Africa: Filling the Global Map of Antimicrobial Resistance PLOS One. 8(7): e68024 doi: 10.1371/journal.pone.0068024

Mgbemere, V.N., Akpapunam, M. A. and Igene, J. O., (2011). Effect of Groundnut FlourSubstitution on Yield, Quality and Storage Stability of Kilishi - a Nigerian Indigenous Dried Meat Product. African Journal of Food, Agriculture, Nutrition and Development, $\quad \mathbf{1 1}(2)$ : 4718-4738. 
BAJOPAS Volume 13 Number 1, June, 2020

Mubarak, A. A., Azeez, M. L., Amos A. O., Opeyemi, O. O. (2016) Assessment of Animal Protein Consumption and Food Security Among Rural Households in Kwara State, Nigeria American Journal of Business and Society, 1(4): 233245.

Ndahi, M., D. Kwaga, J., K. P. Bello, M. Kabir J., V. Umoh, .J. Yakubu, S., E. and Nok, A., J. (2013) Prevalence and Antimicrobial Susceptibility of Listeria Monocytogenes and Methicillin-Resistant Staphylococcus aureus Strains from Raw Meat and Meat Products in Zaria, Nigeria. Applied Journal of Microbiology, 58(3):262-9.

Okonko, I.O., Odu, N.N. and Igboh, I.E. (2013). Microbiological Analysis of Kilishi Sold In Port Harcourt, Nigeria. New York Science Journal, 6 (7):37-43.

Osimani, A., Aquilanti, L. and Clementi, F. (2015) Microbiological Quality of Meatbased Meals and Operation of Control Systems within a Food Service Environment. International Food Research Journal 22(4): 1692-1698.

Onuorah, S. Obika, I. Odibo, F. Orji, M. (2015)An Assessment of the Bacteriological Quality of Tsire-Suya (Grilled Beef) sold in Awka, Nigeria. American. J. Life. Sci. Res. 3(4):287292.

Razavilar, V, Khandaghi, J. Barzgari, A. (2010); Isolation of Eschericia coli 0157:H7 from manure fertilized farms and raw vegetables grown on it, in Tabriz city in
Iran. African Journal of Microbiology Research, 4(9): 891-895.

Scallan, E. Hoekstra, R. M. Angulo, F. J.Tauxe, R. V, Widdowson, M. Roy, S. L et al., (2011).Food borne illness acquired in the United States- Major Pathogens. Emerg. Infec Dis, 17(1): 7-15.

Shamsuddeen U (2009). Microbiological quality of spice used in the production of Kilishi a traditionally dried and grilled meat product. Bayero Journal of Pure andApplied Sciences, 2(2): 66-69.

Shamsuddeen, U. (2015) Microbiological Hazard and Critical control point Analysis of Dried and Minced Meat Snacks Produced in Kano Nigeria. Lambert Academic Publishing; Pp 1-36.

Tijani, O.and Jumare, S. (2014). Microblological Quality Assessment of Meat

Sold in KauraNamoda. International Conference on Earth, Environment and Life sciences (EELS) Dubai (UAE).

Udobi, C. E., Obajuluwa, A. F., and Onaolapo, J. A., (2013) Prevalence and Antibiotic Resistance Pattern of MethicillinResistant Staphylococcus aureus from an Orthopaedic Hospital in Nigeria BioMed Research International; 26(6); 6-7.

WHO, 2015 Foodborne diseases in the WHO African Region.

Yousafzai HA, Rind R, Khan MA, Abro SH, Korejo NA, Ejaz M, Kabir A, Shahid M, Memon S. (2019). Microbiological Contamination of Cattle and Meat in Peshawar, Pakistan. J. Anim. Health Prod. 7(1): 1116. 


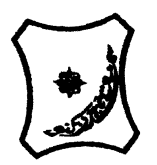

Bayero Journal of Pure and Applied Sciences, 13(1); 40 - 45

Received: September, 2019

Accepted: April, 2020

ISSN $2006-6996$

\title{
BACTERIOLOGICAL QUALITY OF STICK MEAT (Tsire) SOLD IN GARKO LOCAL GOVERNMENT AREA OF KANO STATE, NIGERIA
}

\author{
$*^{1}$ Dahiru A. T. and ${ }^{2}$ Maigari A. K. \\ ${ }^{1}$ Department of Hospitality Management, School of Technology, Kano State Polytechnic, PMB 3348, \\ Kano Nigeria. \\ ${ }^{2}$ Departmnt of Biological Sciences, Bayero University, Kano \\ Corresponding Author: dturajo61@gmail.com; GSM: 08087508262.
}

ABSTRACT

Stick meat, locally called Tsire in Hausa Language, is a significant portion of the diet of a large active population of Northern Nigeria. However, because of the handling and processing methods by the manufacturers as well as the hawking system of stick meat, the meat product may be exposed to both pre- and post-processed product contamination, and thus may poses danger to public health. Therefore, considering the role of Tsire in improving nutrition and increase household income to the populace, the need to improve the processing, distribution and overall quality of the product is simply indispensable. A total of 30 samples (5 samples from each of the 6 sampling points) of Tsire were collected randomly in Garko Town. Aerobic plate counts (APCs) and Total coliform counts (TCCS) of Tsire samples were determined using standard microbiological methods. APCs ranged from $1.02 \times 10^{5}$ to $4.00 \times 10^{5} \mathrm{CFU} / \mathrm{g}$; while TCCs ranged from $8 \mathrm{MPN} / \mathrm{g}$ to $68 \mathrm{MPN} / \mathrm{g}$. From the 30 samples screened, 16(53.33\%) bacteria namely, Campylobacter 2(6.66\%), Escherichia coli 6(20\%), Klebsiella pneumoniae 2(6.66\%), Salmonella spp. 1(3.33\%), Shigella 3(10\%) and Staphylococcus aureus 2(6.66\%) were detected. $E$. coli has the highest isolation rate of 6(20\%), while Salmonella spp. had the least frequency of 1(3.33\%). The distribution of isolated organisms within the study area were as follows: Dausai, 4(80\%), Kofar kudu, 4(80\%), Makwalla, 2(40\%), Rinji, 3(60\%), Tosaro, 2(40\%), and Tsohuwar Kasuwa, 1(20\%). The results have indicated that the Tsire was contaminated with bacteria thus exposing the product to fast deterioration, spoilage and also a vehicle for food borne illness, suggesting for adequate hygienic practices at all the stages, prior to consumption, to ensure safety of the meat product.

Key words: APCs, TCCs, Contamination, Microorganisms, Garko

\section{INTRODUCTION}

Nigeria is one of the developing nations with inadequate food supply and most often deficient in protein content (FAO, 2019). Nigerian's average animal protein intake per head per day is estimated at $7.9 \mathrm{~g}$ as against $35 \mathrm{~g}$ recommended value by Food and Agricultural Organization (Mubarak et al., 2016). These low levels of animal protein intake create great concern as it affects the nutritional status of Nigerians. Hence, there is the need for sufficient supply of animal protein from energy rich animal products to satisfy the nutritional requirements for Nigerians.

Meat is one major source of animal protein largely composed of water, protein and fats which can make it susceptible to microbial contamination within short time leading to spoilage (Apata et al., 2013; Mgbemere et al., 2011). Meat is mostly eaten after it has been cooked or processed in a variety of ways such as sun drying; smoking and roasting with or without fortifications (Borch et al., 1996). In Nigeria meat products such as Tsire, Kilishi and Balangu are locally produced using one or more of these methods in order to meet the nutritional requirements of the teeming Nigerians (Egbebi, 2011).

Tsire is a popular Nigerian traditional processed ready-to-eat roasted stick meat product (Shamsuddeen, 2015). It is sold in public places, along roads, in hotels, parks, quarters and even offices (Falegan et al., 2017). It is prepared from boneless healthy animal flesh such as beef and mutton, spiced with peanut cake, salt, vegetable oil and other flavorings followed by roasting (Shamsuddeen, 2015). Consumption of these products has extended to other parts of African countries such as Ghana, Somali, Cameroun and Chad (Ahmadu and Ibrahim, 2013). 
BAJOPAS Volume 13 Number 1, June, 2020

However, evidence of quality control sticking to procedural hygiene by the handlers during preparation and retailing of these products is poorly documented. Tsire is of great safety risk because of the fact that there are erratic cases of gastroenteritis and symptoms of food infection after consumption (WHO, 2015). Food borne illnesses are one of the major health problems in developing and developed countries (Razavilar, 2010). According to the World Health Organization, WHO (2015), $0.07 \%$ death of the 600 million global burdens of Foodborne illnesses have been reported to be caused by bacteria, viruses, fungi and chemicals. In America $0.27 \%$ of the estimated 48 million affected people is hospitalized and about $0.0063 \%$ deaths are recorded each year (Scallan et al., 2011). More than 91 million people in Africa fall ill and $0.15 \%$ dies each year, making Africa the highest burden bearer of Foodborne diseases per population (WHO, 2015).

Application of a Hazard Analysis Critical Control Point (HACCP) at all stages of meat products preparation is essential in order to ensure its safety. Thus, according to the guidelines of good manufacturing practice, the level of total aerobic bacterial contamination of thermally processed meat products should not exceed $10^{4}\left(\mathrm{cfu} \mathrm{g}^{-1}\right)$. Enterobacteriaceae and faecal coliform contamination in meat products should be within the range of $10^{2}-10^{4}$ and $10-10^{3} \mathrm{cfu} \mathrm{g}^{-1}$, respectively (Shamsuddeen, 2015). The aim of the study is therefore, to assess the total viable bacterial counts of tsire marketed locally within Garko town, and to isolate and identify the organisms at the point of consumption with the intention of promoting public health and food hygiene habits in the Nigerian populace.

\section{MATERIALS AND METHODS Study Area and Population}

Garko is one of the existing 44 local government areas located in Kano south west zone of Kano state with its capital administrative headquarters in the Garko town. It has coordinates $11^{\circ} 39^{\prime} \mathrm{N}$ $8^{\circ} 54^{\prime} \mathrm{E}$, and an area of $450 \mathrm{~km}^{2}$. The projected population of Garko local Government was 225,300 according to the National Population Census report (2018). Garko is known for agricultural activities both farming and animal husbandry. It is popularly known for large scale rice production. Other food crops include sweet potatoes, cassava, onions, sorghum, millet and sugarcane. Cows, sheep and goats are major groups of animals reared by majority of the populace. Meat products processed, retailed and consumed in Garko include roasted meat (Balangu), dried roasted meat (Kilishi), stick meat (Tsire), hide and skin pepper soup (Ragadada) and minced fried meat (Danbunnama).

\section{Samples Collection}

Five samples of Tsire products were collected from 6 different identified locations within Garko town in a sterile foil paper and immediately analyzed for the presence of bacteria.

\section{Sample Preparation}

Sample preparation for the bacteriological analysis was carried out in accordance with the method described by Atlas (1997). Twenty five grams $(25 \mathrm{~g})$ of the sample was homogenized in $225 \mathrm{ml}$ peptone water using Kenwood blender machine to obtain a $10^{1}$ homogenate. The homogenate was thoroughly shaken and $1 \mathrm{ml}$ pipetted into test tubes containing $9 \mathrm{ml}$ of peptone water $\left(10^{2}\right)$. The test tubes were further serially diluted to $10^{5}$.

Total Aerobic Mesophilic Bacterial Count

Total Aerobic mesophilic bacterial count was determined using the method described by Abdullahi et al. (2004) where $1 \mathrm{ml}$ of inoculums from $10^{1}$ to $10^{5}$ dilutions were transferred into duplicate Petri dishes and labeled accordingly. This was followed by pouring aseptically about $15 \mathrm{ml}$ of molten nutrient agar. The culture was homogenized by gentle spinning of the plates and allowed to solidify. The plates were incubated at $37^{\circ} \mathrm{C}$ for 24 hours. Plates containing 30-300 colonies were counted. The number of colony forming units per gram of a sample (cfu/g) was obtained by multiplying the average colony number with the inverse of the dilution factor.

\section{Enumeration and Detection of Coliform bacteria}

Detection and enumeration of coliform was carried out according to method described by Atlas, (1977). A set of 9 test tubes each containing $9 \mathrm{ml}$ of lactose broth and an inverted Durham tubes were autoclaved to expel air and to sterilize. Similarly, $1 \mathrm{ml}$ from the diluents $10^{1}$ was transferred to the first 3 test tubes, followed by $1 \mathrm{ml}$ from the diluents $10^{2}$ to the second set of 3 test tubes and finally the third diluents $10^{3}$ to the $3^{\text {rd }}$ set of 3 test tubes. All the 9 test tubes were incubated at $37^{\circ} \mathrm{C}$ for 24 hours. Tubes that showed gas and acid production after 24 hours were recorded as positive for the presence of Coliform. Negative tubes were further reincubated for 24 hours. Positive tubes were recorded. Estimate of most probable number of Coliform per gram of sample (MPN/g) was determined by comparing the number of gas positive tubes with the most probable number table. 
BAJOPAS Volume 13 Number 1, June, 2020 Identification of Coliform

A loop full of inoculum from gas positive tubes was streaked on to Eosine methylene blue (EMB) agar plate and incubated at $37^{\circ} \mathrm{C}$ for $24 \mathrm{hrs}$. Colonies which formed bluish black color with green metallic sheen, and reddish colonies were isolated on agar slants. Those colonies showing metallic sheen on EMB were sub cultured into tubes of lactose broth and incubated at $45^{\circ} \mathrm{C}$. The tubes were observed after $24 \mathrm{hrs}$ for gas production. This is the completed test for fecal coliform. Gram stain and other biochemical tests such as Indole, Methyl red, Voges-Proskauer and Citrate Utilization tests (IMVIC), Coagulase and Catalase tests were carried out for the Identification and confirmation of isolates.

\section{Procedure for Indole Test}

Indole test was carried out by preparing a Tryptone broth drawn in to test tubes, sterilized by autoclaving, inoculated with loopful of suspension and incubated at $37^{\circ} \mathrm{C}$ for 24 hours. Three drops of xylene was added in tubes, shaken vigorously and kept for the separation of two layers. One millilitre of Kovac's reagent was added and the formation of pink colour ring indicates positive Indole test.

\section{Procedure for Methyl Red Test}

Methyl red test was carried out by preparing Glucose phosphate broth, dispensed in test tubes, sterilized, inoculated with test culture and incubated at $37^{\circ} \mathrm{C}$ for 24 hours. Five drops of methyl-red indicator was added to the medium for the formation of red colour.

\section{Procedure for Voges-Proskauer Test}

Voges-Proskauer test was carried out by inoculating tubes with the bacterial culture followed by incubation for 48 hours at $37^{\circ} \mathrm{C}$. Separate pipettes were used to pipette $1 \mathrm{ml}$ from each culture tube into clean separate tubes. Eighteen drops $(0.5 \mathrm{ml})$ of Barrit's solution A (a-naphthol) was added to each tube containing glucose phosphate broth followed by the addition of an equal amount of solution $B$ into the same tube. The tubes were shaken at 30 seconds interval. A positive reaction was indicated by the development of a pink color, which turns red in 1-2 hours, after vigorous shaking.

\section{Procedure for Citrate Utilization Test}

Citrate Utilization Test was carried out by distributing melted agar (Simmon Citrate Agar) in to test tubes followed by sterilization at $121.5^{\circ} \mathrm{C}$ for 15 minutes. The test tubes were afterward held in slanted position, inoculated with the given bacterial culture and incubated at $37^{\circ} \mathrm{C}$ for $24 \mathrm{hrs}$. Positive test was indicated by color change of the media from green to blue.

\section{RESULTS AND DISCUSSIONS}

The results of this study are presented in tables $1,2,3$ and 4. Among the sampling areas Kofar Kudu had the highest aerobic mesophilic bacteria counts $4.0 \times 10^{5} \mathrm{cfu} / \mathrm{g}$ followed by Rinji $2.72 \times 10^{5} \mathrm{cfu} / \mathrm{g}$, while Tosaro had the least Aerobic mesophilic bacteria counts of $1.02 \times 10^{5}$ $\mathrm{cfu} / \mathrm{g}$ as indicated in Table 1.Makwalla had the highest coliform count $68 \mathrm{MPN} / \mathrm{g}$ followed by Rinji $37 \mathrm{MPN} / \mathrm{g}$. Tsohuwar Kasuwa had the least coliform counts $8 \mathrm{MPN} / \mathrm{g}$, (Table 2). Result from table 1 shows variation in the microbial contents among the samples which suggest variation in their sources, poor handling procedures and contamination from the processing environment. High coliform count and their differences within sampling areas is an indication of poor microbiological quality of the product. Ndahi et al. (2013) reported microbial load to be a function of the handling personnel and the environment. The results indicated that the samples were contaminated with bacteria as the counts exceeded the minimum safety level $\left(10^{4} \mathrm{cfu} / \mathrm{g}\right)$ for members of the Enterobacteriaceae family. However, it might be a reflection of poor hygienic practices which may contribute to health hazard to the potential consumers. Similarly, Inusa and Sa'id (2017); Osimani et al. (2015) reported that, the initial microbial content of the raw material play significant role in influencing the final microbial load of the finished product. Isolation of members of the Enterobacteriaceae such as $E$. coli, Klebsiella pneumoniae, Salmonella and Shigella signifies danger to the public health. These organisms are capable of producing endotoxins which trigger high fevers in infected individuals, and the enterotoxins which colonize the small intestines and lead to extreme dehydration as a result of vomiting and diarrhea sometimes with severe and fatal outcomes (Amaeze et al., 2016). From the 16 isolated organisms $E$. coli had the highest isolation rate $6(37.5 \%)$ (Table 3), this suggest faecal contamination of the products. $E$. coli is a common flora in the gastrointestinal tract responsible for diarrhea and extra-intestinal infections (CDC, 2011). The result is in conformity with the findings of Ndahi et al. (2013) and Shamsuddeen (2009). Also presence of campylobacter might be due to cross contamination from raw meat to finished product (Tsire). Staphylococcus aureus is a normal flora of the skin, nasal, genital, mouth or anal area in both humans and animals without any symptom of an infection (Matthew et al., 2013). Isolation of $S$. aureus in these study concords with the findings of Lucretia et al. (2018) from Suya sold in Rivers State. 
BAJOPAS Volume 13 Number 1, June, 2020

It is also in agreement with the findings of Yousafzai et al. (2018); Onuorah et al. (2015) and Tijjani and Jumare (2014) from tsire samples in different countries. Presence of $S$. aureus in foods is most of the time an indication of poor human handling, poor environment, unhygienic utensils and equipments used during processing (Igene et al., 2016; Okonko et al., 2013). Infections caused by $S$. aureus are difficult to treat leading to long hospitalization with consequent economic loss (Udobi et al., 2013). These include soft tissue infections, pneumonia, hospital-acquired postoperative wound infections, Staphylococcal food poisoning, impetigo and cellulitis (Charlene et al., 2013). Samples obtained from Dausai and Kofar Kudu had the highest isolation rate $4(80 \%)$ (Table 4 ) probably because of the much commercial activities taking place in the area which can lead to environmental contamination.

Table 1: Total Aerobic Mesophilic Bacterial Count of Tsire sold in Garko Town

\begin{tabular}{lll}
\hline Sampling Area & APC cfu/g & Mean \pm STD \\
\hline Dausai & $2.20 \times 10^{5}$ & $110000 \pm 14142.14$ \\
Kofar Kudu & $4.00 \times 10^{5}$ & $133333.3 \pm 23094.01$ \\
Makwalla & $1.30 \times 10^{5}$ & $32500 \pm 7187.953$ \\
Rinji & $2.72 \times 10^{5}$ & $90666.67 \pm 94769.90$ \\
Tosaro & $1.02 \times 10^{5}$ & $51000 \pm 15556.35$ \\
Tsohuwar Kasuwa & $1.75 \times 10^{5}$ & $35000 \pm 11357.82$ \\
\hline
\end{tabular}

Key: APC: Aerobic Mesophilic Counts

STD: Standard Deviation

Table 2: Total Coliform Count of Tsire sold in Garko Town

\begin{tabular}{lcc}
\hline \multicolumn{1}{c}{ Sampling Area } & TCC MPN/g & Mean \pm STD \\
\hline Dausai & 20 & $6.67 \pm 2.5166$ \\
Kofar Kudu & 32 & $16.00 \pm 5.6569$ \\
Makwalla & 68 & $13.60 \pm 8.7062$ \\
Rinji & 37 & $9.25 \pm 4.7871$ \\
Tosaro & 10 & $5.00 \pm 2.8284$ \\
Tsohuwar Kasuwa & 8 & $4.00 \pm 0.0000$ \\
\hline
\end{tabular}

Table 3: Organisms Isolated from Tsire Sold in Garko

\begin{tabular}{lcl}
\hline Isolated Organism & Frequency & Percentage (\%) \\
\hline Campylobacter & 2 & 06.66 \\
Escherichia coli & 6 & 20.00 \\
Klebsiella pneumoniae & 2 & 06.66 \\
Salmonella species & 1 & 03.33 \\
Shigella & 3 & 10.00 \\
Staphylococcus aureus & 2 & 06.66 \\
Total & 16 & \\
\hline
\end{tabular}

Table 4: Distribution of Organisms within Sampling Area

\begin{tabular}{lcc}
\hline \multicolumn{1}{c}{ Sampling Area } & No. Isolated & Percentage (\%) \\
\hline Dausai & 4 & 80 \\
Kofar Kudu & 4 & 80 \\
Makwalla & 2 & 40 \\
Rinji & 3 & 60 \\
Tosaro & 2 & 40 \\
Tsohuwar Kasuwa & 1 & 20 \\
Total & 16 & \\
\hline
\end{tabular}

\section{CONCLUSION}

Results indicated $4.00 \times 10^{5} \mathrm{CFU} / \mathrm{g}$ as the highest APCs count; while $68 \mathrm{MPN} / \mathrm{g}$ was the highest TCCs from the 30 samples analyzed. Among the isolates, $E$. coli has the highest isolation rate of $6(20 \%)$. Dausai and Kofar kudu were having the highest bacteria count of $4(80 \%)$, each, indicating higher contamination in those locations. 
BAJOPAS Volume 13 Number 1, June, 2020 RECOMMENDATIONS

The following recommendations are tenable:

1. Hygienic practices at all stages of production should be improved to safe guard the consumers against potential health hazard.

2. Monitoring of microbiological contamination of Tsire during preparations, packaging and marketing is essential to ensure product of good microbiological quality for consumers' health.

\section{REFERENCES}

Abdullahi, I. O., Umoh, V. J. and Galadima, M. (2004). Hazards Associated with Kilishi Preparations in Zaria. Nigerian Journal of Microbiology, 18 (1-2): $339-345$.

Ahmadu, J. and Ibrahim E. J., (2013): Determinants of Revenue in Suya Production in BeninCity, Edo State, Nigeria. Nigerian journal of agriculture, food and environment.9(3):1-5

Amaeze, N. Aboh, M. Itohan, A. Felix, E. Olatunji, T. and Oladosu, P. (2016) Microbial Profile, Antibiotic Sensitivity and Heat Resistance of Bacterial Isolates from Commercial Roasted Beef (Suya) in Abuja, Nigeria. JOPAT, 15(2): $22-30$.

Apata, E.S., Kuku1, I.A., Apata, O.C. and Adeyemi, K.O. (2013). Evaluation of Suya(Tsire) - An Intermediate Moisture Meat Product in Ogun State, Nigeria. J. Food Res 2 (1): 87.

Atlas, R. M. (1997) Principles of Microbiology Second Edition. C. Brown Publishers. Pp 802-803.

Borch, E. Kant-Muermans, M. L., Blixt, Y. (1996) Bacterial Spoilage of Meat and Cured Meat Products. Int $\mathrm{J}$ Food Microbiol .33(1): 103-20.

Centre for Disease Control, CDC (2011). "Escherichia coli 0157:H7" Division of Bacterial and Mycotic Diseasesht://www.cdc.gov/nczved/divisi ons/dfbmd/diseases/ecoli_0157h7/.

Charlene, R. J., Johnnie, A. D., and John, B. B., (2013) Prevalence and Characterization of Methicillin-Resistant Staphylococcus aureus Isolates from Retail Meat and Humans in Georgia. American society for Microbiology. J. of clinical microbiology. 12(1):123-6 doi:10.1128/JCM.0316612JCM.03166-12

Egbebi, A.O and Seidu, K., T. (2011). Microbiological Evaluation of Suya (dried smoked

meat) Sold in Ado and Akure, South West Nigeria.European Journal of Experinmental Biology, 1(4):1-5
3. Government should establish regulatory bodies responsible for inculcating hygiene habits to the local producers and vendors in order to prevent instant, cross and post processing contaminations by microbial pathogens.

4. Awareness and sensitization of local food producers about good hygienic practices in food handling and processing.

Falegan, C, R., Akoja, S. D., and Oyarekua, M. A., (2017) Microbiological Assessment of Suya (Sliced Roasted Beef) in Ado-Ekiti Metropolis, Ekiti State, Nigeria. MOJ Biology andMedicine.

Fonkem, D., N. Tanya, V., N. and Ebangi, A., L. (2010). Effect of Season on the Microbiological Quality of Kilishi, a Traditional Cameroonian Dried Beef Product. Tropicultura, 28(1): 10-15.

Food and Agricultural Organization of the United Nations (F A O, 1979). Manual of food quality control 4. Microbiological analysis.

Food and Agriculture Organisation of the United Nation (FAO), 2019. Nigeria at a glance.

Igene J.O., Uwadia, O.E., Ebabhamiegbebho, P.A. and Evivie, S.E., (2016) Shelf life Stability Studies of University of Benin (UNIBEN) Proff's Kilishi Product Asian Journal of Science and Technology 7(1): 2268-2274.

Inusa, S. K. and Said, I. S. (2017) Evaluation of the Chemical and Microbiological Properties Of Kilishi Sold in Kano Metropolis. Journal of Dry land Agriculture, 3 (1): $59-69$.

Lucretia, I. B, Patience, C. Obinna-Echem, Sophia, C. A. (2018) Microbiological quality andantibiotic sensitivity of potential pathogens isolated from meat product (Suya) sold in Rivers State University and its environs. International Journal of Biotechnology and Food Science, 6(4): 67-76.

Matthew, E., Drosos, E., John, L. and Ioanna, P. (2013) MRSA in Africa: Filling the Global Map of Antimicrobial Resistance PLOS One. 8(7): e68024 doi: 10.1371/journal.pone.0068024

Mgbemere, V.N., Akpapunam, M. A. and Igene, J. O., (2011). Effect of Groundnut FlourSubstitution on Yield, Quality and Storage Stability of Kilishi - a Nigerian Indigenous Dried Meat Product. African Journal of Food, Agriculture, Nutrition and Development, $\quad \mathbf{1 1}(2)$ : 4718-4738. 
BAJOPAS Volume 13 Number 1, June, 2020

Mubarak, A. A., Azeez, M. L., Amos A. O., Opeyemi, O. O. (2016) Assessment of Animal Protein Consumption and Food Security Among Rural Households in Kwara State, Nigeria American Journal of Business and Society, 1(4): 233245.

Ndahi, M., D. Kwaga, J., K. P. Bello, M. Kabir J., V. Umoh, .J. Yakubu, S., E. and Nok, A., J. (2013) Prevalence and Antimicrobial Susceptibility of Listeria Monocytogenes and Methicillin-Resistant Staphylococcus aureus Strains from Raw Meat and Meat Products in Zaria, Nigeria. Applied Journal of Microbiology, 58(3):262-9.

Okonko, I.O., Odu, N.N. and Igboh, I.E. (2013). Microbiological Analysis of Kilishi Sold In Port Harcourt, Nigeria. New York Science Journal, 6 (7):37-43.

Osimani, A., Aquilanti, L. and Clementi, F. (2015) Microbiological Quality of Meatbased Meals and Operation of Control Systems within a Food Service Environment. International Food Research Journal 22(4): 1692-1698.

Onuorah, S. Obika, I. Odibo, F. Orji, M. (2015)An Assessment of the Bacteriological Quality of Tsire-Suya (Grilled Beef) sold in Awka, Nigeria. American. J. Life. Sci. Res. 3(4):287292.

Razavilar, V, Khandaghi, J. Barzgari, A. (2010); Isolation of Eschericia coli 0157:H7 from manure fertilized farms and raw vegetables grown on it, in Tabriz city in
Iran. African Journal of Microbiology Research, 4(9): 891-895.

Scallan, E. Hoekstra, R. M. Angulo, F. J.Tauxe, R. V, Widdowson, M. Roy, S. L et al., (2011).Food borne illness acquired in the United States- Major Pathogens. Emerg. Infec Dis, 17(1): 7-15.

Shamsuddeen U (2009). Microbiological quality of spice used in the production of Kilishi a traditionally dried and grilled meat product. Bayero Journal of Pure andApplied Sciences, 2(2): 66-69.

Shamsuddeen, U. (2015) Microbiological Hazard and Critical control point Analysis of Dried and Minced Meat Snacks Produced in Kano Nigeria. Lambert Academic Publishing; Pp 1-36.

Tijani, O.and Jumare, S. (2014). Microblological Quality Assessment of Meat

Sold in KauraNamoda. International Conference on Earth, Environment and Life sciences (EELS) Dubai (UAE).

Udobi, C. E., Obajuluwa, A. F., and Onaolapo, J. A., (2013) Prevalence and Antibiotic Resistance Pattern of MethicillinResistant Staphylococcus aureus from an Orthopaedic Hospital in Nigeria BioMed Research International; 26(6); 6-7.

WHO, 2015 Foodborne diseases in the WHO African Region.

Yousafzai HA, Rind R, Khan MA, Abro SH, Korejo NA, Ejaz M, Kabir A, Shahid M, Memon S. (2019). Microbiological Contamination of Cattle and Meat in Peshawar, Pakistan. J. Anim. Health Prod. 7(1): 1116. 


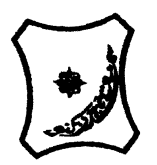

Bayero Journal of Pure and Applied Sciences, 13(1); 40 - 45

Received: September, 2019

Accepted: April, 2020

ISSN $2006-6996$

\title{
BACTERIOLOGICAL QUALITY OF STICK MEAT (Tsire) SOLD IN GARKO LOCAL GOVERNMENT AREA OF KANO STATE, NIGERIA
}

\author{
$*^{1}$ Dahiru A. T. and ${ }^{2}$ Maigari A. K. \\ ${ }^{1}$ Department of Hospitality Management, School of Technology, Kano State Polytechnic, PMB 3348, \\ Kano Nigeria. \\ ${ }^{2}$ Departmnt of Biological Sciences, Bayero University, Kano \\ Corresponding Author: dturajo61@gmail.com; GSM: 08087508262.
}

ABSTRACT

Stick meat, locally called Tsire in Hausa Language, is a significant portion of the diet of a large active population of Northern Nigeria. However, because of the handling and processing methods by the manufacturers as well as the hawking system of stick meat, the meat product may be exposed to both pre- and post-processed product contamination, and thus may poses danger to public health. Therefore, considering the role of Tsire in improving nutrition and increase household income to the populace, the need to improve the processing, distribution and overall quality of the product is simply indispensable. A total of 30 samples (5 samples from each of the 6 sampling points) of Tsire were collected randomly in Garko Town. Aerobic plate counts (APCs) and Total coliform counts (TCCS) of Tsire samples were determined using standard microbiological methods. APCs ranged from $1.02 \times 10^{5}$ to $4.00 \times 10^{5} \mathrm{CFU} / \mathrm{g}$; while TCCs ranged from $8 \mathrm{MPN} / \mathrm{g}$ to $68 \mathrm{MPN} / \mathrm{g}$. From the 30 samples screened, 16(53.33\%) bacteria namely, Campylobacter 2(6.66\%), Escherichia coli 6(20\%), Klebsiella pneumoniae 2(6.66\%), Salmonella spp. 1(3.33\%), Shigella 3(10\%) and Staphylococcus aureus 2(6.66\%) were detected. $E$. coli has the highest isolation rate of 6(20\%), while Salmonella spp. had the least frequency of 1(3.33\%). The distribution of isolated organisms within the study area were as follows: Dausai, 4(80\%), Kofar kudu, 4(80\%), Makwalla, 2(40\%), Rinji, 3(60\%), Tosaro, 2(40\%), and Tsohuwar Kasuwa, 1(20\%). The results have indicated that the Tsire was contaminated with bacteria thus exposing the product to fast deterioration, spoilage and also a vehicle for food borne illness, suggesting for adequate hygienic practices at all the stages, prior to consumption, to ensure safety of the meat product.

Key words: APCs, TCCs, Contamination, Microorganisms, Garko

\section{INTRODUCTION}

Nigeria is one of the developing nations with inadequate food supply and most often deficient in protein content (FAO, 2019). Nigerian's average animal protein intake per head per day is estimated at $7.9 \mathrm{~g}$ as against $35 \mathrm{~g}$ recommended value by Food and Agricultural Organization (Mubarak et al., 2016). These low levels of animal protein intake create great concern as it affects the nutritional status of Nigerians. Hence, there is the need for sufficient supply of animal protein from energy rich animal products to satisfy the nutritional requirements for Nigerians.

Meat is one major source of animal protein largely composed of water, protein and fats which can make it susceptible to microbial contamination within short time leading to spoilage (Apata et al., 2013; Mgbemere et al., 2011). Meat is mostly eaten after it has been cooked or processed in a variety of ways such as sun drying; smoking and roasting with or without fortifications (Borch et al., 1996). In Nigeria meat products such as Tsire, Kilishi and Balangu are locally produced using one or more of these methods in order to meet the nutritional requirements of the teeming Nigerians (Egbebi, 2011).

Tsire is a popular Nigerian traditional processed ready-to-eat roasted stick meat product (Shamsuddeen, 2015). It is sold in public places, along roads, in hotels, parks, quarters and even offices (Falegan et al., 2017). It is prepared from boneless healthy animal flesh such as beef and mutton, spiced with peanut cake, salt, vegetable oil and other flavorings followed by roasting (Shamsuddeen, 2015). Consumption of these products has extended to other parts of African countries such as Ghana, Somali, Cameroun and Chad (Ahmadu and Ibrahim, 2013). 
BAJOPAS Volume 13 Number 1, June, 2020

However, evidence of quality control sticking to procedural hygiene by the handlers during preparation and retailing of these products is poorly documented. Tsire is of great safety risk because of the fact that there are erratic cases of gastroenteritis and symptoms of food infection after consumption (WHO, 2015). Food borne illnesses are one of the major health problems in developing and developed countries (Razavilar, 2010). According to the World Health Organization, WHO (2015), $0.07 \%$ death of the 600 million global burdens of Foodborne illnesses have been reported to be caused by bacteria, viruses, fungi and chemicals. In America $0.27 \%$ of the estimated 48 million affected people is hospitalized and about $0.0063 \%$ deaths are recorded each year (Scallan et al., 2011). More than 91 million people in Africa fall ill and $0.15 \%$ dies each year, making Africa the highest burden bearer of Foodborne diseases per population (WHO, 2015).

Application of a Hazard Analysis Critical Control Point (HACCP) at all stages of meat products preparation is essential in order to ensure its safety. Thus, according to the guidelines of good manufacturing practice, the level of total aerobic bacterial contamination of thermally processed meat products should not exceed $10^{4}\left(\mathrm{cfu} \mathrm{g}^{-1}\right)$. Enterobacteriaceae and faecal coliform contamination in meat products should be within the range of $10^{2}-10^{4}$ and $10-10^{3} \mathrm{cfu} \mathrm{g}^{-1}$, respectively (Shamsuddeen, 2015). The aim of the study is therefore, to assess the total viable bacterial counts of tsire marketed locally within Garko town, and to isolate and identify the organisms at the point of consumption with the intention of promoting public health and food hygiene habits in the Nigerian populace.

\section{MATERIALS AND METHODS Study Area and Population}

Garko is one of the existing 44 local government areas located in Kano south west zone of Kano state with its capital administrative headquarters in the Garko town. It has coordinates $11^{\circ} 39^{\prime} \mathrm{N}$ $8^{\circ} 54^{\prime} \mathrm{E}$, and an area of $450 \mathrm{~km}^{2}$. The projected population of Garko local Government was 225,300 according to the National Population Census report (2018). Garko is known for agricultural activities both farming and animal husbandry. It is popularly known for large scale rice production. Other food crops include sweet potatoes, cassava, onions, sorghum, millet and sugarcane. Cows, sheep and goats are major groups of animals reared by majority of the populace. Meat products processed, retailed and consumed in Garko include roasted meat (Balangu), dried roasted meat (Kilishi), stick meat (Tsire), hide and skin pepper soup (Ragadada) and minced fried meat (Danbunnama).

\section{Samples Collection}

Five samples of Tsire products were collected from 6 different identified locations within Garko town in a sterile foil paper and immediately analyzed for the presence of bacteria.

\section{Sample Preparation}

Sample preparation for the bacteriological analysis was carried out in accordance with the method described by Atlas (1997). Twenty five grams $(25 \mathrm{~g})$ of the sample was homogenized in $225 \mathrm{ml}$ peptone water using Kenwood blender machine to obtain a $10^{1}$ homogenate. The homogenate was thoroughly shaken and $1 \mathrm{ml}$ pipetted into test tubes containing $9 \mathrm{ml}$ of peptone water $\left(10^{2}\right)$. The test tubes were further serially diluted to $10^{5}$.

Total Aerobic Mesophilic Bacterial Count

Total Aerobic mesophilic bacterial count was determined using the method described by Abdullahi et al. (2004) where $1 \mathrm{ml}$ of inoculums from $10^{1}$ to $10^{5}$ dilutions were transferred into duplicate Petri dishes and labeled accordingly. This was followed by pouring aseptically about $15 \mathrm{ml}$ of molten nutrient agar. The culture was homogenized by gentle spinning of the plates and allowed to solidify. The plates were incubated at $37^{\circ} \mathrm{C}$ for 24 hours. Plates containing 30-300 colonies were counted. The number of colony forming units per gram of a sample (cfu/g) was obtained by multiplying the average colony number with the inverse of the dilution factor.

\section{Enumeration and Detection of Coliform bacteria}

Detection and enumeration of coliform was carried out according to method described by Atlas, (1977). A set of 9 test tubes each containing $9 \mathrm{ml}$ of lactose broth and an inverted Durham tubes were autoclaved to expel air and to sterilize. Similarly, $1 \mathrm{ml}$ from the diluents $10^{1}$ was transferred to the first 3 test tubes, followed by $1 \mathrm{ml}$ from the diluents $10^{2}$ to the second set of 3 test tubes and finally the third diluents $10^{3}$ to the $3^{\text {rd }}$ set of 3 test tubes. All the 9 test tubes were incubated at $37^{\circ} \mathrm{C}$ for 24 hours. Tubes that showed gas and acid production after 24 hours were recorded as positive for the presence of Coliform. Negative tubes were further reincubated for 24 hours. Positive tubes were recorded. Estimate of most probable number of Coliform per gram of sample (MPN/g) was determined by comparing the number of gas positive tubes with the most probable number table. 
BAJOPAS Volume 13 Number 1, June, 2020 Identification of Coliform

A loop full of inoculum from gas positive tubes was streaked on to Eosine methylene blue (EMB) agar plate and incubated at $37^{\circ} \mathrm{C}$ for $24 \mathrm{hrs}$. Colonies which formed bluish black color with green metallic sheen, and reddish colonies were isolated on agar slants. Those colonies showing metallic sheen on EMB were sub cultured into tubes of lactose broth and incubated at $45^{\circ} \mathrm{C}$. The tubes were observed after $24 \mathrm{hrs}$ for gas production. This is the completed test for fecal coliform. Gram stain and other biochemical tests such as Indole, Methyl red, Voges-Proskauer and Citrate Utilization tests (IMVIC), Coagulase and Catalase tests were carried out for the Identification and confirmation of isolates.

\section{Procedure for Indole Test}

Indole test was carried out by preparing a Tryptone broth drawn in to test tubes, sterilized by autoclaving, inoculated with loopful of suspension and incubated at $37^{\circ} \mathrm{C}$ for 24 hours. Three drops of xylene was added in tubes, shaken vigorously and kept for the separation of two layers. One millilitre of Kovac's reagent was added and the formation of pink colour ring indicates positive Indole test.

\section{Procedure for Methyl Red Test}

Methyl red test was carried out by preparing Glucose phosphate broth, dispensed in test tubes, sterilized, inoculated with test culture and incubated at $37^{\circ} \mathrm{C}$ for 24 hours. Five drops of methyl-red indicator was added to the medium for the formation of red colour.

\section{Procedure for Voges-Proskauer Test}

Voges-Proskauer test was carried out by inoculating tubes with the bacterial culture followed by incubation for 48 hours at $37^{\circ} \mathrm{C}$. Separate pipettes were used to pipette $1 \mathrm{ml}$ from each culture tube into clean separate tubes. Eighteen drops $(0.5 \mathrm{ml})$ of Barrit's solution A (a-naphthol) was added to each tube containing glucose phosphate broth followed by the addition of an equal amount of solution $B$ into the same tube. The tubes were shaken at 30 seconds interval. A positive reaction was indicated by the development of a pink color, which turns red in 1-2 hours, after vigorous shaking.

\section{Procedure for Citrate Utilization Test}

Citrate Utilization Test was carried out by distributing melted agar (Simmon Citrate Agar) in to test tubes followed by sterilization at $121.5^{\circ} \mathrm{C}$ for 15 minutes. The test tubes were afterward held in slanted position, inoculated with the given bacterial culture and incubated at $37^{\circ} \mathrm{C}$ for $24 \mathrm{hrs}$. Positive test was indicated by color change of the media from green to blue.

\section{RESULTS AND DISCUSSIONS}

The results of this study are presented in tables $1,2,3$ and 4. Among the sampling areas Kofar Kudu had the highest aerobic mesophilic bacteria counts $4.0 \times 10^{5} \mathrm{cfu} / \mathrm{g}$ followed by Rinji $2.72 \times 10^{5} \mathrm{cfu} / \mathrm{g}$, while Tosaro had the least Aerobic mesophilic bacteria counts of $1.02 \times 10^{5}$ $\mathrm{cfu} / \mathrm{g}$ as indicated in Table 1.Makwalla had the highest coliform count $68 \mathrm{MPN} / \mathrm{g}$ followed by Rinji $37 \mathrm{MPN} / \mathrm{g}$. Tsohuwar Kasuwa had the least coliform counts $8 \mathrm{MPN} / \mathrm{g}$, (Table 2). Result from table 1 shows variation in the microbial contents among the samples which suggest variation in their sources, poor handling procedures and contamination from the processing environment. High coliform count and their differences within sampling areas is an indication of poor microbiological quality of the product. Ndahi et al. (2013) reported microbial load to be a function of the handling personnel and the environment. The results indicated that the samples were contaminated with bacteria as the counts exceeded the minimum safety level $\left(10^{4} \mathrm{cfu} / \mathrm{g}\right)$ for members of the Enterobacteriaceae family. However, it might be a reflection of poor hygienic practices which may contribute to health hazard to the potential consumers. Similarly, Inusa and Sa'id (2017); Osimani et al. (2015) reported that, the initial microbial content of the raw material play significant role in influencing the final microbial load of the finished product. Isolation of members of the Enterobacteriaceae such as $E$. coli, Klebsiella pneumoniae, Salmonella and Shigella signifies danger to the public health. These organisms are capable of producing endotoxins which trigger high fevers in infected individuals, and the enterotoxins which colonize the small intestines and lead to extreme dehydration as a result of vomiting and diarrhea sometimes with severe and fatal outcomes (Amaeze et al., 2016). From the 16 isolated organisms $E$. coli had the highest isolation rate $6(37.5 \%)$ (Table 3), this suggest faecal contamination of the products. $E$. coli is a common flora in the gastrointestinal tract responsible for diarrhea and extra-intestinal infections (CDC, 2011). The result is in conformity with the findings of Ndahi et al. (2013) and Shamsuddeen (2009). Also presence of campylobacter might be due to cross contamination from raw meat to finished product (Tsire). Staphylococcus aureus is a normal flora of the skin, nasal, genital, mouth or anal area in both humans and animals without any symptom of an infection (Matthew et al., 2013). Isolation of $S$. aureus in these study concords with the findings of Lucretia et al. (2018) from Suya sold in Rivers State. 
BAJOPAS Volume 13 Number 1, June, 2020

It is also in agreement with the findings of Yousafzai et al. (2018); Onuorah et al. (2015) and Tijjani and Jumare (2014) from tsire samples in different countries. Presence of $S$. aureus in foods is most of the time an indication of poor human handling, poor environment, unhygienic utensils and equipments used during processing (Igene et al., 2016; Okonko et al., 2013). Infections caused by $S$. aureus are difficult to treat leading to long hospitalization with consequent economic loss (Udobi et al., 2013). These include soft tissue infections, pneumonia, hospital-acquired postoperative wound infections, Staphylococcal food poisoning, impetigo and cellulitis (Charlene et al., 2013). Samples obtained from Dausai and Kofar Kudu had the highest isolation rate $4(80 \%)$ (Table 4 ) probably because of the much commercial activities taking place in the area which can lead to environmental contamination.

Table 1: Total Aerobic Mesophilic Bacterial Count of Tsire sold in Garko Town

\begin{tabular}{lll}
\hline Sampling Area & APC cfu/g & Mean \pm STD \\
\hline Dausai & $2.20 \times 10^{5}$ & $110000 \pm 14142.14$ \\
Kofar Kudu & $4.00 \times 10^{5}$ & $133333.3 \pm 23094.01$ \\
Makwalla & $1.30 \times 10^{5}$ & $32500 \pm 7187.953$ \\
Rinji & $2.72 \times 10^{5}$ & $90666.67 \pm 94769.90$ \\
Tosaro & $1.02 \times 10^{5}$ & $51000 \pm 15556.35$ \\
Tsohuwar Kasuwa & $1.75 \times 10^{5}$ & $35000 \pm 11357.82$ \\
\hline
\end{tabular}

Key: APC: Aerobic Mesophilic Counts

STD: Standard Deviation

Table 2: Total Coliform Count of Tsire sold in Garko Town

\begin{tabular}{lcc}
\hline \multicolumn{1}{c}{ Sampling Area } & TCC MPN/g & Mean \pm STD \\
\hline Dausai & 20 & $6.67 \pm 2.5166$ \\
Kofar Kudu & 32 & $16.00 \pm 5.6569$ \\
Makwalla & 68 & $13.60 \pm 8.7062$ \\
Rinji & 37 & $9.25 \pm 4.7871$ \\
Tosaro & 10 & $5.00 \pm 2.8284$ \\
Tsohuwar Kasuwa & 8 & $4.00 \pm 0.0000$ \\
\hline
\end{tabular}

Table 3: Organisms Isolated from Tsire Sold in Garko

\begin{tabular}{lcl}
\hline Isolated Organism & Frequency & Percentage (\%) \\
\hline Campylobacter & 2 & 06.66 \\
Escherichia coli & 6 & 20.00 \\
Klebsiella pneumoniae & 2 & 06.66 \\
Salmonella species & 1 & 03.33 \\
Shigella & 3 & 10.00 \\
Staphylococcus aureus & 2 & 06.66 \\
Total & 16 & \\
\hline
\end{tabular}

Table 4: Distribution of Organisms within Sampling Area

\begin{tabular}{lcc}
\hline \multicolumn{1}{c}{ Sampling Area } & No. Isolated & Percentage (\%) \\
\hline Dausai & 4 & 80 \\
Kofar Kudu & 4 & 80 \\
Makwalla & 2 & 40 \\
Rinji & 3 & 60 \\
Tosaro & 2 & 40 \\
Tsohuwar Kasuwa & 1 & 20 \\
Total & 16 & \\
\hline
\end{tabular}

\section{CONCLUSION}

Results indicated $4.00 \times 10^{5} \mathrm{CFU} / \mathrm{g}$ as the highest APCs count; while $68 \mathrm{MPN} / \mathrm{g}$ was the highest TCCs from the 30 samples analyzed. Among the isolates, $E$. coli has the highest isolation rate of $6(20 \%)$. Dausai and Kofar kudu were having the highest bacteria count of $4(80 \%)$, each, indicating higher contamination in those locations. 
BAJOPAS Volume 13 Number 1, June, 2020 RECOMMENDATIONS

The following recommendations are tenable:

1. Hygienic practices at all stages of production should be improved to safe guard the consumers against potential health hazard.

2. Monitoring of microbiological contamination of Tsire during preparations, packaging and marketing is essential to ensure product of good microbiological quality for consumers' health.

\section{REFERENCES}

Abdullahi, I. O., Umoh, V. J. and Galadima, M. (2004). Hazards Associated with Kilishi Preparations in Zaria. Nigerian Journal of Microbiology, 18 (1-2): $339-345$.

Ahmadu, J. and Ibrahim E. J., (2013): Determinants of Revenue in Suya Production in BeninCity, Edo State, Nigeria. Nigerian journal of agriculture, food and environment.9(3):1-5

Amaeze, N. Aboh, M. Itohan, A. Felix, E. Olatunji, T. and Oladosu, P. (2016) Microbial Profile, Antibiotic Sensitivity and Heat Resistance of Bacterial Isolates from Commercial Roasted Beef (Suya) in Abuja, Nigeria. JOPAT, 15(2): $22-30$.

Apata, E.S., Kuku1, I.A., Apata, O.C. and Adeyemi, K.O. (2013). Evaluation of Suya(Tsire) - An Intermediate Moisture Meat Product in Ogun State, Nigeria. J. Food Res 2 (1): 87.

Atlas, R. M. (1997) Principles of Microbiology Second Edition. C. Brown Publishers. Pp 802-803.

Borch, E. Kant-Muermans, M. L., Blixt, Y. (1996) Bacterial Spoilage of Meat and Cured Meat Products. Int $\mathrm{J}$ Food Microbiol .33(1): 103-20.

Centre for Disease Control, CDC (2011). "Escherichia coli 0157:H7" Division of Bacterial and Mycotic Diseasesht://www.cdc.gov/nczved/divisi ons/dfbmd/diseases/ecoli_0157h7/.

Charlene, R. J., Johnnie, A. D., and John, B. B., (2013) Prevalence and Characterization of Methicillin-Resistant Staphylococcus aureus Isolates from Retail Meat and Humans in Georgia. American society for Microbiology. J. of clinical microbiology. 12(1):123-6 doi:10.1128/JCM.0316612JCM.03166-12

Egbebi, A.O and Seidu, K., T. (2011). Microbiological Evaluation of Suya (dried smoked

meat) Sold in Ado and Akure, South West Nigeria.European Journal of Experinmental Biology, 1(4):1-5
3. Government should establish regulatory bodies responsible for inculcating hygiene habits to the local producers and vendors in order to prevent instant, cross and post processing contaminations by microbial pathogens.

4. Awareness and sensitization of local food producers about good hygienic practices in food handling and processing.

Falegan, C, R., Akoja, S. D., and Oyarekua, M. A., (2017) Microbiological Assessment of Suya (Sliced Roasted Beef) in Ado-Ekiti Metropolis, Ekiti State, Nigeria. MOJ Biology andMedicine.

Fonkem, D., N. Tanya, V., N. and Ebangi, A., L. (2010). Effect of Season on the Microbiological Quality of Kilishi, a Traditional Cameroonian Dried Beef Product. Tropicultura, 28(1): 10-15.

Food and Agricultural Organization of the United Nations (F A O, 1979). Manual of food quality control 4. Microbiological analysis.

Food and Agriculture Organisation of the United Nation (FAO), 2019. Nigeria at a glance.

Igene J.O., Uwadia, O.E., Ebabhamiegbebho, P.A. and Evivie, S.E., (2016) Shelf life Stability Studies of University of Benin (UNIBEN) Proff's Kilishi Product Asian Journal of Science and Technology 7(1): 2268-2274.

Inusa, S. K. and Said, I. S. (2017) Evaluation of the Chemical and Microbiological Properties Of Kilishi Sold in Kano Metropolis. Journal of Dry land Agriculture, 3 (1): $59-69$.

Lucretia, I. B, Patience, C. Obinna-Echem, Sophia, C. A. (2018) Microbiological quality andantibiotic sensitivity of potential pathogens isolated from meat product (Suya) sold in Rivers State University and its environs. International Journal of Biotechnology and Food Science, 6(4): 67-76.

Matthew, E., Drosos, E., John, L. and Ioanna, P. (2013) MRSA in Africa: Filling the Global Map of Antimicrobial Resistance PLOS One. 8(7): e68024 doi: 10.1371/journal.pone.0068024

Mgbemere, V.N., Akpapunam, M. A. and Igene, J. O., (2011). Effect of Groundnut FlourSubstitution on Yield, Quality and Storage Stability of Kilishi - a Nigerian Indigenous Dried Meat Product. African Journal of Food, Agriculture, Nutrition and Development, $\quad \mathbf{1 1}(2)$ : 4718-4738. 
BAJOPAS Volume 13 Number 1, June, 2020

Mubarak, A. A., Azeez, M. L., Amos A. O., Opeyemi, O. O. (2016) Assessment of Animal Protein Consumption and Food Security Among Rural Households in Kwara State, Nigeria American Journal of Business and Society, 1(4): 233245.

Ndahi, M., D. Kwaga, J., K. P. Bello, M. Kabir J., V. Umoh, .J. Yakubu, S., E. and Nok, A., J. (2013) Prevalence and Antimicrobial Susceptibility of Listeria Monocytogenes and Methicillin-Resistant Staphylococcus aureus Strains from Raw Meat and Meat Products in Zaria, Nigeria. Applied Journal of Microbiology, 58(3):262-9.

Okonko, I.O., Odu, N.N. and Igboh, I.E. (2013). Microbiological Analysis of Kilishi Sold In Port Harcourt, Nigeria. New York Science Journal, 6 (7):37-43.

Osimani, A., Aquilanti, L. and Clementi, F. (2015) Microbiological Quality of Meatbased Meals and Operation of Control Systems within a Food Service Environment. International Food Research Journal 22(4): 1692-1698.

Onuorah, S. Obika, I. Odibo, F. Orji, M. (2015)An Assessment of the Bacteriological Quality of Tsire-Suya (Grilled Beef) sold in Awka, Nigeria. American. J. Life. Sci. Res. 3(4):287292.

Razavilar, V, Khandaghi, J. Barzgari, A. (2010); Isolation of Eschericia coli 0157:H7 from manure fertilized farms and raw vegetables grown on it, in Tabriz city in
Iran. African Journal of Microbiology Research, 4(9): 891-895.

Scallan, E. Hoekstra, R. M. Angulo, F. J.Tauxe, R. V, Widdowson, M. Roy, S. L et al., (2011).Food borne illness acquired in the United States- Major Pathogens. Emerg. Infec Dis, 17(1): 7-15.

Shamsuddeen U (2009). Microbiological quality of spice used in the production of Kilishi a traditionally dried and grilled meat product. Bayero Journal of Pure andApplied Sciences, 2(2): 66-69.

Shamsuddeen, U. (2015) Microbiological Hazard and Critical control point Analysis of Dried and Minced Meat Snacks Produced in Kano Nigeria. Lambert Academic Publishing; Pp 1-36.

Tijani, O.and Jumare, S. (2014). Microblological Quality Assessment of Meat

Sold in KauraNamoda. International Conference on Earth, Environment and Life sciences (EELS) Dubai (UAE).

Udobi, C. E., Obajuluwa, A. F., and Onaolapo, J. A., (2013) Prevalence and Antibiotic Resistance Pattern of MethicillinResistant Staphylococcus aureus from an Orthopaedic Hospital in Nigeria BioMed Research International; 26(6); 6-7.

WHO, 2015 Foodborne diseases in the WHO African Region.

Yousafzai HA, Rind R, Khan MA, Abro SH, Korejo NA, Ejaz M, Kabir A, Shahid M, Memon S. (2019). Microbiological Contamination of Cattle and Meat in Peshawar, Pakistan. J. Anim. Health Prod. 7(1): 1116. 


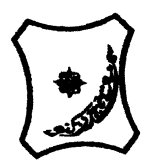

Bayero Journal of Pure and Applied Sciences, 13(1); 40 - 45

Received: September, 2019

Accepted: April, 2020

ISSN $2006-6996$

\title{
BACTERIOLOGICAL QUALITY OF STICK MEAT (Tsire) SOLD IN GARKO LOCAL GOVERNMENT AREA OF KANO STATE, NIGERIA
}

\author{
$*^{1}$ Dahiru A. T. and ${ }^{2}$ Maigari A. K. \\ ${ }^{1}$ Department of Hospitality Management, School of Technology, Kano State Polytechnic, PMB 3348, \\ Kano Nigeria. \\ ${ }^{2}$ Departmnt of Biological Sciences, Bayero University, Kano \\ Corresponding Author: dturajo61@gmail.com; GSM: 08087508262.
}

ABSTRACT

Stick meat, locally called Tsire in Hausa Language, is a significant portion of the diet of a large active population of Northern Nigeria. However, because of the handling and processing methods by the manufacturers as well as the hawking system of stick meat, the meat product may be exposed to both pre- and post-processed product contamination, and thus may poses danger to public health. Therefore, considering the role of Tsire in improving nutrition and increase household income to the populace, the need to improve the processing, distribution and overall quality of the product is simply indispensable. A total of 30 samples (5 samples from each of the 6 sampling points) of Tsire were collected randomly in Garko Town. Aerobic plate counts (APCs) and Total coliform counts (TCCS) of Tsire samples were determined using standard microbiological methods. APCs ranged from $1.02 \times 10^{5}$ to $4.00 \times 10^{5} \mathrm{CFU} / \mathrm{g}$; while TCCs ranged from $8 \mathrm{MPN} / \mathrm{g}$ to $68 \mathrm{MPN} / \mathrm{g}$. From the 30 samples screened, 16(53.33\%) bacteria namely, Campylobacter 2(6.66\%), Escherichia coli 6(20\%), Klebsiella pneumoniae 2(6.66\%), Salmonella spp. 1(3.33\%), Shigella 3(10\%) and Staphylococcus aureus 2(6.66\%) were detected. $E$. coli has the highest isolation rate of 6(20\%), while Salmonella spp. had the least frequency of 1(3.33\%). The distribution of isolated organisms within the study area were as follows: Dausai, 4(80\%), Kofar kudu, 4(80\%), Makwalla, 2(40\%), Rinji, 3(60\%), Tosaro, 2(40\%), and Tsohuwar Kasuwa, 1(20\%). The results have indicated that the Tsire was contaminated with bacteria thus exposing the product to fast deterioration, spoilage and also a vehicle for food borne illness, suggesting for adequate hygienic practices at all the stages, prior to consumption, to ensure safety of the meat product.

Key words: APCs, TCCs, Contamination, Microorganisms, Garko

\section{INTRODUCTION}

Nigeria is one of the developing nations with inadequate food supply and most often deficient in protein content (FAO, 2019). Nigerian's average animal protein intake per head per day is estimated at $7.9 \mathrm{~g}$ as against $35 \mathrm{~g}$ recommended value by Food and Agricultural Organization (Mubarak et al., 2016). These low levels of animal protein intake create great concern as it affects the nutritional status of Nigerians. Hence, there is the need for sufficient supply of animal protein from energy rich animal products to satisfy the nutritional requirements for Nigerians.

Meat is one major source of animal protein largely composed of water, protein and fats which can make it susceptible to microbial contamination within short time leading to spoilage (Apata et al., 2013; Mgbemere et al., 2011). Meat is mostly eaten after it has been cooked or processed in a variety of ways such as sun drying; smoking and roasting with or without fortifications (Borch et al., 1996). In Nigeria meat products such as Tsire, Kilishi and Balangu are locally produced using one or more of these methods in order to meet the nutritional requirements of the teeming Nigerians (Egbebi, 2011).

Tsire is a popular Nigerian traditional processed ready-to-eat roasted stick meat product (Shamsuddeen, 2015). It is sold in public places, along roads, in hotels, parks, quarters and even offices (Falegan et al., 2017). It is prepared from boneless healthy animal flesh such as beef and mutton, spiced with peanut cake, salt, vegetable oil and other flavorings followed by roasting (Shamsuddeen, 2015). Consumption of these products has extended to other parts of African countries such as Ghana, Somali, Cameroun and Chad (Ahmadu and Ibrahim, 2013). 
BAJOPAS Volume 13 Number 1, June, 2020

However, evidence of quality control sticking to procedural hygiene by the handlers during preparation and retailing of these products is poorly documented. Tsire is of great safety risk because of the fact that there are erratic cases of gastroenteritis and symptoms of food infection after consumption (WHO, 2015). Food borne illnesses are one of the major health problems in developing and developed countries (Razavilar, 2010). According to the World Health Organization, WHO (2015), $0.07 \%$ death of the 600 million global burdens of Foodborne illnesses have been reported to be caused by bacteria, viruses, fungi and chemicals. In America $0.27 \%$ of the estimated 48 million affected people is hospitalized and about $0.0063 \%$ deaths are recorded each year (Scallan et al., 2011). More than 91 million people in Africa fall ill and $0.15 \%$ dies each year, making Africa the highest burden bearer of Foodborne diseases per population (WHO, 2015).

Application of a Hazard Analysis Critical Control Point (HACCP) at all stages of meat products preparation is essential in order to ensure its safety. Thus, according to the guidelines of good manufacturing practice, the level of total aerobic bacterial contamination of thermally processed meat products should not exceed $10^{4}\left(\mathrm{cfu} \mathrm{g}^{-1}\right)$. Enterobacteriaceae and faecal coliform contamination in meat products should be within the range of $10^{2}-10^{4}$ and $10-10^{3} \mathrm{cfu} \mathrm{g}^{-1}$, respectively (Shamsuddeen, 2015). The aim of the study is therefore, to assess the total viable bacterial counts of tsire marketed locally within Garko town, and to isolate and identify the organisms at the point of consumption with the intention of promoting public health and food hygiene habits in the Nigerian populace.

\section{MATERIALS AND METHODS Study Area and Population}

Garko is one of the existing 44 local government areas located in Kano south west zone of Kano state with its capital administrative headquarters in the Garko town. It has coordinates $11^{\circ} 39^{\prime} \mathrm{N}$ $8^{\circ} 54^{\prime} \mathrm{E}$, and an area of $450 \mathrm{~km}^{2}$. The projected population of Garko local Government was 225,300 according to the National Population Census report (2018). Garko is known for agricultural activities both farming and animal husbandry. It is popularly known for large scale rice production. Other food crops include sweet potatoes, cassava, onions, sorghum, millet and sugarcane. Cows, sheep and goats are major groups of animals reared by majority of the populace. Meat products processed, retailed and consumed in Garko include roasted meat (Balangu), dried roasted meat (Kilishi), stick meat (Tsire), hide and skin pepper soup (Ragadada) and minced fried meat (Danbunnama).

\section{Samples Collection}

Five samples of Tsire products were collected from 6 different identified locations within Garko town in a sterile foil paper and immediately analyzed for the presence of bacteria.

\section{Sample Preparation}

Sample preparation for the bacteriological analysis was carried out in accordance with the method described by Atlas (1997). Twenty five grams $(25 \mathrm{~g})$ of the sample was homogenized in $225 \mathrm{ml}$ peptone water using Kenwood blender machine to obtain a $10^{1}$ homogenate. The homogenate was thoroughly shaken and $1 \mathrm{ml}$ pipetted into test tubes containing $9 \mathrm{ml}$ of peptone water $\left(10^{2}\right)$. The test tubes were further serially diluted to $10^{5}$.

Total Aerobic Mesophilic Bacterial Count

Total Aerobic mesophilic bacterial count was determined using the method described by Abdullahi et al. (2004) where $1 \mathrm{ml}$ of inoculums from $10^{1}$ to $10^{5}$ dilutions were transferred into duplicate Petri dishes and labeled accordingly. This was followed by pouring aseptically about $15 \mathrm{ml}$ of molten nutrient agar. The culture was homogenized by gentle spinning of the plates and allowed to solidify. The plates were incubated at $37^{\circ} \mathrm{C}$ for 24 hours. Plates containing 30-300 colonies were counted. The number of colony forming units per gram of a sample (cfu/g) was obtained by multiplying the average colony number with the inverse of the dilution factor.

\section{Enumeration and Detection of Coliform bacteria}

Detection and enumeration of coliform was carried out according to method described by Atlas, (1977). A set of 9 test tubes each containing $9 \mathrm{ml}$ of lactose broth and an inverted Durham tubes were autoclaved to expel air and to sterilize. Similarly, $1 \mathrm{ml}$ from the diluents $10^{1}$ was transferred to the first 3 test tubes, followed by $1 \mathrm{ml}$ from the diluents $10^{2}$ to the second set of 3 test tubes and finally the third diluents $10^{3}$ to the $3^{\text {rd }}$ set of 3 test tubes. All the 9 test tubes were incubated at $37^{\circ} \mathrm{C}$ for 24 hours. Tubes that showed gas and acid production after 24 hours were recorded as positive for the presence of Coliform. Negative tubes were further reincubated for 24 hours. Positive tubes were recorded. Estimate of most probable number of Coliform per gram of sample (MPN/g) was determined by comparing the number of gas positive tubes with the most probable number table. 
BAJOPAS Volume 13 Number 1, June, 2020 Identification of Coliform

A loop full of inoculum from gas positive tubes was streaked on to Eosine methylene blue (EMB) agar plate and incubated at $37^{\circ} \mathrm{C}$ for $24 \mathrm{hrs}$. Colonies which formed bluish black color with green metallic sheen, and reddish colonies were isolated on agar slants. Those colonies showing metallic sheen on EMB were sub cultured into tubes of lactose broth and incubated at $45^{\circ} \mathrm{C}$. The tubes were observed after $24 \mathrm{hrs}$ for gas production. This is the completed test for fecal coliform. Gram stain and other biochemical tests such as Indole, Methyl red, Voges-Proskauer and Citrate Utilization tests (IMVIC), Coagulase and Catalase tests were carried out for the Identification and confirmation of isolates.

\section{Procedure for Indole Test}

Indole test was carried out by preparing a Tryptone broth drawn in to test tubes, sterilized by autoclaving, inoculated with loopful of suspension and incubated at $37^{\circ} \mathrm{C}$ for 24 hours. Three drops of xylene was added in tubes, shaken vigorously and kept for the separation of two layers. One millilitre of Kovac's reagent was added and the formation of pink colour ring indicates positive Indole test.

\section{Procedure for Methyl Red Test}

Methyl red test was carried out by preparing Glucose phosphate broth, dispensed in test tubes, sterilized, inoculated with test culture and incubated at $37^{\circ} \mathrm{C}$ for 24 hours. Five drops of methyl-red indicator was added to the medium for the formation of red colour.

\section{Procedure for Voges-Proskauer Test}

Voges-Proskauer test was carried out by inoculating tubes with the bacterial culture followed by incubation for 48 hours at $37^{\circ} \mathrm{C}$. Separate pipettes were used to pipette $1 \mathrm{ml}$ from each culture tube into clean separate tubes. Eighteen drops $(0.5 \mathrm{ml})$ of Barrit's solution A (a-naphthol) was added to each tube containing glucose phosphate broth followed by the addition of an equal amount of solution $B$ into the same tube. The tubes were shaken at 30 seconds interval. A positive reaction was indicated by the development of a pink color, which turns red in 1-2 hours, after vigorous shaking.

\section{Procedure for Citrate Utilization Test}

Citrate Utilization Test was carried out by distributing melted agar (Simmon Citrate Agar) in to test tubes followed by sterilization at $121.5^{\circ} \mathrm{C}$ for 15 minutes. The test tubes were afterward held in slanted position, inoculated with the given bacterial culture and incubated at $37^{\circ} \mathrm{C}$ for $24 \mathrm{hrs}$. Positive test was indicated by color change of the media from green to blue.

\section{RESULTS AND DISCUSSIONS}

The results of this study are presented in tables $1,2,3$ and 4. Among the sampling areas Kofar Kudu had the highest aerobic mesophilic bacteria counts $4.0 \times 10^{5} \mathrm{cfu} / \mathrm{g}$ followed by Rinji $2.72 \times 10^{5} \mathrm{cfu} / \mathrm{g}$, while Tosaro had the least Aerobic mesophilic bacteria counts of $1.02 \times 10^{5}$ $\mathrm{cfu} / \mathrm{g}$ as indicated in Table 1.Makwalla had the highest coliform count $68 \mathrm{MPN} / \mathrm{g}$ followed by Rinji $37 \mathrm{MPN} / \mathrm{g}$. Tsohuwar Kasuwa had the least coliform counts $8 \mathrm{MPN} / \mathrm{g}$, (Table 2). Result from table 1 shows variation in the microbial contents among the samples which suggest variation in their sources, poor handling procedures and contamination from the processing environment. High coliform count and their differences within sampling areas is an indication of poor microbiological quality of the product. Ndahi et al. (2013) reported microbial load to be a function of the handling personnel and the environment. The results indicated that the samples were contaminated with bacteria as the counts exceeded the minimum safety level $\left(10^{4} \mathrm{cfu} / \mathrm{g}\right)$ for members of the Enterobacteriaceae family. However, it might be a reflection of poor hygienic practices which may contribute to health hazard to the potential consumers. Similarly, Inusa and Sa'id (2017); Osimani et al. (2015) reported that, the initial microbial content of the raw material play significant role in influencing the final microbial load of the finished product. Isolation of members of the Enterobacteriaceae such as $E$. coli, Klebsiella pneumoniae, Salmonella and Shigella signifies danger to the public health. These organisms are capable of producing endotoxins which trigger high fevers in infected individuals, and the enterotoxins which colonize the small intestines and lead to extreme dehydration as a result of vomiting and diarrhea sometimes with severe and fatal outcomes (Amaeze et al., 2016). From the 16 isolated organisms $E$. coli had the highest isolation rate $6(37.5 \%)$ (Table 3), this suggest faecal contamination of the products. $E$. coli is a common flora in the gastrointestinal tract responsible for diarrhea and extra-intestinal infections (CDC, 2011). The result is in conformity with the findings of Ndahi et al. (2013) and Shamsuddeen (2009). Also presence of campylobacter might be due to cross contamination from raw meat to finished product (Tsire). Staphylococcus aureus is a normal flora of the skin, nasal, genital, mouth or anal area in both humans and animals without any symptom of an infection (Matthew et al., 2013). Isolation of $S$. aureus in these study concords with the findings of Lucretia et al. (2018) from Suya sold in Rivers State. 
BAJOPAS Volume 13 Number 1, June, 2020

It is also in agreement with the findings of Yousafzai et al. (2018); Onuorah et al. (2015) and Tijjani and Jumare (2014) from tsire samples in different countries. Presence of $S$. aureus in foods is most of the time an indication of poor human handling, poor environment, unhygienic utensils and equipments used during processing (Igene et al., 2016; Okonko et al., 2013). Infections caused by $S$. aureus are difficult to treat leading to long hospitalization with consequent economic loss (Udobi et al., 2013). These include soft tissue infections, pneumonia, hospital-acquired postoperative wound infections, Staphylococcal food poisoning, impetigo and cellulitis (Charlene et al., 2013). Samples obtained from Dausai and Kofar Kudu had the highest isolation rate $4(80 \%)$ (Table 4 ) probably because of the much commercial activities taking place in the area which can lead to environmental contamination.

Table 1: Total Aerobic Mesophilic Bacterial Count of Tsire sold in Garko Town

\begin{tabular}{lll}
\hline Sampling Area & APC cfu/g & Mean \pm STD \\
\hline Dausai & $2.20 \times 10^{5}$ & $110000 \pm 14142.14$ \\
Kofar Kudu & $4.00 \times 10^{5}$ & $133333.3 \pm 23094.01$ \\
Makwalla & $1.30 \times 10^{5}$ & $32500 \pm 7187.953$ \\
Rinji & $2.72 \times 10^{5}$ & $90666.67 \pm 94769.90$ \\
Tosaro & $1.02 \times 10^{5}$ & $51000 \pm 15556.35$ \\
Tsohuwar Kasuwa & $1.75 \times 10^{5}$ & $35000 \pm 11357.82$ \\
\hline
\end{tabular}

Key: APC: Aerobic Mesophilic Counts

STD: Standard Deviation

Table 2: Total Coliform Count of Tsire sold in Garko Town

\begin{tabular}{lcc}
\hline \multicolumn{1}{c}{ Sampling Area } & TCC MPN/g & Mean \pm STD \\
\hline Dausai & 20 & $6.67 \pm 2.5166$ \\
Kofar Kudu & 32 & $16.00 \pm 5.6569$ \\
Makwalla & 68 & $13.60 \pm 8.7062$ \\
Rinji & 37 & $9.25 \pm 4.7871$ \\
Tosaro & 10 & $5.00 \pm 2.8284$ \\
Tsohuwar Kasuwa & 8 & $4.00 \pm 0.0000$ \\
\hline
\end{tabular}

Table 3: Organisms Isolated from Tsire Sold in Garko

\begin{tabular}{lcl}
\hline Isolated Organism & Frequency & Percentage (\%) \\
\hline Campylobacter & 2 & 06.66 \\
Escherichia coli & 6 & 20.00 \\
Klebsiella pneumoniae & 2 & 06.66 \\
Salmonella species & 1 & 03.33 \\
Shigella & 3 & 10.00 \\
Staphylococcus aureus & 2 & 06.66 \\
Total & 16 & \\
\hline
\end{tabular}

Table 4: Distribution of Organisms within Sampling Area

\begin{tabular}{lcc}
\hline \multicolumn{1}{c}{ Sampling Area } & No. Isolated & Percentage (\%) \\
\hline Dausai & 4 & 80 \\
Kofar Kudu & 4 & 80 \\
Makwalla & 2 & 40 \\
Rinji & 3 & 60 \\
Tosaro & 2 & 40 \\
Tsohuwar Kasuwa & 1 & 20 \\
Total & 16 & \\
\hline
\end{tabular}

\section{CONCLUSION}

Results indicated $4.00 \times 10^{5} \mathrm{CFU} / \mathrm{g}$ as the highest APCs count; while $68 \mathrm{MPN} / \mathrm{g}$ was the highest TCCs from the 30 samples analyzed. Among the isolates, $E$. coli has the highest isolation rate of $6(20 \%)$. Dausai and Kofar kudu were having the highest bacteria count of $4(80 \%)$, each, indicating higher contamination in those locations. 
BAJOPAS Volume 13 Number 1, June, 2020 RECOMMENDATIONS

The following recommendations are tenable:

1. Hygienic practices at all stages of production should be improved to safe guard the consumers against potential health hazard.

2. Monitoring of microbiological contamination of Tsire during preparations, packaging and marketing is essential to ensure product of good microbiological quality for consumers' health.

\section{REFERENCES}

Abdullahi, I. O., Umoh, V. J. and Galadima, M. (2004). Hazards Associated with Kilishi Preparations in Zaria. Nigerian Journal of Microbiology, 18 (1-2): $339-345$.

Ahmadu, J. and Ibrahim E. J., (2013): Determinants of Revenue in Suya Production in BeninCity, Edo State, Nigeria. Nigerian journal of agriculture, food and environment.9(3):1-5

Amaeze, N. Aboh, M. Itohan, A. Felix, E. Olatunji, T. and Oladosu, P. (2016) Microbial Profile, Antibiotic Sensitivity and Heat Resistance of Bacterial Isolates from Commercial Roasted Beef (Suya) in Abuja, Nigeria. JOPAT, 15(2): $22-30$.

Apata, E.S., Kuku1, I.A., Apata, O.C. and Adeyemi, K.O. (2013). Evaluation of Suya(Tsire) - An Intermediate Moisture Meat Product in Ogun State, Nigeria. J. Food Res 2 (1): 87.

Atlas, R. M. (1997) Principles of Microbiology Second Edition. C. Brown Publishers. Pp 802-803.

Borch, E. Kant-Muermans, M. L., Blixt, Y. (1996) Bacterial Spoilage of Meat and Cured Meat Products. Int $\mathrm{J}$ Food Microbiol .33(1): 103-20.

Centre for Disease Control, CDC (2011). "Escherichia coli 0157:H7" Division of Bacterial and Mycotic Diseasesht://www.cdc.gov/nczved/divisi ons/dfbmd/diseases/ecoli_0157h7/.

Charlene, R. J., Johnnie, A. D., and John, B. B., (2013) Prevalence and Characterization of Methicillin-Resistant Staphylococcus aureus Isolates from Retail Meat and Humans in Georgia. American society for Microbiology. J. of clinical microbiology. 12(1):123-6 doi:10.1128/JCM.0316612JCM.03166-12

Egbebi, A.O and Seidu, K., T. (2011). Microbiological Evaluation of Suya (dried smoked

meat) Sold in Ado and Akure, South West Nigeria.European Journal of Experinmental Biology, 1(4):1-5
3. Government should establish regulatory bodies responsible for inculcating hygiene habits to the local producers and vendors in order to prevent instant, cross and post processing contaminations by microbial pathogens.

4. Awareness and sensitization of local food producers about good hygienic practices in food handling and processing.

Falegan, C, R., Akoja, S. D., and Oyarekua, M. A., (2017) Microbiological Assessment of Suya (Sliced Roasted Beef) in Ado-Ekiti Metropolis, Ekiti State, Nigeria. MOJ Biology andMedicine.

Fonkem, D., N. Tanya, V., N. and Ebangi, A., L. (2010). Effect of Season on the Microbiological Quality of Kilishi, a Traditional Cameroonian Dried Beef Product. Tropicultura, 28(1): 10-15.

Food and Agricultural Organization of the United Nations (F A O, 1979). Manual of food quality control 4. Microbiological analysis.

Food and Agriculture Organisation of the United Nation (FAO), 2019. Nigeria at a glance.

Igene J.O., Uwadia, O.E., Ebabhamiegbebho, P.A. and Evivie, S.E., (2016) Shelf life Stability Studies of University of Benin (UNIBEN) Proff's Kilishi Product Asian Journal of Science and Technology 7(1): 2268-2274.

Inusa, S. K. and Said, I. S. (2017) Evaluation of the Chemical and Microbiological Properties Of Kilishi Sold in Kano Metropolis. Journal of Dry land Agriculture, 3 (1): $59-69$.

Lucretia, I. B, Patience, C. Obinna-Echem, Sophia, C. A. (2018) Microbiological quality andantibiotic sensitivity of potential pathogens isolated from meat product (Suya) sold in Rivers State University and its environs. International Journal of Biotechnology and Food Science, 6(4): 67-76.

Matthew, E., Drosos, E., John, L. and Ioanna, P. (2013) MRSA in Africa: Filling the Global Map of Antimicrobial Resistance PLOS One. 8(7): e68024 doi: 10.1371/journal.pone.0068024

Mgbemere, V.N., Akpapunam, M. A. and Igene, J. O., (2011). Effect of Groundnut FlourSubstitution on Yield, Quality and Storage Stability of Kilishi - a Nigerian Indigenous Dried Meat Product. African Journal of Food, Agriculture, Nutrition and Development, $\quad \mathbf{1 1}(2)$ : 4718-4738. 
BAJOPAS Volume 13 Number 1, June, 2020

Mubarak, A. A., Azeez, M. L., Amos A. O., Opeyemi, O. O. (2016) Assessment of Animal Protein Consumption and Food Security Among Rural Households in Kwara State, Nigeria American Journal of Business and Society, 1(4): 233245.

Ndahi, M., D. Kwaga, J., K. P. Bello, M. Kabir J., V. Umoh, .J. Yakubu, S., E. and Nok, A., J. (2013) Prevalence and Antimicrobial Susceptibility of Listeria Monocytogenes and Methicillin-Resistant Staphylococcus aureus Strains from Raw Meat and Meat Products in Zaria, Nigeria. Applied Journal of Microbiology, 58(3):262-9.

Okonko, I.O., Odu, N.N. and Igboh, I.E. (2013). Microbiological Analysis of Kilishi Sold In Port Harcourt, Nigeria. New York Science Journal, 6 (7):37-43.

Osimani, A., Aquilanti, L. and Clementi, F. (2015) Microbiological Quality of Meatbased Meals and Operation of Control Systems within a Food Service Environment. International Food Research Journal 22(4): 1692-1698.

Onuorah, S. Obika, I. Odibo, F. Orji, M. (2015)An Assessment of the Bacteriological Quality of Tsire-Suya (Grilled Beef) sold in Awka, Nigeria. American. J. Life. Sci. Res. 3(4):287292.

Razavilar, V, Khandaghi, J. Barzgari, A. (2010); Isolation of Eschericia coli 0157:H7 from manure fertilized farms and raw vegetables grown on it, in Tabriz city in
Iran. African Journal of Microbiology Research, 4(9): 891-895.

Scallan, E. Hoekstra, R. M. Angulo, F. J.Tauxe, R. V, Widdowson, M. Roy, S. L et al., (2011).Food borne illness acquired in the United States- Major Pathogens. Emerg. Infec Dis, 17(1): 7-15.

Shamsuddeen U (2009). Microbiological quality of spice used in the production of Kilishi a traditionally dried and grilled meat product. Bayero Journal of Pure andApplied Sciences, 2(2): 66-69.

Shamsuddeen, U. (2015) Microbiological Hazard and Critical control point Analysis of Dried and Minced Meat Snacks Produced in Kano Nigeria. Lambert Academic Publishing; Pp 1-36.

Tijani, O.and Jumare, S. (2014). Microblological Quality Assessment of Meat

Sold in KauraNamoda. International Conference on Earth, Environment and Life sciences (EELS) Dubai (UAE).

Udobi, C. E., Obajuluwa, A. F., and Onaolapo, J. A., (2013) Prevalence and Antibiotic Resistance Pattern of MethicillinResistant Staphylococcus aureus from an Orthopaedic Hospital in Nigeria BioMed Research International; 26(6); 6-7.

WHO, 2015 Foodborne diseases in the WHO African Region.

Yousafzai HA, Rind R, Khan MA, Abro SH, Korejo NA, Ejaz M, Kabir A, Shahid M, Memon S. (2019). Microbiological Contamination of Cattle and Meat in Peshawar, Pakistan. J. Anim. Health Prod. 7(1): 1116. 


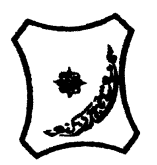

Bayero Journal of Pure and Applied Sciences, 13(1); 40 - 45

Received: September, 2019

Accepted: April, 2020

ISSN $2006-6996$

\title{
BACTERIOLOGICAL QUALITY OF STICK MEAT (Tsire) SOLD IN GARKO LOCAL GOVERNMENT AREA OF KANO STATE, NIGERIA
}

\author{
$*^{1}$ Dahiru A. T. and ${ }^{2}$ Maigari A. K. \\ ${ }^{1}$ Department of Hospitality Management, School of Technology, Kano State Polytechnic, PMB 3348, \\ Kano Nigeria. \\ ${ }^{2}$ Departmnt of Biological Sciences, Bayero University, Kano \\ Corresponding Author: dturajo61@gmail.com; GSM: 08087508262.
}

ABSTRACT

Stick meat, locally called Tsire in Hausa Language, is a significant portion of the diet of a large active population of Northern Nigeria. However, because of the handling and processing methods by the manufacturers as well as the hawking system of stick meat, the meat product may be exposed to both pre- and post-processed product contamination, and thus may poses danger to public health. Therefore, considering the role of Tsire in improving nutrition and increase household income to the populace, the need to improve the processing, distribution and overall quality of the product is simply indispensable. A total of 30 samples (5 samples from each of the 6 sampling points) of Tsire were collected randomly in Garko Town. Aerobic plate counts (APCs) and Total coliform counts (TCCS) of Tsire samples were determined using standard microbiological methods. APCs ranged from $1.02 \times 10^{5}$ to $4.00 \times 10^{5} \mathrm{CFU} / \mathrm{g}$; while TCCs ranged from $8 \mathrm{MPN} / \mathrm{g}$ to $68 \mathrm{MPN} / \mathrm{g}$. From the 30 samples screened, 16(53.33\%) bacteria namely, Campylobacter 2(6.66\%), Escherichia coli 6(20\%), Klebsiella pneumoniae 2(6.66\%), Salmonella spp. 1(3.33\%), Shigella 3(10\%) and Staphylococcus aureus 2(6.66\%) were detected. $E$. coli has the highest isolation rate of 6(20\%), while Salmonella spp. had the least frequency of 1(3.33\%). The distribution of isolated organisms within the study area were as follows: Dausai, 4(80\%), Kofar kudu, 4(80\%), Makwalla, 2(40\%), Rinji, 3(60\%), Tosaro, 2(40\%), and Tsohuwar Kasuwa, 1(20\%). The results have indicated that the Tsire was contaminated with bacteria thus exposing the product to fast deterioration, spoilage and also a vehicle for food borne illness, suggesting for adequate hygienic practices at all the stages, prior to consumption, to ensure safety of the meat product.

Key words: APCs, TCCs, Contamination, Microorganisms, Garko

\section{INTRODUCTION}

Nigeria is one of the developing nations with inadequate food supply and most often deficient in protein content (FAO, 2019). Nigerian's average animal protein intake per head per day is estimated at $7.9 \mathrm{~g}$ as against $35 \mathrm{~g}$ recommended value by Food and Agricultural Organization (Mubarak et al., 2016). These low levels of animal protein intake create great concern as it affects the nutritional status of Nigerians. Hence, there is the need for sufficient supply of animal protein from energy rich animal products to satisfy the nutritional requirements for Nigerians.

Meat is one major source of animal protein largely composed of water, protein and fats which can make it susceptible to microbial contamination within short time leading to spoilage (Apata et al., 2013; Mgbemere et al., 2011). Meat is mostly eaten after it has been cooked or processed in a variety of ways such as sun drying; smoking and roasting with or without fortifications (Borch et al., 1996). In Nigeria meat products such as Tsire, Kilishi and Balangu are locally produced using one or more of these methods in order to meet the nutritional requirements of the teeming Nigerians (Egbebi, 2011).

Tsire is a popular Nigerian traditional processed ready-to-eat roasted stick meat product (Shamsuddeen, 2015). It is sold in public places, along roads, in hotels, parks, quarters and even offices (Falegan et al., 2017). It is prepared from boneless healthy animal flesh such as beef and mutton, spiced with peanut cake, salt, vegetable oil and other flavorings followed by roasting (Shamsuddeen, 2015). Consumption of these products has extended to other parts of African countries such as Ghana, Somali, Cameroun and Chad (Ahmadu and Ibrahim, 2013). 
BAJOPAS Volume 13 Number 1, June, 2020

However, evidence of quality control sticking to procedural hygiene by the handlers during preparation and retailing of these products is poorly documented. Tsire is of great safety risk because of the fact that there are erratic cases of gastroenteritis and symptoms of food infection after consumption (WHO, 2015). Food borne illnesses are one of the major health problems in developing and developed countries (Razavilar, 2010). According to the World Health Organization, WHO (2015), $0.07 \%$ death of the 600 million global burdens of Foodborne illnesses have been reported to be caused by bacteria, viruses, fungi and chemicals. In America $0.27 \%$ of the estimated 48 million affected people is hospitalized and about $0.0063 \%$ deaths are recorded each year (Scallan et al., 2011). More than 91 million people in Africa fall ill and $0.15 \%$ dies each year, making Africa the highest burden bearer of Foodborne diseases per population (WHO, 2015).

Application of a Hazard Analysis Critical Control Point (HACCP) at all stages of meat products preparation is essential in order to ensure its safety. Thus, according to the guidelines of good manufacturing practice, the level of total aerobic bacterial contamination of thermally processed meat products should not exceed $10^{4}\left(\mathrm{cfu} \mathrm{g}^{-1}\right)$. Enterobacteriaceae and faecal coliform contamination in meat products should be within the range of $10^{2}-10^{4}$ and $10-10^{3} \mathrm{cfu} \mathrm{g}^{-1}$, respectively (Shamsuddeen, 2015). The aim of the study is therefore, to assess the total viable bacterial counts of tsire marketed locally within Garko town, and to isolate and identify the organisms at the point of consumption with the intention of promoting public health and food hygiene habits in the Nigerian populace.

\section{MATERIALS AND METHODS Study Area and Population}

Garko is one of the existing 44 local government areas located in Kano south west zone of Kano state with its capital administrative headquarters in the Garko town. It has coordinates $11^{\circ} 39^{\prime} \mathrm{N}$ $8^{\circ} 54^{\prime} \mathrm{E}$, and an area of $450 \mathrm{~km}^{2}$. The projected population of Garko local Government was 225,300 according to the National Population Census report (2018). Garko is known for agricultural activities both farming and animal husbandry. It is popularly known for large scale rice production. Other food crops include sweet potatoes, cassava, onions, sorghum, millet and sugarcane. Cows, sheep and goats are major groups of animals reared by majority of the populace. Meat products processed, retailed and consumed in Garko include roasted meat (Balangu), dried roasted meat (Kilishi), stick meat (Tsire), hide and skin pepper soup (Ragadada) and minced fried meat (Danbunnama).

\section{Samples Collection}

Five samples of Tsire products were collected from 6 different identified locations within Garko town in a sterile foil paper and immediately analyzed for the presence of bacteria.

\section{Sample Preparation}

Sample preparation for the bacteriological analysis was carried out in accordance with the method described by Atlas (1997). Twenty five grams $(25 \mathrm{~g})$ of the sample was homogenized in $225 \mathrm{ml}$ peptone water using Kenwood blender machine to obtain a $10^{1}$ homogenate. The homogenate was thoroughly shaken and $1 \mathrm{ml}$ pipetted into test tubes containing $9 \mathrm{ml}$ of peptone water $\left(10^{2}\right)$. The test tubes were further serially diluted to $10^{5}$.

Total Aerobic Mesophilic Bacterial Count

Total Aerobic mesophilic bacterial count was determined using the method described by Abdullahi et al. (2004) where $1 \mathrm{ml}$ of inoculums from $10^{1}$ to $10^{5}$ dilutions were transferred into duplicate Petri dishes and labeled accordingly. This was followed by pouring aseptically about $15 \mathrm{ml}$ of molten nutrient agar. The culture was homogenized by gentle spinning of the plates and allowed to solidify. The plates were incubated at $37^{\circ} \mathrm{C}$ for 24 hours. Plates containing 30-300 colonies were counted. The number of colony forming units per gram of a sample (cfu/g) was obtained by multiplying the average colony number with the inverse of the dilution factor.

\section{Enumeration and Detection of Coliform bacteria}

Detection and enumeration of coliform was carried out according to method described by Atlas, (1977). A set of 9 test tubes each containing $9 \mathrm{ml}$ of lactose broth and an inverted Durham tubes were autoclaved to expel air and to sterilize. Similarly, $1 \mathrm{ml}$ from the diluents $10^{1}$ was transferred to the first 3 test tubes, followed by $1 \mathrm{ml}$ from the diluents $10^{2}$ to the second set of 3 test tubes and finally the third diluents $10^{3}$ to the $3^{\text {rd }}$ set of 3 test tubes. All the 9 test tubes were incubated at $37^{\circ} \mathrm{C}$ for 24 hours. Tubes that showed gas and acid production after 24 hours were recorded as positive for the presence of Coliform. Negative tubes were further reincubated for 24 hours. Positive tubes were recorded. Estimate of most probable number of Coliform per gram of sample (MPN/g) was determined by comparing the number of gas positive tubes with the most probable number table. 
BAJOPAS Volume 13 Number 1, June, 2020 Identification of Coliform

A loop full of inoculum from gas positive tubes was streaked on to Eosine methylene blue (EMB) agar plate and incubated at $37^{\circ} \mathrm{C}$ for $24 \mathrm{hrs}$. Colonies which formed bluish black color with green metallic sheen, and reddish colonies were isolated on agar slants. Those colonies showing metallic sheen on EMB were sub cultured into tubes of lactose broth and incubated at $45^{\circ} \mathrm{C}$. The tubes were observed after $24 \mathrm{hrs}$ for gas production. This is the completed test for fecal coliform. Gram stain and other biochemical tests such as Indole, Methyl red, Voges-Proskauer and Citrate Utilization tests (IMVIC), Coagulase and Catalase tests were carried out for the Identification and confirmation of isolates.

\section{Procedure for Indole Test}

Indole test was carried out by preparing a Tryptone broth drawn in to test tubes, sterilized by autoclaving, inoculated with loopful of suspension and incubated at $37^{\circ} \mathrm{C}$ for 24 hours. Three drops of xylene was added in tubes, shaken vigorously and kept for the separation of two layers. One millilitre of Kovac's reagent was added and the formation of pink colour ring indicates positive Indole test.

\section{Procedure for Methyl Red Test}

Methyl red test was carried out by preparing Glucose phosphate broth, dispensed in test tubes, sterilized, inoculated with test culture and incubated at $37^{\circ} \mathrm{C}$ for 24 hours. Five drops of methyl-red indicator was added to the medium for the formation of red colour.

\section{Procedure for Voges-Proskauer Test}

Voges-Proskauer test was carried out by inoculating tubes with the bacterial culture followed by incubation for 48 hours at $37^{\circ} \mathrm{C}$. Separate pipettes were used to pipette $1 \mathrm{ml}$ from each culture tube into clean separate tubes. Eighteen drops $(0.5 \mathrm{ml})$ of Barrit's solution A (a-naphthol) was added to each tube containing glucose phosphate broth followed by the addition of an equal amount of solution $B$ into the same tube. The tubes were shaken at 30 seconds interval. A positive reaction was indicated by the development of a pink color, which turns red in 1-2 hours, after vigorous shaking.

\section{Procedure for Citrate Utilization Test}

Citrate Utilization Test was carried out by distributing melted agar (Simmon Citrate Agar) in to test tubes followed by sterilization at $121.5^{\circ} \mathrm{C}$ for 15 minutes. The test tubes were afterward held in slanted position, inoculated with the given bacterial culture and incubated at $37^{\circ} \mathrm{C}$ for $24 \mathrm{hrs}$. Positive test was indicated by color change of the media from green to blue.

\section{RESULTS AND DISCUSSIONS}

The results of this study are presented in tables $1,2,3$ and 4. Among the sampling areas Kofar Kudu had the highest aerobic mesophilic bacteria counts $4.0 \times 10^{5} \mathrm{cfu} / \mathrm{g}$ followed by Rinji $2.72 \times 10^{5} \mathrm{cfu} / \mathrm{g}$, while Tosaro had the least Aerobic mesophilic bacteria counts of $1.02 \times 10^{5}$ $\mathrm{cfu} / \mathrm{g}$ as indicated in Table 1.Makwalla had the highest coliform count $68 \mathrm{MPN} / \mathrm{g}$ followed by Rinji $37 \mathrm{MPN} / \mathrm{g}$. Tsohuwar Kasuwa had the least coliform counts $8 \mathrm{MPN} / \mathrm{g}$, (Table 2). Result from table 1 shows variation in the microbial contents among the samples which suggest variation in their sources, poor handling procedures and contamination from the processing environment. High coliform count and their differences within sampling areas is an indication of poor microbiological quality of the product. Ndahi et al. (2013) reported microbial load to be a function of the handling personnel and the environment. The results indicated that the samples were contaminated with bacteria as the counts exceeded the minimum safety level $\left(10^{4} \mathrm{cfu} / \mathrm{g}\right)$ for members of the Enterobacteriaceae family. However, it might be a reflection of poor hygienic practices which may contribute to health hazard to the potential consumers. Similarly, Inusa and Sa'id (2017); Osimani et al. (2015) reported that, the initial microbial content of the raw material play significant role in influencing the final microbial load of the finished product. Isolation of members of the Enterobacteriaceae such as $E$. coli, Klebsiella pneumoniae, Salmonella and Shigella signifies danger to the public health. These organisms are capable of producing endotoxins which trigger high fevers in infected individuals, and the enterotoxins which colonize the small intestines and lead to extreme dehydration as a result of vomiting and diarrhea sometimes with severe and fatal outcomes (Amaeze et al., 2016). From the 16 isolated organisms $E$. coli had the highest isolation rate $6(37.5 \%)$ (Table 3), this suggest faecal contamination of the products. $E$. coli is a common flora in the gastrointestinal tract responsible for diarrhea and extra-intestinal infections (CDC, 2011). The result is in conformity with the findings of Ndahi et al. (2013) and Shamsuddeen (2009). Also presence of campylobacter might be due to cross contamination from raw meat to finished product (Tsire). Staphylococcus aureus is a normal flora of the skin, nasal, genital, mouth or anal area in both humans and animals without any symptom of an infection (Matthew et al., 2013). Isolation of $S$. aureus in these study concords with the findings of Lucretia et al. (2018) from Suya sold in Rivers State. 
BAJOPAS Volume 13 Number 1, June, 2020

It is also in agreement with the findings of Yousafzai et al. (2018); Onuorah et al. (2015) and Tijjani and Jumare (2014) from tsire samples in different countries. Presence of $S$. aureus in foods is most of the time an indication of poor human handling, poor environment, unhygienic utensils and equipments used during processing (Igene et al., 2016; Okonko et al., 2013). Infections caused by $S$. aureus are difficult to treat leading to long hospitalization with consequent economic loss (Udobi et al., 2013). These include soft tissue infections, pneumonia, hospital-acquired postoperative wound infections, Staphylococcal food poisoning, impetigo and cellulitis (Charlene et al., 2013). Samples obtained from Dausai and Kofar Kudu had the highest isolation rate $4(80 \%)$ (Table 4 ) probably because of the much commercial activities taking place in the area which can lead to environmental contamination.

Table 1: Total Aerobic Mesophilic Bacterial Count of Tsire sold in Garko Town

\begin{tabular}{lll}
\hline Sampling Area & APC cfu/g & Mean \pm STD \\
\hline Dausai & $2.20 \times 10^{5}$ & $110000 \pm 14142.14$ \\
Kofar Kudu & $4.00 \times 10^{5}$ & $133333.3 \pm 23094.01$ \\
Makwalla & $1.30 \times 10^{5}$ & $32500 \pm 7187.953$ \\
Rinji & $2.72 \times 10^{5}$ & $90666.67 \pm 94769.90$ \\
Tosaro & $1.02 \times 10^{5}$ & $51000 \pm 15556.35$ \\
Tsohuwar Kasuwa & $1.75 \times 10^{5}$ & $35000 \pm 11357.82$ \\
\hline
\end{tabular}

Key: APC: Aerobic Mesophilic Counts

STD: Standard Deviation

Table 2: Total Coliform Count of Tsire sold in Garko Town

\begin{tabular}{lcc}
\hline \multicolumn{1}{c}{ Sampling Area } & TCC MPN/g & Mean \pm STD \\
\hline Dausai & 20 & $6.67 \pm 2.5166$ \\
Kofar Kudu & 32 & $16.00 \pm 5.6569$ \\
Makwalla & 68 & $13.60 \pm 8.7062$ \\
Rinji & 37 & $9.25 \pm 4.7871$ \\
Tosaro & 10 & $5.00 \pm 2.8284$ \\
Tsohuwar Kasuwa & 8 & $4.00 \pm 0.0000$ \\
\hline
\end{tabular}

Table 3: Organisms Isolated from Tsire Sold in Garko

\begin{tabular}{lcl}
\hline Isolated Organism & Frequency & Percentage (\%) \\
\hline Campylobacter & 2 & 06.66 \\
Escherichia coli & 6 & 20.00 \\
Klebsiella pneumoniae & 2 & 06.66 \\
Salmonella species & 1 & 03.33 \\
Shigella & 3 & 10.00 \\
Staphylococcus aureus & 2 & 06.66 \\
Total & 16 & \\
\hline
\end{tabular}

Table 4: Distribution of Organisms within Sampling Area

\begin{tabular}{lcc}
\hline \multicolumn{1}{c}{ Sampling Area } & No. Isolated & Percentage (\%) \\
\hline Dausai & 4 & 80 \\
Kofar Kudu & 4 & 80 \\
Makwalla & 2 & 40 \\
Rinji & 3 & 60 \\
Tosaro & 2 & 40 \\
Tsohuwar Kasuwa & 1 & 20 \\
Total & 16 & \\
\hline
\end{tabular}

\section{CONCLUSION}

Results indicated $4.00 \times 10^{5} \mathrm{CFU} / \mathrm{g}$ as the highest APCs count; while $68 \mathrm{MPN} / \mathrm{g}$ was the highest TCCs from the 30 samples analyzed. Among the isolates, $E$. coli has the highest isolation rate of $6(20 \%)$. Dausai and Kofar kudu were having the highest bacteria count of $4(80 \%)$, each, indicating higher contamination in those locations. 
BAJOPAS Volume 13 Number 1, June, 2020 RECOMMENDATIONS

The following recommendations are tenable:

1. Hygienic practices at all stages of production should be improved to safe guard the consumers against potential health hazard.

2. Monitoring of microbiological contamination of Tsire during preparations, packaging and marketing is essential to ensure product of good microbiological quality for consumers' health.

\section{REFERENCES}

Abdullahi, I. O., Umoh, V. J. and Galadima, M. (2004). Hazards Associated with Kilishi Preparations in Zaria. Nigerian Journal of Microbiology, 18 (1-2): $339-345$.

Ahmadu, J. and Ibrahim E. J., (2013): Determinants of Revenue in Suya Production in BeninCity, Edo State, Nigeria. Nigerian journal of agriculture, food and environment.9(3):1-5

Amaeze, N. Aboh, M. Itohan, A. Felix, E. Olatunji, T. and Oladosu, P. (2016) Microbial Profile, Antibiotic Sensitivity and Heat Resistance of Bacterial Isolates from Commercial Roasted Beef (Suya) in Abuja, Nigeria. JOPAT, 15(2): $22-30$.

Apata, E.S., Kuku1, I.A., Apata, O.C. and Adeyemi, K.O. (2013). Evaluation of Suya(Tsire) - An Intermediate Moisture Meat Product in Ogun State, Nigeria. J. Food Res 2 (1): 87.

Atlas, R. M. (1997) Principles of Microbiology Second Edition. C. Brown Publishers. Pp 802-803.

Borch, E. Kant-Muermans, M. L., Blixt, Y. (1996) Bacterial Spoilage of Meat and Cured Meat Products. Int $\mathrm{J}$ Food Microbiol .33(1): 103-20.

Centre for Disease Control, CDC (2011). "Escherichia coli 0157:H7" Division of Bacterial and Mycotic Diseasesht://www.cdc.gov/nczved/divisi ons/dfbmd/diseases/ecoli_0157h7/.

Charlene, R. J., Johnnie, A. D., and John, B. B., (2013) Prevalence and Characterization of Methicillin-Resistant Staphylococcus aureus Isolates from Retail Meat and Humans in Georgia. American society for Microbiology. J. of clinical microbiology. 12(1):123-6 doi:10.1128/JCM.0316612JCM.03166-12

Egbebi, A.O and Seidu, K., T. (2011). Microbiological Evaluation of Suya (dried smoked

meat) Sold in Ado and Akure, South West Nigeria.European Journal of Experinmental Biology, 1(4):1-5
3. Government should establish regulatory bodies responsible for inculcating hygiene habits to the local producers and vendors in order to prevent instant, cross and post processing contaminations by microbial pathogens.

4. Awareness and sensitization of local food producers about good hygienic practices in food handling and processing.

Falegan, C, R., Akoja, S. D., and Oyarekua, M. A., (2017) Microbiological Assessment of Suya (Sliced Roasted Beef) in Ado-Ekiti Metropolis, Ekiti State, Nigeria. MOJ Biology andMedicine.

Fonkem, D., N. Tanya, V., N. and Ebangi, A., L. (2010). Effect of Season on the Microbiological Quality of Kilishi, a Traditional Cameroonian Dried Beef Product. Tropicultura, 28(1): 10-15.

Food and Agricultural Organization of the United Nations (F A O, 1979). Manual of food quality control 4. Microbiological analysis.

Food and Agriculture Organisation of the United Nation (FAO), 2019. Nigeria at a glance.

Igene J.O., Uwadia, O.E., Ebabhamiegbebho, P.A. and Evivie, S.E., (2016) Shelf life Stability Studies of University of Benin (UNIBEN) Proff's Kilishi Product Asian Journal of Science and Technology 7(1): 2268-2274.

Inusa, S. K. and Said, I. S. (2017) Evaluation of the Chemical and Microbiological Properties Of Kilishi Sold in Kano Metropolis. Journal of Dry land Agriculture, 3 (1): $59-69$.

Lucretia, I. B, Patience, C. Obinna-Echem, Sophia, C. A. (2018) Microbiological quality andantibiotic sensitivity of potential pathogens isolated from meat product (Suya) sold in Rivers State University and its environs. International Journal of Biotechnology and Food Science, 6(4): 67-76.

Matthew, E., Drosos, E., John, L. and Ioanna, P. (2013) MRSA in Africa: Filling the Global Map of Antimicrobial Resistance PLOS One. 8(7): e68024 doi: 10.1371/journal.pone.0068024

Mgbemere, V.N., Akpapunam, M. A. and Igene, J. O., (2011). Effect of Groundnut FlourSubstitution on Yield, Quality and Storage Stability of Kilishi - a Nigerian Indigenous Dried Meat Product. African Journal of Food, Agriculture, Nutrition and Development, $\quad \mathbf{1 1}(2)$ : 4718-4738. 
BAJOPAS Volume 13 Number 1, June, 2020

Mubarak, A. A., Azeez, M. L., Amos A. O., Opeyemi, O. O. (2016) Assessment of Animal Protein Consumption and Food Security Among Rural Households in Kwara State, Nigeria American Journal of Business and Society, 1(4): 233245.

Ndahi, M., D. Kwaga, J., K. P. Bello, M. Kabir J., V. Umoh, .J. Yakubu, S., E. and Nok, A., J. (2013) Prevalence and Antimicrobial Susceptibility of Listeria Monocytogenes and Methicillin-Resistant Staphylococcus aureus Strains from Raw Meat and Meat Products in Zaria, Nigeria. Applied Journal of Microbiology, 58(3):262-9.

Okonko, I.O., Odu, N.N. and Igboh, I.E. (2013). Microbiological Analysis of Kilishi Sold In Port Harcourt, Nigeria. New York Science Journal, 6 (7):37-43.

Osimani, A., Aquilanti, L. and Clementi, F. (2015) Microbiological Quality of Meatbased Meals and Operation of Control Systems within a Food Service Environment. International Food Research Journal 22(4): 1692-1698.

Onuorah, S. Obika, I. Odibo, F. Orji, M. (2015)An Assessment of the Bacteriological Quality of Tsire-Suya (Grilled Beef) sold in Awka, Nigeria. American. J. Life. Sci. Res. 3(4):287292.

Razavilar, V, Khandaghi, J. Barzgari, A. (2010); Isolation of Eschericia coli 0157:H7 from manure fertilized farms and raw vegetables grown on it, in Tabriz city in
Iran. African Journal of Microbiology Research, 4(9): 891-895.

Scallan, E. Hoekstra, R. M. Angulo, F. J.Tauxe, R. V, Widdowson, M. Roy, S. L et al., (2011).Food borne illness acquired in the United States- Major Pathogens. Emerg. Infec Dis, 17(1): 7-15.

Shamsuddeen U (2009). Microbiological quality of spice used in the production of Kilishi a traditionally dried and grilled meat product. Bayero Journal of Pure andApplied Sciences, 2(2): 66-69.

Shamsuddeen, U. (2015) Microbiological Hazard and Critical control point Analysis of Dried and Minced Meat Snacks Produced in Kano Nigeria. Lambert Academic Publishing; Pp 1-36.

Tijani, O.and Jumare, S. (2014). Microblological Quality Assessment of Meat

Sold in KauraNamoda. International Conference on Earth, Environment and Life sciences (EELS) Dubai (UAE).

Udobi, C. E., Obajuluwa, A. F., and Onaolapo, J. A., (2013) Prevalence and Antibiotic Resistance Pattern of MethicillinResistant Staphylococcus aureus from an Orthopaedic Hospital in Nigeria BioMed Research International; 26(6); 6-7.

WHO, 2015 Foodborne diseases in the WHO African Region.

Yousafzai HA, Rind R, Khan MA, Abro SH, Korejo NA, Ejaz M, Kabir A, Shahid M, Memon S. (2019). Microbiological Contamination of Cattle and Meat in Peshawar, Pakistan. J. Anim. Health Prod. 7(1): 1116. 


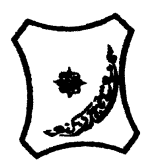

Bayero Journal of Pure and Applied Sciences, 13(1); 40 - 45

Received: September, 2019

Accepted: April, 2020

ISSN $2006-6996$

\title{
BACTERIOLOGICAL QUALITY OF STICK MEAT (Tsire) SOLD IN GARKO LOCAL GOVERNMENT AREA OF KANO STATE, NIGERIA
}

\author{
$*^{1}$ Dahiru A. T. and ${ }^{2}$ Maigari A. K. \\ ${ }^{1}$ Department of Hospitality Management, School of Technology, Kano State Polytechnic, PMB 3348, \\ Kano Nigeria. \\ ${ }^{2}$ Departmnt of Biological Sciences, Bayero University, Kano \\ Corresponding Author: dturajo61@gmail.com; GSM: 08087508262.
}

ABSTRACT

Stick meat, locally called Tsire in Hausa Language, is a significant portion of the diet of a large active population of Northern Nigeria. However, because of the handling and processing methods by the manufacturers as well as the hawking system of stick meat, the meat product may be exposed to both pre- and post-processed product contamination, and thus may poses danger to public health. Therefore, considering the role of Tsire in improving nutrition and increase household income to the populace, the need to improve the processing, distribution and overall quality of the product is simply indispensable. A total of 30 samples (5 samples from each of the 6 sampling points) of Tsire were collected randomly in Garko Town. Aerobic plate counts (APCs) and Total coliform counts (TCCS) of Tsire samples were determined using standard microbiological methods. APCs ranged from $1.02 \times 10^{5}$ to $4.00 \times 10^{5} \mathrm{CFU} / \mathrm{g}$; while TCCs ranged from $8 \mathrm{MPN} / \mathrm{g}$ to $68 \mathrm{MPN} / \mathrm{g}$. From the 30 samples screened, 16(53.33\%) bacteria namely, Campylobacter 2(6.66\%), Escherichia coli 6(20\%), Klebsiella pneumoniae 2(6.66\%), Salmonella spp. 1(3.33\%), Shigella 3(10\%) and Staphylococcus aureus 2(6.66\%) were detected. $E$. coli has the highest isolation rate of 6(20\%), while Salmonella spp. had the least frequency of 1(3.33\%). The distribution of isolated organisms within the study area were as follows: Dausai, 4(80\%), Kofar kudu, 4(80\%), Makwalla, 2(40\%), Rinji, 3(60\%), Tosaro, 2(40\%), and Tsohuwar Kasuwa, 1(20\%). The results have indicated that the Tsire was contaminated with bacteria thus exposing the product to fast deterioration, spoilage and also a vehicle for food borne illness, suggesting for adequate hygienic practices at all the stages, prior to consumption, to ensure safety of the meat product.

Key words: APCs, TCCs, Contamination, Microorganisms, Garko

\section{INTRODUCTION}

Nigeria is one of the developing nations with inadequate food supply and most often deficient in protein content (FAO, 2019). Nigerian's average animal protein intake per head per day is estimated at $7.9 \mathrm{~g}$ as against $35 \mathrm{~g}$ recommended value by Food and Agricultural Organization (Mubarak et al., 2016). These low levels of animal protein intake create great concern as it affects the nutritional status of Nigerians. Hence, there is the need for sufficient supply of animal protein from energy rich animal products to satisfy the nutritional requirements for Nigerians.

Meat is one major source of animal protein largely composed of water, protein and fats which can make it susceptible to microbial contamination within short time leading to spoilage (Apata et al., 2013; Mgbemere et al., 2011). Meat is mostly eaten after it has been cooked or processed in a variety of ways such as sun drying; smoking and roasting with or without fortifications (Borch et al., 1996). In Nigeria meat products such as Tsire, Kilishi and Balangu are locally produced using one or more of these methods in order to meet the nutritional requirements of the teeming Nigerians (Egbebi, 2011).

Tsire is a popular Nigerian traditional processed ready-to-eat roasted stick meat product (Shamsuddeen, 2015). It is sold in public places, along roads, in hotels, parks, quarters and even offices (Falegan et al., 2017). It is prepared from boneless healthy animal flesh such as beef and mutton, spiced with peanut cake, salt, vegetable oil and other flavorings followed by roasting (Shamsuddeen, 2015). Consumption of these products has extended to other parts of African countries such as Ghana, Somali, Cameroun and Chad (Ahmadu and Ibrahim, 2013). 
BAJOPAS Volume 13 Number 1, June, 2020

However, evidence of quality control sticking to procedural hygiene by the handlers during preparation and retailing of these products is poorly documented. Tsire is of great safety risk because of the fact that there are erratic cases of gastroenteritis and symptoms of food infection after consumption (WHO, 2015). Food borne illnesses are one of the major health problems in developing and developed countries (Razavilar, 2010). According to the World Health Organization, WHO (2015), $0.07 \%$ death of the 600 million global burdens of Foodborne illnesses have been reported to be caused by bacteria, viruses, fungi and chemicals. In America $0.27 \%$ of the estimated 48 million affected people is hospitalized and about $0.0063 \%$ deaths are recorded each year (Scallan et al., 2011). More than 91 million people in Africa fall ill and $0.15 \%$ dies each year, making Africa the highest burden bearer of Foodborne diseases per population (WHO, 2015).

Application of a Hazard Analysis Critical Control Point (HACCP) at all stages of meat products preparation is essential in order to ensure its safety. Thus, according to the guidelines of good manufacturing practice, the level of total aerobic bacterial contamination of thermally processed meat products should not exceed $10^{4}\left(\mathrm{cfu} \mathrm{g}^{-1}\right)$. Enterobacteriaceae and faecal coliform contamination in meat products should be within the range of $10^{2}-10^{4}$ and $10-10^{3} \mathrm{cfu} \mathrm{g}^{-1}$, respectively (Shamsuddeen, 2015). The aim of the study is therefore, to assess the total viable bacterial counts of tsire marketed locally within Garko town, and to isolate and identify the organisms at the point of consumption with the intention of promoting public health and food hygiene habits in the Nigerian populace.

\section{MATERIALS AND METHODS Study Area and Population}

Garko is one of the existing 44 local government areas located in Kano south west zone of Kano state with its capital administrative headquarters in the Garko town. It has coordinates $11^{\circ} 39^{\prime} \mathrm{N}$ $8^{\circ} 54^{\prime} \mathrm{E}$, and an area of $450 \mathrm{~km}^{2}$. The projected population of Garko local Government was 225,300 according to the National Population Census report (2018). Garko is known for agricultural activities both farming and animal husbandry. It is popularly known for large scale rice production. Other food crops include sweet potatoes, cassava, onions, sorghum, millet and sugarcane. Cows, sheep and goats are major groups of animals reared by majority of the populace. Meat products processed, retailed and consumed in Garko include roasted meat (Balangu), dried roasted meat (Kilishi), stick meat (Tsire), hide and skin pepper soup (Ragadada) and minced fried meat (Danbunnama).

\section{Samples Collection}

Five samples of Tsire products were collected from 6 different identified locations within Garko town in a sterile foil paper and immediately analyzed for the presence of bacteria.

\section{Sample Preparation}

Sample preparation for the bacteriological analysis was carried out in accordance with the method described by Atlas (1997). Twenty five grams $(25 \mathrm{~g})$ of the sample was homogenized in $225 \mathrm{ml}$ peptone water using Kenwood blender machine to obtain a $10^{1}$ homogenate. The homogenate was thoroughly shaken and $1 \mathrm{ml}$ pipetted into test tubes containing $9 \mathrm{ml}$ of peptone water $\left(10^{2}\right)$. The test tubes were further serially diluted to $10^{5}$.

Total Aerobic Mesophilic Bacterial Count

Total Aerobic mesophilic bacterial count was determined using the method described by Abdullahi et al. (2004) where $1 \mathrm{ml}$ of inoculums from $10^{1}$ to $10^{5}$ dilutions were transferred into duplicate Petri dishes and labeled accordingly. This was followed by pouring aseptically about $15 \mathrm{ml}$ of molten nutrient agar. The culture was homogenized by gentle spinning of the plates and allowed to solidify. The plates were incubated at $37^{\circ} \mathrm{C}$ for 24 hours. Plates containing 30-300 colonies were counted. The number of colony forming units per gram of a sample (cfu/g) was obtained by multiplying the average colony number with the inverse of the dilution factor.

\section{Enumeration and Detection of Coliform bacteria}

Detection and enumeration of coliform was carried out according to method described by Atlas, (1977). A set of 9 test tubes each containing $9 \mathrm{ml}$ of lactose broth and an inverted Durham tubes were autoclaved to expel air and to sterilize. Similarly, $1 \mathrm{ml}$ from the diluents $10^{1}$ was transferred to the first 3 test tubes, followed by $1 \mathrm{ml}$ from the diluents $10^{2}$ to the second set of 3 test tubes and finally the third diluents $10^{3}$ to the $3^{\text {rd }}$ set of 3 test tubes. All the 9 test tubes were incubated at $37^{\circ} \mathrm{C}$ for 24 hours. Tubes that showed gas and acid production after 24 hours were recorded as positive for the presence of Coliform. Negative tubes were further reincubated for 24 hours. Positive tubes were recorded. Estimate of most probable number of Coliform per gram of sample (MPN/g) was determined by comparing the number of gas positive tubes with the most probable number table. 
BAJOPAS Volume 13 Number 1, June, 2020 Identification of Coliform

A loop full of inoculum from gas positive tubes was streaked on to Eosine methylene blue (EMB) agar plate and incubated at $37^{\circ} \mathrm{C}$ for $24 \mathrm{hrs}$. Colonies which formed bluish black color with green metallic sheen, and reddish colonies were isolated on agar slants. Those colonies showing metallic sheen on EMB were sub cultured into tubes of lactose broth and incubated at $45^{\circ} \mathrm{C}$. The tubes were observed after $24 \mathrm{hrs}$ for gas production. This is the completed test for fecal coliform. Gram stain and other biochemical tests such as Indole, Methyl red, Voges-Proskauer and Citrate Utilization tests (IMVIC), Coagulase and Catalase tests were carried out for the Identification and confirmation of isolates.

\section{Procedure for Indole Test}

Indole test was carried out by preparing a Tryptone broth drawn in to test tubes, sterilized by autoclaving, inoculated with loopful of suspension and incubated at $37^{\circ} \mathrm{C}$ for 24 hours. Three drops of xylene was added in tubes, shaken vigorously and kept for the separation of two layers. One millilitre of Kovac's reagent was added and the formation of pink colour ring indicates positive Indole test.

\section{Procedure for Methyl Red Test}

Methyl red test was carried out by preparing Glucose phosphate broth, dispensed in test tubes, sterilized, inoculated with test culture and incubated at $37^{\circ} \mathrm{C}$ for 24 hours. Five drops of methyl-red indicator was added to the medium for the formation of red colour.

\section{Procedure for Voges-Proskauer Test}

Voges-Proskauer test was carried out by inoculating tubes with the bacterial culture followed by incubation for 48 hours at $37^{\circ} \mathrm{C}$. Separate pipettes were used to pipette $1 \mathrm{ml}$ from each culture tube into clean separate tubes. Eighteen drops $(0.5 \mathrm{ml})$ of Barrit's solution A (a-naphthol) was added to each tube containing glucose phosphate broth followed by the addition of an equal amount of solution $B$ into the same tube. The tubes were shaken at 30 seconds interval. A positive reaction was indicated by the development of a pink color, which turns red in 1-2 hours, after vigorous shaking.

\section{Procedure for Citrate Utilization Test}

Citrate Utilization Test was carried out by distributing melted agar (Simmon Citrate Agar) in to test tubes followed by sterilization at $121.5^{\circ} \mathrm{C}$ for 15 minutes. The test tubes were afterward held in slanted position, inoculated with the given bacterial culture and incubated at $37^{\circ} \mathrm{C}$ for $24 \mathrm{hrs}$. Positive test was indicated by color change of the media from green to blue.

\section{RESULTS AND DISCUSSIONS}

The results of this study are presented in tables $1,2,3$ and 4. Among the sampling areas Kofar Kudu had the highest aerobic mesophilic bacteria counts $4.0 \times 10^{5} \mathrm{cfu} / \mathrm{g}$ followed by Rinji $2.72 \times 10^{5} \mathrm{cfu} / \mathrm{g}$, while Tosaro had the least Aerobic mesophilic bacteria counts of $1.02 \times 10^{5}$ $\mathrm{cfu} / \mathrm{g}$ as indicated in Table 1.Makwalla had the highest coliform count $68 \mathrm{MPN} / \mathrm{g}$ followed by Rinji $37 \mathrm{MPN} / \mathrm{g}$. Tsohuwar Kasuwa had the least coliform counts $8 \mathrm{MPN} / \mathrm{g}$, (Table 2). Result from table 1 shows variation in the microbial contents among the samples which suggest variation in their sources, poor handling procedures and contamination from the processing environment. High coliform count and their differences within sampling areas is an indication of poor microbiological quality of the product. Ndahi et al. (2013) reported microbial load to be a function of the handling personnel and the environment. The results indicated that the samples were contaminated with bacteria as the counts exceeded the minimum safety level $\left(10^{4} \mathrm{cfu} / \mathrm{g}\right)$ for members of the Enterobacteriaceae family. However, it might be a reflection of poor hygienic practices which may contribute to health hazard to the potential consumers. Similarly, Inusa and Sa'id (2017); Osimani et al. (2015) reported that, the initial microbial content of the raw material play significant role in influencing the final microbial load of the finished product. Isolation of members of the Enterobacteriaceae such as $E$. coli, Klebsiella pneumoniae, Salmonella and Shigella signifies danger to the public health. These organisms are capable of producing endotoxins which trigger high fevers in infected individuals, and the enterotoxins which colonize the small intestines and lead to extreme dehydration as a result of vomiting and diarrhea sometimes with severe and fatal outcomes (Amaeze et al., 2016). From the 16 isolated organisms $E$. coli had the highest isolation rate $6(37.5 \%)$ (Table 3), this suggest faecal contamination of the products. $E$. coli is a common flora in the gastrointestinal tract responsible for diarrhea and extra-intestinal infections (CDC, 2011). The result is in conformity with the findings of Ndahi et al. (2013) and Shamsuddeen (2009). Also presence of campylobacter might be due to cross contamination from raw meat to finished product (Tsire). Staphylococcus aureus is a normal flora of the skin, nasal, genital, mouth or anal area in both humans and animals without any symptom of an infection (Matthew et al., 2013). Isolation of $S$. aureus in these study concords with the findings of Lucretia et al. (2018) from Suya sold in Rivers State. 
BAJOPAS Volume 13 Number 1, June, 2020

It is also in agreement with the findings of Yousafzai et al. (2018); Onuorah et al. (2015) and Tijjani and Jumare (2014) from tsire samples in different countries. Presence of $S$. aureus in foods is most of the time an indication of poor human handling, poor environment, unhygienic utensils and equipments used during processing (Igene et al., 2016; Okonko et al., 2013). Infections caused by $S$. aureus are difficult to treat leading to long hospitalization with consequent economic loss (Udobi et al., 2013). These include soft tissue infections, pneumonia, hospital-acquired postoperative wound infections, Staphylococcal food poisoning, impetigo and cellulitis (Charlene et al., 2013). Samples obtained from Dausai and Kofar Kudu had the highest isolation rate $4(80 \%)$ (Table 4 ) probably because of the much commercial activities taking place in the area which can lead to environmental contamination.

Table 1: Total Aerobic Mesophilic Bacterial Count of Tsire sold in Garko Town

\begin{tabular}{lll}
\hline Sampling Area & APC cfu/g & Mean \pm STD \\
\hline Dausai & $2.20 \times 10^{5}$ & $110000 \pm 14142.14$ \\
Kofar Kudu & $4.00 \times 10^{5}$ & $133333.3 \pm 23094.01$ \\
Makwalla & $1.30 \times 10^{5}$ & $32500 \pm 7187.953$ \\
Rinji & $2.72 \times 10^{5}$ & $90666.67 \pm 94769.90$ \\
Tosaro & $1.02 \times 10^{5}$ & $51000 \pm 15556.35$ \\
Tsohuwar Kasuwa & $1.75 \times 10^{5}$ & $35000 \pm 11357.82$ \\
\hline
\end{tabular}

Key: APC: Aerobic Mesophilic Counts

STD: Standard Deviation

Table 2: Total Coliform Count of Tsire sold in Garko Town

\begin{tabular}{lcc}
\hline \multicolumn{1}{c}{ Sampling Area } & TCC MPN/g & Mean \pm STD \\
\hline Dausai & 20 & $6.67 \pm 2.5166$ \\
Kofar Kudu & 32 & $16.00 \pm 5.6569$ \\
Makwalla & 68 & $13.60 \pm 8.7062$ \\
Rinji & 37 & $9.25 \pm 4.7871$ \\
Tosaro & 10 & $5.00 \pm 2.8284$ \\
Tsohuwar Kasuwa & 8 & $4.00 \pm 0.0000$ \\
\hline
\end{tabular}

Table 3: Organisms Isolated from Tsire Sold in Garko

\begin{tabular}{lcl}
\hline Isolated Organism & Frequency & Percentage (\%) \\
\hline Campylobacter & 2 & 06.66 \\
Escherichia coli & 6 & 20.00 \\
Klebsiella pneumoniae & 2 & 06.66 \\
Salmonella species & 1 & 03.33 \\
Shigella & 3 & 10.00 \\
Staphylococcus aureus & 2 & 06.66 \\
Total & 16 & \\
\hline
\end{tabular}

Table 4: Distribution of Organisms within Sampling Area

\begin{tabular}{lcc}
\hline \multicolumn{1}{c}{ Sampling Area } & No. Isolated & Percentage (\%) \\
\hline Dausai & 4 & 80 \\
Kofar Kudu & 4 & 80 \\
Makwalla & 2 & 40 \\
Rinji & 3 & 60 \\
Tosaro & 2 & 40 \\
Tsohuwar Kasuwa & 1 & 20 \\
Total & 16 & \\
\hline
\end{tabular}

\section{CONCLUSION}

Results indicated $4.00 \times 10^{5} \mathrm{CFU} / \mathrm{g}$ as the highest APCs count; while $68 \mathrm{MPN} / \mathrm{g}$ was the highest TCCs from the 30 samples analyzed. Among the isolates, $E$. coli has the highest isolation rate of $6(20 \%)$. Dausai and Kofar kudu were having the highest bacteria count of $4(80 \%)$, each, indicating higher contamination in those locations. 
BAJOPAS Volume 13 Number 1, June, 2020 RECOMMENDATIONS

The following recommendations are tenable:

1. Hygienic practices at all stages of production should be improved to safe guard the consumers against potential health hazard.

2. Monitoring of microbiological contamination of Tsire during preparations, packaging and marketing is essential to ensure product of good microbiological quality for consumers' health.

\section{REFERENCES}

Abdullahi, I. O., Umoh, V. J. and Galadima, M. (2004). Hazards Associated with Kilishi Preparations in Zaria. Nigerian Journal of Microbiology, 18 (1-2): $339-345$.

Ahmadu, J. and Ibrahim E. J., (2013): Determinants of Revenue in Suya Production in BeninCity, Edo State, Nigeria. Nigerian journal of agriculture, food and environment.9(3):1-5

Amaeze, N. Aboh, M. Itohan, A. Felix, E. Olatunji, T. and Oladosu, P. (2016) Microbial Profile, Antibiotic Sensitivity and Heat Resistance of Bacterial Isolates from Commercial Roasted Beef (Suya) in Abuja, Nigeria. JOPAT, 15(2): $22-30$.

Apata, E.S., Kuku1, I.A., Apata, O.C. and Adeyemi, K.O. (2013). Evaluation of Suya(Tsire) - An Intermediate Moisture Meat Product in Ogun State, Nigeria. J. Food Res 2 (1): 87.

Atlas, R. M. (1997) Principles of Microbiology Second Edition. C. Brown Publishers. Pp 802-803.

Borch, E. Kant-Muermans, M. L., Blixt, Y. (1996) Bacterial Spoilage of Meat and Cured Meat Products. Int $\mathrm{J}$ Food Microbiol .33(1): 103-20.

Centre for Disease Control, CDC (2011). "Escherichia coli 0157:H7" Division of Bacterial and Mycotic Diseasesht://www.cdc.gov/nczved/divisi ons/dfbmd/diseases/ecoli_0157h7/.

Charlene, R. J., Johnnie, A. D., and John, B. B., (2013) Prevalence and Characterization of Methicillin-Resistant Staphylococcus aureus Isolates from Retail Meat and Humans in Georgia. American society for Microbiology. J. of clinical microbiology. 12(1):123-6 doi:10.1128/JCM.0316612JCM.03166-12

Egbebi, A.O and Seidu, K., T. (2011). Microbiological Evaluation of Suya (dried smoked

meat) Sold in Ado and Akure, South West Nigeria.European Journal of Experinmental Biology, 1(4):1-5
3. Government should establish regulatory bodies responsible for inculcating hygiene habits to the local producers and vendors in order to prevent instant, cross and post processing contaminations by microbial pathogens.

4. Awareness and sensitization of local food producers about good hygienic practices in food handling and processing.

Falegan, C, R., Akoja, S. D., and Oyarekua, M. A., (2017) Microbiological Assessment of Suya (Sliced Roasted Beef) in Ado-Ekiti Metropolis, Ekiti State, Nigeria. MOJ Biology andMedicine.

Fonkem, D., N. Tanya, V., N. and Ebangi, A., L. (2010). Effect of Season on the Microbiological Quality of Kilishi, a Traditional Cameroonian Dried Beef Product. Tropicultura, 28(1): 10-15.

Food and Agricultural Organization of the United Nations (F A O, 1979). Manual of food quality control 4. Microbiological analysis.

Food and Agriculture Organisation of the United Nation (FAO), 2019. Nigeria at a glance.

Igene J.O., Uwadia, O.E., Ebabhamiegbebho, P.A. and Evivie, S.E., (2016) Shelf life Stability Studies of University of Benin (UNIBEN) Proff's Kilishi Product Asian Journal of Science and Technology 7(1): 2268-2274.

Inusa, S. K. and Said, I. S. (2017) Evaluation of the Chemical and Microbiological Properties Of Kilishi Sold in Kano Metropolis. Journal of Dry land Agriculture, 3 (1): $59-69$.

Lucretia, I. B, Patience, C. Obinna-Echem, Sophia, C. A. (2018) Microbiological quality andantibiotic sensitivity of potential pathogens isolated from meat product (Suya) sold in Rivers State University and its environs. International Journal of Biotechnology and Food Science, 6(4): 67-76.

Matthew, E., Drosos, E., John, L. and Ioanna, P. (2013) MRSA in Africa: Filling the Global Map of Antimicrobial Resistance PLOS One. 8(7): e68024 doi: 10.1371/journal.pone.0068024

Mgbemere, V.N., Akpapunam, M. A. and Igene, J. O., (2011). Effect of Groundnut FlourSubstitution on Yield, Quality and Storage Stability of Kilishi - a Nigerian Indigenous Dried Meat Product. African Journal of Food, Agriculture, Nutrition and Development, $\quad \mathbf{1 1}(2)$ : 4718-4738. 
BAJOPAS Volume 13 Number 1, June, 2020

Mubarak, A. A., Azeez, M. L., Amos A. O., Opeyemi, O. O. (2016) Assessment of Animal Protein Consumption and Food Security Among Rural Households in Kwara State, Nigeria American Journal of Business and Society, 1(4): 233245.

Ndahi, M., D. Kwaga, J., K. P. Bello, M. Kabir J., V. Umoh, .J. Yakubu, S., E. and Nok, A., J. (2013) Prevalence and Antimicrobial Susceptibility of Listeria Monocytogenes and Methicillin-Resistant Staphylococcus aureus Strains from Raw Meat and Meat Products in Zaria, Nigeria. Applied Journal of Microbiology, 58(3):262-9.

Okonko, I.O., Odu, N.N. and Igboh, I.E. (2013). Microbiological Analysis of Kilishi Sold In Port Harcourt, Nigeria. New York Science Journal, 6 (7):37-43.

Osimani, A., Aquilanti, L. and Clementi, F. (2015) Microbiological Quality of Meatbased Meals and Operation of Control Systems within a Food Service Environment. International Food Research Journal 22(4): 1692-1698.

Onuorah, S. Obika, I. Odibo, F. Orji, M. (2015)An Assessment of the Bacteriological Quality of Tsire-Suya (Grilled Beef) sold in Awka, Nigeria. American. J. Life. Sci. Res. 3(4):287292.

Razavilar, V, Khandaghi, J. Barzgari, A. (2010); Isolation of Eschericia coli 0157:H7 from manure fertilized farms and raw vegetables grown on it, in Tabriz city in
Iran. African Journal of Microbiology Research, 4(9): 891-895.

Scallan, E. Hoekstra, R. M. Angulo, F. J.Tauxe, R. V, Widdowson, M. Roy, S. L et al., (2011).Food borne illness acquired in the United States- Major Pathogens. Emerg. Infec Dis, 17(1): 7-15.

Shamsuddeen U (2009). Microbiological quality of spice used in the production of Kilishi a traditionally dried and grilled meat product. Bayero Journal of Pure andApplied Sciences, 2(2): 66-69.

Shamsuddeen, U. (2015) Microbiological Hazard and Critical control point Analysis of Dried and Minced Meat Snacks Produced in Kano Nigeria. Lambert Academic Publishing; Pp 1-36.

Tijani, O.and Jumare, S. (2014). Microblological Quality Assessment of Meat

Sold in KauraNamoda. International Conference on Earth, Environment and Life sciences (EELS) Dubai (UAE).

Udobi, C. E., Obajuluwa, A. F., and Onaolapo, J. A., (2013) Prevalence and Antibiotic Resistance Pattern of MethicillinResistant Staphylococcus aureus from an Orthopaedic Hospital in Nigeria BioMed Research International; 26(6); 6-7.

WHO, 2015 Foodborne diseases in the WHO African Region.

Yousafzai HA, Rind R, Khan MA, Abro SH, Korejo NA, Ejaz M, Kabir A, Shahid M, Memon S. (2019). Microbiological Contamination of Cattle and Meat in Peshawar, Pakistan. J. Anim. Health Prod. 7(1): 1116. 


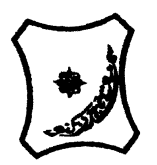

Bayero Journal of Pure and Applied Sciences, 13(1); 40 - 45

Received: September, 2019

Accepted: April, 2020

ISSN $2006-6996$

\title{
BACTERIOLOGICAL QUALITY OF STICK MEAT (Tsire) SOLD IN GARKO LOCAL GOVERNMENT AREA OF KANO STATE, NIGERIA
}

\author{
$*^{1}$ Dahiru A. T. and ${ }^{2}$ Maigari A. K. \\ ${ }^{1}$ Department of Hospitality Management, School of Technology, Kano State Polytechnic, PMB 3348, \\ Kano Nigeria. \\ ${ }^{2}$ Departmnt of Biological Sciences, Bayero University, Kano \\ Corresponding Author: dturajo61@gmail.com; GSM: 08087508262.
}

ABSTRACT

Stick meat, locally called Tsire in Hausa Language, is a significant portion of the diet of a large active population of Northern Nigeria. However, because of the handling and processing methods by the manufacturers as well as the hawking system of stick meat, the meat product may be exposed to both pre- and post-processed product contamination, and thus may poses danger to public health. Therefore, considering the role of Tsire in improving nutrition and increase household income to the populace, the need to improve the processing, distribution and overall quality of the product is simply indispensable. A total of 30 samples (5 samples from each of the 6 sampling points) of Tsire were collected randomly in Garko Town. Aerobic plate counts (APCs) and Total coliform counts (TCCS) of Tsire samples were determined using standard microbiological methods. APCs ranged from $1.02 \times 10^{5}$ to $4.00 \times 10^{5} \mathrm{CFU} / \mathrm{g}$; while TCCs ranged from $8 \mathrm{MPN} / \mathrm{g}$ to $68 \mathrm{MPN} / \mathrm{g}$. From the 30 samples screened, 16(53.33\%) bacteria namely, Campylobacter 2(6.66\%), Escherichia coli 6(20\%), Klebsiella pneumoniae 2(6.66\%), Salmonella spp. 1(3.33\%), Shigella 3(10\%) and Staphylococcus aureus 2(6.66\%) were detected. $E$. coli has the highest isolation rate of 6(20\%), while Salmonella spp. had the least frequency of 1(3.33\%). The distribution of isolated organisms within the study area were as follows: Dausai, 4(80\%), Kofar kudu, 4(80\%), Makwalla, 2(40\%), Rinji, 3(60\%), Tosaro, 2(40\%), and Tsohuwar Kasuwa, 1(20\%). The results have indicated that the Tsire was contaminated with bacteria thus exposing the product to fast deterioration, spoilage and also a vehicle for food borne illness, suggesting for adequate hygienic practices at all the stages, prior to consumption, to ensure safety of the meat product.

Key words: APCs, TCCs, Contamination, Microorganisms, Garko

\section{INTRODUCTION}

Nigeria is one of the developing nations with inadequate food supply and most often deficient in protein content (FAO, 2019). Nigerian's average animal protein intake per head per day is estimated at $7.9 \mathrm{~g}$ as against $35 \mathrm{~g}$ recommended value by Food and Agricultural Organization (Mubarak et al., 2016). These low levels of animal protein intake create great concern as it affects the nutritional status of Nigerians. Hence, there is the need for sufficient supply of animal protein from energy rich animal products to satisfy the nutritional requirements for Nigerians.

Meat is one major source of animal protein largely composed of water, protein and fats which can make it susceptible to microbial contamination within short time leading to spoilage (Apata et al., 2013; Mgbemere et al., 2011). Meat is mostly eaten after it has been cooked or processed in a variety of ways such as sun drying; smoking and roasting with or without fortifications (Borch et al., 1996). In Nigeria meat products such as Tsire, Kilishi and Balangu are locally produced using one or more of these methods in order to meet the nutritional requirements of the teeming Nigerians (Egbebi, 2011).

Tsire is a popular Nigerian traditional processed ready-to-eat roasted stick meat product (Shamsuddeen, 2015). It is sold in public places, along roads, in hotels, parks, quarters and even offices (Falegan et al., 2017). It is prepared from boneless healthy animal flesh such as beef and mutton, spiced with peanut cake, salt, vegetable oil and other flavorings followed by roasting (Shamsuddeen, 2015). Consumption of these products has extended to other parts of African countries such as Ghana, Somali, Cameroun and Chad (Ahmadu and Ibrahim, 2013). 
BAJOPAS Volume 13 Number 1, June, 2020

However, evidence of quality control sticking to procedural hygiene by the handlers during preparation and retailing of these products is poorly documented. Tsire is of great safety risk because of the fact that there are erratic cases of gastroenteritis and symptoms of food infection after consumption (WHO, 2015). Food borne illnesses are one of the major health problems in developing and developed countries (Razavilar, 2010). According to the World Health Organization, WHO (2015), $0.07 \%$ death of the 600 million global burdens of Foodborne illnesses have been reported to be caused by bacteria, viruses, fungi and chemicals. In America $0.27 \%$ of the estimated 48 million affected people is hospitalized and about $0.0063 \%$ deaths are recorded each year (Scallan et al., 2011). More than 91 million people in Africa fall ill and $0.15 \%$ dies each year, making Africa the highest burden bearer of Foodborne diseases per population (WHO, 2015).

Application of a Hazard Analysis Critical Control Point (HACCP) at all stages of meat products preparation is essential in order to ensure its safety. Thus, according to the guidelines of good manufacturing practice, the level of total aerobic bacterial contamination of thermally processed meat products should not exceed $10^{4}\left(\mathrm{cfu} \mathrm{g}^{-1}\right)$. Enterobacteriaceae and faecal coliform contamination in meat products should be within the range of $10^{2}-10^{4}$ and $10-10^{3} \mathrm{cfu} \mathrm{g}^{-1}$, respectively (Shamsuddeen, 2015). The aim of the study is therefore, to assess the total viable bacterial counts of tsire marketed locally within Garko town, and to isolate and identify the organisms at the point of consumption with the intention of promoting public health and food hygiene habits in the Nigerian populace.

\section{MATERIALS AND METHODS Study Area and Population}

Garko is one of the existing 44 local government areas located in Kano south west zone of Kano state with its capital administrative headquarters in the Garko town. It has coordinates $11^{\circ} 39^{\prime} \mathrm{N}$ $8^{\circ} 54^{\prime} \mathrm{E}$, and an area of $450 \mathrm{~km}^{2}$. The projected population of Garko local Government was 225,300 according to the National Population Census report (2018). Garko is known for agricultural activities both farming and animal husbandry. It is popularly known for large scale rice production. Other food crops include sweet potatoes, cassava, onions, sorghum, millet and sugarcane. Cows, sheep and goats are major groups of animals reared by majority of the populace. Meat products processed, retailed and consumed in Garko include roasted meat (Balangu), dried roasted meat (Kilishi), stick meat (Tsire), hide and skin pepper soup (Ragadada) and minced fried meat (Danbunnama).

\section{Samples Collection}

Five samples of Tsire products were collected from 6 different identified locations within Garko town in a sterile foil paper and immediately analyzed for the presence of bacteria.

\section{Sample Preparation}

Sample preparation for the bacteriological analysis was carried out in accordance with the method described by Atlas (1997). Twenty five grams $(25 \mathrm{~g})$ of the sample was homogenized in $225 \mathrm{ml}$ peptone water using Kenwood blender machine to obtain a $10^{1}$ homogenate. The homogenate was thoroughly shaken and $1 \mathrm{ml}$ pipetted into test tubes containing $9 \mathrm{ml}$ of peptone water $\left(10^{2}\right)$. The test tubes were further serially diluted to $10^{5}$.

Total Aerobic Mesophilic Bacterial Count

Total Aerobic mesophilic bacterial count was determined using the method described by Abdullahi et al. (2004) where $1 \mathrm{ml}$ of inoculums from $10^{1}$ to $10^{5}$ dilutions were transferred into duplicate Petri dishes and labeled accordingly. This was followed by pouring aseptically about $15 \mathrm{ml}$ of molten nutrient agar. The culture was homogenized by gentle spinning of the plates and allowed to solidify. The plates were incubated at $37^{\circ} \mathrm{C}$ for 24 hours. Plates containing 30-300 colonies were counted. The number of colony forming units per gram of a sample (cfu/g) was obtained by multiplying the average colony number with the inverse of the dilution factor.

\section{Enumeration and Detection of Coliform bacteria}

Detection and enumeration of coliform was carried out according to method described by Atlas, (1977). A set of 9 test tubes each containing $9 \mathrm{ml}$ of lactose broth and an inverted Durham tubes were autoclaved to expel air and to sterilize. Similarly, $1 \mathrm{ml}$ from the diluents $10^{1}$ was transferred to the first 3 test tubes, followed by $1 \mathrm{ml}$ from the diluents $10^{2}$ to the second set of 3 test tubes and finally the third diluents $10^{3}$ to the $3^{\text {rd }}$ set of 3 test tubes. All the 9 test tubes were incubated at $37^{\circ} \mathrm{C}$ for 24 hours. Tubes that showed gas and acid production after 24 hours were recorded as positive for the presence of Coliform. Negative tubes were further reincubated for 24 hours. Positive tubes were recorded. Estimate of most probable number of Coliform per gram of sample (MPN/g) was determined by comparing the number of gas positive tubes with the most probable number table. 
BAJOPAS Volume 13 Number 1, June, 2020 Identification of Coliform

A loop full of inoculum from gas positive tubes was streaked on to Eosine methylene blue (EMB) agar plate and incubated at $37^{\circ} \mathrm{C}$ for $24 \mathrm{hrs}$. Colonies which formed bluish black color with green metallic sheen, and reddish colonies were isolated on agar slants. Those colonies showing metallic sheen on EMB were sub cultured into tubes of lactose broth and incubated at $45^{\circ} \mathrm{C}$. The tubes were observed after $24 \mathrm{hrs}$ for gas production. This is the completed test for fecal coliform. Gram stain and other biochemical tests such as Indole, Methyl red, Voges-Proskauer and Citrate Utilization tests (IMVIC), Coagulase and Catalase tests were carried out for the Identification and confirmation of isolates.

\section{Procedure for Indole Test}

Indole test was carried out by preparing a Tryptone broth drawn in to test tubes, sterilized by autoclaving, inoculated with loopful of suspension and incubated at $37^{\circ} \mathrm{C}$ for 24 hours. Three drops of xylene was added in tubes, shaken vigorously and kept for the separation of two layers. One millilitre of Kovac's reagent was added and the formation of pink colour ring indicates positive Indole test.

\section{Procedure for Methyl Red Test}

Methyl red test was carried out by preparing Glucose phosphate broth, dispensed in test tubes, sterilized, inoculated with test culture and incubated at $37^{\circ} \mathrm{C}$ for 24 hours. Five drops of methyl-red indicator was added to the medium for the formation of red colour.

\section{Procedure for Voges-Proskauer Test}

Voges-Proskauer test was carried out by inoculating tubes with the bacterial culture followed by incubation for 48 hours at $37^{\circ} \mathrm{C}$. Separate pipettes were used to pipette $1 \mathrm{ml}$ from each culture tube into clean separate tubes. Eighteen drops $(0.5 \mathrm{ml})$ of Barrit's solution A (a-naphthol) was added to each tube containing glucose phosphate broth followed by the addition of an equal amount of solution $B$ into the same tube. The tubes were shaken at 30 seconds interval. A positive reaction was indicated by the development of a pink color, which turns red in 1-2 hours, after vigorous shaking.

\section{Procedure for Citrate Utilization Test}

Citrate Utilization Test was carried out by distributing melted agar (Simmon Citrate Agar) in to test tubes followed by sterilization at $121.5^{\circ} \mathrm{C}$ for 15 minutes. The test tubes were afterward held in slanted position, inoculated with the given bacterial culture and incubated at $37^{\circ} \mathrm{C}$ for $24 \mathrm{hrs}$. Positive test was indicated by color change of the media from green to blue.

\section{RESULTS AND DISCUSSIONS}

The results of this study are presented in tables $1,2,3$ and 4. Among the sampling areas Kofar Kudu had the highest aerobic mesophilic bacteria counts $4.0 \times 10^{5} \mathrm{cfu} / \mathrm{g}$ followed by Rinji $2.72 \times 10^{5} \mathrm{cfu} / \mathrm{g}$, while Tosaro had the least Aerobic mesophilic bacteria counts of $1.02 \times 10^{5}$ $\mathrm{cfu} / \mathrm{g}$ as indicated in Table 1.Makwalla had the highest coliform count $68 \mathrm{MPN} / \mathrm{g}$ followed by Rinji $37 \mathrm{MPN} / \mathrm{g}$. Tsohuwar Kasuwa had the least coliform counts $8 \mathrm{MPN} / \mathrm{g}$, (Table 2). Result from table 1 shows variation in the microbial contents among the samples which suggest variation in their sources, poor handling procedures and contamination from the processing environment. High coliform count and their differences within sampling areas is an indication of poor microbiological quality of the product. Ndahi et al. (2013) reported microbial load to be a function of the handling personnel and the environment. The results indicated that the samples were contaminated with bacteria as the counts exceeded the minimum safety level $\left(10^{4} \mathrm{cfu} / \mathrm{g}\right)$ for members of the Enterobacteriaceae family. However, it might be a reflection of poor hygienic practices which may contribute to health hazard to the potential consumers. Similarly, Inusa and Sa'id (2017); Osimani et al. (2015) reported that, the initial microbial content of the raw material play significant role in influencing the final microbial load of the finished product. Isolation of members of the Enterobacteriaceae such as $E$. coli, Klebsiella pneumoniae, Salmonella and Shigella signifies danger to the public health. These organisms are capable of producing endotoxins which trigger high fevers in infected individuals, and the enterotoxins which colonize the small intestines and lead to extreme dehydration as a result of vomiting and diarrhea sometimes with severe and fatal outcomes (Amaeze et al., 2016). From the 16 isolated organisms $E$. coli had the highest isolation rate $6(37.5 \%)$ (Table 3), this suggest faecal contamination of the products. $E$. coli is a common flora in the gastrointestinal tract responsible for diarrhea and extra-intestinal infections (CDC, 2011). The result is in conformity with the findings of Ndahi et al. (2013) and Shamsuddeen (2009). Also presence of campylobacter might be due to cross contamination from raw meat to finished product (Tsire). Staphylococcus aureus is a normal flora of the skin, nasal, genital, mouth or anal area in both humans and animals without any symptom of an infection (Matthew et al., 2013). Isolation of $S$. aureus in these study concords with the findings of Lucretia et al. (2018) from Suya sold in Rivers State. 
BAJOPAS Volume 13 Number 1, June, 2020

It is also in agreement with the findings of Yousafzai et al. (2018); Onuorah et al. (2015) and Tijjani and Jumare (2014) from tsire samples in different countries. Presence of $S$. aureus in foods is most of the time an indication of poor human handling, poor environment, unhygienic utensils and equipments used during processing (Igene et al., 2016; Okonko et al., 2013). Infections caused by $S$. aureus are difficult to treat leading to long hospitalization with consequent economic loss (Udobi et al., 2013). These include soft tissue infections, pneumonia, hospital-acquired postoperative wound infections, Staphylococcal food poisoning, impetigo and cellulitis (Charlene et al., 2013). Samples obtained from Dausai and Kofar Kudu had the highest isolation rate $4(80 \%)$ (Table 4 ) probably because of the much commercial activities taking place in the area which can lead to environmental contamination.

Table 1: Total Aerobic Mesophilic Bacterial Count of Tsire sold in Garko Town

\begin{tabular}{lll}
\hline Sampling Area & APC cfu/g & Mean \pm STD \\
\hline Dausai & $2.20 \times 10^{5}$ & $110000 \pm 14142.14$ \\
Kofar Kudu & $4.00 \times 10^{5}$ & $133333.3 \pm 23094.01$ \\
Makwalla & $1.30 \times 10^{5}$ & $32500 \pm 7187.953$ \\
Rinji & $2.72 \times 10^{5}$ & $90666.67 \pm 94769.90$ \\
Tosaro & $1.02 \times 10^{5}$ & $51000 \pm 15556.35$ \\
Tsohuwar Kasuwa & $1.75 \times 10^{5}$ & $35000 \pm 11357.82$ \\
\hline
\end{tabular}

Key: APC: Aerobic Mesophilic Counts

STD: Standard Deviation

Table 2: Total Coliform Count of Tsire sold in Garko Town

\begin{tabular}{lcc}
\hline \multicolumn{1}{c}{ Sampling Area } & TCC MPN/g & Mean \pm STD \\
\hline Dausai & 20 & $6.67 \pm 2.5166$ \\
Kofar Kudu & 32 & $16.00 \pm 5.6569$ \\
Makwalla & 68 & $13.60 \pm 8.7062$ \\
Rinji & 37 & $9.25 \pm 4.7871$ \\
Tosaro & 10 & $5.00 \pm 2.8284$ \\
Tsohuwar Kasuwa & 8 & $4.00 \pm 0.0000$ \\
\hline
\end{tabular}

Table 3: Organisms Isolated from Tsire Sold in Garko

\begin{tabular}{lcl}
\hline Isolated Organism & Frequency & Percentage (\%) \\
\hline Campylobacter & 2 & 06.66 \\
Escherichia coli & 6 & 20.00 \\
Klebsiella pneumoniae & 2 & 06.66 \\
Salmonella species & 1 & 03.33 \\
Shigella & 3 & 10.00 \\
Staphylococcus aureus & 2 & 06.66 \\
Total & 16 & \\
\hline
\end{tabular}

Table 4: Distribution of Organisms within Sampling Area

\begin{tabular}{lcc}
\hline \multicolumn{1}{c}{ Sampling Area } & No. Isolated & Percentage (\%) \\
\hline Dausai & 4 & 80 \\
Kofar Kudu & 4 & 80 \\
Makwalla & 2 & 40 \\
Rinji & 3 & 60 \\
Tosaro & 2 & 40 \\
Tsohuwar Kasuwa & 1 & 20 \\
Total & 16 & \\
\hline
\end{tabular}

\section{CONCLUSION}

Results indicated $4.00 \times 10^{5} \mathrm{CFU} / \mathrm{g}$ as the highest APCs count; while $68 \mathrm{MPN} / \mathrm{g}$ was the highest TCCs from the 30 samples analyzed. Among the isolates, $E$. coli has the highest isolation rate of $6(20 \%)$. Dausai and Kofar kudu were having the highest bacteria count of $4(80 \%)$, each, indicating higher contamination in those locations. 
BAJOPAS Volume 13 Number 1, June, 2020 RECOMMENDATIONS

The following recommendations are tenable:

1. Hygienic practices at all stages of production should be improved to safe guard the consumers against potential health hazard.

2. Monitoring of microbiological contamination of Tsire during preparations, packaging and marketing is essential to ensure product of good microbiological quality for consumers' health.

\section{REFERENCES}

Abdullahi, I. O., Umoh, V. J. and Galadima, M. (2004). Hazards Associated with Kilishi Preparations in Zaria. Nigerian Journal of Microbiology, 18 (1-2): $339-345$.

Ahmadu, J. and Ibrahim E. J., (2013): Determinants of Revenue in Suya Production in BeninCity, Edo State, Nigeria. Nigerian journal of agriculture, food and environment.9(3):1-5

Amaeze, N. Aboh, M. Itohan, A. Felix, E. Olatunji, T. and Oladosu, P. (2016) Microbial Profile, Antibiotic Sensitivity and Heat Resistance of Bacterial Isolates from Commercial Roasted Beef (Suya) in Abuja, Nigeria. JOPAT, 15(2): $22-30$.

Apata, E.S., Kuku1, I.A., Apata, O.C. and Adeyemi, K.O. (2013). Evaluation of Suya(Tsire) - An Intermediate Moisture Meat Product in Ogun State, Nigeria. J. Food Res 2 (1): 87.

Atlas, R. M. (1997) Principles of Microbiology Second Edition. C. Brown Publishers. Pp 802-803.

Borch, E. Kant-Muermans, M. L., Blixt, Y. (1996) Bacterial Spoilage of Meat and Cured Meat Products. Int $\mathrm{J}$ Food Microbiol .33(1): 103-20.

Centre for Disease Control, CDC (2011). "Escherichia coli 0157:H7" Division of Bacterial and Mycotic Diseasesht://www.cdc.gov/nczved/divisi ons/dfbmd/diseases/ecoli_0157h7/.

Charlene, R. J., Johnnie, A. D., and John, B. B., (2013) Prevalence and Characterization of Methicillin-Resistant Staphylococcus aureus Isolates from Retail Meat and Humans in Georgia. American society for Microbiology. J. of clinical microbiology. 12(1):123-6 doi:10.1128/JCM.0316612JCM.03166-12

Egbebi, A.O and Seidu, K., T. (2011). Microbiological Evaluation of Suya (dried smoked

meat) Sold in Ado and Akure, South West Nigeria.European Journal of Experinmental Biology, 1(4):1-5
3. Government should establish regulatory bodies responsible for inculcating hygiene habits to the local producers and vendors in order to prevent instant, cross and post processing contaminations by microbial pathogens.

4. Awareness and sensitization of local food producers about good hygienic practices in food handling and processing.

Falegan, C, R., Akoja, S. D., and Oyarekua, M. A., (2017) Microbiological Assessment of Suya (Sliced Roasted Beef) in Ado-Ekiti Metropolis, Ekiti State, Nigeria. MOJ Biology andMedicine.

Fonkem, D., N. Tanya, V., N. and Ebangi, A., L. (2010). Effect of Season on the Microbiological Quality of Kilishi, a Traditional Cameroonian Dried Beef Product. Tropicultura, 28(1): 10-15.

Food and Agricultural Organization of the United Nations (F A O, 1979). Manual of food quality control 4. Microbiological analysis.

Food and Agriculture Organisation of the United Nation (FAO), 2019. Nigeria at a glance.

Igene J.O., Uwadia, O.E., Ebabhamiegbebho, P.A. and Evivie, S.E., (2016) Shelf life Stability Studies of University of Benin (UNIBEN) Proff's Kilishi Product Asian Journal of Science and Technology 7(1): 2268-2274.

Inusa, S. K. and Said, I. S. (2017) Evaluation of the Chemical and Microbiological Properties Of Kilishi Sold in Kano Metropolis. Journal of Dry land Agriculture, 3 (1): $59-69$.

Lucretia, I. B, Patience, C. Obinna-Echem, Sophia, C. A. (2018) Microbiological quality andantibiotic sensitivity of potential pathogens isolated from meat product (Suya) sold in Rivers State University and its environs. International Journal of Biotechnology and Food Science, 6(4): 67-76.

Matthew, E., Drosos, E., John, L. and Ioanna, P. (2013) MRSA in Africa: Filling the Global Map of Antimicrobial Resistance PLOS One. 8(7): e68024 doi: 10.1371/journal.pone.0068024

Mgbemere, V.N., Akpapunam, M. A. and Igene, J. O., (2011). Effect of Groundnut FlourSubstitution on Yield, Quality and Storage Stability of Kilishi - a Nigerian Indigenous Dried Meat Product. African Journal of Food, Agriculture, Nutrition and Development, $\quad \mathbf{1 1}(2)$ : 4718-4738. 
BAJOPAS Volume 13 Number 1, June, 2020

Mubarak, A. A., Azeez, M. L., Amos A. O., Opeyemi, O. O. (2016) Assessment of Animal Protein Consumption and Food Security Among Rural Households in Kwara State, Nigeria American Journal of Business and Society, 1(4): 233245.

Ndahi, M., D. Kwaga, J., K. P. Bello, M. Kabir J., V. Umoh, .J. Yakubu, S., E. and Nok, A., J. (2013) Prevalence and Antimicrobial Susceptibility of Listeria Monocytogenes and Methicillin-Resistant Staphylococcus aureus Strains from Raw Meat and Meat Products in Zaria, Nigeria. Applied Journal of Microbiology, 58(3):262-9.

Okonko, I.O., Odu, N.N. and Igboh, I.E. (2013). Microbiological Analysis of Kilishi Sold In Port Harcourt, Nigeria. New York Science Journal, 6 (7):37-43.

Osimani, A., Aquilanti, L. and Clementi, F. (2015) Microbiological Quality of Meatbased Meals and Operation of Control Systems within a Food Service Environment. International Food Research Journal 22(4): 1692-1698.

Onuorah, S. Obika, I. Odibo, F. Orji, M. (2015)An Assessment of the Bacteriological Quality of Tsire-Suya (Grilled Beef) sold in Awka, Nigeria. American. J. Life. Sci. Res. 3(4):287292.

Razavilar, V, Khandaghi, J. Barzgari, A. (2010); Isolation of Eschericia coli 0157:H7 from manure fertilized farms and raw vegetables grown on it, in Tabriz city in
Iran. African Journal of Microbiology Research, 4(9): 891-895.

Scallan, E. Hoekstra, R. M. Angulo, F. J.Tauxe, R. V, Widdowson, M. Roy, S. L et al., (2011).Food borne illness acquired in the United States- Major Pathogens. Emerg. Infec Dis, 17(1): 7-15.

Shamsuddeen U (2009). Microbiological quality of spice used in the production of Kilishi a traditionally dried and grilled meat product. Bayero Journal of Pure andApplied Sciences, 2(2): 66-69.

Shamsuddeen, U. (2015) Microbiological Hazard and Critical control point Analysis of Dried and Minced Meat Snacks Produced in Kano Nigeria. Lambert Academic Publishing; Pp 1-36.

Tijani, O.and Jumare, S. (2014). Microblological Quality Assessment of Meat

Sold in KauraNamoda. International Conference on Earth, Environment and Life sciences (EELS) Dubai (UAE).

Udobi, C. E., Obajuluwa, A. F., and Onaolapo, J. A., (2013) Prevalence and Antibiotic Resistance Pattern of MethicillinResistant Staphylococcus aureus from an Orthopaedic Hospital in Nigeria BioMed Research International; 26(6); 6-7.

WHO, 2015 Foodborne diseases in the WHO African Region.

Yousafzai HA, Rind R, Khan MA, Abro SH, Korejo NA, Ejaz M, Kabir A, Shahid M, Memon S. (2019). Microbiological Contamination of Cattle and Meat in Peshawar, Pakistan. J. Anim. Health Prod. 7(1): 1116. 


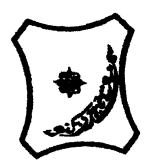

Bayero Journal of Pure and Applied Sciences, 13(1); 40 - 45

Received: September, 2019

Accepted: April, 2020

ISSN $2006-6996$

\title{
BACTERIOLOGICAL QUALITY OF STICK MEAT (Tsire) SOLD IN GARKO LOCAL GOVERNMENT AREA OF KANO STATE, NIGERIA
}

\author{
$*^{1}$ Dahiru A. T. and ${ }^{2}$ Maigari A. K. \\ ${ }^{1}$ Department of Hospitality Management, School of Technology, Kano State Polytechnic, PMB 3348, \\ Kano Nigeria. \\ ${ }^{2}$ Departmnt of Biological Sciences, Bayero University, Kano \\ Corresponding Author: dturajo61@gmail.com; GSM: 08087508262.
}

ABSTRACT

Stick meat, locally called Tsire in Hausa Language, is a significant portion of the diet of a large active population of Northern Nigeria. However, because of the handling and processing methods by the manufacturers as well as the hawking system of stick meat, the meat product may be exposed to both pre- and post-processed product contamination, and thus may poses danger to public health. Therefore, considering the role of Tsire in improving nutrition and increase household income to the populace, the need to improve the processing, distribution and overall quality of the product is simply indispensable. A total of 30 samples (5 samples from each of the 6 sampling points) of Tsire were collected randomly in Garko Town. Aerobic plate counts (APCs) and Total coliform counts (TCCS) of Tsire samples were determined using standard microbiological methods. APCs ranged from $1.02 \times 10^{5}$ to $4.00 \times 10^{5} \mathrm{CFU} / \mathrm{g}$; while TCCs ranged from $8 \mathrm{MPN} / \mathrm{g}$ to $68 \mathrm{MPN} / \mathrm{g}$. From the 30 samples screened, 16(53.33\%) bacteria namely, Campylobacter 2(6.66\%), Escherichia coli 6(20\%), Klebsiella pneumoniae 2(6.66\%), Salmonella spp. 1(3.33\%), Shigella 3(10\%) and Staphylococcus aureus 2(6.66\%) were detected. $E$. coli has the highest isolation rate of 6(20\%), while Salmonella spp. had the least frequency of 1(3.33\%). The distribution of isolated organisms within the study area were as follows: Dausai, 4(80\%), Kofar kudu, 4(80\%), Makwalla, 2(40\%), Rinji, 3(60\%), Tosaro, 2(40\%), and Tsohuwar Kasuwa, 1(20\%). The results have indicated that the Tsire was contaminated with bacteria thus exposing the product to fast deterioration, spoilage and also a vehicle for food borne illness, suggesting for adequate hygienic practices at all the stages, prior to consumption, to ensure safety of the meat product.

Key words: APCs, TCCs, Contamination, Microorganisms, Garko

\section{INTRODUCTION}

Nigeria is one of the developing nations with inadequate food supply and most often deficient in protein content (FAO, 2019). Nigerian's average animal protein intake per head per day is estimated at $7.9 \mathrm{~g}$ as against $35 \mathrm{~g}$ recommended value by Food and Agricultural Organization (Mubarak et al., 2016). These low levels of animal protein intake create great concern as it affects the nutritional status of Nigerians. Hence, there is the need for sufficient supply of animal protein from energy rich animal products to satisfy the nutritional requirements for Nigerians.

Meat is one major source of animal protein largely composed of water, protein and fats which can make it susceptible to microbial contamination within short time leading to spoilage (Apata et al., 2013; Mgbemere et al., 2011). Meat is mostly eaten after it has been cooked or processed in a variety of ways such as sun drying; smoking and roasting with or without fortifications (Borch et al., 1996). In Nigeria meat products such as Tsire, Kilishi and Balangu are locally produced using one or more of these methods in order to meet the nutritional requirements of the teeming Nigerians (Egbebi, 2011).

Tsire is a popular Nigerian traditional processed ready-to-eat roasted stick meat product (Shamsuddeen, 2015). It is sold in public places, along roads, in hotels, parks, quarters and even offices (Falegan et al., 2017). It is prepared from boneless healthy animal flesh such as beef and mutton, spiced with peanut cake, salt, vegetable oil and other flavorings followed by roasting (Shamsuddeen, 2015). Consumption of these products has extended to other parts of African countries such as Ghana, Somali, Cameroun and Chad (Ahmadu and Ibrahim, 2013). 
BAJOPAS Volume 13 Number 1, June, 2020

However, evidence of quality control sticking to procedural hygiene by the handlers during preparation and retailing of these products is poorly documented. Tsire is of great safety risk because of the fact that there are erratic cases of gastroenteritis and symptoms of food infection after consumption (WHO, 2015). Food borne illnesses are one of the major health problems in developing and developed countries (Razavilar, 2010). According to the World Health Organization, WHO (2015), $0.07 \%$ death of the 600 million global burdens of Foodborne illnesses have been reported to be caused by bacteria, viruses, fungi and chemicals. In America $0.27 \%$ of the estimated 48 million affected people is hospitalized and about $0.0063 \%$ deaths are recorded each year (Scallan et al., 2011). More than 91 million people in Africa fall ill and $0.15 \%$ dies each year, making Africa the highest burden bearer of Foodborne diseases per population (WHO, 2015).

Application of a Hazard Analysis Critical Control Point (HACCP) at all stages of meat products preparation is essential in order to ensure its safety. Thus, according to the guidelines of good manufacturing practice, the level of total aerobic bacterial contamination of thermally processed meat products should not exceed $10^{4}\left(\mathrm{cfu} \mathrm{g}^{-1}\right)$. Enterobacteriaceae and faecal coliform contamination in meat products should be within the range of $10^{2}-10^{4}$ and $10-10^{3} \mathrm{cfu} \mathrm{g}^{-1}$, respectively (Shamsuddeen, 2015). The aim of the study is therefore, to assess the total viable bacterial counts of tsire marketed locally within Garko town, and to isolate and identify the organisms at the point of consumption with the intention of promoting public health and food hygiene habits in the Nigerian populace.

\section{MATERIALS AND METHODS Study Area and Population}

Garko is one of the existing 44 local government areas located in Kano south west zone of Kano state with its capital administrative headquarters in the Garko town. It has coordinates $11^{\circ} 39^{\prime} \mathrm{N}$ $8^{\circ} 54^{\prime} \mathrm{E}$, and an area of $450 \mathrm{~km}^{2}$. The projected population of Garko local Government was 225,300 according to the National Population Census report (2018). Garko is known for agricultural activities both farming and animal husbandry. It is popularly known for large scale rice production. Other food crops include sweet potatoes, cassava, onions, sorghum, millet and sugarcane. Cows, sheep and goats are major groups of animals reared by majority of the populace. Meat products processed, retailed and consumed in Garko include roasted meat (Balangu), dried roasted meat (Kilishi), stick meat (Tsire), hide and skin pepper soup (Ragadada) and minced fried meat (Danbunnama).

\section{Samples Collection}

Five samples of Tsire products were collected from 6 different identified locations within Garko town in a sterile foil paper and immediately analyzed for the presence of bacteria.

\section{Sample Preparation}

Sample preparation for the bacteriological analysis was carried out in accordance with the method described by Atlas (1997). Twenty five grams $(25 \mathrm{~g})$ of the sample was homogenized in $225 \mathrm{ml}$ peptone water using Kenwood blender machine to obtain a $10^{1}$ homogenate. The homogenate was thoroughly shaken and $1 \mathrm{ml}$ pipetted into test tubes containing $9 \mathrm{ml}$ of peptone water $\left(10^{2}\right)$. The test tubes were further serially diluted to $10^{5}$.

Total Aerobic Mesophilic Bacterial Count

Total Aerobic mesophilic bacterial count was determined using the method described by Abdullahi et al. (2004) where $1 \mathrm{ml}$ of inoculums from $10^{1}$ to $10^{5}$ dilutions were transferred into duplicate Petri dishes and labeled accordingly. This was followed by pouring aseptically about $15 \mathrm{ml}$ of molten nutrient agar. The culture was homogenized by gentle spinning of the plates and allowed to solidify. The plates were incubated at $37^{\circ} \mathrm{C}$ for 24 hours. Plates containing 30-300 colonies were counted. The number of colony forming units per gram of a sample (cfu/g) was obtained by multiplying the average colony number with the inverse of the dilution factor.

\section{Enumeration and Detection of Coliform bacteria}

Detection and enumeration of coliform was carried out according to method described by Atlas, (1977). A set of 9 test tubes each containing $9 \mathrm{ml}$ of lactose broth and an inverted Durham tubes were autoclaved to expel air and to sterilize. Similarly, $1 \mathrm{ml}$ from the diluents $10^{1}$ was transferred to the first 3 test tubes, followed by $1 \mathrm{ml}$ from the diluents $10^{2}$ to the second set of 3 test tubes and finally the third diluents $10^{3}$ to the $3^{\text {rd }}$ set of 3 test tubes. All the 9 test tubes were incubated at $37^{\circ} \mathrm{C}$ for 24 hours. Tubes that showed gas and acid production after 24 hours were recorded as positive for the presence of Coliform. Negative tubes were further reincubated for 24 hours. Positive tubes were recorded. Estimate of most probable number of Coliform per gram of sample (MPN/g) was determined by comparing the number of gas positive tubes with the most probable number table. 
BAJOPAS Volume 13 Number 1, June, 2020 Identification of Coliform

A loop full of inoculum from gas positive tubes was streaked on to Eosine methylene blue (EMB) agar plate and incubated at $37^{\circ} \mathrm{C}$ for $24 \mathrm{hrs}$. Colonies which formed bluish black color with green metallic sheen, and reddish colonies were isolated on agar slants. Those colonies showing metallic sheen on EMB were sub cultured into tubes of lactose broth and incubated at $45^{\circ} \mathrm{C}$. The tubes were observed after $24 \mathrm{hrs}$ for gas production. This is the completed test for fecal coliform. Gram stain and other biochemical tests such as Indole, Methyl red, Voges-Proskauer and Citrate Utilization tests (IMVIC), Coagulase and Catalase tests were carried out for the Identification and confirmation of isolates.

\section{Procedure for Indole Test}

Indole test was carried out by preparing a Tryptone broth drawn in to test tubes, sterilized by autoclaving, inoculated with loopful of suspension and incubated at $37^{\circ} \mathrm{C}$ for 24 hours. Three drops of xylene was added in tubes, shaken vigorously and kept for the separation of two layers. One millilitre of Kovac's reagent was added and the formation of pink colour ring indicates positive Indole test.

\section{Procedure for Methyl Red Test}

Methyl red test was carried out by preparing Glucose phosphate broth, dispensed in test tubes, sterilized, inoculated with test culture and incubated at $37^{\circ} \mathrm{C}$ for 24 hours. Five drops of methyl-red indicator was added to the medium for the formation of red colour.

\section{Procedure for Voges-Proskauer Test}

Voges-Proskauer test was carried out by inoculating tubes with the bacterial culture followed by incubation for 48 hours at $37^{\circ} \mathrm{C}$. Separate pipettes were used to pipette $1 \mathrm{ml}$ from each culture tube into clean separate tubes. Eighteen drops $(0.5 \mathrm{ml})$ of Barrit's solution A (a-naphthol) was added to each tube containing glucose phosphate broth followed by the addition of an equal amount of solution $B$ into the same tube. The tubes were shaken at 30 seconds interval. A positive reaction was indicated by the development of a pink color, which turns red in 1-2 hours, after vigorous shaking.

\section{Procedure for Citrate Utilization Test}

Citrate Utilization Test was carried out by distributing melted agar (Simmon Citrate Agar) in to test tubes followed by sterilization at $121.5^{\circ} \mathrm{C}$ for 15 minutes. The test tubes were afterward held in slanted position, inoculated with the given bacterial culture and incubated at $37^{\circ} \mathrm{C}$ for $24 \mathrm{hrs}$. Positive test was indicated by color change of the media from green to blue.

\section{RESULTS AND DISCUSSIONS}

The results of this study are presented in tables $1,2,3$ and 4. Among the sampling areas Kofar Kudu had the highest aerobic mesophilic bacteria counts $4.0 \times 10^{5} \mathrm{cfu} / \mathrm{g}$ followed by Rinji $2.72 \times 10^{5} \mathrm{cfu} / \mathrm{g}$, while Tosaro had the least Aerobic mesophilic bacteria counts of $1.02 \times 10^{5}$ $\mathrm{cfu} / \mathrm{g}$ as indicated in Table 1.Makwalla had the highest coliform count $68 \mathrm{MPN} / \mathrm{g}$ followed by Rinji $37 \mathrm{MPN} / \mathrm{g}$. Tsohuwar Kasuwa had the least coliform counts $8 \mathrm{MPN} / \mathrm{g}$, (Table 2). Result from table 1 shows variation in the microbial contents among the samples which suggest variation in their sources, poor handling procedures and contamination from the processing environment. High coliform count and their differences within sampling areas is an indication of poor microbiological quality of the product. Ndahi et al. (2013) reported microbial load to be a function of the handling personnel and the environment. The results indicated that the samples were contaminated with bacteria as the counts exceeded the minimum safety level $\left(10^{4} \mathrm{cfu} / \mathrm{g}\right)$ for members of the Enterobacteriaceae family. However, it might be a reflection of poor hygienic practices which may contribute to health hazard to the potential consumers. Similarly, Inusa and Sa'id (2017); Osimani et al. (2015) reported that, the initial microbial content of the raw material play significant role in influencing the final microbial load of the finished product. Isolation of members of the Enterobacteriaceae such as $E$. coli, Klebsiella pneumoniae, Salmonella and Shigella signifies danger to the public health. These organisms are capable of producing endotoxins which trigger high fevers in infected individuals, and the enterotoxins which colonize the small intestines and lead to extreme dehydration as a result of vomiting and diarrhea sometimes with severe and fatal outcomes (Amaeze et al., 2016). From the 16 isolated organisms $E$. coli had the highest isolation rate $6(37.5 \%)$ (Table 3), this suggest faecal contamination of the products. $E$. coli is a common flora in the gastrointestinal tract responsible for diarrhea and extra-intestinal infections (CDC, 2011). The result is in conformity with the findings of Ndahi et al. (2013) and Shamsuddeen (2009). Also presence of campylobacter might be due to cross contamination from raw meat to finished product (Tsire). Staphylococcus aureus is a normal flora of the skin, nasal, genital, mouth or anal area in both humans and animals without any symptom of an infection (Matthew et al., 2013). Isolation of $S$. aureus in these study concords with the findings of Lucretia et al. (2018) from Suya sold in Rivers State. 
BAJOPAS Volume 13 Number 1, June, 2020

It is also in agreement with the findings of Yousafzai et al. (2018); Onuorah et al. (2015) and Tijjani and Jumare (2014) from tsire samples in different countries. Presence of $S$. aureus in foods is most of the time an indication of poor human handling, poor environment, unhygienic utensils and equipments used during processing (Igene et al., 2016; Okonko et al., 2013). Infections caused by $S$. aureus are difficult to treat leading to long hospitalization with consequent economic loss (Udobi et al., 2013). These include soft tissue infections, pneumonia, hospital-acquired postoperative wound infections, Staphylococcal food poisoning, impetigo and cellulitis (Charlene et al., 2013). Samples obtained from Dausai and Kofar Kudu had the highest isolation rate $4(80 \%)$ (Table 4 ) probably because of the much commercial activities taking place in the area which can lead to environmental contamination.

Table 1: Total Aerobic Mesophilic Bacterial Count of Tsire sold in Garko Town

\begin{tabular}{lll}
\hline Sampling Area & APC cfu/g & Mean \pm STD \\
\hline Dausai & $2.20 \times 10^{5}$ & $110000 \pm 14142.14$ \\
Kofar Kudu & $4.00 \times 10^{5}$ & $133333.3 \pm 23094.01$ \\
Makwalla & $1.30 \times 10^{5}$ & $32500 \pm 7187.953$ \\
Rinji & $2.72 \times 10^{5}$ & $90666.67 \pm 94769.90$ \\
Tosaro & $1.02 \times 10^{5}$ & $51000 \pm 15556.35$ \\
Tsohuwar Kasuwa & $1.75 \times 10^{5}$ & $35000 \pm 11357.82$ \\
\hline
\end{tabular}

Key: APC: Aerobic Mesophilic Counts

STD: Standard Deviation

Table 2: Total Coliform Count of Tsire sold in Garko Town

\begin{tabular}{lcc}
\hline \multicolumn{1}{c}{ Sampling Area } & TCC MPN/g & Mean \pm STD \\
\hline Dausai & 20 & $6.67 \pm 2.5166$ \\
Kofar Kudu & 32 & $16.00 \pm 5.6569$ \\
Makwalla & 68 & $13.60 \pm 8.7062$ \\
Rinji & 37 & $9.25 \pm 4.7871$ \\
Tosaro & 10 & $5.00 \pm 2.8284$ \\
Tsohuwar Kasuwa & 8 & $4.00 \pm 0.0000$ \\
\hline
\end{tabular}

Table 3: Organisms Isolated from Tsire Sold in Garko

\begin{tabular}{lcl}
\hline Isolated Organism & Frequency & Percentage (\%) \\
\hline Campylobacter & 2 & 06.66 \\
Escherichia coli & 6 & 20.00 \\
Klebsiella pneumoniae & 2 & 06.66 \\
Salmonella species & 1 & 03.33 \\
Shigella & 3 & 10.00 \\
Staphylococcus aureus & 2 & 06.66 \\
Total & 16 & \\
\hline
\end{tabular}

Table 4: Distribution of Organisms within Sampling Area

\begin{tabular}{lcc}
\hline \multicolumn{1}{c}{ Sampling Area } & No. Isolated & Percentage (\%) \\
\hline Dausai & 4 & 80 \\
Kofar Kudu & 4 & 80 \\
Makwalla & 2 & 40 \\
Rinji & 3 & 60 \\
Tosaro & 2 & 40 \\
Tsohuwar Kasuwa & 1 & 20 \\
Total & 16 & \\
\hline
\end{tabular}

\section{CONCLUSION}

Results indicated $4.00 \times 10^{5} \mathrm{CFU} / \mathrm{g}$ as the highest APCs count; while $68 \mathrm{MPN} / \mathrm{g}$ was the highest TCCs from the 30 samples analyzed. Among the isolates, $E$. coli has the highest isolation rate of $6(20 \%)$. Dausai and Kofar kudu were having the highest bacteria count of $4(80 \%)$, each, indicating higher contamination in those locations. 
BAJOPAS Volume 13 Number 1, June, 2020 RECOMMENDATIONS

The following recommendations are tenable:

1. Hygienic practices at all stages of production should be improved to safe guard the consumers against potential health hazard.

2. Monitoring of microbiological contamination of Tsire during preparations, packaging and marketing is essential to ensure product of good microbiological quality for consumers' health.

\section{REFERENCES}

Abdullahi, I. O., Umoh, V. J. and Galadima, M. (2004). Hazards Associated with Kilishi Preparations in Zaria. Nigerian Journal of Microbiology, 18 (1-2): $339-345$.

Ahmadu, J. and Ibrahim E. J., (2013): Determinants of Revenue in Suya Production in BeninCity, Edo State, Nigeria. Nigerian journal of agriculture, food and environment.9(3):1-5

Amaeze, N. Aboh, M. Itohan, A. Felix, E. Olatunji, T. and Oladosu, P. (2016) Microbial Profile, Antibiotic Sensitivity and Heat Resistance of Bacterial Isolates from Commercial Roasted Beef (Suya) in Abuja, Nigeria. JOPAT, 15(2): $22-30$.

Apata, E.S., Kuku1, I.A., Apata, O.C. and Adeyemi, K.O. (2013). Evaluation of Suya(Tsire) - An Intermediate Moisture Meat Product in Ogun State, Nigeria. J. Food Res 2 (1): 87.

Atlas, R. M. (1997) Principles of Microbiology Second Edition. C. Brown Publishers. Pp 802-803.

Borch, E. Kant-Muermans, M. L., Blixt, Y. (1996) Bacterial Spoilage of Meat and Cured Meat Products. Int $\mathrm{J}$ Food Microbiol .33(1): 103-20.

Centre for Disease Control, CDC (2011). "Escherichia coli 0157:H7" Division of Bacterial and Mycotic Diseasesht://www.cdc.gov/nczved/divisi ons/dfbmd/diseases/ecoli_0157h7/.

Charlene, R. J., Johnnie, A. D., and John, B. B., (2013) Prevalence and Characterization of Methicillin-Resistant Staphylococcus aureus Isolates from Retail Meat and Humans in Georgia. American society for Microbiology. J. of clinical microbiology. 12(1):123-6 doi:10.1128/JCM.0316612JCM.03166-12

Egbebi, A.O and Seidu, K., T. (2011). Microbiological Evaluation of Suya (dried smoked

meat) Sold in Ado and Akure, South West Nigeria.European Journal of Experinmental Biology, 1(4):1-5
3. Government should establish regulatory bodies responsible for inculcating hygiene habits to the local producers and vendors in order to prevent instant, cross and post processing contaminations by microbial pathogens.

4. Awareness and sensitization of local food producers about good hygienic practices in food handling and processing.

Falegan, C, R., Akoja, S. D., and Oyarekua, M. A., (2017) Microbiological Assessment of Suya (Sliced Roasted Beef) in Ado-Ekiti Metropolis, Ekiti State, Nigeria. MOJ Biology andMedicine.

Fonkem, D., N. Tanya, V., N. and Ebangi, A., L. (2010). Effect of Season on the Microbiological Quality of Kilishi, a Traditional Cameroonian Dried Beef Product. Tropicultura, 28(1): 10-15.

Food and Agricultural Organization of the United Nations (F A O, 1979). Manual of food quality control 4. Microbiological analysis.

Food and Agriculture Organisation of the United Nation (FAO), 2019. Nigeria at a glance.

Igene J.O., Uwadia, O.E., Ebabhamiegbebho, P.A. and Evivie, S.E., (2016) Shelf life Stability Studies of University of Benin (UNIBEN) Proff's Kilishi Product Asian Journal of Science and Technology 7(1): 2268-2274.

Inusa, S. K. and Said, I. S. (2017) Evaluation of the Chemical and Microbiological Properties Of Kilishi Sold in Kano Metropolis. Journal of Dry land Agriculture, 3 (1): $59-69$.

Lucretia, I. B, Patience, C. Obinna-Echem, Sophia, C. A. (2018) Microbiological quality andantibiotic sensitivity of potential pathogens isolated from meat product (Suya) sold in Rivers State University and its environs. International Journal of Biotechnology and Food Science, 6(4): 67-76.

Matthew, E., Drosos, E., John, L. and Ioanna, P. (2013) MRSA in Africa: Filling the Global Map of Antimicrobial Resistance PLOS One. 8(7): e68024 doi: 10.1371/journal.pone.0068024

Mgbemere, V.N., Akpapunam, M. A. and Igene, J. O., (2011). Effect of Groundnut FlourSubstitution on Yield, Quality and Storage Stability of Kilishi - a Nigerian Indigenous Dried Meat Product. African Journal of Food, Agriculture, Nutrition and Development, $\quad \mathbf{1 1}(2)$ : 4718-4738. 
BAJOPAS Volume 13 Number 1, June, 2020

Mubarak, A. A., Azeez, M. L., Amos A. O., Opeyemi, O. O. (2016) Assessment of Animal Protein Consumption and Food Security Among Rural Households in Kwara State, Nigeria American Journal of Business and Society, 1(4): 233245.

Ndahi, M., D. Kwaga, J., K. P. Bello, M. Kabir J., V. Umoh, .J. Yakubu, S., E. and Nok, A., J. (2013) Prevalence and Antimicrobial Susceptibility of Listeria Monocytogenes and Methicillin-Resistant Staphylococcus aureus Strains from Raw Meat and Meat Products in Zaria, Nigeria. Applied Journal of Microbiology, 58(3):262-9.

Okonko, I.O., Odu, N.N. and Igboh, I.E. (2013). Microbiological Analysis of Kilishi Sold In Port Harcourt, Nigeria. New York Science Journal, 6 (7):37-43.

Osimani, A., Aquilanti, L. and Clementi, F. (2015) Microbiological Quality of Meatbased Meals and Operation of Control Systems within a Food Service Environment. International Food Research Journal 22(4): 1692-1698.

Onuorah, S. Obika, I. Odibo, F. Orji, M. (2015)An Assessment of the Bacteriological Quality of Tsire-Suya (Grilled Beef) sold in Awka, Nigeria. American. J. Life. Sci. Res. 3(4):287292.

Razavilar, V, Khandaghi, J. Barzgari, A. (2010); Isolation of Eschericia coli 0157:H7 from manure fertilized farms and raw vegetables grown on it, in Tabriz city in
Iran. African Journal of Microbiology Research, 4(9): 891-895.

Scallan, E. Hoekstra, R. M. Angulo, F. J.Tauxe, R. V, Widdowson, M. Roy, S. L et al., (2011).Food borne illness acquired in the United States- Major Pathogens. Emerg. Infec Dis, 17(1): 7-15.

Shamsuddeen U (2009). Microbiological quality of spice used in the production of Kilishi a traditionally dried and grilled meat product. Bayero Journal of Pure andApplied Sciences, 2(2): 66-69.

Shamsuddeen, U. (2015) Microbiological Hazard and Critical control point Analysis of Dried and Minced Meat Snacks Produced in Kano Nigeria. Lambert Academic Publishing; Pp 1-36.

Tijani, O.and Jumare, S. (2014). Microblological Quality Assessment of Meat

Sold in KauraNamoda. International Conference on Earth, Environment and Life sciences (EELS) Dubai (UAE).

Udobi, C. E., Obajuluwa, A. F., and Onaolapo, J. A., (2013) Prevalence and Antibiotic Resistance Pattern of MethicillinResistant Staphylococcus aureus from an Orthopaedic Hospital in Nigeria BioMed Research International; 26(6); 6-7.

WHO, 2015 Foodborne diseases in the WHO African Region.

Yousafzai HA, Rind R, Khan MA, Abro SH, Korejo NA, Ejaz M, Kabir A, Shahid M, Memon S. (2019). Microbiological Contamination of Cattle and Meat in Peshawar, Pakistan. J. Anim. Health Prod. 7(1): 1116. 


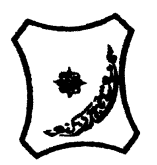

Bayero Journal of Pure and Applied Sciences, 13(1); 40 - 45

Received: September, 2019

Accepted: April, 2020

ISSN $2006-6996$

\title{
BACTERIOLOGICAL QUALITY OF STICK MEAT (Tsire) SOLD IN GARKO LOCAL GOVERNMENT AREA OF KANO STATE, NIGERIA
}

\author{
$*^{1}$ Dahiru A. T. and ${ }^{2}$ Maigari A. K. \\ ${ }^{1}$ Department of Hospitality Management, School of Technology, Kano State Polytechnic, PMB 3348, \\ Kano Nigeria. \\ ${ }^{2}$ Departmnt of Biological Sciences, Bayero University, Kano \\ Corresponding Author: dturajo61@gmail.com; GSM: 08087508262.
}

ABSTRACT

Stick meat, locally called Tsire in Hausa Language, is a significant portion of the diet of a large active population of Northern Nigeria. However, because of the handling and processing methods by the manufacturers as well as the hawking system of stick meat, the meat product may be exposed to both pre- and post-processed product contamination, and thus may poses danger to public health. Therefore, considering the role of Tsire in improving nutrition and increase household income to the populace, the need to improve the processing, distribution and overall quality of the product is simply indispensable. A total of 30 samples (5 samples from each of the 6 sampling points) of Tsire were collected randomly in Garko Town. Aerobic plate counts (APCs) and Total coliform counts (TCCS) of Tsire samples were determined using standard microbiological methods. APCs ranged from $1.02 \times 10^{5}$ to $4.00 \times 10^{5} \mathrm{CFU} / \mathrm{g}$; while TCCs ranged from $8 \mathrm{MPN} / \mathrm{g}$ to $68 \mathrm{MPN} / \mathrm{g}$. From the 30 samples screened, 16(53.33\%) bacteria namely, Campylobacter 2(6.66\%), Escherichia coli 6(20\%), Klebsiella pneumoniae 2(6.66\%), Salmonella spp. 1(3.33\%), Shigella 3(10\%) and Staphylococcus aureus 2(6.66\%) were detected. $E$. coli has the highest isolation rate of 6(20\%), while Salmonella spp. had the least frequency of 1(3.33\%). The distribution of isolated organisms within the study area were as follows: Dausai, 4(80\%), Kofar kudu, 4(80\%), Makwalla, 2(40\%), Rinji, 3(60\%), Tosaro, 2(40\%), and Tsohuwar Kasuwa, 1(20\%). The results have indicated that the Tsire was contaminated with bacteria thus exposing the product to fast deterioration, spoilage and also a vehicle for food borne illness, suggesting for adequate hygienic practices at all the stages, prior to consumption, to ensure safety of the meat product.

Key words: APCs, TCCs, Contamination, Microorganisms, Garko

\section{INTRODUCTION}

Nigeria is one of the developing nations with inadequate food supply and most often deficient in protein content (FAO, 2019). Nigerian's average animal protein intake per head per day is estimated at $7.9 \mathrm{~g}$ as against $35 \mathrm{~g}$ recommended value by Food and Agricultural Organization (Mubarak et al., 2016). These low levels of animal protein intake create great concern as it affects the nutritional status of Nigerians. Hence, there is the need for sufficient supply of animal protein from energy rich animal products to satisfy the nutritional requirements for Nigerians.

Meat is one major source of animal protein largely composed of water, protein and fats which can make it susceptible to microbial contamination within short time leading to spoilage (Apata et al., 2013; Mgbemere et al., 2011). Meat is mostly eaten after it has been cooked or processed in a variety of ways such as sun drying; smoking and roasting with or without fortifications (Borch et al., 1996). In Nigeria meat products such as Tsire, Kilishi and Balangu are locally produced using one or more of these methods in order to meet the nutritional requirements of the teeming Nigerians (Egbebi, 2011).

Tsire is a popular Nigerian traditional processed ready-to-eat roasted stick meat product (Shamsuddeen, 2015). It is sold in public places, along roads, in hotels, parks, quarters and even offices (Falegan et al., 2017). It is prepared from boneless healthy animal flesh such as beef and mutton, spiced with peanut cake, salt, vegetable oil and other flavorings followed by roasting (Shamsuddeen, 2015). Consumption of these products has extended to other parts of African countries such as Ghana, Somali, Cameroun and Chad (Ahmadu and Ibrahim, 2013). 
BAJOPAS Volume 13 Number 1, June, 2020

However, evidence of quality control sticking to procedural hygiene by the handlers during preparation and retailing of these products is poorly documented. Tsire is of great safety risk because of the fact that there are erratic cases of gastroenteritis and symptoms of food infection after consumption (WHO, 2015). Food borne illnesses are one of the major health problems in developing and developed countries (Razavilar, 2010). According to the World Health Organization, WHO (2015), $0.07 \%$ death of the 600 million global burdens of Foodborne illnesses have been reported to be caused by bacteria, viruses, fungi and chemicals. In America $0.27 \%$ of the estimated 48 million affected people is hospitalized and about $0.0063 \%$ deaths are recorded each year (Scallan et al., 2011). More than 91 million people in Africa fall ill and $0.15 \%$ dies each year, making Africa the highest burden bearer of Foodborne diseases per population (WHO, 2015).

Application of a Hazard Analysis Critical Control Point (HACCP) at all stages of meat products preparation is essential in order to ensure its safety. Thus, according to the guidelines of good manufacturing practice, the level of total aerobic bacterial contamination of thermally processed meat products should not exceed $10^{4}\left(\mathrm{cfu} \mathrm{g}^{-1}\right)$. Enterobacteriaceae and faecal coliform contamination in meat products should be within the range of $10^{2}-10^{4}$ and $10-10^{3} \mathrm{cfu} \mathrm{g}^{-1}$, respectively (Shamsuddeen, 2015). The aim of the study is therefore, to assess the total viable bacterial counts of tsire marketed locally within Garko town, and to isolate and identify the organisms at the point of consumption with the intention of promoting public health and food hygiene habits in the Nigerian populace.

\section{MATERIALS AND METHODS Study Area and Population}

Garko is one of the existing 44 local government areas located in Kano south west zone of Kano state with its capital administrative headquarters in the Garko town. It has coordinates $11^{\circ} 39^{\prime} \mathrm{N}$ $8^{\circ} 54^{\prime} \mathrm{E}$, and an area of $450 \mathrm{~km}^{2}$. The projected population of Garko local Government was 225,300 according to the National Population Census report (2018). Garko is known for agricultural activities both farming and animal husbandry. It is popularly known for large scale rice production. Other food crops include sweet potatoes, cassava, onions, sorghum, millet and sugarcane. Cows, sheep and goats are major groups of animals reared by majority of the populace. Meat products processed, retailed and consumed in Garko include roasted meat (Balangu), dried roasted meat (Kilishi), stick meat (Tsire), hide and skin pepper soup (Ragadada) and minced fried meat (Danbunnama).

\section{Samples Collection}

Five samples of Tsire products were collected from 6 different identified locations within Garko town in a sterile foil paper and immediately analyzed for the presence of bacteria.

\section{Sample Preparation}

Sample preparation for the bacteriological analysis was carried out in accordance with the method described by Atlas (1997). Twenty five grams $(25 \mathrm{~g})$ of the sample was homogenized in $225 \mathrm{ml}$ peptone water using Kenwood blender machine to obtain a $10^{1}$ homogenate. The homogenate was thoroughly shaken and $1 \mathrm{ml}$ pipetted into test tubes containing $9 \mathrm{ml}$ of peptone water $\left(10^{2}\right)$. The test tubes were further serially diluted to $10^{5}$.

Total Aerobic Mesophilic Bacterial Count

Total Aerobic mesophilic bacterial count was determined using the method described by Abdullahi et al. (2004) where $1 \mathrm{ml}$ of inoculums from $10^{1}$ to $10^{5}$ dilutions were transferred into duplicate Petri dishes and labeled accordingly. This was followed by pouring aseptically about $15 \mathrm{ml}$ of molten nutrient agar. The culture was homogenized by gentle spinning of the plates and allowed to solidify. The plates were incubated at $37^{\circ} \mathrm{C}$ for 24 hours. Plates containing 30-300 colonies were counted. The number of colony forming units per gram of a sample (cfu/g) was obtained by multiplying the average colony number with the inverse of the dilution factor.

\section{Enumeration and Detection of Coliform bacteria}

Detection and enumeration of coliform was carried out according to method described by Atlas, (1977). A set of 9 test tubes each containing $9 \mathrm{ml}$ of lactose broth and an inverted Durham tubes were autoclaved to expel air and to sterilize. Similarly, $1 \mathrm{ml}$ from the diluents $10^{1}$ was transferred to the first 3 test tubes, followed by $1 \mathrm{ml}$ from the diluents $10^{2}$ to the second set of 3 test tubes and finally the third diluents $10^{3}$ to the $3^{\text {rd }}$ set of 3 test tubes. All the 9 test tubes were incubated at $37^{\circ} \mathrm{C}$ for 24 hours. Tubes that showed gas and acid production after 24 hours were recorded as positive for the presence of Coliform. Negative tubes were further reincubated for 24 hours. Positive tubes were recorded. Estimate of most probable number of Coliform per gram of sample (MPN/g) was determined by comparing the number of gas positive tubes with the most probable number table. 
BAJOPAS Volume 13 Number 1, June, 2020 Identification of Coliform

A loop full of inoculum from gas positive tubes was streaked on to Eosine methylene blue (EMB) agar plate and incubated at $37^{\circ} \mathrm{C}$ for $24 \mathrm{hrs}$. Colonies which formed bluish black color with green metallic sheen, and reddish colonies were isolated on agar slants. Those colonies showing metallic sheen on EMB were sub cultured into tubes of lactose broth and incubated at $45^{\circ} \mathrm{C}$. The tubes were observed after $24 \mathrm{hrs}$ for gas production. This is the completed test for fecal coliform. Gram stain and other biochemical tests such as Indole, Methyl red, Voges-Proskauer and Citrate Utilization tests (IMVIC), Coagulase and Catalase tests were carried out for the Identification and confirmation of isolates.

\section{Procedure for Indole Test}

Indole test was carried out by preparing a Tryptone broth drawn in to test tubes, sterilized by autoclaving, inoculated with loopful of suspension and incubated at $37^{\circ} \mathrm{C}$ for 24 hours. Three drops of xylene was added in tubes, shaken vigorously and kept for the separation of two layers. One millilitre of Kovac's reagent was added and the formation of pink colour ring indicates positive Indole test.

\section{Procedure for Methyl Red Test}

Methyl red test was carried out by preparing Glucose phosphate broth, dispensed in test tubes, sterilized, inoculated with test culture and incubated at $37^{\circ} \mathrm{C}$ for 24 hours. Five drops of methyl-red indicator was added to the medium for the formation of red colour.

\section{Procedure for Voges-Proskauer Test}

Voges-Proskauer test was carried out by inoculating tubes with the bacterial culture followed by incubation for 48 hours at $37^{\circ} \mathrm{C}$. Separate pipettes were used to pipette $1 \mathrm{ml}$ from each culture tube into clean separate tubes. Eighteen drops $(0.5 \mathrm{ml})$ of Barrit's solution A (a-naphthol) was added to each tube containing glucose phosphate broth followed by the addition of an equal amount of solution $B$ into the same tube. The tubes were shaken at 30 seconds interval. A positive reaction was indicated by the development of a pink color, which turns red in 1-2 hours, after vigorous shaking.

\section{Procedure for Citrate Utilization Test}

Citrate Utilization Test was carried out by distributing melted agar (Simmon Citrate Agar) in to test tubes followed by sterilization at $121.5^{\circ} \mathrm{C}$ for 15 minutes. The test tubes were afterward held in slanted position, inoculated with the given bacterial culture and incubated at $37^{\circ} \mathrm{C}$ for $24 \mathrm{hrs}$. Positive test was indicated by color change of the media from green to blue.

\section{RESULTS AND DISCUSSIONS}

The results of this study are presented in tables $1,2,3$ and 4. Among the sampling areas Kofar Kudu had the highest aerobic mesophilic bacteria counts $4.0 \times 10^{5} \mathrm{cfu} / \mathrm{g}$ followed by Rinji $2.72 \times 10^{5} \mathrm{cfu} / \mathrm{g}$, while Tosaro had the least Aerobic mesophilic bacteria counts of $1.02 \times 10^{5}$ $\mathrm{cfu} / \mathrm{g}$ as indicated in Table 1.Makwalla had the highest coliform count $68 \mathrm{MPN} / \mathrm{g}$ followed by Rinji $37 \mathrm{MPN} / \mathrm{g}$. Tsohuwar Kasuwa had the least coliform counts $8 \mathrm{MPN} / \mathrm{g}$, (Table 2). Result from table 1 shows variation in the microbial contents among the samples which suggest variation in their sources, poor handling procedures and contamination from the processing environment. High coliform count and their differences within sampling areas is an indication of poor microbiological quality of the product. Ndahi et al. (2013) reported microbial load to be a function of the handling personnel and the environment. The results indicated that the samples were contaminated with bacteria as the counts exceeded the minimum safety level $\left(10^{4} \mathrm{cfu} / \mathrm{g}\right)$ for members of the Enterobacteriaceae family. However, it might be a reflection of poor hygienic practices which may contribute to health hazard to the potential consumers. Similarly, Inusa and Sa'id (2017); Osimani et al. (2015) reported that, the initial microbial content of the raw material play significant role in influencing the final microbial load of the finished product. Isolation of members of the Enterobacteriaceae such as $E$. coli, Klebsiella pneumoniae, Salmonella and Shigella signifies danger to the public health. These organisms are capable of producing endotoxins which trigger high fevers in infected individuals, and the enterotoxins which colonize the small intestines and lead to extreme dehydration as a result of vomiting and diarrhea sometimes with severe and fatal outcomes (Amaeze et al., 2016). From the 16 isolated organisms $E$. coli had the highest isolation rate $6(37.5 \%)$ (Table 3), this suggest faecal contamination of the products. $E$. coli is a common flora in the gastrointestinal tract responsible for diarrhea and extra-intestinal infections (CDC, 2011). The result is in conformity with the findings of Ndahi et al. (2013) and Shamsuddeen (2009). Also presence of campylobacter might be due to cross contamination from raw meat to finished product (Tsire). Staphylococcus aureus is a normal flora of the skin, nasal, genital, mouth or anal area in both humans and animals without any symptom of an infection (Matthew et al., 2013). Isolation of $S$. aureus in these study concords with the findings of Lucretia et al. (2018) from Suya sold in Rivers State. 
BAJOPAS Volume 13 Number 1, June, 2020

It is also in agreement with the findings of Yousafzai et al. (2018); Onuorah et al. (2015) and Tijjani and Jumare (2014) from tsire samples in different countries. Presence of $S$. aureus in foods is most of the time an indication of poor human handling, poor environment, unhygienic utensils and equipments used during processing (Igene et al., 2016; Okonko et al., 2013). Infections caused by $S$. aureus are difficult to treat leading to long hospitalization with consequent economic loss (Udobi et al., 2013). These include soft tissue infections, pneumonia, hospital-acquired postoperative wound infections, Staphylococcal food poisoning, impetigo and cellulitis (Charlene et al., 2013). Samples obtained from Dausai and Kofar Kudu had the highest isolation rate $4(80 \%)$ (Table 4 ) probably because of the much commercial activities taking place in the area which can lead to environmental contamination.

Table 1: Total Aerobic Mesophilic Bacterial Count of Tsire sold in Garko Town

\begin{tabular}{lll}
\hline Sampling Area & APC cfu/g & Mean \pm STD \\
\hline Dausai & $2.20 \times 10^{5}$ & $110000 \pm 14142.14$ \\
Kofar Kudu & $4.00 \times 10^{5}$ & $133333.3 \pm 23094.01$ \\
Makwalla & $1.30 \times 10^{5}$ & $32500 \pm 7187.953$ \\
Rinji & $2.72 \times 10^{5}$ & $90666.67 \pm 94769.90$ \\
Tosaro & $1.02 \times 10^{5}$ & $51000 \pm 15556.35$ \\
Tsohuwar Kasuwa & $1.75 \times 10^{5}$ & $35000 \pm 11357.82$ \\
\hline
\end{tabular}

Key: APC: Aerobic Mesophilic Counts

STD: Standard Deviation

Table 2: Total Coliform Count of Tsire sold in Garko Town

\begin{tabular}{lcc}
\hline \multicolumn{1}{c}{ Sampling Area } & TCC MPN/g & Mean \pm STD \\
\hline Dausai & 20 & $6.67 \pm 2.5166$ \\
Kofar Kudu & 32 & $16.00 \pm 5.6569$ \\
Makwalla & 68 & $13.60 \pm 8.7062$ \\
Rinji & 37 & $9.25 \pm 4.7871$ \\
Tosaro & 10 & $5.00 \pm 2.8284$ \\
Tsohuwar Kasuwa & 8 & $4.00 \pm 0.0000$ \\
\hline
\end{tabular}

Table 3: Organisms Isolated from Tsire Sold in Garko

\begin{tabular}{lcl}
\hline Isolated Organism & Frequency & Percentage (\%) \\
\hline Campylobacter & 2 & 06.66 \\
Escherichia coli & 6 & 20.00 \\
Klebsiella pneumoniae & 2 & 06.66 \\
Salmonella species & 1 & 03.33 \\
Shigella & 3 & 10.00 \\
Staphylococcus aureus & 2 & 06.66 \\
Total & 16 & \\
\hline
\end{tabular}

Table 4: Distribution of Organisms within Sampling Area

\begin{tabular}{lcc}
\hline \multicolumn{1}{c}{ Sampling Area } & No. Isolated & Percentage (\%) \\
\hline Dausai & 4 & 80 \\
Kofar Kudu & 4 & 80 \\
Makwalla & 2 & 40 \\
Rinji & 3 & 60 \\
Tosaro & 2 & 40 \\
Tsohuwar Kasuwa & 1 & 20 \\
Total & 16 & \\
\hline
\end{tabular}

\section{CONCLUSION}

Results indicated $4.00 \times 10^{5} \mathrm{CFU} / \mathrm{g}$ as the highest APCs count; while $68 \mathrm{MPN} / \mathrm{g}$ was the highest TCCs from the 30 samples analyzed. Among the isolates, $E$. coli has the highest isolation rate of $6(20 \%)$. Dausai and Kofar kudu were having the highest bacteria count of $4(80 \%)$, each, indicating higher contamination in those locations. 
BAJOPAS Volume 13 Number 1, June, 2020 RECOMMENDATIONS

The following recommendations are tenable:

1. Hygienic practices at all stages of production should be improved to safe guard the consumers against potential health hazard.

2. Monitoring of microbiological contamination of Tsire during preparations, packaging and marketing is essential to ensure product of good microbiological quality for consumers' health.

\section{REFERENCES}

Abdullahi, I. O., Umoh, V. J. and Galadima, M. (2004). Hazards Associated with Kilishi Preparations in Zaria. Nigerian Journal of Microbiology, 18 (1-2): $339-345$.

Ahmadu, J. and Ibrahim E. J., (2013): Determinants of Revenue in Suya Production in BeninCity, Edo State, Nigeria. Nigerian journal of agriculture, food and environment.9(3):1-5

Amaeze, N. Aboh, M. Itohan, A. Felix, E. Olatunji, T. and Oladosu, P. (2016) Microbial Profile, Antibiotic Sensitivity and Heat Resistance of Bacterial Isolates from Commercial Roasted Beef (Suya) in Abuja, Nigeria. JOPAT, 15(2): $22-30$.

Apata, E.S., Kuku1, I.A., Apata, O.C. and Adeyemi, K.O. (2013). Evaluation of Suya(Tsire) - An Intermediate Moisture Meat Product in Ogun State, Nigeria. J. Food Res 2 (1): 87.

Atlas, R. M. (1997) Principles of Microbiology Second Edition. C. Brown Publishers. Pp 802-803.

Borch, E. Kant-Muermans, M. L., Blixt, Y. (1996) Bacterial Spoilage of Meat and Cured Meat Products. Int $\mathrm{J}$ Food Microbiol .33(1): 103-20.

Centre for Disease Control, CDC (2011). "Escherichia coli 0157:H7" Division of Bacterial and Mycotic Diseasesht://www.cdc.gov/nczved/divisi ons/dfbmd/diseases/ecoli_0157h7/.

Charlene, R. J., Johnnie, A. D., and John, B. B., (2013) Prevalence and Characterization of Methicillin-Resistant Staphylococcus aureus Isolates from Retail Meat and Humans in Georgia. American society for Microbiology. J. of clinical microbiology. 12(1):123-6 doi:10.1128/JCM.0316612JCM.03166-12

Egbebi, A.O and Seidu, K., T. (2011). Microbiological Evaluation of Suya (dried smoked

meat) Sold in Ado and Akure, South West Nigeria.European Journal of Experinmental Biology, 1(4):1-5
3. Government should establish regulatory bodies responsible for inculcating hygiene habits to the local producers and vendors in order to prevent instant, cross and post processing contaminations by microbial pathogens.

4. Awareness and sensitization of local food producers about good hygienic practices in food handling and processing.

Falegan, C, R., Akoja, S. D., and Oyarekua, M. A., (2017) Microbiological Assessment of Suya (Sliced Roasted Beef) in Ado-Ekiti Metropolis, Ekiti State, Nigeria. MOJ Biology andMedicine.

Fonkem, D., N. Tanya, V., N. and Ebangi, A., L. (2010). Effect of Season on the Microbiological Quality of Kilishi, a Traditional Cameroonian Dried Beef Product. Tropicultura, 28(1): 10-15.

Food and Agricultural Organization of the United Nations (F A O, 1979). Manual of food quality control 4. Microbiological analysis.

Food and Agriculture Organisation of the United Nation (FAO), 2019. Nigeria at a glance.

Igene J.O., Uwadia, O.E., Ebabhamiegbebho, P.A. and Evivie, S.E., (2016) Shelf life Stability Studies of University of Benin (UNIBEN) Proff's Kilishi Product Asian Journal of Science and Technology 7(1): 2268-2274.

Inusa, S. K. and Said, I. S. (2017) Evaluation of the Chemical and Microbiological Properties Of Kilishi Sold in Kano Metropolis. Journal of Dry land Agriculture, 3 (1): $59-69$.

Lucretia, I. B, Patience, C. Obinna-Echem, Sophia, C. A. (2018) Microbiological quality andantibiotic sensitivity of potential pathogens isolated from meat product (Suya) sold in Rivers State University and its environs. International Journal of Biotechnology and Food Science, 6(4): 67-76.

Matthew, E., Drosos, E., John, L. and Ioanna, P. (2013) MRSA in Africa: Filling the Global Map of Antimicrobial Resistance PLOS One. 8(7): e68024 doi: 10.1371/journal.pone.0068024

Mgbemere, V.N., Akpapunam, M. A. and Igene, J. O., (2011). Effect of Groundnut FlourSubstitution on Yield, Quality and Storage Stability of Kilishi - a Nigerian Indigenous Dried Meat Product. African Journal of Food, Agriculture, Nutrition and Development, $\quad \mathbf{1 1}(2)$ : 4718-4738. 
BAJOPAS Volume 13 Number 1, June, 2020

Mubarak, A. A., Azeez, M. L., Amos A. O., Opeyemi, O. O. (2016) Assessment of Animal Protein Consumption and Food Security Among Rural Households in Kwara State, Nigeria American Journal of Business and Society, 1(4): 233245.

Ndahi, M., D. Kwaga, J., K. P. Bello, M. Kabir J., V. Umoh, .J. Yakubu, S., E. and Nok, A., J. (2013) Prevalence and Antimicrobial Susceptibility of Listeria Monocytogenes and Methicillin-Resistant Staphylococcus aureus Strains from Raw Meat and Meat Products in Zaria, Nigeria. Applied Journal of Microbiology, 58(3):262-9.

Okonko, I.O., Odu, N.N. and Igboh, I.E. (2013). Microbiological Analysis of Kilishi Sold In Port Harcourt, Nigeria. New York Science Journal, 6 (7):37-43.

Osimani, A., Aquilanti, L. and Clementi, F. (2015) Microbiological Quality of Meatbased Meals and Operation of Control Systems within a Food Service Environment. International Food Research Journal 22(4): 1692-1698.

Onuorah, S. Obika, I. Odibo, F. Orji, M. (2015)An Assessment of the Bacteriological Quality of Tsire-Suya (Grilled Beef) sold in Awka, Nigeria. American. J. Life. Sci. Res. 3(4):287292.

Razavilar, V, Khandaghi, J. Barzgari, A. (2010); Isolation of Eschericia coli 0157:H7 from manure fertilized farms and raw vegetables grown on it, in Tabriz city in
Iran. African Journal of Microbiology Research, 4(9): 891-895.

Scallan, E. Hoekstra, R. M. Angulo, F. J.Tauxe, R. V, Widdowson, M. Roy, S. L et al., (2011).Food borne illness acquired in the United States- Major Pathogens. Emerg. Infec Dis, 17(1): 7-15.

Shamsuddeen U (2009). Microbiological quality of spice used in the production of Kilishi a traditionally dried and grilled meat product. Bayero Journal of Pure andApplied Sciences, 2(2): 66-69.

Shamsuddeen, U. (2015) Microbiological Hazard and Critical control point Analysis of Dried and Minced Meat Snacks Produced in Kano Nigeria. Lambert Academic Publishing; Pp 1-36.

Tijani, O.and Jumare, S. (2014). Microblological Quality Assessment of Meat

Sold in KauraNamoda. International Conference on Earth, Environment and Life sciences (EELS) Dubai (UAE).

Udobi, C. E., Obajuluwa, A. F., and Onaolapo, J. A., (2013) Prevalence and Antibiotic Resistance Pattern of MethicillinResistant Staphylococcus aureus from an Orthopaedic Hospital in Nigeria BioMed Research International; 26(6); 6-7.

WHO, 2015 Foodborne diseases in the WHO African Region.

Yousafzai HA, Rind R, Khan MA, Abro SH, Korejo NA, Ejaz M, Kabir A, Shahid M, Memon S. (2019). Microbiological Contamination of Cattle and Meat in Peshawar, Pakistan. J. Anim. Health Prod. 7(1): 1116. 


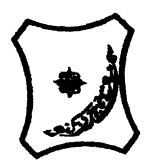

Bayero Journal of Pure and Applied Sciences, 13(1); 40 - 45

Received: September, 2019

Accepted: April, 2020

ISSN $2006-6996$

\title{
BACTERIOLOGICAL QUALITY OF STICK MEAT (Tsire) SOLD IN GARKO LOCAL GOVERNMENT AREA OF KANO STATE, NIGERIA
}

\author{
$*^{1}$ Dahiru A. T. and ${ }^{2}$ Maigari A. K. \\ ${ }^{1}$ Department of Hospitality Management, School of Technology, Kano State Polytechnic, PMB 3348, \\ Kano Nigeria. \\ ${ }^{2}$ Departmnt of Biological Sciences, Bayero University, Kano \\ Corresponding Author: dturajo61@gmail.com; GSM: 08087508262.
}

ABSTRACT

Stick meat, locally called Tsire in Hausa Language, is a significant portion of the diet of a large active population of Northern Nigeria. However, because of the handling and processing methods by the manufacturers as well as the hawking system of stick meat, the meat product may be exposed to both pre- and post-processed product contamination, and thus may poses danger to public health. Therefore, considering the role of Tsire in improving nutrition and increase household income to the populace, the need to improve the processing, distribution and overall quality of the product is simply indispensable. A total of 30 samples (5 samples from each of the 6 sampling points) of Tsire were collected randomly in Garko Town. Aerobic plate counts (APCs) and Total coliform counts (TCCS) of Tsire samples were determined using standard microbiological methods. APCs ranged from $1.02 \times 10^{5}$ to $4.00 \times 10^{5} \mathrm{CFU} / \mathrm{g}$; while TCCs ranged from $8 \mathrm{MPN} / \mathrm{g}$ to $68 \mathrm{MPN} / \mathrm{g}$. From the 30 samples screened, 16(53.33\%) bacteria namely, Campylobacter 2(6.66\%), Escherichia coli 6(20\%), Klebsiella pneumoniae 2(6.66\%), Salmonella spp. 1(3.33\%), Shigella 3(10\%) and Staphylococcus aureus 2(6.66\%) were detected. $E$. coli has the highest isolation rate of 6(20\%), while Salmonella spp. had the least frequency of 1(3.33\%). The distribution of isolated organisms within the study area were as follows: Dausai, 4(80\%), Kofar kudu, 4(80\%), Makwalla, 2(40\%), Rinji, 3(60\%), Tosaro, 2(40\%), and Tsohuwar Kasuwa, 1(20\%). The results have indicated that the Tsire was contaminated with bacteria thus exposing the product to fast deterioration, spoilage and also a vehicle for food borne illness, suggesting for adequate hygienic practices at all the stages, prior to consumption, to ensure safety of the meat product.

Key words: APCs, TCCs, Contamination, Microorganisms, Garko

\section{INTRODUCTION}

Nigeria is one of the developing nations with inadequate food supply and most often deficient in protein content (FAO, 2019). Nigerian's average animal protein intake per head per day is estimated at $7.9 \mathrm{~g}$ as against $35 \mathrm{~g}$ recommended value by Food and Agricultural Organization (Mubarak et al., 2016). These low levels of animal protein intake create great concern as it affects the nutritional status of Nigerians. Hence, there is the need for sufficient supply of animal protein from energy rich animal products to satisfy the nutritional requirements for Nigerians.

Meat is one major source of animal protein largely composed of water, protein and fats which can make it susceptible to microbial contamination within short time leading to spoilage (Apata et al., 2013; Mgbemere et al., 2011). Meat is mostly eaten after it has been cooked or processed in a variety of ways such as sun drying; smoking and roasting with or without fortifications (Borch et al., 1996). In Nigeria meat products such as Tsire, Kilishi and Balangu are locally produced using one or more of these methods in order to meet the nutritional requirements of the teeming Nigerians (Egbebi, 2011).

Tsire is a popular Nigerian traditional processed ready-to-eat roasted stick meat product (Shamsuddeen, 2015). It is sold in public places, along roads, in hotels, parks, quarters and even offices (Falegan et al., 2017). It is prepared from boneless healthy animal flesh such as beef and mutton, spiced with peanut cake, salt, vegetable oil and other flavorings followed by roasting (Shamsuddeen, 2015). Consumption of these products has extended to other parts of African countries such as Ghana, Somali, Cameroun and Chad (Ahmadu and Ibrahim, 2013). 
BAJOPAS Volume 13 Number 1, June, 2020

However, evidence of quality control sticking to procedural hygiene by the handlers during preparation and retailing of these products is poorly documented. Tsire is of great safety risk because of the fact that there are erratic cases of gastroenteritis and symptoms of food infection after consumption (WHO, 2015). Food borne illnesses are one of the major health problems in developing and developed countries (Razavilar, 2010). According to the World Health Organization, WHO (2015), $0.07 \%$ death of the 600 million global burdens of Foodborne illnesses have been reported to be caused by bacteria, viruses, fungi and chemicals. In America $0.27 \%$ of the estimated 48 million affected people is hospitalized and about $0.0063 \%$ deaths are recorded each year (Scallan et al., 2011). More than 91 million people in Africa fall ill and $0.15 \%$ dies each year, making Africa the highest burden bearer of Foodborne diseases per population (WHO, 2015).

Application of a Hazard Analysis Critical Control Point (HACCP) at all stages of meat products preparation is essential in order to ensure its safety. Thus, according to the guidelines of good manufacturing practice, the level of total aerobic bacterial contamination of thermally processed meat products should not exceed $10^{4}\left(\mathrm{cfu} \mathrm{g}^{-1}\right)$. Enterobacteriaceae and faecal coliform contamination in meat products should be within the range of $10^{2}-10^{4}$ and $10-10^{3} \mathrm{cfu} \mathrm{g}^{-1}$, respectively (Shamsuddeen, 2015). The aim of the study is therefore, to assess the total viable bacterial counts of tsire marketed locally within Garko town, and to isolate and identify the organisms at the point of consumption with the intention of promoting public health and food hygiene habits in the Nigerian populace.

\section{MATERIALS AND METHODS Study Area and Population}

Garko is one of the existing 44 local government areas located in Kano south west zone of Kano state with its capital administrative headquarters in the Garko town. It has coordinates $11^{\circ} 39^{\prime} \mathrm{N}$ $8^{\circ} 54^{\prime} \mathrm{E}$, and an area of $450 \mathrm{~km}^{2}$. The projected population of Garko local Government was 225,300 according to the National Population Census report (2018). Garko is known for agricultural activities both farming and animal husbandry. It is popularly known for large scale rice production. Other food crops include sweet potatoes, cassava, onions, sorghum, millet and sugarcane. Cows, sheep and goats are major groups of animals reared by majority of the populace. Meat products processed, retailed and consumed in Garko include roasted meat (Balangu), dried roasted meat (Kilishi), stick meat (Tsire), hide and skin pepper soup (Ragadada) and minced fried meat (Danbunnama).

\section{Samples Collection}

Five samples of Tsire products were collected from 6 different identified locations within Garko town in a sterile foil paper and immediately analyzed for the presence of bacteria.

\section{Sample Preparation}

Sample preparation for the bacteriological analysis was carried out in accordance with the method described by Atlas (1997). Twenty five grams $(25 \mathrm{~g})$ of the sample was homogenized in $225 \mathrm{ml}$ peptone water using Kenwood blender machine to obtain a $10^{1}$ homogenate. The homogenate was thoroughly shaken and $1 \mathrm{ml}$ pipetted into test tubes containing $9 \mathrm{ml}$ of peptone water $\left(10^{2}\right)$. The test tubes were further serially diluted to $10^{5}$.

Total Aerobic Mesophilic Bacterial Count

Total Aerobic mesophilic bacterial count was determined using the method described by Abdullahi et al. (2004) where $1 \mathrm{ml}$ of inoculums from $10^{1}$ to $10^{5}$ dilutions were transferred into duplicate Petri dishes and labeled accordingly. This was followed by pouring aseptically about $15 \mathrm{ml}$ of molten nutrient agar. The culture was homogenized by gentle spinning of the plates and allowed to solidify. The plates were incubated at $37^{\circ} \mathrm{C}$ for 24 hours. Plates containing 30-300 colonies were counted. The number of colony forming units per gram of a sample (cfu/g) was obtained by multiplying the average colony number with the inverse of the dilution factor.

\section{Enumeration and Detection of Coliform bacteria}

Detection and enumeration of coliform was carried out according to method described by Atlas, (1977). A set of 9 test tubes each containing $9 \mathrm{ml}$ of lactose broth and an inverted Durham tubes were autoclaved to expel air and to sterilize. Similarly, $1 \mathrm{ml}$ from the diluents $10^{1}$ was transferred to the first 3 test tubes, followed by $1 \mathrm{ml}$ from the diluents $10^{2}$ to the second set of 3 test tubes and finally the third diluents $10^{3}$ to the $3^{\text {rd }}$ set of 3 test tubes. All the 9 test tubes were incubated at $37^{\circ} \mathrm{C}$ for 24 hours. Tubes that showed gas and acid production after 24 hours were recorded as positive for the presence of Coliform. Negative tubes were further reincubated for 24 hours. Positive tubes were recorded. Estimate of most probable number of Coliform per gram of sample (MPN/g) was determined by comparing the number of gas positive tubes with the most probable number table. 
BAJOPAS Volume 13 Number 1, June, 2020 Identification of Coliform

A loop full of inoculum from gas positive tubes was streaked on to Eosine methylene blue (EMB) agar plate and incubated at $37^{\circ} \mathrm{C}$ for $24 \mathrm{hrs}$. Colonies which formed bluish black color with green metallic sheen, and reddish colonies were isolated on agar slants. Those colonies showing metallic sheen on EMB were sub cultured into tubes of lactose broth and incubated at $45^{\circ} \mathrm{C}$. The tubes were observed after $24 \mathrm{hrs}$ for gas production. This is the completed test for fecal coliform. Gram stain and other biochemical tests such as Indole, Methyl red, Voges-Proskauer and Citrate Utilization tests (IMVIC), Coagulase and Catalase tests were carried out for the Identification and confirmation of isolates.

\section{Procedure for Indole Test}

Indole test was carried out by preparing a Tryptone broth drawn in to test tubes, sterilized by autoclaving, inoculated with loopful of suspension and incubated at $37^{\circ} \mathrm{C}$ for 24 hours. Three drops of xylene was added in tubes, shaken vigorously and kept for the separation of two layers. One millilitre of Kovac's reagent was added and the formation of pink colour ring indicates positive Indole test.

\section{Procedure for Methyl Red Test}

Methyl red test was carried out by preparing Glucose phosphate broth, dispensed in test tubes, sterilized, inoculated with test culture and incubated at $37^{\circ} \mathrm{C}$ for 24 hours. Five drops of methyl-red indicator was added to the medium for the formation of red colour.

\section{Procedure for Voges-Proskauer Test}

Voges-Proskauer test was carried out by inoculating tubes with the bacterial culture followed by incubation for 48 hours at $37^{\circ} \mathrm{C}$. Separate pipettes were used to pipette $1 \mathrm{ml}$ from each culture tube into clean separate tubes. Eighteen drops $(0.5 \mathrm{ml})$ of Barrit's solution A (a-naphthol) was added to each tube containing glucose phosphate broth followed by the addition of an equal amount of solution $B$ into the same tube. The tubes were shaken at 30 seconds interval. A positive reaction was indicated by the development of a pink color, which turns red in 1-2 hours, after vigorous shaking.

\section{Procedure for Citrate Utilization Test}

Citrate Utilization Test was carried out by distributing melted agar (Simmon Citrate Agar) in to test tubes followed by sterilization at $121.5^{\circ} \mathrm{C}$ for 15 minutes. The test tubes were afterward held in slanted position, inoculated with the given bacterial culture and incubated at $37^{\circ} \mathrm{C}$ for $24 \mathrm{hrs}$. Positive test was indicated by color change of the media from green to blue.

\section{RESULTS AND DISCUSSIONS}

The results of this study are presented in tables $1,2,3$ and 4. Among the sampling areas Kofar Kudu had the highest aerobic mesophilic bacteria counts $4.0 \times 10^{5} \mathrm{cfu} / \mathrm{g}$ followed by Rinji $2.72 \times 10^{5} \mathrm{cfu} / \mathrm{g}$, while Tosaro had the least Aerobic mesophilic bacteria counts of $1.02 \times 10^{5}$ $\mathrm{cfu} / \mathrm{g}$ as indicated in Table 1.Makwalla had the highest coliform count $68 \mathrm{MPN} / \mathrm{g}$ followed by Rinji $37 \mathrm{MPN} / \mathrm{g}$. Tsohuwar Kasuwa had the least coliform counts $8 \mathrm{MPN} / \mathrm{g}$, (Table 2). Result from table 1 shows variation in the microbial contents among the samples which suggest variation in their sources, poor handling procedures and contamination from the processing environment. High coliform count and their differences within sampling areas is an indication of poor microbiological quality of the product. Ndahi et al. (2013) reported microbial load to be a function of the handling personnel and the environment. The results indicated that the samples were contaminated with bacteria as the counts exceeded the minimum safety level $\left(10^{4} \mathrm{cfu} / \mathrm{g}\right)$ for members of the Enterobacteriaceae family. However, it might be a reflection of poor hygienic practices which may contribute to health hazard to the potential consumers. Similarly, Inusa and Sa'id (2017); Osimani et al. (2015) reported that, the initial microbial content of the raw material play significant role in influencing the final microbial load of the finished product. Isolation of members of the Enterobacteriaceae such as $E$. coli, Klebsiella pneumoniae, Salmonella and Shigella signifies danger to the public health. These organisms are capable of producing endotoxins which trigger high fevers in infected individuals, and the enterotoxins which colonize the small intestines and lead to extreme dehydration as a result of vomiting and diarrhea sometimes with severe and fatal outcomes (Amaeze et al., 2016). From the 16 isolated organisms $E$. coli had the highest isolation rate $6(37.5 \%)$ (Table 3), this suggest faecal contamination of the products. $E$. coli is a common flora in the gastrointestinal tract responsible for diarrhea and extra-intestinal infections (CDC, 2011). The result is in conformity with the findings of Ndahi et al. (2013) and Shamsuddeen (2009). Also presence of campylobacter might be due to cross contamination from raw meat to finished product (Tsire). Staphylococcus aureus is a normal flora of the skin, nasal, genital, mouth or anal area in both humans and animals without any symptom of an infection (Matthew et al., 2013). Isolation of $S$. aureus in these study concords with the findings of Lucretia et al. (2018) from Suya sold in Rivers State. 
BAJOPAS Volume 13 Number 1, June, 2020

It is also in agreement with the findings of Yousafzai et al. (2018); Onuorah et al. (2015) and Tijjani and Jumare (2014) from tsire samples in different countries. Presence of $S$. aureus in foods is most of the time an indication of poor human handling, poor environment, unhygienic utensils and equipments used during processing (Igene et al., 2016; Okonko et al., 2013). Infections caused by $S$. aureus are difficult to treat leading to long hospitalization with consequent economic loss (Udobi et al., 2013). These include soft tissue infections, pneumonia, hospital-acquired postoperative wound infections, Staphylococcal food poisoning, impetigo and cellulitis (Charlene et al., 2013). Samples obtained from Dausai and Kofar Kudu had the highest isolation rate $4(80 \%)$ (Table 4 ) probably because of the much commercial activities taking place in the area which can lead to environmental contamination.

Table 1: Total Aerobic Mesophilic Bacterial Count of Tsire sold in Garko Town

\begin{tabular}{lll}
\hline Sampling Area & APC cfu/g & Mean \pm STD \\
\hline Dausai & $2.20 \times 10^{5}$ & $110000 \pm 14142.14$ \\
Kofar Kudu & $4.00 \times 10^{5}$ & $133333.3 \pm 23094.01$ \\
Makwalla & $1.30 \times 10^{5}$ & $32500 \pm 7187.953$ \\
Rinji & $2.72 \times 10^{5}$ & $90666.67 \pm 94769.90$ \\
Tosaro & $1.02 \times 10^{5}$ & $51000 \pm 15556.35$ \\
Tsohuwar Kasuwa & $1.75 \times 10^{5}$ & $35000 \pm 11357.82$ \\
\hline
\end{tabular}

Key: APC: Aerobic Mesophilic Counts

STD: Standard Deviation

Table 2: Total Coliform Count of Tsire sold in Garko Town

\begin{tabular}{lcc}
\hline \multicolumn{1}{c}{ Sampling Area } & TCC MPN/g & Mean \pm STD \\
\hline Dausai & 20 & $6.67 \pm 2.5166$ \\
Kofar Kudu & 32 & $16.00 \pm 5.6569$ \\
Makwalla & 68 & $13.60 \pm 8.7062$ \\
Rinji & 37 & $9.25 \pm 4.7871$ \\
Tosaro & 10 & $5.00 \pm 2.8284$ \\
Tsohuwar Kasuwa & 8 & $4.00 \pm 0.0000$ \\
\hline
\end{tabular}

Table 3: Organisms Isolated from Tsire Sold in Garko

\begin{tabular}{lcl}
\hline Isolated Organism & Frequency & Percentage (\%) \\
\hline Campylobacter & 2 & 06.66 \\
Escherichia coli & 6 & 20.00 \\
Klebsiella pneumoniae & 2 & 06.66 \\
Salmonella species & 1 & 03.33 \\
Shigella & 3 & 10.00 \\
Staphylococcus aureus & 2 & 06.66 \\
Total & 16 & \\
\hline
\end{tabular}

Table 4: Distribution of Organisms within Sampling Area

\begin{tabular}{lcc}
\hline \multicolumn{1}{c}{ Sampling Area } & No. Isolated & Percentage (\%) \\
\hline Dausai & 4 & 80 \\
Kofar Kudu & 4 & 80 \\
Makwalla & 2 & 40 \\
Rinji & 3 & 60 \\
Tosaro & 2 & 40 \\
Tsohuwar Kasuwa & 1 & 20 \\
Total & 16 & \\
\hline
\end{tabular}

\section{CONCLUSION}

Results indicated $4.00 \times 10^{5} \mathrm{CFU} / \mathrm{g}$ as the highest APCs count; while $68 \mathrm{MPN} / \mathrm{g}$ was the highest TCCs from the 30 samples analyzed. Among the isolates, $E$. coli has the highest isolation rate of $6(20 \%)$. Dausai and Kofar kudu were having the highest bacteria count of $4(80 \%)$, each, indicating higher contamination in those locations. 
BAJOPAS Volume 13 Number 1, June, 2020 RECOMMENDATIONS

The following recommendations are tenable:

1. Hygienic practices at all stages of production should be improved to safe guard the consumers against potential health hazard.

2. Monitoring of microbiological contamination of Tsire during preparations, packaging and marketing is essential to ensure product of good microbiological quality for consumers' health.

\section{REFERENCES}

Abdullahi, I. O., Umoh, V. J. and Galadima, M. (2004). Hazards Associated with Kilishi Preparations in Zaria. Nigerian Journal of Microbiology, 18 (1-2): $339-345$.

Ahmadu, J. and Ibrahim E. J., (2013): Determinants of Revenue in Suya Production in BeninCity, Edo State, Nigeria. Nigerian journal of agriculture, food and environment.9(3):1-5

Amaeze, N. Aboh, M. Itohan, A. Felix, E. Olatunji, T. and Oladosu, P. (2016) Microbial Profile, Antibiotic Sensitivity and Heat Resistance of Bacterial Isolates from Commercial Roasted Beef (Suya) in Abuja, Nigeria. JOPAT, 15(2): $22-30$.

Apata, E.S., Kuku1, I.A., Apata, O.C. and Adeyemi, K.O. (2013). Evaluation of Suya(Tsire) - An Intermediate Moisture Meat Product in Ogun State, Nigeria. J. Food Res 2 (1): 87.

Atlas, R. M. (1997) Principles of Microbiology Second Edition. C. Brown Publishers. Pp 802-803.

Borch, E. Kant-Muermans, M. L., Blixt, Y. (1996) Bacterial Spoilage of Meat and Cured Meat Products. Int $\mathrm{J}$ Food Microbiol .33(1): 103-20.

Centre for Disease Control, CDC (2011). "Escherichia coli 0157:H7" Division of Bacterial and Mycotic Diseasesht://www.cdc.gov/nczved/divisi ons/dfbmd/diseases/ecoli_0157h7/.

Charlene, R. J., Johnnie, A. D., and John, B. B., (2013) Prevalence and Characterization of Methicillin-Resistant Staphylococcus aureus Isolates from Retail Meat and Humans in Georgia. American society for Microbiology. J. of clinical microbiology. 12(1):123-6 doi:10.1128/JCM.0316612JCM.03166-12

Egbebi, A.O and Seidu, K., T. (2011). Microbiological Evaluation of Suya (dried smoked

meat) Sold in Ado and Akure, South West Nigeria.European Journal of Experinmental Biology, 1(4):1-5
3. Government should establish regulatory bodies responsible for inculcating hygiene habits to the local producers and vendors in order to prevent instant, cross and post processing contaminations by microbial pathogens.

4. Awareness and sensitization of local food producers about good hygienic practices in food handling and processing.

Falegan, C, R., Akoja, S. D., and Oyarekua, M. A., (2017) Microbiological Assessment of Suya (Sliced Roasted Beef) in Ado-Ekiti Metropolis, Ekiti State, Nigeria. MOJ Biology andMedicine.

Fonkem, D., N. Tanya, V., N. and Ebangi, A., L. (2010). Effect of Season on the Microbiological Quality of Kilishi, a Traditional Cameroonian Dried Beef Product. Tropicultura, 28(1): 10-15.

Food and Agricultural Organization of the United Nations (F A O, 1979). Manual of food quality control 4. Microbiological analysis.

Food and Agriculture Organisation of the United Nation (FAO), 2019. Nigeria at a glance.

Igene J.O., Uwadia, O.E., Ebabhamiegbebho, P.A. and Evivie, S.E., (2016) Shelf life Stability Studies of University of Benin (UNIBEN) Proff's Kilishi Product Asian Journal of Science and Technology 7(1): 2268-2274.

Inusa, S. K. and Said, I. S. (2017) Evaluation of the Chemical and Microbiological Properties Of Kilishi Sold in Kano Metropolis. Journal of Dry land Agriculture, 3 (1): $59-69$.

Lucretia, I. B, Patience, C. Obinna-Echem, Sophia, C. A. (2018) Microbiological quality andantibiotic sensitivity of potential pathogens isolated from meat product (Suya) sold in Rivers State University and its environs. International Journal of Biotechnology and Food Science, 6(4): 67-76.

Matthew, E., Drosos, E., John, L. and Ioanna, P. (2013) MRSA in Africa: Filling the Global Map of Antimicrobial Resistance PLOS One. 8(7): e68024 doi: 10.1371/journal.pone.0068024

Mgbemere, V.N., Akpapunam, M. A. and Igene, J. O., (2011). Effect of Groundnut FlourSubstitution on Yield, Quality and Storage Stability of Kilishi - a Nigerian Indigenous Dried Meat Product. African Journal of Food, Agriculture, Nutrition and Development, $\quad \mathbf{1 1}(2)$ : 4718-4738. 
BAJOPAS Volume 13 Number 1, June, 2020

Mubarak, A. A., Azeez, M. L., Amos A. O., Opeyemi, O. O. (2016) Assessment of Animal Protein Consumption and Food Security Among Rural Households in Kwara State, Nigeria American Journal of Business and Society, 1(4): 233245.

Ndahi, M., D. Kwaga, J., K. P. Bello, M. Kabir J., V. Umoh, .J. Yakubu, S., E. and Nok, A., J. (2013) Prevalence and Antimicrobial Susceptibility of Listeria Monocytogenes and Methicillin-Resistant Staphylococcus aureus Strains from Raw Meat and Meat Products in Zaria, Nigeria. Applied Journal of Microbiology, 58(3):262-9.

Okonko, I.O., Odu, N.N. and Igboh, I.E. (2013). Microbiological Analysis of Kilishi Sold In Port Harcourt, Nigeria. New York Science Journal, 6 (7):37-43.

Osimani, A., Aquilanti, L. and Clementi, F. (2015) Microbiological Quality of Meatbased Meals and Operation of Control Systems within a Food Service Environment. International Food Research Journal 22(4): 1692-1698.

Onuorah, S. Obika, I. Odibo, F. Orji, M. (2015)An Assessment of the Bacteriological Quality of Tsire-Suya (Grilled Beef) sold in Awka, Nigeria. American. J. Life. Sci. Res. 3(4):287292.

Razavilar, V, Khandaghi, J. Barzgari, A. (2010); Isolation of Eschericia coli 0157:H7 from manure fertilized farms and raw vegetables grown on it, in Tabriz city in
Iran. African Journal of Microbiology Research, 4(9): 891-895.

Scallan, E. Hoekstra, R. M. Angulo, F. J.Tauxe, R. V, Widdowson, M. Roy, S. L et al., (2011).Food borne illness acquired in the United States- Major Pathogens. Emerg. Infec Dis, 17(1): 7-15.

Shamsuddeen U (2009). Microbiological quality of spice used in the production of Kilishi a traditionally dried and grilled meat product. Bayero Journal of Pure andApplied Sciences, 2(2): 66-69.

Shamsuddeen, U. (2015) Microbiological Hazard and Critical control point Analysis of Dried and Minced Meat Snacks Produced in Kano Nigeria. Lambert Academic Publishing; Pp 1-36.

Tijani, O.and Jumare, S. (2014). Microblological Quality Assessment of Meat

Sold in KauraNamoda. International Conference on Earth, Environment and Life sciences (EELS) Dubai (UAE).

Udobi, C. E., Obajuluwa, A. F., and Onaolapo, J. A., (2013) Prevalence and Antibiotic Resistance Pattern of MethicillinResistant Staphylococcus aureus from an Orthopaedic Hospital in Nigeria BioMed Research International; 26(6); 6-7.

WHO, 2015 Foodborne diseases in the WHO African Region.

Yousafzai HA, Rind R, Khan MA, Abro SH, Korejo NA, Ejaz M, Kabir A, Shahid M, Memon S. (2019). Microbiological Contamination of Cattle and Meat in Peshawar, Pakistan. J. Anim. Health Prod. 7(1): 1116. 


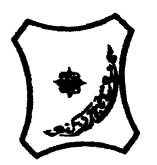

Bayero Journal of Pure and Applied Sciences, 13(1); 40 - 45

Received: September, 2019

Accepted: April, 2020

ISSN $2006-6996$

\title{
BACTERIOLOGICAL QUALITY OF STICK MEAT (Tsire) SOLD IN GARKO LOCAL GOVERNMENT AREA OF KANO STATE, NIGERIA
}

\author{
$*^{1}$ Dahiru A. T. and ${ }^{2}$ Maigari A. K. \\ ${ }^{1}$ Department of Hospitality Management, School of Technology, Kano State Polytechnic, PMB 3348, \\ Kano Nigeria. \\ ${ }^{2}$ Departmnt of Biological Sciences, Bayero University, Kano \\ Corresponding Author: dturajo61@gmail.com; GSM: 08087508262.
}

ABSTRACT

Stick meat, locally called Tsire in Hausa Language, is a significant portion of the diet of a large active population of Northern Nigeria. However, because of the handling and processing methods by the manufacturers as well as the hawking system of stick meat, the meat product may be exposed to both pre- and post-processed product contamination, and thus may poses danger to public health. Therefore, considering the role of Tsire in improving nutrition and increase household income to the populace, the need to improve the processing, distribution and overall quality of the product is simply indispensable. A total of 30 samples (5 samples from each of the 6 sampling points) of Tsire were collected randomly in Garko Town. Aerobic plate counts (APCs) and Total coliform counts (TCCS) of Tsire samples were determined using standard microbiological methods. APCs ranged from $1.02 \times 10^{5}$ to $4.00 \times 10^{5} \mathrm{CFU} / \mathrm{g}$; while TCCs ranged from $8 \mathrm{MPN} / \mathrm{g}$ to $68 \mathrm{MPN} / \mathrm{g}$. From the 30 samples screened, 16(53.33\%) bacteria namely, Campylobacter 2(6.66\%), Escherichia coli 6(20\%), Klebsiella pneumoniae 2(6.66\%), Salmonella spp. 1(3.33\%), Shigella 3(10\%) and Staphylococcus aureus 2(6.66\%) were detected. $E$. coli has the highest isolation rate of 6(20\%), while Salmonella spp. had the least frequency of 1(3.33\%). The distribution of isolated organisms within the study area were as follows: Dausai, 4(80\%), Kofar kudu, 4(80\%), Makwalla, 2(40\%), Rinji, 3(60\%), Tosaro, 2(40\%), and Tsohuwar Kasuwa, 1(20\%). The results have indicated that the Tsire was contaminated with bacteria thus exposing the product to fast deterioration, spoilage and also a vehicle for food borne illness, suggesting for adequate hygienic practices at all the stages, prior to consumption, to ensure safety of the meat product.

Key words: APCs, TCCs, Contamination, Microorganisms, Garko

\section{INTRODUCTION}

Nigeria is one of the developing nations with inadequate food supply and most often deficient in protein content (FAO, 2019). Nigerian's average animal protein intake per head per day is estimated at $7.9 \mathrm{~g}$ as against $35 \mathrm{~g}$ recommended value by Food and Agricultural Organization (Mubarak et al., 2016). These low levels of animal protein intake create great concern as it affects the nutritional status of Nigerians. Hence, there is the need for sufficient supply of animal protein from energy rich animal products to satisfy the nutritional requirements for Nigerians.

Meat is one major source of animal protein largely composed of water, protein and fats which can make it susceptible to microbial contamination within short time leading to spoilage (Apata et al., 2013; Mgbemere et al., 2011). Meat is mostly eaten after it has been cooked or processed in a variety of ways such as sun drying; smoking and roasting with or without fortifications (Borch et al., 1996). In Nigeria meat products such as Tsire, Kilishi and Balangu are locally produced using one or more of these methods in order to meet the nutritional requirements of the teeming Nigerians (Egbebi, 2011).

Tsire is a popular Nigerian traditional processed ready-to-eat roasted stick meat product (Shamsuddeen, 2015). It is sold in public places, along roads, in hotels, parks, quarters and even offices (Falegan et al., 2017). It is prepared from boneless healthy animal flesh such as beef and mutton, spiced with peanut cake, salt, vegetable oil and other flavorings followed by roasting (Shamsuddeen, 2015). Consumption of these products has extended to other parts of African countries such as Ghana, Somali, Cameroun and Chad (Ahmadu and Ibrahim, 2013). 
BAJOPAS Volume 13 Number 1, June, 2020

However, evidence of quality control sticking to procedural hygiene by the handlers during preparation and retailing of these products is poorly documented. Tsire is of great safety risk because of the fact that there are erratic cases of gastroenteritis and symptoms of food infection after consumption (WHO, 2015). Food borne illnesses are one of the major health problems in developing and developed countries (Razavilar, 2010). According to the World Health Organization, WHO (2015), $0.07 \%$ death of the 600 million global burdens of Foodborne illnesses have been reported to be caused by bacteria, viruses, fungi and chemicals. In America $0.27 \%$ of the estimated 48 million affected people is hospitalized and about $0.0063 \%$ deaths are recorded each year (Scallan et al., 2011). More than 91 million people in Africa fall ill and $0.15 \%$ dies each year, making Africa the highest burden bearer of Foodborne diseases per population (WHO, 2015).

Application of a Hazard Analysis Critical Control Point (HACCP) at all stages of meat products preparation is essential in order to ensure its safety. Thus, according to the guidelines of good manufacturing practice, the level of total aerobic bacterial contamination of thermally processed meat products should not exceed $10^{4}\left(\mathrm{cfu} \mathrm{g}^{-1}\right)$. Enterobacteriaceae and faecal coliform contamination in meat products should be within the range of $10^{2}-10^{4}$ and $10-10^{3} \mathrm{cfu} \mathrm{g}^{-1}$, respectively (Shamsuddeen, 2015). The aim of the study is therefore, to assess the total viable bacterial counts of tsire marketed locally within Garko town, and to isolate and identify the organisms at the point of consumption with the intention of promoting public health and food hygiene habits in the Nigerian populace.

\section{MATERIALS AND METHODS Study Area and Population}

Garko is one of the existing 44 local government areas located in Kano south west zone of Kano state with its capital administrative headquarters in the Garko town. It has coordinates $11^{\circ} 39^{\prime} \mathrm{N}$ $8^{\circ} 54^{\prime} \mathrm{E}$, and an area of $450 \mathrm{~km}^{2}$. The projected population of Garko local Government was 225,300 according to the National Population Census report (2018). Garko is known for agricultural activities both farming and animal husbandry. It is popularly known for large scale rice production. Other food crops include sweet potatoes, cassava, onions, sorghum, millet and sugarcane. Cows, sheep and goats are major groups of animals reared by majority of the populace. Meat products processed, retailed and consumed in Garko include roasted meat (Balangu), dried roasted meat (Kilishi), stick meat (Tsire), hide and skin pepper soup (Ragadada) and minced fried meat (Danbunnama).

\section{Samples Collection}

Five samples of Tsire products were collected from 6 different identified locations within Garko town in a sterile foil paper and immediately analyzed for the presence of bacteria.

\section{Sample Preparation}

Sample preparation for the bacteriological analysis was carried out in accordance with the method described by Atlas (1997). Twenty five grams $(25 \mathrm{~g})$ of the sample was homogenized in $225 \mathrm{ml}$ peptone water using Kenwood blender machine to obtain a $10^{1}$ homogenate. The homogenate was thoroughly shaken and $1 \mathrm{ml}$ pipetted into test tubes containing $9 \mathrm{ml}$ of peptone water $\left(10^{2}\right)$. The test tubes were further serially diluted to $10^{5}$.

Total Aerobic Mesophilic Bacterial Count

Total Aerobic mesophilic bacterial count was determined using the method described by Abdullahi et al. (2004) where $1 \mathrm{ml}$ of inoculums from $10^{1}$ to $10^{5}$ dilutions were transferred into duplicate Petri dishes and labeled accordingly. This was followed by pouring aseptically about $15 \mathrm{ml}$ of molten nutrient agar. The culture was homogenized by gentle spinning of the plates and allowed to solidify. The plates were incubated at $37^{\circ} \mathrm{C}$ for 24 hours. Plates containing 30-300 colonies were counted. The number of colony forming units per gram of a sample (cfu/g) was obtained by multiplying the average colony number with the inverse of the dilution factor.

\section{Enumeration and Detection of Coliform bacteria}

Detection and enumeration of coliform was carried out according to method described by Atlas, (1977). A set of 9 test tubes each containing $9 \mathrm{ml}$ of lactose broth and an inverted Durham tubes were autoclaved to expel air and to sterilize. Similarly, $1 \mathrm{ml}$ from the diluents $10^{1}$ was transferred to the first 3 test tubes, followed by $1 \mathrm{ml}$ from the diluents $10^{2}$ to the second set of 3 test tubes and finally the third diluents $10^{3}$ to the $3^{\text {rd }}$ set of 3 test tubes. All the 9 test tubes were incubated at $37^{\circ} \mathrm{C}$ for 24 hours. Tubes that showed gas and acid production after 24 hours were recorded as positive for the presence of Coliform. Negative tubes were further reincubated for 24 hours. Positive tubes were recorded. Estimate of most probable number of Coliform per gram of sample (MPN/g) was determined by comparing the number of gas positive tubes with the most probable number table. 
BAJOPAS Volume 13 Number 1, June, 2020 Identification of Coliform

A loop full of inoculum from gas positive tubes was streaked on to Eosine methylene blue (EMB) agar plate and incubated at $37^{\circ} \mathrm{C}$ for $24 \mathrm{hrs}$. Colonies which formed bluish black color with green metallic sheen, and reddish colonies were isolated on agar slants. Those colonies showing metallic sheen on EMB were sub cultured into tubes of lactose broth and incubated at $45^{\circ} \mathrm{C}$. The tubes were observed after $24 \mathrm{hrs}$ for gas production. This is the completed test for fecal coliform. Gram stain and other biochemical tests such as Indole, Methyl red, Voges-Proskauer and Citrate Utilization tests (IMVIC), Coagulase and Catalase tests were carried out for the Identification and confirmation of isolates.

\section{Procedure for Indole Test}

Indole test was carried out by preparing a Tryptone broth drawn in to test tubes, sterilized by autoclaving, inoculated with loopful of suspension and incubated at $37^{\circ} \mathrm{C}$ for 24 hours. Three drops of xylene was added in tubes, shaken vigorously and kept for the separation of two layers. One millilitre of Kovac's reagent was added and the formation of pink colour ring indicates positive Indole test.

\section{Procedure for Methyl Red Test}

Methyl red test was carried out by preparing Glucose phosphate broth, dispensed in test tubes, sterilized, inoculated with test culture and incubated at $37^{\circ} \mathrm{C}$ for 24 hours. Five drops of methyl-red indicator was added to the medium for the formation of red colour.

\section{Procedure for Voges-Proskauer Test}

Voges-Proskauer test was carried out by inoculating tubes with the bacterial culture followed by incubation for 48 hours at $37^{\circ} \mathrm{C}$. Separate pipettes were used to pipette $1 \mathrm{ml}$ from each culture tube into clean separate tubes. Eighteen drops $(0.5 \mathrm{ml})$ of Barrit's solution A (a-naphthol) was added to each tube containing glucose phosphate broth followed by the addition of an equal amount of solution $B$ into the same tube. The tubes were shaken at 30 seconds interval. A positive reaction was indicated by the development of a pink color, which turns red in 1-2 hours, after vigorous shaking.

\section{Procedure for Citrate Utilization Test}

Citrate Utilization Test was carried out by distributing melted agar (Simmon Citrate Agar) in to test tubes followed by sterilization at $121.5^{\circ} \mathrm{C}$ for 15 minutes. The test tubes were afterward held in slanted position, inoculated with the given bacterial culture and incubated at $37^{\circ} \mathrm{C}$ for $24 \mathrm{hrs}$. Positive test was indicated by color change of the media from green to blue.

\section{RESULTS AND DISCUSSIONS}

The results of this study are presented in tables $1,2,3$ and 4. Among the sampling areas Kofar Kudu had the highest aerobic mesophilic bacteria counts $4.0 \times 10^{5} \mathrm{cfu} / \mathrm{g}$ followed by Rinji $2.72 \times 10^{5} \mathrm{cfu} / \mathrm{g}$, while Tosaro had the least Aerobic mesophilic bacteria counts of $1.02 \times 10^{5}$ $\mathrm{cfu} / \mathrm{g}$ as indicated in Table 1.Makwalla had the highest coliform count $68 \mathrm{MPN} / \mathrm{g}$ followed by Rinji $37 \mathrm{MPN} / \mathrm{g}$. Tsohuwar Kasuwa had the least coliform counts $8 \mathrm{MPN} / \mathrm{g}$, (Table 2). Result from table 1 shows variation in the microbial contents among the samples which suggest variation in their sources, poor handling procedures and contamination from the processing environment. High coliform count and their differences within sampling areas is an indication of poor microbiological quality of the product. Ndahi et al. (2013) reported microbial load to be a function of the handling personnel and the environment. The results indicated that the samples were contaminated with bacteria as the counts exceeded the minimum safety level $\left(10^{4} \mathrm{cfu} / \mathrm{g}\right)$ for members of the Enterobacteriaceae family. However, it might be a reflection of poor hygienic practices which may contribute to health hazard to the potential consumers. Similarly, Inusa and Sa'id (2017); Osimani et al. (2015) reported that, the initial microbial content of the raw material play significant role in influencing the final microbial load of the finished product. Isolation of members of the Enterobacteriaceae such as $E$. coli, Klebsiella pneumoniae, Salmonella and Shigella signifies danger to the public health. These organisms are capable of producing endotoxins which trigger high fevers in infected individuals, and the enterotoxins which colonize the small intestines and lead to extreme dehydration as a result of vomiting and diarrhea sometimes with severe and fatal outcomes (Amaeze et al., 2016). From the 16 isolated organisms $E$. coli had the highest isolation rate $6(37.5 \%)$ (Table 3), this suggest faecal contamination of the products. $E$. coli is a common flora in the gastrointestinal tract responsible for diarrhea and extra-intestinal infections (CDC, 2011). The result is in conformity with the findings of Ndahi et al. (2013) and Shamsuddeen (2009). Also presence of campylobacter might be due to cross contamination from raw meat to finished product (Tsire). Staphylococcus aureus is a normal flora of the skin, nasal, genital, mouth or anal area in both humans and animals without any symptom of an infection (Matthew et al., 2013). Isolation of $S$. aureus in these study concords with the findings of Lucretia et al. (2018) from Suya sold in Rivers State. 
BAJOPAS Volume 13 Number 1, June, 2020

It is also in agreement with the findings of Yousafzai et al. (2018); Onuorah et al. (2015) and Tijjani and Jumare (2014) from tsire samples in different countries. Presence of $S$. aureus in foods is most of the time an indication of poor human handling, poor environment, unhygienic utensils and equipments used during processing (Igene et al., 2016; Okonko et al., 2013). Infections caused by $S$. aureus are difficult to treat leading to long hospitalization with consequent economic loss (Udobi et al., 2013). These include soft tissue infections, pneumonia, hospital-acquired postoperative wound infections, Staphylococcal food poisoning, impetigo and cellulitis (Charlene et al., 2013). Samples obtained from Dausai and Kofar Kudu had the highest isolation rate $4(80 \%)$ (Table 4 ) probably because of the much commercial activities taking place in the area which can lead to environmental contamination.

Table 1: Total Aerobic Mesophilic Bacterial Count of Tsire sold in Garko Town

\begin{tabular}{lll}
\hline Sampling Area & APC cfu/g & Mean \pm STD \\
\hline Dausai & $2.20 \times 10^{5}$ & $110000 \pm 14142.14$ \\
Kofar Kudu & $4.00 \times 10^{5}$ & $133333.3 \pm 23094.01$ \\
Makwalla & $1.30 \times 10^{5}$ & $32500 \pm 7187.953$ \\
Rinji & $2.72 \times 10^{5}$ & $90666.67 \pm 94769.90$ \\
Tosaro & $1.02 \times 10^{5}$ & $51000 \pm 15556.35$ \\
Tsohuwar Kasuwa & $1.75 \times 10^{5}$ & $35000 \pm 11357.82$ \\
\hline
\end{tabular}

Key: APC: Aerobic Mesophilic Counts

STD: Standard Deviation

Table 2: Total Coliform Count of Tsire sold in Garko Town

\begin{tabular}{lcc}
\hline \multicolumn{1}{c}{ Sampling Area } & TCC MPN/g & Mean \pm STD \\
\hline Dausai & 20 & $6.67 \pm 2.5166$ \\
Kofar Kudu & 32 & $16.00 \pm 5.6569$ \\
Makwalla & 68 & $13.60 \pm 8.7062$ \\
Rinji & 37 & $9.25 \pm 4.7871$ \\
Tosaro & 10 & $5.00 \pm 2.8284$ \\
Tsohuwar Kasuwa & 8 & $4.00 \pm 0.0000$ \\
\hline
\end{tabular}

Table 3: Organisms Isolated from Tsire Sold in Garko

\begin{tabular}{lcl}
\hline Isolated Organism & Frequency & Percentage (\%) \\
\hline Campylobacter & 2 & 06.66 \\
Escherichia coli & 6 & 20.00 \\
Klebsiella pneumoniae & 2 & 06.66 \\
Salmonella species & 1 & 03.33 \\
Shigella & 3 & 10.00 \\
Staphylococcus aureus & 2 & 06.66 \\
Total & 16 & \\
\hline
\end{tabular}

Table 4: Distribution of Organisms within Sampling Area

\begin{tabular}{lcc}
\hline \multicolumn{1}{c}{ Sampling Area } & No. Isolated & Percentage (\%) \\
\hline Dausai & 4 & 80 \\
Kofar Kudu & 4 & 80 \\
Makwalla & 2 & 40 \\
Rinji & 3 & 60 \\
Tosaro & 2 & 40 \\
Tsohuwar Kasuwa & 1 & 20 \\
Total & 16 & \\
\hline
\end{tabular}

\section{CONCLUSION}

Results indicated $4.00 \times 10^{5} \mathrm{CFU} / \mathrm{g}$ as the highest APCs count; while $68 \mathrm{MPN} / \mathrm{g}$ was the highest TCCs from the 30 samples analyzed. Among the isolates, $E$. coli has the highest isolation rate of $6(20 \%)$. Dausai and Kofar kudu were having the highest bacteria count of $4(80 \%)$, each, indicating higher contamination in those locations. 
BAJOPAS Volume 13 Number 1, June, 2020 RECOMMENDATIONS

The following recommendations are tenable:

1. Hygienic practices at all stages of production should be improved to safe guard the consumers against potential health hazard.

2. Monitoring of microbiological contamination of Tsire during preparations, packaging and marketing is essential to ensure product of good microbiological quality for consumers' health.

\section{REFERENCES}

Abdullahi, I. O., Umoh, V. J. and Galadima, M. (2004). Hazards Associated with Kilishi Preparations in Zaria. Nigerian Journal of Microbiology, 18 (1-2): $339-345$.

Ahmadu, J. and Ibrahim E. J., (2013): Determinants of Revenue in Suya Production in BeninCity, Edo State, Nigeria. Nigerian journal of agriculture, food and environment.9(3):1-5

Amaeze, N. Aboh, M. Itohan, A. Felix, E. Olatunji, T. and Oladosu, P. (2016) Microbial Profile, Antibiotic Sensitivity and Heat Resistance of Bacterial Isolates from Commercial Roasted Beef (Suya) in Abuja, Nigeria. JOPAT, 15(2): $22-30$.

Apata, E.S., Kuku1, I.A., Apata, O.C. and Adeyemi, K.O. (2013). Evaluation of Suya(Tsire) - An Intermediate Moisture Meat Product in Ogun State, Nigeria. J. Food Res 2 (1): 87.

Atlas, R. M. (1997) Principles of Microbiology Second Edition. C. Brown Publishers. Pp 802-803.

Borch, E. Kant-Muermans, M. L., Blixt, Y. (1996) Bacterial Spoilage of Meat and Cured Meat Products. Int $\mathrm{J}$ Food Microbiol .33(1): 103-20.

Centre for Disease Control, CDC (2011). "Escherichia coli 0157:H7" Division of Bacterial and Mycotic Diseasesht://www.cdc.gov/nczved/divisi ons/dfbmd/diseases/ecoli_0157h7/.

Charlene, R. J., Johnnie, A. D., and John, B. B., (2013) Prevalence and Characterization of Methicillin-Resistant Staphylococcus aureus Isolates from Retail Meat and Humans in Georgia. American society for Microbiology. J. of clinical microbiology. 12(1):123-6 doi:10.1128/JCM.0316612JCM.03166-12

Egbebi, A.O and Seidu, K., T. (2011). Microbiological Evaluation of Suya (dried smoked

meat) Sold in Ado and Akure, South West Nigeria.European Journal of Experinmental Biology, 1(4):1-5
3. Government should establish regulatory bodies responsible for inculcating hygiene habits to the local producers and vendors in order to prevent instant, cross and post processing contaminations by microbial pathogens.

4. Awareness and sensitization of local food producers about good hygienic practices in food handling and processing.

Falegan, C, R., Akoja, S. D., and Oyarekua, M. A., (2017) Microbiological Assessment of Suya (Sliced Roasted Beef) in Ado-Ekiti Metropolis, Ekiti State, Nigeria. MOJ Biology andMedicine.

Fonkem, D., N. Tanya, V., N. and Ebangi, A., L. (2010). Effect of Season on the Microbiological Quality of Kilishi, a Traditional Cameroonian Dried Beef Product. Tropicultura, 28(1): 10-15.

Food and Agricultural Organization of the United Nations (F A O, 1979). Manual of food quality control 4. Microbiological analysis.

Food and Agriculture Organisation of the United Nation (FAO), 2019. Nigeria at a glance.

Igene J.O., Uwadia, O.E., Ebabhamiegbebho, P.A. and Evivie, S.E., (2016) Shelf life Stability Studies of University of Benin (UNIBEN) Proff's Kilishi Product Asian Journal of Science and Technology 7(1): 2268-2274.

Inusa, S. K. and Said, I. S. (2017) Evaluation of the Chemical and Microbiological Properties Of Kilishi Sold in Kano Metropolis. Journal of Dry land Agriculture, 3 (1): $59-69$.

Lucretia, I. B, Patience, C. Obinna-Echem, Sophia, C. A. (2018) Microbiological quality andantibiotic sensitivity of potential pathogens isolated from meat product (Suya) sold in Rivers State University and its environs. International Journal of Biotechnology and Food Science, 6(4): 67-76.

Matthew, E., Drosos, E., John, L. and Ioanna, P. (2013) MRSA in Africa: Filling the Global Map of Antimicrobial Resistance PLOS One. 8(7): e68024 doi: 10.1371/journal.pone.0068024

Mgbemere, V.N., Akpapunam, M. A. and Igene, J. O., (2011). Effect of Groundnut FlourSubstitution on Yield, Quality and Storage Stability of Kilishi - a Nigerian Indigenous Dried Meat Product. African Journal of Food, Agriculture, Nutrition and Development, $\quad \mathbf{1 1}(2)$ : 4718-4738. 
BAJOPAS Volume 13 Number 1, June, 2020

Mubarak, A. A., Azeez, M. L., Amos A. O., Opeyemi, O. O. (2016) Assessment of Animal Protein Consumption and Food Security Among Rural Households in Kwara State, Nigeria American Journal of Business and Society, 1(4): 233245.

Ndahi, M., D. Kwaga, J., K. P. Bello, M. Kabir J., V. Umoh, .J. Yakubu, S., E. and Nok, A., J. (2013) Prevalence and Antimicrobial Susceptibility of Listeria Monocytogenes and Methicillin-Resistant Staphylococcus aureus Strains from Raw Meat and Meat Products in Zaria, Nigeria. Applied Journal of Microbiology, 58(3):262-9.

Okonko, I.O., Odu, N.N. and Igboh, I.E. (2013). Microbiological Analysis of Kilishi Sold In Port Harcourt, Nigeria. New York Science Journal, 6 (7):37-43.

Osimani, A., Aquilanti, L. and Clementi, F. (2015) Microbiological Quality of Meatbased Meals and Operation of Control Systems within a Food Service Environment. International Food Research Journal 22(4): 1692-1698.

Onuorah, S. Obika, I. Odibo, F. Orji, M. (2015)An Assessment of the Bacteriological Quality of Tsire-Suya (Grilled Beef) sold in Awka, Nigeria. American. J. Life. Sci. Res. 3(4):287292.

Razavilar, V, Khandaghi, J. Barzgari, A. (2010); Isolation of Eschericia coli 0157:H7 from manure fertilized farms and raw vegetables grown on it, in Tabriz city in
Iran. African Journal of Microbiology Research, 4(9): 891-895.

Scallan, E. Hoekstra, R. M. Angulo, F. J.Tauxe, R. V, Widdowson, M. Roy, S. L et al., (2011).Food borne illness acquired in the United States- Major Pathogens. Emerg. Infec Dis, 17(1): 7-15.

Shamsuddeen U (2009). Microbiological quality of spice used in the production of Kilishi a traditionally dried and grilled meat product. Bayero Journal of Pure andApplied Sciences, 2(2): 66-69.

Shamsuddeen, U. (2015) Microbiological Hazard and Critical control point Analysis of Dried and Minced Meat Snacks Produced in Kano Nigeria. Lambert Academic Publishing; Pp 1-36.

Tijani, O.and Jumare, S. (2014). Microblological Quality Assessment of Meat

Sold in KauraNamoda. International Conference on Earth, Environment and Life sciences (EELS) Dubai (UAE).

Udobi, C. E., Obajuluwa, A. F., and Onaolapo, J. A., (2013) Prevalence and Antibiotic Resistance Pattern of MethicillinResistant Staphylococcus aureus from an Orthopaedic Hospital in Nigeria BioMed Research International; 26(6); 6-7.

WHO, 2015 Foodborne diseases in the WHO African Region.

Yousafzai HA, Rind R, Khan MA, Abro SH, Korejo NA, Ejaz M, Kabir A, Shahid M, Memon S. (2019). Microbiological Contamination of Cattle and Meat in Peshawar, Pakistan. J. Anim. Health Prod. 7(1): 1116. 


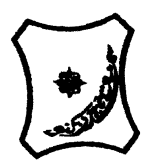

Bayero Journal of Pure and Applied Sciences, 13(1); 40 - 45

Received: September, 2019

Accepted: April, 2020

ISSN $2006-6996$

\title{
BACTERIOLOGICAL QUALITY OF STICK MEAT (Tsire) SOLD IN GARKO LOCAL GOVERNMENT AREA OF KANO STATE, NIGERIA
}

\author{
$*^{1}$ Dahiru A. T. and ${ }^{2}$ Maigari A. K. \\ ${ }^{1}$ Department of Hospitality Management, School of Technology, Kano State Polytechnic, PMB 3348, \\ Kano Nigeria. \\ ${ }^{2}$ Departmnt of Biological Sciences, Bayero University, Kano \\ Corresponding Author: dturajo61@gmail.com; GSM: 08087508262.
}

ABSTRACT

Stick meat, locally called Tsire in Hausa Language, is a significant portion of the diet of a large active population of Northern Nigeria. However, because of the handling and processing methods by the manufacturers as well as the hawking system of stick meat, the meat product may be exposed to both pre- and post-processed product contamination, and thus may poses danger to public health. Therefore, considering the role of Tsire in improving nutrition and increase household income to the populace, the need to improve the processing, distribution and overall quality of the product is simply indispensable. A total of 30 samples (5 samples from each of the 6 sampling points) of Tsire were collected randomly in Garko Town. Aerobic plate counts (APCs) and Total coliform counts (TCCS) of Tsire samples were determined using standard microbiological methods. APCs ranged from $1.02 \times 10^{5}$ to $4.00 \times 10^{5} \mathrm{CFU} / \mathrm{g}$; while TCCs ranged from $8 \mathrm{MPN} / \mathrm{g}$ to $68 \mathrm{MPN} / \mathrm{g}$. From the 30 samples screened, 16(53.33\%) bacteria namely, Campylobacter 2(6.66\%), Escherichia coli 6(20\%), Klebsiella pneumoniae 2(6.66\%), Salmonella spp. 1(3.33\%), Shigella 3(10\%) and Staphylococcus aureus 2(6.66\%) were detected. $E$. coli has the highest isolation rate of 6(20\%), while Salmonella spp. had the least frequency of 1(3.33\%). The distribution of isolated organisms within the study area were as follows: Dausai, 4(80\%), Kofar kudu, 4(80\%), Makwalla, 2(40\%), Rinji, 3(60\%), Tosaro, 2(40\%), and Tsohuwar Kasuwa, 1(20\%). The results have indicated that the Tsire was contaminated with bacteria thus exposing the product to fast deterioration, spoilage and also a vehicle for food borne illness, suggesting for adequate hygienic practices at all the stages, prior to consumption, to ensure safety of the meat product.

Key words: APCs, TCCs, Contamination, Microorganisms, Garko

\section{INTRODUCTION}

Nigeria is one of the developing nations with inadequate food supply and most often deficient in protein content (FAO, 2019). Nigerian's average animal protein intake per head per day is estimated at $7.9 \mathrm{~g}$ as against $35 \mathrm{~g}$ recommended value by Food and Agricultural Organization (Mubarak et al., 2016). These low levels of animal protein intake create great concern as it affects the nutritional status of Nigerians. Hence, there is the need for sufficient supply of animal protein from energy rich animal products to satisfy the nutritional requirements for Nigerians.

Meat is one major source of animal protein largely composed of water, protein and fats which can make it susceptible to microbial contamination within short time leading to spoilage (Apata et al., 2013; Mgbemere et al., 2011). Meat is mostly eaten after it has been cooked or processed in a variety of ways such as sun drying; smoking and roasting with or without fortifications (Borch et al., 1996). In Nigeria meat products such as Tsire, Kilishi and Balangu are locally produced using one or more of these methods in order to meet the nutritional requirements of the teeming Nigerians (Egbebi, 2011).

Tsire is a popular Nigerian traditional processed ready-to-eat roasted stick meat product (Shamsuddeen, 2015). It is sold in public places, along roads, in hotels, parks, quarters and even offices (Falegan et al., 2017). It is prepared from boneless healthy animal flesh such as beef and mutton, spiced with peanut cake, salt, vegetable oil and other flavorings followed by roasting (Shamsuddeen, 2015). Consumption of these products has extended to other parts of African countries such as Ghana, Somali, Cameroun and Chad (Ahmadu and Ibrahim, 2013). 
BAJOPAS Volume 13 Number 1, June, 2020

However, evidence of quality control sticking to procedural hygiene by the handlers during preparation and retailing of these products is poorly documented. Tsire is of great safety risk because of the fact that there are erratic cases of gastroenteritis and symptoms of food infection after consumption (WHO, 2015). Food borne illnesses are one of the major health problems in developing and developed countries (Razavilar, 2010). According to the World Health Organization, WHO (2015), $0.07 \%$ death of the 600 million global burdens of Foodborne illnesses have been reported to be caused by bacteria, viruses, fungi and chemicals. In America $0.27 \%$ of the estimated 48 million affected people is hospitalized and about $0.0063 \%$ deaths are recorded each year (Scallan et al., 2011). More than 91 million people in Africa fall ill and $0.15 \%$ dies each year, making Africa the highest burden bearer of Foodborne diseases per population (WHO, 2015).

Application of a Hazard Analysis Critical Control Point (HACCP) at all stages of meat products preparation is essential in order to ensure its safety. Thus, according to the guidelines of good manufacturing practice, the level of total aerobic bacterial contamination of thermally processed meat products should not exceed $10^{4}\left(\mathrm{cfu} \mathrm{g}^{-1}\right)$. Enterobacteriaceae and faecal coliform contamination in meat products should be within the range of $10^{2}-10^{4}$ and $10-10^{3} \mathrm{cfu} \mathrm{g}^{-1}$, respectively (Shamsuddeen, 2015). The aim of the study is therefore, to assess the total viable bacterial counts of tsire marketed locally within Garko town, and to isolate and identify the organisms at the point of consumption with the intention of promoting public health and food hygiene habits in the Nigerian populace.

\section{MATERIALS AND METHODS Study Area and Population}

Garko is one of the existing 44 local government areas located in Kano south west zone of Kano state with its capital administrative headquarters in the Garko town. It has coordinates $11^{\circ} 39^{\prime} \mathrm{N}$ $8^{\circ} 54^{\prime} \mathrm{E}$, and an area of $450 \mathrm{~km}^{2}$. The projected population of Garko local Government was 225,300 according to the National Population Census report (2018). Garko is known for agricultural activities both farming and animal husbandry. It is popularly known for large scale rice production. Other food crops include sweet potatoes, cassava, onions, sorghum, millet and sugarcane. Cows, sheep and goats are major groups of animals reared by majority of the populace. Meat products processed, retailed and consumed in Garko include roasted meat (Balangu), dried roasted meat (Kilishi), stick meat (Tsire), hide and skin pepper soup (Ragadada) and minced fried meat (Danbunnama).

\section{Samples Collection}

Five samples of Tsire products were collected from 6 different identified locations within Garko town in a sterile foil paper and immediately analyzed for the presence of bacteria.

\section{Sample Preparation}

Sample preparation for the bacteriological analysis was carried out in accordance with the method described by Atlas (1997). Twenty five grams $(25 \mathrm{~g})$ of the sample was homogenized in $225 \mathrm{ml}$ peptone water using Kenwood blender machine to obtain a $10^{1}$ homogenate. The homogenate was thoroughly shaken and $1 \mathrm{ml}$ pipetted into test tubes containing $9 \mathrm{ml}$ of peptone water $\left(10^{2}\right)$. The test tubes were further serially diluted to $10^{5}$.

Total Aerobic Mesophilic Bacterial Count

Total Aerobic mesophilic bacterial count was determined using the method described by Abdullahi et al. (2004) where $1 \mathrm{ml}$ of inoculums from $10^{1}$ to $10^{5}$ dilutions were transferred into duplicate Petri dishes and labeled accordingly. This was followed by pouring aseptically about $15 \mathrm{ml}$ of molten nutrient agar. The culture was homogenized by gentle spinning of the plates and allowed to solidify. The plates were incubated at $37^{\circ} \mathrm{C}$ for 24 hours. Plates containing 30-300 colonies were counted. The number of colony forming units per gram of a sample (cfu/g) was obtained by multiplying the average colony number with the inverse of the dilution factor.

\section{Enumeration and Detection of Coliform bacteria}

Detection and enumeration of coliform was carried out according to method described by Atlas, (1977). A set of 9 test tubes each containing $9 \mathrm{ml}$ of lactose broth and an inverted Durham tubes were autoclaved to expel air and to sterilize. Similarly, $1 \mathrm{ml}$ from the diluents $10^{1}$ was transferred to the first 3 test tubes, followed by $1 \mathrm{ml}$ from the diluents $10^{2}$ to the second set of 3 test tubes and finally the third diluents $10^{3}$ to the $3^{\text {rd }}$ set of 3 test tubes. All the 9 test tubes were incubated at $37^{\circ} \mathrm{C}$ for 24 hours. Tubes that showed gas and acid production after 24 hours were recorded as positive for the presence of Coliform. Negative tubes were further reincubated for 24 hours. Positive tubes were recorded. Estimate of most probable number of Coliform per gram of sample (MPN/g) was determined by comparing the number of gas positive tubes with the most probable number table. 
BAJOPAS Volume 13 Number 1, June, 2020 Identification of Coliform

A loop full of inoculum from gas positive tubes was streaked on to Eosine methylene blue (EMB) agar plate and incubated at $37^{\circ} \mathrm{C}$ for $24 \mathrm{hrs}$. Colonies which formed bluish black color with green metallic sheen, and reddish colonies were isolated on agar slants. Those colonies showing metallic sheen on EMB were sub cultured into tubes of lactose broth and incubated at $45^{\circ} \mathrm{C}$. The tubes were observed after $24 \mathrm{hrs}$ for gas production. This is the completed test for fecal coliform. Gram stain and other biochemical tests such as Indole, Methyl red, Voges-Proskauer and Citrate Utilization tests (IMVIC), Coagulase and Catalase tests were carried out for the Identification and confirmation of isolates.

\section{Procedure for Indole Test}

Indole test was carried out by preparing a Tryptone broth drawn in to test tubes, sterilized by autoclaving, inoculated with loopful of suspension and incubated at $37^{\circ} \mathrm{C}$ for 24 hours. Three drops of xylene was added in tubes, shaken vigorously and kept for the separation of two layers. One millilitre of Kovac's reagent was added and the formation of pink colour ring indicates positive Indole test.

\section{Procedure for Methyl Red Test}

Methyl red test was carried out by preparing Glucose phosphate broth, dispensed in test tubes, sterilized, inoculated with test culture and incubated at $37^{\circ} \mathrm{C}$ for 24 hours. Five drops of methyl-red indicator was added to the medium for the formation of red colour.

\section{Procedure for Voges-Proskauer Test}

Voges-Proskauer test was carried out by inoculating tubes with the bacterial culture followed by incubation for 48 hours at $37^{\circ} \mathrm{C}$. Separate pipettes were used to pipette $1 \mathrm{ml}$ from each culture tube into clean separate tubes. Eighteen drops $(0.5 \mathrm{ml})$ of Barrit's solution A (a-naphthol) was added to each tube containing glucose phosphate broth followed by the addition of an equal amount of solution $B$ into the same tube. The tubes were shaken at 30 seconds interval. A positive reaction was indicated by the development of a pink color, which turns red in 1-2 hours, after vigorous shaking.

\section{Procedure for Citrate Utilization Test}

Citrate Utilization Test was carried out by distributing melted agar (Simmon Citrate Agar) in to test tubes followed by sterilization at $121.5^{\circ} \mathrm{C}$ for 15 minutes. The test tubes were afterward held in slanted position, inoculated with the given bacterial culture and incubated at $37^{\circ} \mathrm{C}$ for $24 \mathrm{hrs}$. Positive test was indicated by color change of the media from green to blue.

\section{RESULTS AND DISCUSSIONS}

The results of this study are presented in tables $1,2,3$ and 4. Among the sampling areas Kofar Kudu had the highest aerobic mesophilic bacteria counts $4.0 \times 10^{5} \mathrm{cfu} / \mathrm{g}$ followed by Rinji $2.72 \times 10^{5} \mathrm{cfu} / \mathrm{g}$, while Tosaro had the least Aerobic mesophilic bacteria counts of $1.02 \times 10^{5}$ $\mathrm{cfu} / \mathrm{g}$ as indicated in Table 1.Makwalla had the highest coliform count $68 \mathrm{MPN} / \mathrm{g}$ followed by Rinji $37 \mathrm{MPN} / \mathrm{g}$. Tsohuwar Kasuwa had the least coliform counts $8 \mathrm{MPN} / \mathrm{g}$, (Table 2). Result from table 1 shows variation in the microbial contents among the samples which suggest variation in their sources, poor handling procedures and contamination from the processing environment. High coliform count and their differences within sampling areas is an indication of poor microbiological quality of the product. Ndahi et al. (2013) reported microbial load to be a function of the handling personnel and the environment. The results indicated that the samples were contaminated with bacteria as the counts exceeded the minimum safety level $\left(10^{4} \mathrm{cfu} / \mathrm{g}\right)$ for members of the Enterobacteriaceae family. However, it might be a reflection of poor hygienic practices which may contribute to health hazard to the potential consumers. Similarly, Inusa and Sa'id (2017); Osimani et al. (2015) reported that, the initial microbial content of the raw material play significant role in influencing the final microbial load of the finished product. Isolation of members of the Enterobacteriaceae such as $E$. coli, Klebsiella pneumoniae, Salmonella and Shigella signifies danger to the public health. These organisms are capable of producing endotoxins which trigger high fevers in infected individuals, and the enterotoxins which colonize the small intestines and lead to extreme dehydration as a result of vomiting and diarrhea sometimes with severe and fatal outcomes (Amaeze et al., 2016). From the 16 isolated organisms $E$. coli had the highest isolation rate $6(37.5 \%)$ (Table 3), this suggest faecal contamination of the products. $E$. coli is a common flora in the gastrointestinal tract responsible for diarrhea and extra-intestinal infections (CDC, 2011). The result is in conformity with the findings of Ndahi et al. (2013) and Shamsuddeen (2009). Also presence of campylobacter might be due to cross contamination from raw meat to finished product (Tsire). Staphylococcus aureus is a normal flora of the skin, nasal, genital, mouth or anal area in both humans and animals without any symptom of an infection (Matthew et al., 2013). Isolation of $S$. aureus in these study concords with the findings of Lucretia et al. (2018) from Suya sold in Rivers State. 
BAJOPAS Volume 13 Number 1, June, 2020

It is also in agreement with the findings of Yousafzai et al. (2018); Onuorah et al. (2015) and Tijjani and Jumare (2014) from tsire samples in different countries. Presence of $S$. aureus in foods is most of the time an indication of poor human handling, poor environment, unhygienic utensils and equipments used during processing (Igene et al., 2016; Okonko et al., 2013). Infections caused by $S$. aureus are difficult to treat leading to long hospitalization with consequent economic loss (Udobi et al., 2013). These include soft tissue infections, pneumonia, hospital-acquired postoperative wound infections, Staphylococcal food poisoning, impetigo and cellulitis (Charlene et al., 2013). Samples obtained from Dausai and Kofar Kudu had the highest isolation rate $4(80 \%)$ (Table 4 ) probably because of the much commercial activities taking place in the area which can lead to environmental contamination.

Table 1: Total Aerobic Mesophilic Bacterial Count of Tsire sold in Garko Town

\begin{tabular}{lll}
\hline Sampling Area & APC cfu/g & Mean \pm STD \\
\hline Dausai & $2.20 \times 10^{5}$ & $110000 \pm 14142.14$ \\
Kofar Kudu & $4.00 \times 10^{5}$ & $133333.3 \pm 23094.01$ \\
Makwalla & $1.30 \times 10^{5}$ & $32500 \pm 7187.953$ \\
Rinji & $2.72 \times 10^{5}$ & $90666.67 \pm 94769.90$ \\
Tosaro & $1.02 \times 10^{5}$ & $51000 \pm 15556.35$ \\
Tsohuwar Kasuwa & $1.75 \times 10^{5}$ & $35000 \pm 11357.82$ \\
\hline
\end{tabular}

Key: APC: Aerobic Mesophilic Counts

STD: Standard Deviation

Table 2: Total Coliform Count of Tsire sold in Garko Town

\begin{tabular}{lcc}
\hline \multicolumn{1}{c}{ Sampling Area } & TCC MPN/g & Mean \pm STD \\
\hline Dausai & 20 & $6.67 \pm 2.5166$ \\
Kofar Kudu & 32 & $16.00 \pm 5.6569$ \\
Makwalla & 68 & $13.60 \pm 8.7062$ \\
Rinji & 37 & $9.25 \pm 4.7871$ \\
Tosaro & 10 & $5.00 \pm 2.8284$ \\
Tsohuwar Kasuwa & 8 & $4.00 \pm 0.0000$ \\
\hline
\end{tabular}

Table 3: Organisms Isolated from Tsire Sold in Garko

\begin{tabular}{lcl}
\hline Isolated Organism & Frequency & Percentage (\%) \\
\hline Campylobacter & 2 & 06.66 \\
Escherichia coli & 6 & 20.00 \\
Klebsiella pneumoniae & 2 & 06.66 \\
Salmonella species & 1 & 03.33 \\
Shigella & 3 & 10.00 \\
Staphylococcus aureus & 2 & 06.66 \\
Total & 16 & \\
\hline
\end{tabular}

Table 4: Distribution of Organisms within Sampling Area

\begin{tabular}{lcc}
\hline \multicolumn{1}{c}{ Sampling Area } & No. Isolated & Percentage (\%) \\
\hline Dausai & 4 & 80 \\
Kofar Kudu & 4 & 80 \\
Makwalla & 2 & 40 \\
Rinji & 3 & 60 \\
Tosaro & 2 & 40 \\
Tsohuwar Kasuwa & 1 & 20 \\
Total & 16 & \\
\hline
\end{tabular}

\section{CONCLUSION}

Results indicated $4.00 \times 10^{5} \mathrm{CFU} / \mathrm{g}$ as the highest APCs count; while $68 \mathrm{MPN} / \mathrm{g}$ was the highest TCCs from the 30 samples analyzed. Among the isolates, $E$. coli has the highest isolation rate of $6(20 \%)$. Dausai and Kofar kudu were having the highest bacteria count of $4(80 \%)$, each, indicating higher contamination in those locations. 
BAJOPAS Volume 13 Number 1, June, 2020 RECOMMENDATIONS

The following recommendations are tenable:

1. Hygienic practices at all stages of production should be improved to safe guard the consumers against potential health hazard.

2. Monitoring of microbiological contamination of Tsire during preparations, packaging and marketing is essential to ensure product of good microbiological quality for consumers' health.

\section{REFERENCES}

Abdullahi, I. O., Umoh, V. J. and Galadima, M. (2004). Hazards Associated with Kilishi Preparations in Zaria. Nigerian Journal of Microbiology, 18 (1-2): $339-345$.

Ahmadu, J. and Ibrahim E. J., (2013): Determinants of Revenue in Suya Production in BeninCity, Edo State, Nigeria. Nigerian journal of agriculture, food and environment.9(3):1-5

Amaeze, N. Aboh, M. Itohan, A. Felix, E. Olatunji, T. and Oladosu, P. (2016) Microbial Profile, Antibiotic Sensitivity and Heat Resistance of Bacterial Isolates from Commercial Roasted Beef (Suya) in Abuja, Nigeria. JOPAT, 15(2): $22-30$.

Apata, E.S., Kuku1, I.A., Apata, O.C. and Adeyemi, K.O. (2013). Evaluation of Suya(Tsire) - An Intermediate Moisture Meat Product in Ogun State, Nigeria. J. Food Res 2 (1): 87.

Atlas, R. M. (1997) Principles of Microbiology Second Edition. C. Brown Publishers. Pp 802-803.

Borch, E. Kant-Muermans, M. L., Blixt, Y. (1996) Bacterial Spoilage of Meat and Cured Meat Products. Int $\mathrm{J}$ Food Microbiol .33(1): 103-20.

Centre for Disease Control, CDC (2011). "Escherichia coli 0157:H7" Division of Bacterial and Mycotic Diseasesht://www.cdc.gov/nczved/divisi ons/dfbmd/diseases/ecoli_0157h7/.

Charlene, R. J., Johnnie, A. D., and John, B. B., (2013) Prevalence and Characterization of Methicillin-Resistant Staphylococcus aureus Isolates from Retail Meat and Humans in Georgia. American society for Microbiology. J. of clinical microbiology. 12(1):123-6 doi:10.1128/JCM.0316612JCM.03166-12

Egbebi, A.O and Seidu, K., T. (2011). Microbiological Evaluation of Suya (dried smoked

meat) Sold in Ado and Akure, South West Nigeria.European Journal of Experinmental Biology, 1(4):1-5
3. Government should establish regulatory bodies responsible for inculcating hygiene habits to the local producers and vendors in order to prevent instant, cross and post processing contaminations by microbial pathogens.

4. Awareness and sensitization of local food producers about good hygienic practices in food handling and processing.

Falegan, C, R., Akoja, S. D., and Oyarekua, M. A., (2017) Microbiological Assessment of Suya (Sliced Roasted Beef) in Ado-Ekiti Metropolis, Ekiti State, Nigeria. MOJ Biology andMedicine.

Fonkem, D., N. Tanya, V., N. and Ebangi, A., L. (2010). Effect of Season on the Microbiological Quality of Kilishi, a Traditional Cameroonian Dried Beef Product. Tropicultura, 28(1): 10-15.

Food and Agricultural Organization of the United Nations (F A O, 1979). Manual of food quality control 4. Microbiological analysis.

Food and Agriculture Organisation of the United Nation (FAO), 2019. Nigeria at a glance.

Igene J.O., Uwadia, O.E., Ebabhamiegbebho, P.A. and Evivie, S.E., (2016) Shelf life Stability Studies of University of Benin (UNIBEN) Proff's Kilishi Product Asian Journal of Science and Technology 7(1): 2268-2274.

Inusa, S. K. and Said, I. S. (2017) Evaluation of the Chemical and Microbiological Properties Of Kilishi Sold in Kano Metropolis. Journal of Dry land Agriculture, 3 (1): $59-69$.

Lucretia, I. B, Patience, C. Obinna-Echem, Sophia, C. A. (2018) Microbiological quality andantibiotic sensitivity of potential pathogens isolated from meat product (Suya) sold in Rivers State University and its environs. International Journal of Biotechnology and Food Science, 6(4): 67-76.

Matthew, E., Drosos, E., John, L. and Ioanna, P. (2013) MRSA in Africa: Filling the Global Map of Antimicrobial Resistance PLOS One. 8(7): e68024 doi: 10.1371/journal.pone.0068024

Mgbemere, V.N., Akpapunam, M. A. and Igene, J. O., (2011). Effect of Groundnut FlourSubstitution on Yield, Quality and Storage Stability of Kilishi - a Nigerian Indigenous Dried Meat Product. African Journal of Food, Agriculture, Nutrition and Development, $\quad \mathbf{1 1}(2)$ : 4718-4738. 
BAJOPAS Volume 13 Number 1, June, 2020

Mubarak, A. A., Azeez, M. L., Amos A. O., Opeyemi, O. O. (2016) Assessment of Animal Protein Consumption and Food Security Among Rural Households in Kwara State, Nigeria American Journal of Business and Society, 1(4): 233245.

Ndahi, M., D. Kwaga, J., K. P. Bello, M. Kabir J., V. Umoh, .J. Yakubu, S., E. and Nok, A., J. (2013) Prevalence and Antimicrobial Susceptibility of Listeria Monocytogenes and Methicillin-Resistant Staphylococcus aureus Strains from Raw Meat and Meat Products in Zaria, Nigeria. Applied Journal of Microbiology, 58(3):262-9.

Okonko, I.O., Odu, N.N. and Igboh, I.E. (2013). Microbiological Analysis of Kilishi Sold In Port Harcourt, Nigeria. New York Science Journal, 6 (7):37-43.

Osimani, A., Aquilanti, L. and Clementi, F. (2015) Microbiological Quality of Meatbased Meals and Operation of Control Systems within a Food Service Environment. International Food Research Journal 22(4): 1692-1698.

Onuorah, S. Obika, I. Odibo, F. Orji, M. (2015)An Assessment of the Bacteriological Quality of Tsire-Suya (Grilled Beef) sold in Awka, Nigeria. American. J. Life. Sci. Res. 3(4):287292.

Razavilar, V, Khandaghi, J. Barzgari, A. (2010); Isolation of Eschericia coli 0157:H7 from manure fertilized farms and raw vegetables grown on it, in Tabriz city in
Iran. African Journal of Microbiology Research, 4(9): 891-895.

Scallan, E. Hoekstra, R. M. Angulo, F. J.Tauxe, R. V, Widdowson, M. Roy, S. L et al., (2011).Food borne illness acquired in the United States- Major Pathogens. Emerg. Infec Dis, 17(1): 7-15.

Shamsuddeen U (2009). Microbiological quality of spice used in the production of Kilishi a traditionally dried and grilled meat product. Bayero Journal of Pure andApplied Sciences, 2(2): 66-69.

Shamsuddeen, U. (2015) Microbiological Hazard and Critical control point Analysis of Dried and Minced Meat Snacks Produced in Kano Nigeria. Lambert Academic Publishing; Pp 1-36.

Tijani, O.and Jumare, S. (2014). Microblological Quality Assessment of Meat

Sold in KauraNamoda. International Conference on Earth, Environment and Life sciences (EELS) Dubai (UAE).

Udobi, C. E., Obajuluwa, A. F., and Onaolapo, J. A., (2013) Prevalence and Antibiotic Resistance Pattern of MethicillinResistant Staphylococcus aureus from an Orthopaedic Hospital in Nigeria BioMed Research International; 26(6); 6-7.

WHO, 2015 Foodborne diseases in the WHO African Region.

Yousafzai HA, Rind R, Khan MA, Abro SH, Korejo NA, Ejaz M, Kabir A, Shahid M, Memon S. (2019). Microbiological Contamination of Cattle and Meat in Peshawar, Pakistan. J. Anim. Health Prod. 7(1): 1116. 


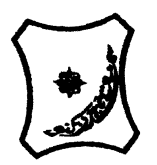

Bayero Journal of Pure and Applied Sciences, 13(1); 40 - 45

Received: September, 2019

Accepted: April, 2020

ISSN $2006-6996$

\title{
BACTERIOLOGICAL QUALITY OF STICK MEAT (Tsire) SOLD IN GARKO LOCAL GOVERNMENT AREA OF KANO STATE, NIGERIA
}

\author{
$*^{1}$ Dahiru A. T. and ${ }^{2}$ Maigari A. K. \\ ${ }^{1}$ Department of Hospitality Management, School of Technology, Kano State Polytechnic, PMB 3348, \\ Kano Nigeria. \\ ${ }^{2}$ Departmnt of Biological Sciences, Bayero University, Kano \\ Corresponding Author: dturajo61@gmail.com; GSM: 08087508262.
}

ABSTRACT

Stick meat, locally called Tsire in Hausa Language, is a significant portion of the diet of a large active population of Northern Nigeria. However, because of the handling and processing methods by the manufacturers as well as the hawking system of stick meat, the meat product may be exposed to both pre- and post-processed product contamination, and thus may poses danger to public health. Therefore, considering the role of Tsire in improving nutrition and increase household income to the populace, the need to improve the processing, distribution and overall quality of the product is simply indispensable. A total of 30 samples (5 samples from each of the 6 sampling points) of Tsire were collected randomly in Garko Town. Aerobic plate counts (APCs) and Total coliform counts (TCCS) of Tsire samples were determined using standard microbiological methods. APCs ranged from $1.02 \times 10^{5}$ to $4.00 \times 10^{5} \mathrm{CFU} / \mathrm{g}$; while TCCs ranged from $8 \mathrm{MPN} / \mathrm{g}$ to $68 \mathrm{MPN} / \mathrm{g}$. From the 30 samples screened, 16(53.33\%) bacteria namely, Campylobacter 2(6.66\%), Escherichia coli 6(20\%), Klebsiella pneumoniae 2(6.66\%), Salmonella spp. 1(3.33\%), Shigella 3(10\%) and Staphylococcus aureus 2(6.66\%) were detected. $E$. coli has the highest isolation rate of 6(20\%), while Salmonella spp. had the least frequency of 1(3.33\%). The distribution of isolated organisms within the study area were as follows: Dausai, 4(80\%), Kofar kudu, 4(80\%), Makwalla, 2(40\%), Rinji, 3(60\%), Tosaro, 2(40\%), and Tsohuwar Kasuwa, 1(20\%). The results have indicated that the Tsire was contaminated with bacteria thus exposing the product to fast deterioration, spoilage and also a vehicle for food borne illness, suggesting for adequate hygienic practices at all the stages, prior to consumption, to ensure safety of the meat product.

Key words: APCs, TCCs, Contamination, Microorganisms, Garko

\section{INTRODUCTION}

Nigeria is one of the developing nations with inadequate food supply and most often deficient in protein content (FAO, 2019). Nigerian's average animal protein intake per head per day is estimated at $7.9 \mathrm{~g}$ as against $35 \mathrm{~g}$ recommended value by Food and Agricultural Organization (Mubarak et al., 2016). These low levels of animal protein intake create great concern as it affects the nutritional status of Nigerians. Hence, there is the need for sufficient supply of animal protein from energy rich animal products to satisfy the nutritional requirements for Nigerians.

Meat is one major source of animal protein largely composed of water, protein and fats which can make it susceptible to microbial contamination within short time leading to spoilage (Apata et al., 2013; Mgbemere et al., 2011). Meat is mostly eaten after it has been cooked or processed in a variety of ways such as sun drying; smoking and roasting with or without fortifications (Borch et al., 1996). In Nigeria meat products such as Tsire, Kilishi and Balangu are locally produced using one or more of these methods in order to meet the nutritional requirements of the teeming Nigerians (Egbebi, 2011).

Tsire is a popular Nigerian traditional processed ready-to-eat roasted stick meat product (Shamsuddeen, 2015). It is sold in public places, along roads, in hotels, parks, quarters and even offices (Falegan et al., 2017). It is prepared from boneless healthy animal flesh such as beef and mutton, spiced with peanut cake, salt, vegetable oil and other flavorings followed by roasting (Shamsuddeen, 2015). Consumption of these products has extended to other parts of African countries such as Ghana, Somali, Cameroun and Chad (Ahmadu and Ibrahim, 2013). 
BAJOPAS Volume 13 Number 1, June, 2020

However, evidence of quality control sticking to procedural hygiene by the handlers during preparation and retailing of these products is poorly documented. Tsire is of great safety risk because of the fact that there are erratic cases of gastroenteritis and symptoms of food infection after consumption (WHO, 2015). Food borne illnesses are one of the major health problems in developing and developed countries (Razavilar, 2010). According to the World Health Organization, WHO (2015), $0.07 \%$ death of the 600 million global burdens of Foodborne illnesses have been reported to be caused by bacteria, viruses, fungi and chemicals. In America $0.27 \%$ of the estimated 48 million affected people is hospitalized and about $0.0063 \%$ deaths are recorded each year (Scallan et al., 2011). More than 91 million people in Africa fall ill and $0.15 \%$ dies each year, making Africa the highest burden bearer of Foodborne diseases per population (WHO, 2015).

Application of a Hazard Analysis Critical Control Point (HACCP) at all stages of meat products preparation is essential in order to ensure its safety. Thus, according to the guidelines of good manufacturing practice, the level of total aerobic bacterial contamination of thermally processed meat products should not exceed $10^{4}\left(\mathrm{cfu} \mathrm{g}^{-1}\right)$. Enterobacteriaceae and faecal coliform contamination in meat products should be within the range of $10^{2}-10^{4}$ and $10-10^{3} \mathrm{cfu} \mathrm{g}^{-1}$, respectively (Shamsuddeen, 2015). The aim of the study is therefore, to assess the total viable bacterial counts of tsire marketed locally within Garko town, and to isolate and identify the organisms at the point of consumption with the intention of promoting public health and food hygiene habits in the Nigerian populace.

\section{MATERIALS AND METHODS Study Area and Population}

Garko is one of the existing 44 local government areas located in Kano south west zone of Kano state with its capital administrative headquarters in the Garko town. It has coordinates $11^{\circ} 39^{\prime} \mathrm{N}$ $8^{\circ} 54^{\prime} \mathrm{E}$, and an area of $450 \mathrm{~km}^{2}$. The projected population of Garko local Government was 225,300 according to the National Population Census report (2018). Garko is known for agricultural activities both farming and animal husbandry. It is popularly known for large scale rice production. Other food crops include sweet potatoes, cassava, onions, sorghum, millet and sugarcane. Cows, sheep and goats are major groups of animals reared by majority of the populace. Meat products processed, retailed and consumed in Garko include roasted meat (Balangu), dried roasted meat (Kilishi), stick meat (Tsire), hide and skin pepper soup (Ragadada) and minced fried meat (Danbunnama).

\section{Samples Collection}

Five samples of Tsire products were collected from 6 different identified locations within Garko town in a sterile foil paper and immediately analyzed for the presence of bacteria.

\section{Sample Preparation}

Sample preparation for the bacteriological analysis was carried out in accordance with the method described by Atlas (1997). Twenty five grams $(25 \mathrm{~g})$ of the sample was homogenized in $225 \mathrm{ml}$ peptone water using Kenwood blender machine to obtain a $10^{1}$ homogenate. The homogenate was thoroughly shaken and $1 \mathrm{ml}$ pipetted into test tubes containing $9 \mathrm{ml}$ of peptone water $\left(10^{2}\right)$. The test tubes were further serially diluted to $10^{5}$.

Total Aerobic Mesophilic Bacterial Count

Total Aerobic mesophilic bacterial count was determined using the method described by Abdullahi et al. (2004) where $1 \mathrm{ml}$ of inoculums from $10^{1}$ to $10^{5}$ dilutions were transferred into duplicate Petri dishes and labeled accordingly. This was followed by pouring aseptically about $15 \mathrm{ml}$ of molten nutrient agar. The culture was homogenized by gentle spinning of the plates and allowed to solidify. The plates were incubated at $37^{\circ} \mathrm{C}$ for 24 hours. Plates containing 30-300 colonies were counted. The number of colony forming units per gram of a sample (cfu/g) was obtained by multiplying the average colony number with the inverse of the dilution factor.

\section{Enumeration and Detection of Coliform bacteria}

Detection and enumeration of coliform was carried out according to method described by Atlas, (1977). A set of 9 test tubes each containing $9 \mathrm{ml}$ of lactose broth and an inverted Durham tubes were autoclaved to expel air and to sterilize. Similarly, $1 \mathrm{ml}$ from the diluents $10^{1}$ was transferred to the first 3 test tubes, followed by $1 \mathrm{ml}$ from the diluents $10^{2}$ to the second set of 3 test tubes and finally the third diluents $10^{3}$ to the $3^{\text {rd }}$ set of 3 test tubes. All the 9 test tubes were incubated at $37^{\circ} \mathrm{C}$ for 24 hours. Tubes that showed gas and acid production after 24 hours were recorded as positive for the presence of Coliform. Negative tubes were further reincubated for 24 hours. Positive tubes were recorded. Estimate of most probable number of Coliform per gram of sample (MPN/g) was determined by comparing the number of gas positive tubes with the most probable number table. 
BAJOPAS Volume 13 Number 1, June, 2020 Identification of Coliform

A loop full of inoculum from gas positive tubes was streaked on to Eosine methylene blue (EMB) agar plate and incubated at $37^{\circ} \mathrm{C}$ for $24 \mathrm{hrs}$. Colonies which formed bluish black color with green metallic sheen, and reddish colonies were isolated on agar slants. Those colonies showing metallic sheen on EMB were sub cultured into tubes of lactose broth and incubated at $45^{\circ} \mathrm{C}$. The tubes were observed after $24 \mathrm{hrs}$ for gas production. This is the completed test for fecal coliform. Gram stain and other biochemical tests such as Indole, Methyl red, Voges-Proskauer and Citrate Utilization tests (IMVIC), Coagulase and Catalase tests were carried out for the Identification and confirmation of isolates.

\section{Procedure for Indole Test}

Indole test was carried out by preparing a Tryptone broth drawn in to test tubes, sterilized by autoclaving, inoculated with loopful of suspension and incubated at $37^{\circ} \mathrm{C}$ for 24 hours. Three drops of xylene was added in tubes, shaken vigorously and kept for the separation of two layers. One millilitre of Kovac's reagent was added and the formation of pink colour ring indicates positive Indole test.

\section{Procedure for Methyl Red Test}

Methyl red test was carried out by preparing Glucose phosphate broth, dispensed in test tubes, sterilized, inoculated with test culture and incubated at $37^{\circ} \mathrm{C}$ for 24 hours. Five drops of methyl-red indicator was added to the medium for the formation of red colour.

\section{Procedure for Voges-Proskauer Test}

Voges-Proskauer test was carried out by inoculating tubes with the bacterial culture followed by incubation for 48 hours at $37^{\circ} \mathrm{C}$. Separate pipettes were used to pipette $1 \mathrm{ml}$ from each culture tube into clean separate tubes. Eighteen drops $(0.5 \mathrm{ml})$ of Barrit's solution A (a-naphthol) was added to each tube containing glucose phosphate broth followed by the addition of an equal amount of solution $B$ into the same tube. The tubes were shaken at 30 seconds interval. A positive reaction was indicated by the development of a pink color, which turns red in 1-2 hours, after vigorous shaking.

\section{Procedure for Citrate Utilization Test}

Citrate Utilization Test was carried out by distributing melted agar (Simmon Citrate Agar) in to test tubes followed by sterilization at $121.5^{\circ} \mathrm{C}$ for 15 minutes. The test tubes were afterward held in slanted position, inoculated with the given bacterial culture and incubated at $37^{\circ} \mathrm{C}$ for $24 \mathrm{hrs}$. Positive test was indicated by color change of the media from green to blue.

\section{RESULTS AND DISCUSSIONS}

The results of this study are presented in tables $1,2,3$ and 4. Among the sampling areas Kofar Kudu had the highest aerobic mesophilic bacteria counts $4.0 \times 10^{5} \mathrm{cfu} / \mathrm{g}$ followed by Rinji $2.72 \times 10^{5} \mathrm{cfu} / \mathrm{g}$, while Tosaro had the least Aerobic mesophilic bacteria counts of $1.02 \times 10^{5}$ $\mathrm{cfu} / \mathrm{g}$ as indicated in Table 1.Makwalla had the highest coliform count $68 \mathrm{MPN} / \mathrm{g}$ followed by Rinji $37 \mathrm{MPN} / \mathrm{g}$. Tsohuwar Kasuwa had the least coliform counts $8 \mathrm{MPN} / \mathrm{g}$, (Table 2). Result from table 1 shows variation in the microbial contents among the samples which suggest variation in their sources, poor handling procedures and contamination from the processing environment. High coliform count and their differences within sampling areas is an indication of poor microbiological quality of the product. Ndahi et al. (2013) reported microbial load to be a function of the handling personnel and the environment. The results indicated that the samples were contaminated with bacteria as the counts exceeded the minimum safety level $\left(10^{4} \mathrm{cfu} / \mathrm{g}\right)$ for members of the Enterobacteriaceae family. However, it might be a reflection of poor hygienic practices which may contribute to health hazard to the potential consumers. Similarly, Inusa and Sa'id (2017); Osimani et al. (2015) reported that, the initial microbial content of the raw material play significant role in influencing the final microbial load of the finished product. Isolation of members of the Enterobacteriaceae such as $E$. coli, Klebsiella pneumoniae, Salmonella and Shigella signifies danger to the public health. These organisms are capable of producing endotoxins which trigger high fevers in infected individuals, and the enterotoxins which colonize the small intestines and lead to extreme dehydration as a result of vomiting and diarrhea sometimes with severe and fatal outcomes (Amaeze et al., 2016). From the 16 isolated organisms $E$. coli had the highest isolation rate $6(37.5 \%)$ (Table 3), this suggest faecal contamination of the products. $E$. coli is a common flora in the gastrointestinal tract responsible for diarrhea and extra-intestinal infections (CDC, 2011). The result is in conformity with the findings of Ndahi et al. (2013) and Shamsuddeen (2009). Also presence of campylobacter might be due to cross contamination from raw meat to finished product (Tsire). Staphylococcus aureus is a normal flora of the skin, nasal, genital, mouth or anal area in both humans and animals without any symptom of an infection (Matthew et al., 2013). Isolation of $S$. aureus in these study concords with the findings of Lucretia et al. (2018) from Suya sold in Rivers State. 
BAJOPAS Volume 13 Number 1, June, 2020

It is also in agreement with the findings of Yousafzai et al. (2018); Onuorah et al. (2015) and Tijjani and Jumare (2014) from tsire samples in different countries. Presence of $S$. aureus in foods is most of the time an indication of poor human handling, poor environment, unhygienic utensils and equipments used during processing (Igene et al., 2016; Okonko et al., 2013). Infections caused by $S$. aureus are difficult to treat leading to long hospitalization with consequent economic loss (Udobi et al., 2013). These include soft tissue infections, pneumonia, hospital-acquired postoperative wound infections, Staphylococcal food poisoning, impetigo and cellulitis (Charlene et al., 2013). Samples obtained from Dausai and Kofar Kudu had the highest isolation rate $4(80 \%)$ (Table 4 ) probably because of the much commercial activities taking place in the area which can lead to environmental contamination.

Table 1: Total Aerobic Mesophilic Bacterial Count of Tsire sold in Garko Town

\begin{tabular}{lll}
\hline Sampling Area & APC cfu/g & Mean \pm STD \\
\hline Dausai & $2.20 \times 10^{5}$ & $110000 \pm 14142.14$ \\
Kofar Kudu & $4.00 \times 10^{5}$ & $133333.3 \pm 23094.01$ \\
Makwalla & $1.30 \times 10^{5}$ & $32500 \pm 7187.953$ \\
Rinji & $2.72 \times 10^{5}$ & $90666.67 \pm 94769.90$ \\
Tosaro & $1.02 \times 10^{5}$ & $51000 \pm 15556.35$ \\
Tsohuwar Kasuwa & $1.75 \times 10^{5}$ & $35000 \pm 11357.82$ \\
\hline
\end{tabular}

Key: APC: Aerobic Mesophilic Counts

STD: Standard Deviation

Table 2: Total Coliform Count of Tsire sold in Garko Town

\begin{tabular}{lcc}
\hline \multicolumn{1}{c}{ Sampling Area } & TCC MPN/g & Mean \pm STD \\
\hline Dausai & 20 & $6.67 \pm 2.5166$ \\
Kofar Kudu & 32 & $16.00 \pm 5.6569$ \\
Makwalla & 68 & $13.60 \pm 8.7062$ \\
Rinji & 37 & $9.25 \pm 4.7871$ \\
Tosaro & 10 & $5.00 \pm 2.8284$ \\
Tsohuwar Kasuwa & 8 & $4.00 \pm 0.0000$ \\
\hline
\end{tabular}

Table 3: Organisms Isolated from Tsire Sold in Garko

\begin{tabular}{lcl}
\hline Isolated Organism & Frequency & Percentage (\%) \\
\hline Campylobacter & 2 & 06.66 \\
Escherichia coli & 6 & 20.00 \\
Klebsiella pneumoniae & 2 & 06.66 \\
Salmonella species & 1 & 03.33 \\
Shigella & 3 & 10.00 \\
Staphylococcus aureus & 2 & 06.66 \\
Total & 16 & \\
\hline
\end{tabular}

Table 4: Distribution of Organisms within Sampling Area

\begin{tabular}{lcc}
\hline \multicolumn{1}{c}{ Sampling Area } & No. Isolated & Percentage (\%) \\
\hline Dausai & 4 & 80 \\
Kofar Kudu & 4 & 80 \\
Makwalla & 2 & 40 \\
Rinji & 3 & 60 \\
Tosaro & 2 & 40 \\
Tsohuwar Kasuwa & 1 & 20 \\
Total & 16 & \\
\hline
\end{tabular}

\section{CONCLUSION}

Results indicated $4.00 \times 10^{5} \mathrm{CFU} / \mathrm{g}$ as the highest APCs count; while $68 \mathrm{MPN} / \mathrm{g}$ was the highest TCCs from the 30 samples analyzed. Among the isolates, $E$. coli has the highest isolation rate of $6(20 \%)$. Dausai and Kofar kudu were having the highest bacteria count of $4(80 \%)$, each, indicating higher contamination in those locations. 
BAJOPAS Volume 13 Number 1, June, 2020 RECOMMENDATIONS

The following recommendations are tenable:

1. Hygienic practices at all stages of production should be improved to safe guard the consumers against potential health hazard.

2. Monitoring of microbiological contamination of Tsire during preparations, packaging and marketing is essential to ensure product of good microbiological quality for consumers' health.

\section{REFERENCES}

Abdullahi, I. O., Umoh, V. J. and Galadima, M. (2004). Hazards Associated with Kilishi Preparations in Zaria. Nigerian Journal of Microbiology, 18 (1-2): $339-345$.

Ahmadu, J. and Ibrahim E. J., (2013): Determinants of Revenue in Suya Production in BeninCity, Edo State, Nigeria. Nigerian journal of agriculture, food and environment.9(3):1-5

Amaeze, N. Aboh, M. Itohan, A. Felix, E. Olatunji, T. and Oladosu, P. (2016) Microbial Profile, Antibiotic Sensitivity and Heat Resistance of Bacterial Isolates from Commercial Roasted Beef (Suya) in Abuja, Nigeria. JOPAT, 15(2): $22-30$.

Apata, E.S., Kuku1, I.A., Apata, O.C. and Adeyemi, K.O. (2013). Evaluation of Suya(Tsire) - An Intermediate Moisture Meat Product in Ogun State, Nigeria. J. Food Res 2 (1): 87.

Atlas, R. M. (1997) Principles of Microbiology Second Edition. C. Brown Publishers. Pp 802-803.

Borch, E. Kant-Muermans, M. L., Blixt, Y. (1996) Bacterial Spoilage of Meat and Cured Meat Products. Int $\mathrm{J}$ Food Microbiol .33(1): 103-20.

Centre for Disease Control, CDC (2011). "Escherichia coli 0157:H7" Division of Bacterial and Mycotic Diseasesht://www.cdc.gov/nczved/divisi ons/dfbmd/diseases/ecoli_0157h7/.

Charlene, R. J., Johnnie, A. D., and John, B. B., (2013) Prevalence and Characterization of Methicillin-Resistant Staphylococcus aureus Isolates from Retail Meat and Humans in Georgia. American society for Microbiology. J. of clinical microbiology. 12(1):123-6 doi:10.1128/JCM.0316612JCM.03166-12

Egbebi, A.O and Seidu, K., T. (2011). Microbiological Evaluation of Suya (dried smoked

meat) Sold in Ado and Akure, South West Nigeria.European Journal of Experinmental Biology, 1(4):1-5
3. Government should establish regulatory bodies responsible for inculcating hygiene habits to the local producers and vendors in order to prevent instant, cross and post processing contaminations by microbial pathogens.

4. Awareness and sensitization of local food producers about good hygienic practices in food handling and processing.

Falegan, C, R., Akoja, S. D., and Oyarekua, M. A., (2017) Microbiological Assessment of Suya (Sliced Roasted Beef) in Ado-Ekiti Metropolis, Ekiti State, Nigeria. MOJ Biology andMedicine.

Fonkem, D., N. Tanya, V., N. and Ebangi, A., L. (2010). Effect of Season on the Microbiological Quality of Kilishi, a Traditional Cameroonian Dried Beef Product. Tropicultura, 28(1): 10-15.

Food and Agricultural Organization of the United Nations (F A O, 1979). Manual of food quality control 4. Microbiological analysis.

Food and Agriculture Organisation of the United Nation (FAO), 2019. Nigeria at a glance.

Igene J.O., Uwadia, O.E., Ebabhamiegbebho, P.A. and Evivie, S.E., (2016) Shelf life Stability Studies of University of Benin (UNIBEN) Proff's Kilishi Product Asian Journal of Science and Technology 7(1): 2268-2274.

Inusa, S. K. and Said, I. S. (2017) Evaluation of the Chemical and Microbiological Properties Of Kilishi Sold in Kano Metropolis. Journal of Dry land Agriculture, 3 (1): $59-69$.

Lucretia, I. B, Patience, C. Obinna-Echem, Sophia, C. A. (2018) Microbiological quality andantibiotic sensitivity of potential pathogens isolated from meat product (Suya) sold in Rivers State University and its environs. International Journal of Biotechnology and Food Science, 6(4): 67-76.

Matthew, E., Drosos, E., John, L. and Ioanna, P. (2013) MRSA in Africa: Filling the Global Map of Antimicrobial Resistance PLOS One. 8(7): e68024 doi: 10.1371/journal.pone.0068024

Mgbemere, V.N., Akpapunam, M. A. and Igene, J. O., (2011). Effect of Groundnut FlourSubstitution on Yield, Quality and Storage Stability of Kilishi - a Nigerian Indigenous Dried Meat Product. African Journal of Food, Agriculture, Nutrition and Development, $\quad \mathbf{1 1}(2)$ : 4718-4738. 
BAJOPAS Volume 13 Number 1, June, 2020

Mubarak, A. A., Azeez, M. L., Amos A. O., Opeyemi, O. O. (2016) Assessment of Animal Protein Consumption and Food Security Among Rural Households in Kwara State, Nigeria American Journal of Business and Society, 1(4): 233245.

Ndahi, M., D. Kwaga, J., K. P. Bello, M. Kabir J., V. Umoh, .J. Yakubu, S., E. and Nok, A., J. (2013) Prevalence and Antimicrobial Susceptibility of Listeria Monocytogenes and Methicillin-Resistant Staphylococcus aureus Strains from Raw Meat and Meat Products in Zaria, Nigeria. Applied Journal of Microbiology, 58(3):262-9.

Okonko, I.O., Odu, N.N. and Igboh, I.E. (2013). Microbiological Analysis of Kilishi Sold In Port Harcourt, Nigeria. New York Science Journal, 6 (7):37-43.

Osimani, A., Aquilanti, L. and Clementi, F. (2015) Microbiological Quality of Meatbased Meals and Operation of Control Systems within a Food Service Environment. International Food Research Journal 22(4): 1692-1698.

Onuorah, S. Obika, I. Odibo, F. Orji, M. (2015)An Assessment of the Bacteriological Quality of Tsire-Suya (Grilled Beef) sold in Awka, Nigeria. American. J. Life. Sci. Res. 3(4):287292.

Razavilar, V, Khandaghi, J. Barzgari, A. (2010); Isolation of Eschericia coli 0157:H7 from manure fertilized farms and raw vegetables grown on it, in Tabriz city in
Iran. African Journal of Microbiology Research, 4(9): 891-895.

Scallan, E. Hoekstra, R. M. Angulo, F. J.Tauxe, R. V, Widdowson, M. Roy, S. L et al., (2011).Food borne illness acquired in the United States- Major Pathogens. Emerg. Infec Dis, 17(1): 7-15.

Shamsuddeen U (2009). Microbiological quality of spice used in the production of Kilishi a traditionally dried and grilled meat product. Bayero Journal of Pure andApplied Sciences, 2(2): 66-69.

Shamsuddeen, U. (2015) Microbiological Hazard and Critical control point Analysis of Dried and Minced Meat Snacks Produced in Kano Nigeria. Lambert Academic Publishing; Pp 1-36.

Tijani, O.and Jumare, S. (2014). Microblological Quality Assessment of Meat

Sold in KauraNamoda. International Conference on Earth, Environment and Life sciences (EELS) Dubai (UAE).

Udobi, C. E., Obajuluwa, A. F., and Onaolapo, J. A., (2013) Prevalence and Antibiotic Resistance Pattern of MethicillinResistant Staphylococcus aureus from an Orthopaedic Hospital in Nigeria BioMed Research International; 26(6); 6-7.

WHO, 2015 Foodborne diseases in the WHO African Region.

Yousafzai HA, Rind R, Khan MA, Abro SH, Korejo NA, Ejaz M, Kabir A, Shahid M, Memon S. (2019). Microbiological Contamination of Cattle and Meat in Peshawar, Pakistan. J. Anim. Health Prod. 7(1): 1116. 


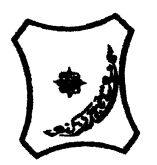

Bayero Journal of Pure and Applied Sciences, 13(1); 40 - 45

Received: September, 2019

Accepted: April, 2020

ISSN $2006-6996$

\title{
BACTERIOLOGICAL QUALITY OF STICK MEAT (Tsire) SOLD IN GARKO LOCAL GOVERNMENT AREA OF KANO STATE, NIGERIA
}

\author{
$*^{1}$ Dahiru A. T. and ${ }^{2}$ Maigari A. K. \\ ${ }^{1}$ Department of Hospitality Management, School of Technology, Kano State Polytechnic, PMB 3348, \\ Kano Nigeria. \\ ${ }^{2}$ Departmnt of Biological Sciences, Bayero University, Kano \\ Corresponding Author: dturajo61@gmail.com; GSM: 08087508262.
}

ABSTRACT

Stick meat, locally called Tsire in Hausa Language, is a significant portion of the diet of a large active population of Northern Nigeria. However, because of the handling and processing methods by the manufacturers as well as the hawking system of stick meat, the meat product may be exposed to both pre- and post-processed product contamination, and thus may poses danger to public health. Therefore, considering the role of Tsire in improving nutrition and increase household income to the populace, the need to improve the processing, distribution and overall quality of the product is simply indispensable. A total of 30 samples (5 samples from each of the 6 sampling points) of Tsire were collected randomly in Garko Town. Aerobic plate counts (APCs) and Total coliform counts (TCCS) of Tsire samples were determined using standard microbiological methods. APCs ranged from $1.02 \times 10^{5}$ to $4.00 \times 10^{5} \mathrm{CFU} / \mathrm{g}$; while TCCs ranged from $8 \mathrm{MPN} / \mathrm{g}$ to $68 \mathrm{MPN} / \mathrm{g}$. From the 30 samples screened, 16(53.33\%) bacteria namely, Campylobacter 2(6.66\%), Escherichia coli 6(20\%), Klebsiella pneumoniae 2(6.66\%), Salmonella spp. 1(3.33\%), Shigella 3(10\%) and Staphylococcus aureus 2(6.66\%) were detected. $E$. coli has the highest isolation rate of 6(20\%), while Salmonella spp. had the least frequency of 1(3.33\%). The distribution of isolated organisms within the study area were as follows: Dausai, 4(80\%), Kofar kudu, 4(80\%), Makwalla, 2(40\%), Rinji, 3(60\%), Tosaro, 2(40\%), and Tsohuwar Kasuwa, 1(20\%). The results have indicated that the Tsire was contaminated with bacteria thus exposing the product to fast deterioration, spoilage and also a vehicle for food borne illness, suggesting for adequate hygienic practices at all the stages, prior to consumption, to ensure safety of the meat product.

Key words: APCs, TCCs, Contamination, Microorganisms, Garko

\section{INTRODUCTION}

Nigeria is one of the developing nations with inadequate food supply and most often deficient in protein content (FAO, 2019). Nigerian's average animal protein intake per head per day is estimated at $7.9 \mathrm{~g}$ as against $35 \mathrm{~g}$ recommended value by Food and Agricultural Organization (Mubarak et al., 2016). These low levels of animal protein intake create great concern as it affects the nutritional status of Nigerians. Hence, there is the need for sufficient supply of animal protein from energy rich animal products to satisfy the nutritional requirements for Nigerians.

Meat is one major source of animal protein largely composed of water, protein and fats which can make it susceptible to microbial contamination within short time leading to spoilage (Apata et al., 2013; Mgbemere et al., 2011). Meat is mostly eaten after it has been cooked or processed in a variety of ways such as sun drying; smoking and roasting with or without fortifications (Borch et al., 1996). In Nigeria meat products such as Tsire, Kilishi and Balangu are locally produced using one or more of these methods in order to meet the nutritional requirements of the teeming Nigerians (Egbebi, 2011).

Tsire is a popular Nigerian traditional processed ready-to-eat roasted stick meat product (Shamsuddeen, 2015). It is sold in public places, along roads, in hotels, parks, quarters and even offices (Falegan et al., 2017). It is prepared from boneless healthy animal flesh such as beef and mutton, spiced with peanut cake, salt, vegetable oil and other flavorings followed by roasting (Shamsuddeen, 2015). Consumption of these products has extended to other parts of African countries such as Ghana, Somali, Cameroun and Chad (Ahmadu and Ibrahim, 2013). 
BAJOPAS Volume 13 Number 1, June, 2020

However, evidence of quality control sticking to procedural hygiene by the handlers during preparation and retailing of these products is poorly documented. Tsire is of great safety risk because of the fact that there are erratic cases of gastroenteritis and symptoms of food infection after consumption (WHO, 2015). Food borne illnesses are one of the major health problems in developing and developed countries (Razavilar, 2010). According to the World Health Organization, WHO (2015), $0.07 \%$ death of the 600 million global burdens of Foodborne illnesses have been reported to be caused by bacteria, viruses, fungi and chemicals. In America $0.27 \%$ of the estimated 48 million affected people is hospitalized and about $0.0063 \%$ deaths are recorded each year (Scallan et al., 2011). More than 91 million people in Africa fall ill and $0.15 \%$ dies each year, making Africa the highest burden bearer of Foodborne diseases per population (WHO, 2015).

Application of a Hazard Analysis Critical Control Point (HACCP) at all stages of meat products preparation is essential in order to ensure its safety. Thus, according to the guidelines of good manufacturing practice, the level of total aerobic bacterial contamination of thermally processed meat products should not exceed $10^{4}\left(\mathrm{cfu} \mathrm{g}^{-1}\right)$. Enterobacteriaceae and faecal coliform contamination in meat products should be within the range of $10^{2}-10^{4}$ and $10-10^{3} \mathrm{cfu} \mathrm{g}^{-1}$, respectively (Shamsuddeen, 2015). The aim of the study is therefore, to assess the total viable bacterial counts of tsire marketed locally within Garko town, and to isolate and identify the organisms at the point of consumption with the intention of promoting public health and food hygiene habits in the Nigerian populace.

\section{MATERIALS AND METHODS Study Area and Population}

Garko is one of the existing 44 local government areas located in Kano south west zone of Kano state with its capital administrative headquarters in the Garko town. It has coordinates $11^{\circ} 39^{\prime} \mathrm{N}$ $8^{\circ} 54^{\prime} \mathrm{E}$, and an area of $450 \mathrm{~km}^{2}$. The projected population of Garko local Government was 225,300 according to the National Population Census report (2018). Garko is known for agricultural activities both farming and animal husbandry. It is popularly known for large scale rice production. Other food crops include sweet potatoes, cassava, onions, sorghum, millet and sugarcane. Cows, sheep and goats are major groups of animals reared by majority of the populace. Meat products processed, retailed and consumed in Garko include roasted meat (Balangu), dried roasted meat (Kilishi), stick meat (Tsire), hide and skin pepper soup (Ragadada) and minced fried meat (Danbunnama).

\section{Samples Collection}

Five samples of Tsire products were collected from 6 different identified locations within Garko town in a sterile foil paper and immediately analyzed for the presence of bacteria.

\section{Sample Preparation}

Sample preparation for the bacteriological analysis was carried out in accordance with the method described by Atlas (1997). Twenty five grams $(25 \mathrm{~g})$ of the sample was homogenized in $225 \mathrm{ml}$ peptone water using Kenwood blender machine to obtain a $10^{1}$ homogenate. The homogenate was thoroughly shaken and $1 \mathrm{ml}$ pipetted into test tubes containing $9 \mathrm{ml}$ of peptone water $\left(10^{2}\right)$. The test tubes were further serially diluted to $10^{5}$.

Total Aerobic Mesophilic Bacterial Count

Total Aerobic mesophilic bacterial count was determined using the method described by Abdullahi et al. (2004) where $1 \mathrm{ml}$ of inoculums from $10^{1}$ to $10^{5}$ dilutions were transferred into duplicate Petri dishes and labeled accordingly. This was followed by pouring aseptically about $15 \mathrm{ml}$ of molten nutrient agar. The culture was homogenized by gentle spinning of the plates and allowed to solidify. The plates were incubated at $37^{\circ} \mathrm{C}$ for 24 hours. Plates containing 30-300 colonies were counted. The number of colony forming units per gram of a sample (cfu/g) was obtained by multiplying the average colony number with the inverse of the dilution factor.

\section{Enumeration and Detection of Coliform bacteria}

Detection and enumeration of coliform was carried out according to method described by Atlas, (1977). A set of 9 test tubes each containing $9 \mathrm{ml}$ of lactose broth and an inverted Durham tubes were autoclaved to expel air and to sterilize. Similarly, $1 \mathrm{ml}$ from the diluents $10^{1}$ was transferred to the first 3 test tubes, followed by $1 \mathrm{ml}$ from the diluents $10^{2}$ to the second set of 3 test tubes and finally the third diluents $10^{3}$ to the $3^{\text {rd }}$ set of 3 test tubes. All the 9 test tubes were incubated at $37^{\circ} \mathrm{C}$ for 24 hours. Tubes that showed gas and acid production after 24 hours were recorded as positive for the presence of Coliform. Negative tubes were further reincubated for 24 hours. Positive tubes were recorded. Estimate of most probable number of Coliform per gram of sample (MPN/g) was determined by comparing the number of gas positive tubes with the most probable number table. 
BAJOPAS Volume 13 Number 1, June, 2020 Identification of Coliform

A loop full of inoculum from gas positive tubes was streaked on to Eosine methylene blue (EMB) agar plate and incubated at $37^{\circ} \mathrm{C}$ for $24 \mathrm{hrs}$. Colonies which formed bluish black color with green metallic sheen, and reddish colonies were isolated on agar slants. Those colonies showing metallic sheen on EMB were sub cultured into tubes of lactose broth and incubated at $45^{\circ} \mathrm{C}$. The tubes were observed after $24 \mathrm{hrs}$ for gas production. This is the completed test for fecal coliform. Gram stain and other biochemical tests such as Indole, Methyl red, Voges-Proskauer and Citrate Utilization tests (IMVIC), Coagulase and Catalase tests were carried out for the Identification and confirmation of isolates.

\section{Procedure for Indole Test}

Indole test was carried out by preparing a Tryptone broth drawn in to test tubes, sterilized by autoclaving, inoculated with loopful of suspension and incubated at $37^{\circ} \mathrm{C}$ for 24 hours. Three drops of xylene was added in tubes, shaken vigorously and kept for the separation of two layers. One millilitre of Kovac's reagent was added and the formation of pink colour ring indicates positive Indole test.

\section{Procedure for Methyl Red Test}

Methyl red test was carried out by preparing Glucose phosphate broth, dispensed in test tubes, sterilized, inoculated with test culture and incubated at $37^{\circ} \mathrm{C}$ for 24 hours. Five drops of methyl-red indicator was added to the medium for the formation of red colour.

\section{Procedure for Voges-Proskauer Test}

Voges-Proskauer test was carried out by inoculating tubes with the bacterial culture followed by incubation for 48 hours at $37^{\circ} \mathrm{C}$. Separate pipettes were used to pipette $1 \mathrm{ml}$ from each culture tube into clean separate tubes. Eighteen drops $(0.5 \mathrm{ml})$ of Barrit's solution A (a-naphthol) was added to each tube containing glucose phosphate broth followed by the addition of an equal amount of solution $B$ into the same tube. The tubes were shaken at 30 seconds interval. A positive reaction was indicated by the development of a pink color, which turns red in 1-2 hours, after vigorous shaking.

\section{Procedure for Citrate Utilization Test}

Citrate Utilization Test was carried out by distributing melted agar (Simmon Citrate Agar) in to test tubes followed by sterilization at $121.5^{\circ} \mathrm{C}$ for 15 minutes. The test tubes were afterward held in slanted position, inoculated with the given bacterial culture and incubated at $37^{\circ} \mathrm{C}$ for $24 \mathrm{hrs}$. Positive test was indicated by color change of the media from green to blue.

\section{RESULTS AND DISCUSSIONS}

The results of this study are presented in tables $1,2,3$ and 4. Among the sampling areas Kofar Kudu had the highest aerobic mesophilic bacteria counts $4.0 \times 10^{5} \mathrm{cfu} / \mathrm{g}$ followed by Rinji $2.72 \times 10^{5} \mathrm{cfu} / \mathrm{g}$, while Tosaro had the least Aerobic mesophilic bacteria counts of $1.02 \times 10^{5}$ $\mathrm{cfu} / \mathrm{g}$ as indicated in Table 1.Makwalla had the highest coliform count $68 \mathrm{MPN} / \mathrm{g}$ followed by Rinji $37 \mathrm{MPN} / \mathrm{g}$. Tsohuwar Kasuwa had the least coliform counts $8 \mathrm{MPN} / \mathrm{g}$, (Table 2). Result from table 1 shows variation in the microbial contents among the samples which suggest variation in their sources, poor handling procedures and contamination from the processing environment. High coliform count and their differences within sampling areas is an indication of poor microbiological quality of the product. Ndahi et al. (2013) reported microbial load to be a function of the handling personnel and the environment. The results indicated that the samples were contaminated with bacteria as the counts exceeded the minimum safety level $\left(10^{4} \mathrm{cfu} / \mathrm{g}\right)$ for members of the Enterobacteriaceae family. However, it might be a reflection of poor hygienic practices which may contribute to health hazard to the potential consumers. Similarly, Inusa and Sa'id (2017); Osimani et al. (2015) reported that, the initial microbial content of the raw material play significant role in influencing the final microbial load of the finished product. Isolation of members of the Enterobacteriaceae such as $E$. coli, Klebsiella pneumoniae, Salmonella and Shigella signifies danger to the public health. These organisms are capable of producing endotoxins which trigger high fevers in infected individuals, and the enterotoxins which colonize the small intestines and lead to extreme dehydration as a result of vomiting and diarrhea sometimes with severe and fatal outcomes (Amaeze et al., 2016). From the 16 isolated organisms $E$. coli had the highest isolation rate $6(37.5 \%)$ (Table 3), this suggest faecal contamination of the products. $E$. coli is a common flora in the gastrointestinal tract responsible for diarrhea and extra-intestinal infections (CDC, 2011). The result is in conformity with the findings of Ndahi et al. (2013) and Shamsuddeen (2009). Also presence of campylobacter might be due to cross contamination from raw meat to finished product (Tsire). Staphylococcus aureus is a normal flora of the skin, nasal, genital, mouth or anal area in both humans and animals without any symptom of an infection (Matthew et al., 2013). Isolation of $S$. aureus in these study concords with the findings of Lucretia et al. (2018) from Suya sold in Rivers State. 
BAJOPAS Volume 13 Number 1, June, 2020

It is also in agreement with the findings of Yousafzai et al. (2018); Onuorah et al. (2015) and Tijjani and Jumare (2014) from tsire samples in different countries. Presence of $S$. aureus in foods is most of the time an indication of poor human handling, poor environment, unhygienic utensils and equipments used during processing (Igene et al., 2016; Okonko et al., 2013). Infections caused by $S$. aureus are difficult to treat leading to long hospitalization with consequent economic loss (Udobi et al., 2013). These include soft tissue infections, pneumonia, hospital-acquired postoperative wound infections, Staphylococcal food poisoning, impetigo and cellulitis (Charlene et al., 2013). Samples obtained from Dausai and Kofar Kudu had the highest isolation rate $4(80 \%)$ (Table 4 ) probably because of the much commercial activities taking place in the area which can lead to environmental contamination.

Table 1: Total Aerobic Mesophilic Bacterial Count of Tsire sold in Garko Town

\begin{tabular}{lll}
\hline Sampling Area & APC cfu/g & Mean \pm STD \\
\hline Dausai & $2.20 \times 10^{5}$ & $110000 \pm 14142.14$ \\
Kofar Kudu & $4.00 \times 10^{5}$ & $133333.3 \pm 23094.01$ \\
Makwalla & $1.30 \times 10^{5}$ & $32500 \pm 7187.953$ \\
Rinji & $2.72 \times 10^{5}$ & $90666.67 \pm 94769.90$ \\
Tosaro & $1.02 \times 10^{5}$ & $51000 \pm 15556.35$ \\
Tsohuwar Kasuwa & $1.75 \times 10^{5}$ & $35000 \pm 11357.82$ \\
\hline
\end{tabular}

Key: APC: Aerobic Mesophilic Counts

STD: Standard Deviation

Table 2: Total Coliform Count of Tsire sold in Garko Town

\begin{tabular}{lcc}
\hline \multicolumn{1}{c}{ Sampling Area } & TCC MPN/g & Mean \pm STD \\
\hline Dausai & 20 & $6.67 \pm 2.5166$ \\
Kofar Kudu & 32 & $16.00 \pm 5.6569$ \\
Makwalla & 68 & $13.60 \pm 8.7062$ \\
Rinji & 37 & $9.25 \pm 4.7871$ \\
Tosaro & 10 & $5.00 \pm 2.8284$ \\
Tsohuwar Kasuwa & 8 & $4.00 \pm 0.0000$ \\
\hline
\end{tabular}

Table 3: Organisms Isolated from Tsire Sold in Garko

\begin{tabular}{lcl}
\hline Isolated Organism & Frequency & Percentage (\%) \\
\hline Campylobacter & 2 & 06.66 \\
Escherichia coli & 6 & 20.00 \\
Klebsiella pneumoniae & 2 & 06.66 \\
Salmonella species & 1 & 03.33 \\
Shigella & 3 & 10.00 \\
Staphylococcus aureus & 2 & 06.66 \\
Total & 16 & \\
\hline
\end{tabular}

Table 4: Distribution of Organisms within Sampling Area

\begin{tabular}{lcc}
\hline \multicolumn{1}{c}{ Sampling Area } & No. Isolated & Percentage (\%) \\
\hline Dausai & 4 & 80 \\
Kofar Kudu & 4 & 80 \\
Makwalla & 2 & 40 \\
Rinji & 3 & 60 \\
Tosaro & 2 & 40 \\
Tsohuwar Kasuwa & 1 & 20 \\
Total & 16 & \\
\hline
\end{tabular}

\section{CONCLUSION}

Results indicated $4.00 \times 10^{5} \mathrm{CFU} / \mathrm{g}$ as the highest APCs count; while $68 \mathrm{MPN} / \mathrm{g}$ was the highest TCCs from the 30 samples analyzed. Among the isolates, $E$. coli has the highest isolation rate of $6(20 \%)$. Dausai and Kofar kudu were having the highest bacteria count of $4(80 \%)$, each, indicating higher contamination in those locations. 
BAJOPAS Volume 13 Number 1, June, 2020 RECOMMENDATIONS

The following recommendations are tenable:

1. Hygienic practices at all stages of production should be improved to safe guard the consumers against potential health hazard.

2. Monitoring of microbiological contamination of Tsire during preparations, packaging and marketing is essential to ensure product of good microbiological quality for consumers' health.

\section{REFERENCES}

Abdullahi, I. O., Umoh, V. J. and Galadima, M. (2004). Hazards Associated with Kilishi Preparations in Zaria. Nigerian Journal of Microbiology, 18 (1-2): $339-345$.

Ahmadu, J. and Ibrahim E. J., (2013): Determinants of Revenue in Suya Production in BeninCity, Edo State, Nigeria. Nigerian journal of agriculture, food and environment.9(3):1-5

Amaeze, N. Aboh, M. Itohan, A. Felix, E. Olatunji, T. and Oladosu, P. (2016) Microbial Profile, Antibiotic Sensitivity and Heat Resistance of Bacterial Isolates from Commercial Roasted Beef (Suya) in Abuja, Nigeria. JOPAT, 15(2): $22-30$.

Apata, E.S., Kuku1, I.A., Apata, O.C. and Adeyemi, K.O. (2013). Evaluation of Suya(Tsire) - An Intermediate Moisture Meat Product in Ogun State, Nigeria. J. Food Res 2 (1): 87.

Atlas, R. M. (1997) Principles of Microbiology Second Edition. C. Brown Publishers. Pp 802-803.

Borch, E. Kant-Muermans, M. L., Blixt, Y. (1996) Bacterial Spoilage of Meat and Cured Meat Products. Int $\mathrm{J}$ Food Microbiol .33(1): 103-20.

Centre for Disease Control, CDC (2011). "Escherichia coli 0157:H7" Division of Bacterial and Mycotic Diseasesht://www.cdc.gov/nczved/divisi ons/dfbmd/diseases/ecoli_0157h7/.

Charlene, R. J., Johnnie, A. D., and John, B. B., (2013) Prevalence and Characterization of Methicillin-Resistant Staphylococcus aureus Isolates from Retail Meat and Humans in Georgia. American society for Microbiology. J. of clinical microbiology. 12(1):123-6 doi:10.1128/JCM.0316612JCM.03166-12

Egbebi, A.O and Seidu, K., T. (2011). Microbiological Evaluation of Suya (dried smoked

meat) Sold in Ado and Akure, South West Nigeria.European Journal of Experinmental Biology, 1(4):1-5
3. Government should establish regulatory bodies responsible for inculcating hygiene habits to the local producers and vendors in order to prevent instant, cross and post processing contaminations by microbial pathogens.

4. Awareness and sensitization of local food producers about good hygienic practices in food handling and processing.

Falegan, C, R., Akoja, S. D., and Oyarekua, M. A., (2017) Microbiological Assessment of Suya (Sliced Roasted Beef) in Ado-Ekiti Metropolis, Ekiti State, Nigeria. MOJ Biology andMedicine.

Fonkem, D., N. Tanya, V., N. and Ebangi, A., L. (2010). Effect of Season on the Microbiological Quality of Kilishi, a Traditional Cameroonian Dried Beef Product. Tropicultura, 28(1): 10-15.

Food and Agricultural Organization of the United Nations (F A O, 1979). Manual of food quality control 4. Microbiological analysis.

Food and Agriculture Organisation of the United Nation (FAO), 2019. Nigeria at a glance.

Igene J.O., Uwadia, O.E., Ebabhamiegbebho, P.A. and Evivie, S.E., (2016) Shelf life Stability Studies of University of Benin (UNIBEN) Proff's Kilishi Product Asian Journal of Science and Technology 7(1): 2268-2274.

Inusa, S. K. and Said, I. S. (2017) Evaluation of the Chemical and Microbiological Properties Of Kilishi Sold in Kano Metropolis. Journal of Dry land Agriculture, 3 (1): $59-69$.

Lucretia, I. B, Patience, C. Obinna-Echem, Sophia, C. A. (2018) Microbiological quality andantibiotic sensitivity of potential pathogens isolated from meat product (Suya) sold in Rivers State University and its environs. International Journal of Biotechnology and Food Science, 6(4): 67-76.

Matthew, E., Drosos, E., John, L. and Ioanna, P. (2013) MRSA in Africa: Filling the Global Map of Antimicrobial Resistance PLOS One. 8(7): e68024 doi: 10.1371/journal.pone.0068024

Mgbemere, V.N., Akpapunam, M. A. and Igene, J. O., (2011). Effect of Groundnut FlourSubstitution on Yield, Quality and Storage Stability of Kilishi - a Nigerian Indigenous Dried Meat Product. African Journal of Food, Agriculture, Nutrition and Development, $\quad \mathbf{1 1}(2)$ : 4718-4738. 
BAJOPAS Volume 13 Number 1, June, 2020

Mubarak, A. A., Azeez, M. L., Amos A. O., Opeyemi, O. O. (2016) Assessment of Animal Protein Consumption and Food Security Among Rural Households in Kwara State, Nigeria American Journal of Business and Society, 1(4): 233245.

Ndahi, M., D. Kwaga, J., K. P. Bello, M. Kabir J., V. Umoh, .J. Yakubu, S., E. and Nok, A., J. (2013) Prevalence and Antimicrobial Susceptibility of Listeria Monocytogenes and Methicillin-Resistant Staphylococcus aureus Strains from Raw Meat and Meat Products in Zaria, Nigeria. Applied Journal of Microbiology, 58(3):262-9.

Okonko, I.O., Odu, N.N. and Igboh, I.E. (2013). Microbiological Analysis of Kilishi Sold In Port Harcourt, Nigeria. New York Science Journal, 6 (7):37-43.

Osimani, A., Aquilanti, L. and Clementi, F. (2015) Microbiological Quality of Meatbased Meals and Operation of Control Systems within a Food Service Environment. International Food Research Journal 22(4): 1692-1698.

Onuorah, S. Obika, I. Odibo, F. Orji, M. (2015)An Assessment of the Bacteriological Quality of Tsire-Suya (Grilled Beef) sold in Awka, Nigeria. American. J. Life. Sci. Res. 3(4):287292.

Razavilar, V, Khandaghi, J. Barzgari, A. (2010); Isolation of Eschericia coli 0157:H7 from manure fertilized farms and raw vegetables grown on it, in Tabriz city in
Iran. African Journal of Microbiology Research, 4(9): 891-895.

Scallan, E. Hoekstra, R. M. Angulo, F. J.Tauxe, R. V, Widdowson, M. Roy, S. L et al., (2011).Food borne illness acquired in the United States- Major Pathogens. Emerg. Infec Dis, 17(1): 7-15.

Shamsuddeen U (2009). Microbiological quality of spice used in the production of Kilishi a traditionally dried and grilled meat product. Bayero Journal of Pure andApplied Sciences, 2(2): 66-69.

Shamsuddeen, U. (2015) Microbiological Hazard and Critical control point Analysis of Dried and Minced Meat Snacks Produced in Kano Nigeria. Lambert Academic Publishing; Pp 1-36.

Tijani, O.and Jumare, S. (2014). Microblological Quality Assessment of Meat

Sold in KauraNamoda. International Conference on Earth, Environment and Life sciences (EELS) Dubai (UAE).

Udobi, C. E., Obajuluwa, A. F., and Onaolapo, J. A., (2013) Prevalence and Antibiotic Resistance Pattern of MethicillinResistant Staphylococcus aureus from an Orthopaedic Hospital in Nigeria BioMed Research International; 26(6); 6-7.

WHO, 2015 Foodborne diseases in the WHO African Region.

Yousafzai HA, Rind R, Khan MA, Abro SH, Korejo NA, Ejaz M, Kabir A, Shahid M, Memon S. (2019). Microbiological Contamination of Cattle and Meat in Peshawar, Pakistan. J. Anim. Health Prod. 7(1): 1116. 


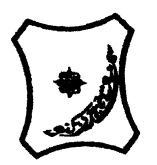

Bayero Journal of Pure and Applied Sciences, 13(1); 40 - 45

Received: September, 2019

Accepted: April, 2020

ISSN $2006-6996$

\title{
BACTERIOLOGICAL QUALITY OF STICK MEAT (Tsire) SOLD IN GARKO LOCAL GOVERNMENT AREA OF KANO STATE, NIGERIA
}

\author{
$*^{1}$ Dahiru A. T. and ${ }^{2}$ Maigari A. K. \\ ${ }^{1}$ Department of Hospitality Management, School of Technology, Kano State Polytechnic, PMB 3348, \\ Kano Nigeria. \\ ${ }^{2}$ Departmnt of Biological Sciences, Bayero University, Kano \\ Corresponding Author: dturajo61@gmail.com; GSM: 08087508262.
}

ABSTRACT

Stick meat, locally called Tsire in Hausa Language, is a significant portion of the diet of a large active population of Northern Nigeria. However, because of the handling and processing methods by the manufacturers as well as the hawking system of stick meat, the meat product may be exposed to both pre- and post-processed product contamination, and thus may poses danger to public health. Therefore, considering the role of Tsire in improving nutrition and increase household income to the populace, the need to improve the processing, distribution and overall quality of the product is simply indispensable. A total of 30 samples (5 samples from each of the 6 sampling points) of Tsire were collected randomly in Garko Town. Aerobic plate counts (APCs) and Total coliform counts (TCCS) of Tsire samples were determined using standard microbiological methods. APCs ranged from $1.02 \times 10^{5}$ to $4.00 \times 10^{5} \mathrm{CFU} / \mathrm{g}$; while TCCs ranged from $8 \mathrm{MPN} / \mathrm{g}$ to $68 \mathrm{MPN} / \mathrm{g}$. From the 30 samples screened, 16(53.33\%) bacteria namely, Campylobacter 2(6.66\%), Escherichia coli 6(20\%), Klebsiella pneumoniae 2(6.66\%), Salmonella spp. 1(3.33\%), Shigella 3(10\%) and Staphylococcus aureus 2(6.66\%) were detected. $E$. coli has the highest isolation rate of 6(20\%), while Salmonella spp. had the least frequency of 1(3.33\%). The distribution of isolated organisms within the study area were as follows: Dausai, 4(80\%), Kofar kudu, 4(80\%), Makwalla, 2(40\%), Rinji, 3(60\%), Tosaro, 2(40\%), and Tsohuwar Kasuwa, 1(20\%). The results have indicated that the Tsire was contaminated with bacteria thus exposing the product to fast deterioration, spoilage and also a vehicle for food borne illness, suggesting for adequate hygienic practices at all the stages, prior to consumption, to ensure safety of the meat product.

Key words: APCs, TCCs, Contamination, Microorganisms, Garko

\section{INTRODUCTION}

Nigeria is one of the developing nations with inadequate food supply and most often deficient in protein content (FAO, 2019). Nigerian's average animal protein intake per head per day is estimated at $7.9 \mathrm{~g}$ as against $35 \mathrm{~g}$ recommended value by Food and Agricultural Organization (Mubarak et al., 2016). These low levels of animal protein intake create great concern as it affects the nutritional status of Nigerians. Hence, there is the need for sufficient supply of animal protein from energy rich animal products to satisfy the nutritional requirements for Nigerians.

Meat is one major source of animal protein largely composed of water, protein and fats which can make it susceptible to microbial contamination within short time leading to spoilage (Apata et al., 2013; Mgbemere et al., 2011). Meat is mostly eaten after it has been cooked or processed in a variety of ways such as sun drying; smoking and roasting with or without fortifications (Borch et al., 1996). In Nigeria meat products such as Tsire, Kilishi and Balangu are locally produced using one or more of these methods in order to meet the nutritional requirements of the teeming Nigerians (Egbebi, 2011).

Tsire is a popular Nigerian traditional processed ready-to-eat roasted stick meat product (Shamsuddeen, 2015). It is sold in public places, along roads, in hotels, parks, quarters and even offices (Falegan et al., 2017). It is prepared from boneless healthy animal flesh such as beef and mutton, spiced with peanut cake, salt, vegetable oil and other flavorings followed by roasting (Shamsuddeen, 2015). Consumption of these products has extended to other parts of African countries such as Ghana, Somali, Cameroun and Chad (Ahmadu and Ibrahim, 2013). 
BAJOPAS Volume 13 Number 1, June, 2020

However, evidence of quality control sticking to procedural hygiene by the handlers during preparation and retailing of these products is poorly documented. Tsire is of great safety risk because of the fact that there are erratic cases of gastroenteritis and symptoms of food infection after consumption (WHO, 2015). Food borne illnesses are one of the major health problems in developing and developed countries (Razavilar, 2010). According to the World Health Organization, WHO (2015), $0.07 \%$ death of the 600 million global burdens of Foodborne illnesses have been reported to be caused by bacteria, viruses, fungi and chemicals. In America $0.27 \%$ of the estimated 48 million affected people is hospitalized and about $0.0063 \%$ deaths are recorded each year (Scallan et al., 2011). More than 91 million people in Africa fall ill and $0.15 \%$ dies each year, making Africa the highest burden bearer of Foodborne diseases per population (WHO, 2015).

Application of a Hazard Analysis Critical Control Point (HACCP) at all stages of meat products preparation is essential in order to ensure its safety. Thus, according to the guidelines of good manufacturing practice, the level of total aerobic bacterial contamination of thermally processed meat products should not exceed $10^{4}\left(\mathrm{cfu} \mathrm{g}^{-1}\right)$. Enterobacteriaceae and faecal coliform contamination in meat products should be within the range of $10^{2}-10^{4}$ and $10-10^{3} \mathrm{cfu} \mathrm{g}^{-1}$, respectively (Shamsuddeen, 2015). The aim of the study is therefore, to assess the total viable bacterial counts of tsire marketed locally within Garko town, and to isolate and identify the organisms at the point of consumption with the intention of promoting public health and food hygiene habits in the Nigerian populace.

\section{MATERIALS AND METHODS Study Area and Population}

Garko is one of the existing 44 local government areas located in Kano south west zone of Kano state with its capital administrative headquarters in the Garko town. It has coordinates $11^{\circ} 39^{\prime} \mathrm{N}$ $8^{\circ} 54^{\prime} \mathrm{E}$, and an area of $450 \mathrm{~km}^{2}$. The projected population of Garko local Government was 225,300 according to the National Population Census report (2018). Garko is known for agricultural activities both farming and animal husbandry. It is popularly known for large scale rice production. Other food crops include sweet potatoes, cassava, onions, sorghum, millet and sugarcane. Cows, sheep and goats are major groups of animals reared by majority of the populace. Meat products processed, retailed and consumed in Garko include roasted meat (Balangu), dried roasted meat (Kilishi), stick meat (Tsire), hide and skin pepper soup (Ragadada) and minced fried meat (Danbunnama).

\section{Samples Collection}

Five samples of Tsire products were collected from 6 different identified locations within Garko town in a sterile foil paper and immediately analyzed for the presence of bacteria.

\section{Sample Preparation}

Sample preparation for the bacteriological analysis was carried out in accordance with the method described by Atlas (1997). Twenty five grams $(25 \mathrm{~g})$ of the sample was homogenized in $225 \mathrm{ml}$ peptone water using Kenwood blender machine to obtain a $10^{1}$ homogenate. The homogenate was thoroughly shaken and $1 \mathrm{ml}$ pipetted into test tubes containing $9 \mathrm{ml}$ of peptone water $\left(10^{2}\right)$. The test tubes were further serially diluted to $10^{5}$.

Total Aerobic Mesophilic Bacterial Count

Total Aerobic mesophilic bacterial count was determined using the method described by Abdullahi et al. (2004) where $1 \mathrm{ml}$ of inoculums from $10^{1}$ to $10^{5}$ dilutions were transferred into duplicate Petri dishes and labeled accordingly. This was followed by pouring aseptically about $15 \mathrm{ml}$ of molten nutrient agar. The culture was homogenized by gentle spinning of the plates and allowed to solidify. The plates were incubated at $37^{\circ} \mathrm{C}$ for 24 hours. Plates containing 30-300 colonies were counted. The number of colony forming units per gram of a sample (cfu/g) was obtained by multiplying the average colony number with the inverse of the dilution factor.

\section{Enumeration and Detection of Coliform bacteria}

Detection and enumeration of coliform was carried out according to method described by Atlas, (1977). A set of 9 test tubes each containing $9 \mathrm{ml}$ of lactose broth and an inverted Durham tubes were autoclaved to expel air and to sterilize. Similarly, $1 \mathrm{ml}$ from the diluents $10^{1}$ was transferred to the first 3 test tubes, followed by $1 \mathrm{ml}$ from the diluents $10^{2}$ to the second set of 3 test tubes and finally the third diluents $10^{3}$ to the $3^{\text {rd }}$ set of 3 test tubes. All the 9 test tubes were incubated at $37^{\circ} \mathrm{C}$ for 24 hours. Tubes that showed gas and acid production after 24 hours were recorded as positive for the presence of Coliform. Negative tubes were further reincubated for 24 hours. Positive tubes were recorded. Estimate of most probable number of Coliform per gram of sample (MPN/g) was determined by comparing the number of gas positive tubes with the most probable number table. 
BAJOPAS Volume 13 Number 1, June, 2020 Identification of Coliform

A loop full of inoculum from gas positive tubes was streaked on to Eosine methylene blue (EMB) agar plate and incubated at $37^{\circ} \mathrm{C}$ for $24 \mathrm{hrs}$. Colonies which formed bluish black color with green metallic sheen, and reddish colonies were isolated on agar slants. Those colonies showing metallic sheen on EMB were sub cultured into tubes of lactose broth and incubated at $45^{\circ} \mathrm{C}$. The tubes were observed after $24 \mathrm{hrs}$ for gas production. This is the completed test for fecal coliform. Gram stain and other biochemical tests such as Indole, Methyl red, Voges-Proskauer and Citrate Utilization tests (IMVIC), Coagulase and Catalase tests were carried out for the Identification and confirmation of isolates.

\section{Procedure for Indole Test}

Indole test was carried out by preparing a Tryptone broth drawn in to test tubes, sterilized by autoclaving, inoculated with loopful of suspension and incubated at $37^{\circ} \mathrm{C}$ for 24 hours. Three drops of xylene was added in tubes, shaken vigorously and kept for the separation of two layers. One millilitre of Kovac's reagent was added and the formation of pink colour ring indicates positive Indole test.

\section{Procedure for Methyl Red Test}

Methyl red test was carried out by preparing Glucose phosphate broth, dispensed in test tubes, sterilized, inoculated with test culture and incubated at $37^{\circ} \mathrm{C}$ for 24 hours. Five drops of methyl-red indicator was added to the medium for the formation of red colour.

\section{Procedure for Voges-Proskauer Test}

Voges-Proskauer test was carried out by inoculating tubes with the bacterial culture followed by incubation for 48 hours at $37^{\circ} \mathrm{C}$. Separate pipettes were used to pipette $1 \mathrm{ml}$ from each culture tube into clean separate tubes. Eighteen drops $(0.5 \mathrm{ml})$ of Barrit's solution A (a-naphthol) was added to each tube containing glucose phosphate broth followed by the addition of an equal amount of solution $B$ into the same tube. The tubes were shaken at 30 seconds interval. A positive reaction was indicated by the development of a pink color, which turns red in 1-2 hours, after vigorous shaking.

\section{Procedure for Citrate Utilization Test}

Citrate Utilization Test was carried out by distributing melted agar (Simmon Citrate Agar) in to test tubes followed by sterilization at $121.5^{\circ} \mathrm{C}$ for 15 minutes. The test tubes were afterward held in slanted position, inoculated with the given bacterial culture and incubated at $37^{\circ} \mathrm{C}$ for $24 \mathrm{hrs}$. Positive test was indicated by color change of the media from green to blue.

\section{RESULTS AND DISCUSSIONS}

The results of this study are presented in tables $1,2,3$ and 4. Among the sampling areas Kofar Kudu had the highest aerobic mesophilic bacteria counts $4.0 \times 10^{5} \mathrm{cfu} / \mathrm{g}$ followed by Rinji $2.72 \times 10^{5} \mathrm{cfu} / \mathrm{g}$, while Tosaro had the least Aerobic mesophilic bacteria counts of $1.02 \times 10^{5}$ $\mathrm{cfu} / \mathrm{g}$ as indicated in Table 1.Makwalla had the highest coliform count $68 \mathrm{MPN} / \mathrm{g}$ followed by Rinji $37 \mathrm{MPN} / \mathrm{g}$. Tsohuwar Kasuwa had the least coliform counts $8 \mathrm{MPN} / \mathrm{g}$, (Table 2). Result from table 1 shows variation in the microbial contents among the samples which suggest variation in their sources, poor handling procedures and contamination from the processing environment. High coliform count and their differences within sampling areas is an indication of poor microbiological quality of the product. Ndahi et al. (2013) reported microbial load to be a function of the handling personnel and the environment. The results indicated that the samples were contaminated with bacteria as the counts exceeded the minimum safety level $\left(10^{4} \mathrm{cfu} / \mathrm{g}\right)$ for members of the Enterobacteriaceae family. However, it might be a reflection of poor hygienic practices which may contribute to health hazard to the potential consumers. Similarly, Inusa and Sa'id (2017); Osimani et al. (2015) reported that, the initial microbial content of the raw material play significant role in influencing the final microbial load of the finished product. Isolation of members of the Enterobacteriaceae such as $E$. coli, Klebsiella pneumoniae, Salmonella and Shigella signifies danger to the public health. These organisms are capable of producing endotoxins which trigger high fevers in infected individuals, and the enterotoxins which colonize the small intestines and lead to extreme dehydration as a result of vomiting and diarrhea sometimes with severe and fatal outcomes (Amaeze et al., 2016). From the 16 isolated organisms $E$. coli had the highest isolation rate $6(37.5 \%)$ (Table 3), this suggest faecal contamination of the products. $E$. coli is a common flora in the gastrointestinal tract responsible for diarrhea and extra-intestinal infections (CDC, 2011). The result is in conformity with the findings of Ndahi et al. (2013) and Shamsuddeen (2009). Also presence of campylobacter might be due to cross contamination from raw meat to finished product (Tsire). Staphylococcus aureus is a normal flora of the skin, nasal, genital, mouth or anal area in both humans and animals without any symptom of an infection (Matthew et al., 2013). Isolation of $S$. aureus in these study concords with the findings of Lucretia et al. (2018) from Suya sold in Rivers State. 
BAJOPAS Volume 13 Number 1, June, 2020

It is also in agreement with the findings of Yousafzai et al. (2018); Onuorah et al. (2015) and Tijjani and Jumare (2014) from tsire samples in different countries. Presence of $S$. aureus in foods is most of the time an indication of poor human handling, poor environment, unhygienic utensils and equipments used during processing (Igene et al., 2016; Okonko et al., 2013). Infections caused by $S$. aureus are difficult to treat leading to long hospitalization with consequent economic loss (Udobi et al., 2013). These include soft tissue infections, pneumonia, hospital-acquired postoperative wound infections, Staphylococcal food poisoning, impetigo and cellulitis (Charlene et al., 2013). Samples obtained from Dausai and Kofar Kudu had the highest isolation rate $4(80 \%)$ (Table 4 ) probably because of the much commercial activities taking place in the area which can lead to environmental contamination.

Table 1: Total Aerobic Mesophilic Bacterial Count of Tsire sold in Garko Town

\begin{tabular}{lll}
\hline Sampling Area & APC cfu/g & Mean \pm STD \\
\hline Dausai & $2.20 \times 10^{5}$ & $110000 \pm 14142.14$ \\
Kofar Kudu & $4.00 \times 10^{5}$ & $133333.3 \pm 23094.01$ \\
Makwalla & $1.30 \times 10^{5}$ & $32500 \pm 7187.953$ \\
Rinji & $2.72 \times 10^{5}$ & $90666.67 \pm 94769.90$ \\
Tosaro & $1.02 \times 10^{5}$ & $51000 \pm 15556.35$ \\
Tsohuwar Kasuwa & $1.75 \times 10^{5}$ & $35000 \pm 11357.82$ \\
\hline
\end{tabular}

Key: APC: Aerobic Mesophilic Counts

STD: Standard Deviation

Table 2: Total Coliform Count of Tsire sold in Garko Town

\begin{tabular}{lcc}
\hline \multicolumn{1}{c}{ Sampling Area } & TCC MPN/g & Mean \pm STD \\
\hline Dausai & 20 & $6.67 \pm 2.5166$ \\
Kofar Kudu & 32 & $16.00 \pm 5.6569$ \\
Makwalla & 68 & $13.60 \pm 8.7062$ \\
Rinji & 37 & $9.25 \pm 4.7871$ \\
Tosaro & 10 & $5.00 \pm 2.8284$ \\
Tsohuwar Kasuwa & 8 & $4.00 \pm 0.0000$ \\
\hline
\end{tabular}

Table 3: Organisms Isolated from Tsire Sold in Garko

\begin{tabular}{lcl}
\hline Isolated Organism & Frequency & Percentage (\%) \\
\hline Campylobacter & 2 & 06.66 \\
Escherichia coli & 6 & 20.00 \\
Klebsiella pneumoniae & 2 & 06.66 \\
Salmonella species & 1 & 03.33 \\
Shigella & 3 & 10.00 \\
Staphylococcus aureus & 2 & 06.66 \\
Total & 16 & \\
\hline
\end{tabular}

Table 4: Distribution of Organisms within Sampling Area

\begin{tabular}{lcc}
\hline \multicolumn{1}{c}{ Sampling Area } & No. Isolated & Percentage (\%) \\
\hline Dausai & 4 & 80 \\
Kofar Kudu & 4 & 80 \\
Makwalla & 2 & 40 \\
Rinji & 3 & 60 \\
Tosaro & 2 & 40 \\
Tsohuwar Kasuwa & 1 & 20 \\
Total & 16 & \\
\hline
\end{tabular}

\section{CONCLUSION}

Results indicated $4.00 \times 10^{5} \mathrm{CFU} / \mathrm{g}$ as the highest APCs count; while $68 \mathrm{MPN} / \mathrm{g}$ was the highest TCCs from the 30 samples analyzed. Among the isolates, $E$. coli has the highest isolation rate of $6(20 \%)$. Dausai and Kofar kudu were having the highest bacteria count of $4(80 \%)$, each, indicating higher contamination in those locations. 
BAJOPAS Volume 13 Number 1, June, 2020 RECOMMENDATIONS

The following recommendations are tenable:

1. Hygienic practices at all stages of production should be improved to safe guard the consumers against potential health hazard.

2. Monitoring of microbiological contamination of Tsire during preparations, packaging and marketing is essential to ensure product of good microbiological quality for consumers' health.

\section{REFERENCES}

Abdullahi, I. O., Umoh, V. J. and Galadima, M. (2004). Hazards Associated with Kilishi Preparations in Zaria. Nigerian Journal of Microbiology, 18 (1-2): $339-345$.

Ahmadu, J. and Ibrahim E. J., (2013): Determinants of Revenue in Suya Production in BeninCity, Edo State, Nigeria. Nigerian journal of agriculture, food and environment.9(3):1-5

Amaeze, N. Aboh, M. Itohan, A. Felix, E. Olatunji, T. and Oladosu, P. (2016) Microbial Profile, Antibiotic Sensitivity and Heat Resistance of Bacterial Isolates from Commercial Roasted Beef (Suya) in Abuja, Nigeria. JOPAT, 15(2): $22-30$.

Apata, E.S., Kuku1, I.A., Apata, O.C. and Adeyemi, K.O. (2013). Evaluation of Suya(Tsire) - An Intermediate Moisture Meat Product in Ogun State, Nigeria. J. Food Res 2 (1): 87.

Atlas, R. M. (1997) Principles of Microbiology Second Edition. C. Brown Publishers. Pp 802-803.

Borch, E. Kant-Muermans, M. L., Blixt, Y. (1996) Bacterial Spoilage of Meat and Cured Meat Products. Int $\mathrm{J}$ Food Microbiol .33(1): 103-20.

Centre for Disease Control, CDC (2011). "Escherichia coli 0157:H7" Division of Bacterial and Mycotic Diseasesht://www.cdc.gov/nczved/divisi ons/dfbmd/diseases/ecoli_0157h7/.

Charlene, R. J., Johnnie, A. D., and John, B. B., (2013) Prevalence and Characterization of Methicillin-Resistant Staphylococcus aureus Isolates from Retail Meat and Humans in Georgia. American society for Microbiology. J. of clinical microbiology. 12(1):123-6 doi:10.1128/JCM.0316612JCM.03166-12

Egbebi, A.O and Seidu, K., T. (2011). Microbiological Evaluation of Suya (dried smoked

meat) Sold in Ado and Akure, South West Nigeria.European Journal of Experinmental Biology, 1(4):1-5
3. Government should establish regulatory bodies responsible for inculcating hygiene habits to the local producers and vendors in order to prevent instant, cross and post processing contaminations by microbial pathogens.

4. Awareness and sensitization of local food producers about good hygienic practices in food handling and processing.

Falegan, C, R., Akoja, S. D., and Oyarekua, M. A., (2017) Microbiological Assessment of Suya (Sliced Roasted Beef) in Ado-Ekiti Metropolis, Ekiti State, Nigeria. MOJ Biology andMedicine.

Fonkem, D., N. Tanya, V., N. and Ebangi, A., L. (2010). Effect of Season on the Microbiological Quality of Kilishi, a Traditional Cameroonian Dried Beef Product. Tropicultura, 28(1): 10-15.

Food and Agricultural Organization of the United Nations (F A O, 1979). Manual of food quality control 4. Microbiological analysis.

Food and Agriculture Organisation of the United Nation (FAO), 2019. Nigeria at a glance.

Igene J.O., Uwadia, O.E., Ebabhamiegbebho, P.A. and Evivie, S.E., (2016) Shelf life Stability Studies of University of Benin (UNIBEN) Proff's Kilishi Product Asian Journal of Science and Technology 7(1): 2268-2274.

Inusa, S. K. and Said, I. S. (2017) Evaluation of the Chemical and Microbiological Properties Of Kilishi Sold in Kano Metropolis. Journal of Dry land Agriculture, 3 (1): $59-69$.

Lucretia, I. B, Patience, C. Obinna-Echem, Sophia, C. A. (2018) Microbiological quality andantibiotic sensitivity of potential pathogens isolated from meat product (Suya) sold in Rivers State University and its environs. International Journal of Biotechnology and Food Science, 6(4): 67-76.

Matthew, E., Drosos, E., John, L. and Ioanna, P. (2013) MRSA in Africa: Filling the Global Map of Antimicrobial Resistance PLOS One. 8(7): e68024 doi: 10.1371/journal.pone.0068024

Mgbemere, V.N., Akpapunam, M. A. and Igene, J. O., (2011). Effect of Groundnut FlourSubstitution on Yield, Quality and Storage Stability of Kilishi - a Nigerian Indigenous Dried Meat Product. African Journal of Food, Agriculture, Nutrition and Development, $\quad \mathbf{1 1}(2)$ : 4718-4738. 
BAJOPAS Volume 13 Number 1, June, 2020

Mubarak, A. A., Azeez, M. L., Amos A. O., Opeyemi, O. O. (2016) Assessment of Animal Protein Consumption and Food Security Among Rural Households in Kwara State, Nigeria American Journal of Business and Society, 1(4): 233245.

Ndahi, M., D. Kwaga, J., K. P. Bello, M. Kabir J., V. Umoh, .J. Yakubu, S., E. and Nok, A., J. (2013) Prevalence and Antimicrobial Susceptibility of Listeria Monocytogenes and Methicillin-Resistant Staphylococcus aureus Strains from Raw Meat and Meat Products in Zaria, Nigeria. Applied Journal of Microbiology, 58(3):262-9.

Okonko, I.O., Odu, N.N. and Igboh, I.E. (2013). Microbiological Analysis of Kilishi Sold In Port Harcourt, Nigeria. New York Science Journal, 6 (7):37-43.

Osimani, A., Aquilanti, L. and Clementi, F. (2015) Microbiological Quality of Meatbased Meals and Operation of Control Systems within a Food Service Environment. International Food Research Journal 22(4): 1692-1698.

Onuorah, S. Obika, I. Odibo, F. Orji, M. (2015)An Assessment of the Bacteriological Quality of Tsire-Suya (Grilled Beef) sold in Awka, Nigeria. American. J. Life. Sci. Res. 3(4):287292.

Razavilar, V, Khandaghi, J. Barzgari, A. (2010); Isolation of Eschericia coli 0157:H7 from manure fertilized farms and raw vegetables grown on it, in Tabriz city in
Iran. African Journal of Microbiology Research, 4(9): 891-895.

Scallan, E. Hoekstra, R. M. Angulo, F. J.Tauxe, R. V, Widdowson, M. Roy, S. L et al., (2011).Food borne illness acquired in the United States- Major Pathogens. Emerg. Infec Dis, 17(1): 7-15.

Shamsuddeen U (2009). Microbiological quality of spice used in the production of Kilishi a traditionally dried and grilled meat product. Bayero Journal of Pure andApplied Sciences, 2(2): 66-69.

Shamsuddeen, U. (2015) Microbiological Hazard and Critical control point Analysis of Dried and Minced Meat Snacks Produced in Kano Nigeria. Lambert Academic Publishing; Pp 1-36.

Tijani, O.and Jumare, S. (2014). Microblological Quality Assessment of Meat

Sold in KauraNamoda. International Conference on Earth, Environment and Life sciences (EELS) Dubai (UAE).

Udobi, C. E., Obajuluwa, A. F., and Onaolapo, J. A., (2013) Prevalence and Antibiotic Resistance Pattern of MethicillinResistant Staphylococcus aureus from an Orthopaedic Hospital in Nigeria BioMed Research International; 26(6); 6-7.

WHO, 2015 Foodborne diseases in the WHO African Region.

Yousafzai HA, Rind R, Khan MA, Abro SH, Korejo NA, Ejaz M, Kabir A, Shahid M, Memon S. (2019). Microbiological Contamination of Cattle and Meat in Peshawar, Pakistan. J. Anim. Health Prod. 7(1): 1116. 


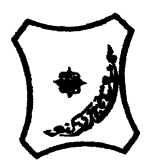

Bayero Journal of Pure and Applied Sciences, 13(1); 40 - 45

Received: September, 2019

Accepted: April, 2020

ISSN $2006-6996$

\title{
BACTERIOLOGICAL QUALITY OF STICK MEAT (Tsire) SOLD IN GARKO LOCAL GOVERNMENT AREA OF KANO STATE, NIGERIA
}

\author{
$*^{1}$ Dahiru A. T. and ${ }^{2}$ Maigari A. K. \\ ${ }^{1}$ Department of Hospitality Management, School of Technology, Kano State Polytechnic, PMB 3348, \\ Kano Nigeria. \\ ${ }^{2}$ Departmnt of Biological Sciences, Bayero University, Kano \\ Corresponding Author: dturajo61@gmail.com; GSM: 08087508262.
}

ABSTRACT

Stick meat, locally called Tsire in Hausa Language, is a significant portion of the diet of a large active population of Northern Nigeria. However, because of the handling and processing methods by the manufacturers as well as the hawking system of stick meat, the meat product may be exposed to both pre- and post-processed product contamination, and thus may poses danger to public health. Therefore, considering the role of Tsire in improving nutrition and increase household income to the populace, the need to improve the processing, distribution and overall quality of the product is simply indispensable. A total of 30 samples (5 samples from each of the 6 sampling points) of Tsire were collected randomly in Garko Town. Aerobic plate counts (APCs) and Total coliform counts (TCCS) of Tsire samples were determined using standard microbiological methods. APCs ranged from $1.02 \times 10^{5}$ to $4.00 \times 10^{5} \mathrm{CFU} / \mathrm{g}$; while TCCs ranged from $8 \mathrm{MPN} / \mathrm{g}$ to $68 \mathrm{MPN} / \mathrm{g}$. From the 30 samples screened, 16(53.33\%) bacteria namely, Campylobacter 2(6.66\%), Escherichia coli 6(20\%), Klebsiella pneumoniae 2(6.66\%), Salmonella spp. 1(3.33\%), Shigella 3(10\%) and Staphylococcus aureus 2(6.66\%) were detected. $E$. coli has the highest isolation rate of 6(20\%), while Salmonella spp. had the least frequency of 1(3.33\%). The distribution of isolated organisms within the study area were as follows: Dausai, 4(80\%), Kofar kudu, 4(80\%), Makwalla, 2(40\%), Rinji, 3(60\%), Tosaro, 2(40\%), and Tsohuwar Kasuwa, 1(20\%). The results have indicated that the Tsire was contaminated with bacteria thus exposing the product to fast deterioration, spoilage and also a vehicle for food borne illness, suggesting for adequate hygienic practices at all the stages, prior to consumption, to ensure safety of the meat product.

Key words: APCs, TCCs, Contamination, Microorganisms, Garko

\section{INTRODUCTION}

Nigeria is one of the developing nations with inadequate food supply and most often deficient in protein content (FAO, 2019). Nigerian's average animal protein intake per head per day is estimated at $7.9 \mathrm{~g}$ as against $35 \mathrm{~g}$ recommended value by Food and Agricultural Organization (Mubarak et al., 2016). These low levels of animal protein intake create great concern as it affects the nutritional status of Nigerians. Hence, there is the need for sufficient supply of animal protein from energy rich animal products to satisfy the nutritional requirements for Nigerians.

Meat is one major source of animal protein largely composed of water, protein and fats which can make it susceptible to microbial contamination within short time leading to spoilage (Apata et al., 2013; Mgbemere et al., 2011). Meat is mostly eaten after it has been cooked or processed in a variety of ways such as sun drying; smoking and roasting with or without fortifications (Borch et al., 1996). In Nigeria meat products such as Tsire, Kilishi and Balangu are locally produced using one or more of these methods in order to meet the nutritional requirements of the teeming Nigerians (Egbebi, 2011).

Tsire is a popular Nigerian traditional processed ready-to-eat roasted stick meat product (Shamsuddeen, 2015). It is sold in public places, along roads, in hotels, parks, quarters and even offices (Falegan et al., 2017). It is prepared from boneless healthy animal flesh such as beef and mutton, spiced with peanut cake, salt, vegetable oil and other flavorings followed by roasting (Shamsuddeen, 2015). Consumption of these products has extended to other parts of African countries such as Ghana, Somali, Cameroun and Chad (Ahmadu and Ibrahim, 2013). 
BAJOPAS Volume 13 Number 1, June, 2020

However, evidence of quality control sticking to procedural hygiene by the handlers during preparation and retailing of these products is poorly documented. Tsire is of great safety risk because of the fact that there are erratic cases of gastroenteritis and symptoms of food infection after consumption (WHO, 2015). Food borne illnesses are one of the major health problems in developing and developed countries (Razavilar, 2010). According to the World Health Organization, WHO (2015), $0.07 \%$ death of the 600 million global burdens of Foodborne illnesses have been reported to be caused by bacteria, viruses, fungi and chemicals. In America $0.27 \%$ of the estimated 48 million affected people is hospitalized and about $0.0063 \%$ deaths are recorded each year (Scallan et al., 2011). More than 91 million people in Africa fall ill and $0.15 \%$ dies each year, making Africa the highest burden bearer of Foodborne diseases per population (WHO, 2015).

Application of a Hazard Analysis Critical Control Point (HACCP) at all stages of meat products preparation is essential in order to ensure its safety. Thus, according to the guidelines of good manufacturing practice, the level of total aerobic bacterial contamination of thermally processed meat products should not exceed $10^{4}\left(\mathrm{cfu} \mathrm{g}^{-1}\right)$. Enterobacteriaceae and faecal coliform contamination in meat products should be within the range of $10^{2}-10^{4}$ and $10-10^{3} \mathrm{cfu} \mathrm{g}^{-1}$, respectively (Shamsuddeen, 2015). The aim of the study is therefore, to assess the total viable bacterial counts of tsire marketed locally within Garko town, and to isolate and identify the organisms at the point of consumption with the intention of promoting public health and food hygiene habits in the Nigerian populace.

\section{MATERIALS AND METHODS Study Area and Population}

Garko is one of the existing 44 local government areas located in Kano south west zone of Kano state with its capital administrative headquarters in the Garko town. It has coordinates $11^{\circ} 39^{\prime} \mathrm{N}$ $8^{\circ} 54^{\prime} \mathrm{E}$, and an area of $450 \mathrm{~km}^{2}$. The projected population of Garko local Government was 225,300 according to the National Population Census report (2018). Garko is known for agricultural activities both farming and animal husbandry. It is popularly known for large scale rice production. Other food crops include sweet potatoes, cassava, onions, sorghum, millet and sugarcane. Cows, sheep and goats are major groups of animals reared by majority of the populace. Meat products processed, retailed and consumed in Garko include roasted meat (Balangu), dried roasted meat (Kilishi), stick meat (Tsire), hide and skin pepper soup (Ragadada) and minced fried meat (Danbunnama).

\section{Samples Collection}

Five samples of Tsire products were collected from 6 different identified locations within Garko town in a sterile foil paper and immediately analyzed for the presence of bacteria.

\section{Sample Preparation}

Sample preparation for the bacteriological analysis was carried out in accordance with the method described by Atlas (1997). Twenty five grams $(25 \mathrm{~g})$ of the sample was homogenized in $225 \mathrm{ml}$ peptone water using Kenwood blender machine to obtain a $10^{1}$ homogenate. The homogenate was thoroughly shaken and $1 \mathrm{ml}$ pipetted into test tubes containing $9 \mathrm{ml}$ of peptone water $\left(10^{2}\right)$. The test tubes were further serially diluted to $10^{5}$.

Total Aerobic Mesophilic Bacterial Count

Total Aerobic mesophilic bacterial count was determined using the method described by Abdullahi et al. (2004) where $1 \mathrm{ml}$ of inoculums from $10^{1}$ to $10^{5}$ dilutions were transferred into duplicate Petri dishes and labeled accordingly. This was followed by pouring aseptically about $15 \mathrm{ml}$ of molten nutrient agar. The culture was homogenized by gentle spinning of the plates and allowed to solidify. The plates were incubated at $37^{\circ} \mathrm{C}$ for 24 hours. Plates containing 30-300 colonies were counted. The number of colony forming units per gram of a sample (cfu/g) was obtained by multiplying the average colony number with the inverse of the dilution factor.

\section{Enumeration and Detection of Coliform bacteria}

Detection and enumeration of coliform was carried out according to method described by Atlas, (1977). A set of 9 test tubes each containing $9 \mathrm{ml}$ of lactose broth and an inverted Durham tubes were autoclaved to expel air and to sterilize. Similarly, $1 \mathrm{ml}$ from the diluents $10^{1}$ was transferred to the first 3 test tubes, followed by $1 \mathrm{ml}$ from the diluents $10^{2}$ to the second set of 3 test tubes and finally the third diluents $10^{3}$ to the $3^{\text {rd }}$ set of 3 test tubes. All the 9 test tubes were incubated at $37^{\circ} \mathrm{C}$ for 24 hours. Tubes that showed gas and acid production after 24 hours were recorded as positive for the presence of Coliform. Negative tubes were further reincubated for 24 hours. Positive tubes were recorded. Estimate of most probable number of Coliform per gram of sample (MPN/g) was determined by comparing the number of gas positive tubes with the most probable number table. 
BAJOPAS Volume 13 Number 1, June, 2020 Identification of Coliform

A loop full of inoculum from gas positive tubes was streaked on to Eosine methylene blue (EMB) agar plate and incubated at $37^{\circ} \mathrm{C}$ for $24 \mathrm{hrs}$. Colonies which formed bluish black color with green metallic sheen, and reddish colonies were isolated on agar slants. Those colonies showing metallic sheen on EMB were sub cultured into tubes of lactose broth and incubated at $45^{\circ} \mathrm{C}$. The tubes were observed after $24 \mathrm{hrs}$ for gas production. This is the completed test for fecal coliform. Gram stain and other biochemical tests such as Indole, Methyl red, Voges-Proskauer and Citrate Utilization tests (IMVIC), Coagulase and Catalase tests were carried out for the Identification and confirmation of isolates.

\section{Procedure for Indole Test}

Indole test was carried out by preparing a Tryptone broth drawn in to test tubes, sterilized by autoclaving, inoculated with loopful of suspension and incubated at $37^{\circ} \mathrm{C}$ for 24 hours. Three drops of xylene was added in tubes, shaken vigorously and kept for the separation of two layers. One millilitre of Kovac's reagent was added and the formation of pink colour ring indicates positive Indole test.

\section{Procedure for Methyl Red Test}

Methyl red test was carried out by preparing Glucose phosphate broth, dispensed in test tubes, sterilized, inoculated with test culture and incubated at $37^{\circ} \mathrm{C}$ for 24 hours. Five drops of methyl-red indicator was added to the medium for the formation of red colour.

\section{Procedure for Voges-Proskauer Test}

Voges-Proskauer test was carried out by inoculating tubes with the bacterial culture followed by incubation for 48 hours at $37^{\circ} \mathrm{C}$. Separate pipettes were used to pipette $1 \mathrm{ml}$ from each culture tube into clean separate tubes. Eighteen drops $(0.5 \mathrm{ml})$ of Barrit's solution A (a-naphthol) was added to each tube containing glucose phosphate broth followed by the addition of an equal amount of solution $B$ into the same tube. The tubes were shaken at 30 seconds interval. A positive reaction was indicated by the development of a pink color, which turns red in 1-2 hours, after vigorous shaking.

\section{Procedure for Citrate Utilization Test}

Citrate Utilization Test was carried out by distributing melted agar (Simmon Citrate Agar) in to test tubes followed by sterilization at $121.5^{\circ} \mathrm{C}$ for 15 minutes. The test tubes were afterward held in slanted position, inoculated with the given bacterial culture and incubated at $37^{\circ} \mathrm{C}$ for $24 \mathrm{hrs}$. Positive test was indicated by color change of the media from green to blue.

\section{RESULTS AND DISCUSSIONS}

The results of this study are presented in tables $1,2,3$ and 4. Among the sampling areas Kofar Kudu had the highest aerobic mesophilic bacteria counts $4.0 \times 10^{5} \mathrm{cfu} / \mathrm{g}$ followed by Rinji $2.72 \times 10^{5} \mathrm{cfu} / \mathrm{g}$, while Tosaro had the least Aerobic mesophilic bacteria counts of $1.02 \times 10^{5}$ $\mathrm{cfu} / \mathrm{g}$ as indicated in Table 1.Makwalla had the highest coliform count $68 \mathrm{MPN} / \mathrm{g}$ followed by Rinji $37 \mathrm{MPN} / \mathrm{g}$. Tsohuwar Kasuwa had the least coliform counts $8 \mathrm{MPN} / \mathrm{g}$, (Table 2). Result from table 1 shows variation in the microbial contents among the samples which suggest variation in their sources, poor handling procedures and contamination from the processing environment. High coliform count and their differences within sampling areas is an indication of poor microbiological quality of the product. Ndahi et al. (2013) reported microbial load to be a function of the handling personnel and the environment. The results indicated that the samples were contaminated with bacteria as the counts exceeded the minimum safety level $\left(10^{4} \mathrm{cfu} / \mathrm{g}\right)$ for members of the Enterobacteriaceae family. However, it might be a reflection of poor hygienic practices which may contribute to health hazard to the potential consumers. Similarly, Inusa and Sa'id (2017); Osimani et al. (2015) reported that, the initial microbial content of the raw material play significant role in influencing the final microbial load of the finished product. Isolation of members of the Enterobacteriaceae such as $E$. coli, Klebsiella pneumoniae, Salmonella and Shigella signifies danger to the public health. These organisms are capable of producing endotoxins which trigger high fevers in infected individuals, and the enterotoxins which colonize the small intestines and lead to extreme dehydration as a result of vomiting and diarrhea sometimes with severe and fatal outcomes (Amaeze et al., 2016). From the 16 isolated organisms $E$. coli had the highest isolation rate $6(37.5 \%)$ (Table 3), this suggest faecal contamination of the products. $E$. coli is a common flora in the gastrointestinal tract responsible for diarrhea and extra-intestinal infections (CDC, 2011). The result is in conformity with the findings of Ndahi et al. (2013) and Shamsuddeen (2009). Also presence of campylobacter might be due to cross contamination from raw meat to finished product (Tsire). Staphylococcus aureus is a normal flora of the skin, nasal, genital, mouth or anal area in both humans and animals without any symptom of an infection (Matthew et al., 2013). Isolation of $S$. aureus in these study concords with the findings of Lucretia et al. (2018) from Suya sold in Rivers State. 
BAJOPAS Volume 13 Number 1, June, 2020

It is also in agreement with the findings of Yousafzai et al. (2018); Onuorah et al. (2015) and Tijjani and Jumare (2014) from tsire samples in different countries. Presence of $S$. aureus in foods is most of the time an indication of poor human handling, poor environment, unhygienic utensils and equipments used during processing (Igene et al., 2016; Okonko et al., 2013). Infections caused by $S$. aureus are difficult to treat leading to long hospitalization with consequent economic loss (Udobi et al., 2013). These include soft tissue infections, pneumonia, hospital-acquired postoperative wound infections, Staphylococcal food poisoning, impetigo and cellulitis (Charlene et al., 2013). Samples obtained from Dausai and Kofar Kudu had the highest isolation rate $4(80 \%)$ (Table 4 ) probably because of the much commercial activities taking place in the area which can lead to environmental contamination.

Table 1: Total Aerobic Mesophilic Bacterial Count of Tsire sold in Garko Town

\begin{tabular}{lll}
\hline Sampling Area & APC cfu/g & Mean \pm STD \\
\hline Dausai & $2.20 \times 10^{5}$ & $110000 \pm 14142.14$ \\
Kofar Kudu & $4.00 \times 10^{5}$ & $133333.3 \pm 23094.01$ \\
Makwalla & $1.30 \times 10^{5}$ & $32500 \pm 7187.953$ \\
Rinji & $2.72 \times 10^{5}$ & $90666.67 \pm 94769.90$ \\
Tosaro & $1.02 \times 10^{5}$ & $51000 \pm 15556.35$ \\
Tsohuwar Kasuwa & $1.75 \times 10^{5}$ & $35000 \pm 11357.82$ \\
\hline
\end{tabular}

Key: APC: Aerobic Mesophilic Counts

STD: Standard Deviation

Table 2: Total Coliform Count of Tsire sold in Garko Town

\begin{tabular}{lcc}
\hline \multicolumn{1}{c}{ Sampling Area } & TCC MPN/g & Mean \pm STD \\
\hline Dausai & 20 & $6.67 \pm 2.5166$ \\
Kofar Kudu & 32 & $16.00 \pm 5.6569$ \\
Makwalla & 68 & $13.60 \pm 8.7062$ \\
Rinji & 37 & $9.25 \pm 4.7871$ \\
Tosaro & 10 & $5.00 \pm 2.8284$ \\
Tsohuwar Kasuwa & 8 & $4.00 \pm 0.0000$ \\
\hline
\end{tabular}

Table 3: Organisms Isolated from Tsire Sold in Garko

\begin{tabular}{lcl}
\hline Isolated Organism & Frequency & Percentage (\%) \\
\hline Campylobacter & 2 & 06.66 \\
Escherichia coli & 6 & 20.00 \\
Klebsiella pneumoniae & 2 & 06.66 \\
Salmonella species & 1 & 03.33 \\
Shigella & 3 & 10.00 \\
Staphylococcus aureus & 2 & 06.66 \\
Total & 16 & \\
\hline
\end{tabular}

Table 4: Distribution of Organisms within Sampling Area

\begin{tabular}{lcc}
\hline \multicolumn{1}{c}{ Sampling Area } & No. Isolated & Percentage (\%) \\
\hline Dausai & 4 & 80 \\
Kofar Kudu & 4 & 80 \\
Makwalla & 2 & 40 \\
Rinji & 3 & 60 \\
Tosaro & 2 & 40 \\
Tsohuwar Kasuwa & 1 & 20 \\
Total & 16 & \\
\hline
\end{tabular}

\section{CONCLUSION}

Results indicated $4.00 \times 10^{5} \mathrm{CFU} / \mathrm{g}$ as the highest APCs count; while $68 \mathrm{MPN} / \mathrm{g}$ was the highest TCCs from the 30 samples analyzed. Among the isolates, $E$. coli has the highest isolation rate of $6(20 \%)$. Dausai and Kofar kudu were having the highest bacteria count of $4(80 \%)$, each, indicating higher contamination in those locations. 
BAJOPAS Volume 13 Number 1, June, 2020 RECOMMENDATIONS

The following recommendations are tenable:

1. Hygienic practices at all stages of production should be improved to safe guard the consumers against potential health hazard.

2. Monitoring of microbiological contamination of Tsire during preparations, packaging and marketing is essential to ensure product of good microbiological quality for consumers' health.

\section{REFERENCES}

Abdullahi, I. O., Umoh, V. J. and Galadima, M. (2004). Hazards Associated with Kilishi Preparations in Zaria. Nigerian Journal of Microbiology, 18 (1-2): $339-345$.

Ahmadu, J. and Ibrahim E. J., (2013): Determinants of Revenue in Suya Production in BeninCity, Edo State, Nigeria. Nigerian journal of agriculture, food and environment.9(3):1-5

Amaeze, N. Aboh, M. Itohan, A. Felix, E. Olatunji, T. and Oladosu, P. (2016) Microbial Profile, Antibiotic Sensitivity and Heat Resistance of Bacterial Isolates from Commercial Roasted Beef (Suya) in Abuja, Nigeria. JOPAT, 15(2): $22-30$.

Apata, E.S., Kuku1, I.A., Apata, O.C. and Adeyemi, K.O. (2013). Evaluation of Suya(Tsire) - An Intermediate Moisture Meat Product in Ogun State, Nigeria. J. Food Res 2 (1): 87.

Atlas, R. M. (1997) Principles of Microbiology Second Edition. C. Brown Publishers. Pp 802-803.

Borch, E. Kant-Muermans, M. L., Blixt, Y. (1996) Bacterial Spoilage of Meat and Cured Meat Products. Int $\mathrm{J}$ Food Microbiol .33(1): 103-20.

Centre for Disease Control, CDC (2011). "Escherichia coli 0157:H7" Division of Bacterial and Mycotic Diseasesht://www.cdc.gov/nczved/divisi ons/dfbmd/diseases/ecoli_0157h7/.

Charlene, R. J., Johnnie, A. D., and John, B. B., (2013) Prevalence and Characterization of Methicillin-Resistant Staphylococcus aureus Isolates from Retail Meat and Humans in Georgia. American society for Microbiology. J. of clinical microbiology. 12(1):123-6 doi:10.1128/JCM.0316612JCM.03166-12

Egbebi, A.O and Seidu, K., T. (2011). Microbiological Evaluation of Suya (dried smoked

meat) Sold in Ado and Akure, South West Nigeria.European Journal of Experinmental Biology, 1(4):1-5
3. Government should establish regulatory bodies responsible for inculcating hygiene habits to the local producers and vendors in order to prevent instant, cross and post processing contaminations by microbial pathogens.

4. Awareness and sensitization of local food producers about good hygienic practices in food handling and processing.

Falegan, C, R., Akoja, S. D., and Oyarekua, M. A., (2017) Microbiological Assessment of Suya (Sliced Roasted Beef) in Ado-Ekiti Metropolis, Ekiti State, Nigeria. MOJ Biology andMedicine.

Fonkem, D., N. Tanya, V., N. and Ebangi, A., L. (2010). Effect of Season on the Microbiological Quality of Kilishi, a Traditional Cameroonian Dried Beef Product. Tropicultura, 28(1): 10-15.

Food and Agricultural Organization of the United Nations (F A O, 1979). Manual of food quality control 4. Microbiological analysis.

Food and Agriculture Organisation of the United Nation (FAO), 2019. Nigeria at a glance.

Igene J.O., Uwadia, O.E., Ebabhamiegbebho, P.A. and Evivie, S.E., (2016) Shelf life Stability Studies of University of Benin (UNIBEN) Proff's Kilishi Product Asian Journal of Science and Technology 7(1): 2268-2274.

Inusa, S. K. and Said, I. S. (2017) Evaluation of the Chemical and Microbiological Properties Of Kilishi Sold in Kano Metropolis. Journal of Dry land Agriculture, 3 (1): $59-69$.

Lucretia, I. B, Patience, C. Obinna-Echem, Sophia, C. A. (2018) Microbiological quality andantibiotic sensitivity of potential pathogens isolated from meat product (Suya) sold in Rivers State University and its environs. International Journal of Biotechnology and Food Science, 6(4): 67-76.

Matthew, E., Drosos, E., John, L. and Ioanna, P. (2013) MRSA in Africa: Filling the Global Map of Antimicrobial Resistance PLOS One. 8(7): e68024 doi: 10.1371/journal.pone.0068024

Mgbemere, V.N., Akpapunam, M. A. and Igene, J. O., (2011). Effect of Groundnut FlourSubstitution on Yield, Quality and Storage Stability of Kilishi - a Nigerian Indigenous Dried Meat Product. African Journal of Food, Agriculture, Nutrition and Development, $\quad \mathbf{1 1}(2)$ : 4718-4738. 
BAJOPAS Volume 13 Number 1, June, 2020

Mubarak, A. A., Azeez, M. L., Amos A. O., Opeyemi, O. O. (2016) Assessment of Animal Protein Consumption and Food Security Among Rural Households in Kwara State, Nigeria American Journal of Business and Society, 1(4): 233245.

Ndahi, M., D. Kwaga, J., K. P. Bello, M. Kabir J., V. Umoh, .J. Yakubu, S., E. and Nok, A., J. (2013) Prevalence and Antimicrobial Susceptibility of Listeria Monocytogenes and Methicillin-Resistant Staphylococcus aureus Strains from Raw Meat and Meat Products in Zaria, Nigeria. Applied Journal of Microbiology, 58(3):262-9.

Okonko, I.O., Odu, N.N. and Igboh, I.E. (2013). Microbiological Analysis of Kilishi Sold In Port Harcourt, Nigeria. New York Science Journal, 6 (7):37-43.

Osimani, A., Aquilanti, L. and Clementi, F. (2015) Microbiological Quality of Meatbased Meals and Operation of Control Systems within a Food Service Environment. International Food Research Journal 22(4): 1692-1698.

Onuorah, S. Obika, I. Odibo, F. Orji, M. (2015)An Assessment of the Bacteriological Quality of Tsire-Suya (Grilled Beef) sold in Awka, Nigeria. American. J. Life. Sci. Res. 3(4):287292.

Razavilar, V, Khandaghi, J. Barzgari, A. (2010); Isolation of Eschericia coli 0157:H7 from manure fertilized farms and raw vegetables grown on it, in Tabriz city in
Iran. African Journal of Microbiology Research, 4(9): 891-895.

Scallan, E. Hoekstra, R. M. Angulo, F. J.Tauxe, R. V, Widdowson, M. Roy, S. L et al., (2011).Food borne illness acquired in the United States- Major Pathogens. Emerg. Infec Dis, 17(1): 7-15.

Shamsuddeen U (2009). Microbiological quality of spice used in the production of Kilishi a traditionally dried and grilled meat product. Bayero Journal of Pure andApplied Sciences, 2(2): 66-69.

Shamsuddeen, U. (2015) Microbiological Hazard and Critical control point Analysis of Dried and Minced Meat Snacks Produced in Kano Nigeria. Lambert Academic Publishing; Pp 1-36.

Tijani, O.and Jumare, S. (2014). Microblological Quality Assessment of Meat

Sold in KauraNamoda. International Conference on Earth, Environment and Life sciences (EELS) Dubai (UAE).

Udobi, C. E., Obajuluwa, A. F., and Onaolapo, J. A., (2013) Prevalence and Antibiotic Resistance Pattern of MethicillinResistant Staphylococcus aureus from an Orthopaedic Hospital in Nigeria BioMed Research International; 26(6); 6-7.

WHO, 2015 Foodborne diseases in the WHO African Region.

Yousafzai HA, Rind R, Khan MA, Abro SH, Korejo NA, Ejaz M, Kabir A, Shahid M, Memon S. (2019). Microbiological Contamination of Cattle and Meat in Peshawar, Pakistan. J. Anim. Health Prod. 7(1): 1116. 


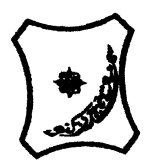

Bayero Journal of Pure and Applied Sciences, 13(1); 40 - 45

Received: September, 2019

Accepted: April, 2020

ISSN $2006-6996$

\title{
BACTERIOLOGICAL QUALITY OF STICK MEAT (Tsire) SOLD IN GARKO LOCAL GOVERNMENT AREA OF KANO STATE, NIGERIA
}

\author{
$*^{1}$ Dahiru A. T. and ${ }^{2}$ Maigari A. K. \\ ${ }^{1}$ Department of Hospitality Management, School of Technology, Kano State Polytechnic, PMB 3348, \\ Kano Nigeria. \\ ${ }^{2}$ Departmnt of Biological Sciences, Bayero University, Kano \\ Corresponding Author: dturajo61@gmail.com; GSM: 08087508262.
}

ABSTRACT

Stick meat, locally called Tsire in Hausa Language, is a significant portion of the diet of a large active population of Northern Nigeria. However, because of the handling and processing methods by the manufacturers as well as the hawking system of stick meat, the meat product may be exposed to both pre- and post-processed product contamination, and thus may poses danger to public health. Therefore, considering the role of Tsire in improving nutrition and increase household income to the populace, the need to improve the processing, distribution and overall quality of the product is simply indispensable. A total of 30 samples (5 samples from each of the 6 sampling points) of Tsire were collected randomly in Garko Town. Aerobic plate counts (APCs) and Total coliform counts (TCCS) of Tsire samples were determined using standard microbiological methods. APCs ranged from $1.02 \times 10^{5}$ to $4.00 \times 10^{5} \mathrm{CFU} / \mathrm{g}$; while TCCs ranged from $8 \mathrm{MPN} / \mathrm{g}$ to $68 \mathrm{MPN} / \mathrm{g}$. From the 30 samples screened, 16(53.33\%) bacteria namely, Campylobacter 2(6.66\%), Escherichia coli 6(20\%), Klebsiella pneumoniae 2(6.66\%), Salmonella spp. 1(3.33\%), Shigella 3(10\%) and Staphylococcus aureus 2(6.66\%) were detected. $E$. coli has the highest isolation rate of 6(20\%), while Salmonella spp. had the least frequency of 1(3.33\%). The distribution of isolated organisms within the study area were as follows: Dausai, 4(80\%), Kofar kudu, 4(80\%), Makwalla, 2(40\%), Rinji, 3(60\%), Tosaro, 2(40\%), and Tsohuwar Kasuwa, 1(20\%). The results have indicated that the Tsire was contaminated with bacteria thus exposing the product to fast deterioration, spoilage and also a vehicle for food borne illness, suggesting for adequate hygienic practices at all the stages, prior to consumption, to ensure safety of the meat product.

Key words: APCs, TCCs, Contamination, Microorganisms, Garko

\section{INTRODUCTION}

Nigeria is one of the developing nations with inadequate food supply and most often deficient in protein content (FAO, 2019). Nigerian's average animal protein intake per head per day is estimated at $7.9 \mathrm{~g}$ as against $35 \mathrm{~g}$ recommended value by Food and Agricultural Organization (Mubarak et al., 2016). These low levels of animal protein intake create great concern as it affects the nutritional status of Nigerians. Hence, there is the need for sufficient supply of animal protein from energy rich animal products to satisfy the nutritional requirements for Nigerians.

Meat is one major source of animal protein largely composed of water, protein and fats which can make it susceptible to microbial contamination within short time leading to spoilage (Apata et al., 2013; Mgbemere et al., 2011). Meat is mostly eaten after it has been cooked or processed in a variety of ways such as sun drying; smoking and roasting with or without fortifications (Borch et al., 1996). In Nigeria meat products such as Tsire, Kilishi and Balangu are locally produced using one or more of these methods in order to meet the nutritional requirements of the teeming Nigerians (Egbebi, 2011).

Tsire is a popular Nigerian traditional processed ready-to-eat roasted stick meat product (Shamsuddeen, 2015). It is sold in public places, along roads, in hotels, parks, quarters and even offices (Falegan et al., 2017). It is prepared from boneless healthy animal flesh such as beef and mutton, spiced with peanut cake, salt, vegetable oil and other flavorings followed by roasting (Shamsuddeen, 2015). Consumption of these products has extended to other parts of African countries such as Ghana, Somali, Cameroun and Chad (Ahmadu and Ibrahim, 2013). 
BAJOPAS Volume 13 Number 1, June, 2020

However, evidence of quality control sticking to procedural hygiene by the handlers during preparation and retailing of these products is poorly documented. Tsire is of great safety risk because of the fact that there are erratic cases of gastroenteritis and symptoms of food infection after consumption (WHO, 2015). Food borne illnesses are one of the major health problems in developing and developed countries (Razavilar, 2010). According to the World Health Organization, WHO (2015), $0.07 \%$ death of the 600 million global burdens of Foodborne illnesses have been reported to be caused by bacteria, viruses, fungi and chemicals. In America $0.27 \%$ of the estimated 48 million affected people is hospitalized and about $0.0063 \%$ deaths are recorded each year (Scallan et al., 2011). More than 91 million people in Africa fall ill and $0.15 \%$ dies each year, making Africa the highest burden bearer of Foodborne diseases per population (WHO, 2015).

Application of a Hazard Analysis Critical Control Point (HACCP) at all stages of meat products preparation is essential in order to ensure its safety. Thus, according to the guidelines of good manufacturing practice, the level of total aerobic bacterial contamination of thermally processed meat products should not exceed $10^{4}\left(\mathrm{cfu} \mathrm{g}^{-1}\right)$. Enterobacteriaceae and faecal coliform contamination in meat products should be within the range of $10^{2}-10^{4}$ and $10-10^{3} \mathrm{cfu} \mathrm{g}^{-1}$, respectively (Shamsuddeen, 2015). The aim of the study is therefore, to assess the total viable bacterial counts of tsire marketed locally within Garko town, and to isolate and identify the organisms at the point of consumption with the intention of promoting public health and food hygiene habits in the Nigerian populace.

\section{MATERIALS AND METHODS Study Area and Population}

Garko is one of the existing 44 local government areas located in Kano south west zone of Kano state with its capital administrative headquarters in the Garko town. It has coordinates $11^{\circ} 39^{\prime} \mathrm{N}$ $8^{\circ} 54^{\prime} \mathrm{E}$, and an area of $450 \mathrm{~km}^{2}$. The projected population of Garko local Government was 225,300 according to the National Population Census report (2018). Garko is known for agricultural activities both farming and animal husbandry. It is popularly known for large scale rice production. Other food crops include sweet potatoes, cassava, onions, sorghum, millet and sugarcane. Cows, sheep and goats are major groups of animals reared by majority of the populace. Meat products processed, retailed and consumed in Garko include roasted meat (Balangu), dried roasted meat (Kilishi), stick meat (Tsire), hide and skin pepper soup (Ragadada) and minced fried meat (Danbunnama).

\section{Samples Collection}

Five samples of Tsire products were collected from 6 different identified locations within Garko town in a sterile foil paper and immediately analyzed for the presence of bacteria.

\section{Sample Preparation}

Sample preparation for the bacteriological analysis was carried out in accordance with the method described by Atlas (1997). Twenty five grams $(25 \mathrm{~g})$ of the sample was homogenized in $225 \mathrm{ml}$ peptone water using Kenwood blender machine to obtain a $10^{1}$ homogenate. The homogenate was thoroughly shaken and $1 \mathrm{ml}$ pipetted into test tubes containing $9 \mathrm{ml}$ of peptone water $\left(10^{2}\right)$. The test tubes were further serially diluted to $10^{5}$.

Total Aerobic Mesophilic Bacterial Count

Total Aerobic mesophilic bacterial count was determined using the method described by Abdullahi et al. (2004) where $1 \mathrm{ml}$ of inoculums from $10^{1}$ to $10^{5}$ dilutions were transferred into duplicate Petri dishes and labeled accordingly. This was followed by pouring aseptically about $15 \mathrm{ml}$ of molten nutrient agar. The culture was homogenized by gentle spinning of the plates and allowed to solidify. The plates were incubated at $37^{\circ} \mathrm{C}$ for 24 hours. Plates containing 30-300 colonies were counted. The number of colony forming units per gram of a sample (cfu/g) was obtained by multiplying the average colony number with the inverse of the dilution factor.

\section{Enumeration and Detection of Coliform bacteria}

Detection and enumeration of coliform was carried out according to method described by Atlas, (1977). A set of 9 test tubes each containing $9 \mathrm{ml}$ of lactose broth and an inverted Durham tubes were autoclaved to expel air and to sterilize. Similarly, $1 \mathrm{ml}$ from the diluents $10^{1}$ was transferred to the first 3 test tubes, followed by $1 \mathrm{ml}$ from the diluents $10^{2}$ to the second set of 3 test tubes and finally the third diluents $10^{3}$ to the $3^{\text {rd }}$ set of 3 test tubes. All the 9 test tubes were incubated at $37^{\circ} \mathrm{C}$ for 24 hours. Tubes that showed gas and acid production after 24 hours were recorded as positive for the presence of Coliform. Negative tubes were further reincubated for 24 hours. Positive tubes were recorded. Estimate of most probable number of Coliform per gram of sample (MPN/g) was determined by comparing the number of gas positive tubes with the most probable number table. 
BAJOPAS Volume 13 Number 1, June, 2020 Identification of Coliform

A loop full of inoculum from gas positive tubes was streaked on to Eosine methylene blue (EMB) agar plate and incubated at $37^{\circ} \mathrm{C}$ for $24 \mathrm{hrs}$. Colonies which formed bluish black color with green metallic sheen, and reddish colonies were isolated on agar slants. Those colonies showing metallic sheen on EMB were sub cultured into tubes of lactose broth and incubated at $45^{\circ} \mathrm{C}$. The tubes were observed after $24 \mathrm{hrs}$ for gas production. This is the completed test for fecal coliform. Gram stain and other biochemical tests such as Indole, Methyl red, Voges-Proskauer and Citrate Utilization tests (IMVIC), Coagulase and Catalase tests were carried out for the Identification and confirmation of isolates.

\section{Procedure for Indole Test}

Indole test was carried out by preparing a Tryptone broth drawn in to test tubes, sterilized by autoclaving, inoculated with loopful of suspension and incubated at $37^{\circ} \mathrm{C}$ for 24 hours. Three drops of xylene was added in tubes, shaken vigorously and kept for the separation of two layers. One millilitre of Kovac's reagent was added and the formation of pink colour ring indicates positive Indole test.

\section{Procedure for Methyl Red Test}

Methyl red test was carried out by preparing Glucose phosphate broth, dispensed in test tubes, sterilized, inoculated with test culture and incubated at $37^{\circ} \mathrm{C}$ for 24 hours. Five drops of methyl-red indicator was added to the medium for the formation of red colour.

\section{Procedure for Voges-Proskauer Test}

Voges-Proskauer test was carried out by inoculating tubes with the bacterial culture followed by incubation for 48 hours at $37^{\circ} \mathrm{C}$. Separate pipettes were used to pipette $1 \mathrm{ml}$ from each culture tube into clean separate tubes. Eighteen drops $(0.5 \mathrm{ml})$ of Barrit's solution A (a-naphthol) was added to each tube containing glucose phosphate broth followed by the addition of an equal amount of solution $B$ into the same tube. The tubes were shaken at 30 seconds interval. A positive reaction was indicated by the development of a pink color, which turns red in 1-2 hours, after vigorous shaking.

\section{Procedure for Citrate Utilization Test}

Citrate Utilization Test was carried out by distributing melted agar (Simmon Citrate Agar) in to test tubes followed by sterilization at $121.5^{\circ} \mathrm{C}$ for 15 minutes. The test tubes were afterward held in slanted position, inoculated with the given bacterial culture and incubated at $37^{\circ} \mathrm{C}$ for $24 \mathrm{hrs}$. Positive test was indicated by color change of the media from green to blue.

\section{RESULTS AND DISCUSSIONS}

The results of this study are presented in tables $1,2,3$ and 4. Among the sampling areas Kofar Kudu had the highest aerobic mesophilic bacteria counts $4.0 \times 10^{5} \mathrm{cfu} / \mathrm{g}$ followed by Rinji $2.72 \times 10^{5} \mathrm{cfu} / \mathrm{g}$, while Tosaro had the least Aerobic mesophilic bacteria counts of $1.02 \times 10^{5}$ $\mathrm{cfu} / \mathrm{g}$ as indicated in Table 1.Makwalla had the highest coliform count $68 \mathrm{MPN} / \mathrm{g}$ followed by Rinji $37 \mathrm{MPN} / \mathrm{g}$. Tsohuwar Kasuwa had the least coliform counts $8 \mathrm{MPN} / \mathrm{g}$, (Table 2). Result from table 1 shows variation in the microbial contents among the samples which suggest variation in their sources, poor handling procedures and contamination from the processing environment. High coliform count and their differences within sampling areas is an indication of poor microbiological quality of the product. Ndahi et al. (2013) reported microbial load to be a function of the handling personnel and the environment. The results indicated that the samples were contaminated with bacteria as the counts exceeded the minimum safety level $\left(10^{4} \mathrm{cfu} / \mathrm{g}\right)$ for members of the Enterobacteriaceae family. However, it might be a reflection of poor hygienic practices which may contribute to health hazard to the potential consumers. Similarly, Inusa and Sa'id (2017); Osimani et al. (2015) reported that, the initial microbial content of the raw material play significant role in influencing the final microbial load of the finished product. Isolation of members of the Enterobacteriaceae such as $E$. coli, Klebsiella pneumoniae, Salmonella and Shigella signifies danger to the public health. These organisms are capable of producing endotoxins which trigger high fevers in infected individuals, and the enterotoxins which colonize the small intestines and lead to extreme dehydration as a result of vomiting and diarrhea sometimes with severe and fatal outcomes (Amaeze et al., 2016). From the 16 isolated organisms $E$. coli had the highest isolation rate $6(37.5 \%)$ (Table 3), this suggest faecal contamination of the products. $E$. coli is a common flora in the gastrointestinal tract responsible for diarrhea and extra-intestinal infections (CDC, 2011). The result is in conformity with the findings of Ndahi et al. (2013) and Shamsuddeen (2009). Also presence of campylobacter might be due to cross contamination from raw meat to finished product (Tsire). Staphylococcus aureus is a normal flora of the skin, nasal, genital, mouth or anal area in both humans and animals without any symptom of an infection (Matthew et al., 2013). Isolation of $S$. aureus in these study concords with the findings of Lucretia et al. (2018) from Suya sold in Rivers State. 
BAJOPAS Volume 13 Number 1, June, 2020

It is also in agreement with the findings of Yousafzai et al. (2018); Onuorah et al. (2015) and Tijjani and Jumare (2014) from tsire samples in different countries. Presence of $S$. aureus in foods is most of the time an indication of poor human handling, poor environment, unhygienic utensils and equipments used during processing (Igene et al., 2016; Okonko et al., 2013). Infections caused by $S$. aureus are difficult to treat leading to long hospitalization with consequent economic loss (Udobi et al., 2013). These include soft tissue infections, pneumonia, hospital-acquired postoperative wound infections, Staphylococcal food poisoning, impetigo and cellulitis (Charlene et al., 2013). Samples obtained from Dausai and Kofar Kudu had the highest isolation rate $4(80 \%)$ (Table 4 ) probably because of the much commercial activities taking place in the area which can lead to environmental contamination.

Table 1: Total Aerobic Mesophilic Bacterial Count of Tsire sold in Garko Town

\begin{tabular}{lll}
\hline Sampling Area & APC cfu/g & Mean \pm STD \\
\hline Dausai & $2.20 \times 10^{5}$ & $110000 \pm 14142.14$ \\
Kofar Kudu & $4.00 \times 10^{5}$ & $133333.3 \pm 23094.01$ \\
Makwalla & $1.30 \times 10^{5}$ & $32500 \pm 7187.953$ \\
Rinji & $2.72 \times 10^{5}$ & $90666.67 \pm 94769.90$ \\
Tosaro & $1.02 \times 10^{5}$ & $51000 \pm 15556.35$ \\
Tsohuwar Kasuwa & $1.75 \times 10^{5}$ & $35000 \pm 11357.82$ \\
\hline
\end{tabular}

Key: APC: Aerobic Mesophilic Counts

STD: Standard Deviation

Table 2: Total Coliform Count of Tsire sold in Garko Town

\begin{tabular}{lcc}
\hline \multicolumn{1}{c}{ Sampling Area } & TCC MPN/g & Mean \pm STD \\
\hline Dausai & 20 & $6.67 \pm 2.5166$ \\
Kofar Kudu & 32 & $16.00 \pm 5.6569$ \\
Makwalla & 68 & $13.60 \pm 8.7062$ \\
Rinji & 37 & $9.25 \pm 4.7871$ \\
Tosaro & 10 & $5.00 \pm 2.8284$ \\
Tsohuwar Kasuwa & 8 & $4.00 \pm 0.0000$ \\
\hline
\end{tabular}

Table 3: Organisms Isolated from Tsire Sold in Garko

\begin{tabular}{lcl}
\hline Isolated Organism & Frequency & Percentage (\%) \\
\hline Campylobacter & 2 & 06.66 \\
Escherichia coli & 6 & 20.00 \\
Klebsiella pneumoniae & 2 & 06.66 \\
Salmonella species & 1 & 03.33 \\
Shigella & 3 & 10.00 \\
Staphylococcus aureus & 2 & 06.66 \\
Total & 16 & \\
\hline
\end{tabular}

Table 4: Distribution of Organisms within Sampling Area

\begin{tabular}{lcc}
\hline \multicolumn{1}{c}{ Sampling Area } & No. Isolated & Percentage (\%) \\
\hline Dausai & 4 & 80 \\
Kofar Kudu & 4 & 80 \\
Makwalla & 2 & 40 \\
Rinji & 3 & 60 \\
Tosaro & 2 & 40 \\
Tsohuwar Kasuwa & 1 & 20 \\
Total & 16 & \\
\hline
\end{tabular}

\section{CONCLUSION}

Results indicated $4.00 \times 10^{5} \mathrm{CFU} / \mathrm{g}$ as the highest APCs count; while $68 \mathrm{MPN} / \mathrm{g}$ was the highest TCCs from the 30 samples analyzed. Among the isolates, $E$. coli has the highest isolation rate of $6(20 \%)$. Dausai and Kofar kudu were having the highest bacteria count of $4(80 \%)$, each, indicating higher contamination in those locations. 
BAJOPAS Volume 13 Number 1, June, 2020 RECOMMENDATIONS

The following recommendations are tenable:

1. Hygienic practices at all stages of production should be improved to safe guard the consumers against potential health hazard.

2. Monitoring of microbiological contamination of Tsire during preparations, packaging and marketing is essential to ensure product of good microbiological quality for consumers' health.

\section{REFERENCES}

Abdullahi, I. O., Umoh, V. J. and Galadima, M. (2004). Hazards Associated with Kilishi Preparations in Zaria. Nigerian Journal of Microbiology, 18 (1-2): $339-345$.

Ahmadu, J. and Ibrahim E. J., (2013): Determinants of Revenue in Suya Production in BeninCity, Edo State, Nigeria. Nigerian journal of agriculture, food and environment.9(3):1-5

Amaeze, N. Aboh, M. Itohan, A. Felix, E. Olatunji, T. and Oladosu, P. (2016) Microbial Profile, Antibiotic Sensitivity and Heat Resistance of Bacterial Isolates from Commercial Roasted Beef (Suya) in Abuja, Nigeria. JOPAT, 15(2): $22-30$.

Apata, E.S., Kuku1, I.A., Apata, O.C. and Adeyemi, K.O. (2013). Evaluation of Suya(Tsire) - An Intermediate Moisture Meat Product in Ogun State, Nigeria. J. Food Res 2 (1): 87.

Atlas, R. M. (1997) Principles of Microbiology Second Edition. C. Brown Publishers. Pp 802-803.

Borch, E. Kant-Muermans, M. L., Blixt, Y. (1996) Bacterial Spoilage of Meat and Cured Meat Products. Int $\mathrm{J}$ Food Microbiol .33(1): 103-20.

Centre for Disease Control, CDC (2011). "Escherichia coli 0157:H7" Division of Bacterial and Mycotic Diseasesht://www.cdc.gov/nczved/divisi ons/dfbmd/diseases/ecoli_0157h7/.

Charlene, R. J., Johnnie, A. D., and John, B. B., (2013) Prevalence and Characterization of Methicillin-Resistant Staphylococcus aureus Isolates from Retail Meat and Humans in Georgia. American society for Microbiology. J. of clinical microbiology. 12(1):123-6 doi:10.1128/JCM.0316612JCM.03166-12

Egbebi, A.O and Seidu, K., T. (2011). Microbiological Evaluation of Suya (dried smoked

meat) Sold in Ado and Akure, South West Nigeria.European Journal of Experinmental Biology, 1(4):1-5
3. Government should establish regulatory bodies responsible for inculcating hygiene habits to the local producers and vendors in order to prevent instant, cross and post processing contaminations by microbial pathogens.

4. Awareness and sensitization of local food producers about good hygienic practices in food handling and processing.

Falegan, C, R., Akoja, S. D., and Oyarekua, M. A., (2017) Microbiological Assessment of Suya (Sliced Roasted Beef) in Ado-Ekiti Metropolis, Ekiti State, Nigeria. MOJ Biology andMedicine.

Fonkem, D., N. Tanya, V., N. and Ebangi, A., L. (2010). Effect of Season on the Microbiological Quality of Kilishi, a Traditional Cameroonian Dried Beef Product. Tropicultura, 28(1): 10-15.

Food and Agricultural Organization of the United Nations (F A O, 1979). Manual of food quality control 4. Microbiological analysis.

Food and Agriculture Organisation of the United Nation (FAO), 2019. Nigeria at a glance.

Igene J.O., Uwadia, O.E., Ebabhamiegbebho, P.A. and Evivie, S.E., (2016) Shelf life Stability Studies of University of Benin (UNIBEN) Proff's Kilishi Product Asian Journal of Science and Technology 7(1): 2268-2274.

Inusa, S. K. and Said, I. S. (2017) Evaluation of the Chemical and Microbiological Properties Of Kilishi Sold in Kano Metropolis. Journal of Dry land Agriculture, 3 (1): $59-69$.

Lucretia, I. B, Patience, C. Obinna-Echem, Sophia, C. A. (2018) Microbiological quality andantibiotic sensitivity of potential pathogens isolated from meat product (Suya) sold in Rivers State University and its environs. International Journal of Biotechnology and Food Science, 6(4): 67-76.

Matthew, E., Drosos, E., John, L. and Ioanna, P. (2013) MRSA in Africa: Filling the Global Map of Antimicrobial Resistance PLOS One. 8(7): e68024 doi: 10.1371/journal.pone.0068024

Mgbemere, V.N., Akpapunam, M. A. and Igene, J. O., (2011). Effect of Groundnut FlourSubstitution on Yield, Quality and Storage Stability of Kilishi - a Nigerian Indigenous Dried Meat Product. African Journal of Food, Agriculture, Nutrition and Development, $\quad \mathbf{1 1}(2)$ : 4718-4738. 
BAJOPAS Volume 13 Number 1, June, 2020

Mubarak, A. A., Azeez, M. L., Amos A. O., Opeyemi, O. O. (2016) Assessment of Animal Protein Consumption and Food Security Among Rural Households in Kwara State, Nigeria American Journal of Business and Society, 1(4): 233245.

Ndahi, M., D. Kwaga, J., K. P. Bello, M. Kabir J., V. Umoh, .J. Yakubu, S., E. and Nok, A., J. (2013) Prevalence and Antimicrobial Susceptibility of Listeria Monocytogenes and Methicillin-Resistant Staphylococcus aureus Strains from Raw Meat and Meat Products in Zaria, Nigeria. Applied Journal of Microbiology, 58(3):262-9.

Okonko, I.O., Odu, N.N. and Igboh, I.E. (2013). Microbiological Analysis of Kilishi Sold In Port Harcourt, Nigeria. New York Science Journal, 6 (7):37-43.

Osimani, A., Aquilanti, L. and Clementi, F. (2015) Microbiological Quality of Meatbased Meals and Operation of Control Systems within a Food Service Environment. International Food Research Journal 22(4): 1692-1698.

Onuorah, S. Obika, I. Odibo, F. Orji, M. (2015)An Assessment of the Bacteriological Quality of Tsire-Suya (Grilled Beef) sold in Awka, Nigeria. American. J. Life. Sci. Res. 3(4):287292.

Razavilar, V, Khandaghi, J. Barzgari, A. (2010); Isolation of Eschericia coli 0157:H7 from manure fertilized farms and raw vegetables grown on it, in Tabriz city in
Iran. African Journal of Microbiology Research, 4(9): 891-895.

Scallan, E. Hoekstra, R. M. Angulo, F. J.Tauxe, R. V, Widdowson, M. Roy, S. L et al., (2011).Food borne illness acquired in the United States- Major Pathogens. Emerg. Infec Dis, 17(1): 7-15.

Shamsuddeen U (2009). Microbiological quality of spice used in the production of Kilishi a traditionally dried and grilled meat product. Bayero Journal of Pure andApplied Sciences, 2(2): 66-69.

Shamsuddeen, U. (2015) Microbiological Hazard and Critical control point Analysis of Dried and Minced Meat Snacks Produced in Kano Nigeria. Lambert Academic Publishing; Pp 1-36.

Tijani, O.and Jumare, S. (2014). Microblological Quality Assessment of Meat

Sold in KauraNamoda. International Conference on Earth, Environment and Life sciences (EELS) Dubai (UAE).

Udobi, C. E., Obajuluwa, A. F., and Onaolapo, J. A., (2013) Prevalence and Antibiotic Resistance Pattern of MethicillinResistant Staphylococcus aureus from an Orthopaedic Hospital in Nigeria BioMed Research International; 26(6); 6-7.

WHO, 2015 Foodborne diseases in the WHO African Region.

Yousafzai HA, Rind R, Khan MA, Abro SH, Korejo NA, Ejaz M, Kabir A, Shahid M, Memon S. (2019). Microbiological Contamination of Cattle and Meat in Peshawar, Pakistan. J. Anim. Health Prod. 7(1): 1116. 


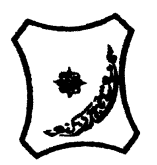

Bayero Journal of Pure and Applied Sciences, 13(1); 40 - 45

Received: September, 2019

Accepted: April, 2020

ISSN $2006-6996$

\title{
BACTERIOLOGICAL QUALITY OF STICK MEAT (Tsire) SOLD IN GARKO LOCAL GOVERNMENT AREA OF KANO STATE, NIGERIA
}

\author{
$*^{1}$ Dahiru A. T. and ${ }^{2}$ Maigari A. K. \\ ${ }^{1}$ Department of Hospitality Management, School of Technology, Kano State Polytechnic, PMB 3348, \\ Kano Nigeria. \\ ${ }^{2}$ Departmnt of Biological Sciences, Bayero University, Kano \\ Corresponding Author: dturajo61@gmail.com; GSM: 08087508262.
}

ABSTRACT

Stick meat, locally called Tsire in Hausa Language, is a significant portion of the diet of a large active population of Northern Nigeria. However, because of the handling and processing methods by the manufacturers as well as the hawking system of stick meat, the meat product may be exposed to both pre- and post-processed product contamination, and thus may poses danger to public health. Therefore, considering the role of Tsire in improving nutrition and increase household income to the populace, the need to improve the processing, distribution and overall quality of the product is simply indispensable. A total of 30 samples (5 samples from each of the 6 sampling points) of Tsire were collected randomly in Garko Town. Aerobic plate counts (APCs) and Total coliform counts (TCCS) of Tsire samples were determined using standard microbiological methods. APCs ranged from $1.02 \times 10^{5}$ to $4.00 \times 10^{5} \mathrm{CFU} / \mathrm{g}$; while TCCs ranged from $8 \mathrm{MPN} / \mathrm{g}$ to $68 \mathrm{MPN} / \mathrm{g}$. From the 30 samples screened, 16(53.33\%) bacteria namely, Campylobacter 2(6.66\%), Escherichia coli 6(20\%), Klebsiella pneumoniae 2(6.66\%), Salmonella spp. 1(3.33\%), Shigella 3(10\%) and Staphylococcus aureus 2(6.66\%) were detected. $E$. coli has the highest isolation rate of 6(20\%), while Salmonella spp. had the least frequency of 1(3.33\%). The distribution of isolated organisms within the study area were as follows: Dausai, 4(80\%), Kofar kudu, 4(80\%), Makwalla, 2(40\%), Rinji, 3(60\%), Tosaro, 2(40\%), and Tsohuwar Kasuwa, 1(20\%). The results have indicated that the Tsire was contaminated with bacteria thus exposing the product to fast deterioration, spoilage and also a vehicle for food borne illness, suggesting for adequate hygienic practices at all the stages, prior to consumption, to ensure safety of the meat product.

Key words: APCs, TCCs, Contamination, Microorganisms, Garko

\section{INTRODUCTION}

Nigeria is one of the developing nations with inadequate food supply and most often deficient in protein content (FAO, 2019). Nigerian's average animal protein intake per head per day is estimated at $7.9 \mathrm{~g}$ as against $35 \mathrm{~g}$ recommended value by Food and Agricultural Organization (Mubarak et al., 2016). These low levels of animal protein intake create great concern as it affects the nutritional status of Nigerians. Hence, there is the need for sufficient supply of animal protein from energy rich animal products to satisfy the nutritional requirements for Nigerians.

Meat is one major source of animal protein largely composed of water, protein and fats which can make it susceptible to microbial contamination within short time leading to spoilage (Apata et al., 2013; Mgbemere et al., 2011). Meat is mostly eaten after it has been cooked or processed in a variety of ways such as sun drying; smoking and roasting with or without fortifications (Borch et al., 1996). In Nigeria meat products such as Tsire, Kilishi and Balangu are locally produced using one or more of these methods in order to meet the nutritional requirements of the teeming Nigerians (Egbebi, 2011).

Tsire is a popular Nigerian traditional processed ready-to-eat roasted stick meat product (Shamsuddeen, 2015). It is sold in public places, along roads, in hotels, parks, quarters and even offices (Falegan et al., 2017). It is prepared from boneless healthy animal flesh such as beef and mutton, spiced with peanut cake, salt, vegetable oil and other flavorings followed by roasting (Shamsuddeen, 2015). Consumption of these products has extended to other parts of African countries such as Ghana, Somali, Cameroun and Chad (Ahmadu and Ibrahim, 2013). 
BAJOPAS Volume 13 Number 1, June, 2020

However, evidence of quality control sticking to procedural hygiene by the handlers during preparation and retailing of these products is poorly documented. Tsire is of great safety risk because of the fact that there are erratic cases of gastroenteritis and symptoms of food infection after consumption (WHO, 2015). Food borne illnesses are one of the major health problems in developing and developed countries (Razavilar, 2010). According to the World Health Organization, WHO (2015), $0.07 \%$ death of the 600 million global burdens of Foodborne illnesses have been reported to be caused by bacteria, viruses, fungi and chemicals. In America $0.27 \%$ of the estimated 48 million affected people is hospitalized and about $0.0063 \%$ deaths are recorded each year (Scallan et al., 2011). More than 91 million people in Africa fall ill and $0.15 \%$ dies each year, making Africa the highest burden bearer of Foodborne diseases per population (WHO, 2015).

Application of a Hazard Analysis Critical Control Point (HACCP) at all stages of meat products preparation is essential in order to ensure its safety. Thus, according to the guidelines of good manufacturing practice, the level of total aerobic bacterial contamination of thermally processed meat products should not exceed $10^{4}\left(\mathrm{cfu} \mathrm{g}^{-1}\right)$. Enterobacteriaceae and faecal coliform contamination in meat products should be within the range of $10^{2}-10^{4}$ and $10-10^{3} \mathrm{cfu} \mathrm{g}^{-1}$, respectively (Shamsuddeen, 2015). The aim of the study is therefore, to assess the total viable bacterial counts of tsire marketed locally within Garko town, and to isolate and identify the organisms at the point of consumption with the intention of promoting public health and food hygiene habits in the Nigerian populace.

\section{MATERIALS AND METHODS Study Area and Population}

Garko is one of the existing 44 local government areas located in Kano south west zone of Kano state with its capital administrative headquarters in the Garko town. It has coordinates $11^{\circ} 39^{\prime} \mathrm{N}$ $8^{\circ} 54^{\prime} \mathrm{E}$, and an area of $450 \mathrm{~km}^{2}$. The projected population of Garko local Government was 225,300 according to the National Population Census report (2018). Garko is known for agricultural activities both farming and animal husbandry. It is popularly known for large scale rice production. Other food crops include sweet potatoes, cassava, onions, sorghum, millet and sugarcane. Cows, sheep and goats are major groups of animals reared by majority of the populace. Meat products processed, retailed and consumed in Garko include roasted meat (Balangu), dried roasted meat (Kilishi), stick meat (Tsire), hide and skin pepper soup (Ragadada) and minced fried meat (Danbunnama).

\section{Samples Collection}

Five samples of Tsire products were collected from 6 different identified locations within Garko town in a sterile foil paper and immediately analyzed for the presence of bacteria.

\section{Sample Preparation}

Sample preparation for the bacteriological analysis was carried out in accordance with the method described by Atlas (1997). Twenty five grams $(25 \mathrm{~g})$ of the sample was homogenized in $225 \mathrm{ml}$ peptone water using Kenwood blender machine to obtain a $10^{1}$ homogenate. The homogenate was thoroughly shaken and $1 \mathrm{ml}$ pipetted into test tubes containing $9 \mathrm{ml}$ of peptone water $\left(10^{2}\right)$. The test tubes were further serially diluted to $10^{5}$.

Total Aerobic Mesophilic Bacterial Count

Total Aerobic mesophilic bacterial count was determined using the method described by Abdullahi et al. (2004) where $1 \mathrm{ml}$ of inoculums from $10^{1}$ to $10^{5}$ dilutions were transferred into duplicate Petri dishes and labeled accordingly. This was followed by pouring aseptically about $15 \mathrm{ml}$ of molten nutrient agar. The culture was homogenized by gentle spinning of the plates and allowed to solidify. The plates were incubated at $37^{\circ} \mathrm{C}$ for 24 hours. Plates containing 30-300 colonies were counted. The number of colony forming units per gram of a sample (cfu/g) was obtained by multiplying the average colony number with the inverse of the dilution factor.

\section{Enumeration and Detection of Coliform bacteria}

Detection and enumeration of coliform was carried out according to method described by Atlas, (1977). A set of 9 test tubes each containing $9 \mathrm{ml}$ of lactose broth and an inverted Durham tubes were autoclaved to expel air and to sterilize. Similarly, $1 \mathrm{ml}$ from the diluents $10^{1}$ was transferred to the first 3 test tubes, followed by $1 \mathrm{ml}$ from the diluents $10^{2}$ to the second set of 3 test tubes and finally the third diluents $10^{3}$ to the $3^{\text {rd }}$ set of 3 test tubes. All the 9 test tubes were incubated at $37^{\circ} \mathrm{C}$ for 24 hours. Tubes that showed gas and acid production after 24 hours were recorded as positive for the presence of Coliform. Negative tubes were further reincubated for 24 hours. Positive tubes were recorded. Estimate of most probable number of Coliform per gram of sample (MPN/g) was determined by comparing the number of gas positive tubes with the most probable number table. 
BAJOPAS Volume 13 Number 1, June, 2020 Identification of Coliform

A loop full of inoculum from gas positive tubes was streaked on to Eosine methylene blue (EMB) agar plate and incubated at $37^{\circ} \mathrm{C}$ for $24 \mathrm{hrs}$. Colonies which formed bluish black color with green metallic sheen, and reddish colonies were isolated on agar slants. Those colonies showing metallic sheen on EMB were sub cultured into tubes of lactose broth and incubated at $45^{\circ} \mathrm{C}$. The tubes were observed after $24 \mathrm{hrs}$ for gas production. This is the completed test for fecal coliform. Gram stain and other biochemical tests such as Indole, Methyl red, Voges-Proskauer and Citrate Utilization tests (IMVIC), Coagulase and Catalase tests were carried out for the Identification and confirmation of isolates.

\section{Procedure for Indole Test}

Indole test was carried out by preparing a Tryptone broth drawn in to test tubes, sterilized by autoclaving, inoculated with loopful of suspension and incubated at $37^{\circ} \mathrm{C}$ for 24 hours. Three drops of xylene was added in tubes, shaken vigorously and kept for the separation of two layers. One millilitre of Kovac's reagent was added and the formation of pink colour ring indicates positive Indole test.

\section{Procedure for Methyl Red Test}

Methyl red test was carried out by preparing Glucose phosphate broth, dispensed in test tubes, sterilized, inoculated with test culture and incubated at $37^{\circ} \mathrm{C}$ for 24 hours. Five drops of methyl-red indicator was added to the medium for the formation of red colour.

\section{Procedure for Voges-Proskauer Test}

Voges-Proskauer test was carried out by inoculating tubes with the bacterial culture followed by incubation for 48 hours at $37^{\circ} \mathrm{C}$. Separate pipettes were used to pipette $1 \mathrm{ml}$ from each culture tube into clean separate tubes. Eighteen drops $(0.5 \mathrm{ml})$ of Barrit's solution A (a-naphthol) was added to each tube containing glucose phosphate broth followed by the addition of an equal amount of solution $B$ into the same tube. The tubes were shaken at 30 seconds interval. A positive reaction was indicated by the development of a pink color, which turns red in 1-2 hours, after vigorous shaking.

\section{Procedure for Citrate Utilization Test}

Citrate Utilization Test was carried out by distributing melted agar (Simmon Citrate Agar) in to test tubes followed by sterilization at $121.5^{\circ} \mathrm{C}$ for 15 minutes. The test tubes were afterward held in slanted position, inoculated with the given bacterial culture and incubated at $37^{\circ} \mathrm{C}$ for $24 \mathrm{hrs}$. Positive test was indicated by color change of the media from green to blue.

\section{RESULTS AND DISCUSSIONS}

The results of this study are presented in tables $1,2,3$ and 4. Among the sampling areas Kofar Kudu had the highest aerobic mesophilic bacteria counts $4.0 \times 10^{5} \mathrm{cfu} / \mathrm{g}$ followed by Rinji $2.72 \times 10^{5} \mathrm{cfu} / \mathrm{g}$, while Tosaro had the least Aerobic mesophilic bacteria counts of $1.02 \times 10^{5}$ $\mathrm{cfu} / \mathrm{g}$ as indicated in Table 1.Makwalla had the highest coliform count $68 \mathrm{MPN} / \mathrm{g}$ followed by Rinji $37 \mathrm{MPN} / \mathrm{g}$. Tsohuwar Kasuwa had the least coliform counts $8 \mathrm{MPN} / \mathrm{g}$, (Table 2). Result from table 1 shows variation in the microbial contents among the samples which suggest variation in their sources, poor handling procedures and contamination from the processing environment. High coliform count and their differences within sampling areas is an indication of poor microbiological quality of the product. Ndahi et al. (2013) reported microbial load to be a function of the handling personnel and the environment. The results indicated that the samples were contaminated with bacteria as the counts exceeded the minimum safety level $\left(10^{4} \mathrm{cfu} / \mathrm{g}\right)$ for members of the Enterobacteriaceae family. However, it might be a reflection of poor hygienic practices which may contribute to health hazard to the potential consumers. Similarly, Inusa and Sa'id (2017); Osimani et al. (2015) reported that, the initial microbial content of the raw material play significant role in influencing the final microbial load of the finished product. Isolation of members of the Enterobacteriaceae such as $E$. coli, Klebsiella pneumoniae, Salmonella and Shigella signifies danger to the public health. These organisms are capable of producing endotoxins which trigger high fevers in infected individuals, and the enterotoxins which colonize the small intestines and lead to extreme dehydration as a result of vomiting and diarrhea sometimes with severe and fatal outcomes (Amaeze et al., 2016). From the 16 isolated organisms $E$. coli had the highest isolation rate $6(37.5 \%)$ (Table 3), this suggest faecal contamination of the products. $E$. coli is a common flora in the gastrointestinal tract responsible for diarrhea and extra-intestinal infections (CDC, 2011). The result is in conformity with the findings of Ndahi et al. (2013) and Shamsuddeen (2009). Also presence of campylobacter might be due to cross contamination from raw meat to finished product (Tsire). Staphylococcus aureus is a normal flora of the skin, nasal, genital, mouth or anal area in both humans and animals without any symptom of an infection (Matthew et al., 2013). Isolation of $S$. aureus in these study concords with the findings of Lucretia et al. (2018) from Suya sold in Rivers State. 
BAJOPAS Volume 13 Number 1, June, 2020

It is also in agreement with the findings of Yousafzai et al. (2018); Onuorah et al. (2015) and Tijjani and Jumare (2014) from tsire samples in different countries. Presence of $S$. aureus in foods is most of the time an indication of poor human handling, poor environment, unhygienic utensils and equipments used during processing (Igene et al., 2016; Okonko et al., 2013). Infections caused by $S$. aureus are difficult to treat leading to long hospitalization with consequent economic loss (Udobi et al., 2013). These include soft tissue infections, pneumonia, hospital-acquired postoperative wound infections, Staphylococcal food poisoning, impetigo and cellulitis (Charlene et al., 2013). Samples obtained from Dausai and Kofar Kudu had the highest isolation rate $4(80 \%)$ (Table 4 ) probably because of the much commercial activities taking place in the area which can lead to environmental contamination.

Table 1: Total Aerobic Mesophilic Bacterial Count of Tsire sold in Garko Town

\begin{tabular}{lll}
\hline Sampling Area & APC cfu/g & Mean \pm STD \\
\hline Dausai & $2.20 \times 10^{5}$ & $110000 \pm 14142.14$ \\
Kofar Kudu & $4.00 \times 10^{5}$ & $133333.3 \pm 23094.01$ \\
Makwalla & $1.30 \times 10^{5}$ & $32500 \pm 7187.953$ \\
Rinji & $2.72 \times 10^{5}$ & $90666.67 \pm 94769.90$ \\
Tosaro & $1.02 \times 10^{5}$ & $51000 \pm 15556.35$ \\
Tsohuwar Kasuwa & $1.75 \times 10^{5}$ & $35000 \pm 11357.82$ \\
\hline
\end{tabular}

Key: APC: Aerobic Mesophilic Counts

STD: Standard Deviation

Table 2: Total Coliform Count of Tsire sold in Garko Town

\begin{tabular}{lcc}
\hline \multicolumn{1}{c}{ Sampling Area } & TCC MPN/g & Mean \pm STD \\
\hline Dausai & 20 & $6.67 \pm 2.5166$ \\
Kofar Kudu & 32 & $16.00 \pm 5.6569$ \\
Makwalla & 68 & $13.60 \pm 8.7062$ \\
Rinji & 37 & $9.25 \pm 4.7871$ \\
Tosaro & 10 & $5.00 \pm 2.8284$ \\
Tsohuwar Kasuwa & 8 & $4.00 \pm 0.0000$ \\
\hline
\end{tabular}

Table 3: Organisms Isolated from Tsire Sold in Garko

\begin{tabular}{lcl}
\hline Isolated Organism & Frequency & Percentage (\%) \\
\hline Campylobacter & 2 & 06.66 \\
Escherichia coli & 6 & 20.00 \\
Klebsiella pneumoniae & 2 & 06.66 \\
Salmonella species & 1 & 03.33 \\
Shigella & 3 & 10.00 \\
Staphylococcus aureus & 2 & 06.66 \\
Total & 16 & \\
\hline
\end{tabular}

Table 4: Distribution of Organisms within Sampling Area

\begin{tabular}{lcc}
\hline \multicolumn{1}{c}{ Sampling Area } & No. Isolated & Percentage (\%) \\
\hline Dausai & 4 & 80 \\
Kofar Kudu & 4 & 80 \\
Makwalla & 2 & 40 \\
Rinji & 3 & 60 \\
Tosaro & 2 & 40 \\
Tsohuwar Kasuwa & 1 & 20 \\
Total & 16 & \\
\hline
\end{tabular}

\section{CONCLUSION}

Results indicated $4.00 \times 10^{5} \mathrm{CFU} / \mathrm{g}$ as the highest APCs count; while $68 \mathrm{MPN} / \mathrm{g}$ was the highest TCCs from the 30 samples analyzed. Among the isolates, $E$. coli has the highest isolation rate of $6(20 \%)$. Dausai and Kofar kudu were having the highest bacteria count of $4(80 \%)$, each, indicating higher contamination in those locations. 
BAJOPAS Volume 13 Number 1, June, 2020 RECOMMENDATIONS

The following recommendations are tenable:

1. Hygienic practices at all stages of production should be improved to safe guard the consumers against potential health hazard.

2. Monitoring of microbiological contamination of Tsire during preparations, packaging and marketing is essential to ensure product of good microbiological quality for consumers' health.

\section{REFERENCES}

Abdullahi, I. O., Umoh, V. J. and Galadima, M. (2004). Hazards Associated with Kilishi Preparations in Zaria. Nigerian Journal of Microbiology, 18 (1-2): $339-345$.

Ahmadu, J. and Ibrahim E. J., (2013): Determinants of Revenue in Suya Production in BeninCity, Edo State, Nigeria. Nigerian journal of agriculture, food and environment.9(3):1-5

Amaeze, N. Aboh, M. Itohan, A. Felix, E. Olatunji, T. and Oladosu, P. (2016) Microbial Profile, Antibiotic Sensitivity and Heat Resistance of Bacterial Isolates from Commercial Roasted Beef (Suya) in Abuja, Nigeria. JOPAT, 15(2): $22-30$.

Apata, E.S., Kuku1, I.A., Apata, O.C. and Adeyemi, K.O. (2013). Evaluation of Suya(Tsire) - An Intermediate Moisture Meat Product in Ogun State, Nigeria. J. Food Res 2 (1): 87.

Atlas, R. M. (1997) Principles of Microbiology Second Edition. C. Brown Publishers. Pp 802-803.

Borch, E. Kant-Muermans, M. L., Blixt, Y. (1996) Bacterial Spoilage of Meat and Cured Meat Products. Int $\mathrm{J}$ Food Microbiol .33(1): 103-20.

Centre for Disease Control, CDC (2011). "Escherichia coli 0157:H7" Division of Bacterial and Mycotic Diseasesht://www.cdc.gov/nczved/divisi ons/dfbmd/diseases/ecoli_0157h7/.

Charlene, R. J., Johnnie, A. D., and John, B. B., (2013) Prevalence and Characterization of Methicillin-Resistant Staphylococcus aureus Isolates from Retail Meat and Humans in Georgia. American society for Microbiology. J. of clinical microbiology. 12(1):123-6 doi:10.1128/JCM.0316612JCM.03166-12

Egbebi, A.O and Seidu, K., T. (2011). Microbiological Evaluation of Suya (dried smoked

meat) Sold in Ado and Akure, South West Nigeria.European Journal of Experinmental Biology, 1(4):1-5
3. Government should establish regulatory bodies responsible for inculcating hygiene habits to the local producers and vendors in order to prevent instant, cross and post processing contaminations by microbial pathogens.

4. Awareness and sensitization of local food producers about good hygienic practices in food handling and processing.

Falegan, C, R., Akoja, S. D., and Oyarekua, M. A., (2017) Microbiological Assessment of Suya (Sliced Roasted Beef) in Ado-Ekiti Metropolis, Ekiti State, Nigeria. MOJ Biology andMedicine.

Fonkem, D., N. Tanya, V., N. and Ebangi, A., L. (2010). Effect of Season on the Microbiological Quality of Kilishi, a Traditional Cameroonian Dried Beef Product. Tropicultura, 28(1): 10-15.

Food and Agricultural Organization of the United Nations (F A O, 1979). Manual of food quality control 4. Microbiological analysis.

Food and Agriculture Organisation of the United Nation (FAO), 2019. Nigeria at a glance.

Igene J.O., Uwadia, O.E., Ebabhamiegbebho, P.A. and Evivie, S.E., (2016) Shelf life Stability Studies of University of Benin (UNIBEN) Proff's Kilishi Product Asian Journal of Science and Technology 7(1): 2268-2274.

Inusa, S. K. and Said, I. S. (2017) Evaluation of the Chemical and Microbiological Properties Of Kilishi Sold in Kano Metropolis. Journal of Dry land Agriculture, 3 (1): $59-69$.

Lucretia, I. B, Patience, C. Obinna-Echem, Sophia, C. A. (2018) Microbiological quality andantibiotic sensitivity of potential pathogens isolated from meat product (Suya) sold in Rivers State University and its environs. International Journal of Biotechnology and Food Science, 6(4): 67-76.

Matthew, E., Drosos, E., John, L. and Ioanna, P. (2013) MRSA in Africa: Filling the Global Map of Antimicrobial Resistance PLOS One. 8(7): e68024 doi: 10.1371/journal.pone.0068024

Mgbemere, V.N., Akpapunam, M. A. and Igene, J. O., (2011). Effect of Groundnut FlourSubstitution on Yield, Quality and Storage Stability of Kilishi - a Nigerian Indigenous Dried Meat Product. African Journal of Food, Agriculture, Nutrition and Development, $\quad \mathbf{1 1}(2)$ : 4718-4738. 
BAJOPAS Volume 13 Number 1, June, 2020

Mubarak, A. A., Azeez, M. L., Amos A. O., Opeyemi, O. O. (2016) Assessment of Animal Protein Consumption and Food Security Among Rural Households in Kwara State, Nigeria American Journal of Business and Society, 1(4): 233245.

Ndahi, M., D. Kwaga, J., K. P. Bello, M. Kabir J., V. Umoh, .J. Yakubu, S., E. and Nok, A., J. (2013) Prevalence and Antimicrobial Susceptibility of Listeria Monocytogenes and Methicillin-Resistant Staphylococcus aureus Strains from Raw Meat and Meat Products in Zaria, Nigeria. Applied Journal of Microbiology, 58(3):262-9.

Okonko, I.O., Odu, N.N. and Igboh, I.E. (2013). Microbiological Analysis of Kilishi Sold In Port Harcourt, Nigeria. New York Science Journal, 6 (7):37-43.

Osimani, A., Aquilanti, L. and Clementi, F. (2015) Microbiological Quality of Meatbased Meals and Operation of Control Systems within a Food Service Environment. International Food Research Journal 22(4): 1692-1698.

Onuorah, S. Obika, I. Odibo, F. Orji, M. (2015)An Assessment of the Bacteriological Quality of Tsire-Suya (Grilled Beef) sold in Awka, Nigeria. American. J. Life. Sci. Res. 3(4):287292.

Razavilar, V, Khandaghi, J. Barzgari, A. (2010); Isolation of Eschericia coli 0157:H7 from manure fertilized farms and raw vegetables grown on it, in Tabriz city in
Iran. African Journal of Microbiology Research, 4(9): 891-895.

Scallan, E. Hoekstra, R. M. Angulo, F. J.Tauxe, R. V, Widdowson, M. Roy, S. L et al., (2011).Food borne illness acquired in the United States- Major Pathogens. Emerg. Infec Dis, 17(1): 7-15.

Shamsuddeen U (2009). Microbiological quality of spice used in the production of Kilishi a traditionally dried and grilled meat product. Bayero Journal of Pure andApplied Sciences, 2(2): 66-69.

Shamsuddeen, U. (2015) Microbiological Hazard and Critical control point Analysis of Dried and Minced Meat Snacks Produced in Kano Nigeria. Lambert Academic Publishing; Pp 1-36.

Tijani, O.and Jumare, S. (2014). Microblological Quality Assessment of Meat

Sold in KauraNamoda. International Conference on Earth, Environment and Life sciences (EELS) Dubai (UAE).

Udobi, C. E., Obajuluwa, A. F., and Onaolapo, J. A., (2013) Prevalence and Antibiotic Resistance Pattern of MethicillinResistant Staphylococcus aureus from an Orthopaedic Hospital in Nigeria BioMed Research International; 26(6); 6-7.

WHO, 2015 Foodborne diseases in the WHO African Region.

Yousafzai HA, Rind R, Khan MA, Abro SH, Korejo NA, Ejaz M, Kabir A, Shahid M, Memon S. (2019). Microbiological Contamination of Cattle and Meat in Peshawar, Pakistan. J. Anim. Health Prod. 7(1): 1116. 


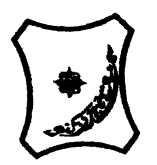

Bayero Journal of Pure and Applied Sciences, 13(1); 40 - 45

Received: September, 2019

Accepted: April, 2020

ISSN $2006-6996$

\title{
BACTERIOLOGICAL QUALITY OF STICK MEAT (Tsire) SOLD IN GARKO LOCAL GOVERNMENT AREA OF KANO STATE, NIGERIA
}

\author{
$*^{1}$ Dahiru A. T. and ${ }^{2}$ Maigari A. K. \\ ${ }^{1}$ Department of Hospitality Management, School of Technology, Kano State Polytechnic, PMB 3348, \\ Kano Nigeria. \\ ${ }^{2}$ Departmnt of Biological Sciences, Bayero University, Kano \\ Corresponding Author: dturajo61@gmail.com; GSM: 08087508262.
}

ABSTRACT

Stick meat, locally called Tsire in Hausa Language, is a significant portion of the diet of a large active population of Northern Nigeria. However, because of the handling and processing methods by the manufacturers as well as the hawking system of stick meat, the meat product may be exposed to both pre- and post-processed product contamination, and thus may poses danger to public health. Therefore, considering the role of Tsire in improving nutrition and increase household income to the populace, the need to improve the processing, distribution and overall quality of the product is simply indispensable. A total of 30 samples (5 samples from each of the 6 sampling points) of Tsire were collected randomly in Garko Town. Aerobic plate counts (APCs) and Total coliform counts (TCCS) of Tsire samples were determined using standard microbiological methods. APCs ranged from $1.02 \times 10^{5}$ to $4.00 \times 10^{5} \mathrm{CFU} / \mathrm{g}$; while TCCs ranged from $8 \mathrm{MPN} / \mathrm{g}$ to $68 \mathrm{MPN} / \mathrm{g}$. From the 30 samples screened, 16(53.33\%) bacteria namely, Campylobacter 2(6.66\%), Escherichia coli 6(20\%), Klebsiella pneumoniae 2(6.66\%), Salmonella spp. 1(3.33\%), Shigella 3(10\%) and Staphylococcus aureus 2(6.66\%) were detected. $E$. coli has the highest isolation rate of 6(20\%), while Salmonella spp. had the least frequency of 1(3.33\%). The distribution of isolated organisms within the study area were as follows: Dausai, 4(80\%), Kofar kudu, 4(80\%), Makwalla, 2(40\%), Rinji, 3(60\%), Tosaro, 2(40\%), and Tsohuwar Kasuwa, 1(20\%). The results have indicated that the Tsire was contaminated with bacteria thus exposing the product to fast deterioration, spoilage and also a vehicle for food borne illness, suggesting for adequate hygienic practices at all the stages, prior to consumption, to ensure safety of the meat product.

Key words: APCs, TCCs, Contamination, Microorganisms, Garko

\section{INTRODUCTION}

Nigeria is one of the developing nations with inadequate food supply and most often deficient in protein content (FAO, 2019). Nigerian's average animal protein intake per head per day is estimated at $7.9 \mathrm{~g}$ as against $35 \mathrm{~g}$ recommended value by Food and Agricultural Organization (Mubarak et al., 2016). These low levels of animal protein intake create great concern as it affects the nutritional status of Nigerians. Hence, there is the need for sufficient supply of animal protein from energy rich animal products to satisfy the nutritional requirements for Nigerians.

Meat is one major source of animal protein largely composed of water, protein and fats which can make it susceptible to microbial contamination within short time leading to spoilage (Apata et al., 2013; Mgbemere et al., 2011). Meat is mostly eaten after it has been cooked or processed in a variety of ways such as sun drying; smoking and roasting with or without fortifications (Borch et al., 1996). In Nigeria meat products such as Tsire, Kilishi and Balangu are locally produced using one or more of these methods in order to meet the nutritional requirements of the teeming Nigerians (Egbebi, 2011).

Tsire is a popular Nigerian traditional processed ready-to-eat roasted stick meat product (Shamsuddeen, 2015). It is sold in public places, along roads, in hotels, parks, quarters and even offices (Falegan et al., 2017). It is prepared from boneless healthy animal flesh such as beef and mutton, spiced with peanut cake, salt, vegetable oil and other flavorings followed by roasting (Shamsuddeen, 2015). Consumption of these products has extended to other parts of African countries such as Ghana, Somali, Cameroun and Chad (Ahmadu and Ibrahim, 2013). 
BAJOPAS Volume 13 Number 1, June, 2020

However, evidence of quality control sticking to procedural hygiene by the handlers during preparation and retailing of these products is poorly documented. Tsire is of great safety risk because of the fact that there are erratic cases of gastroenteritis and symptoms of food infection after consumption (WHO, 2015). Food borne illnesses are one of the major health problems in developing and developed countries (Razavilar, 2010). According to the World Health Organization, WHO (2015), $0.07 \%$ death of the 600 million global burdens of Foodborne illnesses have been reported to be caused by bacteria, viruses, fungi and chemicals. In America $0.27 \%$ of the estimated 48 million affected people is hospitalized and about $0.0063 \%$ deaths are recorded each year (Scallan et al., 2011). More than 91 million people in Africa fall ill and $0.15 \%$ dies each year, making Africa the highest burden bearer of Foodborne diseases per population (WHO, 2015).

Application of a Hazard Analysis Critical Control Point (HACCP) at all stages of meat products preparation is essential in order to ensure its safety. Thus, according to the guidelines of good manufacturing practice, the level of total aerobic bacterial contamination of thermally processed meat products should not exceed $10^{4}\left(\mathrm{cfu} \mathrm{g}^{-1}\right)$. Enterobacteriaceae and faecal coliform contamination in meat products should be within the range of $10^{2}-10^{4}$ and $10-10^{3} \mathrm{cfu} \mathrm{g}^{-1}$, respectively (Shamsuddeen, 2015). The aim of the study is therefore, to assess the total viable bacterial counts of tsire marketed locally within Garko town, and to isolate and identify the organisms at the point of consumption with the intention of promoting public health and food hygiene habits in the Nigerian populace.

\section{MATERIALS AND METHODS Study Area and Population}

Garko is one of the existing 44 local government areas located in Kano south west zone of Kano state with its capital administrative headquarters in the Garko town. It has coordinates $11^{\circ} 39^{\prime} \mathrm{N}$ $8^{\circ} 54^{\prime} \mathrm{E}$, and an area of $450 \mathrm{~km}^{2}$. The projected population of Garko local Government was 225,300 according to the National Population Census report (2018). Garko is known for agricultural activities both farming and animal husbandry. It is popularly known for large scale rice production. Other food crops include sweet potatoes, cassava, onions, sorghum, millet and sugarcane. Cows, sheep and goats are major groups of animals reared by majority of the populace. Meat products processed, retailed and consumed in Garko include roasted meat (Balangu), dried roasted meat (Kilishi), stick meat (Tsire), hide and skin pepper soup (Ragadada) and minced fried meat (Danbunnama).

\section{Samples Collection}

Five samples of Tsire products were collected from 6 different identified locations within Garko town in a sterile foil paper and immediately analyzed for the presence of bacteria.

\section{Sample Preparation}

Sample preparation for the bacteriological analysis was carried out in accordance with the method described by Atlas (1997). Twenty five grams $(25 \mathrm{~g})$ of the sample was homogenized in $225 \mathrm{ml}$ peptone water using Kenwood blender machine to obtain a $10^{1}$ homogenate. The homogenate was thoroughly shaken and $1 \mathrm{ml}$ pipetted into test tubes containing $9 \mathrm{ml}$ of peptone water $\left(10^{2}\right)$. The test tubes were further serially diluted to $10^{5}$.

Total Aerobic Mesophilic Bacterial Count

Total Aerobic mesophilic bacterial count was determined using the method described by Abdullahi et al. (2004) where $1 \mathrm{ml}$ of inoculums from $10^{1}$ to $10^{5}$ dilutions were transferred into duplicate Petri dishes and labeled accordingly. This was followed by pouring aseptically about $15 \mathrm{ml}$ of molten nutrient agar. The culture was homogenized by gentle spinning of the plates and allowed to solidify. The plates were incubated at $37^{\circ} \mathrm{C}$ for 24 hours. Plates containing 30-300 colonies were counted. The number of colony forming units per gram of a sample (cfu/g) was obtained by multiplying the average colony number with the inverse of the dilution factor.

\section{Enumeration and Detection of Coliform bacteria}

Detection and enumeration of coliform was carried out according to method described by Atlas, (1977). A set of 9 test tubes each containing $9 \mathrm{ml}$ of lactose broth and an inverted Durham tubes were autoclaved to expel air and to sterilize. Similarly, $1 \mathrm{ml}$ from the diluents $10^{1}$ was transferred to the first 3 test tubes, followed by $1 \mathrm{ml}$ from the diluents $10^{2}$ to the second set of 3 test tubes and finally the third diluents $10^{3}$ to the $3^{\text {rd }}$ set of 3 test tubes. All the 9 test tubes were incubated at $37^{\circ} \mathrm{C}$ for 24 hours. Tubes that showed gas and acid production after 24 hours were recorded as positive for the presence of Coliform. Negative tubes were further reincubated for 24 hours. Positive tubes were recorded. Estimate of most probable number of Coliform per gram of sample (MPN/g) was determined by comparing the number of gas positive tubes with the most probable number table. 
BAJOPAS Volume 13 Number 1, June, 2020 Identification of Coliform

A loop full of inoculum from gas positive tubes was streaked on to Eosine methylene blue (EMB) agar plate and incubated at $37^{\circ} \mathrm{C}$ for $24 \mathrm{hrs}$. Colonies which formed bluish black color with green metallic sheen, and reddish colonies were isolated on agar slants. Those colonies showing metallic sheen on EMB were sub cultured into tubes of lactose broth and incubated at $45^{\circ} \mathrm{C}$. The tubes were observed after $24 \mathrm{hrs}$ for gas production. This is the completed test for fecal coliform. Gram stain and other biochemical tests such as Indole, Methyl red, Voges-Proskauer and Citrate Utilization tests (IMVIC), Coagulase and Catalase tests were carried out for the Identification and confirmation of isolates.

\section{Procedure for Indole Test}

Indole test was carried out by preparing a Tryptone broth drawn in to test tubes, sterilized by autoclaving, inoculated with loopful of suspension and incubated at $37^{\circ} \mathrm{C}$ for 24 hours. Three drops of xylene was added in tubes, shaken vigorously and kept for the separation of two layers. One millilitre of Kovac's reagent was added and the formation of pink colour ring indicates positive Indole test.

\section{Procedure for Methyl Red Test}

Methyl red test was carried out by preparing Glucose phosphate broth, dispensed in test tubes, sterilized, inoculated with test culture and incubated at $37^{\circ} \mathrm{C}$ for 24 hours. Five drops of methyl-red indicator was added to the medium for the formation of red colour.

\section{Procedure for Voges-Proskauer Test}

Voges-Proskauer test was carried out by inoculating tubes with the bacterial culture followed by incubation for 48 hours at $37^{\circ} \mathrm{C}$. Separate pipettes were used to pipette $1 \mathrm{ml}$ from each culture tube into clean separate tubes. Eighteen drops $(0.5 \mathrm{ml})$ of Barrit's solution A (a-naphthol) was added to each tube containing glucose phosphate broth followed by the addition of an equal amount of solution $B$ into the same tube. The tubes were shaken at 30 seconds interval. A positive reaction was indicated by the development of a pink color, which turns red in 1-2 hours, after vigorous shaking.

\section{Procedure for Citrate Utilization Test}

Citrate Utilization Test was carried out by distributing melted agar (Simmon Citrate Agar) in to test tubes followed by sterilization at $121.5^{\circ} \mathrm{C}$ for 15 minutes. The test tubes were afterward held in slanted position, inoculated with the given bacterial culture and incubated at $37^{\circ} \mathrm{C}$ for $24 \mathrm{hrs}$. Positive test was indicated by color change of the media from green to blue.

\section{RESULTS AND DISCUSSIONS}

The results of this study are presented in tables $1,2,3$ and 4. Among the sampling areas Kofar Kudu had the highest aerobic mesophilic bacteria counts $4.0 \times 10^{5} \mathrm{cfu} / \mathrm{g}$ followed by Rinji $2.72 \times 10^{5} \mathrm{cfu} / \mathrm{g}$, while Tosaro had the least Aerobic mesophilic bacteria counts of $1.02 \times 10^{5}$ $\mathrm{cfu} / \mathrm{g}$ as indicated in Table 1.Makwalla had the highest coliform count $68 \mathrm{MPN} / \mathrm{g}$ followed by Rinji $37 \mathrm{MPN} / \mathrm{g}$. Tsohuwar Kasuwa had the least coliform counts $8 \mathrm{MPN} / \mathrm{g}$, (Table 2). Result from table 1 shows variation in the microbial contents among the samples which suggest variation in their sources, poor handling procedures and contamination from the processing environment. High coliform count and their differences within sampling areas is an indication of poor microbiological quality of the product. Ndahi et al. (2013) reported microbial load to be a function of the handling personnel and the environment. The results indicated that the samples were contaminated with bacteria as the counts exceeded the minimum safety level $\left(10^{4} \mathrm{cfu} / \mathrm{g}\right)$ for members of the Enterobacteriaceae family. However, it might be a reflection of poor hygienic practices which may contribute to health hazard to the potential consumers. Similarly, Inusa and Sa'id (2017); Osimani et al. (2015) reported that, the initial microbial content of the raw material play significant role in influencing the final microbial load of the finished product. Isolation of members of the Enterobacteriaceae such as $E$. coli, Klebsiella pneumoniae, Salmonella and Shigella signifies danger to the public health. These organisms are capable of producing endotoxins which trigger high fevers in infected individuals, and the enterotoxins which colonize the small intestines and lead to extreme dehydration as a result of vomiting and diarrhea sometimes with severe and fatal outcomes (Amaeze et al., 2016). From the 16 isolated organisms $E$. coli had the highest isolation rate $6(37.5 \%)$ (Table 3), this suggest faecal contamination of the products. $E$. coli is a common flora in the gastrointestinal tract responsible for diarrhea and extra-intestinal infections (CDC, 2011). The result is in conformity with the findings of Ndahi et al. (2013) and Shamsuddeen (2009). Also presence of campylobacter might be due to cross contamination from raw meat to finished product (Tsire). Staphylococcus aureus is a normal flora of the skin, nasal, genital, mouth or anal area in both humans and animals without any symptom of an infection (Matthew et al., 2013). Isolation of $S$. aureus in these study concords with the findings of Lucretia et al. (2018) from Suya sold in Rivers State. 
BAJOPAS Volume 13 Number 1, June, 2020

It is also in agreement with the findings of Yousafzai et al. (2018); Onuorah et al. (2015) and Tijjani and Jumare (2014) from tsire samples in different countries. Presence of $S$. aureus in foods is most of the time an indication of poor human handling, poor environment, unhygienic utensils and equipments used during processing (Igene et al., 2016; Okonko et al., 2013). Infections caused by $S$. aureus are difficult to treat leading to long hospitalization with consequent economic loss (Udobi et al., 2013). These include soft tissue infections, pneumonia, hospital-acquired postoperative wound infections, Staphylococcal food poisoning, impetigo and cellulitis (Charlene et al., 2013). Samples obtained from Dausai and Kofar Kudu had the highest isolation rate $4(80 \%)$ (Table 4 ) probably because of the much commercial activities taking place in the area which can lead to environmental contamination.

Table 1: Total Aerobic Mesophilic Bacterial Count of Tsire sold in Garko Town

\begin{tabular}{lll}
\hline Sampling Area & APC cfu/g & Mean \pm STD \\
\hline Dausai & $2.20 \times 10^{5}$ & $110000 \pm 14142.14$ \\
Kofar Kudu & $4.00 \times 10^{5}$ & $133333.3 \pm 23094.01$ \\
Makwalla & $1.30 \times 10^{5}$ & $32500 \pm 7187.953$ \\
Rinji & $2.72 \times 10^{5}$ & $90666.67 \pm 94769.90$ \\
Tosaro & $1.02 \times 10^{5}$ & $51000 \pm 15556.35$ \\
Tsohuwar Kasuwa & $1.75 \times 10^{5}$ & $35000 \pm 11357.82$ \\
\hline
\end{tabular}

Key: APC: Aerobic Mesophilic Counts

STD: Standard Deviation

Table 2: Total Coliform Count of Tsire sold in Garko Town

\begin{tabular}{lcc}
\hline \multicolumn{1}{c}{ Sampling Area } & TCC MPN/g & Mean \pm STD \\
\hline Dausai & 20 & $6.67 \pm 2.5166$ \\
Kofar Kudu & 32 & $16.00 \pm 5.6569$ \\
Makwalla & 68 & $13.60 \pm 8.7062$ \\
Rinji & 37 & $9.25 \pm 4.7871$ \\
Tosaro & 10 & $5.00 \pm 2.8284$ \\
Tsohuwar Kasuwa & 8 & $4.00 \pm 0.0000$ \\
\hline
\end{tabular}

Table 3: Organisms Isolated from Tsire Sold in Garko

\begin{tabular}{lcl}
\hline Isolated Organism & Frequency & Percentage (\%) \\
\hline Campylobacter & 2 & 06.66 \\
Escherichia coli & 6 & 20.00 \\
Klebsiella pneumoniae & 2 & 06.66 \\
Salmonella species & 1 & 03.33 \\
Shigella & 3 & 10.00 \\
Staphylococcus aureus & 2 & 06.66 \\
Total & 16 & \\
\hline
\end{tabular}

Table 4: Distribution of Organisms within Sampling Area

\begin{tabular}{lcc}
\hline \multicolumn{1}{c}{ Sampling Area } & No. Isolated & Percentage (\%) \\
\hline Dausai & 4 & 80 \\
Kofar Kudu & 4 & 80 \\
Makwalla & 2 & 40 \\
Rinji & 3 & 60 \\
Tosaro & 2 & 40 \\
Tsohuwar Kasuwa & 1 & 20 \\
Total & 16 & \\
\hline
\end{tabular}

\section{CONCLUSION}

Results indicated $4.00 \times 10^{5} \mathrm{CFU} / \mathrm{g}$ as the highest APCs count; while $68 \mathrm{MPN} / \mathrm{g}$ was the highest TCCs from the 30 samples analyzed. Among the isolates, $E$. coli has the highest isolation rate of $6(20 \%)$. Dausai and Kofar kudu were having the highest bacteria count of $4(80 \%)$, each, indicating higher contamination in those locations. 
BAJOPAS Volume 13 Number 1, June, 2020 RECOMMENDATIONS

The following recommendations are tenable:

1. Hygienic practices at all stages of production should be improved to safe guard the consumers against potential health hazard.

2. Monitoring of microbiological contamination of Tsire during preparations, packaging and marketing is essential to ensure product of good microbiological quality for consumers' health.

\section{REFERENCES}

Abdullahi, I. O., Umoh, V. J. and Galadima, M. (2004). Hazards Associated with Kilishi Preparations in Zaria. Nigerian Journal of Microbiology, 18 (1-2): $339-345$.

Ahmadu, J. and Ibrahim E. J., (2013): Determinants of Revenue in Suya Production in BeninCity, Edo State, Nigeria. Nigerian journal of agriculture, food and environment.9(3):1-5

Amaeze, N. Aboh, M. Itohan, A. Felix, E. Olatunji, T. and Oladosu, P. (2016) Microbial Profile, Antibiotic Sensitivity and Heat Resistance of Bacterial Isolates from Commercial Roasted Beef (Suya) in Abuja, Nigeria. JOPAT, 15(2): $22-30$.

Apata, E.S., Kuku1, I.A., Apata, O.C. and Adeyemi, K.O. (2013). Evaluation of Suya(Tsire) - An Intermediate Moisture Meat Product in Ogun State, Nigeria. J. Food Res 2 (1): 87.

Atlas, R. M. (1997) Principles of Microbiology Second Edition. C. Brown Publishers. Pp 802-803.

Borch, E. Kant-Muermans, M. L., Blixt, Y. (1996) Bacterial Spoilage of Meat and Cured Meat Products. Int $\mathrm{J}$ Food Microbiol .33(1): 103-20.

Centre for Disease Control, CDC (2011). "Escherichia coli 0157:H7" Division of Bacterial and Mycotic Diseasesht://www.cdc.gov/nczved/divisi ons/dfbmd/diseases/ecoli_0157h7/.

Charlene, R. J., Johnnie, A. D., and John, B. B., (2013) Prevalence and Characterization of Methicillin-Resistant Staphylococcus aureus Isolates from Retail Meat and Humans in Georgia. American society for Microbiology. J. of clinical microbiology. 12(1):123-6 doi:10.1128/JCM.0316612JCM.03166-12

Egbebi, A.O and Seidu, K., T. (2011). Microbiological Evaluation of Suya (dried smoked

meat) Sold in Ado and Akure, South West Nigeria.European Journal of Experinmental Biology, 1(4):1-5
3. Government should establish regulatory bodies responsible for inculcating hygiene habits to the local producers and vendors in order to prevent instant, cross and post processing contaminations by microbial pathogens.

4. Awareness and sensitization of local food producers about good hygienic practices in food handling and processing.

Falegan, C, R., Akoja, S. D., and Oyarekua, M. A., (2017) Microbiological Assessment of Suya (Sliced Roasted Beef) in Ado-Ekiti Metropolis, Ekiti State, Nigeria. MOJ Biology andMedicine.

Fonkem, D., N. Tanya, V., N. and Ebangi, A., L. (2010). Effect of Season on the Microbiological Quality of Kilishi, a Traditional Cameroonian Dried Beef Product. Tropicultura, 28(1): 10-15.

Food and Agricultural Organization of the United Nations (F A O, 1979). Manual of food quality control 4. Microbiological analysis.

Food and Agriculture Organisation of the United Nation (FAO), 2019. Nigeria at a glance.

Igene J.O., Uwadia, O.E., Ebabhamiegbebho, P.A. and Evivie, S.E., (2016) Shelf life Stability Studies of University of Benin (UNIBEN) Proff's Kilishi Product Asian Journal of Science and Technology 7(1): 2268-2274.

Inusa, S. K. and Said, I. S. (2017) Evaluation of the Chemical and Microbiological Properties Of Kilishi Sold in Kano Metropolis. Journal of Dry land Agriculture, 3 (1): $59-69$.

Lucretia, I. B, Patience, C. Obinna-Echem, Sophia, C. A. (2018) Microbiological quality andantibiotic sensitivity of potential pathogens isolated from meat product (Suya) sold in Rivers State University and its environs. International Journal of Biotechnology and Food Science, 6(4): 67-76.

Matthew, E., Drosos, E., John, L. and Ioanna, P. (2013) MRSA in Africa: Filling the Global Map of Antimicrobial Resistance PLOS One. 8(7): e68024 doi: 10.1371/journal.pone.0068024

Mgbemere, V.N., Akpapunam, M. A. and Igene, J. O., (2011). Effect of Groundnut FlourSubstitution on Yield, Quality and Storage Stability of Kilishi - a Nigerian Indigenous Dried Meat Product. African Journal of Food, Agriculture, Nutrition and Development, $\quad \mathbf{1 1}(2)$ : 4718-4738. 
BAJOPAS Volume 13 Number 1, June, 2020

Mubarak, A. A., Azeez, M. L., Amos A. O., Opeyemi, O. O. (2016) Assessment of Animal Protein Consumption and Food Security Among Rural Households in Kwara State, Nigeria American Journal of Business and Society, 1(4): 233245.

Ndahi, M., D. Kwaga, J., K. P. Bello, M. Kabir J., V. Umoh, .J. Yakubu, S., E. and Nok, A., J. (2013) Prevalence and Antimicrobial Susceptibility of Listeria Monocytogenes and Methicillin-Resistant Staphylococcus aureus Strains from Raw Meat and Meat Products in Zaria, Nigeria. Applied Journal of Microbiology, 58(3):262-9.

Okonko, I.O., Odu, N.N. and Igboh, I.E. (2013). Microbiological Analysis of Kilishi Sold In Port Harcourt, Nigeria. New York Science Journal, 6 (7):37-43.

Osimani, A., Aquilanti, L. and Clementi, F. (2015) Microbiological Quality of Meatbased Meals and Operation of Control Systems within a Food Service Environment. International Food Research Journal 22(4): 1692-1698.

Onuorah, S. Obika, I. Odibo, F. Orji, M. (2015)An Assessment of the Bacteriological Quality of Tsire-Suya (Grilled Beef) sold in Awka, Nigeria. American. J. Life. Sci. Res. 3(4):287292.

Razavilar, V, Khandaghi, J. Barzgari, A. (2010); Isolation of Eschericia coli 0157:H7 from manure fertilized farms and raw vegetables grown on it, in Tabriz city in
Iran. African Journal of Microbiology Research, 4(9): 891-895.

Scallan, E. Hoekstra, R. M. Angulo, F. J.Tauxe, R. V, Widdowson, M. Roy, S. L et al., (2011).Food borne illness acquired in the United States- Major Pathogens. Emerg. Infec Dis, 17(1): 7-15.

Shamsuddeen U (2009). Microbiological quality of spice used in the production of Kilishi a traditionally dried and grilled meat product. Bayero Journal of Pure andApplied Sciences, 2(2): 66-69.

Shamsuddeen, U. (2015) Microbiological Hazard and Critical control point Analysis of Dried and Minced Meat Snacks Produced in Kano Nigeria. Lambert Academic Publishing; Pp 1-36.

Tijani, O.and Jumare, S. (2014). Microblological Quality Assessment of Meat

Sold in KauraNamoda. International Conference on Earth, Environment and Life sciences (EELS) Dubai (UAE).

Udobi, C. E., Obajuluwa, A. F., and Onaolapo, J. A., (2013) Prevalence and Antibiotic Resistance Pattern of MethicillinResistant Staphylococcus aureus from an Orthopaedic Hospital in Nigeria BioMed Research International; 26(6); 6-7.

WHO, 2015 Foodborne diseases in the WHO African Region.

Yousafzai HA, Rind R, Khan MA, Abro SH, Korejo NA, Ejaz M, Kabir A, Shahid M, Memon S. (2019). Microbiological Contamination of Cattle and Meat in Peshawar, Pakistan. J. Anim. Health Prod. 7(1): 1116. 


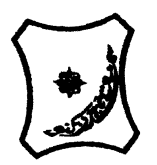

Bayero Journal of Pure and Applied Sciences, 13(1); 40 - 45

Received: September, 2019

Accepted: April, 2020

ISSN $2006-6996$

\title{
BACTERIOLOGICAL QUALITY OF STICK MEAT (Tsire) SOLD IN GARKO LOCAL GOVERNMENT AREA OF KANO STATE, NIGERIA
}

\author{
$*^{1}$ Dahiru A. T. and ${ }^{2}$ Maigari A. K. \\ ${ }^{1}$ Department of Hospitality Management, School of Technology, Kano State Polytechnic, PMB 3348, \\ Kano Nigeria. \\ ${ }^{2}$ Departmnt of Biological Sciences, Bayero University, Kano \\ Corresponding Author: dturajo61@gmail.com; GSM: 08087508262.
}

ABSTRACT

Stick meat, locally called Tsire in Hausa Language, is a significant portion of the diet of a large active population of Northern Nigeria. However, because of the handling and processing methods by the manufacturers as well as the hawking system of stick meat, the meat product may be exposed to both pre- and post-processed product contamination, and thus may poses danger to public health. Therefore, considering the role of Tsire in improving nutrition and increase household income to the populace, the need to improve the processing, distribution and overall quality of the product is simply indispensable. A total of 30 samples (5 samples from each of the 6 sampling points) of Tsire were collected randomly in Garko Town. Aerobic plate counts (APCs) and Total coliform counts (TCCS) of Tsire samples were determined using standard microbiological methods. APCs ranged from $1.02 \times 10^{5}$ to $4.00 \times 10^{5} \mathrm{CFU} / \mathrm{g}$; while TCCs ranged from $8 \mathrm{MPN} / \mathrm{g}$ to $68 \mathrm{MPN} / \mathrm{g}$. From the 30 samples screened, 16(53.33\%) bacteria namely, Campylobacter 2(6.66\%), Escherichia coli 6(20\%), Klebsiella pneumoniae 2(6.66\%), Salmonella spp. 1(3.33\%), Shigella 3(10\%) and Staphylococcus aureus 2(6.66\%) were detected. $E$. coli has the highest isolation rate of 6(20\%), while Salmonella spp. had the least frequency of 1(3.33\%). The distribution of isolated organisms within the study area were as follows: Dausai, 4(80\%), Kofar kudu, 4(80\%), Makwalla, 2(40\%), Rinji, 3(60\%), Tosaro, 2(40\%), and Tsohuwar Kasuwa, 1(20\%). The results have indicated that the Tsire was contaminated with bacteria thus exposing the product to fast deterioration, spoilage and also a vehicle for food borne illness, suggesting for adequate hygienic practices at all the stages, prior to consumption, to ensure safety of the meat product.

Key words: APCs, TCCs, Contamination, Microorganisms, Garko

\section{INTRODUCTION}

Nigeria is one of the developing nations with inadequate food supply and most often deficient in protein content (FAO, 2019). Nigerian's average animal protein intake per head per day is estimated at $7.9 \mathrm{~g}$ as against $35 \mathrm{~g}$ recommended value by Food and Agricultural Organization (Mubarak et al., 2016). These low levels of animal protein intake create great concern as it affects the nutritional status of Nigerians. Hence, there is the need for sufficient supply of animal protein from energy rich animal products to satisfy the nutritional requirements for Nigerians.

Meat is one major source of animal protein largely composed of water, protein and fats which can make it susceptible to microbial contamination within short time leading to spoilage (Apata et al., 2013; Mgbemere et al., 2011). Meat is mostly eaten after it has been cooked or processed in a variety of ways such as sun drying; smoking and roasting with or without fortifications (Borch et al., 1996). In Nigeria meat products such as Tsire, Kilishi and Balangu are locally produced using one or more of these methods in order to meet the nutritional requirements of the teeming Nigerians (Egbebi, 2011).

Tsire is a popular Nigerian traditional processed ready-to-eat roasted stick meat product (Shamsuddeen, 2015). It is sold in public places, along roads, in hotels, parks, quarters and even offices (Falegan et al., 2017). It is prepared from boneless healthy animal flesh such as beef and mutton, spiced with peanut cake, salt, vegetable oil and other flavorings followed by roasting (Shamsuddeen, 2015). Consumption of these products has extended to other parts of African countries such as Ghana, Somali, Cameroun and Chad (Ahmadu and Ibrahim, 2013). 
BAJOPAS Volume 13 Number 1, June, 2020

However, evidence of quality control sticking to procedural hygiene by the handlers during preparation and retailing of these products is poorly documented. Tsire is of great safety risk because of the fact that there are erratic cases of gastroenteritis and symptoms of food infection after consumption (WHO, 2015). Food borne illnesses are one of the major health problems in developing and developed countries (Razavilar, 2010). According to the World Health Organization, WHO (2015), $0.07 \%$ death of the 600 million global burdens of Foodborne illnesses have been reported to be caused by bacteria, viruses, fungi and chemicals. In America $0.27 \%$ of the estimated 48 million affected people is hospitalized and about $0.0063 \%$ deaths are recorded each year (Scallan et al., 2011). More than 91 million people in Africa fall ill and $0.15 \%$ dies each year, making Africa the highest burden bearer of Foodborne diseases per population (WHO, 2015).

Application of a Hazard Analysis Critical Control Point (HACCP) at all stages of meat products preparation is essential in order to ensure its safety. Thus, according to the guidelines of good manufacturing practice, the level of total aerobic bacterial contamination of thermally processed meat products should not exceed $10^{4}\left(\mathrm{cfu} \mathrm{g}^{-1}\right)$. Enterobacteriaceae and faecal coliform contamination in meat products should be within the range of $10^{2}-10^{4}$ and $10-10^{3} \mathrm{cfu} \mathrm{g}^{-1}$, respectively (Shamsuddeen, 2015). The aim of the study is therefore, to assess the total viable bacterial counts of tsire marketed locally within Garko town, and to isolate and identify the organisms at the point of consumption with the intention of promoting public health and food hygiene habits in the Nigerian populace.

\section{MATERIALS AND METHODS Study Area and Population}

Garko is one of the existing 44 local government areas located in Kano south west zone of Kano state with its capital administrative headquarters in the Garko town. It has coordinates $11^{\circ} 39^{\prime} \mathrm{N}$ $8^{\circ} 54^{\prime} \mathrm{E}$, and an area of $450 \mathrm{~km}^{2}$. The projected population of Garko local Government was 225,300 according to the National Population Census report (2018). Garko is known for agricultural activities both farming and animal husbandry. It is popularly known for large scale rice production. Other food crops include sweet potatoes, cassava, onions, sorghum, millet and sugarcane. Cows, sheep and goats are major groups of animals reared by majority of the populace. Meat products processed, retailed and consumed in Garko include roasted meat (Balangu), dried roasted meat (Kilishi), stick meat (Tsire), hide and skin pepper soup (Ragadada) and minced fried meat (Danbunnama).

\section{Samples Collection}

Five samples of Tsire products were collected from 6 different identified locations within Garko town in a sterile foil paper and immediately analyzed for the presence of bacteria.

\section{Sample Preparation}

Sample preparation for the bacteriological analysis was carried out in accordance with the method described by Atlas (1997). Twenty five grams $(25 \mathrm{~g})$ of the sample was homogenized in $225 \mathrm{ml}$ peptone water using Kenwood blender machine to obtain a $10^{1}$ homogenate. The homogenate was thoroughly shaken and $1 \mathrm{ml}$ pipetted into test tubes containing $9 \mathrm{ml}$ of peptone water $\left(10^{2}\right)$. The test tubes were further serially diluted to $10^{5}$.

Total Aerobic Mesophilic Bacterial Count

Total Aerobic mesophilic bacterial count was determined using the method described by Abdullahi et al. (2004) where $1 \mathrm{ml}$ of inoculums from $10^{1}$ to $10^{5}$ dilutions were transferred into duplicate Petri dishes and labeled accordingly. This was followed by pouring aseptically about $15 \mathrm{ml}$ of molten nutrient agar. The culture was homogenized by gentle spinning of the plates and allowed to solidify. The plates were incubated at $37^{\circ} \mathrm{C}$ for 24 hours. Plates containing 30-300 colonies were counted. The number of colony forming units per gram of a sample (cfu/g) was obtained by multiplying the average colony number with the inverse of the dilution factor.

\section{Enumeration and Detection of Coliform bacteria}

Detection and enumeration of coliform was carried out according to method described by Atlas, (1977). A set of 9 test tubes each containing $9 \mathrm{ml}$ of lactose broth and an inverted Durham tubes were autoclaved to expel air and to sterilize. Similarly, $1 \mathrm{ml}$ from the diluents $10^{1}$ was transferred to the first 3 test tubes, followed by $1 \mathrm{ml}$ from the diluents $10^{2}$ to the second set of 3 test tubes and finally the third diluents $10^{3}$ to the $3^{\text {rd }}$ set of 3 test tubes. All the 9 test tubes were incubated at $37^{\circ} \mathrm{C}$ for 24 hours. Tubes that showed gas and acid production after 24 hours were recorded as positive for the presence of Coliform. Negative tubes were further reincubated for 24 hours. Positive tubes were recorded. Estimate of most probable number of Coliform per gram of sample (MPN/g) was determined by comparing the number of gas positive tubes with the most probable number table. 
BAJOPAS Volume 13 Number 1, June, 2020 Identification of Coliform

A loop full of inoculum from gas positive tubes was streaked on to Eosine methylene blue (EMB) agar plate and incubated at $37^{\circ} \mathrm{C}$ for $24 \mathrm{hrs}$. Colonies which formed bluish black color with green metallic sheen, and reddish colonies were isolated on agar slants. Those colonies showing metallic sheen on EMB were sub cultured into tubes of lactose broth and incubated at $45^{\circ} \mathrm{C}$. The tubes were observed after $24 \mathrm{hrs}$ for gas production. This is the completed test for fecal coliform. Gram stain and other biochemical tests such as Indole, Methyl red, Voges-Proskauer and Citrate Utilization tests (IMVIC), Coagulase and Catalase tests were carried out for the Identification and confirmation of isolates.

\section{Procedure for Indole Test}

Indole test was carried out by preparing a Tryptone broth drawn in to test tubes, sterilized by autoclaving, inoculated with loopful of suspension and incubated at $37^{\circ} \mathrm{C}$ for 24 hours. Three drops of xylene was added in tubes, shaken vigorously and kept for the separation of two layers. One millilitre of Kovac's reagent was added and the formation of pink colour ring indicates positive Indole test.

\section{Procedure for Methyl Red Test}

Methyl red test was carried out by preparing Glucose phosphate broth, dispensed in test tubes, sterilized, inoculated with test culture and incubated at $37^{\circ} \mathrm{C}$ for 24 hours. Five drops of methyl-red indicator was added to the medium for the formation of red colour.

\section{Procedure for Voges-Proskauer Test}

Voges-Proskauer test was carried out by inoculating tubes with the bacterial culture followed by incubation for 48 hours at $37^{\circ} \mathrm{C}$. Separate pipettes were used to pipette $1 \mathrm{ml}$ from each culture tube into clean separate tubes. Eighteen drops $(0.5 \mathrm{ml})$ of Barrit's solution A (a-naphthol) was added to each tube containing glucose phosphate broth followed by the addition of an equal amount of solution $B$ into the same tube. The tubes were shaken at 30 seconds interval. A positive reaction was indicated by the development of a pink color, which turns red in 1-2 hours, after vigorous shaking.

\section{Procedure for Citrate Utilization Test}

Citrate Utilization Test was carried out by distributing melted agar (Simmon Citrate Agar) in to test tubes followed by sterilization at $121.5^{\circ} \mathrm{C}$ for 15 minutes. The test tubes were afterward held in slanted position, inoculated with the given bacterial culture and incubated at $37^{\circ} \mathrm{C}$ for $24 \mathrm{hrs}$. Positive test was indicated by color change of the media from green to blue.

\section{RESULTS AND DISCUSSIONS}

The results of this study are presented in tables $1,2,3$ and 4. Among the sampling areas Kofar Kudu had the highest aerobic mesophilic bacteria counts $4.0 \times 10^{5} \mathrm{cfu} / \mathrm{g}$ followed by Rinji $2.72 \times 10^{5} \mathrm{cfu} / \mathrm{g}$, while Tosaro had the least Aerobic mesophilic bacteria counts of $1.02 \times 10^{5}$ $\mathrm{cfu} / \mathrm{g}$ as indicated in Table 1.Makwalla had the highest coliform count $68 \mathrm{MPN} / \mathrm{g}$ followed by Rinji $37 \mathrm{MPN} / \mathrm{g}$. Tsohuwar Kasuwa had the least coliform counts $8 \mathrm{MPN} / \mathrm{g}$, (Table 2). Result from table 1 shows variation in the microbial contents among the samples which suggest variation in their sources, poor handling procedures and contamination from the processing environment. High coliform count and their differences within sampling areas is an indication of poor microbiological quality of the product. Ndahi et al. (2013) reported microbial load to be a function of the handling personnel and the environment. The results indicated that the samples were contaminated with bacteria as the counts exceeded the minimum safety level $\left(10^{4} \mathrm{cfu} / \mathrm{g}\right)$ for members of the Enterobacteriaceae family. However, it might be a reflection of poor hygienic practices which may contribute to health hazard to the potential consumers. Similarly, Inusa and Sa'id (2017); Osimani et al. (2015) reported that, the initial microbial content of the raw material play significant role in influencing the final microbial load of the finished product. Isolation of members of the Enterobacteriaceae such as $E$. coli, Klebsiella pneumoniae, Salmonella and Shigella signifies danger to the public health. These organisms are capable of producing endotoxins which trigger high fevers in infected individuals, and the enterotoxins which colonize the small intestines and lead to extreme dehydration as a result of vomiting and diarrhea sometimes with severe and fatal outcomes (Amaeze et al., 2016). From the 16 isolated organisms $E$. coli had the highest isolation rate $6(37.5 \%)$ (Table 3), this suggest faecal contamination of the products. $E$. coli is a common flora in the gastrointestinal tract responsible for diarrhea and extra-intestinal infections (CDC, 2011). The result is in conformity with the findings of Ndahi et al. (2013) and Shamsuddeen (2009). Also presence of campylobacter might be due to cross contamination from raw meat to finished product (Tsire). Staphylococcus aureus is a normal flora of the skin, nasal, genital, mouth or anal area in both humans and animals without any symptom of an infection (Matthew et al., 2013). Isolation of $S$. aureus in these study concords with the findings of Lucretia et al. (2018) from Suya sold in Rivers State. 
BAJOPAS Volume 13 Number 1, June, 2020

It is also in agreement with the findings of Yousafzai et al. (2018); Onuorah et al. (2015) and Tijjani and Jumare (2014) from tsire samples in different countries. Presence of $S$. aureus in foods is most of the time an indication of poor human handling, poor environment, unhygienic utensils and equipments used during processing (Igene et al., 2016; Okonko et al., 2013). Infections caused by $S$. aureus are difficult to treat leading to long hospitalization with consequent economic loss (Udobi et al., 2013). These include soft tissue infections, pneumonia, hospital-acquired postoperative wound infections, Staphylococcal food poisoning, impetigo and cellulitis (Charlene et al., 2013). Samples obtained from Dausai and Kofar Kudu had the highest isolation rate $4(80 \%)$ (Table 4 ) probably because of the much commercial activities taking place in the area which can lead to environmental contamination.

Table 1: Total Aerobic Mesophilic Bacterial Count of Tsire sold in Garko Town

\begin{tabular}{lll}
\hline Sampling Area & APC cfu/g & Mean \pm STD \\
\hline Dausai & $2.20 \times 10^{5}$ & $110000 \pm 14142.14$ \\
Kofar Kudu & $4.00 \times 10^{5}$ & $133333.3 \pm 23094.01$ \\
Makwalla & $1.30 \times 10^{5}$ & $32500 \pm 7187.953$ \\
Rinji & $2.72 \times 10^{5}$ & $90666.67 \pm 94769.90$ \\
Tosaro & $1.02 \times 10^{5}$ & $51000 \pm 15556.35$ \\
Tsohuwar Kasuwa & $1.75 \times 10^{5}$ & $35000 \pm 11357.82$ \\
\hline
\end{tabular}

Key: APC: Aerobic Mesophilic Counts

STD: Standard Deviation

Table 2: Total Coliform Count of Tsire sold in Garko Town

\begin{tabular}{lcc}
\hline \multicolumn{1}{c}{ Sampling Area } & TCC MPN/g & Mean \pm STD \\
\hline Dausai & 20 & $6.67 \pm 2.5166$ \\
Kofar Kudu & 32 & $16.00 \pm 5.6569$ \\
Makwalla & 68 & $13.60 \pm 8.7062$ \\
Rinji & 37 & $9.25 \pm 4.7871$ \\
Tosaro & 10 & $5.00 \pm 2.8284$ \\
Tsohuwar Kasuwa & 8 & $4.00 \pm 0.0000$ \\
\hline
\end{tabular}

Table 3: Organisms Isolated from Tsire Sold in Garko

\begin{tabular}{lcl}
\hline Isolated Organism & Frequency & Percentage (\%) \\
\hline Campylobacter & 2 & 06.66 \\
Escherichia coli & 6 & 20.00 \\
Klebsiella pneumoniae & 2 & 06.66 \\
Salmonella species & 1 & 03.33 \\
Shigella & 3 & 10.00 \\
Staphylococcus aureus & 2 & 06.66 \\
Total & 16 & \\
\hline
\end{tabular}

Table 4: Distribution of Organisms within Sampling Area

\begin{tabular}{lcc}
\hline \multicolumn{1}{c}{ Sampling Area } & No. Isolated & Percentage (\%) \\
\hline Dausai & 4 & 80 \\
Kofar Kudu & 4 & 80 \\
Makwalla & 2 & 40 \\
Rinji & 3 & 60 \\
Tosaro & 2 & 40 \\
Tsohuwar Kasuwa & 1 & 20 \\
Total & 16 & \\
\hline
\end{tabular}

\section{CONCLUSION}

Results indicated $4.00 \times 10^{5} \mathrm{CFU} / \mathrm{g}$ as the highest APCs count; while $68 \mathrm{MPN} / \mathrm{g}$ was the highest TCCs from the 30 samples analyzed. Among the isolates, $E$. coli has the highest isolation rate of $6(20 \%)$. Dausai and Kofar kudu were having the highest bacteria count of $4(80 \%)$, each, indicating higher contamination in those locations. 
BAJOPAS Volume 13 Number 1, June, 2020 RECOMMENDATIONS

The following recommendations are tenable:

1. Hygienic practices at all stages of production should be improved to safe guard the consumers against potential health hazard.

2. Monitoring of microbiological contamination of Tsire during preparations, packaging and marketing is essential to ensure product of good microbiological quality for consumers' health.

\section{REFERENCES}

Abdullahi, I. O., Umoh, V. J. and Galadima, M. (2004). Hazards Associated with Kilishi Preparations in Zaria. Nigerian Journal of Microbiology, 18 (1-2): $339-345$.

Ahmadu, J. and Ibrahim E. J., (2013): Determinants of Revenue in Suya Production in BeninCity, Edo State, Nigeria. Nigerian journal of agriculture, food and environment.9(3):1-5

Amaeze, N. Aboh, M. Itohan, A. Felix, E. Olatunji, T. and Oladosu, P. (2016) Microbial Profile, Antibiotic Sensitivity and Heat Resistance of Bacterial Isolates from Commercial Roasted Beef (Suya) in Abuja, Nigeria. JOPAT, 15(2): $22-30$.

Apata, E.S., Kuku1, I.A., Apata, O.C. and Adeyemi, K.O. (2013). Evaluation of Suya(Tsire) - An Intermediate Moisture Meat Product in Ogun State, Nigeria. J. Food Res 2 (1): 87.

Atlas, R. M. (1997) Principles of Microbiology Second Edition. C. Brown Publishers. Pp 802-803.

Borch, E. Kant-Muermans, M. L., Blixt, Y. (1996) Bacterial Spoilage of Meat and Cured Meat Products. Int $\mathrm{J}$ Food Microbiol .33(1): 103-20.

Centre for Disease Control, CDC (2011). "Escherichia coli 0157:H7" Division of Bacterial and Mycotic Diseasesht://www.cdc.gov/nczved/divisi ons/dfbmd/diseases/ecoli_0157h7/.

Charlene, R. J., Johnnie, A. D., and John, B. B., (2013) Prevalence and Characterization of Methicillin-Resistant Staphylococcus aureus Isolates from Retail Meat and Humans in Georgia. American society for Microbiology. J. of clinical microbiology. 12(1):123-6 doi:10.1128/JCM.0316612JCM.03166-12

Egbebi, A.O and Seidu, K., T. (2011). Microbiological Evaluation of Suya (dried smoked

meat) Sold in Ado and Akure, South West Nigeria.European Journal of Experinmental Biology, 1(4):1-5
3. Government should establish regulatory bodies responsible for inculcating hygiene habits to the local producers and vendors in order to prevent instant, cross and post processing contaminations by microbial pathogens.

4. Awareness and sensitization of local food producers about good hygienic practices in food handling and processing.

Falegan, C, R., Akoja, S. D., and Oyarekua, M. A., (2017) Microbiological Assessment of Suya (Sliced Roasted Beef) in Ado-Ekiti Metropolis, Ekiti State, Nigeria. MOJ Biology andMedicine.

Fonkem, D., N. Tanya, V., N. and Ebangi, A., L. (2010). Effect of Season on the Microbiological Quality of Kilishi, a Traditional Cameroonian Dried Beef Product. Tropicultura, 28(1): 10-15.

Food and Agricultural Organization of the United Nations (F A O, 1979). Manual of food quality control 4. Microbiological analysis.

Food and Agriculture Organisation of the United Nation (FAO), 2019. Nigeria at a glance.

Igene J.O., Uwadia, O.E., Ebabhamiegbebho, P.A. and Evivie, S.E., (2016) Shelf life Stability Studies of University of Benin (UNIBEN) Proff's Kilishi Product Asian Journal of Science and Technology 7(1): 2268-2274.

Inusa, S. K. and Said, I. S. (2017) Evaluation of the Chemical and Microbiological Properties Of Kilishi Sold in Kano Metropolis. Journal of Dry land Agriculture, 3 (1): $59-69$.

Lucretia, I. B, Patience, C. Obinna-Echem, Sophia, C. A. (2018) Microbiological quality andantibiotic sensitivity of potential pathogens isolated from meat product (Suya) sold in Rivers State University and its environs. International Journal of Biotechnology and Food Science, 6(4): 67-76.

Matthew, E., Drosos, E., John, L. and Ioanna, P. (2013) MRSA in Africa: Filling the Global Map of Antimicrobial Resistance PLOS One. 8(7): e68024 doi: 10.1371/journal.pone.0068024

Mgbemere, V.N., Akpapunam, M. A. and Igene, J. O., (2011). Effect of Groundnut FlourSubstitution on Yield, Quality and Storage Stability of Kilishi - a Nigerian Indigenous Dried Meat Product. African Journal of Food, Agriculture, Nutrition and Development, $\quad \mathbf{1 1}(2)$ : 4718-4738. 
BAJOPAS Volume 13 Number 1, June, 2020

Mubarak, A. A., Azeez, M. L., Amos A. O., Opeyemi, O. O. (2016) Assessment of Animal Protein Consumption and Food Security Among Rural Households in Kwara State, Nigeria American Journal of Business and Society, 1(4): 233245.

Ndahi, M., D. Kwaga, J., K. P. Bello, M. Kabir J., V. Umoh, .J. Yakubu, S., E. and Nok, A., J. (2013) Prevalence and Antimicrobial Susceptibility of Listeria Monocytogenes and Methicillin-Resistant Staphylococcus aureus Strains from Raw Meat and Meat Products in Zaria, Nigeria. Applied Journal of Microbiology, 58(3):262-9.

Okonko, I.O., Odu, N.N. and Igboh, I.E. (2013). Microbiological Analysis of Kilishi Sold In Port Harcourt, Nigeria. New York Science Journal, 6 (7):37-43.

Osimani, A., Aquilanti, L. and Clementi, F. (2015) Microbiological Quality of Meatbased Meals and Operation of Control Systems within a Food Service Environment. International Food Research Journal 22(4): 1692-1698.

Onuorah, S. Obika, I. Odibo, F. Orji, M. (2015)An Assessment of the Bacteriological Quality of Tsire-Suya (Grilled Beef) sold in Awka, Nigeria. American. J. Life. Sci. Res. 3(4):287292.

Razavilar, V, Khandaghi, J. Barzgari, A. (2010); Isolation of Eschericia coli 0157:H7 from manure fertilized farms and raw vegetables grown on it, in Tabriz city in
Iran. African Journal of Microbiology Research, 4(9): 891-895.

Scallan, E. Hoekstra, R. M. Angulo, F. J.Tauxe, R. V, Widdowson, M. Roy, S. L et al., (2011).Food borne illness acquired in the United States- Major Pathogens. Emerg. Infec Dis, 17(1): 7-15.

Shamsuddeen U (2009). Microbiological quality of spice used in the production of Kilishi a traditionally dried and grilled meat product. Bayero Journal of Pure andApplied Sciences, 2(2): 66-69.

Shamsuddeen, U. (2015) Microbiological Hazard and Critical control point Analysis of Dried and Minced Meat Snacks Produced in Kano Nigeria. Lambert Academic Publishing; Pp 1-36.

Tijani, O.and Jumare, S. (2014). Microblological Quality Assessment of Meat

Sold in KauraNamoda. International Conference on Earth, Environment and Life sciences (EELS) Dubai (UAE).

Udobi, C. E., Obajuluwa, A. F., and Onaolapo, J. A., (2013) Prevalence and Antibiotic Resistance Pattern of MethicillinResistant Staphylococcus aureus from an Orthopaedic Hospital in Nigeria BioMed Research International; 26(6); 6-7.

WHO, 2015 Foodborne diseases in the WHO African Region.

Yousafzai HA, Rind R, Khan MA, Abro SH, Korejo NA, Ejaz M, Kabir A, Shahid M, Memon S. (2019). Microbiological Contamination of Cattle and Meat in Peshawar, Pakistan. J. Anim. Health Prod. 7(1): 1116. 


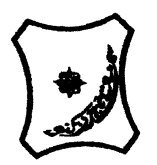

Bayero Journal of Pure and Applied Sciences, 13(1); 40 - 45

Received: September, 2019

Accepted: April, 2020

ISSN $2006-6996$

\title{
BACTERIOLOGICAL QUALITY OF STICK MEAT (Tsire) SOLD IN GARKO LOCAL GOVERNMENT AREA OF KANO STATE, NIGERIA
}

\author{
$*^{1}$ Dahiru A. T. and ${ }^{2}$ Maigari A. K. \\ ${ }^{1}$ Department of Hospitality Management, School of Technology, Kano State Polytechnic, PMB 3348, \\ Kano Nigeria. \\ ${ }^{2}$ Departmnt of Biological Sciences, Bayero University, Kano \\ Corresponding Author: dturajo61@gmail.com; GSM: 08087508262.
}

ABSTRACT

Stick meat, locally called Tsire in Hausa Language, is a significant portion of the diet of a large active population of Northern Nigeria. However, because of the handling and processing methods by the manufacturers as well as the hawking system of stick meat, the meat product may be exposed to both pre- and post-processed product contamination, and thus may poses danger to public health. Therefore, considering the role of Tsire in improving nutrition and increase household income to the populace, the need to improve the processing, distribution and overall quality of the product is simply indispensable. A total of 30 samples (5 samples from each of the 6 sampling points) of Tsire were collected randomly in Garko Town. Aerobic plate counts (APCs) and Total coliform counts (TCCS) of Tsire samples were determined using standard microbiological methods. APCs ranged from $1.02 \times 10^{5}$ to $4.00 \times 10^{5} \mathrm{CFU} / \mathrm{g}$; while TCCs ranged from $8 \mathrm{MPN} / \mathrm{g}$ to $68 \mathrm{MPN} / \mathrm{g}$. From the 30 samples screened, 16(53.33\%) bacteria namely, Campylobacter 2(6.66\%), Escherichia coli 6(20\%), Klebsiella pneumoniae 2(6.66\%), Salmonella spp. 1(3.33\%), Shigella 3(10\%) and Staphylococcus aureus 2(6.66\%) were detected. $E$. coli has the highest isolation rate of 6(20\%), while Salmonella spp. had the least frequency of 1(3.33\%). The distribution of isolated organisms within the study area were as follows: Dausai, 4(80\%), Kofar kudu, 4(80\%), Makwalla, 2(40\%), Rinji, 3(60\%), Tosaro, 2(40\%), and Tsohuwar Kasuwa, 1(20\%). The results have indicated that the Tsire was contaminated with bacteria thus exposing the product to fast deterioration, spoilage and also a vehicle for food borne illness, suggesting for adequate hygienic practices at all the stages, prior to consumption, to ensure safety of the meat product.

Key words: APCs, TCCs, Contamination, Microorganisms, Garko

\section{INTRODUCTION}

Nigeria is one of the developing nations with inadequate food supply and most often deficient in protein content (FAO, 2019). Nigerian's average animal protein intake per head per day is estimated at $7.9 \mathrm{~g}$ as against $35 \mathrm{~g}$ recommended value by Food and Agricultural Organization (Mubarak et al., 2016). These low levels of animal protein intake create great concern as it affects the nutritional status of Nigerians. Hence, there is the need for sufficient supply of animal protein from energy rich animal products to satisfy the nutritional requirements for Nigerians.

Meat is one major source of animal protein largely composed of water, protein and fats which can make it susceptible to microbial contamination within short time leading to spoilage (Apata et al., 2013; Mgbemere et al., 2011). Meat is mostly eaten after it has been cooked or processed in a variety of ways such as sun drying; smoking and roasting with or without fortifications (Borch et al., 1996). In Nigeria meat products such as Tsire, Kilishi and Balangu are locally produced using one or more of these methods in order to meet the nutritional requirements of the teeming Nigerians (Egbebi, 2011).

Tsire is a popular Nigerian traditional processed ready-to-eat roasted stick meat product (Shamsuddeen, 2015). It is sold in public places, along roads, in hotels, parks, quarters and even offices (Falegan et al., 2017). It is prepared from boneless healthy animal flesh such as beef and mutton, spiced with peanut cake, salt, vegetable oil and other flavorings followed by roasting (Shamsuddeen, 2015). Consumption of these products has extended to other parts of African countries such as Ghana, Somali, Cameroun and Chad (Ahmadu and Ibrahim, 2013). 
BAJOPAS Volume 13 Number 1, June, 2020

However, evidence of quality control sticking to procedural hygiene by the handlers during preparation and retailing of these products is poorly documented. Tsire is of great safety risk because of the fact that there are erratic cases of gastroenteritis and symptoms of food infection after consumption (WHO, 2015). Food borne illnesses are one of the major health problems in developing and developed countries (Razavilar, 2010). According to the World Health Organization, WHO (2015), $0.07 \%$ death of the 600 million global burdens of Foodborne illnesses have been reported to be caused by bacteria, viruses, fungi and chemicals. In America $0.27 \%$ of the estimated 48 million affected people is hospitalized and about $0.0063 \%$ deaths are recorded each year (Scallan et al., 2011). More than 91 million people in Africa fall ill and $0.15 \%$ dies each year, making Africa the highest burden bearer of Foodborne diseases per population (WHO, 2015).

Application of a Hazard Analysis Critical Control Point (HACCP) at all stages of meat products preparation is essential in order to ensure its safety. Thus, according to the guidelines of good manufacturing practice, the level of total aerobic bacterial contamination of thermally processed meat products should not exceed $10^{4}\left(\mathrm{cfu} \mathrm{g}^{-1}\right)$. Enterobacteriaceae and faecal coliform contamination in meat products should be within the range of $10^{2}-10^{4}$ and $10-10^{3} \mathrm{cfu} \mathrm{g}^{-1}$, respectively (Shamsuddeen, 2015). The aim of the study is therefore, to assess the total viable bacterial counts of tsire marketed locally within Garko town, and to isolate and identify the organisms at the point of consumption with the intention of promoting public health and food hygiene habits in the Nigerian populace.

\section{MATERIALS AND METHODS Study Area and Population}

Garko is one of the existing 44 local government areas located in Kano south west zone of Kano state with its capital administrative headquarters in the Garko town. It has coordinates $11^{\circ} 39^{\prime} \mathrm{N}$ $8^{\circ} 54^{\prime} \mathrm{E}$, and an area of $450 \mathrm{~km}^{2}$. The projected population of Garko local Government was 225,300 according to the National Population Census report (2018). Garko is known for agricultural activities both farming and animal husbandry. It is popularly known for large scale rice production. Other food crops include sweet potatoes, cassava, onions, sorghum, millet and sugarcane. Cows, sheep and goats are major groups of animals reared by majority of the populace. Meat products processed, retailed and consumed in Garko include roasted meat (Balangu), dried roasted meat (Kilishi), stick meat (Tsire), hide and skin pepper soup (Ragadada) and minced fried meat (Danbunnama).

\section{Samples Collection}

Five samples of Tsire products were collected from 6 different identified locations within Garko town in a sterile foil paper and immediately analyzed for the presence of bacteria.

\section{Sample Preparation}

Sample preparation for the bacteriological analysis was carried out in accordance with the method described by Atlas (1997). Twenty five grams $(25 \mathrm{~g})$ of the sample was homogenized in $225 \mathrm{ml}$ peptone water using Kenwood blender machine to obtain a $10^{1}$ homogenate. The homogenate was thoroughly shaken and $1 \mathrm{ml}$ pipetted into test tubes containing $9 \mathrm{ml}$ of peptone water $\left(10^{2}\right)$. The test tubes were further serially diluted to $10^{5}$.

Total Aerobic Mesophilic Bacterial Count

Total Aerobic mesophilic bacterial count was determined using the method described by Abdullahi et al. (2004) where $1 \mathrm{ml}$ of inoculums from $10^{1}$ to $10^{5}$ dilutions were transferred into duplicate Petri dishes and labeled accordingly. This was followed by pouring aseptically about $15 \mathrm{ml}$ of molten nutrient agar. The culture was homogenized by gentle spinning of the plates and allowed to solidify. The plates were incubated at $37^{\circ} \mathrm{C}$ for 24 hours. Plates containing 30-300 colonies were counted. The number of colony forming units per gram of a sample (cfu/g) was obtained by multiplying the average colony number with the inverse of the dilution factor.

\section{Enumeration and Detection of Coliform bacteria}

Detection and enumeration of coliform was carried out according to method described by Atlas, (1977). A set of 9 test tubes each containing $9 \mathrm{ml}$ of lactose broth and an inverted Durham tubes were autoclaved to expel air and to sterilize. Similarly, $1 \mathrm{ml}$ from the diluents $10^{1}$ was transferred to the first 3 test tubes, followed by $1 \mathrm{ml}$ from the diluents $10^{2}$ to the second set of 3 test tubes and finally the third diluents $10^{3}$ to the $3^{\text {rd }}$ set of 3 test tubes. All the 9 test tubes were incubated at $37^{\circ} \mathrm{C}$ for 24 hours. Tubes that showed gas and acid production after 24 hours were recorded as positive for the presence of Coliform. Negative tubes were further reincubated for 24 hours. Positive tubes were recorded. Estimate of most probable number of Coliform per gram of sample (MPN/g) was determined by comparing the number of gas positive tubes with the most probable number table. 
BAJOPAS Volume 13 Number 1, June, 2020 Identification of Coliform

A loop full of inoculum from gas positive tubes was streaked on to Eosine methylene blue (EMB) agar plate and incubated at $37^{\circ} \mathrm{C}$ for $24 \mathrm{hrs}$. Colonies which formed bluish black color with green metallic sheen, and reddish colonies were isolated on agar slants. Those colonies showing metallic sheen on EMB were sub cultured into tubes of lactose broth and incubated at $45^{\circ} \mathrm{C}$. The tubes were observed after $24 \mathrm{hrs}$ for gas production. This is the completed test for fecal coliform. Gram stain and other biochemical tests such as Indole, Methyl red, Voges-Proskauer and Citrate Utilization tests (IMVIC), Coagulase and Catalase tests were carried out for the Identification and confirmation of isolates.

\section{Procedure for Indole Test}

Indole test was carried out by preparing a Tryptone broth drawn in to test tubes, sterilized by autoclaving, inoculated with loopful of suspension and incubated at $37^{\circ} \mathrm{C}$ for 24 hours. Three drops of xylene was added in tubes, shaken vigorously and kept for the separation of two layers. One millilitre of Kovac's reagent was added and the formation of pink colour ring indicates positive Indole test.

\section{Procedure for Methyl Red Test}

Methyl red test was carried out by preparing Glucose phosphate broth, dispensed in test tubes, sterilized, inoculated with test culture and incubated at $37^{\circ} \mathrm{C}$ for 24 hours. Five drops of methyl-red indicator was added to the medium for the formation of red colour.

\section{Procedure for Voges-Proskauer Test}

Voges-Proskauer test was carried out by inoculating tubes with the bacterial culture followed by incubation for 48 hours at $37^{\circ} \mathrm{C}$. Separate pipettes were used to pipette $1 \mathrm{ml}$ from each culture tube into clean separate tubes. Eighteen drops $(0.5 \mathrm{ml})$ of Barrit's solution A (a-naphthol) was added to each tube containing glucose phosphate broth followed by the addition of an equal amount of solution $B$ into the same tube. The tubes were shaken at 30 seconds interval. A positive reaction was indicated by the development of a pink color, which turns red in 1-2 hours, after vigorous shaking.

\section{Procedure for Citrate Utilization Test}

Citrate Utilization Test was carried out by distributing melted agar (Simmon Citrate Agar) in to test tubes followed by sterilization at $121.5^{\circ} \mathrm{C}$ for 15 minutes. The test tubes were afterward held in slanted position, inoculated with the given bacterial culture and incubated at $37^{\circ} \mathrm{C}$ for $24 \mathrm{hrs}$. Positive test was indicated by color change of the media from green to blue.

\section{RESULTS AND DISCUSSIONS}

The results of this study are presented in tables $1,2,3$ and 4. Among the sampling areas Kofar Kudu had the highest aerobic mesophilic bacteria counts $4.0 \times 10^{5} \mathrm{cfu} / \mathrm{g}$ followed by Rinji $2.72 \times 10^{5} \mathrm{cfu} / \mathrm{g}$, while Tosaro had the least Aerobic mesophilic bacteria counts of $1.02 \times 10^{5}$ $\mathrm{cfu} / \mathrm{g}$ as indicated in Table 1.Makwalla had the highest coliform count $68 \mathrm{MPN} / \mathrm{g}$ followed by Rinji $37 \mathrm{MPN} / \mathrm{g}$. Tsohuwar Kasuwa had the least coliform counts $8 \mathrm{MPN} / \mathrm{g}$, (Table 2). Result from table 1 shows variation in the microbial contents among the samples which suggest variation in their sources, poor handling procedures and contamination from the processing environment. High coliform count and their differences within sampling areas is an indication of poor microbiological quality of the product. Ndahi et al. (2013) reported microbial load to be a function of the handling personnel and the environment. The results indicated that the samples were contaminated with bacteria as the counts exceeded the minimum safety level $\left(10^{4} \mathrm{cfu} / \mathrm{g}\right)$ for members of the Enterobacteriaceae family. However, it might be a reflection of poor hygienic practices which may contribute to health hazard to the potential consumers. Similarly, Inusa and Sa'id (2017); Osimani et al. (2015) reported that, the initial microbial content of the raw material play significant role in influencing the final microbial load of the finished product. Isolation of members of the Enterobacteriaceae such as $E$. coli, Klebsiella pneumoniae, Salmonella and Shigella signifies danger to the public health. These organisms are capable of producing endotoxins which trigger high fevers in infected individuals, and the enterotoxins which colonize the small intestines and lead to extreme dehydration as a result of vomiting and diarrhea sometimes with severe and fatal outcomes (Amaeze et al., 2016). From the 16 isolated organisms $E$. coli had the highest isolation rate $6(37.5 \%)$ (Table 3), this suggest faecal contamination of the products. $E$. coli is a common flora in the gastrointestinal tract responsible for diarrhea and extra-intestinal infections (CDC, 2011). The result is in conformity with the findings of Ndahi et al. (2013) and Shamsuddeen (2009). Also presence of campylobacter might be due to cross contamination from raw meat to finished product (Tsire). Staphylococcus aureus is a normal flora of the skin, nasal, genital, mouth or anal area in both humans and animals without any symptom of an infection (Matthew et al., 2013). Isolation of $S$. aureus in these study concords with the findings of Lucretia et al. (2018) from Suya sold in Rivers State. 
BAJOPAS Volume 13 Number 1, June, 2020

It is also in agreement with the findings of Yousafzai et al. (2018); Onuorah et al. (2015) and Tijjani and Jumare (2014) from tsire samples in different countries. Presence of $S$. aureus in foods is most of the time an indication of poor human handling, poor environment, unhygienic utensils and equipments used during processing (Igene et al., 2016; Okonko et al., 2013). Infections caused by $S$. aureus are difficult to treat leading to long hospitalization with consequent economic loss (Udobi et al., 2013). These include soft tissue infections, pneumonia, hospital-acquired postoperative wound infections, Staphylococcal food poisoning, impetigo and cellulitis (Charlene et al., 2013). Samples obtained from Dausai and Kofar Kudu had the highest isolation rate $4(80 \%)$ (Table 4 ) probably because of the much commercial activities taking place in the area which can lead to environmental contamination.

Table 1: Total Aerobic Mesophilic Bacterial Count of Tsire sold in Garko Town

\begin{tabular}{lll}
\hline Sampling Area & APC cfu/g & Mean \pm STD \\
\hline Dausai & $2.20 \times 10^{5}$ & $110000 \pm 14142.14$ \\
Kofar Kudu & $4.00 \times 10^{5}$ & $133333.3 \pm 23094.01$ \\
Makwalla & $1.30 \times 10^{5}$ & $32500 \pm 7187.953$ \\
Rinji & $2.72 \times 10^{5}$ & $90666.67 \pm 94769.90$ \\
Tosaro & $1.02 \times 10^{5}$ & $51000 \pm 15556.35$ \\
Tsohuwar Kasuwa & $1.75 \times 10^{5}$ & $35000 \pm 11357.82$ \\
\hline
\end{tabular}

Key: APC: Aerobic Mesophilic Counts

STD: Standard Deviation

Table 2: Total Coliform Count of Tsire sold in Garko Town

\begin{tabular}{lcc}
\hline \multicolumn{1}{c}{ Sampling Area } & TCC MPN/g & Mean \pm STD \\
\hline Dausai & 20 & $6.67 \pm 2.5166$ \\
Kofar Kudu & 32 & $16.00 \pm 5.6569$ \\
Makwalla & 68 & $13.60 \pm 8.7062$ \\
Rinji & 37 & $9.25 \pm 4.7871$ \\
Tosaro & 10 & $5.00 \pm 2.8284$ \\
Tsohuwar Kasuwa & 8 & $4.00 \pm 0.0000$ \\
\hline
\end{tabular}

Table 3: Organisms Isolated from Tsire Sold in Garko

\begin{tabular}{lcl}
\hline Isolated Organism & Frequency & Percentage (\%) \\
\hline Campylobacter & 2 & 06.66 \\
Escherichia coli & 6 & 20.00 \\
Klebsiella pneumoniae & 2 & 06.66 \\
Salmonella species & 1 & 03.33 \\
Shigella & 3 & 10.00 \\
Staphylococcus aureus & 2 & 06.66 \\
Total & 16 & \\
\hline
\end{tabular}

Table 4: Distribution of Organisms within Sampling Area

\begin{tabular}{lcc}
\hline \multicolumn{1}{c}{ Sampling Area } & No. Isolated & Percentage (\%) \\
\hline Dausai & 4 & 80 \\
Kofar Kudu & 4 & 80 \\
Makwalla & 2 & 40 \\
Rinji & 3 & 60 \\
Tosaro & 2 & 40 \\
Tsohuwar Kasuwa & 1 & 20 \\
Total & 16 & \\
\hline
\end{tabular}

\section{CONCLUSION}

Results indicated $4.00 \times 10^{5} \mathrm{CFU} / \mathrm{g}$ as the highest APCs count; while $68 \mathrm{MPN} / \mathrm{g}$ was the highest TCCs from the 30 samples analyzed. Among the isolates, $E$. coli has the highest isolation rate of $6(20 \%)$. Dausai and Kofar kudu were having the highest bacteria count of $4(80 \%)$, each, indicating higher contamination in those locations. 
BAJOPAS Volume 13 Number 1, June, 2020 RECOMMENDATIONS

The following recommendations are tenable:

1. Hygienic practices at all stages of production should be improved to safe guard the consumers against potential health hazard.

2. Monitoring of microbiological contamination of Tsire during preparations, packaging and marketing is essential to ensure product of good microbiological quality for consumers' health.

\section{REFERENCES}

Abdullahi, I. O., Umoh, V. J. and Galadima, M. (2004). Hazards Associated with Kilishi Preparations in Zaria. Nigerian Journal of Microbiology, 18 (1-2): $339-345$.

Ahmadu, J. and Ibrahim E. J., (2013): Determinants of Revenue in Suya Production in BeninCity, Edo State, Nigeria. Nigerian journal of agriculture, food and environment.9(3):1-5

Amaeze, N. Aboh, M. Itohan, A. Felix, E. Olatunji, T. and Oladosu, P. (2016) Microbial Profile, Antibiotic Sensitivity and Heat Resistance of Bacterial Isolates from Commercial Roasted Beef (Suya) in Abuja, Nigeria. JOPAT, 15(2): $22-30$.

Apata, E.S., Kuku1, I.A., Apata, O.C. and Adeyemi, K.O. (2013). Evaluation of Suya(Tsire) - An Intermediate Moisture Meat Product in Ogun State, Nigeria. J. Food Res 2 (1): 87.

Atlas, R. M. (1997) Principles of Microbiology Second Edition. C. Brown Publishers. Pp 802-803.

Borch, E. Kant-Muermans, M. L., Blixt, Y. (1996) Bacterial Spoilage of Meat and Cured Meat Products. Int $\mathrm{J}$ Food Microbiol .33(1): 103-20.

Centre for Disease Control, CDC (2011). "Escherichia coli 0157:H7" Division of Bacterial and Mycotic Diseasesht://www.cdc.gov/nczved/divisi ons/dfbmd/diseases/ecoli_0157h7/.

Charlene, R. J., Johnnie, A. D., and John, B. B., (2013) Prevalence and Characterization of Methicillin-Resistant Staphylococcus aureus Isolates from Retail Meat and Humans in Georgia. American society for Microbiology. J. of clinical microbiology. 12(1):123-6 doi:10.1128/JCM.0316612JCM.03166-12

Egbebi, A.O and Seidu, K., T. (2011). Microbiological Evaluation of Suya (dried smoked

meat) Sold in Ado and Akure, South West Nigeria.European Journal of Experinmental Biology, 1(4):1-5
3. Government should establish regulatory bodies responsible for inculcating hygiene habits to the local producers and vendors in order to prevent instant, cross and post processing contaminations by microbial pathogens.

4. Awareness and sensitization of local food producers about good hygienic practices in food handling and processing.

Falegan, C, R., Akoja, S. D., and Oyarekua, M. A., (2017) Microbiological Assessment of Suya (Sliced Roasted Beef) in Ado-Ekiti Metropolis, Ekiti State, Nigeria. MOJ Biology andMedicine.

Fonkem, D., N. Tanya, V., N. and Ebangi, A., L. (2010). Effect of Season on the Microbiological Quality of Kilishi, a Traditional Cameroonian Dried Beef Product. Tropicultura, 28(1): 10-15.

Food and Agricultural Organization of the United Nations (F A O, 1979). Manual of food quality control 4. Microbiological analysis.

Food and Agriculture Organisation of the United Nation (FAO), 2019. Nigeria at a glance.

Igene J.O., Uwadia, O.E., Ebabhamiegbebho, P.A. and Evivie, S.E., (2016) Shelf life Stability Studies of University of Benin (UNIBEN) Proff's Kilishi Product Asian Journal of Science and Technology 7(1): 2268-2274.

Inusa, S. K. and Said, I. S. (2017) Evaluation of the Chemical and Microbiological Properties Of Kilishi Sold in Kano Metropolis. Journal of Dry land Agriculture, 3 (1): $59-69$.

Lucretia, I. B, Patience, C. Obinna-Echem, Sophia, C. A. (2018) Microbiological quality andantibiotic sensitivity of potential pathogens isolated from meat product (Suya) sold in Rivers State University and its environs. International Journal of Biotechnology and Food Science, 6(4): 67-76.

Matthew, E., Drosos, E., John, L. and Ioanna, P. (2013) MRSA in Africa: Filling the Global Map of Antimicrobial Resistance PLOS One. 8(7): e68024 doi: 10.1371/journal.pone.0068024

Mgbemere, V.N., Akpapunam, M. A. and Igene, J. O., (2011). Effect of Groundnut FlourSubstitution on Yield, Quality and Storage Stability of Kilishi - a Nigerian Indigenous Dried Meat Product. African Journal of Food, Agriculture, Nutrition and Development, $\quad \mathbf{1 1}(2)$ : 4718-4738. 
BAJOPAS Volume 13 Number 1, June, 2020

Mubarak, A. A., Azeez, M. L., Amos A. O., Opeyemi, O. O. (2016) Assessment of Animal Protein Consumption and Food Security Among Rural Households in Kwara State, Nigeria American Journal of Business and Society, 1(4): 233245.

Ndahi, M., D. Kwaga, J., K. P. Bello, M. Kabir J., V. Umoh, .J. Yakubu, S., E. and Nok, A., J. (2013) Prevalence and Antimicrobial Susceptibility of Listeria Monocytogenes and Methicillin-Resistant Staphylococcus aureus Strains from Raw Meat and Meat Products in Zaria, Nigeria. Applied Journal of Microbiology, 58(3):262-9.

Okonko, I.O., Odu, N.N. and Igboh, I.E. (2013). Microbiological Analysis of Kilishi Sold In Port Harcourt, Nigeria. New York Science Journal, 6 (7):37-43.

Osimani, A., Aquilanti, L. and Clementi, F. (2015) Microbiological Quality of Meatbased Meals and Operation of Control Systems within a Food Service Environment. International Food Research Journal 22(4): 1692-1698.

Onuorah, S. Obika, I. Odibo, F. Orji, M. (2015)An Assessment of the Bacteriological Quality of Tsire-Suya (Grilled Beef) sold in Awka, Nigeria. American. J. Life. Sci. Res. 3(4):287292.

Razavilar, V, Khandaghi, J. Barzgari, A. (2010); Isolation of Eschericia coli 0157:H7 from manure fertilized farms and raw vegetables grown on it, in Tabriz city in
Iran. African Journal of Microbiology Research, 4(9): 891-895.

Scallan, E. Hoekstra, R. M. Angulo, F. J.Tauxe, R. V, Widdowson, M. Roy, S. L et al., (2011).Food borne illness acquired in the United States- Major Pathogens. Emerg. Infec Dis, 17(1): 7-15.

Shamsuddeen U (2009). Microbiological quality of spice used in the production of Kilishi a traditionally dried and grilled meat product. Bayero Journal of Pure andApplied Sciences, 2(2): 66-69.

Shamsuddeen, U. (2015) Microbiological Hazard and Critical control point Analysis of Dried and Minced Meat Snacks Produced in Kano Nigeria. Lambert Academic Publishing; Pp 1-36.

Tijani, O.and Jumare, S. (2014). Microblological Quality Assessment of Meat

Sold in KauraNamoda. International Conference on Earth, Environment and Life sciences (EELS) Dubai (UAE).

Udobi, C. E., Obajuluwa, A. F., and Onaolapo, J. A., (2013) Prevalence and Antibiotic Resistance Pattern of MethicillinResistant Staphylococcus aureus from an Orthopaedic Hospital in Nigeria BioMed Research International; 26(6); 6-7.

WHO, 2015 Foodborne diseases in the WHO African Region.

Yousafzai HA, Rind R, Khan MA, Abro SH, Korejo NA, Ejaz M, Kabir A, Shahid M, Memon S. (2019). Microbiological Contamination of Cattle and Meat in Peshawar, Pakistan. J. Anim. Health Prod. 7(1): 1116. 


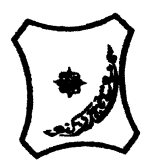

Bayero Journal of Pure and Applied Sciences, 13(1); 40 - 45

Received: September, 2019

Accepted: April, 2020

ISSN $2006-6996$

\title{
BACTERIOLOGICAL QUALITY OF STICK MEAT (Tsire) SOLD IN GARKO LOCAL GOVERNMENT AREA OF KANO STATE, NIGERIA
}

\author{
$*^{1}$ Dahiru A. T. and ${ }^{2}$ Maigari A. K. \\ ${ }^{1}$ Department of Hospitality Management, School of Technology, Kano State Polytechnic, PMB 3348, \\ Kano Nigeria. \\ ${ }^{2}$ Departmnt of Biological Sciences, Bayero University, Kano \\ Corresponding Author: dturajo61@gmail.com; GSM: 08087508262.
}

ABSTRACT

Stick meat, locally called Tsire in Hausa Language, is a significant portion of the diet of a large active population of Northern Nigeria. However, because of the handling and processing methods by the manufacturers as well as the hawking system of stick meat, the meat product may be exposed to both pre- and post-processed product contamination, and thus may poses danger to public health. Therefore, considering the role of Tsire in improving nutrition and increase household income to the populace, the need to improve the processing, distribution and overall quality of the product is simply indispensable. A total of 30 samples (5 samples from each of the 6 sampling points) of Tsire were collected randomly in Garko Town. Aerobic plate counts (APCs) and Total coliform counts (TCCS) of Tsire samples were determined using standard microbiological methods. APCs ranged from $1.02 \times 10^{5}$ to $4.00 \times 10^{5} \mathrm{CFU} / \mathrm{g}$; while TCCs ranged from $8 \mathrm{MPN} / \mathrm{g}$ to $68 \mathrm{MPN} / \mathrm{g}$. From the 30 samples screened, 16(53.33\%) bacteria namely, Campylobacter 2(6.66\%), Escherichia coli 6(20\%), Klebsiella pneumoniae 2(6.66\%), Salmonella spp. 1(3.33\%), Shigella 3(10\%) and Staphylococcus aureus 2(6.66\%) were detected. $E$. coli has the highest isolation rate of 6(20\%), while Salmonella spp. had the least frequency of 1(3.33\%). The distribution of isolated organisms within the study area were as follows: Dausai, 4(80\%), Kofar kudu, 4(80\%), Makwalla, 2(40\%), Rinji, 3(60\%), Tosaro, 2(40\%), and Tsohuwar Kasuwa, 1(20\%). The results have indicated that the Tsire was contaminated with bacteria thus exposing the product to fast deterioration, spoilage and also a vehicle for food borne illness, suggesting for adequate hygienic practices at all the stages, prior to consumption, to ensure safety of the meat product.

Key words: APCs, TCCs, Contamination, Microorganisms, Garko

\section{INTRODUCTION}

Nigeria is one of the developing nations with inadequate food supply and most often deficient in protein content (FAO, 2019). Nigerian's average animal protein intake per head per day is estimated at $7.9 \mathrm{~g}$ as against $35 \mathrm{~g}$ recommended value by Food and Agricultural Organization (Mubarak et al., 2016). These low levels of animal protein intake create great concern as it affects the nutritional status of Nigerians. Hence, there is the need for sufficient supply of animal protein from energy rich animal products to satisfy the nutritional requirements for Nigerians.

Meat is one major source of animal protein largely composed of water, protein and fats which can make it susceptible to microbial contamination within short time leading to spoilage (Apata et al., 2013; Mgbemere et al., 2011). Meat is mostly eaten after it has been cooked or processed in a variety of ways such as sun drying; smoking and roasting with or without fortifications (Borch et al., 1996). In Nigeria meat products such as Tsire, Kilishi and Balangu are locally produced using one or more of these methods in order to meet the nutritional requirements of the teeming Nigerians (Egbebi, 2011).

Tsire is a popular Nigerian traditional processed ready-to-eat roasted stick meat product (Shamsuddeen, 2015). It is sold in public places, along roads, in hotels, parks, quarters and even offices (Falegan et al., 2017). It is prepared from boneless healthy animal flesh such as beef and mutton, spiced with peanut cake, salt, vegetable oil and other flavorings followed by roasting (Shamsuddeen, 2015). Consumption of these products has extended to other parts of African countries such as Ghana, Somali, Cameroun and Chad (Ahmadu and Ibrahim, 2013). 
BAJOPAS Volume 13 Number 1, June, 2020

However, evidence of quality control sticking to procedural hygiene by the handlers during preparation and retailing of these products is poorly documented. Tsire is of great safety risk because of the fact that there are erratic cases of gastroenteritis and symptoms of food infection after consumption (WHO, 2015). Food borne illnesses are one of the major health problems in developing and developed countries (Razavilar, 2010). According to the World Health Organization, WHO (2015), $0.07 \%$ death of the 600 million global burdens of Foodborne illnesses have been reported to be caused by bacteria, viruses, fungi and chemicals. In America $0.27 \%$ of the estimated 48 million affected people is hospitalized and about $0.0063 \%$ deaths are recorded each year (Scallan et al., 2011). More than 91 million people in Africa fall ill and $0.15 \%$ dies each year, making Africa the highest burden bearer of Foodborne diseases per population (WHO, 2015).

Application of a Hazard Analysis Critical Control Point (HACCP) at all stages of meat products preparation is essential in order to ensure its safety. Thus, according to the guidelines of good manufacturing practice, the level of total aerobic bacterial contamination of thermally processed meat products should not exceed $10^{4}\left(\mathrm{cfu} \mathrm{g}^{-1}\right)$. Enterobacteriaceae and faecal coliform contamination in meat products should be within the range of $10^{2}-10^{4}$ and $10-10^{3} \mathrm{cfu} \mathrm{g}^{-1}$, respectively (Shamsuddeen, 2015). The aim of the study is therefore, to assess the total viable bacterial counts of tsire marketed locally within Garko town, and to isolate and identify the organisms at the point of consumption with the intention of promoting public health and food hygiene habits in the Nigerian populace.

\section{MATERIALS AND METHODS Study Area and Population}

Garko is one of the existing 44 local government areas located in Kano south west zone of Kano state with its capital administrative headquarters in the Garko town. It has coordinates $11^{\circ} 39^{\prime} \mathrm{N}$ $8^{\circ} 54^{\prime} \mathrm{E}$, and an area of $450 \mathrm{~km}^{2}$. The projected population of Garko local Government was 225,300 according to the National Population Census report (2018). Garko is known for agricultural activities both farming and animal husbandry. It is popularly known for large scale rice production. Other food crops include sweet potatoes, cassava, onions, sorghum, millet and sugarcane. Cows, sheep and goats are major groups of animals reared by majority of the populace. Meat products processed, retailed and consumed in Garko include roasted meat (Balangu), dried roasted meat (Kilishi), stick meat (Tsire), hide and skin pepper soup (Ragadada) and minced fried meat (Danbunnama).

\section{Samples Collection}

Five samples of Tsire products were collected from 6 different identified locations within Garko town in a sterile foil paper and immediately analyzed for the presence of bacteria.

\section{Sample Preparation}

Sample preparation for the bacteriological analysis was carried out in accordance with the method described by Atlas (1997). Twenty five grams $(25 \mathrm{~g})$ of the sample was homogenized in $225 \mathrm{ml}$ peptone water using Kenwood blender machine to obtain a $10^{1}$ homogenate. The homogenate was thoroughly shaken and $1 \mathrm{ml}$ pipetted into test tubes containing $9 \mathrm{ml}$ of peptone water $\left(10^{2}\right)$. The test tubes were further serially diluted to $10^{5}$.

Total Aerobic Mesophilic Bacterial Count

Total Aerobic mesophilic bacterial count was determined using the method described by Abdullahi et al. (2004) where $1 \mathrm{ml}$ of inoculums from $10^{1}$ to $10^{5}$ dilutions were transferred into duplicate Petri dishes and labeled accordingly. This was followed by pouring aseptically about $15 \mathrm{ml}$ of molten nutrient agar. The culture was homogenized by gentle spinning of the plates and allowed to solidify. The plates were incubated at $37^{\circ} \mathrm{C}$ for 24 hours. Plates containing 30-300 colonies were counted. The number of colony forming units per gram of a sample (cfu/g) was obtained by multiplying the average colony number with the inverse of the dilution factor.

\section{Enumeration and Detection of Coliform bacteria}

Detection and enumeration of coliform was carried out according to method described by Atlas, (1977). A set of 9 test tubes each containing $9 \mathrm{ml}$ of lactose broth and an inverted Durham tubes were autoclaved to expel air and to sterilize. Similarly, $1 \mathrm{ml}$ from the diluents $10^{1}$ was transferred to the first 3 test tubes, followed by $1 \mathrm{ml}$ from the diluents $10^{2}$ to the second set of 3 test tubes and finally the third diluents $10^{3}$ to the $3^{\text {rd }}$ set of 3 test tubes. All the 9 test tubes were incubated at $37^{\circ} \mathrm{C}$ for 24 hours. Tubes that showed gas and acid production after 24 hours were recorded as positive for the presence of Coliform. Negative tubes were further reincubated for 24 hours. Positive tubes were recorded. Estimate of most probable number of Coliform per gram of sample (MPN/g) was determined by comparing the number of gas positive tubes with the most probable number table. 
BAJOPAS Volume 13 Number 1, June, 2020 Identification of Coliform

A loop full of inoculum from gas positive tubes was streaked on to Eosine methylene blue (EMB) agar plate and incubated at $37^{\circ} \mathrm{C}$ for $24 \mathrm{hrs}$. Colonies which formed bluish black color with green metallic sheen, and reddish colonies were isolated on agar slants. Those colonies showing metallic sheen on EMB were sub cultured into tubes of lactose broth and incubated at $45^{\circ} \mathrm{C}$. The tubes were observed after $24 \mathrm{hrs}$ for gas production. This is the completed test for fecal coliform. Gram stain and other biochemical tests such as Indole, Methyl red, Voges-Proskauer and Citrate Utilization tests (IMVIC), Coagulase and Catalase tests were carried out for the Identification and confirmation of isolates.

\section{Procedure for Indole Test}

Indole test was carried out by preparing a Tryptone broth drawn in to test tubes, sterilized by autoclaving, inoculated with loopful of suspension and incubated at $37^{\circ} \mathrm{C}$ for 24 hours. Three drops of xylene was added in tubes, shaken vigorously and kept for the separation of two layers. One millilitre of Kovac's reagent was added and the formation of pink colour ring indicates positive Indole test.

\section{Procedure for Methyl Red Test}

Methyl red test was carried out by preparing Glucose phosphate broth, dispensed in test tubes, sterilized, inoculated with test culture and incubated at $37^{\circ} \mathrm{C}$ for 24 hours. Five drops of methyl-red indicator was added to the medium for the formation of red colour.

\section{Procedure for Voges-Proskauer Test}

Voges-Proskauer test was carried out by inoculating tubes with the bacterial culture followed by incubation for 48 hours at $37^{\circ} \mathrm{C}$. Separate pipettes were used to pipette $1 \mathrm{ml}$ from each culture tube into clean separate tubes. Eighteen drops $(0.5 \mathrm{ml})$ of Barrit's solution A (a-naphthol) was added to each tube containing glucose phosphate broth followed by the addition of an equal amount of solution $B$ into the same tube. The tubes were shaken at 30 seconds interval. A positive reaction was indicated by the development of a pink color, which turns red in 1-2 hours, after vigorous shaking.

\section{Procedure for Citrate Utilization Test}

Citrate Utilization Test was carried out by distributing melted agar (Simmon Citrate Agar) in to test tubes followed by sterilization at $121.5^{\circ} \mathrm{C}$ for 15 minutes. The test tubes were afterward held in slanted position, inoculated with the given bacterial culture and incubated at $37^{\circ} \mathrm{C}$ for $24 \mathrm{hrs}$. Positive test was indicated by color change of the media from green to blue.

\section{RESULTS AND DISCUSSIONS}

The results of this study are presented in tables $1,2,3$ and 4. Among the sampling areas Kofar Kudu had the highest aerobic mesophilic bacteria counts $4.0 \times 10^{5} \mathrm{cfu} / \mathrm{g}$ followed by Rinji $2.72 \times 10^{5} \mathrm{cfu} / \mathrm{g}$, while Tosaro had the least Aerobic mesophilic bacteria counts of $1.02 \times 10^{5}$ $\mathrm{cfu} / \mathrm{g}$ as indicated in Table 1.Makwalla had the highest coliform count $68 \mathrm{MPN} / \mathrm{g}$ followed by Rinji $37 \mathrm{MPN} / \mathrm{g}$. Tsohuwar Kasuwa had the least coliform counts $8 \mathrm{MPN} / \mathrm{g}$, (Table 2). Result from table 1 shows variation in the microbial contents among the samples which suggest variation in their sources, poor handling procedures and contamination from the processing environment. High coliform count and their differences within sampling areas is an indication of poor microbiological quality of the product. Ndahi et al. (2013) reported microbial load to be a function of the handling personnel and the environment. The results indicated that the samples were contaminated with bacteria as the counts exceeded the minimum safety level $\left(10^{4} \mathrm{cfu} / \mathrm{g}\right)$ for members of the Enterobacteriaceae family. However, it might be a reflection of poor hygienic practices which may contribute to health hazard to the potential consumers. Similarly, Inusa and Sa'id (2017); Osimani et al. (2015) reported that, the initial microbial content of the raw material play significant role in influencing the final microbial load of the finished product. Isolation of members of the Enterobacteriaceae such as $E$. coli, Klebsiella pneumoniae, Salmonella and Shigella signifies danger to the public health. These organisms are capable of producing endotoxins which trigger high fevers in infected individuals, and the enterotoxins which colonize the small intestines and lead to extreme dehydration as a result of vomiting and diarrhea sometimes with severe and fatal outcomes (Amaeze et al., 2016). From the 16 isolated organisms $E$. coli had the highest isolation rate $6(37.5 \%)$ (Table 3), this suggest faecal contamination of the products. $E$. coli is a common flora in the gastrointestinal tract responsible for diarrhea and extra-intestinal infections (CDC, 2011). The result is in conformity with the findings of Ndahi et al. (2013) and Shamsuddeen (2009). Also presence of campylobacter might be due to cross contamination from raw meat to finished product (Tsire). Staphylococcus aureus is a normal flora of the skin, nasal, genital, mouth or anal area in both humans and animals without any symptom of an infection (Matthew et al., 2013). Isolation of $S$. aureus in these study concords with the findings of Lucretia et al. (2018) from Suya sold in Rivers State. 
BAJOPAS Volume 13 Number 1, June, 2020

It is also in agreement with the findings of Yousafzai et al. (2018); Onuorah et al. (2015) and Tijjani and Jumare (2014) from tsire samples in different countries. Presence of $S$. aureus in foods is most of the time an indication of poor human handling, poor environment, unhygienic utensils and equipments used during processing (Igene et al., 2016; Okonko et al., 2013). Infections caused by $S$. aureus are difficult to treat leading to long hospitalization with consequent economic loss (Udobi et al., 2013). These include soft tissue infections, pneumonia, hospital-acquired postoperative wound infections, Staphylococcal food poisoning, impetigo and cellulitis (Charlene et al., 2013). Samples obtained from Dausai and Kofar Kudu had the highest isolation rate $4(80 \%)$ (Table 4 ) probably because of the much commercial activities taking place in the area which can lead to environmental contamination.

Table 1: Total Aerobic Mesophilic Bacterial Count of Tsire sold in Garko Town

\begin{tabular}{lll}
\hline Sampling Area & APC cfu/g & Mean \pm STD \\
\hline Dausai & $2.20 \times 10^{5}$ & $110000 \pm 14142.14$ \\
Kofar Kudu & $4.00 \times 10^{5}$ & $133333.3 \pm 23094.01$ \\
Makwalla & $1.30 \times 10^{5}$ & $32500 \pm 7187.953$ \\
Rinji & $2.72 \times 10^{5}$ & $90666.67 \pm 94769.90$ \\
Tosaro & $1.02 \times 10^{5}$ & $51000 \pm 15556.35$ \\
Tsohuwar Kasuwa & $1.75 \times 10^{5}$ & $35000 \pm 11357.82$ \\
\hline
\end{tabular}

Key: APC: Aerobic Mesophilic Counts

STD: Standard Deviation

Table 2: Total Coliform Count of Tsire sold in Garko Town

\begin{tabular}{lcc}
\hline \multicolumn{1}{c}{ Sampling Area } & TCC MPN/g & Mean \pm STD \\
\hline Dausai & 20 & $6.67 \pm 2.5166$ \\
Kofar Kudu & 32 & $16.00 \pm 5.6569$ \\
Makwalla & 68 & $13.60 \pm 8.7062$ \\
Rinji & 37 & $9.25 \pm 4.7871$ \\
Tosaro & 10 & $5.00 \pm 2.8284$ \\
Tsohuwar Kasuwa & 8 & $4.00 \pm 0.0000$ \\
\hline
\end{tabular}

Table 3: Organisms Isolated from Tsire Sold in Garko

\begin{tabular}{lcl}
\hline Isolated Organism & Frequency & Percentage (\%) \\
\hline Campylobacter & 2 & 06.66 \\
Escherichia coli & 6 & 20.00 \\
Klebsiella pneumoniae & 2 & 06.66 \\
Salmonella species & 1 & 03.33 \\
Shigella & 3 & 10.00 \\
Staphylococcus aureus & 2 & 06.66 \\
Total & 16 & \\
\hline
\end{tabular}

Table 4: Distribution of Organisms within Sampling Area

\begin{tabular}{lcc}
\hline \multicolumn{1}{c}{ Sampling Area } & No. Isolated & Percentage (\%) \\
\hline Dausai & 4 & 80 \\
Kofar Kudu & 4 & 80 \\
Makwalla & 2 & 40 \\
Rinji & 3 & 60 \\
Tosaro & 2 & 40 \\
Tsohuwar Kasuwa & 1 & 20 \\
Total & 16 & \\
\hline
\end{tabular}

\section{CONCLUSION}

Results indicated $4.00 \times 10^{5} \mathrm{CFU} / \mathrm{g}$ as the highest APCs count; while $68 \mathrm{MPN} / \mathrm{g}$ was the highest TCCs from the 30 samples analyzed. Among the isolates, $E$. coli has the highest isolation rate of $6(20 \%)$. Dausai and Kofar kudu were having the highest bacteria count of $4(80 \%)$, each, indicating higher contamination in those locations. 
BAJOPAS Volume 13 Number 1, June, 2020 RECOMMENDATIONS

The following recommendations are tenable:

1. Hygienic practices at all stages of production should be improved to safe guard the consumers against potential health hazard.

2. Monitoring of microbiological contamination of Tsire during preparations, packaging and marketing is essential to ensure product of good microbiological quality for consumers' health.

\section{REFERENCES}

Abdullahi, I. O., Umoh, V. J. and Galadima, M. (2004). Hazards Associated with Kilishi Preparations in Zaria. Nigerian Journal of Microbiology, 18 (1-2): $339-345$.

Ahmadu, J. and Ibrahim E. J., (2013): Determinants of Revenue in Suya Production in BeninCity, Edo State, Nigeria. Nigerian journal of agriculture, food and environment.9(3):1-5

Amaeze, N. Aboh, M. Itohan, A. Felix, E. Olatunji, T. and Oladosu, P. (2016) Microbial Profile, Antibiotic Sensitivity and Heat Resistance of Bacterial Isolates from Commercial Roasted Beef (Suya) in Abuja, Nigeria. JOPAT, 15(2): $22-30$.

Apata, E.S., Kuku1, I.A., Apata, O.C. and Adeyemi, K.O. (2013). Evaluation of Suya(Tsire) - An Intermediate Moisture Meat Product in Ogun State, Nigeria. J. Food Res 2 (1): 87.

Atlas, R. M. (1997) Principles of Microbiology Second Edition. C. Brown Publishers. Pp 802-803.

Borch, E. Kant-Muermans, M. L., Blixt, Y. (1996) Bacterial Spoilage of Meat and Cured Meat Products. Int $\mathrm{J}$ Food Microbiol .33(1): 103-20.

Centre for Disease Control, CDC (2011). "Escherichia coli 0157:H7" Division of Bacterial and Mycotic Diseasesht://www.cdc.gov/nczved/divisi ons/dfbmd/diseases/ecoli_0157h7/.

Charlene, R. J., Johnnie, A. D., and John, B. B., (2013) Prevalence and Characterization of Methicillin-Resistant Staphylococcus aureus Isolates from Retail Meat and Humans in Georgia. American society for Microbiology. J. of clinical microbiology. 12(1):123-6 doi:10.1128/JCM.0316612JCM.03166-12

Egbebi, A.O and Seidu, K., T. (2011). Microbiological Evaluation of Suya (dried smoked

meat) Sold in Ado and Akure, South West Nigeria.European Journal of Experinmental Biology, 1(4):1-5
3. Government should establish regulatory bodies responsible for inculcating hygiene habits to the local producers and vendors in order to prevent instant, cross and post processing contaminations by microbial pathogens.

4. Awareness and sensitization of local food producers about good hygienic practices in food handling and processing.

Falegan, C, R., Akoja, S. D., and Oyarekua, M. A., (2017) Microbiological Assessment of Suya (Sliced Roasted Beef) in Ado-Ekiti Metropolis, Ekiti State, Nigeria. MOJ Biology andMedicine.

Fonkem, D., N. Tanya, V., N. and Ebangi, A., L. (2010). Effect of Season on the Microbiological Quality of Kilishi, a Traditional Cameroonian Dried Beef Product. Tropicultura, 28(1): 10-15.

Food and Agricultural Organization of the United Nations (F A O, 1979). Manual of food quality control 4. Microbiological analysis.

Food and Agriculture Organisation of the United Nation (FAO), 2019. Nigeria at a glance.

Igene J.O., Uwadia, O.E., Ebabhamiegbebho, P.A. and Evivie, S.E., (2016) Shelf life Stability Studies of University of Benin (UNIBEN) Proff's Kilishi Product Asian Journal of Science and Technology 7(1): 2268-2274.

Inusa, S. K. and Said, I. S. (2017) Evaluation of the Chemical and Microbiological Properties Of Kilishi Sold in Kano Metropolis. Journal of Dry land Agriculture, 3 (1): $59-69$.

Lucretia, I. B, Patience, C. Obinna-Echem, Sophia, C. A. (2018) Microbiological quality andantibiotic sensitivity of potential pathogens isolated from meat product (Suya) sold in Rivers State University and its environs. International Journal of Biotechnology and Food Science, 6(4): 67-76.

Matthew, E., Drosos, E., John, L. and Ioanna, P. (2013) MRSA in Africa: Filling the Global Map of Antimicrobial Resistance PLOS One. 8(7): e68024 doi: 10.1371/journal.pone.0068024

Mgbemere, V.N., Akpapunam, M. A. and Igene, J. O., (2011). Effect of Groundnut FlourSubstitution on Yield, Quality and Storage Stability of Kilishi - a Nigerian Indigenous Dried Meat Product. African Journal of Food, Agriculture, Nutrition and Development, $\quad \mathbf{1 1}(2)$ : 4718-4738. 
BAJOPAS Volume 13 Number 1, June, 2020

Mubarak, A. A., Azeez, M. L., Amos A. O., Opeyemi, O. O. (2016) Assessment of Animal Protein Consumption and Food Security Among Rural Households in Kwara State, Nigeria American Journal of Business and Society, 1(4): 233245.

Ndahi, M., D. Kwaga, J., K. P. Bello, M. Kabir J., V. Umoh, .J. Yakubu, S., E. and Nok, A., J. (2013) Prevalence and Antimicrobial Susceptibility of Listeria Monocytogenes and Methicillin-Resistant Staphylococcus aureus Strains from Raw Meat and Meat Products in Zaria, Nigeria. Applied Journal of Microbiology, 58(3):262-9.

Okonko, I.O., Odu, N.N. and Igboh, I.E. (2013). Microbiological Analysis of Kilishi Sold In Port Harcourt, Nigeria. New York Science Journal, 6 (7):37-43.

Osimani, A., Aquilanti, L. and Clementi, F. (2015) Microbiological Quality of Meatbased Meals and Operation of Control Systems within a Food Service Environment. International Food Research Journal 22(4): 1692-1698.

Onuorah, S. Obika, I. Odibo, F. Orji, M. (2015)An Assessment of the Bacteriological Quality of Tsire-Suya (Grilled Beef) sold in Awka, Nigeria. American. J. Life. Sci. Res. 3(4):287292.

Razavilar, V, Khandaghi, J. Barzgari, A. (2010); Isolation of Eschericia coli 0157:H7 from manure fertilized farms and raw vegetables grown on it, in Tabriz city in
Iran. African Journal of Microbiology Research, 4(9): 891-895.

Scallan, E. Hoekstra, R. M. Angulo, F. J.Tauxe, R. V, Widdowson, M. Roy, S. L et al., (2011).Food borne illness acquired in the United States- Major Pathogens. Emerg. Infec Dis, 17(1): 7-15.

Shamsuddeen U (2009). Microbiological quality of spice used in the production of Kilishi a traditionally dried and grilled meat product. Bayero Journal of Pure andApplied Sciences, 2(2): 66-69.

Shamsuddeen, U. (2015) Microbiological Hazard and Critical control point Analysis of Dried and Minced Meat Snacks Produced in Kano Nigeria. Lambert Academic Publishing; Pp 1-36.

Tijani, O.and Jumare, S. (2014). Microblological Quality Assessment of Meat

Sold in KauraNamoda. International Conference on Earth, Environment and Life sciences (EELS) Dubai (UAE).

Udobi, C. E., Obajuluwa, A. F., and Onaolapo, J. A., (2013) Prevalence and Antibiotic Resistance Pattern of MethicillinResistant Staphylococcus aureus from an Orthopaedic Hospital in Nigeria BioMed Research International; 26(6); 6-7.

WHO, 2015 Foodborne diseases in the WHO African Region.

Yousafzai HA, Rind R, Khan MA, Abro SH, Korejo NA, Ejaz M, Kabir A, Shahid M, Memon S. (2019). Microbiological Contamination of Cattle and Meat in Peshawar, Pakistan. J. Anim. Health Prod. 7(1): 1116. 